\title{
Julian Schenke
}
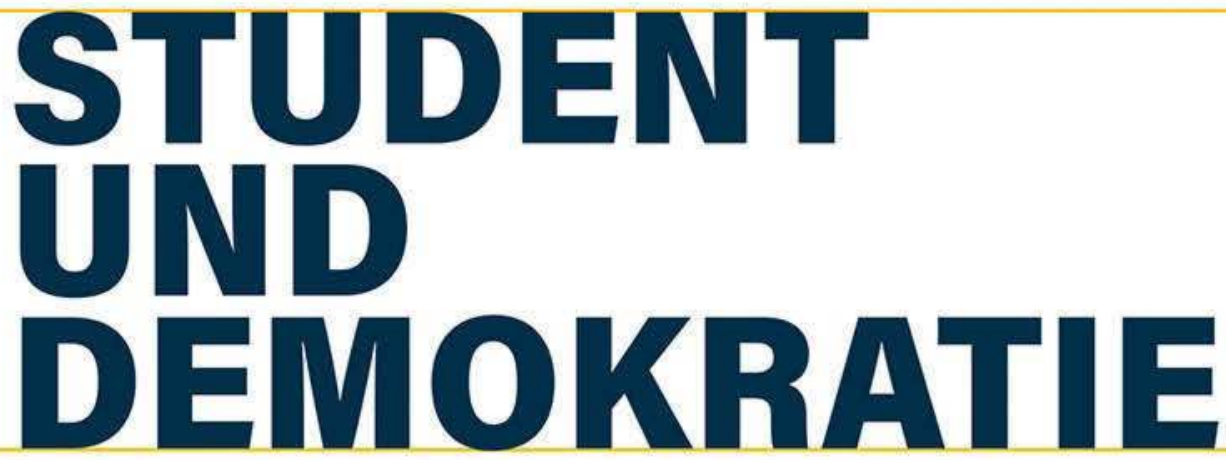

Das politische Potenzial deutscher Studierender in Geschichte und Gegenwart 
Julian Schenke

Student und Demokratie

Studien des Göttinger Instituts für Demokratieforschung zur Geschichte politischer und gesellschaftlicher Kontroversen 
Die freie Verfügbarkeit der E-Book-Ausgabe dieser Publikation wurde ermöglicht durch den Fachinformationsdienst Politikwissenschaft POLLUX

\section{POLLUXX Informationsdienst}

und ein Netzwerk wissenschaftlicher Bibliotheken zur Förderung von Open Access in den Sozial- und Geisteswissenschaften (transcript, Politikwissenschaft 2020)

Die Publikation beachtet die Qualitätsstandards für die Open-Access-Publikation von Büchern (Nationaler Open-Access-Kontaktpunkt et al. 2018), Phase 1

https://oa2020-de.org/blog/2018/07/31/empfehlungen_qualitätsstandards_oabücher/

Universitätsbibliothek Bayreuth |

Universitätsbibliothek der Humboldt-

Universität zu Berlin | Staatsbibliothek

zu Berlin | Universitätsbibliothek FU

Berlin | Universitätsbibliothek Bielefeld

(University of Bielefeld) | Universitäts-

bibliothek der Ruhr-Universität Bochum

| Universitäts- und Landesbibliothek |

Sächsische Landesbibliothek - Staats- und

Universitätsbibliothek Dresden | Universi-

tätsbibliothek Duisburg-Essen | Univer-

sitäts- u. Landesbibliothek Düsseldorf |

Universitätsbibliothek Erlangen-Nürnberg

| Universitätsbibliothek Johann Christian

Senckenberg | Universitätsbibliothek

Gießen | Niedersächsische Staats- und Universitätsbibliothek Göttingen | Universitätsbibliothek Graz | Universitätsbibliothek der FernUniversität in Hagen | Martin-LutherUniversität Halle-Wittenberg | Staats- und Universitätsbibliothek Carl von Ossietzky,

Hamburg | Technische Informations-

bibliothek Hannover | Gottfried Wilhelm

Leibniz Bibliothek - Niedersächsische
Landesbibliothek | Universitätsbibliothek

Kassel | Universitäts- und Stadtbibliothek Köln | Universität Konstanz, Kommunikations-, Informations-, Medienzentrum | Universitätsbibliothek Koblenz-Landau | Universitätsbibliothek Leipzig | Zentral- $\mathrm{u}$. Hochschulbibliothek Luzern | Universitätsbibliothek Mainz | Universitätsbibliothek Marburg | Ludwig-Maximilians-Universität München Universitätsbibliothek | Max Planck Digital Library | Universitäts- und Landesbibliothek Münster | Universitätsbibliothek Oldenburg | Universitätsbibliothek Osnabrück | Universitätsbibliothek Passau | Universitätsbibliothek Potsdam | Universitätsbibliothek Siegen | Universitätsbibliothek Vechta | Universitätsbibliothek der Bauhaus-Universität Weimar | Universitätsbibliothek Wien | Universitätsbibliothek Wuppertal | Universitätsbibliothek Würzburg | Zentralbibliothek Zürich | Bundesministerium der Verteidigung - Bibliothek | Landesbibliothek Oldenburg

Die Reihe wird herausgegeben von Stine Marg.

Julian Schenke, geb. 1988, ist wissenschaftlicher Mitarbeiter am Göttinger Institut für Demokratieforschung. Seine Arbeitsschwerpunkte liegen in den Bereichen qualitativer politischer Kulturforschung und Bewegungsforschung. 
Julian Schenke

\section{Student und Demokratie}

Das politische Potenzial deutscher Studierender in Geschichte und Gegenwart 
Gewidmet meinen Eltern Brenda († 2016) und Gero Schenke sowie meinen Großeltern Ulrike und Hans-Joachim Werneburg

Dissertation, Georg-August-Universität Göttingen, 2020

\section{Bibliografische Information der Deutschen Nationalbibliothek}

Die Deutsche Nationalbibliothek verzeichnet diese Publikation in der Deutschen Nationalbibliografie; detaillierte bibliografische Daten sind im Internet über http:// dnb.d-nb.de abrufbar.

\section{(c) $(1)(9)$}

Dieses Werk ist lizenziert unter der Creative Commons Attribution-NonCommercial-NoDerivs 4.0 Lizenz (BY-NC-ND). Diese Lizenz erlaubt die private Nutzung, gestattet aber keine Bearbeitung und keine kommerzielle Nutzung. Weitere Informationen finden Sie unter https://creativecommons.org/licenses/by-nc-nd/4.o/deed.de Um Genehmigungen für Adaptionen, Übersetzungen, Derivate oder Wiederverwendung zu kommerziellen Zwecken einzuholen, wenden Sie sich bitte an rights@transcript-publishing.com Die Bedingungen der Creative-Commons-Lizenz gelten nur für Originalmaterial. Die Wiederverwendung von Material aus anderen Quellen (gekennzeichnet mit Quellenangabe) wie z.B. Schaubilder, Abbildungen, Fotos und Textauszüge erfordert ggf. weitere Nutzungsgenehmigungen durch den jeweiligen Rechteinhaber.

\section{(ㄷ) 2020 transcript Verlag, Bielefeld}

Umschlaggestaltung: Kordula Röckenhaus, Bielefeld

Druck: Majuskel Medienproduktion $\mathrm{GmbH}$, Wetzlar

Print-ISBN 978-3-8376-5371-7

PDF-ISBN 978-3-8394-5371-1

EPUB-ISBN 978-3-7328-5371-7

https://doi.org/10.14361/9783839453711

Gedruckt auf alterungsbeständigem Papier mit chlorfrei gebleichtem Zellstoff. Besuchen Sie uns im Internet: https://www.transcript-verlag.de Unsere aktuelle Vorschau finden Sie unter www.transcript-verlag.de/vorschau-download 


\section{Inhalt}

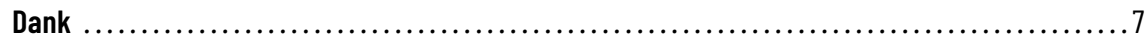

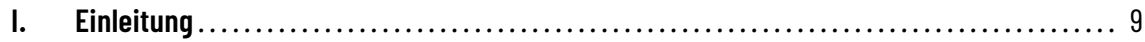

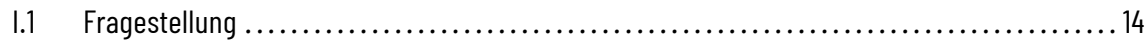

I.2 Zum Aufbau der Studie .............................................. 16

I.3 Das politische Potenzial von deutschen Studierenden. Konkretisierung des Forschungs-

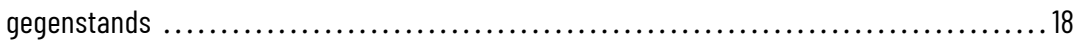

I.4 Bestimmung des Beitrags zur bisherigen Forschung ........................ 30

I.5 Methodologischer und methodischer Zuschnitt ............................. 37

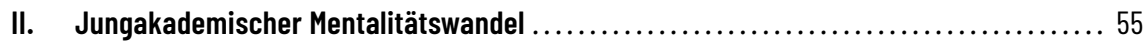

II.1 Vom "gelehrten Stand“ über die „Funktionseliten" zur "Leistungsgesellschaft”: Der soziale und institutionelle Wandel des Studiums ...................................61 6

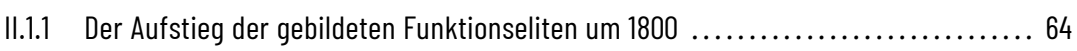

II.1.2 Verselbstständigung des Bildungswachstums ab $1880 \ldots \ldots \ldots \ldots \ldots \ldots \ldots \ldots \ldots \ldots$

II.1.3 Entprivilegierung der Gebildeten in langen Krisenjahren: $1918-1945$.............. 83

II.1.4 Postindustrielle Leistungsgesellschaft: Von der Rekonstruktion der Universität zur "Bildungsrevolution” 1960 bis heute .............................. 91

II.1.5 Seitenblick: Studieren in der universitären Juxtaposition zwischen Markt und Wissenschaftsautonomie ....................................... 118

II.2 Studentische Oppositionsbewegungen und ihre historischen Kontextbedingungen ....... 123

II.2.1 Die nationalliberale Burschenschafts- und Progressbewegung im Vorfeld des Re-

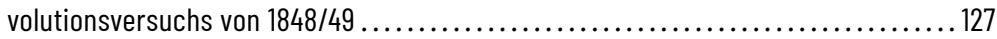

II.2.2 Gescheiterte Außerparlamentarische Opposition, modernisierte politische Kultur: Die westdeutsche Studentenbewegung von "1968“ .................... 164

II.2.3 Antisemitische und völkische Mobilisierung in Weimar 1925-1933: Eine antidemokratische Studentenbewegung ................................. 214

II.3 Politischer Mentalitätswandel: Empirische Studien über Einstellungsmuster und Praxispotenziale von Studierenden in der Bundesrepublik.......................... 247

II.3.1 Von der Skepsis zur Polarisierung: Die Studierenden der Kriegs- und Nachkriegs-

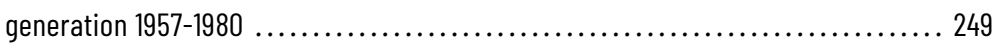


II.3.2 Abklingen der Polarisierung nach der „Friedensgeneration“ und Entpolitisierung: die 1980er Jahre ................................................ 263

II.3.3 Sinkende Relevanz von Politik, Protestnostalgie und neue Bedenken: die 1990er und 2000er Jahre.

II.3.4 Rückkehr der Politik in die Survey-Berichte und fortgesetzter Trend zur weltanschaulichen Fragmentierung: die 2010er Jahre

II.3.5 Generationentypologien und die Vernachlässigung der Frage nach tieferliegenden politisch-sozialen Deutungsmustern: Studierende und Demokratie im empirischen Längsschnitt

II.4 Zwischenbetrachtung und empirischer Ausblick ................................ 304

II.4.1 Karriereplanung, Studienmotivation und Wahrnehmung des Studiums ........... 330

II.4.2 Gesellschaftliches und politisches Interesse, politisches Engagement und Demokratieverständnis .............................................. 332

II.4.3 Vorstellungen idealer gesellschaftlicher Ordnung ....................... 340

III. Auswertung der Fokusgruppenstudie .................................. 343

III.1 Vorgehen und Verlauf der Erhebung ..................................... 343

III.2 Die Fokusgruppenteilnehmer in Zahlen ...................................... 348

III.3 Politisch-soziale Deutungsmuster von Studierenden $2018 \ldots \ldots \ldots \ldots \ldots \ldots \ldots \ldots \ldots \ldots . \ldots \ldots \ldots$

III.3.1 "Stilles commitment": Die studentische Sicht auf das Studium sowie auf Leistungs- und Bildungsprinzipien ................................. 362

III.3.2 Jeder sollte etwas tun: Über politisches Interesse, politische Themen und politisches Engagement ........................................... 408

III.3.3 "Total wichtig!" Demokratie: Verständnis, Begriff, Erfahrung und das konkrete Handlungsproblem AfD .......................................... 446

III.3.4 Rekonstruktion der politisch-sozialen Deutungsmuster und Ertrag der Fokusgruppenstudie .............................................. 470

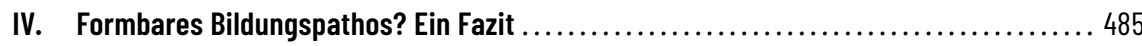

v. Literaturverzeichnis .................................................... 499

V.1 Zitierte Surveys ................................................... 499

V.2 Weitere verwendete Literatur .......................................... 503

V.3 Zeitungsartikel und Online-Quellen .................................... 528

VI. Abbildungsverzeichnis ............................................ 533 


\section{Dank}

In der scheinbaren und in sich ruhenden Abgeschlossenheit voluminöser Bücher verschwindet ihr Entstehungs- und Kommunikationsprozess. Gerade jemand, dessen eher intuitionsgeleitete Arbeitsweise so wenig mit dem Handwerk des frommen Geistesarbeiters gemein hat - also mit dem geduldigen Exzerpteschreiben, dem kleinschrittigen und planvollen Abarbeiten, dem ängstlichen Revidieren und Glätten, usw. -, weiß das. Für den größten Teil jener Fülle historischer Zufälle, die zu dem Entstehen eines Werkes geführt haben, gehören allerdings nicht nur andere Autoren und gesellschaftliche Bedingungen, die, ob zitiert oder nicht, einen prägenden Einfluss gehabt haben mögen. Oft ist es vor allem eine Reihe besonderer Personen, die für das Zustandekommen auf die eine oder andere Weise mitverantwortlich sind, und denen der Verfasser also $\mathrm{zu}$ verbindlichstem Dank verpflichtet ist.

So auch hier. Ich danke zuallererst meinen Eltern Brenda ( $† 2016)$ und Gero Schenke dafür, dass sie mir die langjährige Beschäftigung mit scheinbar lebensfernen Dingen finanziell und emotional ermöglicht haben. Ihre rückhaltlose Unterstützung ist keineswegs selbstverständlich. Dasselbe gilt für meine Großeltern Ulrike und Hans-Joachim Werneburg sowie für Ingeburg ( $\dagger$ 2018) und Wilhelm Schenke ( $\dagger$ 1998).

Natürlich hätte ich in Göttingen deutlich weniger gut Fuß fassen können ohne meine Helmstedter Mitschüler und späteren Mitbewohner Fabian und Frank-Christian. Beim Einstieg in die wissenschaftliche Anstellung und ins Schreiben stützten mich die Geduld und der Zuspruch von Tanita. Auch dafür: Danke.

Entscheidend für meine intellektuelle und menschliche Entwicklung, insbesondere während der Phase des Masterstudiums und danach, war die Förderung durch und die kontinuierliche Diskussion mit meinen akademischen Lehrern Prof. em. Dr. Franz Walter und Dr. Stine Marg, beide Betreuer meiner hier abgedruckten Dissertation, sowie Dr. Siebo Siems. Womöglich wundern sie sich über hier hergestellte Nachbarschaft. Dennoch: Ihnen allen verdanke ich die Einsicht, dass Erkenntnis nicht allein aus Begriffen entsteht, sondern aus der begrifflichen Verarbeitung subjektiver Erfahrung inmitten einer wesentlich veränderlichen und veränderbaren Gesellschaft. Darüber hinaus gilt mein Dank Prof. Dr. Steffen Kühnel für die Zweitbetreuung.

Große freundschaftliche Verbundenheit und Dankbarkeit schulde ich auch einem intellektuellen Zusammenhang, der sich im Sommer des Jahres 2012 zuerst konstituier- 
te, und dem im Laufe der von Unterbrechungen und Neuformierungen gekennzeichneten Jahre Clemens, Lars, Arne, Moritz, Hannes, Julia, Hannah, Siebo, Robert und Mario, später auch Björn, Dominik und Florian angehörten.

Anregend und mental heilsam fiel die sicherlich nicht gewöhnliche Bürogemeinschaft mit Florian Finkbeiner und Hannes Keune im Göttinger Institut für Demokratieforschung aus. Zwar zehrten wir alle vom Arbeitszusammenhang des Instituts, gewannen unseren Stolz dabei allerdings eine nicht ganz kurze Zeit hindurch auch durch intellektuelle wie politische Distinktion. Diese Spannung war und ist - in einem ganz naiven Sinne - produktiv. Und überhaupt: Was wäre der Göttinger Alltag ohne Clemi, Dom und Flo?

Großes Selbstbewusstsein schenkten mir gegen Ende der Schreibphase einige Korrekturleserinnen und Korrekturleser: mein Vater, Florian Finkbeiner, Clemens Boehncke, Lea Hausmann und Hilke Püschner. Das war durchaus entscheidend für eine fristgerechte Abgabe.

Überdies danke ich Anna für ihr Verständnis und für ihre Klugheit; es ist ihr Verdienst, mein Selbstverständnis, wie es für Prüfung und Publikation unerlässlich war, zu bekräftigen.

Mit vielen der hier aufgeführten Personen verbindet mich eine gemeinsame Perspektive, die gemeinhin unter dem Label „kritische Theorie“ firmiert. Gemeint ist damit nicht eine so genannte Schule, schon gar nicht eine akademische, sondern eine fordernde Konstellation von Wegweisern, die dazu verhelfen können, die Sehnsucht nach einer noch nicht eingelösten Zukunft - im alltäglichen Normalbetrieb meist Gegenstand des Spotts - als gesellschaftliches Projekt zu verstehen. Wäre das, was ist, letztlich alles dann wären auch das Denken und das Schreiben überflüssig. Das Staunen über den paradoxen Eifer derjenigen, die davon nichts ahnen wollen und trotzdem fleißig publizieren, lässt sich an der heutigen Universität erlernen. Freilich nicht nur das. Um aber nicht als einer von ihnen missverstanden zu werden, möchte ich voranstellen:

„Wenn wir nicht in irgendeinem Maße unwissenschaftliche Menschen geblieben wären, was könnte uns auch nur an der Wissenschaft liegen! Alles in allem genommen und rund und glatt und voll ausgesprochen: für ein rein erkennendes Wesen wäre die Erkenntnis gleichgültig."

Nietzsche, Friedrich: Menschliches, Allzumenschliches. Ein Buch für freie Ceister, Frankfurt a.M. 1982, S. 351 (Herv. i. O.) 


\section{Einleitung}

Die Welt ist entzaubert. Zumindest, wenn unter dem selbst noch metaphysisch glänzenden Begriff „Welt“ die alltäglich erfahrbare empirische Realität westlicher Demokratien verstanden wird. Denn tatsächlich ist sie aus der Sicht zahlreicher Zeitdiagnostikerinnen und -diagnostiker universell gültiger Ideale und Weisheiten ebenso entledigt wie transzendenter Deutungsfolien und zukunftsgerichteter gesellschaftspolitischer Projekte. Einen langfristigen Prozess bezeichnend, ist an die Stelle dieser kollektiven Orientierungen seit den europäischen Revolutionen des 18. und 19. Jahrhunderts die moderne „Entzweiung“ getreten, der Zerfall des Weltganzen in eine vom materiellen Interessenstreit gezeichnete bürgerliche Gesellschaft, das „System der Bedürfnisse", und in die durch die Traditionszerstörungsarbeit moderner Gesellschafts- und Wirtschaftsordnung bewirkte Sehnsucht nach Orientierung und Sinn - so der letzte Systemphilosoph Hegel. ${ }^{1}$ Das mag auf den ersten Blick als weihevolle universalhistorische Geste erscheinen, im Kern aber handelt sich bei dieser Beobachtung „nur" um die traditionsreiche philosophische Exposition eines handfesten und unvermindert aktuellen politischen Problems, also: um etwas Zeitgemäßes. Legt man sich die Frage nach der Gestaltung freier und freiheitlicher - nach Marx ist hinzuzufügen: Freiheit materiell auch ermöglichender - politischer Ordnungen im Angesicht des Verschwindens von sozialen und kulturellen Gewissheiten sowie sozialer Antagonismen im Ernst vor, wirken zweihundert Jahre gesellschaftsgeschichtliche Distanz seltsam aufgelöst. ${ }^{2}$ Nicht von ungefähr entzündet sich genau hieran die periodisch wiederkehrende und häufig um das berühmte Böckenförde-Diktum - von den notwendigen, aber nicht aus

Hegel, Georg Wilhelm Friedrich: Grundlinien der Philosophie des Rechts oder Naturrecht und Staatswissenschaft im Grundrisse [1821]. Cesammelte Werke Bd. 7, Frankfurt a.M. 2004, S. 346.

2 Man könnte so weit gehen zu sagen: Die amerikanischen und französischen bürgerlichen Revolutionen sind es gewesen, die den westlichen - und damit recht bald auch sämtlichen global vernetzten Gesellschaften - jene Problemstellung aufgegeben haben, die so unvermeidlich wie ihre Lösung unerreichbar scheint: Die Frage nach der adäquaten politischen Verwirklichung einer Ordnung der Freiheit und Cleichheit, verstanden als Befähigung aller, ein gattungsgemäßes Leben qua vernunft- wie bedürfnisgeleitetem "Menschsein“" zu führen, ohne das Faktum widerstreitender Interessen autoritär einzuebnen. Vgl. dazu die leidenschaftliche Auseinandersetzung Joachim Ritters in Ritter, Joachim: Hegel und die französische Revolution [1957], Frankfurt a.M. 1965, S. $24 f$. 
ihm selbst hervorgehenden Voraussetzungen eines liberalen, säkularisierten, multireligiösen und multiethnischen Staates - zentrierte politikwissenschaftliche Diskussion über den einenden sozialmoralischen Integrationsstoff in einer von widerstreitenden Interessen und Lebensstilpräferenzen zerrissenen demokratischen Gesellschaft wie der deutschen, ${ }^{3}$ nicht zuletzt im Zuge des Auftretens einer neuen, bundespolitisch relevanten, parlamentarischen Kraft rechts der Christdemokratie.

Nicht wenige werden ungeduldig die Augen verdrehen, eine politikwissenschaftliche Dissertation aufzuschlagen, die mit diesem altbekannten Krisenszenario beginnt. Doch selbst der Versuch, sich von enervierenden Wissenschafts- und Begriffsmoden zu emanzipieren, kann nicht über die Ungelöstheit der weiterhin bestehenden gesellschaftspolitischen Kernfragen hinwegsehen: Was stabilisiert eine zeitgemäße demokratische Gesellschaft? Welche politischen Interessenkonflikte und Konfrontationen sind in den kommenden Jahren und Jahrzehnten $\mathrm{zu}$ erwarten? Wo entstehen womöglich neue lagerartige Aggregate, wo brauen sich neue soziale und politische Bewegungen zusammen - und wie ist all das in demokratischen Prozessen zu vermitteln? Oder komplementär: Wo ist gerade das Ausbleiben von Wandel, das Nicht-Entzünden gesellschaftskritischer Energien bedenklich? Wer versucht heute, Ideen zu stiften, wo arbeiten noch gestalterische Energien (zumindest dem Selbstverständnis nach) an der besseren Zukunft, eventuell gar an einer Weiterentwicklung der Demokratie, die polemisch gesprochen nicht mehr nur panis et circenses, Brot und Spiele, in einem sozial befriedeten nationalen Gemeinwesen ${ }^{4}$ veranstaltet? Denn nahezu so alt wie die bundesrepublikanische Demokratie ist auch die in den 1960er Jahren gestellte Diagnose von strukturell reaktionären „Involutions“-Tendenzen, d. h. von einer schleichenden Entdemokratisierung hin zur autoritär-rechtsstaatlichen Domestikation von sozialem Konfliktpotenzial unter Ausschluss der zu materiell versorgten Konsumenten degradierten Bürgerinnen und Bürgern ${ }^{5}$ von den eigentlichen, durch elitäre Politik-Experten besorgten Entschei-

Vgl. die hellsichtige Aktualisierung dieser Frage in Menke, Christoph: Philosophiekolumne. Am Tag der Krise, in: Merkur. Gegründet 1947 als Deutsche Zeitschrift für europäisches Denken, 71. Jahrgang, H. 820/2017, S. 49-57, ferner die historisch versierte Erinnerung an das weder durch liberalen Harmonismus noch durch andere Leitideen und Werte zu kittende Crunddilemma der Verwiesenheit von demokratischen Grundsätzen auf eine nicht erzwungene grundsätzliche Übereinstimmung der Bürgerinnen und Bürger in Walter, Franz: Die Janusköpfigkeit des linksliberalen Leitmodells, in: Frankfurter Allgemeine Zeitung (FAZ), 16.03.2018, online einsehbar unter: https://www.faz.net/aktuell/politik/inland/fuehrt-buergerliches-engagement-zur-stabilisierung-der-demokratie-15543519.html [eingesehen am 01.08.2019] und Ribi, Thomas: Das große Wagnis der Freiheit: Was moderne Demokratien zusammenhält, in: Neue Zürcher Zeitung (NZZ), 26.02.2019, online einsehbar unter: https://www.nzz.ch/feuilleton/was-saekulare-staaten-zusammenhaelt-das-grosse-wagnisder-freiheit-Id.1469858?fbclid=IwAR11Cf8MnFcShSl2TK\%E2\%80\%A6 [eingesehen am 01.08.2019]

4 Vgl. Agnoli, Johannes: Zur ApO [1968], in: Ders.: 1968 und die Folgen, Freiburg 1998, S. 31-49, hier S. 37.

$5 \quad$ Im Folgenden wird bei Sammelbezeichnungen von Personengruppen weitgehend das traditionelle generische Maskulinum verwendet. Gewiss nicht zuletzt, weil die sich um das "Gendern" rankende sprachpolitische Diskussion etwas Müßiges an sich hat. Das energische Beharren auf geschlechtsneutralen Formulierungen beeinträchtigt erstens die Leserlichkeit, verstümmelt zweitens aber auch manchen Gedanken, der ohne seine kulturell überlieferten sprachlichen Formprinzipien schlicht an Tiefe verliert. Andererseits muss selbst der Skeptiker der sogenannten ge- 
dungsprozessen. ${ }^{6}$ In vergleichbarer Absicht wird dies in den vergangenen Jahren unter dem Slogan der „Postdemokratie“ wiederaufgegriffen. ${ }^{7}$ Erlahmt ist die Fortschrittsemphase der einstigen liberalen und sozialistischen Emanzipationsbewegungen zwar schon gegen Ende des bürgerlichen 19. Jahrhunderts, aber ganz besonders im jetzigen Zeitalter - das an zwei Weltkriege, die nationalsozialistischen Konzentrationslager und den Abwurf zweier Atombomben auf Japan zu erinnern hat, zudem nach dem Untergang der Sowjetunion einer als alternativloses Fatum erscheinenden kapitalistischen Weltwirtschaftsordnung und einer fortschreitenden ökologischen Verheerung gegenübersteht - , ist der bisher umfassendste Verlust politisch-utopischer Phantasie zu beklagen. ${ }^{8}$ Mehr noch: Der Begriff der „Utopie“, zumal der politischen, ist kaum noch von seinem pejorativen Unterton zu trennen; wer gar die alte Frage nach einer kollek-

schlechtergerechten Sprache konzedieren, dass Stil- und Formulierungsfragen nicht immer die Hoheit über die zweifellos erforderliche Gegenstandsangemessenheit der Sprache behaupten können. Er darf sich nicht in trotzigen Abwehrgesten üben. Daher wird im Folgenden das etwas sperrige und diffuse Wort „Studierende“ bzw. „Studierendenschaft“-diffus, da in gewissem Sinne auch andere Personen als immatrikulierte Studentinnen und Studenten studieren können - anstelle von "Studenten“ bzw. "Studentenschaft" als Sammelbezeichnung eine wiederkehrende Ausnahme bilden, gleichsam als kontinuierliche Erinnerung an die Aporien der durch die sprachliche Darstellung evozierten Bilder. Denn schon 1961, also lange bevor derartige Themen regelmäßige öffentliche Aufmerksamkeit okkupierten, entschieden sich Sozialforscher in dem für diese Studie einschlägigen Gebiet für den Sammelbegriff „Studierende“ - zwar nicht im Titel, aber doch immerhin bei der Aufführung ihrer Ergebnisse, vgl. Stifterverband für die deutsche Wissenschaft: Das geistige Bild der Studenten. Ihre Einstellung zu Politik, Kultur und Hochschulfragen, EssenBredeney 1961, S. 42. Ist hingegen von "Studenten“ oder "Studentenschaft" die Rede, verweist dies auf den lange Zeit hindurch üblichen (nahezu) vollständigen Ausschluss von Frauen aus den höheren Bildungsinstitutionen.

6 Ibid., S. 16 und 49-61.

7 „Der Begriff [Postdemokratie, ]. S.] bezeichnet ein Gemeinwesen, in dem zwar nach wie vor Wahlen abgehalten werden, Wahlen, die sogar dazu führen, daß Regierungen ihren Abschied nehmen müssen, in dem allerdings konkurrierende Teams professioneller PR-Experten die öffentliche Debatte während der Wahlkämpfe so stark kontrollieren, daß sie zu einem reinen Spektakel verkommt, bei dem man nur über eine Reihe von Problemen diskutiert, die die Experten zuvor ausgewählt haben. Die Mehrheit der Bürger spielt dabei eine passive, schweigende, ja sogar apathische Rolle, sie reagieren nur auf die Signale, die man ihnen gibt." Crouch, Colin: Postdemokratie, Frankfurt a.M. 2008, S. 10. Die von Crouch zusammengetragenen Diagnosen der gegenwärtigen westlichen Demokratien scheinen mittlerweile allerdings zu fungiblen und bisweilen verschwörungstheoretisch schimmernden Platitüden herabgesunken zu sein. In jenen Segmenten des Büchermarktes, die die Themenfelder „Politik“ und „Zeitgeschehen“ populärwissenschaftlichessayistisch abdecken, sind die Regale reich gefüllt mit Büchern, die eine „neue Elitenherrschaft“ vermeintlich abgehobener Globalisten (Politiker, Konzernlenker, Lobbyisten, Netzwerker) anprangern, die an allen demokratischen "checks and balances“ vorbei die Geschicke der unbescholtenen Bürger kontrollierten. Vgl. exemplarisch Mausfeld, Rainer: Warum schweigen die Lämmer? Wie Elitendemokratie und Neoliberalismus unsere Gesellschaft und unsere Lebensgrundlagen zerstören, Frankfurt a.M. 2018; Mies, Ullrich/Wernicke, Jens (Hg.): Fassadendemokratie und tiefer Staat: Auf dem Weg in ein autoritäres Zeitalter, Wien 2017 oder Bode, Thilo: Die Diktatur der Konzerne: Wie globale Unternehmen uns schaden und die Demokratie zerstören, Frankfurt a.M. 2018. Vgl. Saage, Richard: Das Ende der politischen Utopie? Zum Begriff der politischen Utopie, in: Ders.: Das Ende der politischen Utopie?, Frankfurt a.M. 1990, S. 13-25. 
tiven Existenz ohne Mangel und Angst ${ }^{9}$ aufwirft, hat Schwierigkeiten, überhaupt ernst genommen zu werden.

Das alles wirkt zunächst abstrakt, doch bildet es den gesellschaftshistorischen Wurzelboden der deutschen politischen Kultur, um die es im Folgenden gehen soll. Denn auch diese politische Kultur erscheint in zunehmendem Maße als metaphysisch entleert: Politische Phänomene und Mentalitätstrends empirisch einzuordnen, ist derzeit ohne den Rückgriff auf die narrative Figur des Verschwindens von Sinnquellen und traditionellen Formen der Interessenaggregation (hauptsächlich milieunahe Parteien, Vereine, Verbände) kaum möglich. Die Zeit, in der das politische Kollektiv noch das einstige religiöse ersetzen konnte, ist vorbei: Die Diversität individualistischer Sinnentwürfe und Lebensstilpräferenzen der tertiarisierten Angestelltengesellschaft tritt an die Stelle früherer Stände- und Klassenzugehörigkeiten (Aristokratie, Bürgertum, Arbeiterschaft, Bauerntum) und einstiger politischer Milieus (Arbeitermilieu, katholisches Milieu, liberales Milieu). ${ }^{10}$ Dabei konnte die politische Kulturforschung dafür hierzulande lange Zeit auf die Persistenz parteipolitischer Lagerbindungen seit dem Deutschen Kaiserreich verweisen, welche sich aus dem Phänomen der kollektive Lebensrealitäten abbildenden und klassen- bzw. gruppenspezifischen Werthaltungen prägenden gesellschaftlichen Milieus speisten. ${ }^{11}$ Noch die alte Bundesrepublik erlebte in den 1960er und 1970er Jahren eine Zuspitzung des parteipolitischen Wettbewerbs in Richtung einer stabilen, bipolaren Konstellation zwischen sozial- und christdemokratischem volksparteilichem Hegemonieanspruch, obwohl die proletarischen, liberalen/protestantischen und katholischen Lebenswelten auch damals längst nicht mehr als primäre politische und sozialmoralische Vergesellschaftungssphären hatten gelten können. ${ }^{12}$ Doch der vom Kritiker des bürgerlichen Jahrhunderts Friedrich Nietzsche beklagte intellektuelle Nihilismus des fin de siècle, der Entwertung kollektiver Wertbestände, hat sich bis Ende des 20. Jahrhunderts unter den Bedingungen auf sich selbst zurückgeworfener nationalstaat-

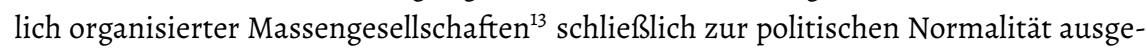

9 „Eine emanzipierte Cesellschaft jedoch wäre kein Einheitsstaat, sondern die Verwirklichung des Allgemeinen in der Versöhnung der Differenzen. Politik, der es darum im Ernst noch ginge, sollte deswegen die abstrakte Gleichheit der Menschen nicht einmal als Idee propagieren. Sie sollte statt dessen [sic] auf die schlechte Gleichheit heute, die Identität der Film- mit den Waffeninteressenten deuten, den besseren Zustand aber denken als den, in dem man ohne Angst verschieden sein kann." Adorno, Theodor W.: Minima Moralia. Reflexionen aus dem beschädigten Leben [1951], Frankfurt a.M. 2003, S. 116.

10 Diese Dynamik affiziert sämtliche Parteifamilien, vgl. Walter, Franz: Zeiten des Umbruchs? Analysen zur Politik, Stuttgart 2018, S. 69-72.

11 Rohe, Karl: Wahlen und Wählertraditionen in Deutschland. Kulturelle Grundlagen deutscher Parteien und Parteiensysteme im 19. und 20. Jahrhundert, Frankfurt a.M. 1992, insbesondere S. 57-97.

12 Vgl. Lehmbruch, Gerhard: Parteienwettbewerb im Bundesstaat. Regelsysteme und Spannungslagen im politischen System der Bundesrepublik Deutschland [1976], Wiesbaden 2000, S. 37-44 sowie Rohe: Wahlen und Wählertraditionen, S. 172f., insbesondere die Hervorhebung des Verschwindens der "geschlossene[n] regionale[n] und lokale[n] Milieus".

13 „Zum erstenmal seit zwei Jahrhunderten besaß die Welt in den neunziger Jahren kein internationales System und keine Struktur. Die Tatsache, daß nach 1989 Dutzende von neuen Territorialstaaten auftauchten, die über keinerlei unabhängige Mechanismen zur Bestimmung ihrer Grenzen verfügten, spricht für sich selbst [...] Wo war das Konsortium der Großmächte, das einst umstrittene Grenzen festgesetzt oder zumindest formell ratifiziert hat?" Hobsbawm, Eric ].: Das Zeitalter 
wachsen. Materielle und mentale Ausdifferenzierungen, auch der Trend zum fragmentierten Vielparteiensystem, kennzeichnen das frühe 21. Jahrhundert:

„Der Charme großer Prinzipien und Ideensysteme scheint in allen Milieus verfolgen. [...] Überhaupt scheinen die Komplexitäten derart zugenommen zu haben, dass die gesellschaftliche Vielfalt nicht mehr durch die eine große Erzählung zu bändigen wäre."14

In gewisser Weise ist dies die aktuelle Episode einer langen historischen Säkularisierungsbewegung, die zuletzt auch das Heils- bzw. Ordnungsversprechen der großen politischen Bewegungen - des liberalen Nationalismus, des Sozialismus, des Konservatismus $^{15}$ - zum Teil realisiert und zum Teil ergebnislos zerschlagen, jedenfalls aber: absorbiert hat. Dieser multiple Zerfall einstiger „Wahrheiten“ und Sinnstrukturen hat, auch im vorparteipolitischen Raum, gravierende Veränderungen im politischen Denken und Empfinden der Einzelnen gezeitigt. Das ist beispielsweise am vielerorts zu beobachtenden Erschlaffen sozialer Integrationskräfte abzulesen, etwa in Gestalt des neu entbrannten Streits um, ja der wachsenden Konfusion über Form, Inhalt und Zweck der Demokratie. Auch die sozialwissenschaftliche Erforschung von politischen Mentalitäten und Bewusstseinsformen hat diesen Dekompositions- bzw. Rekonfigurationsprozess früh registriert. ${ }^{16}$

Der Zweck dieser verfallsgeschichtlich anmutenden Ouvertüre ist, in vorauseilender Verteidigung die Naivität von Fragen nach heute noch verbliebenen, respektive nach womöglich erst noch entstehenden Quellen gesellschaftspolitischer Impulse und Ideen zu rechtfertigen. Die erhebliche Profanisierung der öffentlichen Sphäre scheint solche Fragen nicht mehr zu gestatten. Es sei daher freimütig zugegeben: Die vorliegende Studie ist eine Suchbewegung, die sich auf möglicherweise dünnem Fundament bewegt. Dennoch erklärt sie zu ihrer Basisprämisse, dass ein politikwissenschaftliches Forschungsinteresse einer bestimmten Form von Zynismus trotzen muss, die sich nach mehreren Jahren der Beschäftigung mit seiner disziplinären Sphäre einstellt: dem Eindruck, dass die Geschichte politischer Bewegungen tatsächlich einem Ineinander aus langfristiger Sinnentleerung und kurzfristigem Wiederaufleben von Hoffnungen,

der Extreme. Weltgeschichte des 20. ]ahrhunderts, München 2007 [ursprgl. The Age of Extremes. The short twentieth century 1914-1991, 1994], S. 688f.

14 Walter: Baustelle Deutschland, S. 29.

15 „Die Entwicklung der Weltfrömmigkeit im Laufe des 19. Jahrhunderts hat die kulturell führenden Schichten und die mit ihr besonders im industriellen Prozeß verbundene städtische Arbeiterschaft dem christlichen Clauben zunehmend entfremdet. Sie machte es möglich, daß die höheren, d. h. stark individualisierten Stände ihre Theologie auf eigene Faust durch das Mittel personengebundener Weltanschauung versuchten und die Industriearbeiterschaft Träger einer spezifisch antichristlichen revolutionären Eschatologie wurde. Beide Ersatzformen des christlichen Bewußtseins im Cesichtskreis der Welt, in großen Systemen gedanklich und künstlerisch ausgesprochen, sind bis in ihre durchsichtigen Extreme, die den Kampf gegen das Christentum und eine christlich legitimierte Gesellschaft wirklich aufnahmen, bis Nietzsche und Marx Zeugen für die noch unterirdisch fortwirkende christliche Tradition." Plessner, Helmuth: Die verspätete Nation. Über die politische Verführbarkeit bürgerlichen Geistes [1935], in: Ders. (Hg.): Die Verführbarkeit bürgerlichen Geistes. Gesammelte Schriften Bd. VI, Frankfurt a.M. 2003, S. $84 f$. 
Ängsten, Wünschen und darauf antwortenden scheinbar neuen, letztlich aber doch strukturell bekannten Sinngeneratoren und Sinnprothesen (Bewegungen und Gurus, Parolen und Slogans, politische Protagonisten und Parteien, etc.) gleichkommt, und dabei nur sehr wenige genuine Höhepunkte hervorgebracht zu haben scheint. Oder in etwas pathetischeren Worten: Wenn alles geklärt zu sein scheint, darf es am wenigsten als klar vorausgesetzt werden. ${ }^{17}$

Die Suchbewegung erscheint am aussichtsreichsten, wenn der Zustand der politischen Kultur historisch vergleichend am Gegenstand einer exponierten sozialen Gruppierung untersucht wird. Für die vorliegende Studie wurden die deutschen Studierenden ausgewählt. Die Gründe für diese Themenwahl und das verfolgte Erkenntnisinteresse sind im Folgenden zu explizieren.

\section{I.1 Fragestellung}

Was macht die Studierenden aus politikwissenschaftlicher Perspektive interessant? Erstens: Es existiert eine langlebige kulturell überlieferte Vorstellung, welche Studierenden ein latentes Kräftereservoir freiheitlicher und kritisch-rebellischer politischer Energien zuschreibt; zweitens: Von ihnen, aus deren Kreis ein großer Teil der künftigen Funktionseliten in Bildung, Wirtschaft und Politik hervorgeht, wird immer wieder ein besonders prägender Einfluss auf die künftige politische Kultur erwartet. Ihre spezielle Lebenssituation scheint ihnen, wie über verschiedene gesellschaftliche Umbrüche und Hochschulreformen hinweg wiederholt konstatiert worden ist, exzeptionelle Freiheiten $\mathrm{zu}$ verschaffen, insbesondere ein vergleichsweise großes Maß an frei disponibler Zeit, ein geringes Maß an Pflichten und Verantwortungen sowie eine relative Ungebundenheit von sozialen Konventionen. In den Reihen von Studierenden, so scheint es, schlummert früher wie heute ein politisches Potenzial, auch durch ein besonderes, im Vergleich zu nichtstudierenden Altersgenossen verlängertes, Bildungsmoratorium. ${ }^{18}$

Doch nicht nur die prospektive politische, wirtschaftliche und gesellschaftliche Bedeutung der Studierenden macht deren politisches Potenzial zu einem relevanten Untersuchungsgegenstand. Spätestens seit der zum Mythos geronnenen Studentenbewegung von „1968“19 und der mit dieser evozierten „Ausbreitung des Ungehorsams in

17 „]e einfacher etwas scheint, desto komplizierter muss es gemacht werden." Bourdieu, Pierre: Über den Staat. Vorlesungen am Collège de France 1989-1992, Frankfurt a.M. 2017, S. 205.

18 „Die Aufmerksamkeit, welche die politische Kultur und Haltung der Studierenden findet, hat vor allem drei Cründe: Weitgehend aus ihrem Kreise rekrutiert sich die zukünftige Funktions- und Machtelite, die Studentenschaft gilt als mobiler Träger neuer kultureller und politischer Entwicklungen, und sie kann zeitweise selbst, meist protestierend oder rebellierend, nachhaltig in das politische Geschehen eingreifen." 2. Studierendensurvey 1984/85, S. 241. Zur hier und im Folgenden praktizierten abweichenden Zitierkonvention der einschlägigen Survey-Studien in Kürzeln, die die Leserlichkeit der Nachweise erleichtern soll, vgl. die Aufstellung am Anfang des Abkürzungs- und Literaturverzeichnisses dieser Studie.

19 Chiffren wie „1968“ (vgl. Claussen, Detlev: Chiffre 68, in: Harth, Dietrich/Assmann, Jan (Hg.): Revolution und Mythos, Frankfurt a.M. 1992, S. 219-230) drücken mehr aus als eine Jahreszahl, sie markieren (zeit-)geschichtliche Zäsuren der politischen Kultur. Gewiss nehmen viele der Entwicklungen und Ereignisse, die in ihnen zusammengefasst werden, ihren Ausgang weitaus früher. Den- 
Deutschland“ gegenüber den als verkrustet wahrgenommenen gesellschaftlichen Institutionen $^{20}$ gilt die Studierendenschaft einigen als Reformagent der demokratischen politischen Kultur der Bundesrepublik im Wartestand, gar als schlafender Löwe. Zu dieser Art von Erwartungshaltung gehört immer auch die Hoffnung auf zukunftsgewandte gesellschaftskritische Impulse. Ein „vager linker Konsensus“ bestand jedenfalls noch 1977 trotz einer erwarteten konservativen Tendenzwende unter den deutschen Studierenden, ${ }^{21}$ und auch noch Mitte der 1980er Jahre gehörte es zum Selbstverständnis eines großen Teils der Studierenden, „links“ bzw. „links-alternativ“ zu sein. ${ }^{22}$ Doch kann jenseits dieses kulturell überlieferten Stereotyps von einer langlebigen protestaffinen politischen Kultur der Studierendenschaft tatsächlich die Rede sein? Wenn ja, welches sind ihre Grundzüge? Inwiefern zeichneten sich deutsche Studierende historisch durch ein gruppenspezifisches politisches Potenzial aus - und geben aktuelle studentische Deutungsmuster ${ }^{23}$ über Politik, Gesellschaft und Demokratie Anhaltspunkte für besondere Kräftereservoirs politischer Aktivität (Ängste, Unmut, Hoffnungen, Gestaltungswünsche, Phantasien, o. Ä.)?

noch stellen sie geronnene Zeichen und kulturelle Zitate dar; sie transportieren ein, zugegebenermaßen immer mythisch durchsetztes, Gemisch an Bedeutungsgehalten, das mit präziser Begriffsarbeit nur schwer zu rekonstruieren ist, vgl. dazu etwa die Ausführungen in Greven, Michael Th.: Systemopposition. Kontingenz, Ideologie und Utopie im politischen Denken der 1960er Jahre. Sammlung Budrich - Texte zur Gesellschaft, Opladen 2011, S. 31-50. Aus diesem Grund werden im Folgenden die gängigen Signaljahre zwar verwendet; um aber zugleich die Erinnerung an ihren Charakter als retrospektive Bearbeitung und politkulturelles Zitat zu wahren, werden sie zugleich in Anführungszeichen gesetzt. Zudem: In Forschung, Zeitzeugenberichten und Presse zirkulieren mit „1968“, „68er“, „Achtundsechzig(er)“ und „68er-Bewegung“ verschiedene Kürzel, in der Regel weit jüngeren Datums als die Ereignisse selbst - vgl. dazu Frei, Norbert: 1968. Jugendrevolte und globaler Protest, München 2018, S. 253, Anm. 22. Ebenso gibt es, je nach Akzentuierung der entscheidenden Aspekte jener Jahre, verschiedene Bezeichnungen: Während manche die Zentralität einer "Studentenbewegung" hervorheben, sprechen andere zurückhaltender oder auch pejorativer von studentischer „Revolte“ oder „Rebellion“. Einige wiederum konzentrieren sich stärker auf die deutsche „Außerparlamentarische Opposition“ (APO), stellen die internationale Dimension der Erhebungen in den Vordergrund oder merken an, dass die entscheidenden Ereignisse bereits 1967 stattgefunden bzw. dass wesentliche Tendenzen bereits 1964 ihren Ausgang genommen haben, vgl. exemplarisch Kraushaar, Wolfgang: 1968. 100 Seiten, Ditzingen 2018, S. 21-28 und den Sammelband Lorenz, Robert/Walter, Franz (Hg.): 1964. Das Jahr, mit dem „68“ begann, Bielefeld 2014; ferner ausführlich Kapitel II.2.2 dieser Studie. Im Folgenden sollen je nach Kontext die betreffenden Aspekte (Studentenbewegung, Ereignisse, Akteure, politisches Klima und institutionelle Umbrüche) konkret benannt und im Fortgang der Darstellung begrifflich eingeholt werden. Sofern im Folgenden das diffuse Ineinander verschiedener ruckartig beschleunigter struktureller Entwicklungen einerseits und zentraler Ereignisse andererseits, wie es sich auch in Chiffren wie "1848“ oder „1918“ kondensiert, bezeichnet werden soll, wird von „1968“ die Rede sein.

$20 \mathrm{Vgl}$. Sonnemann, Ulrich: Institutionalismus und studentische Opposition. Thesen zur Ausbreitung des Ungehorsams in Deutschland, Frankfurt a.M. 1968, insbesondere S. 7-18.

21 Fichter, Tilman/Lönnendonker, Siegward: Kleine Geschichte des SDS. Der Sozialistische Deutsche Studentenbund von 1946 bis zur Selbstauflösung, Berlin 1977, S. 8.

22 Im Wintersemester 1984/85 behaupteten 31 Prozent der deutschen Studierenden, einen linken politischen Standort einzunehmen, vgl. Studierendensurvey 1980er, S. 218.

23 Zum Begriff des Deutungsmusters vgl. die Ausführungen zum methodischen Vorgehen in Kapitel I.5 dieser Studie. 


\section{I.2 Zum Aufbau der Studie}

Das Vorhaben sucht also zwar Antworten auf eine politikwissenschaftliche Fragestellung; praktisch ist es jedoch dazu angehalten, sein eng gestecktes disziplinäres Feld bisweilen $\mathrm{zu}$ verlassen und wesentliche Zusammenhänge unter Zuhilfenahme politisch-soziologischer sowie historischer Darstellungen zu rekonstruieren. Befolgt wird auch kein striktes Methodenset; der Anspruch ist, sich von der Struktur der Sache hermeneutisch leiten $\mathrm{zu}$ lassen und dabei zu jenen wissenschaftlichen Werkzeugen zu greifen, die der sukzessiven Klärung von Zusammenhängen zuträglich erscheinen. Warum die Wahl im Falle der selbstständigen empirischen Erhebung auf das Instrumentarium der qualitativen Sozialforschung fällt, wird im Laufe der Darstellung deutlich werden.

Der Überzeugung folgend, dass die Aufgabe einer wissenschaftlichen Einleitung darin liegt, im Fortschreiten vom Abstrakten zum Konkreten das gewählte Vorgehen offenzulegen, entwickelt die Studie im Folgenden einen Vorbegriff des politischen Potenzials von Studierenden, der den bisher nur vage visierten Forschungsgegenstand konkretisieren soll (I.3). Daraufhin ist die Stoßrichtung der vorliegenden Studie (mitsamt des erhofften Erkenntnisgewinns) in der einschlägigen Forschungslandschaft zu verorten (I.4), bevor der methodische Zugriff erläutert wird (I.5).

Der erste Hauptabschnitt unternimmt eine aspektzentrierte Längsschnittbetrachtung politischer Bewegungen und politischer Praxispotenziale von Studierenden seit etwa 1800 bis heute, einer Zeitspanne europäischer Revolutionen, in der die politische Betätigung im Zeichen demokratischer Partizipationsforderungen historische Plausibilität gewinnt. Dabei ist zunächst der sozialgeschichtliche und institutionelle Wandel des Studierens (II.1) aufzuarbeiten, um den radikal veränderten Stellenwert akademischer Karrierewege und die - ebenso historisch veränderliche - Sonderrolle der Hochschulen zwischen staatlich geschützter Bildungsinstitution, elitärem Autonomiestreben und marktorientierter Nachfrage nach hochqualifizierten Arbeitskräften deutlich zu machen. Dieses Kapitel ist dabei chronologisch komponiert: Es entfaltet die Zusammenhänge am gesellschaftsgeschichtlichen Abriss und stellt damit essenzielles Hintergrundwissen für die außergewöhnlichen Phasen studentischer Oppositionsbewegungen bereit. Deren zentrale Ereignisketten, Ermöglichungsbedingungen und Folgen werden sogleich (II.2) erörtert. Schließlich verlangt die qualitativ-empirische Analyse des studentischen politischen Potenzials in der Gegenwart nach einer umfassenden Aufbereitung der nahezu seit Beginn der Bundesrepublik vorliegenden quantitativen Studien: hier (II.3) ist insbesondere herauszuarbeiten, worin das nach Ansicht des Verfassers heute auffälligste Forschungsdesiderat besteht. Eine Zwischenbetrachtung (II.4) trägt die Resultate dieses Abschnitts zusammen und leitet aus ihnen Themenblöcke für einen Gesprächsleitfaden $a b$, welcher dann die Fokusgruppendiskussionen strukturiert.

Im zweiten qualitativ-empirischen Hauptabschnitt wird die Auswertung des Materials präsentiert, das im Sommer und Winter 2018 mithilfe von Fokusgruppendiskussionen mit Göttinger und Frankfurter Studierenden erhoben worden ist. Da qualitative Studien ihre Gütekriterien nicht aus einem Anspruch auf statistische Repräsentativität beziehen, sondern aus der nachvollziehbaren interpretativen Rekonstruktion von Sinnzusammenhängen, werden zunächst Vorgehen und Verlauf der Erhebungsphase 
(III.1) sowie die sozialstrukturelle Zusammensetzung der Gesprächsteilnehmer (III.2) referiert. Die mithilfe eines durch die Software MaxQDA erstellten vorstrukturierenden Codebaums vorgenommene Analyse und Interpretation der politisch-sozialen Deutungsmuster (III.3) bildet das Herzstück des Abschnitts. Dessen tragendes Interesse ist, welche Einstellungsmuster verknüpfenden privaten Gesellschaftstheorien Studierende pflegen, welche Perspektive auf politische Prozesse und politische Praxis sie hegen und worin sich ein etwaiges politisches Potenzial heute messen ließe. Dass das Textvolumen dieses Teils geringer ausfällt als das des historisch-empirischen Abschnitts, hat seinen Grund im Materialreichtum und in der Literaturfülle der dort einzubeziehenden Sekundärdarstellungen und Studien im Rahmen eines Apparats an Nachweisen, dessen die Auswertung der Transkripte so nicht bedarf.

Welche Antworten die Studie insgesamt auf die Frage nach der Existenz und Struktur eines spezifischen politischen Potenzials von Studierenden in der Gegenwart und näheren Zukunft liefert, wird im abschließenden Fazit (IV) diskutiert.

Eine begleitende Anmerkung zum hier visierten Erkenntnishorizont erscheint angezeigt. Denn der dichotome Aufbau mag den Eindruck eines Nebeneinanders zweier Studien erwecken, welche mehr schlecht als recht durch das dünne Band eines zusammenführenden Schlusskapitels zusammengehalten werden. Warum, so ließe sich fragen, nicht den Textkorpus in zwei jeweils selbstständige Publikationen aufteilen, hier eine zur Vorgeschichte, dort eine zur empirischen Aktualität? Die Antwort lautet, dass die hier verfolgte Suchbewegung sich auf einen strukturierenden Fluchtpunkt zubewegt: Es ist das melancholisch durchsetzte Staunen über die lange Geschichte von Versuchen unterschiedlicher studentischer Gruppierungen und Zusammenschlüsse, vermöge einer kollektiven Anstrengung (und eben auch aufsetzend auf einem tradierten, als bindend empfundenden studentischen Kollektivitätsideal) eine wie auch immer geartete Modernisierungsbewegung in Richtung freier und egalitärer Gesellschaftsformen praktisch durchzusetzen, dabei auch Bildungsprivilegien infrage zu stellen und vermittels des vorbereitenden Schritts von Hochschulreformen zu umfassender Gesellschaftsreform fortzuschreiten. Sicher verbietet sich jede romantische Mythisierung: Den meisten studentischen Aktivisten ging es, wie noch zu sehen sein wird, schlicht um die Schaffung und Absicherung beruflicher Privilegien und individueller Lebenschancen - ganz abgesehen von den traditionalistischen, männerbündischen, chauvinistischen und schließlich völkischen Traditionen studentischer Assoziation. Doch immer wieder versuchten Teile der deutschen Studierendenschaft, einen produktiven Umgang mit jenem ambivalenten Gemisch aus akademischer Tradition und reformerischem Fortschrittswunsch zu finden, der die Universitäten schon um 1800 auszeichnete. Das barg (und birgt) eine immer wieder durchscheinende Möglichkeit des Durchbrechens von Zyklen, in denen die Tatkraft einer vorwärtsdrängenden Generation (oder eines einflussreichen Teils von ihr) sich schließlich darin erschöpfte, alte Eliten abzulösen und sich selbst an ihre Stelle zu setzen. Doch gerade der ephemere und fragile Status des potenziell gänzlich Anderen, das auf die Ahnung einer herrschaftsfreien Gesellschaftsform hinausläuft, drohte zugleich stets den inhärenten politischen Ambivalenzen studentischer Emanzipationsideen zum Opfer zu fallen. Das verleiht dem wiederkehrenden studentischen Oszillieren zwischen 
Engagement und Enttäuschung ${ }^{24}$ ein tragisches Aroma. Denn der Zug der Geschichte hinterließ auch im Feld der deutschen Studierendenschaft, insbesondere ihrer liberalen und libertären Strömungen, eine Reihe unvollender Projekte und geradezu zwangsläufig gescheiterter Vorhaben. Die Trauer des Nachgeborenen darüber, dass diese historischen Traditionslinien in der heutigen bundesrepublikanischen Bildungsgesellschaft so fundamental verwischt zu sein scheinen, bildet durchweg Initiativpunkt und Erkenntnishorizont der hier unternommenen grundlegenden Auseinandersetzung mit der Frage nach dem politischen Potenzial deutscher Studierender. Sie ist es, die Rückblick und Gegenwartsanalyse verklammert und die Deutungsarbeit ${ }^{25}$ am zusammengetragenen Material anleitet.

\title{
I.3 Das politische Potenzial von deutschen Studierenden. Konkretisierung des Forschungsgegenstands
}

\author{
„[...] alle Begriffe, in denen sich ein ganzer \\ Prozess semiotisch zusammenfasst, entzie- \\ hen sich der Definition; definirbar [sic] ist \\ nur Das, was keine Ceschichte hat. ${ }^{\text {26 }}$
}

Wie eingangs erwähnt, visiert diese Studie einen Forschungsgegenstand, dessen Gestalt, ja nicht einmal dessen empirische Existenz sie zweifelsfrei voraussetzen kann. Sie wäre daher schlecht beraten mit einem Untersuchungsdesign, welches ihren Gegenstand in ein enges Korsett von Determinanten einschnürt und dabei Gefahr läuft, Zusammenhänge zu übersehen, die bei einem offeneren Vorgehen womöglich sichtbar geblieben wären. Andererseits birgt ein im Wortsinne schrankenloses Laisser-faire das Risiko schlechter Beliebigkeit. Zwischen der Skylla des rigiden Szientivismus und der Charybdis des methodisch ungebundenen Essayismus muss also ein drittes Vorgehen möglich sein, und dieses wird hier angestrebt: die Versenkung in den Gegenstand durch einen denkenden Betrachter, die bei einer vagen Ausgangsfragestellung beginnt, um sich im Fortgang des Forschens sukzessive zu konkretisieren, überdies an entscheidenden Scharnierpunkten Zwischenresultate zu fixieren. Noch vor der Verortung der Studie im einschlägigen Forschungsfeld und der Erläuterung des methodischen Vorgehens soll daher ein analytisch konsistenter Vorbegriff des politischen Potenzials entwickelt werden, welcher den Fortgang der Studie anleitet, ohne sich der späteren Modi-

24 Vg. Hirschman, Albert O.: Engagement und Enttäuschung. Über das Schwanken der Bürger zwischen Privatwohl und Gemeinwohl, Frankfurt a.M. 1984.

25 „Das Tiefste, was vielleicht Deutung dem Ceist überhaupt verspricht, ist, daß sie uns dessen versichert, daß das was ist nicht das letzte [sic] ist, - oder vielmehr das ist, was nicht nur das ist, als was es sich gibt. [...] Deuten heißt tatsächlich, der Spur dessen innewerden, was an dem was ist hinausweist über das bloß Seiende, - und zwar vermöge der Kritik, also vermöge der Einsicht gerade in die Vergängnis, die Unzulänglichkeit und die Fehlbarkeit des bloßen Seins." Adorno, Theodor W.: Zur Lehre von der Geschichte und von der Freiheit [1964/1965], Frankfurt a.M. 2006, S. 194.

26 Nietzsche, Friedrich: Zur Genealogie der Moral. Eine Streitschrift [1887], in: Colli, Giorgio/Montinari, Mazzino: Jenseits von Gut und Böse. Zur Genealogie der Moral. Kritische Studienausgabe, Bd. 5. Deutscher Taschenbuch Verlag, München 1999, S. 71. 
fikation respektive Revision zu sperren. Gemeint ist damit eine auf einer ersten kursorischen Schau basierende einführende begriffliche Konkretisierung dessen, wonach gesucht wird. Diese Konkretisierung aber hat, da sie nichts beweist, sondern nur aufzeigt, den Charakter einer vorläufigen Präsentation der untersuchten Zusammenhänge. Ob sich die Zusammenhänge in dieser oder ähnlicher Gestalt dann auch historisch und/oder empirisch nachweisen lassen, ist hingegen Gegenstand der Studie insgesamt. In diesem Sinne liefern die hier aufgeführten Faktoren noch keinen „gefüllten“ Begriff des politischen Potenzials von Studierenden, sondern eben einen Vorbegriff. ${ }^{27}$

Seit der Mitte des vergangenen Jahrhunderts hat es hier verschiedene Versuche gegeben, das politische Potenzial von Studierenden zu bestimmen und zu erforschen; sie alle sind abhängig von der jeweiligen gesellschaftspolitischen Situation. Das Panorama der Bezugnahmen reicht von der feierlich-pastoralen, feuilletonistischen oder historiographischen Romantisierung über die marxistisch unterfütterte Hoffnung auf eine Trägerschicht des demokratischen Fortschritts bis hin zur nüchternen und zeitlos wiederholbaren sozialforscherischen Operationalisierung.

Wie aus einer anderen Zeit wirken etwa Dokumente der frühen 1960er Jahre, in denen Hoffnungen in den politischen Freiheitsdrang und die antizipative Wachsamkeit der akademischen Jugend in der jungen bundesrepublikanischen Demokratie deutlich artikuliert werden. Der CDU-Politiker, Arzt und Theologe sowie damalige Herausgeber des Akademischen Dienstes in Bonn, Berthold Martin, dem die Ehre des Vorworts für eine Meinungsumfrage unter Studierenden zugefallen war, deklarierte feierlich und mit dem vollen Gewicht historischer Legendenbildung:

„Ihre Beteiligung an geschichtlichen Vorgängen (1813, Hambacher Fest 1848) gibt der Studentenschaft von vornherein ein gewisses Prestige. Sie stellte die Vorhut in manchem Umbruch; sie gilt als wetterfühlig und sensibel für kommende Ereignisse. Ihr traut man zu, daß sie schneller mit Vorurteilen fertig wird und die Kühnheit des Vorgriffs besitzt. Wissenschaft, gegründet auf die Redlichkeit des Fragens und die Offenheit für Wahrheit, wird nur auf dem Boden von Freiheit möglich, stellt in der Realität die Frage nach der Freiheit in der Gesellschaft und im Staat, und so kommt es, daß Studenten bis in unsere Tage die Anwälte politischer Freiheit sind. [...] Das Interesse für die Tendenzen innerhalb der Studentenschaft als eines Teiles der Jugend ist deshalb allgemein."28

Anlass zur Hoffnung auf den jungakademischen Avantgardismus gewann Martin dabei am Phänomen der Jugendbewegung der Jahrhundertwende, verstanden als Jugendgeneration, die sich (zumindest teilweise) tatsächlich als politisches Subjekt verstanden hatte und in Gestalt moderner politischer Jugendorganisationen fortwährende politische Mitwirkungsinstanzen geschaffen habe. ${ }^{29}$ Sicher: Berthold hatte hier auch ein em-

27 Vgl. zum Verständnis von Vorbegriff und Begriff am Gegenstand von Hegels Verständnis von Philosophie den Aufsatz von Fulda, Hans Friedrich: Vorbegriff und Begriff von Philosophie bei Hegel, in: Henrich, Dieter (Hg.): Hegels Logik der Philosophie. Religion und Philosophie in der Theorie des absoluten Geistes, Stuttgart 1984, S. 13-34, hier S. 13f.

28 Stifterverband für die deutsche Wissenschaft: Das geistige Bild der Studenten, S. $5 f$.

29 Vgl. ibid., außerdem den biographisch geprägten Essay über die stark subkulturell geprägte Jugendbewegung und ihre zumindest interpretierbare politische Dimension: Knoll, Joachim $\mathrm{H}$.: 
pirisches Forschungsinteresse zu begründen, aber allein stand er mit seiner Sichtweise nicht. Denn ganz ähnlich liest sich eine 1967 veröffentlichte „Sitten- und Sozialgeschichte" der deutschen Studenten seit dem Hochmittelalter. Auch hier wird ein ehernes Band zwischen studentischem Freiheitsdrang und politischem Emanzipationskampf stipuliert, ja zu einer jahrhundertealten, mithin universalgeschichtlichen Größe stilisiert:

„, Freiheit schreibt auf eure Fahnen!' Der deutsche Student hat diese Freiheit allerdings immer auch politisch und sozialkritisch verstanden. Gegen die Tyrannei der Fürsten protestierten leidenschaftlich die Medizinstudenten Friedrich Schiller und Georg Büchner. Im Kampf gegen Napoleon wurden Studenten zu ,Lützows wilder, verwegener Jagd' und für Einheit und Freiheit standen sie 1848 auf den Barrikaden von Wien, Frankfurt und Berlin, und noch rund hundert Jahre später starben sie als Opfer Hitlers oder Stalins für die gleichen Ideale. ${ }^{\text {“30 }}$

Die Freiheit im Blut, eine Achse von 1848 über 1900 bis 1967 - wie stimmt ein solch launiges, in der westdeutschen Intellektualität der 1960er Jahre keinesfalls seltenes, Resümee mit dem bildungsbürgerlichen Antisemitismus des Deutschen Kaiserreichs zusammen, an dessen Verbreitung und Konsolidierung die deutschen Korpsstudenten maßgeblichen Anteil hatten? ${ }^{31}$ Wie harmoniert der hier reklamierte Status als „Opfer“ des Zweiten Weltkrieges mit der entwaffnenden Leidenschaft, die die deutschen Studenten in den 1920er Jahren bei der Nazifizierung der studentischen Subkultur und der Universität bewiesen, wie mit den antisemitischen Krawallen gegen jüdische, liberale und sozialdemokratische Kommilitonen und Professoren im Zuge ihres ressentimentgeladenen Aufstandes gegen die Ordnung der republikanischen Eliten ab 1925? ?2 $^{32}$

Deutlich analytischer, wenn auch kaum weniger euphorisch brummend, gehen Jürgen Habermas, Ludwig von Friedeburg, Christoph Oehler und Friedrich Weltz in der gemeinhin als klassisch geltenden Studie Student und Politik von 1961 vor. Sie verstanden das politische Potenzial von Studierenden nicht als vage überhistorische Triebkraft, sondern machten es erstmals zum Gegenstand eines empirischen Forschungsprojekts. Dabei deduzierte man die Möglichkeit freier politischer Kräftereservoirs aus Erwägungen über die allgemein beschränkten Partizipationsmöglichkeiten in der parlamentarischen Demokratie; der Hintergrund der Überlegungen war weniger die Rolle studentischen Protests für politische Großveränderungen in soziodemographisch anders strukturierten Gesellschaften - wie dem damaligen Ägypten und Ungarn, in Korea, der Türkei und Japan -, sondern schlicht die Beobachtung der vorübergehenden beruflich-moralischen Ungebundenheit von Studierenden als auch ihrer Zielbeschäfti-

Typisch deutsch? Die Jugendbewegung. Ein essayistischer Deutungsversuch, in: Knoll, Joachim H./Schoeps, Julius: Typisch deutsch: Die Jugendbewegung, Opladen 1988, S. 11-34.

31 Vgl. Jarausch, Konrad H.: Deutsche Studenten 1800-1970, Frankfurt a.M. 1984, S. 84.

32 Vgl. Kater, Michael H.: Studentenschaft und Rechtsradikalismus in Deutschland 1918-1933. Eine sozialgeschichtliche Studie zur Bildungskrise in der Weimarer Republik, Hamburg 1975, S. 145 und $153 f$. 
gung als „Schlüsselgruppe“ für spätere „funktionelle Eliten“. ${ }^{33}$ In anderen Worten: Man hielt ihre politischen Einflussaussichten für vielversprechend. Dabei stellte die von Habermas verfasste Einleitung nicht nur sozialphilosophische Reflexionen an, sondern trägt gewiss Züge eines politischen Manifests: Er bestimmte das „politische Potenzial“ hier kryptosozialistisch-evolutionstheoretisch, über eine spezifische historische Funktion studentischer Impulse für die Beschleunigung einer als im „entwicklungsgeschichtlichen Zusammenhang“ begriffenen und in marxistischen Termini fassbaren sozialen wie politischen Vollendung des Demokratisierungsprozesses der deutschen Gesellschaft, präzise: zur „Entwicklung der formellen zur materialen, der liberalen zur sozialen Demokratie“, also zur Herstellung einer soziale Teilhaberechte garantierenden Wirtschaftsform ${ }^{34}$ sowie eines politischen Herrschaftssystems, das „Herrschaft auf rationale Autorität, nämlich auf Teilung von Arbeit und Erfahrung sowohl im Interesse als auch unter Kontrolle aller Individuen“ begründet. ${ }^{35}$ So heißt es:

„Am ehesten [...] dürfte noch von Studenten eine gewisse Beschäftigung mit den politischen Risiken der Gegenwart und womöglich Einsicht in die Chancen zu erwarten sein, die eine auf ihrem gegenwärtigen Stand erhaltene, und erst recht eine in ihren eigenen Intentionen verwirklichte Demokratie für das Wohl der Gesellschaft im ganzen ebenso eröffnet wie für den Schutz, die Freiheit und vielleicht gar das Clück der persönlichen Lebensgeschichte. ${ }^{\text {"36 }}$

Studentisches politisches Potenzial meint in dieser Konzeptualisierung also eine Form von säkularisierter historischer Mission zur Durchsetzung einer neuen radikaldemokratischen Gesellschaftsform - was dem akademischen Nachwuchs als Trägern des Fortschritts in Richtung egalitärer Teilhabechancen eine erstaunliche Verantwortung auflädt. Überdies blieb der einleitende Aufsatz von Habermas unbehelligt von den teils ernüchternden Ergebnissen der Studie, die das Verhältnis der Studierendenschaft zur Demokratie insbesondere im Krisenfall als eher instabil erwiesen. ${ }^{37}$ Durchsetzen konnten sich jene studentischen Kräfte, die ein solches Ziel in den 1960er Jahren tatsächlich visierten, bekanntlich ohnehin nicht: 1968, nachdem der hochschulpolitische Konflikt an der Freien Universität (FU) Berlin in die westdeutsche Studentenbewegung gemündet war, erinnerten Friedeburg et al. noch einmal an die verpasste Gelegenheit, an der Wegscheide der „historischen Alternative von autoritärer und sozialer Demokratie“ den ersten Schritt in Richtung letzterer zu tun, wie es durch eine Einlösung der vom Sozia-

Habermas, Jürgen/Friedeburg, Ludwig von/Oehler, Christoph/Weltz, Friedrich: Student und Politik. Eine soziologische Untersuchung zum politischen Bewußtsein Frankfurter Studenten, Neuwied 1961, S. 53-55.

Diese Wirtschaftsform habe „die erarbeiteten Mittel der Bedürfnisbefriedigung, die materiellen und geistigen Produktivkräfte im Interesse der Bedürfnisbefriedigung aller Individuen" zu verwenden, „und nicht nur in partikularem Interesse“. Ibid., S. 55. Ibid.

36 Ibid.

37 Nur 9 Prozent bewiesen ein „definitiv demokratisches" Potenzial, 16 Prozent ein „definitiv autoritäres“ - während zwei Drittel der Studierenden ein „unprofiliertes“ Potenzial zeigten. Ibid., S. 232. 
listischen Deutschen Studentenbund (SDS) vorgebrachten Reformvorschläge demnach hätte gelingen können. ${ }^{38}$

Solche Töne klingen heute mehr als ungewohnt. Das ist kein Zufall: Schon seit den frühen 1970er Jahren befindet sich die optimistische Suche nach einer politisch aktivierbaren Studierendenschaft im Rückbau, auch infolge der Bildungsexpansion und des mit ihr verbundenen Charakterwandels akademischer Bildung. Das Bild des studentischen politischen Verhaltens trübte sich in vielfacher Hinsicht ein: Zunächst war es die befürchtete studentische politische Radikalität und Verachtung gegenüber den demokratischen Institutionen, die eine kontinuierliche Beforschung der Stimmungslagen und politischen Orientierungen ins Leben rief - während es seit Ende der 1980er Jahre im Gegenteil die nunmehr diagnostizierte politische Apathie und Apolitizität ist, die Politikwissenschaftler und Soziologen in Stirnrunzeln verfallen lässt. ${ }^{39}$ So hob Uwe Schlicht, ein weiterer Chronist studentischer Bewegungen, angesichts der protestreichen 1970er Jahre und verbreiteter akademischer Arbeitslosigkeit, 1980 einen besonders gefährlichen Zug des politischen Potenzials von Studierenden hervor, nämlich die potenzielle Verbissenheit und innere Uniformierung, ja antidemokratische Verführbarkeit in Zeiten sozialer und kultureller Frustration sowie beschädigter gesellschaftlicher Anerkennung. Er erinnerte an die völkisch agitierenden Studenten der 1920er und 1930er Jahre:

„Wer [...] der heutigen Ceneration der Studenten angesichts einer drohenden Akademikerarbeitslosigkeit die Formel vorhält, Bildung sei ein Wert an sich, kann nicht erwarten, damit Ängste zu überwinden. [...] Noch weniger werden mit Aussagen diese Art die geburtenstarken Jahrgänge abzuspeisen sein, die zwischen 1980 und 1990 von den Schulen und Hochschulen in die Berufe drängen. Wer wird ihre Interessen wahrnehmen, wer wird ihnen Sicherheit und eine von ihnen akzeptierte Zukunft geben? [...] Die Geschichte der Weimarer Republik zeigt, daß sich die junge Generation, wenn die etablierten Parteien sich ihrer nicht annehmen, den radikalen Außenseiterparteien zuwendet. Extremisten leben als Minderheiten davon, sich derer anzunehmen, die in den gesellschaftstragenden Organisationen keine Heimat finden. ${ }^{400}$

Im Jahre 1980 erschien daher eine neue Welle radikaler, womöglich deutlich militanterer, Studentenproteste immerhin denkbar. ${ }^{41}$ Hieraus erklärt sich das in den frühen 1980er Jahren, dem Zeitraum der an den Universitäten reüssierenden Alternativbewegung, auffällig rege Interesse an einer politischen Studentengeschichte. Eine InfratestStudie etwa, die die Protestneigung unterschiedlicher Bevölkerungsgruppen im Vergleich untersuchte, auch um das politische Potenzial der Studierenden zu messen und

38 Friedeburg, Ludwig von/Horlemann, Jürgen/Hübner, Peter/Kadritzke, Ulf/Ritsert, Jürgen/Schumm, Wilhelm: Freie Universität und politisches Potential der Studenten, Neuwied/Berlin 1968, S. 18f. Dass die Kategorie des politischen Potenzials der Studierenden hier weitgehend wie in der Studie von Habermas et al. - als Demokratie stärkendes und expandierendes Potenzial konkretisiert und gemessen wird, ist ibid., S. 216-237 nachzulesen.

40 Schlicht, Uwe: Vom Burschenschafter bis zum Sponti. Studentische Opposition gestern und heute, Berlin 1980, S. 10. 
die in ihren Reihen vermutete Gefahr politischer Radikalität einzuschätzen, machte denn auch eine „besonders zum politischen Protest neigende Bevölkerungsgruppe“ aus, nämlich die ,jungen, formal besser Gebildeten ${ }^{442}$ - und stellte fest, dass 30 Prozent der deutschen Studierenden ein spezifisch linkes ${ }^{43}$ Protestpotenzial aufwiesen - gegenüber 4,4 Prozent in der Gesamtbevölkerung. ${ }^{44}$ Zugrunde lag dabei eine lineare Steigerungslogik, die so genannte „Protestpotenzialskala“45 nach Max Kaase. Den Schlusspunkt setzte hier der bemerkenswerte Rundumschlag des Historikers Konrad H. Jarausch, der 1984 aus zweihundert Jahren Studentengeschichte ein „Grundmuster" studentischer Verhaltenstypen destillierte: die Hegemonie des „Angepaßten“, für den der „Hauptstudienzweck die Berufsausbildung“ gewesen sei, stehe dem marginalen Auftreten des „Aussteigers“ und des „kritischen Akademikers“ gegenüber. ${ }^{46}$ Zwar sei „eine Mehrheit der Studierenden meist apolitisch“ gewesen, doch „Phasen des starken Engagements wechselten mit anderen Phasen der desinteressierten Passivität ab. ${ }^{\text {“47 }}$ Die Struktur des politischen Potenzials von Studierenden sei demnach als „Resultat einer komplexen Interaktion zwischen Bildungswachstum, Subkultur und dahinterliegenden sozialen und politischen Prozessen" aufzufassen. ${ }^{48}$ Jenseits des jeweils gegebenen historischen Zeitpunktes scheinen zumindest demnach keine langfristig gültigen Potenziale auszumachen zu sein. Mit anderen Worten: Das etwaige politische Potenzial sei in der je gegebenen historischen Situation zu bestimmen.

Nach diesen eher nachdenklichen Einschätzungen sank das allgemeine Interesse am politischen Bewusstsein und Verhalten der Studierenden ab. Seit etwa vierzig Jahren sind systematische Studien dieser Art wohl auch aus diesem Grund weitgehend ausgeblieben. An ihre Stelle tritt - bis heute - die surveybasierte Einstellungsforschung, die mit festgelegten und quantifizierbaren Itemkatalogen Stimmungsbilder der deutschen Studierendenschaft zeichnet. Das Interesse an (handhabbar quantifizierbaren) Einstellungen löste früh das Interesse am (mehrschichtigen, anspruchsvoller zu erforschenden) Bewusstsein ab. In den späten 1980er und 1990er Jahren war es nicht mehr die womöglich drohende radikale Politisierung, die wissenschaftliche Sorgenfalten evozierte, sondern im Gegenteil

Infratest Wirtschaftsforschung $\mathrm{GmbH}$ : Politischer Protest in der Bundesrepublik Deutschland. Beiträge zur sozialempirischen Untersuchung des Extremismus, Stuttgart/Berlin/Köln/Mainz 1980, S. 51. Genauer: „Personen mit hohen Werten auf der Protestpotentialskala - sind überdurchschnittlich jung, - besitzen eine gute Schulbildung, - haben relativ häufig Hochschulreife, - sind überdurchschnittlich häufig konfessionslos, - sind überdurchschnittlich häufig ledig, und - sind zu einem überdurchschnittlich hohen Anteil in Ausbildung." Ibid., S. 52 (Herv. i. O.)

Damit ist die Hinneigung zu politischem Protest im Sinne spezifischer Einstellungs- und Orientierungsdimensionen in Form von sieben „Typen“ gemeint, ibid., S. 113-117.

44 Vgl. ibid., S. 54.

45 Ibid., S. 39-45. Die Skalenwerte zur Ermittlung des Protestpotenzials errechnen sich hier über freiwillige Angaben zu zehn Items über das individuelle Aktivitätsniveau: Beteiligung an einer Unterschriftensammlung (Skalenwert 1), Teilnahme an einer Bürgerinitiative (2), Teilnahme an einer genehmigten politischen Demonstration (3), Beteiligung an einem Boykott (4), Weigerung, Mieten, Raten oder Steuern zu bezahlen (5), Blockieren des Verkehrs mit einer Demonstration (6), Beteiligung an einem wilden Streik (7), Besetzung von Fabriken, Ämtern und Gebäuden (8), Beschädigung fremden Eigentums (9) und Anwendung von Gewalt gegen Personen (10). Ibid., S. 41. Jarausch, Konrad H.: Deutsche Studenten 1800-1970, Frankfurt a.M. 1984, S. 247-250.

47 Ibid., S. 245.

48 Ibid., S. 246. 
die Diagnose einer entpolitisierten, teilnahmslosen Studierendenschaft. Die bedenklichsten Passagen einschlägiger Studien finden sich bezeichnender Weise dort, wo wieder einmal - die Atrophie an politischem Engagementwillen und politischer Phantasie unter deutschen Studierenden beklagt wird ${ }^{49} 1996$ beispielsweise stellte eine Studie eine allmählich absinkende Orientierungskraft der traditionellen Deutungsangebote „linker“ wie „rechter“ Provenienz für die Studierenden fest, während die Distanz zur demokratischen Gesellschaft und ihren Institutionen weiter gewachsen sei..$^{50}$ Auch der am Studierendensurvey maßgeblich beteiligte Tino Bargel zog wiederholt vernichtende Bilanzen zum Bewusstseinsstand der Studierenden. 1994 fragte er in der Zeitschrift hochschule ost nach dem „politischen Potential der Studierenden an Universitäten in Ostund Westdeutschland“51 - wenngleich mit dem ernüchternden Ergebnis einer weitgehenden hochschul- und gesellschaftspolitischen Apathie - und legte 2009 mit seiner Diagnose einer „ratlosen Generation“ nach: Studentisch seien nun vor allem „Rückzug, Labilität und Konventionalität“, ferner die Trends „,von der aktiven Beteiligung zur passiven Kundschaft“, „,von Stellungnahmen zu Beliebigkeiten oder Gleichgültigkeiten“, und „vom starken Selbstbewusstsein zu Unsicherheiten“..$^{52}$ Angesichts dieses Abgesangs auf die politischen Qualitäten der Studierenden mag es merkwürdig erscheinen, dass das studentische Protestpotenzial aus der Sicht desselben Autors insgesamt kaum gesunken ist. Die Quellen bzw. Vorzeichen dieses Potenzials aber könnten sich von stärker ideellen Motivlagen in amorphes Unmutspotenzial gewendet haben. 1989, nach den ersten drei Studierendensurveys, hält Bargel noch fest, dass das wiederholt gestiegene „subjektive politische Kompetenzgefühl“ der Studierenden, verbunden mit der Empfindung normativer Verpflichtung zu politischer Verantwortung, als Indiz dafür gewertet werden könne, „daß politische Aktivitäten von Studierenden - bei aktuellen Anlässen jederzeit wieder möglich“53 seien. Etwa zehn Jahre später aber, 1998, zog er sich auf einen sichtlich anspruchsloseren Begriff des politischen Potenzials zurück: Zwar sei keine organisierte Studentenbewegung ${ }^{54}$ mehr zu erwarten, wohl aber sporadische Protestaktionen, auch in der Gestalt egoistisch-materiell motivierter Inzivilität. So führt der langjährige Sozialforscher aus:

„Seit dem studentischen Aufbegehren in der zweiten Hälfte der 6oer Jahre wird immer wieder die Frage gestellt: Wann protestieren die Studierenden? [...] Studierende

49 Vgl. Bargel/Simeaner: Gesellschaftliche Werte und politische Orientierungen der Studierenden, S. 14-16, sowie Demirovic, Alex: Die politische Metapher links S. 371 und S. 389-391, der ibid. die Entwicklung studentischer politischer Orientierungen auf eine „Krise der Linken“ zurückführt.

Vgl. Demirović, Alex/Paul, Gerd: Demokratisches Selbstverständnis und die Herausforderung von rechts: Student und Politik in den neunziger Jahren. Studienreihe des Instituts für Sozialforschung, Frankfurt a.M. 1996, S. 243f. und Demirovic, Alex: Die politische Metapher links und die politischen Orientierungen von Studierenden, in: PROKLA H. 104/1996, S. 371-394, hier S. 389-391.

51 Bargel, Tino: Zum politischen Potential der Studierenden an Universitäten in Ost- und Westdeutschland, in: hochschule ost. politisch-akademisches journal aus ostdeutschland, H. 3/1994, S. 9-18.

52 Bargel, Tino. Student und Politik: die ratlose Generation. Bd. News 30.3. AG Hochschulforschung, Universität Konstanz, 2009, S. 1.

53 Studierendensurvey $1980 \mathrm{er}$, S. 217.

54 Zur Bestimmung von Studentenbewegungen im Unterschied zu Studentenprotest vgl. Kapitel II.2 dieser Studie. 
haben offensichtlich eine grundsätzliche oder latente Neigung zum Protestieren und Demonstrieren; in den Formen sind sie oftmals nicht zimperlich. Die Bereitschaft dazu hatte sich zwar - analog zum politischen Interesse - abgeschwächt, aber: aufgrund unserer Befunde konnte man nicht davon ausgehen, daß die Studierenden ihre Kritik und ihre Protestbereitschaft endgültig an den Nagel gehängt hatten. Ihre grundsätzliche Protestbereitschaft, auch in aggressiveren Formen, war durchaus vorhanden geblieben, bei geringem Abebben. Sie war zudem verbunden mit verbreiteter Unzufriedenheit an den politischen Mitwirkungs- und Einflußmöglichkeiten, in West wie Ost, sowie mit starker Kritik an Parteien und Politik. All dies ist eine Voraussetzung und kann dazu beitragen, daß die Studierenden Anlässe finden, ihre latente Protestbereitschaft wieder zu aktivieren. [...] Bei ihren Forderungen, in unseren Umfragen wie auf ihren Flugblättern und Plakaten, denken sie dabei häufiger an sich und die Verbesserung ihrer Lage, als an andere und die Verbesserung der Welt. ${ }^{455}$

Auch der aktuelle 13. Studierendensurvey, durchgeführt im Wintersemester 2015/16, zeigt, dass die gemessenen Zahlen weiterhin einen solchen Schluss hergeben - obwohl er im Bericht so selbst nicht gezogen wird..$^{56}$

Tatsächlich ist augenfällig, dass es unter den an Hochschulen Immatrikulierten auch in den letzten Jahren immer wieder zu bildungspolitischen Protesten gekommen ist. Selten bleibt der Rekurs auf einen anspruchsvollen Bildungsbegriff neuhumanistisch-Humboldt'scher Prägung dabei aus: Das Studium scheint, wenn auch nur sporadisch, Ressourcen freizusetzen, politische Traditionslinien zu vererben, Ansprüche zu begründen. Ein Hauch von Studentenbewegung weht dort, wo studentische Streiks und Demonstrationen die öffentliche Aufmerksamkeit vereinnahmen - wie zuletzt bei den Studentenstreiks 1997, 2003 und 2009/10. Im Subtext erschien hier häufig der potenziell freiheitliche, kritische oder rebellische Geist des Studierendentums. Das aber erscheint vor dem Hintergrund dieser ersten Erkundung seltsam ahistorisch. Wird die Gruppe der Studierenden derart als Gruppe gefasst, die bisweilen als Brutstätte von zukunftsgewandter Innovationskraft, gesellschaftspolitischer Phantasie und somit auch heilsamer kritischer, subversiver oder oppositioneller Energien erscheint, in Phasen vermuteter Rechtstrends aber auch als Quell bedenklicher, da womöglich autoritär verführbarer Energien, begibt man sich in den Bereich der Mythenbildung. Im ersteren Falle dient meist die Bezugnahme auf die Studentenbewegung von „1968“ als Kontrastfolie, um sich über den intellektuellen und politischen status quo der gegenwärtigen Studierendenschaft zu beklagen oder trotzig die unveränderte Möglichkeit demokratieförderlicher studentischer Subversivität $\mathrm{zu}$ insinuieren. ${ }^{57}$ Mythen dieser Art überblenden, dass massenhafter studentischer Protest sich historisch gesehen nie

55 Bargel, Tino: Wandel des politischen Bewußtseins und der Meinungsführerschaft deutscher Studierender? Befunde des Studierendensurveys 1983-1998. Referat bei der Fachtagung der Hessischen Landeszentrale für Politische Bildung „Politisches Bewußtsein von Studierenden in Hessen 1918 - 1998“, am 17. Juni 1998 im Studentenhaus der J. W. Goethe Universität, Frankfurt a.M. AC Hochschulforschung, Universität Konstanz 1998, S. 11f.

56 Vgl. dazu 13. Studierendensurvey 2015/16, ferner Kapitel II.3.4 dieser Studie.

57 Vgl. exemplarisch Fries, Meike: „Studenten sind ein Unruheherd“. Interview mit Dieter Rucht, in: Zeit Online, 18.01.2011, online einsehbar unter: http://www.zeit.de/studium/hochschule/2011-01/ studenten-tunesien [eingesehen am 01.08.2019]. 
allein aus ideeller Überzeugung, sondern auch und ganz maßgeblich aus dem Drängen in Karrieren, an die diskursive Deutungshoheit sowie aus einem langlebigen elitären Standes- und Sendungsbewusstsein speiste. ${ }^{58}$ Überhaupt bildet sich - folgt man dem Modell des norwegischen Soziologen Johan Galtung, das bezeichnenderweise aus den frühen 1970er Jahren stammt - ein wesentlicher Keim sozialer Revolten dort, wo eine signifikante Masse blockierten aufstiegsorientierten bürgerlichen Nachwuchses eine restriktive "feudale[] Gesellschaftsordnung“ vorfindet, die sich „um eine meritokratische Achse dreht", also auf abgedichtete Hierarchien und versiegelte Karrierewege trifft. ${ }^{59}$ Für die materiell eher saturierte (wenngleich kulturell in gewisser Hinsicht heimatlose) deutsche „68er-Bewegung“, die in einer Phase beispielloser Bildungsexpansion mobilisierte, mag diese Formel zwar nicht vollumfänglich gelten. Doch ist in den unmittelbar zurückliegenden Jahren, etwa im arabischen Raum, in Frankreich oder in den südeuropäischen Ländern, das tatsächliche Protest- und Mobilisierungspotenzial perspektivloser Nachwuchs-Akademiker deutlich geworden. ${ }^{60}$ Für einen aktuellen Begriff des politischen Potenzials von Studierenden ist also auch wichtig: Wie sieht die Gegenwart der Studierenden in Deutschland, eines wirtschaftlich florierenden Staates mit deutlich niedrigerer Jugendarbeitslosigkeit und einer zahlenmäßig eher unterlegenen Jugend, tatsächlich aus?

Hier zeigt ein erster Blick: Obgleich zwischen den jeweiligen Fachrichtungen und Betätigungsfeldern erhebliche Unterschiede herrschen, sieht der akademisch gebildete Nachwuchs im Vergleich mit seiner „Babyboomer“-Elterngeneration zwar einer recht reibungsarmen beruflichen Einmündung, aber kaum nennenswerten Aufstiegschancen entgegen. Ein großer Anteil der Berufseinsteigerinnen und Berufseinsteiger - im branchenübergreifenden Mittel aktuell 45 Prozent - muss sich trotz stabilen volkswirtschaftlichen Verhältnissen zunächst einmal mit befristeten Arbeitsverträgen zufriedengeben; ${ }^{61}$ ganz besonders, wer eine akademische Karriere mit Weiterqualifikation nach der Graduierung verfolgt, ist im Mittel zu knapp 76 Prozent befristet, blickt überdies einer als unplanbar geltenden beruflichen Zukunft entgegen. ${ }^{62}$ Die Unter-30-Jährigen sehen sich derzeit verschlungenen Karriere-Aussichten, nicht selten versiegelten Führungsriegen und steigenden Wohnkosten gegenüber. Sie erreichen im Gegensatz zu ihren Eltern und Großeltern immer seltener die mittleren Einkommensklassen und müssen darüber hinaus auf die relativ sicheren Zinssätze der alten Bausparverträge und Lebensversicherungen verzichten; auch Renteneintrittsalter und Niveau der Altersversorgung erscheinen unsicher. OECD-Experten zufolge schrumpft daher (auch)

58 Vgl. dazu eingehend die Kapitel II.1 und II.2 dieser Studie.

59 Vgl. Galtung, Johan: Eine strukturelle Theorie der Revolution, in: Jänicke, Martin (Hg.): Herrschaft und Krise. Beiträge zur politikwissenschaftlichen Krisenforschung, Opladen 1973, S. 121-167, hier S. 166.

60 Kraushaar, Wolfgang: Der Aufruhr der Ausgebildeten. Vom Arabischen Frühling zur OccupyBewegung, Hamburg 2012.

61 Vgl. Bossler, Mario/Cürtzgen, Nicole/Kubis, Alexander/Moczall, Andreas: Befristungen bei Neueinstellungen. Institut für Arbeitsmarkt- und Berufsforschung (IAB), Nürnberg 2017, S. 4.

62 Vgl. Leischner, Franziska/Krüger, Anne K./Moes, Johannes/Schütz, Anna: Beschäftigungsbedingungen und Personalpolitik an Hochschulen in Deutschland, Projektbericht, Berlin 2016, S. i-iii, S. $23 f$. und S. 14-21. 
die deutsche Mittelschicht zu Ungunsten der „Millennials“: „The middle class dream is increasingly only a dream for many. “63 Trotz alledem aber bleiben Studierende relativ privilegiert: Die Verfügbarkeit attraktiver Karrierewege für prospektive Universitätsabsolventen und den akademischen Nachwuchs hält aufgrund der anhaltenden wirtschaftlichen Konjunktur vergleichsweise gut Schritt mit den fortschreitenden „Akademisierungs“-Dynamiken, also der rasant wachsenden Bildungsexpansion und der zunehmenden Verdrängung anderer Berufsausbildungswege durch das Studium. ${ }^{64}$ Noch immer tragen Bewerberinnen und Bewerber mit Universitäts- und Fachhochschulabschlüssen statistisch gesehen das geringste Risiko, Lohn und Brot einzubüßen. ${ }^{65}$ Angesichts dieser Gemengelage ist es nicht verwunderlich, dass von einer signifikant politisierten deutschen Studentenschaft oder einem kollektiv bekundeten Unmut, der zu hochschul- oder parteipolitischen, gewerkschaftlichen oder außerinstitutionellen Mobilisierungsbewegungen führen würde, aktuell nicht die Rede sein kann. Nur: Raum für manifesten Aufstiegsoptimismus lässt diese relative Sekurität eben auch nicht. ${ }^{66}$ Nicht einmal auf die die traditionellen Sekuritäts-Privilegien der gebildeten Mittelschichten der Eltern- und Großelterngeneration scheint man noch ernsthaft zu pochen. Der für manche Perioden, und in ganz besonderem Maße für die Studierenden der 1960er Jahre prägende Aspirationseifer scheint heute, sicher auch durch die veränderten Arbeitsmarktbedingungen verursacht, dem Wunsch nach einer ausgeglichenen Lebensführung bei komfortablem Auskommen gewichen $\mathrm{zu}$ sein. ${ }^{67} \mathrm{Nur}$ wenige lockt eine steile Karriere oder die Verheißung des sozialen Aufstiegs; die Aussicht auf Einkommen allein motiviert nicht zur Aufnahme eines Studiums. Familie, Freunde und Freizeit werden zunehmend ebenso wichtig gewertet wie Berufserfolg, Karriere und Einkommen. ${ }^{68}$ Politisches Interesse und Interesse am Zustand der Demokratie errei-

63 Vgl. OECD: Under Pressure. The Squeezed Middle Class, Paris 2019, insbesondere S. 13-14 und 42f.; das wörtliche Zitat ibid., S. 16.

64 Wolter, Andrä: Eigendynamik und Irreversibilität der Hochschulexpansion: Die Entwicklung der Beteiligung an Hochschulbildung in Deutschland, in: Banscherus, UIf/Bülow-Schramm, Margret/Himpele, Klemens/Staack, Sonja/Winter, Sarah (Hg.): Übergänge im Spannungsfeld von Expansion und Exklusion. Eine Analyse der Schnittstellen im deutschen Hochschulsystem, Bielefeld 2014, S. 19-38, hier S. 35-37.

65 Die Gefahr der Arbeitslosigkeit ist für sie statistisch gesehen am geringsten, vgl. 5. Bildungsbericht 2014, S. 135.

66 Eines der entscheidenden Motive der Studienaufnahme ist derzeit der Wunsch, vor Erwerbslosigkeit geschützt zu sein - nicht etwa die Erwartung fürstlicher Gehälter. Vgl. 13. Studierendensurvey 2015/16, S. 68. Dass die mit diesem Schicksal Cesegneten aus der Not die berühmte Tugend schmieden und sich die Rastlosigkeit ihrer Erwerbsbiographien mithilfe vormals sozialkritischer Motive nun als Flexibilität der eigenverantwortlichen opportunities zu eigen machen, ist der zentrale Topos einer berühmten Studie, die sich vergleichend mit der Managementliteratur der 1960er und 1990er Jahre auseinandersetzte, vgl. Boltanski, Luc/Chiapello, Ėve: Der neue Geist des Kapitalismus, Köln 2006.

67 Vgl. 13 Studierendensurvey 2015/16, S. $68 \mathrm{f}$.

68 Vgl. 12. Studierendensurvey 2012/13, S. 5 und 13. Studierendensurvey 2015/16, S. 14-16, insbesondere aber S. 79f.: „Partner, eigene Familie“ wurden von 85 Prozent, „Ceselligkeit, Freundes- und Bekanntenkreis“ von 84 Prozent, „Eltern und Ceschwister" von 82 Prozent als sehr wichtig identifiziert, „Politik und öffentliches Leben“ nur von 29 Prozent; ein Interesse an studentischer Politik äußerte mit 32 Prozent (FH) und 36 Prozent (Universität) nur ein Drittel der Studierenden. Vgl. ferner Knopke, Katharina/Krüger, Laura/Siri, Jasmin: Vereinzelt, konfliktscheu, weltof- 
chen gegenüber dem privaten Lebensbereich trotz jüngst leicht steigender Tendenz nur geringe Relevanzwerte; politisches Engagement, insbesondere in der studentischen Politik, lockt nur einen marginalen Teil. Prima facie also scheinen die bundesrepublikanischen Studierenden der späten 2010er Jahre weder über aktivistisches noch über elitäres Selbstbewusstsein zu verfügen, vielmehr eine verhalten optimistische, ${ }^{69}$ bisweilen defensiv anmutende Haltung eingenommen zu haben.

Andererseits aber mehren sich auch Hinweise mit Irritationspotenzial: Mehr und mehr Studierende betonen die kritische Rolle der Opposition in der Demokratie, gewichten das Demonstrationsrecht der Bürgerinnen und Bürger insgesamt höher als die Stabilität der öffentlichen Ordnung; ${ }^{70}$ der aktuelle 13. Studierendensurvey attestiert 55 Prozent unter ihnen eine „gefestigte positive Grundhaltung gegenüber der Demokratie in allen ihren Aspekten." ${ }^{\text {"1 }}$ Und nicht zuletzt gibt fast die Hälfte der Studierenden an Universitäten als Studienmotiv an, „die Gesellschaft verbessern“ zu wollen, ein neben der Einkommensorientierung in den letzten Jahren besonders stark gestiegener Wert. ${ }^{72}$ Handelt es sich hierbei um Lippenbekenntnisse eines Antwortverhaltens, das sich an den erwarteten Kriterien sozialer und politischer Erwünschtheit orientiert oder deuten diese Ergebnisse darauf hin, dass ein großer Teil der Studierenden die Demokratie als potenziell fragile Ordnung wahrnimmt, für die man persönlich, sei es individuell oder kollektiv, eintreten sollte? Schließlich führten nicht nur die mehrheitlich jungen Aktivistinnen und Aktivisten von NoPegida in den Jahren 2015 und $2016 \mathrm{ihr}$ Protestengagement auf die Empfindung staatsbürgerlicher Pflichten und demokratischer Verantwortung gegenüber der Gesellschaft - insbesondere im Falle gefährdeter demokratischer Prinzipien - zurück, ${ }^{73}$ auch unter den 2016 und 2017 vom Institut für Demokratieforschung befragten Jugendlichen und jungen Erwachsenen wurde über weit verbreitete Ängste vor einem Zerbrechen der Gesellschaft in unversöhnliche Fronten und von einem jüngst gewachsenen Bewusstsein über den Wert der Demokratie berichtet, über den man gerade angesichts globaler Entwicklungen wie der Wahl

fen? Studierende und Politik, Bonn 2017 und S. 7, pointiert auch Stoldt, Till-Reimer: Deutschlands Studenten geben sich der Sorglosigkeit hin, in: Welt Online, 06.07.2018, online einsehbar unter: https://www.welt.de/politik/deutschland/article178866492/Studenten-Studie-Beruflicher-Erfolg-verliert-extrem-an-Stellenwert.html [eingesehen am 01.08.2019] Zu den hier verwendeten abgekürzten Verweisen auf die Sozialerhebung des Deutschen Studentenwerks, auf den Studierendensurvey „Studiensituation und studentische Orientierungen“ der AG Hochschulforschung Konstanz und auf den indikatorengestützten Bericht „Bildung in Deutschland“ des Konsortiums Bildungsberichterstattung vgl. das Literaturverzeichnis dieser Studie.

Vgl. 13. Studierendensurvey 2015/16., S. $89 \mathrm{f}$.

Vgl. ibid., S. 91.

Vgl. ibid., S. 15.

73 Vgl. Marg, Stine/Trittel, Katharina/Schmitz, Christopher/Kopp, Julia/Walter, Franz: NoPegida. Die helle Seite der Zivilgesellschaft?, Bielefeld 2016, S. 66 und S. 81f. Damit ist nicht gesagt, dass die hier untersuchten Aktivistinnen und Aktivisten ihre Verpflichtungen durch das Protestengagement auch als erfüllt betrachten. Zudem ist fraglich, ob die von ihnen vertretene Vorstellung von demokratischen Mehrheiten tatsächlich pluralistisch ist, führte diese doch zum tendenziellen normativen Ausschluss der PECIDA-Demonstrantinnen und -Demonstranten aus der Cesellschaft, S. 133-139. 
Donald Trumps zum US-Präsidenten oder dem elektoralen Siegeszug rechtspopulistischer Parteien in Europa einzutreten habe. ${ }^{74}$ Problemwahrnehmungen in Bezug auf den Zustand der Gesellschaft und der sozialen Integrationskräfte inklusive der zivilen Umgangsformen, aber auch Sorgen um die demokratische Stabilität sind, so scheint es, unter Jugendlichen und jungen Erwachsenen im Allgemeinen und unter Studierenden im Besonderen in den letzten Jahren allmählich virulenter geworden. Könnten sich nicht auch derartige Regungen zu einem neuen Kollektivitätsempfinden zusammenziehen, wie es historischen Studentenbewegungen stets vorausgegangen war? Raum für eine Erörterung der spezifischen Ursachen, Ermöglichungsbedingungen und Ereignisketten historischer Studentenbewegungen verbleibt in den Forschungsdesigns der heute gängigen Survey-basierten Einstellungsforschung jedenfalls nicht.

Also: In der Zusammenschau scheint der Glanz studentischen Freiheitsdrangs verblasst. Auch eine selbstbewusste, ausdauernde und strukturierte Studentenbewegung steht zunächst offenbar nicht zu vermuten. Von ohnehin nur noch historischem Interesse scheint heute überdies das Zeitalter des säkularen Messianismus mit seinen reformerischen respektive revolutionären Erlöserfiguren und Trägergruppen (egal ob bürgerlicher, proletarischer oder studentischer Provenienz) zu sein. Zugleich aber entsteht der Eindruck historischer Kontinuitätslinien, der die - zumindest vorläufige Rede vom politischen Potenzial von Studierenden rechtfertigt. Der politische Student war stets und immer wieder ein virulentes Thema, wenn auch mit wechselnden Bedeutungsfacetten und unter verschiedenen historisch-gesellschaftlichen Bedingungen. Lässt sich beispielsweise eine studentische Prädisposition für die Teilnahme an Protesten nachweisen, die ganz profan auf die aus Lebenssituation und Studienfreiheit $\mathrm{zu}$ schöpfenden Ressourcen an Zeit, sozialer Ungebundenheit und einem weniger durch Konzessionen des Erwerbslebens gehemmten Wunsch nach (Um-)Gestaltung der Gesellschaft zurückzuführen ist - oder war studentischer politischer Aktivismus hauptsächlich ein Zufallsprodukt, etwa in Phasen gesamtgesellschaftlicher Politisierung? Insbesondere nötigt die historisch wandelbare Gestalt studentischer Protestereignisse zu einem möglichst weiten und integrativen Verständnis, soll nicht vorab eine normative Distinktion zwischen „echtem“, weil prodemokratischem oder produktivem, und „unechtem“, da unorganisiertem oder inzivilem, politischem Potenzial eingezogen werden.

In einer ersten Annäherung soll daher das politische Potenzial von Studierenden bestimmt werden als vermutete gruppenspezifische Prädisposition zu aktivem politischem Verhalten mit Schwerpunkt aufaußerparlamentarischem Engagement wie Protesten, Demonstrationen und Kundgebungen bis hin zu ausdauernden, von organisierten Netzwerken getragenen Studentenbewegungen, die diejeweils gegebenen gesellschaftlichen Verhältnisse insgesamt in Frage stellen. Für

74 Vgl. Schenke, Julian/Schmitz, Christopher/Marg, Stine/Trittel, Katharina: PECIDA-Effekte? Jugend zwischen Polarisierung und politischer Unberührtheit, Bielefeld 2018, S. 209-214 und S. 306-317. Es ist anzumerken, dass in den dort ausgewerteten Cruppendiskussionen nicht immer geklärt werden konnte, was genau eine Demokratie für die Gesprächspartner ausmacht. 
die Gestalt eines solchen Potenzials scheinen drei netzwerkartig zusammenwirkende ${ }^{75}$ Faktorengruppen ausschlaggebend zu sein:

\section{1) Politische Energiequellen:}

1a) Das durch eine Eintrübung von Berufsaussichten und statusbezogenem Selbstverständnis auslösbare Frustrationspotenzial;

1b) ein allgemein ausgeprägtes politisches Interesse;

1c) die Wahrnehmung gesellschaftlicher Missstände (sozial, kulturell, o. Ä.) bzw. einer aus dem Gleichgewicht geratenen Gesellschaftsordnung; ggf. auch eine spezifische, kritische Sichtweise auf die Funktionsweise der Demokratie bzw. ein verletztes Idealbild von (demokratischer) gesellschaftlicher Ordnung;

\section{2) Politische Formativkräfte:}

2a) Die inhaltliche Stoßrichtung bzw. die Zielvorstellungen der studentischen Gesellschaftskritik, auch die Struktur intellektueller und politischer Konfliktlinien;

2b) die praktische Betätigungsfähigkeit und -bereitschaft;

2c) der politische bzw. zivilgesellschaftliche kollektive Organisationsgrad der Studierenden.

\section{3) Exogene Ermöglichungsbedingungen und historische Situation:}

3a) Langfristige soziale, wirtschaftliche, politische und kulturelle Umbrüche und das mit ihnen zusammenhängende Aufstauen von gesellschaftlichem Konfliktpotenzial, etwa zwischen modernisierungs- und fortschrittsbefürwortenden Kräften und konservativen bzw. traditionalistischen Gegentendenzen;

3b) auslösende Ereignisse und kurzfristige Gelegenheitsfenster.

\section{I.4 Bestimmung des Beitrags zur bisherigen Forschung}

Inwiefern ist der so bestimmte Gegenstand - das politische Potenzial von Studierenden in Geschichte und Gegenwart - bereits erforscht worden, und worin besteht der Beitrag der vorliegenden Studie? Das hier verfolgte Vorhaben knüpft an historische Darstellun-

75 Zum besseren Verständnis erscheinen zwei Anmerkungen hilfreich. Erstens: Diese Faktorengruppen stellen selbstverständlich keinen Katalog gleichwertiger notwendiger Bedingungen dar. Grundsätzlich kann bereits das Auftreten einzelner Phänomene zur Entstehung studentischen Protests führen, so etwa die Faktoren 1a) und 1b). Zweitens: Dem sozialpsychologischen Blick wird das Fehlen (kollektiv-)psychologischer Kategorien und individuell prägender sozialisatorischer Faktoren auffallen. Dadurch soll ebendiesen Faktoren keineswegs die bisweilen konstitutive Bedeutung für die Genese von politischen Bewegungen abgesprochen werden. Vielmehr sieht sich die hier verfolgte politologische Fragestellung mit einer sozialpsychologisch versierten Ursachenforschung überfordert und behandelt daher Affekte, kognitive Dissonanzen ebenso wie die Projektivität gesellschaftlich verbreiteter Wahrnehmungsformen, insbesondere des Ressentiments, stillschweigend als potenzielle Einflussgrößen aller Faktorengruppen. 
gen, an politisch-soziologische Monographien und Studien sowie an die einschlägige Surveyforschung an.

Wer sich mit dem Wandel des Verhältnisses von Studierenden und Politik beschäftigt, stößt zunächst auf historiographische Arbeiten aus dem Umfeld der korporationsnahen Gemeinschaft für deutsche Studentengeschichte e. V., die im bis 2013 bestehenden SH-Verlag publiziert wurden. Diese Arbeiten behandeln Studentengeschichte primär unter dem Aspekt von Korporations- und Universitätsgeschichte; auffällig sind hier die starke konservative Prägung der Darstellungen ${ }^{76}$ sowie die in vielfach feierlich gestimmten Vorworten und Einleitungen hervorgehobene, aber auch durch die Publikation von burschenschaftlichen Stammbüchern geübte Pflege burschenschaftlicher Traditionen. ${ }^{77}$ Ähnliches gilt für die beim Winter-Verlag erschienenen Darstellungen und Quellen zur Geschichte der deutschen Einheitsbewegung im 19. und 20. Jahrhundert, zu deren Herausgebern einige Autoren aus dem Umkreis des SH-Verlags zählen. ${ }^{78}$ Nicht alle der in diesem Umfeld publizierten wissenschaftlichen Arbeiten sind für die vorliegende Studie von Relevanz, jedoch verhelfen viele Abhandlungen und Aufsätze zum Verständnis des politischen Verhaltens von Studenten im 19. und frühen 20. Jahrhundert. ${ }^{79}$ In den 1980er Jahren, auch motiviert durch den Eindruck der protestreichen 1960er und 1970er Jahre, bekam diese Form der Studentengeschichtsschreibung Konkurrenz: Historiker aus dem Umfeld der so genannten „Bielefelder Schule“, genauer: des Bielefelder Arbeitskreises für moderne Sozialgeschichte und hier insbesondere der „Sonderforschungsbereich zur Geschichte des Bürgertums", ${ }^{80}$ monierten die durch die

Als ein Beispiel unter vielen mag ein „1968“-kritischer Sammelband dienen, der im Auftrag der Hanns-Seidel-Stiftung herausgegeben wurde, vgl. Strobel, Karl/Schmirber, Gisela: Drei Jahrzehnte Umbruch der deutschen Universitäten. Die Folgen von Revolte und Reform 1968-1974, Vierow bei Greifswald 1996.

77 Vgl. exemplarisch Kaupp, Peter (Hg.): Stamm-Buch der Jenaischen Burschenschaft. Die Mitglieder in der Urburschenschaft 1815-1819. Abhandlungen zum Studenten- und Hochschulwesen, Bd. 14, Köln 2005.

78 So beispielsweise jüngst die hier veröffentlichte Festschrift zum 200. Jahrestag der Gründung der Jenaer Urburschenschaft, die ihrerseits ein Stammbuch enthält, sowie das darin befindliche Vorwort, vgl. Lönnecker, Harald: Vorwort, in: Ders. (Hg.): Deutschland immer gedient zu haben ist unser höchstes Lob! Zweihundert Jahre Deutsche Burschenschaften. Eine Festschrift zur 200. Wiederkehr des Gründungstages der Burschenschaft am 12. Juni 1815 in Jena, Heidelberg 2015, S. VII-XIV. So Bruch, Rüdiger vom: Abschied von Humboldt? Die deutsche Universität vor dem Ersten Weltkrieg, in: Strobel, Karl (Hg.): Die deutsche Universität im 20. Jahrhundert. Die Entwicklung einer Institution zwischen Tradition, Autonomie, historischen und sozialen Rahmenbedingungen. Abhandlungen zum Studenten- und Hochschulwesen Nr. 5, Greifswald 1994, S. 17-29; Kleifeld, Helge: ,Wende zum Geist'? Bildungs- und hochschulpolitische Aktivitäten der überkonfessionellen studentischen Korporationen an westdeutschen Hochschulen 1945-1961, Köln 2002; Dowe, Christopher: Auch Bildungsbürger: katholische Studierende und Akademiker im Kaiserreich. Kritische Studien zur Geschichtswissenschaft, Bd. 171, Göttingen 2006; Heinemann, Angela Luise: Studenten im Aufbruch - Die Entstehung der Jenaer Urburschenschaft und das Wartburgfest als mediale Inszenierung, in: Lönnecker, Harald (Hg.): Deutschland immer gedient zu haben ist unser höchstes Lob! Zweihundert Jahre Deutsche Burschenschaften. Eine Festschrift zur 200. Wiederkehr des Gründungstages der Burschenschaft am 12. Juni 1815 in Jena, Heidelberg 2015, S. 1-78.

80 Lundgreen, Peter: Sozial- und Kulturgeschichte des Bürgertums. Eine Bilanz des Bielefelder Sonderforschungsbereichs (1986-1997), Göttingen 2000, S. 11 und Schulz, Andreas: Lebenswelt und 
politische Selbstdiskreditierung der Burschenschaften hervorgerufene wissenschaftliche Vernachlässigung der deutschen Studentenschaft als prägender Sozialformation der Geschichte des 19. und frühen 20. Jahrhunderts und die damit zusammenhängende Verengung auf die korporationsgeschichtlichen Arbeiten. Die diesbezügliche Forschungslandschaft, so Wolfgang Hardtwig in einem programmatischen Passus, sei gekennzeichnet durch die "notorische disziplinäre Isolation der sogenannten Studentenhistorie“, die sich „fast durchweg“ auf „kulturgeschichtliche[] Schilderungen älteren Stils“ oder auf „reine[], an Traditionsstiftung und Traditionspflege interessierte[] Korporationsgeschichten“ kapriziere. ${ }^{81}$ Autoren wie Hardtwig oder auch Jarausch bemühten sich daher um eine „Öffnung der Studentenhistorie für neue und allgemeinhistorisch relevante Fragestellungen ${ }^{482}$ bzw. um eine die korpszentrierte Historiographie überflügelnde „neue Art der Studentengeschichte“ ${ }^{83}$ Die „Erfahrung der studentischen Unruhe seit den 6oer Jahren“, so in diesem Arbeitszusammenhang konstatiert, werfe „Fragen nach dem Zusammenhang von Berufs- bzw. Ausbildungssituationen, Wandel der studentischen Lebensformen und Politisierung ${ }^{484}$ auf; der „ziemlich zwiespältige[] Ruf“ der Studenten zwischen „goldener" Studienzeit und studentischem Radikalismus $^{85}$ verlange nach sozialhistorisch informierter Aufklärung. Eine der beeindruckendsten Kollektivleistungen des Arbeitskreises stellen die vier Sammelbände zum Bildungsbürgertum im 19. Jahrhundert dar, die es erlauben, das Verhältnis von deutscher Akademikerschaft und Politik bzw. Demokratie im sozialgeschichtlichen Kontext nachzuvollziehen. ${ }^{86}$ Dass Studenten sich zwischen 1800 und 1918 sozioökonomisch, sub-

Kultur des Bürgertums im 19. und 20. Jahrhundert. Enzyklopädie Deutscher Ceschichte, Bd. 75, Berlin 2014, S. $55 f$.

81 Hardtwig, Wolfgang: Studentische Mentalität - politische Jugendbewegung-Nationalismus. Die Anfänge der Deutschen Burschenschaft, in: Historische Zeitschrift Bd. 242, 1986, S. 581-628, hier S. 582.

82 Ibid

83 Jarausch: Deutsche Studenten, S. 11.

84 Hardtwig: Studentische Mentalität, S. 583.

85 Jarausch: Deutsche Studenten, S. 9.

86 Die genannten vier Bände verfolgen einerseits zwei Kernfragen, nämlich ob es a) das Bildungsbürgertum als abgrenzbare spezifisch deutsche Sozialformation bzw. als "soziale Einheit" überhaupt gegeben habe und ob b) von einem antiliberalen "Sonderweg“ der deutschen Intelligenz die Rede sein könne, der Anteil am Heraufziehen des NS-Unheils gehabt haben könnte, vgl. Conze, Werner/Kocka, Jürgen: Einleitung, in: Conze, Werner/Kocka, Jürgen (Hg.): Bildungsbürgertum im 19. Jahrhundert. Teil I: Bildungssystem und Professionalisierung in internationalen Vergleichen, Stuttgart 1985, S. 9-26. Andererseits untersuchen die vier Bände je für sich „jene Vorgänge, die Bildung aus Ausbildung institutionalisiert hatten“ (Bd. I), ferner die „Erfahrungsfelder [..., ] deren Inhalte als Bildungswissen oder als Bildungsgüter begriffen worden sind“ (Bd. II), sie thematisieren „interne Vergesellschaftungsformen [...,] kraft derer sich das Bürgertum - in der Ehe, in der Familie, in der Ceselligkeit und in den Vereinen - einer spezifischen Identität versicherte, die ohne einen minimalen gemeinsamen Bezug auf Bildung nicht zu verstehen ist“ (Bd. III), und untersuchen schließlich „die politischen Aufgaben und die sozialen Funktionen jenes Bürgertums, das sich implizit und explizit auf seine Bildung berufen konnte - im Cegensatz etwa zum Wirtschaftsbürgertum oder zum sogenannten Kleinbürgertum, die beide teilhaben mochten am Bildungswissen und an den Bildungsgütern, sich aber nicht über ihr Bildungswissen selbst definierten." (Bd. IV) Koselleck, Reinhart: Einleitung - Zur anthropologischen und semantischen Struktur der Bildung, in: Ders. (Hg.): Bildungsbürgertum im 19. Jahrhundert. Teil II: Bildungsgüter und Bildungs- 
kulturell, mental und damit eben auch politisch in erster Linie als Angehörige einer gesellschaftlich exponierten Gebildetenschicht, als Jungbildungsbürger, erfahren und begriffen haben, ist eine diesen historischen Darstellungen zu entnehmende Einsicht; ein nicht weniger entscheidender Hinweis besteht im von Jarausch postulierten und luzide dargestellten Zusammenhang von Bildungswachstumsdynamik, sozialen und gesellschaftspolitischen Entwicklungstrends sowie studentischer Subkultur als entscheidende historische Determinanten studentischen politischen Engagements bis in die 1980er Jahre hinein. ${ }^{87}$ Unterstützendes Überblickswissen liefern hier auch die populärwissenschaftlichen Gesamtdarstellungen von Werner Klose (eher gut gelaunt und optimistisch) und Uwe Schlicht (eher bedenklich und problematisierend). ${ }^{88}$ Aber: Obwohl manche „Bielefelder“ die Absicht proklamieren, aus dem Impuls tagespolitischer Aktualität heraus „Korporationschronik“ und „Universitätsgeschichte“ hinter sich zu lassen, um „Fragestellungen der Bildungssoziologie, Jugendpsychologie und Politikwissenschaft" anzugehen, und „ein komplexeres Problembewußtsein“ zu schaffen, „das aus der Fülle der Überlieferung die entscheidenden Wirkungsstränge auswählt“ ${ }^{89}$ arbeiten auch ihre Darstellungen weiterhin aus einer streng geschichtswissenschaftlichen post festum-Perspektive. Die Analyse aktueller politischer Mentalitätstrends von Studierenden, welche Aufschluss über das politische Potenzial von Studierenden in den nächsten Jahren geben könnte, ist nicht Thema der Historiker; in der Gegenwart angekommen, brechen ihre Darstellungen ab. ${ }^{90}$

Dieser Aufgabe hat sich eine Reihe engagierter Monographien an der Schnittstelle von Soziologie und Politikwissenschaft angenommen, welche mithilfe von aspektzentrierten historischen Rückblicken, empirischen Erhebungen und Sekundärauswertungen nach Gestalt und Entwicklungstrends des politischen Potenzials von Studierenden in der jeweiligen Gegenwart fragten. So ging der Soziologe Helmut Schelsky in einer berühmt gewordenen Studie der Frage nach, welcher Erfahrungskontext das Empfinden und Denken der nichtstudentischen wie studentischen Jugend der 1950er Jahre auszeichne. ${ }^{91}$ Seine Sekundärauswertung kam zu dem Schluss, dass die aus Zeiten der Jugendbewegung bekannte traditionelle „soziale Eigenwelt" Jugend, ja auch die traditionelle Homogenität und Subkultur studentischer Gesellungsformen aus den Reihen nunmehr „skeptischer“, ,entpolitisierter“, ,entideologisierter“ und „privatistisch“ eingestellter junger Menschen verschwunden sei. ${ }^{92}$ Habermas et al. ergründeten ungefähr im

wissen, Stuttgart 1990, S. 11-46, hier S. 12f. Zur Relativierung der Sonderwegs-These, insbesondere der durch sie implizierten „Schwäche“ des deutschen Bürgertums, infolge jüngerer komparativer Betrachtungen vgl. Budde, Gunilla: Blütezeit des Bürgertums. Bürgerlichkeit im 19. Jahrhundert [2009], Wissenschaftliche Buchgesellschaft 2012, S. 126-128 sowie Schulz: Lebenswelt und Kultur des Bürgertums, S. 58.

87 Jarausch: Deutsche Studenten, S. 9-12.

88 Vgl. Schlicht: Vom Burschenschafter bis zum Sponti; Klose: Freiheit schreibt auf eure Fahnen.

89 Jarausch: Deutsche Studenten, S. 11.

90 So bleibt auch Jarauschs Schlusswort, dass die „kritische Selbstreflexion“ der historischen Verhängnisse die "Chance“ biete, "daß sich ein veranwortungsbewußtes, freiheitliches Studententum in der Zukunft durchsetzt“, notwendig unbefriedigend. Ibid., S. 250.

91 Vgl. Schelsky, Helmut: Die skeptische Generation. Eine Soziologie der deutschen Jugend [1957], Berlin 1984. 
selben Zeitraum (veröffentlicht 1961) auf der Grundlage einer methodisch anspruchsvollen empirischen Studie das politische Potenzial von Frankfurter Studierenden, genauer: die Wahrscheinlichkeit, dass deutsche Studierende sich im Krisenfall einer gefährdeten gesellschaftlich-staatlichen Ordnung nach dem Bild Weimars als Phalanx überzeugter Demokraten erweisen würden, und kamen zu unschlüssigen, eher zweifelnden Ergebnissen. ${ }^{93}$ Hierauf folgten einige Jahre eher knapper Surveystudien und Meinungsumfragen, begleitet von der sozialwissenschaftlichen Ergründung der Ursachen des (weltweiten) studentischen Protests der 1960er und 1970er Jahre im Rahmen von Aufsätzen, Symposien und Sammelbänden; ${ }^{44}$ Gerda Bartol erprobte 1978 noch einmal das früh beliebte sozialpsychologische Modell kognitiver Dissonanz für die Erklärung studentischer Politisierung im Rahmen von Vormärz und „1968“..$^{95}$ Jedoch sind diese Perspektiven stark um exponierte Ereignisse wie Studentenbewegungen zentriert, nur marginal wird nach dem politischen Empfinden, Denken und Handeln der studentischen Mehrheit gefragt. Erst 1980 legte ein Forscherteam um Christian Krause einen perspektivreichen Band zur Entwicklung von politischen Einstellungen und politischem Potenzial der deutschen Studierenden insgesamt vor. ${ }^{96}$ Hierin verband man einen Rückblick auf die jüngst zurückliegende studentische Politisierung und verschiedenen konzeptuellen Überlegungen zur damals aktuellen Alternativbewegung mit einer standardisierten Umfrage an mehreren Universitäten. Dabei fiel ein erneuter Rückzug der studentischen Jugend aus der öffentlichen Sphäre sowie ein starker resignativer Zug auf - Stimmungen, die sich aus eingetrübten Berufschancen nach Jahren des Bildungswachstums und daraus resultierenden Überflüssigkeitsempfindungen („No future“) ergaben, und die durch die damals weit verbreitete (Teil-)Adaption alternativbewegter Einflüsse eine spezifische Sprache finden konnten. ${ }^{97}$ Überhaupt wurde in den späten 1970er und frühen 1980er Jahren mehrfach ein enger Zusammenhang von skeptischen Zukunftsaussichten und fundamentaloppositioneller Sozialkritik nachgewiesen. ${ }^{98}$ Inwiefern die bisweilen eskapistischen Deutungsmuster von „menschlicher" Unmittelbarkeit und Innerlichkeit versus marktgesellschaftlicher Leistungsorientierung und „Entfremdung“

93 Habermas et al.: Student und Politik, S. 148f. und 228.

94 Vgl. exemplarisch Kaase, Max: Die politische Mobilisierung von Studenten in der BRD, in: Allerbeck, Klaus R./Rosenmayr, Leopold (Hg.): Aufstand der Jugend? Neue Aspekte der Jugendsoziologie, München 1971, S. 155-177; Beck, Ulrich/Gernsheim, Elisabeth: Zu einer Theorie der Studentenunruhen in fortgeschrittenen Industriegesellschaften, in: Kölner Zeitschrift für Soziologie und Sozialpsychologie, 1971, S. 439-477; Allerbeck, Klaus R.: Eine strukturelle Erklärung von Studentenbewegungen in entwickelten Industriegesellschaften, in: Kölner Zeitschrift für Soziologie und Sozialpsychologie, 1971, 478-93; Galtung: Eine strukturelle Theorie der Revolution.

95 Vgl. Bartol, Gerda: Ideologie und studentischer Protest: Untersuchungen zur Entstehung deutscher Studentenbewegungen im 19. und 20. Jahrhundert, München 1978.

96 Vgl. Krause, Christian/Lehnert, Detlef/Scherer, Klaus-Jürgen: Zwischen Revolution und Resignation? Alternativkultur, politische Grundströmungen und Hochschulaktivitäten in der Studentenschaft. Eine empirische Untersuchung über die politischen Einstellungen von Studenten, Bonn 1980 .

97 Vgl. ibid., S. 194, 198 und $202 f$.

98 Vgl. Does, Karl-Josef: Studenten 1975 - Ergebnisse einer Befragung unter Studenten zu Studium, Beruf, Politik und Hochschule. Sozialwissenschaftliches Forschungsinstitut der Konrad-AdenauerStiftung, St. Augustin 1976, S. 20; Sandberger: Zwischen Legitimation und Kritik, S. 200; 1. Studierendensurvey 1982/83, S. 193, 203 und 209. 
Schablonen zur Bewältigung der bisweilen ziellosen Frustration boten, wird überdies in einer stärker essayistisch auftretenden, 1982 veröffentlichten Interviewstudie von Peter Glotz und Wolfgang Malanowski anschaulich präsentiert. ${ }^{99}$ Ein gutes Jahrzehnt später, 1996, untersuchten Alex Demirović und Gerd Paul unter dem Eindruck rechtsradikaler Gewalt und neurechter Meinungstrends nach der Wiedervereinigung die Verführbarkeit von Studierenden für „,rechte" Politikvorstellungen sowie die Resistenzkraft tradierter „linker“ Selbstverortung. ${ }^{100}$ Am Material einer standardisierten Befragung und mehrerer Gruppendiskussionen wurde hier eine deutliche semantische Entleerung des Richtungsschemas „rechts/links“ unter Studierenden bei kontinuierlich mehrheitlichem linken Selbstverständnis beobachtet; Geländegewinne durch populistische Agitation von rechts erschienen den Autoren daher durchaus erwartbar. ${ }^{101}$ Insbesondere die genannten Studien von Schelsky, Habermas et al. und Krause et al. zeichnen sich dabei durch ein unnachgiebiges Interesse, konzeptuelle Phantasie, die Integration verschiedener Informationsquellen sowie durch ein informiertes Urteilsvermögen aus. Ihr Vorgehen folgt kaum vorgezeichneten Bahnen, es ist „innovativ“. Dass die verschiedenen Autoren konkreten tagesaktuellen Fragestellungen nachgehen und beherzt interpretieren, schärft dabei das Bild und verhilft schließlich auch dem unkundigen Leser zu einem Verständnis der je aktuellen Mentalitätstrends. Zwar hat nur die Studie von Habermas et al. einen Weg gefunden, tiefersitzende potenziell handlungsleitende Motivlagen hinter den verbalen Bekenntnissen zu demokratischen Prinzipien aufzudecken, das aber tut dem keinen Abbruch. An solchen integrativen, konzeptuell anspruchsvollen Studien mangelt es ganz generell spätestens seit der Jahrtausendwende.

Konzeptuell schlanke, standardisierte Erhebungen hingegen liegen in großer Fülle vor. Sie skizzieren, anfänglich im Zuge virulenter tagespolitischer Fragen, ab 1982/83 institutionalisiert durch die Haupt- und Spezialberichte des Studierendensurveys, moralische und politische Stimmungsbilder der studentischen Jugend. Häufig wird die Stimmungslage des als künftige Funktionseliten potenziell einflussreichen Jungakademikertums dabei (ob explizit oder nicht) als Indikator zukünftiger Entwicklungen von Gesellschaft und Demokratie verhandelt, nicht zuletzt erkennbar daran, dass sich spezifische Hoffnungen auf eine wachsame und verantwortungsbewusste, reformorientierte jugendliche Intelligenz ${ }^{102}$ oder diffuse Sorgen über eine institutionenfeindliche, politisch-apathische oder gar frustrierte Schicht künftiger Hochschulabsolventen an die empirischen Beobachtungen knüpfen. Seit den 1970er Jahren verwenden viele dieser Studien die von Max Kaase entwickelte „Demokratie-Skala“, welche den Anspruch

99 Vgl. Glotz, Peter/Malanowski, Wolfgang: Student heute. Angepaßt? Ausgestiegen?, Reinbek bei Hamburg 1982, hier etwa S. 133-163, 162-165, 176, und 185.

100 Vgl. Demirović, Alex/Paul, Gerd: Demokratisches Selbstverständnis und die Herausforderung von rechts: Student und Politik in den neunziger Jahren. Studienreihe des Instituts für Sozialforschung, Frankfurt a.M. 1996.

101 Vgl. ibid., S. 243-245.

102 Vgl. Stifterverband für die deutsche Wissenschaft: Das geistige Bild der Studenten; Institut für Demoskopie Allensbach (IfD): Der deutsche Student. Eine Umfrage im Auftrag des Spiegel, Allensbach 1967, ausgewertet in o. V.: Was denken die Studenten? SPIECEL-Umfrage an deutschen Hochschulen, in: Der Spiegel, H. 26/1967, S. 28-39. 
erhebt, die Unterstützung der demokratischen Prinzipien durch verschiedene Bevölkerungsgruppen zu messen und vergleichbar zu machen. ${ }^{103}$ Wiederholt wurde die Breitenwirkung des vermuteten studentischen „Radikalismus“ einschlägiger Protestgruppen untersucht, wobei sämtliche Studien eine besondere studentische Reformstimmung auf der Grundlage robuster demokratischer Überzeugungen sowie eine starke sozialmoralische Spaltung entlang des Richtungsschemas „links“ (mehrheitliche Selbstzuschreibung) versus „rechts“ beobachteten. ${ }^{104}$ In die Spätphase der Alternativbewegung fällt die Pilotstudie des Studierendensurveys „Studiensituation und studentische Orientierungen“, der seither im Zweijahres- oder Dreijahresrhythmus durchgeführt und publiziert wird und stets Itemblöcke zu politischen und demokratischen Einstellungsmustern enthält. Die seither erschienenen 13 Surveys verstehen sich als „Instrument“ nüchterner wissenschaftlicher Politikberatung; ${ }^{105}$ darüberhinausgehende Gesamteinschätzungen der Ergebnisse finden sich 1994, 1998, 2009 und 2011 in Einzelbeiträgen Tino Bargels und Hans Simeaners, zweier Mitarbeiter des Surveys. Diese zeichnen wiederholt und in dramatischer Verfestigung das Bild einer weitgehend „ratlosen“, d. h. sicherheitsfixierten, orientierungsarmen, positionierungsmüden und politisch-apathischen Studierendenschaft, ohne aber die grundsätzliche Wahrscheinlichkeit studentischen Protests zu leugnen. ${ }^{106}$ Die Frage nach etwaigen künftigen politischen Kräftereservoirs unter deutschen Studierenden bleibt, abgesehen von vorsichtigen Mutmaßungen auf der Grundlage quantitativer Erhebungen, offen: Wann wird Protest wahrscheinlich, welche Gestalt kann er annehmen, welche handlungsleitenden, die einzelnen Antworten strukturierenden, Orientierungen pflegen Studierende? Welches tatsächliche Handlungspotenzial ist im Falle gesellschaftlicher Strukturkrisen, gar einer gefährdeten demokratischen Ordnung, zu erwarten? All das bleibt unklar, obwohl die Studierendensurveys durchaus erklärungsbedürftige, da bisweilen volatil und erratisch erscheinende, Einstellungstrends protokollieren.

Hier setzt die vorliegende Studie ein, indem sie Schlaglichter auf den historischen Hintergrund handlungsleitender politischer Mentalitäten von Studierenden wirft und

103 Vgl. Wildenmann, Rudolf/Kaase, Max: „Die unruhige Generation“. Eine Untersuchung zu Politik und Demokratie in der Bundesrepublik, Mannheim 1968, S. 6; Kaase, Max: Demokratische Einstellungen in der Bundesrepublik Deutschland, in: Wildenmann, Rudolf (Hg.): Sozialwissenschaftliches Jahrbuch für Politik, München/Wien 1971, S. 119-326.

104 Vgl. Institut für Demoskopie Allensbach (IfD): Der deutsche Student; o. V.: Was denken die Studenten?; Kaase, Max: Die politische Mobilisierung von Studenten in der BRD, in: Allerbeck, Klaus R./Rosenmayr, Leopold (Hg.): Aufstand der Jugend? Neue Aspekte der Jugendsoziologie, München 1971, S. 155-177; Does: Studenten 1975; in gewissem Sinne auch noch Infratest Wirtschaftsforschung (Hg.): Politischer Protest in der Bundesrepublik Deutschland. Beiträge zur sozialempirischen Untersuchung des Extremismus, Stuttgart/Berlin/Köln/Mainz 1980.

105 Vgl. Multrus, Frank: Der Studierendensurvey. Konzept, Aufbau und theoretische Grundlagen. Hefte zur Bildungs- und Hochschulforschung, AG Hochschulforschung, Universität Konstanz, H. $87 / 2016$, S. 50; 1. Studierendensurvey 1982/83, S. III; 8. Studierendensurvey 2000/01, S. 3f.; 13 . Studierendensurvey 2015/16, S. 5 .

106 Vgl. Bargel: Zum politischen Potenzial der Studierenden; Bargel, Tino: Wandel des politischen Bewußtseins und der Meinungsführerschaft deutscher Studierender?; Bargel: die ratlose Ceneration; Bargel/Simeaner: Gesellschaftliche Werte und politische Orientierungen der Studierenden. 
diese mit einer eigenständigen qualitativ-empirischen Erforschung heutiger Orientierungen dieser sozialen Gruppe verbindet. Wie die noch folgende detaillierte Diskussion der hier erwähnten empirischen Studien zeigen wird, ${ }^{107}$ bildeten Jugendliche und junge Erwachsene im Allgemeinen und Studierende im Besonderen in der Bundesrepublik zwar stets einen kontinuierlich beforschten Teil der Bevölkerung. Abseits des monitorings durch standardisierte Surveys, die engmaschig und zuverlässig über den Wandel von Zustimmungswerten zu Itemkatalogen über mehrere Jahrzehnte hinweg informieren, existieren bemerkenswert wenige konzeptuell anspruchsvolle und qualitativ-explorative Studien, ${ }^{108}$ die Aufschluss über Struktur und Wandel des politischen Potenzials von Studierenden auf der Ebene tieferliegender, d. h. sinnrekonstruktiv erschlossener, Mentalitätstrends bieten. Pointiert: Das auffällige Defizit der bisherigen Forschungsbemühungen, insbesondere der in diesem Feld hegemonialen Einstellungsforschung, liegt darin, vor der Fassade verbaler Äußerungen und standardisierter Zustimmungswerte zu verharren, ohne etwa die konzeptuellen und methodischen Einsichten der als „Klassiker“109 geltenden Studie von Habermas et al. zur Kenntnis zu nehmen. Dieses Defizit zu beheben, ist der Anspruch des hier geleisteten wissenschaftlichen Beitrags. Das Vorhaben verspricht Erfolg als Rekonstruktion politisch-sozialer Deutungsmuster vor dem Hintergrund der historischen Traditionslinien des Verhältnisses von Studierenden und (außerparlamentarischem) politischem Aktivismus.

\section{I.5 Methodologischer und methodischer Zuschnitt}

Der methodologische Ausgangspunkt für die im III. Kapitel ausgewertete Fokusgruppenstudie ist das Paradigma qualitativ-interpretativer Sozialforschung. Es wird beabsichtigt, soziale (manifeste wie latente) Sinnstrukturen mithilfe nichtstandardisierter Erhebungs- und Interpretationsverfahren aufzudecken und deutend zu verstehen. ${ }^{110}$ Nicht die Errechnung von Korrelationen und Kausalzusammenhängen mithilfe statistisch repräsentativer Daten und formalisierter Verfahren ist also das Ziel, sondern die Offenlegung sozial gültiger, in Interaktion ausgehandelter, Orientierung stiftender und Handlungsräume eröffnender Sinnstrukturen. Qualitative Sozialforschung in diesem Sinne arbeitet nicht hypothesenprüfend, sondern rekonstruktiv. ${ }^{111}$ Nicht die Fallzahl entscheidet über die wissenschaftliche Validität, sondern die Reduktion forscherischer

107 Vgl. Kapitel II.3 dieser Studie.

108 Natürlich reflektieren viele der in Studentenbewegungen involvierten Zeitgenossen ihre biographisch geprägten Erfahrungen, und nicht wenige von ihnen leiten daraus Überlegungen zum Mentalitätswandel „der" (akademischen) Jugend ab. Allerdings entfalten diese Autoren ihre Beobachtungen und Argumentationen häufig in essayistischer Form, weshalb sie (obwohl sie wertvolles Material zum Verständnis der jeweiligen Bewegungen liefern mögen) hier nicht zur Forschungslandschaft im engeren Sinne gezählt werden.

109 Kiel, Sabine: Studierende und Politik. Eine kritische Analyse zur politischen Sozialisation. Forum Wissenschaft Studien, Bd. 32, Marburg 1996, S. 53.

110 Vgl. Kleemann, Frank/Krähnke, Uwe/Matuschek, Ingo: Interpretative Sozialforschung. Eine Einführung in die Praxis des Interpretierens, Wiesbaden 2013, S. 119-123.

111 Bohnsack, Ralf: Rekonstruktive Sozialforschung. Einführung in qualitative Methoden, Opladen 2003, S. 13-24. 
„Eingriffe“ in den Analyse- und Interpretationsprozess zugunsten rezeptiver Offenheit: Es geht darum, den Befragten selbst die Möglichkeit zu geben, Fragestellungen zu interpretieren, Themen „in ihrer eigenen Sprache“ und entlang ihrer persönlichen „Relevanzsysteme“ $\mathrm{zu}$ „entfalten“. ${ }^{112}$ Der Vorzug einer solchen qualitativ arbeitenden Suchbewegung liegt auf der Hand: Quantitativ-standardisierte Befragungen neigen aufgrund der Starrheit ihrer Frage-Items dazu, das Antwortverhalten von Interviewten zu präformieren, ja im schlimmsten Falle Antwortmöglichkeiten zu insinuieren, an die sie selbst nicht unprovoziert gedacht hätten.

Jenseits dieser gemeinsamen Prinzipien wird über die Gültigkeit und Hierarchie der spezifischen „Gütekriterien“113 qualitativer Sozialforschung insbesondere bei der Auswertung qualitativen Datenmaterials rege diskutiert, wie die Auseinandersetzungen zwischen den Vertretern der "Grounded Theory" nach Barney Glaser und Anselm Strauss, der "Narrationsanalyse“ nach Fritz Schütze, der „Objektiven Hermeneutik“ nach Ulrich Oevermann, schließlich der "Dokumentarischen Methode“ nach Ralf Bohnsack mit ihren je spezifischen Vorstellungen gelingender und valider qualitativer Sozialforschung ${ }^{114}$ zeigen. Die vorliegende Studie geht allerdings auf Distanz zu rigide orchestrierten Untersuchungsdesigns und Verfahrensrezepten. Sie geht davon aus, dass qualitative Sozialforschung primär in einem spezifischen wissenschaftlichen Denkstil und einer jeweils gegenstandsangemessenen Arbeitsweise besteht, die fähig und willens ist, Erkenntnisinteresse, Untersuchungsraster und tragende Begriffe für „fortgesetzte Justierung ${ }^{\text {(115 }}$ offenzuhalten. Wissenschaftlichkeit besteht nach seinem Verständnis nicht in der devoten Umsetzung eines methodologischen Programms, sondern in der kontinuierlichen Empathie und selbstkritischen Reflexionsfähigkeit des forschenden Subjekts. Der dadurch implizierte Pragmatismus ist gerade keine wissenschaftliche Ausrede, sondern Reflexion der Einsicht, dass eine zu „elaborierte Methode [...] dem Erkennen und Erklären mitunter auch im Wege stehen kann. “116 Sowohl Gegenstand der Untersuchung als auch die leitende Fragestellung gewinnen ihre Konturen erst im Laufe des Forschungsprozesses; beides kann, wo tatsächlich Neues herausgefunden werden soll, unmöglich in vorab festgelegte Beschränkungen gepresst werden. Gegen diese Betonung der forscherischen Subjektivität im Rahmen qualitativer Studien mag zwar eingewendet werden, dass die Aussagekraft jedweder wissenschaftlichen Aussage auf das Denk-, Deutungs-, und Urteilsvermögen von Forschern angewiesen ist, und zwar unabhängig davon, welchen Daten und welcher Erhebungs- und Auswertungsmethode sie entsprungen sein mag. Das ist sicher wahr: Wissenschaftliche „Objektivität“ besteht nie in der Abwesenheit eines denkend

112 Ibid., S. 20.

113 Strübing, Jörg/Hirschauer, Stefan/Ayaß, Ruth/Krähnke, Uwe/Scheffer, Thomas: Cütekriterien qualitativer Sozialforschung. Ein Diskussionsanstoß, in: Zeitschrift für Soziologie, 47. Jg., H. 2/2018, S. 83-100 und Mayring, Philipp: Einführung in die qualitative Sozialforschung. Eine Anleitung zu qualitativem Denken, Weinheim 1999, S. 14.

114 Vgl. die instruktiven Kurz-Charakterisierungen in Przyborski, Aglaja/Wohlrab-Sahr, Monika: Qualitative Sozialforschung. Ein Arbeitsbuch, München 2010, S. 184-205, S. 217-221, S. 240-246 und S. 271-277.

115 Mayring: Einführung in die qualitative Sozialforschung, S. 88.

116 Marg, Stine: Mitte in Deutschland. Zur Vermessung eines politischen Ortes, Bielefeld 2014, S. 71. 
rezipierenden Subjekts, sondern in der Reflexion auf die subjektiven Konstitutionsbedingungen „objektiver“ Erkenntnis; auch Zahlen sprechen nicht für sich. Qualitatives Interviewmaterial aber ist in besonderem Maße von der interpretativen Arbeit abhängig, weil sich aus dem analysierten Text - anders als bei Zahlen und Datenreihen weder intersubjektiv gültige Wahrscheinlichkeitswerte errechnen noch sich an ihnen arithmetische Modelle exerzieren lassen. Die gleichzeitige bzw. zirkelartige Verarbeitung sowohl von Konstruktionen ersten Grades (Sinnrekonstruktion des Gegenstands) als auch Konstruktionen zweiten Grades (Reflexion der eigenen Forschungspraxis) versteht Ralf Bohnsack im Anschluss an Anthony Giddens daher als zentralen Standard einer qualitativen Studie. ${ }^{117}$ Diese fraglos notwendige „reflexive Beziehung" zwischen „methodischen Regeln einerseits und Forschungspraxis andererseits“118 verlangt daher nach gewissen methodologischen Grundprinzipien, die den Nachvollzug der wissenschaftlichen Urteilsbildung ermöglichen. Entscheidend für die vorliegende Studie sind

- die Orientierung an im Rahmen historisch bedingter Situationen und Formen interagierenden Menschen als sozialwissenschaftliche Einzelfälle, ${ }^{119}$

- die immer wieder induktiv und abduktiv arbeitende größtmögliche Offenheit für Irritationen vorläufiger Thesen durch das Interviewmaterial,

- die transparente Dokumentation des Forschungsprozesses inklusive einer Explikation des forscherischen Vorverständnisses ${ }^{120}$ sowie

- der Einsatz einer oder mehrerer methodischer Kontrollinstanzen.

Dabei ist unter „Offenheit“ der Verzicht auf statische Analyseraster zu verstehen: Die beschreibende und interpretierende Rekonstruktion soll in einer Weise arbeiten, die „Neufassungen, Ergänzungen und Revisionen sowohl der theoretischen Strukturierungen und Hypothesen als auch der Methoden“ ermöglicht, „wenn der Gegenstand dies erfordert.“212 Dabei ist besonders das „induktivistische Selbstmissverständnis“ einer vermeintlich völligen naiven Unvoreingenommenheit ${ }^{122}$ zu vermeiden: Nicht das leere und begriffslose Staunen schärft Verständnis und Empathie für den Gegenstand, sondern die Sensibilisierung der eigenen Begriffe und Konzepte durch die dokumentierte vorbereitende Einarbeitung in die jeweilige Forschungsthematik. Die wissenschaftlich erforderliche „Objektivität“, d. h. intersubjektive Überprüfbarkeit der hier erarbeiteten qualitativen Forschungsergebnisse wird hergestellt

117 Vgl. Bohnsack, Ralf/Przyborski, Aglaja: Diskursorganisation, Gesprächsanalyse und die Methode der Gruppendiskussion, in: Bohnsack, Ralf/Schäffer, Burkhard/Przyborski, Aglaja (Hg.): Das Gruppendiskussionsverfahren in der Forschungspraxis. Verlag Barbara Budrich, Leverkusen 2006, S. 233-248, hier S. 9 und 13.

118 Bohnsack: Rekonstruktive Sozialforschung, S. 10 (Herv. i. O.)

119 Verallgemeinernde Schlüsse beziehen sich stets auf konkrete untersuchte Einzelfälle und müssen argumentativ aus diesen entfaltet werden, vgl. Mayring: Einführung in die qualitative Sozialforschung, S. 14-16.

120 Auswahl aus ibid., S. 13f. und 16f.

121 Ibid., S. 17.

122 Vgl. Kelle, Udo/Kluge, Susann: Vom Einzelfall zum Typus. Fallvergleich und Fallkontrastierung in der qualitativen Sozialforschung, Wiesbaden 2010, S. 18-21. 
- durch die im Erhebungsprozess infolge möglichst sorgfältiger Gesprächsführung hervorgerufene Entfaltung der „Relevanzsysteme“ durch die Befragten selbst und deren argumentativer Rekonstruktion im Auswertungsprozess,

- durch die zugleich fortwährend geübte explizite Reflexion des eigenen Relevanzsystems, also der Prämissen, Vorannahmen, der Erfahrung des Forschers ${ }^{123}$ als Teil des „methodisch kontrollierten Fremdverstehens ${ }^{\text {“124, }}$,

- durch die Dokumentation der durchgeführten - und bis zu einem gewissen Grad „standardisierten“ - Erhebungs- und Auswertungsschritte, die zur Urteilsbildung geführt haben, ${ }^{125}$

- und durch ein doppeltes strukturelles Korrektiv der Interpretationsarbeit, zweier als „Gegengewichte“ fungierenden Informationsquellen.

Bei narrativen Interviews besteht dieses strukturelle Korrektiv häufig in der Fixierung objektiver biographischer Daten, darüber hinaus - wie in vielen anderen Untersuchungsdesigns - in der regelmäßigen Diskussion von Arbeitshypothesen in einem Forscherteam. Im Falle der vorliegenden Studie, durchgeführt im Rahmen einer akademischen Qualifikationsarbeit, existierte ein solches Forscherteam nicht; die Sammlung biographischer Daten wäre im Falle der hier durchgeführten Gruppendiskussionen einerseits kaum praktisch zu bewältigen, andererseits aber auch analytisch nicht zielführend, wo es um kollektiv geteilte politisch-soziale Orientierungen geht. Stattdessen liegt das "Gegengewicht" hier einerseits in der Dokumentation der soziodemographischen Daten der Diskussionsteilnehmer, die eine ungefähre Beurteilung des erzielten Realitätsausschnittes (Wo ist ein bias zuzugeben, wer ist unterrepräsentiert, etc.) ermöglichen, sowie andererseits in der durch das folgende Kapitel (II) entfalteten Darstellung historischer Längsschnittentwicklungen und der einschlägigen empirischen Forschungslandschaft. So wird der interpretierenden Auswertung zum einen eine kritische Perspektive auf die eigene Reichweite, zum anderen die begründete Unterscheidung des Neuen vom Bekannten ermöglicht.

Da es hier nicht nur um die oberflächliche Beschreibung von politischen Einstellungen, Vorstellungen, Denkinhalten oder Diskursen von Studierenden geht, sondern die wissenschaftliche Suche stärker auf grundlegende Orientierungsstrukturen und deren mögliche politische Praxisrelevanz zielt, liegt die Deutungsmusteranalyse als adäquate qualitative Auswertungsmethode nahe: Sie bietet den - vielfach angeführten - Vorzug, über die bloße Deskriptionsebene hinaus an soziale und mentale „gesellschaftliche[] Tiefenstrukturen“ zu gelangen, ${ }^{126}$ die das politische Denken und Empfinden mitsamt den daraus resultierenden Handlungsoptionen strukturieren. Deutungsmuster

123 Vgl. Mayring: Einführung in die qualitative Sozialforschung, S. 30.

124 „Der Prozess des Fremdverstehens ist insofern methodisch kontrolliert, als der Differenz zwischen den Interpretationsrahmen der Forscher und denjenigen der Erforschten systematisch Rechnung getragen wird." Przyborski/Wohlrab-Sahr: Qualitative Sozialforschung, S. 31.

125 Ibd., S. 42.

126 Bögelein, Nicole/Vetter, Nicole: Deutungsmuster als Forschungsinstrument. Crundlegende Perspektiven, in: Dies. (Hg.): Der Deutungsmusteransatz. Einführung - Erkenntnisse - Perspektiven, Weinheim Basel 2019, 12-38, hier S. 16 und - dort ebenfalls zitiert - Kelle/Kluge: Vom Einzelfall zum Typus, S. 17. 
verhelfen den sozial eingebetteten Individuen damit, „objektive Probleme des Handelns" subjektiv zu bewältigen. ${ }^{127}$ Sie sind zu verstehen als „sozial geteilte Routinen der Deutung“, die der Orientierung im sozialen und gesellschaftlichen Feld dienen - und zwar so, dass nicht nur „Orientierung und Identität gestiftet“, sondern „schlussendlich Handlung[en]" ermöglicht und angeleitet werden. ${ }^{128}$ Als Beispiel für eine solche Deutungsroutine wird oft der Glaube an die Wirksamkeit des meritokratischen Funktionsprinzips für die gesellschaftliche Allokation von Gütern und Statuszuweisungen angeführt, also die Überzeugung, soziale Ungleichheit entstehe durch unterschiedliche Leistungsbereitschaften. ${ }^{129}$ Tatsächlich wird an diesem plastischen Beispiel deutlich, dass Deutungsmuster - zumindest die von Patrick Sachweh identifizierten „sozialen Deutungsmuster" - nie rein situativ und individuell gebildet werden, sondern stets „auch auf sozial verfügbare Interpretations- und Deutungsangebote angewiesen " sind. ${ }^{130}$ Die hier visierten politisch-sozialen Deutungsmuster müssen, auch wo sie nicht primär auf die Legitimation von Ungleichheit zielen, daher als intersubjektiv verhandelte und somit auch gesellschaftlich bedeutsame Sinnstrukturen verstanden werden. Aber: Um den Anspruch der solcherart schnell formulierten Absichtserklärungen auch tatsächlich einzulösen, ist der Deutungsmusterbegriff zumindest für das jeweilige Forschungsinteresse präzise zu bestimmen. Dies wird gerade vor dem Hintergrund der in den letzten Jahren abermals entfachten beachtlichen sozialwissenschaftlichen Konjunktur des Deutungsmusters bzw. der Deutungsmusteranalyse zu einem Desiderat ersten Ranges. Denn bereits in den 1980er Jahren ist eine „inflationäre Verwendung des Deutungsmusterbegriffs bei einer abnehmenden Bedeutungsschärfe" moniert worden, die sich bis heute erhält. ${ }^{131}$ Wie Christian Lüders überdies 1991 überzeugend resümierte, mangelt es der Deutungsmusteranalyse an verbindlichen und verbindenden theoretischen Prämissen. Das Deutungsmuster sei daher vorerst als "forschungspragmatisch-heuristisches Konzept“ zu verstehen, nicht als „allgemein gültiges“, gar theoretisch bündig fundiertes Forschungsprogramm. Jede konkrete Studie bedürfe einer „projektspezifischen ,Einverwandelung“" der Deutungsmusteranalyse, und das bedeute: einer Rekonstruktion der jeweiligen Einzelfälle und zugleich einer „theoretische[n] Auffüllung dessen, was im konkreten Projektkontext als Deutungsmuster verstanden wird.“132 Für das hier verfolgte Vorhaben soll der Begriff des Deutungsmusters „aufgefüll" werden als Element privater

127 Ibid., S. 21. Vgl. auch Lüders, Christian/Meuser, Michael: Deutungsmusteranalyse, in: Hitzler, Ronald/Honer, Anne (Hg.): Sozialwissenschaftliche Hermeneutik. Eine Einführung, Wiesbaden 1997, S. $57-80$.

128 Bögelein/Vetter: Deutungsmuster als Forschungsinstrument, S. 12.

129 Vgl. Sachweh, Patrick: Deutungsmuster sozialer Ungleichheit. Wahrnehmung und Legitimation gesellschaftlicher Privilegierung und Benachteiligung, Frankfurt a.M./New York 2010, S. 277; Bögelein/Vetter: Deutungsmuster als Forschungsinstrument, S. 13.

130 Ibid., S. 76.

131 Arnold, Rolf: Deutungsmuster. Zu den Begriffselementen sowie den theoretischen und methodologischen Bezügen eines Begriffs, in: Zeitschrift für Pädagogik, H. 29/1983, S. 893-912, hier S. 893.

132 Lüders, Christian: Deutungsmusteranalyse. Annäherungen an ein risikoreiches Konzept, in: Garz, Detlef/Kraimer, Klaus (Hg.): Qualitativ-empirische Sozialforschung. Konzepte, Methoden, Analysen, Opladen 1991, S. 377-408, hier S. 380 (Herv. i. O.) 
Gesellschaftstheorien ${ }^{133}$, d. h. als gesellschaftshistorisch bedingte Gestalt und Folgeerscheinung der traditionellen Bewusstseinsform (politischer) Ideologie. Anders als traditionelle politische Ideologien - in einiger Verkürzung als umfassende „Deutungssysteme“ zu begreifen erheben Deutungsmuster zwar nicht mehr allgemein den Anspruch, „die Totalität der Gesellschaft zu erfassen“, ${ }^{134}$ wohl aber liefern sie strukturanaloge ideologische Leitlinien zur alltäglichen Identifikation und Interpretation von Funktionsgesetzen der sozialen und politischen Welt. Wie das gemeint ist, soll kurz am auf historischen Wandel reagierenden Ursprungsgedanken der Deutungsmusteranalyse ausgeführt werden.

Der Versuch, den Begriff des Deutungsmusters in die qualitative Sozialforschung einzuführen, geht wesentlich auf lange Zeit apokryphe Entwürfe von Ulrich Oevermann zurück. Dieser verstand das Deutungsmuster 1971 in Anlehnung an M. Rainer Lepsius als „gedachte Ordnung innerhalb der Gesellschaft ${ }^{\text {“135 }}$ bzw. als „nach allgemeinen Konsistenzregeln strukturierte Argumentationszusammenhänge“, die „isolierte Meinungen oder Einstellungen“ sinnhaft verknüpfen und dabei die „Funktion“ (!) haben, eine „Systematik von objektiven Handlungsproblemen“ $z u$ fokussieren, „die deutungsbedürftig sind.“136 Die Pointe dieser Überlegungen besteht nicht etwa nur darin, dass Deutungsmuster „Komplexität“ reduzieren ${ }^{137}$ und Individuen die kognitive Navigation durch die unübersichtliche gesellschaftliche und politische Landschaft ermöglichen, denn das tun auch deutlich volatilere Stimmungen, Meinungen, Einstellungen und Glaubenssätze. Sie besteht auch nicht darin, dass Fragestellungen des „Deutungsmusteransatz[es]“ „an der gesellschaftlichen und kulturellen Bedingtheit dieser Orientierungen interessiert sind“138, denn „,bedingt“ von gesellschaftlichen Verhältnissen ist Bewußtsein stets“. ${ }^{139}$ Vielmehr besteht sie in der auffälligen Beobachtung, dass das durch Deutungsmuster organisierte „Alltagswissen“ Analogien zur wissenschaftlichen Theoriebildung aufweist, Deutungsmuster also wie Elemente privater Gesellschaftstheorien von Individuen und Gruppen fungieren. Sie geben gesellschaftlichen und politischen

133 Diese Formulierung bietet sich unter Rekurs auf den programmatischen Aufsatz von Ulrich Oevermann an, in welchem er konstatiert, „daß das Alltagswissen nicht eine Sammlung oder ein Agglomerat von Einzelerfahrungen darstellt, sondern , analog' zu wissenschaftlichen Theorien organisiert ist. Deutungsmuster organisieren die Alltagserfahrung einer Epoche wie Theorien das wissenschaftliche Datenmaterial, sie sind gewissermaßen die ,Theorien' der Alltagserfahrung. [...] So wie eine bestimmte theoretische Richtung oder Schule innerhalb der Wissenschaften durch spezifische Grundbegriffe und Konstrukte gekennzeichnet ist, so lassen sich für einzelne Deutungsmuster Schlüsselkonzepte und tragende Ideen identifizieren." Oevermann: Zur Analyse der Struktur von sozialen Deutungsmustern, S. 10 (Herv. J. S.) Dabei muss man der Versuchung widerstehen, Deutungsmuster infolge der Analogisierung mit Theoriebildung als umfassende rational-deduktive und auswechselbare „Konstrukte“ im wissenschaftlichen Sinn zu verstehen. Das wäre ein Missverständnis: In Deutungsmustern machen sich Leidenschaften und Interessen ebenso geltend wie zueinander oft genug in Widerspruch stehende Erklärungshypothesen gesellschaftlicher Zustände.

134 Habermas et al.: Student und Politik, S. 152.

135 Oevermann, Ulrich: Die Struktur sozialer Deutungsmuster - Versuch einer Aktualisierung, in: Sozialer Sinn, H. 1/2001, S. 223-229, hier S. 37.

136 Oevermann, Ulrich: Zur Analyse der Struktur von sozialen Deutungsmustern (1973), in: Sozialer Sinn, H. H. 1/2001, S. 3-33, hier S. 5.

137 Lüders: Deutungsmusteranalyse, S. 386 unter Bezug auf Arnold: Deutungsmuster.

138 Bögelein/Vetter: Deutungsmuster als Forschungsinstrument, S. 16.

139 Lenk, Kurt: Ideologie. Ideologiekritik und Wissenssoziologie, Frankfurt a.M./New York 1984, S. 357. 
Vorgängen eine epistemologische und zugleich normative Struktur, sie lenken und verarbeiten Wünsche, Hoffnungen, Ängste und Frustrationen zu möglichst kohärenten Erklärungs- und Orientierungsmodellen. Sie bilden, salopp gesprochen, den Reim ab, den sich gesellschaftlich eingebundene Individuen - hier: Studierende - auf Politik, Gesellschaft und Demokratie machen: Welche Ordnungsprinzipien sind gültig? Gestaltet sich Gesellschaft als Gleichgewicht, das bisweilen in Schieflage gerät, oder als konfliktbehaftetes Feld? „Funktioniert“ das soziale und demokratische Leben? Wenn ja, nach welchen Maßstäben und wenn nicht, warum? Falls Probleme identifiziert werden: Wer ist schuld, und wer für die Lösung zuständig? Welche Werthaltungen pflegen die Menschen und an welchen Ansprüchen messen sie die Realität? Wie nehmen sie ihre eigene soziale und politische Rolle wahr? Beispielsweise: Wie $-d$. h. mithilfe welcher Ordnungsvorstellungen und Normierungen - vermitteln sie den typischen Anspruch, moderner demokratischer „Vollbürger“ einer Gesellschaft (oder gesellschaftlichen Teilgruppe) der Gleichen zu sein, mit der Erfahrung fundamentaler gesellschaftlicher Ungleichheiten auch in der eigenen Biographie? ${ }^{140}$ Überhaupt scheint das Verständnis des Deutungsmusters am leichtesten zu fallen, wenn die von Lepsius identifizierten „Deutungsmuster der Ungleichheit“141 als Archetypus solcher privater Gesellschaftstheorien begriffen werden.

Sicher ist es für Sozialwissenschaftler, die zur Fundierung der Dignität ihrer Gedanken der Berufung auf traditionsschwangere wissenschaftliche Schulen und Autoritäten bedürfen, ohne Weiteres möglich, ganz unterschiedliche große Namen post festum mit diesen basalen Überlegungen zu verknüpfen. Ein jüngst erschienener Sammelband macht als geistige Vorläufer der Oevermann'schen Überlegungen beispielsweise die „emergenten kollektiven Repräsentationen“ Emile Durkheims, Max Webers vermeintliches Diktum der „verstehenden Soziologie“, „kulturelle Gegebenheiten auf das soziale Verhalten Einzelner zurückzuführen" (als wäre dieses Verhalten nicht von ihm selbst zugleich als durch Kultur bedingtes begriffen worden) und Noam Chomskys „Beschreibung der Sprache als System syntaktischer Regeln, in dem Hörersprechende einer Einzelsprache operieren“, aus. ${ }^{142}$ Auch wurden seit den 1990er Jahren mehrfache Versuche unternommen, die Deutungsmusteranalyse wissenssoziologisch zu reformulieren. Das aber muss misstrauisch machen. Denunziert man Oevermanns Deutungsmusterkonzept als „strukturalistisch ${ }^{\text {“143 }}$, um es gemäß antirealistischen wissenssozio-

140 „Die soziale Schichtung wird durch strukturelle Positionskonfigurationen mit im Lebenslauf typischerweise nicht aufhebbaren Ungleichheitseffekten begründet und erhält durch Ordnungsvorstellungen einen Bedeutungsgehalt.“ Mit der „,Cesamtgesellschaft' verbindet sich die Vorstellung einer Vollmitgliedschaft, ein normatives Leitbild von den Rechten und Pflichten eines Mitgliedes dieses sozialen Systems. Ein prinzipieller formaler Gleichheitsanspruch ist bereits in der Vorstellung eines sozialen Systems, dem man sich zugehörig fühlt enthalten. [...] Er findet seinen Ausdruck in einer allgemein verbindlichen Alltagsmoral." Lepsius, M. Rainer: Kulturelle Dimensionen der sozialen Schichtung [1963], in: Ders. (Hg.): Interessen, Ideen und Institutionen, Opladen 1990, S. 96-116, hier S. $110 f$.

141 Ibid., S. 110.

142 Bögelein/Vetter: Deutungsmuster als Forschungsinstrument, S. $18 f$.

143 Symbolisch bestimmt zwar, doch noch immer als eine Wirklichkeit, „die von den Subjekten einerseits durch ihr Deuten und Handeln alltäglich (re-)produziert werden muß, diesen aber andererseits auch in den verschiedensten Praxen und Institutionen als [hinsichtlich ihres Charakters 
logischen Dogmen ${ }^{144}$ „Vom Kopf auf die Füße“ zu stellen, indem man „gesellschaftliche Wirklichkeit [...] nun als eine primär symbolisch bestimmte" fixiert, ${ }^{145}$, dabei aber die Selbstständigkeit der ja gerade intersubjektiv wirksamen Deutungsmuster über die Köpfe hinweg leugnet, ${ }^{146}$ wird eine entscheidende Einsicht eliminiert: dass „die Subjekte“ - gemeint sind wohl gesellschaftlich und politisch denkende, fühlende und agierende Menschen - nicht die diskursive Realität von Deutungsmustern als Summe aller Teile „erzeugen“, sondern diese Wirklichkeit ihnen beispielsweise in Gestalt der Ordnungsvorstellung gesellschaftlicher Gleichheit objektiv als „allgemein verbindliche[] Alltagsmoral ${ }^{\alpha 147}$ mit spezifischen Positionierungs- und Handlungszwängen gegenübertritt ganz so wie auch die alltägliche Wirklichkeit persönlicher Ungleichheitserfahrungen ihnen als institutioneller, schwer zu umgehender Zwang erscheint. Deutungsmuster sind als strukturbildende Faktoren politisch-sozialer Mentalitäten eben nicht nur gesellschaftlich hergestellt, sondern als historisch gewachsene und trotz aller Variabilität prinzipiell langlebige Tiefenstrukturen des Denkens und Fühlens gesellschaftlich eingebetteter Individuen durchaus auch Teil der objektiven sozialen Wirklichkeit und ihrer Eigengesetzlichkeiten. Die Einsicht, dass Deutungsmuster nicht mechanisch auf „objektive Handlungsprobleme" reagieren, sondern sie oft auch selbst hervorbringen, ${ }^{148}$ ist sicher richtig, aber mehr eine notwendige und explizierende Ergänzung zu den Überlegungen Lepsius' und Oevermanns, als eine konzeptuelle Modifikation, die den Rückgriff auf den Ballast wissenssoziologischer Denkwerkzeuge erforderte.

Sehr viel naheliegender ist es, im Deutungsmuster eine zeitgemäße Reformulierung jener Bewusstseinsform zu sehen, die früher (politische) Ideologie hieß, aber seither ihren traditionellen Totalitätsanspruch eingebüßt hat: die Bewältigung gesellschaftlicher Erfahrungen und Handlungsprobleme mithilfe strukturierender, normativ rechtfertigender und Handlungsmaximen anleitender privater (dabei aber auch kollektiv geteilter) Ordnungsentwürfe. Ideologie im klassischen Sinn - d. h. möglichst befreit von allen alltagssprachlich eingeschliffenen polemischen und pejorativen Komponenten -

und ihrer Wirkweise unbestimmte, J. S.] , materielle Cewalt' gegenübertritt." Bögelein/Vetter: Deutungsmuster als Forschungsinstrument, S. 19-22.

144 Dass eine jede Wissenssoziologie, die sich auf das Vokabular der „gesellschaftlichen Konstruktion der Wirklichkeit" nach Peter L. Berger und Thomas Luckmann bezieht (so etwa in Lüders/Meuser: Deutungsmusteranalyse, S. 65), schon auf erkenntnistheoretischer Ebene weitreichende sozialkonstruktivistische Setzungen vornimmt, die auf die Leugnung der objektiven Eigengesetzlichkeit von Gesellschaft hinauslaufen, ist im programmatischen Original nachzulesen. Die Ausgangsfrage: „Wie ist es möglich, daß subjektiv gemeinter Sinn zu objektiver Faktizität wird?" enthält bereits die Prämisse, dass Cesellschaft nichts Anderes sei als kontingent Produziertes oder Konstruiertes, eine bloße imaginäre Fassade, die durch Aufklärung „falschen“ Bewusstseins zu entlarven sei. S. dazu Berger, Peter L./Luckmann, Thomas: Die gesellschaftliche Konstruktion der Wirklichkeit. Eine Theorie der Wissenssoziologie [1969], Frankfurt a.M. 2012, S. VI, 6, 20 und 195 (Herv. i. O.) tungsmuster, in: Sozialer Sinn, H. 3/2001, S. 511-536, hier S. 533.

146 Vgl. Bögelein/Vetter: Deutungsmuster als Forschungsinstrument, S. 21f. und Lüders/Meuser: Deutungsmusteranalyse, S. 63.

147 Lepsius: Kulturelle Dimensionen der sozialen Schichtung, S. 111.

148 Vgl. Lüders/Meuser: Deutungsmusteranalyse, S. 66; Plaß/Schetsche: Grundzüge einer wissenssoziologischen Theorie sozialer Deutungsmuster, S. 533; Bögelein/Vetter: Deutungsmuster als Forschungsinstrument, S. $21 \mathrm{f}$. 
war bestimmt als ein soziales und politisches Denken, das sich „seiner eigenen Konstitution nicht bewußt wird und daher zwischen unbewußter Verschleierung und gesellschaftlich bedingter Selbsttäuschung oszilliert. ${ }^{\text {“149 }}$ In diesem Begriff war die Einsicht enthalten, dass das bloße „Entlarven“ ideologischer Gehalte die spezifische Verbindung von Realität und Realitätswahrnehmung verkennt; Ideologie in diesem Sinne ist nicht „bloß Täuschung und Betrug“, gar nur aufzuklärender Irrtum, besser noch wirklichkeitsfremde Einbildung. Ideologie im klassischen Sinn ist eine Bewusstseinsform, die durch den täglichen Verkehr mit dem gesellschaftlichen - und also auch demokratischen - Prozess nachgerade aufgenötigt wird. ${ }^{150}$ Dass der Einzelne frei und autonom sei in Kaufentscheidungen und Stimmenabgabe, dass seine sittlichen und religiösen Wertbezüge ihm selbst eigen sind, dass es bestimmte Herrschafts- und Zwangsformen geben müsse, dass gesellschaftliche Ungleichheiten legitim sind und eine Funktion erfüllen, usw. - all diese potenziell strittigen Überzeugungen können falsch sein, resultieren aber nicht nur aus „falschem“ Denken, sondern aus erfahrbarer Realität. Stets gehörte zur Ideologie dabei der Aspekt der Rechtfertigung, ${ }^{151}$ sei es der Rechtfertigung der herrschenden Zustände oder der Rechtfertigung von Kritik an diesen Zuständen. Dies ist besonders in den sogenannten politischen „Ideologien“ deutlich, die - lässt man für einen Moment die teils gravierende historische Variabilität beiseite - jeweils einen Gesamtentwurf funktionierender Gesellschaft enthielten: Liberalismus, Konservatismus, Sozialismus. ${ }^{152}$

(Politische) Ideologie war aber auch gebunden an die vergleichsweise geschlossenen Deutungssysteme des 18., 19. und frühen 20. Jahrhunderts. Wie spätestens seit dem Ende des Zweiten Weltkriegs und seit der Transformation der deutschen Gesellschaft in eine massenkulturell und massenmedial strukturierte Konsumgesellschaft häufig konstatiert wurde - für den US-Kontext führten das klassisch Daniel Bell 1960 als The

149 Lenk: Ideologie, S. 357 (Herv. i. O.)

150 Ibid.

151 „Als objektiv notwendiges und zugleich falsches Bewußtsein, als Verschränkung des Wahren und Unwahren, die sich von der vollen Wahrheit ebenso scheidet wie von der bloßen Lüge, gehört Ideologie, wenn nicht bloß der modernen, so jedenfalls einer entfalteten städtischen Marktwirtschaft an. Denn Ideologie ist Rechtfertigung. Sie setzt ebenso die Erfahrung eines bereits problematischen gesellschaftlichen Zustandes voraus, den es zu verteidigen gilt, wie andererseits die Idee der Cerechtigkeit selbst, ohne die eine solche apologetische Notwendigkeit nicht bestünde und die ihr Modell am Tausch von Vergleichbarem hat. Wo bloße unmittelbare Machtverhältnisse herrschen, gibt es eigentlich keine Ideologien." Institut für Sozialforschung: Ideologie, in: Soziologische Exkurse. Nach Vorträgen und Diskussionen, Frankfurter Beiträge zur Soziologie Bd. 4, Frankfurt a.M. 1956, S. 162-181, hier S. 168 (Herv. i. O.)

152 „Ihre Motive knüpfen objektiv eindeutig an die Interessenlagen bestimmter sozialer Cruppen an und entwerfen ein entsprechendes Bild von der Gesellschaft im ganzen: den Liberalen erscheint sie als ein freier Verband konkurrierender Individuen; den Konservativen als ein hierarchisch geordneter Ständeorganismus; die Sozialisten begreifen sie unter dem Aspekt des Klassenkampfes. Stets gelingt es, den eigenen Standort gesamtgesellschaftlich zu interpretieren, die eigenen Interessen aus dem Interesse aller zu rechtfertigen und den politischen Handlungen durch die Suggestion retrospektiver oder wie immer perspektivischer Normen einen eindeutig gerichteten Impuls zu geben." Habermas et al.: Student und Politik, S. $152 f$. 
End of Ideology und Francis Fukuyama als The End of History ${ }^{153}$ aus -, ist der Totalitätsund Erklärungsanspruch politischer Ideologien, verstanden als klassen- und milieuspezifische Ausprägungsformen „großer“ Deutungssysteme und „geschlossene[r] politische[r] Weltanschauungen“ im vermeintlich „postideologischen“ Zeitalter, zerfallen. ${ }^{154}$ Dies führte bereits in den 1950er Jahren zu dem Urteil, Ideologie sei herabgesunken zur „Anerkennung des Bestehenden selber“, zu „Modelle[n] eines Verhaltens, das der Übermacht der Verhältnisse sich fügt. ${ }^{1155}$ Nun muss man das fatalistische Pathos der Vokabeln des „Zerfalls“ und „Verfalls“ nicht kopieren. Auch wenn der damit verbundene Verlust emanzipativer und utopischer Ideale bedenklich sein mag, ist ein solcher „Zerfall" traditioneller Bewusstseinsformen zunächst einmal eine Anpassung an veränderte gesellschaftliche Verhältnisse, welche die einst empfundenen „Wahrheiten“ des Alten schlicht entwertet haben. Unbedingt aber sollte die Einsicht aufgenommen werden, dass viele populäre Zeitdiagnosen der Mitte des vergangenen Jahrhunderts auf einen Dekompositionsprozess hinweisen, welcher als Ablösung der einstigen Deutungssysteme durch fragmentierte, zersplitterte, oft sicher auch unzusammenhängende Deutungsmuster zu verstehen ist. Das Bedürfnis nach Deutung, Erklärung und Rechtfertigung ist keineswegs verschwunden, nur werden Deutungsmuster kaum noch die ersehnte sinnhafte Integration sämtlicher (oder zumindest entscheidender) gesellschaftlicher Vorgänge leisten können. Effekte dieses Wandels fallen in qualitativen Studien häufig auf: Der situative Rückgriff auf Deutungsmuster im qualitativen Gesprächskontext arbeitet oft mit widersprüchlichen Denkschablonen und Schematismen, nicht selten auch mit der demonstrativen Kapitulation vor komplexeren Fragen, wo eben kein System der Deutung die einzelnen Muster zu überbrücken vermag.

Viele Autoren haben diese Nötigung zur konzeptuellen Neuorientierung erkannt, wenige setzten sie methodisch überzeugend um. Originelle Vorarbeiten, die im Verlauf dieser Studie noch mehrfach aufgegriffen werden, leisteten etwa Habermas et al. in Student und Politik. Ausgehend von der Beobachtung, dass der Anspruch der alten politischen Ideologien darin bestand, „die Totalität der Gesellschaft zu erfassen“, indem sie sie am Maßstab eines durch die klassenbedingte Interessenlage konstituierten „normativen Entwurfs der Zustände, wie sie ,eigentlich" sind oder zu sein haben“ misst und „die unanschaulich gegebene Mannigfaltigkeit der Sachverhalte zur plausiblen, aber dogmatisch vorgegebenen Einheit des Ganzen“ fügt, ${ }^{156}$ fragen die Autoren nach dem

153 Vgl. Bell, Daniel: The End of Ideology. On the Exhaustion of Political Ideas in the Fifties, Glencoe 1960 sowie Fukuyama, Francis: The End of History and the Last Man, New York 1992.

Vgl. Lenk, Kurt: Zum Strukturwandel politischer Ideologien im 19. und 20. Jahrhundert - Begriff und Phänomen des ideologischen Bewußtseins (1981), in: Ders.: Rechts, wo die Mitte ist. Studien zur Ideologie: Rechtsextremismus, Nationalsozialismus, Konservatismus, Baden-Baden 1994, S. 27-41, hier S. 37-40 und, empirisch am Beispiel von Frankfurter Studierenden, Habermas et al.: Student und Politik, S. 152-164.

155 Institut für Sozialforschung: Ideologie, S. 178. Außerdem Lenk: Zum Strukturwandel politischer Ideologien, S. 39: „Der Begriff der Ideologie im Sinne einer übergreifenden, mit Anspruch auf objektive Wahrheit gerichteten Rechtfertigung hat sich weithin aufgelöst. Geblieben sind eingeschliffene Vorurteile, deren Funktion vor allem darin besteht, die vorgegebenen gesellschaftlichen Bedingungen zu akzeptieren und sich einzurichten." 
damaligen Zustand derartiger „Gesellschaftsbilder“ unter Studierenden. Zwar seien politische Ideologien weitgehend „zerfallen“ und die zugehörigen „genuinen“ bzw. „autochthonen" Gesellschaftsbilder nur noch in atavistischer Form aufzufinden, auch seien die künstlichen faschistischen und sowjetischen „Ersatzmythen“ rasch wieder verblichen. ${ }^{157}$ „Resignierte Anpassung an das, was der Fall ist, tritt an die Stelle von Spekulationen, Ideologien und Theorien, die uns auf die eine oder andere Weise der Totalität versichern. “158 Statt der Berufung des politischen Urteils auf einen Sinnzusammenhang des Ganzen herrsche nun der konsumkulturelle Konformismus stereotyper Verhaltensweisen, welche den Gedanken praktischer Umgestaltung der Gesellschaft von sich fernhalten. ${ }^{159}$ Allerdings führe dieser „Ideologieverlust “160 in der massenmedial strukturierten Gesellschaft keineswegs zum Abtritt ideologischen Bewusstseins insgesamt. Fragmente der alten moralischen, religiösen und philosophischen Motive vermengten sich mit neuen, stärker individualisierten Auffassungen der Funktionsweise von Gesellschaft und der persönlichen Rolle in ihr. ${ }^{161}$ So mag das unter Studierenden der 1950er Jahre aufgefundene „Modell der inneren Werte“, ein „modifiziertes“ Gesellschaftsbild, das „entlang der Trennungslinie zwischen einem innerlichen, eigentlichen, und einem äußerlichen, uneigentlichen Bereich" organisiert sei, also Gesellschaft wesentlich als „Sphäre der Entfremdung“wahrnehme und alle äußeren Unterscheidungskriterien wie Status, Einkommen, Aussehen und Bildung als künstlich und „uneigentlich" klassifiziere, während Charakter, Bildung und Moral eines Menschen dessen „wahren"Wert bestimmten, ${ }^{162}$ als frühes Beispiel eines sozialwissenschaftlich zutage geförderten politisch-sozialen Deutungsmusters im hier gemeinten Sinne verstanden werden. Eine andere, konzeptuell herausfordernde, aber empirisch zumeist nur partiell umgesetzte, Antwort auf den Wandel der politischen Bewusstseinsformen lieferte Karl Rohe mit seinem qualitativen Verständnis politischer Kulturforschung. In dezidiert kritischer Auseinandersetzung mit dem quantitativen politischen Kulturbegriff der Civic Culture nach Gabriel Almond und Sidney Verba ${ }^{163}$ und mit dem Konzept „politischer Unterstützung" nach David Easton ${ }^{164}$, welche sämtlich (wenn auch in kontinuierlicher Weiterentwicklung und Modifikation) statische Raster demokratischen Bewusstseins

157 Ibid., S. $152 f$.

158 Ibid., S. 156.

159 Ibid., S. $156 f$.

160 Ibid., S. 154.

161 Vgl. ibid., S. 164.

162 Ibid., S. 164, 171-180. Besonders interessant an diesem Modell ist die verborgene - wenn auch von vielen verbal abgelehnte - Schlussfolgerung einer legitimen Vorrangstellung des Akademikers in der Gesellschaft: Als besonders „geistiger“ Mensch verfügt er zwangsläufig über überdurchschnittlich ausgeprägte „eigentliche" Qualitäten. Dieser Aspekt wird ibid. auch diskutiert.

163 Vgl. Almond, Gabriel/Verba, Sidney: The Civic Culture. Political Attitudes and Democracy in Five Nations, Princeton 1963; Almond, Gabriel: Politische Kultur-Forschung - Rückblick und Ausblick, in: Berg-Schlosser, Dirk/Schissler, Jakob: Politische Kultur in Deutschland. Bilanz und Perspektiven der Forschung, Politische Vierteljahresschrift, Sonderheft 18/1987, S. 27-38.

164 Vgl. Easton, David: A Framework for political Analysis, Prentice Hall 1965; Easton, David: A ReAssessment of the Concept of Political Support, in: British Journal of Political Science, H. 5/1975, S. 435-457. 
für die Surveyforschung zur Messung der Stabilität und Legitimität politischer Ordnungen aufstellen, ${ }^{165}$ dynamisiert Rohe politische Kultur als komplexes Ineinander gesellschaftlicher, kollektiver und individueller Mentalitätsbestände sowie oberflächlicher und tiefenstruktureller Orientierungen. Er differenziert zwischen „politischer Sozialkultur" und „politischer Deutungskultur“ ${ }^{166}$ erstere verstanden als Fundament diskursentzogener latenter Selbstverständlichkeiten und auskristallisierter Grundüberzeugungen aller Mitglieder einer Gesellschaft (Mentalitäten, Gewohnheiten, Lebensweisen), letztere aufgefasst als voluminöse Mannigfaltigkeit manifester, also sichtbarer und angreifbarer Rede- und Handlungsweisen, Meinungen, Einstellungen, Werthaltungen, Symboliken, etc. Während politische Sozialkultur „zumindest für eine Zeitlang nicht in Frage gestellt werden“ könne, in seiner historischen Persistenzkraft also „Ermöglichungsvoraussetzung allen politischen Lebens" darstelle, befinde sich politische Deutungskultur stets im Fluss gesellschaftlicher Auseinandersetzungen, in dem Individuen um die Anerkennung ihrer jeweiligen Deutungsvarianten streiten; beide zusammen bilden politische Kultur im anspruchsvollen Sinne. ${ }^{167}$ Auch Rohe stellt die Frage, ob es so etwas wie ein allgemein verbindliches, Gesellschaften trotz aller Konfliktivität integrierendes, Grundsediment politischer Kultur infolge der Erosion klassenbedingter politischer Milieus und Lager (noch) gibt, oder ob die Prämisse einer langfristig intakten homogenen Sozialkultur als Voraussetzung „funktionierender“ Gesellschaft sich nicht vielmehr als folkloristische Idealisierung übersichtlicher klassengesellschaftlicher und vormoderner Gemeinschaften enthülle. ${ }^{168}$ Um das Projekt einer Klärung anzugehen, schlägt er vor, über die Werkzeuge der Umfrageforschung und über ihr Interesse an (oberflächlichen) Einstellungsmustern hinauszugehen; politische Kulturforschung müsse die Frage nach den fundierenden „Grundannahmen über die politische Welt" stellen, d. h. "grundlegende[n] Ordnungsvorstellungen“ nachgehen, „die die Maßstäbe für die Beurteilung eines Systems bereitstellen und dabei zumindest ansatzweise den Charakter einer politischen Theorie besitzen. ${ }^{169}$ Lesbar seien diese Ordnungsvorstellungen in Gestalt der "Ausdrucksseite“ (rhetorische Zitate, Problemrahmungen, Symbole und Codes, Mythen, Handlungen) sowie der "Inhaltsseite“ (Sinnbezüge, Urteile, Aussagen); ${ }^{170}$ hierin bestehe der "subjektive und objektive Doppelcharakter" politischer Kultur. ${ }^{171}$ Mit anderen Worten: Auch die qualitative politische Kulturforschung nach Rohe eröffnet den Blick auf den gesellschaftlichen Verkehr von potenziell handlungsleitenden politisch-sozialen Ordnungsvorstellungen und Deutungsmustern „unterhalb“

Vgl. Pickel, Susanne/Pickel, Gert: Politische Kultur- und Demokratieforschung. Grundbegriffe, Theorien, Methoden. Eine Einführung, Wiesbaden 2006, S. 51-54.

166 Rohe, Karl: Politische Kultur und der kulturelle Aspekt von politischer Wirklichkeit. Konzeptionelle und typologische Überlegungen zu Cegenstand und Fragestellung Politischer Kulturforschung, in: Berg-Schlosser, Dirk/Schissler, Jakob: Politische Kultur in Deutschland. Bilanz und Perspektiven der Forschung. Politische Vierteljahresschrift, Sonderheft 18/1987, S. 39-48.

167 Ibid., S. 42 sowie Rohe, Karl: Politik. Begriffe und Wirklichkeiten, Stuttgart Berlin Köln 1994, S. 164.

168 Vgl. Rohe: Politische Kultur und der kulturelle Aspekt von politischer Wirklichkeit, S. 40 und 46.

169 Rohe: Politik, S. 165.

170 Ibid., S. 166.

171 Rohe, Karl: Politische Kultur. Zum Verständnis eines theoretischen Konzepts, in: Niedermayer, Oskar/Beyme, Klaus von (Hg.): Politische Kultur in Ost- und Westdeutschland, Berlin 1994, S. 1-21, hier S. 7. 
der manifesten Einstellungs- und Meinungsebene; ihr starkes Interesse an Teilbereichen der Gesellschaft (soziale Gruppen, Milieus, Regionen, etc.) und deren politischen (Teil-)Kulturen ${ }^{172}$ kann hier passfähig auf die Gruppe der Studierenden gelenkt werden. Daher ist das Rohe'sche Verständnis politischer Kultur als unterstützende konzeptuelle Rahmung der Deutungsmusteranalyse hilfreich, die Aufschluss über die Mannigfaltigkeit der Äußerungs- und Erscheinungsformen sowie Bezugswege von Deutungsmustern in der Tiefendimension politisch-sozialer Mentalitäten gibt. ${ }^{173}$ Auch wenn Rohes originärer ambitionierterer Intention dabei nicht vollständig Genüge getan werden kann: Qualitative Gesprächsmethoden machen immerhin einen „Ausschnitt“ politischer Kultur der Beobachtung, Beschreibung und Interpretation zugänglich, ${ }^{174}$ und zwar jenen Ausschnitt handlungsleitender ideologischer Bewusstseinsformen, welche sich in sozial- wie deutungskulturellen Äußerungsformen ausdrücken.

Soll der von Christian Lüders herausgearbeitete und unterstrichene Anspruch der Deutungsmusteranalyse, „epochalen gesellschaftlichen Wandel“ „detailversessen“, d. h. am Einzelfall, nachzuvollziehen, um „in der Sprache des Falles den Spuren der Verwerfungen und Fragmentierungen nachzugehen“", ${ }^{175}$ mit dem nötigen Ernst eingelöst werden, ist das Deutungsmuster genau so zu verstehen: als Element privater Gesellschaftstheorien nach dem weitgehenden Ende der Deutungssysteme politischer Ideologien, d. h. als Fragment ideologischer Leitlinien, welche politisch-soziale Meinungen, Urteile und Einstellungen in einer mentalen Tiefenschicht strukturieren, sinnhaft verknüpfen, deutend rechtfertigen und dementsprechend Handlungsoptionen ableiten. Inkonsistenzen zwischen einzelnen politischen Einstellungen können durch Deutungsmuster verbunden und insofern sinnhaft sein; Inkonsistenzen zwischen verschiedenen Deutungsmustern selbst hingegen deuten auf Orientierungsschwierigkeiten, ggf. auf im Wandel befindliche Orientierungen hin. Dabei verbietet sich wohlgemerkt jeder wissenschaftliche Hochmut: Politische und gesellschaftliche Vorgänge werden im alltäglichen Bewusstsein fast immer ideologisch, d. h. rechtfertigend deutend ${ }^{176}$ verarbeitet, auch vom Forschenden selbst, wo er nicht am Schreibtisch sitzt und so lange angestrengt ideologiekritisch arbeitet, bis er weltschmerzliches Stirnrunzeln betreibt wie einen Kampfsport. In diesem spezifischen Sinne wird hier nach politisch-sozialen Deutungsmustern ${ }^{177}$ von Studieren-

172 Vgl. Marg, Stine: Nach Pegida - Politische Orientierungen junger Menschen. Fokusgruppen als Instrument zur Deutungsmusteranalyse, in: Bögelein, Nicole/Vetter, Nicole (Hg.): Der Deutungsmusteransatz. Einführung - Erkenntnisse - Perspektiven, Weinheim Basel 2019, S. 107-127, hier S. 110.

173 Vgl. ibid., S. 108-111.

174 Ibid., S. 111.

175 Lüders: Deutungsmusteranalyse, S. $378 f$.

176 In einem aktuellen Sammelband zur Deutungsmusteranalyse werden Deutungsmuster strikt von „Ideologien“ getrennt. Die Begründung lautet, dass letztere „ein von Interessen geleitetes Rechtfertigungsmuster darstellen“ und dabei „an die Durchsetzung von Interessen gebunden sind“, während „dies für Deutungsmuster zwar auch, aber nicht ausschließlich“ gelte, s. Bögelein/Vetter: Deutungsmuster als Forschungsinstrument, S. 17. Bedauerlicherweise bleiben hier sowohl die wissenschaftlichen Beweggründe als auch die konkreten konzeptuellen und empirischen Konsequenzen dieser begriffsanalytischen Subtilität ungeklärt. Die distinkte Unterscheidung, so apodiktisch knapp sie auch behauptet wird, vermag daher nicht zu überzeugen.

177 Bisweilen wird zwischen „sozialen und kulturellen“ Deutungsmustern einerseits und „politischen“ Deutungsmustern andererseits unterschieden, um nur letzteren die Eignung für politische Kul- 
den gefragt. Dazu noch ein Hinweis auf die Einschränkungen dieses methodischen Zuschnitts: Das Deutungsmusterkonzept leistet keine „Theorie des Handelns“ im Sinne von Bourdieus Habituskonzept, d. h. keine ausgearbeitete Klärung der konkreten sozialisatorischen Herkunft von Deutungsmustern sowie der Mechanismen des Umsetzens von Deutungsmustern in soziales Handeln. ${ }^{178}$ Hier wird lediglich davon ausgegangen, dass Menschen in Gesellschaft auf verschiedene, auch konkurrierende und widersprüchliche, Deutungsmuster zurückgreifen, dass diese Deutungsmuster die „Oberflächen“-Ebene von Meinungen, Einstellungen und Orientierungen in einer irgendwie gearteten (in künftigen Studien sozialpsychologisch versierter zu bestimmenden) mentalen Tiefenschicht mithilfe latenter Sinnstrukturen vermitteln, und dass diese Sinnstrukturen potenziell handlungsleitende Orientierungen stiften - unter Ausklammerung der Frage nach dem Wie. Ob und inwiefern Deutungsmuster dabei doch noch primär durch die soziale Lage oder durch Residuen von Milieuzugehörigkeiten bedingt sind - ursprünglich eine wesentliche Prämisse Bourdieus ${ }^{179}$ - oder in postindustriellen Gesellschaften vielmehr auf impressionistische Weise durch differente biographische Erfahrungskontexte und flexible Gruppenzugehörigkeiten zufällig „erworben“ werden, mithin eher fragmentierten Versatzstücken einstiger klassengebundener „großer“ und konsistenterer Deutungssysteme gleichen, ist hierbei eine der entscheidenden offenen Fragen. Zudem: Ob die Handlungsimperative der vorgebrachten Deutungsmuster tatsächlich faktisch in Handlungen umgesetzt werden, ist schon allein aufgrund der einmalig stattfindenden Gesprächssituation nicht zu klären. Politisches Potenzial kann hier nur näherungsweise in Gestalt einer vermuteten Handlungsdisposition verhandelt werden, die sich aus studentischen Deutungsmustern rekonstruieren lässt.

Die Suche nach einer geeigneten Materialquelle zur Aufdeckung und Analyse solcher Deutungsmuster führt unmittelbar zur Erhebungsmethode der Gruppendiskussion, genauer: der Fokusgruppe. ${ }^{180}$ Fokusgruppen simulieren die diskursive Alltäglichkeit

turforschung zuzusprechen, s. Marg: Nach Pegida, S. 108. Aber auch diese Unterscheidung weckt Zweifel. Denn befreit man sich einmal von dem akademisch gepflegten Zwang zur Departementalisierung sozialwissenschaftlicher „Disziplinen“, die die Fixierung von Zuständigkeiten bis in die Adjektive der eigenen Forschungsdesigns verlängert, und übt man Empathie für das alltägliche politische Denken und Fühlen empirischer Menschen, so darf doch gefragt werden: Was sind private Theorien über das Politische Anderes als Theorien über gesellschaftliche - und damit stets soziale-Ordnungsprinzipien und Funktionsgesetze, auf die man sich einen Reim macht? Wie sind die Wege der Deutung politischer und sozialer Vorgänge in den Köpfen und im Austausch vermittelt, wenn nicht über kulturell (mit-)determinierte Bilder, Symbole, Analogien, und Vokabeln, schließlich Sitten und Handlungsroutinen?

178 Vgl. Bögelein/Vetter: Deutungsmuster als Forschungsinstrument, S. 17f. sowie Lüders: Deutungsmusteranalyse, S. 377.

179 Vgl. ibid.

180 Die Fokusgruppe (bisweilen auch als ad-hoc-Gruppe bezeichnet) wird hier als besondere Variante der Cruppendiskussion verstanden, die ihre sich gegenseitig möglichst fremden Diskussionsteilnehmer nach bestimmten Kriterien auswählt und zur Diskussion fokussierter Themen bringt. Sie ist inbesondere von der Realgruppe abzusetzen, in der Menschen miteinander diskutieren, die sich privat kennen - die aber ihre wechselseitigen Konsenslinien womöglich schon vor dem Stattfinden der Gruppendiskussion ausgelotet haben und mitunter stärker vor persönlichen Konsequenzen von in der Gruppe getätigten Äußerungen zurückschrecken. Vgl. dazu Kühn, Thomas/Koschel, Kay-Volker: Gruppendiskussionen. Ein Praxis-Handbuch, Wiesbaden 2017, S. 20 und 77. 
politischer Urteilsbildung: Der Grundgedanke der Methode ist, eine wirklichkeitsnahe Situation der konfrontativen Aushandlung von individuellen und kollektiven Bewertungen sowie Erklärungsmustern experimentell ${ }^{181}$ abzubilden. Denn Meinungen über komplexe Themen wie politische und gesellschaftliche Vorgänge werden stets in Interaktion zwischen Individuen und Gruppen hergestellt, sie speisen sich immer auch aus „undeutlichen Stimmungen“. ${ }^{182}$ Mündliche Ausführungen über Werthaltungen, Ordnungsvorstellungen, politische Problemwahrnehmungen, persönliches Demokratieverständnis etc. sind immer situativ bedingt, sozialkontextuell eingebettet und gewinnen oft erst in praktischer Interaktion ihre spezifische Kontur. ${ }^{183}$ „Viele subjektive Bedeutungsstrukturen sind so stark in soziale Zusammenhänge eingebunden, dass sie nur in Gruppendiskussionen erhebbar sind. Hier können psychologische Sperren durchbro-

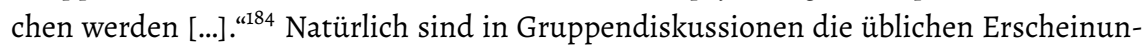
gen sozialer Erwünschtheit in der einen oder anderen Form weiterhin wirksam. Überzeugungen, die gegen eine bereits hergestellte Mehrheitsmeinung verstoßen, werden oft besonders ungerne geäußert; generell sind Menschen ängstlich, im Kreis der Gruppe als „Rechte“ oder „Extremisten“ zu gelten, usw. Dennoch: Die Positionierungen anderer Teilnehmer wirken immer auch als kontinuierlicher Reiz, zuzustimmen, zu ergänzen, $\mathrm{zu}$ widersprechen. In der Gesprächssituation stellen sich so in der Regel - entweder durch wechselseitige Interaktion oder durch ausbleibenden Widerspruch - Meinungshegemonien her, die hier als dominante „Alltagsmoral ${ }^{4185}$ von Studierenden verstanden werden können, während gegenläufige Positionen entweder unterliegen oder in einen offenen Konflikt treten. Manche Dissens- und Konfliktpunkte wiederum werden überhaupt keiner abschließenden Klärung zugeführt - stets lautet die Frage: Wie vollziehen sich diese diskursiven Schicksale und warum? Fokusgruppen fördern somit keine Summe von Einzelmeinungen zutage - sie sind kein Gruppeninterview -, sondern schaffen ein „Produkt kollektiver Interaktionen“, ${ }^{186}$ wie auch politische Kultur eines ist. Sie verzerren nicht etwa den Meinungsbildungsprozess, wie ein oberflächlicher Vergleich mit standardisierten Einzelinterviews nahelegen könnte, sondern bilden ihn realitäts- und alltagsnäher ab als diese. ${ }^{187}$ Sie rekonstruieren einen gemeinsamen Erfahrungsraum der Diskutanten, ${ }^{188}$ hier der Gruppe der Studierenden, welche heuristisch vereinfachend trotz aller zu erwartenden Binnenheterogenitäten als ein gesellschaftlich eingebettetes Kollektivsubjekt aufgefasst werden.

Qualitative Sozialforscher diskutieren insbesondere die Frage nach adäquaten Auswertungsverfahren ausgiebig. Wie schon erwähnt, wird in dieser Studie keines der

Vgl. Faas, Thorsten/Huber, Sascha: Experimente in der Politikwissenschaft. Vom Mauerblümchen zum Mainstream, in: Politische Vierteljahresschrift 51/2010, S. 721-749.

182 Marg: Mitte in Deutschland, S. 72.

183 Vgl. Mangold, Werner: Gruppendiskussionen, in: König, René: Handbuch der empirischen Sozialforschung Bd. 2, Stuttgart 1973, S. 228-259.

184 Mayring: Einführung in die qualitative Sozialforschung, S. 77.

185 Lepsius: Kulturelle Dimensionen der sozialen Schichtung, S. 111.

186 Mangold, Werner: Gegenstand und Methode des Gruppendiskussionsverfahrens. Aus der Arbeit des Instituts für Sozialforschung, Frankfurt a.M. 1960, S. 49.

187 Vgl. Kühn/Koschel: Gruppendiskussionen, S. 61 und 247.

188 Vgl. Bohnsack/Przyborski: Diskursorganisation, Gesprächsanalyse und die Methode der Gruppendiskussion, S. 235. 
durchgebildeten Programme vollumfänglich befolgt; das gewählte Verfahren bezieht gleichwohl wesentliche Impulse aus der Grounded Theory. ${ }^{189}$ Zwar wird nicht die Bildung einer Theorie angestrebt, wohl aber ein im Rahmen eines offenen, d. h. zugleich deduktiv, induktiv sowie abduktiv arbeitenden, „pragmatistischen Forschungsstils“ erzielter ${ }^{190}$ Erkenntnisgewinn im Sinne der Aufdeckung von politisch-sozialen Deutungsmustern als rechtfertigender und handlungsleitender Sinnstrukturen, als „Theorien der Alltagserfahrung “191. Einzelne in der Auswertung vorgetragene Interpretationen nehmen die Funktion von erklärenden Hypothesen ein, die sich im Verlauf des Erhebungsund Rekonstruktionsprozesses als plausibel „bewährt“ haben. Sie resultieren aus dem deduktiven und induktiven Kodieren ${ }^{192}$ der Fokusgruppentranskripte. Freilich ist die entscheidende Frage hier, woran man erkennt, dass politisch-soziale Deutungsmuster in der Gruppendiskussion „in Aktion“ treten? Die Antwort lautet: Sie sind als „Hintergrund“ des Gesagten rekonstruierbar, also als jene Sinnstrukturen, die wechselseitiges intuitives Fremdverstehen in der Gruppensituation $\mathrm{zu}$ ermöglichen scheinen. ${ }^{193}$ Deutungsmuster legen sich somit selbst im Diskussionsprozess offen, stiften Orientierung und Zusammenhänge insbesondere in konfrontativen Situationen, in denen Rechtfertigungen konstruiert, Irritationen und Widersprüche bearbeitet, Urteilsroutinen (wieder-)hergestellt, komplexere Antworten auf problematische Aspekte gesucht werden. Sowohl der Themenkatalog als auch die Gruppenmoderation zielen daher auf das Auslösen von Orientierungskrisen, die den Rückgriff auf Deutungsmuster aktivieren. Über die genetische Kausalquelle der Deutungsmuster ist damit allerdings noch nichts gesagt. Das einseitige Betonen gruppendynamischer Effekte soll während der

189 Das von Oevermann geforderte Verfahren der Objektiven Hermeneutik, welches nicht nur anspruchsvolle Transkriptionsregeln, eine detaillierte Sequenzanalyse sowie eine durch minutiöse Dokumentation der einzelnen Interpretationsschritte „zwingend“ ergebende Interpretation des Interviewmaterials (als wäre das forschende Subjekt am Ende doch noch wegzusubtrahieren) fordert, ist im Rahmen dieser als Dissertation eines einzelnen Forschers angelegten Studie nicht durchführbar. Ähnliches gilt für die Dokumentarische Methode nach Ralf Bohnsack. Vgl. Oevermann: Oevermann, Ulrich: Klinische Soziologie auf der Basis der Methodologie der objektiven Hermeneutik - Manifest der objektiv hermeneutischen Sozialforschung, Institut für hermeneutische Sozial und Kulturforschung e. V. 2002 und, zur Kritik des hier erhobenen objektivistischen Anspruchs, Marg: Mitte in Deutschland, S. 80. Vgl. zu den Anforderungen der Dokumentarischen Methode Bohnsack: Rekonstruktive Sozialforschung, S. 31-68.

190 Strübing, Jörg: Grounded Theory. Zur sozialtheoretischen und epistemologischen Fundierung eines pragmatistischen Forschungsstils, Wiesbaden 2014.

191 Oevermann: Zur Analyse der Struktur von sozialen Deutungsmustern, S. 10.

192 Hierbei resultierten deduktive Codes aus der inhaltlichen Vorstrukturierung durch die aspektzentrierte Längsschnittbetrachtung und, daraus folgend, aus dem Fokusgruppen-Leitfaden, während die induktiven (offenen) Codes sich aus den Relevanzkriterien der Diskutanten ergaben. Vgl. zu dieser aus dem Instrumentarium der Crounded Theory stammenden Distinktion Mayring: Einführung in die qualitative Sozialforschung, S. 92 sowie Przyborski/Wohlrab-Sahr: Qualitative Sozialforschung, S. 207.

193 Vgl. Meuser, Michael: Repräsentation sozialer Strukturen im Wissen. Dokumentarische Methode und Habitusrekonstruktion, in: Bohnsack, Ralf/Nentwig-Gesemann, Iris/Nohl, Arnd-Michael (Hg.): Die dokumentarische Methode und ihre Forschungspraxis, Wiesbaden 2013, S. 209-224, hier S. 221. 
Auswertung ebenso vermieden werden wie ein zu starker Fokus auf individuelle Deutungsmuster. $\mathrm{Zu}$ erwarten ist vielmehr eine wechselseitige Überlagerung von gruppendynamischen Effekten, individuellen sowie sozialmoralisch geprägten Vorstellungen und Mentalitätsfragmenten.

Die hier durchgeführten Fokusgruppen wurden durch einen am Forschungsinteresse und an der aspektzentrierten historisch-empirischen Längsschnittbetrachtung ausgerichteten Themenkatalog strukturiert, der die inhaltliche Fokussierung sowie eine gewisse Vergleichbarkeit der Gruppen untereinander sicherstellt, und durch den Verfasser moderiert. Sowohl bei dem Entwurf des Themenkatalogs als auch bei der Gruppendiskussion ist besondere Sensibilität erforderlich: Die gestellten Fragen sollen offen und erzählgenerierend wirken, insgesamt möglichst wenig an semantischer Rahmung vorwegnehmen. Schließlich wird die Sicht der Teilnehmer nicht nur durch inhaltliche Aussagen, sondern auch durch die Wahl der Ausdrücke, durch Bezugnahmen auf spezifisches Vokabular, durch den Tonfall und die parasprachliche Kommunikation wie Gestik und Mimik, durch Versprecher und Selbstkorrekturen, und ganz besonders auch durch die Art der assoziativen Verknüpfung abstrakt gehaltener Fragen mit der eigenen konkreten Erfahrung, deutlich. In vielen Gesprächen dominieren wenige Sprecher die Gesprächssituation und okkupieren einen Großteil der Redezeit. Diesen Effekten ist (nach Möglichkeit) durch eine geschickte Moderation Rechnung zu tragen. Die zentrale Aufgabe der Moderation liegt insgesamt darin, eine möglichst selbstläufige Diskussion zu evozieren; aus diesem Grund muss sie auch in der Lage sein, sensibel auf Stimmungsverläufe zu reagieren und gegebenenfalls lenkend einzugreifen. Der Rückgriff auf die im Themenkatalog vorbereiteten Formulierungsvorschläge richtet sich im Idealfall flexibel nach dem Verlauf der Diskussion. Neigt eine Gruppe zum zügigen Postulieren der eigenen Relevanzkriterien, hält sich der Moderator zurück; dominiert ein karger und passiver, abwartender Gesprächsstil oder trägt die Diskussion allzu weit fort vom Gesprächsgegenstand, ist ein stärker direktiver Moderationsstil erforderlich. Üblicherweise durchlaufen Gruppendiskussionen eine „Phase der Annäherung“ und des wechselseitigen Kennenlernens, in der Wortbeiträge vorsichtig und unter dem Aspekt gemutmaßter gruppeninterner Reaktionen geäußert werden, eine „Phase der Vertrautheit", in welche die aufschlussreichsten Diskussionspassagen und impulsivsten Äußerungen fallen, und eine "Phase der Konformität“, in welcher zentrale Konsenslinien weitgehend hergestellt sind und eine fortschreitende Ermüdung eintritt. ${ }^{194}$

An dieser Stelle ist noch einmal zu spezifizieren, was mit dem Verzicht auf wissenschaftlichen Hochmut gemeint ist, und zwar am Gegenstand des Verhältnisses von Alltagssprache und Wissenschaftssprache. Erfahrungsgegenstände des qualitativ arbeitenden Forschers sind „Text und Protokoll statt Meßdaten“, ${ }^{195}$ d. h. hier: Transkripte, Kodierprotokolle, Thesenpapiere. Sowohl bei der Moderation der Diskussionen als auch bei der anschließenden Auswertung gerät man in Versuchung, das Gesagte - den Text -

194 Vgl. Bohnsack, Ralf: Gruppendiskussionsverfahren und Milieuforschung, in: Friebertshäuser, Barbara/Langer, Antje/Prengel, Annedore: Handbuch Qualitative Sozialforschung in der Erziehungswissenschaft, Weinheim 1997, S. 492-502, hier S. 499.

195 Vgl. Oevermann: Klinische Soziologie auf der Basis der Methodologie der objektiven Hermeneutik, S. 3 . 
als adäquate Abbildung von Orientierungsstrukturen hinzunehmen. So läuft man Gefahr, bei bloßen Phänomenologien stehen zu bleiben, d. h. die nach der Vorstellung von „Einstellungsmustern“ und Einstellungsforschung (ein Metier quantitativ angelegter Studien) katalogisierten Phänomene deskriptiv zu behandeln, woran schließlich auch nur nachträglich „heruminterpretiert“ werden kann. Das ist ganz besonders dann fatal, wenn Diskutanten inkohärente Aussagen tätigen, sich selbst widersprechende Beobachtungen und Erklärungen vortragen. Denn: Erwartet man klare Positionierungen, wie sie in Fragebögen und strikten Leitfäden gefordert sind und wie sie dem an Widerspruchslosigkeit orientierten wissenschaftlichen Denken gemäß sind, entgeht einem schnell die irritierende Tatsache, dass Widersprüchlichkeiten und Brüche, insbesondere im Falle von Themen- und Perspektivenwechseln, nicht Denkfehler der Befragten sind, sondern geradezu den Normalzustand individueller wie kollektiver Wirklichkeitsverarbeitung darstellen. ${ }^{196}$ Jeder Komplex von Äußerungen, wie gering elaboriert, wie wenig kohärent oder gar ordinär auch immer er zunächst erscheinen mag, gewährt Aufschluss über die konstitutiven „objektiven Bedeutungsstrukturen“, ${ }^{197}$ die mit dem subjektiv gemeinten Sinn im Gesagten eine situative Verbindung eingehen.

Für die Zusammensetzung der Gruppen wurde, anknüpfend an Erfahrungswerte gelungener Diskussionen aus früheren Studien, an denen der Verfasser beteiligt war, ${ }^{198}$ eine Teilnehmerzahl von sechs bis acht Personen angestrebt. Aufgrund der unterschiedlichen Zuverlässigkeit der zuvor verbindlich angemeldeten Teilnehmer ergab sich in der Durchführung eine Varianz von drei bis neun, insgesamt aber eine Durchschnittszahl von sechs bis sieben Teilnehmern. Die Gruppen wurden (wenn auch möglichst wenig direktiv) moderiert und per Themenkatalog thematisch zentriert. Die Interpretationsgrundlage der vorliegenden Studie besteht schließlich aus einem Sample von sieben Fokusgruppen mit einer Dauer von jeweils ungefähr 90 bis 130 Minuten, die zwischen März und November 2018 durchgeführt worden sind, davon fünf in Göttingen und zwei in Frankfurt a.M.. Weitere Details des Vorgehens im Verlauf des Erhebungs- und Auswertungsprozesses werden weiter unten ausgeführt. ${ }^{199}$

196 Zur konstitutiven Widersprüchlichkeit des Alltagsbewusstseins vgl. Schütz, Alfred: Der Fremde. Ein sozialpsychologischer Versuch, in: Cesammelte Aufsätze Bd. 2, Den Haag 1972, S. 53-69.

197 Vgl. Oevermann: Klinische Soziologie, S. 1.

198 Vgl. bspw. die methodische Anlage der Fokusgruppen mit Jugendlichen und jungen Erwachsenen in ausgewählten ost- und westdeutschen Großstädten in Schenke et al.: PEGIDA-Effekte?, S. 29-48. Vgl. Kapitel III.1 dieser Studie. 


\section{Jungakademischer Mentalitätswandel Aspektzentrierter historischer Längsschnitt und empirische Studien}

Der historische Rückblick schafft zunächst Differenzierungen, Komplikationen, Irritationen. Immer wieder - und bis heute - haben Studierende Proteste organisiert; meist waren diese lokal begrenzt und verfolgten hochschul- oder sozialpolitische Absichten. Bisweilen gingen aus ihren Reihen Trägernetzwerke größerer, überregional und bis in nichtstudentische Milieus hineinreichende Bewegungen hervor. Jahrhundertelang waren Studierende in festen subkulturellen Strukturen organisiert und sind als artikulationsstarkes wie organisationskräftiges Kollektivsubjekt aufgetreten, haben insbesondere zu Zeiten von Vormärz ${ }^{1}$ und Kaiserreich gesamtgesellschaftlich politischen Einfluss geltend gemacht, ja waren die politisch radikaleren und tatorientierteren Avantgardisten ihres Elternmilieus, des Bildungsbürgertums. Sie sind Antizipatoren und Katalysatoren emanzipativer, (revolutionär-)demokratischer und sozialistischer Impulse, aber auch nicht minder engagierten nationalchauvinistisch-antidemokratischen, militaristischen, schließlich völkischen Furors - salopp: links- wie rechtspolitisiert - gewesen. Nicht nur, aber vor allem in den zurückliegenden Jahrzehnten folgten auf die starken Politisierungsphasen häufig mehrheitliche politische Apathie und studentische Individualisierung. $\mathrm{Zu}$ fast keinem Zeitpunkt zwar bildeten Studierende eine politisch ho-

Einige Historiker reservieren die Bezeichnung „Vormärz“ im engeren Sinne für die 1830er und 1840er Jahre, also für das zeitliche Vorfeld der deutschen Märzrevolution von 1848/49, wie es von vielen Zeitgenossen aufgrund mehrfacher ineinander greifender Wachstums- und Dynamisierungsprozesse eben auch als Klima einer unmittelbar bevorstehenden Revolution erlebt wurde. Hier und im Folgenden hingegen wird die Vormärzperiode aus heuristischen Gründen im erweiterten Sinne bestimmt, d. h. als Bezeichnung jener nachnapoleonisch-restaurativ geprägten Frühphase des Deutschen Bundes, in welcher sich der deutsche Nationalismus vom Intellektuellenprojekt zur nationalliberalen Massenbewegung entwickelte - also von 1815, dem Jahr des Wiener Kongresses mit seinen terriorialen Rekonfigurationen, bis 1848/49. Dafür, dass eine so gefasste Periodisierung ergiebige Analysen gestattet, gibt es reichhaltige Belege; vgl. exemplarisch den Sammelband: Conze, Werner (Hg.): Staat und Cesellschaft im deutschen Vormärz 1815-1848. Sieben Beiträge von Theodor Schieder, Otto Brunner, Reinhart Koselleck, Wolfgang Zorn, Wolfram Fischer, Erich Angermann, Werner Conze, Stuttgart 1962. 
mogene Gruppe, auch wenn sie lange protestantisch-bildungsbürgerlich und männlich dominiert gewesen sind. Stets aber haben die Klassen- bzw. Schichtensituation und die damit verbundenen Bildungs- und Berufschancen hierbei eine elementare Rolle gespielt.

Die jüngere und jüngste Geschichte der deutschen Studierendenschaft bietet also ein Kaleidoskop unterschiedlichster Facetten zur Frage nach politischem Potenzial und - womöglich zunächst als Realisierung dieses Potenzials aufzufassender - politischer Bewegung. Folgende Aspekte sollen die Beschäftigung mit den historischen $\mathrm{Zu}$ sammenhängen strukturieren: Erstens sind konfliktbehaftete „harte“, d. h. soziale und institutionelle Faktoren wie der Wandel der sozialen Rekrutierung von Studierenden, das erstaunliche Wachstum der Studierendenzahlen und der Gestaltwandel der Universität, ${ }^{2}$ die das Selbstverständnis studierender Menschen und ihrer Lebenschancen radikal verändert haben, $\mathrm{zu}$ untersuchen. Zweitens fällt das Phänomen von oppositionellen Studentenbewegungen auf, die in außergewöhnlichen Perioden breiter Politisierung der Studierendenschaft (z. T. auch der Bevölkerung), auftreten, die eine zumindest temporäre exzeptionelle politische Aktionsfähigkeit bezeugen, und die wahrscheinlich konstitutiv für das kulturell überlieferte Stereotyp des politischen Studenten sind. Drittens schließlich ist die für empirische politische Kulturforschung ganz wesentliche Entwicklung der politischen Einstellungsmuster und der politischen Praxispotenziale, kurz: der politischen Mentalität oder auch politischen Kultur ${ }^{3}$ der Studierendenschaft zu entwirren, wie sie seit Mitte des 20. Jahrhunderts dokumentiert worden ist. Das Ziel dieses Abschnitts ist es, den einleitend aufgestellten Vorbegriff des politischen Potenzials von Studierenden mit gesellschaftshistorischem Kontextwissen zu füllen und ggf. zu modifizieren, die Notwendigkeit einer qualitativen Deutungsmusteranalyse nachträglich historisch-empirisch zu begründen, deduktive Kategorien für den Fokusgruppenleitfaden zu gewinnen, und die Interpretationsarbeit am Interviewmaterial zu stützen. Das Verhältnis Studierender zur Demokratie als teils ersehnter, teils bekämpfter, jedenfalls moderner politischer Herrschaftsform ist daher von durchgängigem Interesse.

Die Herausforderung liegt also darin, die genannten Aspekte im Parforce-Ritt durch zweihundert Jahre deutscher Gesellschaftsgeschichte in ihren wesentlichen Grundzü-

Diese Studie beschäftigt sich primär mit der Entwicklung der Universitäten. Die Technischen Universitäten (ab dem späten 19. Jahrhundert) und Fachhochschulen (ab 1970) stellen in vielen Aspekten eine eigene Thematik dar, sowohl was die Hochschulgeschichte, aber auch die Berufsziele und die Verteilung politischer Einstellungsmuster unter Studierenden betrifft. Die Unterschiede politischer Einstellungsmuster zwischen den Studierenden an Fakultäten klassischer Volluniversitäten - etwa zwischen Geisteswissenschaften, Naturwissenschaften, Medizin und Jura - halten für sich bereits einige analytische Herausforderungen bereit. Sporadische Bezugnahmen auf „TUs“ und „FHs“ müssen daher genügen.

3 Da Veränderungsprozesse politischer Kulturen nach Karl Rohe bisher zuvörderst durch regionalhistorische Charakterstudien untersucht worden sind, wird die Frage einer standes- bzw. ausbildungs- bzw. berufsspezifischen politischen Kultur, wie sie hier für die Gruppe der Studierenden aufgeworfen wird, in Anführungszeichen verhandelt. Ob nicht gerade Einflussfaktoren sozialer Stratifikation, die Bildungsherkunft oder die Präsenz breiter politischer Bewegungen o. Ä. für die Genese politisch-sozialer Deutungsmuster bisweilen entscheidender sein mögen als die Lebensphase des Studierens, ist dann eine der entscheidenden Fragen und sollen daher im weiteren Verlauf aufgegriffen werden. 
gen zu rekonstruieren, ohne die Darstellung zu überfrachten. Selektionen, Fortlassungen, Verdichtungen und Simplifizierungen sind daher unvermeidlich, auch muss die gewissermaßen interdisziplinäre Darstellung - sie berührt Themen der Politikwissenschaft, der politischen Soziologie und der Geschichtswissenschaft - sich weitestgehend auf die Fülle der verfügbaren wissenschaftlichen Sekundärliteratur verlassen. ${ }^{4}$ Die Aufdeckung der historischen Längsschnittfaktoren von Aspekten politischen Potenzials der deutschen Studierenden verlangt nicht nach einer lückenlosen Nacherzählung sämtlicher Entwicklungslinien, sondern nach einer Rekonstruktion des bestimmten Unterschieds, einer „Anamnesis der Genese“. ${ }^{5}$ Der Vorzug des raffenden Längsschnitts liegt dabei darin, über die erdrückende Komplexität historischer Ereignisse und Kausalketten hinweg spezifische Teilaspekte aus der Vogelperspektive ${ }^{6} \mathrm{zu}$ untersuchen, entscheidende Entwicklungslinien und Wandlungsprozesse zu identifizieren, und diese schließlich sozialgeschichtlich wie begriffsgeschichtlich diachron ${ }^{7}$ in Bezug zueinander zu setzen. ${ }^{8}$ Ein auch unter manchen Historiographen beliebter, ${ }^{9}$ zum Prosaischen neigender und glättender Stil zwischen dem Gestus des „Buchhalters“ und dem des „Schriftstellers“10 ist dabei beabsichtigt, wenn auch zum Preis von Einbußen in der Präzision der historischen Faktenlage.

Einige für die folgende Darstellung besonders tragende Referenzen seien vorab herausgegriffen: Als chronologisches Gerüst der Einzeldarstellungen unverzichtbar sind die komprimierten Überblicksdarstellungen Deutsche Studenten 1800-1970 ${ }^{11}$ von Konrad

4 Insbesondere eine aktualisierte umfängliche Geschichte des politischen Verhaltens von Studierenden nach dem Muster der Historiker Klose, Schlicht und Jarausch wäre eine Aufgabe eigener Art, die ohne den Einbezug reichhaltiger Primärquellen kaum zu leisten ist. Vgl. Klose: Freiheit schreibt auf eure Fahnen; Schlicht: Vom Burschenschafter bis zum Sponti; Jarausch: Deutsche Studenten.

5 Vgl. Sohn-Rethel, Alfred: Notizen von einem Gespräch zwischen Th. W. Adorno und A. Sohn-Rethel am 16.03.1965, in: Ders.: Warenform und Denkform. Mit zwei Anhängen, Frankfurt a.M. 1978, S. 137-141, hier S. 139.

6 Vgl. Hobsbawm: Das Zeitalter der Extreme, S. 13.

7 Koselleck teilt die Verfahren von Sozialgeschichte und Begriffsgeschichte modellhaft in zwei Arbeitsweisen ein: „Es lassen sich [...] zwei methodische Zugriffe konstruieren. Der eine richtet sich primär auf die Ereignisse, die Handlungen in Rede, Schrift und Tat, der andere richtet sich in erster Linie auf diachrone Voraussetzungen und deren langfristigen Wandel. Er sucht also nach sozialen Strukturen und deren sprachlichen Äquivalenten." Koselleck, Reinhart: Sozialgeschichte und Begriffsgeschichte, in: Ders.: Begriffsgeschichten. Studien zur Semantik und Pragmatik der politischen und sozialen Sprache, Frankfurt a.M. 2006, S. 9-31, hier S. 23. Sozialgeschichte wird hier dementsprechend aufgefasst als Gesellschaftsgeschichte unter dem Cesichtspunkt gesellschaftlicher Gruppenzusammenhänge und sozialer Formationen, genauer: der Studierenden, der Akademiker, der Bildungsbürger.

8 Vgl. Pandel, Hans-Jürgen: Didaktische Darstellungsprinzipien. Ein alter Sachverhalt im neuen Licht, in: Bernhardt, Markus/Henke-Bockschatz, Gerhard/Sauer, Michael (Hg.): Bilder - Wahrnehmungen - Konstruktionen. Reflexionen über Geschichte und historisches Lernen, Schwalbach/Taunus 2006, S. 152-168.

9 Vgl. Kracauer, Siegfried: Ceschichte - Vor den letzten Dingen, Frankfurt a.M. 1971, S. 53 und White, Hayden: Metahistory: Die historische Einbildungskraft im 19. Jahrhundert in Europa, Frankfurt a.M. 2008.

10 Kracauer: Geschichte, S. 54.

11 Vgl. Jarausch, Konrad H.: Deutsche Studenten. 
H. Jarausch, Vom Burschenschafter bis zum Sponti ${ }^{12}$ von Uwe Schlicht und Freiheit schreibt auf eure Fahnen ${ }^{13}$ von Werner Klose. Aber auch jenseits dieser Werke wären dem hier verfolgten Vorhaben wesentliche Grundzüge der Sozialgeschichte der Gebildeten in Deutschland verborgen geblieben, hätte es nicht auf die umfänglichen, instruktiven und kundigen Darstellungen zum Thema „Bildungsbürgertum“ zurückgreifen können, die sich in verschiedenen Bänden aus dem Umfeld des „Bielefelder Sonderforschungsbereichs zur Geschichte des Bürgertums“ bzw. zur modernisierungstheoretisch inspirierten $^{14}$ „Sozialgeschichte des neuzeitlichen Bürgertums ${ }^{\text {"15 }}$ finden. Selbstverständlich entbindet die hohe Qualität dieser angeführten Kernreferenzen nicht von der Heranziehung weiterer Überblicksdarstellungen zum Bürgertum im 19. Jahrhundert ${ }^{16}$, aber auch konkurrierender und neuerer Darstellungen zu historischen Erscheinungsformen studentischer Subkultur. ${ }^{17}$ Für die Kapitel II.1 und II.3 (also für die Aspekte der sozialen Rekrutierung und der Evolution der politischen Einstellungsmuster von Studierenden) spielen dann quantitative Daten eine tragende Rolle, die seit den frühen 1950er Jahren und insbesondere seit den 1980er Jahren im Rahmen unterschiedlicher Studien und Surveys engmaschig erhoben wurden. Sie gestatten eine nahezu nahtlose Rekonstruktion der Zusammenhänge bis zur Gegenwart. Gemeint sind die beiden führenden Langzeitstudien, die vom Deutschen Zentrum für Hochschul- und Wissenschaftsforschung (DZHW), zuvor Hochschul-Informations-System HIS eG, seit 1951 durchgeführte Sozialerhebung des Deutschen Studentenwerks (DSW) und der seit 1982/83 unter der Leitung

12 Schlicht: Vom Burschenschafter bis zum Sponti.

13 Klose, Werner: Freiheit schreibt auf eure Fahnen.

14 Vgl. Schulz: Lebenswelt und Kultur des Bürgertums, S. 55f. und, zur Kritik des Bielefelder konzeptuellen Rüstzeugs, 59.

15 Vgl. für die erste Formulierung Lundgreen: Sozial- und Kulturgeschichte des Bürgertums, S. 11; für die zweite Formulierung vgl. o. V.: Abgeschlossene Forschungsbereiche, in: Internetpräsenz der Universität Bielefeld, o. D., online einsehbar unter: https://www.uni-bielefeld.de/(de)/Universitaet/Forschung/SFB-CK-Archiv.html [eingesehen am 01.08.2019] Der Arbeitskreis trug von 1986 bis 1997 Daten, Thesen, Fragen, Überblicks- und Einzeldarstellungen - auch unter Beteiligung Jarauschs - zu verschiedenen Aspekten dieser sich wandelnden und durchweg heterogenen Sozialformation im 19. und 20. Jahrhundert zusammen.

16 Hier insbesondere Gall, Lothar: Bürgertum in Deutschland, Berlin 1989; Bauer, Franz J.: Bürgerwege und Bürgerwelten. Familienbiographische Untersuchungen zum deutschen Bürgertum im 19. Jahrhundert. Schriftenreihe der Historischen Kommission bei der Bayerischen Akademie der Wissenschaften, Bd. 43, Göttingen 1991; Kraus, Hans-Christof: Kultur, Bildung und Wissenschaft im 19. Jahrhundert. Enzyklopädie Deutscher Geschichte, Bd. 82, München 2008; Budde: Die Blütezeit des Bürgertums; Schulz: Lebenswelt und Kultur des Bürgertums.

17 Verdienstvoll für Auseinandersetzungen mit zeitgenössischen Quellen und Periodika, die zugleich auch lange Zeit gängige Epochenklischees dekonstruieren oder zumindest differenzierend prüfen, sind beispielsweise für die Kaiserreichszeit Bias-Engels, Sigrid: Zwischen Wandervogel und Wissenschaft. Zur Geschichte von Jugendbewegung und Studentenschaft 1896-1920, Berlin 1988 und Dowe, Christopher: Auch Bildungsbürger; für den Kontext des Ersten Weltkrieges Maurer, Trude: „... und wir gehören auch dazu“. Universität und „Volksgemeinschaft“ im Ersten Weltkrieg, Cöttingen 2015; für studentische Organisationsformen in der Weimarer Republik Walter, Franz: Sozialistische Akademiker- und Intellektuellenorganisationen in der Weimarer Republik. Solidargemeinschaft und Milieu: Sozialistische Kultur- und Freizeitorganisationen in der Weimarer Republik (hgg. von Peter Lösche), Bd. 1, Berlin 1990 und Wipf, Hans Ulrich: Studentische Politik und Kulturreform: Geschichte der Freistudenten-Bewegung 1896-1918, Schwalbach/Taunus 2004. 
der AG Hochschulforschung ${ }^{18}$ der Universität Konstanz veranstaltete Studierendensurvey „Studiensituation und studentische Orientierungen“, im Folgenden und im Einklang mit den offiziellen Abkürzungskonventionen des Bundesministeriums für Bildung und Forschung (BMBF) „Sozialerhebung“19 und „Studierendensurvey“20 genannt. Ergänzende jüngere Daten zur Entwicklung des deutschen Bildungssystems insgesamt liefert darüber hinaus der indikatorengestützte nationale Bericht „Bildung in Deutschland“ der Arbeitsgruppe Bildungsberichterstattung unter Beteiligung verschiedener Institute und der Statistischen Ämter des Bundes und der Länder, ${ }^{21}$ hier unter dem Kürzel „Bildungsbericht“ zitiert. Trotz des mitunter gravierenden Rückgangs der Rücklaufquoten ${ }^{22}$ beanspruchen alle diese Studien statistische Repräsentativität.

Noch ein Wort zur gewählten Zeitspanne des Kapitels II.1: An der Jahrhundertwende zwischen dem 18. und 19. Jahrhundert anzusetzen, begründet sich nicht nur aus der dortigen Formierung der modernen deutschen Universität im Zuge der preußischen Reformen. Soziohistorisch entscheidender ist die ebenfalls in diesen Zeitraum fallende epochale Zäsur der kontinentaleuropäischen bzw. nordamerikanischen Revolutionen, des von den USA 1776 und Frankreich 1789 bzw. 1830 ausgehenden Impulses der bürgerlichen Mittelschichten, ${ }^{23}$ die politische Ordnung der monarchischen ancien régimes durch eine von eigener Hand herbeigeführte Revolution zu stürzen. Aus ebendieser Revolutionsdynamik erwachsen die grundlegenden Konfliktlinien moderner Gesellschaften zwischen traditionellen Herrschaftsformen und modernem Partizipationsanspruch aufstrebender Klassen und Schichten, mithin für den demokratischen Freiheitsimpuls insgesamt. Periodisierungen dieser Art sind zwar nicht unumstritten. ${ }^{24}$ Gewiss wird

18 An dieser Stelle ist der AC Hochschulforschung Konstanz nachdrücklich für die freundliche Unterstützung bei der Recherche der Berichte zu danken. Im Unterschied zur Sozialerhebung des DSW sind die Hauptberichte des Surveys vor 2003 nicht online verfügbar; es stellte daher eine große Arbeitserleichterung dar, dass das Team der AG, insbesondere Sekretärin Doris Lang, mir eine große Auswahl von Berichten seit Beginn der Erhebungen zur Verfügung stellte.

19 Vgl. die Informationen zur DSW-Sozialerhebung auf der Internetpräsenz des Bundesministeriums für Bildung und Forschung: BMBF: Die Sozialerhebung des Deutschen Studentenwerks, online einsehbar unter: https://www.bmbf.de/de/die-sozialerhebung-des-deutschen-studentenwerks-1035. html [eingesehen am 01.08.2019]

20 Vgl. die Informationen zum Studierendensurvey auf der Internetpräsenz des Bundesministeriums für Bildung und Forschung: BMBF: Der Studierendensurvey, online einsehbar unter: https://www. bmbf.de/de/der-studierendensurvey-1036.html [eingesehen am 01.08.2019]

21 Vgl. die Informationen zum Bildungsbericht auf der Internetpräsenz des Bildungsberichts: 0 . V.: Bildung in Deutschland, online einsehbar unter: https://www.bildungsbericht.de/de/nationalerbildungsbericht [eingesehen am 01.08.2019]

22 Im Falle des Studierendensurveys sank die Rücklaufquote der in immer größerer Stückzahl versandten Fragebögen seit Anfang der 1990er Jahre von 45,8 Prozent (WiSe 1992/93) auf 15,2 Prozent (WiSe 2015/16). Vgl. Datenalmanach Studierendensurvey 2017, S. VI-VIII.

23 Dass der „Pöbel“ und das sich aus dessen Reihen allmählich formierende Proletariat als politische Kraft mit dem Ziel der sozialistischen Revolution im vormärzlichen Deutschland zu Anfang noch keineswegs mitgemeint gewesen ist, wird deutlich in einem Aufsatz Werner Conzes, vgl. Conze, Werner: Vom „Pöbel“ zum „Proletariat“. Sozialgeschichtliche Voraussetzungen für den Sozialismus in Deutschland, in: Vierteljahrschrift für Sozial- und Wirtschaftsgeschichte, 41. Jahrgang, $\mathrm{H}$. 4/1954, Stuttgart 1954, S. 333-364, hier S. 333.

24 Reflexionsstark und fundiert thematisiert etwa der Historiker ]ürgen Osterhammel das Problem, die historischen Entwicklungslinien des 19. Jahrhunderts zu periodisieren in seinem eindrucks- 
man sich insbesondere davor hüten müssen, die Idee eines sich ab 1789 schrittweise entfaltenden Freiheits- oder Fortschrittsprinzips universalhistorisch zu überdehnen. ${ }^{25}$ Fraglos aber wird man andererseits davon ausgehen können, dass die Suche nach den verschlungenen Pfaden, auf denen sich das Verhältnis von deutschen Studierenden und politischer Aktivität entfaltete, dort beginnen sollte, wo die politische Gestaltbarkeit von Gesellschaften auf der Grundlage eines gemeinsamen Willens, die Frage nach einer egalitären Verfassung und Herrschaftsordnung, überhaupt erstmals zu einem virulenten gesellschaftlichen - zunächst gleichwohl bürgerlichen - Gedanken hat werden können. Denn erst auf der Grundlage dieses Gedankens und der ihn konstituierenden Erfahrungen erscheint die organisierte Aggregation politischer Interessen als möglicher Weg politischer Einflussnahme, kurzum: wirkt das historische Umfeld von 1800 als Wiege moderner (demokratischer) Emanzipationsbewegungen wie dem deutschen Nationalliberalismus oder der sozialistischen Arbeiterbewegung:

„Politische Vereine und politische Cruppenbildungen entstehen historisch dort, wo die politische Ordnung als eine Sphäre sichtbar wird, die als Reflexionsgegenstand und virtuelles Handlungsfeld in die Verfügung von sich assoziierenden Menschen geraten könnte. Die Figur des politischen Engagements kann zwar als Voraussetzung für politische Parteibildung betrachtet werden, aber sie muß weder unter absolutistischmonarchistischen, noch unter konstitutionell-demokratischen Formen der Staatsgewalt notwendig zur politischen Parteibildung führen. ${ }^{\text {“26 }}$

In anderen Worten: Was im Vormärz geschieht, ist nicht nur von historischem Interesse, es gehört vielmehr schon zu unserer Zeit. Es geht uns an. Denn nicht zuletzt agierten auch die deutschen Studierenden des 19. Jahrhunderts „moderner“ als zuvor:

vollen Versuch, eine - explizit nicht die - Ceschichte desselben zu schreiben. Vgl. Osterhammel, Jürgen: Die Verwandlung der Welt: eine Geschichte des 19. Jahrhunderts. Lizenzausgabe der Bundeszentrale für politische Bildung, Bonn 2010, S. 84-102.

25 Allerdings sollte nicht vergessen werden, dass tatsächliche Versuche einer derart abstrakt-idealistischen Geschichtsschreibung deutlich seltener zu finden sind, als es das mitunter schnell einschnappende Vorurteil wittert. So hat der Philosoph Joachim Ritter dicht belegt darauf hingewiesen, dass etwa G. W. F. Hegel, der von der Nachwelt und ausgehend von Rudolf Hayms gern als eiserner Geschichtsdeterminist und Staatsfetischist gehandelt wird, zunächst einmal nur davon ausgegangen war, dass die Revolutionsperiode des späten 18. Jahrhunderts das Problem der politischen Freiheit für die Zukunft menschlicher Gesellschaften aufgeworfen hat, allerdings ohne die endgültig-adäquate Lösung für die Frage mitzuliefern, wie die so entstehenden Interessenkämpfe und Antagonismen zu vermitteln, die moderne „Entzweiung“ von rational-institutioneller Ordnung und traditionsbedürftiger Subjektivität zu kitten seien, vgl. Ritter, Joachim: Hegel und die französische Revolution, Frankfurt a.M., S. 18, 27, 30, und 48f. Und dabei handelt es sich in der Tat um einen hochaktuellen Gedanken, wie an den wiederkehrenden Debatten um „sozialmoralischen“ gesellschaftlichen Integrationsstoff, um „Böckenförde-Diktum“, „Verfassungspatriotismus“ und "Zivilgesellschaft“ abzulesen ist, vgl. Menke, Christoph: Philosophiekolumne. Am Tag der Krise, in: Merkur. Gegründet 1947 als Deutsche Zeitschrift für europäisches Denken. 71. Jahrgang, H. 820/2017, Stuttgart 2017, S. 49-57.

26 Eßbach, Wolfgang: Die Junghegelianer. Soziologie einer Intellektuellengruppe. Übergänge Bd. 16, München 1988, S. 19. Tatsächlich sollte sich die Absicht der Parteienbindung unter politisierten studentischen Organisationen erst zu Zeiten der Weimarer Republik durchsetzen, vgl. Jarausch: Deutsche Studenten, S. 124. 
Ihr Streben und Handeln löste sich in wachsendem Maße von der vergleichsweise unpolitischen Sitten- und Traditionspflege früherer Zeiten und wandte sich - nicht nur in Gestalt jener fraglos eindrücklichen und exponierten Vorkämpferfiguren, die das politische Engagement zum „Hauptinhalt ihrer Bestrebungen und ihrer Existenz ${ }^{\text {“27 machten }}$ -, dem Ziel der aktiven politischen Veränderung der Gesellschaft, damals: der Herstellung der nationalen Einheit in einem liberalen Staat zu.

Nur unter aspektzentriertem Einbezug dieser bis ins Ende des Aufklärungszeitalters reichenden Vorgeschichte, so die hier verfolgte Prämisse, wird die Beurteilung neuerer empirischer Beobachtungen im Kontext möglich.

\title{
II.1 Vom „gelehrten Stand“ über die „Funktionseliten" zur "Leistungsgesellschaft": Der soziale und institutionelle Wandel des Studiums
}

\begin{abstract}
„Die historisch vielleicht bedeutsamste Wirkung unterschiedlicher Zugänglichkeit von öffentlichen Gütern liegt wohl im Bildungssystem. [...] Die Bevorzugung der städtischen Bevölkerung gegenüber der ländlichen, der protestantischen gegenüber der katholischen, der Mittelschichten gegenüber den Bauern und Arbeitern haben strukturell wesentliche Prägungen in der deutschen Cesellschaft bewirkt." ${ }^{28}$
\end{abstract}

Dieses Kapitel widmet sich dem Wandel des Studiums unter dem Aspekt sozialer Rekrutierung, beruflicher Nutzenerwartungen und institutioneller Reformierungen der Hochschulen im historischen Abriss. Ein einleitender Hinweis verhilft zum besseren Verständnis: Sozialstrukturelle Aspekte wie Schichtzugehörigkeit, Bildungsherkunft oder Konfession spielten lange Zeit hindurch eine entscheidende Rolle für die Bildungschancen junger Studierwilliger. Sie formten ihre Statuserwartungen, ihr Selbstverständnis, ja ihren Stolz als (bildungsbürgerliche) Eliten, verursachten im Fall ökonomischer Krisen aber auch kollektive Kränkungen und nährten aggressive Frustrationen: In den 1920er und 1930 Jahren etwa trug die jungbildungsbürgerliche Erfahrung des Verlusts von Privilegien und Sozialprestige ihrer Herkunftsklasse durch die beginnenden Tendenzen zum Massenstudium, gepaart mit der entwürdigenden materiellen Verelendung der Weimarer Nachkriegsstudenten, zur Attraktivität der

27 Gevers, Lieve/Vos, Louis: Studentische Bewegungen, in: Rüegg, Walter (Hg.): Geschichte der Universität in Europa Bd. III: Vom 19. Jahrhundert zum Zweiten Weltkrieg (1800-1945), München 2004 , S. 227-299, hier S. 227.

28 Lepsius, Mario Rainer: Soziale Ungleichheit und Klassenstrukturen in der Bundesrepublik Deutschland, in: Wehler, Hans-Ulrich (Hg.): Klassen in der europäischen Sozialgeschichte, Göttingen 1979, S. 166-209, hier S. 181. 
nationalsozialistischen Politisierung an den Universitäten bei. ${ }^{29}$ Schnell ist ersichtlich, warum soziale Rekrutierung, Berufschancen und die Erfahrung des Studierens an der Universität für die Genese politischer Stimmungen und den Wandel politkultureller Mentalitäten von Studierenden konstitutiv sein können.

Großes politisches Konfliktpotenzial erwartet man von studentischer Seite in heutigen Tagen zwar nicht. Das aber kann trügen, denn natürlich verbinden sich auch heute - wie im Folgenden zu zeigen sein wird - , lange nach dem Zeitalter des Bildungsbürgertums, mit der Aufnahme eines Studiums spezifische Erwartungen von finanzieller Absicherung und einem Schutz vor Erwerbslosigkeit. Erwartungen einer absolut wie relativ rasant wachsenden Zahl von Studierenden, die in Zeiten geminderten Wirtschaftswachstums oder gar konjunktureller Rezession rasch enttäuscht werden können. In den späten 1970er und frühen 1980er Jahren, nach einer Phase eines beispiellosen, auch politisch forcierten Bildungswachstums und inmitten eines kaum verhallten Mantras von Aufstieg durch Bildung, war dieses Problem ausgesprochen virulent. 1980, als sich die Berufsaussichten junger Hochschulabsolventen eintrübten, war einigen Beobachtern spürbar bange, dass studentischer Zukunftspessimismus zu einer neuen, im Vergleich mit der noch nicht lange zurückliegenden von „1968“ ungleich militanteren, Studentenbewegung führen könnte. ${ }^{30}$ Infolge dieser Sorgen untersuchte man den $\mathrm{Zu}$ sammenhang von Berufserwartung und oppositioneller Politisierung besonders akribisch. ${ }^{31}$ Noch 1998 wurde es als Gefahr für das demokratische Gemeinwesen identifiziert, dass „die Verläßlichkeit, daß sich Anstrengungen im Studium und das Bemühen um zusätzliche Qualifikationen lohnen, bei den Studierenden weithin untergraben“ sei:

„Für viele von ihnen ist besonders belastend, daß durch eigene Leistungen, Entscheidungen und Strategien die berufliche Zukunft immer weniger steuerbar erscheint. Eine Übermächtigkeit des ,Zufälligen` und ,Schicksalhaften` - gerade im Hinblick auf Beruf und Zukunft - macht sich breit. ${ }^{\text {“32 }}$

Also: Die Entwicklung von sozial bedingter Studienrekrutierung und akademischen Berufschancen, aber auch die durch den strukturellen Wandel der Universität bedingte Studienerfahrung, gibt nicht nur auch Aufschluss über den gesellschaftlichen Stellenwert des Studiums, ${ }^{33}$ sondern bedingt auch die Selbstverortung der Studierenden in ihr, affiziert somit ihren Blick auf die Gesellschaft und ihre Institutionen. Nicht von ungefähr nehmen diese Zusammenhänge denn auch eine Scharnierfunktion bei der

Vgl. eingehend Kapitel II.2.3 dieser Studie.

Vgl. Schlicht: Vom Burschenschafter bis zum Sponti, S. 9f. Siehe außerdem ibid. S. 153, wo darauf hingewiesen wird, dass „Alternativpläne für eine Zukunftssicherung ohne erhebliches Wirtschaftswachstum “ für die zunehmend staats- und demokratieskeptischen jungen Akademiker herbeigeschafft werden müssten, „bevor es zu spät ist.“

31 Vgl. exemplarisch Sandberger, Johann-Ulrich: Zwischen Legitimation und Kritik. Vorstellungen von Akademikern, Studenten und Bevölkerung zur sozialen Ungleichheit, in: Zeitschrift für Soziologie, 12. Jahrgang, H. 3/1983, S. 181-202 und eingehend Kapitel II.3.1 und II.3.2 dieser Studie.

Vgl. Bargel: Wandel des politischen Bewußtseins, S. 12.

Vgl. Jarausch: Deutsche Studenten, S. 24. 
interpretierenden Auswertung der politischen Einstellungsmuster von Studierenden in jenen politikwissenschaftlichen Studien ein, die dieser Studie als Vorbild gelten. ${ }^{34}$

Auffällig ist durchweg das Wirken eines spezifischen Motors des sozialstrukturellen und institutionellen Wandels der Universität, der die Bildungs- und Berufschancen der auf den Erwerbsmarkt nachrückenden jungen Erwachsenen beeinflusst: Der zyklenhafte Einfluss der Bildungsexpansion, die ca. ab Mitte des 19. Jahrhunderts wenngleich häufig durch politische Interventionsversuche und Kriege retardiert bzw. amplifiziert - weitgehend eigendynamisch verläuft und ein wiederkehrendes Oszillieren zwischen Schüben sich vollziehender sozialer Öffnung der Hochschulen einerseits und der periodisch wiederkehrenden, bisweilen heftig restriktiven Schließung andererseits verursacht. Am präzisesten werden diese Dynamiken durch das Zyklusmodell akademischen Mangels und akademischer Überfüllungskrisen des Historikers Hartmut Titze - in jüngerer Zeit gestützt durch eine statistische Frequenzbandsperrenund Spektralanalyse Volker Mueller-Benedicts ${ }^{35}$ - beschrieben: Auf diesen Zyklus führt er die Phänomene der Aufstiegsfenster und Selektionsverschärfung zurück, mithin die Wirkung des Sogs bzw. der Abschreckung auf Studieninteressierte. ${ }^{36}$ Es bietet sich an, die von ihm ausgemachten vier Phasen von Bildungsexpansion und Überfüllungskrise zwischen 1780 und $2000^{37}$ als Verdichtungszeiträume zur groben Orientierung heranzuziehen. Sie bezeichnen jenen „zyklisch verlaufende[n] Expansionsprozess“ der deutschen Hochschulentwicklung, der sich als "langfristiger, gleichsam säkularer Trend“ durch die vergangenen zwei Jahrhunderte deutscher Gesellschaftsgeschichte zieht. ${ }^{38}$

Zwei zentrale Aspekte sollen hier herausgearbeitet werden: Erstens hat sich die soziale Rekrutierung des Studiums insofern gewandelt, als dass das Studium nicht mehr der Herausbildung einer eng umgrenzten Funktionselite dient, sondern sich durch den sukzessiven und eigendynamischen Einbezug größerer Teile der Mittelschichten und in geringerem Maße auch Teilen der Arbeiterschaft, ferner durch die anhaltende Expansion höherer Bildungszertifikate als Aufstiegsschranken in vormals nicht-akademi-

34 Vgl. insbesondere Schelsky: Die skeptische Generation, Habermas: Student und Politik sowie Glotz/Malanowski: Student heute.

35 Mueller-Benedict, Volker: Confirming long waves in time series of Cerman student populations 1830-1990 using filter technics and spectral analysis. Historical Social Research, H. 25/2000, S. 3656.

36 Vgl. Titze, Hartmut: Die zyklische Überproduktion von Akademikern im 19. und 20. Jahrhundert, in: Geschichte und Gesellschaft. Zeitschrift für historische Sozialwissenschaft, H. 10/1984, Göttingen 1984, S. 92-121.

37 Vgl. Titze, Hartmut: Bildungskrisen und sozialer Wandel 1780-2000, in: Ceschichte und Cesellschaft, H. 2/2004, S. 339-372. Allerdings muss angemerkt werden, dass Titze je nach Fachrichtung unterschiedliche Zyklen identifiziert, vgl. etwa für die evangelischen Theologen ibid., S. 99. Auch Jarausch: Deutsche Studenten richtet seine sozialgeschichtliche Analyse der Studenten zu großen Teilen an Titzes Periodisierung aus, zieht dafür aber - sein Buch erschien 1984-das ältere Schema zyklischer Überproduktion an, welches angesichts der leicht differenten Entwicklungen im Laufe der $1980 e r$ Jahre überarbeitet wurde, vgl. Titze: Bildungskrisen und sozialer Wandel, S. 340. Vgl. Wolter, Andrä: Eigendynamik und Irreversibilität der Hochschulexpansion: Die Entwicklung der Beteiligung an Hochschulbildung in Deutschland, in: Banscherus, Ulf/Bülow-Schramm, Margret/Himpele, Klemens/Staack, Sonja/Winter, Sarah (Hg.): Übergänge im Spannungsfeld von Expansion und Exklusion. Eine Analyse der Schnittstellen im deutschen Hochschulsystem, Bielefeld 2014, S. 19-38, hier S. 19. 
sche Berufsfelder, zu einem Massenphänomen der höheren Berufsausbildung transformiert hat. Das Studium hat seine einstigen Qualitäten als Moratorium zur Erprobung intellektueller Fähigkeiten weitgehend verloren, ist mehr auf eine Phase „beruflicher Qualifizierung“ im Sinne der employability reduziert. ${ }^{39}$ Dennoch hängt die Bildungsbeteiligung der Jugendkohorten weiterhin substanziell von Bildungsniveau und sozialer Herkunft der Elternschaft ab, sind die hierarchiebildenden Bildungschancen keineswegs egalisiert; darin liegt, zweitens, die unveränderte soziale Funktion des Studiums für das Einschlagen spezifischer höherer Karrierewege begründet, die in modernen Fragebatterien der empirischen Sozialforschung meist als Itemblocks zu „Studienmotivation“ bzw. „Nutzenerwartungen“ abgefragt wird. Die Relevanz dieser Funktion, die sich in spezifischen Erwartungshaltungen ausdrückt, welche individuell freilich ebenso erfüllt wie enttäuscht werden können, ist - so die Prämisse - für die Genese von gesellschaftspolitischen Überzeugungen, Orientierungen und Werthaltungen Studierender als tragend einzuschätzen.

Das folgende Kapitel, dem die Aufgabe einer Ouvertüre zukommt, greift links wie rechts des Weges aus und füllt den Zwischenraum der sonst sterilen Zahlenreihungen mit erzählerischen Elementen, die die für das Gesamtverständnis grundlegenden sozialen, politischen, wirtschaftlichen und kulturellen Entwicklungslinien - die für die Entwicklung studentischer Mentalitäten wichtigsten „Stationen“ der Gesellschaftsgeschichte seit 1800 - rekonstruieren. Das ist nicht als dramaturgische Ornamentik zu verstehen, sondern verfolgt den Zweck, Orientierung im Vogelflug über zwei Jahrhunderte zu stiften und dem Leser zum besseren Nachvollzug der hier und im Folgenden behandelten Einzelaspekte zu verhelfen.

\section{II.1.1 Der Aufstieg der gebildeten Funktionseliten um 1800}

Zwar bedurften schon die im 16. und 17. Jahrhundert nach Reformation und Religionskriegen entstandenen absolutistischen bzw. „aufgeklärt absolutistischen“ Herrschaftsapparate zunehmend funktionierender Bürokratien und einer qualifizierten fürstlichen Beamtenschaft, ${ }^{40}$ doch folgte die Vergabe prestigeträchtiger und höchster Ämter in einer Zeit des noch im Entstehen begriffenen ${ }^{41}$ deutschen Bürgertums hier fast durchweg den feudalaristokratischen Kriterien von Geburt und Besitz. Die modernen Gesellschaften Europas steckten noch in ihren Kinderschuhen, und die Universitäten entwanden sich erst in den Jahren nach 1700 merklich der Tradition der theologisch-scholas-

39 So pointiert es Bargel: Wandel politischer Orientierungen, S. $4 \mathrm{f}$.

40 Besonders in den deutschen Gebieten war das Beamtentum schon früh die entscheidende Trägergruppe der Ausbreitung liberaler und antiständischer Überzeugungen; ihre bereits im 16. und 17. Jahrhundert wachsende Unverzichtbarkeit wird einerseits am Anstieg der ihnen zustehenden Bezüge deutlich, andererseits an ihrer neuen Schlüsselposition als penible, die fürstlichen Finanzen schützenden Buchhalter. Vgl. Valjavec, Fritz: Die Entstehung der politischen Strömungen in Deutschland 1770-1815 [1951], Düsseldorf 1978, S. 77 und 417-421.

41 „Nur ein verhältnismäßig kleiner Teil bürgerlicher Familien läßt sich in Deutschland über die Mitte des 17. Jahrhunderts hinaus aufgrund sicherer Zeugnisse zurückverfolgen. [...] Mitte des 17. Jahrhunderts - das bedeutete das Ende des Dreißigjährigen Krieges, die Wiederherstellung einer leidlich stabilen politischen wie kirchlichen Ordnung bei neuer Seßhaftigkeit." Gall: Bürgertum in Deutschland, S. 27. 
tisch dominierten mittelalterlichen Gelehrtenanstalt des 14. Jahrhunderts. ${ }^{42}$ Wer als Abkömmling bürgerlicher ${ }^{43}$ Schichten im „Jahrhundert der Aufklärung“, der Entstehungsphase der Altertumswissenschaften und der Herausbildung eines neuen, vernunftzentrierten Denkens - hier zumeist noch ohne schulische Vorbildung! - sein philosophisches Propädeutikum antrat, um dann den Grad eines „Magister Artium Liberalis“ oder „Doctor Philosophiae“ in einem theologischen, rechtswissenschaftlichen oder - seltener - medizinischen Fachstudium zu erwerben, konnte sich zwar Hoffnungen auf eine Zulassung für den freiwirtschaftlichen Sektor oder auf niedere bis mittlere Anstellungen in den überschaubaren Bürokratien der Territorialfürstentümer (oder auf eine Anstellung als Hauslehrer für den fürstlichen Nachwuchs wie im Falle von Thomas Hobbes oder Edmund Burke) machen, bei entsprechenden finanziellen Voraussetzungen gar auf ein Leben im Dienste der Wissenschaft - doch war das Studium primär ein Ausbildungsweg für bestimmte gehobene, aber keineswegs höchste Berufszweige. ${ }^{44}$ Eine andere Funktion hatte das Studium für die Sprösslinge aristokratischer Familien, die ein - zumeist juristisches oder theologisches - Studium absolvierten, um, noch ganz in mittelalterlicher Tradition ${ }^{45}$, ihren ständischen Anspruch auf ein hohes Amt im Dienste der Kirche oder der Krone durchzusetzen. Insgesamt aber war das Studium in dieser aristokratisch geprägten Zeit eine randständige Erscheinung, keineswegs - wie später immer wieder - Sehnsuchtsort aufstrebender bürgerlicher Schichten. ${ }^{46}$ Mehr noch: Man kann angesichts des Rückgangs der Studentenzahlen bis 1800 gar von einer Universitätskrise sprechen. ${ }^{47}$

Erst allmählich, mit der Entstehung moderner staatlicher Verwaltungsapparate, schälte sich die persönliche Qualifikation bzw. die durch Reifezeugnisse gemessene Leistungsfähigkeit als Bedingung attraktiver Beamtenposten heraus. Die Regulierung von Zugangsvoraussetzungen $\mathrm{zu}$ Hochschulen entwickelte sich $\mathrm{zu}$ einer staatlichen Aufgabe, drang doch eine neue, exponentiell wachsende bürgerliche Schicht in die Kaderstrukturen der Verwaltung, deren Aspirationen es im Namen der ständisch-

Vgl. Schulze, Friedrich/Ssymank, Paul: Das deutsche Studententum von den ältesten Zeiten bis zur Cegenwart, München 1931, S. 3-46 und S. 160.

43 D. h. jener "mächtige[n] Minderheit" von ca. 5 bis 15 Prozent der damaligen Bevölkerung, deren „Lebensform und Wertewelt" dem 19. Jahrhundert sein Cepräge gab, vgl. Budde: Bürgerlichkeit im 19. Jahrhundert, S. 5, überdies Schulz: Lebenswelt und Kultur des Bürgertums, S. 1.

44 Vgl. Fläschendräger, Werner: Vernunft kontra Autoritäten. Universitäten im ,Jahrhundert der Aufklärung', in: Steiger, Günter/Fläschendräger, Werner (Hg.): Magister und Scholaren, Professoren und Studenten. Geschichte deutscher Universitäten und Hochschulen im Überblick, Leipzig/Jena/Berlin 1981, S. 55-71 hier S. 66f. sowie Kraus: Kultur, Bildung und Wissenschaft, S. 28.

45 Vgl. Fläschendräger, Werner: „Magd der Theologie“. Generalstudien unter der Herrschaft der Scholastik, in: Steiger, Günter/Fläschendräger, Werner (Hg.): Magister und Scholaren, Professoren und Studenten. Geschichte deutscher Universitäten und Hochschulen im Überblick, Leipzig/Jena/Berlin 1981, S. 15-27, hier S. 24.

46 „Das neue Bildungsideal der französisierten Hofkultur propagierte Galanterie, Reiten, Tanzen und Fechten, d. h. adelige Tugenden, die auch durch die grand tour ohne Studium zu erlernen waren." Jarausch: Deutsche Studenten, S. 14. (Herv. i. O.)

47 „Die deutsche Universitätsgeschichte des 19. Jahrhunderts begann mit einer Katastrophe: einem großen Universitätssterben als Folge der allgemeinen politischen Umbrüche seit 1792, dem etwa die Hälfte der im Alten Reich vorhandenen 45 Hochschulen [...] zum Opfer fielen [...]"Kraus: Kultur, Bildung und Wissenschaft, S. 22. 
korporativen Ordnung einzuhegen galt; ${ }^{48}$ die gymnasiale und akademische Ausbildung wurde so zum „politischen Faktor“49. Der Vorreiter unter den deutschen Staaten war das Königreich Preußen. Gegen Ende des 18. Jahrhunderts heißt es im Allgemeinen Preußischen Landrecht: „Es soll niemandem ein Amt aufgetragen werden, der sich dazu nicht hinlänglich qualifiziert und Proben seiner Geschicklichkeit abgelegt hat. ${ }^{\text {"50 }}$ Wohlgemerkt trägt diese Tendenz das Signum des durch Kulturideale und sozialmoralische Selbstdisziplinierung zementierten bürgerlichen Emanzipationsbegehrens in einer keineswegs schon bürgerlich-egalitären Gesellschaft. ${ }^{51}$ Gerade Preußen blieb bekanntlich bis zur Gründung des Deutschen Kaiserreichs und darüber hinaus ständisch bzw. klassenmäßig heterogen; durch ein System von Vorrechten wie der Exemtion vom militärischen Pflichtdienst wusste man das Bürgertum noch im Vormärz in eine „privilegierte, staatsnahe und staatsbewußte Führungsschicht" und in eine den regionalen, weiterhin ständisch organisierten Rechtskreisen unterstellte Pluralität unterprivilegierter bürgerlicher Klassen zu spalten. ${ }^{52}$ Die Funktion der akademischen Ausbildung blieb somit einer Doppelstruktur verhaftet: der Rekrutierungsweg der hier geschulten, nachrückenden Eliten wurde zwar nach und nach aufgelockert durch messbare Leistungskriterien, bot mithin effektiv die Möglichkeit des sozialen Aufstiegs, aber folgte doch angesichts hartnäckiger geburtsständischer Privilegien, auch im Hinblick auf die Ziele von Status und Einkommen, aristokratischen Leitbildern, denen zumindest nahezukommen wiederum erstmals erreichbar schien. ${ }^{53}$ Hinsichtlich der sozialstrukturellen Zusammensetzung waren im 18. Jahrhundert die juristischen Fakultäten am „exklusivsten“; sie vereinten etwa 35 Prozent der Studenten auf sich. ${ }^{54}$

Die Zahl der Universitäten stieg durch den neu entstandenen Arbeitsmarkt in den Jahrzehnten zwischen 1750 und 1800 rasant..$^{55}$ Zugleich verknappten sich allerdings die

48 Die Situation eines bürgerlich-bürokratischen Klassenkampfs gegen die Aristokratie ist anschaulich geschildert in Koselleck, Reinhart: Preußen zwischen Reform und Revolution. Allgemeines Landrecht, Verwaltung und soziale Bewegung von 1791 bis 1848, Stuttgart 1967, S. 19.

49 Vgl. Herrlitz, Hans-Georg: Studium als Standesprivileg, Frankfurt a.M. 1973, S. 12, überdies S. 13: „Die Frage nach den Kriterien der Studierfähigkeit war nämlich von vornherein mit der Frage nach dem Studienrecht als einem gesellschaftlichen Privileg verbunden, und dahinter stand, besonders in Preußen, das Interesse der staatlichen Obrigkeit, durch eine restriktive Immatrikulationspolitik möglichst zu verhindern, daß die Attraktivität gymnasialer und akademischer Studienfreiheit das erwünschte Cleichgewicht der ständischen Berufspyramide gefährden könnte." (Herv. i. O.)

50 Zit. nach Jarausch: Deutsche Studenten, S. 15.

51 Vgl. Budde: Blütezeit des Bürgertums, S. 11-14. Dass der bürgerliche Leistungsgedanke nicht nur die Karriereansprüche des Bürgertums befestigen sollte, sondern als Teil einer „Zielutopie“ (Wehler) der bürgerlichen Cesellschaft eine wesentliche Rolle in der Ceschichte sozialer Emanzipationsbewegungen spielte, wird unter Kapitel II.2.1 dieser Studie vertiefend behandelt.

52 Vgl. Koselleck: Preußen zwischen Reform und Revolution, S. 115 und ergänzend S. 114: „Durch eine Reihe von Privilegien im Gerichtsstand und im Strafrecht, durch Steuerbefreiungen und Erleichterung im Militärdienst, schließlich durch die Ehegesetzgebung teilte der Staat das Bürgertum in zwei Schichten. Je staatsnäher die Stellung, desto größer die persönlichen Freiheiten." Vgl. Herrlitz: Studium als Standesprivileg, S. $39 f$.

54 Vgl. Jarausch: Deutsche Studenten, S. 16.

55 Schulze/Ssymank geben für das Jahr 175040 deutschsprachige Universitäten an, von denen einige bereits im 14. Jahrhundert gegründet wurden: Altdorf, Bamberg, Basel, Breslau, Dillingen, Duisburg, Erfurt, Erlangen, Frankfurt a. O., Freiburg, Fulda, Göttingen, Graz, Gießen, Greifswald, Halle, Heidelberg, Helmstedt, Herborn, Ingolstadt, Innsbruck, Jena, Kiel, Köln, Königsberg, Leipzig, 
Beamtenstellen sichtbar. ${ }^{56}$ Der Andrang an die Hochschulen war so groß, dass zwischen 1780 und 1800 Klagen über eine „Überfüllung“ der Universitäten bzw. über eine „Überproduktion“ von Akademikern obrigkeitlich lanciert wurden, um Aspiranten aus den unteren Schichten möglichst die Tore zum sozialen Aufstieg mithilfe einer restriktiven Immatrikulationspolitik zu verschließen - auch wenn es Indizien dafür gibt, dass es sich hier um eine strategisch-alarmistische Überdehnung der tatsächlichen statistischen Verhältnisse gehandelt hat. ${ }^{57}$ Unabhängig davon, ob nun die Vorstellung eines Akademiker-Überschusses für den genannten Zeitraum empirisch zutrifft oder nicht: Der von Titze festgestellte zyklisch wiederkehrende, sozial selektierende „Abschreckungseffekt“ bzw. die „Entmutigung als ein [...] Massenphänomen“ wirkte. ${ }^{58}$ Inmitten einer allgemein wachsenden Bevölkerung sanken die Studentenzahlen sowohl absolut als auch relativ. So geriet das Studium im Verlauf des 18. Jahrhunderts an den Universitäten Preußens und der deutschen Fürstentümer zum „Standesprivileg“:59 Die Studenten rekrutierten sich etwa zur Hälfte aus dem relativ gut situierten frühen Bildungsbürgertum, verglichen mit etwa 10 Prozent Nachwuchs aus dem Besitzbürgertum, immerhin 10 bis 18 Prozent Aristokratenkindern und einer größeren Zahl kleinbürgerlicher Studenten. ${ }^{60}$ Der bürgerliche Teil der Studentenschaft dieser Zeit laborierte an dem Druck des zwar Hoffnungen und Ansprüche weckenden, doch zugleich stark restringierten Arbeitsmarkts; die Söhne des Bildungsbürgertums empfanden Zukunftsängste, mit denen sie schwer fertig wurden. ${ }^{61}$ Aus dieser Situation entstand eine neue innerstudentische Reformbewegung, das Verbindungswesen. ${ }^{62}$ Man reagierte auf die neue sozialstrukturell vergleichsweise „aristokratisierte“ Konkurrenzsituation mit einer neuartigen Form von Selbstdisziplinierung durch Leistung- und Berufsethos, Charakterfestigkeitsideale, Affektkontrolle und Zivilität ${ }^{63}$, aber auch unter Adaption aristokratisch-feudaler Lebensführungselemente wie dem Tragen des Degens bzw. „herrenmäßiger" Kleidung. ${ }^{64}$ Der derart verstandene, umfassend gebildete, verantwortungsbewusste Student hatte sich somit nicht nur hinsichtlich des neuen gesellschaftlichen Bedarfs an qualifizierten Funktionseliten optimiert. Auch moralisch musste er den Sieg davontragen, die Nase rümpfend über die überkommenen geburtsständischen Privilegien; er sollte als Inbegriff autonomer Persönlichkeit der Avantgardist des bürgerlichen Menschen schlechthin sein, mithin der prädestinierten, da auf eigene Leistung und

Mainz, Marburg, Olmütz, Paderborn, Prag, Rinteln, Rostock, Salzburg, Straßburg, Trier, Tübingen, Wien, Wittenberg, Würzburg; in den Folgejahren bis zur Jahrhundertwende folgten 40 weitere Universitäten, Schulze/Ssymank, Das deutsche Studententum, S. 160.

Vgl. Hardtwig. Wolfgang: Auf dem Weg zum Bildungsbürgertum: die Lebensführungsart der jugendlichen Bildungsschicht 1750-1819, in: Lepsius, M. Rainer (Hg.): Bildungsbürgertum im 19. Jahrhundert. Teil III: Lebensführung und ständische Vergesellschaftung, Stuttgart 1985, S. 19-41, hier S. 38 .

57 Vgl. ibid., S. 32-36 und Jarausch: Deutsche Studenten, S. 16.

58 Vgl. Titze: Die zyklische Überproduktion von Akademikern, S. 93.

59 Vgl. Herrlitz: Studium als Standesprivileg.

60 Vgl. Jarausch: Deutsche Studenten, S. 16.

61 Vgl. Hardtwig: Auf dem Weg zum Bildungsbürgertum, S. 39.

62 Mehr dazu in Kapitel II.2.1 dieser Studie.

63 Vgl. Hardtwig: Auf dem Weg zum Bildungsbürgertum, S. 25.

64 Vgl. ibid., S. 39, S. 40 und S. 45. 
Arbeit gegründeten, verantwortungsbewussten staatlichen Führungsschicht. ${ }^{65}$ Selbstbewusst schritt man dem erwachsenen Bürgertum voran, seine Maximen ökonomischer und politischer Selbstständigkeit inkorporierend. ${ }^{66}$ „Sey dein eigner Herr und Knecht, Das ist des Mittelstandes Recht“ lautete der Wappenspruch der Mannheimer Kaufmannsfamilie Bassermann. ${ }^{67}$

Plausibilität und schließlich auch Durchsetzungskraft gewann dieser Anspruch nicht nur durch die starke Rolle der preußischen Beamten, die sich zunehmend von „Verwaltern“ zu „Reformern“ entwickelten, sondern auch durch eine neuartige Integrations- und Netzwerkform: die freiwillige Assoziation. Die "gebildeten Stände“ konstituierten sich gemeinsam mit dem kaufmännischen Bürgertum - neben der Pflege „bürgerlicher Kultur“ in der Familie, insbesondere durch die „Pädagogisierung“ der Erziehung und eine der öffentlichen Sphäre entzogenen, mithin sozial untergeordneten Gattin und Mutter ${ }^{68}$ - überhaupt erst durch ihre neuartige Vergesellschaftung in Salons, Sozietäten, Assoziationen und Vereinen, mit denen sie auch Einfluss auf Presse und öffentliche Meinungsbildung ausüben konnten, ${ }^{69}$ als Gesellschaftsschicht, die auf eigenwillige Weise antiaristokratische Impulse mit elitären Bildungs- und Lebensstildifferenzierungen verband: ${ }^{70}$

„Im Bürgertum herrschten Sprachkonventionen über Art und Inhalt der Konversation, die auf privaten Abendgesellschaften zu pflegen war. Nicht minder wichtig war die Briefliteratur, die im Familienkreis eingeübte Kultur des Schönschreibens und der sprachlich korrekten Ausdrucksweise. [...] Das Lesen hatte im 19. Jahrhundert eine zentrale Funktion als Mittel bürgerlicher Kommunikation und Ausweis von Bildung. Der Besitz repräsentativer Bibliotheken unterstrich die Zugehörigkeit zum Bürgertum. Es herrschten präzise Vorstellungen von einer angemessenen Bildungslektüre, deren Spektrum die Klassikerreihen bei Cotta oder Reclam absteckten. ${ }^{\text {‘71 }}$

65 „Der Habitus des akademischen Bildungsbürgers glich der Selbststilisierung des Unternehmers, der sich für das Unternehmen hingab. Beides war Ausdruck eines bürgerlichen Arbeitsethos, das sich gegen den vermeintlichen Müßiggang adliger Lebensweise und die entfremdete Lohnarbeit des Proletariats abgrenzte. Der bürgerliche Arbeitsalltag bedurfte einer rationalen Zeiteinteilung, er folgte einem festen Rhythmus akribischer Pflichterfüllung. Auch die Freizeit des Bürgers war genau geplant. Sie hatte der Bildung zu dienen, durch Reisen, Theater- und Museumsbesuche, dem Wissenserwerb und der beruflichen Fortbildung." Schulz: Lebenswelt und Kultur des Bürgertums, S. 21.

66 Vgl. Gall: Bürgertum in Deutschland, S. 80.

67 Zit. nach ibid., S. 75.

68 Vgl. Budde: Blütezeit des Bürgertums, S. 25 und Schulz: Lebenswelt und Kultur des Bürgertums, S. 3-9.

69 Vgl. Budde: Blütezeit des Bürgertums, S. 13f. und 15-21 und Schulz: Lebenswelt und Kultur des Bürgertums, S. 10-13.

70 Vgl. Bödeker, Hans Erich: Die „gebildeten Stände“ im späten 18. und frühen 19. Jahrhundert: Zugehörigkeit und Abgrenzungen, Mentalitäten und Handlungspotentiale, in: Kocka, Jürgen (Hg.): Bildungsbürgertum im 19. Jahrhundert. Teil IV: Politischer Einfluß und gesellschaftliche Formation, Stuttgart 1989, S. 21-52, hier S. 24, 46 und 51f. und Budde: Blütezeit des Bürgertums, S. 19. Vgl. zur, auch politischen, Bedeutung dieser Form von (Selbst-)Organisation Kapitel II.2.1 dieser Studie. Schulz: Lebenswelt und Kultur des Bürgertums, S. 19f. Bei den von Gall untersuchten Bassermanns praktizierte man „Weltläufigkeit, in einem allgemeinen, aber zugleich auch in einem durchaus praktischen, handfesten Sinne“ u. a. kraft der „Vorschrift, daß an drei Tagen in der Woche bei Tisch 
Und aus dieser Schicht, die sich selbst als repräsentativer „allgemeiner Stand“, als Chefinterpreten des Willens der Mehrheit der Bevölkerung und als Advokaten ihrer Rechte, verstand, ja die den Obrigkeitsstaat durch Reformierung von innen zu überwinden trachtete, ${ }^{72}$ sollten schließlich auch die berühmten, neuhumanistischen Hochschulreformer, die Humboldts, die Schleiermachers, u. a. hervorgehen.

Hier begegnet erstmals ein Wesenszug der Studentenschaft, der das gesamte „lange bürgerliche Jahrhundert" ${ }^{473}, d$. h. bis zum Ausbruch des Ersten Weltkriegs, tragend bleiben sollte und auch für die politischen Emanzipationsbestrebungen entscheidend war: die intensive Verkettung von „Wohl und Wehe“ der akademischen Jugend mit dem Schicksal des (Bildungs-)Bürgertums. ${ }^{74}$ Die Studenten der Jahrzehnte zwischen den 1750er Jahren und etwa 1914, in deutlich geringerem Maße bis 1945, waren „Jungbildungsbürger“75 oder auch „jugendliche“ Bildungsbürger. Mehr noch: „Die Studenten spielten [...] eine Vorreiterrolle, da sie neue Strömungen des Bildungsbürgertums schneller und radikaler aufgriffen als die Erwachsenen. ${ }^{476}$ So wie die Bildungsbürger sich selbst im nachnapoleonischen Deutschen Bund später einen politischen Führungsanspruch in Bezug auf die nationalliberalen Kräfte und später auf die kulturelle und moralische Deutungshoheit als staatstreue "Geistesaristokratie“77 zuschrieben, so erhoben schon die Studenten der 1790er Jahre einen spezifischen „Geltungs- und

französisch gesprochen werden sollte." Vgl. Gall: Bürgertum in Deutschland, S. 103. Wohlgemerkt: Hochmütiger Bildungsdünkel scheint erst zur Zeit des Kaiserreichs im Bürgertum grassiert zu sein, wie Gall ibid., S. 143, anmerkt.

72 Vgl. Bödeker: Die "gebildeten Stände“, S. 52.

73 Die Bezeichnung „langes neunzehntes Jahrhundert“ bzw. „langes bürgerliches Jahrhundert" stammt vom Historiker Eric ]. Hobsbawm und versucht, jene Periode zwischen der französischen Revolution 1789, die durch die Etablierung eines kapitalistischen Wirtschaftssystems, durch explosives wirtschaftliches Wachstum und durch die politische und kulturelle Durchsetzung des liberalen Bürgertums gegen die Systeme der anciens régimes und im Rahmen der europäischen Revolutionen gekennzeichnet ist, und dem Ausbruch des Ersten Weltkriegs 1914 zu fassen., vgl. dazu die Trilogie: Hobsbawm, Eric ].: Europäische Revolutionen. 1789 bis 1848, Stuttgart 2004 [ursprgl. The Age of Revolution. Europe 1789-1848, 1962]; Hobsbawm, Eric ].: Die Blütezeit des Kapitals: Eine Kulturgeschichte der ]ahre 1848-1875, Frankfurt a.M. 1980 [ursprgl. The Age of Capital. 1848-1875, 1975]; Hobsbawm, Eric ].: Das imperiale Zeitalter 1875-1914, Frankfurt a.M. 1989 [ursprgl. The Age of Empire, 1987]. Im Cegensatz dazu fasst Hobsbawm die Jahre zwischen Beginn des Ersten Weltkriegs 1914 bis zum Zusammenbruch des Ostblocks ungefähr um 1991 zum „kurzen zwanzigsten Jahrhundert" zusammen, vgl. Hobsbawm: Das Zeitalter der Extreme, insbesondere S. 7. Sowohl gesellschafts- als auch ideengeschichtlich lassen sich diese beiden Zeitspannen so präziser und qualifizierender benennen als mit vergleichsweise vagen chronologischen Zeitabschnitten wie 1800, 1900, 2000.

74 Vgl. Schulze/Ssymank: Das deutsche Studententum, S. 160.

75 Vgl. für Wahl des Begriffs Jarausch, Konrad H.: Die Krise des deutschen Bildungsbürgertums im ersten Drittel des 20. Jahrhunderts, in: Kocka, Jürgen (Hg.): Bildungsbürgertum im 19. Jahrhundert. Teil IV: Politischer Einfluß und gesellschaftliche Formation, Stuttgart 1989, S. 180-205, hier S. 199. Jarausch: Deutsche Studenten, S. 246.

77 Vgl. Wehler, Hans-Ulrich: Deutsches Bildungsbürgertum in vergleichender Perspektive - Elemente eines „Sonderwegs"?, in: Kocka, Jürgen (Hg.): Bildungsbürgertum im 19. Jahrhundert. Teil IV: Politischer Einfluß und gesellschaftliche Formation, Stuttgart 1989, S. 215-237, hier S. 221 sowie Gall: Bürgertum in Deutschland, S. 196. 
Eliteanspruch“ als gesamtgesellschaftliches Vorbild des mündigen, verstandeskräftigen Bürgers $^{78}$ - so wie Johann Gottlieb Fichte es Über die Bestimmung des Gelehrten vorsah:

„Seine für die Gesellschaft erworbene Kenntnis soll er zum Nutzen der Gesellschaft anwenden; er soll die Menschen zum Gefühl ihrer wahren Bedürfnisse bringen und sie mit den Mitteln ihrer Befriedigung bekannt machen [...] Er sieht nicht nur das Cegenwärtige, er sieht auch das Künftige: er sieht nicht blos [sic] den jetzigen Standpunkt, er sieht auch, wohin das Menschengeschlecht nunmehr schreiten muß [...] In dieser Rücksicht ist der Celehrte der Erzieher der Menschheit. ${ }^{\text {‘9 }}$

Die Ambitionen der Studenten der Aufklärungsperiode waren hier trotz mancher frankophilen Revolutionssympathien noch staatstragend. Doch es folgten die Jahre sozialrevolutionärer Bestrebungen, die zum (gesamteuropäischen ${ }^{80}$ ) gescheiterten Revolutionsversuch von 1848 führen sollten. Der preußische Sieg im antinapoleonischen „Befreiungskrieg“ bildete den gesellschaftspolitischen Humus für die Entstehung einer deutschen bürgerlichen Nationalbewegung, als deren Speerspitze sich die verbindungsmäßig organisierten Studenten in der Vormärz-Periode mehr und mehr gerierten. ${ }^{81} 1815$, das Gründungsjahr des Deutschen Bundes, markiert hier ein entscheidendes Datum der mythisch angereicherten antifranzösischen und nationalliberalen Politisierung, auch Radikalisierung der deutschen Studenten, die in mehreren Wellen, beginnend mit dem Wartburgfest 1817, Versuche einer nationalrevolutionären politischen Bewegung unternahmen. ${ }^{82}$ Aber die erste Hälfte des 19. Jahrhunderts, insbesondere die Jahre bis 1830, war auch eine Zeit extensiven Bildungswachstums, ja eigentlich die formative Konstitutionsphase des Bildungsbürgertums als Sozialformation im engeren Sinn, nämlich als eine „Klasse“ von professionalisierten Funktionseliten, die aus der preußischen Beamtenschaft hervorgingen und ihre Berufs-, Karriere- und Einkommensansprüche auf offiziell anerkannte Bildungszertifikate gründeten: ${ }^{83}$ Zunehmend spalteten sich die Karrierewege, Lebenswelten, die intellektuellen, kulturellen und politischen Werthaltungen der Bildungsbürger von denjenigen der unternehmerisch bzw. kommerziell tätigen Wirtschaftsbürger, erst recht von den Besitzbürgern, $\mathrm{ab}^{84}$ - wenn-

78 Vgl. Hardtwig: Auf dem Weg zum Bildungsbürgertum, S. 32 und 36 sowie Kraus: Kultur, Bildung und Wissenschaft, S. 22f.

79 Fichte, Johann Gottlieb: Über die Bestimmung des Gelehrten, Jena 1794, zit. nach Steiger, Günter: „Brotgelehrte“ und „Philosophische Köpfe“. Universitäten und Hochschulen zwischen zwei Revolutionen, in: Steiger, Günter/Fläschendräger, Werner (Hg.): Magister und Scholaren, Professoren und Studenten. Geschichte deutscher Universitäten und Hochschulen im Überblick, Leipzig/Jena/Berlin 1981, S. 72-102, hier S. 74f.

80 Vgl. Langewiesche, Dieter: Wirkungen des „Scheiterns“. Überlegungen zu einer Wirkungsgeschichte der europäischen Revolutionen von 1848, in: Die Revolutionen von 1848 in der europäischen Geschichte. Ergebnisse und Nachwirkungen. Beiträge des Symposions in der Paulskirche vom 21. bis 23. Juni 1998. Historische Zeitschrift, Beihefte New Series, H. 29/2000, S. 5-21, hier S. 7. Die Rolle der politischen Erfahrungen, Ziele und Aktivitäten für die Entwicklung des Bildungsbürgertums und damit auch der Studentenschaft werden unten, Kapitel II.2.1, diskutiert.

82 Vgl. Jarausch: Deutsche Studenten, S. 35-46.

83 Zur Topologie des Bildungsbürgertums vgl. eingehender Kapitel II.2.1.

84 Vgl. Turner, Steven: The Bildungsbürgertum and the Learned Professions in Prussia, 1770-1830: The Origins of a Class, in: Histoire Sociale-Social History, H. 13/1980, S. 105-135, hier S. 105 und 107. Vgl. außerdem Lundgreen, Peter: Zur Konstituierung des „Bildungsbürgertums“: Berufs- und Bildungs- 
gleich auch ohne eine substanzielle Erosion der integrativen und identitätsstiftenden Kraft des im Rückblick unerschütterlich wirkenden Selbstverständnisses bürgerlicher Schichten als Bürgertum im Verlauf des 19. Jahrhunderts; ${ }^{85}$ schließlich verstand man sich durchweg „als Vorhut, als Muster, als Modell der Gesellschaft der Zukunft“ . ${ }^{86}$ Nach den Humboldt'schen Bildungsreformen, der organisatorischen Vereinheitlichung der Universitätslandschaft, der engeren Verknüpfung von „Bildung und Amt“, d. h. von Bildungszertifikaten und beruflichen Positionen, ${ }^{87}$ durch das strenge System der Bildungsvoraussetzungen und die Verpflichtung zu Staatsexamina, erklommen sie die Statusleiter der sich formierenden kapitalistischen Gesellschaft unter militäraristokratischer Herrschaft: zunehmend genossen sie Privilegien, bspw. die Berechtigung von Gymnasialabsolventen bzw. für solche der Real- und höheren Bürgerschule, den prestigeträchtigen einjährigen Militärdienst plus Reservezeit zu durchlaufen. ${ }^{88}$ Nach und nach gelang dem deutschen Bildungsbürgertum in Gestalt der Reformbeamtenschaft trotz weiterhin persistenter feudalaristokratischer Schranken - die Durchsetzung des meritokratischen Prinzips im Bildungssystem, in Verwaltung und Militär, beginnend bei den unteren sozialen Schichten: Messbare Qualifikation, und nur messbare Qualifikation, sollte für öffentliche Ämter befähigen. ${ }^{89}$ Bildung und Leistung begründeten ihren gesellschaftlichen Führungsanspruch. ${ }^{90}$

So blieb ein wesentliches Movens des Studiums - neben einer Tätigkeit als freiberuflicher Akademiker - vornehmlich die Aussicht auf eine Karriere im öffentlichen Dienst, ${ }^{91}$ also als Beamter in Verwaltung, Universitäten, Schulen und Kirchen, als staatsexaminierter Theologe, Jurist, Mediziner oder Philologe (mithin Gymnasialbzw. Oberlehrer, ein zuvor Theologen vorbehaltenes Amt). Über teils widersprüchliche Entwicklungsbewegungen, d. h. ein starkes Wirtschaftswachstum, aber auch Wirtschaftskrisen hinweg, veränderte sich das Studium in sozialstruktureller Hinsicht

auslese der Akademiker in Preußen, in: Conze, Werner und Kocka, Jürgen (Hg.): Bildungsbürgertum im 19. Jahrhundert. Teil 1: Bildungssystem und Professionalisierung in internationalen Vergleichen, Stuttgart 1985, S. 79-108, hier S. 88 sowie jüngst Budde: Blütezeit des Bürgertums, S. 7-11. Die Spannung zwischen den für die verschiedenen „Bürgerwelten“ konstitutiven Polen von kaufmännisch bzw. industriell generiertem Besitz und kulturell wie akademisch genährter Bildung veranschaulichen etwa die Familienbiographien Lothar Galls (Familie Bassermann) und Franz J. Bauers (Familien Dohrn, Hildebrand und Sattler), vgl. Gall: Bürgertum in Deutschland und Bauer: Bürgerwege und Bürgerwelten.

„Und doch steht bei aller Unterschiedlichkeit der Herkunftsmilieus, der materiellen Fundierung und des Lebenszuschnittes, der Wirkungskreise, der Interessen und der Bewußtseinshorizonte die bürgerliche Identität jeder dieser Einzelexistenzen ganz außer Zweifel." Bauer: Bürgerwege und Bürgerwelten, S. 286. Von einem Identitätsverlust könne im ausgehenden 19. Jahrhundert die Rede sein - nämlich als sich bürgerliche Kulturnormen und Lebensformen gesamtgesellschaftlich universalisierten, vgl. ibid., S. 289.

86 Vgl. Gall: Bürgertum in Deutschland, S. 80.

87 Vgl. Bödeker, Hans Erich: Die „gebildeten Stände“ im späten 18. und frühen 19. Jahrhundert, S. 24.

88 Vgl. Turner: The Bildungsbürgertum and the Learned Professions in Prussia, S. $105 f$.

89 Vgl. Lundgreen: Zur Konstituierung des „Bildungsbürgertums“, S. 82f. und S. 88.

90 Vgl. Hardtwig, Wolfgang: Krise der Universität, studentische Reformbewegung (1750-1819) und die Sozialisation der jugendlichen deutschen Bildungsschicht. Aufriß eines Forschungsproblems, in: Geschichte und Gesellschaft, 11. Jahrgang, H. 11/1985, Göttingen 1985, S. 155-176, hier S. 164. 
drastisch. Bildungsaufsteiger drängten vor allem in die Philosophischen Fakultäten, ${ }^{92}$ Kriegsteilnehmer des Napoleonischen Krieges holten ihr Studium nach, und generell stieg das Prestige neuhumanistischer Bildung..$^{93}$ Zwischen 1795 und 1830 wuchs die absolute Zahl der deutschen Studenten von 6.000 auf 16.000, was nur im Vergleich zur noch rasanter wachsenden Gesamtbevölkerung vergleichsweise niedrig erscheinen kann. ${ }^{94}$ Insbesondere zwischen 1815 und 1830, nach einer Phase geschmälerter Anerkennung der Universitäten, verdreifachte sich die Studentenzahl..$^{95}$ Seit etwa 1750 hatte sich die soziale Funktion des Studierens massiv verändert: Man immatrikulierte sich nicht mehr aus „kultureller Motivation“ als Anwärter auf den humanistischen Gelehrtenstand, sondern suchte seine Karrierechancen als Teil der professionalisierten Funktionselite $\mathrm{zu}$ erhöhen. ${ }^{96}$ Studentenfrequenz und Akademikernachfrage waren auch ein zeitgenössisch diskutiertes Thema. Insbesondere unter Juristen und Theologen kam es in den 1840er Jahren zu einer dramatischen Überfüllungskrise mit 5bis 10-jährigen Wartezeiten zwischen Hochschulabschluss und Eintritt in den Staatsdienst, die Erwerbskonkurrenz verschärfte sich bis in die zuvor leicht zugänglichen Berufsfelder. ${ }^{97}$

Diese erste Welle des Bildungswachstums im 19. Jahrhundert arretierte daher jäh um 1830/31; die Zahl der Studenten fiel auf etwa 12.000 bis 13.000 ab und bis etwa 1865/66 blieb die Studentenquote an der Gesamtbevölkerung in etwa gleich. ${ }^{98}$ Verantwortlich dafür war ein Ursachenbündel aus massiver staatlicher Restriktionspolitik (Abiturzwang, Numerus clausus, etc.) und einer generell abschreckenden Wirkung des Erwerbsnotstandes. ${ }^{99}$ Dies führte gemäß des von Titze beschriebenen „typischen“ Zyklus' von Expansion, Überfüllung/Stagnation und erneutem Nachfragewachstum auf höherer Stufenleiter ${ }^{100}$ bis Ende der 1840er Jahre wiederum zu gegenläufigen Entwicklungen, etwa einem Mangel an juristischen Assessoren. Doch die große, die entscheidende Tendenz, die sich insbesondere zur Mitte des 19. Jahrhunderts enthüllte, war das langfristige Bildungswachstum; schließlich fiel die Grundsteinlegung des modernen Bildungssystems in eine Phase der sozialen, politischen und kulturellen Umwälzungen des gesamten Kontinents. Die Bevölkerung zu alphabetisieren und im Humboldt'schen Sinne zu bilden, nicht mehr nur sie zu erziehen, ${ }^{101}$ entwickelte sich mehr und mehr zu

92 Vgl. ibid., S. 92.

93 Vgl. Jarausch: Deutsche Studenten, S. 25.

94 Vgl. Steiger: „Brotgelehrte“ und „Philosophische Köpfe“, S. 75 sowie Jarausch: Deutsche Studenten, S. 25 .

95 Von rund 5.500 auf über 16.000, vgl. Hardtwig: Krise der Universität, S. 159.

96 Vgl. Turner: The Bildungsbürgertum and the Learned Professions in Prussia, S. 112f.

97 Vgl. Titze: Die zyklische Überproduktion von Akademikern, S. 103.

98 Vgl. Jarausch: Deutsche Studenten, S. 26.

99 Vgl. Titze: Die zyklische Überproduktion von Akademikern, S. 103.

100 Vgl. Titze: Bildungskrisen und sozialer Wandel, S. 349. „Der Mangel steht am Anfang und läßt sich als Motor des Wachstums auffassen. [...] In der durch die Überfüllungsphase funktional hervorgebrachten Mangelphase hat die Neuinterpretation von Bedürfnissen dann größere Durchsetzungschancen, und der Zyklus beginnt erneut." Ibid.

101 Zum sozialen Wandel, der sich in der Hinwendung zum Bildungsbegriff ausdrückt, vgl. Vierhaus: Bildung, in: Brunner, Otto/Conze, Werner/Koselleck, Reinhart: Geschichtliche Grundbegriffe. Historisches Lexikon zur politisch-sozialen Sprache in Deutschland. Bd. 1 A-D, Stuttgart 1972, S. 508551, hier S. 512-523. Näheres unten, Kapitel II.3. 
einem staatlichen Projekt. ${ }^{102}$ Bis etwa 1880 war die deutsche Gesellschaft vollständig alphabetisiert. ${ }^{103}$ Dennoch: Aufstiegskanäle für untere soziale Schichten waren die Universitäten mit einer Studienbeteiligung von bloßen zwei Prozent ${ }^{104}$ noch keineswegs. Akademiker und Studenten gerieten allmählich zwar zu einer wahrnehmbaren Gruppe; Bildung war nun nicht mehr Angelegenheit einer verstiegenen Kaste von Gelehrten, sondern die statusbegründende Auszeichnung einer hochdotierten und angesehenen Klasse von Gebildeten, der Bildungsbürger. ${ }^{105}$ Trotzdem hat sich gerade in den 1840er Jahren - im Vorfeld des Revolutionsversuchs - die Aufstiegsmobilität in Richtung Bildungselite deutlich verschlechtert. ${ }^{106}$ Bereits auf dem Gymnasium wurden die Schüler zunehmend schärferen Ausleseprozessen unterzogen, und: „Die Unterschicht bleibt zu jedem Zeitpunkt faktisch ausgeschlossen. ${ }^{107}$ Schließlich galt es lukrative Privilegien $\mathrm{zu}$ sichern, über die das Bildungsbürgertum durchaus auch wachte, wurde diese Gruppe von akademisch gebildeten Beamten aufgrund ihrer administrativen Schlüsselpositionen doch „die praktisch einflußreichste Gruppe in der deutschen Gesellschaft" nach 1800". 108

Das Studium an neuhumanistischen Universitäten bis zu den 1860er Jahren war eine eher urbane, überwältigend bildungsbürgerliche und protestantische ${ }^{109}$, ferner rein männliche Angelegenheit. 90 Prozent aller Studenten hatten ein vorbereitendes Abitur erworben, etwa die Hälfte von ihnen kam aus Akademikerfamilien, zahlenmäßig gefolgt vom Kleinbürgertum - während Abkömmlinge adliger und besitzbürgerlicher Familien die akademische Ausbildung, abgesehen vom zu 80 Prozent aristokratisch dominierten Jurastudium, mieden. ${ }^{110}$ So waren auch die Jungbildungsbürger, die Studenten, sozial homogenisiert und kulturell standesbewusst. Sie strebten in die juristischen und theologischen, in geringerem Maße in die medizinischen Berufe; nach 1850 in den neuen „Kernberuf“ des Lehrers. Trotz des ebenso wachsenden Bedarfs an Freiberuflern wurden die meisten von der Aussicht einer Beamtenlaufbahn angezogen - den staatskritischen nationalistischen Bestrebungen der politisch mobilisierten „48er“-Generation

102 Conze, Werner/Kocka, Jürgen: Einleitung, in: Conze, Werner und Kocka, Jürgen (Hg.): Bildungsbürgertum im 19. Jahrhundert. Teil I: Bildungssystem und Professionalisierung in internationalen Vergleichen, S. 9-26, hier S. 14f.

103 Vgl. Titze: Bildungskrisen und sozialer Wandel, S. 358.

104 Vgl. Jarausch: Deutsche Studenten, S. 30.

105 Vgl. ibid., S. 27 sowie Vierhaus: Umrisse einer Sozialgeschichte und Turner: The Bildungsbürgertum and the Learned Professions in Prussia, S. 113.

106 Vgl. Jarausch, Konrad H.: The Sources of German Student Unrest 1815-1848 (1974), in: Historical Social Research, Supplement, H. 24/2012, S. 80-114, hier S. 98.

107 Vgl. Lundgreen, Zur Konstituierung des „Bildungsbürgertums“, S. 91.

108 Vgl. Vierhaus: Umrisse einer Sozialgeschichte, S. 405.

109 „Durch die Folgen der Säkularisation von 1803 [im Zuge des Reichsdeputationshauptschlusses, ]. S.] und die mannigfachen Universitätsschließungen im westlichen und südlichen Deutschland erlebte das traditionell sehr reiche katholische Bildungswesen einen massiven Einbruch. Dadurch entstand im Laufe des 19. Jahrhunderts eine deutliche Benachteiligung der Katholiken im Bildungsbereich [...]" Kraus: Kultur, Bildung und Wissenschaft, S. 28. 
zum Trotz. ${ }^{111}$ Überdies wurden die Kernberufe der akademisch Professionalisierten in der Regel an die Söhne vererbt. ${ }^{112}$ So zeigt sich ein janusköpfiges Bild: Einerseits integrierte das studierende Bildungsbürgertum „klassenübergreifend“verschiedene Teile des Bürgertums und ermöglichte eine zaghafte soziale Öffnung in Richtung des nichtproletarisierten Kleinbürgertums (Handwerker, Bauern, u. a.), andererseits dichtete sich die Studentenschaft elitär gegen Aufsteiger ab, rekrutierte sich in hohem Maße selbst und verteidigte eisern das bildungsbedingte „Berufsmonopol“ vor allem in den Bereichen des höheren Staatsdienstes. ${ }^{113}$

\section{II.1.2 Verselbstständigung des Bildungswachstums ab 1880}

In den folgenden Jahrzehnten schritt die Industrialisierung rasant voran; insbesondere die 1880er Jahre gelten hier als internationales "Schwellenjahrzehnt" einer sich schubweise intensivierenden privatwirtschaftlichen Kapitalkonzentration, einer expandierenden Energiegewinnung, einer zunehmenden Serienproduktion etwa von Elektromotoren, ferner einer regen Erschließung ausländischer Märkte und zunehmender imperialistischer Bestrebungen der europäischen Großmächte. ${ }^{114}$ Auch wird die Gründung des Deutschen Kaiserreichs 1871 weithin als eine der großen Zäsuren der deutschen Geschichte aufgefasst, sowohl in politischer, kultureller, als auch in sozialer und wirtschaftlicher Hinsicht. Nicht nur wurde die Frage nach der deutschen Einheit unter der Bismarck'schen Ägide auf preußisch-kleindeutsche Weise und unter Entmachtung der bürgerlich-liberalen Elemente "gelöst“, während die Phase innerer Nationenbildung, die „Zweite Reichsgründung“ die 1870er und 1880er Jahre in Anspruch nahm; ${ }^{115}$ es deutete sich eine Phase an, in der sich gesellschaftliche Konfliktlinien des frühen 19. Jahrhunderts verschärfen sollten, und in der sich die Konturen der neuen Klassengesellschaft herausbildeten. Ab 1895 vollzog das wilhelminische Deutschland die Metamorphose vom Agrar- zum Industriestaat ${ }^{116}$ und blieb weithin von konstitutiven Widersprüchen geprägt: einerseits regiert von einer obrigkeitsstaatlichen preußischen Militäraristokratie und einem autoritär-antiliberalem Kaiser ${ }^{117}$, andererseits wirtschaftlich

111 Vgl. Titze: Bildungskrisen und sozialer Wandel, S. 351 und Jarausch: Deutsche Studenten, S. 31. Zu den politischen, revolutionär gerichteten Aktivitäten der vormärzlichen Studenten vgl. Kapitel II.2.1.

112 Vgl. Jarausch: Deutsche Studenten, S. 3of.

113 Vgl. ibid., S. $32 f$.

114 Vgl. Osterhammel: Die Verwandlung der Welt, S. 109-114.

115 Vgl. Winkler, Heinrich August: Der lange Weg nach Westen. Bd. 1: Deutsche Geschichte vom Ende des Alten Reiches bis zum Untergang der Weimarer Republik, München 2000, S. 213-265.

116 Vgl. Conze, Werner: Ereignisse und Entwicklungen 1851-1918, in: Langewiesche, Dieter (Hg.): Das deutsche Kaiserreich 1867/71 bis 1918. Bilanz einer Epoche, Freiburg/Würzburg 1984, S. 81-116, hier S. 100 und Ullmann, Hans-Peter: Das Deutsche Kaiserreich 1871-1918, Frankfurt a.M. 1995, S. 105.

117 „Kaiser Wilhelm II. wurde zum Führer stilisiert [...] Seine Begeisterung für technische, vor allem militärisch nutzbare Neuerungen, Marine, Funktechnik, Autorennen/Motorsport etc. bei gleichzeitiger Verachtung des Liberalismus und der Demokratie verkörperte durchaus das doppelte Cesicht der wilhelminischen Cesellschaft des Kaiserreichs. Autoritäre Anrufung göttlicher Sendung und hybride Selbstüberschätzung des Nationalen als Ausweg aus den inneren Widersprüchen begleiteten die rasante Modernisierung der Gesellschaft, die sich im Zeitraum nur weniger Jahrzehnte von einer agrarischen zu einer industriell-urban bestimmten wandelte [...]" Schildt, Axel: Konser- 
und technologisch fortschrittlich, um 1900 überdies mit einem international bewunderten Bildungs- und Wissenschaftssystem und einem sich kulturell avantgardistisch wähnenden akademischen Bürgertum ausgestattet. ${ }^{118}$ Ein Zwitterstaat mithin, der traditionalistische wie modernistische Züge, d. h. sowohl Aspekte des 19. als auch des 20. Jahrhunderts in sich vereint. ${ }^{119}$ Und unter dessen zahlreichen sprengkräftigen und zukunftsweisenden Tendenzen ist wohl die Genese der sozialen Frage hervorzuheben, genauer: die augenfälligen Klassenspaltungen zwischen Besitzenden und Arbeitenden, die drastische Ungleichheit der Einkommen, das Phänomen proletarisierter Massen, gewerkschaftlicher Interessenvertretungen und einer organisationskräftigen Arbeiterbewegung. In der zweiten Hälfte des 19. Jahrhunderts trat mit dem Aufkommen der neuen industriewirtschaftlichen Zentren auch das Proletariat als soziale Gruppe, bald als politisch organisierte Kraft auf den Plan. Die epochale Zäsur, die hier die Mehrheit der deutschen Bevölkerung - ab 1871 institutionell gefestigt als deutscher Nationalstaat - ergriff, ist kaum zu überschätzen. Die preußischen Verfassungs- und Wirtschaftsreformen, die im Namen der Herstellung einer antiständisch-egalitären Staatsbürgergesellschaft mitsamt liberaler Marktwirtschaft die Ordnung der Herrschafts- und Besitzrechte revolutionierten, wälzten gerade deshalb die traditionellen Lebensverhältnisse um, weil sie auf weitgehend agrargesellschaftliche Strukturen trafen. Zum Vergleich: In den $1800 e r$ Jahren lebten und arbeiteten gut 70 Prozent der preußischen Bevölkerung in land- bzw. forstwirtschaftlichen Verhältnissen, ${ }^{120}$ im kleineren Königreich Bayern auch 1840 noch 65,7 Prozent. ${ }^{121}$

Die Zersplitterung der politischen Landschaft im Kaiserreich hatte zwar sicher unterschiedliche Gründe, die mit der Ausdifferenzierung der sozialen Lagerungen zu tun hatte, einer der wesentlichen aber war die Formierung der Sozialdemokratie in Gotha 1875 und der sich anschließende Aufstieg zur Massenpartei unter dem Banner des Sozialismus, die in ein unter dem Druck obrigkeitsstaatlicher Repression herausgebildetes sozialmoralisches Milieu, in ein System von Vereinsnetzen eingebettet war und auf unvergleichlich loyale Funktionäre zählen konnte. ${ }^{122}$ Reichskanzler Bismarck flankierte die repressiven Sozialistengesetze in den 1880er Jahren nicht zuletzt deshalb mit einer zukunftsweisenden staatlichen Sozialgesetzgebung - der berühmte „Tropfen socialen

vatismus in Deutschland: von den Anfängen im 18. Jahrhundert bis zur Gegenwart, München 1998, S. 114 .

118 Vgl. Ullmann: Das Deutsche Kaiserreich, S. 181-192 und Langewiesche, Dieter: Bildungsbürgertum und Liberalismus im 19. Jahrhundert, in: Kocka, Jürgen (Hg.): Bildungsbürgertum im 19. Jahrhundert. Teil IV: Politischer Einfluß und gesellschaftliche Formation, Stuttgart 1989, S. 95-121.

Vgl. Ullmann: Das Deutsche Kaiserreich, S. 12.

Vgl. Koselleck: Staat und Cesellschaft in Preußen, S. 95.

Vgl. Brunner, Otto: Cesellschaft und Staat im Bayern des Vormärz, in: Conze, Werner (Hg.): Staat und Gesellschaft im deutschen Vormärz 1815-1848, Stuttgart 1962, S. 113-142, hier S. 115.

Vgl. ibid., S. $130 f$ sowie Walter, Franz: Die SPD. Biographie einer Partei von Ferdinand Lassalle bis Andrea Nahles, Reinbek bei Hamburg 2018, S. 20 und 21-56. Für den Begriff des sozialmoralischen Milieus, der auf die über parteipolitische Interessenaggregation hinausreichende kulturelle, freizeitstrukturierende und Solidarität sicherstellende Kohäsion (u. a.) der wilhelminischen Arbeitermilieus abzielt, vgl. Lepsius, Mario Rainer: Parteiensystem und Sozialstruktur. Zum Problem der Demokratisierung der deutschen Cesellschaft (1966), in: Ders.: Demokratie in Deutschland. Soziologisch-historische Konstellationsanalysen. Ausgewählte Aufsätze, Göttingen 1993, S. 25-50. 
Oeles" -, weil er hoffte, dadurch dem elektoralen Siegeszug der Sozialdemokraten den Wind aus den Segeln nehmen zu können. ${ }^{123}$

Die sozialrevolutionär-liberalistischen Jahre der gebildeten bürgerlichen Schichten waren zum Zeitpunkt der Gründung des Deutschen Kaiserreichs 1871 bereits verstrichen. Ihre Hinwendung zur politischen Rechten wird quittiert durch die Unterstützung von Bismarcks antiliberalen Vorhaben (Schutzzollpolitik, Sozialistengesetz) und durch die Reichstagswahlen vom 10. Januar 1877, bei denen die Nationalliberalen herbe Verluste erlitten. ${ }^{124}$ „Liberale Bildungsbürger erfuhren diesen Richtungswechsel als gravierende Zäsur, als Angriff auf die eigene Wertewelt. ${ }^{\text {“125 }}$ Dennoch etablierte sich das deutsche Bildungsbürgertum, insbesondere während der 1880er und 1890er Jahre, zunächst als „funktionale Elite ${ }^{\text {“126 }}$. Um etwa 1900 hatte es seinen Zenit an kultureller Hegemonie $^{127}$, sozialem Prestige und materieller Saturiertheit - wenn auch dabei abseits der Sphären politischer Macht verharrend - erreicht. ${ }^{128}$ Schon in den 1870er Jahren gehörte dem gebildeten Bürgertum, so Gall über dessen Selbstwahrnehmung, „das Zeitalter, sie waren die einzig legitimen Erben der Geschichte, nur sie konnten die Zukunft erfolgreich gestalten [...]“129 Im Kaiserreich stellten die deutschen Bildungsbürger eine einflussreiche, kulturell und moralisch tonangebende Elite, die sich selbstbewusst als leistungsbasierter „Geistesadel“ verstand. ${ }^{130}$ Fritz K. Ringer bezeichnete sie nach dem Vorbild der konfuzianischen Beamtenkaste als „Mandarine“, da sie ihren Status durch Bildungszertifikate gewannen und verteidigten, nicht durch Herkunft oder käuflichen Erwerb. ${ }^{131}$ In den Worten des Historikers Rudolf Vierhaus:

123 Vgl. Schildt: Konservatismus in Deutschland, S. $109 \mathrm{f}$.

124 Vgl. Budde: Blütezeit des Bürgertums, S. $57 f$.

125 Ibid., S. 58. Ähnlich und am familienbiographischen Material Bauer: Bürgerwege und Bürgerwelten, S. 291f.: „Die Figur Heinrich Dohrns, [...] der in seiner marginalen politischen Rolle als Reichstagsabgeordneter den Verfall des Linksliberalismus durch alle Spaltungen und Umgruppierungen und immer wieder scheiternden Neuansätze mitvollzogen hat, verkörpert exemplarisch diese Überlebtheit und Unzeitgemäßheit. Im Elend des politischen Liberalismus in Deutschland spiegelt sich getreulich der Abstieg des Bürgertums, das ihn hundert Jahre zuvor als Programm seines historischen Aufbruchs formuliert hatte."

126 Vgl. Hardtwig: Auf dem Weg zum Bildungsbürgertum, S. 33.

127 Vgl. Schulz: Lebenswelt und Kultur des Bürgertums, S. 22-25.

128 In Anlehnung an Max Webers Beschreibung der chinesischen Beamtengelehrten desselben $\mathrm{Na-}$ mens bezeichnet Ringers „Mandarinentum“ im deutschen (bzw. europäischen Raum) jener Zeit „eine gesellschaftliche und kulturelle Elite [...], welche ihren Status in erster Linie ihren Bildungsqualifikationen und nicht Reichtum oder vererbten Rechten verdankt. Diese Bildungselite besteht aus Ärzten, Rechtsanwälten, Geistlichen, Staatsbeamten, Studienräten und Universitätsprofessoren." Ringer: Die Gelehrten, S. $15 f$. Vgl. Gall: Bürgertum in Deutschland, S. 408.

130 Ringer: Die Gelehrten, S. 18.

131 „Diese Bildungselite besteht aus Ärzten, Rechtsanwälten, Geistlichen, Staatsbeamten, Studienräten und Universitätsprofessoren. [...] Ihnen obliegt es, die Maßstäbe der Qualifikationen für den Eintritt in die Elite aufrechtzuerhalten, und sie fungieren als deren Sprecher in kulturellen Fragen." Ibid., S. 16. Indes ist die von Ringer herausgestrichene illiberale Prägung der von ihm so bezeichneten "Mandarine“ in der Folge mehrfach in Zweifel gezogen worden: „Denn im Rahmen eines breit angelegten Meinungsspektrums gab es eine große Anzahl sowohl sozial, liberal wie auch konservativ und national orientierter Professoren [...]“ Kraus: Kultur, Bildung und Wissenschaft, S. $29 f$. 
„Bildung und Besitz gehörten um 1900 enger zusammen als ein Jahrhundert früher; Bildung war selber zu einem ,Besitz' geworden. Man ,erwarb‘ und ,hatte Bildung; sie war eine Investition mit hoher Aussicht auf Honorierung im bestehenden politischen und sozialen System. Die Erhaltung des Besitzstandes entsprach dem sozialen Interesse der großen Mehrheit der Gebildeten so elementar, daß sie nach der politischen Niederlage des bürgerlichen Liberalismus im preußischen Verfassungskonflikt und nach seinem Zerfall im Zuge der konservativen Wende der deutschen Innenpolitik 1878 unter dem Eindruck wirtschaftlicher Depression und aus Sorge vor der sozialen Revolution zunehmend konservativer und staatsloyaler wurden. [...] Unter Berufung auf die klassisch-neuhumanistische Bildungsidee haben die humanistisch Gebildeten gegenüber denen, die eine ,nur' praktische Berufstätigkeit im Bereich von Wirtschaft und Technik anstrebten, nicht nur ihr kulturelles Prestige behauptet, sondern Exklusivansprüche für eine beträchtliche Reihe von attraktiven Karrieren aufrecht erhalten können, auch noch als die Regierungen schulische Differenzierung durchsetzen. ${ }^{\text {“132 }}$

Allerdings wurden diese bildungsbürgerlichen Schichten, die im Wilhelminismus eigentlich ein unvergleichliches Prestige genossen, von ihren jahrzehntelangen Zugpferden, der akademischen Professionalisierung und der staatlich kontrollierten Spezialisierung des Bildungswissens, doch zusehends überflügelt: Über die 1890er und 1910er hinweg machten sich die stärkere Konkurrenz durch Wirtschaftsbürgertum ${ }^{133}$, die Ausweitung von "Zahl und Bedeutung“ der Akademiker, die Akademisierung von Berufen und die Spezialisierung der Wissenschaften sowie die steigende Bedeutung der praktischen Berufsausbildung bemerkbar. ${ }^{134}$ Die wachsende industrielle Nachfrage nach qualifiziertem Personal stärkte die Rolle der Technischen Universitäten und Fachhochschulen, der Ingenieure und Naturwissenschaftler, die mithin um Gleichwertigkeit der Bildungsabschlüsse, um eigene Graduierungs- und Promotionsrechte, usw. rangen. Das hatte eine Vorgeschichte: Lange Zeit hindurch galten Absolventen der Technischen Universitäten als „halbe“ Akademiker, als bloß erwerbsorientierte „Brotstudenten“ ohne akademisch standesgemäßes „Bildungsstudium“. ${ }^{135}$ Der Zug zur Öffnung der Bildungskanäle, die beschleunigte Industrialisierung bzw. Durchkapitalisierung des Arbeitsmarkts, setzten sich schließlich gegen die Privilegiensicherungsinteressen der öffentlich Bediensteten durch. Aber das neuhumanistische „Akademikermonopol“ brach um die Jahrhundertwende schließlich zusammen: Die Technischen Universitäten des Kaiserreichs erhielten das Promotionsrecht 1899; ein Jahr später wurden sie mit den Universitäten formal gleichgestellt. Das Diplom als fakultätenübergreifender Abschluss wurde eingeführt. ${ }^{136}$ Die von bildungsbürgerlicher Seite verbissen verteidigte Supre-

132 Vierhaus: Umrisse einer Sozialgeschichte der Gebildeten, S. $411 f$.

133 Vgl. Budde: Blütezeit des Bürgertums, S. 11.

134 Ullmann: Das Deutsche Kaiserreich, S. 109.

135 Lundgreen: Zur Konstituierung des „Bildungsbürgertums“, S. $85 f$.

136 „Auf lange Zeit blieb indessen der öffentliche Dienst der weitaus wichtigste Arbeitsmarkt für Akademiker. Von daher erklärt sich die Heftigkeit des Kampfes, mit dem das 1834 errichtete Monopol des neuhumanistischen Gymnasialabiturs (für die Zulassung zu Staatsprüfungen und damit auch zu Fakultätsstudien) angegriffen wurde. Hielt man am Monopol fest, sah man sich gezwungen, das neuhumanistische Gymnasium enzyklopädisch auszuweiten (,Utraquismus'); hielt man am gymnasialen Bildungsprofil fest, dann ließ sich das Monopol auf die Dauer nicht aufrechterhalten 
matie der Geisteswissenschaften über die „praktischen“ bzw. „verwendbaren“ Disziplinen bekam so schon zur Jahrhundertwende sichtbar Risse; was einst die Kohärenz der akademischen Klasse gestiftet hatte, führte schließlich zur Herausbildung und zum Siegeszug des neuartigen technisch-instrumentellen „Leistungswissens“ und zur Zersplitterung der eigenen Reihen. ${ }^{137}$

„Das einst so hoch geschätzte humanistische Bildungsideal verflachte immer mehr zum patentierten Berechtigungswesen und taugte nicht mehr dazu, mit ihm einen gesellschaftlichen und politischen Führungsanspruch zu begründen. Die kulturelle Generalkompetenz bröckelte zusehends. ${ }^{\text {“138 }}$

So erscheint das Bildungsbürgertum des langen 19. Jahrhunderts aus heutiger Sicht als einzigartiges historisches Interimsprodukt des Übergangs von der ständischen Gesellschaft zur modernen „Leistungsgesellschaft“. ${ }^{139}$ Die damit verbundene rasche Entwertung des alten rationalistischen Wissenschaftsverständnisses durch neue empirisch motivierte Zweifel, insbesondere die Fragwürdigkeit des weltumfassenden philosophisch-wissenschaftlichen Systems, reflektiert diesen tiefreichenden Vorgang auch in wissenschaftsendogener Hinsicht. ${ }^{140}$ Doch zehrten auch wirtschaftliche Krisenerscheinungen an den gebildeten Milieus des Kaiserreichs. Der Wiener Börsenzusammenbruch, der 1873 als „großer Krach“ bzw. „große Depression“ auf den seit 1867 währenden und durch die französischen Kriegskredite ab 1871 befeuerten „Gründerboom" folgte, markierte mit seiner massenhaften Entwertung von Aktien auch schon den beginnenden Niedergang des traditionell liberalen Bürgertums, seiner Orientierungen und Werthaltungen. ${ }^{141}$ In jener Zeit verfestigten sich starke antiliberale Kräfte

gegenüber realistischen Bildungsprofilen. Die preußische Bildungspolitik verfolgte zunächst die erste Strategie, gab sie dann von 1870 ab zögernd auf, um 1900 die ,Cleichberechtigung' einzuführen und damit das Prinzip eines arbeitsteiligen Bildungspluralismus zu sanktionieren." Ibid., S. 89.

137 Vgl. Conze/Kocka: Einleitung, S. $25 f$.

138 Budde: Blütezeit des Bürgertums, S. 58.

139 „Aus diesem und anderen Cründen existierte ein einigermaßen einheitliches Bildungsbürgertum um 1900 bereits in geringerem Maße als in der Zeit des Neuhumanismus, und das 20. Jahrhundert brachte ihm weder seinen Zusammenhalt noch seine Abgrenzung zurück." Conze/Kocka: Einleitung, S. 26.

140 Dass gerade das fin de siècle mit seiner "Krise der Wissenschaften“ eine große Zahl an anspruchsvollen, provokanten, leidenschaftlich schreibenden Denkern hervorgebracht habe, ist vielfach bemerkt worden, vgl. für einen Überblick Ringer: Die Gelehrten, S. 273-329. Zu ihnen zählen einerseits Philosophen wie Friedrich Nietzsche, insbesondere Neukantianer wie Edmund Husserl, Wilhelm Dilthey und Heinrich Rickert, andererseits der Ahnherr der Psychoanalyse Sigmund Freud, aber auch Soziologen wie Karl Mannheim und Max Weber, uvm. Den epochalen Wandel, der sich im „revolutionären Bruch“ zwischen den Denkstilen Hegels und Nietzsches ausdrückt, insbesondere die irreparable Beschädigung des Systemgedankens, hat der Philosoph Karl Löwith materialreich ausgeführt in Löwith, Karl: Von Hegel zu Nietzsche. Der revolutionäre Bruch im Denken des neunzehnten Jahrhunderts [1941], Stuttgart 1958, hier in Bezug auf die Unabgeschlossenheit geschichtlicher Widersprüche insbesondere S. 193-198. Inwieweit sich gesellschaftliche Krisenerscheinungen solcherart in bewundernswerte Denkleistungen übersetzten, ist zwar eine mehr als lohnende Frage, die hier allerdings zu weit von der thematischen Zielsetzung wegführt.

141 Vgl. Winkler: Der lange Weg nach Westen, S. 226-236 sowie Ullmann: Das Deutsche Kaiserreich, S. 68-85. 
in den Rängen der deutschen Mittelschichten, die dem wilhelminischen Bildungsbürgertum sukzessive ein konservativ-kaisertreues Gepräge gaben; die Nationalliberalen verloren bei den Wahlen deutlich gegen Zentrum und großgrundbesitzende Konservative; ${ }^{142}$ der moderne Antisemitismus als politische Kraft wurzelte genau hier ${ }^{143}$ und in direktem Zusammenhang mit der Genese eines „neue[n] Typus des deutschnationalen und völkischen Akademikers" im Zuge des verschärften Bildungswettbewerbs der 1890er Jahre. ${ }^{144}$

Universität und Studium durchlebten in der zweiten Hälfte des 19. Jahrhunderts eine Welle von Umstrukturierungen auf dem Weg in die Industriegesellschaft, vor allem aber ein starkes infrastrukturelles Wachstum und eine zunehmende gesellschaftliche Bedeutung als Kaderschmiede einer öffentlich bediensteten Akademikerschicht und zugleich als Ausbildungsstätte von Fachkräften für neue Arbeitsmarktsegmente. ${ }^{145}$ Die Bevölkerung wuchs zwischen 1890 und 1913 von 49 auf 67 Millionen $^{146}$, die Studentenzahl expandierte von rund $18.000 \mathrm{im}$ Jahr 1869 über rund $34.000 \mathrm{um} 1891$ auf rund 66.000 um 1909 bzw. rund 72.000 um 1912, was einer Vervierfachung gleichkommt. ${ }^{147}$ Eine große Zahl ausländischer Studierender drängte an die populären deutschen Universitäten; ab 1894 und 1908 auch verstärkt die zunächst partiell, dann voll zugelassenen jungen Frauen. ${ }^{148}$ Der Blick auf die akademischen Zielberufe fördert zunächst Widersprüchliches zutage: Bis etwa 1880 nahm der wachsende Arbeitsmarkt viele Hochschulabsolventen auf, insbesondere im unteren Schulwesen mangelte es an Lehrkräften während sich auf der anderen Seite im höheren Schulwesen bereits die nächste Überfüllungskrise ankündigte. ${ }^{149}$ Die verhängnisvollen Prozesse der $1780 e r$ und 1830er Jahre wiederholten sich in den $1880 e r$ Jahren: Der, wenn auch rasch gewachsene, Arbeitsmarkt für Hochschulabsolventen füllte sich durch den Zustrom Studierender rasch; graduierte Anwärter auf den Staatsdienst mussten in der zweiten Hälfte der Dekade im Schnitt fünf bis sieben Jahre auf eine Anstellung warten. ${ }^{150}$ Infolge des „erwachenden sozialen Bewußtseins" gerieten der Zustand der Akademiker wie die soziale Schichtung der Studentenschaft bzw. die „Klassenbedingtheit“ der Bildungschancen zu Fragen des öffentlichen Interesses und der sozialpolitischen Steuerung, nicht zuletzt wegen der Furcht vor potenziell umstürzlerischen blockierten Akademikern bzw. einem „akademischen Proletariat“. ${ }^{151}$ Die sich ausbreitende Hebung des Lebensstandards ließ die sozialemanzipative Umschichtung des Studierens erst recht als träge, gerade$\mathrm{zu}$ hinter den Möglichkeiten der Zeit hinterherhinkend, erscheinen. 1886/87 entstand

142 Vgl. Ullmann: Das Deutsche Kaiserreich, S. 60-68.

143 Vgl. Winkler: Der lange Weg nach Westen, S. 226-236. Mehr zu den politisch-weltanschaulichen Umwälzungen dieser Zeit in Kapitel II.2.1 dieser Studie.

144 Vgl. Titze: Bildungskrisen und sozialer Wandel, S. 355.

145 Vgl. Ringer: Die Gelehrten, S. 54.

146 Vgl. Ullmann: Das Deutsche Kaiserreich, S. 105.

147 Entnommen aus Conze: Ereignisse und Entwicklungen, S. 109. Jarausch führt in Deutsche Studenten, S. 72, abweichende Zahlen an und spricht gar von einer Verfünffachung der absoluten Studentenzahlen.

148 Vgl. Jarausch: Deutsche Studenten, S. 73.

149 Vgl. Titze: Bildungskrisen und sozialer Wandel, S. 353.

150 Vgl. Jarausch: Deutsche Studenten, S. 74.

151 Vgl. ibid., S. 71. 
aus diesem Gärungsprozess die Preußische bzw. reichsweite Universitätsstatistik. ${ }^{152}$ Sozialpolitisch aber wusste man die gewonnenen Erkenntnisse nicht in eine wirksame Administration umzusetzen. Im Wilhelminismus konsolidierte sich nicht nur die höhere Schulbildung, es verselbstständigte sich überdies das Bildungssystem aufgrund der knapp ein Jahrhundert zuvor initiierten bürokratischen Steuerung der Bildungsrekrutierung: die Eigendynamik des Bildungssystems entzog sich fortan der Verfügung durch den Staat: „Eine erfolgreiche herrschaftliche Steuerung des Bildungsbedarfs war im Kaiserreich nicht mehr möglich.“153 Die traditionelle Politik der „Verknappung des Bildungsangebots“154 durch die Verengung von Hochschulzugangsberechtigungen, Gebührenerhöhung und Verschärfung der Prüfungsordnungen scheiterte daher an der unkontrollierbar gestiegenen Volatilität der Expansions- und Überfüllungsdynamiken, die schon in den 1890ern wiederum zu einem breiten Mangel, mithin einem neuerlichen Ansturm führten - und wurde innerhalb weniger Jahre fallen gelassen. ${ }^{155}$ Auf diejenigen, die sich mit der Hoffnung auf eine Karriere als Verwaltungsbeamte, Professoren, Ärzte, Richter, Pfarrer oder Lehrer immatrikulierten, und die infolge der steigenden Verschulung von Bildungswegen zu Beginn ihres Studiums meist bereits das 20. Lebensjahr erreicht hatten, wirkte all das desorientierend: „Bei den Studenten selbst wechselten Wachstumseuphorie und Zukunftsangst, je nach den Berufsaussichten des ausgewählten Studienfachs, einander ab. “156

Zukunftsweisend war schon in den Jahren der Hohenzollern-Monarchie die soziale Umschichtung des Studiums. Was von Anfang an als bildungspolitisches Ziel seit den neuhumanistischen Hochschulreformen ausgerufen war, nämlich die Kopplung akademischer Karrieren „an eine universalistische Leistungsauslese“ ${ }^{157}$ wurde aufgrund der oben beschriebenen industriegesellschaftlichen Modernisierungsdynamiken mehr und mehr zur soziostrukturellen Realität. Sowohl das Besitzbürgertum als auch das aufstiegsorientierte Kleinbürgertum drängten in die akademischen Berufe:

„Entwicklungen, die sich in dem Vormärzboom andeuteten, setzten sich nun endgültig durch. Das Resultat war ein doppeltes Muster der weiterbestehenden Privilegierung der Oberschichten (mit einer inneren Umverteilung) und einer begrenzten sozialen Öffnung für die unteren Mittelschichten, so daß auch sie nach 1900 überrepräsentiert waren. ${ }^{\text {1158 }}$

Grundzüge des modernen Massenstudiums zeichneten sich hier also ab. ${ }^{159}$ Trotzdem kann hier von einem „Einbruch der Massen“, gar von einer „Demokratisierung“ des Studiums noch keine Rede sein: Der Rückgang der traditionellen Akademikerkinder, also

152 Vgl. Titze: Bildungskrisen und sozialer Wandel, S. $353 \mathrm{ff}$.

153 Titze: Wie wächst das Bildungssystem?, S. 113. Vgl. auch Titze: Von der natürlichen Auslese zur Bildungsselektion 1780 - 1980. Argumentationsmuster und Bilanz einer zweihundertjährigen Diskussion, in: Zeitschrift für Pädagogik, 42. Jahrgang, H. 3/1996, S. 389-406 hier S. 389 und 403 f. Vgl. Titze: Die zyklische Überproduktion von Akademikern, S. 116.

155 Vgl. Jarausch: Deutsche Studenten, S. 75.

156 Ibid.

157 Vgl. Titze: Die zyklische Überproduktion von Akademikern, S. 116. (Herv. i. O.)

158 Ibid.

159 Vgl. Wipf, Hans Ulrich: Studentische Politik und Kulturreform. Geschichte der FreistudentenBewegung 1896-1918, Schwalbach/Taunus 2004, S. 27, 124f. 
der klassischen „Bildungselite“ unter den Studierenden von 35 Prozent auf 20 Prozent zwischen 1870 und 1911 und das weitgehende Verschwinden von Aristokratenkindern wurde flankiert von nunmehr 20 Prozent Lehrer- und niederer Beamtensprösslinge, 23 Prozent Kindern kleinerer selbstständiger Gewerbetreibender, 10-15 Prozent Nachkommen von Gutsbesitzern und Landwirten, 12 Prozent Erben von großindustriellen Unternehmern, nur zwei Prozent entstammten Arbeiter-, drei Prozent niederer Angestelltenfamilien. ${ }^{160}$ Insofern mag es angemessener erscheinen, wie Ringer von einer „Plutokratisierung“ bzw. einer „unternehmerischen“ Überformung des Studiums zu sprechen. Ebenso unabweisbar aber kulminierten diese Entwicklungen um die Jahrhundertwende in einem faktischen Ende der bildungsbürgerlichen Selbstrekrutierung. ${ }^{161}$ Während die Juristen- und Ärztelaufbahnen vergleichsweise exklusiv blieben (erstere eher jung, urban, protestantisch, letztere eher älter, provinzieller, zudem katholisch oder jüdisch), entwickelten sich die Philosophischen Fakultäten, die zunehmend auch naturwissenschaftliche und praktische Berufe wie Landwirte, Apotheker usw. ausbildeten, ${ }^{162}$ zum „sozialen Schmelztiegel der Universität“ und zum wesentlichen Motor der Bildungsexpansion. ${ }^{163}$ Und das schlug sich auch sozialpsychologisch nieder, nämlich als „Furcht“, „daß ,die Massen sich anschickten, die Institutionen des höheren Bildungswesens zu überschwemmen und die traditionellen Standards der Bildung zu bedrohen. ${ }^{\text {“164 }}$

Zwei zentrale Aspekte der Transformation von Studienrekrutierung und Studienerwartungen bzw. Berufszielen der Jahre zwischen Gründung des Kaiserreichs 1871 und dem Ausbruch des Ersten Weltkriegs 1914 sind in diesem Zusammenhang hervorzuheben: Erstens verwandelten sich auch freiwirtschaftliche Arbeitgeber zunehmend in durchbürokratisierte Großunternehmen, die dieselben zertifikatsbasierten Zugangsvoraussetzungen übernahmen, die sich zuerst im öffentlichen Dienst etabliert hatten ${ }^{165}$ - trotz aller damit verbundenen sozialen Hierarchisierung war somit der nächste große Schritt in Richtung einer qualifikationsbasierten Wettbewerbs- und Leistungsgesellschaft getan. Zweitens führte, diesen Modernisierungsschub konterkarierend, der immer engmaschiger vibrierende Zyklus von Mangel - Überfüllung - Mangel nicht nur zu einer breiteren sozialen Aufstellung der Studierendenschaft, sondern auch zu einem Ausbau der Aufstiegsschranken, versuchten die erfolgreich Aufgestiegenen doch, die Zugangsvoraussetzungen für die Nachrücker zu verschärfen. Bald war für die höheren Positionen etwa bei der Deutschen Reichspost ein juristisches Staatsexamen notwendig, nicht mehr nur das zuvor hinreichende Abitur. ${ }^{166}$ Insgesamt "ging es weiter um Berufsvererbung, Statussicherung und begrenzten Aufstieg ${ }^{\text {“167 }}$ in den Rängen eines

160 Vgl. zu den Zahlen und Stichworten Ringer: Die Gelehrten, S. 6of.

161 Vgl. Jarausch: Deutsche Studenten, S. 78.

162 Vgl. ibid., S. 131.

163 Vgl. ibid., S. 79.

164 Ringer: Die Gelehrten, S. 61 (Herv. i. O.)

165 Vgl. Jarausch: Deutsche Studenten, S. $67 f$.

166 „Besonders die Studenten aus dem Kleinbürgertum, die den Aufstieg in einen Akademikerberuf geschafft hatten, waren daran interessiert, ihren neu errungenen Status gegen andere nachdrängende Studenten abzusichern. Das konnte vor allem durch die Ausweitung des bereits bestehenden Berechtigungswesens geschehen, das bestimmte Bildungspatente als Eingangsvoraussetzungen für gewisse Berufslaufbahnen verlangte." Ibid., S. 80. 
konsolidierten, politisch wie ökonomisch emanzipierten Bürgertums, das sich jedoch zunehmend der politischen und moralischen Verantwortung entzog: Als „Idealbild des deutschen Bürgers“168 in der von imperialistischem Militarismus und einer Konzentration auf wirtschaftlich-industrielles Wachstum wie politische Stabilität geprägten wilhelminischen Ära ${ }^{169}$ galt der charakterlich robuste Reserveoffizier (ein kostspielig zu erlangender Tite $^{170}$ ), und dementsprechend war auch der ideale deutsche Akademiker keineswegs der verantwortungsbewusste oder kritische Intellektuelle, auch nicht der liberaldemokratische Bursche, sondern der politisch im Grunde reaktionäre, ja avantgardistisch antisemitische ${ }^{171}$ Korpsstudent mit elitärer Anspruchshaltung. ${ }^{172}$ Besonders wichtig für eine aussichtsreiche akademische Karriere war daher nicht zuletzt das Netzwerken von Gutsituierten: Die Strukturen der aus der Burschenschaftsbewegung hervorgegangenen elitären Korporationen gerieten zum elementaren Vehikel der Elitenrekrutierung bzw. der „Statussicherung“, verlangten sie von ihren Mitgliedern doch schon während des Studiums hohe zeitliche und finanzielle Aufwände, sodass eine zumindest bessergestellte soziale Herkunft Grundvoraussetzung der Mitgliedschaft war. ${ }^{173}$ Auch, wenn durchaus korpskritische und liberale bis sozialistische Formationen mit niedrigeren Beitrittshürden - wie die Freistudentenschaft - auftraten: Etwa die Hälfte der Studierenden im Kaiserreich war korporiert, zwei Drittel von ihnen akzeptierten das traditionelle Duell als Satisfaktionsprinzip. ${ }^{174}$ So „refeudalisierte“ sich ein großer Teil der Studentenschaft in sozialstruktureller, äußerlicher (Sitten und studentische Subkultur, Kleidung, hierarchische Organisationsform) als auch in mentaler Hinsicht. ${ }^{175}$ Allerdings: Ein ursprünglich zentraler Faktor, die protestantische Konfessionszugehörigkeit, scheint sich, beginnend mit dem Zustrom katholischer Studenten im Kaiserreich, weitgehend nivelliert zu haben. ${ }^{176}$

168 Vgl. Studier, Manfred: Der Corpsstudent als Idealbild der Wilhelminischen Ära, Erlangen 1965, S. $\mathrm{Vf}$.

169 Vgl. Ullmann: Das Deutsche Kaiserreich, S. 37-38 und 95-117.

170 Vgl. Budde: Blütezeit des Bürgertums, S. $94 \mathrm{f}$.

171 Vgl. Kampe, Norbert: Studenten und „Judenfrage“ im Deutschen Kaiserreich. Die Entstehung einer akademischen Trägerschicht des Antisemitismus. Kritische Studien zur Geschichtswissenschaft, Bd. 76, Göttingen 1988, S. 111-124.

172 „Erst in der Rückschau erkennen wir am Beispiel des Corpsstudenten die Kluft in der politischen und gesellschaftlichen Verfassung des wilhelminischen Deutschlands und das Anachronistische dieses studentischen Typs, der in Wahrheit rückwärts gewandt war. [...] Politische Freiheiten, persönliche und nationale Sicherheiten, gesellschaftliches Prestige und finanzieller Reichtum wurden kaum noch als Verpflichtung verstanden, sondern als selbstverständlich hingenommen."Ibid., S. 310f. Vgl. außerdem Kampe, Norbert: Studenten und „Judenfrage“ im Deutschen Kaiserreich. Die Entstehung einer akademischen Trägerschicht des Antisemitismus. Kritische Studien zur Ceschichtswissenschaft, Bd. 76, Göttingen 1988, S. 111-124.

173 Vgl. ibid., S. 310f., ferner Jarausch: Deutsche Studenten, S. 67f. und Wipf: Studentische Politik und Kulturreform, S. 28-31.

174 Vgl. Wipf: Studentische Politik und Kulturreform, S. 28f. und S. 229.

175 Vgl. ibid., S. 28-31.

176 Dass bedeutet gleichwohl nicht, dass ein strukturbildender Einfluss des protestantischen Elements der bildungsbürgerlichen Traditionslinien für Einstellungen und Deutungsmustern heutiger Studierender auszuschließen ist. 
Der Erste Weltkrieg sollte dem langen bürgerlichen Jahrhundert, dem „großartige[n] Bauwerk der Zivilisation des 19. Jahrhunderts“, in politischer, kultureller, sozialer, wirtschaftlicher und sozialpsychologischer Hinsicht ein Ende setzen. ${ }^{177}$ In diesen Krieg, dessen Zäsurcharakter für die europäische und weltweite Geschichte kaum überschätzt werden kann, zog die Mehrheit der deutschen Akademiker und Studenten entweder als Frontsoldaten oder als hochschulpolitisch und agitatorisch umtriebige Kriegsunterstützer mit; die langen der Jahre Beschwörung des nationalen Primats führten zu einem Bündnis aus „Waffen und Wissenschaft“. ${ }^{178}$ Für die allgemeine politische Entwicklung, für den Wertekompass der (Bildungs-)Bürger und insbesondere für das Verbindungsleben und das Verhältnis der Studierenden zur Politik hatten sowohl die Phase der Mobilisierung als auch der desaströse Kriegsverlauf enorme Konsequenzen. ${ }^{179}$ Für die Universitäten bedeuteten die Kriegsjahre in erster Linie eine erdrückende ökonomische und moralische Belastung bis hin zum Stillstand des Lehrbetriebs und des Verbindungswesens; Frontdienst, Hilfsdienst und Lebensmittelknappheit hielten sowohl Lehrende als auch Lernende in Schach. ${ }^{180}$ Insgesamt verbrachte ein Drittel (1914) bzw. zwei Drittel (1918) dieser Studentengeneration ihre Jugend an den Fronten des Weltkriegs, ein Fünftel von ihnen fiel. ${ }^{181}$ Das darauffolgende gestiegene numerische Gewicht studierender Frauen veränderte den Charakter des Studiums in den Weimarer Jahren nachhaltig. ${ }^{182}$

\section{II.1.3 Entprivilegierung der Gebildeten in langen Krisenjahren: 1918-1945}

Das Jahr 1918 brachte nicht nur die Kriegsniederlage, sondern noch zwei weitere historische Ereignisse: einerseits die rätekommunistische Novemberrevolution mit ihrem Zentrum in Bayern unter Kurt Eisner (USPD) ${ }^{183}$ - ein zeitgeschichtlich wenig präsentes, da im Vergleich zum Ausbruch des Ersten Weltkrieges 1914 oder zur russischen Februarrevolution 1917 kaum mit Jubiläen bedachtes Ereignis ${ }^{184}$-, andererseits die Ab-

177 Vgl. Hobsbawm: Das Zeitalter der Extreme, S. 38.

178 „Das häufig beschriebene und von heute aus ungläubig bestaunte Engagement der Gelehrten und Studenten zugunsten der Kriegführung kam keineswegs überraschend, sondern war das Ergebnis langer mentaler Vorbereitung: In der Schule hatten im späten Kaiserreich Aufgewachsene zum Kaisergeburtstag häufiger den ,Sang an Aegir' gehört, den der Kaiser selbst gedichtet und komponiert hatte. [...] Wie zahlreiche Äußerungen aus der Kriegszeit belegen, erfüllte der Zusammenklang ,Waffen und Wissenschaft' die Angehörigen der Universitäten über (fast) alle politischen Grenzen hinweg. Studenten und auch Lehrende mußten also zu Kriegsbeginn nicht mobilisiert werden, sondern sie wurden von sich aus aktiv, meldeten sich freiwillig, denn , Heer und Volk' waren ,eins' [...]“ Maurer: „... und wir gehören auch dazu“, S. 1129 und 1131.

179 Mehr dazu weiter unten in Kapitel II.2.1.

180 Vgl. Jarausch: Deutsche Studenten, S. 106-115 sowie Maurer: „... und wir gehören auch dazu“, S. 18 und 898-975

181 Vgl. Jarausch: Deutsche Studenten, S. 109f. sowie Maurer: „... und wir gehören auch dazu“, S. 322324.

182 Vgl. Maurer: „... und wir gehören auch dazu“, S. 17, 440 ff. und 1027-1033.

183 Möller, Horst: Die Weimarer Republik. Eine unvollendete Demokratie, München 2004 [ursprgl. 1985], S. 321

184 Vgl. Quinn-Judge, Paul: Die Revolution, die keine war, in: Merkur. Gegründet 1947 als Deutsche Zeitschrift für Europäisches Denken. 72. Jahrgang, H. 831/2018, Stuttgart 2018, S. 50-60. 
dankung des Kaisers und die Ausrufung der Weimarer Republik durch Philipp Scheidemann (SPD) in Berlin. ${ }^{185}$ Auch das darauffolgende Jahr war ereignisreich: Im Januar 1919 organisierte die USPD zusammen mit einigen Kommunisten den „Spartakusaufstand" in Berlin, am 15. Januar wurden Rosa Luxemburg und Karl Liebknecht (KPD) ermordet, im Februar Kurt Eisner, schließlich zwangen die Freikorps im Mai die Münchener Räterepublik in die Knie, und am 11. August wurde die Weimarer Verfassung verabschiedet. ${ }^{186}$ Deutschland blieb nach dem - zur narzisstischen Kränkung Vieler verlorenen und mit den schmachvollen Friedensbedingungen von Versailles beendeten - Krieg zwar weiterhin verfassungsgemäß ein Deutsches Reich, fortan aber in der Staatsform einer deutschen Bundesrepublik, genauer: einer föderalen und präsidialen parlamentarischen Demokratie. Die vormaligen sozialdemokratischen „Reichsfeinde“ traten in diesen konstitutiven Monaten und Jahren als Hüter der gefährdeten staatlichen Ordnung auf, gewannen bei den ersten Wahlen den größten Stimmenanteil und stellten mit Friedrich Ebert als erstem Reichskanzler - sowie ab 1919 erstem Reichspräsidenten - erstmals den Regierungschef. ${ }^{187}$ Die sozialdemokratisch-koalitionär regierte liberale Staatsform ${ }^{188}$ führte nicht nur zu einer Vertiefung des Schismas innerhalb der politischen Linken, insbesondere zwischen SPD und USPD bzw. SpartakusBund, welche auf einen sozialistischen Volksstaat hinauswollten, sie vertiefte auch die Distanz großer Teile der bürgerlichen Mittelschichten und der konservativen Monarchisten zur Demokratie ${ }^{189}$ - auch wenn der „Bürgerblock“ ab 1923, zeitweise mit der deutschnationalen DNVP koalierend, das Ruder übernommen hatte. ${ }^{190}$ Das reine Verhältniswahlrecht begünstigte die parlamentarische Partikularisierung der politischen Kräfteverhältnisse. ${ }^{191}$ Große Teile der deutschen Bevölkerung, auch viele grundsätzlich demokratisch gesinnte, empfanden die neue Republik nicht als "die ihre“, ${ }^{192}$ und auch die Verfassungsarchitektur, die dem vergleichsweise starken Reichspräsidenten das Erlassen von Notverordnungen gestattete, zeigte sich den wirtschaftlichen Krisen und der konfrontativen politischen Polarisierung folgenden 14 bzw. 15 Jahre, insbesondere der paramilitärischen Straßenschlachten zwischen Freikorps, Rotem Frontkämpferbund, Schwarzer Reichswehr, SA, Stahlhelm u. a. ${ }^{193}$ nicht gewachsen; so erscheint die Weimarer Republik in der Retrospektive als tragische instabile Konstruktion ohne gefestigtes politisch-kulturelles Fundament, mithin als „unvollendete Demokratie“194 , ja als „kaum

185 Vgl. Möller: Die Weimarer Republik, S. 321.

186 Vgl. ibid. Bezeichnenderweise waren ausgerechnet die just in Regierungsverantwortung gelangten Sozialdemokraten maßgeblich an der Niederschlagung der Revolution beteiligt, vgl. dazu jüngst die leidenschaftliche Dokumentation bei Gietinger, Klaus: November 1918. Der verpasste Frühling des 20. Jahrhunderts, Hamburg 2018, S. 159-201. Vgl. Hermand, Jost/Trommler, Frank: Die Kultur der Weimarer Republik, München 1978, S. 14-19. Vgl. Rosenberg, Arthur: Geschichte der Weimarer Republik, Frankfurt a.M. 1961, S. 5.

189 Vgl. zur Schwäche der demokratischen „Mitte“ in der Weimarer Republik die anschauliche Skizze in Sontheimer, Kurt: Antidemokratisches Denken in der Weimarer Republik. Die politischen Ideen des deutschen Nationalismus zwischen 1918 und 1933, München 1978, S. 306-316.

190 Vgl. Hermand/Trommler: Die Kultur der Weimarer Republik, S. 14-19.

191 Vgl. Möller: Die Weimarer Republik, S. 84-86.

192 Hermand/Trommler: Die Kultur der Weimarer Republik, S. 19. Vgl. außerdem Möller: Die Weimarer Republik, S. 8.

193 Vgl. Rosenberg: Geschichte der Weimarer Republik, S. 125-155.

194 Möller: Die Weimarer Republik, S. 218. 
mehr [...] als ein geschlagenes Kaiserreich minus Kaiser“ ${ }^{195}$ Angesichts der zahlreichen „existenzbedrohenden kriegsbedingten Hypotheken“ wäre es aus Sicht auch jener Historiker, die auf die bemerkenswerten Leistungen der Weimarer Demokratie pochen, ohne Weiteres möglich, die Geschichte der Jahre 1918 bis 1933 „,ausschließlich unter dem Aspekt“ von „Vorbelastungen und Schwächen“ dieser neuen Republik zu schreiben. ${ }^{196}$

Eine Rückkehr zur Vorkriegs-Normalität war auch den bildungsbürgerlichen Eliten nicht mehr möglich. Bereits nach der Reichseinigung 1871 und nach der „Großen Depression“ im Gefolge von 1873 verschoben sich die Verhältnisse drastisch. Das Standesbzw. Klassenbewusstsein der bildungsbürgerlichen Schichten musste schon in den Jahrzehnten bis zum Ausbruch des Ersten Weltkrieges mehrere Schläge verkraften: Finanzkapital wurde massenhaft entwertet, was viele um ihr erspartes und ererbtes Vermögen brachte; zudem kollidierte der neue Reichsnationalismus nach der ,inneren Reichsgründung“ der 1880er Jahre mit dem politisch-moralischen Koordinatensystem des ohnehin unterlegenen liberalen Teils dieser immer noch kulturell deutungskräftigen Sozialformation. Vom Versuch parlamentarischer Einflussnahme hatte sich das Bildungsbürgertum weitgehend zurückgezogen, blieb es von den kaiserlichmilitärischen Entscheiderkreisen ohnehin ausgeschlossen. Im Grunde sind schon in jenem Zeitraum der 1880er, als die deutschen Bildungsbürger sich im Kaiserreich zur saturierten Bildungselite der „deutschen Mandarine ${ }^{\text {“197 }}$ zusammenschlossen, die Erosionstendenzen angelegt gewesen, die ihnen schließlich die wirtschaftliche und sozialmoralische Grundlage entziehen sollten. Die Hyperinflation der Reichsmark in den frühen und die Auswirkungen der Weltwirtschaftskrise in den späten 1920er Jahren schließlich vernichteten geradezu die traditionsschweren ökonomischen Grundlagen des deutschen Bürgertums:

„Erstens zerstörte sie Sparguthaben, entwertete Renten und bereicherte Kreditnehmer auf Kosten von Cläubigern. [...] Zweitens benachteiligte die Inflation die Arbeitnehmer und half den Arbeitgebern, da Löhne und Cehälter hinter den sprunghaft nach oben schnellenden Lebenshaltungskosten zurückblieben. Lohnempfänger und leitende Angestellte der großen Industriekonzerne waren verhältnismäßig gut in der Lage, sich gegen diesen Trend zu schützen, während Arbeitnehmer im öffentlichen Dienst, Freiberufler und Angestellte in den weniger dynamischen Sektoren der Wirtschaft seine hilflosen Opfer waren. Drittens traten bei routinemäßigen geschäftlichen Transaktionen Verluste auf. [...] Insgesamt brachte also die Inflation besonders jenen sozialen Gruppen den ökonomischen Ruin, die im Zeitalter rascher Industrialisierung bereits benachteiligt waren. Sie stärkte in der Tat die neuen unternehmerischen und technischen Eliten, und ihre verheerendsten Auswirkungen konzentrierten sich auf die beiden ältesten Teile der traditionellen Mittelschicht: auf die Rentiers, Beamten, Freiberufler und akademisch Gebildeten einerseits sowie auf die Handwerker, Ladenbesitzer und kleinen Angestellten andererseits. ${ }^{\text {“198 }}$ 
Insbesondere für die Professorenschaft der Universitäten und für die höheren Beamten ergab sich die widersprüchliche Situation eines persistenten sozialen Prestiges bei gleichzeitig „dahinschmelzendem“ Einkommen und sinkenden Gehaltsdifferenzen zu ungelernten Arbeitern - sodass sie sich angesichts ihres standesgemäßen „aufwendigen Lebensstil[s] [...] schwertaten, nicht über ihre Verhältnisse zu leben. ${ }^{199}$ Plötzlich lebte man „in einer verkehrten Welt, in der ein Facharbeiter mehr verdiente als ein hoher Staatsbeamter.“200 Dem Bildungsbürgertum fiel es dadurch zunehmend schwerer, dem eigenen Nachwuchs das Studium zu finanzieren. ${ }^{201}$ So vertieften sich, auch im zeitgenössischen Bewusstsein, die sozialen Kluften, die sich bereits in der Klassengesellschaft des Kaiserreichs um die Jahrhundertwende herausbildeten, weiter: „Die Inflation setzte einfach den sozialen Wandel fort, der bereits mit dem industriellen Boom des ausgehenden 19. Jahrhunderts begonnen hatte; doch sie beschleunigte ihn weit genug, um ihn als Revolution erschienen [sic] zu lassen. ${ }^{202}$ Dem Bildungsbürgertum wurde unmissverständlich klar, dass das anbrechende zwanzigste Jahrhundert immer weniger mit dem vertrauten und bekannten bürgerlichen Zeitalter gemein haben würde. Rechts zog der imperialistische Furor an ihnen vorbei, links die sozialistische Agitation, die ihnen die Fackel des Fortschritts abgenommen hatte. Aus der Sicht der begriffspuristischen Interpretationsschulen in den Geschichtswissenschaften löste sich das „eigentliche“ Bildungsbürgertum daher bereits zum Kriegsausbruch 1914 auf, „als sein Zerfall schon längst eingesetzt hatte, ohne daß es jedoch als historische Sozial-

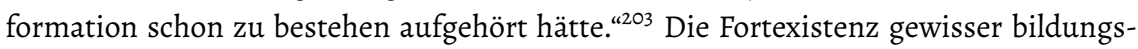
bürgerlicher oder Gebildeten-Milieus über den Verlust der „bürgerlichen Vorrangstellung“204 hinaus wird damit wohlgemerkt nicht bestritten.

Für breite Teile der Studierendenschaft wurde das Studieren zum Existenzkampf: Viele lebten wegen des Wegfalls elterlicher Finanzierung in materiellem Elend unterhalb des Existenzminimums ungelernter Arbeiter, brachten kaum mehr die Mittel für die notwendigsten Bedarfsartikel auf; Tuberkulose-Infektionen grassierten unter vielen unterernährten Jungakademikern. ${ }^{205}$ Ein Drittel bis die Hälfte der Studierenden der unmittelbaren Nachkriegszeit waren unterernährt und lebten in katastrophalen Wohnsituationen, etwa ein Drittel blieb auch die zwanziger Jahre hindurch chronisch „proletarisiert“. ${ }^{206}$ In diese Zeit fällt ein Ausbau der studentischen Selbsthilfe, insbesondere der studentischen Wohnheime und Mensen und des Werkstudententums; ${ }^{207}$ während der Inflationsphase und der „Großen Depression“ musste sich die Mehrheit als Werks-

199 Vgl. ibid.

200 Schulz: Lebenswelt und Kultur des Bürgertums, S. 30.

201 Jarausch, Konrad H.: Die Krise des deutschen Bildungsbürgertums im ersten Drittel des 20. Jahrhunderts, in: Kocka, Jürgen (Hg.): Bildungsbürgertum im 19. Jahrhundert. Teil IV: Politischer Einfluß und gesellschaftliche Formation, Stuttgart 1989, S. 180-205, hier S. 192.

202 Ibid., S. 63.

203 Wehler: Deutsches Bildungsbürgertum, S. 215.

204 Schulz: Lebenswelt und Kultur des Bürgertums, S. 30.

205 Vgl. Kater, Michael H.: Studentenschaft und Rechtsradikalismus in Deutschland 1918-1933. Eine sozialgeschichtliche Studie zur Bildungskrise in der Weimarer Republik, Hamburg 1975, S. 43-56.

206 Vgl. Jarausch: Deutsche Studenten, S. 142.

207 Vgl. Kater: Studentenschaft und Rechtsradikalismus, S. 48f. und 56f. 
studierende verdingen, d. h. ihren Lebensunterhalt durch Nebenarbeit sichern. ${ }^{208}$ Zwar ließen Klassen- bzw. Schichtendifferenzen die soziale Lage der Studierenden stark auseinanderfallen. ${ }^{209}$ Doch der Historiker Michael H. Kater betont am Beispiel der „Wirtschaftshilfe der Deutschen Studentenschaft e. V.“, ab 1929, also nach der Inflationskrise, „Deutsches Studentenwerk e. V.“ genannt, die Angewiesenheit der Mehrheit der Studierenden auf soziale Fürsorge, die dem originären Selbsthilfe-Gedanken letztlich zuwiderlief. ${ }^{210}$ Die soziale Verbitterung bzw. kollektive Kränkung, die dieser tiefe Fall großer Teile des gebildeten Milieus hinterließ, sollte tief in die Mentalität der deutschen Studierendenschaft einsickern und schließlich ihre Hinwendung zu völkischer Agitation maßgeblich begünstigen. ${ }^{211}$

Andererseits löste sich durch die fortgesetzte Bildungsexpansion und die Entwicklung hin zur modernen Massenuniversität gerade dieses Milieu in den Weimarer Jahren zugleich auf. Entscheidende Tendenzen, die in den 1860er Jahren ihren Anfang nahmen und sich im Kaiserreich zeitweise konsolidierten, sollten bis 1930 weiter anhalten; in wirtschaftlicher und sozialer Hinsicht brachten die Weimarer Jahre eine weitere Kaskade von Modernisierungsschüben für die deutsche Gesellschaft. Mehr und mehr Berufszweige wurden akademisiert, die akademische Ausbildung selbst professionalisiert, naturwissenschaftliche und technische Disziplinen gewannen an Bedeutung. ${ }^{212}$ Zwischen 1914 und 1921 stieg die Studierendenzahl an Universitäten trotz der Konskription von rund 60.000 auf rund 87.000, ein Wachstum von 44 Prozent. Bis 1925/26 ging sie auf rund 58.000 zurück, um bis 1931 wieder auf rund 104.000 (mit den technischen Hochschulen zusammengerechnet rund 138.000) anzusteigen; wie im Kaiserreich konzentrierten auch hier die Philosophischen Fakultäten mit ihrem Reichtum an Studi-

208 Vgl. ibid., S. 145. Zu den Auswirkungen dieser Erfahrungen auf das politische Denken und Verhalten der Studierendenschaft vgl. Kapitel II.2.3 dieser Studie.

209 „Während das wohlhabende Drittel der Studierenden im wilhelminischen Stil weiterhin auf großbürgerlichem Fuße lebte und ein mittleres Drittel sich mit Sparsamkeit durchschlug, fühlte sich das notleidende Drittel von Staat und Gesellschaft verlassen." Jarausch: Deutsche Studenten, S. 145.

210 Vgl. Kater: Studentenschaft und Rechtsradikalismus, S. 56. Vgl. auch Schwarz, Jürgen: Studenten in der Weimarer Republik. Die deutsche Studentenschaft in der Zeit von 1918 bis 1923 und ihre Stellung zur Politik, Berlin 1971, S. 77, Fn. 63.

211 Vgl. ibid., S. 95-109. Warum die aus diesen Kränkungserfahrungen resultieren politischen Energien nicht in politisch linke Kanäle fließen konnten, wird in Kapitel II.2.3 dieser Studie ausgeführt.

212 Vgl. McClelland, Charles E.: Professionalization and Higher Education in Cermany, in: Jarausch, Konrad (Hg.): The Transformation of Higher Learning 1860-1930: Expansion, Diversification, Social Opening and Professionalization in England, Germany, Russia and the United States. HistorischSozialwissenschaftliche Forschungen. Quantitative sozialwissenschaftliche Analysen von historischen und prozeß-produzierten Daten Bd. 13, Stuttgart 1982, S. 306-320. Anhand der Spezifika der deutschen Entwicklung wurde mehrfach die These eines antiwestlichen bzw. antiliberalen „Sonderwegs" der deutschen Akademiker diskutiert, welcher in die verhängnisvolle NS-Periode gefürt habe. Ein derartiger Mechanismus wird aufgrund des Facettenreichtums des deutschen Bildungsbürgertums sowie angesichts internationaler Vergleiche heute so nicht mehr vertreten, vgl. Budde: Blütezeit des Bürgertums, S. 126-128; wohl aber verwies der umtriebige Bielefelder Arbeitskreis zum Thema wiederholt auf die "Sonderbedingungen des deutschen Modernisierungspfads", vgl. Wehler, Hans-Ulrich: Elemente eines „Sonderwegs“? S. 237. 
enfächern einen großen Teil des Frequenzwachstums. ${ }^{213}$ Diese Entwicklung ist auf ein ganzes Ursachenbündel zurückzuführen. Nach 1918 mündeten viele Kriegsrückkehrer, die teilweise noch im Alter von 25 ein Studium aufnahmen, in die Hochschulen ein; im Zuge politischer Emanzipationsbewegungen während und nach der Einführung des Frauenwahlrechts 1919 strömten zunehmend Studentinnen in die akademischen Karrieren; zudem öffnete eine Reform der Oberschule auch Nicht-Abiturienten den Zugang zum Studium. ${ }^{214}$ Die sozialstrukturelle Zusammensetzung der Studierendenschaft veränderte sich wieder: 1931 waren ca. 25 Prozent der universitären Studierenden traditionelle Jungbildungsbürger, d. h. Kinder von höheren Beamten, Professoren, Lehrern höherer Schulen, von Pfarrern oder Freiberuflern; 32 Prozent waren kleinbürgerlicher (niedere Beamte und Lehrer ohne akademischen Hintergrund), 11 Prozent wirtschaftsbürgerlicher Herkunft (Industrielle, Manager, Kaufleute); etwa 18 Prozenten entstammten dem Alten Mittelstand, 5 Prozent kamen aus dem Besitzbürgertum, 3 Prozent aus dem Proletariat. ${ }^{215}$ Die Universitäten wurden somit in wachsendem Maße mehrheitlich von jenen neuen Mittelschichtenmilieus frequentiert, die von den krisenhaften Wirtschaftszyklen stark betroffen waren. ${ }^{216}$

Weimar brachte damit insgesamt den Verlust der bildungs- und besitzbürgerlichen Suprematie an den Universitäten - insofern waren die in diesen Jahren forcierten Bildungsreformbemühungen, die genau das erzielen wollten, erfolgreich. An allen Fakultäten dominierten nunmehr die Kinder von Angestellten und mittleren Beamten als nachrückende Bildungsaufsteiger. Gleichzeitig wuchs der Dienstleistungssektor auf dem Arbeitsmarkt gegenüber dem landwirtschaftlichen und dem industriellen. ${ }^{217} \mathrm{Ab}$ gesehen von den weiterhin marginal vertretenen Arbeiterkindern geriet das Studium an der Universität in zuvor ungekanntem Ausmaß zum sozialen Aufstiegskanal, insbesondere an den medizinischen und rechtswissenschaftlichen Fakultäten. ${ }^{218}$ Etwa zwei Drittel der Studierenden waren im betreffenden Zeitraum noch protestantischer Herkunft - gegenüber nunmehr ca. 27 Prozent Katholiken; gleichzeitig hatte die Verdrängung von Akademikern jüdischer Herkunft bereits begonnen. ${ }^{219}$

Von Aufstiegsoptimismus genährt konnten Studienabsichten in den Weimarer Jahren allerdings nicht lange sein. Gewiss: Gegen Ende der Republik lassen sich beachtliche Tendenzen hin zu einer sozialen Öffnung der Hochschulen beobachten. Der Mittel-

213 Vgl. McClelland: Professionalization and Higher Education in Germany, S. 129-131.

214 Vgl. ibid., S. 131-133, insbesondere die einprägsame Formel ibid., S. 133: „Die typischen Weimarer Studenten waren also, kurz gesagt, älter, eher deutsch, urbaner, moderner vorgebildet und eher weiblich."

215 Vgl. Ringer: Die Gelehrten, S. 65. Jarausch hält dem „verbreiteten Eindruck der Stabilität“ entgegen, dass man angesichts des größeren Anteils von Beamtenkindern bei gleichzeitigem Rückgang von Landwirten und Cewerbetreibenden durchaus von einer „Rebürokratisierung“ des Studiums sprechen könne, vgl. Jarausch: Deutsche Studenten, S. $133 f$.

216 Vgl. ibid. sowie zur Genese des neuen Mittelstands Schulz: Lebenswelt und Kultur des Bürgertums, S. 30-36.

217 Vgl. Jarausch: Deutsche Studenten, S. 134f.

218 Vgl. ibid., S. 136.

219 Vgl. ibid., S. 133. 
stand dominierte erstmals das Studium. ${ }^{220}$ Dennoch kam das Studium einem Kampf um knappe Ressourcen gleich: Die Berufsaussichten von Hochschulabsolventen fielen in einer Phase der Massenarbeitslosigkeit denkbar schlecht aus. ${ }^{221}$ Zugleich wuchs der Zustrom neuer Studierender schneller an, als ihn die Hochschulen und die tatsächlich verfügbaren Stellen auf dem Arbeitsmarkt absorbieren konnten; die Zahl der erwerbswilligen Absolventen überstieg die Nachfrage um das Doppelte bis Dreifache. ${ }^{222}$ Viele dehnten ihre Studienzeit als Moratoriumszeit aus, pflegten ein so genanntes „Parkstudium“. ${ }^{223}$ Vielfach ist für diesen Zeitraum von einem „akademischen Proletariat“ bzw. von einer staats- und ordnungsgefährdenden "Proletarisierung“ der Akademiker - so ein zeitgenössischer Slogan - die Rede. ${ }^{224}$ Bis 1930, also innerhalb einer guten Dekade, stellte sich somit wieder eine Situation her, die als „Vermassung“, ja „Ausnahmezustand" wahrgenommen wurde, und tatsächlich eine schwere Überfüllungskrise war, die diejenige der 1890er Jahre übertrumpfen sollte. ${ }^{225}$ Insbesondere in den letzten Jahren der Republik fügte sich die Rede von einer „Existenzkrise“ bzw. von schwindendem „Lebensraum “ der Studierendenschaft in eine allgemeine Krisenstimmung. ${ }^{226}$ Zwar wütete die Arbeitslosigkeit unter dem nichtakademischen Teil der Bevölkerung noch sehr viel gravierender, doch fühlte sich die vergleichsweise standesdünkelnde akademische Jugend von der Weimarer Republik entfremdet und verlassen. ${ }^{227}$ Die kollektive Desillusionierung und der massive Statusverlust der sich zunehmend auch deklassiert fühlenden Akademiker ${ }^{228}$ werden gemeinhin als wesentliche Triebfeder der antidemokratischen Mobilisierung des deutschen Bürgertums aufgefasst. Tatsächlich lehnten sich die einschlägigen Studentenverbände in einem ausgewachsenen Generationenkonflikt gegen die demokratische Reichsverfassung auf; insbesondere die inkorporierten und verbandsmäßig organisierten Studierenden erwiesen sich im Anschluss als begeisterte Selbstnazifizierer. ${ }^{229}$

Nach 1930 sollte dem gebildeten Bürgertum, insbesondere jenen Akademikern, die sich infolge der empfundenen kollektiven Kränkung mit den deutschnationalen und

220 Vgl. ibid., S. 134 sowie für den zeitlichen Verlauf die Abbildungen in Titze: Die zyklische Überproduktion von Akademikern, S. 98.

221 Vgl. Ringer: Die Gelehrten, S. 64 und Jarausch: Deutsche Studenten, S. 136-139.

222 Vgl. Jarausch: Deutsche Studenten, S. 137.

223 Vgl. ibid., S. 129, 132 und $137 f$.

224 Vgl. Ringer: Die Gelehrten, S. 64 und Jarausch: Deutsche Studenten, S. 138.

225 Vgl. Jarausch: Die Krise des deutschen Bildungsbürgertums, S. 182.

226 Vgl. Jarausch: Deutsche Studenten, S. 139.

227 „In den wirtschaftlichen Notlagen der Inflation und der Weltwirtschaftskrise konnte der Widerspruch zwischen der immer einfacheren Herkunft der Studierenden und ihrem noch am kaiserlichen Akademikernimbus orientierten Elitebewußtsein nicht mehr aufgelöst werden." Ibid., S. 138. „Obwohl Akademiker nur eine Randgruppe der wilhelminischen Elite gewesen waren (im Gegensatz zu der etwas überzogenen Mandarinenthese), fühlten viele von ihnen in Weimar einen Statusverlust gegenüber den neuen Führungsgruppen wie Unternehmern, Gewerkschaftsvertretern oder Politikern, vielleicht weil sie für sich selbst mehr erwartet hatten. [...] Zwar verbesserte die Stabilisierung die Soziallage vieler Akademiker, aber Gebührenkürzungen, Beamtenabbau und Rationalisierung schufen weiterhin genug Unruhe, um die Mehrheit der Cebildeten auch während der ,goldenen zwanziger Jahre' in einer Abwehrhaltung zu belassen." Ibid., S. 194 und 196.

229 Vgl. Titze: Bildungskrisen und sozialer Wandel, S. 356-361 sowie Jarausch: Die Krise des deutschen Bildungsbürgertums, S. 199 und 202. Mehr dazu unten, Kapitel II.2.3 dieser Studie. 
völkischen Kräften der „nationalen Bewegung“ eingelassen hatten, rasch klarwerden, dass nicht die erhoffte Restitution des „Geistes“ und der Privilegien seiner bürgerlichen Träger gegen die Drohung des „Interessenkampfes“ und des Sozialismus folgen sollte, sondern die nationalsozialistische Herrschaft. Die paralysierten republikanischen und liberalen Intellektuellen flüchteten sich in Eskapismus, in die „innere Emigration“, sofern sie nicht zur äußeren gezwungen waren; das von Ringer so bezeichnete Mandarinentum war zu Beginn des NSDAP-Regimes „zu Ruinen zerfallen“. ${ }^{230}$ Die deutschen Studenten hingegen, denen die Schwäche und Schicksalsergebenheit der älteren Akademiker zuwider waren, schlossen sich zu großen Teilen der Hakenkreuz-Standarte an. Bei ihnen, wie generell bei der Jugend der Mittelschichten, verfing die Propaganda der Nationalsozialisten; rasch errang der Nationalsozialistische Deutsche Studentenbund (NSDStB) Mehrheiten bei den Hochschulwahlen. ${ }^{231}$ Überhaupt bedeuteten die zwölf Jahre des „Dritten Reichs“ im historischen Längsschnitt einen Bruch mit langfristigen Tendenzen, insbesondere mit der schrittweisen sozialen Öffnung des Studiums. Vor dem Machtwechsel und der Abschaffung der Republik reüssierten die NS-Verbände an den Universitäten mit ihrem Versprechen, den akademischen Konkurrenzkampf in völkischem Sinne zu „ösen“, d. h. qua Vertreibung jüdischer Intellektueller und Studierender von ihren Positionen und Studienplätzen. Nach der Machtübernahme und der Gleichschaltung der Universitäten aber sollte die Offensive gegen das traditionelle studentische Verbandswesen eher zur Entfremdung von Studierendenschaft und NSRegime führen. Der Konflikt zwischen dem Repräsentationsanspruch der Korporationen, vertreten durch die Deutsche Studentenschaft (DSt), dem völkischen Verbandsprinzip des Deutschen Hochschulrings (DHR) und dem Kameradschaftsprinzip des NSDStB bzw. dem Führerprinzip der Reichsstudentenführung führte zum Rückzug einer überwältigenden Mehrheit der Studierenden in organisationsaverse Apathie. ${ }^{232}$

Die nationalsozialistische Bildungspolitik war widersprüchlich. Einerseits sollte laut NSDAP-Parteiprogramm in der ethnisch homogenisierten „Volksgemeinschaft“ die Universität allen „Volksgenossen“ offenstehen, andererseits standen die konkreten Maßnahmen ganz im Zeichen einer scharfen Eliten-Auslese, einer „Reelitisierung“ des Studiums und einer "Reakademisierung“ der Studenten. ${ }^{233}$ Sukzessive wurden kommunistische bzw. pazifistische und jüdische Studierende, auch die zunehmend in die Sphäre häuslicher Arbeit und emotionaler Pflege von „Kinder, Küche und Kirche“ verwiesenen Frauen vom Studium ausgeschlossen, schließlich aber auch ein großer Teil der männlichen Abiturienten. ${ }^{234}$ Diese drastische Restriktionspolitik fiel zusammen mit zyklischen Abschwungbewegungen der Studierendenzahlen, einer schwierigen wirtschaftlichen Gesamtentwicklung, aber auch mit den anwachsenden diversen Zwangsverpflichtungen junger Erwachsener zu Kriegs- und Arbeitsdiensten - abgesehen von jenen im Schnitt 50 Prozent, die als Frontsoldaten eingezogen wurden ${ }^{235}-$, und wurde nur durch die Territorialgewinne und den erneuten Zustrom junger Frauen

230 Vgl. Ringer: Die Gelehrten, S. 385-392, Zitate von S. 392.

231 Vgl. ibid., S. 386.

232 Vgl. Jarausch: Deutsche Studenten, S. 182.

233 Vgl. ibid., S. 176f., 180, 182, und 186.

234 Vgl. ibid., S. 176f.

235 Vgl. ibid., S. 205. 
an die Universitäten während der Kriegsjahre ${ }^{236}$ statistisch leicht aufgewogen: Studierten 1931 noch rund 104.000 junge Menschen an den deutschen Universitäten, waren es 1939 nur noch rund 41.000 bzw. 1943/44 rund 54.000. ${ }^{237}$ Im Verlauf der 1930er Jahre und besonders ab 1935 trübten sich so die Bildungs- und Karrierechancen der jungen Generation durch die scharfen Ausleseprozesse ein. ${ }^{238}$ Gegen die Angehörigen der mittleren bzw. unteren Schichten, besonders gegen die ländliche Bevölkerung wurde der Studienzugang massiv abgedichtet. ${ }^{239}$ Ein erheblicher Bruch mit der langfristigen Tendenz einer schrittweisen sozialen Öffnung der Universitäten - während das nationalsozialistische Deutschland allmählich an einem manifesten Mangel an akademisch qualifiziertem Personal, nicht zuletzt am Verschwinden der jüdischen Intelligenz litt: Die unter dem noch frischen Eindruck der Weimarer Überfüllungskrise massiv vorangetriebene völkische und misogyne "Säuberung“ der Berufe führte um 1937 zur Vollbeschäftigung von Universitätsabsolventen; danach klafften drastische Vakanzen bei allen akademischen Zielberufen. ${ }^{20}$ Diese „verfehlte Strukturpolitik“, stürzte die Hochschulen der NS-Periode in eine schwere Krise, gefährdete gar den Fortbestand einzelner Studienfächer und die Existenz kleinerer Universitäten. ${ }^{241}$ Allein die rasche Rücknahme von Restriktionsmaßnahmen, eine Absenkung von Zugangsschwellen und Prüfungsanforderungen und eine Kehrtwende der offiziellen Rhetorik vermochten die Studierendenzahlen in den letzten Jahren des „Dritten Reichs“ anzuheben. ${ }^{242}$

Die sozialen Umstrukturierungsprozesse von Universität und Gesellschaft, die in Weimarer Zeiten begannen, setzten sich insgesamt aber weiterhin fort. Spätestens mit der Herrschaft des Nationalsozialismus endete daher auch das Zeitalter des Bildungsbürgertums als für die deutsche Universität prägende, ja sozial und kulturell hegemoniale Sozialformation.

\section{II.1.4 Postindustrielle Leistungsgesellschaft: Von der Rekonstruktion der Universität zur „Bildungsrevolution" 1960 bis heute}

Die Jahre zwischen der bedingungslosen Kapitulation NS-Deutschlands 1945 und der Gründung der Bundesrepublik 1949 waren zerfurcht von materieller Armut und wirtschaftlicher Not in den vier Besatzungszonen, von moralischer Desillusionierung, politischer Apathie und einer langsamen Staatenbildung. Die Zukunft des Landes lag in den Sternen, Schichten- und Geschlechterdifferenzen schienen eingeebnet, bisherige Ordnungsraster nicht mehr zu gelten; die Empfindung einer „Zusammenbruchsgesell-

236 Während der Frauenanteil an den Studierenden an Universitäten um 1939 ca. 14 Prozent betrug, stieg er in den frühen $1940 e r$ Jahren wieder auf rund 47 Prozent an, vgl. ibid., S. 181.

237 „Das Crundmuster des Einbruchs um mehr als die Hälfte und einer teilweisen Erholung vor allem durch Studierende neuer Gebiete ist so stark, daß es bei allen Indikatoren, Hochschularten und Fakultäten durchschlägt." Ibid., S. 178.

238 Vgl. ibid., S. 180.

239 Vgl. ibid., S. $181 f$.

240 Vgl. ibid., S. 183.

241 Vgl. ibid., S. 185.

242 Vgl. ibid., S. 186. 
schaft“, einer „Stunde Null“ dominierte. ${ }^{243}$ Nach der doppelten Staatengründung war der gesellschaftspolitische Alltag in Westdeutschland von dem starken Drängen getragen, die unmittelbare Vergangenheit rasch hinter sich zu lassen und zur „Tagesordnung“ einer gefestigten demokratischen Ordnung, die aus den Verhängnissen der Weimarer Jahre entscheidende Lektionen gezogen hatte, und einer Politik der „Westbindung" unter dem ersten Bundeskanzler Adenauer, überzugehen. ${ }^{244}$ Kritiker dieses Prozesses wie die Herausgeber der Frankfurter Hefte Eugen Kogon oder Walter Dirks sahen darin eine konservative Politik der "Restauration“ anstelle eines tatsächlichen demokratischen Neuanfangs. ${ }^{245}$ Theodor W. Adorno witterte im wiederaufgenommenen Kunstund Kulturbetrieb eine monologisierende Ablösung der Intelligenz von tatsächlichen gesellschaftlichen Vorgängen, einen ,gespenstische[n] Traditionalismus ohne bindende

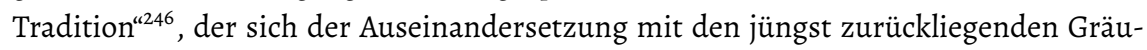
eln entziehe. Für die - auch studentische - Jugend ergab sich zuvörderst das Problem der Orientierungs- und Verhaltensunsicherheit einer (Post-)Adoleszenz „zwischen zwei sozialen Horizonten“, nämlich den mehrheitlich kleinräumlich-vorindustriellen Wertmustern ihrer Eltern- und Großelterngeneration und der Erfahrung einer industriegesellschaftlichen Arbeitswelt, einer von Großorganisationen und urbanisierten wie bürokratisierten strukturierten Welt, die ihnen präzedenzlos erscheinen musste. ${ }^{247}$ Auch in materieller Hinsicht dominierte das Sekuritäts- bzw. Aufstiegsbedürfnis in den Reihen einer jungen Generation, die zum ersten Mal ihren Beruf frei wählen durfte. Insbesondere das Aufstiegsstreben, der Wunsch, „etwas Ordentliches zu lernen“, trug Züge eines intergenerationellen Lernprozesses, als zeitgemäße Gestalt der Suche nach sozialer Sicherheit. ${ }^{248}$ Die Studierenden, in mancherlei Hinsicht noch als „soziale Elite" und „bürgerliche" Subgruppe der Jugend geltend, ${ }^{249}$ begannen ihren akademischen Sonderstatus zu verlieren, mieden das traditionelle subkulturelle Studentenleben und mutierten zu einer „funktionalen wissenschaftlichen Berufsgruppe“. ${ }^{250}$

Die allgemeine Beschäftigung mit der nationalsozialistischen Vergangenheit sollte tatsächlich erst viel später, in den 1960er und 1970er Jahren im Zuge der Transformation politischer Kultur, einsetzen. ${ }^{251}$ Überhaupt mag die beeindruckende Stabilität der

243 Vgl. Winkler, Heinrich August: Der lange Weg nach Westen. Bd. 2: Deutsche Ceschichte vom "Dritten Reich"bis zur Wiedervereinigung, München 2000, S. 121.

244 Vgl. ibid., S. 122f., 131-142 und 166-179.

245 Vgl. ibid., S. 179, auch Dirks, Walter: Der restaurative Charakter der Epoche, in: Frankfurter Hefte, 5. Jg., H. 50/1950, S. 942-954, siehe hier insbesondere S. 942: „Wir sind dabei, den Frieden zu verlieren. Die Völker Europas haben weder den militärischen Zusammenbruch noch den militärischen Sieg zu nutzen verstanden. Sie haben die Aufgabe nicht gelöst, die ihnen gestellt war: nach dem Zusammenbruch der alten Welt eine menschlichere aufzubauen. Sie haben den Weg des geringsten Widerstandes gewählt. In dem harmlosen Wort ,Wiederaufbau' hat sic hdieser Weg bereits 1945 angekündigt. Angst, Bedürfnis nach Sicherheit und Bequemlichkeit waren stärker als Mut, Wahrheit und Opfer, und so leben wir denn in einem Zeitalter der Restauration."

246 Vgl. Adorno, Theodor W.: Die auferstandene Kultur. In: Ders.: Cesammelte Schriften in 20 Bänden, Bd. 20.2. Suhrkamp Verlag, Frankfurt a.M. 1997, S. 453-464, hier S. 458.

247 Vgl. Schelsky: Die skeptische Generation, S. 30-45.

248 Vgl. ibid., S. 177 und S. 181.

249 Vgl. ibid., S. 315.

250 Vgl. ibid., S. 330.

251 Mehr dazu in Kapitel II.2.2 dieser Studie. 
bundesrepublikanischen Demokratie, die zuerst in ihrer „Bonner“ Gestalt von 1949 bis 1990 und dann in ihrer „Berliner“ Form seit 1990, d. h. unter Einschluss des Staatsgebietes der ehemaligen DDR, nunmehr 70 Jahre ihres Bestehens feiern kann, über die zahlreichen ökonomischen, demographischen, politischen und kulturellen Umwälzungen hinwegtäuschen, welche die deutsche Gesellschaft doch durchaus substanziell verändert haben. Dazu zählen die Urbanisierung, Entagrarisierung und Entproletarisierung der sozialen Stratifikation und der Mentalitäten im Zuge der Ausbreitung des Dienstleistungssektors ebenso wie die fortschreitende geschlechtliche Gleichstellung, das Verschwinden des einst erbitterten konfessionellen Konfliktes zwischen Katholiken und Protestanten, oder eben die beeindruckende Bildungsexpansion. ${ }^{252}$ Gerade die vergangenen Jahre, in denen die Emergenz rechtspopulistischer Proteste wie PEGIDA oder der Aufstieg der AfD, einer neuen Partei rechts des christdemokratischen Spektrums mit mehrheitlich nationalkonservativem Profil, die aus der Bundestagswahl 2017 als drittstärkste Kraft und schließlich als Oppositionsführerin gegen die fortgesetzte Koalition von CDU/CSU und SPD hervorging, Aufsehen erregte, scheinen auf eine neue Phase beschleunigten Wandels der politischen Kultur hinzudeuten, ${ }^{253}$ deren Ausgang ungewiss ist.

Dennoch: Nicht nur institutionell, auch hinsichtlich der Datenlage stellen sich der Charakterwandel des Studiums und die Entwicklung der sozialen Lage der Studierendenschaft als nachvollziehbare, beinahe lineare Chronologie dar. Mithilfe der durch Studierendensurvey, Sozialerhebung und Bildungsbericht vorliegenden Daten sind die wesentlichen Entwicklungen in den Gebieten der alten und neuen Bundesrepublik nachzuzeichnen. Zunächst stellte sich so etwas wie die „Normalität“ einer sich formierenden Mittelstandsgesellschaft nach US-amerikanischem Vorbild her. Langfristige Vorkriegsentwicklungen wurden in einer langen Phase beispielloser demokratischer Stabilität wieder aufgenommen. Bildungspolitik galt bald, insbesondere ab den 1960er Jahren, als der entscheidende Hebel zur Egalisierung der Lebensverhältnisse, d. h. einer auch materiellen Demokratisierung der bundesrepublikanischen Bürger. ${ }^{254}$ Die Studierendenzahlen wuchsen, verglichen mit den späteren Boomjahrzehnten ab Mitte der 1960er Jahre, moderat an: Studierten 1931 noch insgesamt rund 104.000 junge Menschen an Deutschlands Universitäten, fiel diese Zahl bis 1949 zunächst auf rund 71.000 zurück, ${ }^{255}$ wuchs bis 1955 auf rund $88.000^{256}$ und erreichte ihren einstweiligen Zenit erst wieder 1957 mit rund 106.000 Studierenden. ${ }^{257}$ Dementsprechend erhielten sich

252 Vgl. Wehler: Deutsche Gesellschaftsgeschichte 1945-1990, S. 153-162, 168-171, 171-179 und 204-207.

253 Vgl. Geiges, Lars/Marg, Stine/Walter, Franz: Pegida. Die schmutzige Seite der Zivilgesellschaft?, Bielefeld 2015, insbesondere zur Einordnung der PECIDA-Proteste S. 179-207. Hinsichtlich der Frage, welche Entwicklungen unter Jugendlichen und jungen Erwachsenen mit Blick auf PECIDA sich aktuell ankündigen, vgl. jüngst Schenke et al.: PECIDA-Effekte?, insbesondere S. 363-378. Zur Diskussion der indikativen Qualitäten des Siegeszugs des politischen Populismus in Deutschland und Europa und der Bedeutung dieser Entwicklungen für den Zustand der Demokratie vgl. die gesammelten Beiträge in Jörke, Dirk/Nachtwey, Oliver: Das Volk gegen die (liberale) Demokratie. Leviathan Sonderband 32, Baden-Baden 2017.

254 Vgl. Wehler: Deutsche Cesellschaftsgeschichte 1949-1990, S. $193 f$.

255 Vgl. 3. Sozialerhebung 1956, S. 15.

256 Vgl. ibid.

257 Vgl. 4. Sozialerhebung 1959, S. 13. 
die 1950er Jahre hindurch im Großen und Ganzen auch die Vorkriegsmuster des Sozialprofils: Noch 1959 entstammten rund 35 Prozent der Studierenden Beamtenfamilien, ca. 27 Prozent waren Kinder von Angestellten; ihnen standen rund 30 Prozent Abkömmlinge von Freiberufler- und Selbstständigenfamilien (inkl. Landwirten), aber weiterhin nur rund 5 Prozent Arbeiterkinder gegenüber. ${ }^{258}$

Die entscheidenden Sprünge des Bildungswachstums, die eigentlichen tektonischen Verschiebungen in der Rolle des Studiums als sozialem Aufstiegskanal für die Mittelschichten machten sich im Gefolge der bisweilen als „Bildungsrevolution ${ }^{\prime 259}$ betitelten Bildungsmobilisierung der 1960er und 1970er Jahre, einer Periode von Reformanstrengungen und Reformdiskussionen mit dem dezidierten Ziel der Massenbildung als Schrittmacher des sozialen „Fahrstuhleffekts“ ${ }^{\text {“260 }}$, bemerkbar. Erst jetzt - durch die bildungspolitisch repressive nationalsozialistische Phase verzögert - konnte jene „Schwelle der Modernisierung“ überschritten werden, „über die das Bildungswesen aus der Traditionsverhaftung an das 19. Jahrhundert heraustrat und Anschluß an die Entwicklungstendenzen vergleichbarer Gesellschaften des Westens gewann“. ${ }^{261}$ In den übrigen westlichen Industrienationen war diese Tendenz schon weiter vorangeschritten; ${ }^{262}$ insbesondere im Zusammenhang mit dem Untergang des Bauerntums, einer einst signifikanten, in Deutschland jahrzehntelang geradezu wahlentscheidenden Gruppe. ${ }^{263}$ Bis in die 1980er Jahre hinein galt: „Akademikerkinder scheinen permanente Startvorteile in der Berufsvererbung zu besitzen, während für Bauern- und Arbeiterkinder der Erwerb der Bildungsqualifikationen eine Ausnahme ist.“264 Während zwischen 1951 und 1979, also in knapp dreißig Jahren, die absolute

258 Vgl. ibid., S. $32 f$.

259 Vgl. Titze: Von der natürlichen Auslese zur Bildungsselektion, S. 402.

260 "Die Bildungspolitik galt lange Zeit als das aussichtsreichste Experimentierfeld, auf dem die überkommene Sozialstruktur verflüssigt werden konnte, um eine egalitäre Aufstiegsmobilität in Cang zu setzen. Auf diese Weise sollte, lautete seit den 1960er Jahren auch in der Bundesrepublik das Credo, der Fahrtstuhleffekt der Wohlstandssteigerung durch eine Mobilisierung aller Begabtenreserven nachhaltig unterstützt werden, damit auf diesem Feld das Gleichheitsideal der modernen Demokratie mit einem großzügigen Mitteleinsatz verwirklicht wurde." Wehler: Deutsche Gesellschaftsgeschichte 1945-1990, S. 193f.

261 Vgl. Titze: Bildungskrisen und sozialer Wandel, S. 361.

262 „Daß Studenten sowohl gesellschaftlich wie politisch eine viel stärkere Macht geworden waren als jemals zuvor, wurde in der Tat erst in den sechziger Jahren deutlich. 1968 sprachen die weltweiten radikalen Studentenerhebungen eine deutlichere Sprache als alle Statistiken zusammen. Nun waren sie einfach nicht mehr zu übersehen. Zwischen 1960 und 1980 erhöhte sich ihre Zahl im europäischen Durchschnitt um das Drei- bis Vierfache; in der Bundesrepublik Deutschland, Irland und Griechenland um das Vier- bis Fünffache; in Finnland, Island, Schweden und Italien um das Fünf- bis Siebenfache und in Spanien und Norwegen um das Sieben- bis Neunfache." Hobsbawm: Das Zeitalter der Extreme, S. 373.

263 „Der dramatischste und weitreichendste soziale Wandel in der zweiten Hälfte dieses Jahrhunderts, der uns für immer von der Welt der Vergangenheit getrennt hat, war der Untergang des Bauerntums. [...] In Japan beispielsweise reduzierte sich der Anteil der Bauern von 52,4 Prozent der Bevölkerung im Jahr 1947 auf 9 Prozent im Jahr 1985, das heißt also in einem Zeitraum, der der Spanne von der Rückkehr eines jungen Soldaten aus dem Zweiten Weltkrieg bis zu seiner Pensionierung als Zivilist entspricht." Ibid., S. 365 und 366.

264 Jarausch: Deutsche Studenten, S. 244. 
Zahl der Studierenden von rund 70.000 auf 656.000 anstieg und sich damit verzehnfachte, ${ }^{265}$ verdoppelte sie sich in den folgenden neun Jahren, also bis 1988 , nochmals auf rund 1.470.000. ${ }^{266}$ Im Jahr 2000 lag die Zahl bei rund 1.800.000, 2008 bei rund 2.000.000; ${ }^{267}$ aktuell studieren rund 2.900.000 Studierende an deutschen Universitäten und Fachhochschulen. ${ }^{268}$ Die Auswirkungen der Bildungsexpansion sind allerdings am deutlichsten sichtbar zwischen 1970 und 1985: In 15 Jahren verdreifachte sich die absolute Zahl an Studenten. ${ }^{269}$ Hatten 1973 noch 27 Prozent der Studierenden verbeamtete Eltern gegenüber 33 Prozent Angestelltenkindern, 26 Prozent Freiberufler- und Selbstständigenkindern und 11 Prozent Arbeiterkindern, ${ }^{270}$ arretierten die Anteile im Verlauf der 1980er Jahre in bis heute nahezu unveränderter Gestalt: 1990 studierten 20 Prozent Beamtenkinder, 41 Prozent Angestelltenkinder, 18 Prozent Freiberufler- und Selbstständigenkinder und 16 Prozent Arbeiterkinder. ${ }^{271}$ Zum Vergleich bieten sich die Jahre 2000 (20 Prozent Beamtenkinder, 42 Prozent Angestelltenkinder, 20 Prozent Freiberufler- und Selbstständigenkinder, 18 Prozent Arbeiterkinder ${ }^{272}$ ) und 2017 (14 Prozent Beamtenkinder, 43 Prozent Angestelltenkinder, 20 Prozent Freiberufler- und Selbstständigenkinder, 17 Prozent Arbeiterkinder ${ }^{273}$ ) an. Die Präsenz von Arbeiterkindern ist, trotz des Anstiegs bis etwa 1982, stets eher gering geblieben, was auch auf das gesamtgesellschaftliche Abschmelzen dieser einst umfänglichen sozialen Gruppe zurückzuführen ist. ${ }^{274}$ Zwischen 1983 und 1987 nahm ihr Anteil an den Studierenden wieder stark ab. ${ }^{275}$ Insgesamt wird schnell deutlich, dass die soziale Herkunft der Studierenden nach den Berufsgruppen der Eltern seit etwa 30 Jahren identisch geblieben ist; allein der Anteil verbeamteter Eltern scheint in den letzten Jahren rückläufig zu sein. Insofern hat die politisch forcierte und milliardenschwere Bildungsmobilisierung der 1970er Jahre tatsächlich zu einem gewissen Grad an sozialer Horizontalisierung bzw. Homogenisierung geführt, insbesondere zugunsten der unteren Mittelschichten. Besonders eindrücklich ist der Verlauf der Studienanfängerquote - des Anteils der Studierenden an einer Alterskohorte: 1950 waren es noch 5, 19606 Prozent; der Wert stieg dann zunächst auf 12 Prozent im Jahr 1970 und 20 Prozent im Jahr 1980, lag

265 Vgl. 3. Sozialerhebung 1956, S. 15 und 9. Sozialerhebung 1979, S. 19.

266 Vgl. 12. Sozialerhebung 1988, S. 44.

267 Vgl. 16. Sozialerhebung 2000, S. 2.

268 Vgl. die Internetpräsenz des Statistischen Bundesamtes: Destatis: Bildung, Forschung und Kultur, online einsehbar unter: https://www.destatis.de/DE/Themen/Cesellschaft-Umwelt/ Bildung-Forschung-Kultur/Hochschulen/Tabellen/studierende-insgesamt-bundeslaender.html [eingesehen am 24.03.2020]

269 Vgl. 12. Sozialerhebung 1988, S. 61.

270 Vgl. 7. Sozialerhebung 1973, S. $27 f$.

271 Vgl. 13. Sozialerhebung 1991, S. 95.

272 Vgl. 16. Sozialerhebung 2000, S. 11 und 122.

273 Vgl. 21 Sozialerhebung 2016, S. $166 f$.

274 „Die Arbeiterkinder konnten offenbar von der Bildungsmobilisierung der 6oer und 7oer Jahre relativ am meisten profitieren, wobei ihre Unterrepräsentanz an den Universitäten noch immer eklatant war. Immerhin nahm der Anteil der Arbeiterkinder an den Universitäten bis 1982 ständig zu, obgleich der Anteil der Arbeiter an der erwerbstätigen Bevölkerung gleichzeitig ständig abnahm. D.h., die Bildungsbeteiligungsquote von Arbeiterkindern nahm bis zu diesem Zeitpunkt deutlich zu."12. Sozialerhebung 1988, S. 108.

Vgl. 13. Sozialerhebung 1991, S. 63. 
dann 2000 bei 33 Prozent und beträgt aktuell ca. 56 Prozent. ${ }^{276}$ Pointiert heißt das: Wer im Jahr 2020 nach seinem Schulabschluss kein Studium aufnimmt, gehört zur statistischen Minderheit seiner Alterskohorte! „Dem elitären Sonderbewußtsein der Gebildeten ist durch diese Entwicklung der Boden entzogen worden. “277

Die soziale Strukturveränderung des Studiums wird auch in der veränderten Erwerbsbeteiligung der Studierenden deutlich: Im Laufe der Jahre ist sie deutlich gestiegen, zwischen den 1950er und den 2000 er Jahren haben immer weniger Studierende die sprichwörtlichen „reichen Eltern“. Im Jahr 1951 finanzierten noch 40,1 Prozent ihren Lebensunterhalt ausschließlich durch ihre Eltern und nur 9,3 Prozent durch eigenen Verdienst, 15 Prozent durch eine Kombination aus beidem, und nur 5 Prozent aus öffentlichen Mitteln; ${ }^{278} 1956$ lebten mehr als 10 Prozent allein vom eigenen Verdienst bei einem Drittel ausschließlicher elterlicher Finanzierung und einem weiteren Drittel elterlicher Bezuschussung; 8,8 Prozent lebten allein von öffentlichen Mitteln, 9,2 Prozent erhielten Beträge. ${ }^{279}$ Im Jahre 1985 erhielten 68 Prozent der Studierenden Geld von ihren Eltern, 55 Prozent aus einer parallelen Erwerbstätigkeit, 27 Prozent bezogen BAföG. Nur 30 Prozent bezogen ihre Mittel aus einer einzigen Quelle. ${ }^{280}$ Der Anteil erwerbstätiger Studierenden steig in der Folge an: Die Sozialerhebung zur Jahrtausendwende weist einen Anteil von 66 Prozent der Studierenden an Universitäten aus (1991 waren es 49 Prozent), die ,auf die eine oder andere Art, in unterschiedlichem Umfang und mit variierender Regelmäßigkeit" erwerbstätig waren; ${ }^{281}$ etwa ein Viertel der Studierenden durchgehend. ${ }^{282}$ Mehr als die Hälfte von ihnen (ca. 60 Prozent) gaben diese Erwerbstätigkeit als „notwendig für den Lebensunterhalt“ an - gegenüber 69 Prozent, die sich dadurch nur "etwas mehr leisten“ wollen. ${ }^{283} 2016$ waren 69 Prozent der Universitätsstudenten erwerbstätig - so viele „wie noch nie“. ${ }^{284}$ Während 72 Prozent angaben, das Geld für einen komfortableren Lebensstandard zu benötigen bzw. 62 Prozent, um von ihren Eltern unabhängig zu sein, benötigten es 59 Prozent für den eigenen Lebensunterhalt. ${ }^{285}$ Seit Mitte der 1990er ist die begleitende Erwerbsarbeit also Teil des „Alltag[s] einer Mehrheit der Studierenden“. Mit höherer Bildungsherkunft und männlichem Geschlecht sinkt diese Zahl leicht; ein Anstieg ist für alle Gruppen zu verzeichnen. Und: Während Studierende niedriger Bildungsherkünfte zu 73 Prozent angeben, dass ihre Nebentätigkeit „notwendig für den Lebensunterhalt“ sei, tun das die studierenden Kinder gebildeter Elternhäuser nur zu 43 Prozent; letztere geben als häufigen Grund (61 Prozent) die karriereförderliche „Sammlung praktischer Erfahrungen“ an. ${ }^{286}$

276 Vgl. Wolter: Eigendynamik und Irreversibilität der Hochschulexpansion, S. 25 sowie Statistisches Bundesamt: Bildung und Kultur. Schnellmeldungsergebnisse der Hochschulstatistik zu Studierenden und Studienanfängern. Vorläufige Ergebnisse Wintersemester 2017/18, 2017, S. 11.

277 Vgl. Titze: Von der natürlichen Auslese zur Bildungsselektion, S. 402.

278 Vgl. 1. Sozialerhebung 1951, S. 54.

279 Vgl. 3. Sozialerhebung 1956, S. 56.

280 Vgl. 11 Sozialerhebung 1985, S. 5 f.

281 Vgl. 16. Sozialerhebung 2000, S. 280.

282 Vgl. ibid., S. 282.

283 Vgl. ibid., S. 299.

284 Vgl. 21. Studierendensurvey 2016, S. 60.

285 Vgl. ibid., S. 63.

286 Vgl. 13. Studierendensurvey 2015/16, S. 60-63. 
Wenig überraschend müssen Studierende „unterer sozialer Herkunftsgruppen“ und ältere Studierende im Vergleich die meiste Zeit für studienbegleitende Erwerbstätigkeiten aufwenden. ${ }^{287}$

Ebenso empfiehlt sich ein Blick auf den sukzessiven Ausgleich des Geschlechterverhältnisses, um den Zug zur „Normalisierung“ zu skizzieren: Von der Jahrtausendwende bis heute hat sich unter Hochschulstudierenden eine allgemeine Geschlechterparität hergestellt: Waren 1950 gerade einmal 20 Prozent der Studierenden weiblich, ${ }^{288}$ stieg der Anteil der studierenden Frauen bis 1970 zunächst auf 31 Prozent, verharrte zwischen den 1980er und 1990er Jahren bei knapp 40 Prozent, ${ }^{289}$ um 2010 auf 48 Prozent und 2017 auf 49 Prozent zu steigen. ${ }^{290}$

Doch haben sich die Ungleichheiten in den Bildungschancen nicht nur aufgelöst, sondern infolge gegenläufiger Tendenzen auch verlagert und wiederum verstetigt. Die Zugehörigkeit der Eltern zu Berufsklassen hat zwar ihren Status als aussagekräftiger Indikator von schichtspezifischen Bildungschancen verloren. Betrachtet man aber die soziale Herkunft nach dem Bildungsniveau der Eltern, findet man tiefgreifende Veränderungen in den Bildungsabschlüssen der Eltern der Studierenden, ${ }^{291}$ insbesondere in der Öffnung der Abiturklassen für die Angestellten- und Arbeiterschichten seit den 1980er Jahren; ${ }^{292}$ aus diesem Grund greifen die einschlägigen sozialstatistischen Expertisen seit einigen Jahren vermehrt auf letztere Daten zurück. Die jüngsten Jahre der sozialen Öffnung der Hochschulen führten zu einem zwiespältigen Ergebnis: Einerseits konnten große Teile der Beamten- und Angestelltenschaft - in deutlich geringerem Maße die gleichwohl immer schmaler gewordene Arbeiterschaft - „abiturisiert“ und „akademisiert" werden, ${ }^{293}$ andererseits hängen die Bildungschancen der nachfolgenden $\mathrm{Ge}$ nerationen zunehmend von dem Bildungsgrad der Eltern ab. Wer in die Familien der originären Bildungsexpansions-Generationen hineingeboren wird, profitiert auch heute. Das ist eindrücklich zu illustrieren mithilfe der verfügbaren Daten zum höchsten Schulabschluss und zum Akademisierungsgrad der Eltern: Verfügten 1981 noch 45 Prozent der Eltern der Studierenden über einen Hauptschul- bzw. Volksschulabschluss, 22 Prozent über einen Realschulabschluss und nur 27 Prozent für ein erfolgreich absolviertes Abitur bzw. eine vergleichbare Hochschulreife, ${ }^{294}$ lag das Verhältnis im Jahr 2000 bei 20 Prozent Hauptschul- bzw. Volksschulabschluss, 27 Prozent Realschulabschluss

287 Vgl. 16. Sozialerhebung 2000, S. 269 und S. 294 sowie 21. Sozialerhebung 2016, S. 62.

288 Vgl. 11. Sozialerhebung 1985, S. 87.

289 Vgl. ibid. Und 16. Sozialerhebung 2000, S. 45.

290 Vgl. Statistisches Bundesamt: Studierende an Hochschulen. Wintersemester 2017/18, S. 13, online einsehbar unter: https://www.destatis.de/DE/Publikationen/Thematisch/BildungForschungKultur/Hochschulen/StudierendeHochschulenEndg2110410187004.pdf?_blob=publicationFile [eingesehen am 01.08.2019]

291 Vgl. 13. Sozialerhebung 1991, S. 108.

292 Vgl. Köhler, Helmut: Bildungsbeteiligung und Sozialstruktur in der Bundesrepublik. Zu Stabilität und Wandel der Ungleichheit von Bildungschancen. Studien und Berichte des Max-PlanckInstituts für Bildungsforschung Nr. 53, Berlin 1992, S. 30, 54-59 und 78f.

293 „Selbst wenn sich also die Bildungsbeteiligung für die einzelnen Untergruppen der Angestelltenund Beamtenkinder nicht entscheidend ändert, so tragen Angestellte und Beamte durch ihre veränderte interne Zusammensetzung zur Expansion bei.“ Ibid., S. 80. 
und 52 Prozent Abitur bzw. ähnliche Hochschulreife. ${ }^{295}$ Im Jahr 2016 schließlich waren nur noch 9 Prozent der Studierenden Kinder von Haupt- bzw. Volksschulabsolventen, 24 Prozent Kinder von Realschulabsolventen, dafür aber ganze zwei Drittel Kinder von Abiturienten bzw. äquivalenter Hochschulzugangsberechtigung. ${ }^{296}$ Parallel wuchs der Anteil der Studierenden mit mindestens einem Elternteil mit akademischem Abschluss (Universität oder Fachhochschule) von 26 Prozent im Jahr $1981^{297}$ über 44 Prozent im Jahr 2000 auf 52 Prozent im Jahr 2016. ${ }^{298}$ Und: Studierende an Universitäten verfügen heute fast sämtlich über ein Abiturzeugnis. ${ }^{299} \mathrm{Zu}$ Beginn des (kalendarisch) letzten Jahrzehnts des zwanzigsten Jahrhunderts liegt die soziale Funktion von Bildung noch immer in ihrem Charakter als statushierarchisierender Filter, als Ferment einer zementierten und anwachsenden sozialen Ungleichheit ${ }^{300}$ - und das ist bis heute so geblieben, auch wenn im deutschen Kontext die gymnasiale Schullaufbahn die entscheidendere Selektionshürde bildet als der Hochschuleintritt: Wer über ein Abitur verfügt, hat in der Regel keine Schwierigkeiten, ein Studium aufzunehmen.

Entgegen der bereits erwähnten, unter vielen Historikern verbreiteten begrifflichen Limitierung des Bildungsbürgertums auf dessen traditionelle Gestalt, wie sie sich im Wilhelminismus verdichtet hat, ${ }^{301}$ überstanden die darunter befassten sozialen Gruppen ökonomisch, kulturell und organisatorisch betrachtet erstaunlich unbeschadet den Zweiten Weltkrieg und das Dritte Reich, mithin die Zeitschwelle $1945 .{ }^{302}$ Zumindest im bundesrepublikanischen Teil Deutschlands behaupteten sie sich als zwar weiterhin marginale, aber doch vergleichsweise deutlich abgrenzbare Sozialformationen - insbesondere im Vergleich mit den sich in den folgenden Jahrzehnten auflösenden bäuerlichen, proletarischen, klein- und großbürgerlichen Milieus im Schmelztiegel der entstehenden Dienstleistungsgesellschaft. ${ }^{303}$ Bildungsbürgerliche Milieus im Sinne von residualer beruflicher Privilegierung, aber auch hinsichtlich von Wertepräferenzen und einer gehobenen moralisch-ästhetischen Bildungs- und Kulturemphase in Freizeitgestaltung und Erziehungsmaximen; kurz: Bildungsbürgerliche Subkultur bzw. bildungs-

295 Vgl. 21. Sozialerhebung 2016, S. 27.

296 Vgl. ibid.

297 Vgl. 10. Sozialerhebung 1981, S. 36.

298 Vgl. 21. Sozialerhebung 2016, S. 27.

299 Vgl. 7. Studierendensurvey 1997/98, S. 52.

300 „In den drei Jahrzehnten vor 1990 hat sich ein unzweideutiger Vorsprung des Nachwuchses von Akademikern und Abiturienten gehalten oder noch weiter herausgeschält. [...] Die Soziale [sic] Ungleichheit wächst, wie die Komposition der Studentenschaft verrät, eher weiter an." Wehler: Deutsche Gesellschaftsgeschichte 1949-1990, S. 196.

301 Vgl. Engelhardt: Bildungsbürgertum, S. 228.

302 „Wie im gehobenen Wirtschaftsbürgertum wirkten sich auch in den akademischen Berufsklassen Sozialisationsprozesse aus, die, grob gerechnet, seit den 1880er Jahren die Angehörigen dieser Bürgertümer geprägt hatten - Prozesse, die ja keineswegs in den 1920er/1930er Jahren abrupt abgebrochen waren und auch nach 1945 einem völligen Identitätswechsel widerstrebten. Ähnlich wie im gehobenen Wirtschaftsbürgertum ließe sich nach dieser Epochenscheide auch der Fortbestand zahlreicher Anwalts-, Ärzte-, Wissenschaftler-, Beamtendynastien feststellen." Wehler, Hans-Ulrich: Deutsche Gesellschaftsgeschichte. Bundesrepublik und DDR 1945-1990, Lizenzausgabe für die Bundeszentrale für politische Bildung, Bonn 2010, S. 139. 
bürgerliche Lebensstile existieren bis heute fort. ${ }^{304}$ Interessant sind hier die Kontinuitäten der intergenerationellen akademischen Reproduktion bei bestimmten, traditionell bildungsbürgerlich dominierten Studienfächern. Insbesondere die Sonderstellung von Medizin und Jura ist hervorzuheben: Hier machen sich die Studierenden die größten Hoffnungen auf einen sicheren Arbeitsplatz und sind (neben den Wirtschaftswissenschaften) am stärksten an einem hohen Einkommen orientiert; ihre berufliche Flexibilität und ihre Neigung zum Studienabbruch sind von allen Studierenden am geringsten; ${ }^{305}$ sie sind vergleichsweise früh - und oft aufgrund familiärer Vorbilder - auf ihr Studienfach festgelegt ${ }^{306}$, und der Grad an „Bildungsvererbung“ ist bei ihnen am größten. ${ }^{307}$ Auf der anderen Seite sind es gerade die sozialen Nivellierungstendenzen - welche indes, wie Helmut Schelskys in den 1950er Jahren geprägte Formel von der „nivellierten Mittelstandsgesellschaft" mehrfach entgegengehalten wurde, keineswegs eine sozial homogenisierte „klassenlose“ Gesellschaft herbeiführten ${ }^{308}$-, die erstmals die Ausbreitung bürgerlicher Ideale auf die Mehrheitsgesellschaft ermöglichten. Der wirtschaftliche Aufschwung der 1950er Jahre sorgte für eine zuvor ungekannte soziale Absicherung und verschaffte der Nachkriegsrepublik den berühmten Fahrstuhl-Effekt, d. h. rasant steigende Nettorealverdienste, einen immer höheren Lebensstandard inklusive finanzierbarer Urlaubsreisen auch für Arbeiterfamilien, insgesamt einen umfassenden sozialen Aufstieg für die Massen. ${ }^{309}$ „Bürgerlichkeit“ bzw. bürgerliche Lebensführung geriet zum normativen Fixpunkt, zum sozialpsychologischen Identifizierungsanker und sozialen Sehnsuchtsort; sich die alte liberale Ideenwelt der Bildungsund Wirtschaftsbürger zum Vorbild zu nehmen, erschien gleichsam plausibel:

„Das ,Kulturmuster Bürgerlichkeit' gewann [...] mit seinem erstaunlich schnellen konjunkturellen Aufstieg neue Verbindlichkeit, nicht als abstraktes Normenensemble, sondern als Traditionsfortsetzung weiterbestehender Sozialformationen. Da vereinigten sich der Leistungsgedanke, die Wertschätzung und Mündigkeit des einzelnen, die Fähigkeit zur individuellen Lebensführung, die Familienorientierung, das Arbeitsethos, die Sparsamkeit, die politische Teilhabe, die Pflege des kulturellen Erbes bis hin zur Wiederbelebung der Bildungsidee. ${ }^{\text {“310 }}$

304 „Zwar erhält sich noch die ständische Vergesellschaftung als Lebensstil, doch sie verliert den Anspruch auf Allgemeingültigkeit und die Mittel, diese Prätention weiter aufrechtzuerhalten. Bildungsbürgerlichkeit wird zur Subkultur, einer von vielen." Lepsius, M. Rainer: Das Bildungsbürgertum als ständische Vergesellschaftung, in: Ders. (Hg.): Bildungsbürgertum im 19. Jahrhundert. Teil III: Lebensführung und ständische Vergesellschaftung, Stuttgart 1992, S. 9-18, hier S. 18. Vgl. 13. Studierendensurvey 2015/16, S. 13-14, S. 78, S. 10.

306 12. Studierendensurvey 2012/13, S. 4.

307 Vgl. 13. Studierendensurvey 2015/16, S. 7.

308 Vgl. Marg, Stine: Mitte in Deutschland. Zur Vermessung eines politischen Ortes. Studien des Göttinger Instituts für Demokratieforschung zur Geschichte politischer und gesellschaftlicher Kontroversen, Bd. 8, Bielefeld 2014, S. 38-41. Vgl. zum Ursprung der Formel der nivellierten Mittelstandsgesellschaft Schelsky, Helmut: Die Bedeutung des Schichtungsbegriffs für die Analyse gegenwärtiger Gesellschaft, in: Ders.: Auf der Suche nach Wirklichkeit, Düsseldorf/Köln 1965, S. 331-336. 
Und mit dieser Verbürgerlichung, die in großen Teilen der Gesellschaft zuvörderst eine „Entproletarisierung“ bedeutete, kündigte sich ein weiterer großer Trend an, der gewöhnlich mit dem Schlagwort „Individualisierung“ bedacht wird; gemeint ist die Entbindung der Einzelnen von traditionellen Familien-, Konfessions-, Klassen- und Milieuzugehörigkeiten, die Erosion sozialmoralisch und mental empfundener Kollektivität, die Ausdifferenzierung von Lebensstilen, Werthaltungen und Präferenzmustern. ${ }^{311}$ Gewiss war auch in dieser Phase der soziale Antagonismus nicht stillgestellt; Schichtenbzw. Klassengrenzen ${ }^{312}$ stratifizierten die deutsche Gesellschaft allen Angleichungstendenzen zum Trotz weiterhin. ${ }^{313}$

Gegen Ende der 1970er Jahre und insbesondere um das Jahr 1980 herum kam es aufgrund des jahrelangen Ansturms auf die Universitäten abermals zu Stauungs- und Überfüllungseffekten in den akademischen Karrieren. Angesichts von ca. 40.000 arbeitslosen Akademikern mit Hochschulzeugnis erschien das Leistungsprinzip delegitimiert, die nachrückenden Qualifizierten ihrer Zukunft beraubt. ${ }^{314}$ „No future“ reüssierte, befeuert durch die Friedensbewegung und die Konfrontation der atomar bewaffneten Großmächte im Kalten Krieg, als gängige Parole auch unter Studierenden. ${ }^{315}$ „Erst pauken - und dann keine Zukunft? “316 Sogar die Sorge vor einer neuen Welle gesellschaftskritischer studentischer Radikalität nach dem Vorbild der frühen 1970er Jahre erschien wieder à jour ${ }^{317}$ - auch wenn sich die tatsächliche studentische Mentalität in einer zeitgenössischen Studie als so moralisch empört wie antriebslos, als so tolerant und harmoniebedürftig wie resignativ und antriebsschwach entpuppte. ${ }^{318}$ Indes: Trotz der intermittierenden Verschlechterung der Berufsaussichten ${ }^{319}$ kam es nicht zu einer gesamtgesellschaftlichen „Neuauflage der Überfüllungsdiskussion“; vom „akademischen Proletariat" sprach niemand. ${ }^{320}$ Die Gründe dafür sind vielschichtig; einer von ihnen ist

311 Vgl. Nachtwey: Die Abstiegsgesellschaft., S. 32-34.

312 Eine Intervention in die immer wieder aufflammende (wirtschafts-)soziologische Debatte, ob und inwiefern heute noch von Klassen, Schichten, usw. die Rede sein könne, soll hier nicht versucht werden. Zu einer Gegenüberstellung der wesentlichen Konzepte am Beispiel der gesellschaftlichen „Mitte“ vgl. Marg: Mitte in Deutschland, S. 36-41.

Im Falle der Universitäten fällt etwa auf, dass die so genannte „soziale Bildungsvererbung“ bzw. „akademische Reproduktion" in Medizin und (danach) Jura noch bis heute fortwirkt. Vgl. Studierendensurvey 1990er, S. 10f.; 10. Studierendensurvey 2006/07, S. 28f.; 13. Studierendensurvey 2015/16, S. 7.

314 Vgl. Jarausch: Deutsche Studenten, S. 242.

315 Vgl. ibid., S. 242 sowie Glotz, Peter/Malanowski, Wolfgang: Student heute. Angepaßt? Ausgestiegen?, Hamburg 1982, S. 19 und S. 26.

316 Vgl. Glotz/Malanowski: Student heute, S. 64.

317 „Was ist von Studenten zu halten, die mit der Gesellschaft, in der sie leben, so über Kreuz sind-und was ist von ihnen zu erwarten? [...] Gehen die Studenten, wie zur Apo-Zeit, wieder in Massen auf die Straße, werden Steine fliegen? Kommt es zu Massenkeilereien mit knüppelnden Polizisten? [...] Oder wird überwiegend unpolitisch angeklagt, blockiert Verdruß an der realen Politik den Zugang zum Politischen? Bleibt folglich Verweigerung die Ultima ratio; rigoroser Moralismus einerseits, hilflose Untätigkeit andererseits?" Ibid., S. 129. Mehr dazu unten, Kapitel II.2.2 dieser Studie. Vgl. ibid., S. 199. Mehr dazu unten, Kapitel II.3.2 dieser Studie.

319 Das schließt nicht aus, dass sich für bestimmte Qualifikationswege nicht auch Berufschancen verbessern konnten, so etwa für den wachsenden EDV-Bereich oder für angehende Lehrkäfte in berufsbildenden Schulformen. Vgl. Titze: Von der natürlichen Auslese zur Bildungsselektion, S. 402. 
sicher die durch soziale Öffnung und Ausdifferenzierung des Bildungssystems evozierte Metamorphose der Bildungsselektion von einer vergleichsweise hermetischen Kaderschmiede für Funktionseliten zum „moderne[n] Modus der Vergesellschaftung،321 aller.

Denn akademische Bildung ist heute ein elementarer, wenn nicht der wesentliche Einflussfaktor der Ressourcenzuteilung und damit der sozialen Position in postindustriellen Verhältnissen - und das in kontinuierlich steigendem Maße. ${ }^{322}$ Die akademische Professionalisierung, d.h. das Prinzip der zertifikatsbasierten Berufsqualifikation vornehmlich in Gestalt formeller Hochschulbildung, ist in den letzten Jahrzehnten in immer größere Bereiche des Arbeitsmarktes expandiert; unter dieser Ausbreitung des meritokratischen Prinzips leiden seit den 1970er Jahren vor allem die nicht akademisch gebildeten Teile der Bevölkerung, die sich mit zunehmend schlechteren Arbeitsmarktchancen arrangieren müssen. ${ }^{323}$ Insbesondere für den Nachwuchs sozial schwacher Familien oder solcher mit Migrationshintergrund gilt die vom Dresdner Bildungsgipfel 2008 stammende Formel vom „Aufstieg durch Bildung“ am wenigsten. ${ }^{324}$ „Der beste Schutz gegen Arbeitslosigkeit", so konstatierte der Historiker Hans-Ulrich Wehler daher sarkastisch, „ist seit langem das Absolvieren eines Hochschulstudiums“. ${ }^{325}$ Wenn man berücksichtigt, dass die Einkommensdifferenzen zwischen den höher und niedriger qualifizierten Berufsgruppen unterdessen nach wie vor auseinanderweisen, so stellt die Frage des Studiums heute sogar mehr denn je die Scheidelinie klassengesellschaftlicher sozialer Gegensätze dar: Die „meritokratische Leitfigur sozialer Ungleichheit“ in der heutigen deutschen „Bildungsgesellschaft“326 zementiert somit nicht nur Strukturen sozialer Ungleichheit und der Allokation von Gütern und Stellen, sondern legitimiert sie: Unterschiede in Intelligenz, Begabung und sozialer Herkunft werden in dieser Vorstellung durch erworbene Kompetenzen, geronnen in Bildungszertifikaten, als verbürgt angesehen. „Dies impliziert die häufig anzutreffende Annahme, dass die ,Sieger' im Bildungswettbewerb ihre Chance genutzt haben, die ,Verlierer die glei-

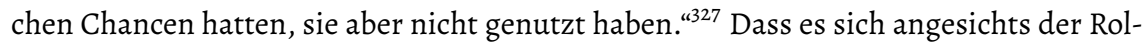
le der sozialen Herkunft, des Zufalls, der personellen Netzwerke usw. hierbei um eine ideologische Vorstellung im klassischen Sinn, d. h. um eine Vermengung realitätswirksamer Aspekte mit einer hoch autosuggestiven und unrealistischen Unterstellung vollendet fairer Startchancen für alle handelt, wird von Soziologinnen und Soziologen

321 Vgl. ibid., S. 404.

322 Vgl. Raphael, Lutz: Jenseits von Kohle und Stahl. Eine Gesellschaftsgeschichte Westeuropas nach dem Boom, Frankfurt a.M. 2019, S. 247-295.

$323 \mathrm{Vgl}$. Solga, Heike: Ohne Abschluss in die Bildungsgesellschaft: die Erwerbschancen gering qualifizierter Personen aus soziologischer und ökonomischer Perspektive, Opladen 2005, S. 247.

324 Vgl. Fokken, Silke: Das leere Versprechen vom Aufstieg durch Bildung, in: Spiegel Online, 22.10.2018, online einsehbar unter: http://www.spiegel.de/lebenundlernen/schule/deutschlanddas-leere-versprechen-vom-aufstieg-durch-bildung-a-1234211.html [eingesehen am 01.08.2019] Vgl. Wehler: Deutsche Cesellschaftsgeschichte 1945-1990, S. 194. Siehe auch ibid.: „Die Inhaber vorteilhafter Positionen tendieren zur Schließung, um ihre Stellung durch Exklusion abzusichern. Der Zugang zu diesen privilegierten Positionen wird immer strenger an Zertifikate des höheren Bildungssystems gebunden." 
zwar weitgehend gesehen; ${ }^{328}$ der praktischen Wirksamkeit des Selektionskriteriums von Bildungszertifikaten im Rahmen der „akademischen Bildungsstory“ und der damit verbundenen drastischen Konsequenzen - schlechte Berufsaussichten, „institutionelle Identitätsbeschädigung", Entwertung des Selbstwertgefühls, Stigmatisierung und Adaption der Limitierungen in den Bereich der Träume und Hoffnungen für den eigenen Lebenslauf - für die zunehmend abgehängten gering Qualifizierten tut das keinen Abbruch. ${ }^{329}$ „In der Bilanz überwiegen Abbrüche, Risse, Zurückweisungen, Verletzungen, nicht die psychisch stärkenden Augenblicke des Gelingens und des Erfolgs.“330 Dass sich die Berufschancen durch Bildung und kulturelles Kapital infolge einer Erhöhung des gesamtgesellschaftlichen Bildungsniveaus eher für ohnehin privilegierte Gruppen erhöhen als für die unteren Schichten, wird hier als „Bildungsparadoxon“ verhandelt. ${ }^{331}$

Freilich: Für jene gute Hälfte der nachrückenden Kohorten, die in der „Leistungsgesellschaft" des 21. Jahrhunderts am modernen Massenstudium teilnimmt, stehen die Berufsaussichten vergleichsweise gut; für sie ergibt die Rhetorik von Leistung und Bildung angesichts einer bereits seit Jahren stabilen Arbeitsmarktsituation Sinn. ${ }^{332}$ In den Nutzenerwartungen eines Studiums bzw. den prospektiven Berufs- und Statusaussichten spiegeln sind diese Komfortansprüche ungebrochen sichtbar, auch wenn sie nicht immer klar artikuliert werden. Befragt nach den Motivationen zur Aufnahme eines Studiums, nannten an Universitäten in den 1980er Jahren (1983, 1985 und 1987) zwar nur etwa 23-26 Prozent der Studierenden, ein „gutes Einkommen zu sichern“ und eine „hohe soziale Position zu erreichen“ - ebenso hoch im Kurs stand die Maxime, mit dem Studium „zur Verbesserung der Gesellschaft beizutragen“ -; wichtiger war ihnen, später einen „interessanten“ Arbeitsplatz zu erlangen (ca. 65 Prozent) oder „mehr über das Fachgebiet zu erfahren“ (70 Prozent); randständig blieb der Wunsch, das Studium als Moratoriumsphase zur Erprobung „alternativer Lebensweisen“ mit ca. 12 Prozent. ${ }^{333}$ Zugleich aber gab die überwältigende Mehrheit der befragten Studierenden an Universitäten durchaus die Erwartung an, als Absolventen über ein höheres Ansehen (ca. 90 Prozent), ein größeres Einkommen (ca. 90 Prozent) und überdies über einen größeren politischen Einfluss (ca. 80 Prozent) zu verfügen. ${ }^{334}$ Drei Viertel von ihnen maßen den Akademikerinnen und Akademikern allgemein eine besondere gesellschaftliche Verantwortung bei. ${ }^{335}$ Im Verlauf der $1990 e r$ Jahre $(1993,1995,1998)$ stellten die Autoren des Studierendensurveys eine Abnahme materieller Motivlagen bei gleichbleibender Suprematie

328 Vgl. ibid., S. 42.

329 Vgl. ibid., S. 48-51, 92f., 137, 170-175 und 247.

330 Walter: Zeiten des Umbruchs?, S. 26.

331 Vgl. klassisch Beck, Ulrich: Risikogesellschaft. Auf dem Weg in eine andere Moderne, Frankfurt a.M. 1986, S. 242-248 sowie Bourdieu, Pierre: Homo academicus, Frankfurt a.M. 1992.

332 Vgl. exemplarisch Klemm, Thomas: Bildung macht reich, in: Frankfurter Allgemeine Sonntagszeitung, 02.03.2017 und o. V.: Deutschland nähert sich der Vollbeschäftigung, in: Frankfurter Allgemeine Zeitung, 29.06.2018.

Vgl. Studierendensurvey 1980er, S. 69. Hier und im Folgenden werden die Werte für Studierende an Universitäten wiedergegeben; die z. T. abweichenden Ergebnisse für Fachhochschulen bleiben unberücksichtigt. 
von Fachinteresse und der Orientierung an der eigenen fachlichen Begabung fest. ${ }^{336}$ Für den Wunsch, nach dem Studium eine „interessante“ Arbeit zu verrichten, erachteten die Studierenden die Immatrikulation zu ca. 73 Prozent als „sehr nützlich“, für die Befriedigung ihres fachlichen Interesses ca. 68 Prozent; ein "gutes Einkommen“ hielten zwar nur ca. 35 Prozent der Befragten und das Erlangen einer „hohen sozialen Position“ ca. 22 Prozent für sehr wahrscheinlich, aber immerhin ca. 80 bzw. 70 Prozent für eher wahrscheinlich. Das Studium als verlängerte Moratoriumsphase zu nutzen („alternative Lebensweisen erproben“ und „die Zeit der Berufstätigkeit möglichst lange hinausschieben"), war ca. 20-25 Prozent der Befragten sehr wichtig, immerhin 50-60 Prozent von ihnen eher wichtig. ${ }^{337}$ Der Trend zum Vorrang ideeller Motive bei der Studienwahl setzte sich in den 2000 er Jahren fort: Im Wintersemester 2006/07 ergab die Rangfolge der „sehr wichtigen“ Studienmotive 71 Prozent Fachinteresse und 58 Prozent eigene Begabung, zugleich fielen immerhin 36 Prozent für den Wunsch nach einem sicheren Arbeitsplatz, aber nur 24 Prozent für das Streben nach attraktiven Einkommenschancen und 17 Prozent für die Aussicht auf eine Führungsposition ab. ${ }^{338}$ Jedoch: Befragt nach den künftigen Nutzenerwartungen des Studiums rangierten die Erwartung „interessanter“ Arbeit bei 75 Prozent und vermehrten Fachwissens bei 72 Prozent, zugleich aber stuften 47 Prozent das Studium als nützlich bis sehr nützlich für ein "gutes" Einkommen - der Wert lag 1983 noch bei 26 Prozent! -, für eine „hohe“ soziale Position 28 Prozent ein; die Berufstätigkeit hinausschieben wollten nur noch 7 Prozent der befragten Studierenden. ${ }^{339}$ Dieser Dualismus aus ideell dominierter (dabei aber zunehmend vom Bedürfnis nach relativer Arbeitsplatzsicherheit durchsetzter) Studienwahl und stark materiell flankierten Nutzenerwartungen, kurzum: der gap zwischen Studienmotiven und Nutzenerwartungen, setzt sich bis heute fort. 2012/13 betrugen die Werte der Studienmotive von Studierenden an Universitäten 74 Prozent Fachinteresse und 60 Prozent eigene Begabung gegenüber 43 Prozent Orientierung an einem sicheren Arbeitsplatz, 28 Prozent Einkommenschancen und 16 Prozent Aussicht auf eine Führungsposition. ${ }^{340}$ Großen Nutzen für eine „interessante“ Arbeit versprachen sich 79 Prozent vom Studium, fundiertes Fachwissen 75 Prozent, ein „gutes“ Einkommen 58 Prozent, eine „hohe“ soziale Position 31 Prozent; den Berufseinstieg hinauszögern wollten 8 Prozent, „anderen helfen“ 40 Prozent und die Gesellschaft „verbessern“ 43 Prozent. ${ }^{341}$ Im Wintersemester 2015/16 - die aktuellsten Zahlen - nahmen 77 Prozent aus speziellem Fachinteresse und 62 Prozent aus persönlicher Begabung ihr Studium auf gegenüber 27 Prozent aus dem Wunsch nach besseren Einkommenschancen, 36 Prozent aus dem Wunsch nach einem sicheren Arbeitsplatz und 15 Prozent aus dem Wunsch, sich für eine Führungsposition zu qualifizieren. ${ }^{342}$ Demgegenüber gaben 74 Prozent der Befragten an, vornehmlich dem eigenen Fachinteresse, 60 Prozent, der eigenen Begabung zu folgen; einen sicheren Arbeitsplatz versprachen sich nunmehr 53 Prozent, gute

336 Vgl. Studierendensurvey $1997 / 98$, S. 7of.

337 Vgl. ibid., S. 78.

338 Vgl. 10. Studierendensurvey 2006/07, S. 32-34.

339 Vgl. ibid., S. 35.

340 Vgl. 12. Studierendensurvey 2012/13, S. 88.

341 Vgl. ibid., S. 93.

342 Vgl. 13. Studierendensurvey 2015/16, S. 13. 
Einkommenschancen 28 Prozent, die Aussicht auf eine Führungsposition 16 Prozent. ${ }^{343}$ Nützlich bis sehr nützlich für den Weg zu einem „interessanten“ Arbeitsplatz erschien 76 Prozent der hier befragten Studierenden das eigene Studium, zu mehr Fachwissen 73 Prozent; Hoffnungen auf erhöhte Chancen, ein „gutes“ Einkommen zu erlangen, machten sich 53 Prozent, auf eine "hohe" soziale Position 30 Prozent. 9 Prozent hofften, mit dem Studium mehr Zeit bis zum Berufseintritt zu gewinnen, 40 Prozent hoffen allerdings, später „anderen zu helfen“ bzw. 45 Prozent, die Gesellschaft zu „verbessern“. ${ }^{344}$ Befragt nach den beruflichen Wertvorstellungen, geben zwei Drittel der Studierenden aktuell an, grundsätzlich großen Wert auf einen sicheren Arbeitsplatz zu legen - direkt nach der Vereinbarkeit von Familie und Beruf, die 83 Prozent der Studierenden am Herzen liegt! ${ }^{345}$ Freiwirtschaftliche Arbeitgeber werden ebenso anvisiert wie die öffentliche Bedienstung.

Die Einschätzung der eigenen Berufsaussichten bzw. die Wahrnehmung der prospektiven Arbeitsplatzsicherheit variiert gemäß den unterschiedlichen gesamtwirtschaftlichen Rahmenbedingungen und abhängig vom Studienfach: So stellen Studierende der Wirtschafts- und Rechtswissenschaften materielle Motive am häufigsten in den Vordergrund, Studierende der Geistes- und Sozialwissenschaften am seltensten. ${ }^{346}$ Insbesondere ab 1985 befürchteten ca. 19 Prozent der Studierenden an Universitäten große Schwierigkeiten bei der beruflichen Einmündung; ${ }^{347}$ in den 1990er Jahren, inmitten des so genannten „Reformstaus“, schnellte dieser Wert auf 34 bis 38 Prozent. Die Belastung wurde insbesondere von den Studentinnen in dieser Phase als drastisch empfunden. ${ }^{348}$ Mit den $2000 e r$ Jahren lösten sich diese Sorgen allerdings ein Stück weit auf: 2007 erwarteten 30 Prozent der Befragten grundsätzlich „kaum Schwierigkeiten“ bei der Stellenfindung, allerdings 35 Prozent beim Finden einer „zusagenden" Stelle; ${ }^{349}$ 2012/13 stieg der Wert der Sorglosen auf 35 Prozent (Schwierigkeiten bei der Findung einer „zusagenden“ Stelle erwarteten gleichbleibend 35 Prozent); 350 2015/16 machten sich 36 Prozent „kaum“ Sorgen und 36 Prozent Sorgen, keine „wirklich zusagende" Stelle zu finden. ${ }^{351}$ Seit Ende der 1990er Jahre scheint sich insgesamt eine gewisse subkutane Unsicherheit eingegraben zu haben. Hier ist der Wunsch, einen sicheren Arbeitsplatz zu erlangen - nicht die Aussicht auf ein hohes Einkommen! - als dominierendes materielles Studienmotiv einzuordnen; der Zustimmungswert

343 Vgl. ibid., S. 15.

344 Vgl. ibid. Inwiefern dieser neue „sozial-altruistische“ Frageblock tatsächliche Wünsche abbildet oder hier eine suggestive Verzerrung am Werk ist - Wer hofft nicht, mit seiner Tätigkeit einen Beitrag zu einer besseren Zukunft zu leisten? -, kann hier freilich nicht entschieden werden. Vgl. 12. Studierendensurvey 2012/13, S. 387 und 13. Studierendensurvey 2015/16, S. 68.

346 Vgl. Studierendensurvey 1980er, S. 75; 7. Studierendensurvey 1997/98, S. 73; 10. Studierendensurvey 2006/07, S. 34f.; 12. Studierendensurvey 2012/13, S. 91

347 Vgl. Studierendensurvey 1980er, S. 203.

348 Vgl. Studierendensurvey 1990er, S. 188. An den Fachhochschulen litten zudem in erster Linie die Immatrikulierten in ingenieurswissenschaftlichen Studiengängen.

349 Vgl. 10. Studierendensurvey 2006/07, S. 239.

350 Vgl. 12. Studierendensurvey 2012/13, S. 376.

351 Vgl. 13. Studierendensurvey 2015/16, S. 73. 
kletterte zwischen 1998 und 2015/16 von 23 auf 36 Prozent. ${ }^{352}$ Zugleich hat die Bereitschaft zu mehr beruflicher und geographischer Flexibilität trotz des insgesamt eher optimistischen Blicks auf die späteren Berufsaussichten zugenommen. ${ }^{353}$ Unklar bleibt angesichts der standardisierten Frage-Items allerdings, welchen Lebensstandard die Studierenden in den von ihnen gewünschten sicheren Arbeitsplätzen als angemessen empfinden.

Welchen Anspruch sie hier anmelden können, hängt allerdings, wie gesehen, vom Stadium des Hochschulexpansionszyklus' ab. Einerseits war Bildung trotz aller Privilegien- und Schichtungsmuster schon im 18. und 19. Jahrhundert eine „Mobilitätsschleuse, ein kalkulierbarer Weg des sozialen Aufstiegs“. ${ }^{354}$ Bis zum Ende des Kaiserreichs gelangten so etwa 20 Prozent Handwerker- und Bauernkinder in ein Studium. ${ }^{355}$ Aufgrund der wirtschaftlichen und demographischen Wachstumssprünge, der Ausdifferenzierung der Arbeitsmärkte, usw. stellten sich immer wieder Phasen des Akademikermangels mit fließendem Übergang in eine Aufschwungbewegung ein, die schubweise den Aufstieg von zuvor ausgeschlossenen Bevölkerungsteilen, meist der unteren und mittleren Mittelschichten, freigaben. In diesen Phasen greifen die Hochschulen auf die Reserven aufstiegswilligen Nachwuchses zurück ${ }^{356}$; in diesen Phasen lockern sich Restriktionen, öffnen sich die Selektionsfilter, kann der Bildungsaufstieg für neue Gruppen gelingen. Das war um 1850ff., um 1900ff. und um 1950ff. der Fall. ${ }^{357}$ Die sukzessive soziale Öffnung der Universitäten (und Fachhochschulen) erscheint vor diesem Hintergrund als logische Fortsetzung eines historischen Makro-Trends hin zur sukzessiven sozialen Egalisierung des Studiums. Doch lassen sich, andererseits, eben auch gegenläufige Abschwungs- und Überfüllungszeiträume ausmachen, die Abschottungstendenzen gegen die nachrückenden Bildungsfernen zeitigten meist in Form von Qualifikationsschranken, gläsernen Decken, aber auch mit einer dramatisierenden Überzeichnung der Arbeitsmarktsituation $\mathrm{zu}$ Abschreckung von Aufstiegsinteressierten ${ }^{358}$-, mit denen nicht zuletzt die kürzlich aufgestiegenen Generationen ihre Privilegien abzusichern versuchten. Die soziale Funktion des Studiums besteht 1815 wie 2019 trotz "fortschreitender Demokratisierung der Bildungschancen“ in der „Bildungsselektion“359, also der Auslese qualifizierter Berufsgruppen, wie in

352 Vgl. 10. Studierendensurvey 2006/07, S. 33 und 13. Studierendensurvey 2015/16, S. 13. Diese Entwicklung mag allerdings auch durch eine Erweiterung der Fragebatterie des Studierendensurveys mitbedingt sein.

Vgl. 10. Studierendensurvey 2006/07, S. 244; 12. Studierendensurvey 2012/13, S. 402 und 13. Studierendensurvey 2015/16, S. $77 f$.

354 Lundgreen: Zur Konstitutierung des „Bildungsbürgertums“, S. 88

355 Vgl. ibid., S. 96.

356 Vgl. ibid., S. 404.

357 Vgl. Titze: Wie wächst das Bildungssystem?

358 „Der Akademikerzyklus entlastet die oberen Sozialschichten von Selektionsdruck, indem er die besseren sozialen Zugangschancen als Leistung tarnt und legitimiert. Der verborgene Mechanismus besteht gerade darin, daß viele an die vorausgesagten schlechten Berufsaussichten glauben. Durch die Voraussagen und vom schleichend veränderten Selektionsklima lassen sich eher die Nachkommen in den unteren Schichten von einer langen akademischen Ausbildung abschrecken und dadurch verbessern sich die Chancen in der Prüfungsauslese für den Nachwuchs aus den oberen Schichten." Titze: Bildungskrisen und sozialer Wandel, S. 363.

Vgl. Titze: Von der natürlichen Auslese zur Bildungsselektion, S. 389. 
solchen Phasen lebendig erfahrbar wird. Schlechte Berufsaussichten und akademische Arbeitslosigkeit, auch das so genannte „Parkstudium“ drohen dann zu Massenphänomenen zu geraten. Verhärtungsperioden dieser Art sind in der Vergangenheit nach Kondratjew'schem Takt etwa alle 50 Jahre aufgetreten und konzentrierten sich grob auf die Schlüsseljahre 1780, 1830, 1880, 1930, und 1980. ${ }^{360}$ Verblüffenderweise verhält sich diese zyklische Bewegung, d. h. die Entwicklung der Bildungsexpansion seit dem ausgehenden 19. Jahrhundert weitgehend eigendynamisch und in engem Kontakt mit wirtschaftlichen Konjunkturen, ist insofern ohne massiven wirtschaftlichen Schaden bildungspolitisch kaum bis gar nicht regulierbar: ${ }^{361}$

„Eine erfolgreiche herrschaftliche Steuerung des Bildungsbedarfs war im Kaiserreich nicht mehr möglich. Wegen der Eigendynamik des kollektiven Bildungsverhaltens bauen sich im historischen Prozeß Strukturen auf, die sich nicht mehr herrschaftlich steuern lassen. ${ }^{\text {“362 }}$

„Die Bildungsexpansion gewinnt [...] eine Eigendynamik, deren Konsequenzen zwar bildungspolitisch bearbeitet werden müssen, die sich aber politischen Steuerungsversuchen im Sinne von Begrenzungsstrategien weitgehend entzieht. Cooling outStrategien oder andere Maßnahmen der Cegensteuerung mögen einen kurzfristigen Erfolg in der Unterbrechung langfristiger Expansionstrends haben, dauerhaft wirksam sind sie nicht."363

Zwar beteiligen sich Wissenschaft, Publizistik und Politik immer wieder an Diskussionen über die langfristige Dysfunktionalität der Bildungsexpansion, kritisieren die Mutation des Studiums zur höheren Berufsausbildung, die das deutsche duale System entwerte, d. h. sowohl die Qualität akademischer Bildung als auch das Angebot an nicht-akademisch beruflich Qualifizierten reduziere. ${ }^{364}$ Der Philosoph Julian NidaRümelin attestierte der Bundesrepublik 2014 in diesem Sinne gar einen „Akademisierungswahn ${ }^{4365}$, als handle es sich hierbei um einen nationalen Verstandesverlust. Und gewiss: Der nächste konjunkturell bedingte „Akademikerüberschuss“ infolge eines Überangebots von Hochschulabsolventen wird kommen, wenn auch nicht zwangsläufig und mit schicksalsdeterministischer Wucht im Jahre 2030. Dennoch sollte vor dem

360 Vgl. Titze: Bildungskrisen und sozialer Wandel, S. 349.

361 Dass sich das Bildungswachstum, genauer: die "Selbststeuerung der Gebildeten von unten“ schon nach 1850 sukzessive "aus herrschaftlicher Kontrolle im Sinne einer Steuerung von oben befreit“ habe, führt Titze auf unterschiedliche Einflüsse zurück, darunter die Entstehung freier akademischer Arbeitsmärkte bzw. eines „freien Rekrutierungsfeldes" beginnend im Bereich der höheren Bildung, freier Presse und freien politischen Wettbewerbs sowie die berufsständische Interessenorganisation des immens gewachsenen Lehrpersonals an Volksschulen ab 1890 und der daraus folgende "Legitimationsdruck"staatlicher Steuerungsmaßnahmen - und nicht zuletzt die auf Ausbau zielende „Eigendynamik des Bildungssystems“. Titze, Hartmut: Wie wächst das Bildungssystem?, in: Zeitschrift für Pädagogik, 45. Jg., H. 1/1999, S. 103-120, hier S. 109-113. Ibid., S. 113. Wolter: Eigendynamik und Irreversibilität der Hochschulexpansion, S. 35 (Herv. i. O.) Vgl. exemplarisch Oder, Lisa: Immer mehr junge Menschen mit Hochschulabschluss - wieso das zum Problem werden kann, in: Handelsblatt, 08.09.2018.

365 Vgl. Nida-Rümelin, Julian: Der Akademisierungswahn. Zur Krise beruflicher und akademischer Bildung, Hamburg 2014. 
Hintergrund des historischen Längsschnitts klar sein, dass der Zustrom zu den Hochschulen so lange anhalten wird, wie „der Arbeitsmarkt eine höhere Qualifikation belohnt ${ }^{\star 366}$. Und das ist, folgt man dem Bildungsforscher Andrä Wolter, noch einige Jahre so. ${ }^{367}$ Doch auch abgesehen davon zählt die Bildungsexpansion, die längst nicht mehr nur höhere Bildungszertifikate, sondern auch hinzutretende „feinere Unterschiede“ (Erfahrungen, Netzwerke, kulturelles Kapital) für die Einlösung gesellschaftlicher Teilhabechancen erforderlich macht, ${ }^{368}$ "gleichsam als gesellschaftliche Grundströmung zu den irreversiblen sozialen Vorgängen in Gesellschaften, die Prozesse der Statuszuweisung marktförmig und leistungsorientiert organisieren oder mindestens so legitimieren [...] $]^{\text {‘369 }}$ Die höhere Bildung, das veranschaulichen diese Ausführungen, gerät für nachfolgende Kohorten mehr und mehr zur „Grundausstattung in der Statuskonkurrenz". 370

Die Veränderung macht sich auch in den Zahlen geltend: Selbst die am stärksten materiell motivierten Studierenden sehnen sich nicht mehr primär nach einem möglichst hohen Einkommen, sondern nach der Absicherung des von ihnen gewohnten Status und Lebensstandards. Stellt man aber genau dies in Rechnung - dass nicht mehr die Sehnsucht nach dem Sozialprestige des klassischen Akademikers oder etwa die Aspirationen auf überdurchschnittlichen Wohlstand, sondern die Absicht, eine den eigenen Präferenzen entsprechende, inhaltlich attraktive und zufriedenstellend bezahlte Erwerbstätigkeit aufzunehmen, die zugleich das eigene Qualifikationsportfolio nach Arbeitsmarktbedürfnissen ausrichtet und somit zuverlässig vor Erwerbslosigkeit schützt, ${ }^{371}$ das primäre materielle Motiv des Studierens auszumachen scheint ${ }^{372}$ - so gilt trotzdem ungebrochen, was vor etwa einer Dekade über Studierende an Universitäten konstatiert wurde: „Die Erwartungen an materielle Vorteile und Gratifikationen sind seit den 8oer Jahren stetig angestiegen.“373 Man erwartet durchaus, des Segens der Qualifizierten sozusagen en passant teilhaftig zu werden, auch wenn man das nicht als primäres Studienmotiv identifiziert. Dies schafft der Vermutung Raum, dass das Universitätsstudium von der Mehrheit der Studierenden heute tatsächlich in erster Linie als höhere Form der Ausbildung - nicht etwa als Stätte holistischer Bildung im neuhumanistischen Sinne -, als Pfad zu einem gehobenen und ausbalancierten Lebensstandard wahrgenommen und genutzt wird - was dem Trend zur Universalisierung von Bildungszertifikaten als Voraussetzung gehobener Karrieren, zur Ersetzung der „Elitehochschulbildung“ durch „Massenhochschulbildung “374 durchaus entspricht. Tatsächlich ist das Erwerbslosigkeitsrisiko für Hochschulabsolventen im Vergleich mit allen anderen Bevölkerungsgruppen nach wie vor am geringsten. ${ }^{375}$ Natürlich ist die Absicht, mithilfe einer Höherqualifizierung auch ein höheres Einkommen zu erzielen,

366 Vgl. Wolter: Eigendynamik und Irreversibilität der Hochschulexpansion, S. 36.

367 Vgl. ibid.

368 Ibid., S. 34 f.

369 Ibid., S. 35.

370 Ibid.

371 Vgl. Bargel: Wandel politischer Orientierungen, S. $4 \mathrm{f}$.

372 Vgl. 13. Studierendensurvey 2015/16, S. 68.

373 10. Studierendensurvey 2006/07, S. 36.

374 Vgl. Wolter: Eigendynamik und Irreversibilität der Hochschulexpansion, S. 37

375 Vgl. 5. Bildungsbericht 2014, S. 135. 
selbstverständlicher Bestandteil jeder Fortbildungsbemühung. Aber wie ist diese Beobachtung in Einklang zu bringen mit den in den Surveys vorgetragenen altruistischen und prosozialen Ansprüchen an die eigene Arbeit als angehende Akademiker, die ja gerade auf einen „höheren“ Zweck des Studierens jenseits von interesse- wie neigungsgemäßer Selbstentfaltung und Einkommen ${ }^{376}$ verweisen? Darauf geben die Surveys keine Antwort.

Es lässt sich resümieren: Die Geschichte der Bildungsexpansion seit 1800 bezeichnet mehrere kleine Wachstums- und Stagnationsphasen, vor allem aber zwei große Wachstumssprünge in den 1870er und 1960er/1970er Jahren. Stets ging der „Eigenausbau" des Bildungssystems durch den Bedarf an Hochschulpersonal und Lehrkräften dem „Breitenwachstum“, also der fortschreitenden Akademisierung der Berufswelt, voran. ${ }^{377}$ Entscheidend für den heutigen Stellenwert der Bildungsselektion ist dabei der beispiellose Wachstumssprung der 1960er und 1970er Jahre, der als weitgehende Überwindung der Kluft zwischen Elite- und Massenbildung aufgefasst werden kann. ${ }^{378}$ Doch die im Vogelflug eindrückliche soziale Öffnung der Hochschulbildung sollte zugleich nicht darüber hinwegtäuschen, dass die individuellen Bildungschancen auch heute noch über "Lebens- und Teilhabechancen“ entscheiden, und dass diese Bildungschancen in Deutschland maßgeblich vom Bildungsniveau der Eltern abhängen. ${ }^{379}$ Persönliche Bildungsentscheidungen steuern die Expansion der Hochschulbildung, insbesondere die wachsende Attraktivität des Bildungswegs Gymnasium - Universität: „Das Abitur eröffnet die meisten und versperrt die wenigsten nachschulischen Ausbildungs- und Berufsoptionen." ${ }^{380}$ Überhaupt liegt der entscheidende Selektionsfilter hierzulande nicht beim Hochschulzugang, sondern genau hier, im Schulsystem, insbesondere im Erwerb oder Nichterwerb des Abiturs. Mit der Verbreitung Bildungszertifikaten und Titeln aber wächst auch die Statuskonkurrenz: „feinere Unterschiede“ (Kontakte, Praktika, Habitus, etc.) werden als Selektionskriterien wichtiger. ${ }^{381}$

Dem ist eine mit Blick auf mögliche Prägungen studentischer politisch-sozialer Deutungsmuster relevante abschließende Bemerkung zum vermeintlichen Niedergang des Bildungsbürgertums anzuschließen: Heute ist es durchaus möglich, dass es trotz des Verblassens des sozial, kulturell und materiell privilegierten traditionellen Bildungsbürgertums im Zuge des Niedergangs des Kaiserreichs und der Genese der modernen Massenuniversität nicht nur weiterhin sedimentierte bildungshumanistische Werthaltungen und gesellschaftliche Ordnungsvorstellungen gibt, die nicht zuletzt in den Begriffen „Bildung“ bzw. „Geist“ oder "Geisteswissenschaften“ aufgespeichert sind. Auch erscheint die Vermutung plausibel, dass durchaus noch

376 Sicher sind das Interesse am Studienfach und die Rahmung der Auswahl durch die persönlichen Begabungen durchaus „authentische“ Motivlagen, die der Forscher ernst zu nehmen hat. Zugleich aber scheint es doch - und diese Beobachtung soll hier hervorgehoben werden - für eine knappe Mehrheit der Studierenden ungebrochen üblich, ja selbstverständlich zu sein, nach dem Abschluss mehr zu verdienen als Nichtstudierte.

377 Vgl. Titze: Wie wächst das Bildungssystem?, S. 116-118.

378 Vgl. ibid., S. 115.

379 Vgl. Wolter: Eigendynamik und Irreversibilität der Hochschulexpansion, S. 29 und 35.

380 Ibid., S. 28.

381 Vgl. ibid., S. $34 f$. 
eine bestimmte Residualform einer Sozialformation „Bildungsbürgertum“ in der deutschen Gesellschaft existiert, die sich im frühen 20 . Jahrhundert mit der demokratischen Herrschaftsform herausgebildet hat: als Phänomen einer subkulturellen Kollektivität unter vielen, welche sich in Lebensstilpräferenzen, einem spezifischen Erziehungs- und Bildungsideal nebst Anspruch auf geistige Elitenzugehörigkeit, gewiss auch in ererbtem Besitz ausdrückt ${ }^{382}$ - aber eben ohne Nähe zur Macht, $d$. h. ohne öffentlichkeitswirksamen gesamtgesellschaftlichen Einfluss. ${ }^{383}$ Man wird sich aufgrund der bisher schmalen soziologischen Forschung zu dieser Frage ${ }^{384}$ mit der so skizzierten hypothetischen Konstruktion begnügen müssen. Auch wenn sie den von vielen Historikern als „wissenschaftlichen Terminus“ qualifizierten Begriff des Bildungsbürgers als „sozialprivilegierte ständische Vergesellschaftung von Trägern akademisch patentierten Bildungswissens mit gesamtgesellschaftlicher Sinnstiftungsund Normsetzungskompetenz ${ }^{\text {“385 }}$ in Richtung eines "umgangssprachlichen Etiketts“ verflacht: Während das szientivistisch exakt bezeichnete Bildungsbürgertum mit dem Ende des langen bürgerlichen Jahrhunderts verschwindet, lässt die „vage konturierte Kollektion ,gutsituierter Bürger mit höherer Schulbildung, diffusen Eigenschaften

382 Vgl. Budde: Blütezeit des Bürgertums, S. 136f.

383 „Der gesamtgesellschaftliche Einfluß beruhte aber primär auf der Chance, den Geltungsanspruch des Bildungswissens in konkrete institutionelle Ordnungen zu übersetzen und diese selbst zu verwalten. [...] Das ändert sich mit dem Ausgang des 19. Jahrhunderts, und damit kommt auch die gesamtgesellschaftliche Bedeutung des Bildungsbürgertums zu seinem Ende. Zwar erhält sich noch die ständische Vergesellschaftung als Lebensstil, doch sie verliert den Anspruch auf Allgemeingültigkeit und die Mittel, diese Prätention weiter aufrechtzuerhalten. Bildungsbürgerlichkeit wird zur Subkultur, einer von vielen. Damit aber ist die ständische Vergesellschaftung aufgelöst." Lepsius, Mario Rainer: Das Bildungsbürgertum als ständische Vergesellschaftung, in: Ders. (Hg.): Bildungsbürgertum im 19. Jahrhundert. Teil III: Lebensführung und ständische Vergesellschaftung, S. 9-18, hier S. 18. Vgl. auch den Exkurs zum Bildungsbegriff in Kapitel II.3.

384 Vorsichtig diskutiert jüngst Gunilla Budde: „Doch heißt das gleichzeitig, dass mit der Diffusion bürgerlicher Werte auch das Bürgertum von der Bildfläche verschwand, dass wir es im 20. und 21. Jahrhundert eher, wie Soziologen wie Heinz Bude und Paul Kaiser vermuten, mit einer ,Bürgergesellschaft ohne Bürgertum' zu tun haben? Zumindest wäre ein klares, ja' auf diese Frage vorschnell, stehen doch die entscheidenden empirischen Studien noch aus. Zu Recht hat Klaus Tenfelde dafür plädiert, gezielt in Institutionen, die von jeher als Stätten bürgerlicher Kulturmuster und Praktiken galten, auf Spurensuche zu gehen. Erste Hypothesen lassen sich wagen, soziologische Studien stützen sie: Bei allem klassenübergreifenden Vereinsleben und bürgergesellschaftlichen Engagement, die bald nach Kriegsende zur Entfaltung kamen, scheint sich in einigen Bereichen dieser Öffentlichkeit weiterhin eine Affinität zwischen Zivilgesellschaft und einer spezifischen bürgerlichen Gruppierung gehalten zu haben. Die Vermutung liegt nahe und erste Auswertungen bestätigen es, dass sich in den zahlreichen Kunstvereinen, Berufsverbänden und Service-Clubs eine geschlossene, exklusive Klientel traf. Ärzte, Rechtsanwälte und Unternehmer blieben lange im Tennis- und Golfverein unter sich, auf dem Fußballplatz waren sie indessen weniger zu finden. Auch in den frühen Bürgerbewegungen, in denen sich dem Namen nach alle Staatsbürger unter dem Banner eines gemeinsamen Interesses vereinten, gab vornehmlich eine bildungsbürgerliche Klientel, dem Erbe der Cemeinwohlorientierung verpflichtet, den Ton an." Budde: Blütezeit des Bürgertums, S. 136f. S. überdies Schulz: Lebenswelt und Kultur des Bürgertums, der S. 90 selbstbewusst konstatiert: „Von der Vorstellung einer ,Auflösung des Bürgertums' in den großen Krisen des Jahrhunderts kann man sich getrost verabschieden."

Vgl. Engelhardt: „Bildungsbürgertum“, S. 205. 
und zeit-/räumlich fast unbegrenzter Verbreitung، ${ }^{486}$ das heutige subkulturelle Auftreten von Bildungsbürgern grundsätzlich $\mathrm{zu}$ - so lässt sich eine allzu dogmatische Vorentscheidung umgehen. Gewiss ist der Begriff des Bildungsbürgers nicht der konzeptuellen Beliebigkeit hinzugeben, auch ist zu bedenken, dass er von seinem bis heute präsenten denunziativen Beiklang - etwa als Bezeichnung eingebildeter „Schöngeistigkeit" eines deplatzierten Bewusstseins als Geisteselite, oder als selbstreferenzielle unpolitische Innerlichkeit -, nicht $\mathrm{zu}$ befreien ist. Soziohistorisch gegenstandslos, mithin „sinnlos“ geworden ${ }^{387}$ ist er deshalb nicht. Das zeigen erstens die Expansionsund Diffusionsprozesse von Bürgerlichkeit in die Mehrheitsgesellschaft: ${ }^{388}$

„Während die Wertschätzung bürgerlicher Kulturtraditionen fortbesteht, hat sich die bürgerliche Klassengesellschaft sozial ausdifferenziert. [...] Stärker als Herkunft und Klasse bestimmen der Bildungsweg und die berufliche Position den sozialen Status. ${ }^{\text {“389 }}$

Zudem sind ökonomisch, kulturell, sozialisatorisch und auch organisatorisch gesehen - zumindest in den Alten Bundesländern - keineswegs alle Stränge familiär konservierter bildungsbürgerlicher Statusvererbung nach 1945 gekappt worden. Im Gegenteil: Verglichen etwa mit den traditionellen agrarischen, kleinbürgerlichen, besitzbürgerlichen und proletarischen Milieus sind vielmehr die historischen Kontinuitätslinien des Bildungsbürgertums, die vergleichsweise ausgeprägte Persistenz bildungsbürgerlicher Milieus von den 1880ern bis in die Bundesrepublik hinein, verblüffend:

„Ähnlich wie im gehobenen Wirtschaftsbürgertum ließe sich nach dieser Epochenscheide auch der Fortbestand zahlreicher Anwalts-, Ärzte-, Wissenschaftler-, Beamtendynastien feststellen. Hatte man die Toten gezählt, die Emigranten endgültig vergessen, die kalte Dusche der Entnazifizierung in aller Regel überstanden, gingen die Rechtsanwälte und Ärzte, die höheren Beamten und Pfarrer, die Studienräte und Professoren wieder ihrer erlernten Tätigkeit nach. Sie fanden sich auch in den vertrauten Verkehrskreisen erneut zusammen, entdeckten die Funktionstüchtigkeit der Honoratiorennetzwerke in großen und kleinen Städten, auch die Vorzüge der Selbstorganisation in Vereinen und Assoziationen, kehrten zur überlieferten Lebensführung möglichst frühzeitig zurück, pflegten ihre Sprachkompetenz, verfochten alsbald wieder zielstrebig ihre Interessen mit Hilfe ihrer Verbände, planten die Karriere ihrer Kinder - und das alles unter einem ,bürgerlichen Wertehimmel', vor dem die dunklen Wolken einer vermeintlich unwiderruflichen Diskreditierung zusehends verschwanden.390

386 Vgl. ibid., S. 215.

387 Vgl. ibid., S. 228.

388 Vgl. Koppetsch, Cornelia: Die Wiederkehr der Konformität. Streifzüge durch die verunsicherte Mitte, Bonn 2015.

389 Schulz: Lebenswelt und Kultur des Bürgertums, S. 2.

390 Wehler: Deutsche Gesellschaftsgeschichte 1949-1990, S. 139. Vgl. bekräftigend Budde: Blütezeit des Bürgertums, S. $135 f$ und Schulz: Lebenswelt und Kultur des Bürgertums, S. 84f. 
Abb. 1: Soziale Herkunft der Studierendenkohorte 1810

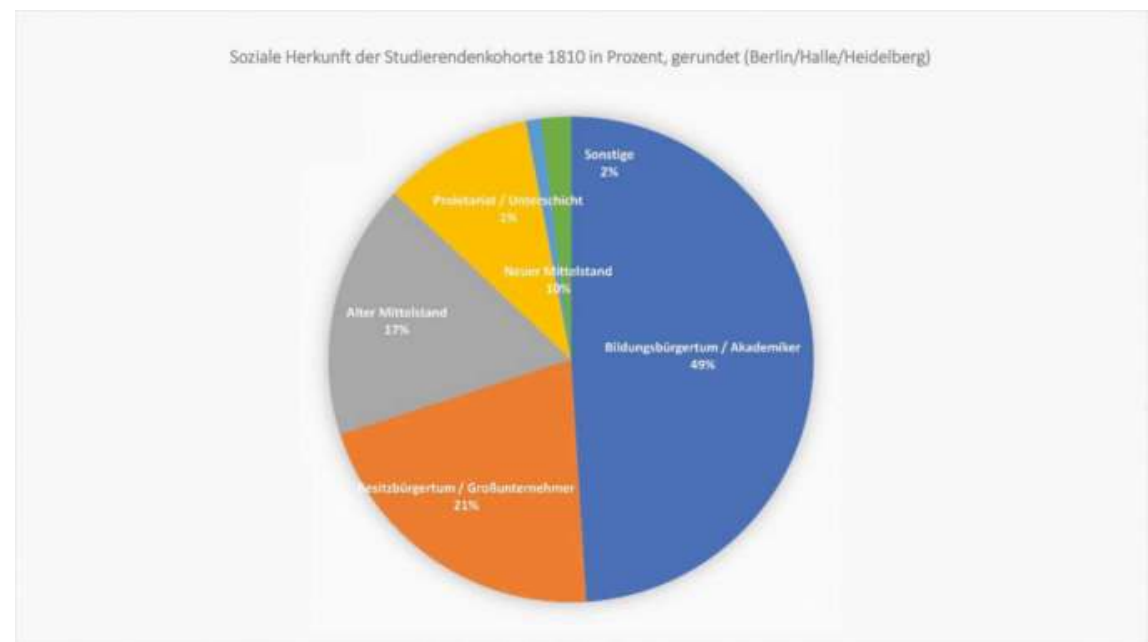

Daten entnommen aus Jarausch, Konrad H.: The Sources of German Student Unrest 1815-1848 (1974), in: Historical Social Research, Supplement 24/2012, S. 80-114, hier S. 112 sowie Titze: Die zyklische Überproduktion, S. 98.

Abb. 2: Soziale Herkunft der Studierendenkohorte 1850

Soziale Herkunft der Studierendenkohorte 1850 in Prozent, gerundet (Berlin/Halle/Heidelberg)

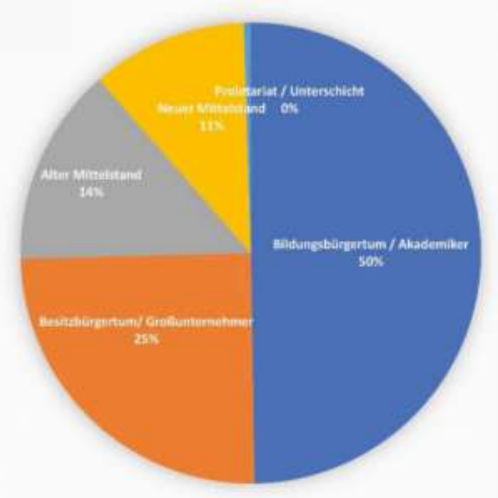

Daten entnommen aus Jarausch: The Sources of German Student Unrest, S. 112 sowie Titze: Die zyklische Überproduktion, S. 98. 
Abb. 3: Soziale Herkunft der Studierendenkohorte 1870

Soziale Herkunft der Studierendenkohorte 1870 in Prozent, gerundet: (Berlin/Halle/Heideiberg)

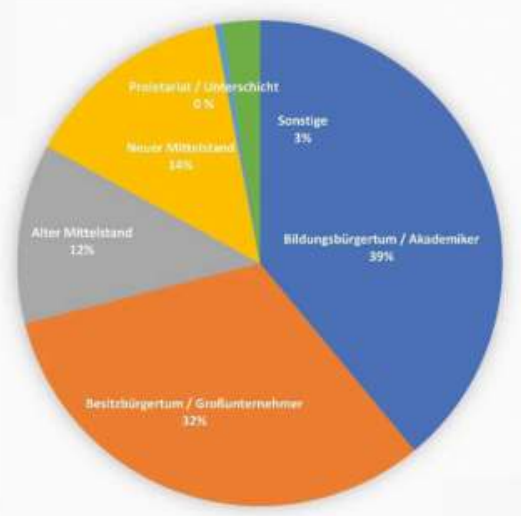

Daten entnommen aus Jarausch: The Sources of German Student Unrest, S. 112 sowie Titze: Die zyklische Überproduktion, S. 98.

Abb. 4: Soziale Herkunft der Studierendenkohorte 1911

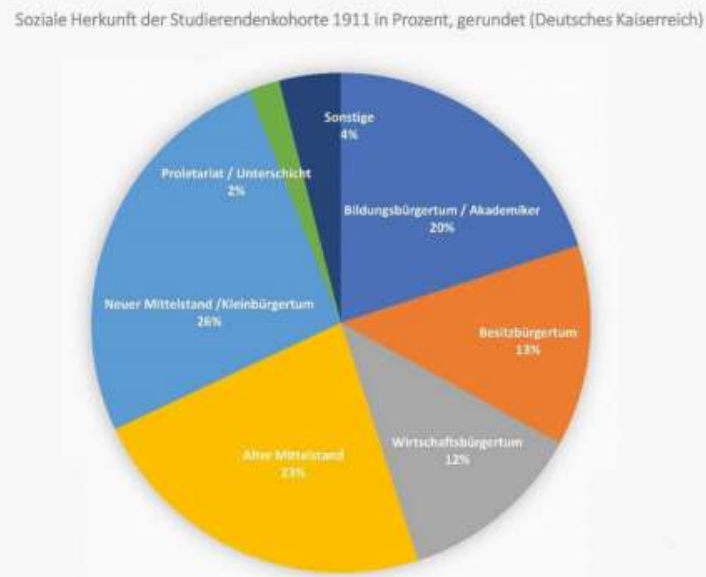

Daten entnommen aus Ringer: Die Gelehrten, S. 6of. und Titze: Die zyklische Überproduktion, S. 98. 
Abb. 5: Soziale Herkunft der Studierendenkohorte 1931

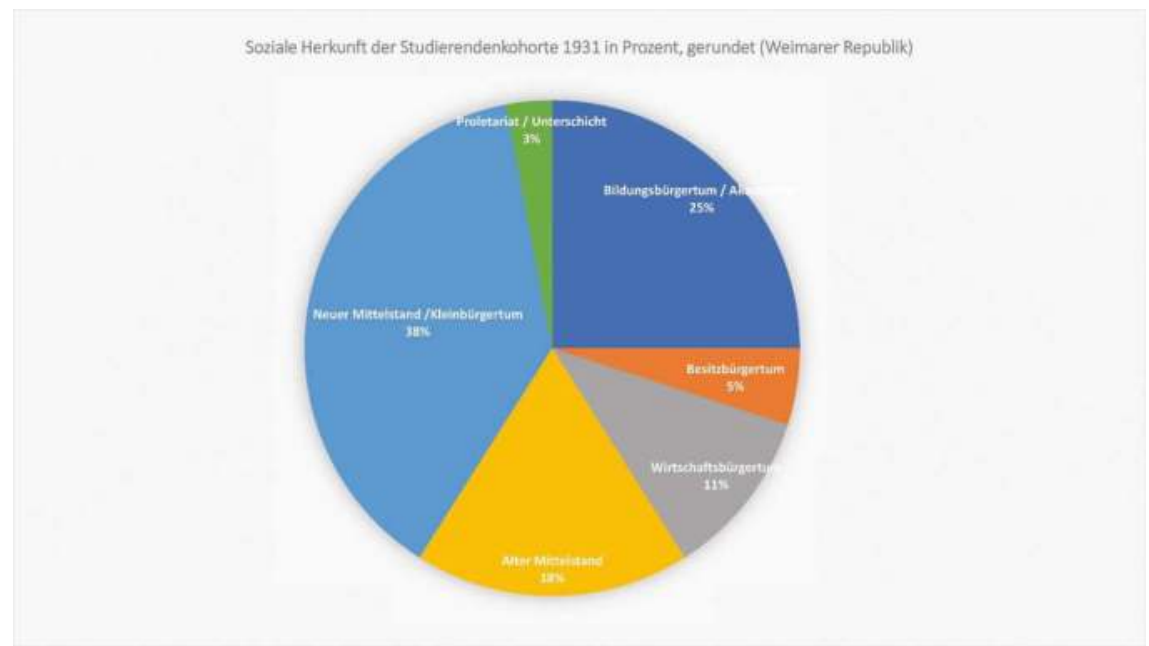

Daten entnommen aus Ringer: Die Gelehrten, S. 65 und Titze: Die zyklische Überproduktion, S. 98.

Abb. 6: Soziale Herkunft der Studierendenkohorte 1959

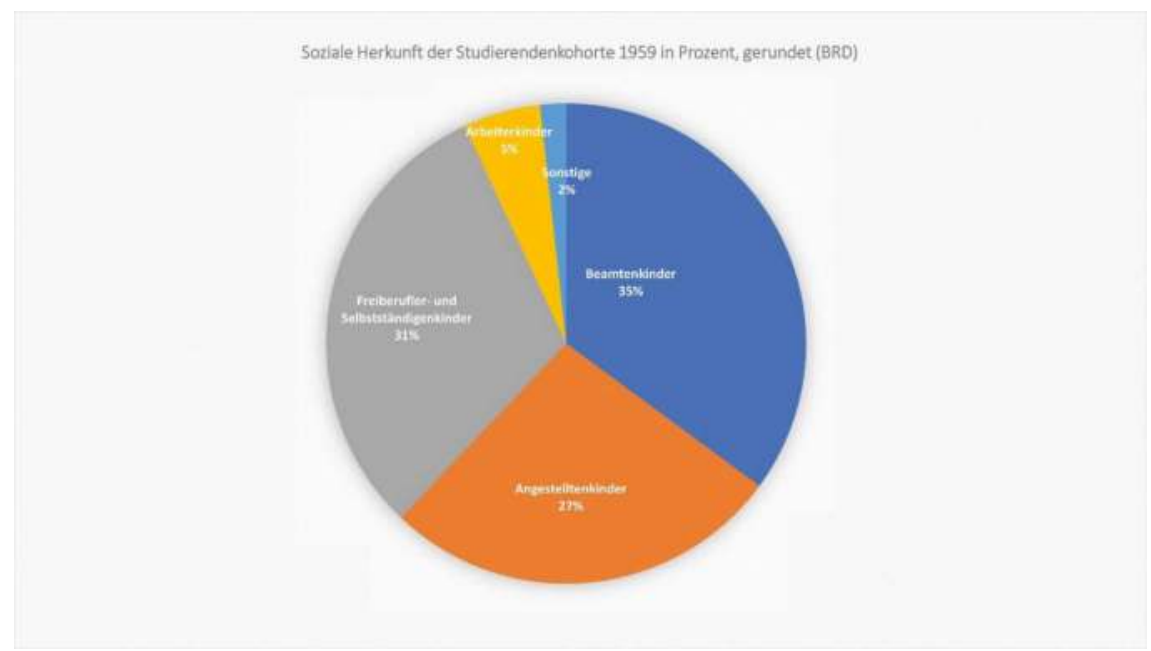

Daten entnommen aus 4. Sozialerhebung 1959, S. $32 \mathrm{f}$. 
Abb. 7: Soziale Herkunft der Studierendenkohorte 1973

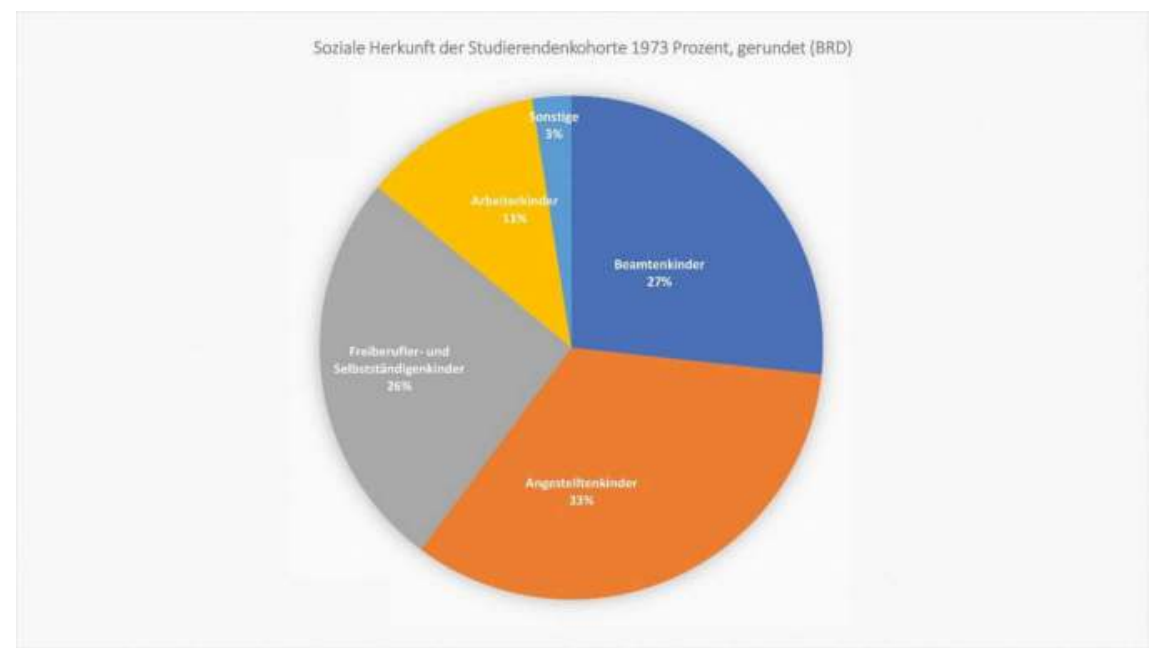

Daten entnommen aus 7. Sozialerhebung 1973, S. $27 f$.

Abb. 8: Soziale Herkunft der Studierendenkohorte 1990

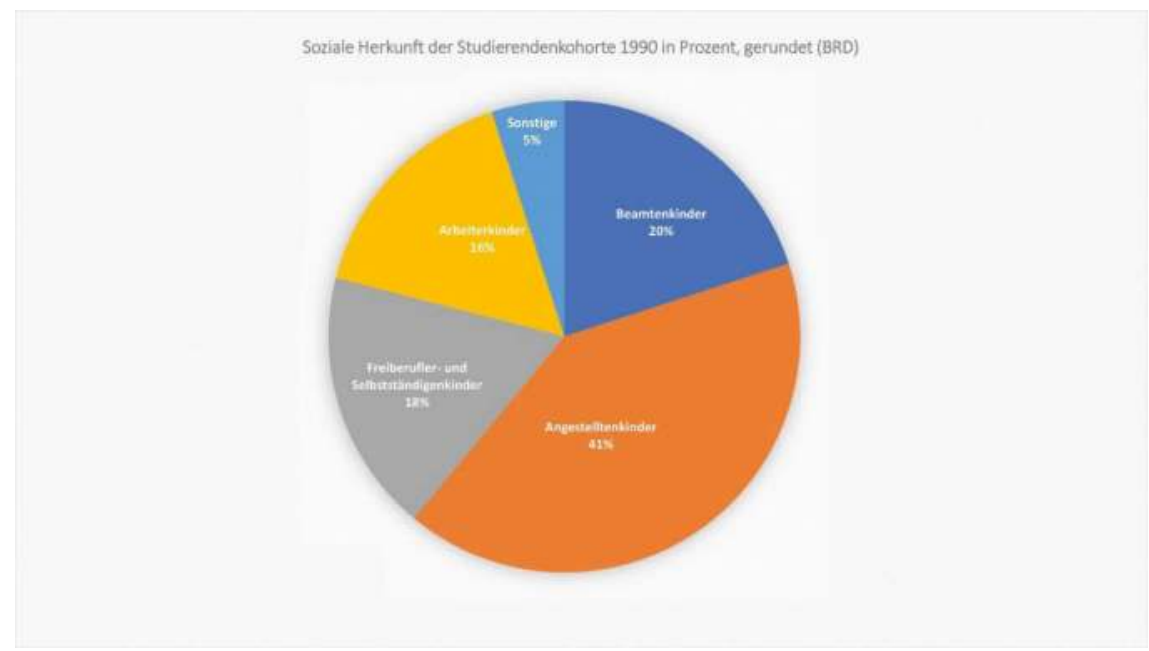

Daten entnommen aus 13. Sozialerhebung 1991, S. 95. 
Abb. 9: Soziale Herkunft der Studierendenkohorte 2017

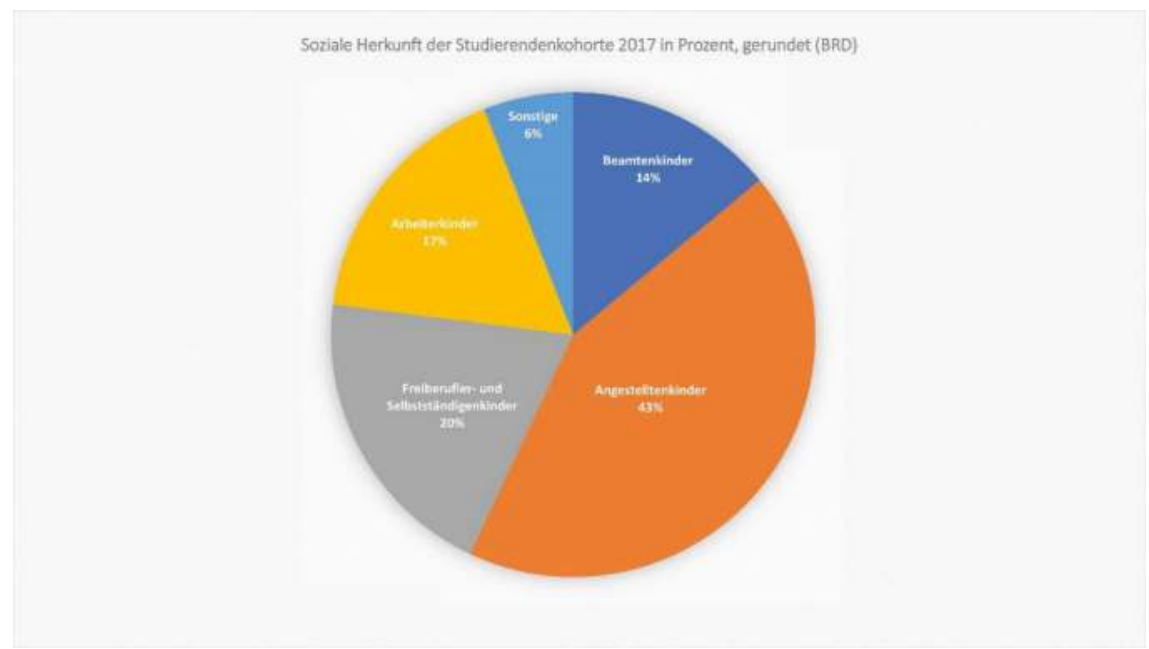

Daten entnommen aus 21. Sozialerhebung 2017, S. 1666 .

Abb. 10: Studienanfängerquote seit 1950

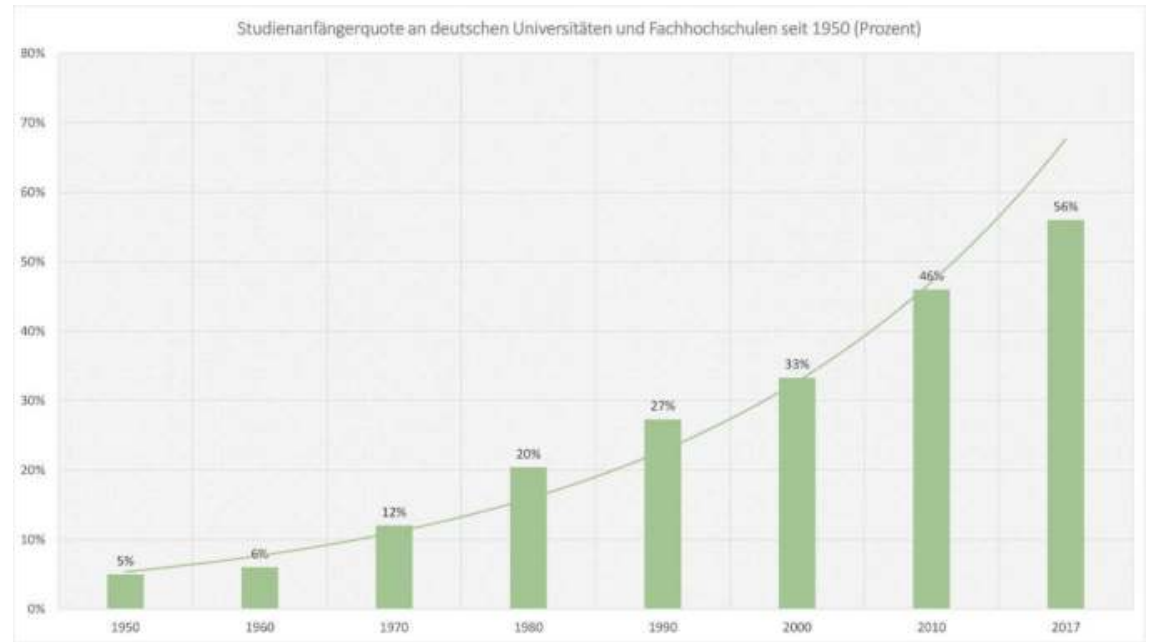

Daten entnommen aus Wolter: Eigendynamik und Irreversibilität der Hochschulexpansion, S. 25, sowie Statistisches Bundesamt: Schnellmeldungsergebnisse Wintersemester 2017/18, S. 11. 
Abb. 11: Studierende an Universitäten und Fachhochschulen seit 1950 nach Geschlecht

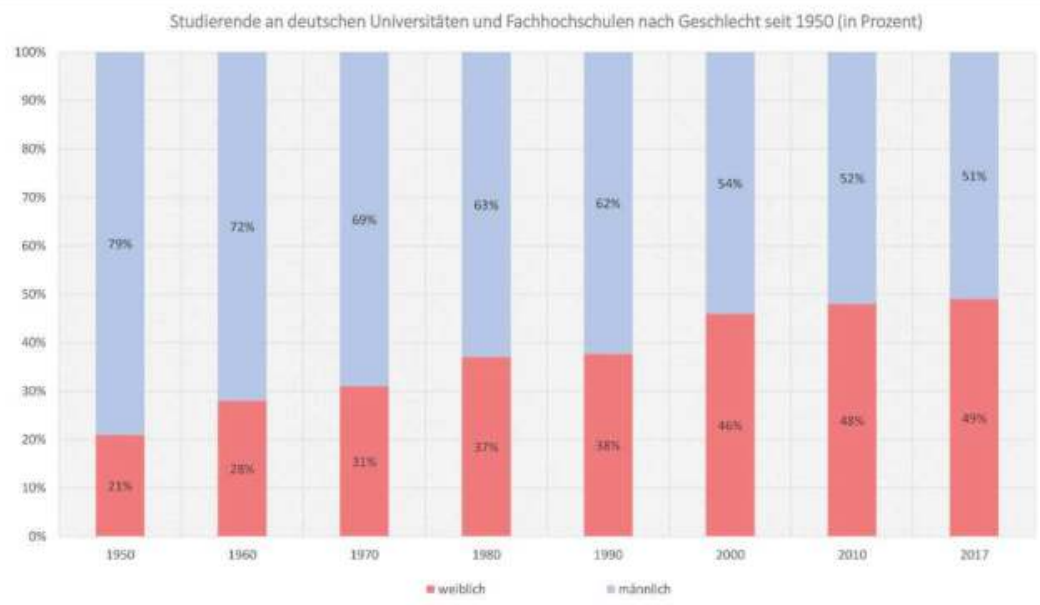

Daten entnommen aus 11. Sozialerhebung 1985, S. 87; 16. Sozialerhebung 2000, S. 45; Statistisches Bundesamt: Bildung und Kultur. Studierende an Hochschulen Wintersemester 2017/18, 2018.

Abb. 12: Studierende an deutschen Universitäten und Fachhochschulen 1830-2019

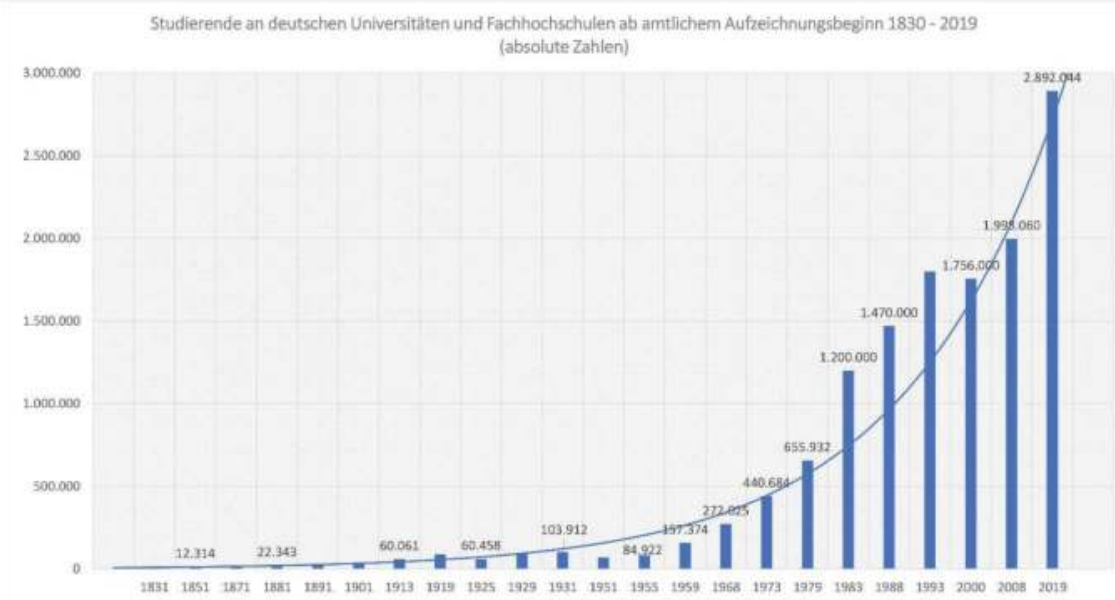

Daten - in der Regel wiedergegebene Kennzahlen der amtlichen Statistiken bzw. der im 19. Jahrhundert erhobenen regionalen und preußischen Universitätsstatistiken - entnommen aus 3. Sozialerhebung 1956, S. 15; 4. Sozialerhebung 1959, S. 11; 6. Sozialerhebung 1968/69, S. 11; 7. Sozialerhebung 1973, S. 203; 9. Sozialerhebung 1980, S. 19; 12. Sozialerhebung 1988, S. 64; 14. Sozialerhebung 1994, S. 44; 16. Sozialerhebung 2000, S. 2; 19. Sozialerhebung 2009, S. 50; die aktuelle Zahl entstammt der Internetpräsenz des Statistischen Bundesamtes: Destatis: Bildung, Forschung und Kultur, online einsehbar unter: https:/www.destatis.de/DE/Themen/Gesellschaft-Umwelt/BildungForschung-Kultur/Hochschulen/Tabellen/studierende-insgesamt-bundeslaender.html [eingesehen am 24.03.2020] 
Abb. 13: Anteil der Studierenden mit akademisch gebildeten Elternteilen

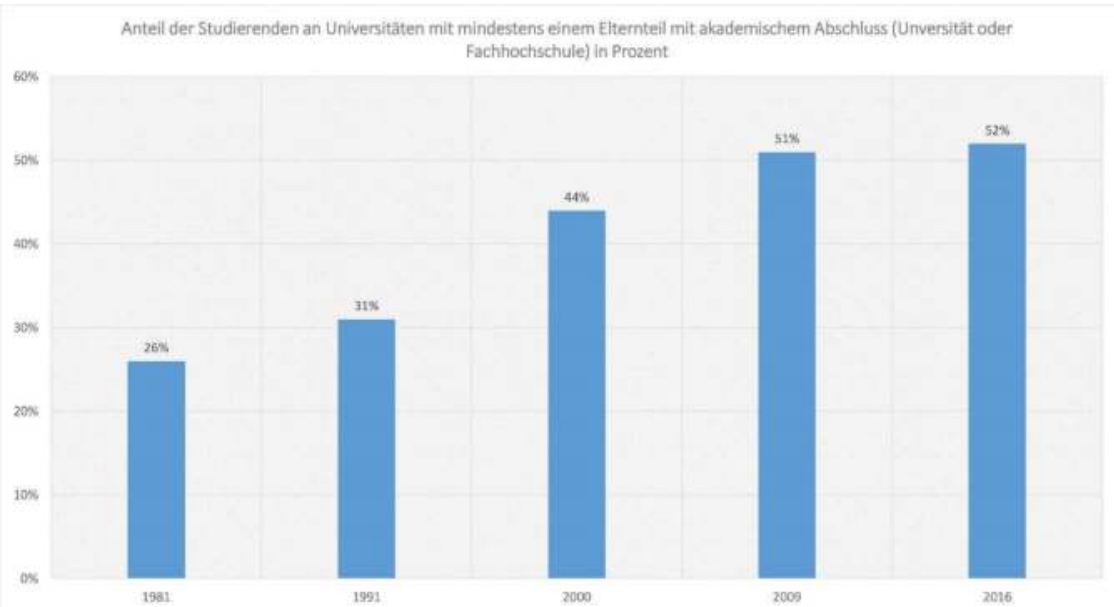

Daten entnommen aus 10. Sozialerhebung 1981, S. 36; 13. Sozialerhebung 1991, S. 109; 21. Sozialerhebung 2016, S. 27.

Abb. 14: Höchster Schulabschluss der Eltern von Studierenden

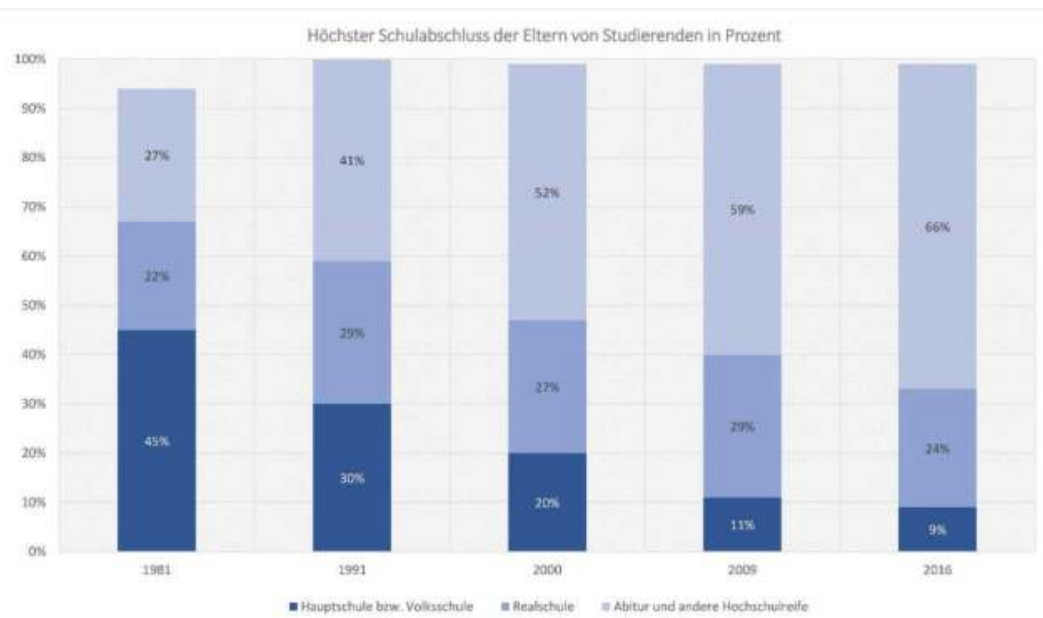

Daten entnommen aus 10. Sozialerhebung 1980, S. 35; 13. Sozialerhebung 1991, S. 107: 21. Sozialerhebung 2016, S. 27. 


\section{II.1.5 Seitenblick: Studieren in der universitären Juxtaposition zwischen Markt und Wissenschaftsautonomie ${ }^{391}$}

Die Anpassung der Hochschulen an die Erfordernisse der Arbeitsmarkt- und Bildungsexpansionsbewegungen verlief wiederholt mithilfe von Reformen, ob aus dem Geiste der Reformpädagogik oder mit dem Ziel der stärkeren Anpassung an die Bedürfnisse des Arbeitsmarkts. Entscheidende Reformdebatten fanden in den $1810 e^{392}$, 1890er, 1960er/70er und 1990er Jahren statt; oft waren sie Teil grundlegender Bildungsreformen. ${ }^{393}$ Dabei reagierten die vielfachen, politisch lancierten Umstrukturierungen des Hochschulsystems - sie umfassen sowohl Rekrutierungs-, Zugangs- und Prüfungsregularien als auch das organisatorische Netzwerk der Hochschulbürokratie, Studieninhalte und Studienbedingungen - immer auch auf die Erfordernisse der sich rasch modernisierenden Arbeitsmärkte und gewandelter Qualifikationsanforderungen, während durch studentisches Engagement bewirkte Änderungen zumeist Demokratisierungsschübe in den Hochschulen als auch in gesellschaftlichem Maßstab herbeiführten. Der Weg zur Herausbildung des modernen Massenstudiums ist durchweg mit einem sukzessiven, bisweilen auch schubweisen Abschleifen traditioneller akademischer Lehr- und Lernformen verbunden. Akademische Einsamkeit und akademische Freiheit, jene reformpädagogischen Prinzipien Humboldts und Fichtes, die nicht nur eine Körperschaft holistisch gebildeter und gesitteter Lernender und Lehrender hervorbringen sollte, sondern auch "Geburtsstätte einer neuen Gesellschaft" hatte sein sollen, ${ }^{394}$ verschwinden mit der einstigen professoralen Hoheit der Ordinarienuniversität im Grunde schon im Verlauf der 1960er Jahre. 1963 warf Helmut Schelsky die Frage auf, „welches Verhältnis denn die deutsche Universität heute überhaupt noch zur Bildungs- und

391 Zwar wäre eine Geschichte der Hochschulreformen, die die in diesem Seitenblick angemerkten Zusammenhänge veranschaulicht und belegt, wünschenswert. Angesichts des zur Verfügung stehenden Platzes aber müssen knappe Verweise genügen.

392 Wobei die Humboldt'schen Bildungsreformen immer auch als Teil des aufklärerisch ausgerichteten Stein-Hardenberg'schen Reformprogamms zu sehen sind, welches das Ziel verfolgte, Preußen nach der Niederlage gegen Napoleon in der Schlacht bei Jena und Auerstedt 1806 und der daraus resultierenden Wahrnehmung eines desolaten und rückständigen Staatswesens zur Wiedererlangung eines Großmachtstatus zu verhelfen. Vgl. Friedeburg, Ludwig von: Bildungsreform in Deutschland. Ceschichte und gesellschaftlicher Widerspruch, Frankfurt a.M. 1989, S. 60-64. Die Reformen der frühen $1800 e r$ Jahre verlangten $u$. a. die Festlegung eines verpflichtenden Universitätsstudiums für angehende Gymnasiallehrer, festigten die stärkere organisatorische Bindung an den preußischen Staat gegen die Kirchen und privaten Förderer durch die direkte Kontrolle des preußischen Kultusministeriums, und beschränkten die Möglichkeit des neuen Abiturabschlusses auf Gymnasien, die zu einem ausreichenden Anteil Griechisch und Latein in ihren Curricula führten. Vgl. Ringer: Die Gelehrten, S. $31 f$. Ein didaktisch versierter Überblick findet sich ibid.

394 Vgl. Schelsky, Helmut: Einsamkeit und Freiheit. Idee und Gestalt der deutschen Universität und ihrer Reformen, Reinbek 1963, S. 79-130, Zitat von S. 109. 
Sozialidee der Humboldt'schen Universität hat.، ${ }^{395}$ Denn: Obwohl als Ideal von „Ideologieträgern" bis heute gültig, hatte die legendäre akademische Leitphilosophie, die sich an den Namen Humboldts bindet, schon damals ihre strukturelle Wirksamkeit eingebüßt; Wissenschaft als Philosophie vertrug sich offenbar schon nicht mehr mit dem spät-industriegesellschaftlichen technokratischen Wissensverständnis. ${ }^{396}$ Mit den 1999 europaweit ins Leben gerufenen Bologna-Reformen scheint nun eine neue Drehung der Reformmühlen angebrochen zu sein, die sich noch destruktiver auf die Residuen klassischer Bildung auswirke als sämtliche vorherigen:

„Ach, Bologna, Du schöne Stadt, in der so viele stolze Türme miteinander wetteifern, der schönste zu sein, wie konntest Du zum Symbol einer Planierraupe werden, die die Vielfalt der Fächer und Vermittlungsarten an unseren Universitäten flächendeckend überrollt?"397

Dem historisierenden Blick aber fällt auf, dass viele Aspekte der häufig kritisierten aktuellen Bologna-Reformen „Vorläufer“ in früheren Reformbemühungen finden. ${ }^{398}$ So ist die empörte Anklage drohender "sachfremde[r] Eingriffe“ außeruniversitärer Interessen auf Kosten der Wissenschaftsfreiheit und der professoralen Privilegien ein wiederkehrendes Motiv, ähnlich die Diagnose einer „Überregulierung“ und einer „Schmälerung der geistigen Vielfalt" jener Traditionsinstitution. ${ }^{399}$ In der Regel erwiesen sich die Hochschulen, „sich selbst überlassen, eher zu Traditionalismus und Immobilität“, während „entscheidende Anstöße zu ihrer Modernisierung von der Staatsgewalt ausgingen. “400 Im historischen Längsschnitt lässt sich die folgende Vermutung anstellen: Die durch die wiederkehrenden Hochschulreformbestrebungen bezeugte institutionelle Evolution der Universität verweist aufden kontinuierlichen Reformdruck, den Bildungswachstum und Arbeitsmarkt ihr langfristig auferlegen, aber auch auf die Deutschland im internationalen Vergleich einzigartige Bindung an den Staat als traditionellen Garanten der Wissenschaftsfreiheit. Aus dieser Spannung zwischen Markt und Staat resultierte stets das Konfliktpotenzial um den gesellschaftlichen Stellenwert und um das Niveau akademischer Bildung, um den Autonomie-Anspruch der Hochschullehrerschaft wie der Studierendenschaft, um die Privilegien und Berufsaussichten der akademischen Absolventen und um die sozialen Schranken des Hochschulzugangs. Selten wurde eine Hochschulreform vollzogen ohne bisweilen dramatische Folgen für das jeweils tradierte Verständnis akademischen Wissens, jeweils quittiert in der Form kritischer Abgesänge auf die Universität.

Kennzeichnend für diese Abgesänge ist ihr Oszillieren zwischen stichhaltiger Kritik am Verschwinden traditioneller, marktferner und kontemplativer Lehr- und Lernformen einerseits und der darin angelegten Fixierung anachronistischer Gehalte gegen

395 Ibid., S. 127.

396 Vgl. ibid., S. 127-130.

397 Eßbach, Wolfgang: Unterm Rad der Planierraupe. Die deutschen Universitäten leiden unter den Bologna-Reformen, in: Süddeutsche Zeitung, Nr. 295, 20.12.2004, S. 16.

398 Vgl. Pöppinghege, Rainer/Klenke, Dietmar: Einführung, in: Dies. (Hg.): Hochschulreformen früher und heute - zwischen Autonomie und gesellschaftlichem Geltungsanspruch, Göttingen 2011, S. 7-24, hier S. 12.

399 Ibid., S. 10 .

400 Ibid., S. 19. 
die aus den Bildungsinstitutionen nicht wegzudenkende Modernisierungsdynamik andererseits. Ob im späten 19. oder im späten 20. Jahrhundert geäußert, ihre zentralen Angriffspunkte treffen sich in derselben Diagnose: „Wahre“ Bildung, wie sie die Idee der Universität vorsehe, werde zugunsten quantifizierbaren Wissenserwerbs von opportunistischen, kollektivnarzisstischen und Karriere-orientierten Fachwissenschaftlern systematisch unterbunden; eine angemessene Förderung, gar Inspiration des studierenden Nachwuchses zur Kontemplation und zur intellektuellen Leistungsfähigkeit hingegen bleibe aus. Zwei Beispiele mögen das stellvertretend für viele illustrieren. Im Jahr 1872 wetterte der noch akademisch eingebundene Friedrich Nietzsche im Kontext von fünf Vorträgen an der Universität Basel:

„Ich für meinen Theil kenne nur einen wahren Cegensatz, Anstalten der Bildung und Anstalten der Lebensnoth: zu der zweiten Gattung gehören alle vorhandenen, von der ersten aber rede ich. - [...] O der elenden verschuldet-Unschuldigen! Denn ihnen [den zeitgenössischen „Bildungsmenschen“, ]. S.] fehlte etwas, was Jedem von ihnen entgegenkommen mußte, eine wahre Bildungsinstitution, die ihnen Ziele, Meister, Methoden, Vorbilder, Genossen geben konnte und aus deren Innerem der kräftige und erhebende Anhauch des wahren deutschen Geistes auf sie zu strömte. So verkümmern sie in der Wildniß, so entarten sie zu Feinden jenes im Grunde ihnen innig verwandten Ceistes [...] Vor diesem Geiste aber fürchtet ihr euch und daher hat sich eine andre Dunstschicht, schwül und schwer, über euren Universitäten zusammengezogen, unter der eure edleren Jünglinge mühsam und belastet athmen, unter der die Besten zu Grunde gehen. “401

Ähnlich beobachtete der Theologe Klaus Heinrich 1987, also ein gutes Jahrzehnt vor dem Beschluss der Bologna-Reformen, den historisch begründeten, beinahe Spenglerisch anmutenden Auszug des Geistes aus der Universität:

„Geist ist ein Triebbegriff, ein zunächst weiblich konzipierter, später männlich okkupierter, von der ruah des Alten Testaments, dem pneuma und spiritus des Neuen an, bis hin zu Böhmes und Hegels Geistlehre. Wir dürfen uns nicht wundern, wenn wir in der von mir beschriebenen Atmosphäre den Ceist vermissen - er läßt sich einem toten Verhältnis auch nicht implantieren. [...] Der neue Forschungspositivismus, der Reflexion verdächtig macht, hat eine einzige Kontrollinstanz, die ihm in die Sphäre der vorweg geronnenen Zukunft folgen kann: die Planung [...] Ein institutioneller Abschnitt unserer Wissenschaftsgeschichte ist vorbei. Vielleicht gewinnen wir einen klareren Kopf, wenn wir nicht länger den Ceist einer Institution zu retten versuchen, sondern uns selbst. ${ }^{\text {}}{ }^{02}$

In den letzten zwanzig Jahren wuchs darüber hinaus eine leidenschaftlich hochschulreformkritische Literatur im Stile des Bologna-Schwarzbuchs an, die den jüngsten

401 Nietzsche, Friedrich: Über die Zukunft unserer Bildungs-Anstalten. Sechs öffentliche Vorträge [1872], in: Ders.: Kritische Studienausgabe (KSA) Bd. I. Die Geburt der Tragödie. Unzeitgemäße Betrachtungen I-IV. Nachgelassene Schriften 1870-1873, S.641-752, hier S. 717 und 747 (Herv. i. O.) 402 Heinrich, Klaus: Zur Geistlosigkeit der Universität heute. Oldenburger Universitätsreden, Nr. 8, Oldenburg 1987, S. 5, 6 und 21. 
Reformen der Universität eine ganze Reihe von "Systemfehlern“ und daraus resultierenden "Problemeruptionen“ vorhielt. ${ }^{403}$ Die bekannteste Kritik der neuen Hochschullandschaft findet sich im 2011 veröffentlichten Buch Akademischer Kapitalismus von Richard Münch. ${ }^{404}$ Ein Auszug soll hier genügen: Die von den Reformen beabsichtigte Schaffung eines europäischen Hochschulraums, der quantifizierten internationalen Vergleichbarkeit von Studienleistungen im Rahmen von ECTS-Punkten, die stärkere privatwirtschaftliche Ausrichtung der Universität und ihrer Verwaltung im Sinne des New Public Management sowie das Ersetzen der akademischen Selbstverwaltung durch eine straffe und "indikatorengestützte" Führungsstruktur (etc.) ${ }^{405}$ habe die akademische Wissensproduktion aus dem historisch gewachsenen Gleichgewicht gebracht und in ein inhaltlich dogmatisches System profilierungssüchtiger und marktschreierischer Netzwerkwissenschaftler verwandelt. Münch beschreibt die Hinwendung akademischer Ausbildung und wissenschaftlicher Tätigkeit zu einem „Überbietungskampf des akademischen Kapitalismus“406, einem run auf rankings und Qualitätssicherungs-Kennzahlen. Die Universitäten würden in dauerevaluierte „Audit-Universitäten “407 und Unternehmen verwandelt, deren Geschäftsmodell in der Einwerbung möglichst großer Fördersummen bestehe. Damit „verändern sich die Koordinaten der Wissensproduktion grundlegend“ , ${ }^{408}$ nämlich in Richtung heteronomer Vorgaben der Forschungsinteressen. Ein „entscheidender Autonomieverlust“ der Wissenschaft begleite die Investition immer größerer Summen in den Prestigewettbewerb der Universitätsstandorte. ${ }^{409}$ Desaströs wirke sich das auf den nunmehr gebremsten „Erkenntnisfortschritt“ aus: Wirkliche fachliche Innovation, gar forscherisches Querdenkertum, werde systematisch unterbunden und weiche den Vorgaben der sich herausbildenden „Oligopolstrukturen“: „Den gleichzeitig verarmenden Standorten der breiten Masse bleibt nichts anderes übrig, als sich der Herrschaft der Elitestandorte zu unterwerfen, indem sie die dort produzierten Publikationen pflichtschuldig rezipieren und zitieren. “410

Ob die Bologna-Reformen, wie oft behauptet, einen besonderen qualitativen Sprung der Bildungsdestruktion bedeuten, soll hier ausdrücklich nicht entschieden werden. Man muss keineswegs agnostisch mit den Achseln zucken: Die Umbruchsphase, in der sich die Universität seit Mitte der 200oer Jahre befindet, ist für Studierende und akademisches Personal fraglos spürbar. Der Modus des Studierens hat sich, verglichen etwa mit Studierendenkohorten der 1980er Jahre, substanziell verändert. Wer im Bachelor/Master-System studiert hat, weiß: Das Pflichtstudium ist Sammelarbeit,

403 Scholz, Christian/Stein, Volker: Einführung der Herausgeber, in: Dies. (Hg.): BolognaSchwarzbuch, Bonn 2009, S. 9-13. Vgl. ähnlich auch Schultheis, Franz/Hector, Franz/Roca i Escoda, Marta (Hg.): Humboldts Albtraum. Der Bologna-Prozess und seine Folgen, Konstanz 2008.

404 Vgl. Münch, Richard: Akademischer Kapitalismus. Zur Politischen Ökonomie der Hochschulreform, Frankfurt a.M. 2011.

405 Vgl. Pöppinghege/Klenke: Einführung, S. 9.

406 Münch: Akademischer Kapitalismus, S. $360 f$.

407 Ibid., S. 364.

408 Ibid., S. 370 f.

409 Ibid., S. 378.

410 Ibid., S. $379 f$. 
nicht Denkarbeit. Selbst in Fächern, die früher auf die selbstständige Auseinandersetzung mit anspruchsvollen Texten zielten, hat das Akkumulieren von Credits und Einzelnoten in Teilprüfungen und vorab festgelegten Bahnen die Suche nach individuellen Schwerpunkten und Antworten auf übergeordnete Fragestellungen ersetzt. Wer sich fachfremde Credits anrechnen lassen möchte, überfordert das elektronische Prüfungsverwaltungssystem. Einen intellektuellen Zusammenhang zwischen den in Module zerlegten und verschulten Lehrgehalten der Kerncurricula zu stiften, dürfte nur noch jenen gelingen, die bereits vor dem Studium starke individuelle Zugänge und Frageperspektiven bzw. intellektuelle Projekte (und handle es sich nur um Suchbewegungen) entwickelt haben. Dennoch: Verwiesen werden soll hier nur auf einen langfristigen Strukturzusammenhang, nämlich auf die über sämtliche Bildungsexpansionsdynamiken hinweg konstante Juxtaposition der Institution Universität selbst, die oft hinter der akademischen Mythenbildung einer staatszentrierten deutschen Tradition verschwindet. Die Situation der Hochschulen in der Gesellschaft ist erkennbar durch die konfligierenden Anforderungsauffassungen zwischen Marktimperativen (Ausleseprinzip) und einem durch den Staat gewährleisteten universitären AutonomieAnspruch bestimmt ${ }^{411}$ - Spannungen, die sich stets in den von Titze beschriebenen Verdichtungsphasen von Bildungswachstum und Bildungskrise verschärfen. „Universities existed before capitalism, and therefore the latter had to come to terms with them. ${ }^{412}$ Stärker funktionalistisch, aber doch voll zutreffend formuliert das Münch wie folgt:

„Forschung und Lehre vollziehen sich im Spannungsfeld zwischen innerer akademischer Freiheit und äußerer gesellschaftlicher Zweckbestimmung. Die Universität steht mitten in diesem Spannungsfeld und muss in jeder neuen historischen Epoche unter jeweils veränderten Bedingungen die richtige Balance zwischen diesen beiden Polen finden, wenn sie dem Erkenntnisfortschritt und dem Cemeinwohl der Gesellschaft zugleich dienen will. “413

Sich gegenüber solchen gesellschaftsgeschichtlichen Strukturveränderungen (oder auch: Modernisierungsdynamiken) und gegen die vermeintlich wachsende Dominanz ordinärer „Verwertungs“-Interessen auf vermeintlich ewige Ideen ${ }^{414}$ oder auch nur die kritische Funktion marktferner Sphären zu berufen, ${ }^{415}$ kann daher kaum überzeugen. Der universitäre Kampf gegen das streamlining, in Deutschland unter Berufung auf die starke Hand des Staates geführt, ist so alt wie die Universität selbst, ihn zu führen diente nicht nur hehren Idealen, sondern immer auch sozialen (seit dem Kaiserreich

411 Mann, Michael: The Ideology of Intellectuals and Other People in the Development of Capitalism, in: Lindberg, Leon N./Alford, Robert/Crouch, Colin/Offe, Claus (Hg.): Stress and Contradiction in Modern Capitalism. Public Policy and The Theory of the State, Lexington/Massachusetts/Toronto/London 1975, S. 275-307, insbesondere S. 299-301.

412 Ibid., S. 298.

413 Münch: Akademischer Kapitalismus, S. 361.

414 Ribolits, Erich: Abschied vom Bildungsbürger: über die Antiquiertheit von Bildung im Gefolge der dritten industriellen Revolution, Wien 2013, insbesondere S. 9-20.

415 Vgl. Liessmann, Konrad Paul: Theorie der Unbildung. Die Irrtümer der Wissensgesellschaft, München Zürich 2006, S. 164-175. 
zumeist elitär-professoralen) Interessen gegen die Durchsetzung eines (in der Regel aufsteigerfreundlichen) leistungs- und marktorientierten Ausleseprinzips im Zuge der Bildungsexpansion. ${ }^{416}$ Im tiefgreifenden wissenschaftsgesellschaftlichen Wandel, der Verschiebung in Richtung „hochqualifizierter Arbeit“, also der so genannten „starken Tertiarisierung von Beschäftigung und Wertschöpfung “417, liegt das stärkste Argument gegen akademische Traditionsnostalgie. Studium hieß und heißt immer auch der Qualifikationserwerb für bestimmte Berufsbilder. Das ist Autoren wie dem Politikwissenschaftler Ekkehart Krippendorff entgegenzuhalten, welcher 1996 in einem Aufsatz forderte, eine „selbstkritische[] Reflexion“ der Universität „über ihren historischen, politischen, soziologischen und wissenschaftlichen Standort" anzustellen - als wäre nicht die Bildungsexpansionsdynamik, sondern ein akademischer Bewusstseinsverlust die Triebkraft des Strukturwandels. ${ }^{418}$

Das Dilemma der universitären Traditionszerstörung liegt angesichts der treibenden Kraft gesamtgesellschaftlicher Veränderungen also in einer gewissen Unausweichlichkeit. Nochmals: Das ist kein Einwand gegen die durchaus berechtigten MissstandsDiagnosen und kritischen Inventuren des akademischen Bildungsbetriebs. Aber es ist eben nicht nur der Wandel des Studierens, der zu den zu berücksichtigenden Aspekten bei der Auswertung empirischen Materials zu Studienerfahrungen von Studierenden heute, mithin des daraus erwachsenden politischen Protestpotenzials, zählt, sondern eben auch die historisch gewachsene und sich mit innerer Notwendigkeit weiter fortsetzende Anpassung der höheren Bildungsinstitutionen an die Anforderungen des Marktes bei gleichzeitiger Stützung akademischer Beharrungskräfte durch einen schützenden und Freiräume sichernden Staat.

\section{II.2 Studentische Oppositionsbewegungen und ihre historischen Kontextbedingungen}

Um das politische Potenzial von Studierenden hinsichtlich bedingender Faktoren $\mathrm{zu}$ untersuchen, ist es erforderlich, Anzeichen eines Protestpotenzials von denen eines Bewegungspotenzials zu unterscheiden - schließlich wurde einleitend bereits erwähnt, dass langlebigere studentische Bewegungsphasen von punktuell aufflammendem Protest abzugrenzen sind. Daher wird im Folgenden gefragt: Was waren die Ursachen und Umstände studentischer Oppositionsbewegungen, ihre historischen und soziostrukturellen Ermöglichungsbedingungen und Kontextfaktoren, wie gestalteten sich formative Phasen und Gelegenheitsfenster, politische Ziele und Projekte, wer waren ihre maßgeblichen Trägergruppen - und in welchen Situationen wird das Auftreten solcher Bewegungen wahrscheinlicher? Die Darstellung konzentriert sich auf die drei Aspekte der sozialen, kulturellen, wirtschaftlichen und politischen Ermöglichungsbedingungen der jeweiligen Bewegungen, des Agierens ihrer wesentlichen Trägergruppen,

416 Mann: The Ideology of Intellectuals, S. 299.

417 Wolter: Eigendynamik und Irreversibilität der Hochschulexpansion, S. 32.

418 Krippendorff, Ekkehart: Die Idee der Universität, in: PROKLA, 26. Jg., H. 104/1996, S. 431-439. 
und des Einflusses auf die politischen Entwicklungen unter Einbezug der politkulturellen Prägekraft sowie (kursorisch) der sich post festum über die Ereignisse legenden Rezeptionsschichten.

Schnell zeigt sich: Studentenbewegungen ${ }^{419}$ sind in vielerlei Hinsicht Ausnahmeerscheinungen exzeptionell stark ausgeprägten politischen Engagements einer großen Zahl von Studierenden, während historisch gesehen insgesamt gerade nicht der Typus des politisch aktiven Rebellen dominiert, sondern der des politisch apathischen „Angepassten“. ${ }^{420}$ Sie bildeten sich, wie in diesem Kapitel gezeigt werden soll, in gesellschaftspolitischen Übergangsperioden und in Zeiten rapide beschleunigter Veränderungsprozesse. Solcherart immer auch an allgemeinen Gesteinsverschiebungen politischer Kräfteverhältnisse partizipierend, knüpften sie „an eine politische Strömung oder eine breitere Befreiungsbewegung an, spielte[n] darin oft die Rolle einer radikalen Vorhut und diente[n] ihr auch als mobilisierende Kraft.“421 Zudem waren studentische Oppositionsbewegungen stets auf einen Nukleus umtriebiger Aktivisten angewiesen, auf politische Unternehmer, Kampagnenplaner und Netzwerker, die das Gelegenheitsfenster ihrer Zeit nutzten und das schwelende Konfliktpotenzial zu bündeln, anzuheizen und in ein Spektrum von Aktionen umzusetzen wussten. ${ }^{422}$ Nicht der - fraglos unerlässliche - stumme Druck gesamtgesellschaftlicher Fortschrittsdynamiken war es, der Studentenbewegungen initiierte und ihre über Jahre währende Persistenz sicherte, sondern die geschickte Pflege kontinuierlich reaktivierbarer Mythen und Rituale: das Memorieren und Inszenieren von Orten, Feiertagen, Symbolen und Parolen; das Organisieren von Festen, Umzügen und Fahnenmeeren; die Kolportage von Märtyrerund Heldengeschichten, usw. Dass „soziale Konflikte in ihrer manifesten, d. h. also politisch wirksamen Form stets das Produkt umfangreicher sozialer Veranstaltungen sind“423, wird an diesen außergewöhnlichen Hochphasen politisierter Studierendenschaften deutlich.

Um die besonderen Charakteristika von Studentenbewegungen zu bestimmen, bietet es sich an, auf den Definitionsvorschlag von Gerhard Bauß, eines Chronisten der

419 Im Zusammenhang mit „1968“ ist der Begriff „Studentenbewegung“ bisweilen in Anführungszeichen gesetzt worden, um den Aktivisten die politische Legitimität abzusprechen bzw. ihren Repräsentationsanspruch für die Studierendenschaft anzufechten, vgl. exemplarisch Infratest Wirtschaftsforschung: Politischer Protest in der Bundesrepublik, S. 55. Tatsächlich wäre das Bild einer „für alle" sprechenden Studentenbewegung durchweg verfehlt, doch wer aus diesem Grund auf die Gelegenheit verzichtet, den Begriff analytisch zu füllen, setzt sich über Wesentliches hinweg. „Bei allen Tendenzwenden und Brüchen zeigt die Entwicklung der deutschen Studenten seit 1800 auch ein Grundmuster akademischer Verhaltensweisen, das noch heute [1984, J. S.] relevant ist. Der dominante Typ war fast zu jeder Zeit der Angepaßte, natürlich je nach herrschender Ordnung von unterschiedlicher Couleur. Neben den höheren Zielen der Allgemeinbildung oder der wissenschaftlichen Forschung war für die meisten Brotstudenten der Hauptstudienzweck die Berufsausbildung." Jarausch: Deutsche Studenten, S. 245.

421 Gevers/Vos: Studentische Bewegungen, S. 227.

422 Vgl. ibid., S. 228.

423 Lepsius, Mario Rainer: Demokratie in Deutschland als historisch-soziologisches Problem, in: Adorno, Theodor W. (Hg.): Spätkapitalismus oder Industriegesellschaft? Verhandlungen des 16. Deutschen Soziologentages in Frankfurt a.M. 1968, Stuttgart 1969, S. 197-213, hier S. 207. 
Studentenbewegung der sechziger Jahre, zurückzugreifen. Zu einer Studentenbewegung im engeren Sinn gehören demnach die zahlenmäßig signifikante politische Mobilisierbarkeit bzw. Politisierung der Studierendenschaft, ferner das Vorhandensein tatsächlicher politische Aktivitäten, aber auch der Einbezug außerparlamentarischer Oppositionsformen. Präziser: Studentenbewegungen existieren, wenn

„erstens die jeweils wiederholbare oder längerandauernde Mobilisierbarkeit quantitativ relevanter Teile der Studentenschaft für politische, hochschulpolitische, soziale und/oder ökonomische Ziele gegeben ist, zweitens sich dies in einem entsprechenden Spektrum von Aktivitäten niederschlägt, und sie drittens als oppositionelle Bewegung sich nicht auf die Durchsetzung ihrer Ziele vermittels der Institutionen und Organisationen, die unter gegebenen gesellschaftlichen Herrschafts- und Machtverhältnissen den Interessenausgleich und die politische Willensbildung bewirken sollen, beschränkt (oder diese sogar dafür ganz untauglich hält), also auch (oder nur) außerhalb dieses Rahmens aktiv wird.“424

Erläuternd hinzuzufügen ist, dass Studentenbewegungen immer auch die „Machtfrage" stellen, also die Legitimität der etablierten gesellschaftlichen Institutionen und ihrer Vertreter in Zweifel ziehen. Sie protestieren und agitieren gegen die herrschende Regierungsform mitsamt der sie tragenden Eliten - wenn auch mitunter in ganz unterschiedlicher Weise.

Während studentischer Protest, zumal lokal begrenzter, in den vergangenen zweihundert Jahren wiederholt aufgetreten ist, können nur drei Phasen identifiziert werden, in denen es studentische Oppositionsbewegungen im Bauß'schen Sinne gegeben hat: die Burschenschafts- bzw. Progressbewegung des Vormärz 1815-1848, die westdeutsche Studentenbewegung 1966-1968 und die militant-antisemitische Mobilisierung in Weimar 1918-1933. Ihnen soll sich die nun folgende Darstellung zuwenden. Dabei wird

424 Bauß, Gerhard: Die Studentenbewegung der sechziger Jahre in der Bundesrepublik und Westberlin. Handbuch, Köln 1977, S. 13f. (Herv. J. S.) Ähnlich wirkt die auf den Fall „1968“ angewandte spätere Definition sozialer Bewegungen nach Dieter Rucht, mit der die Studentenbewegung von „1968“ als ein „auf gewisse Dauer gestelltes und durch kollektive Identität abgestütztes Handlungssystem mobilisierter Netzwerke von Cruppen und Organisationen, welche sozialen Wandel mit Mitteln des Protests - notfalls bis hin zur Cewaltanwendung - herbeiführen, verhindern oder rückgängig machen wollen", zu fassen wäre. S. dazu Rucht, Dieter: Modernisierung und neue soziale Bewegungen, Frankfurt a.M. 1994, S. 77, zit. nach: Ders.: Die Ereignisse von 1968 als soziale Bewegung: Methodologische Überlegungen und einige empirische Befunde, in: Gilcher-Holtey, Ingrid (Hg.): 1968. Vom Ereignis zum Cegenstand der Ceschichtswissenschaft. Ceschichte und Cesellschaft, Sonderheft 17, Göttingen 1998, S. 116-130, hier S. 117. Rucht selbst jedoch füllt diese recht minimalistische Definition in erläuternden Ergänzungen mit einer Reihe anspruchsvoller Detailmerkmale - etwa die Absicht, umfassende gesellschaftliche Transformation herbeizuführen bzw. zu verhindern, ferner ein durch ein „Wir-Gefühl“ gestifteten Organisationszusammenhang und die Ausrichtung auf eine Massenöffentlichkeit -, was ihn dazu führt, „1968“ nur mehr als „tentativen“ Anwendungsfall gelten zu lassen, s. Rucht: Die Ereignisse von 1968 als soziale Bewegung, S. 117f. Ruchts soziale Bewegungen sind erkennbar am Vorbild von Bürgerbewegungen der zweiten Hälfte des 20. Jahrhunderts gebildet. Demgegenüber erscheint der Bauß'sche Definitionsvorschlag aufgrund seiner größeren Offenheit als geeigneter, um die drei hier identifizierten Studentenbewegungen gleichermaßen einzufangen. 
nicht gänzlich chronologisch vorgegangen. Die Darstellung bezieht die grundlegenden politischen Stoßrichtungen der drei Studentenbewegungen, genauer: ihr Verhältnis zur Leitidee der Liberalisierung bzw. Demokratisierung gesellschaftlicher Verhältnisse in die Analyse ein. Denn während die Bewegungen von „1848“ und „1968“ emanzipative, "progressive" und sozial egalitäre Ziele verfolgten, wollte die völkische Studentenbewegung, die angesichts neuartiger Modernisierungsschübe darauf hoffte, kaiserzeitliche bildungsbürgerliche Privilegien zu restaurieren, auf das Gegenteil hinaus. Die völkische Studentenbewegung von Weimar zielte auf die aggressive Verdrängung jüdischer und anderer nichtkorporierter Konkurrenten aus den akademischen Karrieren. Aus diesem Grund ist es in der Forschungsliteratur offenbar unüblich, die romantisierungsunfähige Selbstnazifizierung der deutschen Studentenschaft in den 1920er Jahren als Studentenbewegung einzuordnen - eine wissenschaftliche Sitte, die zumindest auf der Grundlage der zitierten begrifflichen Präzisierung unschlüssig erscheint.

Um die Darstellung nicht zu überfrachten, müssen gewisse Einschränkungen vorgenommen werden. So wird das Themenfeld des politisch motivierten Terrorismus und der politischen Attentate, obwohl gesellschaftspolitisch relevant und sozialpsychologisch aufschlussreich, hier weitgehend ausgeklammert. Denn einerseits handelt es sich bei diesem sensiblen Thema um eine eigenständige, gesondert und behutsam aufzuarbeitende Thematik; zudem bezieht sie sich auf deutlich kleinere Aktivistenkreise, die trotz des fraglos einflussreichen Phänomens des Sympathisantentums - nicht als repräsentativ für die teils zeitgleich zu, teils kurz vor ihren Anschlägen mobilisierenden Studentenbewegungen aufgefasst werden können. ${ }^{425}$ Im Falle der antisemitischen Mobilisierung von Weimar ist es freilich besonders prekär, diese Trennungslinie einzuziehen - aber doch unvermeidlich. Nicht aufgenommen wird außerdem eine inhaltliche Auseinandersetzung mit den philosophischen, literarischen und theoretischen Einflüssen der jeweiligen Bewegungen - etwa mit der Rolle des Deutschen Idealismus und des Junghegelianismus für die Herausbildung der Burschenschaftsbewegung oder mit dem Stellenwert der reichhaltigen (neo-)marxistischen und anarchistischen Theoriebildung für die Formierung der Studentenbewegung der 1960er Jahre um SDS und Neue Linke -, die über knappe Bezugnahmen auf die für das Entstehen der Protestdynamiken maßgeblichen intellektuellen Impulse hinausginge. Mit dieser Fortlassung ist keine Deklassierung oder gar Trivialisierung derartiger Einflüsse, zumindest für die beiden emanzipativ auftretenden Studentenbewegungen, beabsichtigt; sie angemessen darzustellen, würde indes mindestens eine selbstständige Studie füllen. ${ }^{426} \mathrm{Ganz}$ besonders das verblüffende Phänomen politischer Renegaten - beispielhaft zu nennen ist der Weg Horst Mahlers, Bernd Rabehls, u. a. vom SDS zum Rechtsextremismus ${ }^{427}$ - kann nicht

425 Insbesondere für die Studentenbewegung der sechziger Jahre ist hervorgehoben worden: „Der Terrorismus, aus der Studentenbewegung hervorgegangen, war nicht die konsequente Fortführung der Studentenbewegung, sondern ihr Mißverständnis. Nicht zuletzt deshalb blieb er auf Splittergruppen beschränkt." Schlicht: Vom Burschenschafter bis zum Sponti, S. 82.

426 Ein solches Buch wurde in jüngerer Zeit von Michael Th. Greven vorgelegt, der das politische Denken der APO-„Systemopposition“ empathisch, nüchtern und unter geduldiger Abtragung des Rezeptionsballasts rezipiert, vgl. Greven: Systemopposition.

427 Ein jüngerer Beitrag zur Klärung dieses Forschungsdesiderates findet sich in Seitenbecher, Manuel: Mahler, Maschke \& Co. Rechtes Denken in der 68er-Bewegung?, Paderborn 2013. 
berücksichtigt werden. Für das hier verfolgte Vorhaben sollen daher die sporadischen Hinweise auf die kanalisierende und katalysierende Wirkung intellektueller Impulse als Teil der politischen Formativkräfte ${ }^{428}$ genügen.

\section{II.2.1 Die nationalliberale Burschenschafts- und Progressbewegung im Vorfeld des Revolutionsversuchs von 1848/49}

Wenn heute von Studentenbewegungen gesprochen wird, dann ist zumeist die Protestchronologie von „1968“ gemeint. Diese beherrscht, sicher auch aufgrund der einvernehmlich attestierten zeitgeschichtlichen Relevanz der protestierenden Studentinnen und Studenten der 1960er und 1970er Jahre, das öffentliche Gedächtnis so stark, dass im Grunde der Singular dominiert: Die deutsche Studentenbewegung, da scheint man sich einig, das war jene politisch aktivierte, linkssozialistisch bis antiautoritär auftretende, vor allem aber auch kulturell und ästhetisch wirkmächtige Generation, die der Bundesrepublik - je nach politischer Färbung der Kommentare - ihr modernes liberales Gepräge gab bzw. sie durch ihr kollektivnarzisstisches Gebaren auf die Probe stellte. ${ }^{429}$ Doch wirft man einen Blick auf das politisch weitaus unruhigere 19. Jahrhundert, so entdeckt man in Deutschland - genauer: in den Herrschaftsgebieten des Deutschen Bundes während der Vormärz-Periode - den Ausgangspunkt einer liberal-nationalistischen, in mehreren Wellen (1815 bis 1819, 1827 bis 1832 und in Gestalt der nachfolgenden Progressbewegung ab 1837 und fortwirkend bis etwa 1855) auftretenden und um verschiedene Ereignisse konzentrierten Studentenbewegung, die mit der Herausbildung und Etablierung der Burschenschaften, spätestens mit Gründung der Urburschenschaft und mit dem mythisch umrankten Wartburgfest von 1817 ihren Anfang nahm. ${ }^{430}$ Tatsächlich waren viele der deutschen Studenten zwischen 1815 und 1848, mehrheitlich protestantisch geprägte Jungbildungsbürger, geradezu Avantgardisten des bürgerlichen Klassenkampfes gegen die aristokratischen und monarchischen Eliten Europas, mithin Teil der einerseits demokratisch und emanzipativ gerichteten, andererseits kämpferischen und (vor allem nach 1848) bisweilen fanatisch eifernden ${ }^{431}$ Emanzipationsbewegung mit dem Ziel eines einheitlichen, liberal verfassten Nationalstaats - und somit eine entscheidende, besonders engagierte, ja tragende Aktivistengruppe des Revolutionsversuchs von $1848 .{ }^{432}$

Zunächst ist der gesellschaftliche und politische Kontext dieser Bewegung zu rekonstruieren. In territorialstaatlicher Hinsicht glichen die Gebiete des Deutschen Bundes

428 Gemeint ist hiermit, nach Maßgabe der einleitend herausgearbeiteten Faktoren, der Einfluss dieser Impulse auf die inhaltliche Stoßrichtung und Zielvorstellungen der studentischen Gesellschaftskritik sowie auf das kollektive Selbstverständnis der politisch aktiven Gruppen.

429 Vgl. dazu Kapitel II.2.2 dieser Studie.

$430 \mathrm{Vgl}$. dazu auch den europäisch vergleichenden Überblick in Gevers/Vos: Studentische Bewegungen, S. 229-248.

431 Vgl. Klenke, Dietmar: Deutsche Nationalreligiosität zwischen Vormärz und Reichsgründung. Zur innen- und außenpolitischen Dynamik der deutschen Nationalbewegung, in: Historisches Jahrbuch, H. 123/2003, S. 389-448.

432 Vgl. Jarausch: Deutsche Studenten, S. 51. 
mit dem Königreich Preußen in Westen und Osten, dem Königreich Hannover im Norden dem Kaiserreich Österreich und dem Königreich Bayern in Süden nebst zahlreicher kleinerer Königreiche, Herzog- und Fürstentümer zwar einem territorialen Flickenteppich. Dennoch begann die vom liberalen Bürgertum getragene Nationalbewegung, sich vom bildungsbürgerlichen Intellektuellenprojekt - zunächst waren es Historiker, Dichter und Philosophen wie Johann Gottfried Herder oder Johann Gottlieb Fichte, die von einer durch Sprache gestifteten deutschen „Kulturnation“ ausgingen ${ }^{433}$ - zur Leidenschaften und Hoffnungen weckenden Volksbewegung zu entwickeln. Wohlgemerkt: Weder die frühen Denker der deutschen Nation noch das preußisch-deutsche Bildungsbürgertum des frühen 19. Jahrhunderts betätigten sich „politisch“ oder arbeiteten an konkreten revolutionären Projekten, bekleideten sie alle doch Ämter in den Bürokratien und Behörden der deutschen Gliedstaaten. ${ }^{434}$ Ihre Tätigkeit, die stärker im Eingreifen in die Regierungs- und Verwaltungsarbeit und in der Kritik der Obrigkeit durch die von ihnen dominierten Presse- und Meinungskanäle bestand, nutzte vielmehr dem Aufbau politischen Drucks auf die regierenden Eliten ${ }^{435}$ - aber auch im Bemühen um die Mobilisierung der Bevölkerung reüssierte man, schürte und formte man doch pronationales Bewusstsein, weckte agitierend Leidenschaften unter dem sukzessive antinapoleonisch ergriffenen Massen. Vom Gründungsjahr des Deutschen Bundes an wirkte und wuchs so der „kulturelle Nationsbildungsprozess“, auch aufgrund der rasanten Alphabetisierung der Bevölkerung. ${ }^{436}$ Das zunehmend durch eine bürgerliche Öffentlichkeit (Zeitungen, Flugblätter, Petitionen, Vereinstreffen, etc.) beeinflusste politische Klima nach 1815 stand ganz im Zeichen der antinapoleonischen „Befreiungskriege“, des Dranges $\mathrm{zu}$ einem liberalen Rechtsstaat und der Suche nach Traditionslinien einer deutschen Nation. ${ }^{437}$ Die zentrale politische Konfliktlinie verlief zwischen den Proponenten des liberalen bzw. nationalistischen „Fortschritts“, in überwältigender Mehrheit Angehörige des Bürgertums, und den - meist aristokratischen und besitzenden - konservativen Kräften der ancien régimes, kurzum: jenen, die den Progress in die moderne demokratische - zunächst: bürgerliche - Gesellschaft zu beschleunigen suchten, und jenen, die diese Bewegung auszubremsen, wenn nicht zu verhindern trachteten. Das bürgerlichantiständische Vorbild der Französischen Revolution von 1789 - und später noch einmal der französischen Julirevolution von 1830 - und der damit verbundene gesamteuropäische Emanzipationsimpuls, ${ }^{438}$ welcher bereits in den 1780 er Jahren im englischen Cambridge und 1793 in Polen prorevolutionäres studentisches (auch militärisches!) Engage-

433 Vgl. Müller, Frank Lorenz: Die Revolution von 1848/49, Darmstadt 2012, S. 14.

434 Vgl. ibid., S. 26.

435 „Die Kontrolle des obrigkeitlichen Regiments wurde als Aufgabe der Presse begriffen, und die öffentliche Meinung lernten die Gebildeten als politisch räsonnierende gegengouvernementale Gewalt und als Medium der politischen Willensbildung zu verstehen." Bödeker, Hans Erich: Die „gebildeten Stände“ im späten 18. und frühen 19. Jahrhundert, S. 50. Man mag aus der Vernetzungsfunktion der bildungsbürgerlichen Öffentlichkeitsarbeit heraus auch sogleich verstehen, wieso der vehemente Einsatz für die Pressefreiheit einer bürgerlichen „Teilhabe am Staat“ (ibid.) gleichkommen musste und mehr als nur ein Kampf um autonomen Klassenstolz gewesen ist.

436 Vgl. ibid. S. 19.

437 Vgl. Müller: Die Revolution von 1848/49, S. 13-49.

438 Vgl. Ritter: Hegel und die französische Revolution. 
ment inspiriert hatte ${ }^{439}$, übersetzte sich in den 180oer Jahren in die antinapoleonische deutsche Gemengelage:

„Überall wurde der moderne Nationalismus zu einer politischen Religion. Er blieb aber auch jahrzehntelang, und das ist von der älteren Nationalismusforschung oft übersehen worden, eine frühliberale Emanzipations- und Oppositionsideologie, welche die ständische Ungleichheit, die Vormacht der Aristokratie, den Spätabsolutismus, die deutsche Kleinstaaterei beseitigen wollte. Deshalb wurde die Vision des nationalen, liberalen Einheitsstaats, wurde die Forderung nach Partizipation im nationalen Verfassungsstaat von den Konservativen gleich welcher Richtung als prinzipielle Herausforderung und Sprengladung für ihre Welt bedingungslos bekämpft.“440

Dass „die Möglichkeit eines unmittelbaren Bruches mit den fürstlichen Gewalten“ erstmals als gesellschaftspolitische Realität erschien, ist kaum zu unterschätzen, ${ }^{441}$ ganz besonders in Verbindung mit der preußischen Niederlage von 1806, die „für die studentische Jugend zum Schlüsselerlebnis“442 ${ }^{\text {“ }}$ wrde: Erst im „Widerstand gegen die französische Besetzung“ erwuchs ihnen der „Freiheitsdrang des mündigen Bürgers vom individuellen Anliegen zur gemeinsamen Aufgabe des deutschen Volkes. ${ }^{4443}$ Allein, die tatsächlichen Machtverhältnisse in den deutschen Gebieten gaben eine bürgerliche Revolution nach französischem Vorbild nicht her; man war zunächst auf die intellektuelle, d. h. philosophische und ästhetische Verarbeitung der Revolution verwiesen. ${ }^{444}$ So entsteht inmitten der ersten Generation der Burschenschaftsbewegung in den 1810er Jahren eine "extrem starke und historisch neue Symbiose“ von jugendlichem Ringen um eine ich-identische Persönlichkeitsstruktur und dem pathetischen Einfordern einer neuen Gesellschafts- und Staatsform - eine Symbiose, die den oben skizzierten

\begin{abstract}
„Übergang von der relativ ständischen zur mobilen bürgerlichen Cesellschaft ebenso voraus[setzt] wie den Autoritätsverlust absolutistischer Herrschaft und den Aufstieg des Bildungsbürgertums zu einer neuen, am Leitbild des autonomen Individuums orientierten politisch-gesellschaftlichen Elite. ${ }^{\text {“445 }}$
\end{abstract}

In der Luft lag die Revolution in den 1810er, 1820er, auch 1830er Jahren daher nicht. Zwar sollte das Massenphänomen des „Pauperismus“, der Verarmung, ja Verelendung großer Teile der Bevölkerung in den deutschen Gliedstaaten während einer Phase breiter Massenarbeitslosigkeit bei gleichzeitigem Bevölkerungswachstum ein wesentlicher

439 Vgl. Gevers/Vos: Studentische Bewegungen, S. $229 \mathrm{f}$.

440 Wehler, Hans-Ulrich: Deutsches Bildungsbürgertum in vergleichender Perspektive - Elemente eines „Sonderwegs"?, in: Kocka, Jürgen (Hg.): Bildungsbürgertum im 19. Jahrhundert. Teil IV: Politischer Einfluß und gesellschaftliche Formation, Stuttgart 1989, S. 215-237, hier S. 232.

Vgl. Bartol: Ideologie und studentischer Protest, S. 98. „Denn bis 1789 gab es in Europa für sie [die demokratischen Kräfte, J. S.] praktisch nur eine politische Wirkungsmöglichkeit: mit den Fürsten zu arbeiten, nicht gegen sie." Ibid. (Herv. i. O.)

442 Gevers/Vos: Studentische Bewegungen, S. 230.

443 Ibid.

444 Vgl. ibid., S. 98 sowie Joachim Ritter, der die Hegel'sche Philosophie eindrücklich als sublime Verarbeitungsform des revolutionären Impulses charakterisiert, vgl. Ritter: Hegel und die französische Revolution.

Hardtwig: Studentische Mentalität, S. 607. 
katalysierender Faktor der Expansion des liberalen Nationalismus zur politischen Oppositionsbewegung sein. ${ }^{446}$ Andererseits aber ist mehrfach darauf hingewiesen worden, dass „1848“ ein gesamteuropäisches Phänomen gewesen sei, das sich stärker aus kurzfristigen Eskalationsdynamiken speiste denn aus einem graduell gestiegenen umstürzlerischen Klima. ${ }^{447}$ Zudem sollte es abgesehen von jenem gesamteuropäischen Ruck mehrerer Jahrzehnte und zahlreicher geschickt lancierter politischer Kampagnen bedürfen, bis der Versuch des Umsturzes tatsächlich unternommen wurde. ${ }^{448}$ Und auch der Mehrheit der politisch aktiven Studenten, die sich in erster Linie der Reformierung des Studentenlebens, der Gleichstellung aller Studenten und der Vereinigung der regional zersplitterten Landsmannschaften durch die Burschenschaft verschrieben hatten, ging es nicht explizit um den revolutionären Umsturz. ${ }^{449}$ Von Beginn an schied sich die Burschenschaftsbewegung in ein dominierendes pragmatisches bzw. kompromissorientiertes „bürgerlich-liberales“ und in ein zahlenmäßig unterlegenes, doch deutlich aktiveres, emotionalisiertes und utopistischer orientiertes sowie agitatorisch umtriebigeres (dadurch bisweilen deutlicher sichtbares) „radikaldemokratisches“ Lager. ${ }^{450}$ Doch ob akkomodativ oder radikal, ob in Verfassungsfragen mit einer konstitutionellen Monarchie versöhnlich oder auf der rigorosen Abschaffung ständisch-aristokratischer Überreste insistierend: Fraglos war der große liberal gesinnte Teil der deutschen Studenten eine wesentliche Trägergruppe nationalliberaler Agitation. Dadurch entwickelten sie sich mit ihrem starken großdeutsch-sozialrevolutionären Einschlag zu politischen Avantgardisten des Bildungsbürgertums, die die intellektuellen Impulse von vernunftzentrierter Aufklärungsphilosophie, Romantik und Deutschem Idealismus als Direktiven zur praktischen Umgestaltung der Gesellschaft verarbeiteten, ${ }^{451}$ somit den Mentalitätswandel breiterer bürgerlicher Kreise hin zum liberal verfassten Nationalstaat vorwegnahmen, das Selbstbewusstsein der aufsteigenden gebildeten Mittelschichten artikulierten und einen entscheidenden Schrittmacher der Liberalisierung, Demokratisierung und Vereinheitlichung der im Vergleich zu europäischen Nachbarn sozial rückständigen deutschen Gesellschaft bildeten. ${ }^{452}$ Trotz des Scheiterns der Revolution von

446 Vgl. Müller: Die Revolution von 1848/49, S. 50.

447 „Die Revolution von 1848/49 ist kein spezifisch deutsches Phänomen, sondern ein europäisches. [...] Die Verflechtungen und Konfrontationen der europäischen Staaten und ihrer herrschenden, aber auch ihrer opponierenden Kräfte sind überaus vielgestaltig und auch widersprüchlich.“ Hardtwig, Wolfgang: Einleitung, in: Ders. (Hg.): Revolution in Deutschland und Europa 1848/49, Göttingen 1998, S. 7-10, hier S. 9.

448 „In der rückwärts gewandten Beleuchtung historischer Betrachtung werfen Ereignisse Schatten in ihre Vergangenheiten. Es ist wichtig, nicht zu vergessen, dass dies ein künstlicher Vorgang ist. Vor Beginn der Märzrevolution wusste niemand, dass er im „Vormärz“ lebte. [...] Die Revolution war nicht der unvermeidliche Fluchtpunkt aller politischen, sozialen und kulturellen Entwicklungen im Deutschen Bund." Müller: Die Revolution von 1848/49, S. 12.

449 Vgl. Bartol: Ideologie und studentischer Protest, S. 59 und 76.

450 Vgl. ibid., S. 141-143.

451 Vgl. ibid., S. 80-83 und S. 97 sowie Bruch: Die Universitäten in der Revolution, S. 152.

452 Vgl. Bartol: Ideologie und studentischer Protest, S. 77. Dem Klischee des „jugendlichen Rigorismus“ hält Jarausch generell entgegen, dass politisch aktive Studenten stets in erster Linie Vorreiter anstehender sozialer Veränderungen gewesen seien; sie „lassen sich auf neue Strömungen schneller und rückhaltloser ein." Jarausch: Deutsche Studenten, S. 11. 
1848 trugen die deutschen Studenten des Vormärz, indem sie jene gesellschaftspolitische Vakanzen ausfüllten, die ein schwach ausgeprägtes und kaum organisiertes deutsches Bürgertum freiließ, überdies dazu bei, den Boden für die bis Ende des 19. Jahrhunderts folgende industriegesellschaftliche Transformation zu bereiten.

Die Ermöglichungsbedingungen dieses studentischen Engagements für nationale Einheit unter rechtsstaatlichen und demokratischen Vorzeichen wurzelte dabei tief in der einzigartigen Tradition des modernen Verbindungswesens, der Burschenschaften - nach Einschätzung von Jarausch die „erste moderne Jugendbewegung der deutschen

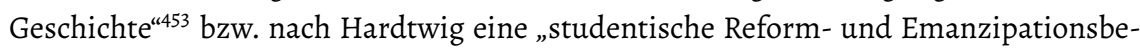
wegung“, ja ein „erster gesamtnationaler politischer Organisationsansatz in Deutschland“454 -, die den Verbindungsstudenten bereits seit den 1770er Jahren als geistig-moralisches Vorbild und Führungsfigur der heraufdämmernden Nation visierte. ${ }^{455}$ Konstituiert als bildungsbürgerliche „Alternative“ zur exklusiv-traditionellen, überdies von bildungsbürgerlicher Seite perhorreszierten Verbindungselite aus Adel und Großbürgertum $^{456}$, stellten die bald überregional agierenden Netzwerke der Burschenschaften sowohl ideologische als auch Organisations- und Personalressourcen bereit, die für den Bewegungsaktivismus notwendig waren. Jene nostalgisch gefärbten Vorstellungen von studentischer "Sitte“, „Studentenleben“, auch „Burschenherrlichkeit“, die sich im 19. und 20. Jahrhundert an das kulturell kolportierte ${ }^{457}$ Bild des Studentendaseins hefteten, sie sind der Nachhall jener Bewegung, die zunächst als apolitische Tugendbewegung, als „Verhaltens- und Wertewandel“ im Namen des aufgeklärten, mündigen Bürgers begann, der zuvörderst die weitgehend inzivilen studentischen Sitten reformieren wollte. ${ }^{458}$ So wollte es das von Philosophen, Bürokraten und Hochschulreformern wie Friedrich Schleiermacher und Wilhelm von Humboldt forcierte Bildungsideal des Neuhumanismus: Umfängliche Bildung des Menschen, das schloss neben fachlicher Gelehrsamkeit und fortschrittsorientiertem technisch-naturwissenschaftlichem Wissen auch ästhetisches Bewusstsein, einen kultivierten Charakter und ein Streben nach Entfaltung der individuellen Persönlichkeit ein. Bildung sollte kein abgeschlossener Zustand sein, sondern ein Prozess der „Entdeckung“ bzw. „Entfaltung“ persönlicher Anlagen. ${ }^{459}$ Der ausgebildete Absolvent sollte, um seiner Verantwortung als zukünftiges Mitglied der Elite der bürgerlichen Gesellschaft gerecht zu werden, als mündiger und aufgeklärter Bürger die Universität verlassen. Apolitisch zwar - doch sozialreformerisch und moralisierend, ging doch die „studentische Sozietätsbewegung“, an-

453 Vgl. ibid., S. 35.

454 Hardtwig: Studentische Mentalität, S. 581.

455 „In ihrem hohen Selbstverständnis als Führungsgruppe des Vaterlands manifestierte sich das Bildungsideal des Neuhumanismus wie die Herausforderung des aufsteigenden Bildungsbürgertums." Jarausch: Deutsche Studenten, S. 35.

456 Vgl. ibid., S. 39.

457 Vgl. Schulze/Ssymank: Das deutsche Studententum, S. 274-299.

458 Vgl. Hardtwig, Wolfgang: Auf dem Weg zum Bildungsbürgertum: die Lebensführungsart der jugendlichen Bildungsschicht 1750-1819, in: Lepsius, M. Rainer (Hg.): Bildungsbürgertum im 19. Jahrhundert. Teil III: Lebensführung und ständische Vergesellschaftung, Stuttgart 1992, S. 19-41, hier S. 19 und 20.

459 Vgl. Weil, Hans: Die Entstehung des deutschen Bildungsprinzips [1930], Bonn 1967, S. 84-148, insbesondere S. $120 f$. 
fangs eine „Gesittungs- und Disziplinierungsbewegung، ${ }^{460}$, ab 1770 doch über die frühen Kernintentionen ihres gesamtbürgerlichen Reformvorbildes, des sich im 18. Jahrhundert entfaltenden Vereins- und Assoziationswesen des erwachsenen Bürgertums hinaus, welches zunächst auf die „vergnügte“ und unterhaltende Geselligkeit „jenseits der Beschränkungen von Haus, Stand, Beruf und traditionellem Zeremoniell“461 ${ }^{\text {, die ge- }}$ meinsame künstlerische oder wissenschaftliche Betätigung hinauswollte und vor allem darin die Erfüllung gemeinnütziger Zwecke sah: ${ }^{462}$ Erst in den $1790 e r$ Jahren nahmen größere bürgerliche Kreise die neuhumanistische Bildungsidee in sich auf, verbanden erst in diesen Jahren ihr Geselligkeitsbedürfnis mit der Emphase der fortschreitenden Selbstbildung und wechselseitigen Belehrung zur neuen, aufgeklärten Gesinnung. ${ }^{463}$ Auf studentischer Seite aber konnten Vereins- und Assoziationswesen früh auf eine Subkultur sui generis zurückgreifen, die sie sukzessive politisierten: Das traditionelle Gewohnheitsrecht der so genannten „Burschenfreiheit“ garantierte eine juristische Sonderbehandlung durch eigene Gerichtsbarkeit und Karzerhaft (universitäre Arrestzelle statt Gefängnis) und schützte die Studenten nach außen hin vor königlicher Jurisdiktion, während nach innen hin spezifische Verhaltens- und Ehrenkodizes (die „Burschenräson") den kollektiven Umgang regulierten, etwa indem sie Fehden zivilisierten und das Duellwesen sukzessive einschränkten. ${ }^{464}$ Subkultur und juristische Sonderstellung schufen vielerorts ein spezifisches, an Autonomie und Unabhängigkeit orientiertes, wenn auch nicht zwangsläufig faktisch zivilisierendes Standesbewusstsein. ${ }^{465} \mathrm{Neu}$

460 Vgl. Hardtwig: Studentische Mentalität, S. 588.

461 Vgl. Nipperdey, Thomas: Verein als soziale Struktur im späten 18. und frühen 19. Jahrhundert, in: Boockmann, Hartmut/Esch, Arnold/Heimpel, Hermann/Nipperdey, Thomas/Schmidt, Heinrich: Geschichtswissenschaft und Vereinswesen im 19. Jahrhundert. Beiträge zur Ceschichte historischer Forschung in Deutschland. Veröffentlichungen des Max-Planck-Instituts für Ceschichte, Bd. 1, Göttingen 1972, S. 1-44, hier S. 5.

462 Vgl. ibid., S. 5-7.

463 Vgl. ibid., S. 6. Sicher ist richtig, dass das neue bürgerliche Vereins- und Assoziationswesen schon vermöge seiner Organisationsprinzipien, die den als autonome Individuen verstandenen Bürgern die Freiheit zum Beitritt und zum Verlassen der Vereine ließ und durch die allgemeine Zugänglichkeit eine spezifische Form von bürgerlicher Öffentlichkeit bereitstellte, eo ipso zur fortschreitenden Schwächung der traditionellen „korporativen“ Institutionen und Herrschaftsstrukturen, mithin zur Herausbildung der bürgerlichen Cesellschaft des 19. Jahrhunderts beitrug, vgl. ibid., S. 12. Andererseits aber bestehen beträchtliche Unterschiede zwischen der ursprünglichen Geselligkeitsintention und der späteren Aufladung mit neuhumanistischen Ideen in den 1790er Jahren bzw. der Politisierung in den $1810 e r$ und $1840 e r$ Jahren - und in dieser Entwicklung spielten die Burschenschaftsstudenten die Rolle von Vorreitern und Schrittmachern allgemeiner Tendenzen. Auch hat das bürgerliche Vereinswesens keine gesellschaftlichen Umwälzungen aus eigener Kraft initiiert, vielmehr quittiert, konsolidiert, forciert; „der Verein ist weder einfach Folge noch einfach Ursache der bürgerlichen Cesellschaft, aber er ist eines ihrer Elemente, ein Symptom für ihren Aufstieg und gerade in den Anfängen ein Faktor, der die weitere Ausbildung dieser Cesellschaft begünstigt und beschleunigt hat." Ibid., S. 12.

464 Vgl. Jarausch: Deutsche Studenten, S. 16f. sowie Schulze/Ssymank: Das deutsche Studententum, S. $181-185$.

465 „Das wirkliche Leben war im ganzen bedeutend freier und fortschrittlicher, als die damalige Rechtsauffassung gestattete, und der Student nahm oder ertrotzte sich das Maß von Freiheit, das ihm wünschenswert erschien. So bildete sich im Gegensatz zur rechtlichen Unfreiheit des akademischen Bürgers durch Cewohnheitsrecht etwas Neues heraus, die sogenannte Burschenfreiheit, 
war das Phänomen eines studentischen Standesbewusstseins also zwar nicht, wohl aber die schrittweise „Verbürgerlichung“ der Studenten:

„Die studentischen Orden, die Korps und die Burschenschaften sind Teil dieser umfassenden Sozietätsbewegung, sie kultivieren wie die anderen Vereinstypen die bürgerlichen Wertvorstellungen von Bildung, Leistungsethos und Verantwortungsbereitschaft zusammen mit einem erhöhten bürgerlichen Machtanspruch, sie bereiten vor allem auch schon in den Jahren vor 1815/19 eine gesamtnationale Organisationsstruktur vor.“466

Der Zug zur Organisation zwischen 1750 und 1819 ergriff $^{467}$ sowohl die traditionalistischen Landsmannschaften und Korps als auch die liberalen und apolitischen Burschenschaften bzw. die in der Freimaurertradition stehenden profranzösischen studentischen Orden und förderte insgesamt die Genese überregionaler Vernetzungsarbeit und von Dachorganisationen. ${ }^{468}$ Kennzeichnend für das so entstandene Verbindungswesen sind die weit verbreiteten freiheitlichen politischen Impulse, die immer wieder Verbote und obrigkeitsstaatliche Repression zur Folge hatten.

Im frühen 19. Jahrhundert gerieten diese noch mehrheitlich frankophilen Revolutionssympathien mit der politisch reüssierenden und bald auch durch Bildungsreformen der Universitäten und des Gymnasiums institutionalisierten ${ }^{469}$ neuhumanistischen Philosophie, selbst eine idiosynkratische „Verquickung von neo-klassischen, rationalistischen, idealistischen und nationalen Impulsen" und "deutsche Antwort auf die geistig-politische Herausforderung des revolutionären Frankreichs“, ${ }^{470}$ aneinander. Nicht nur wuchs die Spaltung zwischen Bildungs- und Wirtschaftsbürgertum ab 1808 über die Frage der Bildungsreformen, hier insbesondere über die Notwendigkeit der Maturitätspflicht und über den „Nutzen“ eines allgemeinbildenden philosophischen Grundstudiums als neue, posttheologische „Königsdiziplin“ der Wissenschaft, ${ }^{471}$ auch

die oft kaum mehr bedeutete als eine alle Cesetze verachtende rohe Willkür." Schulze/Ssymank: Das deutsche Studententum, S. 183.

466 Hardtwig: Studentische Mentalität, S. 614.

467 Vgl. zur zeitlichen Eingrenzung zwischen Beginn der studentischen Reformbewegung und den Beschlüssen von Karlsbad Hardtwig: Krise der Universität.

468 Vgl. Schulze/Ssymank: Das deutsche Studententum, S. 159-180.

469 „Durch das nun obligatorische Gymnasium [...] vereinheitlichte sich die Vorbildung, so daß die Studentenschaft zwar sozial heterogen blieb, aber intellektuell homogener wurde. Durch den neuen, dynamischen Wissenschaftsbegriff wandelte sich der Sinn des Studiums von der Erlernung des Berufswissens zur Suche nach der philosophischen Wahrheit." Jarausch: Deutsche Studenten, S. 21.

470 Vgl. ibid., S. 18.

471 Die sich an den Bildungsreformen entzündende Genese des Gegensatzes zwischen den unternehmerisch tätigen Gruppen des Bürgertums, die sich als „praktisch“ orientierte Agenten von Wachstum und Fortschritt verstanden, und dem mehrheitlich staatlich bediensteten Bildungsbürgertum, das gegenüber den aus ihrer Sicht unzureichend gebildeten, ordinär-materiellen Maximen folgenden Wirtschaftsbürgern oftmals hochmütige Ceringschätzung empfand, ist aufschlussund folgenreich, handelt es sich doch weniger um einen Disput über die Frage der quantitativen Suprematie im erworbenen Wissen, sondern um die qualitative Differenz von „bloß praktischem“, instrumentellen Wissen und pragmatischer Klugheit auf der einen und „echter" akademischer Bildung auf der anderen Seite. „Der entscheidende Gegensatz, auf dem der Vorwurf der fehlenden 
war dem revolutionär gesinnten Teil der Studenten die Staatsnähe der Bildungsreformer zuwider. Nicht wenige von ihnen fanden sich um 1800 in einer spannungsreichen Mixtur aus zukunftsgewandter aufklärerischer Modernität und anachronistisch gewordenen, doch gemeinschaftsstiftenden Bräuchen wieder. ${ }^{472}$ Doch unverkennbar entsprachen sich Reformvorhaben „von oben“ und Reformbedürfnis „von unten“ in dem Drang nach gesellschaftlicher Umgestaltung unter bürgerlichen Vorzeichen. ${ }^{473}$ Am Vorabend der so genannten Befreiungskriege gegen das napoleonische Frankreich siegte die kollektivierende und integrative Kraft der Idee einer freien deutschen Nation; Revolutionssympathie schlug infolge des Kriegserlebnisses um in Franzosenfeindschaft und ebnete so den Boden für die deutsche Nationalbewegung nach $1815 ;{ }^{474}$

„die letztgültige Loyalität, der sich die Burschenschaften zuordneten, war der moderne Nationalgedanke - konkretisiert in den Forderungen nach staatlicher Einheit aller deutschen Territorien und nach Beteiligung des ,Volkes' an der staatlichen Willensbildung und Cesetzgebung. “475

In den darauffolgenden Jahrzehnten luden sich die studentischen Assoziationsformen im Sinne des „deutschen Geistes" mehr und mehr nationalistisch auf. Die organisierte akademische Jugend beanspruchte „die Rolle der treibenden Kraft“476, und tatsächlich antizipierte sie die spätere Politisierung des bürgerlichen Vereinswesens - jener früh etablierten Zivilgesellschaftlichkeit, in der bereits Ende des 18. Jahrhunderts „nahezu alle Gebildeten" organisiert gewesen sind. ${ }^{477}$

Diese frühe Studentenbewegung, von Idolen, Gurus und Professoren wie „Turnvater" Friedrich Ludwig Jahn, Ernst Moritz Arndt und Jakob Friedrich Fries u. a. sowohl inspiriert und angetrieben ${ }^{478}$ als auch von ihnen als Gruppe „nationaler Idealisten“ be-

Bildung vor allem beruhte, war der zwischen wissenschaftlich-akademischer Bildung einerseits und der reinen Fachbildung andererseits. Bildungsbürger und Wirtschaftsbürger scheiden sich in dieser Frage am Gegensatz zwischen neuhumanistischem und realistischem Bildungsprinzip. Als Männer der Praxis und des zweckrationalen Denkens hielten die Unternehmer die den pragmatischen Berufsaufgaben nicht entsprechende Ausbildung für unnütz und eher schädlich. Ihre ,Standesschule' war die höhere Bürger- oder Rektoratsschule, später die Realschule, deren Lehrpläne Mathematik und Naturwissenschaften sowie die modernen Sprachen bevorzugten." Zunkel, Friedrich: Das Verhältnis des Unternehmertums zum Bildungsbürgertum zwischen Vormärz und Erstem Weltkrieg, in: Lepsius, M. Rainer (Hg.): Bildungsbürgertum im 19. Jahrhundert. Teil III: Lebensführung und ständische Vergesellschaftung, Stuttgart 1992, S. 82-101. hier S. 85f.

472 „Studieren in dieser Zeit des Umbruchs machte Spaß, regte an, ob man nun dem Humboldtschen Ruf zur Wissenschaft oder dem traditionellen Impuls zum Trinken und Fechten folgen wollte." Jarausch: Deutsche Studenten, S. 22.

473 Vgl. Hardtwig: Krise der Universität, S. 175.

474 Vgl. Jarausch: Deutsche Studenten, S. 22.

475 Hardtwig: Studentische Mentalität, S. 610.

476 Vgl. Hardtwig: Krise der Universität, S. 176.

477 Bödeker, Hans Erich: Die "gebildeten Ständeïm späten 18. und frühen 19. Jahrhundert, S. 46.

478 „Ernst Moritz Arndt (1769-1860) entfachte 1813 unter den Studenten die vaterländische Begeisterung sowohl mit seinem berühmten Lied, das auf die Frage ,Was ist des Teutschen Vaterland?' die Antwort gibt: ,Soweit die deutsche Zunge klingt' wie auch mit seinem Aufsatz ,Über den deutschen Studentenstaat', in dem er seine Hoffnungen auf die Studentengeneration seiner Zeit setzte. [...] In Berlin gründeten Friedrich Ludwig Jahn (1778-1852), der Schöpfer der Turnbewegung, und Jakob Friedrich Fries (1773-1843), ein bei den Studenten sehr beliebter Philosophieprofessor, 1811 den ge- 
wundert, ferner von monarchistischen Restauratoren wie dem Fürsten von Metternich als potenzielle Aufrührer bekämpft, ${ }^{479}$ sollte ihre offizielle intellektuelle und politische Gründung am 12. Juni 1815 im damals liberalen und geographisch zentral gelegenen ${ }^{480}$ Jena vollziehen: Hier konstituierten sich ehemalige studentische Kriegsfreiwillige bzw. Freikorps-Veteranen im Gasthaus „Zur Tanne“ zur „Urburschenschaft“. ${ }^{481}$ Ihr Wahlspruch lautete „Ehre, Freiheit, Vaterland“; ihr erklärtes Ziel war die „Selbsterziehung“ der akademischen Jugend hin zu politischen, d. h. liberalnationalistischen Idealen mit einer starken Emphase auf dem studentischen Vorbildcharakter der „deutschen Tugend" und auf dem als klassenübergreifend gedachten gesamtdeutschen „Vaterland“. ${ }^{482}$ Dieser Zug zur vaterländischen Einheit drückte sich auch im damals anstößigen Tragen eines bürgerlichen schwarzen Rockes aus - und auch in der Verwendung der schwarzrot-goldenen Fahne, zuvor Farbcode der Uniformen des unter den Gründungsmitgliedern breit vertretenen Lützower Freikorps ${ }^{483}$, die das nun als partikularistische Gestrigkeit begriffene bunte Flaggenmeer der Landsmannschaften ersetzte: ${ }^{44}$

„Sie lösten die bisher an der Hochschule bestehenden studentischen Verbindungen mit ihren landsmannschaftlichen Bezeichnungen wie ,Franconia', Saxonia' oder ,Thuringia' auf. Deren Fahnen wurden symbolisch gesenkt und niedergelegt. In Zukunft sollte nur noch eine einzige, alle Studierenden umfassende Verbindung in Jena bestehen: die ,Burschenschaft', wobei Burschenschaft soviel wie ,Studentenschaft' bedeutete. ${ }^{\text {“485 }}$

$\mathrm{Zu}$ den Gründungsmitgliedern der Urburschenschaft gehörten Köpfe wie Wilhelm Heinrich Freiherr von Gagern, später ein zentraler Wortführer der nationalliberalen Bewegung, 1848/49 erster Präsident der Frankfurter Nationalversammlung und in den Folgejahrzehnten ein wichtiger politischer Widersacher Bismarcks. ${ }^{486}$ Die ursprünglich 143 Studenten, die die urburschenschaftliche Verfassung mit ihrer Forderung nach gleichen Rechten für alle Immatrikulierten unterzeichneten, ${ }^{487}$ wuchsen bis

heimen studentischen ,Deutschen Bund' zur Vorbereitung eines Befreiungskrieges." Gevers/Vos: Studentische Bewegungen, S. 230. „Überhaupt muß bei der Entwicklung der Burschenschaft zu einer politischen Kraft neben der bürgerlichen ,Adressenbewegung' und dem Turnwesen stets die lebendige Beeinflussung durch die Jenaer Professoren gesehen werden." Steiger, Günter: Aufbruch. Urburschenschaft und Wartburgfest, Leipzig Jena Berlin 1967, S. 73.

479 Vgl. Jarausch: Deutsche Studenten, S. 35.

480 Vgl. Gevers/Vos: Studentische Bewegungen, S. 231.

481 Steiger: Urburschenschaft und Wartburgfest, S. $33 \mathrm{f}$.

482 Vgl. Jarausch: Deutsche Studenten, S. 36.

483 Vgl. Gevers/Vos: Studentische Bewegungen, S. 231 und Heinemann, Angela Luise: Studenten im Aufbruch - Die Entstehung der Jenaer Urburschenschaft und das Wartburgfest als mediale Inszenierung, in: Lönnecker, Harald (Hg.): "Deutschland immer gedient zu haben ist unser höchstes Lob!SZweihundert Jahre Deutsche Burschenschaften. Eine Festschrift zur 200. Wiederkehr des Gründungstages der Burschenschaft am 12. Juni 1815 in Jena, Heidelberg 2015, S. 1-78, hier S. 25.

484 Vgl. Bartol: Ideologie und studentischer Protest, S. $62 \mathrm{f}$.

485 Steiger: Urburschenschaft und Wartburgfest, S. 34.

486 Von Gagern (1799-1880) wird als Gründungsmitglied und führender Vertreter der Jenaer Urburschenschaft aufgeführt in Kaupp, Peter: Stamm-Buch der Jenaischen Burschenschaft. Die Mitglieder in der Urburschenschaft 1815-1819, Köln 2005, S. 125 f.

Vgl. Steiger: Urburschenschaft und Wartburgfest, S. 34. 
zur Jahreswende auf 500 von insgesamt 650 Jenaer Studierenden an; dieses Signal inspirierte auch an vielen anderen Universitäten des Deutschen Bundes die Gründung von Burschenschaften. ${ }^{488} 1818$ gab sich die Urburschenschaft eine Verfassung, die nationale Einheit und Freiheit nach Herder'schem Vorbild zum politischen Ziel erklärte, d. h. eine philosophisch begründete Gesellschaftsreform, die Untertanen in Bürger verwandeln sollte. Dieses revolutionäre Programm war in doppelter Hinsicht unverkennbar bildungsprotestantisch durchwirkt; der traditionelle studentische „Standesehre“-Begriff (also Standesrecht, Sittlichkeit und Tugend, romantisierende Deutschtümelei) verband sich darin mit einem vergleichsweise modernen politischen Programm (nationale Einheit, neuhumanistischer Kosmopolitismus) - ein latent zum politischen Aktivismus aufforderndes Maximenset und ein „nationales Selbsterziehungsprogramm“ - , auf das sich immerhin etwa ein Drittel aller damaligen Studenten verpflichtete. ${ }^{489}$

„Die Burschenschaften kultivierten [...] zwischen 1815 und 1819 ein um den Ehrbegriff zentriertes Selbstverständnis, in dem Relikte der alten ,studentischen Freiheit' als libertär-ständisches Sonderbewußtsein und die Selbsteinschätzung als Elite auf der Basis grundsätzlicher rechtlicher Gleichheit in der bürgerlichen Gesellschaft spannungsvoll miteinander verbunden waren oder sich überlagerten. ${ }^{4}{ }^{490}$

Den vorläufigen Höhepunkt dieser Entwicklung bildete die Gründung der „Allgemeinen Burschenschaft" auf dem so genannten großen „Burschentag“ in Jena am 18. Oktober 1818, eines Dachverbandes, dessen erklärtes Ziel es wiederum war, nationale Einheit und freiheitliche Verfassung in burschenschaftlichen Milieus quasi-monastisch, als "Studentenstaat", vorwegzunehmen. ${ }^{491}$ Etwa 30 Prozent der deutschen Studenten erklärten ihre Zugehörigkeit zu diesem Dachverband. ${ }^{492}$ In weltanschaulicher Hinsicht beinhaltete diese Selbstverpflichtung auf das nationalistische burschenschaftliche Programm nicht nur eine leidenschaftliche Freiheitsemphase, sondern auch früh die romantisch-kulturnationalistische Verklärung „deutschen Volkstums“ im Sinne einer gleichnamigen Schrift Jahns von 1819, d. h. mitsamt nationalchauvinistischer und antisemitischer Elemente, die, jedenfalls bis zu den Burschentagen 1830 und 1831, auch zum Ausschluss ausländischer und jüdischer Studierender aus den Burschenschaften führte. ${ }^{493}$

Als politisch und organisatorisch entscheidendere Zäsur aber wird weitgehend das so genannte Wartburgfest von 1817 verhandelt, eine anlässlich des 300 . Jahrestages der Reformation auf der symbolträchtigen Wartburg bei Eisenach initiierte Versammlung von über 450 Studenten, „Von denen die eine Hälfte aus Jena stammte, die andere aus Berlin, Erlangen, Gießen, Göttingen, Halle, Heidelberg, Kiel und Leipzig“4944 sowie ei-

488 Vgl. Bartol: Ideologie und studentischer Protest, S. 63 sowie Gevers/Vos: Studentische Bewegungen, S. 231.

489 Vgl. Jarausch: Deutsche Studenten, S. 36 und $39 f$.

490 Hardtwig: Studentische Mentalität, S. 598.

491 Vgl. Jarausch: Deutsche Studenten, S. 39.

492 Vgl. Gevers/Vos: Deutsche Studenten, S. 232.

493 Vgl. ibid., S. 232.

494 Ibid., S. 231. 
nigen nationalliberalen Professoren. $\mathrm{Zu}$ diesem Fest lud die Jenaer Urburschenschaft ${ }^{495}$ im Geiste der von Jahn, Arndt und anderen mit Nachdruck geforderten ${ }^{496}$ Volks- und Nationalfeste; man erzielte hiermit - hinsichtlich der nun erzielten Außenwirkung einer zuvor auf verschworene Gemeinschaften setzenden Reformbewegung - ein frühes Medienereignis mit dem Ziel des Hervorrufens nationalistischer Emotionen auch in der nichtstudentischen Bevölkerung. ${ }^{497}$ Diese erste überregionale nationalistische Protestkundgebung, seither Fixpunkt romantisierender Mythenbildung um den Studenten als Vorkämpfer der deutschen Einheit, wirkte katalysierend und bündelnd auf die Mobilisierungsenergien der sich gerade erst konstituierenden nationalliberalen Studentenbewegung. ${ }^{498}$ Die verschiedenen reformorientierten Strömungen der einzelnen Hochschulen schlossen sich erstmals zu einer politischen Einheit zusammen, und es war ausdrückliches Ziel, im Namen eines kommenden vereinigten Deutschlands „nationale Tugenden“ vorzuleben. Die institutionellen Schranken der existierenden deutschen Territorialstaaten konnten einem solchen Vorhaben auf Dauer nicht genügen. Hierin lag die eigentliche Entfaltung des politischen Gehalts, ja der Umschlag des urburschenschaftlichen Programms in eine frühliberale politische Bewegung:

„Als Hochziel schwebte ihr die Schaffung eines großen Zusammenschlusses vor, der an jeder Universität alle deutschen Studenten umfassen sollte, wie es vor 1815 auf den Hochschulen an der Ostsee der Fall gewesen war, wo Burschenschaft soviel wie Studentenschaft bedeutet hatte. [...] Die neue Form des Studentenstaates sollte ein bedeutungsvolles Sinnbild für den politischen Staat sein, dessen Einheit man erträumte [...] Gewiß war die Urburschenschaft keine politische Schöpfung und wollte eine solche auch gar nicht sein [...] Aber in ihrer Wirkung war die Burschenschaft doch politisch, insofern sie ihr Erziehungsideal einer großen, über ganz Deutschland verbreiteten Masse von Gebildeten aufdrückte. “499

Dass der bereits erwähnte antisemitische und völkische Unterstrom dem burschenschaftlichen großdeutschen Nationalliberalismus mit seinem Hass auf alles vermeintlich Partikularisierende, Kompromittierende und vermeintlich Spaltende im Grunde $a b$ ovo zu eigen war ${ }^{500}$, zeigte sich übrigens auch hier: „Wehe über die Juden, so da festhalten an ihrem Judenthum und wollen über unser Volksthum und Deutschthum spotten und schmähen!“501 lautete der triumphierende Ausruf des Turners Hans Ferdinand Maßmann, als er die kritische Schrift „Germanomanie“ des deutsch-jüdischen Autors

495 Vgl. Jarausch: Deutsche Studenten, S. 160.

496 Vgl. Steiger: Urburschenschaft und Wartburgfest, S. $80 f$.

497 Vgl. Heinemann: Studenten im Aufbruch, S. 2 und S. 44-47.

498 Vgl. ibid., S. $77 f$.

499 Schulze/Ssymank: Das deutsche Studententum, S. 223 (Herv. i. O.)

500 So die leitende These in Heither, Dietrich/Gehler, Michael/Kurth, Alexandra/Schäfer, Gerhard: Blut und Paukboden. Eine Geschichte der Burschenschaften, Frankfurt a.M. 1997.

501 Maßmann, Hans Ferdinand: Kurze und wahrhaftige Beschreibung des großen Burschenfestes auf der Wartburg bei Eisenach am 18ten und 19ten des Siegesmondes 1817, Eisenach 1817, online einsehbar unter: https://archive.thulb.uni-jena.de/collections/rsc/viewer/HisBest_derivate_00015889/THUESA_BurschenfestWartburg_Massmann_387154183_1817_0040.tif [eingesehen am 28.02.2020], S. 26f. Zur Bücherverbrennung vgl. Heither et al.: Blut und Paukboden, S. 2631. Zur Figur Saul Ascher vgl. auch Jasper, Willi: Gegen die Cermanomanie, in: Der Tagesspie- 
Saul Ascher gemeinsam mit einigen Burschenschaftern während der Bücherverbrennung auf dem Wartenberg 1817 nebst weiteren Schriften, preußischem Ulanenschnürleib, Soldatenzopf und Korporalstock in die Flammen warf. ${ }^{502}$ Allerdings: Ob der Akt der Verbrennung selbst, frei nach dem Zitat aus der Heine-Tragödie „Almansor“ von 1821 („Das war ein Vorspiel nur, dort wo man Bücher / verbrennt, verbrennt man auch am Ende Menschen ${ }^{4503}$ ), als vielsagend antizipative, gar in sich völkische Symbolik im Sinne der NS-Bücherverbrennungen von 1933 gewertet werden kann, ist gesondert zu diskutieren ${ }^{504}$ und soll hier nicht entschieden werden.

Die immer selbstbewusster auftretende umstürzlerische Herausforderung infolge der zur politischen Demonstration avancierten Zusammenkunft auf der Wartburg wurde von obrigkeitsstaatlicher Seite unmissverständlich wahrgenommen. Ein Affront gegen Staat und Adel, provozierte diese Bewegung einen Generationenkonflikt zwischen alten und jungen Akademikern, ${ }^{505}$ überdies auch eine zunehmende obrigkeitliche Dünnhäutigkeit ${ }^{506}$ gegenüber studentischen Verbindungen. Die Eskalationsdynamik nahm insbesondere in Folge von Aktivitäten radikaler burschenschaftlicher Splittergruppen wie dem sozialrevolutionären ${ }^{507}$ „Kreis der Unbedingten“ um Karl Follen und Karl Ludwig Sand ihren Lauf, welche in einem geradezu modernen terroristischen Akt den Schriftsteller und russischen Spion August von Kotzebue ermordeten. ${ }^{508}$ Dieser Vorfall wurde vom Kreis der Restauratoren um Metternich rigoros ausgeschlachtet: Im August 1819 erließ der Bundestag des damaligen Deutschen Bundes infolge mehrerer Sitzungen der Ministerialkonferenzen die so genannten Karlsbader Beschlüsse, die für das liberale Bürgertum u. a. ein Verbot der öffentlich-schriftlichen Meinungsfreiheit, Pressezensur, ein Verbot der Burschenschaften - die eher traditionalistischen Korporationen blieben geduldet -, Berufsverbote, polizeiliche Repression und die Einrichtung eines quasi-zentralstaatlichen „Bundeskriminalamts“ zur Durchsetzung all dieser Maßnahmen bedeuteten. ${ }^{509}$

Auf der anderen Seite sollten nicht die studentischen Organisatoren und reformerischen intellektuellen Agitatoren des Wartburgfests heroisiert werden, sondern ausge-

gel, 07.08.2017, online einsehbar unter: https://www.tagesspiegel.de/kultur/der-reformator-saulascher-gegen-die-germanomanie/20149716.html [eingesehen am 28.02.2020]

502 Vgl. Steiger: Urburschenschaft und Wartburgfest, S. 106-117.

503 Zit. nach Lipp, Volker/Möllers, Christoph/von der Pfordten, Dietmar (Hg.): Heinrich Heine. Dichter und Jurist in Göttingen. Cöttinger Juristische Schriften, Bd. 1, Cöttingen 2007, S. 36.

504 Vgl. Heither et al.: Blut und Paukboden, S. $30 f$.

505 Vgl. Jarausch: Deutsche Studenten, S. 37 und Schulze/Ssymank: Das deutsche Studententum, S. 229.

506 Keineswegs sollte die Haltung der Cliedstaaten mit einem rigiden Karlsbader Ceist gleichgesetzt werden. Das vergleichsweise kleine Herzogtum Sachsen-Weimar-Eisenach etwa, Bühne von Wartburgfest und Kotzebue-Mord und regiert durch den alternden Großherzog Carl August, hatte große Mühen, der auf 1817 und 1819 folgenden politischen Krisendynamik zu begegnen - gerade angesichts des ansteigenden Drucks vonseiten der Croßmächte Preußen und Österreich. Vgl. dazu Tümmler, Hans: Wartburg, Weimar und Wien. Der Staat Carl Augusts in der Auseinandersetzung mit den Folgen des Studentenfestes von 1817, in: Historische Zeitschrift, H. 1/1972, S. 49-106.

508 Vgl. Jarausch: Deutsche Studenten, S. 40.

509 Vgl. Müller: Die Revolution 1848/49, S. 21 und Steiger: Urburschenschaft und Wartburgfest, S. 204213. 
rechnet der Radikaldemokrat und Kotzebue-Attentäter Sand, welcher bereits im unmittelbaren Nachgang seiner Hinrichtung 1820 zur posthum, auch von breiteren Bevölkerungskreisen geehrten, Märtyrerfigur der nationalliberalen Bewegung aufstieg: ${ }^{510} \mathrm{Am}$ Mannheimer Hinrichtungsort entfernten ansässige Bürger Locken, Holzsplitter und andere Objekte wie Reliquien, während eine Tochter der Kaufmannsfamilie Bassermann die Kopie eines Sand-Portraits in ihrem Schlafzimmer aufhängte. ${ }^{51}$ Dabei zeichnet Sands biographische Vorgeschichte eher das Bild eines leicht konfusen Einzelgängers, der die Erfahrung seines politischen Scheiterns durch einen tatorientierten, narzisstisch durchzogenen Fanatismus kompensierte, nicht auf einen durch die Burschenschaftsbewegung zeitlebens geehrten Anführer. So ist von einem „kurzen, schwermütigen“ und zugleich "schwärmerisch-träumerischem“ Leben die Rede. ${ }^{512}$ Sand entwickelte offenbar schon in seiner Jugend, offenbar bedingt durch die infolge der napoleonischen Besatzung erlittenen materiellen Nöte seiner Familie bei gleichzeitiger Kollaborationshaltung seines Vaters, eine leidenschaftliche Abneigung gegenüber jeder opportunistischen Verwässerung politischer Ziele. ${ }^{513}$ Dementsprechend waren ihm politstrategische Kompromissbildungen zuwider, die seinem tiefempfundenen Wunsch nach einem revolutionären Siegesstreich im Stile einer tabula rasa widersprachen. Er verstand sich als Vordenker nationaler und liberaler Ideale, wollte als „Missionar" für die deutsche Sache tätig sein und fasste auch seine Teilnahme am Wartburgfest als „Wallfahrt“ auf, ließ sich im Anschluss in Jena immatrikulieren, wurde dort Mitglied der Burschenschaft, 1818 auch des Vorstandes und „engeren Vereins“, und träumte, inspiriert von Follen, von einem revolutionären Geheimbund entschlossener Burschenschafter. ${ }^{514}$ Doch laborierte Sand wieder und wieder an der schmerzlich empfundenen Isolierung: Weder seine auf der Wartburg verteilte Flugschrift noch seine Agitationsversuche in Richtung der Bevölkerung, ja nicht einmal seine das Attentat begleitenden Pressemitteilungen fanden inhaltliche Resonanz, wohl auch aufgrund „schwer verständliche[r] Sprache mit unzusammenhängenden Gedankengängen“ 515 bzw. „verworrenen Gefühlen und unge-

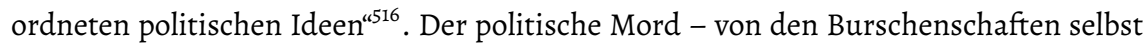
mehrheitlich abgelehnt ${ }^{517}$ - kann wohl als projektiver Befreiungsschlag eines burschenschaftlichen Solitärs aufgefasst werden, dem die geduldige, strategische und bisweilen auch paktierende politische Praxis zuwider gewesen ist - und seine späte Ehrung (gemeinsam mit seiner Anhängerschaft zu Follens Kreis der „Unbedingten“) zugleich als Hinweis auf die inneren Ambivalenzen der durch die nachnapoleonischen Burschenschafter und ihre bürgerlichen Akklamateure proklamierten freiheitlichen Ideale, ins-

510 „Bereits bei seiner Hinrichtung war S[and] ein Symbol für Einheit und Freiheit geworden, sein Grab wurde ein Wallfahrtsort. Im Vormärz wurde S[and] zum politischen Heiligen stilisiert und stieg zur Identifikationsfigur v. a. im radikaldemokratischen und -nationalen Flügel der Burschenschaft auf." Lönnecker, Harald: Sand, Carl Ludwig, in: Neue Deutsche Biographie (NDB), Bd. 22, Berlin 2005, S. 413-414, hier S. 414

511 Vgl. Gall: Bürgertum in Deutschland, S. $220 f$.

512 Vgl. Steiger: Urburschenschaft und Wartburgfest, S. 180.

513 Vgl. ibid.

514 Vgl. ibid., S. 181-183 sowie Lönnecker: Sand, S. 413.

515 Vgl. Steiger: Urburschenschaft und Wartburgfest, S. 182

516 Lönnecker: Sand, S. 414.

517 Vgl. ibid. 
besondere ihres früh lauernden Umschlags in kompromisslos-nationalreligiöse ${ }^{518}$ und gewalttätige Aggression.

Jedenfalls, die Demagogenverfolgung nach Karlsbad bedeutete einen vernichtenden Rückschlag für die Studentenbewegung. ${ }^{519}$ Als unmittelbare Konsequenz folgte der Rückzug in lokale und konspirative Treffen; erst 1826 kam es wieder zu Neugründungen und einer langsamen Regeneration der Organisationsstrukturen. ${ }^{520}$ À la longue aber förderten die Karlsbader Beschlüsse und die sich anschließende repressive Periode der „Demagogenverfolgung“ die Einmündung bzw. Umleitung der politischen Impulse in vordergründig apolitische, doch wachsende und sozialmoralisch entschlossene bürgerliche Subkulturen - analog zu den Entwicklungen im erwachsenen Bürgertum. Nach 1819 zerfiel zunächst die „relative Konsistenz der burschenschaftlichen Reformprogrammatik“ zunehmend in "moralisch-zivilisatorische Gesittungsbewegung“ auf der einen und politische Bewegung auf der anderen Seite. ${ }^{521}$ Diese Verselbstständigung des deutschen Nationalismus als politisches Projekt aber ermöglichte erst dessen Expansion zur über (jung-)bildungsbürgerliche Milieugrenzen hinausreichenden Massenbewegung ${ }^{522}$ in den folgenden beiden Jahrzehnten.

Der Humus dafür bildete sich erst nach und nach in den 1820er, 1830er und 1840er Jahren. Klassenkämpferische Glut aufseiten der Beamten etwa flammte erst in den 1820er Jahren auf, als sich die Aussichten des Aufstiegs in die staatlichen Verwaltungskarrieren aufgrund von Stellenverknappung, Bevölkerungswachstum und Rearistokratisierung der Karrieren eintrübten. ${ }^{523}$ Dieser „adelige Rückstoß“ wirkte vor allem in Preußen und den norddeutschen Staaten. ${ }^{524}$ Das Ausmaß oppositioneller Radikalität bildungsbürgerlicher Kreise lässt sich im deutschen Fall offenbar recht genau am Integrationsgrad in saturierte Stellungen bemessen:

„Die Verwaltungs- und Justizbeamten [in den landständischen Kammern, J. S.] konnten zu den gefährlichsten Kritikern der konkreten Regierungsgeschäfte werden, weil sie von Amts wegen in die Funktionsweise des sich modernisierenden Staates den tiefsten Einblick hatten. Dabei riskierten sie aber ihr Amt, und wo sie es verloren,

518 Vgl. Klenke: Deutsche Nationalreligiosität.

519 „Das politische Resultat des Mordes war das genaue Gegenteil der Hoffnungen Sands - der Triumph der Restauration." Jarausch: Deutsche Studenten, S. 41. Vgl. auch Schulze/Ssymank: Das deutsche Studententum, S. $234 \mathrm{f}$.

520 Vgl. Jarausch: Deutsche Studenten, S. 41.

521 Vgl. Hardtwig: Studentische Mentalität, S. 598.

522 Gleichwohl bemühten sich schon einzelne Protagonisten der ersten Burschenschaftergeneration um Massenwirksamkeit, so etwa Sand, der bereits 1817/18 „mehrfach und mit geringem Erfolg bemühte, Kontakte mit breiteren Kreisen der Bevölkerung aufzunehmen und agitatorisch zu wirken." Steiger: Urburschenschaft und Wartburgfest, S. 183.

523 „[Die] Adelsrestauration im Stellenbereich, die seit den zwanziger Jahren einsetzende Stelleneinsparung im öffentlichen Dienst und die - mit dem Bevölkerungsanstieg einhergehende - größere Zahl der Stellenbewerber schufen mit den ausgebildeten Beamtenanwärtern ein kritisches Protestpotential. Privatdozenten wie Arnold Ruge oder Karl Nauwerck wurden zu radikalen Systemkritikern, Privatdozenten waren 1830 auch in Göttingen am revolutionären Aufstand führend beteiligt." Siemann, Wolfram: Die deutsche Revolution von 1848/49, Frankfurt a.M. 1985, S. $24 f$. Vgl. Siemann ibid., S. 24, der die Formulierung von Werner Conze bezieht. 
waren sie in der Regel Exponenten eines konstitutionellen, mehr noch eines parlamentarisch-demokratischen Liberalismus. ${ }^{\text {"525 }}$

Die vormärzlichen Studenten, mehrheitlich Kinder des Bildungsbürgertums und somit durch dessen Mentalitäten, Ansprüche, Erwartungen und Ziele substanziell geprägt, ${ }^{526}$ registrierten Probleme wie die Stellenverknappung, ohne aber bereits beruflich eingemündet zu sein und entsprechenden Kompromissbedarf mit den Herrschaftsträgern zu sehen. Vielmehr sahen sie die ihnen aus ihrer Sicht zustehenden Führungs- und Elitenpositionen blockiert. Zudem konnten sie um 1830 an eine gesamteuropäische Tendenz oppositioneller studentischer Subversivität anschließen, wie die niederländischen Historiker Lieve Gevers und Louis Vos herausstellen: „Bei der nationalen und liberalen Revolution von 1830 bildeten die Studenten überall in Europa die Vorkämpfer, ja sie waren an etlichen Orten ihre eigentlichen Initianten und Auslöser. “527

Dies scheint das historische Debüt von mobilisierungsstarkem politischem Radikalismus unter deutschen Studenten zu sein; nicht weil hier - so das von Jarausch attackierte Klischee - „erwachsener Pragmatismus“ und „jugendlicher Rigorismus“ aufeinandergestoßen wären, sondern weil Studenten das Sensorium und die Freiheit hatten, „schneller und rückhaltsloser" auf politische Tendenzen zu reagieren, den künftigen gesellschaftlichen Mentalitätswandel zu antizipieren. ${ }^{528} 1830$ lag, im Gegensatz zu 1817, gerade kein Generationskonflikt vor. Im Unterschied zur „1815er-Generation“ waren die „1830er"keine jugendliche Kriegsgeneration, sondern gingen aus einer 15-jährigen zwar restaurativen, aber doch friedlichen Wachstumsperiode hervor. Inspiriert durch die französische Julirevolution von 1830, den belgischen Sezessionskrieg 1830/31 und den polnischen Novemberaufstand 1830/31 wurden die liberalen Teile der deutschen Studenten abermals politisch aktiviert. ${ }^{529}$ Der Drang, eine bürgerliche Revolution praktisch herbeizuführen, trieb daraufhin europaweit zahlreiche Studenten in militanten Aktionismus. In den deutschsprachigen Gliedstaaten gründeten sie - neben den wiederauflebenden Burschenschaften - politische Klubs und Waffenringe, veranstalteten Versammlungen, verbreiteten Aufrufe. ${ }^{530}$ Erstmals entstand eine größere, milieü̈bergreifende nationalliberale Bewegung, die auch Teile des Besitz- und Stadtbürgertums ergriff. ${ }^{531}$ Auf dem Hambacher Fest von 1832 forderten die nunmehr aus verschiedenen gesellschaftlichen Schichten stammenden 20.000 bis 30.000 Teilnehmer ${ }^{532}$ nationale Souveränität, Einheit und Freiheit; der „lange Schatten der Französischen Revolution“ und des durch sie entfachten nationalistischen und liberalistisch-antimonarchistischen Impulses ${ }^{533}$ hatte also binnen vierzig Jahren zu einer ernstzunehmenden revolutionären

526 Vgl. Kapitel II.1 dieser Studie.

527 Gevers/Vos: Studentische Bewegungen, S. $236 \mathrm{f}$.

528 Vgl. Jarausch: Deutsche Studenten, S. 11.

529 Vgl. ibid., S. 42.

530 „Der Burschentag 1832 in Stuttgart verkündete ausdrücklich als Ziel der Studentenbewegung, die Erregung einer Revolution, um durch diese die Freiheit und Einheit Deutschlands zu erreichen'.“ Gevers/Vos: Studentische Bewegungen, S. 240.

531 Vgl. Jarausch: Deutsche Studenten, S. 43.

532 Vgl. Bartol: Ideologie und studentischer Protest, S. 74.

533 Vgl. Müller: Die Revolution von 1848/49, S. 13-25. 
Opposition in Deutschland geführt - auch wenn gerade das Hambacher Fest ob dessen unmittelbarer politischer Konsequenzlosigkeit zunächst belächelt worden ist, und obwohl das unmittelbare Hauptmotiv der Teilnahme nicht nationaler Freiheitsdrang, sondern die Wut über hohe Lebensmittelpreise gewesen sein mag. ${ }^{534}$ Der Frankfurter Wachensturm - als immerhin „erste[r] bewaffnete[r] Aufstand in Deutschland“535 ein praktischer Versuch, einen Volksaufstand zu initiieren, an welchem jedoch nur ca. fünfzig Studenten und einigen Handwerkern teilnahmen ${ }^{536}$ - scheiterte 1833, Georg Büchners egalitaristisches Pamphlet Der Hessische Landbote zirkulierte 1834. Beantwortet wurden diese Aktionen und Sammlungsbewegungen mit einer erneuten Welle an Repressalien (zwischen 1832 und 1838 etwa 1.800 Anklagen, darunter 1.200 gegen Studenten und Professoren, wegen politischer Verschwörung und Hochverrats ${ }^{537}$ ) und 1833 mit einer wiederholten Zerschlagung der Burschenschaften, welche sich wiederum erst ab 1837 allmählich reorganisieren konnten. ${ }^{538}$ Um einem falschen romantischen Bild unbeugsamer plebiszitär-nationalistischer Vorkämpfer zu widerstehen, sollte aber daran erinnert werden, dass die Burschenschaften auch in ihrer späteren Wiedererstarkungsphase ab 1827, der „Demagogenzeit “539, ihre Juxtaposition zwischen bürgerlichen und quasiständischen Ansprüchen beibehielten - erkennbar etwa am Sitte, Selbstentfaltung und politische Rolle integrierenden studentischen Ehrbegriff, der zwar im Zeichen einer „Verbürgerlichung ihrer Ethik“ konzipiert war, allerdings „ohne daß sie andererseits bereit gewesen wären, die Relikte aristokratischer Standesehre [insbesondere das Duell, J. S.] völlig preiszugeben. ${ }^{1540}$

Überdies war das Verbindungswesen der 1830er Jahre aufgrund der Verfolgung politisch liberaler Gruppierungen durch staatliche und akademische Behörden insgesamt eher vom ständischen Traditionalismus der landsmannschaftlichen Korps und der studentischen Orden dominiert ${ }^{541}$; kaum mehr als ein Fünftel der Gesamtstudentenschaft gehörte den burschenschaftlichen Reformern an. ${ }^{542}$ Die „relative Konsistenz der bur-

534 Vgl. Dreesen, Josef: Das Fürstentum Lichtenberg (1816-1834) im Vormärz. Ein Provisorium, Selbstverlag 2008.

535 Gevers/Vos: Studentische Bewegungen, S. 240.

536 Vgl. ibid.

537 Vgl. ibid. sowie Thielbeer, Heide: Universität und Politik in der Deutschen Revolution von 1848, Bonn 1983, S. 146.

538 Vgl. Jarausch: Deutsche Studenten, S. 43.

539 Vgl. Heer, Georg: Ceschichte der Deutschen Burschenschaft, Bd. 2: Die Demagogenzeit. Von den Karlsbader Beschlüssen bis zum Frankfurter Wachensturm (1820-1833), Heidelberg 1927, und Gevers/Vos: Studentische Bewegungen, S. 240.

540 „Sie begründeten das Duell theoretisch zwar neu im Sinne des bürgerlichen Individualismus als Verteidigung der Kernzone unantastbarer persönlicher Integrität, tradierten aber praktisch damit doch einen quasiständischen Exklusivitätsanspruch. Die Burschenschaften bezogen damit eine Zwischenstellung zwischen der Tradition korporativer Liberalität einerseits und dem Anspruch andererseits, eine Elite innerhalb der nachständischen bürgerlichen Gesellschaft zu sein - mit spezifisch bürgerlichen Vorstellungen von moralisch-disziplinierter Lebensführung, bürgerlichem Leistungsethos nd bürgerlicher Kultur der Kommunikation." Hardtwig: Studentische Mentalität, S. 596.

541 Vgl. Gevers/Vos: Studentische Bewegungen, S. 241.

542 Vgl. Jarausch: Deutsche Studenten, S. 43. und Hardtwig: Studentische Mentalität, S. 598. 
schenschaftlichen Reformprogrammatik "löste sich dadurch auf. ${ }^{543}$ In der Folge, und besonders bis 1848, zerfiel die Studentenschaft mehr und mehr in jene politischen Strömungen, die bis dahin noch vom urburschenschaftlichen Interimskonsens zusammengehalten werden konnten:

„Studieneifer, soziale Disziplin, Dienstbereitschaft, Verinnerlichung und Individualisierung des Ehrverständnisses und damit die Ausbildung einer Mentalität, die den Kommunikations- und Funktionsbedingungen der bürgerlichen Cesellschaft entspricht, waren bis dahin mit Patriotismus, mit bürgerlichem Selbstbewußtsein, mit der Forderung nach bürgerlichen Freiheits- und Mitwirkungsrechten zusammengegangen. Jetzt dagegen zerfällt diese Einheit [... “544

Nicht nur der alte Konflikt zwischen traditionalistischen Korps und burschenschaftlichen Reformern um den Repräsentationsanspruch der Studentenschaft spielte hier eine Rolle, auch Auseinandersetzungen zwischen gemäßigt liberalen und den eher kleinen radikalen demokratischen Gruppierungen. ${ }^{545}$ Hier standen die radikalen republikanischen-demokratischen und aktivistisch orientierten "Germanen“, die auch 1830 und 1831 illegale Studententage veranstalteten ${ }^{546}$, den eher staatsloyalen und am Moralkodex der Bildungsidee festhaltenden „Arminen“ gegenüber, ${ }^{547}$ zwischen 1827 und 1833 hinterließ dies „die Spaltung in eine sehr kleine Gruppe radikaler Aktivisten und eine Mehrheit mehr oder weniger entpolitisierter angehender Bildungsbürger.“548 Eine der in der radikal-demokratischen Burschenschaftstradition wurzelnden Tendenzen, die in den 1840er Jahren ausgehend von Göttingen ${ }^{549}$ gleichsam den „dritten Anlauf “550 respektive die „dritte Phase ${ }^{\text {“551 }}$ des nationalliberalen politischen Bewegungsimpulses aus den Reihen der Studenten bildete, verdient besondere Aufmerksamkeit: die „Progressbewegung“ bzw. die "Progressburschenschaften“. ${ }^{552}$ Zwar waren die Proponenten des Progresses zahlenmäßig eher randständig, blieben lange Zeit auch von Historiographen unbeachtet. Doch zugleich gehörten sie auch zu den „Aktivsten“553 und „Modernsten ${ }^{\text {“554 }}$ unter den politisierten Studenten. Durchaus erscheinen sie hinsichtlich

543 Hardtwig: Studentische Mentalität, S. 598.

544 Ibid., S. 599.

545 Bruch, Rüdiger: Die Universitäten in der Revolution von 1848/49. Revolution ohne Universität Universität ohne Revolution?, in: Hardtwig, Wolfgang (Hg.): Revolution in Deutschland und Europa 1848/49, S. 133-160, hier S. 147.

546 Vgl. Cevers/Vos: Studentische Bewegungen, S. 240.

547 Vgl. Hardtwig: Studentische Mentaltität, S. 599 sowie Gevers/Vos: Studentische Bewegungen, S. 240.

548 Hardtwig: Studentische Mentaltität, S. 600.

549 „Ohne zentral geleitet zu sein, breitete sie [die Progressbewegung, ]. S.] sich in drei Phasen aus: 1838-40 an den Ursprungsuniversitäten Göttingen, Jena, Marburg, Würzburg. 1841-42 in Bonn, Breslau, Heidelberg, Königsberg, Tübingen. 1842-43 schließlich in Berlin, Erlangen, Freiburg, Gießen, Greifswald, Halle, Kiel und Leipzig." Thielbeer: Universität und Politik 1848, S. 146.

550 Vgl. Jarausch: Deutsche Studenten, S. 47.

551 Gevers/Vos: Studentische Bewegungen, S. 241.

552 Vgl. Bartol: Ideologie und studentischer Protest, S. $74 \mathrm{f}$.

553 Vgl. Bruch: Die Universitäten in der Revolution, S. 152.

554 Vgl. Jarausch: Deutsche Studenten, S. 48. 
ihrer intellektuellen Durchdringung und ihres demokratischen, z. T. auch schon sozialpolitisch angereicherten Programms aus heutiger Sicht zukunftsweisend, geradezu als fortschrittliche Spitze der Studenten des 19. Jahrhunderts; so wurden sie denn auch um „1968“ als romantisierungsfähiges Vorbild wiederentdeckt. Bruch bezeichnet sie als „theoriegeleitete Bewegung ${ }^{u 555}$, als

„jene kleinen Studentengruppen, die schon vor Beginn des ,tollen ]ahres' [gemeint ist 1848, J. S.] aus linkshegelianisch-philosophischem Gedankengut Grundsätze für eine widerspruchsfrei verankerte allgemeine Hochschule in einer allgemeinen Bürgergesellschaft entwickelt hatten. In der Regel studierten sie Jurisprudenz, nicht selten literarisch beeinflußt von dem scharfsinnigen Radikalismus der in Frankfurt tagenden Dozenten. So verwundert nicht, daß 120 Jahre später [..., 1968 ein historisch vergewissernder Rückbezug auf 1848/49 als Legitimationsfolie ebenso wie als Nachweis kontextualer Einzigartigkeit ins Spiel gebracht wurde. “556

Die Progressbewegung war sowohl Produkt enttäuschter liberalpatriotischer Hoffnungen während der Regentschaft des preußischen Königs Friedrich Wilhelm IV. als auch Bestandteil der sich sammelnden nationalliberalen Volksbewegung in einer sich rekonstituierenden bürgerlichen Öffentlichkeit. Ihre beiden, von der ungebrochenen neuhumanistischen Vernunft- und Bildungsemphase angeleiteten Ziele lauteten „studentische Lebensreform" und „politische Erneuerung" in nationalem Sinne. ${ }^{557}$ Sie kritisierten Studentenleben und Universitätsstudium aus überwiegend egalitärer Perspektive, lehnten den aristokratischen Geist der Corps und ihrer Riten (Mensur, Satisfaktion durch Duell, Bierkomment) ab und zielten auf die Nivellierung der Standesdifferenzen zwischen Student und Bürger ${ }^{558}$; zugleich waren sie organisiert als „loser Verein“ mit demokratischer Binnenstruktur, eigenen Teilvereinen und Publikationsorganen. ${ }^{559}$ In ihrer Forderung nach einer Universitätsreform, die die Hochschulbildung als „Nationalanstalten“ organisieren und die studentische „Lehr- und Lernfreiheit" erhalten sollte, ist zwar der Humboldt'sche Impetus unverkennbar; zugleich aber nahmen die ProgressStudenten - alle republikanisch gesinnten Studenten waren ihres Zeichens Bildungsbürger, die auf eine Beamten- oder Angestelltenkarriere im öffentlichen Dienst hofften: So fanden sich im von Heide Thielbeer ausgemachten, 193 Personen umfassenden „eng zusammenhängende[] Kreis, der in Volksversammlungen und demokratischen Vereinen aktiv wurde, die Studentenausschüsse beherrschte und auf der Wartburg-Tagung den Ton angab“560, 46 Prozent Jura-Studenten, 29 Prozent Medizin-Studenten, 22 Prozent Theologie-Studenten, aber nur 17 Prozent Philosophie-Studenten ${ }^{561}$, zudem mündeten 65 von 114 untersuchten 48er-Revolutionären im Laufe ihres beruflichen Werdegangs in den Staatsdienst ein ${ }^{562}$ - einen modernen sozialen Zug in ihren Forderungska- 
talog auf: Sie agitierten, merklich unter dem Eindruck des Vormärz-Pauperismus und dem Einfluss des Junghegelianismus stehend, gegen die Trennung von Wissenschaft und „Leben“, d. h. die Spaltung der Bürger in Gelehrte und „ärmere Bürgerklasse“. ${ }^{563}$ Tatsächlich gaben sie einen großen Teil ihres Fichte'schen Elitismus zugunsten der Sprengung gesellschaftlicher Hierarchien durch eine „soziale Republik“ auf, gründeten gar karitative Hilfsvereine für notleidende Bürger. ${ }^{564}$ Indes: Auch sie waren gespalten in einen traditionalistischen (Verbindungsehre, politische Befreiung der Studenten, akkomodative Haltung gegenüber staatlichen Eliten) und einen modernen Flügel (radikale Demokraten, soziale Öffnung der Hochschule), die sich untereinander etwa über Detailfragen stritten; insbesondere die von traditionellen Verbindungsstudenten verteidigte akademische Gerichtsbarkeit erschien einigen im Progress als ständisches Relikt. ${ }^{565}$ Wenn auch häufig als unpolitische Lese- und Geselligkeitsvereine getarnt, so waren die einzelnen Progresszirkel doch politische Netzwerke und Gruppierungen mit revolutionären, genauer: republikanischen bis kommunistischen Zielvorstellungen. ${ }^{566}$

In diese bewegten 1840er Jahre fällt auch der Beginn einer durch den Progress maßgeblich initiierten hochschuldemokratischen Bewegung; sie ist als Vorläufer der Ausschussbewegung bzw. der Herausbildung von Infrastrukturen studentischer Selbstverwaltung im Kaiserreich und in Weimar aufzufassen. Vereinsmäßige Selbsthilfe, überregionale Organisation und der Kampf um institutionelle Beteiligung wurde in dieser Frühphase der Industrialisierung, die die ständische Differenz zunehmend in Klassendifferenzen auflöste und damit auch viele bildungsbürgerliche Familien ergriff, immer wichtiger. Zugleich wurde, wo man 1815 noch weitgehend auf sittliche Selbstreform setzte, erstmals der Staat als Adressat und Instrument der politischen Umgestaltung des Gemeinwesens erkannt. ${ }^{567}$ Auf dem zweiten Wartburgfest 1848 versammelten sich mehr als 1.000 Studenten zum ersten „Allgemeinen Studententag“ nicht nur unter nationalliberalen Vorzeichen, sondern auch um hochschulpolitische Forderungen an die neue Frankfurter Nationalversammlung zu beschließen, darunter die Forderung nach demokratischer Beteiligung der Studenten an der Besetzung von Professuren; ${ }^{568}$ weitere vier Kongresse folgten. ${ }^{569}$

Wie kam es zum Revolutionsversuch von 1848? Zwar ist eine kausale Gewichtung der involvierten Kontextfaktoren hier nicht zu leisten, doch besteht in der einschlägigen Literatur kein Zweifel an der konstitutiven Rolle der massenhaften Verarmung, z. T. Verelendung, für die anwachsenden sozialen und politischen Frustrationen. Ein wachsendes Bevölkerungswachstum bei gleichzeitiger, konjunkturell bedingter Massenarbeitslosigkeit, und durch Missernten verstärkte Hungerkrisen ließen dezentrale „Lebensmittelunruhen“, „Hunger“- bzw. „Teuerungs-Tumulte“ entstehen, ${ }^{570}$ die primär

563 Vgl. Jarausch: Deutsche Studenten, S. 50-52. Vgl. außerdem die konzise Darstellung der Progressbewegung und ihrer Ziele in Thielbeer: Universität und Politik 1848, S. 144-151.

565 Vgl. ibid., S. 52.

566 Vgl. Thielbeer: Universität und Politik 1848, S. 147-149.

567 Vgl. Bruch: Die Universitäten in der Revolution, S. 133.

568 Thielbeer: Universität und Politik 1848, S. 141-144.

569 Vgl. Schulze/Ssymank: Das deutsche Studententum, S. 264-266 und Bruch: Die Universitäten in der Revolution, S. 133.

570 Vgl. Siemann: Die deutsche Revolution von 1848/49, S. 42-48. 
von den am schwersten betroffenen Gruppen der Handwerksgesellen, der Landbevölkerung, der Arbeiter und der städtischen „unterbürgerlichen“ Schichten ausgingen. ${ }^{571}$ Dies beflügelte, allen seit 1815 vorangegangenen landesfürstlichen und monarchischen Versuchen zum Trotz, die nationalliberalen Regungen durch Einbindung der sie tragenden bürokratischen Eliten in den parlamentarischen Prozessen zu domestizieren, die Entstehung einer gesamtdeutschen nationalen Massenbewegung. ${ }^{572}$ Insbesondere nach 1845 und 1847 häuften sich diese Protestaktionen, zugleich trug das zensurbedingte Kommunikationsdefizit zur Verschlimmerung der Situation bei: vereinzelt, etwa im von „unbeschreiblichem“ Elend betroffenen Oberschlesien wurden die Berichte gar aktiv unterdrückt, was die bürgerlichen Forderungen nach freier Presse legitimatorisch befeuerte. ${ }^{573}$ Die reale Not und der politische Unmut eines städtischen „Proletariats“, dazu verunsicherte und zweifelnde Behörden: Das Bewusstsein einer grundlegenden „sozialen Frage“ kam auch den bürgerlichen Schichten in diesen Jahren überhaupt erst $\mathrm{zu}$ Bewusstsein. ${ }^{574}$ Auch im gesamteuropäischen Blick ergoss sich um 1845 eine „Flut der Gesellschaftskritik“, die sich „nicht nur gegen das Metternichsche politische System“ richtete, „sondern grundsätzlich gegen Macht und Besitz. “575 Die seit 1750 immer enger geknüpften, ursprünglich apolitischen bürgerlichen Organisationsnetzwerke politisierten sich in den 1840ern nach den langen Jahren der Repression und entfalteten so ihre volle Mobilisierungskraft:

„In Volksversammlungen, Demonstrationen und programmatischen Proklamationen nahmen sich die Revolutionäre das Recht, das ihnen während des Vormärz konsequent vorenthalten worden war: sich in politischer Absicht zu versammeln und zu organisieren. Die plötzlich freigesetzte politische Energie äußerte sich in vielgestaltigen Formen: in Vereinen, Gesellschaften, Klubs, Komitees, Assoziationen, Lesezirkeln, spontanen und gelenkten Versammlungen. ${ }^{476}$

Prägend aber blieb die neuhumanistische Traditionslinie auch hier: Die „ansteigende Welle der Politisierung des Vereinswesens" war durch das hochschulreformerische Bildungsideal durchwirkt; neu war nur, dass es in Teilen auch katholische und konservative Zirkel sowie Arbeiter- und Gesellenvereine ergriff, kurzum: dass auch Nicht-

571 Vgl. ibid., S. 43.

572 „So ist der einzelstaatliche Konstitutionalismus im Sinne seiner Schöpfer zwar ein wirksames Instrument geworden, die jungen Staatsbildungen zusammenzuschweißen, die gesamtnationale Tendenz des Liberalismus dagegen konnte er nicht abbremsen. Seit dem Beginn der 40er Jahre beginnt vielmehr der Liberalismus mit seinen verschiedenen landschaftlichen Schwerpunkten in Süd-, Südwest- und Ostdeutschland zu einer gesamtdeutschen Bewegung zusammenzuwachsen." Schieder, Theodor: Partikularismus und Nationalbewußtsein im Denken des deutschen Vormärz", in: Conze, Werner (Hg.): Staat und Gesellschaft im deutschen Vormärz 1815-1848. Sieben Beiträge von Theodor Schieder, Otto Brunner, Reinhart Koselleck, Wolfgang Zorn, Wolfram Fischer, Erich Angermann, Werner Conze, Stuttgart 1962, S. 9-38, hier S. $28 \mathrm{f}$.

573 Vgl. Siemann: Die deutsche Revolution von 1848/49, S. 47.

574 Vgl. ibid., S. 48.

575 Gevers/Vos: Studentische Bewegungen, S. 242.

576 Siemann: Die deutsche Revolution von 1848/49, S. 90. 
Bildungsbürger die volle Teilhabe an der bürgerlichen Gesellschaft einzufordern begannen. ${ }^{577}$

Wohlgemerkt: Die drastischen ökonomischen Entwicklungen nährten zwar den kollektiven Wunsch nach grundsätzlichem gesellschaftlichem Wandel und motivierten mehr und mehr lokale Insurrektionen; von einer Interessengemeinschaft zwischen politisiertem Bildungsbürgertum und nichtbürgerlicher Bevölkerung aber kann keine Rede sein. Politische Opposition - „Für viele hieß das [...] nichts anderes als der Weg zurück zum alten bäuerlichen Recht und zur Wiederbelebung der überkommenen Zunftverfassung. ${ }^{578}$ Auf bildungsbürgerlicher Seite hingegen vermengten sich grundsätzliche politische Überzeugungen mit einem für sie opportunen Klasseninteresse. Gewiss zerfällt das Bürgertum des Vormärz in unterschiedliche Interessengruppen: Wirtschaftsbürger („Bourgeoisie“), „Beamten- und Bildungsbürgertum im Staatsdienst", "freiberufliche Intelligenz" und Kleinbürgertum, sicher waren mithin nicht alle gebildeten Bürgerlichen verbeamtet. ${ }^{579}$ Dennoch teilte das deutsche Bildungsbürgertum aller Fragmentiertheit zum Trotz das Fernziel einer postständischen, konstitutionell bis demokratisch verfassten Gesellschaftsform ohne Erb- und Besitzvorrechte. Der liberale Nationalstaat war daher vor allem ihr politisches Projekt. Aber: Eine einheitliche, schlagkräftige politische Bewegung zu bilden, misslang selbst in ihren Reihen; „an der Schwelle der Macht“ setzte der Zerfall „nach politischen, sozialen und religiösen oder staatlichen Trennungslinien“ ein. ${ }^{580}$ Insbesondere entzweiten sich die erwachsenen Akademiker, ganz wie das studentische Jungbildungsbürgertum, in steigendem Maße über die Frage des Ausmaßes der politischen Umgestaltung der deutschen Gliedstaaten: Die radikaldemokratischen „Hambacher“ wollten sich nicht mehr mit jener konstitutionellen Ordnung zufriedengeben, auf der die gemäßigten Frühliberalen gerade beharrten. ${ }^{51}$

Auch deswegen scheiterte die Märzrevolution von 1848/49 bekanntlich, jedenfalls gemessen an ihren primären Zielen: weder der demokratische Umsturz noch die Universitäts- und Lebensreform wurden herbeigeführt. Noch im selben Jahr, also 1848, trat im Deutschen Bund und dessen Nachbarstaaten die Gegenbewegung der „Revolutionswende“ ein. ${ }^{582}$ Die sekundären Erfolge der Ereignisse aber sind zahlreich: „Ein europäisches politisches System zerbrach 1847/48“583, nämlich das auf den Wiener Verträgen basierende politische Gleichgewicht, und zwar allen Beharrungskräften der ancien régimes zum Trotz. Die hier vollzogene Kette von Ereignissen führte tieferliegende gesellschaftliche Entwicklungen nicht herbei, sie kehrte sie vielmehr an die Oberfläche: Über die Etablierung von Presse, Vereinswesen und Parlamenten erreichten die Bürger (zum Teil auch Bürgerinnen) des Deutschen Bundes auch trotz des Scheiterns der Nationalstaatsbildung eine nachhaltige „Institutionalisierung der

577 Vgl. Nipperdey: Verein als soziale Struktur, S. 39.

578 Vgl. ibid.

579 Vgl. ibid., S. 21.

580 Vgl. Jarausch: Deutsche Studenten, S. 53.

581 Vgl. Siemann: Die deutsche Revolution von 1848/49, S. 99.

582 Vgl. ibid., S. 157.

583 Vgl. ibid., S. 49 (Herv. i. O.) 
Revolution“. ${ }^{584}$ Pointiert: „1848 erscheint [...] als Fluchtpunkt oder Zwischenstation langfristiger Entwicklungstrends, die ,nationale Einigung, ,Parlamentarisierung oder ,Klassenbildung heißen können. “585 Die Demokratisierung des Deutschen Bundes, der Legitimitätsgewinn von Parlamenten und Parteien, somit auch die Kanalisierung oppositioneller politischer Energien - sie lassen sich durchaus als politkultureller „Sieg der Erben“ der Revolutionäre bzw. als "politisches Vermächtnis an die Nachfahren“ auffassen. ${ }^{586}$ Die „Märzforderungen“, u. a. nach der Schaffung eines einheitlichen deutschen Bundesstaates, nach allgemeiner Presse-, Vereins- und Versammlungsfreiheit und nach öffentlichen Gerichtsverfahren, waren fortan bekannte und legitime Einsätze im politischen Wettbewerb, die sich organisatorisch bündeln ließen und demokratisch vertreten werden konnten. ${ }^{587}$ Überhaupt etablierten sich die modernen "gesellschaftlich organisierte[n] politische[n] Gruppierungen“, die seither „Parteien“ heißen, in der Folge gesamtgesellschaftlich; so galt selbst Konservativen und Konstitutionalisten die Parteibildung ab den 1860er Jahren als Voraussetzung funktionierender parlamentarischer Arbeit. ${ }^{58}$ Womöglich ist in politkultureller Hinsicht der Aspekt entscheidend, dass das Wort „Partei“ seine anrüchig-partikularistische, „Volksferne“ Konnotation verloren hatte. Auch wenn diese frühen Parteien noch wenig mit jenen industriegesellschaftlichen, politische Lager repräsentierenden Großorganisationen gemein hatte, die sich im Kaiserreich herausbildeten; ${ }^{589}$ der oft regional wurzelnde Bündelungsprozess politischer Kräfte „von der Honoratioren- zur Massenpartei“ war zunächst nur angestoßen, ${ }^{590}$ sodass sich erst 1861 die „linksliberalen“ demokratischen Republikaner zur Fortschrittspartei und erst 1866 die „Konstitutionellen“ zur Nationalliberalen Partei zusammenfanden. ${ }^{591}$

Gewiss ist das nicht als sich zwangsläufig entfaltende lineare Modernisierung zu verstehen: regionale Ungleichzeitigkeiten, Widersprüche, gegenläufige Tendenzen, auch differierende Zielvorstellungen zwischen den beteiligten bürgerlichen Vereinen und Gruppierungen einerseits und den von Arbeitern, Bauern und Handwerkern getragenen Unruhen verunmöglichen das. ${ }^{592}$ Zudem handelt es sich um ein ambivalentes Vermächtnis, entfesselte es doch wie jede Modernisierungsdynamik zugleich partizipatorische Fortschritte als auch destruktive Energien: Nach 1848 entstand einerseits ein europäischer „großräumiger Kommunikationsraum“ mit neuen demokratischen

584 Vgl. Müller: Die Revolution von 1848/49, S. 146.

585 Siemann: Die deutsche Revolution von 1848/49, S. 175.

586 Vgl. Langewiesche, Dieter: Wirkungen des „Scheiterns“, S. 8 und 9.

587 Vgl. ibid., S. $27 f$.

588 Vgl. Siemann: Die deutsche Revolution von 1848/49, S. 91.

589 Vgl. Rohe, Karl: Wahlen und Wählertraditionen in Deutschland. Kulturelle Grundlagen deutscher Parteien und Parteiensysteme im 19. Und 20. Jahrhundert, Frankfurt a.M. 1992, S. 57-73 sowie Ritter, Gerhard A.: Die deutschen Parteien 1830-1914. Parteien und Gesellschaft im konstitutionellen Regierungssystem, Göttingen 1985, S. 10f. und S. 14-19.

590 „Der Modernisierungsschub des Jahres 1848 trieb von der Honoratioren- zur Massenpartei, vom lediglich parlamentarisch wirksamen Parteiklub zum gesellschaftlich tätigen politischen Willensverband, mag man ihn als ,Partei' ansehen wollen oder nicht. Denn wann die Ceschichte der deutschen ,Parteien' beginnt, bleibt abhängig davon, mit welchen Merkmalen sie versehen werden." Vgl. Siemann: Die deutsche Revolution von 1848/49, S. $91 \mathrm{f}$.

591 Vgl. ibid., S. 99 sowie Ritter: Die deutschen Parteien 1830-1914, S. 14-19.

592 Vgl. Siemann: Die deutsche Revolution von 1848/49, S. 176. 
Vernetzungsformen, andererseits nahm die gleichzeitige „Nationalisierung der Politik ${ }^{\text {“593 }}$ politische Sprengkräfte, ja ein ganzes „Schlachtfeld der nationalen Rivalitäten“594 vorweg, die erst mit dem Weltkrieg 1914-1918 zum vollen Ausbruch kommen sollten. Sogar ein „heiliger Krieg“ im Namen der europäischen Hegemonie der deutschen Nation wurde ab den 1840er Jahren gefordert. ${ }^{595}$

Allerdings hinderten diese Veränderungen das deutsche Bürgertum nach der gescheiterten Revolution nicht daran, rasch zur akkomodativen Normalität in den Kammern der Landtage zurückzukehren. Vielmehr war man schon 1848 ,vielfach schnell einverstanden, ,die Revolution zu schließen' “596 Die Erfahrung des reichen Sets an staatlichen Druckmitteln ließ sie die „Balance auf dem schmalen Grat zwischen verfassungsmäßig verordnetem Kompromiß und Fundamentalopposition“ einüben. ${ }^{597}$

Die glorifizierende Überformung der Ereignisse indes begann grosso modo unmittelbar ab 1849. Die Generation der 1848er gilt seither als Pionierbewegung und Phalanx eines modernen demokratischen Deutschlands, und, aufgrund des international dezentralen Charakters der revolutionären Aufstände, auch Europas; ${ }^{598}$ die gescheiterte Revolution „als eine wesentliche Etappe auf dem Weg Deutschlands zur parlamentarischen Demokratie und zu einem partizipativen Nationalstaat. ${ }^{4599}$ Dass die Revolution, geflossen aus „zornigen“ Jahren „sozialer Anerkennungskämpfe“, 600 dabei von überaus heterogenen Partialtumulten und Volkserhebungen getragen worden ist, welche "mitunter durchaus traditionalistische“ Ziele, Werte und Motive verfolgten, ${ }^{601}$ wird im heutigen geschichtswissenschaftlichen Rückblick gesehen. So stellt sich die Frage, inwieweit sich die oftmals energischer, ja fanatischer werdenden nationalliberalen Zielsetzungen mit den tatsächlichen Wünschen und Hoffnungen der Bevölkerung decken. Hier ist die Informationslage denkbar dünn. $\mathrm{Zu}$ vermuten ist aber, dass ein großer Teil die deutsche Nation in erster Linie als Erbin der Reichstradition des Heiligen Römischen Reichs (HRR) imaginiert hat, also als föderativen Zusammenschluss der Teilstaaten und ihrer weiterhin zu pflegenden regionalen Traditionen und Patriotismen. Das zumindest würde erklären, warum der zur großdeutsch-plebiszitären Ausprägung des deutschen Frühnationalismus neigenden Burschenschaftsbewegung - ihre Selbstbezeichnungen als „Teutonen“, „Germanen“, „Arminen“, „Vandalen“ und „Ghibellinen“ sowie ihre frühe Betonung landsmannschaftlicher Traditionen sind dabei als Referenz

593 Vgl. Langewiesche: Wirkungen des „Scheiterns“, S. 21.

594 Vgl. ibid., S. 20.

595 Vgl. Klenke: Deutsche Nationalreligiosität zwischen Vormärz und Reichsgründung, S. 389-448, hier S. 389.

596 Vgl. Siemann: Die deutsche Revolution von 1848/49, S. 27.

597 „Die Abgeordneten hatten in der Nähe staatlicher Macht deren Disziplinierungsmöglichkeiten erfahren: Urlaubsverweigerung bei gewählten Beamten, Wahlbeeinflussung, Auflösung widersetzlicher Kammern, Drohung mit Amtsenthebung, Strafversetzung und vorzeitiger Ruhestand." Ibid. Vgl. Kaelble, Hartmut: 1848: Viele nationale Revolutionen oder eine europäische Revolution?, in: Hardtwig, Wolfgang (Hg.): Revolution in Deutschland und Europa 1848/49, Cöttingen 1998, S. 260278.

599 Vgl. Hardtwig: Einleitung, S. 8.

600 Vgl. Kaschuba, Wolfgang: 1848/49: Horizonte politischer Kultur, in: Hardtwig, Wolfgang (Hg.): Revolution in Deutschland und Europa 1848/49, Göttingen 1998, S. 56-78, hier S. 62-67.

Vgl. Hardtwig: Einleitung, S. 9. 
auf die vermeintliche Geburt des Reichs aus dem Zusammenschluss einstiger deutscher Stämme zum deutschen „Gesamtvolk“ zu verstehen ${ }^{602}$ - eine solche Breitenmobilisierung gelingen konnte. Die „dynastisch-monarchische Gesinnung“ des von aristokratischen und bürokratischen Eliten gepflegten partikularistischen Nationalbewusstseins jedenfalls lag Studentenschaft wie Bevölkerung zunehmend fern, ja erscheint mehr und mehr als bloße „Zwischenstufe“ der Jahre 1815 und $1848{ }^{603}$ spätestens nach der gescheiterten Revolution hatte sich dann die gesamtnationale Folklore durchgesetzt oder wurde zumindest durch nationale Feste zelebriert. So sorgten, wie Dieter Langewiesche herausgestellt hat, bildungsbürgerliche Veranstalter in den 1850er und 1860er Jahren für große Nationalfeste in integrativer Absicht. Dabei hatten sich die Teilnehmer der Sänger-, Schützen- und Nationalfeste allerdings an die bildungsbürgerlichen Kulturund Normvorstellungen zu assimilieren. ${ }^{604}$ Dazu gehörte etwa, Friedrich Schiller als ein nationsstiftendes Idol zu verehren, wie die nahezu kultischen Schillerfeste verraten; ähnlich zeremoniell gestaltete sich aber auch das Frankfurter Schützenfest von $1862 .{ }^{605}$ „Niederes Volk“ blieb hier ausgeschlossen: „Volk“ war generell kulturell, nicht sozial gemeint. ${ }^{606}$ „Das Volk, die unterbürgerliche Mehrheit der Bevölkerung, sang keine Volkslieder, sondern [...] das Volk grölte Pöbellieder.“607 Mehr noch: Aus bildungsbürgerlicher Sicht waren große Teile der Deutschen noch gar keine zur - weiterhin ausdrücklich föderativ gedachten ${ }^{608}$ - Nation fähige Masse, weshalb man große pädagogische Anstrengungen leisten zu müssen glaubte: „Nationsbildung“ erschien ihnen als „kulturelle Erziehungsaufgabe“609. Insbesondere Dietmar Klenke entdeckt in den Jahren „Zwischen Vormärz und Reichsgründung“ eine starke Zunahme von Nationalreligiosität in der bürgerlichen Öffentlichkeit, d. h. einer Bewusstseinsform, die die aufklärerischen Ursprungsimpulse zunehmend in einen aggressiven, bekenntnisreligiösen Nationalismus als "gottunmittelbare Heils- und Sittengemeinschaft" $z$ u verwandeln tendierte, der schließlich den „Opfertod“ im Kampf gegen innere und äußere Feinde idealisierte. ${ }^{610}$ Es bedurfte so gesehen nicht erst der Reichsgründung, um das libertäre Erbe des ohnehin in sich ambivalenten Nationalliberalismus breitenwirksam abzuschmelzen:

„Nationalreligiosität erwies sich als solch mächtige Zeitströmung, daß sie am Vorabend der Einigungskriege nahe daran war, auf dem Cebiet des Deutschen Bundes die Deutungshoheit in der Beurteilung gesellschaftlicher Grundsatzfragen zu erringen. ${ }^{\text {6611 }}$

602 Vgl. Hardtwig: Studentische Mentalität, S. 590 und 595 sowie Schieder: Partikularismus und Nationalbewußtsein, S. 31.

603 Schieder: Partikularismus und Nationalbewußtsein, S. 25 und 28.

604 Vgl. Langewiesche, Dieter: Kulturelle Nationsbildung im Deutschland des 19. Jahrhunderts, in: Hettling, Manfred/Nolte, Paul (Hg.): Nation und Cesellschaft in Deutschland. Historische Essays, München 1996, S. 46-64, hier S. 49. Vgl. ibid., S. $49 f$.

606 Vgl. ibid., S. 58.

607 Ibid., S. 49.

608 Man trug auf Schützen- und Sängerfesten regionalfolkloristische Trachten, um seine antizentralistische Grundhaltung zur Schau zu stellen, vgl. ibid., S. 58.

609 Vgl. ibid, S. 49.

610 Vgl. Klenke: Deutsche Nationalreligiosität, S. 390.

611 Vgl. ibid., S. 389. 
Freilich spielte die breite bürgerliche Öffentlichkeit, deren Teil die vormärzlichen Studenten waren ${ }^{612}$ - Presse, Kulturbetrieb in Theatern, Opern, Museen, Nationalsymboliken, Lieder, usw. - für die Verbreitung und sozialmoralische Institutionalisierung von Nationalreligiosität eine tragende Rolle. ${ }^{613}$ Sie sollte die innerbürgerlichen Konfliktlinien noch einmal drastisch verschärfen, herrschte doch lange - bis tief in die 1870er Jahre hinein - eine starke kulturelle Distanz zwischen Protestanten und Katholiken in der deutschen Nationalbewegung: Die Behauptung der eigenen Überkonfessionalität kollidierte mit der faktischen „protestantische[n] Durchsäuerung“, die sich in der Mythenbildung der Nationalbewegung niederschlug. ${ }^{614}$ Dass der liberale Nationalismus sukzessive zu einem säkularen Religionsersatz geriet, spürte das katholische Deutschland früh. Das wiederum nährte die Distanz zur überwiegend protestantisch-bildungsbürgerlichen Nationalbewegung. ${ }^{615}$ Und wie bereits erwähnt: Hatten die deutschen Studenten nicht schon auf dem Wartburgfest 1817 unter proto-völkischem Furor „Schandschriften des Vaterlandes" verbrannt wie unreines geistiges Blendwerk? ${ }^{616}$

In den Scharnierjahren 1848 und 1849 gehörten die „progressiven“ Studenten zu den engagiertesten Aktivisten der Revolution. Sie kämpften für die Demokratisierung und Liberalisierung des Staatswesens, für eine Reform der Hochschule, und sie streuten „Propaganda für die Parlamente in Berlin und Frankfurt“, zum Teil auch für eine sozialistische Revolution. ${ }^{617}$ Damit waren „die Studenten und ihre Vereinigungen [...] der sichtbarste Ausdruck der Unzufriedenheit im gebildeten Bürgertum des Vormärz. ${ }^{618}$ Hier lohnt sich ein Blick auf ihre Beteiligung an den Geschehnissen in den jeweiligen lokalen Kontexen. Zunächst: Die treibendsten Veränderungsimpulse gingen von jenen Universitätsstädten aus, die bereits vergleichsweise liberale Bedingungen boten: In Leipzig dominierte damals „ein wohlhabendes, selbstbewußtes Bürgertum, das von Handel und Gewerbe lebte ${ }^{\star 619}$ und geistige Autonomie als Voraussetzung des Fortschritts betrachtete; „Die Gemeindeordnung war liberal, die Zensur wurde großzügig gehandhabt und leidenschaftlich bekämpft, um geistige Freiheit, die Basis des wirtschaftlichen Wohlstandes, zu hüten.“ ${ }^{220}$ Die ansässige Universität kooperierte hier zwischen 1845 und 1849 mit der (studentischen) bürgerlichen Opposition und verwandelte die Stadt in das „Zentrum der revolutionären Bewegung Sachsens“621. Ähnlich Göttingen: Geprägt vom norddeutschen Liberalismus, einer langjährigen Distanz zwischen

612 Borowsky, Peter: Studenten in der deutschen Revolution 1848, in: Ders.: Schlaglichter historischer Forschung. Studien zur deutschen Geschichte im 19. und 20. Jahrhundert. Aus dem Nachlass herausgegeben von Rainer Hering und Rainer Nicolaysen, Hamburg 2005, S. 187-199, hier S. 190. Vgl. Klenke: Deutsche Nationalreligiosität, S. 437-442.

614 Vgl. Langewiesche: Kulturelle Nationsbildung, S. 62, darin auch das folgende Zitat: „Wenn die Nation feierte, sang man protestantische Lieder, verehrte Luther und stilisierte die Reformation zur deutschen Revolution, man überhöhte den Sieg der deutschen Truppen 1870 über die französische Armee religiös zum Sieg des protestantischen Gottes auf deutscher Seite über den katholischen Gott, der den Franzosen und zuvor den Österreichern nicht helfen konnte." Vgl. ibid. Vgl. ibid

616 Vgl. Bartol: Ideologie und studentischer Protest, S. 65.

617 Vgl. Gevers/Vos: Studentische Bewegungen, S. 242 und 245.

618 Vgl. Borowsky: Studenten in der deutschen Revolution, S. 191.

619 Thielbeer: Universität und Politik 1848, S. 25.

620 Ibid.

621 Ibid. 
Staat und Universität sowie einer seit 1837 traditierten oppositionellen Grundstimmung, an welcher der größte Teil der Hochschule partizipierte - Der hannoveranische König Ernst August I. hob in diesem Jahr in reaktionärer Absicht das Staatsgrundgesetz von 1833 auf, worauf die berühmten Göttinger Sieben mit ihrer Protestation antworteten ${ }^{-622}$, wurde die südniedersächsische Kleinstadt zwar nicht zum revolutionären Aktionszentrum, aber stiftete doch ein Klima, in welchem sich aktionsorientierte Zirkel wie jener um Johannes Miquel konstituieren und, trotz Reserviertheit aufseiten der studentischen Mehrheit, agitieren konnten. ${ }^{623}$ Und in Jena, Gründungsstadt der Urburschenschaft, Zentrum des Richtungsstreits zwischen Germanen und Arminen ${ }^{624}$ sowie Ort der „einzige[n] Hochschule in Deutschland, wo sich das Verbindungsleben in den Jahrzehnten der Revolution frei entfalten konnte ${ }^{4625}$, kam es, trotz Ausbleibens eines gesamtuniversitären Aktionspotenzials, zur „Verbindung eines progressiven Teils der Studentenschaft mit der Bürgerschaft ${ }^{\text {626 }}$. So wuchs in Jena, begleitet durch wiederholte Spaltungen der ansässigen Burschenschaft ${ }^{627}$, bis 1848 eine veritable politische Avantgarde heran:

„Der freiheitliche Geist der Universität Jena im Großherzogtum Sachsen-WeimarEisenach war so sehr gefürchtet, daß Preußen, Oesterreichern [sic] und Russen der Besuch der Universität untersagt wurde. [...] Im Revolutionsjahr waren 113 - also 25 \% der 441 Jenaer Studenten - Mitglieder des Burgkellers, einer der wichtigsten progressistischen Verbindungen Deutschlands. Aus dem Burgkeller ging sowohl die liberale Elite, die im März politisch einflußreich wurde, hervor als auch der revolutionäre Nachwuchs, der diese Liberalen an die Macht brachte und sie anschließend in Frage stellte. ${ }^{\text {628 }}$

Neben den politisch vorpreschenden Schwerpunktstädten Leipzig, Göttingen und Jena mobilisierte die sich aus den Reihen der Studenten, der ansässigen Bürger und z. T. der Universitätseliten rekrutierende nationalliberale Opposition auch in Heidelberg, Erlangen, Würzburg, Gießen, Marburg, Freiburg, Berlin, Bonn, Breslau, Halle, Greifswald und Rostock. ${ }^{629}$

Dabei differierten die konkreten Anlässe, Aktionsformen, Bündnisstrukturen und Erfolgschancen zum Teil beträchtlich. Während in Göttingen, Würzburg, Gießen, Marburg und Freiburg die historisch gewachsene Auseinandersetzung mit den „unteren Chargen des Polizeistaats" und darüber hinaus in Göttingen der reformeuphorische

622 Vgl. ibid., S. 35. Bereits 1831 war es hier zum Aufstand der weitgehend mittellosen Privatdozenten gekommen; unmittelbar danach drohte der Göttinger Universität die Schließung durch den Hannoverschen König Wilhelm IV, vgl. Bruch: Die Universitäten in der Revolution, S. 143.

623 Vgl. Thielbeer: Universität und Politik 1848, S. 38-40 und 127.

624 Thomann, Björn: Die Rolle der Burschenschaften in Jena, Bonn und Breslau in der Revolution 1848/49, in: Cerwinka, Günter/Kaupp, Peter/Lönnecker, Harald/Oldenhage, Klaus: 200 Jahre burschenschaftliche Geschichte. Von Friedrich Ludwig Jahn zum Linzer Burschenschafterturm. Ausgewählte Darstellungen und Quellen, Heidelberg 2008, S. 312-401, hier S. 315.

625 Thielbeer: Universität und Politik 1848, S. 40.

626 Ibid.

627 Vgl. Thomann: Die Rolle der Burschenschaften in Jena, Bonn und Breslau, S. 313-320.

628 Thielbeer: Universität und Politik 1848, S. 41.

629 Vgl. ibid. 
Kampf für eine unabhängige städtische und akademische Gerichtsbarkeit die maßgebliche Konfliktarena bildeten ${ }^{630}$, fochten die studierenden und lehrenden Oppositionellen in Leipzig und Jena auch ohne Intimidierung der universitären Autonomie bzw. ohne auffällig exekutivkritische Vorgeschichte für bürgerliche Freiheit und gegen die fürstlichen bzw. staatlichen Gewalten. ${ }^{631}$ Einerseits beteiligte sich in Göttingen nach "langfristig vorbereitete[r] politische[r] Sensibilisierung“, „wie sie anderswo nur selten gegeben war", die gesamte Universität (Studenten und Lehrkörper) 1848 am Auszug und fügte der Stadt damit erheblichen ökonomischen Schaden $\mathrm{zu}^{632}$; in Würzburg und Erlangen verhielten sich die Universitätseliten ähnlich kooperativ. ${ }^{633}$ Andererseits mussten die „progressiven“ Studenten in Jena ohne die Hilfe der Hochschullehrerschaft, in Leipzig, Freiburg und Heidelberg sogar gegen den Widerstand eines hochschulreformkritischen Senats agieren. ${ }^{634}$ Im vergleichsweise stillen Berlin hingegen verhinderte die politische Polarisierung nebst „wechselnde[n] Stellungnahmen und Stimmungsschwankungen " unter Hochschullehrern und Studenten ${ }^{65}$ das Überspringen eines breitenwirksamen revolutionären Funkens; und auch in den anderen preußischen Universitäten Bonn, Breslau, Halle, Königsberg und Greifswald, überdies Rostock blieb es abgesehen von „politischen Kundgebungen“ und „Aktionen einzelner Gruppen“ bzw. „Ansätzen gemeinsamen Handelns“ vergleichsweise ruhig, ja entstand nicht einmal in den Reihen der Studentenschaft eine konzertierte gemeinschaftliche Aktivität. ${ }^{636}$

630 Vgl. ibid., S. 43 und $89 f$.

631 Vgl. ibid., S. 26-32 und 40-42.

632 Vgl. Bruch: Die Universitäten in der Revolution, S. 144 und Thielbeer: Universität und Politik 1848, S. 43.

633 Vgl. Thielbeer: Universität und Politik 1848, S. 89 f. und 231 f.

634 Vgl. ibid., S. 43, 45-48 und 232.

635 Vgl. ibid., S. 233. Vgl. auch die detaillierte Darstellung der Ereignisse in Obermann, Karl: Die Berliner Universität am Vorabend und während der Revolution von 1848/49, in: Göber, Willi/Herneck, Friedrich: Forschen und Wirken. Festschrift zur 150-Jahr-Feier der Humboldt-Universität zu Berlin 1810-1960. Beiträge zur wissenschaftlichen und politischen Entwicklung der Universität, Bd.1, Berlin 1960, S. 165-202, insbesondere S. 175-190.

636 Vgl. Thielbeer: Universität und Politik 1848, S. 109f. Selbstverständlich neigen derartige übergreifende Einordnungsversuche der politischen Kräfteverhältnisse dazu, einige bemerkenswerte historische Ereignisse zu überblenden. Durchaus hatte die „Märzbegeisterung" auch bspw. in Bonn einige Studenten und Hochschullehrer - „eine große Zahl von Hin- und Herschwankenden und eine kleine Demokratenschar" - ergriffen und einige von ihnen zur Selbstbewaffnung getrieben, vgl. dazu Braubach, Max: Bonner Professoren und Studenten in den Revolutionsjahren 1848/49. Wissenschaftliche Abhandlungen der Arbeitsgemeinschaft für Forschung des Landes NordrheinWestfalen Bd. 38, Köln und Opladen 1967, S. 9-18. Das Zitat ibid., S. 47. Einer der aktivsten Bonner Studenten, Carl Schurz, wirkte an der Befreiung des Professors und Studentenführers Cottfried Kinkel aus dem Spandauer Gefängnis mit, exilierte nach einem Fluchtversuch und einer darauffolgenden Anklage in den $1850 e r$ Jahren in die Vereinigten Staaten, begegnete später als amerikanischer Staatsmann dem deutschen Reichskanzler Bismarck und wurde 1877 unter dem Republikanischen Präsidenten Rutherford B. Hayes US-Innenminister. Vgl. ibid., S. 93-104, 116-119 und 123f. Dennoch: „Trotz des Einflusses, den die demokratische Bewegung in Bonn besaß, blieb die Stadt in ihrer Haltung nahezu durchgängig liberal. Gleiches gilt für die Mehrheit der Professoren und auch die Studentenschaft. Insbesondere das Fehlen eines zahlenmäßig starken Proletariats verhinderte, daß sich Bonn zu einem Brennpunkt der Revolution entwickeln konnte." Thomann: Die Rolle der Burschenschaften in Jena, Bonn und Breslau, S. 369. 
Mehr noch: In Halle kämpfte selbst während der entscheidenden Märztage eine durch die Autorität des leidenschaftlich antijunghegelianischen Professors und „Studentenvaters" Heinrich Leo inspirierte corpsnahe konservative burschenschaftliche Mehrheit aktiv gegen die demokratische Minderheit. ${ }^{637}$

Auch die Aktionsformen variierten je nach lokalem Kontext. In Göttingen pflegte man die Kooperation mit Universität und Stadtverordneten, in Leipzig mit einer selbstständigen bürgerlich-oppositionellen städtischen Bewegung, welcher die ansässige Universität allmählich nachfolgte. ${ }^{638}$ Mithilfe von Volksversammlungen, Adressen, Petitionen, Deputationen, Demonstrationen, Auszügen und Vorlesungsstreiks suchte man öffentlichen Druck aufzubauen. ${ }^{639}$ Anderswo bemühten sich studentische Zirkel insbesondere, dem Ziel einer von studentischer Intelligenz angeführte Volksbewegung unter Einschluss von Bauern und Industrieproletariat näherzukommen. Die Erlanger Studentenverbindung „Concordia“, die sich auch die „Grauen“ nannte, schloss sich gemeinsam mit dem Arbeiterbildungsverein zu einem demokratisch-sozialistischen Volksverein zusammen. ${ }^{60}$ In Jena gelang 50 Burschenschaftern ein Protestzug unter Einschluss von ca. 5.000 Bauern und Handwerksgesellen, der die Entlassung des regierenden Kabinetts und die Ernennung eines neuen durch den regierenden Großherzog erwirkte. ${ }^{641}$ In Berlin mobilisierte am 18. März 1848 der umtriebige und rhetorisch versierte Student Gustav Adolph Schlöffel, Redakteur der Zeitschrift Der Volksfreund und zeitweilig auch Korrespondent von Karl Marx ${ }^{642}$, Arbeiter der Borsig Lokomotivfabrik zur Unterstützung der Barrikadenkämpfer ${ }^{643}$ (an jenem Tag verloren etwa 300 Studenten und Arbeiter während der dortigen Straßenkämpfe ihr Leben; der Trauerzug für die „Märzgefallenen“ vom 22.03.1848 wurde zum Großereignis). ${ }^{644}$ Und in Wien bewaffneten sich die Studenten, um gemeinsam mit Professoren, Privatdozenten, Promovierten, später auch Arbeitern, eine „akademische Legion“ zu gründen und sich, geschmückt mit schwarz-rot-goldenen Schärpen und Konkarden, der Nationalgarde $\mathrm{zu}$ unterstellen ${ }^{645}$; überdies konstituierten sich weitere Arbeiter in den Wiener Vorstädten zu sozialistischen Komitees. ${ }^{646}$ Insgesamt aber gelangten die Versuche ei-

637 Vgl. Thielbeer: Universität und Politik 1848, S. $105 f$. und 110.

638 Vgl. ibid., S. 43.

639 Vgl. ibid., S. 111 und Borowsky: Borowsky: Studenten in der deutschen Revolution, S. 191.

640 Vgl. Thielbeer: Universität und Politik 1848, S. 62.

641 Vgl. ibid., S. 43f. und Borowsky: Borowsky: Studenten in der deutschen Revolution, S. 192.

642 Obermann, Karl: Gustav Adolph Schlöffel, in: Ders.: Männer der Revolution von 1848, Westberlin 1970, S. 191-216, hier S. 214f.

643 Vgl. Jarausch: The Sources of German Student Unrest 1815-1848, S. 103, der dieses Ereignis ibid. als „brief period“ bezeichnet, in welcher „the fraternization between students and the peasantartisans seemed real“.

644 Vgl. Gevers/Vos: Studentische Bewegungen, S. 245 sowie Obermann: Die Berliner Universität am Vorabend und während der Revolution, S. 190-201.

645 Frey, Klaus-Walter: Die bürgerliche Revolution des Jahres 1848 an den Universitäten in Wien, Graz und Innsbruck unter dem Einfluß der freiheitlich-burschenschaftlichen Bewegung. Univ.-Diss., Würzburg 1983, S. 67-73.

646 Vgl. Gevers/Vos: Studentische Bewegungen, S. 246. Der durch die akademische Legion getragene putschistische „Oktoberaufstand“ wurde schließlich durch kaiserliche Truppen untr Feldmarschall Windischgrätz blutig niedergeschlagen. Vgl. Frey: Die bürgerliche Revolution in Wien, Graz und Innsbruck, S. 228-236. 
nes Bündnisses zwischen Intelligenz und nichtakademischen bzw. unterbürgerlichen Bevölkerungsgruppen, auch aufgrund des elitären Selbstverständnisses und der weltanschaulichen Selbstreferenzialität der Studenten ${ }^{647}$, nicht über singuläre Kooperationen und hervorstechende Einzelereignisse hinaus.

Auch ein Blick auf den „progressiven“ Aktivistenkern - insgesamt nur etwa 5 Prozent der rund 11.500 deutschen Studenten bei ca. 12 weiteren Prozent studentischer Sympathisanten $^{648}$ - lohnt sich. Keineswegs machte sich allerorten die studentische Mehrheit, auch deren bis zur politischen Rechten reichenden ${ }^{649}$ gesellschaftskritischen Segmente nicht, die demokratisch-revolutionären Auffassungen der vorkämpfenden republikanischen Burschen zu eigen, vielmehr unterstützte man sie in der Absicht, bürgerliche Freiheiten wie das Assoziationsrecht und die juristische Gleichstellung mit dem erwachsenen Bürgertum zu erstreiten oder anlässlich der Verfolgung republikanisch gesinnter Kommilitonen die traditionelle studentische Ehre in generis zu verteidigen. ${ }^{650}$ Interessant ist überdies, insbesondere mit Blick auf Kapitel II.1 dieser Studie, dass die in den Rechtswissenschaften Immatrikulierten unter den „48er“ revolutionären Studenten verglichen mit der Gesamtstudentenschaft überrepräsentiert waren (46 statt 32 Prozent) ${ }^{651}$ wohlgemerkt gegen Ende einer jahrzehntelangen scharfen Erwerbskonkurrenz gerade in dieser Berufsgruppe. ${ }^{652}$ Wahrscheinlich kämpften gerade die mit Vorliebe im eigenen sozialen Milieu agitierenden hochpolitisierten Studenten auch um die berufliche Absicherung und damit um die soziale Anerkennung als reputierliche Elite des fortschrittlichen Bürgertums. ${ }^{653}$

Ob Universitätsreform - die Einrichtung einer allgemeinen Studentenschaft als Antwort auf die zunehmende Fragmentierung in Fakultäten nebst Abschaffung der Statusdifferenzen gehörte zu ihren Märzforderungen ${ }^{654}$-, nationalstaatliche Einigung auf der Grundlage liberaler Verfassung oder radikaldemokratische Abschaffung der Monarchie - nahezu alle Strömungen sahen das entscheidende Gelegenheitsfenster für die

647 Vgl. Jarausch: The Sources of German Student Unrest 1815-1848, S. 103 sowie Thielbeer: Universität und Politik 1848, S. 238.

648 Vgl. Thielbeer: Universität und Politik 1848, S. 140 und Borowsky: Studenten in der deutschen Revolution, S. 188

649 Vgl. Gevers/Vos: Studentische Bewegungen, S. 242.

650 Vgl. Thielbeer: Universität und Politik 1848, S. 114 und Borowsky: Studenten in der deutschen Revolution, S. 193.

651 Vgl. Thielbeer: Universität und Politik 1848, S. 128.

652 „Die vormärzliche Welle, die unmittelbar nach den Freiheitskriegen ansetzte und an den meisten Universitäten in den frühen $1840 e r$ Jahren auslief, führte in den $1830 e r$ Jahren zu einem Überandrang in den Staatsdienst und zu 5- bis 10jährigen Wartezeiten der Assessoren. Da der nicht in beamteten Karrieren untergekommene Juristennachwuchs in die Advokatur drängte, verschärfte sich die Statuskonkurrenz auch auf diesem leichter zugänglichen Berufsfeld. Bis ins Revolutionsjahr 1848 bildete die Frage, ob der Zugang in die Advokatur durch einen Numerus clausus zu beschränken sei, unter den regionalen Anwaltsvereinigungen eines der heißen, immer wieder kontrovers diskutierten Themen der standesinternen Auseinandersetzungen." Titze: Die zyklische Überproduktion von Akademikern, S. 103.

653 Vgl. Thielbeer: Universität und Politik 1848, S. 237-239 und Borowsky: Studenten in der deutschen Revolution, S. 195.

654 Vgl. Bruch: Die Universitäten in der Revolution, S. 137-142 und Thielbeer: Universität und Politik 1848 , S. $223 f$. 
Herbeiführung einer zeitgemäßen Umgestaltung der Gesellschaft gekommen. Doch Anführer, dominante Gruppe oder gar Sprecher der nationalliberalen Massenbewegung als ganzer waren sie nicht. Ihre Ideen waren allem Bemühen um eine zeitgemäße Reformulierung der deutschen Bildungsidee zum Trotz gealtert ${ }^{655}$, teilweise gar zur Tradition erstarrt, mussten blass wirken gegenüber der nun ganz realen Revolutionsdynamik. In erster Linie sind es wie gesehen kleine und fortschrittsorientierte Universitätsstädte, die ökonomisch wie kulturell von Hochschul- und Verbindungsstrukturen dominiert waren ${ }^{656}$ und in denen es rascher zu situativen Bündnissen aus politisierten Akademikern und städtischem Bürgertum kommen konnte, die sich mit Recht als Aktionszentren der "48er"-Revolution bezeichnen lassen. ${ }^{657}$ Obwohl sich also zahlreiche Studenten am Revolutionsversuch von 1848 beteiligten, kam ihnen nicht mehr die einstige Pionierrolle der politischen Bewegung $\mathrm{zu}$; im Gegenteil sahen sich die burschenschaftlichen Oppositionellen einer immer stärker politisierten Bevölkerung gegenüber. ${ }^{658}$ Die Bedeutung studentischer Gruppen hatte ihren Zenit genau genommen schon nach dem gescheiterten Frankfurter Wachensturm in den 1830er Jahren überschritten:

„Dem Aktivismus einzelner Studentengruppen kam nun nicht mehr die Bedeutung zu wie in den vorausgegangenen Jahrzehnten. Allmählich begannen die großen politischen Strömungen sich zu entfalten und ihre Anhänger außerhalb der Universitäten und unabhängig vom studentischen Leben und seinen Erscheinungen zu suchen, der konstitutionelle Liberalismus, der demokratische Radikalismus, die Anfänge des Sozialismus, der politische Katholizismus und auch schon die bewußt konservativantiliberale Gesinnungsströmung. “659

Sie gingen geradezu unter - was nicht zu einem geringen Teil gerade ein Erfolg der nationalistischen Schrittmacherfunktion war, welche die Studenten für das deutsche Bürgertum zuvor erfüllt hatten. Auch der politisch so überaus entschlossenen studentischen Progressbewegung gelang letztlich nicht einmal die Bündelung und Kanalisierung der oppositionellen Energien in den Reihen der Studentenschaft; sie zerbrach an den nicht mehr zu vermittelnden Auseinandersetzungen über Charakter und Ziele der eigenen Reformansätze. ${ }^{660}$ Insofern lässt sich resümieren: „Nicht zur Auslösung und

655 „Während Humboldt eine Erneuerung der Universität von ihrer Isolation von gesellschaftlichen Anforderungen erwartete, versprachen sich die Reformer des Jahres 1848 eine Regeneration der Hochschule von ihrem Anschluß an die Gesellschaft. Die neu einströmenden Ideen einer Rechtsgleichheit und Emanzipation lösten jedoch nur einen Aufbruch der Gruppeninteressen, keine gestaltende Veränderung aus. [...] Die neu zu schaffende Nation, unter deren Leitung ein neuer Universitätstypus gedeihen sollte, spielte bei den 48er Reformern eine ähnliche Rolle wie die Idee vom Kulturstaat, auf den die Wissenschaftsanstalten ausgerichtet werden sollten, bei Humboldt: Die Zweifel an der Regenerationsfähigkeit der Universität förderten die Projektion einer Heilserwartung auf einen Modellstaat." Thielbeer: Universität und Politik 1848, S. $245 \mathrm{f}$.

656 Vgl. Bruch: Die Universitäten in der Revolution, S. 143.

657 Vgl. ibid., S. 145.

658 „Sie leisteten einen wichtigen Beitrag zur Vorbereitung der Revolution, lösten sie allerdings nicht aus und spielten auch nur gelegentlich eine führende Rolle in ihr." Borowsky: Studenten in der deutschen Revolution, S. 191.

659 Bartol: Ideologie und studentischer Protest, S. 74.

660 „Noch bevor die politischen Differenzen die Spaltung vertieften, konnte man sich über die gemeinsame Basis einer Reform des Studentenlebens kaum einigen. [...] Die Frage nach dem Ver- 
Durchsetzung der Revolution, sondern vor allem zu ihrer Vorbereitung vermochte die Burschenschaftsbewegung entscheidend beizutragen. ${ }^{“ 661}$ So oder so siegten die Beharrungskräfte: 1849 kam es vielerorts zum Stimmungsumschwung in der Bevölkerung, schließlich zur Verschärfung der Spannung zwischen Liberalen und - zunehmend von anderen Studenten, aber auch von Staatsseite als anarchistische Umstürzler denunzierten - Radikaldemokraten. ${ }^{662}$ Die Reihen der konservativen und christlichen Corps schlossen sich in Reaktion auf die Progressbewegung; im Mai 1848 gründeten auch sie in Jena einen ersten Dachverband, in den restaurativen $1850 e r$ Jahren folgten weitere. ${ }^{663}$ Nach der gescheiterten Revolution mündeten gleichwohl nicht nur die von politischer Verfolgung verschonten gemäßigten und bündnisorientierten Oppositionellen - auch im Rahmen der dauerhaft errungenen Vereinsfreiheit - in berufliche und politische Karrieren ein. Selbst die Konsequenzen für die radikalen „48er" waren insgesamt begrenzt ${ }^{664}$ - womöglich nicht zuletzt wegen der in der gescheiterten Revolution erlittenen finalen Niederlage ${ }^{665}$ der nationalliberalen Burschenschaftsbewegung.

Allmählich waren in allen europäischen Ländern die politischen Energien zu den beiden großen Fronten des 19. Jahrhunderts geronnen: Jene, die den 1789 angestoßenen Prozess - Auflösung der Stände (später auch der Klassen) im Sinne des Gleichheitsprinzips - als unaufhaltsamen Fortschritt ansahen und an dessen Beschleunigung arbeiteten, standen jenen gegenüber, die die traditionelle ständische Ordnung verteidigten, also konservative bis reaktionäre Ziele verfolgten. Oder in den Begriffen des in jenen Jahren zum Klassiker avancierenden Richtungsschemas: „Links“, das Neue, gegen „Rechts“, das Alte. ${ }^{666}$ Wie weit dieser Konflikt zwischen „Progression“ und den

sagen des Progresses als politische Kraft sollte diese innere Zerrissenheit berücksichtigen. Ebenso wichtig war jedoch die Unfähigkeit der Progressisten, zu dieser sich vollziehenden politischen Meinungsbildung ein positives Verhältnis zu bekommen. Spaltung galt in ihren Augen als Zerfall. [...] Die Vorteile politischer Parteibildung, fruchtbarer Auseinandersetzung und einer, wenn nötig, kämpferischen Interessenvertretung, wurden nicht erkannt." Thielbeer: Universität und Politik 1848, S. 150 und 151

661 Bartol: Ideologie und studentischer Protest, S. 76.

662 Vgl. Thielbeer: Universität und Politik 1848, S. 28-32, 38f. und 42.

663 Vgl. Gevers/Vos: Studentische Bewegungen, S. 246 und 248. 1859 erklärte der Kösener-SeniorenConvents-Verband (KSCV) die Mensur zur Pflicht für alle deutschen Korporierten, während die nichtkorporierten Finken- und Wildenschaften erst im Verlauf der $1860 e r$ Jahre wieder zu Selbstbewusstsein fanden und sich überregional zu reorganisieren begannen. Vgl. ibid., S. 249.

664 Thielbeer schließt aus der verfügbaren Datenlage, „daß Verbalradikalismus in der Revolution relativ großzügig behandelt wurde. Zwei Drittel derjenigen, die in demokratischen Vereinen, in Volksversammlungen und bei den Bauern zur Revolution aufgerufen hatten, waren auf Dauer nicht in ihrer Berufswahl beeinträchtigt. Sie erachteten es auch nicht für notwendig, ins Ausland zu fliehen." Nur zehn Studenten erhielten Haftstrafen, und selbst unter den bewaffneten Aufständischen fanden die meisten später einen Weg „in Amt und Würden“. Thielbeer: Universität und Politik 1848, S. 131. Vgl. außerdem die Tabelle zur weiteren beruflichen Laufbahn der einstigen Revolutionäre ibid., S. 250-254.

665 „Die Zäsur war radikaler als die der Jahre 1819 und 1833, da mit der Zerschlagung der demokratischen Studentenbewegung eine allgemeine Entpolitisierung der Burschenschaften in den fünfziger Jahren eingeleitet wurde." Thomann: Die Rolle der Burschenschaften in Jena, Bonn und Breslau, S. 401.

666 Vgl. Raschke, Joachim: Die Erfindung von Links/Rechts als politisches Richtungsschema, in: Greve, Michael Th./Münkler, Herfried/Schmalz-Bruns, Rainer (Hg.): Bürgersinn und Kritik. Festschrift 
Kräften der ancien régimes in den 1830er Jahren gediehen war, lässt sich am Siegeszug des Nationalismus - hier noch das zentrale „linke“ Kernprojekt - ablesen, der nicht nur in Deutschland zunehmend reüssierte. Der liberale Verfassungsstaat, zuvor Kerngegenstand der entschlossen erwarteten bildungsbürgerlichen „Zielutopie“667, war zum Ziel nationalistisch bewegter Massen und zugleich zum Schrecken aller konservativen Kräfte geworden. ${ }^{668}$ Bis 1871 fächerte sich dieser politische Dualismus je nach Stellung zu Nationalstaat und Religion in unterschiedlichen Parteien auf: Der protestantischmonarchistisch-kleindeutsche Konservatismus Preußens bzw. Ostelbiens unterschied sich vom politischen Katholizismus ebenso wie von den reichsorientierten Konservativen bzw. den großdeutschen Ultramontanisten im Süden; der Liberalismus spaltete sich in eine linksliberale und in eine rechtsliberale Strömung; überdies wuchs sich der Sozialismus zur parteiförmigen Kraft aus.

In den 1840er Jahren ging die Fackel der liberalen Nationalbewegung über an das „erwachsene“ bürgerliche Vereinswesen, ähnlich wie sich schon nach dem Verbot der Burschenschaften 1819 die politischen Impulse subkulturell kodifizierten und zu den Sänger-, Turn-, und Schützenvereinen als „institutionelle[m] Rückgrat der Nationalbewegung" hinüberwechselten. ${ }^{669}$ Die jetzige Transformation aber war nicht mehr obrigkeitlicher Repression geschuldet, sondern dem Scheitern der Revolution. Sie erfolgte auch aus gleichsam kollektivbiographischen Gründen: Viele Aktivisten der „1815erGeneration ${ }^{4670}$ hatten sich zu Wortführern und Politikern der nationalliberalen Bewegung in einer spürbar demokratisierten Gesellschaft entwickelt und bemühten sich nunmehr - hierin ironischer-, aber auch tragischerweise nach alter bürgerlicher Façon - in Landtagen, Reichstagen, Bundestag und Nationalversammlung um die Aushandlung politischer Reformen mit den konservativen Gegenspielern. In gewissem Sinne kam der Assoziationsimpuls des Bürgertums in der auf Kanalisierung von gesellschaftsverändernden Energien zielenden Parteibildung zu sich selbst. Denn die Partei war in ihrem vormärzlichen Ursprung gleichsam ein bürgerliches Phänomen par excellence, ihren konservativen Gegenspielern - also den Phalanxen von Krone und Kirche - gerade deswegen so verhasst. Nur langsam und widerstrebend fügten diese - und unter ihnen vorrangig die Klasse der ostdeutschen Rittergutsbesitzer - sich in die parteiliche

für Udo Bermbach zum 60. Geburtstag, Baden-Baden 1998, S. 185-206, hier S. 194. Wohlgemerkt entstand das Richtungsschema Links/Rechts nicht erst zwischen 1800 und 1900, sondern fand sein Vorbild in der berühmten Ständeversammlung von 1789 bzw. der noch berühmteren ersten Nationalversammlung von 1791, vgl. ibid., S. 187. Die Durchsetzung als international gültiges Synonym für den Konflikt zwischen Progressiven und Konservativen aber sollte noch ebenso lange dauern, wie die zugrunde liegende Auseinandersetzung zum gesellschaftspolitischen Heranreifen benötigte - oder mit anderen Worten: So lange, bis die Modernisierung von Ökonomie, Kultur, Politik auch die modernen, symbolisch aufgeladenen Formen von ideologischem Bewusstsein ermöglichten, vgl. ibid., S. 196-199.

667 Wehler: Deutsches Bildungsbürgertum in vergleichender Perspektive, S. 230. Diese Zielutopie, so Wehler ibid., enthält einen wesentlichen Kerngedanken: „Es galt als sicher, daß die Zukunft auf ihrer Seite sei, daß das Ziel einer breiten, gebildeten, politisch einflußreichen bürgerlichen Mittelklasse, der jeder Leistungsfähige mit Besitz und Bildung willkommen war, stetig näherrückte."

668 „Überall wurde der moderne Nationalismus zu einer politischen Religion." Ibid., S. 232.

669 Müller: Die Revolution von 1848/49, S. $23 f$.

670 Vgl. Hardtwig: Auf dem Weg zum Bildungsbürgertum, S. 24. 
Organisationsform, deren interessenförderlichen Nutzen, aber auch deren Unumgänglichkeit als „Reaktion“ auf die politische Hausse der Liberalen, Nationalisten und Demokraten, sie erkannten ${ }^{671}$ - und sei es nur, um dem kochenden „Volksgeist“ Ablassventile zuzubilligen oder im Falle des Zerfalls der Monarchie über eine sichernde „Ausfallbürgschaft" zu verfügen (so der konservative Sozialreformer Victor Aimé Huber). ${ }^{672}$ So geriet die Partei, anfangs angestoßen durch den emanzipativ-oppositionellen Impuls und katalysiert durch die sozialkatholische Gegenwehr, zur universalen Organisationsform aller relevanten politischen Strömungen: Die politische Auseinandersetzung hielt somit Einzug in die Parlamente, was nahezu eigendynamisch Demokratisierungstendenzen beschleunigte und schließlich die parlamentarische Auseinandersetzung als allgemein akzeptierte Arena des Interessenkampfes konsolidierte - auch wenn die Konservativen in der Frankfurter Paulskirche sich wie erwähnt noch einige Jahre der Parteibildung widersetzten. Zwischen den späten $1850 e r$ Jahren und 1875 bildete sich hier das klassische Fünfparteiensystem heraus, das die deutsche Gesellschaft und die deutsche politische Kultur lange Zeit prägen sollte. ${ }^{673}$

Vom Scheitern der Revolution sollte sich die Burschenschaftsbewegung nie wieder erholen. Ihr erging es wie die große nationalliberale Sammlungsbewegung, welche nachhaltig beschädigt blieb: Die anhaltende politische Wirkungslosigkeit führte schließlich zum Zerfall in akkomodative Reformer einerseits und in nationalreligiöse Radikalisten andererseits. ${ }^{674}$ Ganz ähnlich die jungbildungsbürgerlichen Burschen: Vier Jahrzehnte lang und in drei Wellen hatten sie die studentische politisch-oppositionelle Offensive angeführt und es vermocht, selbst in den Phasen erdrückender Repression Kräfte zu sammeln, die es ihnen erlaubten, sich hernach zu regenerieren. Doch das war nun vorbei: Die liberale akademische Jugend trieb in einer lähmenden Katerstimmung vor sich hin. ${ }^{675}$ Organisationsleben und Sozialmoral faserten ins Subkulturelle aus. Davon profitierten die Konkurrenzorganisationen, neben verschiedenen protestantischen und neuen katholischen Verbindungen ${ }^{676}$ insbesondere die traditionalistischen Corps, die im Laufe der $1850 e r$ Jahre zu neuer Stärke und überregionaler Organisationskraft fanden. Sie waren es nun, die den Zeitpunkt gekommen sahen, ihren Führungsanspruch in der deutschen Studentenschaft geltend zu machen - und zwar unter konservativen, ausdrücklich apolitischen und anti-progressiven Vorzeichen. ${ }^{677}$ Der nationalliberale Impuls der Urburschenschaft hingegen verblasste weiter, blieb fragmentiert und randständig; eine Weile noch existierten die Strömungen der liberaldemokratischen "Germanen“, der altburschenschaftlichen „Teutonen“ und der eher apolitischen „Arminen“ fort, ohne je wieder überregionalen Einfluss zu gewinnen. ${ }^{678}$ Sie gingen $\mathrm{ab}$

671 Vgl. Erbentraut, Philipp: Theorie und Soziologie der politischen Parteien im deutschen Vormärz 1815-1848, Tübingen 2016, S. 278-286.

672 Vgl. ibid., S. 136-140 und 147-150.

673 Vgl. Ritter: Die deutschen Parteien 1830-1914, S. 14-19.

674 Vgl. Klenke: Deutsche Nationalreligiosität.

675 Vgl. Schulze/Ssymank: Das deutsche Studententum, S. 300.

676 Vgl. Jarausch: Deutsche Studenten, S. 55.

677 Vgl. ibid. und Schulze/Ssymank: Das deutsche Studententum, S. $300 f$.

678 Vgl. Jarausch: Deutsche Studenten, S. 56. 
1859 schließlich in den Freistudenten- bzw. Finkenschaften auf, die im späteren Wilhelminismus eine dritte, gegen die hegemonialen Corps gerichtete, Reformbewegung anstoßen sollten. ${ }^{679}$ Überhaupt: Eine allgemeine Konsequenz der gescheiterten bürgerlichen Revolution, die letztlich von allen studentischen Verbindungen gezogen worden ist, war die Abkehr von dem Versuch, die gesamte akademische Jugend organisatorisch zu vereinigen - größere Zusammenschlüsse von einzelnen Verbindungen betrieb man nur mehr in lose organisierten Ringen. ${ }^{60}$ Zudem wurde das organisatorische Leben der Studentenvereinigungen durch die Beteiligung der Studenten an den deutschen Einigungskriegen der 1860er und frühen 1870er Jahre ein weiteres Mal schwer in Mitleidenschaft gezogen. ${ }^{681}$

So steht das Jahr 1848 sowohl für einen Kulminationspunkt als auch für eine verlorene Entscheidungsschlacht des Versuchs studentischer Gesellschaftsreform. Trotz Abschaffung der Karlsbader Beschlüsse und einer durch die preußische Verfassung garantierten - und in der Folge auch faktischen praktizierten! - universitären Autonomie: „Alles in allem war die Bilanz für die Studenten eher negativ.“682 Die Ereignisse gerieten für die politisch aktiven Jungbildungsbürger, ganz so wie für das liberale Bürgertum insgesamt, zu einer Mixtur aus primärem Scheitern und sekundärem Erfolg. Aber vielleicht hätte auch eine gelungene Revolution die liberalen Studenten gerade nicht zu neuer organisatorischer Blüte getrieben: sie zogen ihre Überzeugungen, ihre Sozialmoral, aber auch ihr gesellschaftspolitisches Momentum und ihre Legitimität aus den vielen ungelösten Konflikten jener „Phase des Umbruchs“ vom „fürstlich-patriarchalischen Staatswesen zum konstitutionellen Verfassungsstaat.“683 Und tatsächlich: in Fragen gesellschaftlicher und politischer Liberalisierung hatte sich Wesentliches verbessert, große Teile der Bevölkerung hatten sich politisiert. Die vormaligen Regenerationskräfte, die die Burschenschaften in Zeiten der Repression haben überwintern und die mehrfachen Zerschlagungsversuche haben scheitern lassen, sind so gesehen womöglich auch durch den sekundären, langfristigen Erfolg versiegt.

Andererseits liegt doch eine gewisse Tragik darin, dass Urburschenschaft und Progress an jenen Widersprüchen zerbrechen mussten, die von Beginn an in dieser Interimsformation angelegt gewesen sind: Sie bildeten als Reformbewegung nur temporär ein politisch funktionsfähiges Amalgam zwischen Gesittungs- und politischer Bewegung. So mangelte es ihnen, ähnlich den späteren Freistudenten oder der antiautoritären Strömung der Studentenbewegung von 1968, an konkreten politischen Zielsetzungen, verbindlicher Kadermentalität und dadurch auch an langfristiger politischer Organisationskraft. Auch in der Frage nach adäquaten Bündnisstrategien in Richtung

679 Vgl. ibid., S. 56 und Schulze/Ssymank: Das deutsche Studententum, S. 303f. Vgl. ferner weiter unten Kapitel II.2.1 dieser Studie.

680 Vgl. Schulze/Ssymank: Das deutsche Studententum, S. 300.

681 Vgl. ibid., S. 320.

682 Borowsky: Studenten in der deutschen Revolution, S. 199.

683 Vgl. Sellert, Wolfgang: Die Aufhebung des Staatsgrundgesetzes und die Entlassung der Göttinger Sieben [1987], in: Blanke, Edzard/Kamp, Norbert/Schöne, Albrecht/Sellert, Wolfgang/von Thadden, Rudolf/Wellenreuther, Hermann (Hg.): Die Göttinger Sieben. Ansprachen und Reden anläßlich der 150. Wiederkehr ihrer Protestation, Göttingen 1988, S. 23-45, hier S. 38. 
Mehrheitsbevölkerung oder auch nur in Richtung des zersplitterten Bürgertums insgesamt kam man über drei Jahrzehnte hinweg nicht wirklich voran:

„Die Hauptschwäche der burschenschaftlichen Organisation selbst und Grund für ihre Auflösung lag vor allem darin, daß reale engere Verbindungen zu den breiten Schichten der Bevölkerung trotz mancher Bemühungen nicht zustande kamen, daß weder eine revolutionäre Klasse noch machtpolitische Kräfte damals vorhanden waren, die der Bewegung das notwendige Rückgrat hätten geben können. “684

Schließlich erlosch der anfängliche bürgerliche Avantgardismus angesichts veränderter politkultureller Verhältnisse, ohne dass man eines der beiden großen Ziele, nationale „Einigung“ oder bürgerliche „Befreiung“ inklusive umfassender Lebensreform, tatsächlich praktisch herbeigeführt hätte. ${ }^{685}$ Es mag also legitim sein, den „progressistisch“ politisierten Studenten des Vormärz und ihrer zweifellos vielerorts praktizierten verbalradikalen sowie kollektivnarzisstischen Nabelschau ein fehlendes Sensorium für die Erfordernisse politischen Taktierens, „kämpferischer Interessenvertretung“ und strategischer Kooperation zu attestieren. ${ }^{686}$ Andererseits ist das tragende Dilemma damit wahrscheinlich nicht gelöst: Als die deutschen Studenten auf dem Weg zur Reichseinigung schließlich „die Macht als entscheidenden Faktor der Politik“ akzeptierten, vollzogen sie auch ihre antiliberale Wende hin zu Männerbünden, Nationalchauvinismus und Imperialismus. ${ }^{687}$

Insgesamt lässt sich die Burschenschafts- und Progressbewegung des Vormärz als eine frühliberale und nationalistische Emanzipationsbewegung auffassen, die als „Archetypus moderner Studentenbewegung ${ }^{\prime 688}$ in drei Phasen, nämlich 1815 bis 1819 , in den $1830 e r$ Jahren und noch einmal in den 1840er Jahren, oppositionellen Protest mobilisierte, wiederholten Repressalien trotzte und somit, pointiert gesprochen, eine ganze Studentengeneration, mithin einen großen Teil des Bildungsbürgertums in nationalem und liberalem Sinne politisierte. ${ }^{689}$ Sie wurde wechselvoll rezipiert: Kritisch beurteilt im Deutschen Kaiserreich und unter angloamerikanischen Historikern, wurden sie in Weimar und von der DDR-Geschichtsschreibung positiv erinnert, von NS-Historikern gar zu völkischen Pionieren avant la lettre stilisiert. ${ }^{690}$ Derartige Lesarten und Rezeptionsstile sind sicherlich nur durch die inhärenten Widersprüchlichkeiten der Burschenschaftsbewegung möglich gewesen: Von Anfang an war ihr Kennzeichen eine Doppeltradition aus bürgerlich-frühliberalen und radikaldemokratischen Strömungen. ${ }^{691}$ Zudem: „Fortschrittliche Tendenzen verquickten sich mit schwärmerischen Elementen, gemäßigte Reformansätze der Mehrheit mit terroristischen und revolutionären Bestrebungen der Minderheit. “692 Begonnen hatte man als frühliberale Gesittungsbewegung im ausgehenden 18. Jahrhundert. Gemäß dem Humboldt'schen Bildungsideal

684 Bartol: Ideologie und studentischer Protest, S. 77.

685 Vgl. Jarausch: Deutsche Studenten, S. 44.

686 Vgl. Thielbeer: Universität und Politik 1848, S. 150 of.

687 Borowsky: Studenten in der deutschen Revolution, S. 199.

688 Jarausch: Deutsche Studenten, S. 44.

689 Vgl. ibid., S. 41-43.

690 Vgl. ibid.

691 Vgl. Bartol: Ideologie und studentischer Protest, S. 143.

692 Jarausch: Deutsche Studenten, S. 44. 
galt es hier, als freier Zusammenschluss gebildeter und engagierter Individuen jene Keimzellen-Zirkel herzustellen, welche die angestrebte, grundstürzend neue „bürgerliche“ Gesellschaft vorwegnehmen sollte ${ }^{693}$ - eine „Nation im Kleinen“694. Man setzte an zivilen Organisationsformen, Selbstdisziplinierung und sittlicher Lebensführung an, um sich zur Mitgliedschaft in den bürgerlichen Führungsschichten zu qualifizieren; die oppositionelle Politisierung folgte erst mit der „1815er" Kriegsteilnehmer-Generation. ${ }^{695}$ Alsbald geriet die politische Wende mit der institutionellen Zähigkeit des in Monarchien und Fürstentümer zersplitterten Deutschen Bundes - Artikel 57 der Deutschen Bundesakte erklärte jene alte aristokratische Elite allen bisher erstrittenen administrativen Konzessionen zum Trotz ganz traditionell zu Staatsoberhäuptern und zentralen Staatsgewalten in den Gliedstaaten ${ }^{696}$ - aneinander. Dies natürlich nicht allein durch unverhältnismäßige Dämonisierung der nationalliberal aktiven Studenten: Nicht nur die Tugendromantiker in ihren Lesegesellschaften, auch der Radikaldemokrat und politische Attentäter Karl Follen konnte von den philosophischen Leitgedanken und auch von der praktischen Einmischung von Hochschullehrern wie Fichte oder Fries zehren. ${ }^{697} \mathrm{Ihr}$ Reichtum an inneren Widersprüchen - fortschrittsorientierte Schwärmerei, lebensreformerischer Furor und politischer Terrorismus, letzteres etwa aufseiten von Follens Kreis der „Unbedingten“ bzw. „Schwarzen“698 und ähnlichen agitatorisch produktiven „engeren Kreisen“ ${ }^{699}$ konnten lange frei wuchern - vertiefte sich im Laufe der Jahrzehnte und führte schließlich auch von innen zur Spaltung. Gegen Ende der 1830er Jahre schließlich mussten die jungbildungsbürgerlichen Aktivisten einsehen, dass ein Revolutionsversuch ohne eine breite Volksbewegung aussichtslos sein würde ${ }^{700}-$ die Studenten büßten sichtbar die Verve der vormals für sich reklamierten Führungsrolle ein. Man kann also zwar im Stile Jarauschs nüchtern bis steril bilanzieren:

„Trotz des Fehlschlags der nationalen und liberalen Aspirationen eines erheblichen Teils der Studentenschaft bleibt die Bildung einer fortschrittlichen Studentenbewegung eine historische Errungenschaft der Studentengenerationen nach 1815.“701

Legitim erscheint es aber auch, im Rückblick den - zumindest zu vermutenden - studentischen Einfluss auf gesamtgesellschaftliche Mentalitätsströme anzuführen. Denn vor dem Hintergrund langfristiger historischer Entwicklungslinien verweist die Scharnierfunktion der Burschen und Progress-Studenten für Nationalliberalismus und Revolution doch auf einen Wahrheitskern, ein fundamentum in re der späteren Überzeichnungen und Mythisierungen (sei es zu Heroen der Demokratie oder des deutschen „Volkes“, sei es zu umstürzlerischen Traditionszerstörern und Ikonoklasten der Autorität). Den

693 Vgl. Hardtwig: Auf dem Weg zum Bildungsbürgertum, S. 31.

694 Heinemann: Studenten im Aufbruch, S. 1.

695 Vgl. Hardtwig: Auf dem Weg zum Bildungsbürgertum, S. 21, 24 und 31.

696 Vgl. Uhlenbrock, Henning: Der Staat als juristische Person. Dogmengeschichtliche Untersuchung zu einem Grundbegriff der deutschen Staatsrechtslehre, Berlin 2000, S. 24.

697 Vgl. Bartol: Ideologie und studentischer Protest, S. 60f. und 80-83.

698 Vgl. ibid., S. 68-71.

699 „Diese ,engeren Vereine' entwickelten sich zu politischen Willensträgern der Burschenschaft und waren ihr aktiver, vorwärtstreibender Kern." Steiger: Urburschenschaft und Wartburgfest, S. 152.

700 Vgl. Jarausch: Deutsche Studenten, S. 44f.

701 lbid., S. 57. 
Mentalitätswandel hin zu nationalen und demokratischen Prinzipien hat man - zuerst im Bildungsbürgertum, später auch in der Gesamtbevölkerung - durch die frühe und umtriebige Agitation erfolgreich beschleunigt. Das wiederum förderte die Herausbildung einer reiferen, durch parlamentarische Vermittlungsformen disziplinierten, politischen Kultur im heutigen Deutschland - in der Tat eine „progressive“ Leistung der Vormärz-Studenten.

Welche besonderen Kontextbedingungen sind darüber hinaus aus der Periode des Deutschen Bundes zu destillieren? Die zwischen 1815 und 1848 in der burschenschaftlichen Oppositionsbewegung organisierten deutschen Studenten füllten ein „politisches Vakuum ${ }^{\prime 702}$ aus, indem sie die Frustrationen des gebildeten Bürgertums artikulierten und radikalisierten, indem sie die Rolle einer Bündelung und Vermengung intellektueller, genauer: spezifisch deutscher aufklärerisch-romantischer Traditionsbestände ${ }^{703}$ mit politisch-oppositionellen Energien übernahmen. Damit befeuerten sie - obwohl nie geschlossen revolutionär oder verbindlich durchideologisiert, vielmehr von Anfang an von den widersprüchlichen Anforderungen einer gesamtgesellschaftlichen Umbruchssituation bestimmt ${ }^{704}$ - anstelle einer hierzulande fragmentierten, $\mathrm{zu}$ nicht geringen Teilen staatlich bediensteten und daher politisch kaum handlungsfähigen erwachsenen (Bildungs-)Bürgerlichkeit die oppositionelle Politisierung breiterer Bevölkerungskreise. ${ }^{705}$ Sie übernahmen eine Funktion, die ein im Vergleich zu anderen westlichen Staaten schwach ausgeprägtes und politisch unorganisiertes (Bildungs-)Bürgertum nicht leisten konnte. ${ }^{706}$ Sie waren, der gescheiterten „48er“-Revolution zum Trotz, ein wesentlicher Träger der Demokratisierung und politischen Einigung der deutschen Gebiete - und dementsprechend auch ein besonders aktiver und antizipatorisch wirkender Teil der in Deutschland spät auftretenden bürgerlichen Emanzipationsbewegung des 19. Jahrhunderts, „,Vorhut' ihrer eigenen Klasse“707. In keinem anderen der heutigen demokratischen Staaten ist eine vergleichbare Vorgeschichte des akademischen Nachwuchses - der ja überall zuvörderst das Reservoir von durch Bildung „professionalisierten“ Anwärtern auf höhere Expertenberufe gewesen ist ${ }^{708}$ - aufzufinden. Das lässt

702 Bartol: Ideologie und studentischer Protest, S. 76.

703 Vgl. ibid, S. 97.

704 „Die entscheidende Schwierigkeit - und Leistung - bestand in den Anfangsjahren [...] darin, Äußeres und Inneres, ältere und bekannte Strukturen und neue politisch-soziale Ansprüche und Vorgaben in Einklang zu bringen. Die Integration bisheriger Traditionen, vornehmlich des Duells, in eine sich verändernde, mehr und mehr durch national-liberale Ideen geprägte studentische Lebenswelt schuf eine Brücke, die Interesse für die neue Verbindungsform bei möglichst vielen Studenten wecken und zugleich einen Veränderungsprozeß in Gang setzen sollte." Heinemann: Studenten im Aufbruch, S. 33.

Vgl. Bödeker: Die „gebildeten Stände“ und Bartol: Ideologie und studentischer Protest, S. 76 und 97.

706 „Die zum Teil hochgespannten, idealistischen Schwärmereien von sozialer Gerechtigkeit, von Freiheit und deutscher Einheit, waren sozusagen der Gegenpol der wirtschaftlich und sozial zurückgebliebenen Verhältnisse und der Reflex auf das Ausbleiben einer schlagkräftigen gesamtdeutschen Bourgeoisie." Bartol: Ideologie und studentischer Protest, S. 76. Vgl. auch ibid., S. 152. 
die Vermutung zu, dass das politkulturelle Stereotyp einer politisch wachsamen bis kritischen, potenziell aufmüpfig-subversiven Studentenschaft, das gewöhnlich mit „1968“ assoziiert wird, ein entscheidendes Vorbild im frühen 19. Jahrhundert hat, ja subkutan

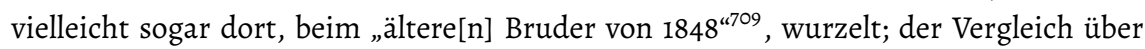
die hier konstatierte Achse freiheitlicher Traditionen jedenfalls wurde in den 1960er und 1970er Jahren oft angestellt. ${ }^{710}$

\section{II.2.2 Gescheiterte Außerparlamentarische Opposition, modernisierte politische Kultur: Die westdeutsche Studentenbewegung von „1968”}

„68 ist [...] immer noch hochbelastet mit den privaten Mythen der Beteiligten, sei es, dass sie nun als Veteranen des Barrikadenkampfes über das Versiegen des Elans in der heutigen Jugend klagen, oder sei es dass sie nunmehr etabliert ihre Jugendsünden vertuschen oder belächeln, oder sei es, dass sie ein unausrottbares Ressentiment hegen, dass so etwas überhaupt passieren konnte, oder sei es, dass sie nach schwierigen Prozessen, wie soll man sagen, der Amnesie und der Amnestie, des Vergebens und Vergessens das Ganze ohnehin zu einer Bagatelle werden lassen. ${ }^{\text {“711 }}$

Diese ermüdete Einschätzung von Wolfgang Eßbach, dem ehemaligen Vorsitzenden des SDS-dominierten Göttinger AStAs der Jahre 1967 und 1968, der heute zur Position des versiert-deskriptiven geistesgeschichtlichen Chronisten neigt, illustriert eine besondere epistemologische Hürde der Auseinandersetzung mit dem Thema dieses Kapitels. Das Signum „1968“ sperrt sich, sowohl aufgrund der Vieldeutigkeit der in ihm sich kreuzenden Entwicklungen, Ereignisse und Bilder, ${ }^{712}$ aber auch wegen der konkurrierenden Einschätzungen und Deutungsversuche, einem unvoreingenommenen Exkurs. Die Frage „Wie über 1968 schreiben? ${ }^{4713}$ treibt auch die versiertesten Kenner der Materie um. Sicher liegt in dem Akt der Historisierung ausgewählter Zeitspannen ein generelles Problem auch geschichtswissenschaftlicher Zugänge. Das Entscheidende ist hier

709 Agnoli, Johannes: 1968 und die Folgen, Freiburg 1998, S. 31.

710 Vgl. ibid., ferner Fichter/Lönnendonker: Kleine Ceschichte des SDS, S. 5, retrospektiv Thielbeer: Universität und Politik 1848, Vorwort, und die vergleichende Anlage der bereits zitierten Arbeit von Bartol: Ideologie und studentischer Protest.

711 Eßbach, Wolfgang: 8. Vorlesung: II. Marxbilder, in: Karl Marx und die Frage nach der Gesellschaft (Theorie I), Podcasts der Albert-Ludwigs-Universität Freiburg, Winter 2004-2005, 01:16-2:00, online einsehbar unter: https://www.podcasts.uni-freiburg.de/geschichte-gesellschaft/gesellschaft/karl-marx-und-die-frage-nach-der-gesellschaft-theorie-i-winter-2004-2005 [eingesehen am 01.08.2019]

712 Michael Th. Greven liefert eine Auswahl von elf „Protestepisoden“ der 1960er Jahre jenseits der Studentenbewegung, deren spezifische Verläufe und Auseinandersetzungen zu berücksichtigen seien: Ostermarsch-Bewegung, Anti-Vietnamkriegs-Bewegung, Universitätsreformbewegung, AntiNotstandsbewegung, US-inspirierte Bürgerrechtsbewegung, Kommune-Bewegung, „Rote Punkt Bewegungen“, Schüler- und Lehrlingsbewegungen, „Literaturproduzenten-Bewegung“, marxistisch-leninistische Parteikommunisten und neue Frauenbewegung. Vgl. Greven: Systemopposition, S. 24f. Der wohl umfangreichste Überblick über die Vorgeschichte studentischen Protests in der Bundesrepublik ab 1957 findet sich in Spix, Boris: Abschied vom Elfenbeinturm? Politisches Verhalten Studierender 1957-1967. Berlin und Nordrhein-Westfalen im Vergleich, Essen 2008. Kraushaar, Wolfgang. 1968 als Mythos, Chiffre und Zäsur, Hamburg 2000, S. 7. 
jedoch: Fünfzig Jahre verstrichener Zeit haben es augenscheinlich nicht vermocht, Zeitgeschichte in Historie aufzulösen. ${ }^{714}$ Die Erinnerung an „1968“ war und ist, nicht nur in Deutschland, Gegenstand von „Deutungskämpfen“"715. Lange dominierten autobiographische (Selbst-)Zeugnisse das Bild der Ereignisse, erst im Verlauf der 1980er Jahre trat die verstärkte politische und wissenschaftliche Beschäftigung mit dem Thema hinzu. Die schon zur Jahrtausendwende unüberschaubar gewordene Literatur wächst immer weiter - zumeist anlässlich von Jubiläumsjahren wie 1998, 2008 und 2018 - an. Insbesondere jüngere Rückblicke und Revisionen treten dabei mit dem Gestus unvoreingenommener Frische und mythendekonstruierenden Scharfsinns auf ${ }^{716}$; zu dem Ritual gehört aber auch, dass den jeweiligen Neuerscheinungen ihr geringer Neuigkeitswert vorgehalten wird. ${ }^{717}$ An dieser zeithistorischen Debatte soll hier möglichst nicht teilgenommen werden. Dennoch: Wer sich mit der der studentischen Oppositionsbewegung der 1960er Jahre auseinandersetzt, hat die Aufgabe, ein grundlegendes Verständnis der bedingenden gesamtgesellschaftlichen Entwicklungen, Voraussetzungen und kollektiven Triebfedern, der auslösenden Ereignisse, formativen Auseinandersetzungen und gesellschaftspolitischen Folgen dieser Bewegung herauszuarbeiten und das Spektrum der Bewertungen verständlich zu machen. Dabei sollte vorab festgehalten werden, dass studentischer Protest linksradikaler Provenienz zwar schon ab 1960 wiederholt aufgetreten war, und es auch nach „1968“ weiterhin tat. Doch von einer Studentenbewegung „in voller Herausbildung “718 , d. h. von einem zusammenhängenden und koordinationsfähigen Aktionsbündnis, kann - wie im Folgenden gezeigt werden soll - nur im Hinblick auf die zwischen 1966 und 1967 als konstituierte und 1968 bereits wieder zu zerfallen beginnende Außerparlamentarische Opposition (APO) die Rede sein. Insofern wird im Folgenden nur am Rande auf die gesamtgesellschaftliche und internationale Tragweite der um die „Chiffre $68^{\text {“719 }}$ zentrierten transformativen und an politischen Bewegtheiten reichen Jahre eingegangen; die von SDS-Aktivisten geschmiedete APO ist eben

714 Der von Kraushaar im Jahr 2000 angegebene entscheidende Grund für die Unmöglichkeit der Historisierung von „1968“, nämlich dass „die meisten der Beteiligten selbst noch von dem, was sie erlebt haben, Zeugnis abliefern [sic] können“, gilt auch heute noch. Ibid.

715 Behre, Silja: Bewegte Erinnerung. Deutungskämpfe um ,1968' in deutsch-französischer Perspektive, Tübingen 2016, S. 3 und 17.

716 Vgl. exemplarisch Hodenberg, Christina von: Das andere Achtundsechzig. Gesellschaftsgeschichte einer Revolte, München 2018 - eine Monographie, die vermittels ihres Klappentextes den wenig bescheidenen Anspruch erhebt, „das in den Blick“ zu nehmen, „was sonst meist ausgeblendet wird“ (nämlich das gesamtgesellschaftliche Resonanzfeld von „1968“) und damit „die erste wahre [!] Gesellschaftsgeschichte der Revolte von 1968“ zu liefern.

717 Zwei Literaturberichte zu den Publikationswellen von 2008 und 2018, die den auf der Hand liegenden kommerziellen Verlagsinteressen und dem erhofften Reputationszugewinn der beteiligten Autorinnen und Autoren genüsslich die geringe inhaltliche Originalität der zeitgenössischen Beiträge vorhalten, stellen die Wiederholung zentraler Motive ebenso heraus wie die weiterhin bestehende Schwierigkeit, abschließende Urteile zu fällen: Vgl. Söllner, Alfons: „,1968'-eine Nachlese“, in: Mittelweg 36, H. 6/2008/09, S. 33-60 und Schmidt, Rudi: Der späte Nachhall von '68 - Alte Erkenntnisse in neuen Gewändern?, in: Kölner Zeitschrift für Soziologie und Sozialpsychologie, 70. Jg., H. 4/2018, S. 705-725.

718 Bauß: Die Studentenbewegung der sechziger Jahre, S. 14

719 Claussen: Chiffre 68. 
nur ein (deutscher) Teil von „1968“, ${ }^{720}$ wenn auch der hier maßgeblich interessierende Teil. Die in Westdeutschland maßgebliche katalysierende Wirkung der Ereignisse von 1967 wird dabei zeigen, dass die Formulierungen „1968“ und „68er-Bewegung“, die den Gesamtzusammenhang globaler Protesterscheinungen in den westlichen Industrienationen bezeichnen, im deutschen Kontext schon wegen der politischen Heterogenität der beteiligten Strömungen Missverständnisse provozieren.

Um aber das Vorfeld der entscheidenden Umbrüche der 1960er Jahre in den Griff zu bekommen, welche sich zum „soziomentale[n] Vulkanausbruch“721 von 1967/68 aufgebaut haben, empfiehlt es sich, noch einmal an der vielfach konstatierten politischen Katerstimmung der Nachkriegsjahre und der darauf folgenden Phase des wirtschaftlichen Wiederaufbaus sowie der - je nach Sichtweise und politischer Färbung - gesellschaftlichen „Restauration“ bzw. „Modernisierung“722 anzusetzen. Jugendliche und junge Erwachsene, zumal die Akademiker unter ihnen, waren gezeichnet vom Krieg ein Drittel von ihnen stammte etwa in Bremer Schulen aus einer „ausgebombten“ Familie $^{723}$-, litten am materiellen Elend, dem vielfachen Statusverlust der Elternhäuser und am ruinösen Zustand der im langsamen Wiederaufbau befindlichen Bildungsinstitutionen. ${ }^{724}$ In wenigen Jahren wurden die Tage der Wohnungsnot und des Hungers allerdings durch ein beispielloses wirtschaftliches Wachstum, durch eine breite Integration der Vertriebenen und Flüchtlinge und durch eine allgemeine Anhebung des Lebensstandards abgelöst. ${ }^{725}$ Wo der Nationalsozialismus noch die „Politisierung“ der Massen forcierte, herrschte nun die Direktive der - insbesondere materiellen „Normalisierung“ ${ }^{726}$ An den Universitäten und unter den zahlreicher werdenden Studierenden erblühte ein reges Interesse an der Restauration vermeintlicher kultureller Traditionen und an der geradezu realitätsabgewandt-intellektualisierten Suche nach Erkenntnis und Wahrheit, wo mancher Exilant des NS-Terrors eigentlich die Notwendigkeit einer Aufarbeitung der Vergangenheit gesehen hätte. ${ }^{727}$ Zwischen 1950 und 1960 wuchs die westdeutsche Bevölkerung, auch durch Wanderungsgewinne (durch Flüchtlinge und zurückkehrende Vertriebene), um ca. 11 Prozent, noch bis 1961/62 stieg die Heiratsneigung und sank das Heiratsalter infolge des Wirtschaftswachstums, die Arbeitslosenquote sank von 11 auf 1,3 Prozent; „Ordnungsliebe und Fleiß“ gerieten zu den

720 Vgl. Etzemüller, Thomas: 1968 - Ein Riss in der Geschichte? Gesellschaftlicher Umbruch und 68erBewegungen in Westdeutschland und Schweden, Konstanz 2005, S. 7.

721 Lorenz, Robert/Walter, Franz: 1968. Kulminationspunkt und politische Eruption, in: Dies. (Hg.): 1964. Das Jahr, mit dem „68“ begann, Bielefeld 2014, S. 327-372, hier S. 346.

722 Vgl. Schildt: Die Sozialgeschichte der BRD, S. $77 f$.

723 Kurz, Karl: Lebensverhältnisse der Nachkriegsjugend. Eine soziologische Studie, Bremen 1949, S. 115 .

724 Vgl. ibid., S. 114-118 und Jarausch: Deutsche Studenten, S. $214 \mathrm{f}$.

725 Vgl. Schildt: Die Sozialgeschichte der BRD, S. 12f. und S. $79 f$.

726 Vgl. ibid., S. 13.

727 Vgl. Jarausch: Deutsche Studenten, S. 214f. Aufschlussreich ist in diesem Zusammenhang auch die 1949 notierte Beobachtung Adornos, dass der „gespenstische Traditionalismus ohne bindende Tradition“ nur vor dem Hintergrund erdrückender Ohnmachtserfahrungen gegenüber den gesellschaftlichen Umwälzungen verständlich zu machen sei, s. Adorno, Theodor W.: Die auferstandene Kultur [1949], in: Ders.: Gesammelte Schriften in 20 Bänden, Bd. 20.2, Frankfurt a.M. 1997, S. 453464, hier S. 458 und 461. 
dominanten Erziehungsmaximen. ${ }^{728}$ Zudem verdrängte die Angestellten- und Beamtenschaft einer sich tertiarisierenden Arbeitswelt zunehmend die dörflich-agrarischen und proletarischen Milieus. ${ }^{729}$ Das sich in den 1950er Jahren verdoppelnde Bruttosozialprodukt hob das Wohlstandsniveau für alle gesellschaftlichen Schichten an, verlängerte aber auch schrittweise die Arbeitszeiten; Einkommen wurden einerseits immer häufiger gespart, andererseits zunehmend für die fortschreitende Automobilisierung, Massenmediatisierung durch Radio und Zeitung ${ }^{730}$, aber auch für die Ausgestaltung der Freizeit und des häuslichen und familiären Raums verausgabt. ${ }^{731}$ Als mentalitäre Begleiterscheinungen dieser Entwicklungen wurden mehrfach der Rückzug der Orientierungen und Werthaltungen der Bevölkerung in die private Sphäre und in Pragmatismus, ferner der mehrheitliche Verzicht auf politische Betätigung, Parteibindung oder Aktivismus insbesondere in den Reihen Jugend festgestellt. ${ }^{732}$ Politische Initiativen vonseiten der Nachkriegsstudierenden ${ }^{733}$ blieben tatsächlich weitgehend lokal begrenzt. Zwar hatte es 1958 durchaus eine studentische Protestwelle gegeben (im April demonstrierten 5.000 Studierende der FU Berlin), die sich im Geiste der Friedensbewegung gegen die deutsche Wiederbewaffnung und gegen die militärische Nutzung der Atomkraft; langfristige Ausdauer aber war ihr nicht beschieden. ${ }^{734}$ Insgesamt ist bei einem großen Teil der Studierenden der 1950er Jahre ein starker antikommunistischer Zug auszumachen, der sich in die politischen Mehrheitsverhältnisse der Adenauer-Ära einpasste; der Konflikt zwischen „Links“ und „Rechts“ wurde vornehmlich am Gegenstand der Westbindungspolitik ausgetragen. ${ }^{735}$ Bestandteil einer bereits in den 1950er

728 Vgl. Schildt: Die Sozialgeschichte der BRD, S. 13-20.

729 Vgl. ibid., S. 20-22.

730 „Den größten Teil der frei disponiblen Zeit nahm der Medienkonsum in Anspruch. Es wurde immer mehr Zeit für die Lektüre der Tageszeitung verwandt, die während der 1950er Jahre [...] endgültig zum Massenmedium wurde. [...] Dies entsprach der ubiquitären Durchsetzung des Hörfunks, der geradezu als ,Hegemon der häuslichen Freizeit' fungierte." Ibid., S. 26.

731 Vgl. ibid., S. 22-28.

732 Vgl. Schelsky: Die skeptische Generation, S. 74 und Jarausch: Deutsche Studenten, S. 213.

733 Zu nennen wäre etwa die als „Schlüter-Affäre“ bekannte Berufung des rechtsradikal gesinnten Leonhard Schlüter (FDP) zum niedersächsischen Kultusminister im Jahr 1955. Auf sie folgte eine Welle der Erregung in der akademischen Öffentlichkeit ausgehend von der Universität Göttingen, die zu seinem Rücktritt führte. Die lokale Studentenschaft unterstützte damals die aus Protest zurückgetretene Universitätsleitung und veranstaltete einen Fackelzug, auch der AStA trat selbst zurück. Vgl. Szabó, Anikó: Vertreibung. Rückkehr. Wiedergutmachung. Göttinger Hochschullehrer im Schatten des Nationalsozialismus, Göttingen 2000, S. 286-312, zur Rolle der Studierenden auch Nentwig, Teresa: „Kultusminister der vierzehn Tage“. Der Skandal um Leonhard Schlüter 1955, in: Walter, Franz/Nentwig, Teresa (Hg.): Das gekränkte Gänseliesel. 250 Jahre Skandalgeschichten in Göttingen, Göttingen 2015, S. 126-138, hier S. 132.

734 „In den späten fünfziger Jahren bildete sich dann aber eine breite studentische Bewegung gegen Atomwaffen heraus, von der der ,Göttinger Appell' der Professoren durch ASTA-Resolutionen und Petitionen (Heidelberg) unterstützt wurde. Am 20. Mai 1958 demonstrierten Tausende von Studenten an vierzehn westdeutschen Hochschulen gegen den ,Atomtod' trotz der Distanzierung des RCDS. Aber diese Protestwelle verebbte bald wieder." Jarausch: Deutsche Studenten, S. 222. Vgl. auch Schlicht: Vom Burschenschafter bis zum Sponti, S. $50 f$.

Vgl. Jarausch: Deutsche Studenten, S. $221 \mathrm{f}$. 
und frühen 1960er Jahren herausgebildeten Protestkultur in der Bundesrepublik ${ }^{736}$ waren die Studierenden dennoch, trugen sie doch zur Vorbereitung der 1960 erstmals auftretenden Ostermärsche bei, die allerdings auch stark von SPD, Gewerkschaften, evangelischen Christen und arrivierten Akademikern getragen waren. ${ }^{737}$

Bereits in den frühen 1960er Jahren hatte sich also eine "verbürgerlichte“ Mittelstands- bzw. Mittelschichtsgesellschaft herausgebildet, ${ }^{738}$ die kaum noch Ähnlichkeiten mit den klassengesellschaftlichen Verhältnissen des frühen 20. Jahrhunderts aufwies. Massenkonsum, Massenmotorisierung, Unterhaltungsindustrie und Massentourismus nach US-amerikanischem Vorbild bildeten sich heraus. ${ }^{739}$ Das durchschnittliche Nettoeinkommen der Arbeitnehmer, das sich zwischen 1950 und 1960 bereits um 70 Prozent erhöht hatte, verdoppelte sich bis 1970 ein weiteres Mal. ${ }^{740}$ Die Universitäten entwickelten sich, wie weiter oben bereits erwähnt ${ }^{741}$, allmählich $\mathrm{zu}$ einem der entscheidenden Aufstiegsmotoren, abzulesen am Anstieg der Studierendenzahl: Zwischen 1948 und 1960/61 verdoppelte diese sich von 123.000 auf 206.500. ${ }^{742}$ Die Studierenden der späten 1960er Jahre sind Kinder dieser gesamtgesellschaftlichen Aufstiegsperiode, die im Verlauf des Jahrzehnts durch die weitere Tertiarisierung der Erwerbstätigkeit und durch eine Absenkung der Arbeitszeit noch einmal an Zugkraft gewann. ${ }^{743}$ In politkultureller Hinsicht aber sahen sie sich noch immer eher rückständigen Gepflogenheiten gegenüber. $\mathrm{Zu}$ ihren wesentlichen Sozialisationserfahrungen gehörten zwar materielle Sekurität, ansteigende Bildungschancen, aber auch ein (wenn auch im Vergleich zu vorigen Jahrzehnten sanfterer) Wertetraditionalismus der Elterngeneration nebst rigider Sexualmoral ebenso wie der als erlahmt empfundene politische Wettbewerb der „Adenauer-Republik“. ${ }^{744}$ Viele von ihnen empfanden die gesellschaftlichen Verhältnisse schon früh als verkrustet, beengend und durchzogen von „spiritueller Leere“; vermöge der durch sie provozierten „latenten Sinnsuche“ bildete der Wohlstandsschub somit geradezu „die Grundlage“ der „späteren Protestbereitschaft" ${ }^{\text {"755 }}$, die Mobilisierungsbasis der späteren Politisierung und oppositionellen Regungen. Allmähliche kulturelle Liberalisierungstendenzen begünstigten das gesellschaftskritische Selbstbewusstsein: So ist schon für das Jahr 1964 ein „Konglomerat

736 Zu nennen sind hier neben der Friedensbewegung und der popkulturell beeinflussten Jugendprotest der „Halbstarkenkrawalle" auch die Arbeiterproteste in der frühen Bundesrepublik, etwa der Schweigemarsch der Ruhrkumpel durch Bonn am 26. September 1959, an dem ca. 60.000 Teilnehmer, die sich als Modernisierungsverlierer des Wirtschaftswunders empfanden, gegen den Rückbau der Kohleindustrie demonstrierten. Vgl. Gassert: Bewegte Gesellschaft, S. 94-102.

737 Vgl. ibid., S. 78-90 und Etzemüller: Ein Riss in der Ceschichte?, S. 20-22.

738 Vgl. Schildt: Die Sozialgeschichte der BRD, S. 31f.; Wehler: Deutsche Cesellschaftsgeschichte 19451990, S. 194 und Krause et al.: Zwischen Revolution und Resignation?, S. 19. Ruppert, Wolfgang: Zur Konsumwelt der 6oer Jahre, in: Schildt, Axel/Siegfried, Detlef/Lammers, Karl Christian (Hg.): Dynamische Zeiten: die 6oer Jahre in den beiden deutschen Cesellschaften. Hamburger Beiträge zur Sozial- und Zeitgeschichte, Bd. 37, Hamburg 2000, S. 752-767.

740 Vgl. Schildt: Die Sozialgeschichte der BRD, S. 41.

741 Vgl. Kapitel II.1 dieser Studie.

742 Vgl. Jarausch: Deutsche Studenten, S. 215.

743 Vgl. Schildt: Die Sozialgeschichte der BRD, S. 40.

744 Vgl. Lorenz/Walter: 1968. Kulminationspunkt und politische Eruption, S. 354-359.

745 Ibid., S. 356. 
gesellschaftlicher Modernisierung “746 auszumachen, welches sich sowohl in behutsam wachsender parteipolitischer Öffnung (in ostpolitischer Hinsicht, aber auch im Sinne der Erschließung breiterer Wählerschichten), in stärkerer kultureller, moralischer und sexueller Aufgeschlossenheit geltend machte, als auch in der verbreiteten Einforderung bildungspolitischer, institutioneller und sozialer Reformen inmitten eines „Modernitätsrückstands" (Dahrendorf) ${ }^{747}$, ferner in einer wachsenden Sensibilität und medialen Aufmerksamkeit für die nationalsozialistischen Verbrechen und Elitenkontinuitäten in der Bundesrepublik infolge von Gerichtsverfahren gegen SS-Angehörige, überhaupt die Herausbildung eines kritischen Selbstverständnisses journalistischer Berichterstattung. ${ }^{748}$ Hinzu traten Schlüsselereignisse, die das Entstehen einer linksgerichteten Protestkultur begünstigten: so etwa die medial visualisierte Brutalität des 1964 beginnenden Vietnamkrieges und die von der Großen Koalition vorbereitete, aber bis 1968 verschobene Verabschiedung der Notstandsgesetze trafen auf „die weitverbreitete Wahrnehmung weltanschaulich homogenisierter Parteien und entradikalisierter Gewerkschaften, die eine Leerstelle für fundamentalkritische Konzepte für Gesellschaft und politisches System hinterließen. ${ }^{\text {“749 }}$

Soweit jedenfalls die soziomentale Gemengelage von „1968“, die dem parallel zur Koalition aus SPD und FDP verlaufenden „sozialliberalen Umschwung der ,neuen Mittelschichten ${ }^{\text {“750 }}$ Vorschub leistete. Die heute mit dieser Jahreszahl assoziierte Bewegung um den Sozialistischen Deutschen Studentenbund (SDS) und die Außerparlamentarische Opposition (APO) konstituierte sich in den frühen 1960er Jahren aus drei maßgeblichen Protestimpulsen und den sie tragenden Organisationsnetzwerken: der für atomare Abrüstung optierenden Ostermarschbewegung, den Protesten gegen die $a b$ 1960 diskutierte Grundgesetzänderung (Notstandsgesetzgebung) und die beginnende eigentliche Studentenbewegung um den 1961 von der SPD ausgeschlossenen SDS. ${ }^{751}$ „Die Notstandsgesetze bildeten das ,Achsenthema der Außerparlamentarischen Opposition, um welches herum sich die drei Teilbewegungen zu einer sozialen Bewegung formierten. ${ }^{4752}$ Der SDS ist dabei insbesondere in den Jahren 1967 und 1968 als jener

746 Lorenz, Robert/Walter, Franz: 1964. Anfänge des tiefgreifenden gesellschaftlichen Wandels, in: Dies. (Hg.): 1964. Das Jahr, mit dem „68“ begann, Bielefeld 2014, S. 9-31, hier S. 9.

747 Zit. nach ibid., S. 27.

748 Vgl. ibid., S. 12-29, insbesondere S. 15 sowie die etwas oberflächliche, aber ausgewogene Darstellung der "68er" und der Genese des antifaschistischen Selbstverständnisses der Außerparlamentarischen Opposition (APO) aus der Protestkultur der 1950er und 1960er Jahre in Frei: 1968, S. 79-88.

749 Lorenz/Walter: 1964. Anfänge, S. 24f.

750 Krause et al.: Zwischen Revolution und Resignation?, S. 22.

751 Richter, Pavel A.: Die Außerparlamentarische Opposition in der Bundesrepublik Deutschland 1966 bis 1968, in: Gilcher-Holtey, Ingrid (Hg.): 1968. Vom Ereignis zum Gegenstand der Geschichtswissenschaft. Geschichte und Gesellschaft, Sonderheft 17, Göttingen 1998, S. 35-55, hier S. 37-41.

752 Ibid., S. 36. „Sowohl die Ostermarschbewegung/Kampagne für Abrüstung als auch die Studentenbewegung bearbeiteten im Verlauf der sechziger Jahre - teils parallel, teils sequentiell - eine Vielzahl unterschiedlichster Themen, von der Hochschulreform bis zur atomaren Rüstung, vom Vietnamkrieg bis zur Macht des Pressekonzerns von Axel Springer. Indes, nur im gemeinsamen Kampf gegen die Notstandsgesetze kam es zu einem erfolgreichen Aufbau und Erhalt eines, durch kollektive Identitä abgestützten Handlungssystems'.“ Ibid., S. 36f. (Herv. i. O.) 
organisatorischer Nukleus der APO aufzufassen, der die öffentlich wirksamen Köpfe (v. a. Rudi Dutschke) hervorbrachte und die griffigen Slogans produzierte („Außerparlamentarische Opposition“, „langer Marsch durch die Institutionen“, „gezielte Regelverletzung“) oder popularisierte („Große Weigerung“), der den marxistisch begründeten internationalen Anschluss an „Freiheitskämpfe“ und Emanzipationsbewegungen die voluminösen antiparlamentarisch-fundamentaloppositionellen Philippiken auf den überkommenen gesellschaftlichen status quo formulierte.

Doch die Evolution des lange Zeit hindurch eher innerparlamentarisch und theorielastig denkenden SDS zum zentralen Träger der Studentenbewegung war teils Produkt verschiedener Ereignisse, teils Ergebnis einer gezielten organisatorischen Umbildung durch die antiautoritäre „Subversive Aktion“ um Rudi Dutschke und andere. Zwischen 1948 und 1961 hatte der SDS zunächst als Hochschulverband der SPD fungiert; als die sozialdemokratische Partei infolge der unbefriedigenden Bundestagswahlergebnisse von 1953 verstärkt in Richtung Regierungsfähigkeit drängte und 1959 das hinsichtlich der einstigen sozialistischen Prinzipien weitgehend revisionistische Godesberger Programm beschloss, wuchsen jedoch die wechselseitigen Spannungen. Der SDS sah das geringe Wählerecho nicht in einer mangelnden Attraktivität für bürgerliche Milieus, sondern gerade in einer „zu wenig sozialistisch[en]“ und „zu wenig revolutionär[en]“ Ausrichtung begründet, und torpedierte den Kurs der Mutterpartei. ${ }^{753}$ Eine emotionalisierte Diskussion um die dem SDS vorgeworfene sympathisierende Haltung zum DDR-Kommunismus im Vorfeld des Mauerbau-Jahres $1961^{754}$ ließ die Friktionen eskalieren: 1960 spaltete sich erst der parteitreuere Sozialdemokratische Hochschulbund (SHB) vom SDS ab, 1961 verabschiedete die SPD trotz beschwichtigender Signale seitens des SDS einen Unvereinbarkeitsbeschluss, der den Studentenverband vor die Tür setzte. ${ }^{755}$ In diesem Vorgang wurzelte die besondere, anfänglich lähmende, Juxtaposition der immer auch um gesellschaftsanalytische Fundierung ihrer Kritik ringenden ${ }^{756}$ SDS-Sozialisten zwischen nun als kompromittiert empfundener Sozialdemokratie und parteikommunistischer Diktatur. Ein legitimer parlamentarischer Agent linker Politik existierte für sie nicht mehr. ${ }^{757}$ Der SDS rang in der Folge um eine theoretisch fundierte Selbstverortung: Wie eine fundamentale linke Kritik an Demokratie und Gesellschaft möglich sein könnte, die nicht sogleich den Pakt mit bestimmten Herrschaftsinteressen auf Kosten „der Arbeiterklasse“ schließt, und ob die adäquate Aktionsform zur Umgestaltung der Gesellschaft in „Reform“, „Revolte“ oder „Revolution“ liege, sollte die wenige

753 Fichter/Lönnendonker: Kleine Geschichte des SDS, S. $26 f$.

754 „Der Sozialistische Deutsche Studentenbund wurde unter den Studentenorganisationen der Schrittmacher auf dem Weg zu einer Aufwertung der Kommunisten, nicht, weil er ihnen besondere Sympathien entgegenbrachte, wie damals fälschlich angenommen wurde, sondern weil er keine andere Möglichkeit mehr sah, eine gesamtdeutsche Diskussion aufrechtzuerhalten." Schlicht: Vom Burschenschafter bis zum Sponti, S. 51 .

755 Vgl. Fichter/Lönnendonker: Kleine Geschichte des SDS, S. 68-72.

756 Der SDS veranstaltete seit den frühen 1950er Jahren Theorie-Diskussionen mit sozialistischen Intellektuellen, vgl. ibid., S. 23.

757 Vgl. Brückner, Peter: Paradoxien der „Protestbewegung“ [1973/74], in: Ders.: Zerstörung des Gehorsams. Aufsätze zur Politischen Psychologie, Berlin 1983, S. 86-108, hier S. 88. 
Jahre später intellektuelle und politische Suchbewegung antizipieren, die auch die spätere "Neue Linke“ (nicht nur) in Deutschland umtrieb. ${ }^{758}$

„Altlinks war der Arbeiterbewegungsmarxismus, der Primat der Ökonomie, der Kollektivismus, die Dogmatisierung des Erbes revolutionärer Theorie. [...] Bei den neulinken Essentials handelte es sich um direkte Gegenpositionen. [...] Neulinks wurde der altmarxistische Glaube an die Geschlossenheit der Bürokratie als Bürokratisierung kritisiert. Kritik der Macht, gerade auch Kritik der Machtstrukturen in linken Organisationen war das erste Essential. Zweitens: Neulinks war, Kultur als ein Feld politischer Kämpfe zu definieren, das der Tendenz nach wichtiger wurde als das Feld der Ökonomie. Drittens: Neulinks war, dem Marschkolonnenkollektivismus altlinken Typs einen libertären Individualismus und die Idee autonomer, sich selbst verwaltender Gruppen entgegenzusetzen. ${ }^{759}$

Trotz dezimierter finanzieller Ressourcen ${ }^{760}$ arbeitete man sich an derlei Fragen schon in den frühen 1960er Jahren förmlich ab. ${ }^{761}$ Es scheint gar, als hätte der Ausschluss aus der SPD erst recht das Bewusstsein einer kollektiv verpflichtenden politischen Aufgabe geweckt, da man sich sendungsbewusst „als einen Teil der internationalen Arbeiterbewegung" bzw. der internationalen Neuen Linken verstand und damit auch als Schrittmacher der Herstellung einer sozialistischen Demokratie. ${ }^{762}$ In dieser von praxisorientierten Kommentatoren später etwas verächtlich „seminarmarxistisch“763 ${ }^{4 i t u l i e r t e n}$ Phase befand sich der SDS bis etwa 1964:

„Die Diskussion im SDS in der Phase vom Unvereinbarkeitsbeschluß bis Ende 1964 kreiste immer wieder um die Probleme, welchen Standort und welche Funktion der sozialistischen Intelligenz in der Klassengesellschaft zukomme [sic] und ob Wissenschaft eine revolutionäre Produktivkraft sein könne. Dabei handelte es sich keineswegs um eine prägnante und bündige Argumentation, selbst in den Artikeln der nk [der neuen kritik, ]. S.] schweiften die Autoren vom Thema ab und ergingen sich z. B. zeitweise in Marx-Exegese. Die Frage: wie kann der SDS seine Zielgruppen, Studentenschaft und sozialwissenschaftliche und technische Intelligenz, mobilisieren und politisieren? wurde erst zaghaft gestellt und andiskutiert. ${ }^{4764}$

758 Vgl. Schmidtke, Michael A.: Reform, Revolte oder Revolution? Der Sozialistische Deutsche Studentenbund (SDS) und die Students for a Democratic Society (SDS) 1960-1970, in: Cilcher-Holtey, Ingrid (Hg.): 1968. Vom Ereignis zum Gegenstand der Geschichtswissenschaft. Geschichte und Gesellschaft, Sonderheft 17, Göttingen 1998, S. 188-206.

759 Eßbach: Aufstand der Werte?, S. 16.

760 Vgl. Richter: Die Außerparlamentarische Opposition, S. 41 und Bock: Ceschichte des, linken Radikalismus', S. 194.

761 Das bezeugen nicht nur das ab 1960 erschienene SDS-Organ neue kritik und die Diskussionen auf den weiterhin abgehaltenen Delegiertenkonferenzen, sondern auch der Gründungskongress der "Sozialistischen Förderer-Gesellschaft der Freunde, Förderer und ehemaligen Mitglieder des SDS" vom 08. Oktober 1961, auf dem sich die Referenten Wolfgang Abendroth, Ossip K. Flechtheim und Fritz Lamm über die Frage des Umgangs mit der demokratischen Ordnung und Verfassung auseinandersetzten. Vgl. Fichter/Lönnendonker: Kleine Geschichte des SDS, S. 72-78.

763 Fichter/Lönnendonker: Kleine Geschichte des SDS, S. 72.

764 Ibid., S. $77 f$. 
Die späteren großen Namen der Studentenbewegung - Rudi Dutschke, Bernd Rabehl und Dieter Kunzelmann - waren zu diesem Zeitpunkt noch nicht beteiligt: Sie gehörten damals der Gruppe „SPUR“ an, die sich als deutsche dépendance der Künstler- und Intellektuellengruppierung „Situationistische Internationale“ (S. I. ${ }^{765}$ verstand; Dutschke und Rabehl ab 1963 der „Subversiven Aktion“, welche den Akzent gerade auf „Aktionsfähigkeit" und kleinere antiautoritäre Protestaktionen setzte. ${ }^{766}$ Diese theoretisch und praktisch aktive Gruppe stieß erst im Januar 1965 zum SDS, als Pläne zur Unterwanderung des SDS am Widerstand von Münchner Aktivisten der Subversiven Aktion um Dieter Kunzelmann und Frank Böckelmann scheiterten. ${ }^{767}$ Von Strömungen der „New Left" in den USA und Großbritannien sowie der „Nouvelle Gauche“ in Frankreich inspiriert, ${ }^{768}$ verstand sich der SDS nun zunehmend als studentischer Verband der „Neuen Linken“ und ihrer „radikale[n] Neuinterpretation sozialistischer Politikkonzepte“. Der Dissens in Fragen theoretischer Analyse, politischer Ziele und praktischer Strategien aber blieb ein für den SDS konstitutives Spannungsfeld; dieser zerfiel auch in den Phasen seiner stärksten Kohäsion in einen linkssozialistischen bzw. „traditionalistischen“ und in einen antiautoritären Flügel, wenn sich auch letzterer schließlich durchsetzen sollte. $^{769}$

In den Jahren 1964 und 1965 begannen verschiedene Teile des SDS, welcher aus seiner Selbstverortung als „Neue Linke“ ein neues Selbstbewusstsein schöpfen konnte, ${ }^{770}$ sich als „Vertreter der Interessen nicht nur der sozialistischen Studenten, sondern aller nichtprivilegierten Mitglieder der Universität" zu begreifen und suchten nach Wegen breiter angelegter Mobilisierung: ${ }^{771}$

„Die abstrakt geführte Strategiedebatte der Neuen Linken wurde im SDS tendenziell seit 1965 verdrängt durch Auseinandersetzungen über Fragen der Taktik und der Organisation, die aus den wachsenden praktischen Differenzen zwischen der Verbandsspitze, der Mehrheit des Frankfurter Bundesvorstandes und einer anfänglichen Minderheit im Berliner Landesverband entstanden. ${ }^{\text {"772 }}$

Man stritt u. a. über die zuvor weitestgehend als zentral verhandelte „aktiv-stimulierende“ Avantgarderolle der Intellektuellen für das Wiederaufflammen einer sozialistischen

765 Vgl. Gilcher-Holtey, Ingrid: „Die Phantasie an die Macht“. Mai 68 in Frankreich, Frankfurt a.M. 1995, S. 73-81.

766 Vgl. Fichter/Lönnendonker: Kleine Geschichte des SDS, S. 78-81, auch Bock: Geschichte des ,linken Radikalismus', S. 205.

767 Vgl. Fichter/Lönnendonker: Kleine Geschichte des SDS, S. 81 und 91.

768 Vgl. Schmidtke: Reform, Revolte oder Revolution? und Gilcher-Holtey: „Die Phantasie an die Macht", S. 96-104.

769 Richter: Die Außerparlamentarische Opposition, S. 41. Erhellend ist auch die nüchterne Darstellung von Bock: „Die in der SDS-Diskussion zur Strategie der Neuen Linken sich abzeichnenden Positionen lassen sich in die Geschichte des SDS einordnen als Übergangsstufe von der linkssozialistischen Fixierung der anfänglichen sozialdemokratischen Opposition des Verbandes zu seinem späteren mehrheitlichen antiautoritären Selbstverständnis." Bock: Ceschichte des ,linken Radikalismus', S. 205.

770 Vgl. Richter: Die Aueßrparlamentarische Opposition, S. 41.

771 Fichter/Lönnendonker: Kleine Geschichte des SDS, S. 78.

772 Bock: Geschichte des, linken Radikalismus', S. 205. 
Massenbewegung (der wesentliche Inhalt der bis hierhin geführten und von vielen Beteiligten mittlerweile als fruchtlos wahrgenommenen „Strategiediskussionen“) im Kontrast zu stärker spontan agierenden single purpose movements nach US-amerikanischem Vorbild. ${ }^{773}$

Bei diesem umkämpften Drang nach außen kam dem SDS neben dem ohnehin bestehenden Erregungspotenzial durch Notstandsgesetzgebung, Vietnamkrieg, Westbindung und unzureichend verfolgte NS-Verbrechen bzw. altnationalsozialistische Elitenkontinuität die gestiegene Sensibilität der Studierenden gegenüber der hochschulpolitischen Situation, insbesondere der Belastung der Studiengänge durch steigende Studierendenzahlen, zupass. Bereits im Rahmen der Hochschulreformdiskussion von 1961 hatte der SDS mithilfe der institutionellen Unterstützung des jüngst außerordentlicher Professor gewordenen Jürgen Habermas eine Denkschrift herausgegeben, die auf der gesellschaftlichen Einbettung der Hochschule und der daraus folgenden Notwendigkeit einer „Demokratisierung der Gesellschaft“ durch eine angemessene Hochschulreformpolitik insistierte. ${ }^{774}$ Aber als die Schrift 1965 unter demselben Titel und von denselben Autoren neu aufgelegt wurde, ${ }^{775}$ traf sie auf ein deutlich verändertes politisches Klima unter den Studierenden. Bereits im Sommer 1965 gelang mit der vom Verband Deutscher Studentenschaften (VDS) getragenen „Aktion 1. Juli - Bildung in Deutschland“ eine umfänglicher dezentraler Aktionstag mit insgesamt über 50.000 Demonstrierenden in der Bundesrepublik und Westberlin - deutlich mehr als bei den zeitgleich stattfindenden Demonstrationen gegen den Vietnamkrieg, gegen „Imperialismus“ und „Kolonialismus“, aber auch gegen einen NPD-Parteitag in Karlsruhe $1966 .{ }^{776}$ Die überregional vernetzte Kritik am Vietnamkrieg und an der Notstandsgesetzgebung machte sich in entsprechenden Veranstaltungen geltend: Kongresse fanden 1965 und 1966 statt; insbesondere die Gravitationskraft des Vietnamkongress vom 22. Mai 1966 in Frankfurt a.M. ist an der Besetzung der Referentinnen und Referenten abzulesen, zu denen u. a. Herbert Marcuse, Oskar Negt, Wolfgang Abendroth, Frank Deppe und Jürgen Habermas zählten. ${ }^{777}$

Trotzdem blieb der Aktionsschwerpunkt der Studentenbewegung zwischen 1964 und 1967 auf den Westberliner SDS und die durch ihn politisierten Studierenden, „die Lokomotive der Revolte ${ }^{4778}$, beschränkt. Berlin war, insbesondere in den Jahren 1965, 1966 und 1967, eines der entscheidenden Zentren der deutschen „68er“-Bewegung. Möglich war das durch besondere lokale Bedingungen geworden: dazu zählen der durch Kontakte mit der damaligen DDR-Realität frühzeitig geschwächte Antikommunismus - man war „an der Schnittstelle von zwei konkurrierenden Gesellschaftsmodellen“779 -,

773 Ibid.

774 Bauß: Die Studentenbewegung der sechziger Jahre, S. 228-236.

775 Vgl. Nitsch, Wolfgang/Gerhardt, Uta/Offe, Claus/Preuß, Ulrich K.: Hochschule in der Demokratie. Kritische Beiträge zur Erbschaft und Reform der deutschen Universität, Berlin/Neuwied am Rhein 1965.

776 Vgl. Bauß: Die Studentenbewegung der sechziger Jahre, S. $29 f$.

777 Vgl. Fichter/Lönnendonker: Kleine Geschichte des SDS, S. 88-97.

778 Ibid., S. 85.

779 Michels, Eckard: Schahbesuch 1967. Fanal für die Studentenbewegung, Berlin 2017. 
eine vorherrschende pazifistische Grundhaltung bei ausgesetzter Wehrpflicht, die besonderen Bedingungen des „Berliner Modells“, aber auch die dortige Dominanz des auf Popularisierung zielenden antiautoritären Flügels um die Subversive Aktion ermöglichten die Herausbildung eines starken SDS-Aktionszentrums. ${ }^{780}$ Nur aus diesen Bedingungen heraus sind die politische Sensibilität der Berliner Studierenden für deutschlandpolitische Fragen sowie die vergleichsweise reputierliche Sonderstellung des Berliner SDS zu verstehen: 1959 initiierte letzterer - lange bevor derartige Themen öffentlich breit diskutiert wurden - maßgeblich die von verschiedenen Ortsgruppen getragene Wanderausstellung Ungesühnte Nazijustiz, die die anstehende Verjährung von NS-Verbrechen skandalisierte; im Sommersemester 1965 geriet er mit der Leitung der FU Berlin wiederholt öffentlichkeitswirksam aneinander, als der damalige Rektor der FU Berlin Herbert Lüers ein Redeverbot für den Journalisten Erich Kuby, einen Kritiker der damaligen DDR-feindlichen Deutschlandpolitik, erließ ${ }^{781}$ Unter Berufung auf einen Slogan von Aktivisten der Universität Berkeley forderten Studierende der FU Berlin: „Jedermann zu jedem Thema und zu jeder Zeit hören und mit ihm darüber diskutieren können." Sie organisierten eine Protestkundgebung und sammelten ca. $3.000 \mathrm{stu}$ dentische Unterschriften: „Das war der Anfang der Studentenbewegung ${ }^{472}$ - denn der Konflikt hatte in den Augen der Studierendenschaft zu einem dramatischen Legitimitätsverlust der autoritär handelnden Hochschulleitung geführt. ${ }^{783}$ Ein wachsender Teil der Studierenden an der FU Berlin neigte daher dazu, anders als bei früheren Auseinandersetzungen mit der Hochschulleitung, „die Universitäts- und Studienprobleme in ihren strukturellen Zusammenhängen zu sehen. ${ }^{\text {“784 }}$ Sie waren bereit, in ihnen pars pro toto grundsätzliche Missstände der westdeutschen Demokratie zu erkennen. Schließlich hatte man praktische Erfahrungen gesammelt und aufsehenerregende Rückschläge erlitten, da die studentischen Vertreter des „Berliner Modells“

„durch die bescheidenen, aber dennoch in dieser Form einzigartigen Partizipationsrechte in den Universitätsgremien den Widerspruch zwischen ihren Cestaltungswünschen und der Ordinarienallmacht leibhaftig erfahren und die daraus resultierenden Reibungsflächen stets auch ihren Kommilitionen vor Augen geführt ${ }^{\text {“785 }}$

780 Vgl. Fichter/Lönnendonker: Kleine Geschichte des SDS, S. 85-88 und Bauß: Die Studentenbewegung der sechziger Jahre, S. 44-51.

781 Schlicht: Vom Burschenschafter bis zum Sponti, S. 53-55 und Fichter/Lönnendonker: Kleine Geschichte des SDS, S. $88 f$.

782 Schlicht: Vom Burschenschafter bis zum Sponti, S. 54.

783 Vgl. Friedeburg: Freie Universität und politisches Potential der Studenten, S. 279-310. Weiter verschärft wurden die Auseinandersetzungen des Sommersemesters 1965 durch die heftige Zurechtweisung von Ekkehart Krippendorff, einem wissenschaftlichen Assistenten der FU, welcher fälschlicherweise behauptete, die Einladung des im Schweizer Exil lebenden Philosophen Karl Jaspers sei aufgrund politischer Motive der Hochschulleitung zurückgezogen worden, durch Rektor Lüers. Wie Krippendorff später korrigierte, hatte Jaspers die Einladung aus gesundheitlichen Cründen abgelehnt - dennoch erschien das Handeln der Hochschulleitung vielen als Verstoß gegen die selbstverordnete demokratisch kontrollierte Konfliktkultur der FU. Ibid.

784 Ibid., S. 311 und 320.

785 Krause et al.: Zwischen Revolution und Resignation?, S. 28. 
bekamen. Bereits 1965 hatte es ein SDS-dominierter AStA vorübergehend zur Mehrheit im Studierendenparlament (in Berlin Konvent genannt), gebracht. Der erste sit-in Deutschlands fand ebendort am 22. Juni 1966 statt und wurde mit Disziplinarmaßnahmen beantwortet, ein weiterer am 19. April 1967 mit einem Polizeieinsatz. ${ }^{786}$ Hier lässt sich nachvollziehen, dass hochschulpolitische und allgemeinpolitische Zielsetzungen den Beteiligten insbesondere nach dem 02. Juni 1967 als verklammerte Problemstellungen, ja als ein und dieselbe Aufgabe erscheinen konnten. ${ }^{787}$ Bildungsreform und Demokratisierung der Gesellschaft (nicht nur der staatlichen Institutionen ${ }^{788}$ ), trotz teils heftigen Auseinandersetzungen zwischen den Konzepten „traditionalistischer" und „sozialistischer" Universitätsideale ${ }^{789}$ explizit auch als Einlösung einer zeitgemäßen Ausprägung einer „ursprünglichen“ Idee der Universität gedacht, wurden bis Ende des Jahres 1966 von einem wachsenden Teil der Studierenden als zwei Seiten derselben Medaille aufgefasst ${ }^{790}$ - und als Anlass praktischer Betätigung in einer Situation allgemein anerkannter Reformnotwendigkeiten, aber weitgehend konsequenzlosen „permanenten Vertröstungen“. ${ }^{791}$

Den verblüffenden allgemeinen Mentalitätsumschwung in der deutschen Studierendenschaft aber erklärt der starke Berliner Nukleus alleine nicht: Noch bis Mitte der 1950er Jahre stimmten die deutschen Studierendenverbände mit der Politik der regierenden CDU, in geringerem Maße der SPD, überein; ${ }^{792}$ dementsprechend war die von Boris Spix ausgemachte - wenn auch wenig erfolgreiche - erste studentische Politisierungswelle nach 1945 konservativ-national ausgerichtet und zielte zwischen 1957 und 1963/65, etwa mithilfe von Solidaritätssammlungen und ritualisierten Feiern zum 17. Juni (seit 1954 bundesrepublikanischer „Tag der Deutschen Einheit“ zum Gedenken an den Aufstand vom 17. Juni 1953 in der DDR), auf den deutschen Gesamtstaat. ${ }^{793}$ Auch die erste Hälfte der 1960er Jahre hindurch blieb das Gros der studentischen Selbstverwaltung in Bundesrepublik und Westberlin überdies in den Händen von Korporationen und RCDS. ${ }^{794}$ Auch die Burschenschaften waren trotz wiederholter Existenzkämpfe und der historischen Erblast antiliberaler Traditionen noch keineswegs ausgeblutet: Am 12. Juni 1965 erschienen zu einem Festkommers (einer großen Verbindungsfeier) anlässlich der 150-Jahr-Feier der Deutschen Burschenschaft in Berlin immerhin 5.000 Teilnehmer. ${ }^{795}$ Offenkundig aber hatte der subkutane mentalitäre Gärungsprozess der deutschen Studierendenschaft in der Phase zwischen 1964 und 1967 seinen Umschlagspunkt erreicht. Schon 1965 war die Ära der rechtsdominierten Studierendenschaft an der FU

786 Vgl. Bauß: Die Studentenbewegung der sechziger Jahre, S. 248-253.

787 Vgl. ibid., S. 402.

788 Vgl. Schlicht: Vom Burschenschafter bis zum Sponti, S. $90 f$.

789 Vgl. Bauß: Die Studentenbewegung der sechziger Jahre, S. 283-239.

790 Vgl. Friedeburg: Freie Universität und politisches Potential der Studenten, S. 340f.

791 Bauß: Die Studentenbewegung der sechziger Jahre, S. 254.

792 Vgl. Schlicht: Vom Burschenschafter bis zum Sponti, S. 49.

793 Vgl. Spix: Abschied vom Elfenbeinturm?, S. 336-341.

794 Vgl. Fichter/Lönnendonker: Kleine Geschichte des SDS, S. 81.

795 Vgl. Lönnecker, Harald: Vorwort, in: Ders. (Hg.): „Deutschland immer gedient zu haben ist unser höchstes Lob!“ Zweihundert Jahre Deutsche Burschenschaften. Eine Festschrift zur 200. Wiederkehr des Gründungstages der Burschenschaft am 12. Juni 1815 in Jena, VII-XIV. Heidelberg 2015, S. XI. 
Berlin beendet: „Jeder, der sich [...] gegen die Politik des [vom SDS dominierten, J. S.] AStA ausgesprochen hätte, wäre damit als Gegner der studentischen Interessen und objektiver Agent der Ordinarienuniversität entlarvt worden. “796 Für den bundesweiten „soziomentale[n] Vulkanausbruch“ der deutschen „68er“, also für das gelingende Entfachen des durch die Bündnispolitik der Neuen Linken mit den mobilisierungskräftigen „Einpunktbewegungen“ (Ostermärsche, Notstandsopposition, Jugend- und Studierendenverbände $)^{797}$ akkumulierte Mobilisierungspotenzial in weiteren Universitätsstädten der Bundesrepublik sorgte dann eine Reihe von auslösenden, verstärkenden und kollektivierend wirkenden Ereignissen insbesondere im Jahr $1967 .{ }^{798}$ Da sich das Kerngeschehen der durch diese Erfahrungen zusammengeschweißten Studentenbewegung auf den kurzen Zeitraum zwischen 1966 und 1968 konzentriert, lohnt sich ein näherer Blick auf die Abfolge der Ereignisse mit ihren integrierenden und spaltenden Situationen.

Zunächst: Als sich im September 1966 die Große Koalition aus CDU/CSU und SPD bildete, war in den Augen der gerade expandierenden Studentenbewegung jede Möglichkeit der „systemimmanenten“, d. h. parlamentarischen Durchsetzung linker Politik erloschen. ${ }^{799}$ Sie werteten den Oppositionsverzicht der Sozialdemokratischen Partei als „Indiz für den Funktionsverlust des Parlaments“ und als Schritt in Richtung eines autoritären Staates im Dienste des „kapitalistischen Herrschaftsapparates“, welcher die Entstehung von „Protestwählern“ begünstige und diese in die Arme der NPD treibe. ${ }^{800}$ Dazu gesellten sich besonders in Berlin zunehmende Zweifel an der Realisierbarkeit der Reformforderungen allein durch hochschulpolitische Arbeit: Radikaldemokratische und sozialistische Verbände drängten auf die „Erweiterung des politischen Potentials der Studentenschaft" und die Expansion in die Mehrheitsgesellschaft durch Kampagnen einer breit politisierten Studierendenschaft. ${ }^{801}$ Tatsächlich lässt sich für Mitte der 1960er Jahre von einem Linksruck in der deutschen Studierendenschaft sprechen, der eine lange Hegemonie von RCDS und Korporationen beendete. ${ }^{802}$

Aus dieser Verbindung von kollektiver Enttäuschung und neuem Mobilisierungspotenzial erwuchs die von Dutschke angeregte strategische Perspektive, eine außerparlamentarische Oppositionsbewegung, eben die APO, zu bilden. Konstitutiert war diese Bewegung ab Oktober 1966 mit der Gründung des Kuratoriums „Notstand der Demokratie“, das sich aus Vertretern der drei Teilbewegungen und von Gewerkschaf-

796 Ibid., S. 89.

797 Vgl. Richter: Die Außerparlamentarische Opposition, S. 44f.

798 Vgl. Lorenz/Walter: 1968. Kulminationspunkt, S. $346 \mathrm{f}$.

799 Vgl. Krause et al.: Revolution oder Resignation?, S. 28.

800 Bauß: Die Studentenbewegung der sechziger Jahre, S. 33-41.

801 „In dem Maße, in dem sich der plebiszitäre Charakter inneruniversitärer Aktionen verstärkte, nützten die politischen Studentenverbände auch das neue Potential kritisch gewordener Studenten für politische Aufklärung und demonstrative Stellungnahmen in der Öffentlichkeit." Friedeburg: Freie Universität und politisches Potential der Studenten, S. 342.

802 „Bis Mitte der 6oer Jahre war die überwiegende Mehrheit der studentischen Selbstverwaltungsgremien der Universitäten und Hochschulen West-Berlins und der Bundesrepublik fest in Händen der schlagenden Verbindungen und des RCDS." Fichter/Lönnendonker: Kleine Geschichte des SDS, S. 81 . 
ten zusammensetzte und regelmäßige Koordinations- und Planungstreffen abhielt. ${ }^{803}$ Dieses neue Netzwerk, das die Organisations- und Koordinationsressourcen der Ostermarschbewegung ${ }^{804}$ und der Notstandsopposition mit dem konzeptuellen Überbau der studentenbewegten Neuen Linken vermittelte, ${ }^{805}$ erwies sich als schlagkräftig und expansiv: Zwischen November 1966 und Februar 1967 gründeten sich lokale Aktionskomitees des Kuratoriums „Notstand der Demokratie“ in 80 deutschen Städten, bis Ende 1967 in insgesamt 150. Weitere Kundgebungen und Aktionen unter dem Dach der Kampagne gegen die Notstandsgesetzgebung waren ausgerechnet für den Juni 1967 geplant, als die strategische Planung durch eine neue Radikalisierungsdynamik über den Haufen geworfen werden sollte. ${ }^{806}$

Denn es ist insbesondere ein Datum gewesen, welches die Protagonistinnen und Protagonisten der Studentenbewegung am nachhaltigsten prägte, sei es als Trauma oder als Startschuss zu einer neuen Offensivität; ein Datum, dem in Deutschland am ehesten jener Zäsurcharakter zukommt, der für gewöhnlich mit dem Signum „1968“ identifiziert wird: der 02. Juni $1967 .{ }^{807}$ Die Teilnehmerinnen und Teilnehmer einer Demonstration gegen den Besuch des als oppressiven, ausbeuterischen und US-treuen Diktator wahrgenommenen ${ }^{808}$ iranischen Schahs Mohammad Reza Pahlavi in Berlin abgesehen vom „Schahfaktor“ eigentlich „eine in der zweiten Hälfte der sechziger Jahre durchaus übliche Bonner Einladung an einen Diktator aus der Dritten Welt“809 wurden an diesem Tag durch die mit unvergleichlicher Brutalität vorgehende Polizei eingekesselt und wiederholt physisch angegriffen; als trauriger Höhepunkt und Schlüsselereignis der Studentenbewegung fand die Erschießung des Studenten Benno Ohnesorg durch den Polizeiobermeister Karl-Heinz Kurras Eingang in die Geschichtsbücher. ${ }^{810}$ Nicht nur das Ereignis selbst, der von hinten getätigte Kopfschuss, sorgte für den eskalativen „Wendepunkt“ der Studentenbewegung, auch und ganz besonders die anschließende Verteidigung des polizeilichen Vorgehens durch Polizei, Berliner Senat und Abgeordnetenhaus ${ }^{811}$ sowie durch die Berliner Presse und BILD-Zeitung, welche die Studenten kriminalisierten und für den Vorfall verantwortlich machten:

803 Richter: Die Außerparlamentarische Opposition, S. 36.

804 Die Ostermärsche waren bereits in den Jahren zwischen 1961 und 1964 zu einer "Massenbewegung“ avanciert, vgl. Bebnowski, David: Die Ostermärsche und das Jahr 1964, in: Lorenz, Robert/Walter, Franz (Hg.): 1964. Das Jahr, mit dem "68"begann, Bielefeld 2014, S. 259-274, hier insbesondere S. 260 und 269-272.

805 Vgl. Richter: Die Außerparlamentarische Opposition., S. $45 f$.

806 Vgl. ibid., S. 47.

807 Vgl. zur Vorgeschichte, zum Kontext und zu den zeithistorisch oft vernachlässigten konkreten Ereignissen dieses Tages jüngst Michels: Schahbesuch 1967.

808 Vgl. Bauß: Die Studentenbewegung der sechziger Jahre, S. 52 und Michels: Schahbesuch 1967, S. 293.

809 Michels: Schahbesuch 1967, S. 14.

810 Vgl. ibid., S. 183-218. Erst sehr viel später wurde bekannt, dass Kurras bereits seit 1955 als „Inoffizieller Mitarbeiter" des DDR-Ministeriums für Staatssicherheit tätig und SED-Mitglied gewesen ist; ein direkter Mordauftrag konnte ihm gleichwohl nicht nachgewiesen werden. Vgl. o. V.: Verrat vor dem Schuss, in: DER SPIEGEL, H. 22/2009, S. 42-51. 
„Während der Totenfeier und des anschließenden Trauerkonduktes für ihren erschossenen Kommilitonen hörten die Studenten über Transistorradios, wie der SDS und andere linke Studentenverbände unter dem Beifall des gesamten Berliner Abgeordnetenhauses mit den Nazis gleichgesetzt wurden. ${ }^{\text {8812 }}$

In den darauffolgenden Tagen reagierte die westdeutsche und Westberliner Studierendenschaft mit einer breiten Solidarisierungswelle. Der „Funke der Rebellion“ sprang auf andere Universitätsstädte über, studentische Zeitschriften veröffentlichten Sonderausgaben zum Thema, studentische Verbände unterschrieben gemeinsame Erklärungen; allein in der Woche vom 02. bis 09. Juni demonstrierten über 100.000 Studierende auf den Straßen der Bundesrepublik im Rahmen von Kundgebungen, Schweigemärschen und Protestversammlungen ${ }^{813}$ - so etwa in Frankfurt ca. 8.000 Studenten, in Köln ca. 6.000 Studenten, in Aachen, Düsseldorf, Hamburg und Kiel jeweils ca. 2.000. ${ }^{814}$ Kurze Zeit später sekundierten auch Gewerkschafter, Betriebsräte, überdies Schriftsteller wie Hans Magnus Enzensberger und Günter Grass der Studentenbewegung und erklärten ihre - zumindest anlassbezogene - Solidarität. Selbst vorherige Kritiker der Studentenbewegung und des SDS erkannten erstmals deren Anspruch als „Sprecher der gesamten Studentenschaft“ an. ${ }^{815}$ Der APO wiederum erschien der 02. Juni als antizipatives Ereignis eines ohnehin heraufdämmernden Polizeistaates, als „manöverartige Vorwegnahme der antidemokratischen Notstandsgesetze “ ${ }^{816}$ deren erste Lesung im Bundestag für das Monatsende avisiert war. ${ }^{817}$ Für viele war das die Bestätigung einer schon 1966 diagnostizierten „Entdemokratisierung“ der Bundesrepublik, ${ }^{818}$ auch Zeugnis eines durch die staatliche Exekutive einseitig aufgekündigten Gewaltverzichts, der in der Folge die Frage nach der Legitimität militanter Aktionsmethoden vonseiten der Oppositionellen provozierte. ${ }^{819}$ Auch beschuldigte man den bereits zuvor als politischen Gegner bekämpften Springer-Konzern mitsamt der von ihm herausgegebenen BILD-Zeitung, das den Vorfall begünstigende „faschistoide“ politische Klima geschaffen $\mathrm{zu}$ haben, und forderte dessen Enteignung - eine neue Kampagne entsprang bis Anfang 1968 daraus: ${ }^{820}$

„Die Verbreitung einer Pogromstimmung gegen die protestierenden Studenten durch die Boulevardzeitungen des Springer-Konzerns, in welchem viele politische Aktivisten den eigentlichen Schuldigen für die Kurzschlußhandlung des Polizeibeamten Kurras

812 Fichter/Lönnendonker: Kleine Geschichte des SDS, S. 106.

813 Vgl. Bauß: Die Studentenbewegung der sechziger Jahre, S. 53-55.

814 Vgl. Michels: Schahbesuch 1967, S. 235.

815 Bauß: Die Studentenbewegung der sechziger Jahre, S. 58-61, Zitat von S. 58.

816 Richter: Die Außerparlamentarische Opposition, S. 48.

817 Ibid.

818 Ibid.

819 Vgl. Bauß: Die Studentenbewegung der sechziger Jahre, S. 65f., siehe außerdem Richter: Die Außerparlamentarische Opposition, S. 36: „Als Reaktion auf den 2. Juni 1967 und angefacht nicht zuletzt durch die Äußerungen des Berliner Bürgermeisters und der Presse, die beide den Studenten die Schuld am Tode Benno Ohnesorgs zusprachen, kulminierte ein Prozeß, der sich bereits seit Oktober 1966 entwickelt hatte."

820 Vgl. Bauß: Die Studentenbewegung der sechziger Jahre, S. 77-86 und Fichter/Lönnendonker: Kleine Geschichte des SDS, S. $121 f$. 
erblickten, wurde erst seit diesem Zeitpunkt umfassend zum Cegenstand einer medienpolitischen Kampagne. Auch die Cewährleistung des Grundrechtes der Meinungsund Informationsfreiheit erschien von nun an immer zweifelhafter, wobei die Bezüge zu den Eigentumsverhältnissen des Kapitalismus (,Enteignet Springer') verstärkt hervortraten. ${ }^{\text {821 }}$

„Die Springer-Presse hat die Atmosphäre geschaffen, in der der Todesschuß überhaupt fallen konnte, sie hat , mitgeschossen.“' ${ }^{222}$

Insofern wurden die Ereignisse des Schahbesuchs durchaus auch okkasionalistisch instrumentalisiert. ${ }^{823}$ Die Folge war eine neue „fundamentaloppositionelle[] Grundhaltung ${ }^{424}$ großer Teile der deutschen Studierendenschaft gegen die Autoritäten in Regierung, Parlamenten und Behörden, auch wenn sicher nicht alle der nun Mobilisierten dazu bereit gewesen sein mochten, in den Ereignissen des 02. Juni das unbezweifelbare Symptom einer umfassenden Entdemokratisierung zu sehen. ${ }^{825}$ Der SDS verdoppelte seine Mitgliederzahl von 1.200 auf 2.500 und überholte damit erstmals die Personenstärke des RCDS ${ }^{826}$ - wenngleich die größte Wirkkraft in der Impulsgeberfunktion (seine „avantgardistische Funktion in Ideologie und Aktionsformen“) des SDS für die sozialdemokratischen und liberalen Studierendenverbände lag. ${ }^{827}$ Der Verband selbst gab sein vorheriges Vorgehen, das „auf die symbolische Kraft von Demonstrationen, Kongressen und Resolutionen vertraute", auf und wandte sich der von der Berliner Ortsgruppe um Dutschke routinierten Aktionsstrategie der „offensiven Durchbrechung der demokratischen Spielregeln der Bundesrepublik“ zu. ${ }^{828}$ An der FU Berlin riefen Studierende in Reaktion auf den 02. Juni die „Kritische Universität“ aus, um die seit Längerem erarbeiteten Hochschulreformpläne (Demokratisierung der Entscheidungsstrukturen und gemeinschaftliche Arbeit der Lehrenden und Lernenden im Zeichen gesellschaftspolitischer „Verantwortung“, d. h. radikaldemokratischer Opposition) vor Ort selbsttätig „experimentell“ durchzusetzen. ${ }^{829}$ Auch sonst war die Geduld der protestierenden Studierendenschaft aufgebraucht: Gesellschaftliche Veränderung sollte nun, wo jeder institutioneller Weg der Einflussnahme zerronnen war, direkt über die Aktion,

821 Krause et al.: Zwischen Revolution und Resignation?, S. 29.

822 Högemann, Jörg: Die Rebellion der Studenten - Ursachen und Möglichkeiten, in; Marxistische Blätter, H. 6/1967, S. 39, zit. nach Bauß: Die Studentenbewegung der sechziger Jahre, S. 69.

823 „Der ursprüngliche Anlass für die Proteste, also die Einladung des Schahs und die Verhältnisse im Iran, wie auch der Beitrag der persischen Kommilitonen zum Widerstand gegen dieses protokollarische Großereignis rückten dagegen in der sich formierenden westdeutschen Studentenbewegung schnell in den Hintergrund. Das Agieren der Behörden während des Staatsbesuchs reduzierte sich für viele westdeutsche Studenten im Nachhinein mehr oder minder auf eine von vielen denkbaren Gelegenheiten, die der Staat früher oder später genutzt hätte, um gegen die APO vorzugehen." Michels: Schahbesuch 1967, S. 231f.

824 Krause et al.: Zwischen Revolution und Resignation?, S. 29.

825 Vgl. Michels: Schahbesuch 1967, S. 299.

826 Vgl. Bauß: Die Studentenbewegung der sechziger Jahre, S. 79.

827 Krause et al.: Zwischen Revolution und Resignation?, S. 30.

828 Richter: Die Außerparlamentarische Opposition, S. 49.

829 Vgl. die ausführliche Darstellung dieses Vorhabens und der sich daran anschließenden Konflikte in Friedeburg: Freie Universität und politisches Potential der Studenten, S. 402-481. 
auch die „illegale Aktion“, erzielt werden. ${ }^{830}$ Dass die konkrete Rolle der Gewalt bei den visierten kalkulierten Regelbrüchen nur vage thematisiert wurde, war schon früh als eine der empfindlichen Grenzen dieses Konzepts identifiziert worden: Auf dem am 09. Juni unmittelbar nach der Beisetzung Ohnesorgs in Hannover stattfindenden Kongress „Hochschule und Demokratie“ (an der Beisetzung und dem anschließenden Schweigemarsch nahmen 10.000 Studierende teil, am Kongress selbst ganze $5.000^{831}$ ) warf Jürgen Habermas, damals Professor in Frankfurt a.M., Rudi Dutschke und damit dem SDS „voluntaristische Ideologie" und „linken Faschismus" vor. ${ }^{832}$ Die strategischen Aporien der APO zwischen linkssozialistischem Kader-bzw. Planungsprinzip und antiautoritärkreativem Spontaneismus blieben trotz gemeinsamer Aktionspotenziale ungelöst. ${ }^{83}$

Das Dilemma des nunmehr medial präsenten SDS lag darin, in das Zentrum der öffentlichen Aufmerksamkeit gelangt zu sein, ohne aber seinem Ziel der sozialistischen Massenbewegung wirklich näherzukommen. Die Aktivisten führten das auf die auch medial induzierte Verunmündigung der Bevölkerung zurück, der es an hinreichenden Informationen über die Ziele des SDS ermangele. ${ }^{834}$ Tatsächlich aber wuchs schlicht das Missverhältnis zwischen der immer stärker Agitprop-ähnlichen revolutionären Rhetorik und den tatsächlichen praktischen Veränderungsaussichten.

„Der SDS wurde in den Jahren 1967/68 zum Emblem der Außerparlamentarischen Opposition, obwohl seine geringen organisatorischen Mittel es ihm keineswegs erlaubten, auf Beginn und Verlauf der großen Protestaktionen dieser Jahre maßgeblichen Einfluß zu nehmen. “835

Auch deswegen entglitten dem seinem Selbstverständnis nach avantgardistischen Verband die Zügel ausgerechnet im Augenblick der stärksten Beschleunigung; zunehmend vollzog sich der Großteil der durch die internationale „68er-Bewegung“ angeregte und subkulturell unterfütterte Protestdynamik unabhängig von seinem Einfluss und seinem Deutungs- und Führungsanspruch. Das ist auch an der fortschreitenden Ablösung der internen Debatten und identitätsstiftenden Kollektivrituale von den konkreten tagespolitischen Auseinandersetzungen abzulesen. Die 22. Delegiertenkonferenz des SDS im September 1967, die unter der Fahne der südvietnamesischen Guerilla-Organisation

830 Vgl. Bauß: Die Studentenbewegung der sechziger Jahre, S. 62. Siehe auch die Pointierung auf S. 68 : „Wenn auf Parlament und Sozialdemokratie, auf die dritte Gewalt und die tolerante Friedfertigkeit der politischen Machthaber alle die, denen in der BRD und Westberlin manches kritikwürdig erschien, endgültig nicht vertrauen durften, so blieb ihnen nur die eigene politische Aktion, die Selbsttätigkeit."

831 Vgl. ibid., S. 61.

832 „Ich hätte gerne geklärt, ob er [Dutschke, ]. S.] nun willentlich die manifeste Gewalt herausfordert nach dem kalkulierten Mechanismus, der in diese Cewalt eingebaut ist, und zwar so, daß er das Risiko von Menschenverletzung, um mich vorsichtig auszudrücken, absichtlich einschließt oder nicht." Jürgen Habermas am 09.06.1967 in Hannover, zit. nach Fichter/Lönnendonker: Kleine Ceschichte des SDS, S. 108. Vgl. auch die Darstellung in Bauß: Die Studentenbewegung der sechziger Jahre, S. 64 und in Richter: Die Außerparlamentarische Opposition, S. $51 \mathrm{f}$.

833 Vgl. Richter: Die Außerparlamentarische Opposition, S. $53 f$.

834 Vgl. ibid., S. 52.

835 Bock: Geschichte des, linken Radikalismus', S. 213. 
FNL tagte, und insbesondere die Wortbeiträge Dutschkes, wurde per Video massenmedial im In- und Ausland verbreitet. ${ }^{836}$ Im Verlauf der einwöchigen Diskussionen, die sich um SDS-Organisation, Hochschulpolitik, mediale Manipulation, Notstandsgesetze, KPD-Verbot, Vietnamkrieg und lateinamerikanische Guerillas drehte, wurde unter anderem die Initiierung der später, Anfang 1968 beginnenden, Anti-SpringerKampagne beschlossen. ${ }^{837}$ Man erging sich daher in Erörterungen über die „Organisationsfrage“, nach Greven geradezu der „Fetisch des Politikersatzes“ schlechthin, der die zunehmende Isolierung von der eigentlichen Demokratisierungsbewegung in Studierendenschaft und Bevölkerung kitten sollte. ${ }^{838}$ Zudem setzte sich die antiautoritäre Strömung mit ihrem prinzipiellen Antiparlamentarismus gegen den von den Traditionalisten verfochtenen „revolutionären Parlamentarismus“ durch; von nun an berief sich der größte Teil des Verbandes - in doppelter Frontstellung gegen die westlichen parlamentarischen Demokratien, aber auch gegen den Parteikommunismus des sowjetischen Blocks - vage auf die Ideen des Rätekommunismus bzw. der Rätedemokratie Weimarer und bolschewistischer Provenienz. ${ }^{839} \mathrm{Zu}$ durchgebildeten Rezepten und glaubwürdigen Handlungsperspektiven gelang dieser eiserne Voluntarismus allerdings nie: Er blieb ein abstraktes Denkexperiment, sichtlich geboren aus Negations- und Abgrenzungsbewegungen und krankend am geringen politischen Einfluss des SDS in der Bundesrepublik. ${ }^{840}$

Insofern erscheint es aus der heutigen Perspektive durchaus denkbar, dass Tempo und Momentum des SDS bzw. der APO in den darauffolgenden Monaten schon aufgrund immanenter Aporien verglimmt wären, hatte doch eine stark selbstreferenzielle „sozialpsychologische Eigendynamik ${ }^{\text {“841 }}$ in der Studentenbewegung eingesetzt. Rückblickend aber begann die allmähliche Desintegration der Studentenbewegung mit dem Mordanschlag auf ihre zentrale und beinahe kultische Figur, Rudi Dutschke, am Gründonnerstag, den 11. April 1968: Der Hilfsarbeiter Josef Bachmann schoss ihn auf dem Berliner Kurfürstendamm an diesem Tag mit drei Revolverschüssen nieder. ${ }^{842}$ Nach Dutschkes durch die schweren Verletzungen bedingtem Ausscheiden aus der SDS-Führung endete auch nach und nach die kurze Phase der Studierendenführerschaft des Verbandes. Zwar begann in unmittelbarer Reaktion auf das Attentat das „spektakulärste[] Stadium“ der Springer-Kampagne, hatte doch selbst der RCDS eine gesellschaftliche, politisch wie medial geschürte, Dehumanisierung der studentischen Aktivisten zumindest teilverantwortlich gemacht. ${ }^{843}$ In den folgenden Tagen wuchsen

836 Vgl. Fichter/Lönnendonker: Kleine Geschichte des SDS, S. 116.

837 Vgl. ibid. und ibid., S. 121f. sowie Bauß: Die Studentenbewegung der sechziger Jahre, S. 71-92.

838 Greven: Systemopposition, S. 31.

839 „Die Räte-Idee wurde in den Jahren 1967 bis 1969 zum dominanten Leitbild gesellschaftlich-politischer Transformationsvorstellungen der Antiautoritären, zur radikalen Alternative gegenüber der parlamentarischen Demokratie. Dutschke bejahte Mitte 1967 die Frage, ob er für die Abschaffung des Parlamentarismus, so wie er in der BRD existiere, sei [...]“ Bock: Ceschichte des ,linken Radikalismus', S. 249.

840 Vgl. ibid., S. 250.

841 Krause et al.: Zwischen Revolution und Resignation?, S. 30.

842 Vgl. Fichter/Lönnendonker: Kleine Geschichte des SDS, S. 126 und Bauß: Die Studentenbewegung der sechziger Jahre, S. 96-98.

843 Bauß: Die Studentenbewegung der sechziger Jahre, S. 97. 
die Kundgebungen und Demonstrationen gegen den Springer-Konzern an, wiederholt kam es zu „Straßenschlachten, wie sie es [sic] seit den letzten Jahren der Weimarer Republik nicht mehr gegeben hatte [...]“ und mehreren Verletzten. ${ }^{844}$ Allein am für die Ostermärsche wichtigsten Tag Ostermontag, so die am häufigsten zitierten Zahlen, waren 21.000 Polizeikräfte im Einsatz, es gab zwei Tote und 400 Schwer- und Leichtverletzte; über die Feiertage hinweg nahmen insgesamt 300.000 Menschen an verschiedenen Aktionen teil, die Demonstrationen erstreckten sich über 50 Städte. ${ }^{845}$ Die Demonstrierenden forderten die Absetzung des Berliner Senats mit dem Zweck der Schaffung "demokratischer Verhältnisse“, die Enteignung des Springer-Konzerns, die „Demokratisierung“ der Rundfunkanstalten und „für die Zeit bis zum 1. Mai täglich eine Stunde Sendezeit für die außerparlamentarische Opposition“. ${ }^{846}$ Kraushaar spricht für diesen Zeitraum von den „größten innenpolitischen Unruhen [...], die die Bundesrepublik bis dahin erlebt hat. ${ }^{\text {} 847}$ Kurz darauf erreichte auch die Kampagne gegen die Notstandsgesetzgebung einen „letzten Mobilisierungshöhepunkt ${ }^{4848}$ mit 70.000 Demonstrierenden anlässlich der zweiten Lesung der Notstandsgesetze: Am 11. Mai 1968, kurz nach den von Nanterre ausgehenden Pariser Mai-Aufständen, kam ein großer Sternmarsch nach Bonn zusammen, ${ }^{849}$ in den Maitagen kam es anlässlich der dritten Lesung mancherorts trotz Gegenwehr des DGB sogar zu betrieblichen Warnstreiks. ${ }^{850}$ Im Gegensatz zu den Osterunruhen, aber auch im Kontrast zur Situation in Frankreich mit ihren brennenden Barrikaden, Wasserwerfer- und Chlorgaseinsätzen sowie vielen hundert Verletzten ${ }^{851}$ verlief diese Massendemonstration allerdings friedlich. Doch dass die innere Kohärenz der Studentenbewegung längst bröckelte, dass auch die Integrationsfigur Dutschke durch dessen intellektuell auftretenden Nachfolger und Adorno-Schüler Hans-Jürgen Krahl nicht ersetzt werden konnte, ja dass sich unter der jungakademischen Linken „seit Mitte 1968 aufgrund der gesellschaftlichen Isolierung ein regelrechter Ghettoisierungsprozeß" vollzogen hatte, ${ }^{852}$ ist an der vernichtenden Wirkung der nun folgenden Rückschläge abzulesen.

Als die Notstandsgesetze am 30. Mai 1968 im Bundestag verabschiedet wurden, zogen sich die Gewerkschaften und damit eine der wichtigsten Finanzierungsquellen aus dem Kuratorium „Notstand der Demokratie“ zurück; die APO hatte ihr entscheidendes „Achsenthema“ ${ }^{853}$ verloren, und unter den beteiligten Studierenden machte sich Resignation breit. Sie waren gescheitert. ${ }^{854}$ Vielen erschien eine Massenbewegung ohne breite Beteiligung der Bevölkerung - und insbesondere der Arbeiterschaft - nunmehr

844 Fichter/Lönnendonker: Kleine Geschichte des SDS, S. 128.

845 Bauß: Die Studentenbewegung der sechziger Jahre, S. 104.

846 Ibid., S. $99 f$.

847 Kraushaar, Wolfgang: 1968. Das Jahr, das alles verändert hat, München 1998, S. 104.

848 Krause et al.: Zwischen Revolution und Resignation?, S. 30.

849 Vgl. Richter: Die außerparlamentarische Opposition, S. 53.

850 Vgl. Bauß: Die Studentenbewegung der sechziger Jahre, S. 157.

851 Vgl. Kraushaar: 1968. Das Jahr, das alles verändert hat, S. 125-139 und Fichter/Lönnendonker: Kleine Geschichte des SDS, S. 130.

852 Krause et al.: Zwischen Revolution und Resignation?, S. 30.

853 Richter: Die außerparlamentarische Opposition, S. 53, auch ibid., FN. 53.

854 „Zehntausende von Studenten gingen nach den euphorisierenden Streik- und Besetzungserlebnissen in die Semesterferien und realisierten, daß der Deutsche Bundestag trotz des massenhaften Widerstandes der akademischen Jugend, der Schüler und großer Teile der Cewerkschaftsbe- 
vollends aussichtslos; auch der antiautoritäre Ansatz hatte sich faktisch blamiert. ${ }^{855}$ Mit dem Kuratorium war das „mobilisierte Netzwerk“ zerbröselt, insbesondere der inhaltliche und organisatorische Richtungskonflikt war nicht mehr durch eine geteilte „kollektive Identität“ zu vermitteln; die „eine“ Bewegung zerfiel in viele. ${ }^{856}$ Auch die „Enteignet Springer“-Kampagne konnte weder die Vakanz des Achsenthemas ausfüllen noch das sich ausbreitende Ohnmachtsempfinden lindern. So kann es nicht überraschen, dass sich im Spätsommer 1968 der Eindruck einer allgemeinen Entkräftung von APO und Studentenbewegung ausbreitete. ${ }^{857}$ Stattdessen wuchs die frustrierte Ungeduld, verlangte man in wachsendem Maße nach Taten und lieferte sich zunehmend auch gewalttätige Auseinandersetzungen. Dass der enervierte Ruf nach Praxisrezepten vielerorts die Geduld für theoretische Auseinandersetzungen unterband, ist beispielsweise am Einfordern praktischer Ratschläge von Herbert Marcuse anlässlich eines Vortrags am 13. Mai 1968 in West-Berlin zu erkennen; eine Rolle, welche dieser vehement ablehnte. ${ }^{858}$ Danach setzte sich ein besonders unversöhnlicher Zug „vom Protest zum Widerstand ${ }^{4859}$ durch, der die politische Isolierung nur noch weiter verschärfte. ${ }^{860}$ Die späteren RAF-Terroristen Andreas Baader und Gudrun Ensslin verübten bereits im April einen Brandanschlag gegen zwei Frankfurter Kaufhäuser, „durch den die Öffentlichkeit auf die Grausamkeit des Vietnam-Krieges aufmerksam gemacht und politisch aufgerüttelt werden sollte [...]“. ${ }^{861}$ Das von Fichter und Lönnendonker in vielsagend projektive Worte gekleidete „Gefühl der Studentenschaft, das Freiwild der bürgerlichen Gesellschaft zu sein", ${ }^{862}$ wird denn auch für die Gewaltorgie bei der so genannten Schlacht am Tegeler Weg vom 04. November 1968 verantwortlich gemacht: Bei einer Solidaritätsdemonstration für den von Axel C. Springer angeklagten damaligen Dutschke-Anwalt Horst Mahler vor dem Landgericht am Tegeler Weg griffen etwa 1.000 Studierende unter SDS-Führung die in Minderheit befindlichen Polizeibeamten an; verletzt wurden hier 130 von ihnen und 21 Studierende. ${ }^{863}$ Mit der mangelnden Problematisierung der Gewaltfrage verpasste der SDS, der weitere Diskussionen umging, die eigentlich dringend notwendige Auseinandersetzung und erreichte schließlich seinen finalen Spalt-

wegung die Notstandsgesetze verabschiedet hatte. Dieser Kampf war verloren." Fichter/Lönnendonker: Kleine Geschichte des SDS, S. 135.

855 Vgl. Bauß: Die Studentenbewegung der sechziger Jahre, S. $165 f$.

856 Richter: Die Außerparlamentarische Opposition, S. 52 und 55.

857 Vgl. Friedeburg: Freie Universität und politisches Potential der Studenten, S. 480.

858 Vgl. Kraushaar: 1968. Das Jahr, das alles verändert hat, S. 149 und Fichter/Lönnendonker: Kleine Geschichte des SDS, S. 133 f.

859 Bauß: Die Studentenbewegung der sechziger Jahre, S. $106 \mathrm{f}$.

860 Vgl. Schlicht: Vom Burschenschafter bis zum Sponti, S. $79 f$.

861 Krause et al.: Zwischen Revolution und Resignation?, S. 31.

862 Fichter/Lönnendonker: Kleine Geschichte des SDS, S. 136. Projektiv, weil keine Theorie (oder Kritik) der bürgerlichen Gesellschaft zu haben ist, die plausibel begründen könnte, warum bestimmte in einer solchen Cesellschaft lebenden Cruppen (mögen sie auch „systemkritisch" auftreten) ihr zugleich nicht angehörten. Die zugrunde liegende, psychologisch unterfütterte, Denkoperation solcher Formulierungen scheint in der Personalisierung abstrakter Zusammenhänge über die Imagination einer noch immer „herrschenden“ Personengruppe zu liegen, ein infantiles Muster der Angstbewältigung. Vgl. dazu die empirischen Beispiele in Adorno et al.: Studien zum autoritären Charakter, S. 187-191 und 195-199.

Vgl. Fichter/Lönnendonker: Kleine Geschichte des SDS, S. $136 \mathrm{f}$. 
punkt. ${ }^{864}$ In der politischen Polarisierung der 1970er Jahre spielte er keine Rolle mehr: „Die Pfingstzeit der neomarxistischen Theorie war vorbei. Merkwürdigerweise folgte, was doch hätte vorangehen sollen: die Walpurgisnacht des kommunistisch-orthodoxen Hexensabbats. ${ }^{\text {(865 }}$

Mit dem Niedergang des SDS-Bundesverbands erlosch auch die westdeutsche Studentenbewegung der 1960er Jahre. $\mathrm{Zu}$ ihrer Dämmerungsphase gehörte, dass Adorno, Friedeburg und Habermas am 18. Dezember 1968 das anlässlich einer Revision der Institutssatzung von Studierenden besetzte Soziologische Seminar in Frankfurt a.M. polizeilich räumen ließen und damit das - von ihnen so nie gedeckte - Tischtuch endgültig zerschnitten. ${ }^{866}$ Während die letzte SDS-Delegiertenkonferenz im September 1968 in unversöhnlichen Frontenbildungen zwischen Traditionalisten, antiautoritären Räte-Idealisten und wachsendem feministischem Einspruch gegen die Dominanz der „Paschas“ im Verband versank, diskutierten spätestens ab 1969 die sich in einem „Linksruck“ befindlichen Jungsozialisten in der SPD über antikapitalistische Reformen und Aktionsstrategien. ${ }^{867}$ Auch die mit den Jungen Liberalen (JuLis) rivalisierenden Jungdemokraten (Judos) in der FDP entdeckten die sozialistische und radikaldemokratische Rhetorik für sich und „spielten 1969 die Stücke der APO aus den Vorjahren nach. ${ }^{\text {“868 }}$ Zeitgleich arbeitete ein zunehmend größerer Teil der (ehemaligen) SDSMitglieder an kaderkommunistischen „Aufbauorganisationen“ und „K-Gruppen“ mit. ${ }^{869}$ Sozialismus war sexy, doch auf Kosten des seinem Namen nach „eigentlichen“ Sozialistischen Deutschen Studentenbunds. Im Februar 1970 schließlich kam Hans-Jürgen Krahl bei einem Autounfall ums Leben; im Anschluss an sein Begräbnis am 20. Februar beschloss der SDS „informell“ seine Selbstauflösung und vollzog sie am 21. März 1970. 870 Die unrühmliche Banalität dieses Beendigungsprozesses, per Akklamation durch „eine mehr oder minder zufällig zusammengewürfelte Versammlung im Frankfurter Studentenhaus“ ${ }^{\text {“871 }}$ lässt sich kaum schmücken: „Die formelle Selbstliquidation des SDS“, so schreiben andere, „war nur noch ein politisch bedeutungsloser Verwaltungsakt. “872 Die zwischen „Reformern“ und „Revolutionären“ zerstrittene studentische Linke war somit seit 1969/70 ohne zentralen bzw. übergreifenden Verband. ${ }^{873}$ Allerdings sollte noch einmal wiederholt werden, dass die durch die APO und den SDS getragene Studentenbewegung von Anfang an wesentlich eine Sammlungsbewegung heterogener Strömungen und Gruppen gewesen war. Insofern ist die Rede vom „Zerfall“ der Studentenbewegung,

864 „Historisches Versagen des SDS war, daß er nach den Erfahrungen am Tegeler Weg nicht weitere derartige Aktionen offensiver Cewalt verhindert hat und davor zurückschreckte, mit den Studenten über die tatsächlichen gesellschaftlichen und politischen Machtverhältnisse in der Bundesrepublik und West-Berlin zu diskutieren." Ibid., S. 137. Vgl. auch ibid., S. $137 f$.

865 Walter: Rebellen, Propheten, und Tabubrecher, S. 94.

866 Vgl. Fichter/Lönnendonker: Kleine Geschichte des SDS, S. 138-140.

867 Vgl. ibid., S. 143.

868 Walter: Rebellen, Propheten, und Tabubrecher, S. 130.

869 Vgl. Krause et al.: Zwischen Revolution und Resignation?, S. 30.

870 Vgl. Fichter/Lönnendonker: Kleine Geschichte des SDS, S. 140.

871 Ibid.

872 Krause et al.: Zwischen Revolution und Resignation?, S. 31.

873 Vgl. Schlicht: Vom Burschenschafter bis zum Sponti, S. 79 und Fichter/Lönnendonker: Kleine Geschichte des SDS, S. 143. 
die das Bild eines homogenen Kaders evoziert, so gesehen etwas wohlfeil und missverständlich. Zerfallen war zwischen 1968 und 1970 ein zwar aktions- und mobilisierungsstarkes, aber auch kurzlebiges, von Anfang an instabiles Bündnis. ${ }^{874}$

Sicher, eine solche kurze Chronologie der „68er"-Bewegung verleitet zu einer weit verbreiteten reduktionistischen Rezeptionsweise: Man erfährt viel über zentrale Ereignisse sowie über die klassischen Heldengeschichten, d. h. über die Wortführer und Aktivistenkerne in den Hochburgen der Bewegung (primär Berlin, „Aktionshauptstadt an der Spree“ und Frankfurt, „Theorietank am Main“ ${ }^{875}$ ), häufig jedoch wenig über die lokalen Bedingungen und Abläufe im Rest der Republik. ${ }^{876}$ Dabei ist ein Blick auf die Lokalspezifika durchaus lohnenswert, schafft er doch ein plastischeres und lebendigeres Bild dieser studentischen Bewegungsphase. Keineswegs kann von einer großen studentischen Einheitsbewegung die Rede sein, insbesondere außerhalb von Berlin, Frankfurt und auch München nicht. In jeder der damaligen Universitätsstädte herrschte ein jeweils spezifisches „Nebeneinander von nach wie vor weit verbreiteter apolitischer $\mathrm{Ru}$ he, politisiertem Dissens und schließlich reformistisch orientiertem oder revolutionärem Protest, der sich in sichtbaren Aktionen manifestierte. ${ }^{\text {“877 }}$ Ein Beispiel: Wie groß die Bedeutung regionalspezifischer Protesttraditionen im Vorfeld von „1968“ gewesen ist, lässt sich am damals als provinziell und traditionsgeprägt geltenden, die Veränderungsprozesse überdies verzögert aufnehmenden ${ }^{878}$ Westfalen beobachten: Nicht nur die Bürgerproteste der 1950er Jahre gegen Wiederbewaffnung, Wehrpflicht und die Stationierung von Trägerraketen waren hier rührig gewesen - 1957 opponierten Gewerkschaftsredner gegen die geplante atomare Bewaffnung -, auch eine starke Tradition arbeiterbewegter Gegenkultur besonders im ruhrgebietsgeprägten Westen mit ihren sozialistischen Vereinen und Jugendbünden sorgte schon in den ersten beiden Jahrzehnten der Bundesrepublik für oppositionellen politischen Aktivismus; immer wieder hatte man „um Arbeitsbedingungen, Arbeitszeiten und Löhne" gekämpft und dabei auch wild gestreikt. ${ }^{879}$ Zudem hatte es hier in den $1950 e r$ Jahren Protest vonseiten der ansässigen Bauern oder auch militanten jugendlichen Unmut vonseiten der „Halbstarken“ gegeben. ${ }^{880}$ Zudem ist auf die grundsätzlich variierenden Bedingungen zwischen Universitäten mit umfänglicher Beteiligung Studierender an der akademischen Selbstverwaltung - etwa in Berlin - und solchen mit relativ restringierten Beteiligungsformen - etwa an den auch nach dem 02. Juni 1967 vergleichsweise konfliktarmen Hochschulen Nordrhein-Westfalens - hinzuweisen, gerade angesichts der tragenden Bedeutung des Themenkomplexes Hochschulreform bzw. Demokratisierung der Hochschule für das politische Engagement Studierender bis (mindestens) zum Zäsurjahr $1967 .{ }^{881}$ So wirkte der Tod Ohnesorgs zwar bundesweit als aktivierendes und politisierendes

874 Vgl. Greven: Systemopposition, S. 18-31 und 37.

875 Vgl. Leggewie, Claus: 50 Jahre '68. Köln und seine Protestgeschichte, Köln 2018, S. 13.

876 Vgl. Hodenberg: Das andere Achtundsechzig, S. 11.

877 Spix: Abschied vom Elfenbeinturm?, S. 694.

878 Großbölting, Thomas: 1968 in Westfalen. Akteure, Formen und Nachwirkungen einer Protestbewegung. Regionalgeschichte kompakt Bd.1, Münster 2018, S. 15 und 142-144.

879 Vgl. ibid., S. 33-35.

880 Vgl. ibid.

881 Vgl. Spix: Abschied vom Elfenbeinturm?, S. 22. 
Ereignis; dass sich aber die Eskalationsdynamik in der Folge vor allem an der FU Berlin in ein Lahmlegen des Lehrbetriebs ${ }^{882}$ und in die durch die Mehrheit der Studierenden gestützte „Entmachtung ${ }^{483}$ des studentischen Konvents und des AStA durch den SDS umsetzen konnte, war - neben den erwähnten lokalkulturellen Besonderheiten auch durch die lange Vorgeschichte hiesiger inneruniversitärer Konflikte bedingt. Mehr und mehr wurde nicht nur die Hochschullehrerschaft, sondern auch der Berliner Senat zum erbitterten Feind stilisiert - auch in Antizipation des „in den kommenden Jahren zunehmene[n] direkten Eingriff[s] des Staates in bisher autonome Bereiche der Universität“ ${ }^{884}$ Auch in NRW wirkte der 02. Juni breitenwirksam politisierend: An sämtlichen Universitäten fanden Schweigemärsche mit 1.000 bis 10.000 Personen statt. ${ }^{885}$ Auch später, in der Phase der Springer-Proteste infolge des Dutschke-Attentats, kam es in Bochum, Dortmund und Duisburg zu größeren Protesten: Am Osterwochenende verband sich der studentische Unmut vor allem in den beiden letztgenannten Städten mit den traditionellen Friedensmärschen. In der Dortmunder Westfalenhalle kamen zur Schlusskundgebung der Ostermärsche 1968 zwischen 15.000 und 18.000 Demonstrierende zusammen. ${ }^{86}$ In manchen westfälischen Städten wie Paderborn konzentrierten die Studierenden derweil auch in dieser Spätphase ihre politischen Aktionen auf hochschulpolitische Themen. ${ }^{887}$ Zudem begünstigte die westfalenspezifische Erweiterung der Wohnfläche seit den 1950er Jahren, die ihrerseits schon früh individuelle und lebensgestalterische Freiräume gefördert hatte, die rasche Ausbreitung und eine zwar allmählichere, aber dadurch tatsächlich auch nachhaltigere Institutionalisierung alternativer Wohnprojekte und neuer (zunächst jugendkultureller) Gesellungsformen. ${ }^{888}$ Ähnliches scheint weiter südwestlich im Nordrheinischen der Fall gewesen zu sein: Claus Leggewie spricht von einem „Kölner Aufbruch“ und verortet im dortigen „1968“ zwar kein aufsehenerregendes und strahlkräftiges Aktionszentrum, aber doch eine früh blühende „lebendige, mainstreamfähige Subkultur, die Einübung demokratischer Mitbestimmung und Ansätze einer alternativen Wohlfahrtsökonomie.“889 Streiksemester,

882 „Trotz zeitweiligen Kundgebungsverbotes wechselten sich in Berlin binnen der folgenden zwei Wochen teilweise mehrfach täglich Demonstrationen mit bis zu 15.000 Teilnehmern, Vollversammlungen, Vorträge und Diskussionsveranstaltungen ab. Damit erreichte die studentische Mobilisierung ihren Höhepunkt. Das gesamte Leben der Universität wurde von diesen Aktionen bestimmt. Die Lehrveranstaltungen fielen fast vollständig aus. Es kann davon ausgegangen werden, dass jeder Berliner Student zumindest an einer Veranstaltung zum Tode Ohnesorgs teilnahm." Ibid., S. 639.

883 Ibid.

884 Vgl. ibid., S. $649 f$.

885 Vgl. ibid., S. 673.

886 Vgl. Großbölting: 1968 in Westfalen, S. 44f.

887 Vgl. ibid., S. 49.

888 „Der Trend ging dahin, größere individuelle Ansprüche zu erfüllen. Seit den 1950er Jahren nahm nicht nur die Wohnfläche insgesamt, sondern auch die Zahl der separierten Wohnräume in den Häusern zu. Immer mehr Familienmitgliedern standen einzelne, in sich geschlossene Zimmer zur Verfügung. Das brachte dem Einzelnen in der Familie größere Freiräume, ermöglichte eine intimere Lebensführung und hatte auf diese Weise große Konsequenzen beispielsweise für die Entwicklung von Jugendkulturen." Ibid., S. 129, vgl. zur Beobachtung einer stärkeren Verzahnung von Gegen- und Normalkultur in der westfälischen Öffentlichkeit und Zivilgesellschaft ibid., S. 143f. 
Hörsaalblockaden, Demonstrationen, Besetzungen und weitere Protestaktionen hatte es auch hier gegeben, überdies eine studentische politische Spannung zwischen insurrektionalistischen „Maximalisten“ und reformistischen "Gradualisten“; zudem brachte die Stadt mit dem später früh verstorbenen Klaus Novy sogar einen „intellektuellen Netzwerker" hervor, der in verschiedenen Wohnprojekten Arbeitsgemeinschaften organisierte - dies alles jedoch wohl in einem ausgelassenen, schnelllebigen, experimentierfreudigen und doch zugleich kompromissoffenen Stadtklima. ${ }^{890}$ Überhaupt war man im Westen der Republik gerade nicht verbissen, verschworen oder feindselig: Die nordrhein-westfälische studentische Mehrheit (mit Ausnahme von Münster ${ }^{891}$ ) nahm die fernen „Ereignisse in Berlin überwiegend als Einzelfall und Folge der dortigen besonderen lokalen Gegebenheiten ${ }^{4892}$ wahr, nicht als Ausdruck gesamtgesellschaftlicher Repressionstendenzen. ${ }^{893}$ So wurden nicht einmal nach dem 02 . Juni 1967 die akademischen Eliten in NRW - abgesehen von der damaligen Bundeshauptstadt Bonn als Gegner perzipiert,

„was nicht zuletzt daran lag, dass die akademische Seite den studentischen Protestaktionen nicht nur keine Steine in den Weg legte, sondern ihre Trauerkundgebungen und Vollversammlungen teilweise unterstützte oder sogar offizielle akademische Trauerfeiern abhielt, während der die Lehrveranstaltungen ruhten. ${ }^{\text {“894 }}$

Erkennbar lag im Kurras-Schuss also mancherorts - nicht nur „in der Provinz “895 grundsätzlich das Potenzial einer gesamtuniversitären Gedenk- und Solidaritätsbewegung begründet, eines Schulterschlusses zwischen Lehrenden und Lernenden. Einen unmittelbaren Kontrast hierzu bildet die ebenfalls in der „Provinz ${ }^{4896}$ liegende Universitätsstadt Heidelberg, Standort des Hauptquartiers der US-Armee in Europa sowie Sitz des Oberbefehlshabers derselben in Deutschland: ${ }^{897}$ Hier war jedes Einvernehmen zwischen Studierenden, Universitätsvertretern, Stadtverwaltung und Stadtöffentlichkeit nachgerade undenkbar. Die hiesige studentische Protestwelle brach mit fundamentaloppositioneller Intransigenz in die Stadtgesellschaft ein und wurde mit ebenso unnachgiebiger Härte vonseiten des Universitätsrektorats wie den städtischen Behörden beantwortet. Die Berliner Juni-Ereignisse 1967 wirkten auch hier sensibilisierend und aktivierend; insbesondere für den Heidelberger SDS galt es als erwiesen, „dass die Exekutive demokratische und rechtsstaatliche Formen der Konfliktbewältigung ersetzt ha-

890 Vgl. ibid., S. 14, 22, 24f., und 90.

891 Vgl. Spix: Abschied vom Elfenbeinturm?, S. 677 sowie Großbölting: 1968 in Westfalen, S. 38.

892 Spix: Abschied vom Elfenbeinturm?, S. 676.

893 Vermutlich nicht zuletzt, weil der SDS hier die hochschulpolitische Arbeit vernachlässigte und sich in „orthodox-marxistische[r]" Manier allein auf allgemeinpolitische Fragen konzentrierte, vgl. ibid., S. 143. Aber auch sonst spiegelten sich „die Ereignisse der Protestmonate zwischen dem Juni 1967 und dem Sommer 1968 [...] in der Provinz allenfalls in einer schwächeren Form wider", vgl. Großbölting: 1968 in Westfalen, S. 140.

894 Spix: Abschied vom Elfenbeinturm?, S. 678.

895 Vgl. Etzemüller: Ein Riss in der Geschichte?, S. 9.

896 Nagel, Katja: Die Provinz in Bewegung. Studentenunruhen in Heidelberg 1967-1973. Buchreihe der Stadt Heidelberg, Bd. XIII, Heidelberg - Ubstadt-Weiher - Neustadt a. d. W. - Basel 2009.

897 Vgl. ibid., Geleitwort. 
be durch eine gewaltsame Unterdrückung politischer Meinungen“. ${ }^{898}$ Die studentische Wut richtete sich ähnlich wie in Berlin und Frankfurt auf die Vertreter des „Systems“, eine Kategorie, in die man in projektiver Manier wahlweise Universitätseliten, Exekutivund Ministerialbeamte wie auch Pressevertreter und -organe einsortieren konnte. ${ }^{899}$ Im amtierenden Oberbürgermeister Reinhold Zundel (SPD), der als Ordnungshüter auftrat und sich - so ein vielfach kolportiertes Statement - gegen die Bezeichnung als „Technokraten“ explizit nicht wehrte, fand man zudem eine unnachgiebige Feindfigur. ${ }^{900}$ Die Auseinandersetzungen wurden hier wiederholt durch sit-ins, teach-ins, Veranstaltungsboykotte, Sitzstreiks und Blockaden sekundiert. Ein kurzer Blick auf die Ereignisse illustriert die Drastik des Heidelberg'schen „1968“: Als Zundel infolge des Sechstagekrieges gewalttätige Ausschreitungen zwischen arabischen und israelischen Studenten vor Ort befürchtete, erließ er ein Demonstrationsverbot für die Heidelberger Hauptstraße und rief damit eine Reihe von studentischen Protesten unter dem Zeichen der „begrenzten Regelverletzung“ (Auflösung und Neuformierung der Demonstration im Rahmen eines „Spaziergangs") hervor; ${ }^{901}$ in der Folge entbrannte in Heidelberg eine „Debatte über die Grenzen der Meinungs- und Demonstrationsfreiheit“. ${ }^{902}$ Wenige Wochen nachdem der Heidelberger SDS im Januar 1968 seine „Stadthallenaktion“ durchführte - eine Störaktion anlässlich einer vom Akademischen Auslandsamt organisierten Festveranstaltung - ${ }^{903}$, erstattete Zundel Anzeige gegen die Aktivisten; diese antworteten in zwei Phasen mit einer Kampagne gegen "politische Justiz". ${ }^{904}$ Im Dezember 1968 sollte der "Stadthallenprozess“ eröffnet werden: Die fünf Angeklagten erschienen erst am 08. Januar 1969 und forderten eine Aufhebung des Haftbefehls. ${ }^{905}$ Am Folgetag drang die Polizei in die Räume des lokalen AStA ein und verhaftete mehrere Anwesende. ${ }^{906}$ Im Rahmen einer Vietnamdemonstration des Heidelberger SDS kam es im Dezember 1968 zu schweren Zusammenstöße mit Polizisten. ${ }^{907}$ Teil der weiteren Entwicklungen ist auch ein Prozess gegen vier Heidelberger SDSler wegen Beschmierung von NPD-Wahlplakaten ${ }^{908}$ sowie die Festnahme dreier SDSler beim Versuch, NPD-Landtagswahlplakate zu entfernen. ${ }^{909}$ Und die Eskalationsdynamik sollte noch weiter an Fahrt aufnehmen: Ab Februar 1969 gab es im Zuge des „Stadthallenprozesses“ und der hier vermeintlich geübten „Klassenjustiz“ wiederholt weitere Auseinandersetzungen zwischen Studenten und Polizei. ${ }^{910}$ Auch in den Jahren 1970 bis 1973

898 Vgl. ibid., S. 34.

899 Vgl. ibid., S. 39.

900 Vgl. ibid., S. 35-37. Zur von SDS-Mitgliedern ins Leben gerufenen „Projektgruppe Zundel“, deren Ziel das Streuen denunzierender Informationen unter den Kommilitonen war vgl. ibid., S. 40.

901 Vgl. ibid., S. 50-95.

902 Ibid., S. 114.

903 Vgl. ibid., S. 147-157 und 393.

904 Vgl. ibid., S. 157-203.

905 Vgl. ibid., S. 402f.

906 Vgl. ibid., S. 201-225 und 402f. Während der Prozesstage und -jahre traten Otto Schily, HansChristian Ströbele und Horst Mahler, späterer rechtsextremer Renegat, als APO-Anwälte auf, vgl. ibid., S. 381 und 406.

907 Vgl. ibid., S. 245-261 und 400.

908 Vgl. ibid., S. 400.

909 Vgl. ibid., S. 394.

910 Vgl. ibid., S. 405. 
nahm das Konfliktpotenzial über verschiedene Anlässe hinweg weiter zu. Bereits im Juni 1970, infolge von gewalttätig eskalierten Demonstrationen gegen die Teilnahme des Weltbankpräsidenten und früheren amerikanischen Verteidigungsministers Robert McNamara an einer internationalen Konferenz zur Entwicklungshilfepolitik, schritt die baden-württembergische Landesregierung ein und erließ ein Verbot des Heidelberger SDS. ${ }^{911} \mathrm{Zu}$ den traurigen Höhepunkten der Trümmerbilanz jener Jahre zählen neben einigen Verletzten und Festgenommenen: eine verbrannte Universitätstür, zertrümmerte Glasscheiben des ansässigen Amerikahauses, ${ }^{912}$ ferner ein Bombenanschlag der RAF auf das US-Hauptquartier mit drei toten und mehreren verletzten Soldaten. ${ }^{913}$ Erkennbar hielten „die Konflikte in der Stadt und an der Universität Heidelberg zum damaligen Zeitpunkt [sic] weite Teile der Öffentlichkeit in Atem“. ${ }^{914}$ Dabei begegnete die lokale Öffentlichkeit den studentischen Protestaktionen von Anfang an mit Unverständnis und Erregung, auch zu Gegendemonstrationen und zur Bildung einer „Arbeitgemeinschaft Heidelberger Bürger", die ein repressives Durchgreifen „als Mittel gegen die Störer“ forderte, kam es hier. ${ }^{915}$ Im Falle Heidelbergs verbieten sich daher offenkundig auch heute noch die versöhnlichen, einstige Antagonismen durch einen differenzierenden Längsschnitt einebnenden Rückblicke, die für andere aktuelle Studien üblich sind: ${ }^{916}$ Noch im Jahr 2009 konstatierte die Historikerin Katja Nagel eine verbitterte Polarisierung zwischen einstigen SDS-Aktivisten und ihren Sympathisanten auf der einen Seite sowie deren Kritikern (die ihnen nicht weniger als eine gescheiterte Attacke auf Demokratie und Rechtsstaat vorwerfen) auf der anderen Seite. ${ }^{917}$

911 Vgl. ibid., S. 281-302 und 414.

912 Vgl. ibid., S. 412.

913 Vgl. ibid., S. 418.

914 Vgl. ibid., S. 24.

915 Vgl. ibid., S. 47, 125, 377 und 404.

916 „Die politische ,Revolution' erscheint [...] als Reflex auf die ,Lebensstilrevolution' der modernen Konsumgesellschaft, die wiederum die ,silent revolution', den Wertewandel der westlichen Gesellschaften entscheidend vorangetrieben hat. Das wiederum überführte die politische Revolution in das ganz alltägliche politische Leben der postmodernen Gesellschaft. [... Dies] macht deutlich, daß ,1968' vielmehr einer längst in Bewegung geratenen Cesellschaft als Katalysator die Möglichkeit bot, die Veränderungen zu diskutieren.“ Etzemüller: Ein Riss in der Ceschichte?, S. 13; „Der Demokratie der Bundesrepublik wie auch der mit ihr verbundenen politischen Kultur stellt [der] Befund der Diffusion und Integration von ,1968' ein gutes Zeugnis aus: Cesellschaft und Politik waren nicht nur auf dem nationalen Level, sondern auch in der Provinz in den vergangenen Jahrzehnten in der Lage, die Impulse von ,1968' nicht nur aufzunehmen, sondern diese zu integrieren und sich selbst an ihnen weiterzuentwickeln. “ Großbölting: 1968 in Westfalen, S. 144f.; „Auf der Haben-Seite von ,1968' steht, dass die außer-, zum Teil antiparlamentarische Opposition unterm Strich die Demokratisierung der Bundesrepublik beflügelte und zur ,Beteiligungsrevolution' der 1970er-Jahre und der Entstehung einer selbstbewussten Bürgergesellschaft in Deutschland beitrug. Aus scharfen Kritikern des politischen Liberalismus wurden vielfach seine Anhänger [...]“ Leggewie: Köln und seine Protestgeschichte, S. 95f.; „Die Demokratisierung der Gesellschaft war eingebettet in eine Lebensstilrevolution. Medial war ,1968' die erste Protestbewegung des Fernsehzeitalters. Die relativ kleine Avantgarde der ,68er' prägte diesen Wandel entscheidend mit, hat ihn aber, was noch wichtiger war, gesellschaftlich kommuniziert und in diesem Sinne zu ,bewältigen' geholfen." Gassert: Bewegte Gesellschaft, S. 130.

Vgl. Nagel: Die Provinz in Bewegung, S. 8. 
Das Heidelberger Beispiel verweist auf allgemeine Tendenzen an den konfliktträchtigen Schauplätzen der Studentenbewegung nach dem Dutschke-Attentat. „Ab 1968 radikalisierten sich [...] Teile der zunehmend zersplitterten Bewegung, die Gewalt durchaus als legitime Gegenmaßnahme zur staatlichen Gewalt erachteten.“918 Auf die Studentenbewegung folgten die 1970er Jahre, ein Jahrzehnt fundamentaler Veränderungen und politischer Polarisierung. Viele Motive der linksradikalen Gesellschaftskritik wurden in diesen Jahren offen ausgetragen. Erst zwischen 1970 und 1973 erreichte die Auseinandersetzung zwischen Studierenden und dem von reformskeptischen Professoren gegründeten Bund Freiheit der Wissenschaft (BFW) um die „Demokratisierung der Universitäten“ ihren Zenit. ${ }^{919}$ Ob man nun den Koenen'schen Weg geht und die Periode zwischen 1967 und 1977, als der Zustrom zu den Organisationen, Splittergruppen und Strukturen der Alten wie Neuen Linken am stärksten war und die vielgestaltigen Liberalisierungsprozesse in Kultur, Alltag und Politik sich ein linkes bzw. linksliberales Selbstverständnis gaben, als „Kulturrevolution" und „rotes Jahrzehnt" rubriziert, ${ }^{920}$ oder demgegenüber darauf insistiert, dass es zeitgleich eine durchaus wachsende und einflussreiche konservative bzw. „rechte“ „Gegen-Generation“ an den westdeutschen Universitäten und in der Gesellschaft lange vor der eigentlichen „Tendenzwende“ ab den Krisenjahren 1973/74 ${ }^{921}$ gegeben hat, die gar die Rede von einem "schwarzen Jahrzehnt“ legitimieren könnte: ${ }^{922}$ Die gesellschaftsgeschichtlich entscheidenden Konflikte einer werdenden postindustriellen Dienstleistungsgesellschaft nach dem Wachstumsboom, insbesondere nach dem Ölpreisschock von 1973, einer kriselnden wirtschaftlichen Situation und einer seit Langem erstmals wieder steigenden Erwerbslosigkeit, machte die Bundesrepublik erst in jenen späteren Jahren durch. ${ }^{923}$ Schon als die reformfreudige Koalition aus SPD und FDP unter Willy Brandt (der in seiner Regierungserklärung im Oktober 1969 ankündigte: „Wir wollen mehr Demokratie wagen!“) die Regierungsgeschäfte aufnahm, waren die konstitutiven Auseinandersetzungen des SDS zwischen 1961 und 1967 im Grunde längst vergessen. Es waren die Kommunistischen Bünde und K-Gruppen, mit ihrem Klassenkampfpathos und ihrem autoritären Kaderprinzip - dem

918 Lorenz/Walter: 1968. Kulminationspunkt und politische Eruption, S. 349.

919 Vgl. Wehrs, Nikolai: Protest der Professoren. Der „Bund Freiheit der Wissenschaft“ in den 1970er Jahren, Göttingen 2014, S. 29 und 196-386.

920 Vgl. Koenen: Das rote Jahrzehnt, insbesondere die Ausführungen zum „Gründungsfieber" nach der Auflösung des SDS S. 183-206.

921 Vgl. Finkbeiner, Florian: Schicksalsjahre des Konservatismus. Konservative Intellektuelle und die Tendenzwende in den 1970er Jahren, Stuttgart 2017, S. 94-130.

922 Vgl. Schmidt, Daniel/Sturm, Michael: „Wir sind die, vor denen Euch die Linken immer schon gewarnt haben." Eine Einleitung, in: Livi, Massimiliano/Schmidt, Daniel/Sturm, Michael (Hg.): Die 1970er Jahre als schwarzes Jahrzehnt. Politisierung und Mobilisierung zwischen christlicher Demokratie und extremer Rechter, Frankfurt/New York 2010, S. 7-29, vgl. außerdem im selben Band besonders von der Coltz, Anna: Eine Gegen-Generation von 1968? Politische Polarisierung und konservative Mobilisierung an westdeutschen Universitäten, in: Livi, Massimiliano/Schmidt, Daniel/Sturm, Michael (Hg.): Die 1970er Jahre als schwarzes Jahrzehnt. Politisierung und Mobilisierung zwischen christlicher Demokratie und extremer Rechter, Frankfurt/New York 2010, S. 73-89.

923 Vgl. Schildt: Die Sozialgeschichte der BRD, S. 56-59 und Jarausch, Konrad H.: Verkannter Strukturwandel. Die siebziger Jahre als Vorgeschichte der Probleme der Gegenwart, in: Ders. (Hg.): Das Ende der Zuversicht? Die siebziger Jahre als Geschichte, Göttingen 2008, S. 9-26. 
„Organisationswahn der pseudoproletarischen Sekten “924 -, die anarchistisch-antiautoritäre Sponti-Szene und die linksterroristischen Zirkel um die RAF, die in den 1970er Jahren die öffentliche Aufmerksamkeit bestimmten. Während aus einem großen Teil der Neuen Linken bzw. der linkspolitisierten Studenten die Alternativ- und Anti-AKWBewegung sowie später, 1980, die Friedensbewegung hervorgingen und am Ende des „langen Marsches durch die Institutionen“ nicht nur eine neue Reihe von Funktionseliten in öffentlichem Dienst, Politik, Kultur und Wirtschaft sowie die parlamentarische Reintegration des oppositionellen Impulses durch die Gründung der Grünen Partei stand, stürzten sich viele orthodox-kommunistische Aktivisten in den Aufbau neuer Hierarchien, kanalisierten teils auch ihre lang gehegte „ohnmächtige Wut“ in neue Militanz. ${ }^{925}$ Zumindest taten sie all das noch bis etwa 1977; dann aber

„scheint die Entwicklung innerhalb dieser beiden Pole ausgelaufen zu sein. Die Toten von Stammheim und der Deutsche Herbst bezeichneten diesen Endpunkt. Was danach kam, war Grabgesang [...] Der linksradikalen Identität der Militanten entsprach fortan keine Praxis mehr, und somit gab es auch keine weitere Entwicklung, keine neuen Erfahrungen und Ideen. ${ }^{\text {“926 }}$

Eine Konsequenz dieses Auslaufens bildete die „große[] Wende der Linksradikalen zur Innerlichkeit ${ }^{4927}$, nicht nur in Gestalt des alternativen Rückzugs in die Subkultur, sondern auch als Hinwendung zur solipsistischen Politik der ersten Person, wie sie schließlich die Frankfurter und Berliner Hausbesetzerbewegung, mithin die autonome Szene kennzeichnen sollte. ${ }^{928}$ Aber nochmals: Die durch die Anti-AKW-Bewegung vorangetriebenen großen, teils ungeahnt eskalativ verlaufenden Demonstrationen der "Schlachten“ um Grohnde und Brokdorf; ${ }^{929}$ die Affäre um ein „klammheimliche Freude“ signalisierendes anonymes Sympathisantenschreiben aus der Feder des „Göttinger Mescalero“ anlässlich der Ermordung des Generalbundesanwalts Siegfried Buback durch die RAF und die sich anschließende, durch den Göttinger RCDS geschickt angestoßene Welle öffentlicher Empörung über die studentische radikale Linke und ihr leichtsinniges Verhältnis zur Gewaltfrage insgesamt (die dann auch der nun insgesamt suspekt erscheinenden Sponti- bzw. Alternativbewegung erhebliche Attraktionskraft kostete); ${ }^{930}$ die wachsenden Konflikte um Wohnraumpolitik und Stadtplanung in Großstädten wie Göttingen, Berlin und Hamburg, die vielerorts $\mathrm{zu}$ Bündnissen zwischen Anwohnern und linken Szene-Strukturen führten, überhaupt die allgemeine politische und „politisch-intellektuelle" Polarisierung, die die Regeneration des intellektuellen Konservatismus „aus liberaler Reformskepsis“ beflügelte, ${ }^{931}$ die

924 Vgl. Wolfgang Kraushaar, Die Frankfurter Sponti-Szene. Eine Subkultur als politische Versuchsanordnung, in: Archiv für Sozialgeschichte H. 44/2004, S. 105-121, hier S. 106 f. Jarausch: Deutsche Studenten, S. 228f., vgl. auch

926 Fischer, Joschka: Von grüner Kraft und Herrlichkeit, Reinbek 1984, S. $103 f$.

927 Ibid., S. 104.

928 Vgl. Geronimo: Feuer und Flamme. Zur Geschichte der Autonomen, Berlin/Amsterdam 1990, S. 168 sowie Kraushaar: Die Frankfurter Sponti-Szene.

929 Vgl. Gassert: Bewegte Gesellschaft, S. 146-151.

930 Vgl. die differenzierte und didaktische Darstellung der Abläufe in Walter: Rebellen, Propheten und Tabubrecher, S. 95-103. 
neuen Studentenstreiks 1976/77 in Berlin, ausgehend von der FU und anlässlich von Radikalenerlass und neuem Hochschulrahmengesetz, die hinsichtlich ihres wiederum deutlich den Eingang der netzwerkhaften, initiativenbasierten und auf die „mittlere Reichweite" zielenden Aktionsrepertoires von der einstigen APO in die "Neuen Sozialen Bewegungen" demonstrieren, ${ }^{932}$ auch die in schier unlösbaren Selbstfindungs- und Perspektivenkonflikten befindliche postsozialistische „Alternativbewegung“933, die sowohl während der Phase der K-Gruppen-Dominanz an den Universitäten als auch der darauf folgenden Sponti-Mobilisierung ${ }^{934}$ die Erfahrung machte, „daß die landläufige, angebotene Sozialität so leer und die revolutionäre keinen Deut besser ist“" ${ }^{\star 935}$ - all das gehört einer Dekade nach der Studentenbewegung von „1968“ an, so langfristig prägend diese auch für jene gewesen sein mag. Die 1970er, insbesondere ab 1973, waren auch das Jahrzehnt der Ölpreiskrisen und des Einbruchs der wirtschaftlichen Wachstumsdynamiken, damit eines fortgesetzten „Strukturwandel[s]“936 der deutschen Gesellschaft. Tatsächlich ließe sich mit einigem Recht behaupten, dass sich erst in den 1970er Jahren jene ganz großen Umbrüche voll durchsetzten, die sich im Jahrzehnt davor als neue Konfliktlinien aufgebaut hatten, und von deren Heraufdämmern die „68er" als neuartige konsumgesellschaftliche Protestbewegung antizipativ kündeten. ${ }^{937}$

Indes, all das ist nicht mehr Teil der Geschichte der großen westdeutschen Studentenbewegung der 1960er Jahre im engeren Sinne. Vieles, was heute mit „1968“ assoziiert wird - insbesondere der sozialliberale Mentalitätsumschwung und die Demokratisierungsemphase einer Generation - gehört dazu. Zwar lässt sich - so ein möglicher Einwand - die Zeitspanne zwischen 1976/77 und 1983, als viele politisierte Studierende, zuvörderst in Berlin, sich von den K-Gruppen ${ }^{938}$ und damit überhaupt von „organisationsund theoriebezogenen Politikformen ${ }^{4339}$ ab- und den spontaneistischen, antiautoritären, nun alternativbewegten Formen (an den Universitäten etwa den „Basisgruppen“) zuwandten $^{940}$, ebenfalls als Phase des studentischen oppositionellen Aktivismus auf-

932 Vgl. Krause et al.: Zwischen Revolution und Resignation?, S. 36-39 und 238ff. sowie Gassert: Bewegte Gesellschaft, S. 136-139; s. auch besonders Etzemüller: Ein Riss in der Ceschichte?, S. 11: „Der Staat und die Organisationen der Alten Linken haben das Monopol auf Reform, Umbau und Kritik der Cesellschaft verloren; seit den siebziger Jahren ist das in zahllosen Bürgerinitiativen gewissermaßen ,vergesellschaftet'. Das ist der unvorhergesehene, aber zweifellos bleibende Effekt von ,1968'."

933 Zu den Debatten über politische, praktische und strategische Aussichten einer „Alternativbewegung“, die im „Entwicklungsgrad positiver Lebensentwürfe“ - „nicht mehr die soziale Wirksamkeit eines Klassenkampfkonzeptes“ - das „Erfolgskriterium für ihre Arbeit“ erblickt, vgl. den Sammelband Kraushaar, Wolfgang (Hg.): Autonomie oder Cetto? Kontroversen über die Alternativbewegung, Frankfurt a.M. 1978, der auch Beiträge von Peter Brückner, Thomas Schmid und Bernd Leineweber enthält (Zitate vom Buchrücken).

934 Vgl. Krause et al.: Zwischen Revolution und Resignation?, S. 50.

935 Schmid, Thomas: Stämme und Stammtisch oder Bescheidener Vorschlag, die alternativen Institutionen wieder abzuschaffen, in: Kraushaar, Wolfgang (Hg.): Autonomie oder Getto? Kontroversen über die Alternativbewegung, Frankfurt a.M. 1978, S. 86-94, hier S. 91.

936 Jarausch: Verkannter Strukturwandel.

937 Vgl. Etzemüller: Ein Riss in der Ceschichte?, S. 13 und 220f.

938 Vgl. Krause et al.: Zwischen Revolution und Resignation?, S. 50.

939 Vgl. ibid., S. 45.

940 Vgl. Walter: Rebellen, Propheten, Tabubrecher, S. 97. 
fassen. Krause et al. sprechen hier im Falle Berlins gar von „eine[r] der stärksten politischen Mobilisierungen der Studentenschaft“. ${ }^{941}$ Zudem agitierte der weiterhin nach dem marxistisch-leninistischen Kaderprinzip strukturierte „Marxistische Studentenbund Spartakus“ (MSB Spartakus), DDR-treuer Studentenverband der DKP, weiterhin diszipliniert und erfolgreich; unter den politischen Hochschulorganisationen bildete er bis in die späten 1970er Jahre eine durchaus ernstzunehmende Kraft ${ }^{942}$ und mobilisierte in den 1980er Jahren, während einer Phase akademischer Überfüllung ${ }^{943}$, gemeinsam mit anderen DKP-nahen Organisationen für die westdeutschen Friedensbewegung. ${ }^{944}$ Oppositionelle Bewegung von studentischer Seite gab es also durchaus. Allerdings blieb deren gesamtgesellschaftliche Wirkung mager. „1977 [dem Schwerpunktjahr der linksterroristischen Anschläge, J. S.] war auch das Jahr der großen Wende der Linksradikalen hin zur Innerlichkeit. ${ }^{945}$ Man führte zunehmend dogmatisierte inneruniversitäre Auseinandersetzungen in esoterisch anmutenden Idiolekten; ${ }^{946}$ der studentische Linksradikalismus sank daher, trotz weiterhin postulierten gesellschaftsreformerischen Absichten, hinab in die Isolierung vom „Meinungsspektrum“ der Mehrheitsbevölkerung. ${ }^{947}$

Daher ist noch einmal zu fragen: Was sind die entscheidenden Besonderheiten und Charakteristika der von SDS und APO angeführten Studentenbewegung von „1968“ im engeren Sinne, worin liegt ihre Bedeutung für gesellschaftliche und politkulturelle Veränderungen? Will man das Flechtwerk sich überkreuzender Zusammenhänge entwirren, ist eine Konzentration auf ausgewählte Aspekte auch hier unausweichlich. Sie sollen wie folgt sortiert werden: a) „Generationskonflikt“versus Suche nach kollektiver Zugehörigkeit, b) internationale Einbettung und mediale Präsenz, c) subkulturelle Dynamik im gesamtgesellschaftlichen Mentalitätswandel, d) Distanz zu klassischen sozialen Bewegungen, und e) Gerinnen zum mythisch-kulturellen Artefakt.

a) „Generationskonflikt" versus Suche nach kollektiver Zugehörigkeit: In Deutschland werden Entnazifizierung und Antifaschismus oft als zentrale Anliegen der „68er“ angeführt, ja bisweilen erscheint die Beschäftigung mit der NS-Vergangenheit nicht nur als wichtiges „Politikum ${ }^{4948}$, sondern gar als identitätsstiftende säkular-religiöse Obsession der Studenten. ${ }^{949}$ Auch ist zu lesen, dass die Vergangenheitsbewältigung im „roten Jahrzehnt“ zu einer „deutsche[n] Selbstfaszination“ avanciert sei. ${ }^{950}$ Andere widerspre-

941 Vgl. Krause et al.: Zwischen Revolution und Resignation?, S. 50.

942 Vgl. das grafische Schema in ibid., S. 43.

943 Vgl. dazu eingehend Kapitel II.3.2 dieser Studie.

944 Vgl. Walter: Rebellen, Propheten, Tabubrecher, S. 104-114.

945 Fischer: Von grüner Kraft und Herrlichkeit, S. 104.

946 Vgl. Krause et al.: Zwischen Revolution und Resignation?, S. 35 und 45.

947 Ibid., S. 44. Manchem historisch versierten Leser mag diese Abgrenzung schematisch erscheinen. Verglichen mit der ausgreifenden gesellschaftlichen Relevanz der drei in dieser Studie herausgegriffenen Mobilisierungsphasen erscheint sie nichtsdestotrotz einerseits naheliegend. Andererseits deutet die in diesem Feld spärliche wissenschaftliche Literatur auf eine Forschungslücke hin, die zu füllen die Zielsetzung der hier unternommenen Längsschnittbetrachtung weit überstiege. Lorenz/Walter: 1968. Kulminationspunkt und politische Eruption, S. 363.

949 Vgl. Kießling, Simon: Die antiautoritäre Revolte der 68er. Postindustrielle Konsumgesellschaft und säkulare Religionsgeschichte der Moderne, Köln 2006, S. 274-283. 
chen hier und bezweifeln eine entscheidende Funktion der Auseinandersetzung mit der NS-Vergangenheit als „Kernbestandteil der Kollektiven Identität und des Framings für studentisches politisches Denken und Handeln“, habe dieser Themenkomplex doch nur in Bonn und an der FU Berlin eine entscheidende Politisierungsdynamik entfalten können. ${ }^{951}$ Tatsächlich hatte erst vor allem der Berliner SDS, später die APO immer auch die öffentliche Aufmerksamkeit auf die eigenen „Nazi-Eltern“ zu lenken versucht - mit diesem Selbstverständnis trug man selbst zur anfänglichen Beliebtheit der These eines „Generationskonflikts ${ }^{\text {"952 }}$ zwischen Studenten und Elterngeneration bei. Empirisch belegt werden konnte diese These allerdings nie: „Die Generationsthese wurde von manchen Wissenschaftlern aufgegriffen, ist aber nie durch biographisches Material hinreichend bestätigt worden, schon gar nicht in der Variante der NS-belasteten Eltern.“953 Wie der Soziologie Klaus R. Allerbeck auf der Grundlage eines Vergleichs deutscher und US-amerikanischer Studentenunruhen schon 1971 herausarbeitete, beteiligten sich insbesondere jene Studenten aktiv an den „68er“-Bewegungen, die im eigenen Elternhaus politischen und moralischen Rückhalt fanden. ${ }^{954}$ Überhaupt beobachtete Allerbeck entgegen aller Klischees vom rebellierenden Studenten als starkes Motiv des studentischen Engagements die Suche nach weitgehendem politischem und normativem Konsens mit dem eigenen sozialen Umfeld - den man, da die peers meist selbst aktive Studenten waren, auch fand. ${ }^{955}$ Trotz aller Auflösungstendenzen bildungsbürgerlicher Prägung der Studentenschaft einte sie ein spezifisches Verantwortungsempfinden angesichts der jeweiligen politischen Anlässe, waren sie doch

„wesentlich mehr politisiert als andere Jugendliche (56 \% zu $25 \%$ !), weil die besondere Studentenrolle den Jungakademikern nicht nur ein Solidaritätsgefühl, sondern auch den Anspruch einer besonderen Verantwortung vermittelte. ${ }^{\text {“956 }}$

Insofern wird man den Wahrheitsgehalt der klischeebehafteten Vorstellung vom „Generationskonflikt" auf die Formel bringen dürfen, dass die Studentenbewegung der

951 Vgl. Spix: Abschied vom Elfenbeinturm?, S. 445.

952 Vgl. Gassert: Bewegte Gesellschaft, S. 124-130 und Lorenz/Walter: 1968. Kulminationspunkt und politische Eruption, S. 363-366. Für ein exemplarisches Beispiel siehe Beck, Heinrich: Machtkampf der Generationen? Zum Aufstand der Jugend gegen den Autoritätsanspruch der Cesellschaft, Frankfurt a.M. 1970, wo davon gesprochen wird, dass „keine Schule, kein Betrieb, auch kaum eine Familie“ mehr existiere, „in der nicht die Jungen den Alten den Prozeß machen." (Buchrücken) Der Autor, seines Zeichen Professor für Philosophie, erhebt in dem Band den Anspruch, wie ein Gesprächsmoderator zwischen den solcherart gezeichneten Cenerationsfronten zu vermitteln, neigt aber zur Pädagogisierung des beobachteten Konfliktpotenzials, wenn er die Lösung in einer „inneren Umstellung“ in Richtung gegenseitigen Verständnisses, des Verzichts auf „Verabsolutierungen" und wechselseitiger Anerkennung erblickt, ibid., S. 50-73. Schmidt: Der späte Nachhall von '68, S. 710.

954 „Studenten aus politisch liberalen und linken Elternhäusern unterstützen die Studentenbewegungen wesentlich häufiger als Studenten, deren Eltern politisch konservativ sind." Allerbeck, Klaus R.: Eine strukturelle Erklärung von Studentenbewegungen in entwickelten Industriegesellschaften, in: Kölner Zeitschrift für Soziologie und Sozialpsychologie, H. 23/1971, S. 478-493, hier S. 479.

955 Vgl. ibid., S. $481 f$.

956 Jarausch: Deutsche Studenten, S. 235. 
sechziger Jahre den juristisch, politisch und massenmedial schon vorhandenen Trend ${ }^{957}$ zur Aufarbeitung der NS-Vergangenheit bekräftigt und zur weiteren Sensibilisierung der Bevölkerung beigetragen hat - die entscheidenden „Initiatoren einer selbstkritischen Vergangenheitsreflexion“ ${ }^{4958}$ aber hatte sie nicht hervorgebracht. ${ }^{959}$ Die Empörung über die in die NS-Vergangenheit verwickelten bundesrepublikanischen Autoritäten ist auch als Identität und Zugehörigkeit stiftendes Element der Studentenbewegung zu sehen, ablesbar am okkasionalistischen Monieren vermeintlich herrschender oder drohender „faschistoider“ Zustände in der Bundesrepublik, etwa in Gestalt eines Transparents am Architekturgebäude der TU Berlin vom 28. Mai 1968, das den Protest gegen die Notstandsgesetzgebung in die Formel „STREIKT GEGEN DIE NS-GESETZE“ goss. ${ }^{960}$ „Die Generationserzählung von den Achtundsechzigern als den Vorkämpfern gegen das braune Erbe der Väter wurde von den Angehörigen dieser Altersgruppen begierig aufgegriffen. Denn erst durch diese nachholende Erzählhandlung konstituierten sie sich als eine politische Generation.“961

b) Internationale Einbettung und mediale Präsenz: Zudem überformte der antifaschistisch verbrämte jungakademische Antiautoritarismus eine in vielen westlichen Ländern $\mathrm{zu}$ beobachtende Politisierung der Jugend. ${ }^{962}$ Ohne dieses Phänomen einer weltweiten Jugendrevolte ist die besondere Dynamik der Studentenbewegung von „1968“ nicht zu verstehen. ${ }^{963}$ Sie erst machte die Selbstverortung in einem globalen „Antiimperialis-

957 „Die massenmedial verbreiteten Informationen der Flakhelfergeneration, kombiniert mit diversen Kulturerzeugnissen (insbesondere verstörende Filme und Bilder), stimulierten seinerzeit wissenschaftliche Forschungsarbeiten und allgemeines Nachdenken. [...] Wichtige Etappen auf dem Weg zu einem aufgeklärten Vergangenheitsbild, in dem vor allem die simple Schuldzuweisung an den ,Führer' und eine zahlenmäßig kleine NS-Elite aufhörte, wurden einige Jahre vor ,68' und ohne die 68er genommen [...] "Lorenz/Walter: 1968. Kulminationspunkt und politische Eruption, S. 364 und 365. Zu nennen sind überdies Gerichtsverfahren wie der Eichmann-Prozess in Israel 1961 und die deutschen Auschwitz-Prozesse ab 1963.

958 Ibid., S. 363.

959 Siehe dazu jüngst auch Hodenberg: Das andere Achtundsechzig, S. 74: „An die Stelle des Mythos von gefühlskalten Eltern und revoltierenden Söhnen tritt ein Bild, in dem beidseitig hergestelltes, selektives Schweigen die Harmonie absicherte."

960 Vgl. Gassert: Bewegte Cesellschaft, S. 127, Abb. 9.

961 Hodenberg: Das andere Achtundsechzig, S. 74.

962 „The eruption of student protest in the 1960s was a global phenomenon, the magnitude of which was acknowledged by contemporary observers, enthusiastic supporters, and fierce critics alike." Klimke, Martin: The Other Alliance. Student Protest in West Germany and the United States in the Global Sixties, Princeton and Oxford 2010, S. 1.

963 „Als deutsche Variante einer internationalen Jugendrevolte besaß die Studentenbewegung einen eigentümlichen Charakter. Obwohl die Teilnehmer sich dessen kaum bewußt waren, standen sie in der linksradikalen Tradition der deutschen Studenten von 1848, der Finkenschaft oder Weimarer Sozialisten. Gleichzeitig waren sie aber auch eine lokale Ausprägung des weltweiten Intellektuellenprotests gegen die amerikanische Beteiligung am Vietnamkrieg, der sich von amerikanischen Hochschulen in andere Länder ausbreitete. Während in anderen entwickelten Industrienationen die Frustrationen der Massenhochschule Studenten zum Protest anregten, kam in Deutschland noch das Restaurationsklima der Ordinarienuniversität dazu. Weit verbreitete Ressentiments gegen autoritäre politische Strukturen (de Gaulle in Frankreich) wurden hier durch den Schatten des ,Dritten Reichs' verschärft, der Notstandsgesetze und Große Koalition besonders drohend erscheinen ließ." Jarausch: Deutsche Studenten, S. $226 \mathrm{f}$. 
mus“ bzw. in einer postkolonialen Solidaritätsbewegung ${ }^{964}$ - bzw. in einer „transnational imaginierte[n] Revolution“965 - plausibel, ${ }^{966}$ und verlieh den jeweiligen nationalen Konfliktthemen den Charakter stellvertretender Auseinandersetzungen. ${ }^{967}$ In den USA lag der Schwerpunkt der Auseinandersetzung beispielsweise in den Jahren 1963 bis 1966, beginnend mit dem Mord an US-Präsident John F. Kennedy, setzte sich aber u. a. über die Bürgerrechtsbewegung bis Ende der 1960er Jahre fort; ${ }^{968}$ in Frankreich entzündete sich die Wut der „Nouvelle Gauche“ im Mai 1968 an der unnachgiebigen Linie des Präsidenten und Generals Charles de Gaulle ${ }^{969}$ und in Griechenland und Spanien richtete sich der juvenile Unmut gegen die damaligen Militärdiktaturen, ${ }^{970}$ während im langjährig sozialdemokratisch regierten Schweden die Jugendrevolte stärker einer verbalradikal politisierten „Lebensstilrevolution“ inklusive gewalttätiger Eskalationsspirale nach deutschem Muster ähnelte, dabei allerdings quittiert mit deutlich empathischeren Reintegrationsofferten in Richtung der aufgebrachten Jugend. ${ }^{971}$ Insbesondere von der US-amerikanischen New Left, der dortigen Bürgerrechtsbewegung und der ebenfalls unter dem Kürzel SDS (Students for a Democratic Society) firmierenden studentischen Linken bezog der deutsche SDS - inspiriert von Dutschke, jedoch vorangetrieben durch Netzwerker wie Michael Vester und theoretisch untermauert durch SDS-Mitglieder wie Ekkehart Krippendorff - Bewegungswissen und Inspirationen für das eigene gegenkulturelle Aktionsrepertoire (Stichwort: sit-ins und teach-ins), zudem zusätzliche Legitimation für die Selbstverortung im globalen antiimperalistischen und antifaschistischen Kampf. ${ }^{972}$ Viele der politischen Impulse von „1968“ wie etwa die Gegnerschaft gegen die Beteiligung der USA im Vietnamkrieg, innervierten zeitgleich in verschiedenen Ländern die oppositionelle Grundhaltung und bestimmten das politische Empfinden. Man fühlte sich vernetzt mit den „Freiheitskämpfen“ gegen den „neoimperialistischen“ Westen, die man in den Kriegen in Algerien, Kuba, Kongo, Iran, Vietnam, später auch in palästinensischen Paramilitärs sah, projizierte auf diese Auseinandersetzungen die

964 Vgl. Gassert: Bewegte Gesellschaft, S. 120-124.

965 Etzemüller: Ein Riss in der Geschichte?, S. 159.

966 „Die Dritte Welt mit den dort ausgefochtenen Dekolonisationskonflikten und Stellvertreterkriegen galt seit den frühen sechziger Jahren für immer mehr sich links orientierende Studenten in den westlichen Ländern als Schauplatz anhaltender Ausbeutung und gewaltsamer Unterdrückung durch die kapitalistischen Staaten." Michels: Schahbesuch 1967, S. 89.

967 Vgl. Klimke: The Other Alliance, S. 5.

968 Vgl. Kraushaar: 1968. Das Jahr, das alles verändert hat, S. 124.

969 Vgl. ibid., S. 125-139, außerdem Gilcher-Holtey, Ingrid: „Die Phantasie an die Macht“. Mai 68 in Frankreich, Frankfurt a.M. 1995, S. 232-258.

970 Vgl. Klimke: The Other Alliance, S. 5.

971 Vgl. Etzemüller: Ein Riss in der Ceschichte?. S. 13, 111-129, 145-158 und 218f.

972 Vgl. Schmidtke, Michael A.: Reform, Revolte oder Revolution? Der Sozialistische Deutsche Studentenbund (SDS) und die Students for a Democratic Society (SDS) 1960-1970, in: Gilcher-Holtey, Ingrid (Hg.): 1968. Vom Ereignis zum Gegenstand der Geschichtswissenschaft. Geschichte und Gesellschaft, Sonderheft 17, Göttingen 1998, S. 188-206, insbesondere S. 193-196 und 205f. sowie Klimke: The Other Alliance, S. 10-39 und 86-100. Klimke streicht ibid., S. 115, zur Bedeutung der Bürgerrechtsbewegung für den SDS heraus: „The fate of revolutionary change was inextricably tied to the progress of the African American movement, which served as a guide, source of inspiration, and partner for the student movement." 
eigenen Hoffnungen auf fundamentalen gesellschaftlichen Wandel. ${ }^{973}$ Diese Impulse, bisweilen einem „undurchschaute[n] Kult um den Internationalismus“974 aufsitzend, konnten auch zum plötzlichen und politisch verhängnisvollen Bruch mit bisherigen Verbündeten führen. Als eines der vielen möglichen Beispiele mag hier die Solidarisierungswelle mit der so genannten Palästinensischen Befreiungsorganisation (PLO) nach dem Sechstagekrieg 1967 dienen, in welchem Israel sich erfolgreich gegen den Angriff der arabischen Staaten Ägypten, Jordanien und Syrien zur Wehr setzte und dabei mehrere Gebiete, u. a. den Gaza-Streifen, die Golanhöhen und das Westjordanland, okkupierte. Während es bis 1967 eine proisraelische „einheitliche Linie“ der westdeutschen und US-amerikanischen Linken gegeben hatte, spalteten sich nun hier wie dort die Fronten zwischen prozionistischen (meist älteren) und antizionistischen (meist jüngeren) Gruppen, da letztere den palästinensischen „Befreiungskampf“ als Teil „antiimperialistischen" Widerstands wahrnahmen. ${ }^{975}$ Solidaritätsbewegungen entstanden weltweit, motiviert und vorangetrieben durch die PLO und den postkolonialen Internationalismus. ${ }^{976}$ Manche APO-Kreise pflegten gute Kontakte etwa mit der palästinensischen Partei Fatah, die bereits seit 1964 die Vernichtung Israels zum Ziel hat. ${ }^{977}$ In diesem Zusammenhang ist auffällig, dass zumindest die rabiat antiwestlichen Teile der Studentenbewegung Türen in Richtung antisemitischer Vernichtungsphantasien öffneten, wie der - gescheiterte - Anschlag auf das Jüdische Gemeindehaus in Berlin am 09. November 1969 verrät, zu dem sich die linksterroristische Gruppe „Tupamaros WestBerlin“, gegründet von Dutschkes Weggefährten Dieter Kunzelmann - der im selben Jahr eine militärische Kurzausbildung in einem Fatah-Trainingslager erhielt ${ }^{978}$-, bekannte. ${ }^{979}$ Als anderes eindrucksvolles Beispiel des Internationalismuskultes mag auch der von Martin Klimke rekonstruierte Kontakt zwischen deutschen SDS-Aktivisten und der US-amerikanischen antiimperialistischen Black Panther Party dienen, welche ähnlich wie die deutsche antiimperialistische Linke über die Frage militanter Praxis zerbrochen war. ${ }^{980}$ In Westdeutschland gründeten sich nach der Ermordung von Martin Luther King am 04. April 1968 Black Panther-Solidaritätskomitees, darüber hinaus or-

973 Gassert: Bewegte Gesellschaft, S. 121f.

974 Kraushaar: 1968. Das Jahr, das alles verändert hat, S. 321.

975 Vgl. Ben Prestel, Joseph: Palästina-Solidarität. Bruchstelle einer globalen Linken, in: Merkur. Gegründet 1947 als Deutsche Zeitschrift für europäisches Denken, 73. Jg., H. 839/2019, S. 61-67, hier S. 61.

976 Vgl. ibid. In den USA erfüllte darüber hinaus das Milieu um die Black Panther Party, das die „Palästina-Solidarität als Teil afroamerikanischer Politik in den $1960 e r$ und 1970er Jahren“ aufasste, eine wichtige Scharnierfunktion. Ibid., S. $62 f$.

977 Vgl. Introduction to the Fateh Constitution. The Essential Principles of the Constitution, in: Ariel Center for Policy Research, online einsehbar unter: http://www.acpr.org.il/resources/fatehconstitution.html[eingesehen am 01.08.2019]

978 Vgl. Koenen: Das rote Jahrzehnt, S. 176f.

979 Vgl. Kraushaar, Wolfgang: Die Bombe im Jüdischen Gemeindehaus, Hamburg 2005.

980 Vgl. Klimke: The Other Alliance, S. 126. Einige Black Panthers optierten in den frühen 1970er Jahren unter Berufung auf eine voluntaristisch gestimmte eklektizistische Theorie-Mixtur aus Che Guevara, Georg Lukácz, Herbert Marcuse und Frantz Fanon für den bewaffneten Kampf gegen gesellschaftlich bedingte ökonomische und rassistische Unterdrückung, während andere ihre Praxisperspektiven in sozialen Projekten und Stadtteilarbeit erblickten. Vgl. ibid., S. 108-142. 
ganisierten insbesondere Frankfurter Studierende Solidaritätsdemonstrationen. ${ }^{981}$ Die kaum verhohlene Instrumentalisierung der US-amerikanischen innen- und außenpolitischen Konflikte für die Auseinandersetzungen des deutschen SDS, erkennbar etwa in der Vermengung mit der bundesrepublikanischen NS-Vergangenheit ${ }^{982}$ und einer vermeintlich drohenden Faschisierung hier wie dort ${ }^{983}$, erreichte in der Zeitschrift Agit 833 ihren Höhepunkt: Die Mai-Ausgabe warb, illustriert mit dem Logo des schwarzen Panthers, für eine Demonstration gegen eine US-Militärparade („U.S.A. SA = SS“, „Amis raus aus Westberlin“), und die Juni-Ausgabe veröffentlichte, ebenfalls garniert mit schwarzem Panther, das Gründungsmanifest der RAF, „Die Rote Armee aufbauen!“984 Offenbar verhalfen die Auseinandersetzungen um Bürgerrechtsbewegung, ethnische Diskriminierung und die Frage antistaatlicher „Gegengewalt“ im transatlantischen Transfer dem deutschen Studentenprotest zu neuer Entschlossenheit, und nicht zuletzt auch dem genannten Nukleus antiimperialistischer Terroristen zu legitimatorischem Material. ${ }^{985}$

Eine entscheidende, ebenfalls international eingebettete, Voraussetzung für die öffentliche Präsenz der „68er“ wie für die Reichweite ihrer Parolen, Symbole, Provokationen und Aktionen war technologischer Natur: die Ausbreitung der Massenmedien, insbesondere des Fernsehens und des Bildjournalismus. ${ }^{986}$ Die APO konnte sich auf eine Vietnam-Kriegsberichterstattung stützen, die sich den deutschen Bürgerinnen und Bürgern visuell eingebrannt hatte. Und sie nutzte selbst die Kanäle von TV, Zeitung und Fernsehen, um sich öffentlich Geltung zu verschaffen und die Bevölkerung zu polarisieren. ${ }^{987}$ Die Studentenbewegung erzeugte politkulturell persistente Bilder und visuelle Codes: „1968 wirkt im Vergleich zu früheren Protestbewegungen in Deutschland sehr viel stärker über sein visuelles und performatives Repertoire als über die konkreten Inhalte, Motive und politischen Verlautbarungen derjenigen, die opponierten. ${ }^{“ 988}$ „1968“ trug somit zu einem nicht geringen Teil zur Revolutionierung der „Wahrnehmung“ gesellschaftlicher Zusammenhänge insgesamt bei. ${ }^{989}$ Im virtuellen Museum der politischen

981 Vgl. ibid., S. 116-122.

982 Vgl. ibid., S. 129.

983 Schon 1968 und 1969 verglichen die SDS-Aktivisten Ekkehart Krippendorff und Karl Dietrich Wolff das Handeln der USA während des Vietnamkriegs mit dem europäischen Faschismus der 1930er und 1940er Jahre: „Drawing upon the German past and upon a Marxist analysis, Krippendorff interpreted the actions of the U. S. government as a gradually evolving, globally operating fascism that made cooperation between the German and American movements an existential necessity [...]", ibid., S. 92. Wolff, der auf Einladung des amerikanischen SDS die USA bereiste, wurde dort vor das Komitee für unamerikanische Umtriebe geladen, beschimpfte den anwesenden Senatoren als „criminal bandit“ und wurde schließlich des Landes verwiesen. „Wolff purposely extended the reference to fascism to include the American system, indicating the close similarities between the German past and current U. S. politics in the German New Left's interpretation of global power relations." Ibid., S. 105.

984 Zit. nach ibid., S. 125 und 128.

985 Vgl. ibid., S. $142 f$.

986 Vgl. Gassert: Bewegte Gesellschaft, S. 129.

987 Vgl. ibid., S. $106 f$.

988 Ibid., S. 105.

989 Gassert, Philipp: „1968“ als Wahrnehmungsrevolution. Eine kluge These, die umfassender untersucht werden müsste, in: Gilcher-Holtey, Ingrid (Hg.): „1968“ - eine Wahrnehmungsrevolution? 
Kultur (West-)Deutschlands sind „1968“ und dazugehörige Bilderwelt heute unerlässliches Exponat:

„Dynamisch, im Rhythmus lauter Rufe voranstrebender Ketten von Protestlern, Ho Chi Min-Plakate und -Cebrüll, gewalttätige Konfrontationen mit Ordnungshütern und Wasserwerfern, daneben viele kleinere Protestinszenierungen wie Sit-Ins, Teach-Ins und,gezielte Regelverletzungen', ostentativ zur Schau gestellter Nonkonformismus in Hörsälen und vor Gerichten, Vollversammlungen mit bekannten Rednern am Podium, Diskussionen in verrauchten Seminarräumen und Wohnzimmern, neue Lebensformen wie Kommunen und Kinderläden, nackte Körper als Chiffren der, sexuellen Befreiung. Diese Bilder sind durch Filmdokumentationen, großformatige Bildbände und Ausstellungen im kulturellen Gedächtnis der Deutschen fest verankert und kanonisiert. “990

Diese tragende Bedeutung medialer Repräsentationstechnologie macht sich auch in der neuartigen c) subkulturellen Dynamik der Studentenbewegung im gesamtgesellschaftlichen Mentalitätswandel geltend. Denn vieles, was damals als Partizipation einfordernde und gegenkulturelle Politisierung aufgefasst wurde und heute noch wird, erscheint bei genauerem Hinsehen als subkulturelle Lebensstilrevolte in einer neuen USgeprägten Konsumgesellschaft. ${ }^{991}$ Die 1960er Jahre waren auch der Auftakt jener „neuen Jugendkultur in den urbanen Gesellschaften“, die, getragen durch „Blue jeans und Rockmusik [...] zur Markenzeichen der ,modernen“ Jugend“ wurden - „der Minoritäten, die sich zu Majoritäten wandeln sollten. ${ }^{\text {“992 }}$ Von der älteren Generation tatsächlich als rebellisch empfunden, trug diese mittelschichtsübergreifende Jugendkultur für europäische Ohren ungewohnte karibische, lateinamerikanische und afrikanische Rhythmen $^{993}$ in die Platten- und Kassettenspieler; sozialintegrative Tanzstile wie der Twist ${ }^{994}$, Pop- und Rockmusik, lange Haare, lässige Kleidung und sexuelle Liberalität waren die Mittel des konsumgetragenen, zugleich die "kulturelle Hegemonie der USA“ symbolisierenden, Bruchs mit Konventionen, ${ }^{995}$ der über "transnationale Umwege“ zwischen 1961 und 1965 auch Deutschland erreichte:

„Pop wurde zur ersten funktionierenden Universalsprache und über kommerzialisierbare Musik setzte eine nie dagewesene globale Kommunikation über Zeichen ein. [...] Die Massenmedien - allen voran das Fernsehen, Radio, Illustrierte, Tageszeitungen, aber auch die seriell und massenhaft reproduzierten Tonträger selbst - standen im

Horizont-Verschiebungen des Politischen in den $1960 e r$ und 1970 Jahren. Zeitgeschichte im Gespräch, Bd. 16. München 2013, S. 123-134.

990 Gassert: Bewegte Cesellschaft, S. 105 (Herv. i. O.). Vgl. auch Hodenberg: Das andere Achtundsechzig, S. 11.

991 Vgl. Grazia, Victoria de: Irresistible Empire. America's Advance through Twentieth-Century Europe, Cambridge 2006.

992 Hobsbawm: Das Zeitalter der Extreme, S. 410.

993 Mrozek, Bodo: Jugend - Pop - Kultur. Eine transnationale Geschichte, Berlin 2019, S. 443-454.

994 Ibid., S. 441.

995 Hobsbawm: Das Zeitalter der Extreme, S. 410f. 
Dienste einer Multiplikation und Ausbreitung jener Ereignisse, in denen ,counterculture' sich äußerte." ${ }^{996}$

Auf diese Universalsprache konnte die Studentenbewegung aufsatteln. Sie konnte sich angesichts der counterculture, dem Sehnsuchtsort Kalifornien, im Recht fühlen mit ihren „kalkulierten Regelverletzungen“997, ihrem Angriff auf als verkrustet empfundene gesellschaftliche Hierarchien, wie sie sie in verantwortlichen Autoritäten, in traditionellen Höflichkeits- und Sittlichkeitsregeln und in rigider Sexualmoral verkörpert sahen:

„Autorität, Ordnung, Gehorsam, Pflicht, Leistung, Zuverlässigkeit, Sauberkeit sowie Ethik und Moral insgesamt - der gesamte Kanon an sozialen Werten wurde auf den Prüfstand gestellt. Und das neue Schlüsselwort lautete ,Emanzipation'““998

Damit trafen sie trotz allmählicher Liberalisierungstendenzen - auch eines sukzessive freizügiger werdenden Geschlechterverhältnisses - durchaus den Nerv vieler provoziert reagierender „konservativer Werteverfechter“999, die einen durch den American Way of Life getriebenen Kulturverfall witterten. Auch die Protestformen der go-ins, sit-ins und teach-ins waren der US-amerikanischen Bürgerrechtsbewegung entlehnt, insofern vorexerzierte und vorlegitimierte Praktiken. Schließlich gingen die "systemkritischen“ Parolen der APO auf Demonstrationen und Veranstaltungen Hand in Hand mit Popund Rockmusik - eine völlig neue Verbindung von „Genuss und Politik“ unter dem nun lifestye-durchsetzten Motto der "Demokratisierung“ - darin liegt die kollektivierende und beflügelnde Einbettung „in eine Lebensstilrevolution“. ${ }^{1000}$ Ironischerweise zementierte gerade diese neue Form ästhetisierter Rebellion die neuen Wahrnehmungsformen und Kommunikationswege einer amerikanisierten Konsumgesellschaft, die über die bisweilen antiamerikanischen Tiraden des SDS angegriffen wurde. ${ }^{1001}$ Kurzum: Es entstand eine neue studentische Subkultur. Damit erfüllte die Studentenbewegung für einen großen Teil der Studierenden Funktionen, die der diskreditierte und auch offensiv bekämpfte Korporatismus vakant gelassen hatte, war somit in gewisser Hinsicht ein Surrogat für den verblichenen Studentenstolz des früheren Verbindungswesens, stiftete neue Identität:

„Einmal etabliert, bot die Studentenrevolte als Bewegung eine Gegenrolle zum Brotstudium, eine neue Gruppenidentität und eine andere Wertskala, so daß sie sich sozusagen selber fortsetzte. Obwohl sie den traditionellen Korporatismus radikal ablehnte, füllte die Studentenbewegung doch ähnliche gesellschaftliche Bedürfnisse mit ihrer Sondersprache, ihren Initiationsriten (Demos) und ihrer Gegengeselligkeit (Beatmusik). “1002 Obwohl nur wenige Studenten in ideologischen Wohngemeinschaf-

996 Tanner, Jakob: „The Times They Are A-Changin". Zur subkulturellen Dynamik der 68er Bewegungen, in: Cilcher-Holtey, Ingrid (Hg.): 1968 - Vom Ereignis zum Gegenstand der Ceschichtswissenschaft. Geschichte und Gesellschaft, Sonderheft 17, Göttingen 1998, S. 207-223, hier S. 211.

997 Vgl. Jarausch: Deutsche Studenten, S. 232.

998 Kraushaar: 1968. 100 Seiten, S. 25 f.

999 Lorenz/Walter: 1968. Kulminationspunkt und politische Eruption, S. 353

1000 Gassert: Bewegte Gesellschaft, S. 130.

1001 Vgl. Klimke: The Other Alliance, S. $6 f$.

1002 Jarausch: Deutsche Studenten, S. 235. 
ten hausten, übte die sich dort herausbildende Gegenkultur einen starken Einfluß auf den Lebensstil der anderen Kommilitionen aus, die sich ähnlich salopp kleideten und oft auch rebellisch gebärdeten. [...] In der Erfindung neuer Lebensformen entwickelte die Studentenbewegung eine eindrucksvolle Schöpferkraft." ${ }^{\text {"1003 }}$

In der Folge gelang es den „68ern“ in der zweiten Hälfte des Jahrzehnts, ein „nonkonformistisches Meinungsklima“ zu etablieren und einen „Bedeutungswandel des kritischen Linksintellektuellen vom gesellschaftlichen Außenseiter zur Symbolfigur des Akademikers“ zu leisten - „ein wichtiger Einschnitt in der Entwicklung des tertiären Bildungssektors " ${ }^{1004}$ und eine "umfassende gesellschaftliche Irritationserfahrung ${ }^{\text {“ }}{ }^{1005}$ Lobt man die Studentenbewegung der 1960er Jahre heute für die von ihnen forcierte „Kulturrevolution“, ist dieser "Sturmlauf auf die Institutionen“ gemeint, „auf Universitäten und Schulen, auf Gerichte und Parlamente, auf Verlage und Redaktionen. Kaum eine der nach ihrer Legitimität befragten Einrichtungen ist von dieser Offensive unangetastet geblieben. ${ }^{1006}$ Es ist wichtig, in einer Zeit, in der die Ästhetisierung des Rebellischen zum kulturindustriell omnipräsenten Kitsch heruntergekommen ist, sich an Empathie für dieses einst gesamtgesellschaftlich einschneidende Phänomen zu versuchen, auch weil das wohl als größter langfristiger Effekt von „1968“ in der Bundesrepublik anzusehen ist. Die gesellschaftlichen Konfliktlinien verlagerten sich infolgedessen stärker von materiellen bzw. sozialen auf kulturelle Arenen. ${ }^{1007}$ Entscheidend ist aber auch hier die Feststellung, dass wesentliche Liberalisierungsprozesse bereits früher eingesetzt hatten. „1968“ beschleunigte einen bereits in vollem Gang befindlichen soziomentalen „Wertewandel“ in der deutschen Gesellschaft, aber initiierte ihn nicht. ${ }^{1008}$ Insofern wäre es selbstverständlich eine schwere Verzerrung, die gesamtgesellschaftlichen Veränderungsschübe um „1968“ allein auf „eine kleine studentische Elite in den Hochburgen der Protestbewegung, die damals nicht mehr als ein paar tausend zählte ${ }^{\text {1009 }}$, zurückzuführen.

Allerdings: Mitunter scheint der subkulturelle Aspekt der Studentenbewegung überschätzt, ja die studentischen Aktivisten mit der sie umgebenden Jugendrevolte schlechterdings in eins gesetzt zu werden. So merkt der Historiker Philipp Gassert an, dass es sich bei den "68ern“ um eine weitgehend veranstaltete, $d$. h. primär metaphorisch zu verstehende, Rebellion gehandelt habe. ${ }^{1010}$ Tatsächlich kann er dafür plausible Beispiele anführen. Die pathetische Parole der „sexuellen Befreiung“ etwa verdeckt erstens, dass der Zug zur sexuellen Liberalisierung bereits die gesamte Gesellschaft

1003 Ibid., S. 238.

1004 Krause et al: Zwischen Revolution und Resignation?, S. 15.

1005 Kraushaar: 1968.100 Seiten, S. $25 f$.

1006 Ibid.

1007 Ibid., S. $106 \mathrm{f}$.

1008 Vgl. Lorenz/Walter: 1968. Kulminationspunkt und politische Eruption, S. 351.

1009 Hodenberg: Das andere Achtundsechzig, S. 11.

1010 „Was konservative Kritiker damals wie heute nicht verstanden und verstehen: Die Rebellion von 1968 war ein Stück weit inszenierter, wie Joachim Fest in seinem Jahresrückblick 1968 deutlich machte." Gassert: Bewegte Gesellschaft, S. 111; ähnlich Hodenberg: Das andere Achtundsechzig, S. gf. und $185 f$. 
ergriffen hatte, ${ }^{1011}$ zweitens aber auch, dass es dem größten Teil der politisierten Studierenden zuvörderst um eine Enttabuisierung des Themas „Sexualität“ und um eine freiere Gestaltung der eigenen - zumeist weiterhin monogamen - Partnerwahl bei bemerkenswert intakten klassischen Geschlechterrollen hinsichtlich Lebensplanung und Ehe sowie bei zunehmend durch die sich formierende Frauenbewegung ${ }^{1012}$ angeprangerten Macho-Strukturen, welche die Frage geschlechtlicher Gleichstellung angesichts der primären „Klassenfrage“ tendenziell zum „Nebenwiderspruch“1013 depotenzierte, bis in die Reihen des SDS hinein - berühmt hier die in der konkret abgedruckten Rede Helke Sanders auf der 23. Delegiertenkonferenz des SDS am 13. September $1968-{ }^{1014}$ gegangen war, nicht um ungezügelte Libertinage im Stile der „Kommune I“. ${ }^{1015}$ „Im Kern“, so Gassert weiter, hätten sich die „68er" weitgehend „konform zur neuen Gesellschaft“ verhalten, obwohl das weder ihrem Selbstbild noch der Fremdwahrnehmung von außen entsprach, noch den daraus später erwachsenen Mythen.“1016 Aber: Was als versöhnliche Ehrenrettung dieser Bewegung gegen alarmistische konservative Kritiker damals und heute gemeint ist, wirkt angesichts der Suche nach und dem theoretisch-intellektuellen Bemühen um eine linke Politik jenseits der kompromissorientierten parlamentarischen Bahnen, auch angesichts der institutionell entbundenen „regierungs- und staatskritischen Haltung ${ }^{\text {“1017 }}$ in den linken Jugendorganisationen inklusive des SDS, schließlich angesichts des authentisch nachzulesenden ohnmächtig-aktionistischen Zorns der Jahre nach 1967 doch seltsam entmündigend, verniedlichend, ja „vergemütlichend“. ${ }^{1018}$

d) Distanz zu klassischen sozialen Bewegungen: Ein Grund für die heute zu beobachtende Neigung, die Protestimpulse der APO durch gönnerhafte Einordnungen zu relativieren und auf ihre inszenatorisch-subkulturellen Aspekte zu reduzieren, liegt sicherlich im Scheitern an der Bildung einer schichten- und milieuübergreifenden sozialen Bewegung im klassischen Sinne: „Die soziale Ironie der Studentenbewegung war, daß sie nicht zur Erneuerung der Gesellschaft, sondern zur Formierung einer oppositionellen Subkultur führte. “1019 Das fällt insbesondere im kontrastiven Vergleich mit der französischen (aber auch der italienischen) „68er“-Bewegung auf. Dort sprang der oppositionelle Funke der „Nouvelle Gauche“ trotz analogen politisch-organisatorisch-strategischen

1011 „Achtundsechzig markiert [...] keine Zäsur in der Ceschichte der Sexualität.“ Es „schlug sich ein versprengtes Grüppchen von Achtundsechzigern seitwärts nach links in die Büsche, wo es sich einige periphere Scharmützel mit einem kleinen, schon länger besiegten Flügel betagter Sexualkonservativer lieferte." Hodenberg: Das andere Achtundsechzig, S. 186.

1012 Vgl. Etzemüller: Ein Riss in der Ceschichte?, S. 183-187.

1013 Ibid., S. 177.

1014 Vgl. Hodenberg: Das andere Achtundsechzig, S. 103-150, zur Rede Sanders S. 114f. und Etzemüller: Ein Riss in der Geschichte?, S. 176-

1015 Vgl. Gassert: Bewegte Gesellschaft, S. 113. „Weil dieser kleine Flügel die Bindung von Sex an Treue, romantische Liebe und Ehe aufzulösen suchte, wurde er von der Eltern- und Großelterngeneration wie auch von der großen Mehrheit der Jugend und vielen Frauen abgelehnt." Hodenberg: Das andere Achtundsechzig, S. 185.

1016 Gassert: Bewegte Gesellschaft, S. 111.

1017 Lorenz/Walter: 1968. Kulminationspunkt und politische Eruption, S. 349.

1018 Eßbach: Aufstand der Werte?, S. 4.

1019 Jarausch: Deutsche Studenten, S. 238. 
Aporien ${ }^{1020}$ und trotz der vergleichbaren Geburt der Studentenbewegung aus „winzige[n] Dissidentenzirkel[n] “1021 im Mai 1968 auf die Arbeiterschaft über; es kam, beginnend bei Arbeitsniederlegungen in den Flugzeugwerken Sud-Aviation in Bougenais bei Nantes am 14. Mai 1968, ${ }^{1022}$ zu einem ganz Frankreich erschütternden Generalstreik: „Nur in Frankreich mündete der Studentenprotest in einen Arbeitskampf, der das ganze Land in eine soziale Krise stürzte ${ }^{\text {“1023 }}$ - wenn auch natürlich mitbedingt durch bereits im Vorfeld virulente Verteilungskonflikte. Natürlich hatten die Protagonisten des SDS diese Entwicklungen genau beobachtet und in ihre Theoriedebatten einmünden lassen. Doch während man hier, salopp gesprochen, nach dem revolutionären Subjekt suchte, das man im Proletariat nicht mehr zu haben glaubte, vollzog sich im gaullistischen Frankreich die soziale Mobilisierung. Jenseits des temporären Brückenschlags in Richtung Gewerkschaften in Gestalt der Allianz gegen die Notstandsgesetzgebung gab es dafür hierzulande keine tragfähigen Ansätze. Es ist daher oft festgestellt worden, dass es zum Zeitpunkt der deutschen Studentenbewegung kein vergleichbares Bewegungspotenzial in nichtstudentischen Gruppen gegeben hat, ${ }^{1024}$ keine breiteren Bündnisperspektiven in Richtung der arbeitenden Bevölkerung. SDS und Studentenbewegung blieben eine primär jungakademische Linke, ${ }^{1025}$ genossen daher auch in ganz treffender Weise die Unterstützung des deutschen Bildungsbürgertums. ${ }^{1026}$

Auch deswegen ist so etwas wie eine tatsächliche soziale Revolution aus der Initiative der deutschen Studentenbewegung der 1960er Jahre heraus undenkbar. Aber nicht nur deswegen: Das sozialrevolutionäre Selbstmissverständnis der Studentenbewegung wird durch die eigenartige privilegierte Lebenssituation der deutschen „68er“ unterstrichen. Rein materiell betrachtet gehörte man zum aufstiegsorientierten Mittelschichtsnachwuchs in einer wirtschaftlichen Wachstumsperiode ohne „echten“ Klassenfeind: „Die 68er bilden eine besonders privilegierte Geburtskohorte. Sie können die in großer Zahl frei werdenden Stellen am Arbeitsmarkt füllen und in der boomenden Wirtschaft der 6oer Jahre, in denen günstigere Aufstiegsbedingungen herrschen als zu irgendeinem späteren Zeitpunkt in der Bundesrepublik[,] private und berufliche Selbstverwirklichung betreiben.“1027 Man sah sich „durchweg ausgezeichneten Berufs- und

1020 Gilcher-Holtey, Ingrid: „Mai 68 in Frankreich“, in: Dies. (Hg.): 1968. Vom Ereignis zum Mythos, Frankfurt a.M. 2008, S. 15-45, hier S. 21f.

1021 Eßbach: Aufstand der Werte?, S. 16. In Frankreich handelte es sich dabei vor allem um Altkommunisten sowie um postmarxistische, existenzialistische und situationistische Philosophen, vgl. Gilcher-Holtey: „Die Phantasie an die Macht“, S. 47-81.

1022 Vgl. Hilcher-Holtey: „Die Phantasie an die Macht“, S. 270.

1023 Ibid., S. 271.

1024 Vgl. Allerbeck: Eine strukturelle Erklärung von Studentenbewegungen, S. 491

1025 Krause et al.: Zwischen Revolution und Resignation?, S. 23.

1026 „Was als elitäre Verzerrung einer ,Bewegung von unten' erscheinen kann, beleuchtet doch auch einen Aspekt, der bislang stark unterschätzt wurde: die breite und intensive Unterstützung, die die ,1968er' von Anfang an aus der bürgerlichen Kultur erfuhren, und zwar nicht nur, wie zu erwarten, aus dem Kreis der Linksintellektuellen und des politischen Nonkonformismus, sondern, jedenfalls was die Kunstszene betrifft, auch aus dem Establishment, das nunmehr den Festivaleffekt der ,Kulturrevolution' entdeckte.“ Söllner: „1968“- eine Nachlese, S. 58.

1027 Vgl. Bebnowski, David: Generation und Geltung: Von den ,45ern' zur ,Generation Praktikum' übersehene und etablierte Generationen im Vergleich, Bielefeld 2012, S. 80. Vgl. auch Schildt, Axel: Materieller Wohlstand - pragmatische Politik - kulturelle Umbrüche. Die sechziger Jahre in der 
Aufstiegsaussichten und gesicherten Einkommensverhältnissen“ gegenüber. ${ }^{1028} 1970$, in der Phase des Lehrermangels, waren dann ganze zwei Drittel der erwerbstätigen Akademiker im relativ sicheren öffentlichen Dienst beschäftigt. ${ }^{1029}$ Anders etwa als der studentische Nationalliberalismus zu Vormärzzeiten, der in seinem Aufstiegsstreben durchaus eine emanzipative soziale Trägergruppe bildete, die sich aus einer politischen und statusbezogenen subalternen Position befreien wollte, durchaus auch wiederholt an massenhafter akademischer Arbeitslosigkeit litt: Der von ihnen verfochtene Leistungs- und Bildungsgedanke war ein Mittel in diesem Klassenkampf gegen eine ständische Herrschafts- und Elitenschicht, wie bürgerlich-borniert ihr Emanzipationsbegriff dabei auch immer gewesen sein mag. ${ }^{1030}$ Paradoxerweise bewirkte jedoch gerade die Erfahrung gesellschaftlicher Liberalisierung und ansteigenden Wohlstands durch die sozialen Angleichungstendenzen der 1960er Jahre eine „studentische Deklassierungserfahrung“, eine im Vergleich zu den Jahrzehnten vor der Bildungsexpansion rückblickend zu beobachtende „bürgerlich-studentische Unbehaustheit“ an der heraufdämmernden Massenuniversität. ${ }^{1031}$ Die 1960er Jahre waren für die weitgehend mit traditionellen Bildungsansprüchen sich immatrikulierenden Studenten schlicht moralisch-kulturell entsichert und daher verstörend. Dennoch: Eine soziale Bewegung in diesem klassischen Sinne war die Studentenbewegung von „1968“ tatsächlich nicht:

„Alle Beobachter der Studentenrevolte der zweiten Hälfte der sechziger Jahre treffen sich in der Feststellung, daß die Akteure dieser jugendlich-intellektuellen Opposition sich überwiegend aus dem Kleinbürgertum bzw. aus den Mittelschichten rekrutierten. Die Außerparlamentarische Opposition dieser Jahre blieb eine reine IntellektuellenBewegung mit dominant sozialistischem Bewußtsein. ${ }^{\text {"1032 }}$

Aus diesem Grund kann auch die oft süffisant angemerkte Reintegration der „Systemopposition“ in die Institutionen der bundesrepublikanischen Demokratie, ihr Einmünden in die an finanziellem, kulturellen und Bildungsressourcen reichen postindustriellen „neuen Eliten“ bzw. „soziokulturell Berufstätigen“1033 mit ihrer damaligen Symbolfigur Brandt nicht überraschen. Hierauf beruht sicher manches (insofern berechtigtes) Belächeln, allerdings auch viel wohlfeiles „68er“-bashing, das den studentischen Aktivismus auf einen Ausfluss apolitisch-postadoleszenten Aufmerksamkeitsbedürfnisses unverdient privilegierter und in einem bloß „transitorischen Status“ befindlicher Scheinrebellen reduziert, die erst noch die entscheidenden Sprossen zur Reife politischer Verantwortungsübernahme zu erklimmen hätten. ${ }^{1034}$

Bundesrepublik, in: Schildt, Axel/Siegfried, Detlef/Lammers, Karl Christian: Dynamische Zeiten. Die 6oer Jahre in den beiden deutschen Gesellschaften, Hamburg 2000, S. 21-53.

1028 Kaase, Max: Die politische Mobilisierung von Studenten in der BRD, in: Allerbeck, Klaus R./Ders.: Aufstand der Jugend? Neue Aspekte der Jugendsoziologie, München 1971, S. 155-177, hier S. 164.

1029 Vgl. Titze: Wie wächst das Bildungssystem?, S. $116 \mathrm{f}$.

1030 Vgl. Wehler: Deutsches Bildungsbürgertum in vergleichender Perspektive, S. 219 und 221.

1031 Kießling: Die antiautoritäre Revolte der 68er, S. 163 und 165.

1032 Bock: Geschichte des, linken Radikalismus', S. $223 \mathrm{f}$.

1033 Nickel, Carsten: Rückbau der Cesellschaft, in: Merkur. Gegründet 1947 als Deutsche Zeitschrift für Europäisches Denken, H. 839/2019, S. 27-36, hier S. 27.

1034 So klassisch bei Knoll, Joachim H.: Kritik und Verantwortung, in: Schoeps, Hans Julius/Dannenmann, Christopher: Die rebellischen Studenten. Elite der Demokratie oder Vorhut eines linken 
Geht man allerdings noch einen Schritt über diese sozialgeschichtliche Entzauberung einer Bewegung hinaus, so stellt sich doch in der Tat die Frage, ob SDS und APO überhaupt „linke“, gar „linksradikale“ politische Phänomene gewesen sind - zumindest gemessen an einem der wenigen analytischen Begriffsbestimmungsversuche des Abendroth-Schülers Hans Manfred Bock, der die am Rande der Arbeiterbewegung auftretende rätekommunistische Bewegung in Weimar als „linksradikale Bewegung par excellence ${ }^{\star 1035}$ identifizierte. Zunächst: Die studentischen Aktivisten laborierten sichtlich an der Isolierung vom empirisch noch vorhandenen Proletariat. Die Frage, wie man überhaupt ohne echte sozialrevolutionäre Perspektive den Anspruch einer gebildeten sozialistischen Avantgarde hat erheben können, führte schließlich zu den abenteuerlichsten rhetorischen Verrenkungen. Man flüchtete sich in die Vorstellung eines „substitutionalistischen“ Auftrags der Intellektuellen im Sinne der „Rekonstruktion der sozialistischen Bewegung" bei historisch abwesendem revolutionärem Subjekt, verstand sich im Rahmen bemühter Konstruktionen als Statthalter der „objektiven“ Interessen der arbeitenden Klassen und damit, nach alter revolutionstheoretischer Manier, der Gesellschaft insgesamt. ${ }^{1036}$

„In der sozialen Isolierung der antiautoritären Bewegung der Jahre 1966 bis 1969 von der Arbeiterschaft und in ihrem ,Substitutionalismus', in dem man teilweise eine Rechtfertigungsideologie dieser faktischen Isolierung erblicken kann, liegt der wesentliche Unterschied zu den älteren linksradikalen Bewegungen. Aus der fehlenden Stützung der antiautoritären Studentenbewegung durch radikale Arbeiter läßt sich sowohl das vergleichsweise abrupte Ende dieser Bewegung erklären als auch die Labilität des individuellen Engagements der Antiautoritären. Ihr ,Substitutionalismus schloß den Rekurs auf die von unmittelbarer Revolutionserwartung geprägte ökonomische Krisen-Theorie des älteren Linksradikalismus aus, während in allen anderen wesentlichen Fragen der Theorie, der Organisationspolitik und der Taktik der antiautoritären Bewegung die Diskussionsergebnisse der historischen Vorläufer teilweise rezipiert wurden. ${ }^{\text {“1037 }}$

Andererseits aber speiste sich die durchweg konstitutive Heterogenität der APO eben nicht nur aus der selektiven Bezugnahme auf (neo-)marxistische, sozialistische und anarchistische Theorietraditionen. Antiimperialistisches Selbstverständnis, Aktionsorientierung der Subversiven Aktion und der Einbezug situationistischen wie postkolonialen Denkens verbanden sich, besonders nach 1967, auch zu einem antiwestlichen und antimodernen, letztlich dem Geiste der postmodernen Denkbewegung sich annähernden Gemisch. Man polemisierte gegen die Konfrontation der beiden Großmächte des Kalten

Faschismus?, München und Esslingen/Neckar 1968, S. 9-17 und im selben Band: Schoeck, Helmut: Der Student als Gesellschaftskritiker, in: Schoeps, Hans Julius/Dannenmann, Christopher: Die rebellischen Studenten. Elite der Demokratie oder Vorhut eines linken Faschismus?, München und Esslingen/Neckar 1968, S. 154-160.

1035 Bock: Ceschichte des, linken Radikalismus' in Deutschland. Ein Versuch, Frankfurt a.M. 1976, S. 74.

1036 Vgl. Bock: Geschichte des ,linken Radikalismus', S. 205 und 223-230.

1037 Ibid., S. 230. 
Kriegs und schielte nach „dritten Wegen“, nach Gegenprojekten ${ }^{1038}$ - auch wenn dabei wohl die meisten in den Vereinigten Staaten den entscheidenden Aggressor, den imperialistischen Erzfeind schlechthin ${ }^{1039}$, erblickten. Man stellte sich die Frage nach der Vereinigung sozialer und „künstlerischer“ Existenz. Zeitgleich dazu wurde der Terminus post-modernism exakt im Jahre 1968 in Deutschland in die akademische Fachdebatte eingeführt, und zwar im Rahmen eines Vortrags von Leslie A. Fiedler. ${ }^{1040}$

„Machtkritik, Kulturrevolution, Individualismus - in der Reflexion dieser Themen bilden sich in den 6oer Jahren Figuren modernitätsskeptischer und postmoderner Denkweisen aus. ,1968' ist auch eine postmoderne Revolte. [...] '1968' war eben keine Revolution wie die von 1848 oder 1919, bei denen soziale Klassen mit ihrer Geschichte und ihren Interessen beteiligt waren, sondern eine Revolte, ein Aufbegehren, das sich in vielem von der alten Welt des europäischen Emanzipationsdenkens verabschieden wollte. ,1968' waren alle Motive der Kritik an der Rationalität der Moderne präsent. ${ }^{\text {“1041 }}$

Dieser situationistisch-ästhetizistische Zug der Studentenbewegung war jedenfalls nicht „klassisch“ (d. h. sozialpolitisch) links. Er nahm die „modernisierungsskeptische Wende der bundesdeutschen Protestkultur" durch die Ökologiebewegung vorweg. ${ }^{1042}$ Das wiederum lässt doch zweifeln, ob ein Großteil der vermeintlichen Politisierung nicht doch eine „ästhetische Revolte“ gewesen sein mag, ${ }^{1043}$ die sich stets im sicheren Fahrwasser des status quo wusste. Solche Zweifel sind es jedenfalls, die die Einordnung von „1968“ in die Chronologie neuerer Bürgerbewegungen der Bundesrepublik motivieren, deren Funktion weitgehend darin gesehen wird, allgemeine Reformbedürftigkeit und gesellschaftliche Problemlagen provokant $\mathrm{zu}$ indizieren und Veränderungen der politischen Mentalitäten $\mathrm{zu}$ beschleunigen, ${ }^{1044}$ nicht aber darin, selbst tragfähige

1038 „Die postmoderne Dekonstruktion des Kommunismus und die anti-westliche Politik, diese zwei Seiten internationaler Solidarität, sie wurden untergründig von der Sehnsucht nach dritten Wegen und dritten Welten gespeist, die das kurze 20. Jahrhundert von 1917 bis 1989 hervorgebracht hat. Diese Internationalisierung fand noch in den Strukturen der bipolaren Weltordnung des Kalten Krieges statt, und die Anstrengungen der sowjetischen Seite, den Protest zu funktionalisieren und zu unterwandern, waren beträchtlich. Aber die 6oer Jahre sind trotz der Unterstützung Nordvietnams durch die Sowjetunion auch der Beginn des Zerfalls des Weltkommunismus." Eßbach: Aufstand der Werte?, S. 19.

1039 Vgl. Jarausch: Deutsche Studenten, S. 238.

1040 Vgl. Eßbach: ,1968' - Aufstand der Werte?, S. 18. Der Titel des Vortrags lautete „Cross the BorderClose the Cap - the Case for Post-Modernism“, publiziert als Fiedler, Leslie A.: Cross the BorderClose the Gap, New York 1972. Er sollte für die Literatur- und Kulturwissenschaften, später insbesondere für die Cender Studies, eine geradezu kanonische Wirkung entfalten.

1041 Eßbach: Aufstand der Werte?, S. 17 und 18.

1042 Gassert: Bewegte Gesellschaft, S. 135.

1043 „Die Idee vom Leben im Modus des Ästhetischen als geglückte Kompensation eines Krisenbewusstseins stellt sich dabei als verborgene Schnittmenge zwischen politisch/sozialer und kulturell/literarischer Ebene der Protestbewegung dar, an die sich das Konzept einer Postmoderne anschließen ließ." Luckscheiter, Roman: Der postmoderne Impuls. ,1968' als literaturgeschichtlicher Katalysator, in: Klimke, Martin/Scharloth, Joachim (Hg.): 1968. Handbuch zur Kultur- und Mediengeschichte der Studentenbewegung, Bonn 2007, S. 151-159, hier S. 155.

1044 Für den Fall „1968“ vgl. Lorenz/Walter: 1968. Kulminationspunkt und politische Eruption, S. 371. 
politische Lösungen zu erarbeiten und durchzusetzen. ${ }^{1045}$ Nationalliberalismus und Arbeiterbewegung hingegen sei es um den politischen Umsturz, um die praktische Revolution gegangen. ${ }^{1046}$ Dieser Einschätzung ist zwar in der Tat wenig entgegenzuhalten, andererseits ist dieses Auflösen der Studentenbewegung in das große Kollektiv der Bürgerproteste seit 1945 auch Instrument der historiographischen Neutralisierung, letztlich wiederum der „Vergemütlichung“, überdies nicht ganz ohne paternalistische Häme: Die originäre Frage des frühen SDS, wie radikal-egalitäre politische Impulse in den demokratischen Prozess eingegeben werden können, die nicht sogleich von einer im Zweifelsfall kompromissorientierten und akkomodativ agierenden Parteibürokratie im Namen des „sozialen Friedens“1047 absorbiert werden, ist bis heute ungeklärt.

Im e) Gerinnen von „1968“ zum mythisch-kulturellen Artefakt lassen sich viele der aufgeführten Aspekte, insbesondere hinsichtlich der verbreiteten Tendenz zur „Vergemütlichung“, zusammenführen. Denn trotz der wahrscheinlich entscheidenderen Relevanz des Jahrzehnts vor 1967 bzw. 1968: ${ }^{1048}$ Es gibt einen Mythos des vermeintlich gesellschaftstransformierenden „1968“ und eine identitätsstiftende politische Spielmarke „1968“. Wie ist es dazu gekommen? Die erstaunliche und erklärungsbedürftige - damals neue! - Beobachtung der 1980er Jahre lautete: „Fast jeder der damals 20und 30jährigen will dabei gewesen sein. “1049 Dabei war das in den frühen 1980er Jahren angesichts von Hausbesetzerszene und Alternativbewegung rückblickend entstehende Signum „68“ bzw. „68er“ pejorativ gemeint. ${ }^{1050}$ In den Folgejahren setzte jedoch

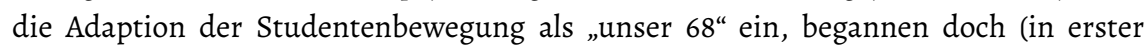
Linie biographisch involvierte) Publizisten, Wissenschaftler und Politiker, der APO eine wichtige Funktion für die Transformation der politischen Kultur in Richtung liberalerer, autoritätskritischerer und partizipationsorientierterer Verhältnisse zuzuerkennen. Die kurzlebige Eruption der Studentenbewegung erscheint seither als ruckartige Beschleunigung des politischen Kulturwandels in Richtung einer modernen Massengesellschaft, als Beitrag von „1968“ zur institutionellen wie politisch-kulturellen Demokratisierung der Bundesrepublik. Die Rede ist etwa von „wichtige[n] Impulse[n] für die politische und kulturelle Entwicklung der Bundesrepublik ${ }^{\text {(1051 }}$, von einem „be-

1045 Vgl. Gassert: Bewegte Gesellschaft, S. 272-279.

1046 Vgl. ibid., S. 275.

1047 Agnoli: Die Transformation der Demokratie, S. 25.

1048 Vgl. Spix: Abschied vom Elfenbeinturm?, S. $10 f$.

1049 Jarausch: Deutsche Studenten, S. 236. Im Jahre 1998 wurde für den französischen Kontext festgestellt: „1968 kann [...] als ein umfassender, singulärer Mythos bezeichnet werden, bei dem es sich um einen Gründungsmythos, wenigstens in bezug [sic] auf eine Generation, handelt. Als eine Art ,generationelle' Erinnerung verschaffte das Cedenken an 1968 jenen, die damals jung waren, eine Gruppenidentität [...] Symbol einer neuen Politischen Kultur, die durch Solidarität, eine kritische und wachsame Haltung und ein neues Set kultureller Praktiken gekennzeichnet ist, übernimmt dieser Mythos des sozialen Wandels die Funktion eines verbindenden Gründungsmythos, der als Legitimationsbasis für das Handeln einer Generation dient." Frank, Robert: 1968 - ein Mythos? Fragen an die Vorstellung und an die Erinnerung, in: Gilcher-Holtey, Ingrid (Hg.): 1968. Vom Ereignis zum Gegenstand der Geschichtswissenschaft. Geschichte und Gesellschaft, Sonderheft 17, Göttingen 1998, S. 301-307, hier S. $306 \mathrm{f}$.

1050 Kraushaar, Wolfgang: 1968. Das Jahr, das alles verändert hat, S. 312.

1051 Richter: Die Außerparlamentarische Opposition, S. 55. 
trächtliche[n] Maß an wechselseitiger Anverwandlungsbereitschaft“ zwischen „68ern“ und Bevölkerung sowie von einer Veränderung von „Gesicht und Mentalität der Republik“1052 , oder davon, dass „1968“ „uns [!] für die Zukunft wachsamer gemacht ${ }^{\text {“1053 }}$ habe. Auch konservative Kritiker bestreiten das nicht, wenngleich sie zurecht darauf hinweisen, dass „keine Einigkeit über das Ausmaß der Veränderungen“ herzustellen ist, noch sich die „Auswirkungen durch die 68er" zweifelsfrei „mit ihren Intentionen decken", ${ }^{1054}$ insbesondere also die Vorstellung einer klandestin strategisch durchorganisierten und dadurch politisch-konzertierten, einflussreichen „linksgrünen“ Elite verfehlt ist, die heute von weit rechts in Stellung gebracht wird. Trotzdem: Von sehr vielen wurde das Kunststück der Nationalisierung von „1968“vollzogen, also der Einverleibung der oppositionellen Impulse in einen vermeintlich bundesrepublikanischen Wertekonsens, ja zumindest angesichts der teils beachtlichen Karrieren ${ }^{1055}$ einiger nun geläuterter ehemaliger Rebellen und „kritischer“ Geister gewisse Plausibilität aufwies. Die Aktivisten von damals erschienen um die Jahrtausendwende als mehrheitlich arrivierte Elite, verkörpert etwa durch Joschka Fischer. Der Politikwissenschaftler Claus Leggewie sieht darin den Versuch, „1968“ als „Gründungsmythos" einer liberaldemokratischen Bundesrepublik, verstanden als "glücklich gescheiterte Umgründung“1056, in Stellung zu bringen, der auch nach 1989 zumindest im Westen Deutschlands für viele kollektiv identitätsstiftend wirkt. ${ }^{1057}$ Gerd Koenen spricht im Untertitel seines roten Jahrzehnts von „unserer kleinen deutschen Kulturrevolution“. ${ }^{1058}$ „1968“ avanciert in den 1980er Jahren zum kulturellen Artefakt, zur „nachträgliche[n] Konstruktion der Erinnerungskultur“ bzw. zur „nachträgliche[n] publizistische[n] Konstruktion“"1059 , die gerade aufgrund ihrer erinnerungspolitischen Stellung gegen die „düstere[] Blutspur 1967-1977“ so „vergemütlichend“ ausfällt. ${ }^{1060}$ In den 1970er Jahren hatte man noch den Bezug auf die Revolutionäre von 1848 gebraucht, um sich die Studentenbewegung verständlich zu machen. ${ }^{1061}$ Das erste „Jubiläum“, erkennbar an einer ersten Welle von Schriften, wurde 1977 zelebriert - nicht 1978. ${ }^{1062}$ Nun aber, ein Jahrzehnt danach, gewann „1968“ Gewicht als politische Spielmarke bzw. „Münze im Kampf um das

1052 Frei: 1968. Jugendrevolte und globaler Protest, S. 227 und 228.

1053 Vogel, Bernhard: Vorwort. 68 hat uns für die Zukunft wachsamer gemacht, in: Vogel, Bernhard/Kutsch, Matthias (Hg.): 40 Jahre 1968. Alte und neue Mythen - Eine Streitschrift, Freiburg im Breisgau 2008, S. 7-8, hier S. 7.

1054 Jesse, Eckhard: 1968 - und 50 Jahre später. Eine deutsch-deutsche Bestandsaufnahme, in: INDES. Zeitschrift für Politik und Gesellschaft, H. 1/2018, S. 88-99, hier S. 94.

1055 Natürlich handelte es sich dabei auch um ein Klischee, vgl. Kraushaar: 1968. Das Jahr, das alles veränderte, S. 321.

1056 Leggewie, Claus: Der Mythos des Neuanfangs - Cründungsetappen der Bundesrepublik Deutschland: $1949-1968-1989$, in: Berding, Helmut (Hg.): Mythos und Nation. Studien zur Entwicklung des kollektiven Bewußtseins in der Neuzeit 3, Frankfurt a.M. 1996, S. 275-302, hier S. 294-296.

1057 Vgl. ibid., S. 297-300.

1058 Koenen: Das rote Jahrzehnt, Buchdeckel (Herv. J. S.)

1059 Greven: Systemopposition, S. 9 und 18.

1060 Vgl. auch Michels: Schahbesuch 1967, S. 9.

1061 Vgl. Bruch: Die Universitäten in der Revolution, S. 134 sowie Bartol: Ideologie und studentischer Protest.

1062 Vgl. Kraushaar: 1968. Das Jahr, das alles veränderte, S. 312. 
politische Selbstverständnis der Republik “1063, die sich von gealterten Zeitgenossen, auch im parteipolitischen Umfeld, für legitimatorische und identitätsstiftende Zwecke einsetzen ließ - in positiver, selbstauszeichnender, wie in negativ-abgrenzender, die Studentenbewegung zur Vorhut traditions- und kulturzerstörender Anomie erklärenden, Absicht:

„,1968' wurde zum Zuordnungspunkt für Ärzte, Pastoren, Unternehmer, Verwaltungsbeamte usw., die nun den Jüngeren, dann ihren Kindern offenbarten, sie waren damals irgendwie mit dabei, hatten auch protestiert. Die Mehrheit der Sozialdemokraten hatte die Verstoßung des SDS und SHB und den Radikalenerlaß vergessen und memorierte nun auch Willy Brandt als einen Achtundsechziger. Auch in der CDU und CSU outeten sich plötzlich Achtundsechziger." ${ }^{\text {1064 }}$

„Für diejenigen, die [...] etwa pauschal die 68er angreifen, als könne man von ihnen wie von einer immer noch existierenden Ceburtenkohorte sprechen, ist dies zumeist nur eine Folie, eine Art Kontrastmedium, um ganz andere Positionen salonfähig zu machen. “1065

Mit anderen Worten: Man entdeckte „1968“ als Einsatz in tagespolitischen Auseinandersetzungen. Somit gehört nicht nur die beliebte Liberalisierungs-Beschleunigungsnarration, sondern auch die Evolution zum „Bezugsgeschehen für Wertedebatten ${ }^{\text {“1066 }}$ zum mythisch-kulturellen Artefakt „1968“.

Spätestens wenn man sich vor Augen hält, dass die neue positive Besetzung des Meinungsstreits und des politischen Konflikts im gebildeten Bürgertum nach „1989“ dazu geführt hat, das aktive Einfordern partizipativer Teilhabe zu neuen Bürgertugenden des „mündigen“ bzw. „kompetenten“ Bürgers in einer aktiven „Zivilgesellschaft“ zu promovieren, ${ }^{1067}$ ist Skepsis angebracht. Zum besseren Verständnis der Studentenbewegung 1966-1968 im engeren Sinne - nicht der gesamtgesellschaftlichen Liberalisierungsbewegung in Richtung „Antiautoritarismus, Partizipation, Utopie“, welche tatsächlich mehr durch das Experimentieren in privatem Alltagshandeln und Lebensgestaltung angetrieben wurde als durch studentische Aktivisten ${ }^{1068}$ - ist es lohnenswert, abschließend vier Aspekte aufzuführen, die diesen folkloristisch anmutenden ArtefaktCharakter sprengen, mit anderen Worten: zu extrapolieren, warum es „unser“ 68 so nicht gegeben hat. Obwohl beinahe schon zur Plattitüde der einschlägigen Forschung geworden, ist hier zuerst zu wiederholen: „1968“ beendet eine Periode gesellschaftlicher

1063 Ibid., S. 313.

1064 Eßbach: Aufstand der Werte?, S. 4.

1065 Kraushaar: 1968. Das Jahr, das alles veränderte, S. 313.

1066 Eßbach: Aufstand der Werte?, S. 4.

1067 Vom idealen demokratischen Bürger wird etwa seit den 1990er Jahren erwartet, dass er partizipationsbereit, partizipationsfähig und zur Übernahme von Gemeinwohl-förderlichen Aufgaben bereit sei. Vgl. Münkler, Herfried: Der kompetente Bürger, in: Klein, Ansgar/Schmalz-Bruns, Rainer (Hg.): Politische Beteiligung und Bürgerengagement in Deutschland. Möglichkeiten und Grenzen, Baden-Baden 1997, S. 153-172, hier S. 155. Siehe außerdem Dubiel, Helmut: Ungewißheit und Politik, Frankfurt a.M. 1994, S. 67: „Mit eigentümlicher Dynamik ist im letzten Jahrzehnt der Begriff der ,zivilen Cesellschaft' aus der Tiefe einer jahrtausendealten Geschichte auf die Vorderbühne eines deutungsbedürftigen Weltgeschehens getreten."

1068 Vgl. Hodenberg. Das andere Achtundsechzig, S. $192 f$. 
Reformen. „Die Achtundsechziger agierten als - meist blinde - Passagiere im Modernisierungsexpress. “1069 Der Wandel der politischen Kultur war - anders als die Erfolge bei der Durchsetzung bestimmter Hochschulreformaspekte ${ }^{1070}$ - insgesamt nicht primär die Leistung der Studentenbewegung. ${ }^{1071}$ Darüber hinaus ist es äußerst fraglich, ob SDS und APO eine solche Auszeichnung überhaupt als Lob empfunden hätten, denn ihr Ziel war nicht die Modernisierung der Bundesrepublik, sondern deren radikal antikapitalistische Umstülpung. Diese wiederum ist natürlich rundheraus gescheitert. „Wer dies nicht als Hauptpunkt anführt, geht am Kern vorbei.“1072 Die verbreitete Tendenz zur „Vergemütlichung“ der Studentenbewegung hingegen führt nicht nur zum Ausblenden ihrer antiliberalen Tendenzen. Sie legt außerdem den Fehlschluss nahe, aus bloßer historischer Distanz von der Auseinandersetzung mit den theoretisch fundierteren Avancen und mit den tatsächlichen politischen Absichten der studentischen Gesellschaftskritik dispensiert zu sein. Dieses Missverständnis ist besonders eindrücklich am Leitbegriff der „Demokratisierung“ zu illustrieren: Die „Reformära“ der späten 1960er und frühen 1970er Jahre bis zur so genannten „Tendenzwende“ nach 1973/74 erfuhr „Demokratisierung“ in erster Linie als „politisch-kulturelle Leitvokabel“, die „Fortschrittsoptimismus“, den „Machbarkeitsglaube[n] der langen Jahre des Nachkriegsbooms“ und die „in den 1960er Jahren ruckartig gestiegenen Partizipations- und Emanzipationsansprüchen der westdeutschen Gesellschaft" assoziativ verknüpft hatte. ${ }^{1073}$ Auch die Mehrheit der Studierendenschaft in den 1970er Jahren verstand unter „Demokratisierung“ am ehesten die sanfte, schrittweise Reform - „mehr Engagement, gelebte Demokratie, Ehrlichkeit und Streben nach sozialer Gerechtigkeit“ -, nicht aber die von SDS und APO visierte radikale gesellschaftliche Umwälzung. ${ }^{1074}$ Denn die teils heftig streitenden Teilgruppen des SDS immerhin die eine Grundüberzeugung, dass „wahre“ Demokratie nicht mit einem kapitalistischen Wirtschaftssystem vereinbar sei; im Antikapitalismus fanden die systemoppositionellen Strömungen - nicht primär in der Kritik politischer Herrschaft - den negativ-gesellschaftskritischen „kleinste[n] gemeinsame[n] Nenner“, während sie über die positive, d. h. inhaltliche Bestimmung der angestrebten besseren Gesellschaft stets in Dissens zerfielen. ${ }^{1075}$ Die Abschaffung des Privateigentums an Produktionsmitteln blieb, ganz in der Tradition des klassischen Marxismus, notwendige Bedingung der angestrebten grundstürzenden „Demokratisierung“ im Zeichen voll-

1069 Große, Jürgen: 1968: Revolte und Regression, in: Merkur. Gegründet 1947 als Deutsche Zeitschrift für Europäisches Denken, H. 829/2018, S. 79-87, hier S. 81.

1070 Vgl. Kapitel II.1 dieser Studie.

1071 „[...] die Protestakteure der späten 1960er Jahre waren weniger Katalysator als Epiphänomene der Modernisierung." Gassert: Bewegte Gesellschaft, S. 105.

1072 Kraushaar, Wolfgang: 1968. Das Jahr, das alles verändert hat, München 1998, S. 320.

1073 Wehrs: Protest der Professoren., S. 9.

1074 Wildenmann/Kaase: „Die unruhige Ceneration“, S. 56.

1075 „Historisch war Systemopposition stets antikapitalistisch, der Wunsch nach endgültiger Überwindung des Kapitalismus ihr kleinster gemeinsamer Nenner. Erst in dieser zukünftigen - und hier endet bereits die Cemeinsamkeit der Systemopposition - mal ,soziale Demokratie', mal ,Sozialismus' oder gleich ,Kommunismus' genannten Gesellschaft, könnten die universalistischen Versprechen der Aufklärung des 18. Jahrhunderts, wie sie politisch in der US-amerikanischen und vor allem der Französischen Revolution vom Bürgertum im eigenen Klasseninteresse proklamiert worden seien, endgültig verwirklicht werden." Greven: Systemopposition, S. 221. 
endeter Selbstbestimmung. Die frühe (und bis heute wirksame) Fixierung der öffentlichen Diskussion über die Studentenbewegung auf formalistische Aspekte (Grad der Radikalität und des „Ernstmeinens“ von Forderungen, Rückführung auf die Schemata demokratische Ordnung vs. tumultuarisches Chaos respektive etablierte Autoritäten vs. rebellische Jugend) veranlasste einen intellektuell versierten Aktivisten der Neuen Linken, Johannes Agnoli, an die Kernintention der APO zu erinnern: das Einklagen echter (und angesichts der Situation eben außerparlamentarischer) politischer Opposition im Namen der „Befreiung der Abhängigen“. ${ }^{1076}$ Das protestfeindliche ordnungspolitische Fühlen der bundesrepublikanischen Bürger, die Einbindung der SPD in ein „Bündnis mit der Herrschaft" kapitalfreundlicher Politik, das völlige Fehlen fundamentaler politischer Alternativen in einem neuen, verfeinerten „parlamentarisch-technokratischen Staat autoritärer Prägung" mit seinen sozialpolitischen Brosamen zur Niederhaltung sozialen Konfliktpotenzials - all das mache es unvermeidlich, an den essenziellen Grundgedanken egalitärer Emanzipation zu gemahnen, der in den vorgesehenen Kanälen politischer Einflussnahme schlicht versande. Demokratisierung heiße, an die Notwendigkeit fundamentaler Befreiung der Einzelnen aus ihrer Abhängigkeit von gesellschaftlich (und dadurch eben auch parteiförmig) vermittelter Herrschaft, vulgo: an einer modernen Form von Revolution zu arbeiten. ${ }^{1077}$

Gewiss ist hier dann die Kritik anzubringen, dass die „politisch institutionalisierte Form dieser zukünftigen Herrschaftslosigkeit“1078 - auch aufgrund der Ablehnung utopistischer Phantasien - nie konkret bestimmt werden konnte. ${ }^{1079}$ Derartige Aporien ließ die APO insbesondere nach dem Juni 1967 hinter sich, als „Kritikfähigkeit und Diskussionsbereitschaft" infolge des hitzigen politischen Klimas abnahmen und sich der medial präsente Rudi Dutschke sichtlich orthodox-sozialistischen MachtübernahmePhantasien hingab. ${ }^{1080}$ Heute verleitet die begriffliche Konvergenz dazu, die sozialistische Gesellschaftskritik des SDS in der Gesamtbewegung einer nur verbal überdrehten kritisch-rebellischen Studierendenschaft aufzulösen, die trotz oder gerade wegen ihrer inhaltlichen Fehlbarkeit und ihres oft gönnerhaft konstatierten Über-die-SträngeSchlagens ${ }^{1081}$ als Schrittmacher der kulturellen Liberalisierung und der Verbreitung eines demokratischen Bürgerbewusstseins in der deutschen Gesellschaft fungiert habe. Derartige paternalistische Platzzuweisungen der westdeutschen Studentenbewegung sowie der nachfolgenden kommunistischen und spontanistischen Gruppierungen aber verfehlt wie gesehen Wesentliches, war doch die sozialmoralische Festigung der demokratischen Institutionen

\footnotetext{
1076 Agnoli: Zur ApO, S. 36.

1077 Ibid., S. 32-36.

1078 Greven: Systemopposition, S. 222 (Herv. i. O.)

1079 „Ex negativo lebt [...] die systemoppositionelle Demokratiekritik der sechziger Jahre [...] vom impliziten, gelegentlich als ,wahre Demokratie' angesprochenen normativen Kontrast zur perhorreszierten Gegenwart." Ibid., S. 222.

1080 Ibid., S. 223 f.

1081 „Noch ihre [der Studentenbewegung, J. S.] Radikalisierung, die speziell in der Bundesrepublik klar illiberale Züge aufwies, kann als überschießende Potenzierung dieser politisch-kulturellen Prozesse verstanden werden." Ibid., S. 21.
} 
„weder das Verdienst dieser Systemopposition noch ihr Ziel. Konsequenter Weise fand die sozialliberale Reformpolitik nach 1969 auch nur in den seltensten Fällen Zustimmung bei ihren Repräsentanten, und nicht wenige fühlten sich in diesem ,roten Jahrzehnt weiterhin eher in den zahlenmäßig eher gewachsenen Organisationen und Zirkeln der Systemopposition als in der sozial-liberal geführten Republik politisch beheimatet."1082

Dabei verfehlt die Vorstellung eines undurchschauten oder fanatischen Dogmatismus insbesondere die frühe „Neue Linke“ zwischen 1961 und 1965. Theoretisches Reflexionsvermögen konnte trotz oder gerade wegen der strukturellen Aporien und Dilemmata durchaus entwickelt werden; und auch was die späteren Jahre des radikalisierten Protests betrifft, sollte die eskalative Wirkung der politischen und medialen Denunziationen, schließlich der teils drastischen polizeilichen Repressionsmaßnahmen, nicht unterschätzt werden, die für viele erst den Eindruck einer undemokratischen, „faschistoiden" Republik plausibel machten. Drittens ist den noch immer verbreiteten Vorstellungen einer rebellischen "Generation“ von Studierenden entgegenzuhalten, dass das „Bewegungsnetzwerk ${ }^{\text {“1083 }}$ der APO gerade in ihrer formativen Phase nur durch das Engagement umtriebiger, geschickt agitierender und eher theorieferner Köpfe wie dem Charismatiker Dutschke und seinem Gefährten Rabehl entstehen konnte, ja förmlich von ihnen zusammengeschmiedet worden ist. Der „seminarmarxistische“ SDS der frühen 1960er Jahre wäre ohne diesen vergleichsweise kleinen Trägerzirkel wirkungslos geblieben:

„Erst durch die Thesen der Neuen Linken und ihrer Verbreitung über Zeitschriften, personelle Verbindungen und auf Kongressen wurden die Ostermarschbewegung, die Opposition gegen die Notstandsgesetze und die einzelnen Studenten- und Jugendverbände in die Lage versetzt, ihre bis dato getrennten Aktionsfelder jeweils als einen Teil einer tiefergehenden Transformation des bundesrepublikanischen politischen Systems zu begreifen. [...] Damit besteht die eigentliche historische ,Leistung' der Neuen Linken [...] darin, die drei single-purpose-movements Ostermarsch, Studentenbewegung und Opposition gegen die Notstandsgesetze zu einer Bewegung formiert zu haben. ${ }^{\text {"1084 }}$

Womöglich wäre im Falle einer weniger aktiven, weniger auf die theoretische Auseinandersetzung oder den Westberliner lokalen Raum beschränkten Neuen Linken um den SDS der Auftritt einer anderen Form gegenkultureller (akademischer) Jugendbewegung wahrscheinlich gewesen. Doch im historisch gegebenen Fall entstand die Studentenbewegung eben aus einem Nukleus von Organisatoren, Netzwerkern und Einpeitschern, die für die Initiierung, Formung und Aufrechterhaltung des Protestgeschehens sorgten. ${ }^{1085}$ Schließlich wird viertens aus all dem ersichtlich, dass die identitätsstiftenden bzw. identitätspolitischen Aspekte der Studentenbewegung von „1968“ nicht allein auf

1082 Greven: Systemopposition, S. 234 (Herv. i. O.)

1083 Richter: Die Außerparlamentarische Opposition, S. 45.

1084 Ibid. (Herv. i. O.)

1085 Für die zeitgenössische Sicht scheint die Organisations- und Agitationskraft der Studierenden dabei sogar eher Anlass für Konsterniertheit gewesen zu sein, die Glrofizierung zu politkulturellen 
eine linkspolitisierte Studierendenschaft zurückzuführen sind, sondern auch auf einer starken „rechten“ Gegenformation beruhten. Die APO blieb ja zu keinem Zeitpunkt ohne studentische Gegenspieler: Selbst auf dem Höhepunkt seines Mitgliederwachstums im Jahr 1967 zählte der SDS „nur“ 2.500 Mitstreiter - zeitgleich sammelten sich im RCDS, der sich bis zum Wintersemester 1969/70 zur größten Einzelgruppe in den Studentenparlamenten bundesweit emporarbeiten sollte, 2.300 Mitglieder. Sie bildeten zwei mobilisierungskräftige Minderheiten. ${ }^{1086}$ Die durch diese Polarisierung hervorgerufenen Wahrnehmungsformen gesellschaftspolitischer Vorgänge werden von manchen als so tiefgreifend angesehen, dass sie sich, so der Kultursoziologe Clemens Albrecht in Anlehnung an Wolfgang Eßbach, noch 50 Jahre später mit religionssoziologischen Kategorien fassen ließen: als Etablierung des erfahrungsresistenten Richtungsschemas „links/rechts“ („Bekenntnisreligion“), als Destruktion traditioneller Höflichkeitsregeln und christlicher Ordnungsvorstellungen zugunsten ökologischer moralischer Imperative der "guten Tat“ („Rationalreligion“), als eschatologische Aufladung der Theorie, die über die wissenschaftliche Erschließung des Ganzen zur gesellschaftsumstürzenden Wahrheit führen soll („Wissenschaftsreligion“), auch als ein über Gruppenplena, Satzungen, Lesekreise, usw. gefestigter Organisationsfetischismus (,Verfahrensreligion"). ${ }^{1087}$ Folgt man dieser Deutung, wird erklärlich, warum sich ursprünglich emanzipative Impulse in neue, selbst wiederum verfestigte und zählebige Gewissheiten übersetzen konnten: „Der eruptive Enthusiasmus revolutionärer Bewegungen fließt in neue Glaubensformen, verzweigt sich, erkaltet und erstarrt.“1088 Wenn der scharfe Kritiker Hermann Lübbe „Schadensrelikte der 68er Bewegtheit“ bilanziert und dabei die Studentenbewegung als „politromantischen Rückfall ${ }^{\text {“1089 }}$ denunziert, zielt er unter anderem auf ebendiese Bekenntnishaftigkeit, ja Irrationalität des im Kern apolitischen ${ }^{1090} \mathrm{Be}$ kenntnisses zu imaginierten Politcliquen. Ja: Ganz von der Hand zu weisen ist es nicht, dass im Jahrzehnt von 1967 bis 1977 - wenn auch nicht allein durch „die“ „68er“ - die bundesrepublikanischen Grundsteine identitätspolitisch verhärteter Bewusstseinsformen und konformistischer Gruppenmoral ${ }^{1091}$ gelegt worden sein könnten. Auch wenn man keineswegs so weit gehen muss, der APO ein „ursprünglich regressives Motiv“ zu

Reformbeschleunigern setzte erst später ein. Die Sehnsucht nach der politischen Jugend ist ein Produkt der späten 1980er Jahre - vgl. dazu Kapitel II.3.2 dieser Studie.

1086 Vgl. von der Goltz: Eine Gegen-Generation von 1968?, S. 75 und $76 f$.

1087 Vgl. Albrecht, Clemens: Umziehende Götter. 1968 und die Transformation des revolutionären Enthusiasmus, in: Merkur. Gegründet 1947 als Deutsche Zeitschrift für Europäisches Denken, H. 832/2018, Berlin 2018, S. 65-70.

1088 Ibid., S. 66.

1089 Lübbe, Hermann: 1968. Zur deutschen Wirkungsgeschichte eines politromantischen Rückfalls, in: Ders.: Politik nach der Aufklärung. Philosophische Aufsätze, München 2001, S. 129-149, hier S. 131.

1090 „Konservierte intellektuelle Wirtschaftsferne und schwach entwickelter Sinn für die moralischen Potentiale ökonomischer Rationalität - das ist der noch heute auffälligste Rest mentaler Prägung durch die restaurativen, modernitätsverweigernden ideologischen Orientierungsgehalte des 68er vermeintlichen Aufbruchs." Ibid., S. 149.

1091 „Der Cliquengeist der Radikalrevoluzzer, selbst der K-Cruppen, fügte sich harmonisch zum Verlangen nach möglichst reiner Meinungskonsumtion, nach Meinungsgemeinschaft jener, , mit denen man klarkommt' (Rainer Langhans). Die post-68er Winkelvielfalt der Alternativszenen bedeutet keine Schwächung, sondern eine Aus- und Ableitung der 1968 aktivierten konformistischen Impulse, des entfalteten Konsums aus bereitstehendem, bald auch handgefertigtem Daseins- und 
unterstellen, nämlich „keine ideologisch weißen Flecken auf der Seelenkarte zu dulden“ und dem „Begehr nach Eindeutigkeit, Ambivalenzreduktion, Nuancenabbau“ nachzugeben. ${ }^{1092}$

Es gibt viel Faszinierendes an der Studentenbewegung der sechziger Jahre. Dazu gehört nicht nur die Sonderstellung des aus verschiedenen teils gegenläufigen Strömungen bestehenden SDS in seiner Orientierungs-, Reformations- und Findungsphase zwischen 1961 und 1965, dessen Kongresse, Denkschriften, Delegiertenkonferenzen und öffentlich geführte Auseinandersetzungen ein reges Debattenklima, ja eine intellektuelle Rauflust bezeugen. Dazu gehört auch das nach 1967 weit über den SDS hinausgreifende und kollektiv geteilte Selbstbewusstsein der deutschen Studierendenschaft als Sprengkraft rigider, überkommener Strukturen. Man kann darin wiederum bildungshumanistische und frühliberale Traditionslinien erkennen: Wieder verstand sich der akademische Nachwuchs, wenn auch diesmal unter Rückgriff auf das Theorem des "Substitutionalismus“ der objektiv gebotenen sozialistischen Revolution, als unverzichtbare Vorhut bzw. Avantgarde der gesellschaftlichen Transformation. Wie selbstverständlich dachte man sich selbst die unverzichtbare Anführerrolle zu. Das verleiht der Studentenbewegung der sechziger Jahre jene säkular religiöse Aura, die schon der nationalliberalen Burschenschaftsbewegung eigen gewesen war; ihre

„überbordende Defizienzerfahrung“ aber „erwuchs in ihrem Falle nicht aus materieller Not, sondern im Gegenteil aus einer Liberalisierung und einem stetig ansteigenden Wohlstand, die Ansprüche auf umfassende, schrankenlose Freisetzung und Triebbefriedigung nach sich zogen. ${ }^{\text {11093 }}$

Dass zumindest die antiautoritären „68er“ womöglich tatsächlich Avantgardisten gewesen sind, allerdings eher im Sinne der frühzeitigen Herausbildung einer „produktiven“ postindustriell-konsumgesellschaftlichen Subjektivität ${ }^{1094}$ horizontalisierter Hierarchien und projektbezogener Kreativität, zählt dabei zu den vielen Ironien von „1968“.

\section{II.2.3 Antisemitische und völkische Mobilisierung in Weimar 1925-1933: Eine antidemokratische Studentenbewegung}

Deutlich geringere wissenschaftliche Aufmerksamkeit wurde einer studentischen Mobilisierungswelle zuteil, die sich in den 1920er Jahren gegen die demokratische Republik von Weimar formierte. Von einer Studentenbewegung von „1933“, gar von einer „33er"-Generation kündet kaum eine Sekundärdarstellung. ${ }^{1095}$ Das ist wenig überra-

Denkformenangebot." Große: 1968: Revolte und Regression, S. 85f. Sicherlich ist diese schroffe Abqualifizierung nicht vollends sine ira et studio verfasst worden.

1092 Ibid., S. 86.

1093 Kießling: Die antiautoritäre Revolte der 68er, S. 289.

1094 „Mit ihrer öffentlichen Inszenierung des eigenen Ich (ihrer Feier eines auf sich fokussierten, jede ihm übergeordnete Instanz ablehnenden Subjekts) griff die Revolte die Tendenz der postindustriellen Gesellschaft auf, die bürgerliche Innerlichkeit (Spontaneität und Kreativität) in den öffentlich-gesellschaftlichen Raum zu leiten und wirtschaftlich produktiv zu machen." Ibid., S. 285.

1095 Die seltenen Einlassungen in dieser Richtung sind in provokativer Absicht geschrieben und ziehen Parallelen zwischen den „33ern“ und den „68ern“, so prominent der Historiker Cötz Aly: „Es mag die einst aktiv Beteiligten irritieren, doch knüpfte die linksradikale Studentenbewegung von 1968 
schend: Nichts an dieser Bewegung kann heute rühmlich erscheinen. Weder hat sie für Fortschritt und Demokratie optiert noch den Weg für kulturelle Liberalisierungsprozesse geebnet. Die unverkennbare Sprache des aggressiven, auf Erhalt kaiserzeitlicher Privilegien und Abbau der akademischen Stellenkonkurrenz schielenden Ressentiments, letztlich der rohen physischen Gewalt, taugt nicht zur Romantisierung oder Heroisierung. Tatsächlich aber zeigen diese Vorgänge im Vergleich mit „1848“ und „1968“ unverkennbare, bisweilen zynische Strukturanalogien, die es plausibel machen, zwischen 1925 und 1933 von einer antidemokratischen Studentenbewegung zu sprechen: Schließlich war ein "quantitativ relevanter ${ }^{\text {“1096 }}$ und wachsender Teil der Weimarer Studenten für die antisemitischen und völkischen, schließlich nationalsozialistischen Verheißungen empfänglich, was zur Delegitimierung des demokratisch-großdeutschen Gesamtvertretungsanspruchs der eher apolitisch-korporativ geprägten Deutschen Studentenschaft (DSt) ${ }^{1097}$ führte; ferner kam es in rascher Abfolge zu Demonstrationen, Kundgebungen und auch gewalttätigen Übergriffen auf jüdische und liberale Kommilitionen; auch verschaffte die republikfeindlich-oppositionelle Radikalisierung im Deutschen Hochschulring (DHR) und schließlich die Unterordnung der Studenten in das Kameradschafts- und Führerprinzip des Nationalsozialistischen Deutschen Studentenbunds (NSDStB) den völkischen Studenten von Weimar kollektiven außerparlamentarischen Rückhalt für ihre staatskritischen Umtriebe. Nicht zuletzt begriffen sich die studentischen Protagonisten selbst - darin den erwachsenen Nationalsozialisten ganz ähnlich - als Teil einer Bewegung. ${ }^{1098}$ Als im Schlüsseljahr 1933 eine Koalition aus NSDAP, DNVP und Stahlhelm unter Adolf Hitler damit begann, die Weimarer parlamentarische Demokratie in eine nationalsozialistische Diktatur zu verwandeln, hatte sich ein Großteil der Jungakademiker bereits selbst nazifiziert; ihnen kommt das makabre „Verdienst“ $z u$, die Universitäten und die deutsche Intelligenz (also hauptsächlich das erwachsene Bildungsbürgertum) „früher als jede andere öffentliche Institution“1099 als Brückenköpfe der nationalsozialistischen Machtübernahme konsolidiert zu haben.

Über diese Entwicklungen, ihre Entstehungsbedingungen und Folgen kann sich eine Darstellung studentischer Bewegungsphasen daher nicht hinwegsetzen. Sie entnimmt ihnen die Einsicht, dass die subkulturell verankerten Assoziations- und Ver-

in mancher Beziehung an die Erbmasse der rechtsradikalen Studentenbewegung der Jahre 1926 bis 1933 an." Aly, Götz: Unser Kampf. 1968 - Ein irritierter Blick zurück, Frankfurt a.M. 2008, S. 10.

1096 Bauß: Die Studentenbewegung der sechziger Jahre, S. $13 \mathrm{f}$.

1097 „Die DSt verstand sich als der politisch neutrale, alle politischen Richtungen zusammenfassende, demokratisch-parlamentarische, repräsentative, großdeutsche Verband aller deutschen Studentenschaften des Deutschen Reiches, Danzigs, des Sudetenlandes und Österreichs. Seine Aufgaben waren die Interessenvertretung der Studentenschaft nach außen und innen und die wirtschaftliche Hilfe für die Studentenschaft. Seine Idee war die einer gesamtstudentischen Cemeinschaft mit umfassenden geistig-kulturellen, wissenschaftlichen, sozialen und hochschulreformerischen Zielsetzungen. Die DSt faßte sich deshalb in ihrer Mehrheit bis 1922 als staatlich integrierte, anerkannte und gestützte Organisation mit völliger Neutralität gegenüber parteipolitischen Problemen auf." Schwarz: Studenten in der Weimarer Republik, S. 404.

1098 Vgl. Aly: Unser Kampf, S. 170.

1099 Walter, Franz: Sozialistische Akademiker- und Intellektuellenorganisationen in der Weimarer Republik. Solidargemeinschaft und Milieu: Sozialistische Kultur- und Freizeitorganisationen in der Weimarer Republik (hgg. von Peter Lösche), Bd. 1, Bonn 1990, S. 86. 
bandsnetzwerke der deutschen Studenten im Falle entsprechender gesellschaftlicher Voraussetzungen zu einer NS-Vorkämpferinstitution werden konnten, und dass die studentisch forcierten Politisierungsdynamiken des deutschen Bürgertums nicht nur fortschrittsförderliche, sondern auch nachgerade destruktive und enthemmende Konsequenzen zeitigten. Entgegen der durch das kulturell überlieferte Stereotyp vom rebellischen Studenten nahegelegten Assoziation von studentischen Bewegungsphasen mit freiheitlichen politischen Traditionslinien illustriert der Blick auf die 1920er und 1930er Jahre damit die Schattenseiten einer organisierten und politisierten Studentenschaft.

Der akademische Antisemitismus war kein Novum der Nachkriegsphase. Im Gegenteil: Er gehörte schon zur Normalität der alles andere als liberalen wilhelminischen Universität. ${ }^{1100}$ Die hierfür bestimmenden Tendenzen macht ein kurzer Rückblick auf die Entwicklung des einst mehrheitlich nationalliberal inspirierten Bildungsbürgertums nach der Gründung des Deutschen Kaiserreichs 1871 und nach der Gründerzeitkrise ab 1873 deutlich. Das Bürgertum konnte sich aufgrund seiner starken Präsenz in den deutschen Parlamenten und seiner kulturellen Deutungsmacht ${ }^{1101}$ noch bis in die 1870er Jahre hinein als „Vordenker und Vorreiter" des liberalen Verfassungsstaats und der auch ideellen Verbürgerlichung der deutschen Gesellschaft imaginieren, kurz: als maßgebliche Sozialformation, der „schlechthin die Zukunft gehören werde.“1102 Der unvergleichliche, durch die französischen Reparationszahlungen angefachte Wirtschaftsboom trieb diese Hoffnungen auf die finale, bald altliberale, Morgenröte zu einer letzten Blüte. Dann aber setzte eine Serie von substanziellen, sich wechselseitig amplifizierenden Erschütterungen ein: Der Börsenkrach und die wirtschaftliche Depression stürzten große Teile des Bürgertums - viele von ihnen hatten sich nach dem Deutsch-Französischen Krieg zu spekulativen Unternehmensgründungen und Investitionen hinreißen lassen - zwischen 1873 und 1879 in finanzielle Nöte und lädierte damit das Selbstbewusstsein des deutschen Bürgertums; „binnen weniger Wochen war es vorbei mit dem überbordenden Zukunftsoptimismus der unmittelbaren Gründerzeit. ${ }^{\text {“1103 }}$ Dies delegitimierte die noch junge Marktwirtschaft liberalen Typs, schürte geradezu antiliberalen Furor und eine „allgemeine Entliberalisierung des öffentlichen Lebens"; nach dem Attentat auf Wilhelm I. schließlich waren die Altliberalen sogar bereit, Bismarcks Sozialistengesetz von $1878 \mathrm{zu}$ unterstützen und sich damit selbst zu verunglimpfen. ${ }^{1104}$ „Auf die Anklagebank sah sich seit 1873

1100 Vgl. Gevers/Vos: Studentische Bewegungen, S. 26of.

1101 Die Gemengelage trug auch hier noch erkennbar Züge der 1830er und 1840er Jahre: „Im Zeichen solcher Zielperspektiven konnten bildungsbürgerliche Bürokraten, literarische Intellektuelle, großbürgerliche Unternehmer, kleinbürgerliche Handwerker bei der schwierigen Verwirklichung einer gemeinbürgerlichen liberalen Staats- und Gesellschaftsordnung zusammenstehen. Insofern ging von dem Ideenkonglomerat des Liberalismus auch eine vereinheitlichende Wirkung auf die unterschiedlichen bürgerlichen Schichten und Klassen aus." Wehler: Deutsches Bildungsbürgertum, S. 231.

1102 Ibid., S. 232 und 233.

1103 Walter, Franz: 1873-1923-1973. Krisendramen im 50-Jahre-Takt?, in: INDES. Zeitschrift für Politik und Cesellschaft, H. 1/2018, S. 35-55, hier S. 37.

1104 Wehler: Deutsches Bildungsbürgertum, S. 233. Die Rolle taktischer Winkelzüge Bismarcks bei der Sammlung dieser Mehrheiten ordnet Wehler dabei den Wirkungen der multiplen "anonymen“ Krisen klar nach. Vgl. auch Winkler: Der lange Weg nach Westen, S. 239f. und $245 f$. 
der Liberalismus gesetzt.“1105 Überhaupt dominierte gesellschaftlich ein völlig neues politisches Projekt: Es waren dies die Jahre der „inneren Reichsgründung“, in denen die militäraristokratische preußische Führungsschicht des Kaiserreichs versuchte, dem neuen Nationalstaat und der dynastischen Hohenzollernherrschaft eine Staatsidee $\mathrm{zu}$ verleihen, die auf der Sendung eines „evangelischen Kaisertums“ beruhte. ${ }^{1106}$ Bis 1878/79 rückten die liberalen Kräfte durch die jahrelange Mitarbeit an Bismarcks „Revolution von oben“ - gemessen an ihren freiheitlichen politischen Ursprüngen - ins Zwielicht; als der Reichskanzler allen liberalen und sozialdemokratischen Kräften den innenpolitischen Krieg erklärte, war der einst bürgerlich-liberale Nationalismus konservativ okkupiert, aus dem „linken“ Nationenverständnis ein "rechtes“ geworden. ${ }^{1107}$ Das beschädigte auch die neuhumanistische Bildungsidee, die zur formalen, offenbar kaum mehr geglaubten, ideologischen Deckschicht einer politisch marginalisierten Interessengruppe verfiel. ${ }^{1108}$ Kurze Zeit später waren dann die liberalen Kräfte weitgehend aus der Reichspolitik verdrängt und politisch entmachtet. Während der alte Nationalliberalismus im politischen Abseits (meist behielt er nur in größeren Städten Prägekraft) verharrte, spaltete sich von ihm die neue Fortschrittspartei ab, um Bismarcks „neukonservativen“ Kurs zu unterstützen. ${ }^{1109}$ In der Konsequenz war bis zum Ende der 1870er Jahre nicht nur jener klassenübergreifend angelegte, antiliberal und antiproletarisch aufgeladene neue Reichsnationalismus etabliert, der in den 1890er Jahren dem alldeutschen Expansionismus und Imperialismus applaudierte, ferner nach außen die „angeblich überlegene deutsche ,Kultur' gegen die herandrängenden zersetzenden Einflüsse der korrupten westlichen ,Zivilisation“ und nach innen den „gesellschaftliche[n] Status quo mit einer rigorosen Abgrenzung von allen Reformkräften“ in Stellung bringen sollte. ${ }^{110}$ Es war auch der „Beginn der fatalen Pathogenese vor allem des protestantischen Bildungsbürgertums“, $d$. h. der politischen Tendenzwende der Gebildeten hin zu einer antiliberalen, nationalchauvinistischen, antiwestlichen, xenophoben und schließlich antisemitischen Bewusstseinsform. ${ }^{111}$ Sie schuf ein verändertes politisches Klima, in dem der moderne, konfessionell bis ethnisch verbrämte Antisemitismus wuchern konnte; nach 1873 wurde das emanzipierte Judentum zunehmend zur Repräsentanz des modernen „Angriff[s] auf die Tradition“ erklärt, die Juden als „eigentliche Reichsfeinde“ identifiziert, als Vertreter des unproduktiven „raffenden“ Kapitals gegenüber dem produktiven christlichen „schaffenden“ Kapital. ${ }^{112}$ Im Kreise von „weltlichen“ wie protestantischen Publizisten wie Constantin Frantz, Wilhelm Marr

1105 Winkler: Der lange Weg nach Westen, S. 227.

1106 Ibid., S. 214f. Im Zuge dieser Auseinandersetzung entfachte der „Kulturkampf“ zwischen (neben anderen europäischen Staaten) Deutschem Kaiserreich und katholischer Kirche, vgl. ibid., S. $222 f$.

1107 Ibid., S. 217 und $244 f$.

1108 „Er [der Bildungsgedanke, ]. S.] verfiel zum karrierefördernden Berechtigungswesen der Gymnasial- und Universitätendiplome, der zahlreichen Staatsexamina, des Rechts auf Titelführung. Mit dieser Verwässerung ging eine dauerhafte Schwächung der humanistischen, kosmopolitischen, zivilisatorischen Impulse einher, die den Neuhumanismus in seiner Clanzzeit einmal ausgezeichnet hatten. "Wehler: Deutsches Bildungsbürgertum, S. 234.

1109 Ibid., S. 233.

1110 Ibid., S. 234.

1111 Ibid.

1112 Winkler: Der lange Weg nach Westen, S. 229. 
und Adolf Stoecker entstand die Denunziation von Juden als "fremde Rasse“ mitsamt dem daraus folgenden Vernichtungswahn, ja überhaupt der Begriff „Antisemit“, damals noch als politische Selbstzuschreibung. ${ }^{1113}$ Ausgerechnet ein altliberaler Veteran, Heinrich von Treitschke, avancierte zu einem beliebten antisemitischen Agitator; 1879 setzte er die verhängnisvolle Formel: „die Juden sind unser Unglück“ in die Welt. ${ }^{1114}$ Dies alles war möglich neben bzw. auf dem Boden einer Universitätslandschaft, die bis 1900 jene geradezu sagenhaft verklärte, international reüssierende deutsche Wissenschaft hervorbrachte, welche einerseits um ihren „modernen, universitär zentrierten Forschungsimperativ" in der Tradition Humboldt'scher forscherischer Autonomie ${ }^{1115}$ jenseits des Atlantiks beneidet wurde ${ }^{1116}$ und sich andererseits zugleich zu einer das klassische (wenngleich damals geradezu agitatorisch kanonisierte ${ }^{1117}$ ) Bildungsideal überflügelnden Ausbildungsstätte qualifizierter Arbeitskräfte und Produktionsstätte praktisch verwertbaren Fachwissens entwickelte. ${ }^{1118}$

Viel ist über die Mitverantwortung eines antidemokratisch und antiliberal gestimmten deutschen Bildungsbürgertums für den Niedergang der Weimarer Demokratie geschrieben worden, ${ }^{1119}$ eines Bildungsbürgertums, welches seiner Verbitterung über Privilegien- und Einflussverluste seit Kaiserreichszeiten nicht mehr Herr geworden sei: ${ }^{1120}$

1113 Vgl. ibid., S. 23of.

1114 Zit. nach ibid., S. 232.

1115 Bruch: Abschied von Humboldt?, S. 18

1116 Während sich die Herausbildung eines modernen Hochschulsystems in den USA dem Betreiben umtriebiger Universitätspräsidenten verdankte, die sich um eine industrieförderliche Ausrichtung der akademischen Strukturen bemühten, stiftete die traditionelle staatlich-bürokratische Bindung der deutschen Universität die vergleichsweise Unabhängigkeit von Marktinteressen sowie die starke Position der deutschen Professoren; beides Komponenten der vielgerühmten deutschen Forschungsfreiheit. Vgl. dazu Liebersohn, Harry: The American Academic Community before the First World War. A comparison with the German ,Bildungsbürgertum', in: Conze, Werner/Kocka, Jürgen (Hg.): Bildungsbürgertum im 19. Jahrhundert. Teil I: Bildungssystem und Professionalisierung in internationalen Vergleichen, Bd. 1, Stuttgart 1985, S. 163-185, hier S. 173-175 und S. 181-184.

1117 Vgl. Bruch: Abschied von Humboldt?, S. 24.

1118 Die neuen massengesellschaftlich aufgegebenen Konflikte, die die Rede eines „Abschieds von Humboldt“ um 1900 rechtfertigen, bringt Rüdiger Bruch auf die Formel: „Planungsgesteuerte Wissenschaftspolitik anstelle autonomiegestützter Wissenschaftsfreiheit, praxisorientierte Ausbildungsmodelle anstelle einer wissenschaftsorientierten universitas litterarum mit der Folge einer Trennung von Lehre und Forschung, Auseinanderdriften von Frequenzbewegung und Professorenchancen, fachliche Spezialisierung als Aushebelung einer civitas academica, gesellschaftliche Verwertbarkeit von Wissen anstelle wissenschaftlicher Persönlichkeitsformung [...]“ Ibid., S. 21.

1119 Zur Erinnerung: Der gesamte Bielefelder Sonderforschungsbereich zum Bildungsbürgertum ist zur Beantwortung der Frage angetreten, ob ein deutscher "Sonderweg" des Bürgertums und eine damit verbundene spezifische Illiberalität der deutschen Akademiker für das Verhängnis der NS-Herrschaft mitverantwortlich gewesen seien, vgl. Lundgreen: Einführung, außerdem für den Diskurs antidemokratischer Intellektueller Sontheimer: Antidemokratisches Denken in der Weimarer Republik. Zur aktuellen Kritik an der Sonderwegsthese vgl. Budde: Blütezeit des Bürgertums, S. 126-128.

1120 Vgl. für eine Skizze der mentalen Verarbeitung wiederholter Kränkungsempfindungen am Beispiel der Soziologen Ringer: Die Gelehrten, S. 152ff. Deutlich wird das Cewicht der Herabsetzungserfahrung, wenn man sich noch einmal vergegenwärtigt, wie gut die deutschen Bildungsbürger ihre Privilegien und ihre Deutungsmacht zu schützen wussten: „Unter Berufung auf die klassisch- 
"Es war die Anhänglichkeit an das alte Reich und seine monarchische Staatsform, durch welche die deutsche Hochschule dahin gebracht wurde, der Demokratie nicht nur die moralische Unterstützung zu versagen, sondern auch an ihrem Teile die Cemüter abspenstig zu machen. ${ }^{\text {“1121 }}$

Hinter dieser Haltung habe die verhängnisvolle „unklare Hoffnung“ gestanden, die antidemokratische Polemik „werde zur Wiederkehr entschwundener Zustände beitragen. “1122 Die dabei oft angeführte materielle, kulturelle und auch sozialmoralische Erosion dieser Sozialformation ist tatsächlich unübersehbar. Zu den Modernisierungserscheinungen ihrer Kerninstitution, der Universität, zählte immer auch die soziale Durchmischung des Studiums und des Lehrkörpers, die Nobilitierung von Technischen Universitäten zu gleichrangigen Hochschulen, die Ausweitung von Bildungszertifikaten als Berufsberechtigung auf weitere Arbeitsmarktbereiche (insbesondere die „Erfolgsstory“ des Diploms) und die mit all dem verbundene tendenzielle Auflösung der quasi-ständischen Grundlagen der bildungsbürgerlichen Eliten. ${ }^{1123}$ Der „Anteil der Aufsteiger" am Bildungsbürgertum der 1890er Jahre gilt als „beträchtlich“'1124 Heldengeschichten implizieren einen tiefen und tragischen Fall, und das gilt ganz besonders für die vormärzliche Heldengeschichte des liberalen Bürgertums, welches sich eine spezifische „Zielutopie“ einer herzustellenden bürgerlichen Gesellschaft gegeben hatte, nämlich die

„Vereinigung rechtlich freier, durch Besitz und Bildung ausgezeichneter, wirtschaftlich ungestört konkurrierender, besitzindividualistisch orientierter, politisch handlungsfähiger Individuen [...], die im Medium der Öffentlichkeit oder auf dem Forum des

neuhumanistische Bildungsidee haben die humanistisch Gebildeten gegenüber denen, die eine „nur"praktische Berufstätigkeit im Bereich von Wirtschaft und Technik anstrebten, nicht nur ihr kulturelles Prestige behauptet, sondern Exklusivansprüche für eine beträchtliche Reihe von attraktiven Karrieren aufrecht erhalten können, auch noch als die Regierungen schulische Differenzierung durchsetzen. Im Streit zwischen humanistischer und, realistischer' Bildung, um Schultypendifferenzierung, Gleichberechtigung der Technischen Hochschulen mit den Universitäten hat sich mehr als ein Kampf um Bildungskonzeptionen und pädagogische Weltanschauungen abgespielt, nämlich ein sozialer Grabenkampf, dessen Auswirkungen weit in die Cesamtgesellschaft hineinreichten, insofern sie die Gestalt des Sekundarschulbereichs prägten. Fiel doch mit der Entscheidung der Eltern für den einen oder anderen Schultyp nicht nur zugleich eine folgenreiche Entscheidung über künftige Berufsaussichten der Kinder, sondern auch darüber, in welchem Grade diese später als, Voll'- oder auch, Halbgebildete' angesehen werden würden. Kein Wunder, daß auch im Wirtschaftsbürgertum viele Eltern, ohne daß Familientradition und kulturelles Interesse das nahelegten, ihre Kinder aufs Gymnasium schickten. "Vierhaus: Umrisse einer Sozialgeschichte der Gebildeten, S. $411 \mathrm{f}$.

1121 Litt, Theodor: Hochschule und öffentliches Leben in der Weimarer Republik, in: Zilius, Wilhelm/Grimme, Adolf (Hg.): Kulturverwaltung der zwanziger Jahre. Alte Dokumente und neue Beiträge, Stuttgart 1961, S. 49-59, hier S. 54.

1122 Ibid.

1123 Vgl. Bruch: Abschied von Humboldt?, S. 22 und 26f. sowie Kapitel II.1 dieser Studie.

1124 Kocka, Jürgen: Bildungsbürgertum - Gesellschaftliche Formation oder Historikerkonstrukt?, in: Ders. (Hg.): Bildungsbürgertum im 19. Jahrhundert. Teil IV: Politischer Einfluß und gesellschaftliche Formation, Stuttgart 1989, S. 9-20, hier S. 19. 
Parlaments als einem freien Marktplatz der Ideen das Cemeinwohl in vernünftiger Diskussion ermittelten und in Cesetzesform gossen."1125

$\mathrm{Zu}$ den höchsten Zielen gehörte, „monarchisch-aristokratische[] Willkür“ durch die „Herrschaft des Gesetzes“ in einer Republik zu ersetzen, Qualifikation auf „Leistung und Talent" zu gründen und damit auch soziale Aufstiegsmobilität sicherzustellen. ${ }^{1126}$ Ihr Anspruch also war, wenn auch nicht durchweg praktisch egalitär ${ }^{1127}$ und auch gewiss nicht zwangsläufig individuell genussförderlich ${ }^{1128}$, so doch ideell universalistisch und fraglos emanzipativ. Bürgerliche Ideale prägten das kulturelle Selbstverständnis des gesamten deutschen Raums. ${ }^{1129}$ Die zwischen 1800 und 1850 in ihrer formativen Phase befindlichen Bildungsbürger werden daher oft als „praktisch einflußreichste“ Sozialformation des vormärzlichen, aber auch nachmärzlichen deutschen Raumes aufgefasst. ${ }^{1130} \mathrm{Zu}$ ihnen zählten führende Beamte ebenso wie Professoren, Ärzte, Anwälte und Richter, Pastoren, Apotheker, Künstler und Kaufleute, später Ingenieure, Architekten und Chemiker und, nach den Hochschulreformen im frühen 19. Jahrhundert, ein „Kernberuf “ Lehrer. ${ }^{1131}$ Dann aber siegte die preußische Militäraristokratie und übernahm die politische Herrschaft über den neuen Nationalstaat - sowohl aus taktischen Imperativen als auch aus politischem Unterliegen und nicht zuletzt aufgrund des Zugeständnisses reichhaltiger Privilegien (Prestige, Einkommen, kulturelle Deutungshoheit) zog sich das Bildungsbürgertum aus der Politik zurück ${ }^{1132}$-, der nicht der ersehnte bürgerlich-liberale wurde; der "politische Elan des Bürgertums“ war gebrochen. ${ }^{1133}$ Einst politische Platzhirsche des Deutschen Bundes, denen 550 der 830 Sitze in der Frankfurter Nationalversammlung gehörten, ${ }^{1134}$ einst „Verkünder und Träger politischer Reformen und bürgerlicher Emanzipation“, assimilierten sich die

1125 Wehler, Hans-Ulrich: Die Zielutopie der, Bürgerlichen Cesellschaft' und die ,Zivilgesellschaft' heute, in: Lundgreen, Thomas (Hg.): Sozial- und Kulturgeschichte des Bürgertums. Eine Bilanz des Bielefelder Sonderforschungsbereichs (1986-1997), Göttingen 2000, S. 85-92, hier S. 86.

1126 Ibid., S. $86 \mathrm{f}$.

1127 Vgl. ibid., S. 87.

1128 „Ebenso starr wie der äußere Ausschluß vom Kreis der Privilegierten nahm sich die psychische Zwangsapparatur aus, denn harte, frühzeitig in Sozialisationsprozessen verinnerlichte Normen regulierten die Sexualmoral, das Hygieneverhalten, das Familienleben." Ibid.

1129 „Die bürgerliche Hegemonie triumphierte in der Öffentlichkeit und im Vereinswesen, im Wohnstil und in der Lebensführung, in der Literatur und in allen Künsten, im Arbeitsethos und Leistungsdenken, in der Bejahung aller Wissenschaften und der Hochkultur. Überall setzte sich der Siegeszug der liberal-bürgerlichen Leitwerte fort. Weder der Adel noch das städtische Proletariat vermochten dem eine überlegene Gegenkultur entgegen zu setzen." Ibid., S. 88.

1130 Vgl. Vierhaus, Rudolf: Umrisse einer Sozialgeschichte der Gebildeten in Deutschland, in: Quellen und Forschungen aus italienischen Bibliotheken und Archiven, Bd. 60, 1980, S. 395-419, hier S. 405 und, zitierend, Jarausch: Deutsche Studenten, S. 27.

1131 Vgl. Conze/Kocka: Einleitung, S. 11 und Kocka, Jürgen: Bildungsbürgertum - Cesellschaftliche Formation oder Historikerkonstrukt?, in: Ders. (Hg.): Bildungsbürgertum im 19. Jahrhundert. Teil IV: Politischer Einfluß und gesellschaftliche Formation, Stuttgart 1989. S. 9-20, hier S. 12; vgl. ferner für das Stichwort „Kernberuf“ Jarausch: Deutsche Studenten, S. 31.

1132 Vgl. Ringer, Fritz K.: Die Gelehrten. Der Niedergang der deutschen Mandarine 1890-1933, Stuttgart 1987, S. 21.

1133 Wehler: Die Zielutopie der,Bürgerlichen Gesellschaft', S. 89.

1134 Vgl. Ringer: Die Gelehrten, S. 49. 
gebildeten Bürger im Kaiserreich - teils aus Mangel an Optionen, teils aus Opportunismus - als "staatsbejahende“ Schicht, die sich vom einstigen Fortschrittsprojekt losgesagt hatte, ja sich nachgerade reelitisierte: „Massenresonanz hatten sie weder gesucht noch gefunden; die Kluft zwischen Gebildeten und Nicht-Gebildeten war nicht überbrückt, sondern im Laufe des 19. Jahrhunderts tiefer geworden. “1135 Nach 1848 verschwand rasch die mobilisierte Übergangsgesellschaft, die das Bündnis aus revolutionärem Bürgertum und arbeitender Bevölkerung ermöglichte: Es folgte die rasante Urbanisierung und Technisierung von ganz Europa in den 1850er und 1860er Jahren. Versuche, den liberalen Nationalismus auch nach der gescheiterten Revolution zu zelebrieren gab es, so in Gestalt der 50-Jahr-Feier der Burschenschaft vom 14. bis 16. August 1865 in Jena. ${ }^{1136}$ Dennoch: Eine politische Einheit, gar eine verklammernde Partei des Bildungsbürgertums hatte es auch in dieser Periode nicht gegeben. Und wie nach 1848 ging der Riss der zeitgenössischen politischen Frontlinien auch am fin de siècle durch diese gesellschaftlich einflussreiche Gruppe, ${ }^{1137}$ auch noch als der Symbolkampf zwischen altem und neuem Nationalismus ausgefochten wurde. Zwar errichteten die Nationalliberalen noch 1872 ihr Denkmal für „Turnvater“ Jahn auf der Hasenheide als nationale Kultstätte. ${ }^{1138}$ Doch: „Die preußische Monarchie brüskierte die bürgerliche Nationalfeier und errichtete statt dessen [sic] ein Jahr danach mit der Siegessäule ihr eigenes Nationaldenkmal.“1139 Mit der späten und partiellen Realisierung des einst ersehnten Nationalstaats erlosch schließlich der alte Liberalismus als Bewegung: ${ }^{1140}$ Um 1900 war die alt- bzw. linksliberale Traditionslinie mehr denn je an bestimmte Personengruppen, die „Alt-48er“ gebunden, welche nach und nach aus dem öffentlichen Leben ausschieden; in den frühen 1930er Jahren schließlich verschwanden dann zunächst die überalterten einstigen Protagonisten dieser Bewegung, ${ }^{1141}$ während der NS-Herrschaft dann, auch aufgrund nonexistenter Milieustrukturen, die letzten Reste „liberaler Lebenswelten“ vollständig. ${ }^{1142}$ Nun, ab 1880 und insbesondere ab 1890, führte das gebildete Bürgertum seinen stetigen Generalangriff auf die von ihnen wahrgenommenen Konsequenzen der gesellschaftlichen Modernisierung, etwa in Gestalt der defensiven Insistenz auf die tiefen Urgründe deutscher „Kultur“1143 und auf intel-

1135 Vierhaus: Umrisse einer Sozialgeschichte der Gebildeten, S. 411f.

1136 Vgl. Lönnecker: Vorwort, S. X.

1137 „[...] vor allem für das späte 19. und 20. Jahrhundert gilt, daß es kaum eine politische Position gab, die nicht auch von Bildungsbürgern vertreten wurde. Die meisten politischen Strömungen (einschließlich des aufsteigenden Nationalsozialismus) fanden bildungsbürgerliche Sprecher. Die politische Plastizität des Bildungsgedankens scheint fast unbegrenzt. Auch politisch läßt sich das Bildungsbürgertum nicht als Einheit definieren. Best zeigt, wie sein beamteter und sein freiberuflicher Flügel 1848/49 auseinanderdrifteten. Über kollektive Handlungsfähigkeit verfügte es nicht, entsprechende Organisationen bildete es nicht heraus." Kocka: Bildungsbürgertum, S. 15.

1138 Langewiesche: Kulturelle Nationsbildung, S. 59.

1139 Vgl. Ibid., S. 60.

1140 Die „Idee einer deutschen Reichsnation ohne gemeinsamen Staat zerbrach erst, als ein einheitlicher deutscher Nationalstaat aus drei Kriegen hervorging. Jetzt wurde auch in Deutschland Nation gleichgesetzt mit einem einzigen gemeinsamen Nationalstaat - immer noch föderalistisch [...], aber eben doch ein einheitlicher Staat." Ibid., S. 48.

1141 Vgl. Lösche/Walter: Katholiken, Konservative und Liberale, S. 482.

1142 Ibid., S. 483.

1143 Bekannt ist die Persiflage dieser Hybris in Heinrich Manns Der Untertan. 
lektuellen „Idealismus“" gegen die angloamerikanische „Zivilisation“ sowie einen durch diese propagierten schnöden „Materialismus“, jetzt fetischisierten wachsende Teile der deutschen Akademiker die vermeintlich exzeptionellen Qualitäten ihrer „Volks“ gegen "Masse“ und „Rasse“ sowie gegen das „Völkerchaos“ der neuen globalisierten Welt. ${ }^{1144}$ In der Weimarer Republik schließlich blieb die antiliberale Tradition stark und trieb das Bildungsbürgertum früh auf die Seite der "Republikfeindlichkeit“. ${ }^{1145}$ Von den Nationalsozialisten erhoffte man sich vage und sicher auch zweifelnd die Restitution des einstigen Status, da keine schlagkräftige „Dachorganisation“ existierte, die es vermocht hätte, die „inneren Gegensätze“ des Bildungsbürgertums zu „überbrücken und seine Interessen in einem verschärften Überlebenskampf der frühen dreißiger Jahre wirkungsvoll“ zu vertreten. ${ }^{1146}$ Zwar geben die historischen Vorgänge keine gerade Linie „aus teleologischer Fixierung auf das Jahr $1933^{\text {“1147 }}$ her, es besteht kein Automatismus von antiliberaler Tendenzwende der Gebildeten zur Kapitulation derselben vor der NSDAP. ${ }^{1148}$ Insgesamt ist offenkundig, dass die parteipolitische Abstinenz des prestigeträchtigen Bildungsbürgertums ab 1880, dessen mangelnde kollektiv-politische Handlungsfähigkeit, ${ }^{1149}$ der sukzessive Abstieg als Deutungsmacht in den kulturellen und moralischen Surrogatsphären und schließlich die daraus resultierende Verführbarkeit für antidemokratische Zivilgesellschaftlichkeit einen wesentlichen Destabilisierungsfaktor für die politische Ordnung der Weimarer Republik gebildet haben. ${ }^{1150}$ Der sich dann verhängnisvoll entfaltende „Januskopf der oft allein in verklärtes Licht getauchten Zivilgesellschaft" lief sich in Gestalt der Alldeutschen, Flotten- und Ostmarkvereine bereits im Kaiserreich warm. ${ }^{1151}$ So ist die weitgehende

1144 Wipf: Studentische Politik und Kulturreform, S. 74f.

1145 Wehler: Die Zielutopie der,Bürgerlichen Cesellschaft', S. 89.

1146 Jarausch: Die Krise des deutschen Bildungsbürgertums, S. 202. „Die vielschichtigen Gründe für den NS-Einbruch in das Bildungsbürgertum sind nach zahlreichen Selbstzeugnissen in einem Gemisch von wirtschaftlichen Schwierigkeiten, illiberalen Traditionen, beruflicher Marginalität, politischer Naivität und Opportunismus zu suchen." Ibid., S. $201 f$.

1147 Ibid., S. 203.

1148 „Trotz ihres erschreckenden Ausmaßes hat diese tiefgreifende Krise des Bildungsbürgertums noch keine überzeugende historische Erklärung gefunden. [...] Der Versuch, Unbegreifliches zu begreifen, hinterläßt letztlich einen unerklärbaren Rest." Ibid. und ibid., S. 204.

1149 Vgl. ibid., S. 202.

1150 Wie die US-amerikanische Politikwissenschaftlerin Sheri Berman herausgearbeitet hat, leistete die unvergleichlich lebendige Weimarer Zivilgesellschaft gerade keine politische Integration des deutschen Bürgertums, sondern verschärfte im Gegenteil dessen Entfremdung von den politischen Institutionen. Die bereits am Vorabend des Ersten Weltkriegs nachweisbare „Reichsverdrossenheit" insbesondere der protestantischen Mittelklassen erlebte demnach nach der Großen Inflation von 1922/23 eine neue, antisozialistisch und antikapitalistisch aufgeladene Renaissance; so zählte der Veteranenverein „Stahlhelm“ zwischenzweitlich zwischen 500.000 und 600.000 Mitgliedern. All diese Entwicklungen halfen maßgeblich dabei, die nationalsozialistische Machtübernahme vorzubereiten. Vgl. Berman, Sheri: Civil Society and the Collapse of the Weimar Republic, in: World Politics, H. 49/1997, S. 401-429, hier S. 412f. und 416-424.

1151 „Schon hier kehrte sich der Januskopf der oft allein in verklärtes Licht getauchten Zivilgesellschaft heraus. Die neuen freiwilligen Assoziationen brachten Einzelne für gemeinsame Vorhaben zusammen, förderten mithin bürgergesellschaftliches Engagement und Selbstinitiative. Aber ein kommunitär-solidarisches, republikanisches Gemeinwesen brauchte sich daraus nicht zu formieren. Im Gegenteil: Die zivilgesellschaftliche Mobilisierungsund Organisationsenergie vervielfäl- 
Entliberalisierung des deutschen Bildungsbürgertums schon in den 1870er Jahren eindrücklich, gerade weil die Mehrheit der Bevölkerung in den 1870er Jahren zwar „von Vorurteilen gegen die Juden nicht frei“ war, aber der antisemitischen Agitation wohl insgesamt (noch) eher gleichgültig gegenübergestanden haben mag. ${ }^{1152}$ Erst allmählich konstituierte sich ein gesamtbürgerliches „nationale[s] Lager“, welches dann allerdings politkulturell dominant wurde:

„[...] die Verkehrskreise von liberalen und konservativen Bürgern [gingen, J. S.] ineinander über; sie orientierten sich gemeinsam an nationalen Symbolen, die sie an den Feiertagen des vaterländisch gesinnten Deutschlands einträchtig in Szene setzten. Bei Wahlen rochierten ihre Wähler zwischen konservativen und liberalen Parteien.“1153

Zum „Basiskonsens“ des Konservatismus zählte „die Heimatverbundenheit, das christlich-protestantische Bekenntnis, das berufsständische und elitäre Gesellschaftsbild [...] zu dem bald noch die nationalistische Gesinnung trat" - wie auch „schließlich die gemeinsame Vereinskultur [...], auch wenn diese Gruppe parteipolitisch weiterhin aufgesplittert blieb.“1154 Überhaupt existierten im Kaiserreich zunächst „nur partiell Milieustrukturen“. ${ }^{1155}$ In den 1890er Jahren dann formierte sich angesichts der raschen Industrialisierungsprozesse eine wachsende modernisierungskritische Reaktionsbewegung: Katholische und welfische Vereine etwa bildeten sich als „unmittelbare Antworten auf sozialdemokratische Organisationsgründungen“. ${ }^{1156}$ Die Phase der „inneren Reichsgründung" schuf somit auch die verhängnisvolle Grundlage der antiliberalen und antisemitischen Tendenzwende der Studentenschaft in den 1880er Jahren.

Der Wandel bildungsbürgerlicher Mentalitäten machte sich auch unter der studierenden Jugend geltend. Dass die bürgerlichen Schichten im Zuge der wirtschaftlichen Krisendynamiken und der heraufdämmernden modernen Industriegesellschaft des ausgehenden 19. Jahrhunderts ihres Status immer wieder unsicher wurden, wird in verschiedenen Suchbewegungen der bürgerlichen Jugend zur Jahrhundertwende deutlich. Lebensreform und Wandervogel etwa können als „Produkt einer ihrer selbst nicht mehr sicheren Bildungsbürgerlichkeit“ in der langen Phase ihres Abstiegs gelesen werden. ${ }^{1157}$ Die Jugendbewegung der Jahrhundertwende romantisierte, suchte Alternativen zur gesellschaftlichen Realität. Sie strotzte vor Ambivalenzen, reaktivierte Impulse der romantisch-literarischen „Sturm und Drang"-Bewegung, aber auch der Urburschenschaft; ${ }^{1158}$ in ihrer anfänglich apolitischen Auflehnung gegen Tradition und erwachsene Autoritäten zeigten sich freiheitliche, aber auch antimodernistische, esoterisch-eskapistische Impulse: „Die zornigen jungen Männer des Jahres 1900 waren überall in Euro-

tigte Dynamik, Disziplin und Durchsetzungsfähigkeit von Antisemitismus und Antiliberalismus erheblich." Walter: $1873-1923-1973$, S. 43.

1152 Winkler: Der lange Weg nach Westen, S. 236.

1153 Lösche/Walter: Katholiken, Konservative und Liberale, S. 474 unter Bezugnahme auf Rohe: Wahlen und Wählertraditionen, S. 21.

1154 Ibid., S. $477 f$.

1155 Ibid., S. 476.

1156 Ibid., S. 477.

1157 Walter: Rebellen, Propheten, Tabubrecher, S. 17. Vgl. außerdem ibd., S. 23-49.

1158 Laqueur, Walter: Die deutsche Jugendbewegung [1962]. Eine historische Studie, 1978, S. 14. 
pa in den gebildeteren Schichten der jungen Generation zu finden. “1159 Demgegenüber hatten die Studenten des Kaiserreichs deutlich klarere politische Vorstellungen. Angeführt von den elitären Korporationen, zu denen etwa die Hälfte der Immatrikulierten zählte, ${ }^{1160}$ erklärten sie sich selbst früh und kompromisslos zur Vorhut der Bismarck'schen Nation. Zum einen internalisierten sie energisch den wilhelminischen Militarismus - wie bereits gesehen ${ }^{1161}$, war der gesellschaftlich arrivierte Bürger Reserveoffizier, der respektable deutsche Student indes Mitglied in den elitären Karrierenetzwerken der Korporationen -, zum anderen radikalisierten sie die politisch weit rechten Mentalitätstrends des Bildungsbürgertums. Zwischen 1880 und 1900 hatte sich ein aggressiver studentischer Nationalismus konsolidiert, der sich der Bindung an überlebte freiheitliche Bildungsideale ledig wusste. ${ }^{1162}$ Völkisches Denken und ethnisch begründeter Antisemitismus griffen hier, verstärkt durch die akademische Überfüllungskrise der 1890er Jahre, schneller und umfassender um sich als bei ihrer Elterngeneration. ${ }^{1163}$ Das im Vormärz noch nationalliberal aufgetretene studentische Verbindungswesen entwickelte sich schon im Kaiserreich $\mathrm{zu}$,antiliberale[n] und antidemokratische[n] Sozialisationsinstanzen der jugendlichen Bildungsschicht“" ${ }^{1164}$ Die Studenten nahmen damit, kaum weniger als zu Vormärzzeiten, eine Pionierrolle für die antiliberale Tendenzwende der Gebildeten im Kaiserreich ein. ${ }^{1165}$ Schon 1880 schufen sie mit dem „Verein Deutscher Studenten“(VDSt) einen christlich-monarchistischen, großdeutschen und antijüdischen Dachverband, mithin eine „erste größere Studentenbewegung im Kaiserreich“, die viele liberale Professoren wie Hans Mommsen oder Rudolf Virchow nachgerade schockierte. ${ }^{1166}$ Auch einstige konfessionelle Konfliktlinien traten

1159 Vgl. ibid., S. 13.

1160 Vgl. Studier: Der Corpsstudent als Idealbild der Wilhelminischen Ära, S. VI. sowie Schulze/Ssymank: Das deutsche Studententum, S. 181-185.

1161 Vgl. Kapitel II.1.2 dieser Studie.

1162 „Konnte etwa ein neuer studentischer Nationalismus 1817 noch mit dem Ethos der reformierten Forschungs- und Bildungsuniversität vermittelt und somit in der civitas academica aufgehoben werden, so drängte um 1900 ein signifikant aggressiver und zunehmend antisemitisch besetzter Nationalismus von den Vereinen Deutscher Studenten bis hin in die Freistudentenschaft auf Absonderung und lebensweltliche Selbstbestimmung, ohne daß es einer überwölbenden Universitätsidee bedurfte." Bruch: Abschied von Humboldt?, S. 29. Vgl. auch Gevers/Vos: Studentische Bewegungen, S. 26of.

1163 Vgl. Wipf: Studentische Politik und Kulturreform, S. 28-31, außerdem Jarausch: Deutsche Studenten, S. 90.

1164 Hardtwig: Studentische Mentalität, S. 581.

1165 „Der neue Nationalismus der Studenten um 1880 war eine radikalere und verbreiterte Version des Stimmungswandels des Bildungsbürgertums allgemein." Jarausch: Deutsche Studenten, S. 84.

1166 Ibid., S. 82, vgl. außerdem ibid., S. 86 und 92. Dass diese und folgende politische Mobilisierungen in der vorliegenden Studie nicht als eigenständige Studentenbewegung aufgeführt werden, hat seinen Grund im gewählten begrifflichen Zuschnitt auf oppositionelle Bewegungen. Zudem lässt es die relative Simplizität der hier zu beobachtenden Entwicklungen zu, in einem an den Weimarer Verhältnissen interessierten Rückblick das Wesentliche zu erfassen: Die Korpsstudenten adaptierten und organisierten den neuen antiliberalen Nationalismus gegen „äußere“ und „innere“ Feinde früher und breiter als das erwachsene Bildungsbürgertum. Dabei ließen sie an ihrer Staats- und Kaisertreue keinen Zweifel. Ihre destruktivsten „Früchte“ trug die hier gestiftete völkisch-antiliberale Traditionslinie in ihrer Entbindung von den Institutionen des Herrschaftssystems. 
hinter dieser neuen gemeinschaftsstiftenden „Integrationsideologie“1167 allmählich zurück und sollten nach dem Ersten Weltkrieg nahezu verschwinden. ${ }^{1168}$ Diese langfristig prägende subkulturelle und mentale „Refeudalisierung“ eines großen Teils der Studentenschaft ${ }^{1169}$ war es, die noch bis Anfang der 1960er Jahre hinein das heutzutage kaum noch zugängliche Urteil motivierte, die "Studentenschaft in Deutschland“ habe ein knappes Jahrhundert lang „traditionell rechts“ gestanden. ${ }^{1170}$ Zwar gelangte auch die sich zeitgleich konstituierende korpskritische und kosmopolitische - aber ebenso modernisierungskritische - lose organisierte Freistudentenschaft $\mathrm{zu}$ einem gewissen Einfluss, vor allem in größeren Universitätsstädten mit weitgehend anonymisiertem Hochschulbetrieb. ${ }^{1171}$ Sie setzte auf eine Reform des universitären Lebens und auf die Förderung freier Intellektualität zur Herstellung einer „Kulturgemeinschaft“ umfänglich gebildeter Menschen nach dem Vorbild der vormärzlichen Progressbewegung. ${ }^{1172}$ Ihre Vorstellung einer civitas academica von intellektuell und charakterlich durchgebildeten Menschen, die sich über die „Verknöcherung“ zum bloßen Brotgelehrtentum ${ }^{1173}$ hinwegsetzen sollte und auch einen starken Akzent auf studentische Sozialarbeit im Sinne von Wohnvermittlung, Beratung, Ämtern und Service-Einrichtungen setzte, ${ }^{1174}$ war vor allem für kleinbürgerliche Aufsteiger attraktiv. ${ }^{1175}$ Sie bildete insofern vornehmlich eine „Klassenbewegung “1176 der Nichtinkorporierten. Doch auch unter diesen Freistudenten setzte sich bis 1914 der militaristische und imperialistische Nationalismus durch. Zu Kriegsbeginn buhlten schließlich beide - korporierte wie nichtkorporierte Studentenorganisationen - um die nationale Vorkämpferrolle im Schulterschluss von „Waffen und Wissenschaft“. ${ }^{1177}$ Nationale Mythen wie die Leipziger „Völkerschlacht" 1813 und der deutsch-französische Krieg 1870/71 mit der darauffolgenden Reichsgründung wurden, ungeachtet ihrer teils diametralen politischen Traditionslinien, zu den „Ideen von 1914“, „eine[r] Mischung von Patriotismus und Kulturmission“ eingeschmolzen, der heraufdämmernde Krieg zur Angelegenheit nationaler Bewährung und akademischer

1167 Ibid., S. $91 \mathrm{f}$.

1168 „Das Spektrum der vertretenen Nationsverständnisse weitete sich bis ins Völkische. [...] Zugleich nahm die Bedeutung antikatholischer Ressentiments innerhalb des Bildungsbürgertums ab, während andere Trennlinien, beispielsweise der Antisemitismus oder die Haltung zu Demokratie und Republik, deutlich an Gewicht gewannen. Angesichts dieser Veränderungen spricht vieles dafür, dass für diese soziale Großgruppe die Segmentgrenze der christlichen Konfession im Ersten Weltkrieg untergegangen ist." Dowe, Christopher: Auch Bildungsbürger: katholische Studierende und Akademiker im Kaiserreich. Kritische Studien zur Geschichtswissenschaft, Bd. 171, Göttingen 2006, S. 303.

1169 Wipf: Studentische Politik und Kulturreform, S. 28-31.

1170 Fichter/Lönnendonker: Kleine Geschichte des SDS, S. 7.

1171 Vgl. ibid., S. 248 und Gevers/Vos: Studentische Bewegungen, S. $266 \mathrm{f}$.

1172 Vgl. Wipf: Studentische Politik und Kulturreform, S. 19f., 74 und 82.

1173 Schulze/Ssymank: Das deutsche Studententum, S. 378.

1174 „Insgesamt atmete die Freistudentenschaft einen modernen, demokratischen Ceist, der die Nichtinkorporierten aufweckte und studentische Sozialarbeit anregte." Jarausch: Deutsche Studenten, S. 98.

1175 Vgl. Gevers/Vos: Studentische Bewegungen, S. 267.

1176 Schulze/Ssymank: Das deutsche Studententum, S. $432 f$.

1177 Vgl. Jarausch: Deutsche Studenten, S. 107f. sowie Maurer: „... und wir gehören auch dazu“, S. 1129 und 1131. 
„Sendung“ stilisiert. ${ }^{1178}$ Die Studenten wussten um den moralischen Rückhalt eines universitären Lehrkörpers, der - wo nicht selbst in die Regimenter eingerückt - seine wissenschaftliche Arbeit in den Dienst an der Nation stellte und sich um regelmäßige Proben der vaterländischen Gesinnung, etwa im Rahmen öffentlicher Auftritte, bemühte. ${ }^{1179}$ Aus den Blutbädern des Weltkriegs - wie dem später mythisch verklärten Gefecht in der Nähe des belgischen Langemarck - kehrte eine vernarbte Generation zurück, die „die Sonne der Kriegserfahrungen“ als bessere Lebensschule wahrgenommen hatte als die im Vergleich dazu blutleere und scholastisch erscheinende Universität. ${ }^{1180}$ Sie, die in der mehrheitlichen Ablehnung der bisherigen politischen Ordnung ein gemeinsames Motiv mitbrachte, zerfiel in eine studentenpolitisch konzentrierte Mehrheit ${ }^{181}$, ferner in eine pazifistisch-sozialistisch inspirierte und in eine verbissene deutsch-völkische, einen Veteranen- und Gefallenenkultur pflegende, Fraktion. ${ }^{1182}$ „Der Krieg erdrückte den Freiraum der Hochschule, militarisierte die Studentenschaft physisch (Wehrbund) und geistig (Chauvinismus) und zerstörte weitgehend ihre unabhängige Subkultur.“1183

Nach dem Weltkrieg waren das Kaisertum und die politischen Privilegien der konservativen Bürger verloren sowie die materiellen Grundlagen insbesondere der Mittelschichten insgesamt gefährdet. In Reaktion auf diese erschütternden äußeren Entwicklungen bildete sich ein konservatives Vereins- und Organisationswesen nach liberalem, sozialdemokratischem und katholischem Vorbild: „Millionen von konservativen Bürgern agierten aggressiv in nationalistischen Krieger-, Turn-, Schützen- und Gesangsvereinen. ${ }^{\text {“184 }}$ Unverkennbar war diese Entwicklung zum Milieu von der antimodernistischen „Abwehrerfahrung “1185 getragen. Der deutsche Konservatismus der 1920er Jahre war damit „organisiert, dynamisch und aktionsfähig“ - nur eben nicht um eine einzige Partei zentriert. ${ }^{1186}$ Demgegenüber fällt die Milieuschwäche des liberalen Bürgertums in Weimar auf: Es fehlte an verbindlicher weltanschaulicher Durchstrukturierung; die alte Emphase auf das autonome Individuum, auf den Meinungsstreit und den freien und pluralen Diskurs stiftete keine eisernen Kaderstrukturen. Überdies war ihr Eintreten für die liberale Verfassung im Wortsinne konservierend ausgerichtet, bot keine auf die Zukunft oder das Noch-nicht zielende „Vision einer ganz anderen, besseren Gesell-

1178 Jarausch: Deutsche Studenten, S. 106f.

1179 Maurer: „... und wir gehören auch dazu“, S. $325 \mathrm{ff}$.

1180 lbid., S. 892.

1181 „Wie eine neue Ordnung des Reiches, des Vaterlandes und des Volkes nach dem Kriege aussehen sollte, konnten die Studenten im Felde oder in der Heimat [...] niemals mit hinlänglicher Klarheit sagen. Ihr Nachdenken darüber blieb - und das ist symptomatisch - in so vielen verschiedenartigen Ansätzen stecken, daß es kaum in Tendenzen zu fassen ist. [...] Die größte Einmütigkeit herrschte sowohl im Felde als auch in der Heimat in der Auffassung, daß vor allem im studentischen Bereich nach dem Kriege Entscheidendes neu zu ordnen wäre [...], daß man in neuem Geiste eine geeinte Studentenschaft mit positiver Einstellung zu Universität und gesamter Gesellschaft aufzubauen habe." Schwarz, Jürgen: Studenten in der Weimarer Republik. Die deutsche Studentenschaft in der Zeit von 1918 bis 1923 und ihre Stellung zur Politik, Berlin 1971, S. 43.

1182 Vgl. Jarausch: Deutsche Studenten, S. 113.

1183 lbid., S. 112.

1184 Lösche/Walter: Katholiken, Konservative und Liberale, S. 478.

1185 Ibid., S. 476.

1186 Ibid., S. 478. 
schaft ${ }^{\text {“1187 }}$ und wirkte dadurch in einer Zeit der Desorientierung entsetzlich schwach. Der Liberalismus kam im Grunde als klassische Vernunftphilosophie daher, die gegen die an Leidenschaften und Emotionen appellierenden politischen Konkurrenten blass wirken musste. Zudem zersplitterte er in Links- und Rechtsliberale; letztere kooperierten in Gestalt der DVP mit konservativen Milieus. Der schon früher kennzeichnende politische Opportunismus des deutschen Bürgertums resultierte aus der wiederholten Fixierung auf die bloße Eigentumssicherung; daher bildete es auch in der Weimarer Krise einen besonders labilen Faktor, erkenntlich daran, dass das Wahlverhalten der deutschen Bürgerlichen in den 1920er Jahren "quer durch das rechte Spektrum des Parteiensystems" irrlichterte. ${ }^{1188}$

Auch die noch monarchistisch-nationalistisch innervierte Studentenschaft stürzte 1918/19 - mit Ausnahme einer linken Minderheit, die in München Revolution und Räterepublik unterstützte ${ }^{1189}$ - in die Orientierungslosigkeit, diesmal jedoch mit weitreichenden Konsequenzen. Zwar hatten schon die wilhelminischen Studenten auf die gesellschaftlichen Entwicklungen und die beginnende Erosion ihres geistesaristokratischen Status mit antiliberalem politischem Radikalismus reagiert. Indes: Entscheidender Faktor der relativen Einhegung studentischer Aggressionen gegen alles Liberale, Sozialdemokratische, Jüdische (ab den 1890er Jahren weiterhin, wenn auch kaum noch: Katholische ${ }^{1190}$ ) blieb trotz aller bedenklichen und für viele Zeitgenossen ohne Frage schockierenden Erscheinungen die Staats- und Kaisertreue der Korpsstudenten. Nach dem verlorenen Weltkrieg änderten sich diese politischen Vorzeichen entscheidend: Das Neue und Gefährliche an der antiliberalen Studentenschaft Weimars waren nicht nur ihre Depossedierungs- und Entprivilegierungserfahrung zwischen 1918 und 1923, sondern auch ihre dadurch amplifizierte leidenschaftliche Feindschaft gegenüber Republik, Parteienwettbewerb und demokratischem Verfassungsstaat. Dabei dominierte anfänglich noch die alte studentische Staatsloyalität. Zunächst zog die Mehrheit der Weimarer Studenten aus dem Krieg die Lehre eines möglichst friedlichen, in studentischer Hinsicht sozial und mental geeinten, Lebenswandels jenseits von Religion und Partei:

„Nun hieß es, für sich zu sorgen, für den Schutz der Familie, für die Rückkehr in den Beruf und ins gewandelte bürgerliche Leben. [...] Aber trotz aller harten Proben [...] blieb für die Grundhaltung der Studenten das Erlebnis der Kameradschaft mit allen Schichten der Studentenschaft und des Volkes bestimmend, das Erlebnis des ,Reinmenschlichen im Unmenschlichen;, wie Arnold Bergstraesser sagt [...] “1191

Die kriegserfahrenen Studenten, sämtlich den alten Wilhelminismus ablehnend, strebten nach „konstruktiver“ politischer Praxis im Dienst einer entstehenden "nationalen“ und „sozialen“ neuen Ordnung. ${ }^{1192}$ Sie hofften, mit der in der DSt geübten demokratisch-parlamentarischen Praxis als Vorbild verantwortungsbewusster Tatkraft zu

\footnotetext{
1187 Ibid., S. 479.

1188 Ibid., S. 480.

1189 Vgl. Gevers/Vos: Studentische Bewegungen, S. 287.

1190 Vgl. ibid., S. 269.

1191 Schwarz: Studenten in der Weimarer Republik, S. 55 und 56.

1192 Ibid., S. $397 f$.
} 
fungieren; aus der mehrheitlichen Ablehnung der Revolution von 1919 resultierte ihre verhaltene Unterstützung des Weimarer Staates, wenn auch nicht ohne großdeutsche Fernziele. ${ }^{1193}$ Allerdings empfanden sie alle die Friedensbedingungen von Versailles „bis in die sozialistische Linke hinein" als nationale Schande; ${ }^{1194}$ der Schock der katastrophalen Niederlage verschärfte daher schon früh die Spaltungslinien unter den politischen Teilen der Studentenschaft und radikalisierte sie: „Hochschulrevolution“ im Namen der sozialen Öffnung und der Demokratisierung versus „Hochschulreaktion“ im Zeichen der antidemokratischen Restitution eines verletzten vaterländischen Stolzes. ${ }^{1195}$ So stellten sich die autoritätshörig konditionierten Studenten an die Seite des nun sozialdemokratisch regierten Staates und halfen während der "Spartakuswoche“ in Berlin der Aufrechterhaltung der öffentlichen Ordnung gegen linke Revolutionsversuche durch die spontane Bildung einer bewaffneten „Studentenwehr“. ${ }^{1196}$ Ähnliche konterrevolutionäre Dienste erwiesen die in vielen kleineren Universitäten von Frontstudenten gegründeten Freikorps in Ostpreußen, der Münchner Räterepublik, in Württemberg und im Ruhrgebiet. ${ }^{1197}$ Dabei gerieten sie selbst in den Verdacht rechtsrevolutionärer umstürzlerischer Absichten und fühlten sich mit Undank bezahlt. Vollends zerschnitten war das Tischtuch zwischen Regierung und Studentenschaft nach der so genannten „Tragödie von Mechterstedt“, als 15 festgenommene Arbeiter durch 14 Mitglieder des „Studentenkorps Marburg“ erschossen wurden. ${ }^{1198}$ Es folgten Racheaktionen und eine breite öffentliche Skandalisierungswelle, der Reichstag debattierte; als ein Kriegsgericht der Reichswehr die Studenten mit Verweis auf einen Fluchtversuch der Arbeiter freisprach, gab der Kultusminister Konrad Haenisch (SPD) seinen Unmut in der Presse zu Protokoll. ${ }^{1199}$ Als auch ein Berufungsverfahren zugunsten der Studenten entschied, bemühte sich Haenisch in einem Brief an den Vorsitzenden der DSt um Entschuldigung, doch

„das Porzellan blieb zerschlagen. [...] Die Folgen jedenfalls [...] waren bis zum Ende der Republik zu spüren. Wann immer die Studenten Grund sahen, sich mit Regierung und Staat auseinanderzusetzen, immer zog das Argument: Wir haben diese Republik verteidigt, aber statt den Dank des Vaterlandes ernteten wir Schimpf und Schande.“1200

Solchen Grund sahen die Studenten in den nun folgenden Jahren häufig. Denn die entscheidende Quelle des Unmuts in den frühen 1920er Jahren bildeten die veränderten Lebensverhältnisse des Jungbildungsbürgertums in einer sich weiter modernisierenden Wirtschaft und Sozialstruktur. Zwar war die Situation der Studenten in der Schlussphase der Demobilisierung 1919, als unter der wachsenden Zahl von Immatrikulierten

\footnotetext{
1193 Ibid., S. 398.

1194 Jarausch: Deutsche Studenten, S. 118.

1195 Ibid., S., 120.

1196 „Die Autoritätsgläubigkeit der Studenten zusammen mit der alten Reichsideologie und ihrem Staatsbewußtsein überwanden alle Ressentiments gegen die neuen Machthaber." Bleuel, Hans Peter/Klinnert, Ernst: Deutsche Studenten auf dem Weg ins Dritte Reich. Ideologien - Programme-Aktionen 1918-1935, Gütersloh 1967, S. 66.

1197 Vgl. ibid., S. $71 f$.

1198 Vgl. ibid., S. 72-78.

1199 Vgl. ibid., S. 74-77.

1200 Ibid., S. 78.
} 
die Wohnungsnot drastisch anstieg, noch Teil einer allgemeinen materiellen Armut. ${ }^{1201}$ Während sich jedoch die arbeitende Bevölkerung im Zuge der sich regenerierenden wirtschaftlichen Konjunktur über eine mäßig wachsende Kaufkraft freuen konnte, blieb das studentische Existenzminimum unter den Augen der Öffentlichkeit „stets um ein wesentliches unter dem des gelernten Arbeiters. “1202 Die Studenten, von wenig wohlhabenden abgesehen, befanden sich über Jahre im permanenten wirtschaftlichen Notstand; dabei evozierte es besondere Verbitterung, dass das durchs Studium angestrebte Qualifikationsniveau nicht einmal beim Abschluss eine signifikante Erwerbssteigerung versprach. ${ }^{1203}$ Viele waren auf Speisungen angewiesen und unterernährt; in den frühen 1920er Jahren grassierten Krankheiten wie die Tuberkulose. Staatliche und zivilgesellschaftliche Fürsorge, etwa in Gestalt der Förderung von Studentenwohnheimen oder Darlehenskassen, vermochten diesen Zuständen kaum Abhilfe zu schaffen. ${ }^{1204}$ Eine ihrer unmittelbaren Konsequenzen war die Ausbreitung des Werkstudententums: Es gab „bereits in den Anfangsjahren der Republik der deutschen Studentenschaft, mit all ihren Sorgen und Problemen, geradezu das Gepräge“. ${ }^{1205}$ Das Erfordernis, den eigenen Lebensunterhalt durch zusätzliche Arbeit - nicht selten Gelegenheitsjobs und Aushilfstätigkeiten - zu beschaffen, wurde sowohl von den Studenten als auch von einem großen Teil der Öffentlichkeit als eine besondere Schmach empfunden, die dem traditionellen jungakademischen Standesstolz eklatant widersprach. Anfangs verheimlichten die Studenten ihre Tätigkeiten; zwischen 1921 und 1923 aber wurden diese „ganz einfach unter dem Druck der wirtschaftlichen Not" unverkennbare Normalität. ${ }^{1206}$ Das Studium selbst litt beträchtlich unter dem dafür nötigen Zeitaufwand. ${ }^{1207}$ Im Jahre 1923 schließlich verunmöglichte die Inflation für viele ganz die Existenz: „Gegen Ende des Jahres mußte eine große Zahl Studenten angesichts der Notlage das Studium aufgeben. “1208 Diese Entwicklung wurde von behördlicher Seite mit der allergrößten Sorge registriert. ${ }^{1209}$ Trotzdem wird für die frühen Weimarer Jahre insgesamt eine Durchhaltementalität konstatiert: Jürgen Schwarz bemerkt, es sei angesichts der für viele naheliegenden Staatsverdrossenheit

„um so erstaunlicher festzustellen, welch eine große Anzahl von Studenten [es] trotz der Zwangssituation [...] für unangemessen hielt, aus der wirtschaftlichen Notlage [...] die ,Verantwortlichen' in Staat und Regierung mit vorschneller Kritik zu attackieren. Der Student wußte vielmehr sehr genau zu differenzieren und seine wirtschaftliche Notlage nach sachlichen Cründen in die allgemeine Nachkriegssituation einzuordnen. Deshalb versuchte er, mit zweckmäßigen Unternehmungen die materiellen Bedingungen seines Studiums zu verbessern. ${ }^{\text {.1210 }}$

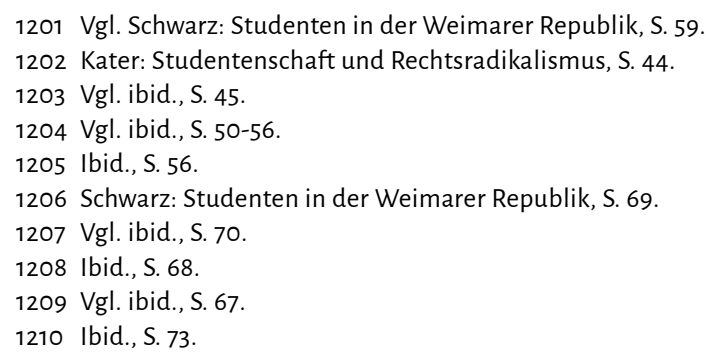


Gerade in der Nachkriegs-Armut erwies sich die Arbeit in der wiederaufgebauten studentischen Selbstverwaltung, d. h. in der AStA-, StuPa- und Ausschussbewegung als erfolgreich, sorgte sie doch für Selbstwirksamkeits- und „Demokratieerfahrung im Kleinen“. ${ }^{1211}$ Die Kriegsgeneration verlieh der Studentenschaft einen starken Bewegungscharakter, basierend auf der „Idee einer gesamtstudentischen Gemeinschaft" und, darauf aufbauend, einer hier noch vage bestimmten großdeutsch-nationalen „Volksgemeinschaft“. ${ }^{1212}$ Die studentische Subkultur wurde nach Kriegsende sukzessive ins Leben zurückgerufen; man bemühte sich um Restauration des alten Organisationsgeflechts und verband die Suche nach gesellschaftspolitischer Orientierung mit hochschulreformerischen Forderungen. ${ }^{1213}$ Der Kreis der ASten und ihres Dachverbands, der DSt, war von einer neuen, spontan entstandenen „Selbsthilfe-Idee“ mit kollektivgemeinschaftlichem Anspruch und kämpferischen Elementen getragen; es bildete sich hier ein neuartiges „studentische[s] Solidaritätsgefühl“ heraus, das auf „die Grundkraft studentischer Genossenschaft" setzte. ${ }^{1214}$ In ihm amalgamierten sich kollektive Wirtschaftshilfe und sittlich-pädagogischer Anspruch. In stolzer Abgrenzung vom Fürsorgegedanken schuf die studentische Selbsthilfe und Selbstverwaltung ein spezifisches neues Solidaritäts- und Kameradschaftspathos. ${ }^{1215}$ Dieser neue Gemeinschaftsgedanke begann auch, eine „höhere“ egalitäre soziale Ordnung zu visieren, die sich „den egoistischen Auswüchsen des Gesellschaftslebens" entwinde, idealisierte ferner die kernige Tat gegenüber „Problematisierung“ und „Politisierung“ von Problemen. ${ }^{1216}$ Tatsächlich förderte das energische Engagement die reichsweite Entstehung von Studentenwerken und erreichte 1925 die Gründung der Studienstiftung des Deutschen Volkes. ${ }^{1217}$ Darüber hinaus suchte man vielerorts das Bündnis mit der Arbeiterschaft, um der „Isolierung einer Kaste“ zu entkommen, auch wenn die Überwindung der traditionslastigen „Klassenfremdheit“ nie gelang. ${ }^{1218}$ Aufseiten des klassischen Verbindungswesens deutete sich zeitgleich das schlussendliche Verglimmen der liberalen Verbindungstradition an: Nach der Wiedererlangung der Vereins- und Versammlungsfreiheit - eigentlich ein Erfolg der Freistudentenschaft - repolitisierten und rekorporatisierten sich die allmählich selbstbewussteren Verbindungen in eigendynamischer Weise. Der Korporatismus erlebte seinen „Spätsommer“, während die Freistudentenschaft zunehmend unterging - auch, weil sie 1919 mit der Gründung der Deutschen Studentenschaft ihr primäres Ziel der Einrichtung einer gesamtstudentischen Verfassung erreicht hatte und entweder in der studentischen Selbstverwaltung oder in völkischen Vereinigungen aufging. ${ }^{1219}$ Der

1211 Jarausch: Deutsche Studenten, S. 121.

1212 Nipperdey, Thomas: Die deutsche Studentenschaft in den ersten Jahren der Weimarer Republik, in: Zilius, Wilhelm/Grimme, Adolf (Hg.): Kulturverwaltung der zwanziger Jahre. Alte Dokumente und neue Beiträge, Stuttgart 1961, S. 19-48, hier S. 27 und 36-38.

1213 Vgl. Jarausch: Deutsche Studenten, S. 122 und Nipperdey: Die deutsche Studentenschaft, S. 29.

1214 Schwarz: Studenten in der Weimarer Republik, S. 75, Zitat von S. 83.

1215 Vgl. Kater: Studentenschaft und Rechtsradikalismus, S. 56, ferner Schwarz: Studenten in der Weimarer Republik, S. 74 und Nipperdey, Thomas: Die deutsche Studentenschaft, S. $21 f$.

1216 Kater: Studentenschaft und Rechtsradikalismus, S. 83-85.

1217 Vgl. Nipperdey: Die deutsche Studentenschaft, S. 22.

1218 Ibid., S. $43 f$.

1219 „Weil sie sich durch den Sieg ihrer Ideen selber überflüssig gemacht hatte, ging die progressive Freistudentenschaft entweder im ASTA auf, wurde völkisch oder führe zu der jugendbewegten 
DHR vermochte es, die Studenten der Weimarer Republik sukzessive politisch zu aktivieren und mit antidemokratischer Agitation nach weit rechts zu treiben - während die prodemokratischen Studenten in dieser Gemengelage früh unterliegen sollten. ${ }^{1220}$ Gleichwohl, dem als „Bewegung“ auftretenden DHR mangelte es an weltanschaulicher Kohärenz und politischer Eintracht: Unterhalb des „wolkige[n] Programms“ stritten (völkische) Jungkonservative, korporierte Altkonservative und völkisch-paramilitärische Gruppen in der Tradition der Freikorps. ${ }^{1221}$

Gegen Mitte der 1920er Jahre konvergierten die anhaltende Verschärfung der studentischen Lebenssituation mitsamt der daraus resultierenden fortschreitenden studentischen „Bewußtseinskrise“1222 und die immer offener republikfeindliche Aufladung der korporierten Studentenschaft; hier entstand das Ursachenbündel einer sich $a b 1925^{1223}$ formierenden militant-antidemokratischen Studentenbewegung, die schließlich politische Zuflucht bei den neuen nationalsozialistischen Organisationen suchte. Ihre Entstehung wurde durch die permanenten Krisenprozesse der studentischen Lebensformen angetrieben. Denn mit der Inflations- und Wirtschaftskrise wurde den jungen Akademikern wie überhaupt dem erwachsenen Bürgertum klar, dass sich ihr traditioneller Status nachhaltig aufgelöst hatte. „Für die Gebildeten war 1923 eine echte Zäsur, eine veritable Erschütterung ihrer Lebensform und elitären Selbsteinschätzung der eigenen Rolle in der Gesellschaft. “1224 Die Einkommensdifferenzen zwischen Professorenschaft und ungelernten Arbeitern hatten sich drastisch reduziert. Hyperinflation und Weltwirtschaftskrise hatten die traditionellen Mittelschichten am härtesten getroffen. ${ }^{1225}$

„Zwei Schichten vor allem hatten ihre sozialen Positionen eingebüßt, die Rentner des Mittelstandes und die höheren Beamten. [...] Das Exklusivitäts- und Elitebewußtsein der Akademiker wurde zuerst auf der Hochschule und in der Korporation genährt, und umgekehrt lebten Hochschule und Korporation von der Exklusivität und dem elitären Status, die ihre Alten Herren in der Gesellschaft genossen. Nach Kriegsende aber wuchs die Zahl der Studenten aus den Kreisen der mittleren und unteren Beamten, der Handwerker und Angestellten. Der Inflation des Celdes drohte eine Inflation der Bildungsexklusivität zu folgen. So jedenfalls stellte es sich den Privilegierten dar. “1226

In hypertropher Wiederholung der Dynamiken von 1873 richteten nun große Teile der Bevölkerung ihre Wut auf alles, was sie mit unverdientem Neureichtum, mit liberalem Laisser-faire und „raffendem“ Kapital verbanden. Antisemitische Bewusstseinsformen universalisierten sich 1923 in breiten Teilen der Bevölkerung, halfen sie doch, die ziellose

Großdeutschen Gildenschaft hin." Jarausch: Deutsche Studenten, S. 124. Vgl. auch Wipf: Studentische Politik und Kulturreform, S. 246 und Nipperdey: Die deutsche Studentenschaft, S. 22-25.

1220 Vgl. Jarausch: Deutsche Studenten, S. 126.

1221 Vgl. Cevers/Vos: Studentische Bewegungen, S. 289.

1222 Kater: Studentenschaft und Rechtsradikalismus, S. 95.

1223 „Von 1925 an kann man von einer völkisch-revolutionären Periosde sprechen, in welcher der, Weimarer Staat' immer stärker als ,Feind des deutschen Volkes' abgestempelt wurde." Cevers/Vos: Studentische Bewegungen, S. 289.

1224 Walter: $1873-1923-1973$, S. 50.

1225 Vgl. Ringer: Die Gelehrten, S. 62 sowie Kapitel II.1.3 dieser Studie.

1226 Bleuel/Klinnert: Deutsche Studenten auf dem Weg ins Dritte Reich, S. 79. (Herv. J. S.) 
Verzweiflung auf die Repräsentanten jener unglücksbehafteten modernen Zivilisation $\mathrm{zu}$ richten, und zwar die

„kess auftrumpfenden Schieber, Spekulanten, Hochstapler, Schwindler und Parvenüs, die mit ihrem neureichen Übermut zynisch die Zurückgebliebenen verspotteten. Dies wurde der neue verhasste Sozialtypus in der Gesellschaft der Inflationsverlierer: der ,Raffke', der vorher selbst nichts hatte, nie viel war und konnte, jetzt aber, wo die Welt verrücktspielte und alles auf dem Kopf stand, mit schmutzigen Geschäften schnellen Reichtum auftürmte. Dieses Bild, schon 1873 oft verwendet, war nun 1923 allgegenwärtig, hielt sich und verband sich mit dem überlieferten Stereotyp, sodass Raffkes und Juden als Figuren weithin verschmolzen." ${ }^{\text {“1227 }}$

An verschiedenen Orten des Reichs kam es zu ersten Pogromen, während das deutsche Bildungsbürgertum angesichts der entsetzlichen Besitzverluste noch mit der Empfindung kämpfte, von einem anonymen Schuldigen um alles betrogen worden zu sein. ${ }^{1228}$ Mit Rücksicht auf die statistischen Kennzahlen bewerten Historiker die Rede von einer „Existenzkrise“ der deutschen Akademiker in den Weimarer Jahren zwar als dramatisierende Übertreibung, litt doch die Gesamtbevölkerung an Schwankungen des Lebensstandards, ${ }^{1229}$ insgesamt an einer noch höheren Arbeitslosenquote. ${ }^{1230}$ Doch einerseits war das Akademikertum auch in Weimar trotz der nivellierten Vergütung mehr als eine Berufsgruppe: Es zehrte noch immer vom „kaiserlichen Akademikernimbus“, interpretierte sich selbst als Trägerschicht nationaler Hochkultur; außerdem traute man gerade ihrem Standesstolz potenziell staatsgefährdende Energien zu. ${ }^{1231}$ Daher ist die sozialpsychologische Wirkung akademischer Arbeitslosigkeit in dieser Zeit nicht zu unterschätzen, verdichtete diese doch die allgemeine Krisenstimmung und Umsturzangst ${ }^{1232}$ wie in einem Brennglas. Andererseits, und das ist entscheidend, wurde der Anspruch, eine gesellschaftliche Elite zu bilden, von den Studenten trotz widerstreitender Realitäten weiterhin empfunden, ${ }^{1233}$ ja zunehmend verbissen verteidigt gegen die zeitgenössische Empfindung, die geordneten Verhältnisse des Kaiserreichs seien abgelöst worden von einem permanenten Ausnahmezustand Weimar, konkret der Überfüllung der Universität, der „Vermassung“ akademischer Bildung und der „Proletarisierung“ der aka-

1227 Walter: $1873-1923-1973$, S. 46.

1228 Vgl. ibid., S. 48f., siehe außerdem das Zitat ibid., S. 50: „Während sich die Besitzer von Ländereien und Produktionsstätten 1923 probat entschulden konnten, zerrannen die Ersparnisse der verbeamteten Akademiker in Windeseile. In den schlimmsten Wochen der Inflation, als in diesen städtischen Schichten ebenfalls der Hunger um sich griff, gingen sogar häufig all die oft ererbten wertvollen Accessoires, Kunstgemälde, Musikinstrumente, Teppiche, Porzellanteile und Vasen verloren, weil man sie auf dem Land in Bauernhäusern gegen Fleisch, Eier, Mehl, Milch und Cemüse eintauschte."

1229 Vgl. Studentenschaft und Rechtsradikalismus, S. 43.

1230 Vgl. Jarausch: Deutsche Studenten, S. 139.

1231 Ibid.

1232 „Von einer fieberhaften Zeit war erneut allenthalben die Rede; die Metapher der Flut war zur IIlustration eines permanenten Menetekels zurückgekehrt. Alles schien ständig im Fluss, ununterbrochen, aber ziellos vorantreibend."Walter: 1873-1923-1973, S. 46.

1233 Vgl. Jarausch: Deutsche Studenten, S. 139. 
demischen Berufe. ${ }^{1234}$ Nicht nur in den frühen Jahren der Weimarer Republik litt der größte Teil der Studenten an entsetzlichem materiellem Elend. ${ }^{1235}$ Das einstige wilhelminisch-bildungsbürgerliche „Elitebewußtsein“, das unter Jungakademikern noch 1918 intakt gewesen war, ${ }^{1236}$ wurde durch die soziale Misere in kontinuierlicher Weise schwer beschädigt; gleich mehrere Studentengenerationen fühlten sich nicht nur von der Elterngeneration vernachlässigt, sondern auch von der Weimarer Gesellschaft insgesamt. Die Studentenzahl verdoppelte sich bis Ende der 1920er Jahre - nach dem schon rasanten Bildungswachstum des späten 19. Jahrhunderts - noch einmal, ${ }^{1237}$ auch durch den Zustrom von Studentinnen; die Konkurrenzsituation verschärfte sich im Verlauf des Jahrzehnts, ${ }^{1238}$ sodass sich

„während der Weimarer Phase für die Studenten aller akademischen Richtungen das kollektive Bewußtsein existentieller Unsicherheit nicht ab-, sondern zugenommen hat, und zwar, wegen der Unberechenbarkeit der Zukunft zu jedem gegebenen Zeitpunkt, selbst in den relativ glücklichen Disziplinen." ${ }^{\text {“239 }}$

Um 1925, als die Berufsnot einen Höhepunkt erreichte, etablierte sich das Parkstudium zur Hinauszögerung des Berufseintritts. ${ }^{1240}$ Die trotz der sich regenerierenden Konjunktur noch bis 1927 anhaltende Arbeitslosigkeit und ein kontinuierlich niedriges bzw. noch sinkendes Lohnniveau verminderten zudem die Zahl freier Werkstudentenstellen bzw. machte diese Tätigkeit vollends unrentabel - „mit dem Ergebnis, daß das Werkstudententum zahlenmäßig gewaltig reduziert wurde“, wenn auch de facto „zum Schaden der vielen, die nun überhaupt keine Überlebensmöglichkeit an den Hochschulen mehr

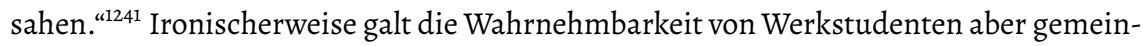
hin als Index studentischer Not, sodass das persistente Elend aus dem öffentlichen Bewusstsein verschwand. Die Studenten fühlen sich nun von Staat und Gesellschaft regelrecht im Stich gelassen. ${ }^{1242}$ Dies tatsächlich zurecht: Politik, Industrie, Landwirtschaft und Öffentlichkeit reagierten mehrheitlich mit „Indifferenz“. ${ }^{1243}$ Diese Situation besserte sich bis zum Ende der Republik nicht mehr. Noch 1931 bilanzierten die Historiker und einstigen Freistudenten Friedrich Schulze und Paul Ssymank:

1234 Kater: Studentenschaft und Rechtsradikalismus, S. 67-73.

1235 Vgl. Kater: Studentenschaft und Rechtsradikalismus, S. 43-56 sowie Kapitel II.1 dieser Studie.

1236 Ibid., S. 95

1237 Vgl. Jarausch: Deutsche Studenten, S. 130.

1238 „Die typischen Weimarer Studenten waren [...], kurz gesagt, älter, eher deutsch, urbaner, moderner vorgebildet und eher weiblich." Ibid., S. 133.

1239 Kater: Studentenschaft und Rechtsradikalismus, S. 72. (Herv. i. O.)

1240 Vgl. Jarausch: Deutsche Studenten, S. 129 und 132.

1241 Kater: Studentenschaft und Rechtsradikalismus, S. 57.

1242 „Es ist bezeichnend, daß studentische Stimmen inmitten der generell einsetzenden Prosperität immer wieder darauf hinweisen mußten, mit der äußerlich sichtbaren Abnahme des Werkstudententums sei das Phänomen an sich, als Symptom größter studentischer Notstände, noch keineswegs verschwunden. Durch die optische Verzerrung der studentischen Situation aus der Perspektive des Wohlstandes aber wurde das Elend der Kommilitonen, die noch immer litten, um ein Vielfaches erhöht, denn nun fehlte die mitleidsvolle Publizität der öffentlichen Meinung." Ibid., S. 57. 
„Zweifellos befindet sich das deutsche Studententum mitten in einer überaus bedenklichen Krise weltanschaulicher, politischer und sozialer Natur, die mit der allgemein-deutschen eng zusammenhängt. Es besitzt nichts mehr von der satten Selbstzufriedenheit und der genußfrohen Romantik der wilhelminischen Zeit, sondern verspürt als nüchtern, sachlich und illusionslos gewordenes Geschlecht die ruhelosen Kämpfe und quälenden Nöte der Gegenwart am eigenen Leibe. Die Überfüllung der Hochschulen, die Aussichtslosigkeit der akademischen Berufe und die zunehmende Verarmung des deutschen Volkes bedrücken es schwer."1244

Die sich in der Folge zusammenbrauende politische Radikalisierung unter den Studenten verlief auf verschlungenen Pfaden. Denn zwar neigten neue politische Studentenverbände und Ortsgruppen dazu, sich als Studentenorganisationen an Reichstagsparteien - etwa an DDP und DVP - zu binden, ein historisches Novum der Weimarer Republik. ${ }^{1245}$ Allerdings war das Ressentiment gegen den „Parteienstreit" so stark, dass diese Gruppen nur etwa 5 Prozent der Studentenschaft ausmachten; parteipolitische Aktivitäten wurden von der Mehrheit gar als Angriff auf die harmonische Einheit nationaler Gesinnung aufgefasst, als „Einbruch der Interessenhaufen“. ${ }^{1246}$ Als erfolgreicher erwies sich der aus einem Zusammenschluss der schlagenden Verbindungen hervorgegangene, 1920 gegründete antirepublikanisch und völkisch gesinnte - und vor allem als „apolitisch“ auftretende - Deutsche Hochschulring (DHR), der bis zur Mitte der 1920er Jahre mit zwei Dritteln Wähleranteil die stärkste Hochschulpartei stellte und innerhalb der DSt, dem Dachverband der Allgemeinen Studentenausschüsse (AStA) die deutsche Studentenschaft als Ganze zu vertreten beanspruchte. Schon 1922 ging, in der Terminologie der materialreichen Arbeit von Jürgen Schwarz, die seit 1919 herrschende „,ölkisch-nationale Phase“ in eine „völkisch-revolutionäre Periode“ über: Die organisierte Studentenschaft - unter ihnen kaum noch Protagonisten der Kriegsgeneration - politisierte sich fundamentaloppositionell und tauschte die vormalige kühle Loyalität gegenüber dem Staat - schließlich galt er als wichtigste Bastion gegen das Gräuel der Revolution $^{1247}$ - gegen offene Republikfeindlichkeit ein:

„Die Kriegsstudentenschaft war aus der Hochschul- und Studentenpolitik nahezu ausgeschieden, die DSt nun in der Mehrheit völkisch ausgerichtet. Ebenso hatte sich in der gesamten Studentenschaft die völkische Bewegung als dominierende politische Orientierung durchgesetzt. [...] Die den ,Staat von Weimar' bisher nur kritisierende Haltung wandelte sich in offene Ablehnung. Die bislang auf die Einigung des Volkes

1244 Schulze/Ssymank: Das deutsche Studententum, S. 492.

1245 Vgl. Jarausch: Deutsche Studenten, S. 124. Siehe außerdem ibid., 126f.: „Die echte Chance eines Bündnisses zwischen der akademischen Jugend und der Weimarer Republik wurde schon in den Anfangsjahren bis 1923 weitgehend vertan. Zwar unterstützten außer den Kommunisten und den DNVP-Anhängern alle politischen Studentengruppen die neue Demokratie. Aber ihre Mitgliederzahl war gering und ihr Einfluß begrenzt. [...] Die anfängliche Offenheit selbst der Burschenschaft und der Vereine Deutscher Studenten, am neuen Staat loyal mitzuarbeiten, ging vor allem in der Enttäuschung über das Versailler ,Diktat' unter, so daß sich in den Verbindungen konservativere Kräfte gegen eine Neuorientierung durchsetzten."

1246 Ibid., S. 125.

1247 Vgl. Nipperdey: Die deutsche Studentenschaft, S. 33-35. 
und auf Aufrechterhaltung von Ruhe und Ordnung abzielende Einstellung war durch die kämpferische, revolutionäre völkische Bewegung abgelöst worden.“1248

Die völkisch-nationalsozialistische Mobilisierung konnte auf dem studentischen großdeutschen Gemeinschaftspathos der frühen 1920er Jahre aufsatteln. Zwar war die aus dem Kriegserlebnis bezogene Sehnsucht nach der kollektiv verpflichtenden nationalen „Volksgemeinschaft“ anfänglich nicht zwangsläufig völkisch gedacht, auch wenn wachsende Teile der Studentenschaft den Begriff schon 1919 genau so verstanden hatten. ${ }^{1249}$ Doch die mit ihr verbundene Priorisierung des Kollektivs, der „gestiftete[n] oder gewachsene[n] Gemeinschaft" verlangte die Aufgabe individualistischer und intellektualistischer Regungen, letztlich die unbedingte Hingabe an die gemeinsame Sache. ${ }^{1250}$ Und die Sache, das war die großdeutsche Nation, die schon einmal als Abstammungsgemeinschaft nach dem Rasseprinzip konzipiert worden war. Gewiss, auch Juden gehörten zu den studentischen Gründervätern der studentischen Organisationen in Weimar. Doch wie schon in Österreich früh der Ausschluss der Juden und „Judenfreunde“ (Sozialisten, Demokraten, Liberale) aus den studentischen Verbänden diskutiert wurde, ${ }^{1251}$ so siegte auch in Deutschland die völkisch-antisemitische Lesart der studentischen Kollektivmoral. Bereits ab 1921 wurde die auch durch das Handeln der politischen Eliten verstärkte und wachsende Staatsdistanz der völkisch-nationalromantischen studentischen Mehrheit offen ausgetragen. Die schwindenden Kriegsstudenten versuchten zwar ein letztes Mal, die politischen Spaltungen rational zu vermitteln und „nun mit aller Konsequenz den Studentenstaat [gemeint ist die DSt, J. S.] an der Republik von Weimar zu orientieren und an diese zu binden.“1252 Doch die „Zeit der größten Möglichkeiten “1253 und der politischen Orientierungssuche, die aus dem WeltkriegsSolidaritätsbewusstsein resultierte, war noch vor dem Ausscheiden der Kriegsstudentenschaft verstrichen. „Die neue Bewegung“, getragen durch den DHR, mutierte „zu jener revolutionären Kampfbewegung, als die sie 1923 in die Wirren des Hitler-Putsches eingriff.“1254 1923 stellte die DSt das völkische über das alte politisch neutrale, großdeutsch-demokratische Gleichheitsprinzip und setzte die „deutscharischen“ Studentenschaften als alleinige Repräsentanten ein. ${ }^{1255}$ Zwar traten hier noch „kleine Minderheiten in Opposition“ aus "kriegsstudentischen“, freistudentischen, republikanischen und katholischen Kreisen auf, ${ }^{1256} 1924$ aber brach der letzte Widerstand republikanischer Studenten zusammen. ${ }^{1257}$ Als der DHR den Machtkampf für sich entschied, war es ihm ein Leichtes, den Weg für die nationalsozialistische Agitation zu ebnen. Als der preußische Kultusminister Carl Heinrich Becker 1927 mithilfe von Urwahlen versuchte, den antirepublikanisch radikalisierten DSt auf den Boden der Hochschulverfassung zu

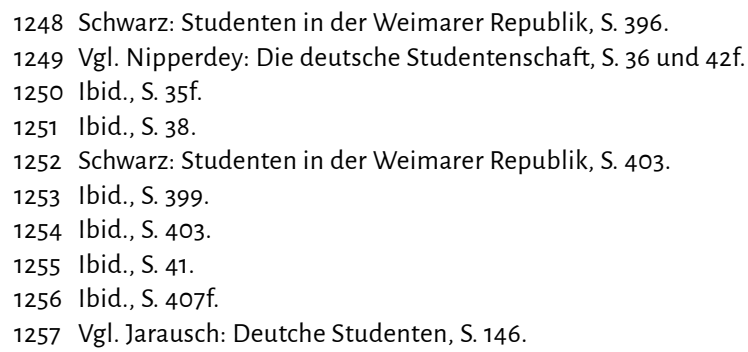


verpflichten, lehnten 77 Prozent dies ab. Dieser „offene Bruch [...] enthüllte schließlich das ganze Ausmaß der erschreckenden Entdemokratisierung der Studentenschaft.“1258 Drei Jahre bevor die NSDAP ihren Erfolgszug bei den Reichstagswahlen begann, bekannte sich die Mehrheit der deutschen Studenten damit zu Feinden der Weimarer Demokratie. Ausgehend von den Universitäten entwickelte sich der völkische Impuls erst zu einer Jugend-, dann in Verbindung mit dem Aufstieg der NSDAP zu einer Massenbewegung. Schon früh war der Funke auf die zivilgesellschaftlichen Strukturen der Vorkriegs-Jugendbewegung übergesprungen; von dort aus nährte er den Mythos einer an Fahrt gewinnenden „Jugendrevolution. ${ }^{1259}$ Nach 1927 trugen die Studenten, sekundiert von den korporierten Alten Herren, ihre Republikfeindlichkeit immer offener zur Schau, agitierten unverhohlen gegen das „Diktat von Versailles“, gründeten überdies Stahlhelm-Hochschulgruppen und Wehrsportgruppen. ${ }^{1260}$ Die Wut auf die Institutionen der älteren Autoritäten, stilisiert zu einem Generationenkonflikt, wuchs sich zu klassenübergreifenden Sympathien mit dem Gedanken eines Umsturzes der Republik aus. Prestige- und Privilegienverlust evozierten eine spöttische Sicht auf die finanziell versorgten Bildungsbürger und ihre wissenschaftlichen Lehren, schließlich ein „Ressentiment des Jungakademikers gegen die fertigen Bildungsbürger“, das „selbst vor den Philistern der Korporationen nicht haltmachte. ${ }^{\text {“261 } 61}$ Folgt man dem Historiker Kater, legte diese Situation fünf Reaktionen nahe: Hoffnung auf Besserung, Disziplinlosigkeit und Kriminalität, Resignation und Studienabbruch, Verzweiflungsparalyse und Suizid - oder, nicht zuletzt, die „Anklage der Gesellschaft, als deren Kreatur, wenngleich nicht Mitglied, der Student sich auch in den Zeiten der Krise noch verstand“, mithin politische Radikalität. ${ }^{1262}$ Letzteres bildete den Ansatzpunkt für die völkische Mobilisierung und schließlich den Nationalsozialismus „als dem einzigen Garanten künftigen Glückes“ unter den deutschen Studenten. ${ }^{1263}$ Dieser nutzte die Glorifizierung des Werkstudententums, für viele eine solidaritätsbegründende und gemeinschaftsstiften-

1258 Ibid., S. 147.

1259 Ibid., S. 141. Gleichwohl blieben die Organisationen der alten Jugendbewegung ohne größeren politischen Einfluss: „Fragmentierung und Sonderinteressen-Politik charakterisierte auch die Situation der jugendbewegten Studentenkreise nach dem Ersten Weltkrieg. Aus der Freideutschen Bewegung entstand 1919 der Jungdeutsche Bund, der in der Mehrheit von Studenten gestützt wurde. Seine weltanschauliche Ausrichtung war nun ganz eindeutig völkisch. Dieser, die gesamte Jugendbewegung kennzeichnende Rechtstrend ließ zwar eine gewisse Angleichung der jugendbewegten Bestrebungen an die völkisch-studentische Verbandsstruktur zu, was beispielsweise an den Querverbindungen zwischen Jungdeutschen und Deutschem Hochschulring zum Ausdruck gelangte. Dennoch blieb die beiderseitige Ausschließlichkeit von Jugendbewegungs-Idee und Korporationswesen aus der Vorkriegszeit im Prinzip bestehen, so daß die Wandervogel- und bündischen Gruppen in der Cesamtheit der Studentenschaft bis 1933 kaum Einfluß auf die hochschulpolitischen Ereignisse, schon gar nicht auf die Sozialpolitik, ausüben konnten." Kater: Studentenschaft und Rechtsradikalismus, S. 93.

1260 Jarausch: Deutsche Studenten, S. 149.

1261 Kater: Studentenschaft und Rechtsradikalismus, S. 106.

1262 Ibid., S. $108 f$.

1263 Ibid., S. 173. 
de Kollektiverfahrung, ${ }^{1264}$ als Mobilisierungsverstärker. Die Gefährlichkeit dieser aggressiven Jugendrebellion wurde von der Weimarer Politik lange Zeit nicht erkannt. ${ }^{1265}$

Doch auch der Erfolg des DHR währte nicht lange: 1926 bekam er Konkurrenz durch den neu gegründeten Nationalsozialistischen Studentenbund (NSDStB), welcher sich in den Folgejahren in "erdrutschartiger" Geschwindigkeit zur wichtigsten Studentenorganisation entwickelte. ${ }^{1266}$ Schon Ende des Jahres zählte er 21 lokale Hochschulgruppen. Sein Erfolgsrezept lag darin, den in Korporationen und Selbstverwaltungsgremien nach wie vor starken traditionalistischen Elitismus zu verspotten und diesem einen auf Radikalität und Härte fußenden Elitismus eigener Art entgegenzusetzen. Der NSDStB präsentierte sich „als Träger eines neuen Lebensgefühls, eines generationellen Stils“. ${ }^{1267}$ Mit seinem „völkisch-populistischen Programm“ wusste er zudem geschickt den Argwohn jener zahlreichen Studenten zu kanalisieren, die im täglichen Existenzkampf nichts zu lachen hatten, und ihn auf Sozialisten, Juden, Republikaner und Liberale zu richten. ${ }^{1268}$ Zwar ebbte der Zulauf zum NSDStB nach dem gescheiterten Hitler-Putsch zunächst $a b$, wurde aber durch einen zweiten, durch neokonservativ-intellektualistisches Auftreten flankierten, Anlauf wieder entfacht. Die Annäherung an den Korporationsstolz trug Früchte, auch wenn es zweifellos unüberbrückbare Differenzen gab: Statt großbürgerlicher Trinkfestigkeit strebte der politische Aktivismus der Nationalsozialisten, der sich inhaltlich zunehmend konkretisierte, schon früh einen asketischen und sportlichen Parteikämpfer-Typus an. ${ }^{1269}$ Größere Erfolge waren der intransigenten Basisarbeit der Nationalsozialisten in den Reihen der studentischen Selbstverwaltung beschieden: Die antisemitische Agitation bot vielen notleidenden Studenten eine Antwort auf die Überfüllungskrise, versprach sie doch durch Fernhaltung jüdischer Anwärter den Konkurrenzdruck zu heben. ${ }^{1270}$ Der Nationalsozialismus versprach „Zukunftsgarantien“, er erschien als „Zweckbündnis“ für die Förderung jungakademischer Interessen und eine Lösung ihrer existenziellen Probleme, schien gar die Perspektive auf eine Restitution bildungsbürgerlicher Privilegien zu eröffnen. ${ }^{1271}$ Flugblätter, Kundgebungen, Diskussionsabende und weitere öffentlichkeitswirksame Methoden ließen den

1264 Vgl. Schwarz: Studenten in der Weimarer Republik, S. 83.

1265 Vgl. Jarausch: Deutsche Studenten, S. 150.

1266 Ibid., S. 152 und 153f. Zu den frühen Standorten des NSDStB zählte die Universität Tübingen. Hier gründete sich bereits im März 1926 eine NSDStB-Ortsgruppe; dem war nationalsozialistische Basisarbeit seit 1923 vorangegangen, als die NSDAP in Tübingen erstmals Fuß fasste - mit 289 Ortsgruppenmitgliedern, von denen 41 der Studentenschaft angehörten. Vgl. Levsen, Sonja: Elite, Männlichkeit und Krieg. Tübinger und Cambridger Studenten 1900-1929. Kritische Studien zur Geschichtswissenschaft, Bd. 170, Göttingen 2006, S. 349.

1267 Vgl. Cöllnitz, Martin: Der Student als Führer? Handlungsmöglichkeiten eines jungakademischen Funktionärskorps am Beispiel der Universität Kiel (1927-1945), Ostfildern 2018, S. 61.

1268 Vgl. Jarausch: Deutsche Studenten, S. 153f. und Kater: Studentenschaft und Rechtsradikalismus, S. $111-125$.

1269 Vgl. Jarausch: Deutsche Studenten, S. $154 \mathrm{f}$.

1270 „Wegen ihrer, sozialen' Aspirationen waren NSDStBer besonders in den Sozialhilfeeinrichtungen der Studentenschaft aktiv. Gesellschaftliche Verunsicherung paarte sich mit Rassedenken in den Numerus-Clausus-Anträgen gegen Juden. Mit weitaus übertriebenen Zahlen jüdischer Akademiker operierend, versuchte diese Agitation die Frustration der Studenten über die Überfüllung der Hochschulen und schlechten Berufsaussichten auszubeuten." Ibid., S. 155.

1271 Kater: Studentenschaft und Rechtsradikalismus, S. 137-144 und 125. 
NSDStB allmählich wachsen; 1931 zählte er bereits 4.000 Mitglieder. Im Verlauf dieser Expansionsbewegung glich sich die Struktur der Mitglieder langsam der Gesamtstruktur der Studenten an - ein Effekt, der auf Breitenwirksamkeit und beginnende Normalisierung der nationalsozialistischen Mobilisierung schließen lässt. ${ }^{1272}$ Zwar bildeten die deutlich zahlenstärkeren Korporationen mit ihren etwa 79.000 Mitgliedern ein numerisches Bollwerk, doch waren auch sie selbst bereits durchsetzt mit völkisch-antisemitischen und irrationalistischen Überzeugungen. Viele von ihnen sympathisierten mit der „nationalen Bewegung“ (nicht: Partei!) der Eiferer im Braunhemd, insbesondere mit den umstürzlerischen Verheißungen gegenüber dem "Systemstaat“ des gescheiterten Liberalismus und im Namen des kommenden „Dritten Reiches“, auch wenn einige Alte Herren mit dem konkurrierenden Alleinvertretungsanspruch fremdelten; ${ }^{1273}$ nur etwa ein aus katholischen, jüdischen und demokratischen Studierenden bestehendes Drittel setzte sich gegen das nationalsozialistische Programm aktiv zur Wehr. ${ }^{1274}$ Der Mehrheit erschien dieses Programm in vielerlei Hinsicht plausibel: Die „nationale Sendung“ der Akademiker, das Ressentiment gegen akademischen Standesdünkel, die antirationalistischen Tiraden gegen die „blutleere“ Gesellschaft, die Emphase auf eine das Frontsoldatentum mythisierende Volksgemeinschaft, die den „marxistischen Klassenhass“ und ökonomisch bedingte Entzweiungen hinter sich lässt, mithin mit geschlossenen Reihen die unterstellte Vorherrschaft jüdischer Zirkel bricht. ${ }^{1275}$ Vieles davon war bereits Konsens in der Studentenschaft. Aber: „Im Gegensatz zu früher bot sich eine Bewegung an, die eine praktisch-politische Alternative versprach. “1276 Zwischen 1927 und 1931 etablierte sich der NSDStB, auch infolge professioneller Agitationsmethoden und „harter Wahlarbeit“, als stärkste politische Kraft unter den Studenten. Zunehmend konvertierten aktive Korporierte und Freistudenten, vor allem in kleineren Universitätsstädten. ${ }^{1277}$ Trotz vereinzelt heftigen Widerstands übernahm er auf dem 15. Studententag im Juli 1931 in Graz die Führung der DSt und verpflichtete sie auf das Führerprinzip. ${ }^{1278}$ „Achtzehn Monate vor der Machtergreifung Adolf Hitlers war die Organisation der Deutschen Studentenschaft fest in nationalsozialistischer Hand [...]. “1279 1932 finalisierte sich diese Selbstnazifizierung der DSt; nahezu reichsweit waren die AStAs in den Händen des NSDStB. Dieser wiederum ließ nicht nach mit seinem Ausbau der organisatorischen Infrastruktur: Mithilfe von Versailles-Ressentiment, Jugendbewegungsrhetorik und dem Leitbild „volksgesunder" Askese wurden paramilitärische Wehrsportverbände nach SA-Vorbild für Studenten gegründet, in ähnlicher Manier Arbeitsdienste u. Ä., die

1272 Vgl. Jarausch: Deutsche Studenten, S. 156.

1273 Vgl. Bleuel/Klinnert: Deutsche Studenten auf dem Weg ins Dritte Reich, S. $231 f$.

1274 Vgl. Jarausch: Deutsche Studenten, S. 157.

1275 Vgl. ibid., S. 157f. und Bleuel/Klinnert: Deutsche Studenten auf dem Weg ins Dritte Reich, S. 104106.

1276 Bleuel/Klinnert: Deutsche Studenten auf dem Weg ins Dritte Reich, S. 232.

1277 Vgl. Jarausch: Deutsche Studenten, S. 158-160. Die Unterwanderung der studentischen Selbstverwaltungsstrukturen gelang den NS-bewegten Studenten auch außerhalb der DSt-Strukturen: Zum Beispiel der Infiltration der Ämter in der Kieler Studentenschft (KSt) bei schwacher Cegenwehr vonseiten der mit sich selbst uneinigen Korporierten vgl. Cöllnitz: Der Student als Führer?, S. 69-79.

1278 Vgl. Bleuel/Klinnert: Deutsche Studenten auf dem Weg ins Dritte Reich, S. 214f.

1279 Jarausch: Deutsche Studenten, S. 160. 
$\mathrm{zu}$ einer neuen Form von Gemeinschaft sozialisieren sollten. ${ }^{1280}$ Derartige diktatorische Begleiterscheinungen der Nazifizierung sorgten auch für beträchtliche Entfremdungserscheinungen zwischen Studentenschaft und NSDStB nach dem Zenit von 1931. Dem drohenden Abebben der Bewegung kam die Wahl Hitlers zum Reichskanzler 1933 zuvor. ${ }^{1281}$ In den ersten Jahren der NS-Herrschaft genossen die Nationalsozialisten die tatkräftige Unterstützung vieler Studenten bei Bücherverbrennungen, Fackelzügen und der „weltanschaulichen“ Disziplinierung der Bildungsanstalten. ${ }^{1282}$ Bald aber häuften sich die Friktionen zwischen dem Totalitätsanspruch des nationalsozialistischen Staates und dem Selbstbehauptungsinteresse der Korporationen. Das studentische Verbindungswesen endete nach einer Welle von Friktionen mit dem Hitlerstaat im Herbst 1935: Einige Verbände lösten sich im Stillen selbst auf, ${ }^{1283}$ die übrigen wurden gleichgeschaltet, eingegliedert und einer einheitlichen „Reichsstudentenführung“ bestehend aus Heinrich Himmler und Gustav Adolf Scheel unterstellt wurde, um die Linientreue der deutschen Intelligenz zu gewährleisten. Eine Mehrheit von drei Vierteln der Studenten ging daraufhin zur Passivität über. „Ein klares Indiz für den Widerwillen eines erheblichen Teils der Studentenschaft gegen Indoktrination und Reglementierung ${ }^{\text {(1284 }}$ - aber eben auch kein Zeichen aktiven Widerstands. Das studentische Verbindungswesen fiel jener Bewegung zum Opfer, die an die Macht zu tragen sie geholfen und zu deren Teil sie sich erklärt hatte. Die antidemokratische Studentenbewegung zwischen 1925 und 1933 verpuffte nicht, sie ging als eine „der stärksten antisemitisch gestimmten Gruppierungen in der Gesellschaft “1285 in der Herrschaft der Nationalsozialisten auf. So gesehen erstickte sie an ihrem eigenen Erfolg und an der Durchsetzung ihrer primären Ziele.

Die Methoden der völkischen Studenten erschöpften sich nicht in Protesten, Schriften, Kundgebungen, in der Vernetzungs- und Missionsarbeit oder in der alltäglichen Verbindungspraxis. Während der 1920er und frühen 1930er Jahre erging sich der völkische Radikalismus des Weimarer Jungbürgertums darüber hinaus in militantem Protest und gewalttätigen antisemitischen Enthemmungen. Diskriminierung von jüdischen Kommilitonen hatte es - wie bereits im Kaiserreich - schon in den frühen 1920er Jahren gegeben, etwa durch Minderprivilegierungen im korporativen Alltag (etwa durch den Ausschluss von Juden aus Entscheidungsgremien oder durch „Arierparagraphen“). ${ }^{1286}$ Jenseits der Universitäten ließen die Studenten früh die Parole „Kauft nicht beim Juden! “1287 kursieren. Doch in den späten 1920er Jahren, nach dem offenen Bruch mit den Weimarer Verfassungsprinzipien, wussten die Studenten einflussreiche und wachsende gesellschaftliche Gruppen hinter sich. Sie veranstalteten „wahre Haßorgien“. ${ }^{1288}$ Angestachelt durch die nationalsozialistische Agitation, die mit dem Bild eines in der

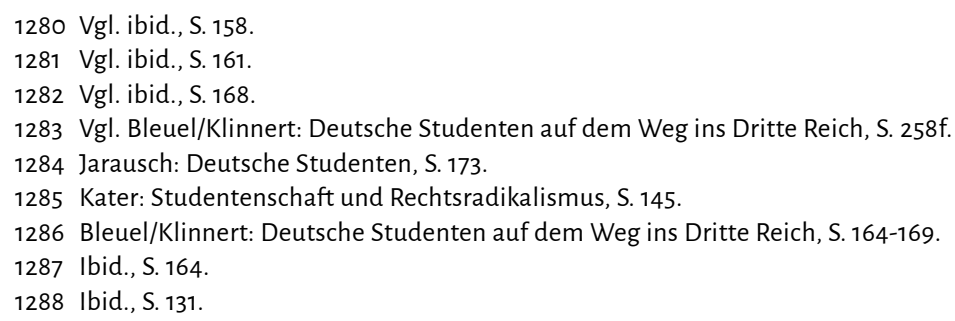


deutschen Akademikerschaft überrepräsentierten Judentums hantierte (die vorgetragenen Anteile von 25 Prozent an den deutschen Studenten übertraf die tatsächlichen Werte um mehr als das Doppelte), ${ }^{1289}$ zudem durch den auch auf die im Dunkeln der öffentlichen Wahrnehmung agierenden nicht-praktizierenden „Ostjuden“ gelenkten ethnisierten Hass, ${ }^{1290}$ überdies durch den NSDStB organisierend und bündelnd begleitet, entlud sich der jahrzehntelang kultivierte akademische Antisemitismus nach 1925 in zahlreichen „Krawallen an den Hochschulen des Reiches“; mit dem wachsenden Einfluss des NSDStB nahm dabei auch deren Intensität $\mathrm{zu} .{ }^{1291} \mathrm{Zu}$ „einem fast alltäglichen Spektakel" gerieten studentische Demonstrationen gegen republikanische wie jüdische Professoren und Kommilitonen; vielerorts griffen einige der Demonstranten, die gemeinsam Parolen wie "Heil Hitler" und „Deutschland erwache" skandierten und Regierung wie Republik schmähten, auf andersdenkende und jüdische Kommilitonen über. ${ }^{1292}$ Folgende Ereignisse des 13. November 1930 in Berlin illustrieren, was vielerorts geschah:

„Bei den sich entwickelnden Schlägereien wurde ein sozialdemokratischer Student blutig geschlagen und mußte sich in ärztliche Behandlung begeben. Im Innern der Universität wurde eine jüdische Studentin von Nationalsozialisten angegriffen, zu Boden geworfen und mit Füßen getreten. Die republikanischen Studenten wurden aus dem Vorraum der Universität in den Garten gedrängt ... Die Universitätsgänge widerhallten von den Pfiffen und Schreien der radikalisierten Studentenschaft. Abwechselnd wurde im Chorus ,Deutschland erwache!" und ,Juden raus!' gerufen. “1293

Aber auch die verhasste, als träge und „verknöchert“ perzipierte Professorenschicht wurde zunehmend angegangen. ${ }^{1294}$ Die akademische Jugend machte ernst mit ihrer lange angekündigten antibürgerlichen Rebellion, natürlich insbesondere in Gestalt als jüdisch identifizierter Hochschullehrer - diese galten den von nationalsozialistischen Publizisten wie Alfred Rosenberg inspirierten Studenten

„nicht nur als lebende Symbole für die Demokratie von Weimar, sondern, ebenso stark, als die sprichwörtlichen Vertreter der Rationalität. Hier sollte der Intellekt des Juden, der angeblich alles organisch Cewachsene zerstörte, im Zuge einer aktivistisch verstärkten Fortsetzung jenes studentischen Antiintellektualismus aus den frühen zwanziger Jahren endlich zur Strecke gebracht werden." ${ }^{1295}$

Die Studenten schlossen das als "destruktiv“ und „zersetzend“ denunzierte universitäre Lehrpersonal, welches die von ihnen heiß ersehnte führende „väterliche“ Autorität nicht füllen konnte, ${ }^{1296}$ daher konsequent als Ziel ihres „Radauantisemitismus“1297 mit ein. An der Kieler Christian-Albrechts-Universität (CAU) - Ausgangspunkt

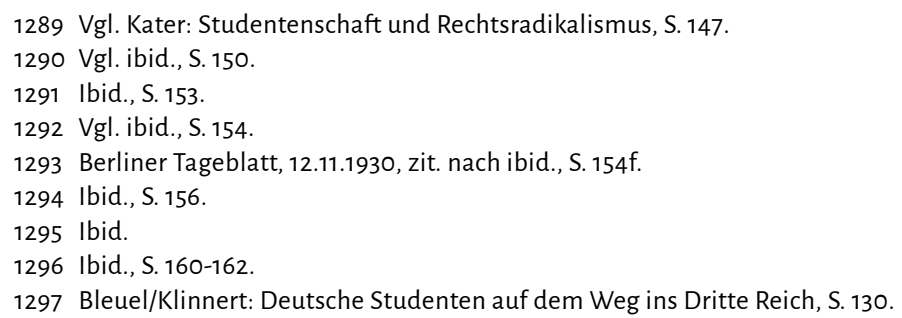


der für die nationalsozialistische Studentenbewegung organisatorisch relevanten „NS-Musterhochschulgruppe “1298 um Joachim Haupt - etwa richteten sich die studentischen Agitationen und Ausschreitungen gegen den emeritierten Theologieprofessor Otto Baumgarten und gegen den als Referent angereisten Völkerrechtler Walther Schücking. ${ }^{1299}$ Ihnen war eine etappenweise Radikalisierung der Studentenschaft unter spöttelnder Ignoranz gegenüber den weitgehend wirkungslosen Weisungen des Universitätsrektorats vorangegangen. ${ }^{1300}$ Baumgarten, zwischen 1903 und 1904 Rektor CAU, sollte beim Kieler Bachfest vom 04. bis 06. Oktober 1930 als Festprediger auftreten. Studenten des FKSt (Freie Kieler Studentenschaft) und des NSDStB agitierten

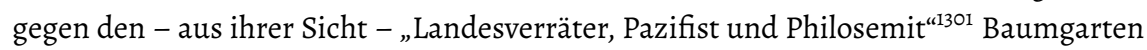
und kündigten Störungen seines Auftritts an. Im Zuge eines Disziplinarverfahrens entzog die CAU dem NSDStB die Anerkennung als akademischen Verein, woraufhin die Auseinandersetzungen zunächst versandeten. ${ }^{1302}$ Am 30. Juni 1931 jedoch warf der im NSDStB organisierte Medizinstudent Hans Joachim Eichhoff, wahrscheinlich unterstützt durch eine Gruppe von Mittätern, eine Tränengas-Patrone in den Saal der Kieler Seeburg-Mensa, wo Walther Schücking - u. a. aufgrund seiner öffentlichen Parteinahme für die Weimarer Reichsverfassung schon zuvor Zielscheibe völkischer Proteste - einen Vortrag vor 150 bis 200 Personen hielt. ${ }^{1303}$ Ähnliches wurde kurze Zeit anlässlich einer Filmvorführung von Erich Maria Remarques Im Westen nichts Neues versucht, ähnlich wie im Fall Schücking wurde das aus militärischen Beständen stammende Tränengas von NSDStB- oder NSDAP-Netzwerken beschafft. ${ }^{1304}$ Obwohl Eichhoff nach dem Schücking-Anschlag von der CAU disziplinarisch exmatrikuliert wurde, fiel seine gerichtliche Verurteilung indes - offenbar aufgrund überforderter und beunruhigter bürgerlicher Behörden - milde aus. ${ }^{1305}$ Im Februar 1933, unmittelbar nach der Hitler'schen Machtübernahme, mündete eine studentische Demonstration an der CAU in eine Massenschlägerei zwischen KPD- und NSDAP-Angehörigen; der dadurch entbrannte "Winterhochschulkonflikt" endete mit einer durch das Rektorat unterstützten Verdrängung der linken Hochschulgruppen aus der akademischen Selbstverwaltung. ${ }^{1306}$

1298 Eine Cruppe umtriebiger Studentenfunktionäre sorgte hier für eine dauerhaft erfolgreiche nationalsozialistische Jugendarbeit und stimmte die Zusammenarbeit zwischen Studentenverband und NSDAP ab, vgl. Cöllnitz: Der Student als Führer?, S. 79 und 122-125.

1299 Vgl. ibid., S. 110-122.

1300 Vgl. ibid., S. 103-110.

1301 Zit. nach ibid., S. 112.

1302 Vgl. ibid., S. 115-117.

1303 Vgl. ibid., S. $117 f$.

1304 Vgl. ibid., S. $120 f$.

1305 „Der Tränengasanschlag auf Schücking macht [...] die große Nervosität im bürgerlichen Milieu während der letzten Jahre der Republik deutlich: So wurde der neunzehnjährige Attentäter im Dezember 1931 lediglich zur Übernahme der Verfahrenskosten und zu einem Monat Gefängnis verurteilt - obwohl der Staatsanwalt ihn der Versammlungssprengung in Tateinheit mit teils vorsätzlicher, teils fahrlässiger Körperverletzung überführt hatte. In der Begründung dieses milden Urteils verwies das Schöffengericht auf, einen Dummenjungenstreich des Angeklagten, der noch sehr jung sei und sich habe hinreißen lassen."' Ibid., S.121.

1306 Vgl. ibid., S. 130-134. 
Jedenfalls: „Verbale und physische Angriffe gegen Professoren und Dozenten gab es bald an jedem Hochschulort" - so beispielsweise in Jena, Leipzig, Heidelberg, Breslau und Kiel -, „sie unterschieden sich lediglich durch ihre Intensität“ ${ }^{1307}$ Bis 1933 trieben sie aus jüdischen Familien stammende, offen republikanische Professoren wie Günther Dehn und Emil Julius Gumbel (Heidelberg), Hans Nawiasky (München), Ernst Cohn (Breslau) $^{1308}$ und Theodor Lessing aus dem Staatsdienst, ins Exil - oder in den Tod. Lessing wurde am 30. August 1933 auf der Flucht in der Tschechoslowakei von sudetendeutschen Nationalsozialisten erschossen. ${ }^{1309}$ Die antidemokratische Studentenbewegung von Weimar war also nicht nur radikal antisemitisch gesinnt, sondern auch bereit zu zunehmend blutiger Praxis. Dabei wurden die Gewaltausbrüche durchaus planvoll eingesetzt und propagandistisch flankiert:

„Die einzelnen NS-Hochschulgruppen verfolgten die reichsweiten Ceschehnisse genau, wobei die andauernde Thematisierung derartiger Übergriffe - sowohl im ,Völkischen Beobachter' als auch in der lokalen Studentenpresse - ein Abflauen des studentischen Interesses an der Eroberung der Hochschulen verhinderte. Mit Ehrenerklärungen unterstützten die Studierenden aus der Ferne ihre ,kämpfenden Kommilitonen und lenkten damit auch den Blick auf die Situation an der eigenen Universität.“1310

Sicher konvergierten in der Spätphase der Weimarer Republik die inneruniversitären Entwicklungen mit den gesamtgesellschaftlichen. Die Ursachen und Bedingungen dieses Prozesses der Faschisierung in Deutschland sind komplex und hier nicht in Gänze zu rekonstruieren. Generell zeichnet sich dieser Zeitraum durch die destabilisierend wirkende politische Fragmentierung der Gesellschaft und die Abwanderung der bürgerlichen Schichten in tribalisierte zivilgesellschaftliche Strukturen aus, bedingt auch durch eine nicht mehr integrierbare Explosion sozialstruktureller Konfliktlagen, die zur Wählerfluktuation in Richtung nationalsozialistischer (NSDAP) und kommunistischer (KPD) Kräfte führte, ${ }^{1311}$ die politische „Mitte“ aufrieb und das Klima für militante Auseinandersetzungen zwischen paramilitärischen Wehrverbänden (Stahlhelm, Reichsbanner, Rotfrontkämpferbund) schaffte, letztlich zu bürgerkriegsähnlichen $\mathrm{Zu}$ ständen führte. Jedoch fällt auf, wie früh die nationalsozialistische Bewegung unter den Weimarer Studenten reüssieren konnte: Sie erreichte den Aufbau eines frühen republikfeindlichen Vorkämpferverbandes in Gestalt des vom vergleichsweise kleinen NSDStB getragenen, aber von der Mehrheit der Korporationsstudenten goutierten antidemokratischen Studentenbewegung zwischen 1925 und 1933. Mehrere sich überkreuzende Bedingungsfaktoren ermöglichten diesen „Erfolg“: Erstens bildete die Verbreitung und Sedimentierung völkischer und antisemitischer Mentalitäten seit dem Kaiserreich einen entscheidenden Humus des nationalsozialistischen Mobilisierungserfolgs in der „Epoche der gesellschaftlichen Entsicherung ${ }^{\text {“1312 }}$. Zweitens enthielt das von der Kriegs-

1307 Vgl. ibid., S. 103.

$1308 \mathrm{Vgl}$. ibid.

1309 Vgl. Kater: Studentenschaft und Rechtsradikalismus, S. 157 und 293, Anmerkung 97.

1310 Göllnitz: Der Student als Führer, S. 104.

1311 Vgl. Falter, Jürgen W.: The social bases of political cleavages in the Weimar Republic, 1919-1933 (1992), in: Historical Social Research, Supplement H. 25/2013, S. 194-216.

1312 Plessner: Die verspätete Nation, S. 20. 
generation ins Verbands- und Verbindungswesen getragene Gemeinschaftspathos $a b$ ovo antiliberale, antirationalistische und antiindividualistische Elemente, die etwa die spätere Ethnisierung der vormals integrativ gedachten „Volksgemeinschaft“ strukturell vorbereitet hatten. Und drittens verdankte der NSDStB seinen sprunghaften Erfolg der unermüdlichen Basisarbeit entschlossener Kader wie dem geschickt lancierten und demagogisch durchsetzten Versprechen, die drastische materielle Not einer großen Zahl aufstiegsblockierter Jungakademiker zu beenden. Nicht zuletzt dieses Versprechen lockte auch die erwachsenen bildungsbürgerlichen Eliten, welche auf die Repristination ihres einstigen Status hofften. ${ }^{1313}$ So begrüßte die Mehrheit des gebildeten Bürgertums und der deutschen Akademiker 1933 den Nationalsozialismus: ${ }^{1314}$

„Am 18. Oktober 1817 feierte die Urburschenschaft ihr Wartburgfest. Am 18. Oktober 1935 versammelte sich die Burschenschaft wieder auf der Wartburg, die Deutsche Burschenschaft. Sie tat es, um sich zu den Ideen der Urburschenschaft zu bekennen - indem sie sich korporativ in die Reihen des nationalsozialistischen Studentenbundes Adolf Hitlers eingliederte. Feierlich wurde die Fahne der Urburschenschaft den nationalsozialistischen Statthaltern überreicht. Ihre Farben waren Schwarz-Rot-Cold, und es war die erste deutsche Fahne, die diese Farben trug. Gauleiter Adolf Wagner dankte für die Fahne der Freiheit." ${ }^{\text {“1315 }}$

Im Winter 1935/36 schluckte der NSDStB die traditionellen Korporationen, 1938 wurden die konfessionellen Verbindungen aufgelöst. ${ }^{1316}$ Noch unter den Studenten der Nachkriegsperiode erbten sich „völkische Reflexe“ und apolitischer Privatismus als „Vermächtnis“ des Nationalsozialismus fort. ${ }^{1317}$

Bitter sind diese Geschehnisse auch, weil die politische Gegenwehr „linker“, liberaler und katholischer studentischer Verbände im Rückblick beinahe unvermeidlich schwach erscheint. Dies liegt nicht nur im Fehlen eines „festumrissenen Alternativprogramm[s]" begründet, welches die zwischen liberaldemokratischem und sozialistischem bzw. kommunistischem Denken changierende antivölkische Minderheitsopposition hätte bündeln können. ${ }^{1318}$ Lohnenswert ist ein abschließender kurzer Blick auf die Beispiele der freistudentischen und sozialistischen Studenten Weimars, die es

1313 „Die auffällige Hinwendung vieler ,Geistesarbeiter' zum Nationalsozialismus ist, aus dieser Perspektive gesehen, ein verblendetes Aufbegehren gegen die gleichberechtigte Teilhabe aller Menschen an der Massengesellschaft. Besonders die Frauen, die sozialen Aufsteiger aus den unteren Mittelschichten und ,die Juden' wurden als gefährliche Konkurrenten wahrgenommen, die die überkommene Rangordnung bedrohten. Vom Dritten Reich erhofften viele Bildungsbürger, ihren angestammten Platz an der Spitze der ,Volksgemeinschaft' wieder einnehmen zu können. [...] Es entsprach dem Zeitgeist, daß in dieser Phase der, geistigen Währungskrise' gegen die Ansprüche der Massenbildung vor allem die Naturgrenzen geistiger Bildung betont wurden." Titze, Hartmut: Wie wächst das Bildungssystem?, in: Zeitschrift für Pädagogik, 45. Jg., H. 1/1999, S. 103-120, hier S. 115 (Herv. i. O.)

1314 Vgl. Titze: Bildungskrisen und sozialer Wandel, S. 361.

1315 Bleuel/Klinnert: Deutsche Studenten auf dem Weg ins Dritte Reich, S. 259.

1316 Vgl. Gevers/Vos: Studentische Bewegungen, S. 290.

1317 Vgl. Jarausch: Deutsche Studenten, S. 210.

1318 Schwarz: Studenten in der Weimarer Republik, S. 402. 
nicht zur Mobilisierungskraft einer studentischen Oppositionsbewegung gebracht haben und die beide weitgehend mit der ersten deutschen Republik untergegangen sind. Wie gesehen, bildeten die freistudentischen Gruppierungen das radikalliberale, hierarchiekritische und individualistische Gegenstück zum Korporationsstudententum. Von beinahe gleichem Alter, reichten deren Traditionslinien nicht nur bis zur Progressbewegung der 1840er Jahre zurück, von der sie ihre neuhumanistischen Motive bezogen; schon im späten 18. Jahrhundert hatte es so genannte „Renoncenbewegungen“ gegeben, „Formierungen von Nichtorganisierten“, die sich gegen die strikten Vorschriften und Kollektivierungszwänge der Verbindungen auflehnten. ${ }^{1319}$ Durchaus beeindruckend erscheint, dass die im Vormärz herausgebildete Emphase auf Bildung, Individuum, Mündigkeit und aufgeklärt-rationaler studentischer Gemeinschaft in freistudentischer Gestalt (trotz der oben erwähnten Auflösungsprozesse ab 1920) noch einige Jahre lebendig blieb: Die Weimarer Freistudenten reagierten, anders als die antisemitische Mehrheit, „auf den Statusverlust“ nämlich gerade „nicht mit Ausgrenzungsstrategien gegenüber vermeintlich minderwertigen Sozialschichten“, ja nicht einmal „mit dem Rückzug auf elitäre und selbstgenügsame Gemeinschaftsformen wie die Bünde der Jugendbewegung. “1320 Stattdessen bemühten sie sich um eine moderne, der demokratischen Auseinandersetzung gemäße, Anverwandlung ihrer tradierten Prinzipien:

„Die in den Freistudentenschaften gepflegte rationale Grundhaltung verstellte nicht den Blick auf die sozialen und kulturellen Folgen des Modernisierungsprozesses, die in den vielen Abteilungen zum Gegenstand des wissenschaftlichen Interesses wurden. Der ,heimliche Lehrplan' der Freistudenten-Bewegung, der die Befähigung zu individueller Selbststeuerung und aufgeklärter Mündigkeit förderte, bereitete die Mehrheit ihrer Anhänger exemplarisch auf die Pluralität der Weimarer Demokratie vor.“1321

Praktisch lief diese Liberalität jedoch auf die Fetischisierung der integrierenden, versöhnenden, befriedenden Kräfte von „Bildung“, auch als „Volksbildung“ verstanden, mithin auf inhaltlichen Relativismus hinaus. Der Anspruch, zeitgemäße Antworten zu finden, scheiterte daran, „Bildungsideologie und Emanzipationsanspruch“ überzeugend zu vermitteln, $d$. h. in ein politisches Programm zu übersetzen. ${ }^{1322}$ Die edlen Modernisierungs-Maximen der Weimarer Freistudenten blieben damit im schlechten Sinne idealistisch, schließlich praktisch wirkungsarm. ${ }^{1323}$ Zudem hegten auch unter ihnen viele politisch ambivalente, „irrationalistische“ Sehnsüchte: Die aus den Reihen der Freistudenten hervorgehende Lebensreformbewegung, die nach einer autonomen

1319 Hardtwig: Studentische Mentalität, S. 597.

1320 Wipf: Studentische Politik und Kulturreform, S. 250.

1321 Ibid.

1322 Ibid., S. 249.

1323 „Liberal und tolerant gegenüber anders Denkenden oder jüdischen Studenten war das freistudentische Milieu vor allem deshalb, weil eine Involvierung in studentenpolitische Tageskämpfe als dem Akademiker unwürdig abgelehnt wurde. [...]Angesichts der antirepublikanischen Politisierung nach dem Krieg, als sich die Frage des Sonderweges zwischen ,Mammonismus und Sozialismus' nicht mehr in der bisherigen Weise stellte, scheiterte das freistudentische Konzept folgerichtig, weil es ihm nicht gelang, einen verbindlichen Standpunkt innerhalb der sich auch an den Hochschulen artikulierenden sozialen und politischen Interessengegensätze zu formulieren." Ibid. 
"Jugendkultur" strebte und das Selbstbildungsideal mit dem an Heimat, Natur und kameradschaftlicher Gemeinschaft orientierten Geist der Wandervogelbewegung ${ }^{1324} \mathrm{zu}$ verknüpfen suchte, sympathisierte mit Abstinenzlertum und sexueller Enthaltsamkeit, war teils volkstümlich-mythopoetisch ausgerichtet. Das partielle Einmünden in die völkische Studentenbewegung war hier nicht nur für den „vaterländischen“ Flügel der Freistudenten ein folgerichtiger Schritt. ${ }^{1325}$ Auch aufseiten sozialistischer Studierender gab es Mobilisierungshürden. So existierte in den Anfangsjahren Weimars "nur eine schwer $\mathrm{zu}$ entwirrende Vielfalt von sozialistischen Studentengruppen, die schnell und enthusiastisch gegründet“ wurden, „nicht selten aber kurz danach schon wieder desillusioniert und enttäuscht aufgegeben wurden“, oft wegen unüberwindlicher Konflikte und Spaltungs- bzw. Zersplitterungsprozessen; ein geeinter Verband, der sich als sozialdemokratischer Studentenverband Deutschlands und Österreichs verstand, bildete sich ab 1922. ${ }^{1326}$ Von der SPD sowie ihren Funktionären mit Skepsis bedacht, erlangte der unter verschiedenen Namen auftretende sozialistische Studentenverband erst Ende der 1920er den Status der offiziellen sozialdemokratischen Hochschulorganisation, nun auch mit der offiziellen Bezeichnung "Sozialistische Studentenschaft" (SSt). ${ }^{1327}$ In ihrem Kreis engagierten sich viele ehemalige Freistudenten, die nun die Idee der sozialistischen Revolution idealisierten; überhaupt hatte die Mehrheit von ihnen einen bildungsbürgerlichen Hintergrund. ${ }^{1328}$ Zwischen 1923 und 1931 stiegen sowohl die Mitgliederzahlen der SSt von anfänglich 1.200 auf $5.500^{1329}$ ebenso wie sich die sozialstrukturelle Zusammensetzung verproletarisierte: Auf dem Höhepunkt ihrer organisatorischen Schlagkraft entstammten ca. 68,8 Prozent der SSt den Schichten der Arbeiter und einfachen Angestellten - „den beiden Sozialgruppen, die in der gesamten Studentenschaft nur den geringen Anteil von 9,07 \% ausmachten. ${ }^{(1330}$ Die disziplinierte Arbeit an der Verbesserung der sozialen Lage proletarischer Studierender verdrängte den linksradikalen „Seminarmarxismus“ der frühen Jahre. ${ }^{1331}$ Das gesellschaftsweite Bündnis mit der Arbeiterklasse gelang trotz im Rahmen der studentischen Selbsthilfebewegung gesammelten Erfahrungen im Kontakt mit nichtstudentischen Milieus $^{1332}$ nicht, man blieb Anwalt studentischer Arbeiterkinder. ${ }^{1333}$ Trotzdem: Die sozialistischen Studenten bildeten inmitten des mehrheitlich perhorreszierten Feldes parteigebundener Hochschulgruppen 1931 den zahlenmäßig größten und in ihrem Milieu erfolgreichsten Verband:

„Die Sozialistische Studentenschaft besaß nun mithin alle Vorzüge eines typisch sozialdemokratischen Verbandes: er war organisationsstark, er erzielte quantitativ

1324 Vgl. Bias-Engels, Sigrid: Zwischen Wandervogel und Wissenschaft. Zur Geschichte von Jugendbewegung und Studentenschaft 1896-1920. Edition Archiv der deutschen Jugendbewegung, Bd. 4, Köln 1988.

1325 Vgl. Jarausch: Deutsche Studenten, S. 102.

1326 Walter: Sozialistische Akademiker- und Intellektuellenorganisationen, S. 27.

1327 Vgl. ibid., S. 84.

1328 Vgl. ibid., S. 27.

1329 Vgl. ibid., S. $57 f$.

1330 Ibid., S. 60.

1331 lbid., S. 84.

1332 Vgl. Schwarz: Studenten in der Weimarer Republik, S. 79.

1333 Vgl. Kater: Studentenschaft und Rechtsradikalismus 
beachtliche Erfolge, er erreichte ziemlich umfassend diejenigen Studenten, die aus großstädtisch-industriellen Arbeitnehmerfamilien kamen. ${ }^{\text {“1334 }}$

Das zunehmende Zusammenwachsen mit der sozialdemokratischen „Solidargemeinschaft" und der damit zusammenhängende Aufbau von Gegeninstitutionen studentischer Selbsthilfe wie Selbstverwaltung isolierten den Verband als „Trutzburg“ von den nationalistisch-völkisch dominierten AStAs. ${ }^{1335}$ „[Ü]ber den ideologischen und mentalen Tellerrand des eigenen Lagers hinauszublicken ${ }^{\alpha 1336}$ gelang dem nach wie vor die „Diktatur des Proletariats“ fordernden und für die Abschaffung der traditionellen Hochschulautonomie durch einen rational verwaltenden Staat eintretenden SSt kaum, politische Offerten für die bildungsbürgerliche Mehrheit der Weimarer Studenten wurden nicht erarbeitet:

„Damals wähnten sich die sozialistischen Studenten allen Ernstes in einer ideologischen Vorreiterrolle. Dabei konfrontierten sie ihre Kommilitonen mit einem Vokabular, das selbst in den Ohren sozialistischer Arbeiter schon ein wenig fremd geklungen haben dürfte, das bei den Angehörigen der Mittelschichten, in Angestellten- und Beamtenkreisen, aus denen die Mehrheit der deutschen Studenten stammte, seit jeher Ängste und Ressentiments auslöste. ${ }^{\text {“1337 }}$

Die SSt setzte zwar auf die "staatsbejahend-republikanische[] Richtung in der SPD“, pflegte Kontakte zu sozialdemokratischen Spitzenpolitikern und suchte das Bündnis mit den schwächelnden liberalen Studentenverbänden. ${ }^{1338}$ Ähnlich aber wie das 1922 infolge der Ermordung Walter Rathenaus und als Kampfmittel gegen den studentischen nationalistischen Antisemitismus in Jena gegründete Republikanische Studentenkartell, lange Zeit Bündnispartner des SSt und ab 1928 eigenständiger Verband (Deutscher Republikanischer Studentenbund), ${ }^{1339}$ scheiterte man schlicht an der Übermacht der nationalsozialistischen Mobilisierungsarbeit an den Hochschulen. ${ }^{1340}$ Nach dem organisatorischen Höhepunkt 1931 spalteten sich linkssozialistische und kommunistische Verbandsmitglieder in Richtung SAP und KPD ab, 1933 wurde der SSt von den Nationalsozialisten aufgelöst. „Politisch und moralisch“1341 stechen die sozialistischen Studenten Weimars aus der antidemokratischen Mehrheit ihrer Kommilitonen wohl hervor, aufhalten aber konnten sie diese nicht.

1334 Walter: Sozialistische Akademiker- und Intellektuellenorganisationen, S. 85.

1335 Ibid., S. $84 f$.

1336 lbid., S. 85 .

1337 Ibid., S. 85.

1338 lbid., S. 86.

1339 Vgl. ibid., S. 69-75.

1340 „In den frühen $30 e r$ Jahren gingen die republikanischen Studentengruppen im völkischen und antisemitischen Radau vor und in den Hörsälen regelrecht unter. Den Meinungsterror, den die nationalistischen Studenten gegen republikanische und jüdische Hochschullehrer ausübten, vermochten sie nicht zu vereiteln oder zurückzudrängen." Ibid., S. 86.

1341 Ibid. 


\section{II.3 Politischer Mentalitätswandel: Empirische Studien über Einstellungsmuster und Praxispotenziale von Studierenden in der Bundesrepublik}

Zeit, den Schwenk von den irregulären Bewegungsphasen zum allgemeinen politischen Klima an den Hochschulen seit 1949 zu vollziehen: Wie haben sich die politischen Einstellungsmuster der Studierenden entwickelt? Welchen Effekt hatten politische Mobilisierungsphasen tatsächlich auf ihr Mobilisierungs- und Aktionspotenzial? Seit dem Ende des Zweiten Weltkriegs wurden, entsprechend der breiten Etablierung moderner Instrumentarien der empirischen Sozialforschung zur Erforschung der Bevölkerung im Allgemeinen, ${ }^{1342}$ nicht nur die soziale Lage, sondern auch die politischen Orientierungen und Einstellungsmuster der Studierenden der Bundesrepublik engmaschig erforscht. Der Blick auf das studentische politische Bewusstsein ist dabei von vergleichbaren Erkenntniskonjunkturen durchwirkt wie das wissenschaftliche Interesse an der Jugend allgemein. ${ }^{1343}$ Der Deutungshorizont der sozial- und politikwissenschaftlichen Erforschung der Studierenden klebt nämlich, trotz mancher skeptischer Distanzierung, in ähnlicher Weise an Generationen-Chronologien: Ähnlich wie dort erhoffen sich viele Autoren Rückschlüsse auf den Zustand der sozialen Integrität der Gesellschaft anhand der Studierendenschaft als exponierter Subgruppe der deutschen Jugend und deren vermeintlichen tatkräftig-freiheitlichen ${ }^{1344}$ bzw. egoistisch-apathischen, orientie-

1342 Freilich gestaltete sich dieser Durchsetzungsprozess auch konfliktreich und begleitet durch einen Empirismusstreit an den deutschen Universitäten. Dass aber im Zuge des wachsenden allgemeinen - auch politischen - Interesses an soziologischen Fragestellungen schlicht eine neue Nachfragesituation gegeben war, die die Installation und Professionalisierung empirischer Sozialforschung in Deutschland antrieb, ist anschaulich dargelegt in Kern, Horst: Empirische Sozialforschung: Ursprünge, Ansätze, Entwicklungslinien, München 1982, S. 217-229 und S. 246-252. Erfrischender Weise liefert Kern dabei keine seichte Erfolgsgeschichte, sondern weist auch, darin ganz Didaktiker, auf die Schwierigkeiten einer langfristigen Evolution des früheren Begriffs einer fragenden, ihrer Crenzen bewussten und potenziell scheiternden Forschung zu „methodenperfekter" Hilfswissenschaft von öffentlicher Planung und Verwaltung hin. Unweigerlich werde in einer sich derart präsentierenden Wissenschaftlichkeit die entscheidende Aufgabe, nämlich die Erschließung tatsächlich neuer Sachverhalte, verfehlt; die jeder Studie eigenen „Ecken und Kanten“ würden ex post stets abgerieben: „Statt sich mutig und mit einer gewissen Großzügigkeit den in unserem Fach immer noch beträchtlichen weißen Felder zuzuwenden, wird Erkenntniszugewinn vielfach in der genaueren Erforschung von im Grundsatz bereits bekannten Sachverhalten gesucht. Man schlägt weniger Schneisen als früher und bewegt sich lieber auf schon gebahnten Strecken. Das Bedürfnis, weder in inhaltlicher noch in formaler Hinsicht anzuecken, dominiert viele Studien." Ibid., S. 247, ferner S. 274.

1343 Vgl. Schenke et al.: PECIDA-Effekte?, S. 15-28.

1344 „Wenn die Führung im Ceistigen und Politischen unsicher wird, richtet sich die Erwartung auf die Jugend. Aus ihren Verhaltensweisen möchte man ablesen, wie die nächste Generation fühlt und denkt und welche Haltungen und Entscheidungen von ihr zu erwarten sind. [...] DIE STUDENTEN übernehmen dabei naturgemäß eine besonders geartete Rolle. Ihre Beteiligung an geschichtlichen Vorgängen (1813, Hambacher Fest 1848) gibt der Studentenschaft von vornherein ein gewisses Prestige. Sie stellte die Vorhut in manchem Umbruch; sie gilt als wetterfühlig und sensibel für kommende Ereignisse." Stifterverband für die deutsche Wissenschaft: Das geistige Bild der Studenten, S. 5. Vgl. ferner Klose: Freiheit schreibt auf eure Fahnen. 
rungslosen und positionierungsmüden ${ }^{1345}$ Mentalitäten. Insbesondere das prospektive politische bzw. demokratische Potenzial der Studierenden (bzw. dessen Absenz) wird hier als prognostischer Gradmesser gesellschaftlicher Gesamtentwicklungen gewertet und verheißt Hoffnungen auf ersehnte Fortschritts- und Reformimpulse. ${ }^{1346}$ Und ähnlich wie dort ist der größte Teil des Forschungskorpus politisch bedarfsorientiert: Den vom Bundesministerium für Bildung und Forschung (BMBF) finanzierten repräsentativen Studierendensurvey interessieren - nebst der historisch bedingten Erforschung politischen Konfliktpotenzials und drohender Radikalität unter Studierenden in den frühen 1980er Jahren - vornehmlich Wahrnehmung und Beurteilung der Studiensituation und die daraus abzuleitenden Erfordernisse für Readjustierungen der Hochschulverwaltungen bzw. der Hochschul- und Bildungspolitik. ${ }^{1347}$ Ein starker Akzent liegt im Falle der Studierendenschaft allerdings - im Unterschied zu den breiteren Jugendstudien - auf der gewichtigen Bedeutung von politischen Mentalitätstrends in den Reihen einer Gruppe, die in späteren Karrieren, etwa als künftige Führungseliten in Verwaltung, Wirtschaft und Politik besonders starken Einfluss ausüben mag, ${ }^{1348}$ die größtenteils eben jene „Schlüsselinstitutionen der modernen Gesellschaft“, die Universitäten, durchläuft. ${ }^{1349}$

Im Folgenden sollen repräsentative Daten und wesentliche Resultate empirischer Studien zusammengetragen werden, um die entscheidenden Veränderungen der politischen Einstellungsmuster von Studierenden gegenüber Politik, Gesellschaft und Demokratie seit den 1950er Jahren zu identifizieren und die Entwicklung des gemessenen politischen Potenzials nachzuzeichnen. Dabei werden wesentliche Hauptentwicklungen für die hier interessierenden Zusammenhänge freigelegt. Den Anspruch einer umfassenden Wesensschau der jeweiligen Zeiträume und Dekaden kann die Darstellung nicht erheben, denn „den einen Geist, die eine Entwicklung, das eine und verbindliche Signum weisen Jahrzehnte in modernen Gesellschaften nicht aus.“1350 Das Kapitel erfüllt zwei Funktionen: Erstens dient es der späteren methodischen Kontrolle bei der Interpretation des Fokusgruppenmaterials: Die zusammengetragenen Ergebnisse der quantitativen Studien zeichnen ein Panorama studentischer Einstellungsmuster, mit dem eigene Arbeitshypothesen verglichen werden können; die fehlenden Diskussionen mit einem Forscherteam im Auswertungsprozess können so weitgehend kompensiert werden. Zweitens rechtfertigt die umfängliche Aufarbeitung der empirischen Studien

1345 Vgl. Bargel, Tino: Student und Politik: die ratlose Generation, in: News 30.3, AG Hochschulforschung, Universität Konstanz 2009, S. 1.

1346 Vgl. Bargel: Wandel politischer Orientierungen, S. 3.

1347 Frank Multrus bezeichnet den Studierendensurvey als „Instrument der wissenschaftlichen Politikberatung", Multrus, Frank: Der Studierendensurvey. Konzept, Aufbau und theoretische Grundlagen. Hefte zur Bildungs- und Hochschulforschung, AG Hochschulforschung, Universität Konstanz, H. 87/2016, S. 50. Vgl. ferner den initialen 1. Studierendensurvey 1982/83, S. III; vor dem Hintergrund der Hereinnahme ostdeutscher Studierender den zusammenfassenden Band Studierendensurvey 1990er, Vorwort; 8. Studierendensurvey 2000/01, S. 3f.; vgl. auch 13. Studierendensurvey 2015/16, S. 5 .

1348 Vgl. Habermas et al.: Student und Politik, S. 52-55 sowie Glotz/Malanowski: Student heute, S. 9 und S. 49-63.

1349 Glotz/Malanowski: Student heute, S. 62.

1350 Walter: Rebellen, Propheten, Tabubrecher, S. 331 (Herv. i. O.) 
das hier verfolgte Studiendesign, indem es den Nachweis erbringt, dass die in diesem Feld hegemoniale Einstellungsforschung zwar eindrücklich die Entwicklung von Einstellungswerten zu politischen und demokratischen Themen dokumentiert, aber aus konzeptuellen Gründen - insbesondere durch den methodisch bedingten Verzicht auf die Rekonstruktion politisch-sozialer Deutungsmuster, verstanden als ideologische Strukturen bzw. private Gesellschaftstheorien - insgesamt nicht in der Lage ist, tiefenstrukturelle Mentalitätsverschiebungen von Studierenden zu erfassen, und daher auch das tatsächliche politische Handlungspotenzial von Studierenden kaum beurteilen kann.

\section{II.3.1 Von der Skepsis zur Polarisierung: Die Studierenden der Kriegs- und Nachkriegsgeneration 1957-1980}

In den früheren sozialwissenschaftlichen Studien der Bundesrepublik werden Studierende oftmals als - gesellschaftlich besonders maßgebliche - Teilgruppe der Jugendlichen bzw. jungen Erwachsenen insgesamt gehandelt. So ging auch der Soziologe Helmut Schelsky in seinem für die Jugendforschung klassischen Band Die skeptische Generation von 1957 vor. Er sezierte die Werthaltungen und politischen Orientierungen der Jugendlichen und jungen Erwachsenen in einer Zeit der generellen Abwendung von Parteien und politischen Institutionen. ${ }^{1351}$ Dabei sah Schelsky sämtliche Aspekte, die ihm zufolge das von Erwachsenen gepflegte Bild des spezifisch „Jugendgemäßen“ ausmachten - eine eigenständige „soziale Eigenwelt" und eine besondere Gesellungsform als jugendliche Gemeinschaft ${ }^{1352}$ - als weitgehend erodiert an. Vielmehr glichen sich die jugendlichen Lebensweisen jenen der Gesamtgesellschaft an: Schelsky zeichnete das Bild einer „privatistischen“ (auf das private Umfeld als „Lebenshalt“ fixierten) ${ }^{1353}$, „,ent-

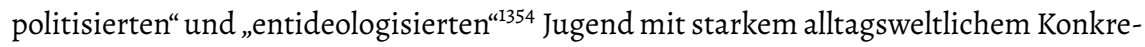
tismus (im Sinne eines „geschärften Wirklichkeitssinn[s]“ und eines „unerbittliche[n] Realitätsverlangen[s] ${ }^{\alpha 1355}$ ) und einer leidenschaftlichen Abneigung gegenüber abstrakten Prinzipien und romantischen Idealen. ${ }^{1356}$ Zwar lege die Jugend in ihrem „Streben nach Verhaltenssicherheit ${ }^{\star 1357}$ auch eine ausgeprägte Leistungsbereitschaft, Anpassungsfähigkeit und Selbstständigkeit an den Tag, ${ }^{1358}$ zugleich fiel Schelsky aber auf, dass derartige Orientierungen, Verhaltensmuster und Handlungsmaximen wie äußerliche Koketterien wirkten, die latente Insekuritäten und Orientierungsmängel camouflieren sollten. ${ }^{1359}$ In dieser „Pseudo-Erwachsenheit“ der Jugend sah er wiederum die deutlichsten Gefahren. ${ }^{1360}$ Speziell zur akademischen Jugend notierte er überdies eine

1351 Schelsky: Die skeptische Generation. Vgl. zum politischen Klima der Nachkriegszeit Kapitel II.2.2 dieser Studie.

1352 Ibid., S. 84, 85, 93 f.

1353 Ibid., S. 80.

1354 Ibid., S. 74.

1355 Ibid., S. $77 f$.

1356 Ibid.

1357 Ibid., S. 75.

1358 Vgl. ibid., S. 77.

1359 Vgl. ibid., S. 81.

1360 Ibid. 
Auflösung der früheren klassen- bzw. schichtspezifischen „sozialen Einheit“ der Studierendenschaft im Zuge der fortschreitenden Akademisierung der Erwerbswelt sowie die breite Ablehnung des klassischen studentischen Gemeinschaftslebens inklusive des früheren Standesbewusstseins unter den Studierenden. ${ }^{1361}$ Die scheinbar gegenläufige Tendenz einer Regeneration des Korporationslebens konterte er dabei mit dem Verweis auf den politischen und sozialmoralischen Partikularismus dieser von der Mehrheit der Kommilitoninnen und Kommilitionen und auch von den Hochschulleitungen nunmehr eher abgelehnten Organisationsform. ${ }^{1362}$

Schelsky platzierte mit seiner Studie, hernach hegemoniale Interpretations- wie Kontrastfolie der darauffolgenden Jugendstudien, publikumswirksame Schlagworte. ${ }^{1363}$ „Ihm war es gelungen, die schlüssigen Formeln für die sekundäre Literatur zu prägen.“1364 Tatsächlich inspirierte Schelsky eine ganze Reihe von jugendsoziologischen Monographien, die sich kritisch an ihm und damit an der Jugend der 1950er Jahre abarbeiteten. Dazu gehört die vom Deutschen Jugendinstitut (DJI) beauftragte Studie Eine neue Generation? aus der Feder des Psychologen Walter Jaide (1961), die Einzelfallinterviews auswertete, ${ }^{1365}$ aber auch die sekundär auswertende Studie Die Generation der Unbefangenen von Viggo Graf Blücher (1965), die erklärtermaßen zu einer „Apologie“ der von ihm so benannten „Generation der Unbefangenen“ anhebt. Unter ironischem Rekurs auf die überlieferten Sokratischen (und die damals recht aktuellen, vom Psychoanalytiker Erich Fromm formulierten) Klagen über das Fehlverhalten und den sozialmoralischen Verfall der Jugend verteidigt dieser die vermeintlich skeptische Generation gegen den Skeptizismus der Jugendforscher: Die fehlende Bindung an ideologische Lager und politisches Engagement wertet er - nebenbei bemerkt: in einem irritierend gönnerhaften Ton - als Haltung einer zeitgemäßen, individualisierten und zugleich konformistischflexiblen Mäßigung in einer sich rasch modernisierenden Welt. ${ }^{1366}$ Es passt zu dem hier gezeichneten deutlich komplexeren Bild der Nachkriegsjugend der 1950er Jahre, dass

1361 Ibid., S. 316-326 und 330f., siehe insbesondere das schroffe Urteil auf S. 330: „Auch für die studentische Jugend gilt wie für alle anderen Schichten der jungen Generation, daß sie weder eine sozial autonome Gruppe noch gar eine soziale Elite darstellt; ihr geben weder ihre soziale Lage und ihre sozialen Ziele eine irgendwie bemerkenswerte Eigenständigkeit gegenüber den anderen gleichaltrigen Jugendlichen, noch lassen ihre sozialen Verhaltensformen darauf schließen, daß sie insgesamt als eine Art Verhaltenselite zu betrachten wäre. [...] Das ,Akademische' hat in dieser Studentengeneration genauso seinen traditionellen Wirklichkeitsgehalt eingebüßt wie das ,Jugendgemäße’ für die ganze Jugend. “Vgl. dazu auch ausführlich Kapitel II.1 dieser Studie.

1362 Vgl. ibid., S. $326 f$.

1363 Kersting, Franz-Werner: Helmut Schelskys „Skeptische Generation“ von 1957. Zur Publikationsund Wirkungsgeschichte eines Standardwerkes, in: Vierteljahrshefte für Zeitgeschichte, 50. Jg., H. 3/2002, S. 465-495.

1364 Stifterverband für die deutsche Wissenschaft: Das geistige Bild der Studenten, S. 7.

1365 Vgl. Jaide, Walter: Eine neue Generation? Eine Untersuchung über Werthaltungen und Leitbilder der Jugendlichen, hg. vom Deutschen Jugendinstitut, München 1961, insbesondere S. 127-133.

1366 Blücher, Viggo Graf: Die Generation der Unbefangenen. Zur Soziologie der jungen Menschen heute, Düsseldorf/Köln 1966, S. 391-403. „Man ist bemüht, sich dieser Gesellschaft möglichst früh zu integrieren, um an ihren Möglichkeiten voll teilhaben zu können. Anpassung ist das dominante Verhaltensmuster. [...] Das System zeigt noch überall die Symptome der Ausfaltung. Es wird erst von den Nachfolgenden im vollen Sinne entwickelt und vervollkommnet werden können. Die Weltoffenheit, Aufgeschlossenheit, Vielseitigkeit, Wachheit, Interessenverzweigung, Funktions- 
Schelsky infolge einer Auseinandersetzung mit Leopold Rosenmayr, welcher ihm vorwarf, in der Auseinandersetzung mit der Jugend hauptsächlich das Identitätsbedürfnis seiner eigenen, der „45er-Generation“, gestillt zu haben, die Kerncharakteristika seiner „skeptischen“ Jugend später partiell revidiert hat. ${ }^{1367}$ Das Lob der ihm nachfolgenden Forscher war trotzdem gesichert, hatte er doch „mehr bleibendes als zeitgeschichtlich begrenztes Material“ zusammengetragen, das der weiteren jugendsoziologischen Forschung „unentbehrlich“ geblieben sei. ${ }^{1368}$ Wie auch immer: Spezifischen Aufschluss über die Befindlichkeiten der Studierenden bieten in allen Studien nur kleinere Einzelabschnitte; sämtliche der in diesen materialreichen und erstaunlich lesenswerten Studien herausgearbeiteten Generations-Charakteristika wurden auch für sie als gültig erachtet.

Bald jedoch schenkte man den Studierenden als Sozialgruppe sui generis stärkere wissenschaftliche Aufmerksamkeit. Im Sommersemester 1960 führte das Institut für Demoskopie Allensbach (IfD) im Auftrag des Stifterverbands der deutschen Wissenschaft eine repräsentative Umfrage unter westdeutschen Studierenden durch, der Bericht erschien 1961. In deutlicher Abgrenzung zur Schelsky'schen Skizzierung der Nachkriegsjugend wird hier insistiert: „Der demokratische Staat wird allmählich zu einem positiven Erlebnis. Sein Kern, Wahrung der Freiheit, wird mehr und mehr bejaht und die persönliche Existenz auf die politische bezogen. ${ }^{\text {(1369 }}$ Noch einmal rief daher Berthold Martin die vormärzlich-bildungsbürgerliche Rolle der Akademiker als tugendhafter Elite an, die über ihre Suche nach der Wahrheit die freiheitliche nationale Gesellschaft mitgestalte. ${ }^{1370}$ Tatsächlich sah er keinesfalls mehr eine "skeptische“ akademische Jugend vor sich, sondern eine entschlossene und gesellschaftspolitisch interessierte Studierendenschaft: 69 Prozent der befragten Studierenden lasen demnach regelmäßig Tageszeitungen, ca. 20 Prozent sogar zwei und mehr Zeitungen. 40 Prozent von ihnen studierten überdies regelmäßig den damals als „Publikumszeitschrift“ rubrizierten SPIEGEL. ${ }^{1371} 50$ Prozent von ihnen unterhielten sich nach eigenen Angaben häufig über Politik, 41 Prozent gelegentlich. ${ }^{1372}$ Zwar wollten immerhin noch 60 Prozent „von Weltanschauungen nichts mehr wissen“ und Politik stärker auf das Wohlbefinden der Menschen ausgerichtet sehen, ${ }^{1373}$ allerdings gaben 78 Prozent an, Ideen

fähigkeit und Handlungsbereitschaft der Generation der Unbefangenen lassen hoffen, daß sie dieser Aufgabe gerecht werden können." Ibid., S. 403.

1367 Vgl. Rosenmayr, Leopold: „Skeptische Ceneration“ - oder Skepsis der älteren Ceneration, in: Wort und Wahrheit. Monattschrift für Religion und Kultur, H. 14/1959, S. 388-390 sowie Schelsky, Helmut: Zur Diskussion der Jugendsoziologie. Stellungnahme zu einem Buch und einer Rezension, in: Kölner Zeitschrift für Soziologie und Sozialpsychologie, H. 17/1965, S. 400-406; beide zit. nach Kersting: Helmut Schelskys „Skeptische Generation“, hier S. 487, Fn. 123.

1368 Blücher: Die Generation der Unbefangenen, S. 17.

1369 Stifterverband für die deutsche Wissenschaft: Das geistige Bild der Studenten, S. 8.

1370 „Bekenntnis und aktive Teilnahme an der Konsolidierung Deutschlands sind wesentliche Folge der ethischen Bindung des Akademikers an die Wahrheit, die immer auf Freiheit aus ist: in ihr sind Führung des persönlichen Lebens und Gestaltung der allgemeinen Ordnung untrennbar verbunden.“ Ibid.

1371 Ibid., S. 9.

1372 Vgl. ibid., S. 25.

1373 Ibid. 
$\mathrm{zu}$ folgen, für die das Leben einzusetzen sich lohne - wenngleich nur 6 Prozent damit die existierende bundesrepublikanische Demokratie meinten, während 35 Prozent sich auf „Freiheit, Humanität, Menschenwürde“, 22 Prozent sich auf „Christliche Religion, religiöse Ideale“ bezogen. ${ }^{1374}$ Spezifische Fragen zu demokratischen Einstellungen und demokratischem Aktionspotenzial wurden hier noch nicht gestellt.

Ein Jahr später erschien die bis heute berühmteste Studie zum Thema, Student und Politik von Habermas et al. Kaum eine der später folgenden Monographien verzichtete darauf, diesem Band ihre Reverenz zu erweisen: Als „Klassiker“ und „Standardwerk“1375 wurde sie gelobt, als ebnende, „berühmt gewordene“ und „bahnbrechende Arbeit“"1376, oder auch einfach - weniger glorifizierend, aber doch exponiert im erste Satz eines Vorworts - als inspirierendes, aber aktualisierungsbedürftiges „altes Buch“1377. Ähnlich wie Schelskys Skeptische Generation war diese 1957 durchgeführte ausführliche Befragung von 171 Frankfurter Studierenden ${ }^{1378}$ getragen von der grundlegenden Frage nach den Aussichten einer noch jungen bundesrepublikanischen Demokratie. Im einleitenden Aufsatz der Studie distanzierte man sich allerdings von Fetischisierungen der politischen Beteiligung als „Wert an sich“. ${ }^{1379}$ Stattdessen fragte man nach einem spezifisch studentischen politischen Potenzial, das als emanzipativer Fortschrittsmotor fungieren könnte, d. h. die in der Idee der Demokratie angelegte Tendenz zu einer auch materiell und herrschaftlich „freien Gesellschaft“ $z$ u realisieren vermöge. ${ }^{1380}$ Der nachwachsenden akademischen Elite kommt in diesen an eine Kampfschrift erinnernden Passagen die Rolle eines Schrittmachers historischer Gesellschaftsevolution zu, die die Entscheidung zwischen (drohender) „autoritärer Demokratie“ und (möglicher) „sozialer Demokratie“ im Sinne der gemeinschaftlich fundierten „rationalen Autorität“ der allseitigen Bedürfnisbefriedigung herbeiführen könnte. ${ }^{1381}$ Die tatsächliche Reife des politischen Bewusstseins sei an dieser realen Potenzialität des „entwicklungsgeschichtlichen $\mathrm{Zu}$ sammenhangs" zu prüfen. ${ }^{1382}$

Daher gab man sich nicht zufrieden mit bloßen Zustimmungswerten zu demokratischen Prinzipien; vielmehr arbeitete das Autorenteam mithilfe der Interviews verschiedene Typen des „politischen Habitus“, der „politischen Tendenz“ und der Neigung $\mathrm{zu}$ orientierungsleitenden Gesellschaftsbildern heraus, um das politische Potenzial der Studierenden zu messen und prognostische Antworten auf die Frage zu gewinnen, „in

1374 Ibid., S. 29.

1375 Kiel, Sabine: Studierende und Politik. Eine kritische Analyse zur politischen Sozialisation. Forum Wissenschaft Studien, Bd. 32, Marburg 1996, S. 53.

1376 Krause, Christian/Lehnert, Detlef/Scherer, Klaus-Jürgen: Zwischen Revolution und Resignation. Alternativkultur, politische Grundströmungen und Hochschulaktivitäten in der Studentenschaft. Eine empirische Untersuchung über die politischen Einstellungen von Studenten. Bonn 1980, Buchrücken und S. 1.

1377 Glotz/Malanowski: Student heute, S. 7.

1378 Vgl. Habermas et al.: Student und Politik, S. 9 und 279-313. Die Stichprobe wurde durch 1959 erhobene Vergleichsdaten von weiteren 550 Studierenden ergänzt, vgl. ibid., S. 314-315.

1379 Ibid., S. 13-17.

1380 Ibid., S. $16 f$. und 53-55.

1381 Ibid., S. 34-49, insbesondere S. 35, ferner S. 55.

1382 lbid., S. 55. 
welchem Maß die Demokratie auch und gerade unter veränderten objektiven Verhältnissen, in Krisensituationen, auf die Unterstützung der Studenten rechnen kann“ ${ }^{1383}$ Denn auf der Grundlage der Einteilung des Interviewmaterials in Syndrome politischer Orientierungen (die „politische Tendenz" zerfällt hier in ein „genuin-demokratisches“, ein „formal-demokratisches“, ein „autoritäres“ und ein ,indifferentes“ Syndrom ${ }^{1384}$ ) und in Typen des politischen Verhaltens („unpolitisch“, affektiv bzw. „irrational distanziert“, „rational distanziert“, „naiv und reflektiert“ sowie „politisch engagiert“1385) war zwar das Ergebnis zu gewinnen, dass „die demokratische Ordnung unter den bestehenden Verhältnissen in der Öffentlichkeit auf Unterstützung der Mehrzahl der Befragten rechnen kann“. ${ }^{1386}$ Unklar jedoch blieb, wie robust die gemessenen Überzeugungen im Falle einer Gefährdung der demokratischen Ordnung zu mobilisieren sein würden, insbesondere da nur eine Minderheit der Befragten als potenziell tatkräftige Demokratie-Verteidiger eingeschätzt wurden und eine sehr große Zahl Züge des Mitläufertums (eine labile Sammelgruppe aus „naiven Staatsbürgern“ und „rational Distanzierten“) trug. ${ }^{1387}$ Gewiss ist eine solche Unklarheit, wie auch von den Autoren angemerkt ${ }^{1388}$, kaum auszuräumen, da die in einer empirischen Studie vorgebrachte Frage nach dem politischen Potenzial von Studierenden notgedrungen von jener objektiven politischen Situation, d. h. von Kontextfaktoren, Kräftekonstellation und Gelegenheitsfenstern absehen muss, die für die politische Praxis bisweilen entscheidend ist. Der Versuch jedoch, über das zu erwartende subjektseitige Potenzial im Falle von Krisenzeiten und Umsturzgefahren ob sich allgemeine demokratische Zustimmung und informiert-engagiertes politisches Verhalten im Ernstfall mit tatsächlichem prodemokratischem Verhalten verbinden würden $^{1389}$ - trotzdem annäherungsweise Vermutungen anzustellen, führte die Autoren zu dem instruktiven Gedanken, nach übergreifenden „Gesellschaftsbildern“ zu suchen, $d$. h. nach orientierungsstiftenden ideologischen Leitlinien und „Interpretationsschlüsseln“, in die die politischen Tendenz- und Habitustypen eingebettet seien. ${ }^{1390}$ Sie kartografierten fünf verschiedene Gesellschaftsbilder, die sich untereinander hinsichtlich ihrer Geschlossenheit, ihrer Verteilung über die Studienfächer und ihres Geltungsanspruchs voneinander unterschieden: Das Gesellschaftsbild „Vom absteigenden akademischen Mittelstand“ (ein atavistisch auftretender Bildungshumanismus, der protes-

1383 Ibid., S. 235 .

1384 Ibid., S. 131-144.

1385 lbid., S. 75-123.

1386 Ibid., S. 149.

1387 Vgl. ibid., S. $148 f$.

1388 Vgl. ibid., S. 148.

1389 „Wenn eine Reihe von Gesellschaftsbildern in ihrer Funktion als politische Ideologien nachgewiesen werden könnte, nämlich darin, daß sie das politische Verhalten und Bewußtsein ihrer Träger steuern und stabilisieren, dann, so meinen wir, wären wir berechtigt, den bisherigen Befund über das demokratische Potential der Studenten auf die Zukunft derart zu verlängern, daß er auch für Situationen der Krise Geltung beanspruchen dürfte." Ibid., S. 151. An derselben Stelle wird aber auch hinzugefügt, dass von bündigen und umfassenden politischen Ideologien im Stile des 19. Jahrhunderts nicht mehr ausgegangen werden könne - vielmehr sei gerade die Frage zu stellen, inwieweit „der längst diagnostizierte Zerfall der politischen Ideologien“ unter der studierenden Jugend vorangeschritten ist.

1390 Ibid. 
tantische Innerlichkeit mit Bildungsuniversalität verknüpft und dabei den alten Reflex gegen schnöde Materialität, „Geldadel“ und „Neureiche“ pflegt, vertreten mit 5 Prozent der Befragten), dasjenige „der inneren Werte“ (Gesellschaft als „Sphäre der Entfremdung“, 10 Prozent), „der geistigen Elite“ (Akademiker als führungsbefähigte Leistungselite, 23 Prozent), „der sozialen Gleichheit“ (Gesellschaftliche Herstellung der Gleichheit aller im Sinne „des Menschen“, 15 Prozent), und „des nivellierten Mittelstandes“ (Meritokratischer Leistungsindividualismus, 20 Prozent). ${ }^{1391}$ Ferner verfügte ein knappes Viertel (23 Prozent) der befragten Studierenden demnach über kein identifizierbares bzw. über ein „individuelles Gesellschaftsbild“. ${ }^{1392}$ Interessanterweise erlaubte die Typologisierung der Gesellschaftsbilder auch, historische Dynamiken zu erfassen: So wird beispielsweise ausgeführt, inwiefern das älteste Gesellschaftsbild, das des absteigenden akademischen Mittelstandes, qua inhärenter Tendenzen sowohl den Übergang zum Modell der inneren Werte als auch zum Modell des nivellierten Mittelstandes zulässt, sich sukzessive modifiziert und so potenziell in egalitäre wie auch elitäre Konzepte transformiert. ${ }^{1393}$ Vermöge dieses besonderen interpretativen Vorgehens weist die Studie über die im Forschungsfeld sonst dominierende Einstellungs- und Umfrageforschung hinaus und nähert sich der Frage nach der Transformation tieferliegender ideologischer Formen an.

In einer zusammenführenden Analyse resümierten Habermas et al., dass sowohl die Vertreter elitärer bzw. autoritärer als auch die Proponenten egalitärer Gesellschaftsbilder grundsätzlich handlungsleitende Maximen aus ihren Orientierungen ableiteten, während weder das „realistische“, d. h. materiell und leistungsorientierte Modell noch das der inneren Werte wirksam würden, „vielmehr für das tatsächliche Verhalten tendenziell unverbindlich und folgenlos bleiben.“1394 Verbunden mit den Ausführungen zu politischem Habitus und politischer Tendenz förderten die Autoren ein sichtlich instabiles demokratisches Potenzial der Studierenden zutage: 9 Prozent bewiesen ein „definitiv demokratisches“ Potenzial, 16 Prozent ein "definitiv autoritäres“, 9 Prozent ein „disparates“ (d. h. auf widersprüchlichen Aussagen basierendes, mithin unberechenbares) Potenzial - und eine überwältigende Mehrheit von 66 Prozent mit „unprofiliertem“ Potenzial, darunter 20 Prozent „eher demokratisch“, 26 Prozent „ganz unprofiliert“ und 20 Prozent „eher autoritär“ ${ }^{1395}$ Ein eindeutiger Schluss ist aus diesen Zahlen kaum zu ziehen. Insbesondere, weil weitere Faktoren, etwa die Rekrutierung des größeren demokratischen Potenzials aus niedrigeren Schichten mit geringerem Aufstiegspotenzial, das Urteil komplizieren. ${ }^{1396}$ Insgesamt aber erscheinen die im Krisenfall bereitstehenden prodemokratischen Phalanxen unter den Studierenden der 1950er Jahre eher schwach und bisweilen brüchig - auch und ganz besonders, weil die Überzahl der Unprofilierten zu diesem Zeitpunkt keine haltbare Prognose zuließ.

\footnotetext{
1391 Ibid., S. 165-199 und 201.

1392 Ibid., S. 201.

$1393 \mathrm{Vgl}$. die versprengten Anmerkungen auf den zitierten Seiten, aber auch die veranschaulichende Grafik ibid., S. 200.

1394 Ibid., S. 228.

1395 Ibid., S. 232.

1396 Vgl. ibid., S. 234.
} 
Eine weitere Stärke dieser vielgelobten (aber methodisch kaum als verbindlich erachteten) Studie liegt in dem Nachweis der strukturbildenden Funktion des Gegensatzes von bildungshumanistischer und meritokratischer Tradition für die in den Interviews vorgetragenen Wahrnehmungs- und Ordnungsschablonen gesellschaftlicher Prozesse. Am Beispiel des Gesellschaftsbildes vom nivellierten Mittelstand wird elaboriert:

„[...] mit der Innerlichkeit selber verschwindet eine ganze Sprachschicht, die Rede vom ,Gebildeten, vom Echten und Eigentlichen, von der Auszeichnung des Ceistes per se. Statt dessen [sic] tritt jenes zweite Motiv ganz in den Vordergrund: der Nivellierungsprozeß, dem die Konturen der Standes-, aber auch der Klassengesellschaft zum Opfer fallen. Die Individuen scheinen die Hüllen ihrer gesellschaftlichen Herkunft zu sprengen. Ganz auf ihre Leistung gestellt, verdanken sie den Kurswert, den die Cesellschaft ihnen verleiht, angeblich sich selbst." ${ }^{\text {"1397 }}$

Der Hinweis, dass es sich bei diesem innerakademischen Antagonismus zu großen Teilen um einen historischen Ablösungs- und Übergangsprozess handelt, ist bereits zitiert worden. Allerdings: Weder hat in den 1960er Jahren und danach jemand ein völliges Verschwinden bildungshumanistischer Denktraditionen konstatiert, auch verweist die von Habermas et al. skizzierte Adaptionsfähigkeit der Gesellschaftsbilder auf die Möglichkeit der Um- und Neubildung orientierungsstiftender Deutungsmuster unter jungen Akademikerinnen und Akademikern hin - etwa die Hälfte der Befragten griff auf Modelle zurück, „die bildungshumanistische Motive [...] verarbeiten ${ }^{\text {“1398 }}$, und auch das Gesellschaftsbild der sozialen Gleichheit nährte sich „weitgehend aus dem Kultus der Innerlichkeit. ${ }^{\text {“1399 }}$ Vor diesem Hintergrund muss erstaunen, dass ausgerechnet dieser für politische Orientierungen und politisches Potenzial von Studierenden offenbar konstitutive Zusammenhang von nachfolgenden Studien - bis heute! - nie wieder aufgegriffen worden ist. ${ }^{1400}$

Fortan dominierte die tagespolitische Aktualität das Forschungsinteresse. Unter dem Eindruck der deutschen Studentenproteste von 1967 ff. und der internationalen Studentenbewegung der späten 1960er Jahre gerieten das politische Potenzial der deutschen Studierenden und vor allem die Frage nach politischer Radikalität bzw. politischem Radikalismus in den Fokus sozialwissenschaftlicher Aufmerksamkeit. Insbesondere die durch die Proteste evozierten Bilder einer „Austragung sozialer oder politischer Konflikte unter Anwendung physischer Gewalt “1401 sorgten noch bis in die frühen 1970er Jahre für politikwissenschaftlichen und soziologischen Diskussionsstoff. Die

\footnotetext{
1397 Ibid., S. 193.

1398 Ibid., S. 216.

1399 Ibid., S. 223.

1400 Ein Grund liegt sicher darin, dass die von Habermas et al. ausgemachten Gesellschaftsbilder, die ja in gewissem Sinne subjektive Gesellschaftstheorien sind, sich nicht im quantitativ-empirischen Sinne „messen“ lassen wie die Zustimmungswerte von Surveys.

1401 Kaase, Max: Demokratische Einstellungen in der Bundesrepublik Deutschland, in: Wildenmann, Rudolf (Hg.): Sozialwissenschaftliches Jahrbuch für Politik, München/Wien 1971, S. 119-326, hier S. 119. Vgl. ähnlich auch Kaase: Die politische Mobilisierung von Studenten.
} 
selbstbewusst auftretende „Neue Linke“ rief mit ihren Forderungen nach der sozialistischen Revolution, der Einrichtung von Räten, der Durchsetzung von direkten Mandaten bzw. allgemein nach einer fundamentalen Demokratisierung der Bundesrepublik nicht nur wiederholt intellektuelle Kommentatoren von links und rechts auf den Plan, sondern aktualisierte auch das Interesse an den politischen Orientierungen der Bevölkerung, insbesondere der Jugend. Angesichts von öffentlichen Rezeptionsweisen, die zwischen Alarmismus und Staunen oszillierten, wuchs der Wunsch nach differenzierten Analysen. Vielen Jugendsoziologen erschienen die Ereignisse als historisches Novum, hatte diese Form von postadoleszentem Protest mit politisch-kultureller Breitenwirkung doch wenig gemein mit früheren Jugendaufständen und „Generationskonflikten“. ${ }^{1402}$ Man rang um theoretische Modelle, die das Auftreten der "Studentenunruhen" in „entwickelten“ bzw. „fortgeschrittenen Industriegesellschaften“ - in Anlehnung an die Bemühungen Erwin K. Scheuchs und Hans-Dieter Klingemanns um eine international vergleichende Theorie des industriegesellschaftlichen Rechtsradikalismus, die sie zur Feststellung eines ubiquitären Potenzials, einer „normalen Pathologie“ mobilisierbarer Orientierungen führte ${ }^{1403}$ - ursächlich erklären sollten; man ergründete die Ursachen für den oft als seit Kriegsende präzedenzlos beschriebenen linken Radikalismus. ${ }^{1404}$ Viele populäre Erklärungsmuster, darunter schlechte Studienbedingungen, Wohlstandschauvinismus, übermäßig autoritäre Erziehungspraxis bzw. das Ausbrechen eines „Generationskonfliktes“ wurden hier von Allerbeck in Zweifel gezogen: Tatsächlich herrsche breiter politischer Konsens zwischen Studierenden und ihren Eltern; viele Aktivisten stammten gerade aus „politisch liberalen und linken Elternhäusern“. ${ }^{1405}$ Entscheidend für die Partizipation am studentischen Protest sei nicht der rebellierende Impuls, sondern nachgerade der Rückhalt der eigenen Bezugsgruppen:

„Es sind durchweg diejenigen Studenten am häufigsten Anhänger der Studentenbewegung, die in ihrer Umwelt (sei es Elternhaus, Studienfach, antizipierte Berufskollegen) hierfür am meisten Zustimmung bzw. am wenigsten Ablehnung finden. Für die Muster der empirischen Ergebnisse ist charakteristisch nicht eine Maximierung, sondern eine Minimierung von Konflikten für Individuen.."1406

1402 „Wir haben es mit strukturell neuen und historisch erstmaligen Phänomenen zu tun, welche auf die neuen Entwicklungen der Bildungsgesellschaft, der verwalteten Welt, der internationalen Machtkonstellationen und auf die ihren Aufgaben nicht mehr gewachsenen gesellschaftlichen Institutionen antworten bzw. diese herausfordern." Rosenmayr, Leopold: Vorbemerkung, in: Allerbeck, Klaus R./Ders.: Aufstand der Jugend? Neue Aspekte der Jugendsoziologie, München 1971, S. 7-10, hier S. 7.

1403 Scheuch, Erwin K./Klingemann, Hans-Dieter: Theorie des Rechtsradikalismus in westlichen Industriegesellschaften, in: Hamburger Jahrbuch für Wirtschafts- und Sozialpolitik, H. 12/1967, S. 11-19, insbesondere S. 12.

1404 Vgl. Beck, Ulrich/Gernsheim, Elisabeth: Zu einer Theorie der Studentenunruhen in fortgeschrittenen Industriegesellschaften, in: Kölner Zeitschrift für Soziologie und Sozialpsychologie, H. 23/1971, S. 439-477 bzw. in derselben Ausgabe Allerbeck, Klaus R.: Eine strukturelle Erklärung von Studentenbewegungen in entwickelten Industriegesellschaften. Kölner Zeitschrift für Soziologie und Sozialpsychologie, H. 23/1971, S. 478-493.

1405 Allerbeck: Eine strukturelle Erklärung, S. 479.

1406 Ibid., S. 481. Hierin liegt sicher auch die Berechtigung von formalistischen Erklärungsmodellen, welche - wie Beck und Cernsheim - „kognitive Dissonanzen“ zwischen industriegesellschaftlich- 
Allerdings wirke, neben Großereignissen und Veränderungen des politischen Systems, auch die gesellschaftliche „Rollenerwartung von politischer Teilnahme und Nonkonformismus" als verstärkender Faktor gerade in der formativen Phase von Studentenbewegungen. ${ }^{1407}$

Eine der offensichtlich drängendsten Fragen der späten 1960er und frühen 1970er Jahre speziell in der Bundesrepublik und im Zeitraum zwischen 1967 und 1969 aber war, ob sich die Studierenden von den demokratischen Institutionen distanzierten, als Nachwuchs künftiger Funktionseliten - insofern eine potenzielle elite population im Gegensatz zur mass population ${ }^{1408}$ - gar antidemokratisch agitieren könnten. Hieraus entwickelte sich ein überaus reges Interesse an den Spezifika studentischer Einstellungsmuster; auch konzeptuelle Innovationen wurden durch diese Forschungsbewegung angestoßen. An der Gegenüberstellung demokratischer Einstellungen von Studierenden und Jugendlichen im Vergleich mit der Gesamtbevölkerung erarbeitete etwa Max Kaase 1968 und 1971 seine „Demokratieskala“, ${ }^{1409}$ die das Kunststück vollbringen wollte, einen anspruchsvollen Demokratiebegriff unter Einbezug von Schriften Dahrendorfs und Lipsets, aber auch des Vorworts von Habermas et al. aus Student und Politik zu entwickeln, der sich im Sinne empirischer Forschung „operationalisieren“ bzw. „operational definieren“ lasse. ${ }^{1410}$ Das Ziel war, zum Zwecke der Einstellungsmessung Frage-Items zu gewinnen, die die Messung demokratischer Einstellungen unterschiedlicher Bevölkerungsgruppen zuließen. Neben den elementaren Komponenten der friedlichen Konfliktaustragung und der wechselseitigen Anerkennung politischer Ziele zählen hierzu der Schutz von Partizipations- und Minderheitsrechten, die Kontrolle politischer Institutionen durch regelmäßige Wahlen und ein demokratischer Wertekonsens. ${ }^{1411} \mathrm{Be}-$ zeichnenderweise reduziert der von seinem Konzept sichtlich überzeugte Kaase allerdings die Frage nach dem demokratischen Potenzial auf die zivile Gesinnungstreue zum demokratischen Verfassungsstaat; das von Habermas et al. emphatisch fixierte Inter-

„struktur-anomisch" bedingtem sozialem Konfliktpotenzial, sozialisatorisch bedingten Werthaltungen und subjektiven Idealvorstellungen von Studierenden als Geflecht von Kausalursachen ansehen, vgl. Beck/Cernsheim: Theorie der Studentenunruhen, S. 463-474.

1407 Allerbeck: Eine strukturelle Erklärung, S. 490.

$1408 \mathrm{Vgl}$. zu den damals untersuchten weltanschaulichen Differenzen - den variierenden beliefsystems - zwischen Elitenzugehörigen und Massenvertretern die Studie Converse, Philip E.: The nature of belief systems in mass publics (1964), in: Critical Review, H. 18/2006, S. 1-74, insbesondere S. 30-32. 1409 Vgl. zum Hergang auch 13. Studierendensurvey 2015/16, S. 89.

1410 Kaase: Demokratische Einstellungen S. 125-138 zur zeitgenössischen Demokratiediskussion und S. 138-166 zum Transfer auf die empirische Arbeit.

1411 Kaase benennt als Grundbedingungen demokratischer politischer Systeme „a) die Garantie individueller Partizipationsrechte einschließlich des Schutzes von Minderheitsrechten; b) die Organisation politischer Herrschaftsinstitutionen nach dem Prinzip der Kontrolle dieser Institutionen durch regelmäßige Wahlen mit der Chance des Auswechselns von Führungspersonal; c) die grundsätzliche Anerkennung der Legitimität von Mittel- und Zielkonflikten; d) die Ablehnung von Cewalt als Mittel der politischen Auseinandersetzung; e) ein[en] Konsens über die fundamentalen demokratischen Wertsetzungen, der überhaupt erst die Voraussetzungen für die regelrechte Austragung der Konflikte schafft." Ibid., S. 142. Vgl. zu einer früheren Form seines Konzepts Wildenmann, Rudolf/Kaase, Max: „Die unruhige Ceneration“. Eine Untersuchung zu Politik und Demokratie in der Bundesrepublik, Mannheim 1968, S. 6. 
esse an politischen Verhaltenstendenzen der Studierenden in Krisensituationen lässt er fallen.

Tatsächlich lassen sich die empirischen Ergebnisse nicht anders denn als Entwarnung in mehreren Akten beschreiben. In sämtlichen wichtigen Studien fällt sofort das Bild einer prodemokratischen, engagierten und verantwortungsbewussten Studierendenschaft auf - sowohl in Kaases Studien als auch bei anderen. Schon Ludwig von Friedeburg stellte in seiner umfangreichen Monografie zur Entstehung der Studentenbewegung von „1968“ an der Freien Universität (FU) Berlin, rückblickend von 1968 auf eine repräsentative Umfrage von $1963 / 64^{1412}$ und unter Vergleich mit anderen Befragungen (darunter die bereits zitierten), fest, dass die Studierenden ein starkes politisches Verantwortungsbewusstsein aus ihrem im Vergleich mit anderen jungen Erwachsenen hohen politischen Informationsniveau ableiteten; ein über eine „nicht unbeträchtliche aktive Minderheit" hinausweisendes Drittel von ihnen erwog die Mitarbeit in politischen Parteien und Organisationen. ${ }^{1413}$ Ferner konnte dieses rege politische Potenzial hinsichtlich der „politische[n] Tendenz ${ }^{\text {“1414 }}$ ausdrücklich auch als ein demokratisches Potenzial erwiesen werden: Sympathien für autoritäre Gesellschaftsmodelle fanden sich kaum, die übergroße Mehrheit befürwortete die parlamentarische Demokratie. Insgesamt 95 Prozent von ihnen sprachen eine klare Wahlentscheidung für die drei damals größten Parteien aus: Jeweils 39 Prozent für SPD und CDU, 17 Prozent für die FDP. ${ }^{1415}$ Ein knappes Drittel bestand demnach aus „engagierte[n] oder doch interessierte[n] Demokraten“, der größte Teil aus potenziell demokratiestützenden „Mitläufern oder politisch Indifferenten“, also in Anlehnung an Habermas et al. durchaus als im Krisenfall abrufbares demokratisches Kräftepotenzial. Nur ein ungefähres Zehntel „undemokratisch gesonnener" Studierender sei aufzufinden, dieses dazu ohne signifikante politische Kräftereservoirs. ${ }^{1416}$

Auch eine Umfrage des Instituts für Demoskopie Allensbach (IfD) kam $1967 \mathrm{zu}$ dem Ergebnis, dass Studierende nicht weniger denn als „sattelfeste Demokraten ${ }^{\text {“1417 }} \mathrm{zu}$ bezeichnen seien - mit beachtlichem Kenntnisstand, überdurchschnittlicher Meinungsstärke und hohem politischem Mobilisierungspotenzial ausgestattet, obendrein „mehr als andere Bürger um politische Orientierung bemüht. ${ }^{\text {(1418 }} 90$ Prozent der Studierenden konnten sich „keine bessere Staatsform für Deutschland als die Demokratie vorstellen“ und wussten dabei durchaus um die Notwendigkeit von Wahlen, Interessenverbänden, etc. ${ }^{1419}$ Nur ein Viertel hielt sich für die „Elite der Nation“, drei Viertel zeigten „kein akademisches Standesbewußtsein“. ${ }^{1420}$

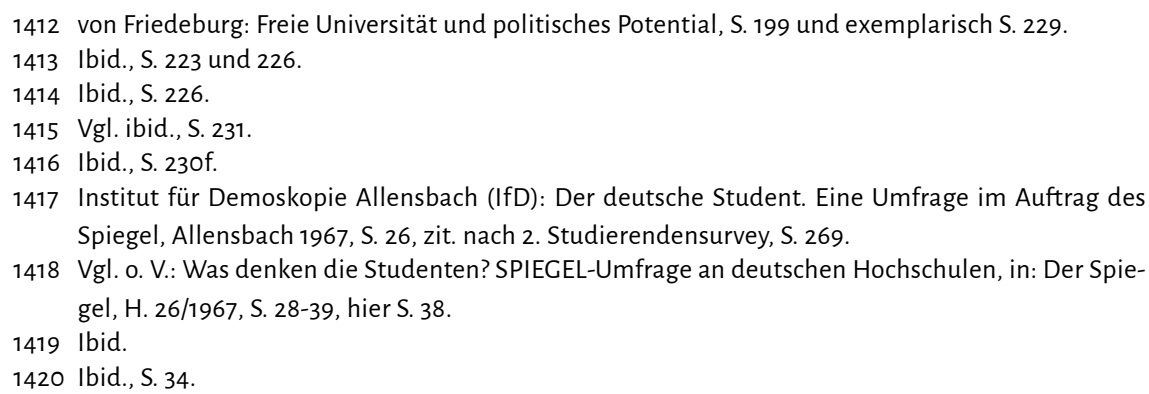


Rudolf Wildenmann und Max Kaase legten 1968 mit „Die unruhige Generation“ nach: Die Studierenden dieses Jahres seien "autoritären Ideen und dem Nationalsozialismus“ deutlich stärker abgeneigt als andere Jugendliche oder die Gesamtbevölkerung; sie bekräftigten die Notwendigkeit starker demokratischer Institutionen, griffen deutlich seltener auf Vorurteile zurück als ihre nicht-akademischen Altersgenossen, interessierten sich weit häufiger für Politik und beurteilten ihre eigenen Partizipationsmöglichkeiten optimistischer. ${ }^{1421}$ Auch die Wahrnehmung sozialer Ungleichheiten, abgefragt über Gesellschaftsbilder, spiele eine zentrale Rolle: Starke demokratische Einstellungen ließen an Chancengleichheit im Beruf und in Bezug auf soziale Aufstiegschancen zweifeln. ${ }^{1422}$ Unter Rekurs auf Habermas et al. wird, bezugnehmend auf die Frage nach der Notwendigkeit einer Führungselite in der Demokratie, beobachtet, dass „die Studenten [...] weniger elitär und erheblich mehr egalitär“, ja geradezu schlechthin antiautoritär gestimmt seien. ${ }^{1423}$ Zwar vermochte man die Frage, wieso es ausgerechnet der SDS zu seiner explosiven Mobilisierungsfähigkeit brachte und wie Situationsgewalt auf studentischen Demonstrationen zu erklären sei, nicht letztgültig zu beantworten - wurde doch die „Kritik an den Hochschulverhältnissen“ als „auslösendes Moment für die studentischen Aktionen“ und als entscheidendes Movens der umfassenderen „Kritik an den bestehenden gesellschaftlichen Verhältnissen“ erwiesen ${ }^{1424}$-; wohl aber erschien den Verfassern augenfällig, dass sich nach den Osterunruhen ein großer Teil der Studierenden vom SDS abwenden würde. ${ }^{1425}$ Überhaupt liegt hierin wohl ein so entscheidendes wie überraschendes Doppelergebnis dieser Studie: Zwar falle die Unterstützung der Studierendenproteste enorm breit aus, aber sie sei nicht - wie vermutet - eine Angelegenheit kleiner Aktivistenzirkel. ${ }^{1426}$ Zugleich aber ziele das linksradikale Vokabular nur für eine kleine Minderheit auf den tatsächlichen revolutionären Umsturz respektive auf eine fundamentale Ablehnung von Parteiensystem und Verfassungsstaat; für die meisten lieferte es die dringend benötigten Chiffren der allgemeinen Absicht einer praktischen Verbesserung der Gesellschaft. ${ }^{1427}$ Die überwiegende Mehrheit wünsche sich vielmehr Reformen - „mehr Engagement, gelebte Demokratie, Ehrlichkeit und Streben nach sozialer Gerechtigkeit“. ${ }^{1428}$ Beeindruckend liest sich daher das Zeugnis, das Wildenmann und Kaase dem erheblichen politischen Potenzial der Studierenden ausstellen: „Die von der Studentenschaft vorliegenden Einstellungen lassen jedenfalls ein demokratisches Potential erkennen, wie es - auf andere Weise - vielleicht nur von den Studenten vor 1848 entwickelt worden ist." Obwohl das Misstrauen der Studierenden gegenüber den politischen Institutionen und Eliten außerordentlich hoch ausfiel, handle es sich hier „um eine Reformbewegung, die es mit der Verfassung der Bundesrepublik ernst meint.“1429

1421 Wildenmann/Kaase: „Die unruhige Generation“, S. 68f. und S. 34-42.

1422 Vgl. ibid., S. 43.

1423 Ibid., S. 47.

1424 Ibid., S. 78.

1425 Vgl. ibid., S. 84.

1426 Vgl. ibid., S. 84.

1427 Vgl. ibid., S. 85.

1428 Ibid., S. 56.

1429 Ibid., S. 85. Siehe auch Kaase: Die politische Mobilisierung von Studenten, S. 158: „-Studenten sind eher tolerant, progressiv, hoch informiert und haben eine hohe Partizipationsneigung; - nicht- 
Interessanterweise ging dieses breite Potenzial von hochschulpolitischem Aktivismus aus, ${ }^{1430}$ während noch in den frühen 1960er Jahren „Informationsmangel und Gleichgültigkeit" die Sichtweise der Studierenden auf ihre Vertretung in den Gremien der studentischen Selbstverwaltung bestimmt hatten. ${ }^{1431}$ An der FU Berlin wusste zu diesem Zeitpunkt gerade einmal die Hälfte der Immatrikulierten um die Existenz ihres AStA und des von 1949 bis 1969 bestehenden Studierendenkonvents. ${ }^{1432}$ Im Sommersemester 1967 schließlich, so Friedeburg, schlug der Funke des seit 1965 schwelenden Konflikts der FU Berlin um die Reform der Hochschule auf die gesamte Republik über, gelang der Transfer der hochschulpolitischen in allgemeinpolitische Opposition. ${ }^{1433}$ Die enge Verbindung beider Sphären blieb bis in die 1970er Jahre erhalten. Insofern ist das starke Bewusstsein von bzw. das damit einhergehende Partizipationsbedürfnis in den Strukturen der studentischen Selbstverwaltung als eine der entscheidenden Besonderheiten jener studentischen Politisierungsphase in den späten 1960er Jahren anzusehen. Und das durchaus im Sinne der Förderung gesellschaftspolitischer Integration: Durchweg, das belegen alle der hier zitierten Studien, waren die demokratischen Überzeugungen bei denjenigen am gefestigtsten, die sich in Hochschulgruppen engagierten. ${ }^{1434}$

In den 1970er Jahren blieb die Auseinandersetzung zwischen „linken“ und „rechten" Studierenden noch einige Jahre prägend, entfernte sich aber, sicher auch bedingt durch die 1969 einsetzende sozialliberale Ära, nach und nach von der originären außerparlamentarischen Stoßrichtung und bewegte sich in Richtung einer stärker parteigebundenen politischen Polarisierung. Aus welchen Motiven sich die studentische linksradikale Gesellschaftskritik nähre, blieb dabei eine der leitenden Fragen der einschlägigen Forschung. Vor dem Hintergrund der nunmehr durchgeführten, von Studierendenseite vielfach negativ beurteilten Hochschulreformen und der damit verbundenen Studienverhältnisse - gemeint sind insbesondere die als „einschneidend“ bezeichneten Zugangsbeschränkungen, etwa in Gestalt eines Numerus clausus ${ }^{1435}$ - führte das Sozialwissenschaftliche Forschungsinstitut der Konrad-Adenauer-Stiftung gemeinsam mit dem damaligen Zentrum für Umfragen, Methoden und Analysen (ZUMA) Mannheim

akademische Jugendliche sind eher intolerant, konservativ und zeigen nur eine geringe Partizipationsneigung; - die Gesamtbevölkerung ist in allen Gruppierungen am wenigsten tolerant und informiert. Sie ist konservativ und ist nicht zur Partizipation bereit." Vgl. ferner die ähnliche Kurzzusammenfassung in Kaase, Max: Politisches Verhalten von Studenten im Vergleich mit anderen Gruppen, in: Albrecht, Günter/Daheim, Hansjürgen/Sack, Fritz (Hg.): Soziologie. Sprache, Bezug zur Praxis, Verhältnis zu anderen Wissenschaften. René König zum 65. Geburtstag, Opladen 1973,

S. 560-572, insbesondere S. $569 f$.

1430 „Studentische Kritik ist in erheblichem Maße Cesellschaftskritik. Und auch die Frage nach der Reform der Hochschule wird stark auf die Demokratisierung dieser Institution bezogen." Ibid., S. 82 .

1431 Friedeburg: Freie Universität und politisches Potential, S. 199.

1432 Vgl. ibid., S. 202.

1433 Vgl. ibid., S. 402.

1434 Vgl. exemplarisch ibid., S. 233 f.

1435 Does, Karl-Josef: Studenten 1975-Ergebnisse einer Befragung unter Studenten zu Studium, Beruf, Politik und Hochschule, St. Augustin 1976, S. 1 und 4-11. 
und dem Lehrstuhl für Politik der Universität Kiel im Spätsommer 1975 eine weitere repräsentative Umfrage unter westdeutschen Studierenden durch und verglich die Zahlen dabei zum Teil mit jenen von Kaase aus dem Erhebungsjahr $1968 .{ }^{1436}$ Unverkennbar sind die Nachwirkungen der Politisierung von „1968“: Die Studierenden äußerten reges Interesse an der Hochschulpolitik; 81 Prozent votierten für die Ausweitung der studentischen Mitbestimmung. ${ }^{1437}$ Allerdings ist hier die Dringlichkeit allgemeinpolitischer Fragen gegenüber 1968 wieder deutlich verblasst; den Studierenden war - wie 1965 vorrangig an der Verbesserung ihrer Studienbedingungen gelegen. ${ }^{1438}$ Eine überwältigende Mehrheit von drei Vierteln der Studierendenschaft verortete sich politisch links; wer sich links verortete, interessierte sich in besonderem Maße für politische Themen und war eher $\mathrm{zu}$ „unkonventionellen“ Protestformen wie Boykotten, Besetzungen und Beschädigungen bereit; insgesamt war das politische Interesse unverändert hoch. ${ }^{1439}$ Die Zustimmung zu demokratischen Grundprinzipien erwies sich weiterhin als omnipräsent, zugleich kritisierte aber ein beträchtlicher Teil der Studierenden - eher die politisch Interessierten - die demokratische Wirklichkeit der Bundesrepublik. ${ }^{1440} \mathrm{Ne}$ ben dem seit 1968 deutlich gestiegenen demokratischen „Problembewußtsein“ und dem differenzierten Antwortverhalten (höhere Unterstützung des politischen Systems und stärkere Konzentration der Kritik auf Detailaspekte) ${ }^{1441}$ fiel insbesondere das außerordentliche politische Aktivitätspotenzial der Studierenden auf: 32 Prozent befürworteten wilde Streiks, etwa ein Viertel erklärte sich zur Teilnahme bereit; ein weiteres Viertel befürwortete die „Besetzung von Fabriken, Ämtern oder Behörden“, 39 Prozent waren von der Wirksamkeit solcher Protestformen überzeugt. ${ }^{1442}$ Die im Vergleich zu 1968 deutlich stärkere Parteibindung ${ }^{1443}$ der Studierenden wird in den folgenden Zahlen deutlich: Knapp 39 Prozent entschieden sich, mit der berühmten Sonntagsfrage konfrontiert, ihre Zweitstimme der SPD zu geben, gute 21 Prozent für die CDU, 18 Prozent für die FDP - eine stabile sozialliberale Mehrheit von zusammen 57 Prozent. Sowohl die DKP-Wähler (3,8 Prozent) als auch die Nichtwähler (2,5 Prozent) waren weit abgeschlagen; allerdings verweigerten ca. 18 Prozent hier die Angabe ihrer Wahlpräferenz. ${ }^{144}$ Die Perzeption der "gegnerischen“ Parteien trug Züge eines starken Lagerdenkens; Wechselwählerinnen und Wechselwähler waren die Studierenden der 1970er Jahre also nicht. ${ }^{1445}$ Dass mit der Verhärtung der Fronten zwischen „Links“ und „Rechts“ infolge von „1968“ eine gewisse identitätspolitische Bekenntnisverpflichtung - mit starkem moralischem Hochmut insbesondere der linken Seite - politisch etabliert worden sein könnte, ${ }^{1446}$ erscheint zumindest für den studierenden Teil der Gesellschaft plausibel.

\author{
1436 Vgl. ibid., S. 4. \\ 1437 Vgl. ibid., S. $47 f$. \\ 1438 Vgl. ibid., S. 48. \\ 1439 Vgl. ibid., S. 1, 18 und $19 f$. \\ 1440 Vgl. ibid., S. $4 f$. \\ 1441 Ibid., S. 2 und 28. \\ 1442 Ibid., S. $22 f$. \\ 1443 Vgl. ibid., S. 2 und 45. \\ 1444 Vgl. ibid., S. 38. \\ 1445 Vgl. ibid., S. 43. \\ 1446 „Die Achtundsechziger waren links, ihre Gegner rechts, daran gab es keine Zweifel. Während die- \\ ser alte politische Gegensatz früher weitgehend milieugebunden war, über soziale Herkunft zu
}


Die von der Konrad-Adenauer-Stiftung beauftragte Studie von 1975 entdeckte überdies einen engen Zusammenhang von linken politischen Überzeugungen und verhaltener bis schlechter Beurteilung der individuellen Berufschancen; das Vertrauen in die Abhängigkeit des beruflichen Erfolges von der eigenen Leistungsbereitschaft hingegen verfing besonders unter jenen Studierenden, die sich eher politisch rechts einstuften. ${ }^{1447}$ Does fühlte sich gar zu einer linearen Skalierung dieser Korrelation ermutigt und erblickte darin signifikantes soziales Konfliktpotenzial:

„Je schlechter die perzipierte berufliche Perspektive, desto extremer ist die Linksorientierung. [...] Dies ist politisch umso bedeutsamer, als extrem linke Positionen mit vergleichsweise sehr hohem politischen [sic] Interesse verbunden sind, und es zu erwarten wäre, daß spätere sozioökonomische Probleme unmittelbar politisch artikuliert werden. Zur Artikulation dieser Probleme würde einer neuen Protestgeneration im Cegensatz zur früheren ein breites Spektrum von Erfahrungen mit unkonventionellen politischen Partizipationsformen zur Verfügung stehen. ${ }^{\text {“1448 }}$

Man muss das tendenziöse Vokabular nicht goutieren, um in diesem Ergebnis das grundsätzliche Potenzial einer weiteren, lautstark und energisch auftretenden Welle studentischen Protests zu erkennen - auch wenn einige Studierende an der hochschulpolitischen Problemlösungskompetenz linker Hochschulgruppen zu zweifeln begannen und den konservativen RCDS stärker als fähige, da „ideologiefreie“ alternative Interessenvertretung wahrzunehmen begannen. ${ }^{1449}$ Insbesondere der konkrete Bezug der studentischen Kritik auf bildungs- und sozialpolitische Fragen - sie habe sich nicht auf „prinzipielle Dinge“ gerichtet ${ }^{1450}$ - verleiht diesem Potenzial Gewicht. Die Studierenden der 1970er Jahre bewiesen eine „breite und mobilisierbare Basis zur Artikulation von Bedürfnissen und zur Durchsetzung von studentischen Interessen. ${ }^{\text {“1451 }}$ Daher kann es kaum überraschen, dass die Frage nach studentischem Unmut und linksradikaler Gesellschaftskritik noch bis in die frühen 1980er Jahre hinein virulent blieb.

Allerdings gilt es zu berücksichtigen, dass diese Kerndekade der politischen Polarisierung immer auch ein rechtes „Gegenlager“ implizierte: Nicht nur fand man in diesen Jahren starke linke Gruppen vor, sondern eben auch einen robusten Sockel konventioneller und ordnungspolitischer Orientierungen von ca. 40 bis 50 Prozent der Studierenden; dieser wurde im Laufe der 1970er Jahre - parallel zum Zerfasern der linken in alternative Orientierungen und schließlich in die vielfach konstatierte Entpolitisierung - sukzessive abgetragen und sollte bis Ende der 1980er Jahre auf ein Potenzial von etwa einem Viertel der Studierenden absinken. ${ }^{1452}$ Da Genese und Reproduktion der

entschuldigen, löste er sich nun von der Klassenlage und wurde frei für den reinen Bekenntnisakt, der dadurch moralisch aufladbar war. Wer rechts ist, obgleich es inm nicht in die Wiege gelegt wurde, den kann man dafür verantwortlich machen!" Albrecht, Clemens: Umziehende Cötter. 1968 und die Transformation des revolutionären Enthusiasmus, in: Merkur. Gegründet 1947 als Deutsche Zeitschrift für Europäisches Denken, 72. Jg., H. 832/2018, S. 65-70, hier S. $66 f$.

1447 Vgl. Does: Studenten 1975, S. 1, 17 und 20.

1448 Ibid., S. 20.

1449 Vgl. ibid., S. 64.

1450 Ibid., S. 33.

1451 Ibid., S. $2 f$.

1452 Vgl. Studierendensurvey 1980er, S. 227. 
politischen Polarisierung auf der Agitation und Pflege durch engagierte Trägergruppen beruhten, somit das kollektive Selbstverständnis wesentlich aus der Konfrontation mit dem jeweiligen politischen Gegenüber hervorging, sind Züge eines Lagerkonflikts unverkennbar - freilich in primär kulturellen Arenen, mithin ohne tatsächliche soziale Antagonismen oder Milieuzusammenhänge abzubilden. ${ }^{1453}$ Dennoch: Dieser Hinweis tut der Exzeptionalität der 1970er Jahre mit ihrer „eindeutig nach links“ tendierenden „ideologische[n] Ausrichtung der Studenten“1454 keinen Abbruch. Bedenkt man, dass dieser Zeitraum zugleich „das entscheidende Jahrzehnt der Bildungsexpansion in der Bundesrepublik, die zuvor und danach langsamer verlief“, gewesen ist, ${ }^{1455}$ lässt sich die politische Polarisierung als weltanschaulich ausgetragene Auseinandersetzung in den Reihen einer akademischen Jugend auffassen, die sich zunehmend aus Bildungsaufsteigern zusammensetzte.

Mit der Anwendung der Demokratie-Skala unter Studierenden ${ }^{1456}$ hatte Max Kaase sich schon 1968 unterschwellig als neuer Klassiker der Erforschung von Studierenden und Politik in Stellung gebracht - zu Ungunsten des seit wenige Jahre zuvor vorgelegten, analytisch überlegeneren, aber weniger formalistisch fungiblen Konzepts von Habermas et al. Kaases Fragebatterien bildeten fortan das Standard-Instrumentarium vieler Studien, insbesondere des in den frühen 1980er Jahren initiierten Studierendensurveys.

\section{II.3.2 Abklingen der Polarisierung nach der "Friedensgeneration“ und Entpolitisierung: die 1980er Jahre}

Letztmalig systematisch untersucht wurde die bald „alte“ politische Polarisierung zwischen linken und rechten Studierenden mit dem Infratest-Bericht Politischer Protest in der Bundesrepublik 1980, der das Protest- und Radikalismuspotenzial verschiedener Gruppen der deutschen Bevölkerung vergleichend untersuchte und ein starkes linkes Protestpotenzial - insgesamt 30 Prozent der Studierenden - feststellte, das sich von einem bevölkerungsweiten Gesamtpotenzial von 4,4 Prozent markant absetzte. ${ }^{1457} \mathrm{Zu}$ gleich fiel die verstärkende Rolle eines zu Hochzeiten der „68er“-Studentenrevolte politisch sozialisierten Lehrpersonals auf, insbesondere aber auch die größere Virulenz dieses linken Potenzials unter Studierenden und Lehrenden der sozial- und geisteswissenschaftlichen Studienfächer. ${ }^{1458}$ Als wesentliche Determinante linken politischen Protests machte man dabei „relative Deprivation“ aus, d. h. die „Enttäuschung des Anspruchs- und Erwartungsniveaus" an die eigene Lebenssituation. ${ }^{1459}$ Unzufriedenheit mit der eigenen wirtschaftlichen Situation oder mit der Studiensituation, aber

1453 Vgl. Rohe: Wahlen und Wählertraditionen, S. 21.

1454 Schildt, Axel: Die Sozialgeschichte der Bundesrepublik Deutschland bis 1989/90. Enzyklopädie deutscher Geschichte, Bd. 80, München 2007, S. 42.

1455 Vgl. ibid.

1456 Vgl. Kaase: Demokratische Einstellungen, S. 142 und 166-220.

1457 Vgl. Infratest Wirtschaftsforschung $\mathrm{GmbH}$ : Politischer Protest, S. 54 sowie die Einleitung dieser Studie.

1458 Vgl. ibid., S. 55.

1459 Ibid., S. 61. 
insbesondere der pessimistische Blick auf die persönlichen Berufsperspektiven wurden hier als starke Einflüsse des linken Protestpotenzials der Studierenden identifiziert. Die Rolle dieses Zusammenhangs wurde dadurch verstärkt, dass linksstudentische berufliche Erwartungen nicht nur (aber auch) finanzielle Hoffnungen beinhalten, sondern auch den Anspruch auf arbeitspraktische Freiheiten und ideelle Erwartungen wie freie Entfaltung der eigenen Fähigkeiten und „Selbstverwirklichung“. ${ }^{1460} 94$ Prozent der linken Studierenden bezeichneten sich (qua Bejahung des Prinzips der Freiheit, der Volksherrschaft und der im Grundgesetz fixierten Menschenrechte sowie der Ablehnung diktatorischer Staatsformen) als überzeugte Demokraten, ${ }^{1461}$ obwohl 93 Prozent von ihnen „Diskrepanzen zwischen Verfassungsanspruch und Verfassungswirklichkeit“ (vornehmlich aufgrund des noch bis 1985 bundesweit gültigen „Extremistenbeschlusses“ $\$ \$ 88 \mathrm{a}, 126 \mathrm{StGB}$ ) ausmachten ${ }^{1462}$ und nur 51 Prozent von ihnen - bzw. 73 Prozent der Studierenden insgesamt - der amtierenden Bundesregierung vertrauten. ${ }^{1463}$

Dabei ist eine weit verbreitete Zeitdiagnose des Dezennienwechsels zu berücksichtigen: die ziellose Frustration und kollektive Überflüssigkeitsempfindung einer Jugend, die durch eine jahrelang kriselnde Wirtschaft um die Einlösung des sozialliberalen politischen Versprechens auf Autonomie und Partizipation qua moderner Bildungspolitik betrogen worden sei. „Heute, im Zeichen der längsten Wirtschaftskrise der Nachkriegszeit,“ - so Richter 1979 in einem Sammelband - „steht die Jugend, ein knappes Viertel der Bevölkerung, vor betrogenen Hoffnungen und uneingelösten Perspektiven. Auf neue Bildungsmodelle sind Schulstreß und Numerus Clausus gefolgt, auf Ausbildungsreformen Jugend- und Akademikerarbeitslosigkeit, auf die versprochene Zukunftspolitik der Verlust von Orientierung und Vertrauen. ${ }^{\text {“1464 }}$ Das Spektrum befürchteter Konsequenzen reichte damals offenbar bis zum substanziellen Legitimitätsverlust der bundesrepublikanischen Demokratie: „Von den Politikern kaum erkannt, drohen die Reaktionsweisen einer Generation im gesellschaftlichen Abseits die Stabilität unseres politischen Systems zu erschüttern. ${ }^{\text {"1465 }}$ Aus heutiger Sicht erscheint verblüffend, wie die politisch aktive akademische Jugend im Gefolge von „1968“ die Erwartungshaltung der älteren Generation verändert hat - denn ironischerweise machen manche der zum Teil vernichtenden Kommentare ausgerechnet die nunmehr resignierten Jugendlichen und jungen Erwachsenen für das dieser Tage zur Mode gewordene defätistische Klima verantwortlich:

„Daß der Pessimismus gepflegt und jedermann als eine Pflicht auferlegt wird, gehört $z u$ den negativen Merkmalen unserer Zeit, die das Mitleid vorwiegend in der Form des Selbstmitleides auftreten läßt und die weniger Probleme löst als darüber klagt,

1460 „Die Enttäuschung der beruflichen Erwartungen ist also nicht nur Auslöser persönlicher, ökonomisch motivierter Unzufriedenheit; sie trägt auch zur Enttäuschung ideeller Werte bei.“ Ibid., S. 70.

1461 Vgl. ibid., S. $87 f$.

1462 lbid., S. 89.

1463 Vgl. ibid., S. 95, außerdem die Skalen zum Vertrauen gegenüber der politischen Führung S. 101.

1464 Richter, Claus (Hg.): Die überflüssige Generation. Jugend zwischen Apathie und Aggression, Königstein/Ts 1979, Zitate aus dem Klappentext.

1465 lbid. 
daß sie überhaupt entstanden sind. So ist es offenbar auch die Pflicht der jungen Generation, sich selber leid zu tun und keine Hoffnungen zu haben [...] $]^{\alpha 1466}$

Wirft man einen Blick in zwei weitere, 1979 und 1982 durchgeführte, Studien (Zwischen Revolution und Resignation? von Christian Krause et al. und Student heute. Angepaßt? Ausgestiegen? von Glotz und Malanowski), so fällt tatsächlich auf, dass sich die lagerkonfliktähnliche Auseinandersetzung zwischen „linken“ und "rechten“ Studierenden - ohne dass dieses Richtungsschema dadurch schon obsolet geworden wäre! - bereits weitgehend in eine stark subkulturell gefärbte Auseinandersetzung zwischen „alternativen“ und „konventionellen“ Mentalitäten verwandelt hatte. Politische Zieldebatten schlugen vielerorts in ökologische und friedensbewegte Ethik-, Konsum- und Lebensstildiskussionen um; die alternativen Milieus differenzierten sich subkulturell aus und erinnerten stärker an die bürgerliche Lebensreformbewegung des späten long century als an den Parteienstreit der Weimarer Zeit. Vorbei war die Periode der APO und des KBW, überhaupt der verbalkommunistischen und über das Kaderprinzip organisierten Fundamentalopposition; die vielfach als "privatistisch“ und „entpolitisiert" gescholtenen Reformatorinnen und Reformatoren alternativer „Lebenszusammenhänge“ traten das Erbe vor allem der antiautoritären Segmente der Studentenbewegung in den urbanen Zentren der durch die 1970er Jahre geschaffenen alternativkulturellen Infrastruktur an. ${ }^{1467}$ Die Alternativbewegung, die eine neue Konjunktur von Jugend- und Studierendenstudien auslöste, war deutlich stärker - etwa in Alternativszene, quasi-monastischen Alternativprojekten und Alternativmentalität - auf subkulturelle und lebensstilbezogene Dimensionen fixiert: die „Betonung der Subjektivität für jede individuelle oder gesellschaftliche Praxis“ verband sich mit der „Infragestellung traditioneller Politikund Organisationsformen. “1468 Damit sollen zwar keineswegs die politischen Impulse depotenziert werden, die sich im lautstarken Auftreten einer Alternativbewegung, in Forderungen wie der Abschaffung der Atomkraft, der Gleichstellung der Geschlechter oder der politischen Organisation in Basisgruppen, ferner in alternativen Listen und Parteien, ${ }^{1469}$ später nicht zuletzt in der Gründung der Grünen Partei geltend machte. Dennoch fällt auf: Das Politische wurde in den frühen 1980er Jahren (wieder) zum Teilbereich einer Reformbewegung, welche ihre Befreiungsperspektive in vielerlei Hinsicht in die Sphäre der Innerlichkeit zurücknahm und dabei nicht selten esoterisch verbrämte. Hierin liegt wohl einer der Gründe für die zeitdiagnostisch beliebte Metapher des „Rückzugs“ aus der öffentlichen Sphäre.

Indes: Das studentische Gegenmilieu schien auch in seiner alternativen Gestalt einen Nährboden für gesellschaftskritische und anti-institutionelle Subversivität zu bieten. Da sich die von der „No future“-Parole durchzogenen frühen 1980er Jahre, eine Phase der deutlich abgebremsten Bildungsexpansion, zudem durch eine breite Eintrübung der studentischen Berufsaussichten auszeichneten, ergab sich die Frage nach

1466 Rommel, Manfred: Die überflüssige Generation - Übersteigerte Hoffnungen, in: Richter, Claus (Hg.): Die überflüssige Generation. Jugend zwischen Apathie und Aggression, Königstein/Ts 1979,

S. 88-95, hier S. 88.

1467 Vgl. Krause et al.: Zwischen Revolution und Resignation?, S. 32.

1468 Ibid., S. 186f., vgl. auch ibid. S. 189-194.

1469 Vgl. ibid. 
einer potenziell erneuerten, diesmal frustrationsgetragenen, radikalen studentischen Oppositionsbewegung, einem zweiten „1968“. Man befürchtete die Distanzierung der „postmaterialistisch“ innervierten künftigen Funktionseliten von den demokratischen Institutionen. Denn wie schon 1975 nachgewiesen, existierte durchaus ein statistischer Zusammenhang zwischen individueller Erfolgs- bzw. Statuserwartung und Politisierungsgrad bzw. Neigung zu linkem Protestpotenzial. Es wird, wenn auch in enggeführtem tendenziösem Vokabular „ein sehr stark ausgeprägter“ Zusammenhang zwischen „perzipierter beruflicher Perspektive“, „,extremer Linksorientierung“ und „hohem politischen Interesse" ausgemacht, wenn auch die Kausalitätenfrage - mit anderen Worten: die Identifikation abhängiger und unabhängiger Variablen - ungeklärt bleibt. ${ }^{1470}$ Und auch eine vergleichende Sekundärauswertung dreier verschiedener Surveys zu Einstellungen von Gesamtbevölkerung, Akademikern und Studenten konstatierte 1983, dass Studierende, die um ihren Status wie ihre Berufs- und Lebenschancen fürchteten, soziale Ungleichheiten und Chancenungleichheiten häufiger als zentrales gesellschaftliches Problem wahrnahmen und kritisierten, während die optimistischer gestimmten Studierenden zu Mustern der Legitimation dieser Ungleichheiten tendierten; ${ }^{1471}$ auch eine zunehmende, statusgruppenübergreifende Spaltung von geistes- bzw. sozialwissenschaftlicher und „ökonomisch-technischer" Intelligenz über diese Frage wurde abermals angemerkt. ${ }^{1472}$

Ansonsten sprechen die empirischen Ergebnisse für ein starkes demokratisches Selbstverständnis der Studierenden. Krause et al. konstatierten infolge ihrer von der Friedrich-Ebert-Stiftung in Auftrag gegebenen Umfrage in den deutschen Universitätsstädten Frankfurt, Berlin (FU), Hamburg, Heidelberg und Bonn, dass 89 Prozent der Studierenden „prinzipielle Befürworter“ der Demokratie seien, insbesondere jene 55 Prozent, die die „gesellschaftspolitische Grundhaltung“ der sozialliberalen Koalititon teilten; nur knapp 9 Prozent sprachen dem parlamentarischen Weg der politischen Einflussnahme die Effektivität ab. ${ }^{1473}$ Sortiert nach „politisch-weltanschaulichen Denktraditionen“ gruppierten sich die Studierenden in 13 Prozent „Konservative“, 32,6 Prozent „Liberale“, 22,4 Prozent „Sozialisten“, 23 Prozent „Neue Linke“ und 9 Prozent „Kommunisten“. ${ }^{1474}$ Beeindruckend erscheint aus heutiger Sicht die Verankerung alternativer Strömungen in der Universität, auch über die Kernorte Frankfurt a.M. und Berlin hinaus: 85,7 Prozent der Studierenden wussten von alternativen Lebensformen („solidarische“Wohngemeinschaften und selbstverwaltete „Arbeitskollektive“wie Werkstätten, Bäckereien, Cafés), ein Viertel beanspruchte, sie selbst umzusetzen; eine über-

1470 Does: Studenten 1975, S. 20.

1471 Vgl. Sandberger, Johann-Ulrich: Zwischen Legitimation und Kritik. Vorstellungen von Akademikern, Studenten und Bevölkerung zur sozialen Ungleichheit, in: Zeitschrift für Soziologie, 12. Jg., H. 3/1983, S. 181-202, hier S. 181, ferner ibid., S. 200, wo konstatiert wird, „daß Hochschulabsolventen, denen eine nach gängiger Vorstellung ausbildungsadäquate Berufseinmündung verschlossen ist, in erhöhtem Maße zur Sozialkritik tendieren werden."

1472 Ibid., S. 200.

1473 Krause, Christian/Lehnert, Detlef/Scherer, Klaus-Jürgen: Zwischen Revolution und Resignation. Alternativkultur, politische Grundströmungen und Hochschulaktivitäten in der Studentenschaft. Eine empirische Untersuchung über die politischen Einstellungen von Studenten. Bonn: Verlag Neue Gesellschaft, 1980, S. 104 und $157 f$.

1474 Ibid., S. 105. 
wältigende Mehrheit von 80 bis 90 Prozent stand ihnen grundsätzlich aufgeschlossen gegenüber, und die zunächst gering erscheinenden 11,9 Prozent „harten“ Alternativen waren unterfüttert durch „deutliche Einflüsse alternativer Mentalität“ bei der Hälfte aller Studierenden. ${ }^{1475}$ Die Alternativkultur im Jahr 1979 wird von Krause et al. mithin als „wesentliches Element des studentischen Selbstverständnisses“ angesehen. ${ }^{1476}$ Ferner sympathisierte ein lagerübergreifender Teil von 21,7 Prozent der Befragten mit rätedemokratischen Prinzipien als Mittel direktdemokratischer Partizipation im Sinne einer „doppelstrategischen“ Verknüpfung von „institutioneller Arbeit mit außerparlamentarischen Aktionen“, also ohne damit antiparlamentarische oder „linksautoritäre“ Ziele zu verfolgen. ${ }^{1477} 72,4$ Prozent befürworteten überdies den Einsatz von Bürgerinitiativen, nur 22,7 Prozent vertrauten allein auf „konventionelle Methoden der politischen Beteiligung in Parteien, Gewerkschaften und gesellschaftlichen Institutionen. “1478 Mancherorts wurde dieses zunächst irritierende Bild als widersprüchliches Verhältnis zur Demokratie bzw. als Abkehr von deren westlichem Verständnis wahrgenommen. ${ }^{1479}$ Doch zeigte sich in der Studie von Krause et al.: Außerparlamentarische Aktivitäten - inklusive alternativer Gesellungsformen - wurden mehrheitlich als ergänzende Methode der reformbasierten Herstellung einer besseren Gesellschaft verstanden, nicht als Ersatz der für die politische Aktivität vorgesehenen Institutionen. ${ }^{1480}$ Nur 40 Prozent der kommunistischen Minderheit wehrten die Prinzipien der Mehrheit und Gewaltlosigkeit strikt ab. ${ }^{1481}$ Das so genannte „linksextreme Potenzial“ (also das Ausmaß der Unterstützung kommunistischer und anarchistischer Prinzipien), bemessen an Zustimmungswerten $\mathrm{zu}$ acht verschiedenen Frage-Items, bezifferten die Autoren auf gerade einmal 5,6 Prozent („,vorherrschend linksextrem“) bzw. 7,2 Prozent („teilweise linksextrem“). ${ }^{1482}$ Die tatsächliche handlungsnormierende Qualität der vermöge der Items befürworteten Aussagen wird nicht untersucht, doch stellte man unter Befürwortern „linksextremer“ Positionen ein „überdurchschnittliches theoretisches Differenzierungsvermögen“ fest was die Vorstellung einer Genese der teilweise harschen Gesellschaftskritik aus analysearmem Eskapismus widerlege. ${ }^{1483}$ Im Hinblick auf die materielle Situation gab den Autoren der Studie zwar zu denken, dass etwa ein Drittel der Studierenden Behinderungen des Studiums durch Nebenjobs in Kauf nehmen müsse - Hunger oder größere Probleme beim Bestreiten des Alltags litte jedoch niemand, weshalb 52 Prozent von ih-

\footnotetext{
1475 Vgl. ibid., S. 194, 198 und $202 f$.

1476 Ibid., S. 194.

1477 Ibid., S. $158 f$.

1478 Ibid., S. 159.

1479 Vgl. 2. Studierendensurvey 1984/85, S. 269.

1480 „Die hohe Zustimmungsquote von 71,7 \% zum reformstrategischen Prinzip der demokratischen Ausgestaltung durch zahlreiche ,kleinere Veränderungen' unterstreicht nachdrücklich, daß auch die meisten Studenten des linken Spektrums relativ weitgehende Transformationsziele auf einem ,spielregelkonformen' Weg anstreben." Krause et al.: Zwischen Revolution und Resignation?, S. 160.

1481 Ibid., S. 161 und 105.

1482 Ibid., S. 166-169.

1483 Vgl. ibid., S. 177.
} 
nen angaben, mit ihrer Studiensituation überwiegend zufrieden zu sein (nur 12 Prozent waren eher unzufrieden). ${ }^{1484}$

Dennoch erschienen die Themen sozialer Ungleichheit und potenzieller politischer Radikalität der Studierenden infolge der protestreichen 1970er Jahre und die damit zusammenhängende Polarisierung der Studierenden und Akademiker in ein eher linkes, d. h. ungleichheitskritisches, und in ein eher rechtes, d. h. ungleichheitslegitimierendes Lager einigen Forscherinnen und Forschern weiterhin zentral. Das motivierte die zweite soeben erwähnte Studie, die 100 Frankfurter Studierende im Stichjahr 1980 befragte. Auch diese Studie versteht sich, wenn auch mit deutlich größeren methodischen und stilistischen Freiheiten verfasst, explizit als Folgestudie der „berühmte[n] Studie“ von Habermas et al. ${ }^{1485}$ In dem ihr eigenen schwungvollen Stil wird an die Erhebungssituation der 1950er Jahre angeknüpft: „Die Studenten von damals sind die Eltern der Studenten von heute; sie sind das Gegenbild, die Autorität, von der man sich absetzt, sie haben die Lebensgeschichte gelebt, die die Heutigen nicht leben wollen. ${ }^{1486}$ Die Autoren der Studie beobachteten starke gesellschaftliche Entfremdungsempfindungen der Studierenden: $\mathrm{zu}$ kalt und leistungsorientiert, zu autoritätshörig und künstlich nahmen sie demnach den sozialen Umgang wahr. ${ }^{1487}$ Solidarität, Kollektivität, Gemeinschaft und „Lebensqualität“" vermissten sie in ihrem Kultus der Unmittelbarkeit ebenso wie Räume zur ungebundenen Selbstverwirklichung; ${ }^{1488}$ „mehr Menschwerdung“ bzw. „Menschsein" und die Emanzipation der Frau forderten sie, und unter ihnen besonders die Alternativen. ${ }^{1489}$ Das alles verbinde sich zu einer beachtlichen Sensibilität gegenüber den Schwächen des gesellschaftlichen Normalvollzugs. Zur oppositionellen politischen Organisation und zum radikalen Gegenentwurf, gar zum praktischen Ausstieg aber genüge der Missmut nicht:

„Antikapitalismus ist Grundstimmung, aber nicht mehr, wie zu Apo-Zeiten, Gegenprogramm, das Stoff für hitzige Theoriedebatten abgäbe. Die jungen Leute setzen weder auf die Diktatur des Proletariats noch auf die andere Heilsverkünder (Sinnproduzenten). [...] Apathie und Abkehr von der Cesellschaft und Feindschaft gegen einen Staat, der angeblich rigoros Gewalt ausübt, der unterdrückt und verfolgt, hat das Cewaltpotential unter Studenten [...] offenbar nicht vergrößert. Ohnmacht gegenüber der Übermacht, Anpassung trotz zorniger Parolen und die Einsicht, daß Terrorismus sinn- oder jedenfalls erfolglos ist, mögen dazu beigetragen haben $[. . .]^{\text {“1490 }}$

Die Studierenden des Jahres 1980 erscheinen in dieser Studie als moralisch entrüstet und verbalradikal, aber politisch aktionsunfähig; die Suche nach individuellem Glück,

1484 Vgl. ibid., S. 259 und 254. Insgesamt liefert die Studie - trotz ihres Umfangs und Facettenreichtums - zwar viele derartige Systematisierungen, auch lesenswerte Zusammenfassungen zeitgenössisch virulenter Themen. Insgesamt aber bleiben viele ihrer Ergebnisse unbefriedigend, da zwar im Stile der Einstellungsforschung Daten zusammengetragen werden, aber keine Analyse der sich historisch verändernden tieferliegenden ideologischen Orientierungsrahmen geleistet wird.

1485 Vgl. Clotz/Malanowski: Student heute, S. 7.

1486 Ibid., S. 8.

1487 Vgl. ibid., S. 112.

1488 Vgl. ibid., S. 116f. und 127.

1489 Vgl. ibid., S. 124 und 185.

1490 Ibid., S. 119 und 145. 
zunehmend auch im Privaten, bestimme das alltägliche Handeln. ${ }^{1491}$ Mehr noch: Nicht einmal jene, die marxistisches und anarchistisches Vokabular gebrauchten, seien noch im herkömmlichen Sinne politisch aktiv, sondern vielmehr „undogmatisch, antipolitisch und antiparteilich, mit Theorie wenig befrachtet, apparate- und organisationsfeindlich und privatistisch. ${ }^{\text {(1492 }}$ Entfremdet zeigten sich die Studierenden auch von den politischen Parteien: „Abgehoben“ und selbstferenziell erschien ihnen der demokratische Prozess, Sympathien hegte man für die Vorstellung direkter Demokratie nach Rousseau'schem Ideal, kurz: für die Identität von allgemeinem Willen und Staatsräson. ${ }^{1493}$ Nicht einmal die damals neue Partei der Grünen als Partei der "Alternativen“ schien ihnen eine Aussicht auf unkompromittierte politische Einflussnahme zu bieten. ${ }^{1494}$ Der vor allem unter Alternativen omnipräsente Ruf nach „Demokratisierung“ erschien in den Interviewpassagen als Synonym für den inneren (Abkehr von Ehe und Zweierbeziehung) oder äußeren (Wohngemeinschaften, ländliche Subsistenzwirtschaft) Eskapismus, für die Flucht vor Verantwortungsübernahme und Auseinandersetzung. ${ }^{1495}$ Politische Betätigung in den konventionellen wie unkonventionellen Formen der vorherigen Jahrzehnte lag der Mehrheit der Befragten fern, obwohl sie paradoxerweise eine starke Verpflichtung zu politischer Praxis empfanden: „Aktive Beteiligung bei Studenten ist selten, obgleich sie ihnen von der Idee her dringend geboten scheint. ${ }^{11496}$ Das polemisch gewürzte Fazit von Glotz und Malanowski lässt die Studierenden des Jahres 1980 einzigartig unreif, ja infantil erscheinen:

„Die Werte dieser Studentengeneration sind demokratischer als die der früheren Alterskohorten; aber sie sind der Gegenkontrolle durch die Wirklichkeit nie ausgesetzt worden. Die Studenten spüren, daß die protestantisch-kapitalistischen Tugenden in der postmateriellen Cesellschaft fragwürdig werden; aber mit ihrer rudimentären Sozialethik würden sie eine lebensfähige Industriekultur nicht gestalten können. [...] Sie sind toleranter, weicher, lockerer als ihre Vorgänger, aber auch sprunghafter, antriebsschwächer und schreckhafter."1497

Interessanterweise setzte sich ausgerechnet unter dieser Oberfläche alternativer Mentalitäten und zielloser Wut die defätistische Tendenz als langfristige Entpolitisierung fort. Der Verlust politischer Gewissheiten erlaubte in der Folge eine rasche Umkehr der Werthaltungen und Handlungsmaximen der Studierenden, die an die von Schelsky beschriebenen Nachkriegsmentalitäten erinnert. Die „Entwicklung zu einem rationalen Pragmatismus“ wurde daher später als „eine vorherrschende Grundströmung der 8oer

\footnotetext{
1491 Vgl. ibid., S. 133-136.

1492 Ibid., S. 133.

1493 Vgl. ibid., S. 162-165 und 176.

1494 Vgl. ibid., S. $169 f$.

1495 Vgl. ibid., S. 185.

1496 Ibid., S. $162 f$.

1497 Ibid., S. 199. Siehe auch die Kurzzusammenfassung in der Einleitung des Bandes: „Wir konstatieren ein Verschwinden des Akademikerdünkels, aber auch eine Abschwächung der Leistungsethik, ein stabiles demokratisches Potential mit stark radikaldemokratischer Komponente, aber auch einen ausgeprägten Anti-Institutionalismus und einen seltsam deutschen Ekel gegenüber der Macht.“ Ibid., S. 8.
} 
Jahre ${ }^{\text {1498 }}$ identifiziert, während die „postmaterialistischen“ Innervationen verpufften: Perzipierte Berufschancen gewannen bei Studienmotivation und Fachwahl angehender Studierender an Bedeutung, außerdem konvergierte die „Abnahme ideell-sozialer" mit einer „Zunahme materialistisch-egoistischer Werthaltungen“ und einer zügig wachsenden Ablehnung „alternativer“ Überzeugungen. ${ }^{1499}$

Zunächst speiste sich auch das Interesse der 1984 veröffentlichten Pilotstudie des Studierendensurveys ${ }^{1500}$ an den politischen Orientierungen der Studierenden im Wintersemester 1982/83 unmittelbar aus der Beobachtung der damaligen beruflichen Unsicherheiten junger Hochschulabsolventen. ${ }^{1501}$ Nicht nur Orientierungsprobleme während des Studiums und psychische Belastungsempfindungen häuften sich demnach infolge der vergleichsweise schlechten Berufsaussichten der Studierenden in den frühen 1980er Jahren, ${ }^{1502}$ auch der mehrfach konstatierte korrelative Zusammenhang zwischen bestimmten politischen, präziser: gesellschaftskritischen Einstellungstendenzen und den eingetrübten Zukunftsaussichten wurde hier abermals erhärtet. ${ }^{1503}$ Berücksichtigt man, dass die schon oben erwähnte weltanschauliche Polarisierung zum Zeitpunkt der Publikation des 1. Studierendensurveys als hochgradig virulente, ja „immer wichtiger“1504 werdende Konfliktlinie erschien, wird auch verständlich, warum in diesen Jahren ein geradezu distinkter Antagonismus zwischen konservativer politischer Positionierung und einer reformorientierten bzw. „radikal-sozialistischen“ Positionierung, jeweils in Übereinstimmung mit der Selbstverortung im politischen Richtungsschema "Links/Rechts“, ${ }^{1505}$ anzutreffen gewesen ist. Und in der Tat ergab die repräsentative Befragung eine Hierarchisierung politischer Ziele entlang zweier „Hauptmuster": eines, „das bewahrende und sichernde bis hin zu genuin konservativen Zielen beinhaltet", und eines, „das verändernde, reformorientierte bis hin zu radikal-sozialistischen Zielen umfaßt" - und zwar in starker Übereinstimmung mit der Selbsteinstufung als politisch „rechts“ bzw. „links“. ${ }^{1506} 31$ Prozent der Befragten bezeichneten sich als „deutlich links“, 26 Prozent als „eher links“ gegenüber gerade einmal 5 Prozent „deutlich“ und 11 Prozent „eher" rechts Orientierten; die Positionierungsfreude war wenig überraschender Weise bei den politisch Interessierten am größten. ${ }^{1507}$ In summa kann man auch für das Wintersemester 1982/83 von einer linksorientierten Mehrheit sprechen und damit überdies von einem großen Kräftereservoir an engagementfreudigen Studierenden: 62 Prozent

\footnotetext{
1498 Studierendensurvey $1980 e r$, S. III. Vgl. auch ibid., S. 9.

1499 Ibid.

1500 Zwar wurden im Studierendensurvey nicht nur Daten zu Universitätsstudierenden, sondern in zunehmendem Maße auch Vergleichszahlen zu Fachhochschulen erhoben. Da sich die vorliegende Studie aber vornehmlich mit Studierenden an Volluniversitäten befasst, werden diese Vergleichszahlen im Folgenden ausgeblendet.

1501 Vgl. zur Feststellung einer „erheblichen Verunsicherung“ bezüglich der eigenen Berufschancen 1. Studierendensurvey 1982/83, S. 193 und 203, ferner eingehend Kapitel II.1 dieser Studie.

1502 Vgl. ibid., S. 203.

1503 Vgl. ibid., S. 209, wo unter Rekurs auf einschlägige Erhebungen und Studien auch die Vernachlässigung dieses Zusammenhangs bei Allerbeck und Kaase moniert wird.

1504 1. Studierendensurvey $1982 / 83$, S. $209 f$.

1505 Vgl. ibid., S. 229.

1506 Ibid., S. 223.

1507 Ibid., S. 225-228.
} 
derjenigen, die sich als links bezeichneten, äußerten sich interessiert an studentischer Politik. ${ }^{1508}$ Während Studierende der Sozial-, Sprach-, und Kulturwissenschaften stärker reformorientierte Ziele reklamierten, äußerten sich die angehenden Wirtschaftsund Rechtswissenschaftler sowie Mediziner stärker konservativ. ${ }^{1509}$

Der Studierendensurvey differenzierte diesen allgemeinen Befund insofern, als dass die Intensität des politischen Interesses an sich zwar nicht von den Berufsaussichten der Befragten beeinflusst wurde, wohl aber das Interesse an studentischer bzw. Hochschulpolitik $^{1510}$ - und dass „in allen Fächern Studierende mit besonders schlechten Berufsaussichten sich deutlicher links einstufen“ -, und zwar unabhängig davon, ob sie in aussichtsreichere oder weniger erfolgversprechende Studiengänge immatrikuliert waren. ${ }^{1511}$ Schlechtere Berufsaussichten bedingten demnach eine stärkere „Konfliktund Gewaltnähe“ und einen antiinstitutionellen Impuls (d. h. eine größere Zustimmung zu dem Item, „wirkliche Demokratisierung sei nur außerhalb der bestehenden Institutionen möglich") ${ }^{1512}$ nebst größerem Misstrauen gegenüber politischem Personal, Parteien und Parlamenten ${ }^{1513}$, nicht aber eine geringere Zustimmung zu demokratischen Prinzipien ${ }^{1514}$ - während Studierende, die günstige Berufsaussichten erwarteten, deutlich häufiger der Meinung waren, dass sich „unsere Demokratie bewährt“ habe und häufige Reformen ablehnten. ${ }^{1515}$ Als „brisant“ erschienen diese Ergebnisse vor allem deshalb, weil das beobachtete „kritische Klima“ die allgemeine „radikale Protestbereitschaft" über Fächer- und Fakultätsgrenzen hinweg fördere. ${ }^{1516}$ Rein ökonomischmateriell motiviere sich diese Frustration gleichwohl nicht; entscheidend sei vielmehr die „erlebte oder befürchtete Verhinderung der eigenen Selbstverwirklichung in einem autonomen Tätigkeitsrahmen“, d. h. in einer qualifikationsadäquaten Tätigkeit. ${ }^{1517}$ So wird unter Bekräftigung jener Tendenzen der von Infratest kartografierten 1970er Jahre resümiert:

„Unzufriedenheit mit dem gegenwärtigen politischen System, die Abwendung von etablierten Parteien, die Distanzierung gegenüber Parlamentarismus und gegenwärtiger Demokratie, all dies ist demnach vor allem auch eine Folge enttäuschter ideeller Werte und Erwartungen. “1518

1508 Vgl. ibid., S. 228.

1509 Vgl. ibid., S. 225.

1510 Vgl. ibid., S. 211.

1511 Ibid.

1512 Ibid.

1513 „Wer schlechte Berufsaussichten wahrnimmt, stellt häufiger die etablierten politischen Parteien in Frage, bezweifelt eher, daß der Parlamentarismus ausreichende Möglichkeiten für eine demokratische Interessenvertretung der Bevölkerung bietet, meint entschiedener, daß sich die gegenwärtige Politik zu wenig an der Lebensqualität der Menschen orientiere, und ist in stärkerem Maße davon überzeugt, daß sich die etablierten Parteien zu wenig um die tatsächlich wichtigen und drängenden Probleme kümmern." Ibid., S. 213.

1514 Ibid., S. 211.

1515 Ibid. und ibid., S. 212.

1516 Ibid., S. 213.

1517 Ibid.

1518 „Hinsichtlich der politischen Beteiligung wird einerseits befürchtet, die Studierenden verhielten sich heute allzu apathisch und desinteressiert, andererseits wird vor der vorhandenen Protestbereitschaft gewarnt. Demokratische Einstellungen werden den Studierenden von einer Seite in 
Aus diesem gesellschaftlich wie politisch befürchteten Anstieg politischer Radikalität einerseits, aber auch einer im Legitimitätsverlust politischer Institutionen begründeten „staatsverdrossenen“ politisch-apathischen, womöglich gar demokratieskeptischen Studierendenschaft andererseits speiste sich der Wunsch, die politischen Orientierungen der Studierenden detaillierter auszuleuchten. ${ }^{1519}$ Man befand einen „hohen Stand des allgemein-politischen Interesses“, aber eine geringe „Informiertheit und Interesse für Hochschulpolitik und Studentenpolitik“, ferner 10 Prozent bis zu einem Drittel von Studierenden, die „harte“ Protestformen wie Störungen von Lehrveranstaltungen und Besetzungen von Instituten in bestimmten Fällen für legitim hielten. ${ }^{1520} 54$ Prozent der Befragten gaben an, „sehr stark“ am politischen Geschehen interessiert zu sein, nur 4 Prozent meldeten völliges Desinteresse an. ${ }^{1521}$ Gegenüber diesem grundsätzlichen Interesse aber fielen Lokalpolitik (starkes Interesse: 19 Prozent, Desinteresse: 22 Prozent), studentische Politik (starkes Interesse: 9 Prozent, Desinteresse: 34 Prozent) an der eigenen Hochschule sowie hochschulpolitische Fragen im Allgemeinen (starkes Interesse: 18 Prozent, Desinteresse: 18 Prozent) deutlich ab. ${ }^{1522}$ Hinsichtlich der aktiven politischen Beteiligung dominierten „unverbindliche und informierende“Aktivitäten wie das Besuchen politischer Vorträge, Diskussionen und Veranstaltungen; eine Mehrheit von 73 Prozent bekundete, nicht in klassischen Vereinen, Verbänden, Organisationen oder Parteien aktiv mitzuwirken, während immerhin 43 Prozent zu Protokoll gaben, sich zumindest gelegentlich für bestimmte Parteien oder Kandidaten „einzusetzen“. ${ }^{1523}$ Das affektive Misstrauen gegenüber „Unfairness“ und „Unehrlichkeit“ im Politikbetrieb war, ähnlich wie in den 1960er Jahren, ebenso mehrheitsfähig wie latente Sympathien gegenüber außerparlamentarischem Protest. ${ }^{1524}$ Allerdings tat dies weder der Einschätzung der eigenen politischen Kompetenzen noch einer grundsätzlichen Verpflichtungsempfindung gegenüber politischen Themen Abbruch: Ganze 94 Prozent stimmten voll oder teilweise der Aussage zu, „Gleichgültigkeit gegenüber Politik“ sei „verantwortungslos“, 84 Prozent verneinten ganz oder teilweise die These, ein Urteil über komplexe politische Zusammenhänge sei schwer zu fällen. ${ }^{1525}$ Dementsprechend urteilsstark äußerten sie sich in den Fragebögen: „Überwiegend kritisch und distanziert “1526 sah man

hohem Maße zugesprochen, während die andere Seite bezweifelt, daß Grundpositionen westlichen Demokratieverständnisses noch geteilt werden. [...] Schließlich wird einerseits ein Überwiegen alternativer Grundströmungen in den politischen Zielen vermutet, die die gegenwärtigen gesellschaftspolitischen Verhältnisse sprengen, andererseits wird daran festgehalten, die Studenten würden nicht in überwiegendem Maße radikale Vorstellungen vertreten. Allein wegen dieser vielen Kontroversen kann selbst ein einfacher Überblick zur politischen Kultur der Studenten zu einer gewissen Klärung und zu einem besseren Verständnis ihres politischen Bewußtseins beitragen." Ibid., S. 214.

1519 So dargelegt ibid.

1520 Ibid., S. 19.

1521 Vgl. ibid., S. $214 f$.

1522 Vgl. ibid., S. 215.

1523 Ibid., S. 216.

1524 Vgl. ibid., S. 217: 91 Prozent der Befragten stimmten teilweise bis voll der Aussage zu: „Wenn ich merke, daß die Verantwortlichen in der Politik Fehler machen oder eigenmächtig handeln, würde ich mich immer denen anschließen, die protestieren."

1525 Ibid.

1526 Ibid., S. 221. 
die politischen Verhältnisse der frühen 1980er Jahre, zu wenig gehe es um „Lebensqualität" und zu viel um wirtschaftliches Wachstum. Angesichts drängender Probleme des alltäglichen Lebens sei das Handeln der politischen Eliten unverständlich. ${ }^{1527}$ Ferner widersprächen die „Überwachungspraxis“ und der herrschende „Umgang mit Demonstranten" den von ihnen stipulierten demokratischen Prinzipien. ${ }^{1528}$ Zweifel an der Veränderungskraft parlamentarischer Instrumente nährten bei einem großen Teil der Studierenden Sympathien für außerparlamentarische Wege der Interessendurchsetzung wie Bürgerinitiativen oder soziale Bewegungen. ${ }^{1529} \mathrm{Zu}$ den wichtigsten Zielen aller befragten Studierenden gehörte die „Durchsetzung gleicher Bildungschancen für alle Kinder“, die „Durchsetzung der vollen Gleichstellung der Frau im Beruf“, die „Priorität des Umweltschutzes vor wirtschaftlichem Wachstum“ und die „Stabilität sozialer und wirtschaftlicher Verhältnisse“ ${ }^{1530}$

Unter verbaler Berufung auf die „schon klassische[] ${ }^{\text {“1531 }}$ Studie von Habermas et al. und der damals aktuellen Folgestudie von Glotz/Malanowski fragte der Studierendensurvey unter Rückgriff auf die „Demokratieskala“ von Max Kaase präzise nach der Haltung der Studierenden zu demokratischen Prinzipien. ${ }^{1532}$ Die Befunde sprachen für eine Übereinstimmung der studentischen Orientierungen mit demokratischen „Grundvoraussetzungen“, wobei die Zustimmung zu Meinungsfreiheit und Demonstrationsrecht mit 93 Prozent und die Ablehnung des gewaltsamen Austragens von Konflikten mit 85 Prozent am höchsten ausfiel, während etwa ein Drittel der Studierenden Einschränkungen des Streik- und Demonstrationsrechts oder der kritischen Funktion der Opposition für legitim hielten. ${ }^{1533}$ Der offensichtliche Schluss: „Gesellschaftsordnungen autoritären wie totalitären Zuschnitts hätten bei ihnen so gut wie keine Chance. ${ }^{\text {(1534 }} \mathrm{Im}$ Längsschnitt von 1968 bis 1982/83 lasse sich eine deutliche Erhöhung des „demokratischen Anspruchsniveau[s]“ inklusive einer Höherbewertung individueller Rechte und einer stärkeren Bereitschaft zu Konflikt und Protest feststellen; ${ }^{1535}$ Fächerdifferenzen fand man nur in geringem Maße, ${ }^{1536}$ wohl aber einen starken Zusammenhang zwischen Festigkeit der demokratischen Grundüberzeugungen und kritischer Haltung ge-

\footnotetext{
1527 Ibid., S, $221 f$.

1528 Ibid., S. 223.

1529 Vgl. ibid.

1530 Ibid., S. 224

1531 Ibid., S. 218.

1532 Als fünf exponierte Aspekte benennt man hier in Abwandlung der Kaase'schen Demokratieskala die „Befürwortung von Interessengruppen und deren Forderungen“, die „Anerkennung des Rechts auf Streiks und Demonstrationen“, die „Ablehnung des gewaltsamen Austragens von Konflikten“, die „Anerkennung der kritischen Funktion der politischen Opposition“ und die „Zustimmung zur Meinungs- und Demonstrationsfreiheit“. Ibid. Zu Kaases originärem Konzept vgl. Kaase: Demokratische Einstellungen, S. 142.

1533 Ibid.

1534 Ibid.

1535 Ibid., S. 220.

1536 So bewiesen sich die Studierenden der Sozial- und Geisteswissenschaften gegenüber Wirtschaftswissenschaftlern und Juristen „tendenziell demokratischere Haltungen“ hinsichtlich des „Primats öffentlicher Ordnung" und der Bewertung der politischen Opposition. Ibid., S. 221.
} 
genüber der demokratischen Realität in der Bundesrepublik bzw. der Befürwortung außerparlamentarischer Politikformen. ${ }^{1537}$

Abschließend legte man den Studierenden Fragen zu gesellschaftlichen Entwicklungen und gesellschaftspolitischen Zielen vor, die sich um drei seinerzeit virulente gesellschaftliche Kernthemen gruppierten: soziale Ungleichheit bzw. soziale Gerechtigkeit (infolge des entsprechenden „hochgradigen Problembewußtsein[s]“ der Studentenbewegung der 1960er Jahre), alternativ-ökologische Strömungen (infolge der wachsenden Friedens- bzw. Anti-Atomkraft-Bewegung), und der gesellschaftliche Stellenwert des technischen Fortschritts (aufgrund einer damit verbundenen wachsenden Antagonismus zwischen Fortschrittsfreude und Technikfeindlichkeit). ${ }^{1538}$ Dabei sah, von Fächerdifferenzen abgesehen, eine überwältigende Mehrheit von 90 Prozent mittlere bis große soziale Ungleichheiten in der Bundesrepublik, 34 Prozent von ihnen empfanden diese als ungerecht, weitere 53 Prozent als teilweise ungerechtfertigt. ${ }^{1539}$ Materiellen Wohlstand schätzten 62 Prozent als zu hoch gehängtes politisches Ziel ein, Solidarität vermissten demgegenüber 80 Prozent. ${ }^{1540}$ Studentinnen und Studierende der Sozialwissenschaften neigten stärker zur Perzeption von Ungleichheiten und Ungerechtigkeiten und $\mathrm{zu}$ einer stärker ablehnenden Haltung gegenüber dem Wettbewerb; demgegenüber befürworteten Studierende der Wirtschafts- und Rechtswissenschaften die bestehenden sozialen Verhältnisse deutlich häufiger. ${ }^{1541}$ Über die Hälfte der Studierenden stellten die etablierten politischen Parteien infrage, ${ }^{1542}$ ein Drittel von ihnen engagierte sich regelmäßig oder gelegentlich in der Friedensbewegung, ${ }^{1543}$ ein Viertel befürwortete „autonome Lebens- und Arbeitskollektive“, wobei nur wenige unter ihnen solchen tatsächlich angehörten. ${ }^{1544}$ Schließlich fiel eine im Vergleich zur Gesamtbevölkerung weit verbreitete Skepsis gegenüber einer zunehmend als potenziell bedrohlich wahrgenommenen technologischen Entwicklung unter den Studierenden auf, was auch mit mangelnder gymnasialer Schulbildung in diesem Bereich in Verbindung gebracht wurde. ${ }^{1545}$

Der Weltanschauungskonflikt zwischen „alternativen“ und „konventionellen“ Werthaltungen bzw. Politikverständnissen blieb in den 1980er Jahren zunächst weiterhin prägend, verlor allerdings nach und nach an Relevanz. Eine durch Persönlichkeitsentfaltung, ökologisch-friedenspolitisch-feministischer Sensibilität und relative Geringschätzung materieller Fragen gekennzeichnete „Alternativ-Mentalität“ erfreute sich 1984/85 noch unter 12 Prozent der Studierenden großer Beliebtheit, weitere 21 Prozent standen ihr aufgeschlossen, 34 Prozent indifferent gegenüber; Vorbehalte empfanden

1537 So wird konstatiert, „daß in den Fächergruppen, in denen die demokratischen Grundüberzeugungen weiter verbreitet sind, zugleich die vorhandenen demokratischen Verhältnisse distanzierter betrachtet werden." Ibid.

1538 Ibid., S. 228.

1539 Vgl. ibid., S. 231.

1540 Vgl. ibid., S. 230.

1541 Vgl. ibid., S. 232.

1542 Ibid., S. 234.

1543 Vgl. ibid., S. 236.

1544 Ibid., S. 234.

1545 Vgl. ibid., S. $238 f$. 
24 Prozent, strikte Ablehnung 9 Prozent. ${ }^{1546}$ Das entsprach einem Rückgang alternativer Orientierungen und einer beginnenden „Wende zu konventionelleren Einstellungen“. Die „kulturelle Kluft“ zwischen den Fächergruppen blieb erhalten. ${ }^{1547}$ Und abermals erwies sich die Konfliktkonstellation zwischen „alternativen“ und "konventionellen“ Studierenden als analog zum traditionellen Richtungsschema „links“ bzw. „rechts“ - gemessen an den politischen Vorstellungen über „Gleichheit und Mitbestimmung, Emanzipation und Partizipation“. ${ }^{1548}$ „Alternative“ und „konventionelle“ Studierende verfügten demnach, auch über den Konflikt der „Lager“ vermittelt, über jeweils strukturierende Orientierungshilfen $\mathrm{zu}$ verschiedenen gesellschaftlichen Themen. ${ }^{1549}$ Das macht sich insbesondere auch im differierenden Demokratieverständnis deutlich:

„Alternative sind fast stets militante, kritische Demokraten, für die Demokratie Aus-
einandersetzung und Konflikt sowie Opposition und Demonstration bedeutet. Ein Teil
von ihnen geht davon aus, daß bestimmte Konflikte auch in demokratischen Cesell-
schaften gewaltsam gelöst werden müssen. [...] Die Konventionellen stellen sich im
Zweifelsfalle dann mehrheitlich auf die Seite von Ruhe und Ordnung, die Alternativen
votieren einhellig für Demonstrationen und Streiks. ${ }^{\text {“1550 }}$ Jedoch scheint sich die Schärfe dieses Konflikts zwischen 1982/83 und 1984/85 bereits abgemildert zu haben. ${ }^{1551}$

Da die Studierenden im 2. Studierendensurvey als prospektive Funktions- und Machtträger, als Pioniere „neuer kultureller und politischer Entwicklungen“ und als potenziell politisch-rebellisch intervenierende Sozialgruppe identifiziert wurden, ${ }^{1552}$ fragte man erneut detailliert nach politischen und demokratischen Orientierungen. Im Ergebnis bezeichneten sich 48 Prozent der Studierenden an Universitäten als sehr stark politisch interessiert am allgemeinen politischen Geschehen (6 Prozent desinteressiert), an der Lokalpolitik 18 Prozent (23 Prozent desinteressiert), an hochschulpolitischen Fragen 15 Prozent (20 Prozent desinteressiert) und an der unmittelbaren studentischen Politik 7 Prozent (39 Prozent desinteressiert). ${ }^{1553} 31$ Prozent verorten sich im „extrem“ linken Spektrum, weitere 26 Prozent mittig-links - gegenüber 12 Prozent mittig-Rechten und 5 Prozent „extrem“ Rechten. ${ }^{1554}$ Gemessen an parteipolitischen „Grundrichtungen“ war grüne bzw. alternative Politik mit ca. 25 Prozent Identifikation unter den Studierenden am beliebtesten, gefolgt von sozialdemokratischer Politik mit ca. 15 Prozent; christlich-konservative Politik wurde von 16 Prozent befürwortet, aber von 45 Prozent strikt abgelehnt; kommunistische (3 Prozent) und nationalkonservative (1 Prozent) politische Prinzipien blieben randständig. ${ }^{1555}$ Die vordringlichsten politischen Ziele waren nun die Gleichstellung der Geschlechter, ein politischer Fokus auf Umweltschutz zuungunsten

1546 2. Studierendensurvey $1984 / 85$, S. 284 und $288 \mathrm{f}$.

1547 Ibid., S. 291-293.

1548 Ibid., S. 306.

1549 Vgl. ibid., S. $310 f$.

1550 Ibid., S. 308.

1551 Vgl. ibid.

1552 Ibid., S. 241.

1553 Vgl. ibid., S. 243.

1554 Vgl. ibid., S. 247.

1555 Ibid., S. 254-258. 
der Wirtschaftskraft, und die Stabilität der sozialen und wirtschaftlichen Verhältnis-

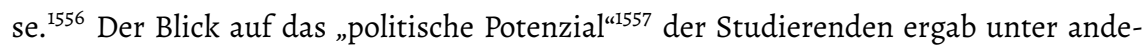
rem, dass hohes politisches Interesse und starkes Engagement in sozialwissenschaftlichen Fächern vornehmlich eine „linke“ Angelegenheit war, während in wirtschafts- und rechtswissenschaftlichen Studiengängen eine besonders interessierte und aktive „Mitte" dominierte; großes politisches Potenzial zeigte sich durchweg sowohl in geistesals auch in naturwissenschaftlichen Studiengängen. ${ }^{1558}$ Drei Fünftel der Studierenden empfand eine Verpflichtung zur politischen Betätigung, etwa die Hälfte monierte mangelnde politische Partizipationsmöglichkeiten. ${ }^{1559}$ An autonomen Arbeitskollektiven und Wohngemeinschaften beteiligten sich 6 bzw. 11 Prozent, weitere 20 bzw. 12 Prozent beabsichtigten dies in Zukunft; 25 Prozent engagierten sich in Bürgerinitiativen und 31 Prozent in der Friedensbewegung, weitere 36 bzw. 23 Prozent konnten sich ein solches Engagement vorstellen. ${ }^{1560}$ Indes: Nach Zusammenhängen der politischen Orientierungen und des politischen Verhaltens mit den von ihnen wahrgenommenen künftigen Berufs- und Statuschancen wurde nicht mehr gefragt.

Die große Mehrheit der Studierendenschaft votierte auch 1984/85 wieder für wesentliche demokratische Grundprinzipien und lehnte autoritäre bzw. diktatorische Regierungsformen strikt ab; 94 Prozent sprachen sich ferner gegen „Gewalt als Mittel der Politik“ aus. ${ }^{1561}$ Eine Einteilung der Befragten in Typen demokratischer Unterstützung ergab ein Mischungsverhältnis von 36 Prozent „vehementen Demokraten“, 37 Prozent „eindeutigen Demokraten“ (zusammen drei Viertel), 21 Prozent „labilen Demokraten“ und 6 Prozent „tendenzielle Anti-Demokraten“ ${ }^{1562}$ Diese mehr als robusten Werte taten aber der unverändert kritischen Bewertung der demokratischen Realität der Bundesrepublik keinen Abbruch: 58 Prozent zweifelten an der Verwirklichung demokratischer Ideale, etwa ein Drittel von ihnen hielt die bisherigen institutionellen Mittel für unzureichend ${ }^{1563}$ - wobei die Funktionsfähigkeit der demokratischen Institutionen „von linken [d. h. stärker reformorientierten, J. S.] und rechten [d. h. stärker affirmativen, J. S.] Studenten nahezu diametral unterschiedlich“ eingeschätzt wurde. ${ }^{1564}$

Der 3. Studierendensurvey (durchgeführt im Wintersemester 1987/88) bestätigte viele der durch die beiden Vorgängerstudien bereits angezeigten Trends. Zwar blieb das allgemeine politische Interesse mit 50 Prozent „sehr stark“ Interessierten (5 Prozent „sehr gering") unverändert hoch, doch geriet die Beschäftigung mit Hochschulpolitik immer unattraktiver: Nur mehr 14 Prozent beschäftigten sich aktiv mit hochschulpolitischen Fragen, 7 Prozent mit konkreter studentischer Politik vor Ort. ${ }^{1565}$ Weiterhin

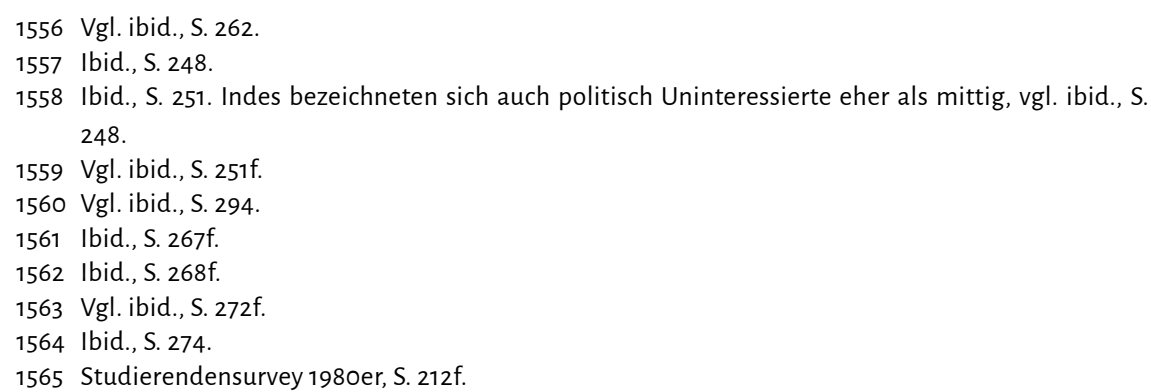


ordnen sich 31 Prozent der Studierenden einem „linken“ politischen Standort zu. ${ }^{1566}$ Konstant blieben außerdem die Unzufriedenheit über politische Partizipationschancen und die verbreitete Distanz zur institutionalisierten Politik bei ungebrochener politischer Verpflichtungsempfindung (60 Prozent betonten ihre diesbezügliche Verantwortlichkeit), ${ }^{1567}$ überdies auch die fachbezogenen Differenzen im politischen Interesse. Das „subjektive politische Kompetenzgefühl“ der Studierenden ist gleichzeitig angestiegen wie die Bereitschaft zu Protest bei politischen Fehlentwicklungen (20 Prozent gaben an, prinzipiell dazu bereit zu sein, weitere 50 Prozent, es teilweise bzw. themenabhängig zu $\operatorname{sein}^{1568}$ ) und wird, verbunden mit der Empfindung normativer Verpflichtung zu politischer Verantwortung, als Indiz dafür gewertet, „daß politische Aktivitäten von Studierenden - bei aktuellen Anlässen - jederzeit wieder möglich sind. “1569 An entsprechenden inhaltlichen Motiven jedenfalls mangelte es nicht: Drei Viertel der Studierenden monierten eine zu starke Orientierung der Politik an Wachstum und industriellen Interessen, dagegen mangelndes Engagement für die „Lebensqualität der Menschen“. 1570

Befragt nach den gesellschaftlichen Verhältnissen der späten 1980er Jahre lobten mehr Studierende die politische Realisierung individueller Freiheiten, kritisierten aber eine mangelnde Verwirklichung sozialer Gleichheit, ${ }^{1571}$ einen Verlust an sozialer Sekurität bzw. sozialem Frieden ${ }^{1572}$ und eine steigende Ungerechtigkeit sozialer Diskrepanzen. ${ }^{1573}$ Chancengerechtigkeit (gleiche Aufstiegschancen für alle Bürger) sah etwa ein Drittel als gesellschaftlich nicht gegeben an, Leistungsgerechtigkeit (Abhängigkeit des Einkommens von der persönlichen Anstrengung) demgegenüber jeweils ein Viertel realisiert bzw. nicht realisiert. ${ }^{1574}$ Als dramatischste Trendwende wird die Umkehr von Technikskepsis in Techniksympathie ${ }^{1575}$ und, parallel dazu, die zügige Erosion alternativer Orientierungen wie der postmateriellen Selbstverwirklichungsemphase nebst Renaissance materieller Prioritäten und Genese einer neuen konventionalistischen Mehrheit zwischen 1983 und $1987^{1576}$ gewertet. Um eine Selbstverortung im Richtungsschema „Links/Rechts“ wurden die Befragten nicht mehr gebeten.

Bezüglich des studentischen Demokratieverständnisses wies man abermals auf die substanzielle Transformation seit den mehrheitlich konventionalistischen, aber auch stärker gewalttoleranten späten 1960er Jahren hin: Im Unterschied zu 1968 (17 Prozent)

1566 Vgl. ibid., S. 218.

1567 Vgl. ibid., S. $215 f$.

1568 Vgl. ibid., S. 217.

1569 Ibid.

1570 Ibid., S. 231.

1571 Vgl. ibid., S. $233 f$.

1572 Vgl. ibid., S. 235.

1573 Vgl. ibid., S. $239 f$.

1574 Vgl. ibid., S. 240.

1575 „Die Haltung gegenüber dem technischen Fortschritt hat sich massiv verändert; war noch vor vier Jahren bei einem großen Teil [...] Technik-Skepsis, ja Technikfeindlichkeit verbreitet, so ist gegenwärtig Technik-Vertrauen wieder am verbreitetsten [...]", ibid., S. 237.

1576 Vgl. ibid., S. 241-246. „Alle einzelnen Elemente der alternativen Orientierungen sind von diesem Rückgang betroffen, in auffälliger Weise vor allem der alternative Grundwert der Selbstverwirklichung sowie die Formen eines anderen Lebens [...] Dem entspricht die wieder häufigere Betonung von ,materiellem Wohlstand' und die stärkere Ausprägung materiell-instrumenteller Vorstellungen in anderen Bereichen (wie Studienmotive, berufliche Werte).“ Ibid., S. $241 f$. 
stimmten 1987 nur noch 7 Prozent der Studierenden der Aussage, bestimmte Konflikte in einer demokratischen Gesellschaft müssten je nach Situation eventuell gewalttätig ausgetragen werden, $\mathrm{zu}^{1577}$ der Zustimmungswert $\mathrm{zu}$ einer unkritischen, regierungsstützenden Opposition sank im selben Zeitraum von 28 auf 16 Prozent. Dass das Recht zu Streiks und Demonstrationen bei Gefährdung der öffentlichen Ordnung entzogen werden sollte, befürworteten statt vormals 46 Prozent nur noch 25 Prozent der Studierenden. ${ }^{1578}$ Infolge der unverändert starken Befürwortung demokratischer Grundprinzipien wie Meinungs- und Demonstrationsfreiheit und der von zwei Dritteln der Befragten kritisierten Mängel demokratischer Mitbestimmungsmöglichkeiten ${ }^{1579}$ wird der Schluss einer „Verbreiterung und Stabilisierung der demokratischen Überzeugungen“ gezogen. ${ }^{1580}$ Erstmals aber führte das Selbstverständnis der Studierenden als überzeugte Demokratinnen und Demokraten in deutlich geringerem Maße zum Ruf nach Partizipation und plebiszitären Instrumenten; demgegenüber wuchs, von Fächerdifferenzen abgesehen, das Vertrauen in demokratische Institutionen - wenngleich keineswegs in Parteien, politische Eliten und deren politische Praxis! $!^{1581}$

Die Aufführung der Daten rechtfertigte man im zusammenfassenden Band 1989 damit, den Klischees „einer vermuteten ,radikalen Extremität‘ [sic] oder ,apathischen Desinteressiertheit“" mit einem differenzierten „Meinungsbild“ begegnen zu wollen. ${ }^{1582}$ Erkennbar ist das forscherische Erkenntnisinteresse infolge der gesunkenen Konfliktivität der einstigen politischen Polarisierung hier auf eine Aktualisierung der Daten zusammengeschrumpft. Gewiss, in den politischen Einstellungsdimensionen war sie noch messbar, die Spaltung zwischen unverändert hohem (wenn auch stagnierendem) Zuspruch zu „grün-alternativen" und sozialdemokratischen Strömungen einerseits und einem leichten Zugewinn an liberalen und christlich-konservativen Positionen ${ }^{1583}$ andererseits. Doch der neue dominierende Trend zwischen 1985 und 1987, diametral demjenigen zwischen 1983 und 1985 entgegengesetzt, ${ }^{1584}$ wies in Richtung Harmonie- und Sekuritätsorientierung. Schließlich fiel die Unterstützung sozialistischer Ziele wie die Festlegung einer Einkommenshöchstgrenze oder die Abschaffung des Privateigentums stark; demgegenüber reüssierten stabilitätsorientierte wie markt- und wettbewerbsfreundliche Positionen, generell „moderate Reformziele“, aber auch ein erhöhtes Risikobewusstsein. ${ }^{1585}$ Spürbar also haben sich - insbesondere mit Blick auf die 1990er Jahre - die Studierenden hinsichtlich ihrer politischen Präferenzen entpolarisiert.

1577 Dennoch ist der an anderer Stelle getätigte Hinweis, dass die Ablehnung gewalttätiger Handlungen gegen Sachen noch einmal deutlich geringer ausfällt (25 Prozent) als im Falle von gegen Personen gerichteter Gewalt (8 Prozent), zu berücksichtigen. Vgl. Jaide, Walter/Veen, Hans-Joachim: Bilanz der Jugendforschung. Ergebnisse empirischer Analysen in der Bundesrepublik Deutschland von 1975 bis 1987, Paderborn 1989, S. 209.

1578 Vgl. Studierendensurvey 1980er, S. $226 \mathrm{f}$.

1579 Vgl. ibid., S. 235.

1580 lbid., S. 228.

1581 Vgl. ibid., S. 229-232.

1582 Ibid., S. 212.

1583 Ibid., S. 222-225.

1584 Vgl. 4. Studierendensurvey 1989/90, S. 60.

1585 Studierendensurvey 1980 er, S. 220 f. und S. 241. 
Im Wintersemester 1989/90 erreichte das studentische politische Interesse mit 55 Prozent ein letztes Mal den vormaligen Höhepunkt von 1983, während das distanzierte Verhältnis zur Hochschulpolitik mit 7 Prozent stark Interessierten und ca. 40 Prozent überhaupt nicht Interessierten unverändert blieb. Erstmals überholten die Studierenden der Rechtswissenschaften sowohl hinsichtlich des politischen Interesses (70 Prozent stark Interessierten) als auch in Kategorien des politischen Engagements die Sozialwissenschaften. ${ }^{1586}$ Das Selbstverständnis als Phalanx der Demokratie festigte sich weiter: Das „Grundverständnis einer pluralistischen, offenen und kontroversen, dabei gewaltfreien Demokratie“ wurde „nahezu einmütig geteilt“. ${ }^{1587}$ Im Konflikt zwischen der Priorität des Rechts auf Streiks und Demonstrationen und des Rechts auf öffentliche Ordnung neigten die Studierenden knapp, aber doch tendenziell letzterer $\mathrm{uu}^{1588}$ Eine überwältigende Mehrheit von 90 Prozent lehnte Gewalt als Mittel der Konfliktaustragung ab. ${ }^{1589}$ Erhöhter Popularität erfreuten sich die Sicherung der freien Marktwirtschaft und des privaten Unternehmertums (74 Prozent Zustimmung) sowie die Forderung nach harter Bestrafung von Kriminellen (49 statt 42 Prozent 1985); dagegen verloren der Ausbau der Kernenergie, die Erhöhung der Militärausgaben, aber auch sozialistische Ideen wie die Abschaffung des Privateigentums im selben Zeitraum drastisch an Rückhalt. ${ }^{1590}$ Die Zustimmung zur Aussage: „Ohne Wettbewerb strengen sich die Menschen nicht an" stieg seit 1983 von 30 auf 45 Prozent, war somit beinahe mehrheitsfähig, wobei Studentinnen sowohl die Chancen- als auch Leistungsgerechtigkeit deutlich skeptischer beurteilten und ein fortschreitendes Abtragen gesellschaftlicher Solidarität monierten. ${ }^{1591}$ Als die drei wichtigsten gesellschaftspolitischen Ziele identifizierte man die Geschlechtergleichstellung, den Primat des Umweltschutzes vor ökonomischem Wachstum und die Stabilität der sozialen und wirtschaftlichen Verhältnisse. ${ }^{1592}$ Obwohl man zudem die wirtschaftliche Stabilität und soziale Sekurität als grundsätzlich konsolidiert, die eigenen Aufstiegschancen zunehmend als günstig wahrnahm, stieg die Distanz zu den „politischen Verhältnissen“: die „Lebensqualität der Menschen“ werde zugunsten industrieller Interessen vernachlässigt. ${ }^{1593}$ Alternative Orientierungen verloren an Universitäten weiter an Rückhalt, während mittlerweile 51 Prozent der Studierenden (1983: 38 Prozent) den Verzicht auf materiellen Wohlstand ablehnten. ${ }^{1594}$

So sind die 1980er Jahre, das Jahrzehnt nach dem bisher größten Bildungsexpansionsschub, mit Blick auf die politischen Einstellungen und Orientierungen der bundesrepublikanischen Studierenden insgesamt gekennzeichnet durch einen verblassenden Konflikt zwischen „linken“ (bzw. alternativen) und „rechten“ (bzw. konventionalistischen) Selbstverständnissen, mithin durch einen Zug zur mentalitären „Vermittung“ der Studierendenschaft, d. h. einem Abschmelzen sowohl des links-progressiven bzw. alternativen Lagers als auch des bürgerlich-traditionellen Lagers. Die Studierenden ent-

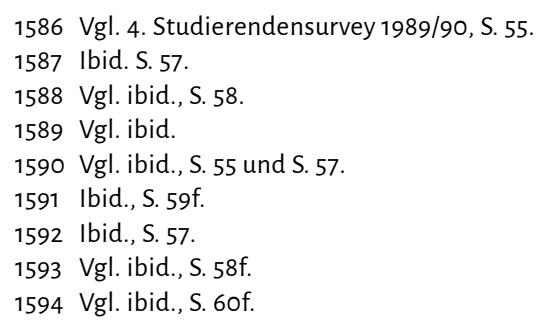


politisierten sich, übten einen „Rückzug aus dem öffentlichen Leben ${ }^{\text {“1595 }}$, aber intensivierten auch ihre prodemokratischen Überzeugungen. Im Laufe der Beforschung der Studierenden verlor das wenige Jahre zuvor intensiv diskutierte Verhältnis der Studierenden zu Demokratie und gesellschaftlichen Institutionen an prosaisch-dramatischer Qualität, sicher auch schlicht an Aktualität. So geriet unter anderem die anfängliche, an Studien der 1970er Jahre anschließende Frage nach Interdependenzen zwischen perzipierten Berufschancen, gesellschaftskritischen Impulsen und politischer Radikalität aus dem Blickfeld. Zwar wurde das politische Potenzial, verstanden als politische Aktivitätsbereitschaft, von den Autoren des Studierendensurveys unverändert als hoch eingeschätzt, dennoch kommen die hier diagnostizierten Entwicklungen retrospektiv betrachtet einer zukunftsweisenden politischen Ausdifferenzierung und Individualisierung, mithin einer bildungsgesellschaftlichen Modernisierung der studentischen Orientierungen gleich.

Für den politikwissenschaftlichen Blick ist mit diesen Entwicklungen seit den späten 1980er Jahren ein wahrer evergreen der Erforschung von Studierenden im Speziellen und Jugendlichem bzw. jungen Erwachsenen im Allgemeinen vorgegeben: die Diagnose eines schwindenden Vertrauens in demokratische Institutionen und eines versiegenden Interesses an der politischen Praxis, vulgo: einer grassierenden „Politikverdrossenheit" ${ }^{1596}$

\section{II.3.3 Sinkende Relevanz von Politik, Protestnostalgie und neue Bedenken: die 1990er und 2000er Jahre}

$\mathrm{Zu}$ Anfang dieses Kapitels ist bereits auf jene Mehrdimensionalität gesellschaftlicher Entwicklungen verwiesen worden, die sich grundsätzlich gegen eine bündige Charakteristik von Dekaden sperrt. Dem ist hinzuzufügen, dass die 1990er Jahre „ein besonders vielschichtiges, auch widersprüchliches Jahrzehnt“, eine spezifische Mixtur aus „Veränderung und Stillstand“ ${ }^{1597}$ beschreiben. Die Wiedervereinigungseuphorie ging zum Tagesgeschäft der Strukturentwicklung der Ex-DDR über, deren Bevölkerung zunehmend von Sorgen um die eigene Existenzsicherung geplagt wurde; vielfach wurde ein „Rollback“der Liberalisierungserfolge seit „1968“ konstatiert, die soziale Horizontalisierung der Bildungsexpansion stagnierte, und im Zuge neoliberaler Politikmoden sowie des „New Economy“-Booms wurde nicht nur der Sozialstaat, sondern wurden in besonderem Maße auch die Bildungsinstitutionen nach wirtschaftlichen Effizienzkriterien restrukturiert. ${ }^{1598}$ Wirtschaftsfreundliche Stimmen monierten einen Reformstau im vermeintlich schwerfälligen, überlebten Wohlfahrtsstaat Deutschland, ${ }^{1599}$ während die zur Mobilisierung ihrer Kräfte aufgerufene Erwerbsbevölkerung zunehmend mit dem von Stefan Hradil beobachteten „Wandel des Wertewandels“, der „neue[n] Suche nach

1595 Bargel: Wandel politischer Orientierungen, S. 3.

1596 Ibid., S. $3 f$.

1597 Walter: Rebellen, Propheten, Tabubrecher, S. 331.

1598 Vgl. ibid., S. 330-335 sowie Kapitel II.1 dieser Studie.

1599 Vgl. ibid., S. 332. 
Sicherheit, Ordnung und Gemeinschaft in einer individualisierten Gesellschaft ${ }^{\text {(1600 }}$ reagierte: Nicht mehr (nur) Selbstverwirklichungsräume und Autonomiegrade, sondern auch Orientierungsmöglichkeiten und Zugehörigkeiten, Polster gegen die als risikobehaftet und entstrukturiert perzipierte Erwerbs- und Alltagswelt, etablierten sich zunehmend als Sehnsuchtsorte vor allem junger Menschen. ${ }^{1601}$ „Die Klagen über Erschöpfung begannen in diesem Jahrzehnt. [...] Die fortschreitende Mehrung postmaterieller Einstellungen stoppte signifikant. Das Pendel des Wertewandels schien zurückzuschlagen, zumindest auszusetzen, zu pausieren.“1602 Entwicklungen, die sich - nicht nur, aber auch - im Zuge der um die Signalbegriffe und Slogans von „Chancen“, „Leistung“, „Bildung“, „Fördern und Fordern“, dem „lebenslangen Lernen“, dem „aktivierenden Staat" etc. zentrierten workfare- bzw. Agenda-Politik der bis 2005 regierenden Koalition von Sozialdemokraten und Grünen in den $2000 e r$ Jahren fortsetzten, ${ }^{1603}$ und die bis heute das Spektrum gesellschaftspolitischer Kernmaximen dominieren. Denn „das meritokratische Prinzip ist weiterhin common sense, vielleicht zu Beginn des einundzwanzigsten Jahrhunderts stärker denn je. ${ }^{1604}$ Leistungs-, Chancen-, und Bildungsgerechtigkeit, im Kern (bildungs-)bürgerliche Maximen und seit dem 19. Jahrhundert als triebstrukturell konditionierte Sklavenmoral kapitalistisch vergesellschafteter Individuen wiederholt ideologiekritisch attackiert ${ }^{1605}$, ja bei näherem Hinsehen sowohl von der gegenüber dem sozialen „Unten“ sich panzernden gesellschaftlichen Mitte ${ }^{1606}$ als auch von jungen Erwachsenen ${ }^{1607}$ mit Zweifeln bedacht, bilden ungebrochen die dominante Deutungsfolie sozialpolitischer Ansprüche, Hoffnungen und Frustrationen, vielleicht tatsächlich das letzte Residuum einer sinnstiftenden und alltagsleitenden „Meistererzählung «1608.

1600 Hradil, Stefan: Der Wandel des Wertewandels. Die neue Suche nach Sicherheit, Ordnung und Gemeinschaft in einer individualisierten Cesellschaft, in: Budrich Journals, Jg. 51, H. 4/2002, S. 409420.

1601 Vgl. ibid.

1602 Walter: Rebellen, Propheten, Tabubrecher, S. 330.

1603 Vgl. Walter: Zeiten des Umbruchs?, S. 88-97.

1604 Walter, Franz/Marg, Stine: Von der Emanzipation zur Meritokratie. Betrachtungen zur 150-jährigen Geschichte von Arbeiterbewegung, Linksintellektuellen und sozialer Demokratie, Göttingen 2013, S. 96.

1605 Vgl. exemplarisch Marcuse, Herbert: Triebstruktur und Cesellschaft. Ein philosophischer Beitrag zu Sigmund Freud [1955], Frankfurt a.M. 1967, S. 49f., vgl. ferner den instruktiven Akzent auf dem Doppelcharakter ideologischen Bewusstseins zwischen „richtiger" Abbildung gesellschaftlicher Verhältnisse und zugleich „falscher" Rechtfertigung ebendieser in Lenk, Kurt: Ideologie. Ideologiekritik und Wissenssoziologie, Frankfurt a.M./New York 1984, S. 36of. Zu neueren, wenngleich intellektuell deutlich dürftigeren Versuchen, die im Meritokratiegedanken ein verwerfliches „Verwertungsprinzip“ am Werk sehen, vgl. Ribolits: Abschied vom Bildungsbürger S. 9-20 und Distelhorst, Lars: Leistung. Das Endstadium der Ideologie, Bielefeld 2014, S. 33-55.

1606 Vgl. Walter/Marg: Von der Emanzipation zur Meritokratie, S. 109f. sowie Marg: Mitte in Deutschland, S. 175-182.

1607 Vgl. Schenke et al.: PECIDA-Effekte?, S. 236.

1608 Vgl. Jarausch, Konrad H./Sabrow, Martin: „Meistererzählung“. Zur Karriere eines Begriffs, in: Dies. (Hg.): Die historische Meistererzählung. Deutungslinien der deutschen Nationalgeschichte nach 1945, Göttingen 2002, S. 9-31. 
Vor diesem Hintergrund wird verständlich, warum sich die deutsche Studierendenschaft auch in den 1990er Jahren immer weniger durch (fundamental-)oppositionelles Potenzial oder weltanschauliche Antagonismen auszeichnete - eine veritable Trendfortsetzung seit etwa Mitte der 1980er Jahre. Dass die Thematik schon zuvor an gesellschaftlicher Virulenz eingebüßt hatte, spiegelt sich in der bereits erwähnten Begründungsarmut des Interesses am Verhältnis von Studierenden und Politik im zusammenfassenden Bericht zu den ersten drei Studierendensurveys von 1989. Vorerst letztmalig und ohne Erläuterung des zugrundeliegenden Erkenntnisinteresses wurde dieser Bereich im Hauptbericht des 4. Studierendensurveys aufgeführt. ${ }^{1609}$ Vergleichsdaten erhob man zwar weiterhin kontinuierlich - mit der singulären Ausnahme des 8. Studierendensurveys zur Jahrtausendwende ${ }^{1610}$-, führte sie jedoch zwischen 1993 und 2012 nach Rücksprache mit dem Auftraggeber nicht mehr auf, einerseits um die Berichte insgesamt zu kürzen, andererseits um Platz für wechselnde aktuelle Themen zunächst natürlich prominent: die Angliederung der ehemaligen DDR - zu schaffen. ${ }^{1611}$ Tatsächlich geht es seit den 1990er Jahren im hier interessierenden Bereich politischer Orientierungen deutlich weniger bewegt zu. Studentische Einstellungsmuster verändern sich, auch bis weit in das neue Jahrtausend hinein, mehr graduell als sprunghaft; der Neuigkeitswert der jeweils erscheinenden Zahlen nimmt angesichts veränderter gesellschaftspolitischer Rahmenbedingungen ab. Diskussionen über die „Politikverdrossenheit" der (akademischen) Jugend, die bereits in den 1980er Jahren einsetzten, werden in diesem Zeitraum allmählich zur verbreiteten Kerndiagnose. $\mathrm{Da}$ - abgesehen von einzelnen Schwerpunktberichten und Zeitungsaufsätzen - die erhobenen Daten nicht mehr auf gesamtgesellschaftliche Entwicklungen rückbezogen und diskutiert werden, mag nun eine geraffte Darstellung der groben Entwicklungen zwischen 1993 und 2007 ausreichen.

Das politische Interesse der Studierenden, nun unter Einbezug der Studierenden in den Neuen Bundesländern und insgesamt als „sattelfeste Demokraten“ bezeichnet ${ }^{1612}$,

1609 Vgl. 4. Studierendensurvey 1989/90, S. 55-61.

1610 Die Erhebungsdurchführung wird für die 1990er Jahre nachgewiesen im 8. Studierendensurvey 2000/01, S. 5; zur Bekräftigung für das darauffolgende Jahrzehnt vgl. die Zusammenstellung der Zahlen von 1993 bis 2013. im 12. Studierendensurvey 2012/13, S. 48f. und S. 407-438 ferner den Datenalmanach Studierendensurvey 2017.

1611 So die schriftliche Auskunft eines langjährigen Mitarbeiters der AG Hochschulforschung Konstanz.

1612 Bargel, Tino: Studierende und Politik im vereinten Deutschland. Bildung-Wissenschaft-aktuell, $\mathrm{H}$. 3/1994. Tino Bargel stellte 1994 zwar eine stärkere Orientierung der ostdeutschen Studierenden in Richtung einer „schnellen Angleichung der Lebensbedingungen [d. h. sowohl in Bezug auf materielle Sicherheiten als auch hinsichtlich demokratischer Partizipationsmöglichkeiten, J. S.] in den alten und neuen Bundesländern" fest, ferner eine stärkere Polarisierung in nationalkonservative und "sozialistisch-marxistische“ politische Grundrichtungen, vgl. Bargel, Tino: Zum politischen Potential der Studierenden an Universitäten in Ost- und Westdeutschland, in: hochschule ost. politisch-akademisches journal aus ostdeutschland, 3. Jg., H. 3/1994, S. 9-18, hier S, 12f. Gewiss haben diese differierenden Orientierungen einen großen Einfluss auf die in den 1990er Jahren schwankenden Zahlen. Dabei scheinen aber wesentliche politische Mentalitätstrends - mit einzelnen Ausnahmen wie der Akzeptanz demokratischer Konfliktivität - bis Ende des Jahrzehnts zunehmend parallel zu verlaufen, vgl. Bargel, Tino: Wandel des politischen Bewußtseins, insbesondere S. 4-6 sowie Bargel: Wandel politischer Orientierungen, S. 5. Zudem fehlen gesonderte Auswertungsdaten in den Datenalmanachen, und auch die Hauptberichte des Studierendensurveys füh- 
schwankte in jenem Zeitraum, weist insgesamt aber einen abnehmenden Trend auf: Waren 1983 noch 54 Prozent und 1993 noch 47 Prozent von ihnen sehr stark interessiert (5 Prozent überhaupt nicht), sank der Wert zunächst auf 41 Prozent 1998 (8 Prozent überhaupt nicht) und schließlich auf 37 Prozent 2007 (10 Prozent überhaupt nicht). Einen auffälligen Ausreißer bildet das Jahr 2001 mit 47 Prozent sehr starkem Interesse. ${ }^{1613}$ Immer weniger Studierende beurteilten sich als politisch „links“ oder „rechts" stehend: Während man noch in den 1990er Jahren auf der Grundlage dieser Zahlen das „linke Potential“ an Universitäten auf etwa ein Drittel beziffern konnte, schrumpfte ebendieses bis 2007 auf ein Viertel, wobei zwei weitere Viertel sich als „eher links" und mittig einstuften; demgegenüber blieb - hierin relativ stabil - der Anteil der „klar Rechten“ mit 2 bis 3 Prozent (1983: 5 Prozent) wie der „eher Rechten“ mit 10 Prozent (1983: 12 Prozent) marginal. ${ }^{1614}$ Dem korrespondierend, beobachtete man andernorts eine Beschleunigung der Entpolitisierung, einen wachsenden „politischen Rückzug“ der Studierenden und ein massives Misstrauen gegenüber dem Parteiensystem und den demokratischen Institutionen (bei unveränderter Unterstützung der Parteien SPD und Bündnis 90/Die Grünen und mehrheitlicher Befürwortung der Demokratie). ${ }^{1615}$ Eine von der ZEIT in Auftrag gegebene Studie von Infratest Burke kam hier allerdings zu provokant abweichenden Ergebnissen einer politisch hoch interessierten Studierendenschaft, einer gesunkenen Parteienverdrossenheit, einer gewachsenen politischen Aktivitäts- bzw. Engagementbereitschaft und einer durchaus gegebenen Kompatibilität mit rechten bzw. autoritären Politikvorstellungen. ${ }^{1616}$

Dass die Studierenden immer stärker in Richtung politischer Abstinenz tendierten, zeigen die Zahlen zum politischen Aktivitätsgrad, zur Protestbereitschaft und zu Wertehierarchien: Der Kreis der Inaktiven in allen traditionellen und flexiblen Engagementformen weitete sich aus (Bürgerinitativen: von 60 Prozent nicht Beteiligten und nicht Interessierten 1995 auf 72 Prozent 2004; Parteien: von 74 Prozent nicht Beteilig-

ren ihre Ergebnisse zu politischen Orientierungen seit der Wiederaufnahme dieses Bereichs 2012 nicht mehr zwischen Ost und West vergleichend auf. Aus diesen Cründen wird die deutsche Studierendenschaft auch hier als Gesamtheit verhandelt.

1613 Vgl. Datenalmanach Studierendensurvey 2017, S. 215 sowie Bargel: Wandel politischer Orientierungen, S. 7.

1614 Bargel: Wandel politischer Orientierungen, S. 13.

1615 Vgl. Brämer, Rainer: Studis im Vakuum. Empirische Befunde zum politischen Rückzug der studentischen Jugend, in: WSI-Mitteilungen, Jg. 46, H. 4/1993, S. 194-200, zit. nach Demirović, Alex/Paul, Gerd: Demokratisches Selbstverständnis und die Herausforderung von rechts: Student und Politik in den neunziger Jahren, Frankfurt a.M. 1996, S. 31. Ähnlich aber auch Bargel: Wandel politischer Orientierungen, S. 14.

1616 Vgl. Fritz-Vannahme, Joachim: Die optimistische Generation Student '95: Die große ZEIT-Umfrage unter Deutschlands Studenten korrigiert das Klischee von den unpolitischen Bummelanten. Sie halten Werte hoch, engagieren sich in ihrem privaten Umkreis und jobben neben dem Studium, in: Die Zeit, 20.10.1995, online einsehbar unter: https://www.zeit.de/1995/43/Die_optimistische_ Ceneration_Student_95_Die_grosse_ZEIT-Umfrage [eingesehen am 01.08.2019] Die zugrundeliegende Studie findet sich in Infratest Burke: Student '95. Eine repräsentative Umfrage von Infratest Burke $\mathrm{GmbH}$ Berlin im Auftrag der Wochenzeitung Die Zeit, Hamburg/Berlin 1995. Kritiker vermissen hier allerdings eine einordnende Differenzierung der Ergebnisse zwischen Ost und West, vgl. Demirović/Paul: Demokratisches Selbstverständnis, S. $31 \mathrm{f}$. 
ten und nicht Interessierten 1995 auf 79 Prozent $2004^{1617}$; „Umweltschutzgruppen“: 62 Prozent „teilnahmslose“ Studierende im Jahr 2004 statt 43 Prozent 1995! ${ }^{1618}$ ). Alternative Orientierungen haben unter den Studierenden bis 2004 ihre einstmalige Kohärenz eingebüßt, seien „stärker in einzelne Elemente zerfallen“, bezeichneten mehr entleerte Slogans als spezifische Sets von Denkinhalten und Zielen. Selbstverwirklichung bilde nicht mehr das dominante „Lebensziel“, und auch das Streben nach Autonomie richte sich nicht mehr auf „andere“ Arbeits- und Lebensformen, sondern markiere „vordergründige Selbstbehauptung bei allgemeiner Anpassung und Konventionalität“ ${ }^{1619}$ Demgegenüber fiel die „starke Renaissance der Herkunftsfamilie, verstanden als eine Rückbesinnung auf die private Einbindung und Tradition ${ }^{41620}$, auf. Politische Vorgänge erschienen einem leicht größeren Teil der Befragten komplizierter, die Verantwortlichkeitsempfindung gegenüber Politik sank. ${ }^{1621}$ Traditionell gering blieb durchweg das Interesse an Hochschulpolitik und studentischer Politik. ${ }^{1622}$

Die demokratischen Einstellungen und politischen Zielpräferenzen bezeugen im betrachteten Zeitraum einen steigenden Wunsch nach Ordnung, Stabilität sowie nach Absicherung gegenüber Risiken und Ängsten, ${ }^{1623}$ aber auch ein robustes prodemokratisches Wertesetting: Die entschiedene Verteidigung der Meinungs- und Demonstrationsfreiheit fiel 2007 mit 77 Prozent der Studierenden zwar geringer aus als in den zwei Jahrzehnten zuvor (die Werte schwankten zwischen 80 und 90 Prozent), blieb aber fraglos hegemonial; auch fand durchweg nur eine verschwindend geringe Minderheit Gewalt als Mittel der Konfliktaustragung legitim. ${ }^{1624}$ Dass Auseinandersetzungen zwischen Interessengruppen dem Gemeinwohl schaden könnten, fanden 1993 nur 18 Prozent der Befragten plausibel, 2004 dann 33 bzw. 200728 Prozent, ${ }^{1625}$ während das Verständnis für diese Interessenstreits allgemein zwischen 1990 und 2007 von 69 Prozent auf nur mehr 32 Prozent zusammensackte. ${ }^{1626}$ Die Priorität des Demonstrationsrechts gegenüber der öffentlichen Ordnung verteidigten 2007 nur noch 31 Prozent der Studierenden statt einer knappen Hälfte wie noch von 1983 bis $1990 .{ }^{1627}$ Für eine kritische Opposition optierten immer weniger Studierende (nur noch 22 Prozent entschieden Zustimmende 2004 bzw. 24 Prozent 2007 statt 53 Prozent im Jahr 1990!), während 37 Prozent (2007 gegenüber 20 Prozent 1993) deren Aufgabe vor allem in der Unterstützung der Regierungsarbeit sahen; Das Recht, für die eigenen Überzeugungen auf die Straße zu gehen, wird durchweg von gut 90 Prozent der Studierenden bekräftigt und von fast niemandem bezweifelt. ${ }^{1628}$ Bargel leitet aus den verfügbaren Zahlen $1998 \mathrm{ab}$, dass sich

1617 Vgl. Bargel: Wandel politischer Orientierungen, S. 9.

1618 Ibid., S. 10.

1619 Ibid., S. $39 f$.

1620 Ibid., S. 9.

1621 Vgl. ibid., S. 11.

1622 Vgl. ibid., S. 27.

1623 Ibid., S. 19.

1624 Vgl. ibid. und ibid., S. 21.

1625 Vgl. Datenalmanach Studierendensurvey 2017, S. 216.

1626 Vgl. Bargel: Wandel politischer Orientierungen, S. 21.

1627 Vgl. ibid.

1628 Vgl. ibid. 
die Studierenden in zunehmendem Maße von der konkreten parlamentarisch-politischen Arbeit und von den demokratischen Institutionen abgestoßen fühlten und differenziert sie in "prinzipiell-vehemente“, „moderat-unauffällige“ sowie „konventionellformale" Demokraten mit ihren je spezifischen Gefährdungspotenzialen. ${ }^{1629}$ Insgesamt hält er einen „tiefgreifenden Wandel im Demokratieverständnis“ der Studierenden fest: Kontroverse bzw. konfliktive Elemente der Demokratie träten erkennbar auf ein zunehmend geringeres Verständnis; im Grunde optierten die Studierenden 2004 und 2007 demnach „für eine ,große Koalition" bei geringer Opposition“. ${ }^{1630}$ Und noch eine weitere grundlegende Veränderung fiel auf: Studierende schreckten in einem solchen Maße vor „Festlegungen“ und öffentlichen Positionierungen zurück, neigten in derart bedenklicher Weise zu labilen „diffusen“ Haltungen und zur Distanzierung von demokratischer Pluralität bzw. Konfliktivität, dass schließlich das demokratische Potenzial nachhaltig beschädigt werde; ${ }^{1631}$ als „labile Demokraten“ werden sie mithin tituliert. ${ }^{1632}$

Auch in den Zustimmungswerten zu gesellschaftspolitischen Zielen macht sich für die betrachteten Jahre ein Trend zu einem restriktiveren Schutz der bestehenden öffentlichen Ordnung und zu stärkeren materiellen Orientierungen geltend: Die Befürwortergruppe einer „harten Bestrafung von Kriminalität“ wuchs zwischen 1993 und 2007 von 67 auf 73 Prozent (während die Gruppe der ablehnenden Stimmen von 20 auf 14 Prozent schrumpfte), die Abwehr „kultureller Überfremdung“ wünschten sich statt 18 Prozent (1993) nunmehr 32 Prozent (2007). Zugleich wünschte sich eine größere Zahl der Studierenden eine „verstärkte Förderung technologischer Entwicklungen“ (79 Prozent 2007 statt 58 Prozent 1993), eine geringere Zahl favorisierte die „Priorität des Umweltschutzes vor wirtschaftlichem Wachstum“ (72 Prozent 2004 bzw. 76 Prozent 2007 statt 90 Prozent 1993). Die Gleichstellung der Geschlechter bleibt durchweg eines der wichtigsten politischen Ziele, auch wenn Zahl der entschlossenen Verfechter von 85 Prozent (1985) auf 71 Prozent (2007) sank. ${ }^{1633}$ Insgesamt blieb eine Vorstrukturierung der politischen Zielhierarchien durch die politisch-weltanschaulichen Grundhaltungen (,kom-

1629 „Die prinzipiell-vehementen Demokraten finden sich vor allem in den Sozialwissenschaften und im Sozialwesen sowie in den Ceistes- und Sprachwissenschaften; für sie ist zumeist die Kluft zwischen demokratischen Prinzipien und demokratischer Wirklichkeit besonders groß; ihre Kritik an Parteien und Politk härter. Die moderaten-unauffälligen Demokraten sind am häufigsten in den Naturwissenschaften und in der Medizin vertreten; ihr politisches Interesse und Engagement ist zwar geringer, sie erscheinen aber zugleich wenig durch anti-demokratische Tendenzen verführbar; Die konventionell-formalen Demokraten sind häufig in der Rechtswissenschaften an Universitäten zuhause sowie in den Wirtschafts- und Ingenieurwissenschaften an Fachhochschulen wie Universitäten; sie vertrauen überwiegend den vorhandenen Institutionen, äußern nur wenig Reformbedarf und setzen mehrheitlich auf Ruhe und Ordnung. Bei diesen jeweiligen Typen bleiben spezifische Gefährdungen zu beachten: Beim konventionellen Typus kann formaler Legalismus zu blinder Anpassung führen, auch an unvertretbare Verhältnisse. Beim prinzipiellen Typus vermag Kritik und Idealismus dogmatisch zu erstarren und in sektiererischen Aktionen enden. Derartige Gefährdungen sind bei gewissen Teilen der Studierenden durchaus zu beobachten." Bargel: Wandel des politischen Bewußtseins, S. 6.

1630 Ibid., S. 22.

1631 Ibid.

1632 Ibid., S. 26.

1633 Datenalmanach Studierendensurvey 2017, S. 220, vgl. auch Bargel: Wandel politischer Orientierungen, S. 17. 
munistisch“, „grün/alternativ“, „, sozialdemokratisch“, „liberal“, „christlich-konservativ“, „national-konservativ“) erhalten, allerdings in eher schwindenden Konturen: Es ist für die Erhebung von 2007 nur noch von einer "gewisse[n] Lagerbildung“ die Rede. ${ }^{1634}$

Angesichts der Kontrastfolie der 1970er und 1980er Jahre schienen diese Zahlen zunächst ein drastisch gesunkenes politisches Potenzial unter den Studierenden nahezulegen. Es hatte sich offenbar weder die Bereitschaft zu Demonstrationen noch zu „öffentlich-aggressivem“, d. h. zu Boykottaktionen und Institutsbesetzungen bereitem Protest zwischen 1983 und 2007 erkennbar reduziert; nur etwa ein Drittel der Studierenden zeigte sich dem gänzlich abgeneigt. ${ }^{1635}$ Und tatsächlich meldeten die Studierenden gegen Ende der 200oer Jahre deutliche Zweifel an der Gerechtigkeit sozialer Unterschiede in der Bundesrepublik an, insbesondere auch an der Gültigkeit des Leistungsprinzips als Vehikel des sozialen Aufstiegs, eine Verschärfung seit den 1990er Jahren. ${ }^{1636}$ Ihr Gesellschaftsbild fiel somit restriktiv, chaotisch, kaum noch normen- oder wertedurchwirkt aus, was auch das verlegene, fast trotzige Ausweichen auf vereinzelte optimistische Züge kaum verbergen kann. ${ }^{1637}$ Dass hierin ein gravierendes Frustrationspotenzial liegen könnte, ist eine naheliegende Schlussfolgerung. ${ }^{1638}$ Mit Blick auf die weitgehend zergangenen politischen Konfliktlinien war allerdings auch 2007 schon fraglich, ob und inwiefern sich dieses weiterhin vorhandene Potenzial überhaupt noch im Sinne einer breiteren, organisierten und weltanschaulich gebündelten „Bewegung“ realisieren mag. ${ }^{1639}$

Im diametralen Gegensatz zu jenen Beiträgen, die in den 1970er Jahren die Ursachen des vorwiegend linksradikalen studentischen Protests ergründeten, ist es daher nun nicht mehr die drohende Radikalität bzw. Polarisierung der Studierendenschaft gewesen, die konsternierte Kommentare auslöste, sondern gerade deren Positierungsmüdigkeit und Apathie in Fragen politischer Praxis. So resümiert Tino Bargel, Mitgründer und langjähriger Mitarbeiter des Studierendensurveys mit dem Schwerpunkt politischer und gesellschaftlicher Orientierungen, schon 1998, dass Studierende zwar „mehrheitlich nicht als apathisch bezeichnet werden“ können, da sie „überwiegend und noch immer ein relativ aktives und mitgehendes Publikum (eher buhend als applaudierend)“

1634 Vgl. Bargel: Wandel politischer Orientierungen, S. 17-19.

1635 Ibid., S. 43-45.

1636 Vgl. ibid., S. $35 f$.

1637 Vgl. ibid., S. $36 f$.

1638 „Der sich stabilisierende Trend eines Zweifels an fairen Aufstiegschancen und an der Geltung des Leistungsprinzips ist für die junge Generation der Studierenden besonders problematisch, insbesondere für die Bildungsaufsteiger unter ihnen, für die der Hochschulbesuch eine besondere Leistung bedeutet." Ibid., S. 35

1639 „Das Protestpotential, auch in aggressiver Weise, ist unter den Studierenden groß genug, so dass es jederzeit aufflammen kann. [...] Ob es sich allerdings um mehr als ein ,Strohfeuer' des Protestes handelt, das hängt einerseits von den Reaktionen der Instanzen an den Hochschulen und in der Politik ab, andererseits vom Umstand, ob sich daraus ein auf Konzepten und Prinzipien gegründete Bewegung bildet. Breitere und schärfere Formen, auch in langfristiger Weise, erhält der Protest mit höherer Aggressivität erst dann, wenn eine ,System - und Machtfrage' damit gestellt wird. Eine solche ,Protestwelle' größeren Ausmaßes ist für den nächsten Zeitraum nicht absehbar. Sie könnte sich erst mit einer neuen Studentengeneration bilden." Ibid., S. 45. 
seien. ${ }^{1640}$ Stark zurückgegangen aber sei die Fähigkeit zum aktiven politischen Engagement insbesondere in der Hochschulpolitik und insbesondere unter Studierenden der Geistes- und Sozialwissenschaften, zur Herausbildung von Organisationskompetenz und zum Wahrnehmen eines "selbstbewußten politischen Mandates“; so seien sie „viel seltener als früher engagiert oder bewegte Akteure, noch seltener Gladiatoren in

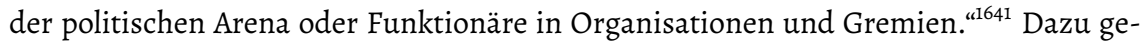
selle sich die Renaissance konventioneller und materieller Orientierungen sowie das völlige Verpuffen „weitreichender System- und Herrschaftskritik“: Weder die bis in die frühen 1970er Jahre prägenden sozialistisch-kommunistischen Ideen ${ }^{1642}$ noch die bis zu den frühen 1990er Jahren auffindbaren alternativen Orientierungen erfreuten sich noch substanziellen Rückhalts. Insgesamt mangele es an Kohärenz der zunehmend „diffus und disparat" ausfallenden politischen Orientierungen. ${ }^{1643}$ Auch der Studierendenstreik von 1997, so gesehen ein „Strohfeuer“, habe keine breitere Politisierung über den unmittelbaren Aktivistenkreis hinaus bewirken können: „Studierende lassen sich lieber auf Ideen und Bewegungen ein, verbunden mit Betätigungen in informellen Aktionen und Gruppierungen. ${ }^{\text {“644 }}$ Eine Entwicklung, die sich allerdings bereits seit Kriegsende angedeutet habe. Insgesamt mache sich „eine eigentümliche Gleichgültigkeit breit, ein Rückzug auf die Zuschauerrolle. Eine Mischung aus Ernüchterung und Resignation ist eingetreten. ${ }^{، 645}$ Bedenklich sei das unter anderem deshalb, weil Gleichgültigkeit auch Verantwortungslosigkeit bedeuten könne, ferner weil „ein egoistischer Individualismus mit manchen Zügen des sozialen Autismus und der Inhumanität" sich insbesondere „bei jenen“ bemerkbar mache, die „an die Schalthebel der Macht streben“. ${ }^{1646}$ Eine angesichts des historischen Vorlaufs besonders entscheidende Beobachtung verdient hier hervorgehoben zu werden: „[D]ie, Friedensbewegung w war die letzte dieser Art, die noch größere Teile der Studentenschaft erfaßt hat. ${ }^{\text {"1647 }}$

Bei vielen, die sich politisches Engagement vonseiten der Studierendenschaft wünschten - sei es, weil sie sich davon Innovationskraft für den „Standort Deutschland" oder einen Motor linkssozialistisch-reformerischer Bestrebungen erhofften -, wuchs sich der Bedeutungsschwund der Thematik des politischen Potenzials von Studierenden gegen Mitte der 1990er Jahren nachgerade zu einer Protestnostalgie aus. Nicht nur beklagten alarmistische Stimmen - angesichts eines Rückgangs der Hochschullehrern bei wachsenden Studierendenzahlen und angesichts der vielerorts

1640 Bargel: Wandel des politischen Bewußtseins, S. 3.

1641 Ibid.

1642 Hier ignoriert Bargel allerdings eines der zentralen Ergebnisse der Studie zur „unruhigen Ceneration" von Wildenmann und Kaase, nämlich dass die Mehrheit der linken Studierenden Ende der 1960er Jahre gerade nicht die revolutionären Ziele des SDS teilte, sondern die linksradikale Rhetorik zuvörderst nutzte, um ihr Bedürfnis nach partizipationsfördernden gesellschaftlichen Reformen zu verbalisieren. Vgl. Wildenmann/Kaase: „Die unruhige Generation“, S. 56 sowie Demirović: Die politische Metapher „links“, S. 372.

1643 Bargel: Wandel des politischen Bewußtseins, S. 4.

1644 Ibid., S. 3.

1645 Ibid., S. 7.

1646 Ibid., S. 13.

1647 Ibid., S. 7 (Herv. J. S.) 
schlechten finanziellen Studiensituation den Niedergang der Universität und der vermeintlichen vormaligen verantwortungsbewussten Autonomie der Wissenschaft - ein „politisches Vakuum“ unter den zunehmend „politikverdrossenen“ Studierenden. ${ }^{1648}$ Ungefähr 30 Jahre nach „1968“ richtete sich der Blick insbesondere auch auf jenen „umworbenen akademischen Nachwuchs“ als Adressaten des Reformwunsches:

„Nicht wenige wünschen, sie [die Studierenden, J. S.] würden endlich politisch agieren, nicht immer nur abwarten. Hatte nicht auch Ende der sechziger Jahre eine StudentInnengeneration einen längst überfälligen Modernisierungsschub bewirkt, der zum Bau des ,Modell Deutschland' notwendig war? Hatte eine rebellische Studierendengeneration nicht geholfen, endlich die totgeschwiegene Nazi-Vergangenheit öffentlich zu machen und zu bewältigen, die Wirtschaftswunder-Cesellschaft zu zivilisieren?"1649

So beklagt der Soziologe und Politikwissenschaftler Alex Demirović 1996 in der Zeitschrift PROKLA die Entpolitisierung der Studierendenschaft unter Bezug auf eine auch von ihm durchgeführte Umfrage ${ }^{1650}$ an hessischen Hochschulen im Sommersemester 1994. Trotz der desolaten, ja unzumutbaren Studiensituation an deutschen Universitäten komme es „kaum zu relevanten Protesten von seiten [sic] der Studierenden. “1651 In seiner Analyse der Ergebnisse stellt er auch die Frage nach der verbliebenen Aussagekraft des politischen Richtungsschemas „Links/Rechts“ und kommt zu dem Ergebnis, dass eine Mehrheit von 61 Prozent der Studierenden sich weiterhin selbst als „links“ einstuft, was durchaus präzise ein „spezifisches Bündel von Orientierungen“ bedinge, nämlich eine Unterstützung des Sozialstaats, eine „weitere Realisierung von demokratischen Normen“ sowie „eine antinationalistische und antirassistische Haltung“. Zugleich aber sei nur ein kleiner Teil von ihnen für grundsätzlich alternative Gesellschaftsformen $\mathrm{zu}$ begeistern, und die meisten haben in ihrer grundsätzlichen Sympathie gegenüber freier Marktwirtschaft und privatem Unternehmertum Schwierigkeiten mit der einst so konstituierenden Kapitalismuskritik. ${ }^{1652}$ Insgesamt und vor dem Hintergrund einer verbreiteten „Politikverdrossenheit“ unter Studierenden (29 Prozent gaben an, deutlich politikverdrossen, weitere 45 Prozent, es teilweise $\mathrm{zu}$ sein; auch unter "Linken“ waren nur 10 Prozent in studentischen Politgruppen aktiv, 18 Prozent in Fachschaften, 3 Prozent in Studierendenparlamenten und AStAs ${ }^{1653}$ ) aber kommt Demirović zu dem Schluss, dass auch die politische Metapher „links“ stark an Kontur, Attraktivität

1648 Vgl. für einen Debattenüberblick und eine Bestandsaufnahme, die viele der hier referierten Punkte aufgreift und empirische Studien der 1970er und 1980er Jahre referiert, ferner Kiel: Studierende und Politik, S. 13-18 und S. 115-118. Vgl. ferner Fritz-Vannahme: Humboldts Erbe wird verspielt, sowie Kapitel II.1 dieser Studie. Das Schlagwort des „politischen Vakuums“ stammt aus Studie von Rainer Brämer, vgl. Brämer, Rainer: Studis im Vakuum. Empirische Befunde zum politischen Rückzug der studentischen Jugend, in: WSI-Mitteilungen, Jg. 46, H. 4/1993, S. 194-200, zit. nach Demirović, Alex/Paul, Gerd: Demokratisches Selbstverständnis.

1649 Oberndörfer, Ralf: Studentische Politik oder politische StudentInnen, in: PROKLA. Zeitschrift für kritische Sozialwissenschaft. Jg. 26, H. 104/1996, S. 395-414, hier S. 395

1650 Demirović/Paul: Demokratisches Selbstverständnis.

1651 Demirović: Die politische Metapher ,links', S. 371.

1652 Ibid., S. 372 und $382 f$.

1653 Ibid., S. 386. 
und vor allem an „artikulatorische[r] Kraft“ eingebüßt habe ${ }^{1654}$ - insbesondere weil sich selbst die von ihm so rubrizierten "pluralistischen Konservativen“ politisch links verorteten. ${ }^{1655}$ Zugleich wurden, auch aufgrund der bröckelnden politischen Resistenzkräfte, die Aussichten einer neurechten Mobilisierung, Ausgangsfrage der zugrunde liegenden Studie, unter konservativen und unpolitischen Studierenden und über das Vehikel populistischer Agitation im Sinne vermeintlicher Ideologiefreiheit als potenziell günstig eingeschätzt. ${ }^{1656}$

Etwa ein Jahrzehnt darauf, ausgerechnet im Jahr des Bildungsstreiks 2009, konstatierte Bargel infolge einer Längsschnittbetrachtung auf der Grundlage des Studierendensurveys von 1983 bis 2007, mit unvergleichlicher Schärfe das Heranwachsen einer „ratlosen“, d. h. teilnahmslosen und uneindeutigen Generation, eine „der Konventionalität und der labilen Demokraten“ ${ }^{1657}$ Die angeführten subkutanen Tendenzen, die sich im Antwortverhalten geltend gemacht hätten, zeichnen das Bild einer ganz und gar solipsistischen und entscheidungsunfähigen Studierendenschaft: „Beliebigkeiten und Gleichgültigkeiten“ prägten die Zahlen, nicht mehr die selbstbewusste Stellungnahme; Privatismus und „Rückzug in die Familie“ lösten das einstige „Engagement am öffentlichen Leben“ ab; statt Alternativen und Handlungsoptionen auszuloten, bescheide man sich konformistisch mit Gegebenheiten. Unsicherheit, die Furcht vor Misserfolg und Opportunismus der Studienplanung dominiere die Handlungsstrategien; Idealismus und Selbstverwirklichungsinteressen, gar die Übernahme von Verantwortung, seien vollständig hinter einer Neigung zum „egoistischen Konsumieren“ zurückgetreten. ${ }^{1658}$ Mehr noch: Die politischen Orientierungen bezeugten eine gravierende Erosion ordnender und sinnstiftender Strukturen, mithin durch eine größere „Anomie“. ${ }^{1659}$ All das wird zugleich aber auch als Ergebnis objektiver Veränderungen identifiziert: Grundierende gesellschaftliche Entwicklungen sind Bargel zufolge die Durchsetzung einer „postindustriellen Dienstleistungsgesellschaft“ bzw. „Wissensgesellschaft"

1654 Ibid., S. 389-391, vgl. außerdem Demirović/Paul: Demokratisches Selbstverständnis, S. $243 f$.

1655 Demirović/Paul: Demokratisches Selbstverständnis, S. 241.

1656 Vgl. ibid., S. 243-245. Die Studie führte eine standardisierte Befragung und mehrere Gruppendiskussionen durch. In den quantitativen Zahlen zerfiel die hessische Studierendenschaft in folgende „politische Meinungsmilieus“ bzw. „Typen politischer Orientierung“: 14 Prozent „linke Basisdemokraten“, 10 Prozent „linke Pessimisten“, 16 Prozent „unsichere Linke“, 18 Prozent „optimistische Linksliberale“, 9 Prozent „Unpolitische“, 7 Prozent „pluralistische Konservative“,10 Prozent „Neokonservative“ und 13 Prozent „Rechte“, ibid., S. 217-237. Diese zunächst recht artifiziell erscheinende Kategorisierung erweist ein gewisses analytisches Potenzial als „Modellierungsversuch“ insofern, als sie eine differenzierende Antwort auf die initiale Frage nach neurechter Verführbarkeit erlaubt: Man konnte u. a. zeigen, dass ein linkes Selbstverständnis per se wenig Aussagekraft besitzt, da bspw. auch bestimmte rechte Meinungsgruppen es teilen, während nur die linke Teilgruppe der „Basisdemokraten“ weltanschaulich homogen auftritt und sich insofern resilient gegen derartige Agitation zeigt. Dennoch bleibt diese insgesamt letztlich subsumtionslogische Einteilung hinter dem mit drei verschieden Dimensionen arbeitenden analytischen Niveau der Studie von Habermas et al. zurück, insbesondere da nach übergeordneten ideologischen Deutungssystemen, die das Antwortverhalten der Studierenden konstituieren mögen, nicht mehr gefragt wird.

1657 Bargel: Die ratlose Generation, S. 1.

1658 Ibid.

1659 Ibid., S. 2. 
und die durch sie bedingten Flexibilitätsimperative, die Globalisierung bzw. Internationalisierung der Lebensbedingungen und Hochschulen, ein Wertewandel unter individualistischen und hedonistischen Vorzeichen, eine komplexer gewordene politische Kultur sowie die veränderte „soziale Rolle“ der Studierenden als durchkonditionierter Anwärter auf „berufsbefähigende“ Kompetenzen ohne Raum für „außerfachliche, politische oder kulturelle Aktivitäten“ ${ }^{1660}$

Insgesamt haben die ersten zwanzig Jahre der „neuen“ Bundesrepublik also, spitzt man insbesondere die Längsschnittbetrachtungen Bargels zu, zu einer Metamorphose

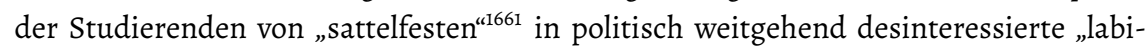
le Demokraten ${ }^{\text {“1662 }}$ geführt, zu einer Erosion der "Gefestigtheit“ ihrer demokratischen Überzeugungen und gerade dort $\mathrm{zu}$ weltanschaulichem Orientierungsverlust, wo einst politische Lager Deutungsangebote offerierten. Interessanterweise aber wird daraus nicht gefolgert, dass das politische Potenzial der - Konfliktivität und Pluralität mehrheitlich ablehnenden - Studierenden, insbesondere deren Protestpotenzial, abgenommen habe. Denn nicht nur standen der Masse der „entpolitisierten“ Studierenden weiterhin engagementkräftige Aktivistenzirkel gegenüber. Auch wird der Verzicht auf politische Partizipation im Bereich von Parteien, Organisationen, Politgruppen und Hochschulgremien durch einen erratisch erscheinenden Missmut gegenüber den verfügbaren Partizipationsmöglichkeiten konterkariert. Man ist also auch im Spitzenjahr des Konventionalismus 2007 keineswegs harmonisch ,angepasst“, sondern diffus unzufrieden. $^{1663}$

\section{II.3.4 Rückkehr der Politik in die Survey-Berichte und fortgesetzter Trend zur weltanschaulichen Fragmentierung: die 2010er Jahre}

Im Sommersemester 2010 führten Mitarbeiter des Studierendensurveys und des Hochschul-Informations-Systems (HIS) Hannover eine gesonderte Online-Erhebung durch. Die ohnehin fast nur noch residualen Konfliktfronten unter den Studierenden lösten sich demnach weiter auf, insbesondere die Anhängerschaft einer grundsätzlichen „Systemkritik“ dezimierten sich; soziale Sekuritäten und eine starke Orientierung an der Herkunftsfamilie gewannen demgegenüber zunehmend an Wichtigkeit. ${ }^{1664}$ Noch einmal wird hier - wenngleich äußerst zurückhaltend und unter explizitem Degout gegenüber derartigen „einprägsamen Etikettierungen“ - die Frage nach den Konturen einer „Studentengeneration 2010“ gestellt. ${ }^{1665}$ Hier stellte man eine gewachsene „Angst vor Misserfolg“ fest und bezeichnete die mit dieser verbundenen, zunehmend verbreiteten „Befürchtungen, trotz aller eigenen Anstrengung und bei

1660 Ibid., S. 3f. sowie Bargel: Wandel politischer Orientierungen, S. 4 f.

1661 Bargel, Tino: Studierende und Politik im vereinten Deutschland. Bildung-Wissenschaft-aktuell, $\mathrm{H}$. 3/1994.

1662 Bargel: Wandel politischer Orientierungen, S. 26.

1663 Ibid.

1664 Bargel, Tino/Simeaner, Hans: Gesellschaftliche Werte und politische Orientierungen der Studierenden. Online-Erhebung im Rahmen des Studierendensurveys im Sommer 2010, Bonn/Berlin 2011, S. 13.

1665 Ibid., S. 5 und S. 14. 
allem beruflichen Optimismus, letztlich zu den Verlierern zu gehören“, als historisches Novum unter Studierenden seit der Nachkriegsperiode. ${ }^{1666}$ Darüber hinaus fiel das zunehmend zaghafte Antwortverhalten auf, ein stärkeres Wegducken in Richtung der checkboxes "teils/teils“, „weiß nicht“ und „kann ich nicht sagen“ - ein Phänomen, das als „Konzept- und Positionslosigkeit“ bzw. „Scheu vor der eigenen Meinungsbildung“ interpretiert wurde. ${ }^{1667}$ Eine klare Generationsgestalt sei daher nicht zu haben, abgesehen von der möglichen Kennzeichnung als „unauffällige Generation“ - „ohne spezifisches Profil, ohne eigene Kanten oder besondere Farbe“. ${ }^{1668}$ In diesem Zusammenhang ist sicher auch das geschwundene Mitteilungsbedürfnis von Studierenden zu sehen, ablesbar an der sukzessive abnehmenden Bereitschaft zur Teilnahme am Studierendensurvey insgesamt. ${ }^{1669}$ Die Konturen verwischende Widersprüchlichkeit der studentischen Orientierungen wird auf folgende Formel gebracht:

„Was vordem den Studierenden als unvereinbarer Gegensatz erschien, das erleben sie heute seltener und weniger ausgeprägt als Widerspruch. Wir beobachten also, dass mehr und mehr Studierende zugleich Utilitarismus, aber auch mehr Idealismus vertreten; weniger soziale Solidarität üben, aber mehr auf Familie und Freundschaft setzen; weniger öffentliches Engagement zeigen, aber viel Kritik an den gesellschaftlichen Verhältnissen äußern. ${ }^{\text {1670 }}$

Indes: Sowohl die allgemeine Akzeptanz von Protestaktionen als auch die persönliche Bereitschaft zur Teilnahme an ebensolchen fiel in dieser Umfrage vergleichsweise hoch aus. $^{1671}$

Infolge dieser Studie nahmen die Hauptberichte des Studierendensurveys, beginnend mit dem 12. Survey, ${ }^{1672}$ die Frage-Items zu politischen und gesellschaftlichen Orientierungen wieder auf. Ein spezifisches, damit verbundenes Erkenntnisinteresse wurde nicht mehr formuliert; auch inwiefern für diese Entscheidung die Erfahrung des Bildungsstreiks von 2009 und 2010 ausschlaggebend gewesen ist, geht aus den Berichten nicht explizit hervor - wenngleich diese Vermutung zweifelsohne naheliegt. ${ }^{1673}$

In den Ergebnissen des 12. Surveys, durchgeführt im Wintersemester 2012/13, sank zunächst das politische Interesse weiter: Nur noch 32 Prozent der Studierenden bezeichneten sich als „sehr stark“ politisch interessiert - gegenüber 46 Prozent im Jahr 2001. ${ }^{1674}$ Parallel dazu geriet die Selbstverortung im linken politischen Spektrum im-

\footnotetext{
1666 Ibid., S. 15.

1667 Ibid., S. 15f., auch ibid., S. 16: „Auch nach den neueren Befunden ist festzuhalten: Ideale, noch mehr Visionen sind den Studierenden heute eher fremd, jedenfalls weit mehr als früheren Studentengenerationen. Sie richten sich in der Rolle des Kunden ein, verlieren damit aber an Verantwortung und Mitgestaltung."

1668 Ibid., S. 16.

1669 Zwischen 1997 und 2004 sank die Rücklaufquote von über 40 auf unter 30 Prozent; seit 2006 auf unter 20 Prozent, vgl. Multrus: Der Studierendensurvey, S. 9.

1670 Bargel/Simeaner: Gesellschaftliche Werte und politische Orientierungen, S. 14.

1671 Vgl. ibid., S. 35-48. Vgl. auch 12. Studierendensurvey 2012/13, S. $42 f$.

1672 Vgl. 12. Studierendensurvey 2012/13, S. 407-438.

1673 Nicht auszuschließen ist außerdem ein wiedererwachtes ministerielles Interesse an dieser Thematik.

1674 Vgl. ibid., S. 38.
} 
mer unbeliebter (von 59 Prozent 1993 und 1995 auf 45 Prozent 2013) bei nichtsdestotrotz hegemonial bleibender rot-grüner Wählerklientel. ${ }^{1675}$ Weiterhin äußerte nur eine Minderheit Interesse an der Arbeit in Hochschulgremien oder politischen Vereinigungen: aktiv engagiert waren nur 2 bzw. 4-5 Prozent der Studierenden, während sich für die Arbeit der vergleichsweise unpolitisch auftretenden Fachschaften immerhin 48 Prozent der Befragten grundsätzlich interessieren und 14 Prozent aktiv partizipieren. ${ }^{1676}$ Deutlich durchwachsener fiel die Zustimmung zu anderen demokratischen Prinzipien aus: nur 37 Prozent outeten sich als entschiedene Verfechter pluralistischer Interessenpolitik, aber ein Drittel sprach sich gegen eine regierungskritische Opposition aus. ${ }^{1677}$ Dem Typus der "gefestigten Demokraten“ gehörten nunmehr 16 Prozent der Studierenden an - insgesamt ein weiterhin geringer Wert (1993: 30 Prozent, 2004: 12 Prozent). ${ }^{1678}$ Gegenüber den Bildungsprotesten von 2009 und 2010 hatte sich das studentische Protestpotenzial reduziert: Sowohl die Aktionsformen der Demonstrationen und Kundgebungen als auch der Boykott von Lehrveranstaltungen und Institutsbesetzungen fanden im Vergleich zur Online-Erhebung von 2010 deutlich geringere Akzeptanz. ${ }^{1679}$

Der aktuelle, knapper gefasste, 13. Studierendensurvey (Erhebungszeitraum Wintersemester 2015/16) verzeichnet eine - im Übrigen parallel zu einem Anstieg des politischen Interesses in der Gesamtbevölkerung verlaufende - erratisch erscheinende Tendenz zur Repolitisierung der Studierendenschaft, zumindest hinsichtlich des Interesses am allgemeinen politischen Geschehen. ${ }^{1680}$ Besonders verblüffend sind die Zahlen, wenn man in Betracht zieht, dass die Sphäre des Privaten, also Partnerschaft und Herkunftsfamilie, Bekannte und Freunde sowie Geschwister als am höchsten geschätzter „Lebensbereich“ die Emotionen, Wertschätzungen und Strebungen der Studierenden bindet wie nie zuvor: ${ }^{1681}$ Das "sehr starke“ Interesse stieg hier nach dem Tiefstwert von 37 Prozent (2007) und 32 Prozent (2012/13) wieder an; 2015/16 lag der Wert bei 43 Prozent. ${ }^{1682}$ Sicherlich ist dabei zu berücksichtigen, dass tagespolitische Entwicklungen wie die stark emotionalisierte und teils polarisierte Diskussion um das Thema „Flüchtlinge“ 2015 einen kurzfristigen Einfluss ausüben können; überhaupt „nimmt die Wichtigkeit des Politischen in der Studentenschaft einen konjunkturellen Verlauf, es gibt keinen einfachen linearen Trend; die Spannweite von niedrigstem und höchstem Wert der Wichtigkeit ist mit neun Prozentpunkten als erheblich einzuschätzen. ${ }^{\text {“683 }}$ Zudem zei-

1675 Vgl. ibid., S. $39 f$.

1676 Vgl. ibid., S. 39 und 38.

1677 Vgl. ibid., S. 41.

1678 Ibid.

1679 Ibid., S. 43. „Daran lässt sich ablesen, dass die Auseinandersetzungen um die Studienbedingungen in den Jahren 2009 und 2010 sich deutlich beruhigt haben, aber noch nachklingen. Sowohl das Protestpotential unter den Studierenden insgesamt ist demnach merklich zurückgegangen als auch die mögliche Schärfe und Aggressivität in den Kritikpunkten haben nachgelassen." Ibid.

1680 Vgl. Statistisches Bundesamt (Destatis, Hg.), und Wissenschaftszentrum Berlin für Sozialforschung (WZB, Hg.): Datenreport 2018. Ein Sozialbericht für die Bundesrepublik Deutschland. Schriftenreihe der Bundeszentrale für Politische Bildung. Bonn 2018, S. 351.

1681 Vgl. 13. Studierendensurvey 2015/16, S. 79.

1682 Datenalmanach Studierendensurvey 2017, S. 215.

1683 12. Studierendensurvey 2015/16, S. 409. 
gen die sonstigen Items eine eigenwillige Mixtur aus Fortführung langfristiger Trends einerseits und auffällig wachsender Inkohärenz andererseits.

Aus diesem Grund lohnt sich ein abschließender detaillierter Blick auf diese Trendentwicklungen. Zunächst zeichnet die Frage nach der Unterstützung demokratischer Prinzipien ein uneinheitliches Bild: Konstant hoch bleibt die Zustimmung zu Demonstrationsfreiheit (2012/13: 69 Prozent $^{1684}$, 2015/16: 91 Prozent ${ }^{1685}$ ) und Gewaltverzicht (2012/13: 88 Prozent $^{1686}$, 2015/16: 89 Prozent $^{1687}$ ). Zudem scheinen Konflikte zwischen Interessengruppen weniger stark gegen das Gemeinwohl ausgespielt, demokratische Konfliktivität wieder stärker akzeptiert zu werden: Die Skepsis gegenüber derartigem „Parteienstreit“ ist von 33 Prozent 2004 bzw. 28 Prozent 2007 auf 17 Prozent 2013 bzw. 22 Prozent 2015/16 gefallen, also immerhin von einem Drittel auf ein Viertel der Studierenden. ${ }^{1688}$ Auch die Sympathien gegenüber einer regierungskritischen Opposition sind angestiegen: 57 Prozent negieren die Aussage, deren Rolle sei primär die Unterstützung der amtierenden Regierung (gegenüber 66 Prozent 1995, aber auch 39 Prozent 2004). ${ }^{1689}$ Ungebrochen eingefordert wird auch das Recht aller Bürgerinnen und Bürger, „notfalls für seine Überzeugungen auf die Straße zu gehen.“1690 Demgegenüber ist allerdings eine Tendenz zur Höherwertung der öffentlichen Ordnung gegenüber dem Demonstrations- bzw. Streikrecht zu verzeichnen: 35 Prozent (2016) halten einen Entzug bei Ausschreitungen für gerechtfertigt (2007: 29 Prozent). ${ }^{1691}$ Unmittelbar partizipieren wollen weiterhin nur die wenigstens: Gerade einmal 5 Prozent melden Interesse an studentischer Politik in ihrer Hochschule an. Insgesamt kommt der Studierendensurvey zu dem Schluss, dass die „demokratische Grundhaltung“ bzw. der "demokratische Habitus“ der Befragten nunmehr "gefestigter" sei, wenngleich der Anteil der „labilen Demokraten“ mit 34 Prozent und jener der „zweifelnden Demokraten“ bzw. der „Antidemokraten“ mit zusammengenommen 11 Prozent noch immer bedenkenswert ausfalle. ${ }^{1692}$

Die Positionierung der Studierenden zu den seit 1982/83 abgefragten gesellschaftspolitischen Zielen sprengt immer deutlicher die Orientierungsschablonen der „klassischen“ politischen Lager. So befindet sich die Zustimmung zur Maxime „Sicherung der freien Marktwirtschaft" seit der Jahrtausendwende auf dem Sinkflug: Die entsprechenden Werte fielen drastisch von 70 Prozent 2004 auf 55 Prozent 2015/16 - ein Tiefstrekord verglichen mit 66 Prozent 1985 und 68 Prozent zwischen 1995 und $1998 .{ }^{1693}$ Dem entspricht einerseits, dass die Befürworter einer „Reduzierung des Wohlfahrtsstaats und der sozialen Sicherungssysteme“ von 28 Prozent 2004 auf 12 Prozent 2015/16 geschrumpft (und die diese Forderung Ablehnenden im selben Zeitraum von 53 auf 68

1684 Vgl. 12. Studierendensurvey 2012/13, S. 41.

1685 Vgl. 13. Studierendensurvey 2015/16, S. 89 und 91.

1686 Vgl. 12. Studierendensurvey 2012/13, S. 41.

1687 Vgl. 13. Studierendensurvey 2015/16, S. 89 und 91.

1688 Vgl. Datenalmanach Studierendensurvey 2017, S. 216 und 13. Studierendensurvey 2015/16, S. 89.

1689 Vgl. Datenalmanach Studierendensurvey 2017, S. 216 und 13. Studierendensurvey 2015/16, S. 89.

1690 Datenalmanach Studierendensurvey 2017, S. 216.

1691 Vgl. ibid., S. 216.

1692 13. Studierendensurvey 2015/16, S. 91.

1693 Datenalmanach Studierendensurvey 2017, S. 220, vgl. außerdem Datenalmanach Studierendensurvey 2007 , S. 227. 
Prozent gewachsen) sind. ${ }^{1694}$ Zudem wird Umweltschutz zunehmend vor Wirtschaftskraft priorisiert (72 Prozent 2004, 80 Prozent 2015/16 $6^{1695}$ ), und auch die Zustimmung zum sozialistischen Prinzip der „Abschaffung des Privateigentums an Industrieunternehmen und Banken" ist auffällig gestiegen, nämlich von 20 Prozent Zustimmung 1985 über 15 Prozent 1993 und 16 Prozent 2007 auf 25 Prozent 2015/16, also auf immerhin ein Viertel der Studierenden! ${ }^{1696}$ Auch fordert man die harte Bestrafung von Kriminalität (drei Viertel stimmten dem $2016 \mathrm{zu}$ ) immer häufiger. ${ }^{1697}$ Hier hat sich also einerseits offenbar ein gerüttelt Maß an Sekuritätsbedürfnis, etatistischen bzw. protektionistischen Sehnsüchten etabliert. ${ }^{1698}$ Andererseits aber sind auch politische Prinzipien beliebter geworden, die gerade Weltoffenheit und Fortschritt fokussieren, so etwa die stärkere Förderung technologischer Innovationen (83 Prozent 2015/16) ${ }^{1699}$ als auch ein kosmopolitischer werdendes Deutschland: Immer weniger Studierende wünschen sich die Abwehr von Immigration (30 Prozent 2015/16 statt 42 Prozent 2007).

Die gleichwohl noch vorhandenen Residuen einer weltanschaulichen Polarisierung werden bei einem Vergleich der verschiedenen Fachbereiche sichtbar. Studierende der Sozial-, Kultur-, und Sprachwissenschaften bleiben „ausgeprägte Kontrahenten“ ihrer wirtschafts-, ingenieur-, und rechtswissenschaftlichen Kommilitoninnen und Kommilitonen: Während erstere deutlich stärker egalitäre, ökologische, materiell-solidarische und kosmopolitische politische Ziele befürworten, legen letztere den Akzent auf technologische Förderung, härtere Bestrafung von Kriminalität und marktwirtschaftliche Prinzipien; auch die Kritik an Zuwanderung und „kultureller Überfremdung“ findet unter ihnen stärkeren Widerhall, während sie merklich distanzierter zu Interessenpluralität und kritischer Opposition stehen. ${ }^{1700}$

Aufschlussreich wäre an dieser Stelle sicherlich ein weiterer Kommentar der Konstanzer Forscher zur Auswahl der Antwortmöglichkeiten „weiß nicht“ und „teils/teils“ sowie zur Nichtbeantwortung der einzelnen Items gewesen, die 2010 deutlich häufiger frequentiert wurden. ${ }^{1701}$ Der zu vermutende Trend zur politischen Indifferenz bzw. Fragmentierung, der sich auch in den gesunkenen Rücklaufquoten ausdrückt, hätte sich hieran noch einmal prüfen lassen. Aber: Dass der bereits 1996 von Demirović konstatierte Bedeutungsverlust auch der schematischsten politischen Orientierungsprothese, der Richtungsskala von „Links“ und „Rechts“, sich weiter verstetigt bzw. verstärkt hat, wird man als gesichert ansehen dürfen.

\footnotetext{
1694 Datenalmanach Studierendensurvey 2017, S. 221.

1695 Ibid., S. 220.

1696 Ibid., S. 220 und Datenalmanach Studierendensurvey 2007, S. 227.

1697 Datenalmanach Studierendensurvey 2017, S. 220.

1698 Vgl. 13. Studierendensurvey 2015/16, S. 87. Ob und inwiefern sich dieses Muster in Parteipräferenzen abbildet, wurde hier leider nicht zu Protokoll gegeben.

1699 Datenalmanach Studierendensurvey 2017, S. 220.

1700 13. Studierendensurvey 2015/16, S. $89 f$.

1701 Vgl. Bargel/Simeaner: Gesellschaftliche Werte und politische Orientierungen, S. 15f.
} 


\section{II.3.5 Generationentypologien und die Vernachlässigung der Frage nach tieferliegenden politisch-sozialen Deutungsmustern: Studierende und Demokratie im empirischen Längsschnitt}

Versuche, die politischen Orientierungen und das politische Potenzial einer so heterogenen, mit fortschreitender Zeit sich gar tendenziell ausdifferenzierenden Gruppe wie der deutschen Studierenden abschließend auf universelle Attribute zu reduzieren, müssen scheitern. Wenn es aber darum gehen soll, neue qualitative empirische Resultate einzuordnen, ist es unerlässlich, wesentliche Grundzüge der jüngeren Entwicklungen zu benennen. Verdichtend zusammengefasst, lässt die Sichtung der Studien und Surveys im Längsschnitt so erstens Rückschlüsse auf den Wandel der politischen Mentalitäten der Studierenden zu, zweitens erlaubt sie eine vorläufige Antwort auf die Frage nach politisch-praktischen Dispositionen bzw. möglichen heutigen politischen Kräftereservoirs.

Zunächst ein Resümee der Generationen-Chronologie und der mit ihr stets verbundenen Frage nach der demokratischen Unterstützung durch die Studierenden. Wie bereits erwähnt, stellt die Frage nach dem sozialmoralischen und politischen Zustand "der" Jugend das klassische Movens der soziologischen Jugendforschung dar. Angesichts der bereits in den 1950er Jahren augenfälligen Heterogenität jugendlicher Lebensverhältnisse, die die Not der unmittelbaren Nachkriegszeit ${ }^{1702}$ ablöste, suchte man nach konturierbaren Generationsgestalten, die die Identifikation wesentlicher Entwicklungstrends ermöglichten. Klassisch findet man diese Frage, die ihre Inspiration immer auch aus der jugendlichen Generationsgestalt par excellence des frühen 20 . Jahrhunderts, der Jugendbewegung zieht, formuliert in Schelskys Die skeptische Generation (1957), in Jaides Eine neue Generation? (1961) oder in Blüchers Die Generation der Unbefangenen (1965). Sicher gibt es keine konsensualen Bezeichnungsvorschläge, wohl aber einige hegemoniale Schlagworte, die bestimmte Tendenzen virulenter gesellschaftspolitischer Hintergrundthematiken extrapolieren (und dabei explizit andere fortlassen). Auch argumentieren manche Autoren stärker wissenschaftlich, während andere ihre Namensgebung essayistisch überspitzen. Je nach Dominanz eines Lagerkonflikts oder übergreifender Gemeinsamkeiten wurden hier mit Blick auf die Studierenden der Bundesrepublik bisweilen mit der nichtstudierenden Jugend zusammengefasst - folgende Generationskonturen ausgemacht:

1702 Vgl. für das Beispiel Bremens Kurz: Lebensverhältnisse der Nachkriegsjugend, insbesondere S. 114118. 
Tabelle 1: Studentische Generationskonturen und ihre gesellschaftspolitischen Hintergrundthematiken"

\begin{tabular}{|c|c|c|}
\hline Zeitraum & Generationskontur & $\begin{array}{l}\text { Gesellschaftspolitische Hinter- } \\
\text { grundthematik }\end{array}$ \\
\hline Späte 1950er Jahre & „Skeptische Generation" & $\begin{array}{l}\text { Frage nach Distanz bzw. Nähe der } \\
\text { Jugend zur Demokratie in der jun- } \\
\text { gen Bundesrepublik }\end{array}$ \\
\hline $\begin{array}{l}\text { Frühe 1960er } \\
\text { Jahre }\end{array}$ & $\begin{array}{l}\text { "Generation der Unbefange- } \\
\text { nen }{ }^{\text {“b }}\end{array}$ & $\begin{array}{l}\text { Hoffnung auf demokratische Unter- } \\
\text { stützung vonseiten der Jugend bzw. } \\
\text { der Studierenden }\end{array}$ \\
\hline $\begin{array}{l}\text { Späte 1960er und } \\
\text { frühe 1970er Jahre }\end{array}$ & "Unruhige Ceneration“c & $\begin{array}{l}\text { Studentischer Protest, Radikalitäts- } \\
\text { frage und politische Polarisierung }\end{array}$ \\
\hline 1980er Jahre & $\begin{array}{l}\text { „Die überflüssige Ceneration “d } \\
\text {-,Zwischen Revolution und Re- } \\
\text { signation"e }\end{array}$ & $\begin{array}{l}\text { Entpolitisierung bzw. Politikver- } \\
\text { drossenheit der (akademischen) } \\
\text { Jugend }\end{array}$ \\
\hline 1990er Jahre & "Generation Colfuf & $\begin{array}{l}\text { "Materialismus" und Entpolitisie- } \\
\text { rung bzw. Politikverdrossenheit der } \\
\text { (akademischen) Jugend }\end{array}$ \\
\hline 2000er Jahre & "Pragmatische Ceneration"g & $\begin{array}{l}\text { Keine, aber weiterhin Diagnose der } \\
\text { Entpolitisierung bzw. Politikver- } \\
\text { drossenheit der (akademischen) } \\
\text { Jugend }\end{array}$ \\
\hline 2010er Jahre & $\begin{array}{l}\text { "Unauffällige Ceneration" - } \\
\text { ohne spezifisches Profil, } \\
\text { ohne eigene Kanten oder } \\
\text { besondere Farbe.".h }\end{array}$ & $\begin{array}{l}\text { Keine, aber Diagnose politischer } \\
\text { Cleichgültigkeit und weltanschauli- } \\
\text { cher Fragmentierung }\end{array}$ \\
\hline
\end{tabular}

*Vgl. - neben den in dieser Studie vielfach zitierten Primärstudien - die Zusammenstellungen in Bargel: Wandel politischer Orientierungen, S. 3f. und Demirović/Paul: Demokratisches Selbstverständnis, S. 25-33.

$a$ : Schelsky: Die skeptische Generation; $b$ : Blücher: Die Generation der Unbefangenen; $c$ : Wildenmann/Kaase: „Die unruhige Generation“; $d$ : Richter: Die überflüssige Generation; $e$ : Krause et al.: Zwischen Revolution und Resignation?; f: Illies, Florian: Generation Golf. Eine Inspektion. Frankfurt a.M. 2001; g: Vgl. Shell Deutschland Holding (Hg.): Jugend 2006. Eine pragmatische Generation unter Druck. bpb Lizenzausgabe, Bonn 2006; $h$ : Bargel/Simeaner: Gesellschaftliche Werte und politische Orientierungen, S. 15

Nochmals: Es handelt sich bei diesen Generationstiteln um einen popularisierbaren Überblick, nicht um ein analytisch tragfähiges Raster. Die Namensgeber derartiger Generationskonturen bemühen sich um idealtypische Systematisierungen, nicht aber um bündige soziologisch-empirische Deskriptionen. Im Grunde genommen wird nicht einmal der Anspruch erhoben, die eine entscheidende, Mannheim'sche Generationsgestalten stiftende Kollektiverfahrung aufgedeckt zu haben. Nicht zuletzt, weil der Neuigkeitswert der beobachteten Tendenzen durch allzu eilfertige Rezeptionsweisen bisweilen überdehnt erscheint, scheinen etwa die Mitarbeiterinnen und Mitarbeitern 
des Studierendensurveys selbst dieses Vorgehen mit Distanz zu betrachten. Nach wie vor gilt: „Was einen Vergleich zwischen Generationen weithin erschwert, ist die Streuung der Einstellungen innerhalb ein und derselben Generation. ${ }^{\text {“1703 }}$

Trotzdem ist ein solcher Schematismus in der Rückschau dabei behilflich, die Entwicklung des vielfach ergründeten demokratischen Potenzials der deutschen Studierendenschaft zu ordnen: ${ }^{1704}$ Nach der Erfahrung der NS-Diktatur grassierte in der jungen Bundesrepublik die Befürchtung antidemokratischer Tendenzen unter den Studierenden, die man als Rekrutierungspool zukünftiger Eliten auffasste - auch aufgrund des Zulaufs zu Korporationen in den 1950er Jahren. Wie gesehen, war das Ergebnis von Habermas et al. zwiespältig: Zwei Drittel der Studierenden galten als im ökonomischen Krisenfall unberechenbar, ein Drittel als formal demokratisch; das autoritäre Potenzial wurde mit 16 Prozent als stärker eingeschätzt als das robust demokratische (9 Prozent). Diese Verhältnisse verkehrten sich, wahrscheinlich auch durch eine erhebliche analytische Ausdünnung infolge des Wechsels zu den Kaase'schen Fragebatterien der „Demokratie-Skala“ bedingt, ruckartig: Mitte der 1960er konstatierten Friedeburg et al. eine mehrheitlich demokratisch eingestellte Studierendenschaft. Neuen Anlass zur Sorge gab dann zunächst 1968 eine von Wildenmann und Kaase untersuchte befürchtete neue Tendenz zu aggressiver Radikalität bzw. sozialistischem Umstürzlertum. Die Messung mit den Kaase'schen Fragebatterien lieferte allerdings partielle Entwarnung: stark und anspruchsvoll sei das studentische Demokratieverständnis, wenn auch nicht ohne elitäre Züge und unter mehrheitlicher Distanzierung von den etablierten Parteien; indes bedeutete der damalige Linksradikalismus für die Mehrheit seiner Unterstützer in erster Linie Demokratisierung, nicht praktische Revolution unter sozialistischen Vorzeichen. Die 1980er Jahre, eingeleitet durch die Studie von Krause et al., dokumentierte die Genese der Alternativkultur der „No Future“-Generation: Ca. 12 Prozent galten als engagierte Alternative, etwa die Hälfte als Sympathisanten. Die Diskussion um eine zunehmende Entfremdung der „postmaterialistisch“ innervierten Studierenden von demokratischen Institutionen und Verfahren verursachte neue Besorgnis, man fragte auch hier nach dem politischen Kompass der künftigen Funktionseliten. Glotz und Malanowski stellten früh fest, dass unter der Oberfläche Defätismus und ziellose Wut gärten, ferner eine Tendenz zur Entpolitisierung einsetzte. Breites Protestpotenzial wurde zwar noch vermutet, sollte sich aber in der Folge nicht bestätigen. Nahezu zeitgleich, im Wintersemester 1982/83, begann der Studierendensurvey seine Erhebungen, parallel erschienen noch weitere Studien. Man verzeichnete bis Ende der 1980er Jahre einen kräftigen Zug zur Vermittung und zum Konformismus: drei Viertel der Studierenden galten nun als prodemokratisch, andererseits kartografierte man auch eine Studierendenschaft (ebenfalls drei Viertel), die mit der institutionell verankerten Politik auffällig fremdelte. Erstmals seit Langem aber ermangelte es an linken oder alternativen Deutungsangeboten, die die resignativen Energien hätten binden können. Bis in die 1990er hinein etablierte sich, nach anfänglich stark differierenden studentischen Mentalitäten in Ost und West, das Thema der Entpolitisierung bzw. „Politik-

1703 Jaide: Eine neue Generation?, S. 10.

1704 Vgl. auch die übersichtliche, wenn auch im Jahr 1996 endende Chronologie in Demirović/Paul: Demokratisches Selbstverständnis, S. 25-33. 
verdrossenheit" der von öffentlichen Belangen sich abwendenden Studierenden als dominierendes Thema, der Bereich wurde in den Hauptberichten des Studierendensurveys ausgespart. Die damals paradox erscheinende Feststellung einer prodemokratischen politischen Apathie wurde dabei bisweilen von Skepsis über die zu erwartenden künftigen Entwicklungen begleitet. Eine Studie, die nach der neurechten Verführbarkeit von Studierenden fragte, verzeichnete einen eminenten Bedeutungsverlust der politischen Selbstzuschreibung als „links“, mithin eine wachsende Erosion der weltanschaulichen Deutungspuffer. Wiederholte Protestaktionen von Studierenden im Namen bildungspolitischer Forderungen, etwa in den Jahren 1997 und 2003, führten nicht zu neuen Themenkonjunkturen. Erst mit dem „Bildungsstreik“ von 2009/10 gelangten die politischen Befindlichkeiten der Studierendenschaft wieder auf den öffentlichen Aufmerksamkeitsradar. Eine Online-Erhebung im Sommersemester 2010 fand allerdings keine Anzeichen eines nachhaltigen Politisierungseffekts; stattdessen fand man eine eher profillose, positionierungsunfähige, privatistische, diffus unzufriedene Studierendenschaft vor. Der Studierendensurvey berichtet seither wieder über seine Frage-Items zu Politik und Demokratie und weckt jüngst den Eindruck einer - trotz wieder gestiegenen politischen Interesses - grundsätzlich politisch gleichgültigen und weltanschaulich desorientierten, aber immerhin unverändert prodemokratischen Studierendenschaft. Umfänglichere, insbesondere tiefenanalytische, Studien sind zuletzt nicht erschienen.

Überhaupt ist ausgesprochen auffällig, dass in den zurückliegenden 30 bis 40 Jahren kaum noch systematische gesellschaftspolitische bzw. politiksoziologische Fragen über die Spezifika der Studierendenschaft als durch Generationserfahrung und Lebenssituation konstituierte Sozialformation gestellt werden. Es geht um bloße Stimmungsbilder. Zugespitzt lässt sich sagen, dass das Geschäft der Gesamtreflexion des Verhältnisses von Studierenden und Politik bzw. der mutigeren Interpretation jüngerer Entwicklungen weitgehend an die Feuilletons oder an Gedenkschriften und Sammelbände zum Thema der „68er-Generation“ delegiert worden ist - und dort wenig Originelles zutage fördert. Ursächlich mag die gesunkene tagespolitische Aktualität dieser Fragen gegenüber den von politischer Konfliktivität geprägten 1970er und frühen 1980er Jahren als auch in der deutlich aufgelösten soziodemographischen Homogenität der Studierendenschaft seit den starken Bildungsexpansionsschüben jener Jahrzehnte sein. ${ }^{1705}$ Der gesellschaftliche Bedeutungsverlust des politischen Potenzials von Studierenden ist auch daran abzulesen, dass die einschlägigen Erhebungen nach und nach immer weniger fragegeleitet ausfallen, ja konzeptuell eigentlich atrophieren. Zuletzt bleibt den Verfasserinnen und Verfassern der Berichte nur, die Orientierungslosigkeit der von ihnen untersuchten Gruppe zu adaptieren und immer neue Strophen desselben Abgesangs anzustimmen. ${ }^{1706}$

1705 Vgl. eingehend Kapitel II.1 dieser Studie.

1706 Das entspricht gleichwohl durchaus dem Auftrag des Finanziers: Nicht mehr gesellschaftsanalytisches, sondern nur mehr technokratisch-regulatorisches Interesse spricht aus dem Vorwort des aktuellen 13. Studierendensurveys, unterzeichnet von der damaligen Bundesministerin für Bildung und Forschung Johanna Wanka: „Die Organisationsstrukturen und -prozesse an Hochschulen müssen weiterentwickelt werden, um Innovationskraft, Forschung sowie exzellentes Lernen und Lehren in Deutschland voranzutreiben." 13 . Studierendensurvey 2015/16, S. 5. 
Für die politischen Mentalitäten ist nun erstens zu notieren, dass die Unterstützung demokratischer Prinzipien vonseiten der Studierendenschaft seit Mitte der 1960er Jahre als grundsätzlich stabil und breit gilt. Die Studierenden heute halten sich selbst für überzeugte Demokratinnen und Demokraten. Trotz der seit der Jahrtausendwende einbrechenden Werte zur kritischen Funktion der Opposition und zur Akzeptanz des Streits von Interessengruppen herrscht demnach durchweg Eintracht in Fragen der nach Maßgabe der Kaase'schen Demokratieskala als entscheidend angesehenen Bejahung von Meinungs- und Demonstrationsfreiheit einerseits sowie des Gewaltverzichts andererseits. Durchweg blieb der so gemessene Anteil „latenter“ oder „deutlicher“ Antidemokraten unter einem Prozent der Studierenden. ${ }^{1707}$ Darüber hinaus meldet die deutsche Studierendenschaft wechselhaftes, zuletzt durchaus gestiegenes politisches Interesse an. Wo zwischen 1967 und 1983 lager- und parteigebundene politische Agonalität herrschte, ist seit den letzten Jahren des alten Jahrtausends weitgehende Konfliktund Positionierungsscheu eingekehrt.

Im Hinblick auf gesellschaftspolitische Fragen hat sich in den letzten zwanzig bis dreißig Jahren ein Trend zur Sekuritäts- und Stabilitätsorientierung bei grundierendem kosmopolitischem Wertesetting konsolidiert. Hegemonial blieb durchweg beispielsweise der Wunsch nach Beschleunigung der Geschlechtergleichstellung - aber auch die Forderung, Umweltschutz gegenüber wirtschaftlichem Wachstum prioritär zu behandeln. Nach den markt- und unternehmerfreundlichen 1990er bzw. 2000er Jahren haben sich ansonsten deutliche protektionistische und wohlfahrtsstaatliche Neigungen eingestellt, selbst sozialistische Prinzipien gewinnen wieder an Attraktivität; die Technikskepsis der 1980er Jahre hingegen ist nahezu vollständig verschwunden. Ansonsten fällt die Gesellschaftswahrnehmung der Studierenden zunehmend widersprüchlich aus: Man ist kosmopolitischer geworden, aber auch ordnungs- und stabilitätsfixierter; egozentrisch, aber auch familiär orientiert; gesellschaftskritisch, aber auch politisch apathisch; das ist aus Sicht langjähriger Forscher durchaus „diffus und disparat“, außerdem nicht mehr ,ideell-konzeptuell gebündelt“ ${ }^{1708}$

Eine interessante Kontinuität, die sich über den betrachteten Zeitraum hinweg kaum verändert hat, liegt in der studienfachspezifischen Aufteilung von weltanschaulichen Traditionslinien zwischen Geistes- und Sozialwissenschaften (eher links, eher partizipationsorientiert und politischem Konflikt bzw. Protestaktionen eher aufgeschlossen) auf der einen, Wirtschafts-, Rechts-, Natur-, und Ingenieurswissenschaften (eher rechts, eher ordnungsorientiert und mit politischen Konflikten eher fremdelnd) auf der anderen Seite, die sogar in der aktuellen Phase der weltanschaulichen Fragmentierung bis zu einem gewissen Grad erhalten bleiben. ${ }^{1709}$ Auch die zwiespältige

1707 Vgl. 12. Studierendensurvey 2012/13, S. 42.

1708 Bargel: Wandel des politischen Bewußtseins, S. 4.

1709 Drei Nachweise mögen das noch einmal veranschaulichen: 1971 „besteht ein starker Zusammenhang zwischen Studienfach und Unterstützung von Studentenbewegungen. Die Rangfolge der verschiedenen Fächer ist in den meisten Untersuchungen gleich oder ähnlich: am höchsten ist der Anteil der Anhänger der Studentenbewegungen in den Sozial- und Geisteswissenschaften. Beträchtlich geringer ist er in den Naturwissenschaften. Die kleinsten Anteile finden sich unter Studenten der Ingenieurswissenschaften, Betriebswirtschaftslehre, usw." Allerbeck: Studentenbewegungen in Industriegesellschaften, S. 480; 1998: „Auf der einen Seite die eher konventionel- 
Haltung zum Leistungsprinzip ist Studierenden durchweg eigentümlich, oszillieren die Wahrnehmungen doch zwischen bildungshumanistischen Gleichheitsidealen (welche unverändert stark für soziale Ungleichheiten sensibilisieren) und materieller Aufstiegsorientierung (welche die Abhängigkeit des Berufserfolgs von der eigenen Leistungsbereitschaft betont). ${ }^{170}$ Allerdings scheint das politische Kompetenzniveau insgesamt seit den politisierten 1960er/70er-Jahren und besonders ruckartig in den 1990er Jahren gesunken zu sein. Davon legt das Misstrauen der Autoren des Studierendensurveys Zeugnis $\mathrm{ab}$, die sich häufende Inkohärenzen der immer weniger auskunftsfreudigen Studierenden wahrnehmen; man spricht seit den späten 200oer Jahren davon, „mehr labile und distanzierte Demokraten“ aufzufinden. ${ }^{1711}$ Der großen und ohne Frage beeindruckenden Akribie der Surveys zum Trotz aber scheint man derartigen Trends erstaunlich rezeptiv und ratlos gegenüberzustehen; ein Grund dafür ist sicherlich darin $\mathrm{zu}$ sehen, dass auf ein diffizileres methodisches und analytisches Instrumentarium im Stile von Habermas et al., welches der quantitativen Einstellungsmessung eine qualitative Analyse der übergreifenden ideologischen Leitlinien und Deutungsmuster, auch der historischen Wandlungen ebendieser, gegenüberstellt und damit das demokratische Handlungspotenzial unterhalb der Oberfläche verbaler Bekenntnisse zu ergründen versucht, stets verzichtet wurde.

Zwar liegt für die Zahlen der 2010er Jahre keine so emphatisch-konsternierte Einschätzung vor, wie sie 2009 von Bargel gegeben wurde. ${ }^{1712}$ Doch es liegt auf der Hand, dass seine Diagnose einer weltanschaulichen und orientierungsmäßigen „Anomie“ unter den Studierenden eher an Plausibilität gewonnen hat. Das (beinahe) zurückliegende Jahrzehnt brachte, abgesehen von Anzeichen einer sanften Trendwende in einzelnen Frage-Items, keine substanziellen Unterschiede, sondern offenbar vielmehr eine Erhärtung des Trends zur „Entpolitisierung“ und „Entideologisierung“ sowie zur Zersplitterung von zuvor distinkt getrennten Orientierungslinien. Das Nebeneinander „materieller“ und „postmaterieller“ bzw. „idealistischer" Positionierungen wird nicht mehr als

len Juristen, Ökonomen und Ingenieure, die überwiegend auf Ruhe und Ordnung setzen, auf der anderen Seite die kritischeren Sozial- und Geisteswissenschaftler, die auf Demonstrationen und Streiks beharren." Bargel: Wandel des politischen Bewußtseins, S. 24; 2008 stellte man erneut fest, dass insbesondere unter sozial-, kultur- und sprachwissenschaftlichen Studierenden "gefestigte Demokraten" reüssierten, während die "labilen und distanzierten Demokraten" vor allem Jura, Medizin und Naturwissenschaften studierten, die „distanzierten Demokraten“ hingegen eher wirtschaftswissenschaftliche Fächer. Bargel: Wandel politischer Orientierungen, S. 24.

1710 „Im Grunde haben die Studierenden das Leistungsprinzip immer geteilt, selbst wenn das studentische Leben mit Feiern und Partys nicht immer danach aussieht. Als gesellschaftliches Kriterium für Aufstieg und Anerkennung wird das Leistungsprinzip von den Studierenden am meisten befürwortet; vielen erscheint es aber in der Cesellschaft nicht angewandt, zwar beschworen, aber ohne Celtung. Daher ist der Eindruck von sozialer Ungerechtigkeit weit verbreitet; offenbar wächst das Unbehagen, faire Aufstiegschancen gingen zurück." Bargel/Simeaner: Gesellschaftliche Werte und politische Orientierungen, S. $10 f$.

1711 Bargel: Die ratlose Generation, S. 22. Siehe auch Bargel: Wandel politischer Orientierungen, S. 26: „Da das wesentliche Kennzeichen des Wandels der Verlust an demokratischer Cefestigtheit ist und vor allem die Distanz zu Kontroversen und Pluralität zugenommen hat, bietet es sich an, die neue Studentengeneration als , labile Demokraten' zu bezeichnen."

1712 Vgl. noch einmal Bargel: Die ratlose Generation. 
widersprüchlich aufgefasst. Wer hier die alten milieugeprägten industriegesellschaftlichen politischen Alternativen als Maßstab anlegt und einen Schuss Böswilligkeit addiert, kann angesichts des widersprüchlich anmutenden Antwortverhaltens geradezu zu dem Schluss kommen, dass heutigen Studierenden die politische Urteilsfähigkeit per se abgehe. Hierin spiegeln sich grundlegende gesellschaftliche Mentalitätsverschiebungen der letzten Jahre, die von ideologischer Entzauberung und zivilgesellschaftlicher Entbindung zeugen:

„Der Charme großer Prinzipien und Ideensysteme scheint in allen Milieus verfolgen. [...] Überhaupt scheinen [!] die Komplexitäten derart zugenommen zu haben, dass die gesellschaftliche Vielfalt nicht mehr durch die eine große Erzählung zu bändigen wäre. ${ }^{\text {“1713 }}$

Und wo dieser Charme noch wahrgenommen wird, greift man auf synkretistische Ersatzbefriedigungen zurück, wird insofern ,eher individuell, situationistisch, nach Maßgabe der Alltagstauglichkeit in freier Kombination oft ganz heterogener Philosophien

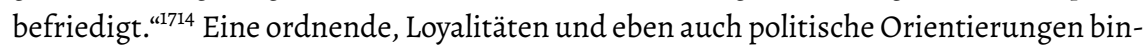
dende zivilgesellschaftliche Vernetzung jedenfalls prägt die politische Sozialisation der Menschen (fast) nicht mehr; so haften sich auch Stimmungen und Zustimmungswerte in Umfragen volatiler an tagespolitische Entwicklungen - wie in den Jahren $2016 \mathrm{ff}$. etwa die Furcht vor einem drohenden „Rechtsruck“ durch den elektoralen Siegeszug der AfD. Dies gilt nicht zuletzt für jungbürgerliche „Lebenswelten“1715. Denn der Eindruck einer desorientierten und von Widersprüchlichkeiten durchzogenen Studierendenschaft - „ein bisschen ratlos, ein bisschen meinungslos, ein bisschen gleichgültig“ bzw. „Zwischen ,ratlos und unsicher', ,aufgeschlossen und eifrig', ,farblos und langweilig'“1716 - ist nicht abzuwehren. Sinnstiftende und strukturierende Pole, nach denen sich ihr weltanschaulicher Kompass im Hinblick auf sozialethische und politische Fragen wie nach einem Fluchtpunkt ausrichten könnte - eben etwa konturierte politische Lager mit ihren je spezifischen Deutungsangeboten -, sind den Studierenden offenbar weiter abhandengekommen. So verwundert es kaum, dass ihr Kompass, um im navigatorischen Bilde zu bleiben, in verschiedene Richtungen zugleich ausschlägt. Bezeichnenderweise sind in den 2010er Jahren Auslassungen zum politischen Potenzial von Studierenden rar gesät. Auch engagierte Monographien, die dem Zustand des demokratischen Bewusstseins und einem möglichen politischen Aktionspotenzial - inklusive agitatorischer Verführbarkeit - der Studierenden nachgehen, sind nicht mehr $\mathrm{zu}$ finden. $\mathrm{Ab}$ und $\mathrm{zu}$ fallen gewiss Einzelmeldungen und Schlagzeilen auf, etwa wenn

1713 Walter: Baustelle Deutschland, S. 29.

1714 Ibid., S. $34 f$.

1715 Ibid., S. 7. Vgl. auch ibid., S. 31-34.

1716 Bargel, Tino: Entwicklung von sozialer Lage, Studienbedingungen und studentischem Bewusstsein. Interview von Heinz Heinemann, Rosa Luxemburg Stiftung 2012, online einsehbar unter: https://www.rosalux.de/publikation/id/5592/tino-bargel-entwicklung-von-sozialerlage-studienbedingungen-und-studentischem-bewusstsein/ [eingesehen am 01.08.2019] 
eine starke Vorurteilsbelastung der akademischen Jugend diagnostiziert wird ${ }^{1717}$, wenn Studierende als rechte Aktivisten auftreten ${ }^{1718}$ oder antiliberale bzw. autoritäre Tendenzen im Zeichen der diversitätssensiblen political correctness zeigen. ${ }^{1719}$ Entscheidend aber erscheint eine Beobachtung, die sich so bisher nirgendwo formuliert findet: In - respektive: zwischen - diesen Einzelaspekten ist keine Entwicklung mehr auffindbar, die nicht auch schon die Lebenswelten, Orientierungen und Bewusstseinsformen der Erwachsenen und Älteren prägen würden. Motive wie die Priorisierung von Umweltschutz und Geschlechtergleichstellung werden, insbesondere im (links-)liberalen Bürgertum, derzeit gesellschaftlich breit geteilt, ${ }^{1720}$ ferner kann weder die Abkehr von klassischen parteipolitischen und zivilgesellschaftlichen Organisationsformen noch das Verblassen politischer Konfliktlinien seit den $2000 e r$ Jahren in irgendeiner Hinsicht als ein Spezifikum der Jugend gelten; all das ist bereits seit vielen Jahren gesamtgesellschaftlich wirksam. Legt man die jüngeren Studien aus den Jahren 1998, 2008 und 2016 nebeneinander, so fällt auf: Die seit rund 20 Jahren anwachsende weltanschauliche Fragmentierung, die die akademische Jugend mit einem Großteil der Gesellschaft vereint, scheint geradezu eine Epoche abzulösen, in der Studierende eine wesentliche Prägekraft der politischen Kultur gewesen sind. ${ }^{1721}$

1717 Vgl. o. V.: Diskriminierungs-Umfrage geht gewaltig nach hinten los, in: Die Welt, 27.02.2016, online einsehbar unter: https://www.welt.de/vermischtes/article152704626/Diskriminierungs-Umfragegeht-gewaltig-nach-hinten-los.html [eingesehen am 01.08.2019]

1718 Vgl. Kix, Martina: Einer von denen, in: Zeit Online, 26.09.2016, online einsehbar unter: https://www.zeit.de/campus/2016/05/pegida-hochbegabter-student-rechte-protestbewegung [eingesehen am 01.08.2019]

1719 Vgl. Wagner, Gerald: Das Recht gehört den Beleidigten, in: Frankfurter Allgemeine Zeitung, 17.02.2016, online einsehbar unter: https://www.faz.net/aktuell/feuilleton/forschung-und-lehre/ ein-jahr-nach-blooger-angriff-auf-herfried-muenkler-14072301.html [eingesehen am 01.08.2019]; vgl. ferner Craw, Ansgar: Die politisch Hyperkorrekten erobern US-Unis, in: Die Welt, 27.01.2016, online einsehbar unter: https://www.welt.de/politik/ausland/article151523626/Die-politisch-Hyperkorrekten-erobern-US-Unis.html [eingesehen am 01.08.2019] sowie die eher offenherzige Einschätzung dieser neuen „antiakademischen Bewegung" in Kaldewey, David: Der Campus als "Safe Space". Zum theoretischen Unterbau einer neuen Bewegung, in: Mittelweg 36, H. 4-5/2017, S. 132153.

1720 Vgl. exemplarisch Europäische Kommission, Generaldirektion Justiz und Verbraucher: Cleichstellung der Geschlechter 2017. Spezial Eurobarometer 465, 2017; ferner o. V.: Zwei Drittel begrüßen „Fridays for Future", in: ZDF-Politbarometer, online einsehbar unter: https://www.zdf.de/nachrichten/heute/politbarometer-zwei-drittel-begruessen-fridays-for-future-100.html [eingesehen am 01.08.2019]; sowie Bundesministerium für Umwelt, Naturschutz und nukleare Sicherheit (Hg.): Naturbewusstsein 2017. Bevölkerungsumfrage zu Natur und biologischer Vielfalt, Berlin/Bonn 2018, insbesondere S. 6-9.

1721 Wohlgemerkt bleibt diese Vermutung mit allen Makeln der Vorläufigkeit behaftet. Tatsächlich mangelt es derzeit (2019) an aktuelleren Zahlen, die Aufschluss über den weiteren Verlauf des Antwortverhaltens geben könnten. Ob sich also tatsächlich so etwas wie eine Erhärtung der weltanschaulichen Fragmentierung durchgesetzt haben könnte, wie sie 2009 von Bargel und noch einmal 2010 von Bargel und Simeaner deklamiert worden ist, bleibt wissenschaftlich zu klären - und soll weiter unten auf der Crundlage des Fokusgruppenmaterials wieder aufgegriffen werden, vgl. dazu Kapitel III.3.4 dieser Studie. 
Das ist auch deshalb von Gewicht, weil zweitens die einschlägigen Studien zwar durchaus auf die durch die studentische Lebenssituation bedingte ${ }^{1722}$ unveränderte Möglichkeit studentischen Frustrations-, Protest-, und Aktionspotenzials hinweisen, aber zugleich die Unwahrscheinlichkeit einer ideologisch und organisatorisch strukturierten, ausdauernden Bewegung herausstreichen. Der Grund für diesen Zweifel liegt nicht allein in der trotz politischen Interesses verbreiten politischen Praxisabstinenz, der noch an den Realisierungschancen des zum Teil verbal bekundeten Partizipationswillens zweifeln lässt, auch nicht in der Absage an dauerhafte Mitgliedschaften in politischen und zivilgesellschaftlichen Vereinigungen. Denn selbstverständlich existieren auch heute noch kleinere Zirkel, Hochschul- und Politgruppen, die als Nukleus energischen, auch aggressiven Protests bereitstünden, und für die diese praktische Reserviertheit nicht gilt. Aber dauerhaftes Mobilisierungspotenzial bedarf mehrheitsfähiger Parolen und plausibler Deutungsangebote, die an das Empfinden einer größeren Zahl von Studierenden anknüpfen und dieses in Orientierung spendende Sinnzusammenhänge übersetzen können. Angesichts der nachgezeichneten weltanschaulichen Fragmentierung erscheint es unwahrscheinlich, dass für möglichen Missmut und Zorn bei sich verschlechternden Studienbedingungen oder Berufschancen noch eine solche kanalisierende bzw. integrierende Sprache zur Verfügung steht. Eine Entwicklung, die, wie angedeutet, auch ein Abbild gesamtgesellschaftlicher Mentalitätstrends zu sein scheint und daher kaum durch eine neue agitatorische Offensive - sei es auf der Grundlage von voluntaristischen Parolen, entschlossenen Leitbildern, medial lancierten Kampagnen oder engagierten Pamphleten auf Internet-Blogs dauerhaft umzukehren sein wird.

Die entscheidende Veränderung liegt damit nicht in der Quantität, sondern in der Qualität des politischen Potenzials. Denn das Engagement in den unmittelbar verfügbaren Arenen von Universität und Studierendengruppen blieb trotz des bewegten „roten Jahrzehnts“ historisch gesehen insgesamt die Ausnahme. Traditionell gering war das Interesse an hochschulpolitischem Engagement oder der Aktivität in studentischen Politgruppen auch schon in der alten Bundesrepublik. Dicht belegt ist seit den frühen 1980er Jahren, dass die an studentischer Politik stark Interessierten nie mehr als ein Zehntel der Studierendenschaft bildeten, während sich ca. 30 bis 40 Prozent kaum bis gar nicht für eine derartige politische Aktivität begeistern konnten. ${ }^{1723}$ Allen protestnostalgischen Generationenprofilklagen, die das Fehlen agonaler Orientierungen und rebellischer Subversivität unter der (akademischen) Jugend monieren, ist daher entgegenzuhalten, dass es periodisch wiederkehrende Möglichkeitsräume von studentischem Protest grundsätzlich gibt, und dass sich diese in ganz traditioneller Weise überwiegend an bildungspolitischen Belangen entzünden - anders wäre das Auftreten der kleineren Protestereignisse der letzten Jahrzehnte, auch des Bildungsstreiks 2009/10, nicht zu erklären. Neu aber ist die fundamentale Abkehr der deutschen Studierenden

1722 „Das kann auch heute noch passieren. Denn ihre soziale Situation ist so, wie man auch in anderen Ländern sieht, dass die Studenten relativ schnell organisierbar sind, weil sie noch nicht so stark in berufliche und familiäre Verantwortlichkeiten eingebunden sind, auf die sie Rücksicht nehmen müssen." Bargel: Entwicklung von sozialer Lage, Studienbedingungen und studentischem Bewusstsein.

1723 Bargel: Wandel politischer Orientierungen, S. 27. 
von dem Anspruch der politischen Gestaltung der Gesellschaft kraft der in die Zukunft einer besseren Gesellschaft hinausdeutenden Reformierung der Universität, die sich irgendwann in den 1980er und 1990er Jahren vollzogen hat. Überhaupt scheint die normative Kraft des Fortschrittsgedankens in diesem Zeitraum zu zerbröseln - in der Tat eine beliebte Zeitdiagnose. ${ }^{1724}$

Insgesamt ist das politische Potenzial von Studierenden also nicht verschwunden - doch es hat einen substanziellen Charakterwandel vollzogen. Spontaner, auch inziviler und gewalttätiger Protest erscheint für ein Szenario wachsender Unzufriedenheiten nicht unwahrscheinlich. Ein Blick auf die Ereignisse des so genannten Arabischen Frühlings oder auch nach Frankreich und Südeuropa zeigt, welche Protestenergien von beruflich desorientierten, hochqualifizierten jungen Menschen ausgehen können. ${ }^{1725}$ Nur können derartige Unruhen nicht mehr auf die politische Bündelung durch die Mobilisierungsarbeit studentischer Organisationsstrukturen setzen. Mit anderen Worten: Ein neuer Bildungsstreik scheint auf der Grundlage der referierten empirischen Studien denkbar, eine neue Studentenbewegung nicht.

Hält dieser Befund zum jungakademischen Mentalitätswandel einer näheren qualitativen Untersuchung Stand? Und überhaupt: Was könnte heute politische Energien unter deutschen Studierenden freisetzen? Diese Fragen lassen sich nur beantworten, wenn es gelingt, die grundierenden politisch-sozialen Deutungsmuster der studentischen Sicht auf Gesellschaft, Politik und Demokratie aufzudecken.

\section{II.4 Zwischenbetrachtung und empirischer Ausblick}

Die nun deutlich gewordene soziohistorische Zerklüftung der Thematik lässt die zu Beginn dieser Studie formulierte Frage nach dem politischen Potenzial von Studierenden geradezu naiv erscheinen. Lassen sich Rückblick und Gegenwartsanalyse überhaupt sinnvoll verbinden? Lässt sich insgesamt überhaupt eine Kernbedeutung von studentischem politischem Potenzial destillieren? Oder hat es sich trotz der während des „Bildungsstreiks“ von 2009/10 zuletzt erwiesenen Möglichkeit studentischen Protests in Deutschland aus wissenschaftlicher Sicht bei dieser Frage stets um eine - hoffnungsvoll schimmernde - Suche nach einem $\pi \rho \tilde{\omega} \tau o v ~ \psi \varepsilon \tilde{v} \delta \circ \varsigma$ (proton pseudos), einem nichtvorhandenen Ding, gehandelt, um eine unzusammenhängende Kette irregulärer Einzelereignisse? Wenn es heute noch politisches Potenzial unter den Studierenden gibt - wie könnte dieses aussehen? Ist es jenseits der politisch-kulturellen Folklore der (eigentlich eher westlichen) Bundesrepublik überhaupt (noch) naheliegend, unter Studierenden besondere Dispositionen für politisches Engagement zu suchen?

Tatsächlich ist nicht abzustreiten, dass sich im Verlauf von zwei Jahrhunderten gesellschaftlicher Entwicklungsdynamiken auch die Studierendenschaft substanziell ver-

1724 Vgl. etwa den unter Rekurs auf die vom Publizisten Sebastian Haffner geprägte Formel „Der Liberalismus hat sich totgesiegt“ geschriebenen späten Aufsatz Schelskys: Schelsky, Helmut: Der „Begriff des Politischen“ und die politische Erfahrung der Gegenwart. Überlegungen zur Aktualität von Carl Schmitt, in: Der Staat, 22. Jg., H. 3/1983, S. 321-345, hier S. $321 f$.

1725 Vgl. Kraushaar: Der Aufruhr der Ausgebildeten. 
Abb. 15: Politisches Interesse der Studierendenschaft im Vergleich zur Gesamtbevölkerung 1983-2016

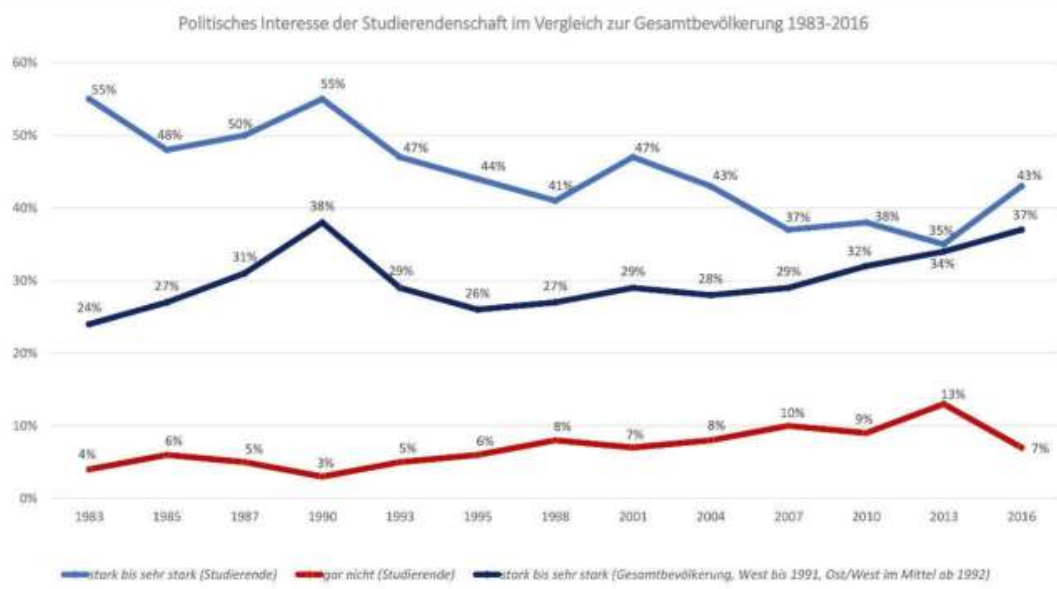

Daten entnommen aus Datenalmanach Studierendensurvey 2007, S. 219; Datenalmanach Studierendensurvey 2017, S. 215; Statistisches Bundesamt/WZB: Datenreport 2018, S. 351.-

Abb. 16: Zustimmung zur harten Bestrafung vom Kriminalität

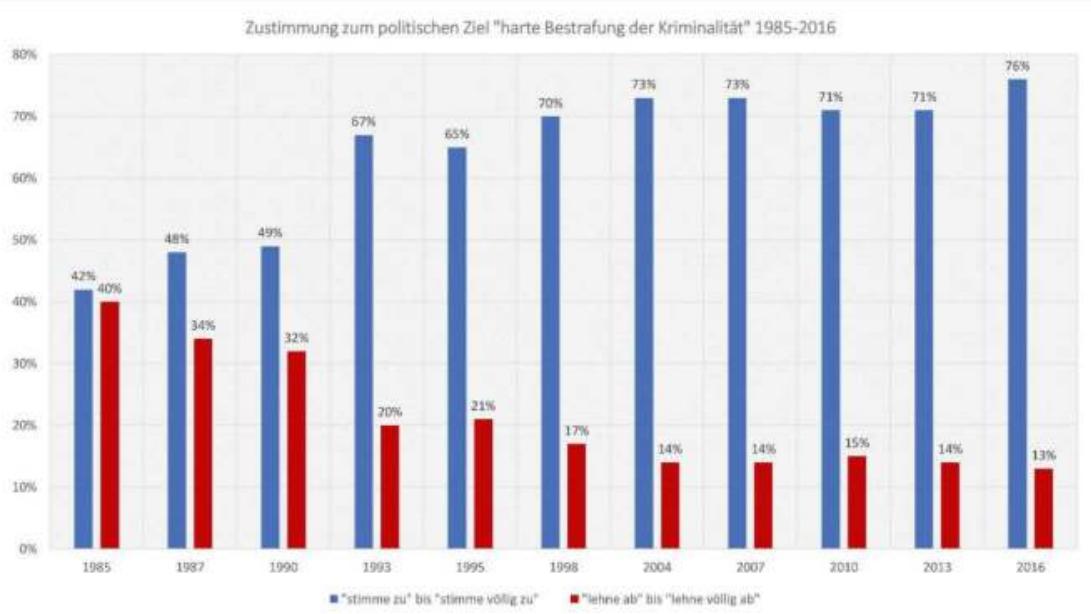

Daten entnommen aus Datenalmanach Studierendensurvey 2007, S. 227; Datenalmanach Studierendensurvey 2017, S. 220.

ändert hat. Pointiert gesprochen, steht am Ende dieser Geschichte der individualisierte Massenstudent, der infolge wiederholter sozialer Öffnung des Studiums und peri- 
Abb. 17: Zustimmung zur Begrenzung von Immigration

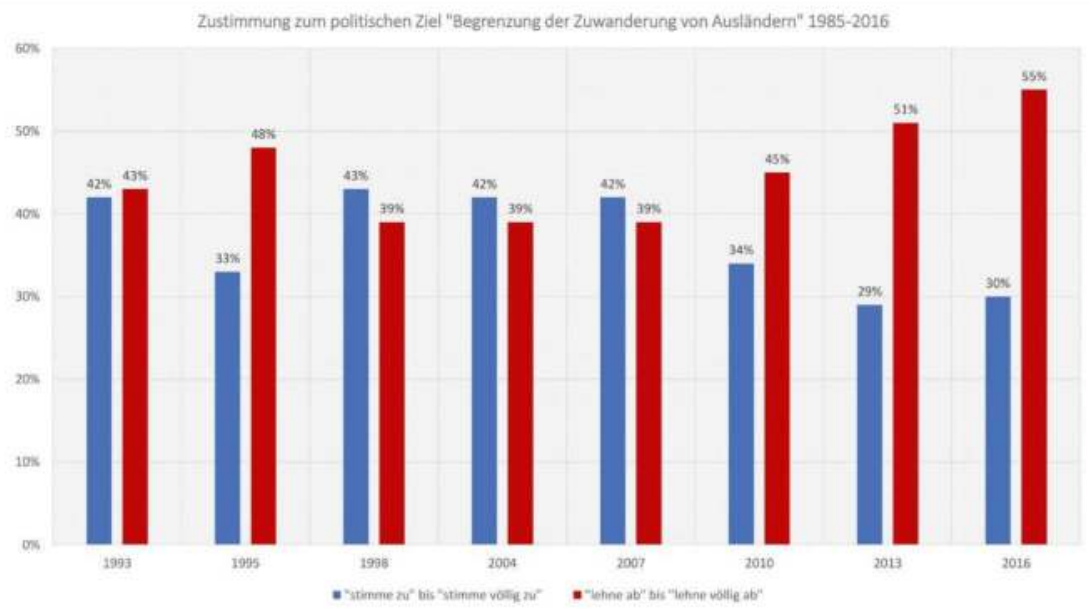

Daten entnommen aus Datenalmanach Studierendensurvey 2007, S. 228; Datenalmanach Studierendensurvey 2017, S. 221.

Abb. 18: Zustimmung zur Abschaffung des Privateigentums

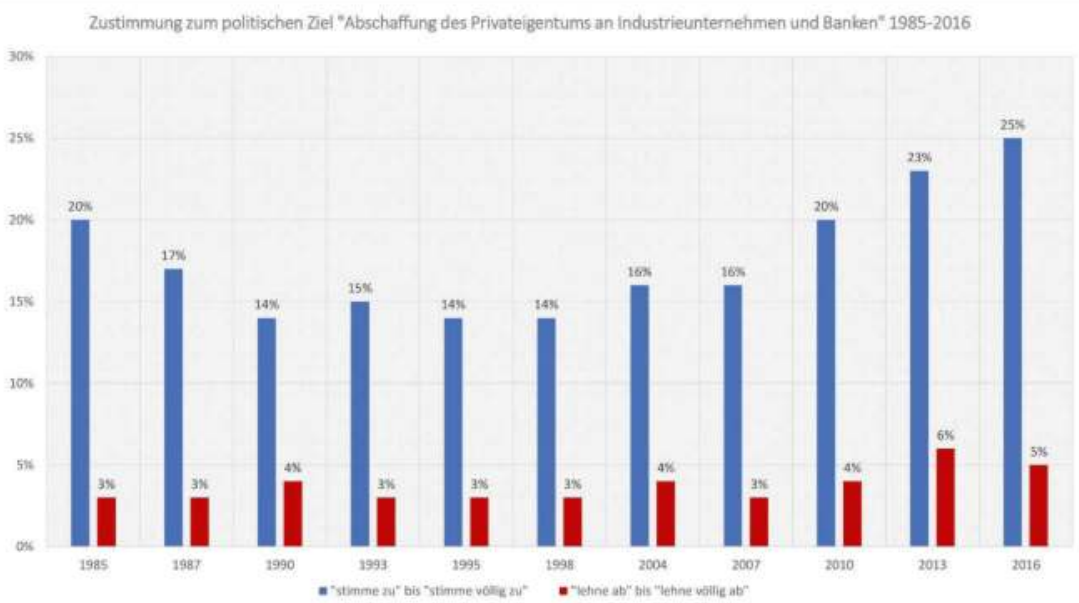

Daten entnommen aus Datenalmanach Studierendensurvey 2007, S. 227; Datenalmanach Studierendensurvey 2017, S. 220.

odisch wiederkehrender Marktorientierung der Universität keinem identifizierbaren Milieu mehr angehört, nicht mehr in verbindliche subkulturelle Organisationsformen eingebunden ist, überhaupt die Immatrikulation an der Universität nicht einmal mehr 
Abb. 19: Zustimmung zur Sicherung von Marktliberalismus

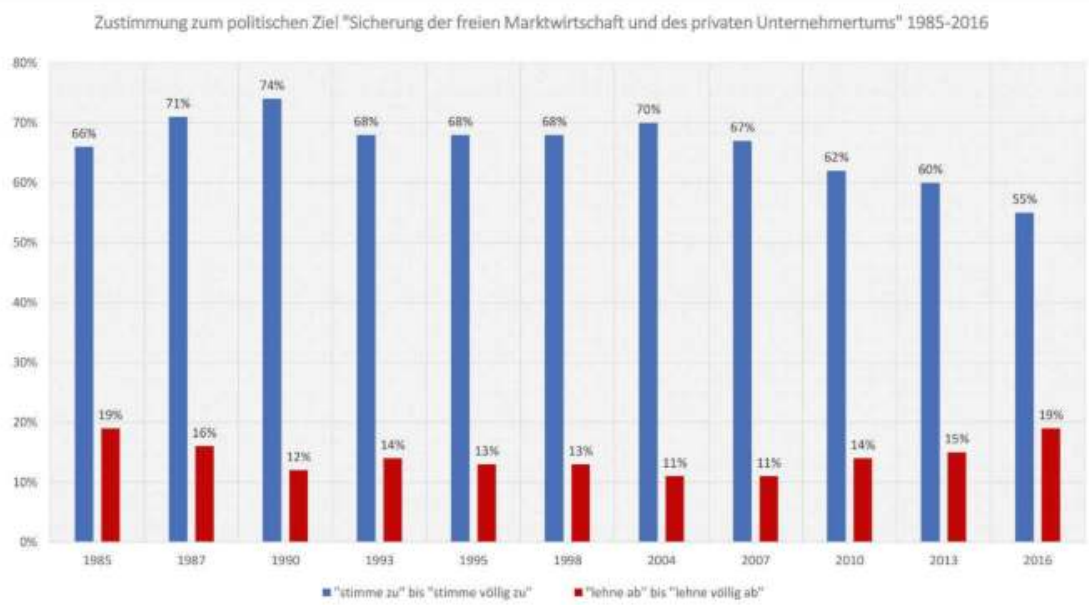

Daten entnommen aus Datenalmanach Studierendensurvey 2007, S. 227; Datenalmanach Studierendensurvey 2017, S. 220.

Abb. 20: Zustimmung zur Förderung der technologischen Entwicklung

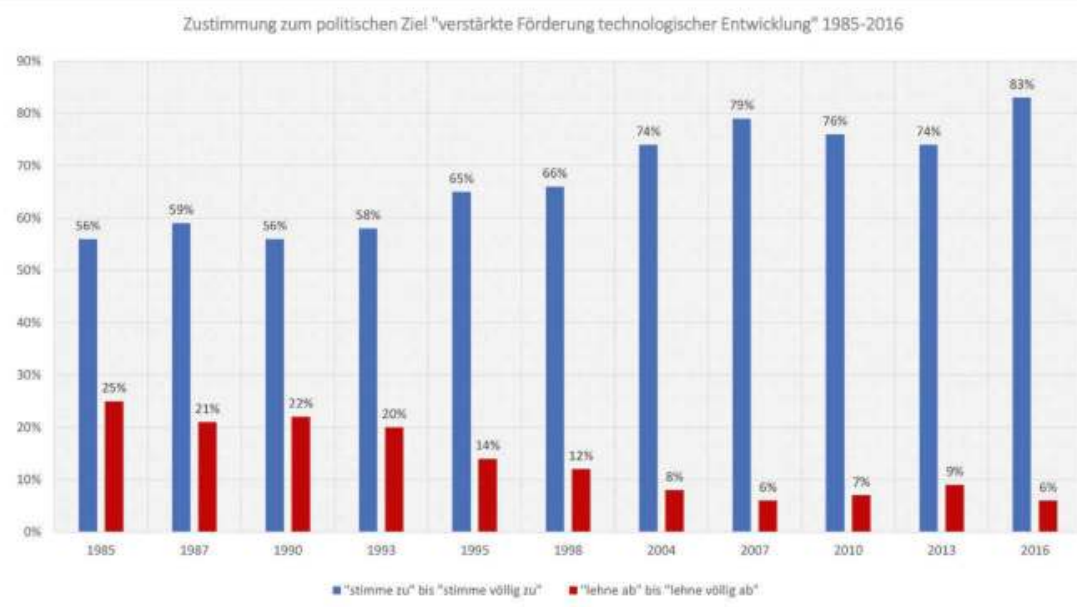

Daten entnommen aus Datenalmanach Studierendensurvey 2007, S. 227; Datenalmanach Studierendensurvey 2017, S. 220.

als Verpflichtung auf ein spezifisches Standes- oder Sozialethos ${ }^{1726}$ empfindet, sondern

1726 Das wohl beeindruckendste Zeugnis des einstigen aus dem studentischen Reformimpuls geborenen, aber noch durch quasiständische Elite- und Exklusivitätsansprüche durchsetzten Versuchs, studentisches Leben, individuelle Selbstentfaltung und politisches Rollenverständnis in einem 
schlicht als Beginn einer Ausbildungsphase neben anderen. Im Konfliktgemisch der sich entfaltenden Industrialisierung und der Expansion der Hochschulbildung ging diese soziale Spezifität sukzessive verloren; schon in Weimar begannen sich dann jene massengesellschaftlichen Tendenzen durchzusetzen, ${ }^{1727}$ die sich, unterbrochen durch eine von Wirtschaftskrisen und Kriegen bedingte Latenzperiode, nach etwa 1970 in Gestalt der postindustriellen Dienstleistungsgesellschaft durchsetzen. ${ }^{1728} 1980$ führten sie zur letzten Überfüllungskrise der akademischen Karrieren, einem zyklisch wiederkehrenden Phänomen einer Steigerungsdynamik der Bildungsexpansion, die sich über zunächst blockiertes Wachstum (Vormärz), schlagartige Expansion (mit Unterbrechungen von 1860 bis 1930), und rigorose Drosselung (Nationalsozialismus) hinweg durchsetzte. ${ }^{1729}$ Zur sozialen Öffnung des Studiums gesellt sich das Verschwinden des klassischen Studentenlebens: Zwischen 1960 und 1980, dem Zeitraum des bislang erstaunlichsten Bildungswachsstumsschubs der deutschen Geschichte, war das schon länger politisch diskreditierte Verbindungswesen irreversibel marginalisiert. Das darf zwar nicht darüber hinwegtäuschen, dass noch die APO ein Selbstverständnis des intellektuellen und politischen Avantgardismus pflegen konnte, ja den auf der abgelebten Verbindungstradition aufsattelnden Anspruch ${ }^{1730}$ erhob, die gesamte Studierendenschaft zu repräsentieren. Spätestens in den 1980er Jahren hat sich diese Entwicklung vervollständigt: Studierende haben die für sie lange Zeit prägende (weitgehende) soziale und sozialmoralische Spezifität verloren. Damit verschwinden auch wesentliche Differenzen zu nichtstudierenden Gleichaltrigen. $\mathrm{Zu}$ dieser grundlegenden Beobachtung führt der historische Längsschnitt den

historisch neuen bürgerlichen Sittenverständnis zu integrieren, stellt wohl der Kodex der „studentischen Ehre" aus dem Kontext der Urburschenschaft 1815-1819 dar: „Unter dem Sammelbegriff der studentischen ,Ehre' suchen die Burschenschafter eine verbindliche und alle Aspekte des studentischen Lebens integrierende Antwort auf die Fragen nach dem Sinn und dem Stellenwert dieser Altersphase im Kontext der individuellen Lebensperspektive überhaupt, nach ihrer persönlichen Selbsteinschätzung, ihrer Stellung in der Gesellschaft und im Verhältnis zum Staat. Als beherrschendes Motiv tritt dabei die allmähliche Modifikation des ständisch-korporativen Ehrverständnisses in Richtung auf einen emphatischen Begriff der Individualität hervor." Hardtwig: Studentische Mentalität, S. 591.

1727 Natürlich waren diese Entwicklungen schon im Kaiserreich zu spüren: die darauf reagierende Wahrnehmung eines „Kulturverfalls“ ist als bildungsbürgerliches Deutungsmuster einer um ihre Privilegien bangenden Sozialformation anzusehen. Um dieses Phänomen dreht sich die von Ringer verfochtene und von Lundgreen (aufgrund der keineswegs modernistischen Entwicklung der deutschen Akademikerschaft nach dem Niedergang der "Mandarine“) kritisierte These eines agressiven politischen und kulturellen Antimodernismus der akademischen Eliten, vgl. Ringer: Die Gelehrten und Lundgreen, Peter: Bildung und Besitz - Einheit oder Inkongruenz in der europäischen Sozialgeschichte? Kritische Auseinandersetzung mit einer These von Fritz Ringer, in: Geschichte und Cesellschaft, H. 7/1981, S. 262-275.

1728 Vgl. Raphael: Jenseits von Kohle und Stahl.

1729 „Obwohl sie von den beteiligten Studenten als einmalige Existenzbedrohung empfunden werden, sind die Probleme der1970er und 1980er Jahre nur eine verschärfte Form eines langfristigen Strukturwandels der Universität. In allen Industriestaaten waren die Expansion, Differenzierung, soziale Öffnung und Professionalisierung der Hochschule mit erheblichen Schwierigkeiten verbunden." Jarausch: Deutsche Studenten, S. 243, vgl. außerdem ibid., S. 244.

1730 Im Vormärz erhoben selbst kleinere radikale Zirkel der Burschenschaftsbewegung wie die zur „progressiven“ politischen Praxis drängenden Germanen diesen Anspruch, vgl. Hardtwig: Studentische Mentalität, S. 599. 
Forscher nahezu unweigerlich. Insbesondere angesichts der besonderen Vorgeschichte: Das lange 19. Jahrhundert hindurch ist die politische Geschichte der Jungakademiker eng mit derjenigen ihres hauptsächlichen Herkunftsmilieus, des aus dem Beamtentum der deutschen Gliedstaaten hervorgehenden Bildungsbürgertums, und damit auch des deutschen Bürgertums insgesamt verkettet. Diese Geschichte begann, als die überregionale Vernetzung der studentischen Organisationsformen ab 1750 den ersten gesamtnationalen politischen Organisationszusammenhang des deutschen Bürgertums stiftete, ${ }^{1731}$ und endete mit der Kriegsniederlage des Deutschen Kaiserreichs, als die kulturell einflussreiche und materiell saturierte Schicht der "deutschen Mandarine“ zerging.

„Ihre Entwicklung verlief innerhalb der gewaltigen Aufwärtsbewegung des Bürgertums, und die Studentenschaft nahm sogar in den Tagen des Wartburgfestes von 1817 für kurze Zeit die Führung in die Hand. Seitdem teilte sie Wohl und Wehe mit dem Bürgertum, und mit ihm zusammen stürzte sie schließlich am 9. November 1918 von der erreichten stolzen Höhe herab. ${ }^{\text {“1732 }}$

Insofern sind Studierende schon seit Weimar eigentlich nicht mehr im vollen Sinne als jene radikalen Antizipatoren bildungsbürgerlicher Mentalitätstrends zu verstehen, als die Konrad H. Jarausch sie 1984 noch sah $^{1733}$ - und ganz besonders heute, in Zeiten eines fortgesetzten, immer neue Rekorde brechenden Bildungswachstums, ist der Sinn einer solchen Generalaussage noch weniger klar.

Beginnend mit der auslösenden (nicht ursächlichen) antinapoleonischen Kriegserfahrung waren studentische Oppositionsbewegungen Teil dieser Geschichte, die nicht nur gesamtgesellschaftliche Entwicklungen bezeugt, sondern auch die Verflochtenheit der Studierendenschaft mit den jeweiligen sozialen wie kulturellen Auseinandersetzungen, ferner ihre Rolle bei der Verbreitung und Popularisierung moderner bürgerlicher Assoziations- und Organisationsformen in Deutschland. Emanzipativ auftretende Studentenbewegungen speisten sich dabei aus der Traditionslinie des frühliberalen urburschenschaftlichen Reformimpulses, der sich auf die Grundgedanken der neuhumanistisch inspirierten Förderung intellektueller und charakterlicher Reife der studierenden Individuen jenseits von Stand und Geburt, die bürgerliche Zivilisierung und Disziplinierung studentischer Gesellungsformen und die damit verbundene Verpflichtung auf eine liberale (erst später im modernen Sinne demokratische und sozial ausgleichende) Staatsform stützt. ${ }^{1734}$ Im langen 19. Jahrhundert beriefen sich nicht nur die drei sukzessive politisch radikaleren Generationen der liberalen Burschenschaften (1815-1819, 1827-1832 und die Progressbewegung 1837-1855) auf diese Traditionslinie, sondern auch das verbindungskritische, erkennbar ungebrochen auf dem Ideal der „Selbsterziehung“ zu Mündigkeit

1731 Vgl. ibid., S. 581.

1732 Schulze/Ssymank: Das deutsche Studententum, S. 160.

1733 Vgl. Jarausch: Deutsche Studenten, S. 246.

1734 Zur Genese jenes spezifischen, nur für einen begrenzten Zeitraum stabilen Gemischs von „Gesittungs- und Disziplinierungsbewegung“ und politischer Bewegung vgl. noch einmal Hardtwig: Studentische Mentalität, S. 591-600. In diesem Zusammenhang gilt es immer auch zu beachten, dass ein großer Teil der Reformstudenten, dem es primär um Reform der "Cesittung“ ging, stets dezidiert unpolitisch aufgetreten ist. 
und Streitkultur als Grundlage studentischer Autonomie fußende ${ }^{1735}$ urbane Freistudententum (1840er-1920er Jahre), das sich im Vormärz, stärker aber noch im jugendbewegten Kaiserreich und in der Weimarer Republik die antikorporative Organisationsform der Finkenschaften respektive Wildenschaften gab. Auch das solidaritätsbasierte Zusammengehörigkeitsbewusstsein der frühen studentischen Selbsthilfe- und Selbstverwaltungsbewegung in den Weimarer Elendsjahren zehrte in gewissem Sinne noch eine Weile von dieser Tradition, bevor der Gedanke volksgemeinschaftlicher Kollektivität das liberale Erbe abzureiben begann. ${ }^{1736}$ Schließlich vermochte die Studentenbewegung von „1968“ trotz der Argumentationsfigur der „substitutionalistischen“ Avantgarderolle für die sozialistische Revolution - in einer Phase studentisch-bildungsbürgerlicher kultureller „Unbehaustheit"! - ein im Grunde sehr altes studentisches Autonomieund Verantwortungsempfinden zu reaktivieren, auch subkulturelle Surrogate für die verblichene Verbindungstradition bereitzustellen. ${ }^{1737}$ Seinen Widerhall fand der egalitäre Impetus insgesamt im Drang zur Demokratisierung studentischer Organisationsformen und in der Forderung nach Hochschulreformen, in der Insistenz auf studentische Lern- und Lebensfreiheit, in der Leidenschaft für die politische Diskussion, und in einer Kritik der Lebensverhältnisse ökonomisch schlechter gestellter Studenten. Nie kam er ohne ein spezifisches Amalgam aus Traditionspflege und „progressivem“ Modernisierungsanspruch aus. War der bildungsbürgerliche Nationalliberalismus noch erkennbar männlich und protestantisch geprägt, optierte die Freistudentenschaft bereits für geschlechterparitätische Mitgliederstrukturen. Dabei bedarf ganz besonders der Vergleich von „1848“ und „1968“ einiger Einschränkungen. Der herausgearbeitete Traditionsbruch zwischen klassischer sozialer Emanzipationsbewegung und den „Performanz"-orientierten Aktionsrepertories modern-mittelschichtigen Bürgerprotests $^{1738}$ streut Sand in das Getriebe der Analogisierungsmaschine. Die antiliberale, restriktiv-elitäre und sozialchauvinistische Traditionslinie studentischer politischer Bewegung wurzelte stärker im korporativ-landsmannschaftlichen Traditionalismus der kleineren Universitätsstädte, stützte sich wesentlich aufgemeinschaftsstiftende ständisch-aristokratische Rituale, auf Tugendmaximen im Sinne der „Ehrenwahrung“ und aufdas Männerbundprinzip. ${ }^{1739}$ Schon zu

1735 Vgl. Wipf: Studentische Politik und Kulturreform, S. 229 und 249.

1736 Vgl. Nipperdey: Die deutsche Studentenschaft in den ersten Jahren der Weimarer Republik, S. 2628 und $32-38$.

1737 Unzureichend wissenschaftlich untersucht erscheint die Einmündung freistudentischer Intellektualität in die neomarxistische Theorietradition, wie sie von dem Frankfurter Institut für Sozialforschung unter Max Horkheimer visiert worden ist. Als frühere Freistudenten sind beispielsweise die Intellektuellen Ernst Bloch, Karl Korsch, Walter Benjamin und Helmuth Plessner oder die Politiker Adolf Grimme und Gustav Radbruch zu nennen. Die Reformbewegung der Freistudentenschaft kann bis zu einem gewissen Crad durchaus als Schule späterer linker Eliten in der Weimarer Republik aufgefasst werden, vgl. Wipf: Studentische Politik und Kulturreform, S. $14 f$.

1738 Vgl. Gassert: Bewegte Gesellschaft, S. 275f.

1739 „Studentische Sitte und Lebensführungsart wurden in der alten Welt an allen protestantischen Universitäten des Reichs von den alten Landsmannschaften beherrscht. Die Zugehörigkeit war mehr oder weniger Pflicht. Organisationsprinzip war, wie der Name sagt, die regionale Zusammengehörigkeit, die sich mit den territorialstaatlichen Grenzen nur in Ausnahmefällen deckte.“ Hardtwig: Auf dem Weg zum Bildungsbürgertum, S. 20. Vgl. außerdem zur Wahrnehmung dieser Traditionslinie als mittelalterlichem Atavismus durch die Freistudenten Wipf: Studentische und Politik und Kulturreform, S. 229-233. Auch hier gilt, dass die konservativ-traditionalistischen 
Vormärzzeiten die Mehrheit der studentischen Verbindungsformen ausmachend, wurde der Corpsstudent zum „Idealbild der Wilhelminischen Ära“ und ihrer militaristischen Gesellschaftsorganisation, ganz wie der Reserveoffizier das „Idealbild des deutschen Bürgers" darstellte. ${ }^{170}$ Die Ehre der Nation zu fördern, wurde zum erklärten politischen Ziel der Verbindungsstudenten im Kaiserreich. Dies verläuft parallel zur Umstülpung des deutschen Nationalismus, dem (bildungs-)bürgerlichen politischen Projekt par excellence, von einer liberalen Emanzipations- und Fortschrittsideologie in eine konservative und chauvinistische Herrschaftsideologie des 1871 zum Nationalstaat zusammengefügten imperialistischen Deutschlands im Zuge der ,inneren Reichsgründung" und der Ausschaltung der altliberalen Kräfte als Trägerschicht des Nationalismus bis $1890 .{ }^{1741}$ Insofern waren die Korps in jenen Jahren zwar durchaus politisiert, agierten aber nicht jenseits der etablierten Organisationsformen und insbesondere nicht oppositionell. Anders ist das im Falle der völkischen Studentenbewegung der 1920er und 1930er Jahre gelagert, in deren Formationsprozess das antiliberal-traditionalistische Erbe eine ambivalente Rolle spielte: Das akademische Bündnis mit der nationalsozialistischen Bewegung, das zunächst die Studenten und später die erwachsenen Akademiker mit der Absicht bildungsbürgerlicher Privilegiensicherung eingingen, kehrte sich in den 1930er Jahren in passive Widerstände des korporativen Traditionalismus gegen die fortgesetzte „Mobilmachung“ um.

Einige besondere Gemeinsamkeiten von Studentenbewegungen sind in der Gesamtschau festzuhalten: Stets partizipierte nur ein kleiner Teil der Studierenden aktiv an den Bewegungen ihrer Zeit, den Nukleus bildeten zumeist kleine, hochaktive Zirkel. Trotzdem können Bewegungen einen nachhaltigen Einfluss auf das Selbstverständnis und die politischen Ziele eines numerisch signifikanten Teils der Studentenschaft haben. Im Falle der bundesrepublikanischen Studentenbewegung von „1968“ ist das wie gesehen empirisch belegt und über die Zeitspanne zwischen 1967 und 1982/83 hinweg klar nachvollziehbar. Natürlich bedeutet die breite Übernahme symbolkräftiger Slogans aus dem Angebot von Bewegungen dabei nicht zwangsläufig, dass aktivistische und nur sympathisierende Studierende unter ihnen dieselben Bedeutungsgehalte verstehen hier sei an das Beispiel der nachhaltig wirksamen Maxime der "Demokratisierung“ erinnert. Insofern: Das Bild schlummernder politischer Energien, welche in besonderen Konfliktkonstellationen aktiviert werden und dann, gleich einem Dammbruch, eruptiv zu Studentenbewegungen führen, wäre simplifizierend. Ebensowenig sind Studentenbewegungen irregulär-plötzliche Phänomene. Protest kann sich zwar jederzeit spontan an Einzelthemen entzünden, aber auch verglühen; Bewegungen aber hatten Vorlaufzeiten, reagierten auf spezifische gesamtgesellschaftliche Entwicklungen und wurden in ihrer

Kreise der Studentenschaft zumeist zwar verhalten staatstreu, aber doch mehrheitlich unpolitisch aufgetreten sind. Die imperialistisch-militaristische Parteinahme für "die deutsche Nation" war schließlich ein Produkt der 1880 r Jahre.

1740 Vgl. Studier: Der Corpsstudent als Idealbild der Wilhelminischen Ära, S. VI. sowie Schulze/Ssymank: Das deutsche Studententum, S. 181-185.

1741 Vgl. Winkler: Der lange Weg nach Westen, Bd. 2, S. 236-247, insbesondere S. 245: „Der Bedeutungswandel des Begriffs, national' wurde von einem Wandel der Trägerschichten des Nationalismus begleitet. Seit sich die preußischen Konservativen 1876 in , Deutschkonservative Partei' umbenannt hatten, beanspruchten sie auch, die wahren Vertreter des nationalen Gedankens zu sein." 
formativen Phase wesentlich durch gut organisierte Netzwerke "gemacht“. Dazu gehört es, dass die Studentenbewegungen der Signaljahre „1848“, „1968“ und „1933“ zum Zeitpunkt ihrer größten öffentlichen Aufmerksamkeit jene gesellschaftlichen Veränderungen, für die sie berühmt wurden, finalisierten, nie initiierten. Das ist nicht nur anhand der nationalrevolutionären Mobilisierung der 1830er und 1840er Jahre oder am sozialliberalen Mentalitätswandel Ende der 1960er Jahre nachzuzeichnen; schon die Hinwendung der Burschenschaftsbewegung zur Nation als sämtliche Reformimpulse verklammernden Kernidee fußte auf der schrittweisen „Verbildungsbürgerlichung“ der Studentenschaft seit 1750 durch bürgerliches Sozietätswesen („eine neue Art partiell ständeverschmelzender Geselligkeit" in Form von Lese- und Geheimgesellschaften, Zeitungen, etc. ${ }^{172}$ ) und Wertvorstellungen; der oft als ursächlich angenommene Antinapoleonismus erscheint demgegenüber vielmehr "nur" als auslösendes Moment. ${ }^{1743}$ Somit: „Was man für das Typische eines Jahrzehnts oder eines Jahrhunderts nimmt, hat in der Regel seinen formativen Ausgang weit früher [...] ${ }^{\text {“1744 }}$, da

„sich gesellschaftliche Entwicklungen politisch oft genug erst dann umsetzen, wenn der soziale Prozess bereits abgeschlossen ist, die untergründigen kulturellen Bewegungen sich schon in eine neue Richtung geschoben haben. ${ }^{\text {“1745 }}$

Im direkten Vergleich von „1848“ und „1968“ fällt neben dem analogen Scheitern an den politischen Nah- und Fernzielen, neben dem Mobilisierungsbeginn in hochschulund bildungspolitischen Auseinandersetzungen, neben den ruckartigen Politisierungserfolgen, neben dem Zerfall in heterogene Teilströmungen zum Zeitpunkt der größten Mobilisierungskraft und neben dem langfristigen Einfluss auf gesellschaftliche Modernisierungsprozesse $\mathrm{e}^{1746}$ überdies das oft beobachtete Dilemma historischer Fortschrittsbewegungen auf: Da sie ihren „Treibstoff“ wesentlich aus der Oppositionsrolle beziehen, erschlaffen sie nicht primär im Moment des Scheiterns, sondern verzehren sich viel eher noch über ihren langfristigen Siegeszug hinweg, schließlich durch die Übernahme von Elite- und Machtpositionen. Für ihre Trägergruppen (in beiden Fällen das aufstiegsorientierte Jungakademikertum) gilt: „Sie kommen an, sind saturiert, taugen demzufolge nicht mehr als Motoren kraftvoller Fortschrittlichkeit. “1747 Tatsächlich handelte es sich in beiden Fällen um „ausgebremste Gegeneliten“ bzw. um „bürgerliche[n] Kadernachwuchs", der sich - wenn auch nur im Vormärz wirklich erfolgreich - zum Kräftereservoir für Massenbewegungen machen wollte. Ihre Energien entstanden nicht aus Leid oder Elend, sondern aus Aufstiegsdrang, ${ }^{1748}$ ihr Selbstbewusstsein drehte sich

1742 Hardtwig: Studentische Mentalität, S. $612 \mathrm{f}$.

1743 Ibid., S. 610-617.

1744 Walter: Rebellen, Propheten, Tabubrecher, S. 327.

1745 Walter: Baustelle Deutschland, S. 162.

1746 Den Vergleich zwischen „1968“ (damals noch „1967“) und „1848“ zu ziehen, lag daher für viele Zeitgenossen der alten Bundesrepublik durchaus nahe. Es ist - wie weiter oben, Kapitel II.2.1, erwähnt - nicht ganz unplausibel, dass das kulturell überlieferte Stereotyp vom kritischen Studenten zwar wesentlich durch die Bilder von „1968“ aufrechterhalten wird, aber doch in Tiefenschichten der politischen Kultur auf 1815 bzw. 1848 zurückverweist.

1747 Walter: Rebellen, Propheten, Tabubrecher, S. 17.

1748 Ibid., S. 122. 
um eine robuste, durch die historische Entwicklung legitimierte, „meritokratische Achse“. ${ }^{1749}$ In Phasen akademischer Überfüllung und stark eingetrübter Berufsaussichten hingegen scheint eskapistisch-subkulturelle Gesellschaftskritik stärker zu reüssieren: So treffen sich die spätwilhelminische Lebensreform-, Wandervogel- und Jugendbewegung einerseits und die „No future“-Alternativbewegung um 1980 andererseits in ihrer emphatischen Betonung von „Kultur“, Innerlichkeit und Ursprünglichkeit gegen die unzumutbare Entfremdungserfahrung kalter Zivilisation; beide Impulse drücken die mäandernde Suche nach dem „Bild einer Gesellschaft, in der man als Mensch wahrhaftig leben könne“, 1750 aus. Ein weiteres auffällig konstantes Phänomen liegt ferner in dem noch bis in die 1960er Jahre prägenden Anspruch jungakademischer Gruppen „links“ wie „rechts“ (und dementsprechend auch vieler älterer Bildungsbürger), als Clique ausgewählter Eliten die Studierendenschaft und damit die die Gesellschaft insgesamt kulturell und/oder politisch anzuführen: im Vormärz als Funktionselite der bürgerlichen Gesellschaft und ihrer „Zielutopie“, im Falle der APO als „substitutionalistische“ Revolutionäre. Der Status der in vielerlei Hinsicht privilegierten, zwar politisch neutralisierten, aber doch materiell saturierten und zumindest kulturell deutungsmächtigen deutschen „Mandarine“ im Kaiserreich kommt der Ehrenrolle der Intellektuellen, wie sie zumindest die Anführerfiguren der Studentenbewegungen offensichtlich für sich selbst reklamierten, wohl am nächsten. ${ }^{1751}$ Pointiert gesprochen: Karl Follen, Cheftheoretiker der frühen Burschenschaften und charismatisches Zentrum des Kreises der Gießener „Unbedingten“, und Rudi Dutschke, Wortführer der Studenten von „1968“, sind in vielerlei Hinsicht vergleichbare Charaktere. Die Beispiele des Korporatismus im Kaiserreich und des DHR bzw. NSDStB in Weimar zeigen allerdings auch, warum die bisweilen positiv konnotierte Schwärmerei über den studentischen Avantgardismus ahistorisch ist: Studenten waren eben nicht nur Fahnenträger der Freiheit, sondern auch begeisterte Standartenträger der Reichskriegsflagge und des Hakenkreuzbanners. Schließlich: Ein entscheidender, aber seltener Moment von Studentenbewegungen bricht an, wenn es diesen nicht nur gelingt, die Arena hochschulpolitischer Konflikte um gesamtgesellschaftlich virulente Thematiken zu ergänzen, sondern auch nichtstudentische Milieus $\mathrm{zu}$ aktivieren und eine Massenbewegung entstehen $\mathrm{zu}$ lassen. Der dritten Welle der Burschenschaftsbewegung ist das in den späten 1830er und 1840er Jahren gelungen, wiederum nach einer langen Phase des Scheiterns und ohne den studentischen Führungsanspruch aufrechterhalten zu können; das wiederum wäre nicht möglich gewesen

1749 Galtung: Eine strukturelle Theorie der Revolution, S. 166. Natürlich spielten Aufstiegsblockaden auch während der durch kollektivnarzisstische Kränkungserfahrungen befeuerten Selbstnazifizierung der deutschen Studentenschaft eine wichtige Rolle: „Die faschistischen Massenbewegungen der 1920er und 1930er Jahre lebten wesentlich von den Frustrationsenergien beruflich ausgebremster bürgerlicher Jungkader." Walter: Rebellen, Propheten, Tabubrecher, S. 122. Dennoch stützt diese Beobachtung die These, dass aus einer Phase relativen Elends eben kein Progressismus, sondern Aggressivität erwächst.

1750 Stifterverband für die deutsche Wissenschaft: Das geistige Bild der Studentenschaft, S. 5 (Herv. ). S.) Vgl. ferner Krause et al.: Zwischen Revolution und Resignation?, S. 186-194 sowie Glotz/Malanowski: Student heute, S. 82-96 und 176-192.

1751 Für die frühen Burschenschafter gilt: „In der Forderung nach dem einen Deutschland manifestiert sich auch bei den Burschenschaften von Anfang an ein neuartiger Anspruch der angehenden Bildungsbürger, mächtig zu sein." Hardtwig: Studentische Mentalität, S. 608. 
ohne die (ersatz-)religiöse Aufladung der milieuübergreifenden deutschen Nationalbewegung. Ein wesentlicher Unterschied zwischen „1848“ und „1968“ besteht allerdings im sozialen Charakter der Studentenbewegungen: Während die vormärzlichen Studenten sich sukzessive als emanzipative Avantgarde eines klassenkämpferisch-revolutionären Bürgertums verstanden und dies auch tatsächlich waren, trägt die APO zur Hochzeit ihrer Mobilisierung trotz sozialistisch-revolutionärer Rhetorik Züge modernen Bürgerprotests von Angehörigen der bereits etablierten Mittelschichten: Diese Studentenbewegung war mehr „Resonanzraum“ als „Motor“ gesellschaftlichen Wandels, ${ }^{1752}$ oder in den Worten Gasserts über diesen neueren Bürgerprotest seit 1945: „Wandel kommt eher dadurch zustande, dass andere auf Protest reagieren. ${ }^{\text {(1753 }}$ Darüber hinaus lassen sich über die Umstände der Entstehung von Studentenbewegungen, über die Lebensdauer oder auch nur über die politische Stoßrichtung der beteiligten Personen, Gruppen und Organisationen keine persistenten Muster ausmachen. ${ }^{1754}$ So sind Studierende keineswegs die meiste Zeit hindurch „links“ oder staatskritisch gewesen. Natürlich: Nach dem Muster der klassisch „progressiv“-radikaldemokratischen Kräftekonstellation im frühliberalen Sinne war die Burschenschaftsbewegung durchaus revolutionär „links“, und auch die um die APO zentrierte Studentenbewegung optierte zumindest verbal für eine sozialistische Gesellschaftsform. Zwischen 1871 und 1945 aber waren die nichtkorporierten, nicht-konservativen und nicht-staatstragenden Studentengruppen (mit Ausnahme der antidemokratischen Studentenbewegung ab ca. 1925) weitgehend marginalisiert, auch blieb der Linksradikalismus im gesamten 19. wie in der ersten Hälfte des 20. Jahrhunderts „ein politisch-soziales Phänomen an der Peripherie der Arbeiterbewegung“. ${ }^{1755}$ Sicher befanden sich in den parteipolitisch durchzogenen Weimarer Jahren auch viele Studenten an dieser Peripherie, doch nur für kurze Zeit. Schließlich zeigten die politisierten Studierenden der 1970er Jahre starke reformerische und postmodern-antiwestliche Züge, was ihre Rubrizierung als unbezweifelbar ${ }^{1756}$ „linke“ Gruppierungen erschwert. ${ }^{1757}$ Nicht zuletzt lässt ihre Nähe zum modernen performativen, organisatorisch wie programmatisch flexibilisierten Bürgerprotest jede damalige Aussicht auf praktisch-sozialrevolutionären Progressismus fraglich erscheinen. Insofern war größerer politischer Aktivismus von Studierenden tatsächlich stets „Resultat einer komplexen Interaktion zwischen Bildungswachstum, Subkultur und dahinterliegenden sozialen und politischen Prozessen ${ }^{\text {“1758 }}$ - und bedarf eben der Analyse am Einzelfall. Das

1752 Vgl. Gassert: Bewegte Gesellschaft, S. 273. Vgl. auch ibid., S. 279.

1753 lbid., S. 279.

1754 „Weder die gerade Linie in das ,Dritte Reich', noch die entgegengesetzte Tendenz zum Linksradikalismus sind substanziell korrekt. Eher bekämpften sich seit dem Vormärz radikale liberale, nationale und konservative Strömungen, wobei die eine oder andere, je nach Organisationsgrad und Wohlwollen der Universitätsbehörden oder Einflüssen der Gesellschaft und Politik dominierten.“ Jarausch: Deutsche Studenten, S. 246.

1755 Bock: Ceschichte des, linken Radikalismus', S. 7 und 24.

1756 Abgesehen davon, dass schroffe begriffliche Zuordnungswünsche von der analytischen Unschärfe des Richtungsschemas „rechts/links“ ohnehin enttäuscht werden müssen.

1757 Auch kämpfte man in Vokabular und Attitüde für ein Proletariat, das es angesichts der sozialstrukturellen „Fahrstuhleffekte“ einer sich konstituierenden Mittelstandsgesellschaft nach USamerikanischem Vorbild so bereits Ende der 1960er Jahre kaum noch gab.

1758 Jarausch: Deutsche Studenten, S. $246 f$. 
zeigt auch die tragende Rolle verbandsmäßiger Kräfteverhältnisse im Falle der drei betrachteten Bewegungen: Die Sammlung bzw. Expansion vereinzelter protestierender Gruppen zu hochschulpolitische Ziele transzendierenden Studentenbewegungen wurde immer dann möglich, wenn ein größerer Teil der Studierendenschaft mit gemeinsamen politischen Zielen sich zu einem Studierendenverband mit (zumindest temporär legitimem) allgemeinem Repräsentationsanspruch zusammenfasste. Die Burschenschaftsbewegung des Vormärz musste ihre schwersten Rückschläge hinnehmen, als durch staatliche Repressionsmaßnahmen ihre Organisationen zerschlagen und ihnen die Aufrechterhaltung eines bundesweiten Verbandes in Gestalt der 1818 gegründeten Allgemeinen Deutschen Burschenschaft versagt war; die Studentenbewegung von „1968“ zerfiel in unversöhnliche Richtungskämpfe, als der Sozialistische Deutsche Studentenbund (SDS) als Gesamtverband jungsozialistischer Studierender sich auflöste; und auch die völkische Mobilisierung der deutschen Studenten im Vorfeld des Nationalsozialismus gelang nur in jener vorübergehenden Periode, in der die völkisch-revolutionären Bestrebungen der Studenten zuerst dem Deutschen Hochschulring (DHR) und schließlich dem Nationalsozialistischen Deutschen Studentenbund (NSDStB) dazu verhalfen, ihren Repräsentationsanspruch gegen korporatistischen Traditionsstolz und prorepublikanische Deutschen Studentenschaft (DSt) durchzusetzen. ${ }^{1759}$ Zum Gesamtkontext gehörte dabei allerdings stets der sich auf aufsteigender Stufenleiter vollziehende Zyklus aus Akademikermangel und Überfüllungskrise mit der grundierenden Gesamttendenz sozialer Öffnung. ${ }^{1760}$

Was verrät ein an den Bewegungsphasen geschulter Blick auf die jüngeren und jüngsten politischen Proteste von Studierenden in der Bundesrepublik? Die Antwort fällt nun leicht: In ihnen sind die frühliberalen, freistudentischen und antiautoritären Traditionslinien in einer nahezu unentwirrbaren Mixtur grundsätzlich weiterhin lebendig. Sie sind dominiert von einem leidenschaftlichen - allerdings mittlerweile gesellschaftlich mehrheitsfähigen! - Bildungspathos. Wie zu Anfang der großen Bewegungen setzen sie dabei in der Regel bei konkreten hochschul- bzw. bildungspolitischen Belangen wie Prüfungsdruck, Zugangshürden und Überfüllungserscheinungen oder der sozialen Bedingtheit von Bildungszugängen an. Immer waren (ausbleibende oder anstehende) universitäre Umstrukturierungsprozesse zündende Auslöser des Unmuts; kanalisiert und verklammert wurde der Protest durch einen emphatischen Bildungsbegriff. Insgesamt aber fehlt in vielen Fällen ein langfristig planendes überregionales Organisationsnetzwerk. Das ist an allen studentischen Protestereignissen nach der Studentenbewegung von „1968“ zu beobachten, so etwa an den Streiks gegen das Hochschulrahmengesetz 1977/78, ${ }^{1761}$ an den Ansätzen zur „Volksuni“ $1985^{1762}$ und

1759 Vgl. Jarausch: Deutsche Studenten, S. 43-45; Fichter/Lönnendonker: Kleine Geschichte des SDS, S. 140-143; Schwarz, Jürgen: Studenten in der Weimarer Republik. Die deutsche Studentenschaft in der Zeit von 1918 bis 1923 und ihre Stellung zur Politik, Berlin 1971, S. 404-407; Jarausch: Deutsche Studenten, S. 148-150 und 152-162.

1760 Vgl. Titze: Wie wächst das Bildungssystem?, S. 116-118.

1761 Vgl. Krause: Zwischen Revolution und Resignation?, S. $238 \mathrm{ff}$.

1762 Vgl. Gabler, Andrea: Sturm in Elfenbeinturm. Positionen und Aktionsformen des Göttinger AStA zu Wissenschaftsbetrieb und politischem Mandat von 1967 bis 1987, Göttingen 1993, S. 54-57. 
den Universitätsstreiks $1987^{1763}$ - beides Göttinger Ereignisse -, ferner am größeren „UniMut“-Streik an der FU Berlin und in Frankfurt a.M. 1988, der zu Vollversammlungen, der Besetzung von Instituten und Hochschulgebäuden führte, ${ }^{1764}$ und an der nach „1968“ größten diesbezüglichen Ereigniskette „Lucky Streik“ 1997, ausgehend von der Universität Gießen. ${ }^{1765}$ Ihre politischen Perspektiven und Forderungen haben die Aktivisten des „Lucky Streik“ im darauffolgenden Jahr gebündelt in Gestalt eines Sammelbandes herausgegeben. Hier wird deutlich, dass die Studierenden an konkreten Missständen der Studiensituation wie der mangelhaften Versorgungslage der Universitäten, den bildungspolitischen Rückständigkeiten und der angespannten Lehrsituation $^{1766}$ ansetzten, aber erst in einem zweiten, abgeleiteten Schritt allgemeine gesellschaftspolitische Ziele formulierten. Sie forderten „freie Wissenschaft“ und eine Enthierarchisierung der Universität, brachten unter Rückgriff auf antikapitalistisches Vokabular eine „freie“, „emanzipatorische“ (im Gegensatz zur „entfremdeten“ und „repressiven“, auf berufliche Qualifizierung abzielenden) Bildungs- und Kollektivitätsform in Stellung. ${ }^{1767}$ Am Beispiel von vier „bildungspolitischen Grundfragen“1768 erblickten sie, ausgehend von den „Vorgänge[n] im Bildungssystem“, „Ansatzpunkte einer grundsätzlichen Diskussion unserer gesellschaftlichen Zukunft“ im Zeichen der „Demokratisierung ${ }^{1769}$ Diese Grundfragen kondensieren sich zu der Suche nach einer Handlungsperspektive, die Herausbildung einer vom sozialen Abstieg geprägten „4/5 Gesellschaft“, die nachrückende Akademiker in die „Massenerwerbslosigkeit“ und die gesellschaftliche Wirkungslosigkeit zurückstoße, abzuwenden. ${ }^{170}$ Das all dem gegenüber zu stellende Verständnis von „Demokratie“ misst die realen politischen Verhältnisse an den Partizipations- und Demokratisierungsmaximen der 1970er Jahre, sieht Demokratisierung folgerichtig als noch nicht voll realisierten Prozess - und verpflichtet die Autoren zum Bekenntnis gegen den „neoliberalen Schulterschluss“ der gesellschaftlichen Eli-

1763 Vgl. ibid., S. 57-58.

1764 Vgl. Himpele, Klemens: Vom Bildungsstreik zur Bewegung?, in: Blätter für deutsche und internationale Politik, H. 8/2009, S. 11-15, hier S. 12 f.

1765 Vgl. ibid., S. $13 f$.

1766 Vgl. Brandt, Georg/HerausgeberInnengruppe Lucky Streik: „Lucky Streik“- ein Kampf um Bildung: Gießener Studierende berichten, Gießen 1998, S. 13-32 und 33-38.

1767 Vgl. ibid., S. 11-30.

1768 „Bei der gesellschaftlichen Frage geht es darum, wer wieviel Bildung in unserer Gesellschaft hat, was fängt diejenige mit ihr an, welche gesellschaftliche Verfügungsmacht erhält die Person, die Bildung erwerben durfte, und was wird denjenigen versperrt, die von ihr ferngehalten bzw. denen nur ein Mindeststandard an Bildung gewährt wird? [...] Es folgt die bildungsökonomische Frage [...] Angeblich erwerben zu viele ihr Abitur und zu viele studieren. Wann ist die Zeit reif, daß für die Elite auch eine neunjährige Hauptschulbildung noch zu teuer wird, weil die Absolventlnnen ja sowieso keine Ausbildung und auch keine berufliche und damit gesellschaftliche Verwendung finden." Drittens die „pädagogische Frage“: „Wer erzieht wen, wozu, an welchen Inhalten und wie?" und viertens der „Demokratisierungsgrad“: „Wie demokratisch ist die Gesellschaft und das jeweilige Subsystem? Wer wird wieweit beteiligt, wer tendenziell ausgeschlossen?" Ibid., S. 14f.

1769 Ibid., S. 11.

1770 Ibid. 
ten. ${ }^{1771}$ Ein essenzielles Scharnier der Argumentation besteht in einem erstaunlichen Bildungspathos, das im Anschluss an den Aufsatz Krippendorffs ${ }^{1772}$ entfaltet wird:

„Bildung ist die kreative und aktive Entfaltung der Kultur und die Aneignung ihrer Techniken. Bildung ist ein emanzipatorischer Prozeß, die Befreiung aus Abhängigkeiten bei gleichzeitigem Abbau von Macht und Herrschaftsverhältnissen. Bildung ist ein Prozeß permanenter Reflexion und Kritik des Bestehenden. [...] Bildung ist nicht auf ökonomische Verwertbarkeit reduzierbar. Bildung darf nicht fremdbestimmt und nicht ökonomischen oder [sic] oder herrschaftlichem Denken verpflichtet sein. In diesem Sinne bedürfen wir einer zweiten Bildungsreform. ${ }^{\text {“1773 }}$

Bildung im emphatischen Sinne, also in Abgrenzung zu „entfremdeten“, d. h. auf Erwerbstätigkeit gerichteten, Bildungskonzeptionen, ziele demnach „auf die Gleichheit der Menschen, die Gleichheit der Bildungschancen und die Erweiterung der demokratischen Selbst- und Mitbestimmung, in alle gesellschaftlichen Bereiche hinein. ${ }^{11774}$ Bildung, hier wird Oskar Negt zitiert, solle „Bürgerrecht“ sein und als „lebendige Bildung“ die gesamte Gesellschaft „emanzipatorisch“ umgestalten. ${ }^{1775}$ Die Universität sei ihrer "Idee“ nach „orientiert auf Autonomie“ und erfordere eine „Gemeinschaft von LehrerInnen und SchülerInnen“, ${ }^{1776}$ überdies "frei von herrschaftlichen Vorgaben oder Erkenntnisinteressen. “1777 Sicher: Die Studierenden können sich auf das 1948 als Menschenrecht festgeschriebene "right to education“ gemäß Artikel 26 der Allgemeinen Erklärung der Menschenrechte berufen ${ }^{1778}$ - nur führt die deutsche Übersetzung „Recht auf Bildung“ eben spezifische Humboldt'sche Bedeutungsgehalte mit sich. Daher kann

1771 lbid., S. 20-27.

1772 Vgl. Krippendorff: Die Idee der Universität.

1773 Brandt/HerausgeberInnengruppe Lucky Streik: „Lucky Streik“, S. 28.

1774 Ibid., S. 28. Dies werten die Verfasser en passant als Einlösung ihres historisch verliehenen „politische[n] Mandat[s], „daß Auschwitz nicht wieder sein darf“, ferner als „Auftrag zur Kritik und Umgestaltung der kapitalistischen Gesellschaftsordnung." Ibid. Erstaunliche ist auch die Überzeichnung der eigenen Wirkmacht, die an die Durchhalteparolen linksradikaler Zirkel erinnert: Im zitierten, zwischen autobiographischen, monographischen und dokumentarischen Schreibstilen changierenden Band, der mehrheitlich von Teilnehmern der „Einführungsveranstaltung zur politischen Bildung“ des Gießener universitären Instituts für Politikwissenschaft zusammengestellt wurde, heißt es protzig in einem Kapitelnamen: „Nirgends wird so gestreikt wie in Deutschland“; als Gewährsmänner werden ausländische Studierende aus den USA, Finnland, Griechenland, Frankreich und Litauen angeführt, ibid., S. 11 und 182-196. Zudem ist dem gesamten Band die zwanghaft selbstverordnete Aufbruchsstimmung anzumerken, die Überzeugung, eine „bundesweite Bewegung“ initiiert zu haben, die „um etwas kämpfen muß, was früher selbstverständlich war", die "Medienwirksamkeit" und die Abschaffung der Examensgebühr in Hessen erreicht habe und schließlich die Studierendenschaft „politisiert“ habe. Ibid., Rückseite des Bandes, ferner S. 129-146, insbesondere S. 139, und 213. Mit anderen Worten: Jene wiederkehrenden Kritiker studentischen Protests, die schon der Studentenbewegung von „1968“ hypertrophen Verbalradikalismus vorwarfen, werden auch im zitierten Band reichhaltiges Material vorfinden.

1775 Ibid., S. 27-32.

1776 Ibid., S. 30.

1777 Ibid., S. 30.

1778 United Nations: Universal Declaration of Human Rights, 10.12.1948, online einsehbar unter: https://www.ohchr.org/EN/UDHR/Documents/UDHR_Translations/eng.pdf [eingesehen am 01.08.2019] Entscheidende Vorläufer der Auffassung von Bildung als Menschenrecht finden sich 
die zitierte Emphase auf soziale Egalität nicht darüber hinwegtäuschen, dass auch die „Lucky Streik“-Aktivisten letztlich den Erhalt (bzw. Ausbau) beinahe zerronnener akademischer Freiheiten, ja Standesprivilegien einfordern: eben Freiräume akademischer Betätigung und geschützte Karrierewege inmitten einer marktbasierten Wirtschaftsordnung. ${ }^{1779}$ Ihre Universitäts- und Gesellschaftskritik ist spürbar bildungsbürgerlichfrühliberal gepolt. Diese Deutungsmuster von 1997 sind in ihren Grundlinien repräsentativ für studentischen Protest bis heute: Auch die stärker spontan entstehenden $2000 \mathrm{er}$ und 2010er Jahre, sichtbar etwa an den (eher kleinen, unvorbereiteten und überdies schnell erschöpften) Universitätsstreiks und Protestaktionen in Weimar, Bonn, München, Berlin, Dresden, Leipzig, Frankfurt a.M. und Göttingen 2003/04 unter dem Motto „Spar Wars“ anlässlich von geplanten Kürzungen und der Einführung von Studiengebühren, ${ }^{1780}$ ferner die bislang letzte (und von einem im Voraus planenden Netzwerk von Schülern, Verbänden und Gewerkschaften ausgehenden ${ }^{1781}$ ) studentische Protestwelle, der Bildungsstreik 2009/10, die sich hinter Slogans wie „Bildungsklau“ und „Reiche Eltern für alle" versammelte, zehrten von ihnen. ${ }^{1782}$ Gerade der Entstehungsverlauf dieses letzten Studentenstreiks erinnert dabei stark an Dynamiken von „1968“: Der ProtestImpuls durchzuckte zunächst Frankreich (hier fanden im Sommer 2009 Hochschulstreiks statt, die die einjährige Verschiebung anstehender Bildungsreformen durch den damaligen Staatspräsidenten Nicolas Sarkozy erzwangen), Spanien und Griechenland, ehe der Funke im Juli 2009 auf den deutschen Raum übersprang. Bundesweit kam es zu Streiks, Hörsaalbesetzungen und Protesten zahlreichen Hochschulen, mehr als 200.000 Studierende und Schüler nahmen zur Hochzeit der Proteste an den verschiedenen Demonstrationen teil. ${ }^{1783}$ Zwar fiel dieser Bildungsstreik gegenüber dem Spontaneismus 2003/04 durch eine konzertiertere Vorbereitung auf, zerfiel aber dennoch in wenigen Wochen. Ein Reaktivierungsversuch scheiterte schließlich 2011: Das kurze Aufflammen von Protesten für „kostenlose“ Bildung und einen Abbau der Bildungsselektion führte zwar zu Besetzungen in Berlin und Regensburg, blieb aber lokal begrenzt und wurde dort durch repressives Vorgehen von Behörden und Polizei zügig

unter den französischen Aufklärern, etwa Mirabeau und Condorcet, vgl. Friedeburg: Bildungsreform in Deutschland, S. 53-59.

1779 Vgl. Mann: The Ideology of Intellectuals.

1780 Vgl. Kolwitz, Kai/Hudemann, Steffen: Studenten geht die Luft aus, in: Spiegel Online, 06.01.2004, online einsehbar unter: https://www.spiegel.de/lebenundlernen/uni/berliner-streikkehraus-studenten-geht-die-luft-aus-a-280728.html [eingesehen am 01.08.2019] und Landsberger, Antonio/Bühler, Andreas/Schmidt, Tobias/ Fest, Andreas/Schulze, Henning/Ott, Simone/Winter, Marcel/Wernicke, Jens: Proben für den großen Krach. Handbuch zur studentischen Protestorganisation, Münster 2005, online einsehbar unter: https://ffmdieunibrennt.files.wordpress.com/ 2012/08/protesthandbuch.pdf [eingesehen am 01.08.2019], S. 11-18.

1781 Vgl. Himpele: Vom Bildungsstreik zur Bewegung?, S. 14.

1782 Vgl. die web-archivierte Internetpräsenz des bundesweiten Bildungsstreiks 2009, online einsehbar unter: https://web.archive.org/web/20090802074629/http://www.bildungsstreik2009.de/ [eingesehen am 01.08.2019] Darüber hinaus kann der Verfasser dieser Studie als ehemaliger Teilnehmer an einer Göttinger Großdemonstration im Spätsommer 2009 auch auf persönliche Erinnerungen zurückgreifen.

1783 Vgl. Kühne, Anja: Funktionieren ist kein Lernziel, in: Zeit Online, 17.06.2009, online einsehbar unter: https://www.zeit.de/online/2009/25/bildungsstreik-demonstration [eingesehen am 01.08.2019] 
erdrückt. ${ }^{1784}$ Insgesamt fällt auf: Der Atem der Studentenproteste ist immer kürzer geworden, und das im Grunde schon seit den späten 1970er Jahren: Erfahrungswissen und Organisationskraft gingen und gehen mit dem Kohortenaustausch, ältere Protestveteranen mit Erfahrungen aus dem „roten Jahrzehnt“ scheiden aus, dauerhafte Organisation gelingt nicht mehr. Die Achse von wiederkehrenden Studentenstreiks 1988 - 1997 - 2009 demonstriert zwar aktivierbare Protestenergien, dennoch erreichte man es nie, diese Impulse „,in ein dauerhaftes Engagement zu überführen“, aus „dem einmaligen Streik tatsächlich eine Bewegung“ zu machen, die dann auch die „Option, eine grundlegend andere Bildungspolitik politisch durchzusetzen“, erwirken könnte. ${ }^{1785}$ Insofern gibt diese einordnende Beobachtung der Proteste von 2003/04 durchaus so etwas wie eine Blaupause studentischer „Rebellions“-Versuche nach der Jahrtausendwende:

„Mit den Weihnachtsferien ist alles vorbei. Und dann dauert es wieder zwischen sechs und zehn Jahre, bis erneut eine Studentengeneration heranwächst, die ebenfalls in irgendwelchen Novemberwochen den Streik ausruft und dann nach den Weihnachtsferien abermals enttäuscht und resigniert in die Hörsäle zurückkehrt."1786

Die jüngeren Proteste gingen in der Regel von kleineren Aktivistenkreisen zumeist geistes-, sozial-, und kulturwissenschaftlichen Hintergrundes aus; es ist davon auszugehen, dass die erdrückende Mehrheit der Studierenden diesem Protest eher achselzuckend bis spöttisch gegenüber steht. ${ }^{1787}$ Dennoch wäre es verfehlt, diese jüngeren Proteste $\mathrm{zu}$ belächeln, erzeugten sie doch öffentliche Aufmerksamkeit und vielerorts auch kleinere Erfolge, etwa in Gestalt von Modifikationen der Prüfungsordnungen. Der Bildungsstreik von 2009/10 erreichte sogar noch mehr, nämlich die politische Delegitimation der Bologna-Reformen: Hatte die damalige Bildungsministerin Anette Schavan die Aktivisten, die sie als renitente Reformunwillige angesichts alternativloser Umstrukturierungen wahrnahm, anfänglich noch als „gestrig“1788 denunziert, musste sie sich bald in die Reihe der konzessiven Verantwortungsträger einreihen. Die Hochschulrektorenkonferenz, viele Politiker, auch der Wissenschaftsrat waren sich nun einig: Man habe nachzubessern, eine „Reform der Reform" sei notwendig. ${ }^{1789}$ Die Bologna-Reformen vollumfänglich verteidigen wollte ab diesem Zeitpunkt niemand mehr. Im Gegenteil: Man lobte die Streikenden - und beraubte sie dadurch der durch sie heraufbeschwörten

1784 Vgl. o. V.: Occupy? Von wegen, in: SPIECEL ONLINE, 17.11.2011, online einsehbar unter: https:// www.spiegel.de/lebenundlernen/uni/bundesweite-bildungswut-occupy-von-wegen-a-798370.

html [eingesehen am 01.08.2019]

1785 Himpele: Vom Bildungsstreik zur Bewegung?, S. 15.

1786 Walter, Franz: Bildungsgläubiger Studentenprotest, in: Ders.: Die ziellose Republik. Cezeitenwechsel in Gesellschaft und Politik, Köln 2006, S. 35-42, hier S. 37.

1787 Vgl. Bender, Justus: Die Revolution ist nicht zu erwarten. Interview mit dem Protestforscher Dieter Rucht, in: Die Zeit, 26.11.2009.

1788 Vgl. Titz, Christoph/Menke, Birger/Waleczek, Torben/Leffers, Jochen: Mehr als 100.000 Schüler und Studenten auf den Straßen, in: SPIEGEL ONLINE, 17.06.2009, online einsehbar unter: https://www.spiegel.de/lebenundlernen/uni/bildungsstreik-mehr-als-100-000-schueler-undstudenten-auf-den-strassen-a-630965.html [eingesehen am 01.08.2019]

1789 Vgl. o. V.: Nachbessern an der Uni, in: SZ.de, 17.05.2010, online einsehbar unter: https://www.sueddeutsche.de/karriere/nach-dem-bildungsstreik-nachbessern-an-der-uni-1.124587 [eingesehen am 01.08.2019] 
Konfrontation. ${ }^{1790}$ Das „Mürbemachen durch Umarmung ${ }^{\alpha 1791}$ geriet zur verbreitetsten politischen Reaktionsform, SPD und Grüne solidarisierten sich am überschwänglichsten mit den Streiks. So wurden „die schlimmsten Spitzen [...] entfernt, an der grundlegenden Ausrichtung des Bildungssystems“, so wurde frustriert festgestellt, „ändert sich aber nichts. “1792 Auch darin liegt ironischerweise eine große Mobilisierungshürde für studentischen Protest: „In einer gewissen Weise haben die gegenwärtigen Studenten zu viele Freunde und zu wenige Gegner. Alle Welt ist schließlich für Bildung. “1793 Womit der Kreis geschlossen wäre: Jedwedes politisches Mobilisierungspotenzial von Studierenden entstand aus dem Geiste hochschulreformerischer Bestrebungen. Sämtlicher genuin studentischer Protest begann mit universitären Reformzielen und bezog von diesen durchweg oppositionelle Legitimität; wenig gelangte dauerhaft über sie hinaus. Hier wirkt es sich natürlich verhängnisvoll aus, dass das wiederholt in Stellung gebrachte Humboldt'sche Bildungsverständnis, seinerseits einst als spezifische Fortschrittsideologie gefasst, bereits seit einem guten Jahrhundert und besonders seit der zweiten Bildungswachstumswelle von der Modernisierungsdynamik der zertifikatsbasierten Allokation von Berufspositionen überholt ist. Scharf formuliert: Die Bildung der Gesamtpersönlichkeit mitsamt des kulturellen und ästhetischen Urteilsvermögens sowie der Entfaltung sittlich bestimmter Charakterzüge als Leistungskriterium kann einem „zeitgemäßen“ Karriereplaner nur als vormoderner Ballast erscheinen, erforderlich höchstens für Wege in bestimmte bildungsbürgerliche Subkulturen. Insofern ist dem Studentenprotest der letzten Jahre entgegenzuhalten: Die wirkliche Tradition - oder objektiv wirksame „Idee“ - der Universität besteht historisch betrachtet nicht in einem seit 1810 eingefrorenen preußischen Bildungshumanismus, sondern in der wiederholten Anpassung der Hochschulen an die in Deutschland vor allem durch die steigende Zahl gymnasialer Absolventen angetriebene Bildungsexpansion und an die Effizienzkriterien des Marktes. ${ }^{1794}$

Jenseits der besonderen Phasen oppositioneller Studentenbewegungen sind, je nach gesellschaftlicher Situation, die verschiedensten Facetten politischen Verhaltens von Studierenden auszumachen, nicht aber die eine „kritische“, „rebellische“ oder gar „linke“ Tradition, die Studierende für fortschrittliches Engagement prädestiniert hätte. Die antisemitische und nationalchauvinistische Mehrheitsbildung der Korporationen im Wilhelminismus belegt eindrücklich, dass studentische Kollektivität als solche nicht eo ipso freiheitliche oder prodemokratische Stoßrichtungen entfaltet. Aber: In der noch heute

1790 „Zu Anfang der Proteste rieben sich vor allem die Protestierenden selbst ungläubig die Augen angesichts der warmen Wellen von Solidarität und Zuspruch allüberall. Statt klarer Konfrontation wurden die Studierendenproteste gelobt und die Verantwortlichen der aktuellen Bildungsmisere lassen sich auf offener Streikbühne im geschwisterlichen Umtrunk mit den ProtestlerInnen ablichten." Kunze, Manuel/Tielesch, Simon: Bologna auf dem Markt der Meinungsmöglichkeiten. Was mit den Studierendenprotesten gesagt werden sollte - und was verstanden wurde, in: Psychologie \& Gesellschaftskritik, H. 34/2010, S. 105-112, hier S. 106.

1791 Kolwitz/Hudemann: Studenten geht die Luft aus.

1792 Himpele: Vom Bildungsstreik zur Bewegung?, S. 14.

1793 Walter: Bildungsgläubiger Studentenprotest, S. 37.

1794 Wenngleich hier, dies ist noch einmal zu betonen, kein mechanischer Automatismus wirksam ist: Die sich in Reformen spiegelnden institutionellen Neuausrichtungen der Hochschulen sind natürlich immer auch von staatlichen und universitären Interessen mitbestimmt, wie in Kapitel II.1 dieser Studie deutlich geworden ist. Vgl. Münch: Akademischer Kapitalismus. 
bestehenden relativen Ungebundenheit der studentischen Lebensphase scheint grundsätzlich Freiraum für Protestpotenziale zu bestehen, anders wäre das Auftreten von Bildungsstreiks nicht zu erklären. Das allerdings wirft erst recht die Frage auf, warum Studierende heute insgesamt so politisch inaktiv sind - obwohl sie doch nach wie vor die dafür nötigen Freiheiten genießen? Fehlender „ökonomischer Druck“1795 in Zeiten der Vollbeschäftigung und sozialpolitische Abfederungsmechanismen ${ }^{1796}$ allein können als Erklärungsgrundlage politischer Abstinenz keineswegs ausreichen. Die Antwort auf das Rätsel könnte, folgt man den Ergebnissen der Survey-Studien, im Mangel an studentischem „Standesbewusstsein“ liegen, damit auch am Mangel an als verbindlich empfundenen politischen Projekten, Zielen und Utopien, aufdie das Bildungspathos jenseits der Privilegienverteidigung hinauslaufen könnte, ferner an dem Verlust des einstigen Organisationsgrades: Politische Mobilisierung resultierte ja nicht nur aus gesellschaftlichen Kontextbedingungen wie etwa der schlichten demographischen Dominanz von Jugendlichen, sondern auch aus der durch Organisationsetzwerke und ideell zusammengehaltene kollektive Sozialmoral gestifteten „Kampfpotenz“. Die erdrückende Mehrheit der Studierenden ist nicht mehr (hochschul-)politisch assoziiert, begreift sich nicht mehr als soziale Formation mit spezifischen Interessen. ${ }^{1797}$ Es fehlt insbesondere an Organisationskompetenzen und Assoziationsformen, die es ermöglichen, aus der Masse der Studierenden ein politisches Subjekt zu formen, aber auch an einer gemeinsam geteilten (Symbol-)Sprache, auch an Leitideen jenseits der gesellschaftlich ohnehin nahezu konsensualen Bildungsapotheose. Derartiges politisch-organisatorisches Erfahrungswissen, derartiger semantischer und kommunikativer kollektiver Kitt konnte in den 1970er und 1980er Jahren noch aus Arbeiterbewegungstraditionen in K-Gruppen, Sponti- und Ökopax-Bewegung bezogen werden. Es verebbt erkennbar in der beginnenden Phase post-wohlfahrtsstaatlicher Entwicklungen $\mathrm{ab}$ den späten 1970er Jahren und in den Jahrzehnten danach, in denen mit dem Auslaufen des sozialdemokratisch initiierten Pakts von Kapital und Arbeit und mit dem Erodieren der mitglieder-, milieu-, sozialmoralstarken Großorganisationen ${ }^{1798}$ auch die abtrünnigen, heterodoxen usw. Gegen-Organisationsformen verblassen. Schließlich fehlt es zur Herausbildung all dieser benötigten Ressourcen an konstitutiven Auseinandersetzungen und an einem sozialmoralisch einenden Gegner. ${ }^{1799}$ Freiheiten gibt es, die genutzt werden könnten - doch dafür müsste man wissen, wie und wofür. In diesem Zusammenhang fiel überdies auf, dass sich in den 1990er und

1795 Bebnowski: Generation und Geltung, S. 246. Ebenso wenig gibt es einen kurzen Weg von „materielle[r] Absicherung und rosige[n] Zukunftsaussichten“ $z u$ „politisch-gesellschaftlicher Enthaltsamkeit", wie das Beispiel der materiell abgesicherten und perspektivenreichen Urburschenschaft zeigt. Das gibt auch der Studentenhistoriker Harald Lönnecker der WELT zu Protokoll, vgl. Stoldt, Till-Reimer: Hauptsache gechillt, in: WELT Online, 09.07.2018, online einsehbar unter: https://www.welt.de/print/welt_kompakt/print_politik/article179016726/Hauptsache-gechillt. html [eingesehen am 01.08.2019]

1796 Vgl. Bebnowski: Generation und Geltung, S. 252.

1797 Unter dem „Interesse“ sozialer Gruppen sind hier insbesondere materielle und statusbezogene Absichten gemeint - die „Gesamtheit der Möglichkeiten des einzelnen [sic], seine Konkurrenzposition zu verbessern oder zu erhalten." Deutsch, Karl W.: Der Nationalismus und seine Alternativen, München 1972, S. 36.

1798 Vgl. Walter: Zeiten des Umbruchs?, S. 69-76.

1799 Vgl. Walter: Bildungsgläubiger Studentenprotest, S. 37. 
2000er Jahren die sukzessive Restrukturierung der Hochschulen nach Arbeitsmarktanforderungen auch in den politischen Orientierungen und im politischen Verhalten der studentischen Mehrheit niederschlug. Die politischen Einstellungsmuster diversifizieren sich auch, weil das Studium viele seiner "traditionellen“ Züge verliert und damit eine einerseits durch die gesamtgesellschaftliche Auflösung von Milieustrukturen im Allgemeinen, andererseits die durch die exponentiell steigende Studierendenzahl angetriebene Auflösung akademischer Milieus im Speziellen weiter vertieft: den Verlust der Selbstverortung in einer Studierendenschaft oder Fachschaft, d. h. in einem sozialen Kollektiv mit potenziellen gemeinsamen Interessen. Die Effekte fielen den Surveyforschern als weltanschauliche Fragmentierung, ja als zunehmende Inkonsistenz auf. Dass diese Fragmentierung auch als Rekonfiguration von Einstellungsmustern in neuen Verknüpfungsweisen aufgefasst werden könnte, wird dabei allerdings nicht diskutiert. Die Interpretationsfolie bleibt bisher klassisch industriegesellschaftlich-volksparteilich orientiert, angesichts der Persistenz der politischen Polarisierung zwischen Geistes- und Sozialwissenschaftsstudenten einerseits und Wirtschafts-, Ingenieurs- und Naturwissenschaften andererseits nicht ganz ohne Grund. Insgesamt ist der Schluss, den Bargel aus den Surveystudien zog, zunächst plausibel und einleuchtend: Angesichts des unverändert hohen politischen Interesses von Studierenden und angesichts der verbliebenen Freiheiten während der Studienphase besteht fortwährendes (sowohl gesellschaftskritisch begründetes als auch materiell motiviertes und inzivil auftretendes) Protestpotenzial; eine neue Studentenbewegung hingegen ist nicht zu erwarten. ${ }^{1800}$ Dennoch: Die bisherigen empirischen Kenntnisse lassen nur Vermutungen $z u$. Die Frage, welche grundlegenden politisch-sozialen Deutungsmuster ${ }^{1801}$ die disparat erscheinenden Einstellungswerte strukturieren, ist bisher ungeklärt.

Auffällig ist heute allerdings auch das Fehlen von intellektuellen Stichwortgebern, Vordenkern und Idolen, die als Deutungselite wirken konnten - einst ein verstärkender und katalysierender Faktor in studentischen Politisierungsphasen. Diese Funktion übernahmen im frühen 19. Jahrhundert die nationalromantischen Philosophen und (vornehmlich Jenaer) Universitätsprofessoren ${ }^{1802}$ (zu den Professoren, die nach 1815 ihre Lehrerposition verließen und sich zu Mentoren der politischen Jugend aufschwangen, zählten $u$. a. Ludwig „Turnvater" Jahn, Johann Christian Stark und Jacob Friedrich Fries ${ }^{1803}$ ), während die Protagonisten der internationalen „68er“-Bewegung neomarxistische, existenzialistische und postkolonialistische Philosophen zitierten, ja bei festivalartigen Vorträgen nach konkreten politischen Anweisungen befragten. Während in Frankreich politische Intellektuelle wie Jean-Paul Sartre, Guy Debord und Henri Lefebvre besonders gefragt

1800 Das passt zur generellen Beobachtung der Jugendforschung, dass politisches Engagement junger Menschen sich an flexible Projekte heftet, aber die traditionellen professionalisierten Organisationen meidet. Vgl. Busse, Britta/Hashem-Wangle, Alexandra/Tholen, Jochen/Wolnik, Kevin: Parallele Welten politischer Partizipation. Junge Menschen und politische Partizipation in Deutschland, in: Kühnel, Wolfgang/Willems, Helmut (Hg.): Politisches Engagement im Jugendalter. Zwischen Beteiligung, Protest und Gewalt, Weinheim/Basel 2017, S. 77-102.

1801 Gemeint sind sinnhaft strukturierende und rechtfertigend deutende private Gesellschaftstheorien der Studierenden, wie in Kapitel I.5 dieser Studie herausgearbeitet.

1802 Vgl. Bartol: Ideologie und studentischer Protest, S. 60-62.

1803 Vgl. Hardtwig: Studentische Mentalität, S. 594 und Kraus: Kultur, Bildung und Wissenschaft, S. 29. 
waren, bezogen SDS und APO viele ihrer zentralen Begriffe von sozialistischen und neomarxistischen Professoren wie Wolfgang Abendroth oder Oskar Negt - oder eben aus den missverstandenen Werken jener der „Kritischen Theorie“ zugerechneten Autoren Max Horkheimer, Theodor W. Adorno und Herbert Marcuse, von denen sich aber wahrscheinlich nur letzterer überhaupt eine Zeitlang als Lehrer der Bewegung verstand. Im bundesrepublikanischen Fall ist es zwar insgesamt fraglich, ob es sich - abgesehen von den epistemologischen und moralischen Handreichungen Marcuses - bei der Berufung der „68er" insbesondere auf Horkheimer und Adorno, die sich Mitte der 1960er Jahre in ungeduldige Enttäuschung und - im Falle der Subversiven Aktion in „publizistischen Vatermord“ - verwandeln musste ${ }^{1804}$, nicht doch um ein gravierendes Missverständnis gehandelt hat. Die historisch blinde Einforderung revolutionärer Perspektiven von den Autoren der Dialektik der Aufklärung, welche das originäre neomarxistische Projekt der Kritischen Theorie angesichts der nationalsozialistischen Konzentrationslager eigentlich bereits im US-amerikanischen Exil der 1940er Jahre für beendet erklärten, ${ }^{1805}$ bezeugen dies. Denn: Die Kritische Theorie als denkschulenhaftes System von „Ideen“ aufzufassen und mit dem Gleichnis der „Eigendynamik“ von „Geister[n], die sie riefen“, doch „weder zu koordinieren noch zu kontrollieren“ vermocht hätten, ${ }^{1806} \mathrm{zu}$ bedenken, verfehlt die Besonderheit eines Denkens, welche sich gegen die Erstarrung zur „Schule“ gerade zur Wehr gesetzt hatte. ${ }^{1807}$ Das tut der richtigen Beobachtung, dass "die“ Kritische Theorie aufgrund ihrer früheren Revisionsarbeit am klassischen historischen Materialismus „auf die kognitive Orientierung der studentischen Linken ein[gewirkt] “1808 hat, keinen Abbruch. Und auch dem Einwand nicht, dass der kalifornische Professor Marcuse der globalen „68er-Bewegung“ im Gegensatz zu seinen früheren Frankfurter Institutsgenossen dezidiert sympathisierend gegenüberstand, ja die späte Karriere als Bewegungs-Guru genossen haben mag. ${ }^{1809}$ Schließlich wurde auch der völkische Fanatismus der akademischen Jugend in Weimar gegen Republik, demokratische Eliten und „Parteienwirtschaft ${ }^{\text {“1810 }}$ durch die erwachsene antidemokratische, antiliberale und militaristische Intelligenz inspiriert und angefeuert, wie sie sich in staatsrechtlichen Streits (u. a. zwischen Carl Schmitt und Hermann Heller), in der die Bündische Jugend insgesamt inspirierenden ${ }^{1811}$ philosophischen und bellizistischen Literatur (u. a. Ernst Jünger, Hermann Löns, Hans Grimm) und in der jungkonservativen, deutsch-nationalen, nationalrevolutionären, nationalbolschewistischen, völkischen und schließlich nationalsozialistischen Publizistik (u. a. Oswald Spengler, Edgar Julius Jung, Arthur

1804 Vgl. Spix: Abschied vom Elfenbeinturm?, S. 503-506.

1805 Vgl. Claussen, Detlev: Abschied von gestern. Kritische Theorie heute, Hannover 1985, S. 12-15.

1806 Gilcher-Holtey, Ingrid: Kritische Theorie und Neue Linke, in: Dies. (Hg.): Vom Ereignis zum Cegenstand der Geschichtswissenschaft. Geschichte und Gesellschaft, Sonderheft 17, Göttingen 1998, S. 168-187, hier S. 186f.

1807 Vgl. Keune, Hannes/Schenke, Julian: „Weitsicht und Naivität“. Ein studentischer Blick auf die Ambivalenz der Frankfurter Schule, in: INDES. Zeitschrift für Politik und Cesellschaft, H. 3/2014, S. 78-86.

1808 Gilcher-Holtey, Ingrid: Kritische Theorie und Neue Linke, S. 185.

1809 Vgl. Walter: Rebellen, Propheten, Tabubrecher, S. 79-94.

1810 Vgl. Jarausch: Deutsche Studenten, S. 141.

1811 Vgl. Ahrens: Bündische Jugend, S. 153. 
Moeller van den Bruck, Julius Binder) ${ }^{1812}$ teils bereits seit Kaiserreichszeiten wortreich betätigte. ${ }^{1813}$ Heute hingegen ist generell überaus fraglich, ${ }^{1814}$ inwiefern Studierende noch bestimmte politische Inspiratoren oder idealisierungsfähige Lichtgestalten kennen, seien es (neue oder alte) Köpfe oder Bücher. Die Gründe für diese Entwicklung in der gebotenen Genauigkeit zu diskutieren, würde wiederum eigene Abhandlungen erfordern, liegt es nahe, sie im Kontext des Abschleifens organisatorisch gebündelter sozialer Konflikte zu sehen. Phasen ausgeglichener sozialer Verhältnisse, wie sie sich seit den 1960er Jahren hergestellt hatten und trotz rückläufiger Entwicklungen in vielerlei Hinsicht auch heute noch bestehen, sind stets die „schlimmste Zeit für Intellektuelle ${ }^{\text {(1815 }}$ - denn politisch wirksame Intellektualität bedurfte immer der antagonistischen Spannung angesichts sozialer Verwerfungen, auch kollektiver Kränkungen, und der davon kontrastiv sich absetzenden Zukunftsvision.

Bevor nun Schlüsse aus dieser Zwischenbetrachtung für den empirischen Zuschnitt der Fokusgruppenstudie gezogen werden, ist noch kurz auf ein beliebtes Erklärungsmuster für jugendliches bzw. studentisches Bewegungspotenzial einzugehen: das Konzept des Mannheim'schen „Generationszusammenhangs“. Der hier zugrundeliegende Gedanke ist, dass bestimmte Geburtskohorten in gesellschaftlichen Übergangsphasen (die qua Lebensalter zu einer gemeinsamen "Generationslagerung“ gehören) kollektive Erfahrungsgehalte teilen können und sich in diesem besonderen Fall zu einem „Generationszusammenhang“ im „soziologischen Sinne“ zusammenfassen lassen, mit anderen Worten:

„Von einem Cenerationszusammenhang werden wir also nur reden, wenn reale soziale und geistige Cehalte gerade in jenem Cebiete des Aufgelockerten und werdenden Neuen eine reale Verbindung zwischen den in derselben Generationslagerung befindlichen Individuen stiften. ${ }^{\text {(1816 }}$

1812 Vgl. Sontheimer: Antidemokratisches Denken in der Weimarer Republik, S. 141-191.

1813 Mit dem Zeitalter des Bildungsbürgertums (also zwischen dem Ende des Ersten Weltkriegs und der nationalsozialistischen Machtübernahme) endete überhaupt die für den Wilhelminismus so prägende Rolle von Professoren als exzeptionell charismatische Figuren, als "geistige Zentren" und "Wegweiser für Volk und Politiker", die ihre Berufung auf traditionelle neuhumanistische Bildungsprivilegien mit einer spezifischen apolitisch-staatstreuen Cesinnung amalgamiert hatten und als Mittler zwischen den Klassenlagern galten. Vgl. Maurer: „... und wir gehören auch dazu“, S. 174-178.

1814 Zumindest liefern die neueren Surveystudien auf diese Frage keine Antworten - ein Crund, sie in Fokusgruppeninterviews zu stellen.

1815 Walter: Zeiten des Umbruchs?, S. $119 f$.

1816 Mannheim, Karl: Das Problem der Generationen [1928], in: Ders.: Wissenssoziologie. Auswahl aus dem Werk, Berlin/Neuwied 1964, S. 509-565, hier S. 543 (Herv. i. O.) Zu diesem Cenerationszusammenhang können verschiedene Teilgruppen, als "Cenerationseinheiten“ benannt, mit je eigenen Erfahrungsschichten zählen: „Dieselbe Jugend, die an derselben historisch-aktuellen Problematik orientiert ist, lebt in einem ,Generationszusammenhang', diejenigen Cruppen, die innerhalb desselben Cenerationszusammenhanges in jeweils verschiedener Weise diese Erlebnisse verarbeiten, bilden jeweils verschiedene ,Generationseinheiten' im Rahmen desselben Cenerationszusammenhanges." Ibid., S. 544 (Herv. i. o.) 
Nun werden Jugendliche aus sozialwissenschaftlicher Sicht im Allgemeinen als „politische Seismografen “1817 gehandelt, und die studierende Jugend im Besonderen. Daher nährt die Vorstellung einzigartiger Generationszusammenhänge immer auch Hoffnungen in die doch noch heraufdämmernde Triebkraft gesellschaftshistorischen Reformgeistes aus den Reihen der (Post-)Adoleszenten, schafft sie doch Raum für das Auftreten eines (heute unabsehbaren) neuen, womöglich studentischen, Generationszusammenhangs mit politisierender Breitenwirkung: „When everything's collapsing, trust the kids! “1818 Seinen Ursprung hat diese Denkfigur ironischerweise in den Reihen der Studentenbewegung im frühen 19. Jahrhundert: Urheber waren die agitationsstarken Aktivisten und Mentoren (wie Jahn, Stark, Arndt und Fries) der burschenschaftlichen Bewegung selbst, die sowohl ihrem Selbstverständnis ${ }^{1819}$ als auch ihrer sozialgeschichtlichen Wirklichkeit ${ }^{1820}$ nach ja als Protagonisten der ersten deutschen Jugendbewegung angesehen werden können. Sie stilisierten die Lebensphase des Studierens zum Ermöglichungsraum unverfälschter Kreativität und geistiger Entfaltungskräfte, inszenierten ihr Projekt als exzeptionelle und durch das Revolutionszeitalter politisierte „studentische Freiheit" - und zwar dezidiert

„als Gegenbild zur Enge und Trockenheit des Bürgerlebens. [...] In dieser Bedeutung können und sollen sie [die Merkmale der studentischen Existenzform, J. S.] dann das Entwicklungsferment für die ganze gesellschaftlich-politische Verfassung abgeben, und zwar gerade mit Hilfe der jugendlichen, noch nicht von der Alltagsrealität abgeschliffenen und auf vermeintlich triviale Zwecke umgelenkten Energie."1821

Sie begriffen sich somit als durch ihren Generationszusammenhang im historischen Moment nominierten Agenten des Fortschritts und als Vorhut künftiger, entsprechend sittlich-politisch zu schulenden Generationen. ${ }^{1822}$ Was für diese „fortschrittliche“ studentische Jugend $\mathrm{ab}$ 1800, an der das Mannheim'sche Modell mit gebildet ist, aufgrund dieser Selbstzeugnisse durchaus plausibel erscheint, wird von heutigen Jugendforschern allerdings gerne zugleich universalisiert und simplifiziert: „Generationen“ erscheinen hier als zusammengefasste Geburtskohorten, die sich durch bestimmte Einstellungsmuster und Mentalitäten auszeichneten, etwa als „Generation Golf“, „Generation X“ oder „Generation $Y^{“} .{ }^{1823}$ Sicher: Derartige Typisierungsvorschläge bieten Orientierung bei der Interpretation neuer Ergebnisse und der Benennung von Wandlungs-

1817 Hurrelmann, Klaus, und Gudrun Quenzel. Lebensphase Jugend. Eine Einführung in die sozialwissenschaftliche Jugendforschung, Weinheim/Basel 2013, S. 218.

1818 Diese - wahrscheinlich nicht primär politisch gemeinte - Parole gab der deutsche Singer/Songwriter Zeki Min 2014 in Form eines Stickers aus, vgl. Zeki Min: „When everything's collapsing, trust the kids!", in: zekimin.com, 03.04.2014, online einsehbar unter: https://zekimin.com/2014/04/03/ when-everythings-collapsing-trust-the-kids/ [eingesehen am 01.08.2019] Vgl. auch den anschaulichen Sammelband in Koebner, Thomas/Janz, Rolf-Peter/Trommler, Frank (Hg.): Mit uns zieht die neue Zeit. Der Mythos Jugend, Frankfurt a.M. 1985.

1819 Vgl. Hardtwig: Studentische Mentalität, S. 604.

1820 Vgl. Jarausch: Deutsche Studenten, S. 11.

1821 Hardtwig: Studentische Mentalität, S. 602. Vgl. ergänzend ibid., S. 603-606.

1822 Vgl. ibid., S. 605.

1823 Vgl. exemplarisch Albert, Mathias/Hurrelmann, Klaus/Quenzel, Gudrun: Jugend 2015. Eine neue Generationsgestalt?, in: Shell Deutschland Holding (Hg.), Jugend 2015. Eine pragmatische Cenera- 
prozessen. Doch neigen sie auch dazu, Beobachtungen zu Generationserscheinungen $\mathrm{zu}$ verdichten und verdinglichen, die sich ebenso gut oder besser als gesamtgesellschaftliche Mentalitätswandel interpretieren ließen. Das jedenfalls monieren die Kritiker eines solchen Vorgehens seit der frühen Bundesrepublik. So polterte Erwin Scheuch schon 1975: „Die Jugend gibt es nicht“; sozialwissenschaftliche Studien seien zu häufig von tagesaktuellen „Ängste[n] und Hoffnungen getragen“ als von durchdachten Fragestellungen, ihre Befunde angesichts der Volatilität jugendlicher Stimmungen und Haltungen überdies kaum belastbar. ${ }^{1824}$ Protestbereitschaft sei „nach Bildungsgruppen und nach Sozialschichten zu orten“, nicht nach Lebensalter - „Damit wird die Analyse des ,Jugendprotestes' notwendig auch zu einer Untersuchung der ,Erwachsenenwelt ${ }^{\star 1825}$, sprich: zu einer Analyse des gesamtgesellschaftlichen Mentalitätswandels. ${ }^{1826}$ Noch weiter ging der Soziologe Martin Schröder 2018: Von einem Unterschied zwischen „strebsamen“ und „aufmüpfigen“ Generationen auszugehen, sei schlicht der Fehlschluss eines "Generationenmythos“, Ergebnis der wiederholten Schaffung wissenschaftlicher Artefakte im Namen des news value, die nicht einmal qua Zuspitzung und Überpointierung entscheidende gesellschaftliche Entwicklungen erfassen, sondern nur gefällige Schimären produzieren könne. ${ }^{1827}$ Schröders empirische Überprüfung der populären Generationstitel jüngerer Geburtenkohorten seit 1945 mithilfe des Sozio-ökonomischen Panels ergab jüngst, dass weder die in Literatur und Medien verhandelten Generationen $\mathrm{X}$ und $\mathrm{Y}$, noch die Babyboomer, ja nicht einmal die geradezu klassischen „68er“ oder Schelskys skeptische Generation als konturierbare Generationengestalten jemals empirisch existiert haben. Provokanter könnten seine Ergebnisse kaum sein: Schröder „zeigt, dass deutsche Nachkriegskohorten sich kaum in ihren Einstellungen unterscheiden, weder in Bezug auf Lebensziele noch in Bezug auf Sorgen oder gesellschaftliches und politisches Engagement" - und erklärt dementsprechend die gegenwärtige Praxis insbesondere der Shell-Jugendstudien für überflüssig. ${ }^{1828}$ Bereits seit dem Zweiten Weltkrieg gebe es keine Alterskohorten mehr, die sich durch einschneidende und kohortenspezifische Erfahrungsgehalte auszeichneten. Insgesamt gebe es „nur geringfügig[e]“ Unterschiede zwischen den Einstellungsmustern verschiedener Geburtenkohorten. ${ }^{1829}$ Die wirkliche Ursache der empirisch dicht belegten Einstellungsunter-

tion im Aufbruch. 17. Shell Jugendstudie, Bonn 2016, S. 33-46 sowie Schenke et al.: PECIDA-Effekte?, S. $17 f$.

1824 Scheuch, Erwin K.: Die Jugend gibt es nicht. Zur Differenziertheit der Jugend in heutigen Industriegesellschaften, in: O. V.: Jugend in der Cesellschaft. Ein Symposion, München 1975, S. 54-78, hier S. 54.

1825 Ibid., S. 75.

1826 Und für diesen hat Scheuch, entgegen der Vorstellung einer avantgardistisch-postmaterialistischen Jugend (eine Diskussion in der Bundesrepublik der 1970er und 1980er Jahre), eine bestechend simple Formel anzubieten: „Je entwickelter ein Land ist, um so privatistischer sind die Lebensziele und Wertvorstellungen. Es ist charakteristisch für einen hohen Entwicklungsstand, daß hier Werte betont werden, die für eine angenehme Freizeit und für die Planung des Lebens als Privatsache wichtig sind."Ibid., S. 65.

1827 Schröder, Martin: Der Generationenmythos, in: Kölner Zeitschrift für Soziologie und Sozialpsychologie H. 2/2018, S. 1-26.

1828 Ibid., S. 1.

1829 Ibid., S. 22. 
schiede seien, zumindest seit 1945, gesamtgesellschaftliche Mentalitätsveränderungen, die sich auch im Denken und Empfinden von Älteren als Anpassungsprozess im Lebenslauf durchgesetzt hätten, nicht jedoch durch jugendspezifische Erfahrungen gestiftete Generationsdifferenzen. ${ }^{1830}$ Die in Jugendstudien gemessenen Einstellungsunterschiede stellten vielmehr ein Abbild gesamtgesellschaftlicher Veränderungen dar; jugendspezifische Einstellungsmuster habe es seit 1945 so nicht gegeben. Die beständige Suche nach neuen Generationsgestalten befriedige ein Bedürfnis nach der „Konstruktion gesellschaftlicher Mythen". ${ }^{1831}$

Natürlich: Das umstrittene Hilfskonzept des Generationszusammenhangs war immer schon komplexitätsreduzierend, ein „so einfaches wie klares Gerüst, in dem die einzelnen Effekte von Geburtskohorte, zeitlicher Prägung und verschiedenen sozialen Einflussfaktoren vereint werden“ können. ${ }^{1832}$ Ohne metaphysisch anmutenden Überschuss, ohne das Exponieren einer als besonders repräsentativ angesehenen Teilgruppe geht es nicht. Angesichts der teils gewichtigen Kritik erscheint es allerdings zweifelhaft, in den Jahrzehnten der Bundesrepublik nach „Generationen“ und ihren Mentalitäten $\mathrm{zu}$ suchen. Es ist in der Tat fraglich, ob in einer Ära, in denen die Bürger von Demokratien sich in tendenziell auflösbaren Milieuzugehörigkeiten befinden und in ein politisch schwerer repräsentierbares Kaleidoskop von Lebensstilpräferenzen aufsplittern, ${ }^{1833}$ überhaupt noch jene gesellschaftlichen Strukturgesetze vorliegen, die einst den Rückgriff auf den Generationenbegriff plausibel, wenn auch nicht zweifelsfrei analytisch treffend, machten. ${ }^{1834}$ Es ist sicher richtig, dass seit den späten 1970er Jahren an die Stelle industriegesellschaftlicher "normalen“ Karrierewege nach und nach die lebenslange Quasi-Moratoriumsphase lückenloser Flexibilitätsanforderungen und kontinuierlicher Weiterbildung getreten ist. ${ }^{1835}$ Doch ist das gerade keine spezifische Erfahrung einer besonderen, distinguierten Alterskohorte mehr, sondern eine universale. Kurzum: Die frühliberale Burschenschaftsbewegung war wahrscheinlich von einem spezifischen bildungsbürgerlichen Generationszusammenhang getragen, die Bewegung von „1968“ wahrscheinlich nicht. Das hat auch die Rekonstruktion der soziohistorischen Kontextbedingungen dieser Studentenbewegungen gezeigt. Insofern genügt das Konzept der Generation nicht zur Erklärung der Genese von Studentenbewegungen, und auch studentischer Protest im Allgemeinen ist für das Vorhaben dieser Studie besser als raumzeitlich situiertes Bewegungsphänomen zu fassen denn als Generationsphänomen, auch wenn Protestaktionen bestimmte kollektive Erfahrungsgehalte und persistente Gruppenzugehörigkeiten stiften mögen. Daher ist es auch nicht notwendig, hier ein Urteil über die Leistungsfähigkeit

1830 „Eine Ceneration entsteht [...], wenn ein Ceburtenjahrgang während seiner besonders prägsamen Jugend- und jungen Erwachsenenjahre von den gleichen gesellschaftlichen Ereignissen beeinflusst wurde und lebenslang beeinflusst bleibt, ohne dass der Rest der Gesellschaft dadurch ebenfalls beeinflusst wurde. Die Zwangsläufigkeit, mit der alle 15 Jahre eine neue Generation ausgerufen wird, widerspricht jedoch diesem Konzept einer ,Generationslagerung als Potentialität.' Denn danach kann eine neue Generation periodisch entstehen, sie muss es aber nicht." Ibid., S. 3 (Herv. i. O.)

1831 Ibid., S. 24.

1832 Vgl. Bebnowski: Generation und Geltung, S. 16.

1833 Vgl. Walter, Franz: Baustelle Deutschland: Politik ohne Lagerbindung, Frankfurt a.M. 2008.

1834 Vgl. Bebnowski: Generation und Geltung, S. 236 und $238 f$.

1835 Vgl. ibid., S. 243. 
des soziologischen Generationskonzeptes im Allgemeinen zu fällen. Was auch deswegen schwerfällt, weil sich im Für und Wider über dieses Konzept erkennbar politische Einfärbungen geltend machen: Soziologische und politologische Kritiker politisierter Jugendlicher treten besonders gerne als Zweifler und Mythen-Dekonstrukteure auf, während Generationengestalten häufig von jenen kartografiert werden, die Hoffnungen auf eine politisch aktive Jugend hegen. Diese Auseinandersetzung gipfelte in den frühen 1980er Jahren in diametralen Diagnosen über eine zu starke studentische Radikalität einerseits und zu schwache studentische Radikalität andererseits. ${ }^{1836}$

Für das Erkenntnisinteresse der Fokusgruppenstudie bedeuten diese Resultate, dass es durchaus Sinn ergibt, von einem spezifischen politischen Potenzial von Studierenden auszugehen, auch wenn dieses Potenzial einen dramatischen Charakterwandel (Kontinuität diffusen Protest- und Aktionspotenzials, aber Erlöschen des weltanschaulich und organisatorisch strukturierten Bewegungspotenzials) vollzogen hat - ein Wandel, auf den aktuelle empirische Studien einzugehen haben. Insbesondere sollen im Folgenden zwei entscheidende Schwächen der reichhaltigen jüngeren Studien angegangen werden: Der Fokus des repräsentativ arbeitenden Studierendensurveys auf Frage-Items, die sich an die Konzepte "demokratischer Unterstützung" nach David Easton, der „politischen Kultur“ nach Gabriel Almond und Sydney Verba, an der am Dahrendorf'schen Modell der Konfliktakzeptanz orientierten „Skala über die demokratischen Einstellungen“ nach Rudolf Wildenmann und Max Kaase ${ }^{1837}$ anlehnen, leisten keine Analyse der sich mit Begriffen wie „Demokratie“ verbindenden Assoziationen, Affekte, Deutungsmuster und Bilder. So können - teils gravierende - Orientierungsverschiebungen erst erfasst werden, wenn sie sich in abweichenden Zustimmungswerten ausdrücken - und auch dann nur im Korsett vorab festgelegter Antwortoptionen. Hinzu tritt der Verzicht auf eine Analyse grundierender ideologischer Leitlinien, die die konstituierenden und umgreifenden Sinnstrukturen „hinter“ den gemessenen Einstellungswerten ergründen (und auf die Habermas et al. mit dem Konzept der „Gesellschaftsbilder“ 1961 abzielten). Das verblüfft insbesondere angesichts der erklärungsbedürftigen Stagnation des Wandels politischer Einstellungsmuster von Studierenden seit dem letzten Jahrzehnt des 20. Jahrhunderts sowie angesichts der schon 1998 getätigten „beachtenswerten“ Feststellung, „daß tragfähige und integrierende Konzepte als ,Ideologie‘ selbst zerfallen sind, sich offenbar für die politischen Akteure wie für das politische Publikum eine weitgehende ,Unübersichtlichkeit' eingestellt hat. ${ }^{\text {“1838 }}$ Handelt es sich tatsächlich, wie angenommen, um eine schlichte Fragmentierung vormaliger weltanschaulicher Kohärenz, um einen Verlust von „Gewissheiten“ auch unter Studierenden - oder schlicht um einen Wandel der grundierenden, Orientierung spendenden studentischen bzw. akademischen Bewusstseinsformen, der als

1836 Im 1. Studierendensurvey wird die Diskussionslage 1984 so skizziert: Es werde „einerseits ein Überwiegen alternativer Grundströmungen in den politischen Zielen vermutet, die die gegenwärtigen gesellschaftspolitischen Verhältnisse sprengen, andererseits wird daran festgehalten, die Studenten würden nicht in überwiegendem Maße radikale Vorstellungen vertreten." 1 . Studierendensurvey $1982 / 83$, S. 214.

1837 Vgl. Multrus: Der Studierendensurvey, S. $33 \mathrm{f}$.

1838 Bargel: Wandel des politischen Bewußtseins, S. 14. 
solcher zu verstehen und aufzudecken ist ${ }^{1839}$ Die Frage nach dem politischen Potenzial von Studierenden wird dementsprechend im Folgenden als Suche nach Orientierung stiftenden, rechtfertigend deutenden und potenziell handlungsleitenden politisch-sozialen Deutungsmustern im einleitend bestimmten Sinne ${ }^{1840}$ fortgeführt. Insbesondere spontanes Protestpotenzial ist, wie gesehen, in hohem Maße von Gelegenheitsstrukturen und besonderen Ereignissen abhängig, über die sich wenig bis nichts prophezeien lässt. Es kann hier daher nur um Dispositionen für politisches Handeln gehen, also um Sinnstrukturen politischer Energiequellen (Vorbegriff 1a)-1c)) und politischer Formativkräfte (Vorbegriff 2a)-2c)), die in Richtung empfundener politischer Handlungserfordernisse deuten.

Der für die Diskussionen erforderliche Themenkatalog kann nun aus dem Vollen schöpfen. Als über gut zweihundert Jahre wirksame Determinanten des politischen Potenzials von Studierenden - im weitesten Sinne als Protest- und Aktionspotenzial verstanden - haben sich die stark variierenden, jeweils historisch gültigen akademischen Berufschancen und Statuserwartungen (Vorbegriff 1a), 1c) und 3)) ebenso bestätigt wie die Ausprägung gesellschaftskritischer (was in erster Linie zumeist bedeutet: universitätskritischer) „politisierter“ Mentalitäten (Vorbegriff 1b), 1c), 2a) und 3)) und der Grad studentisch-organisatorischer Vernetzung (Vorbegriff 2b) und 2c)). Auf der Grundlage dieser Determinanten wurde ein Themenkatalog für die Fokusgruppen entworfen, der drei Themenblöcke umfasst und die Diskussionen anleitete. ${ }^{1841}$ In den Fokusgruppen wurden die folgenden Themenblöcke angesteuert: 1) Karriereplanung, Studienmotivation und Wahrnehmung des Studiums, 2) Gesellschaftliches und politisches Interesse, politisches Engagement und Demokratieverständnis, 3) Vorstellungen idealer gesellschaftlicher Ordnung. Das hier zugrundeliegende Erkenntnisinteresse soll im Folgenden nebst der auf Basis der oben präsentierten aktuellen Zahlen zu erwartenden Einstellungsmuster kurz umrissen werden. Sollten sich die jeweiligen Muster bestätigen, lautet die vordringliche Frage, auf welche tieferliegenden politisch-sozialen Deutungsmuster Studierende heute zurückgreifen, um ihre zum Teil disparaten Orientierungen in der diskursiven Interaktion mit Sinn zu füllen und zu verknüpfen - und wie sie Begriffe wie Leistung, Bildung, Studium bzw. Politik, Demokratie und Gesellschaft dabei konkret verstehen. Dabei lässt das qualitative Vorgehen Raum für völlig neue, auch konterkarierende Ergebnisse: Denn wie sich ebenfalls gezeigt hat, können Momentaufnahmen politischer Orientierungen ihre Gültigkeit in kurzen Zeiträumen verlieren. Dass das politische Denken und Empfinden der Studierenden im Längsschnitt so außerordentlich volatil erscheint, ist dabei

1839 Spätestens seit den 1990er Jahren jedenfalls fehlt es, wie gesehen, an sozialwissenschaftlichen Studien, die sich diesem Rätsel widmen. Obwohl nach wie vor als gesellschaftliche Schlüsselgruppe gehandelt, finden sich keine umfassenderen Studien, die einer spezifischen Fragestellung unter Rückgriff auf die verschiedenen verfügbaren Daten und Zahlen nachgehen. Die letzten Versuche dieser Art wurden 1982 und 1996 unternommen, vgl. Glotz/Malanowski: Student heute und Demirović/Paul: Demokratisches Selbstverständnis. Von der Studierendenschaft scheint nach dem Ende ihrer relativen soziodemographischen Homogenität bzw. ihrer schichtmäßigen Ausdifferenzierung nach allgemeiner Auffassung kein spezifischer Impuls mehr auszugehen, der sich nicht in Fragen generationeller Stimmungs-Seismographie erschöpft; daher tragen die vorhandenen Studien Züge des „Monitoring“.

1840 Vgl. Kapitel I.5 dieser Studie.

1841 Zur Praxis der Fokusgruppenmoderation vgl. die Ausführungen in Kapitel I.5 sowie den Bericht zur Erhebung in Kapitel III.1 dieser Studie. Der Themenkatalog findet sich überdies im Anhang. 
nicht nur der Entwicklungsdynamik von Bildungsexpansion und steigenden Studierendenzahlen, die die einstige relative Homogenität studentischer Mentalitäten und Lebensformen aufgelöst hat, zuzurechnen, sondern auch dem basalen Faktum der für Universitäten grundsätzlich kennzeichnenden Fluktuation der Studierendenschaft als in Qualifikationsphasen befindlichen jungen Erwachsenen. ${ }^{1842}$

\section{II.4.1 Karriereplanung, Studienmotivation und Wahrnehmung des Studiums}

Erkenntnisinteresse des Themenblocks: Wesentliches Movens des Studiums war es im Zeitalter des Bildungsbürgertums, die eigene, ständisch-traditional durchwirkte Klassenzugehörigkeit insofern zu bekräftigen, als sie ein Nachrücken in attraktive, nicht selten (gesellschaftliche Führungs-)Positionen ermöglichte, vor allem im Rahmen des Staatsbeamtentums. Nach dem Ende der klassischen bürgerlichen Gesellschaft wich diese Funktion der akademischen Professionalisierung einer vergleichsweise breiten Liberalisierung dieser Karrierewege und einer Horizontalisierung von Bildungszertifikaten zum Qualifikationsnachweis von höheren Erwerbspositionen auch in der freien Wirtschaft. Wer heute studiert, kann auch in Zeiten des rasanten Bildungswachstums auf gute Berufschancen hoffen. Dabei scheint sich die Mehrheit der Studierenden zwar stärker an finanzieller Sekurität und einer den eigenen Präferenzen entsprechenden Tätigkeit zu orientieren als an Spitzeneinkünften. Dennoch: Ob bewusst-reflektiert oder implizit-intuitiv, heutige Studierende erwarten materielle Sicherheit nach dem Studium, nicht wenige von ihnen bringen sich wahrscheinlich immer auch als potenzieller Kadernachwuchs gesellschaftlicher Funktionseliten in Stellung. Zweifellos sind sie relativ privilegiert gegenüber allen anderen Formen beruflicher Ausbildung. Zumindest an den Universitäten reproduziert sich dabei zu einem gewissen Grad ein akademisches Milieu; wessen Eltern studiert haben, wird im Vergleich mit Kindern „bildungsferner“ Schichten wohl auch für den eigenen Lebensweg ein Studium plausibler und folgerichtiger, vielleicht gar für unumgänglich halten. ${ }^{1843}$ Zugleich normieren noch immer neuhumanistische Traditionslinien (vorwiegend in geistes- und sozialwissenschaftlichen Studiengängen) die Vorstellungen von akademischer Bildung; bei

1842 „Studentenschaften sind als ganzes [sic] ein unstrukturiertes, stark individualisiertes soziales Stratum. Es ist dauernden Wandlungen seiner Zusammensetzung unterworfen, ein Sechstel bis ein Achtel pro Jahr und Universität. Kein anderer Wahlkörper in der Gesellschaft weist solche Veränderungen trotz aller sozialer Mobilität auf."Wildenmann, Rudolf: Studentische Beteiligung an universitären Wahlen. Stellungnahme, Explorationsstudie, Grundauszählung, in: Studenten '79. Forum des Hochschulverbandes, H. 21/1980, S. 15, zit. nach Jaide/Veen: Bilanz der Jugendforschung, S. 213.

1843 Das zumindest legen die empirischen Resultate der einschlägigen Surveyforschung nahe, siehe 13. Studierendensurvey 2015/16, S. 7: „Die Verteilung verweist auf deutliche Unterschiede zwischen den Hochschularten. An den Universitäten überwiegt die akademische Herkunft, denn 56 Prozent der Studierenden haben mindestens einen Elternteil mit Studienabschluss (45 Prozent mit Universitäts- und 11 Prozent mit Fachhochschulabschluss [...] An den Fachhochschulen stammen nur 40 Prozent der Studierenden aus akademischen Elternhäusern. Dafür sind die Bildungsaufsteigerinnen und -aufsteiger, d. h. Studierende mit Eltern ohne Hochschulerfahrung, mit 58 Prozent an Fachhochschulen deutlich häufiger vertreten als an den Universitäten mit 42 Prozent (jeweils 2 Prozent machten keine Angaben zur elterlichen Ausbildung).“ 
einigen mag der Wunsch, ein Gebildeter zu werden, sogar den dominanten Motivationskomplex ausmachen. Jedenfalls ist von einem grundlegenden Wertekonflikt zwischen Humboldt'schem Bildungsanspruch und individualistisch-meritokratischen Leistungskonzeptionen ${ }^{1844}$ auszugehen - auch wenn nicht davon ausgegangen werden kann, dass die eher seltenen Studierenden traditionell bildungsbürgerlichen Hintergrunds im Erhebungszeitraum an den Fokusgruppen teilnehmen. Also: Begreifen die Studierenden in den Fokusgruppen das Studium primär als Sprungbrett zu einem attraktiven Karriereweg wahr - oder sind andere Motive (Fachinteresse, „Gesellschaft verbessern“, Zugehörigkeit zu einem bestimmten akademischen Milieu, usw.) ausschlaggebend? Was verstehen sie unter Leistung und Bildung, unter Studieren und studentischem Leben? Spielen Erwartungen ihres Elternhauses, Umfeldes, usw. dabei eine Rolle? Gibt es (noch) ein besonderes Bildungsmoratorium, welches nutzbare Freiräume für intellektuelle Suchbewegungen oder politische Praxis schafft? Nutzenerwartungen und Studienerfahrungen beeinflussen wahrscheinlich die Wahrnehmung der eigenen Wertigkeit in Fragen des intellektuellen Vermögens, aber auch der eigenen Position im gesellschaftlichen Zusammenhang, mithin die Gesellschaftskonzeptionen und Ordnungs- bzw. Stabilitätsvorstellungen von Studierenden. Sie geben - insbesondere vor dem Hintergrund des in den 1970er und 1980er Jahren nachgewiesenen Zusammenhangs von Gesellschaftskritik, linker Selbstpositionierung und perzipierten Berufsaussichten - auch Aufschluss über mögliches politisches Frustrationspotenzial in Situationen eingetrübter akademischer Berufschancen. Aktionsorientierte politische Energien von Studierenden, die über hochschulpolitische Belange hinausgriffen, fassten schließlich auch historisch gesehen dort Fuß, wo Phasen blockierter Karrieren und akademischer Arbeitslosigkeit herrschten oder eine wirtschaftliche und soziale Aufschwungbewegung kollektive Ansprüche und Aspirationen weckte und sich die Aufstiegskanäle akademischer Bildung öffneten, kurz: als Modernisierungsdruck herrschte. ${ }^{1845}$ Rapide steigende Studierendenzahlen bilden hierbei zwar nicht den alleinigen Auslöser, aber doch eine elementare Zutat der Ursuppe studentischen Protests. Aus diesem Grund sind hier strukturbildende Faktoren politisch-sozialer

1844 Bildungs- und Leistungsbegriff waren historisch einst als Einheit bildungsbürgerlicher Berufsmaximen konzipiert, sind seit Kaiserreichszeiten aber in Konflikt geraten. Das gibt dem durch wirtschaftlichen Fortschritt und Bildungsexpansion entbundenen traditionellen Bildungsbegriff seine ständisch-vormoderne Aura, während die Leistungsidee als modern, pragmatisch und unverziert erscheint.

1845 Pointiert: In den 1830er/40er und 1960er/70er Jahren griff diese Dynamik nach einer etwa 20-bis 30-jährigen Friedens- und Wachstumsperiode. Perioden persistenter Stagnation hingegen zeitigten eher ein Abdichten akademisch professionalisierter Karrieren gegen nachrückende Aufsteiger, ferner apathische bzw. aggressive Frustration. Natürlich genügt ein solches simplifizierendes Schema nicht als ursächliche Erklärung von Studentenbewegungen: In den frühen 1980er Jahren, der letzten „Überfüllungskrise“ der Universitäten und Akademikerkarrieren mit u. a. vielen arbeitslosen Jungingenieuren, reagierten die Studierenden mit politisch empörter Apathie, nicht aber mit Militarisierung und Selbst-Faschisierung wie in Weimar. Gesamtgesellschaftliche Entwicklungen, Konfliktkonstellationen und Gelegenheitsfenster, auch das ist klargeworden, waren hier stets von konstitutiver Bedeutung. 
Deutungsmuster zu vermuten. ${ }^{1846}$

\section{Erwartete Einstellungsmuster:}

- Im Falle der alltagsweltlichen Werthaltungen sind ein starker Egozentrismus und eine überwiegende Orientierung am privaten Nahraum (Familie, Freunde, Bekannte etc.) zu erwarten, verbunden mit einer mehrheitlich affektiven Distanzierung von der öffentlichen bzw. politischen Sphäre, wo diese als Bereich von Konflikten und Auseinandersetzungen erscheint.

- Zugleich werden traditionalistische Werthaltungen (Religion, Nation, traditionelle Familie und Sexualmoral, etc.) soweit abgetragen sein, dass sie höchstens sporadisch, als Teil selektiver und eklektizistischer Wertbezüge, eine Rolle spielen.

- Der Wunsch nach finanzieller Sekurität wird wahrscheinlich höher rangieren als die Aussicht auf ein besonders hohes Einkommen und überdies von der Absicht getragen sein, Erwerbsleben und Freiräume der „Selbstentfaltung“ miteinander zu harmonisieren.

- Hinsichtlich des Verständnisses von Studium und (Berufsaus-)Bildung ist ein starker bildungshumanistischer Einschlag $\mathrm{zu}$ vermuten, der sich aber nicht mehr zu einem strukturierten und strukturierenden Deutungssystem, zu einem „Gesellschaftsbild“ organisiert. Wahrscheinlich alternieren bzw. konkurrieren Vorstellungen und Konzepte einer persönlichkeitsbildenden und Freiräume erfordernden „wahren“ Bildung, verbunden mit Urteilen zu kulturellen, sozialen und wirtschaftlichen Ermöglichungs- und Verhinderungsbedingungen gesellschaftlichen Entfaltungsfreiraums, mit stärker meritokratischen und leistungsindividualistischen Ordnungsmodellen, die das Hochschulzeugnis vornehmlich als berufsbefähigenden Beleg bewiesener Leistungsbereitschaft auffassen. Es ist dabei durchaus möglich, dass dieselben Personen Elemente beider Stränge verbinden; die vom Studierendensurvey ausgewerteten Daten jedenfalls suggerieren eine historisch resistente Parallelität beider Traditionslinien: „Stets standen Aspekte autonomer Leistungsorientierungen im Vordergrund, gefolgt von Aspekten einer sozial-idealistischen Werthaltung. Vergleichsweise unwichtig waren Werte wie Karrierestreben, hohes Einkommen und Anstrengungsvermeidung. ${ }^{1847}$

\section{II.4.2 Gesellschaftliches und politisches Interesse, politisches Engagement und Demokratieverständnis}

Erkenntnisinteresse des Themenblocks: Naheliegender Weise sollen Gesprächsdynamiken zu politischen Themen evoziert werden, die die Rekonstruktion politisch-sozialer Deutungsmuster zulassen: Welche politischen Themen beschäftigen die Studentinnen und

1846 Man könnte es auch so formulieren: Die sich historisch wandelnden Bildungs- und Erwerbschancen berühren sowohl den objektiven (Berufseinmündung, Erwerbsniveau, Arbeitsmarktsituation, etc.) als auch den subjektiven (Erwartungen, Ansprüche, Hoffnungen) Stellenwert des Studiums in der Gesellschaft.

1847 Vgl. 1. Studierendensurvey 1982/83, S. 188. 
Studenten? Inwiefern sind sie politisch interessiert oder desinteressiert? Findet sich bei ihnen dieselbe Mixtur aus Interesse und praktischer Abstinenz bei Annahme der selbstständigen Funktionsfähigkeit gesellschaftlicher Strukturen (in einer Studie, an der der Autor beteiligt war, als „politische Unberührtheit“ verstanden), die im Falle von Fokusgruppen mit Jugendlichen allgemein zum Vorschein kommen ${ }^{1848}$ Lassen sich bei qualitativer Tiefenanalyse Grundlinien hegemonialer Deutungsmuster oder im Gegenteil politkultureller Grundkonflikte nachzeichnen, gar Residuen einer alten oder Ansätze einer neuen politischen Polarisierung? Werden mehr hochschulpolitische oder mehr allgemein gesellschaftspolitische Ziele visiert? Worin sehen sie die größten gesellschaftlichen Probleme, wie modellieren sie entsprechende Lösungsansätze? Welches Verhältnis nehmen sie zu Institutionen und Eliten ein?

Die Frage nach politischem oder zivilgesellschaftlichem Engagement zählt geradezu zum Standardwerkzeug politikwissenschaftlicher Studien. Hier aber ist stets das Wissen um die reichhaltige Geschichte des besonderen studentischen Aktivismus als Kontrastfolie mitzudenken. Studentischer politischer Aktivismus (ob parteioder bewegungsförmig geartet) hatte historisch betrachtet Organisationskompetenzen bzw. organisatorisches Erfahrungswissen zumindest eines gut vernetzten Nukleus von studentischen Personen- oder Gruppennetzwerken zur notwendigen Bedingung. Eine hochschulpolitisch aktive Studierendenschaft bildete stets auch gleichsam die erste Mobilisierungsschwelle auf dem Weg zu einer allgemeinpolitisch intervenierenden Studentenbewegung: Der organisierte Aktivismus im Namen gesellschaftspolitischer Ziele folgte historisch gesehen stets auf die Wahrnehmung bildungs- und hochschulpolitischer Missstände und damit zusammenhängender innerakademischer Auseinandersetzungen um eine Reform der Hochschule. Voraussetzung war stets das Selbstverständnis und Selbstbewusstsein eines signifikanten Teils der Studierendenschaft als politisches Subjekt mit spezifischen Interessen und einem reformavantgardistischen Sendungsbewusstsein. ${ }^{1849}$ Im Zeitalter des Jungbildungsbürgertums mit seinem weitgefächerten Verbindungswesen (Korporationen und Landsmannschaften, studentische Orden, Burschenschaften, Wildenschaften, protestantische und katholischen Verbindungen, später studentische Selbsthilfe- und Selbstverwaltungsorganisationen und parteigebundene Hochschulgruppen, etc.) war noch die Mehrheit der Studenten in irgendeiner Form (wenn auch nicht immer mit politischem Anspruch) organisiert. Sie übersetzte ab der Mitte des 18. Jahrhunderts den bürgerlichen Impuls der Gestaltung des öffentlichen Lebens - den fortschrittsoptimistischen Anspruch, eine selbstorganisierte „bürgerliche Gesellschaft“ mündiger und aufgeklärter, $d$. h. verlässlicher, leistungsorientierter und bescheidener, Individuen auf

1848 Vgl. Schenke et al.: PEGIDA-Effekte?, S. 186-192, siehe insbesondere S. 208: „Die Befragten scheinen in einem nicht-politisierten Kontext und Umfeld aufzuwachsen, ihnen werden kaum andere Beziehungen zu und Auffassungen von Politik vermittelt. Auch insofern ist die Annahme der Politikverdrossenheit der jungen Menschen unzutreffend, da es nicht um Frustration, sondern um Unberührtheit durch Politik geht.

1849 Das gilt auch für die stärker urban und intellektualistisch orientierten Strömungen aus dem Umfeld der Freistudenten. Ähnlich wie im Falle von Urburschenschaft und Progressbewegung handelte es sich um moralische und kulturelle Reformimpulse, die fließend in politische Zielsetzungen übergehen konnten. 
der Grundlage eines dicht vernetzten Assoziationswesens einzurichten ${ }^{1850}$ - als erste gesellschaftliche Gruppe zunächst in eine Selbstdisziplinierungs- und Gesittungsbewegung, dann bald in eine politische-revolutionäre Bewegung. Damit förderten die Studenten die Ausbreitung moderner politischer Interessen- und Parteiorganisation auch in die Reihen der politischen Rechten hinein. ${ }^{1851}$ Lange Zeit hindurch waren Verbindungen ein so konstitutives Element studentischen Lebens und studentischer Kollektivität gewesen, dass „Bursche“ im 19. Jahrhundert synonym für „Student" stehen konnte. ${ }^{1852}$ Das oft nostalgisch verklärte Studentenleben um die spezifisch deutsche „Burschenfreiheit“1853 war stets auch eine jugendliche Subkultur, wenn nicht gar Archetypus jeder weiteren, die reformorientierte Burschenschaftsbewegung darüber hinaus ${ }^{1854}$ die „erste moderne Jugendbewegung der deutschen Geschichte“. ${ }^{1855}$ Aber die besondere studentische Kollektivität war immer auch Index des Verständnisses

1850 Organisatorisches Erfahrungswissen jenseits staatlicher Strukturen ist ohne diesen heute „zivilgesellschaftlich“ genannten Ursprung nicht zu denken. Vgl. Nipperdey, Thomas: Verein als soziale Struktur, S. 30: „Die Vereine beanspruchten zunächst einen Raum privater Aktivität, der über den häuslichen und den ökonomischen Bereich des einzelnen hinausging und der vom Staat freigelassen, ihm gegenüber autonom sein sollte. Die liberale Forderung nach einer von staatlicher Bevormundung und korporativen Regelungen emanzipierten Freiheitssphäre des Individuums galt auch für den Zusammenschluß der Individuen und ihren gemeinsam organisierten Freiheitsraum. Dieser Freiheitsraum wurde bei den Vereinsgründungen des 18. Jahrhunderts gemeinhin als unpolitisch verstanden. Formal schlossen die Vereine Politik aus ihren Aktivitäten aus. Faktisch gewinnen die Vereine jedoch vielfach politische Bedeutung. Wenn die in ihnen zu einer Art kollektiver Privatheit zusammentretenden Personen diskutieren, werden sie zu einem Faktor der öffentlichen Meinung, und damit mindestens zu einer Quasi-Öffentlichkeit. Sie bestreiten das Interpretationsmonopol von Staat und Kirche, indem sie bisher nicht fragwürdige Dinge zur Frage stellen." Vgl. ferner Lundgreen, Peter: Einführung, in: Ders. (Hg.): Sozial- und Kulturgeschichte des Bürgertums. Eine Bilanz des Bielefelder Sonderforschungsbereichs (1986-1997), Göttingen 2000, S. 13-39, hier S. 37.

1851 „Die Gesellschaften der 8oer Jahre des 18. Jahrhunderts, zumal die Lesegesellschaften, spielten [...] durch Diskussion, Propagierung von Grundsätzen und Anteilnahme an öffentlichen Dingen ganz sicher eine wichtige politische Rolle. Sie können als Vorformen der Parteibildung gelten. Selbst die antirevolutionären, später konservativen Kräfte wählten die Form der Assoziation, um sich politisch zu organisieren." Nipperdey: Verein als soziale Struktur, S. 35.

1852 Vgl. Jarausch: Deutsche Studenten, S. 35. Die verschiedenen Verbindungsarten spiegelten dabei aber durchaus auch politische Konfliktlinien, denen der Anspruch des jeweiligen Gegners auf allgemeine Vertretung widerstrebte, was die organisatorische Sammlung erschwerte.

1853 Dieses besondere System aus Gewohnheitsrechten enthielt, wenn auch zunehmend durch innerstudentische Reformimpulse in Zweifel gezogen, die besondere studentische Gerichtsbarkeit ebenso wie die Verhaltens- und Ehrenkodizes, die studentische Sitten wie das Duell, das ritualisierte Trinken und die Sexualmoral reglementierten, vgl. Jarausch: Deutsche Studenten, S. 243 und Schulze/Ssymank: Das deutsche Studententum, S. 181-185 und 274-299. Nostalgisch verklärt ist die „Burschenfreiheit" deswegen, weil das banale Faktum, dass diese zumindest in korporatistischen und landsmannschaftlichen Kreisen zumeist auf „eine alle Gesetze verachtende rohe Willkür" hinauslief-so Schulze/Ssymank: Das deutsche Studententum, S. 183-selten Erwähnung findet.

1854 Hardtwig datiert den Ursprung der Burschenschaft als studentischer Reformbewegung auf den Zeitraum zwischen 1790 und 1819, d. h. zwischen dem Schlüsseljahr einer etablierten meritokratischen Beamtenelite und der beginnenden Übersetzung des antinapoleonischen Kriegsfurors in nationalrevolutionäre Energien im gebildeten Bürgertum, vgl. Hardtwig: Krise der Universität.

1855 Vgl. Jarausch: Deutsche Studenten, S. 35. 
von Universität als Ort politischer Willensbildung nicht nur in Bewegungsphasen. Sie wirkte vielmehr kollektivierend, disziplinierend, und bis zu einem gewissen Grad auch koordinierend auf das politische Verhalten von Studierenden insgesamt ein. Hier schlägt der historische Verlust des studentischen "Sozialcharakters“, also der sozialen Homogenität und der gemeinschaftsstiftenden Attribute und Rituale, in kaum zu ermessener Stärke durch: Die „sozial durch die Gemeinschaft der Klassenzugehörigkeit und [durch] die hohe Integrationskraft der klassenspezifischen Insignien und Rituale geprägten Korporationen“ bedeuteten

„ein hohes Maß an prästabilierter Integration. Die Universität als Großorganisation mit funktioneller Struktur hat keine primären sozialen Selektionen; Schichtzugehörigkeit ist zwar nach wie vor ein (indirektes) Selektionskriterium des Zugangs, aber die Universität hat selbst, wenn überhaupt, nur noch geringe Reste sozialer Zuordnungsund Abgrenzungsmodi.“1856

Bis zum Ende der nationalsozialistischen Herrschaft galt die Organisationskraft der Studierenden, der „nichtberufstätige[n] ältere[n] Jugend“, als entscheidendes Kennzeichen dieser sozialen Gruppe: In „all ihren organisierten Erscheinungsweisen vom Korporationsstudententum bis zur jugendbewegten Akademischen Freischar", so Schelsky 1957 im Rückblick auf die zurückliegenden Jahrzehnte, hätten die Studierenden die Vorstellung jugendlicher Autonomie „am deutlichsten“, nämlich als soziale, subkulturelle und in weiten Teilen auch politische Einheit, genährt von einem autonomiebegründenden spezifischen Standesbewusstsein, verkörpert. ${ }^{1857}$ Mitte der 1950er Jahre hingegen zeigten sich die Studierenden den traditionellen studentischen Gemeinschaft- und Gesellungsformen mehrheitlich abgeneigt; die homogenisierende und sinnstiftende Kraft sowohl ihres korporatistischen als auch ihres jugendbewegten Erbes war schon hier erloschen. Weder „sozial autonom“ noch "sozial elitär“, jedenfalls jedes Standesbewusstseins und jeder „irgendwie bemerkenswerte[n] Eigenständigkeit gegenüber den anderen gleichaltrigen Jugendlichen“ bar erschien dieser neue, nach wissenschaftlich qualifizierten Funktionen strebende Typus des Studierenden. ${ }^{1858}$ Das kurze Wiederaufleben der nun vollends diskreditierten Korporationen etwa blieb ein restaurativ-retardierender Akt, von studentischer Seite eher durch die Suche nach „banaler Geselligkeit“ als nach einem standesgemäßen Ethos bestimmt, d. h. ohne die studentische Mentalität noch einmal zu imprägnieren, ohne sie sozialmoralisch zu formen, mithin letztlich ein Strohfeuer. ${ }^{1859}$ Schließlich: Mit der gegenwärtigen tendenziellen Universalisierung des Studiums als beliebtestem nachschulischem Qualifikationsweg (zur Erinnerung: eine Mehrheit von bereits 56 Prozent der jeweiligen Geburtskohorte nimmt aktuell ein Studium auf ${ }^{1860}$ ) geht die Nivellierung aller spezifischen Differenzen einher, welche die Studierendenschaft als soziale Gruppe einmal konstituiert hatten. In den vergangenen Jahrzehnten ist zudem die langfristige organisatorische Bindung an die vormaligen

1856 Schülein: Veränderungen der Studentenrolle?, S. 145.

1857 Vgl. Schelsky: Die skeptische Generation, S. 315.

1858 Vgl. ibid., S. 330.

1859 Vgl. ibid., S. 328.

1860 Daten entnommen aus Wolter: Eigendynamik und Irreversibilität der Hochschulexpansion, S. 25, sowie Statistisches Bundesamt: Schnellmeldungsergebnisse Wintersemester 2017/18, S. 11. 
industriegesellschaftlichen Großorganisationen (Parteien, Jugendorganisationen, Kirchen, Vereine, etc.) auch gesamtgesellschaftlich erheblich zurückgegangen, und die vielen, ihrer historischen Genese nach überkreuz liegenden studentischen Gesellungs- und Organisationsformen (studentische Selbstverwaltung und Studentenwerke ${ }^{1861}$, Hochschulpolitik, Politgruppen, Lesezirkel, Verbindungen und Burschenschaften, Verbandswesen) locken nur noch einen kleinen Anteil ${ }^{1862}$ der Immatrikulierten. Zudem: Das Studieren ist etwa seit den 1960er/70er Jahren - auch bedingt durch die Verschulung der Curricula - im Grunde ohne nennenswerte Adaption eines spezifisch studentischen Lebensstils möglich. Diese Entwicklung lässt das studentische politische Verhalten (von Apathie über die Sammlung in flexiblen und labilen Bündnissen bis hin zum spontanen Tumultismus) heute unberechenbar ${ }^{1863}$ erscheinen. Insbesondere studentischer Protest kann plötzlich auftreten und unvorhersehbare Wendungen nehmen:

„Es ist durchaus zutreffend, dass Studierende aufgrund ihrer sozialen Situation leicht für Proteste zu gewinnen und zu Demonstrationen zu bewegen sind. Studierende können dazu ganz verschiedene Anlässe wählen und auch aggressive Formen anwenden, bis hin zu Nötigungen und Beschädigungen. In ihren Parolen und Pamphleten zeigen sie dann öfters einen Hang zu Ironie, Satire, Parodie (bis hin zu Zynismus). [...] Ob es sich allerdings um mehr als ein ,Strohfeuer' des Protestes handelt, das hängt einerseits von den Reaktionen der Instanzen an den Hochschulen und in der Politik ab, andererseits vom Umstand, ob sich daraus ein auf Konzepten und Prinzipien gegründete Bewegung bildet. Breitere und schärfere Formen, auch in langfristiger Weise, erhält der Protest mit höherer Aggressivität erst dann, wenn eine ,System und Machtfrage' damit gestellt wird. Eine solche ,Protestwelle' größeren Ausmaßes ist für den nächsten Zeitraum nicht absehbar."1864

Über mögliche Anlässe für einen solchen Unmut lieferte die Längsschnittbetrachtung reichhaltige Aufklärung: Sie reichen von einer möglichen Überfüllungskrise akademischer Berufe und daraus resultierender Zukunftsskepsis über als unzumutbar empfundene Studienbedingungen bis hin zu tagespolitischen Entwicklungen wie Geset-

1861 Bei ihnen handelte es sich um eine Mixtur aus studentischer Selbsthilfe und staatlich finanzierter Fürsorge, vgl. Kater: Studentenschaft und Rechtsradikalismus, S. 43-56.

1862 In absoluten Zahlen gemessen bildeten die überdurchschnittlich engagierten Studierenden zu allen Zeiten eine Minderheit. Zwischen 1962 und 1966 etwa zählte auch der SDS, damals auf dem Höhepunkt seiner Organisations- und Attraktionskraft, nur ca. 500 bis 700 aktive Mitglieder, vgl. Bock: Geschichte des ,linken Radikalismus', S. 194. Das historische Novum seit den 1970er Jahren besteht vielmehr im relativen Bedeutungsverlust dieser Strukturen, $d$. $h$. in der immer drastischer sinkenden Beteiligungsquote der Studierenden an (hochschul-)politischem Engagement und subkultureller Einbindung. Insbesondere das Korporationswesen aber vermochte sich nach dem Zweiten Weltkrieg nicht mehr zu regenerieren: Nach 1945 gehörten ihm niemals mehr als 5 Prozent der Studierenden an, vgl. Jarausch: Deutsche Studenten, S. 243.

1863 Damit soll keine vormalige umfängliche „Berechenbarkeit“ suggeriert, geschweige denn behauptet werden, es habe jemals so etwas wie eine vollends einheitliche Sozialfigur des Studenten oder ein vollends einheitliches politisches Verhalten von Studierenden gegeben. Vgl. Jarausch: Deutsche Studenten, S. 247-250.

1864 Bargel: Wandel politischer Orientierungen, S. 43 und 45. 
zesentwürfen, öffentlichen Skandalen und parteipolitischen Richtungsdebatten. ${ }^{1865} \mathrm{Al}$ lein, diese Organisations- und Kollektivitätsdiffusion hat sich bisher keineswegs in jeder Hinsicht durchgesetzt. Dagegen spricht nicht nur die Kontinuität der genannten Assoziationsformen und durchaus vorhandener Formen eines subkulturell bestimmten „Studentenlebens“, ${ }^{1866}$ auch die bis heute konservierten Traditionen studentischen Elite- und Standesbewusstseins mit Blick auf die Bereitschaft zu hochschulpolitischem Engagement nötigen dazu: (Hochschul-)Politischen Handlungsdruck scheinen insbesondere jene zu empfinden, die sich mit ihrem Studium bzw. mit ihrer Rolle als Studierender am stärksten identifizieren. ${ }^{1867}$ Unbestreitbar aber hat sich die politische Aktivitätsbereitschaft von Studierenden in großem Maße individualisiert, partikularisiert, sublimiert. Insbesondere Hochschulpolitik wirkt auf die heutigen offenbar harmoniebedürftigen Studierenden wie eine Arena überfordernder Konfliktivität; an den Berliner Universitäten übersteigt die studentische Beteiligung an den Gremienwahlen selten mehr als zehn Prozent. ${ }^{1868}$ Zudem: Der historische Längsschnitt demonstrierte nicht nur die Diffusion studentischen Verbandswesens und studentischer Subkultur. Er zeigte ebenso deutlich, dass Organisationskompetenz und Aktionsstärke keineswegs eo ipso liberale, demokratische oder auch nur oppositionelle Potenziale hervorbringen müssen, sondern insbesondere zwischen 1871 und 1945 ebenso gut und ebenso folgenreich die konformistische Sammlung antiliberaler, antisemitischer und völkischer Kräfte befeuern konnten, die eine so verhängnisvolle Rolle spielen sollten. Die voreilige Assoziation studentischen Rebellentums mit wünschenswerten, d. h. emanzipativen und pluralistischen Reformimpulsen ist jedenfalls ein Kurzschluss, der sich an der vielschichtigen historischen Realität bricht.

Im Folgenden interessieren nun diese Fragen: Wird ein politischer Handlungsdruck unter Studierenden generell empfunden - und falls ja, wie rechtfertigt man praktischpolitische Apathie? Welche Motivationsquellen für die politische Betätigung gibt es bzw.: Entlang welcher Ziele und Konfliktlinien, auf der Grundlage welcher Ideale, Werthaltungen oder Kritikansätze entzündet sich der politische Handlungswunsch? ${ }^{1869}$ Wie

1865 „Das Protestpotential, auch in aggressiver Weise, ist unter den Studierenden groß genug, so dass es jederzeit aufflammen kann. Solche härteren Protestformen können bei partiellen Interessenskonflikten (z.B. Thema Studiengebühren, Einsparungen im Hochschulbereich, Stipendienfragen) ebenfalls angewandt werden, nicht nur bei grundsätzlichen politischen Richtungsdebatten (etwa zur Bildungs-, Sicherheits- oder zur Außenpolitik)." Ibid., S. 45.

1866 Gerade in Städten mit Volluniversität ist die studentische Prägung des öffentlichen Lebens unübersehbar. Es existieren weiterhin aktive Organisationen und intakte universitäre Gremienstrukturen wie Hochschulgruppen, Studierendenparlamente, Fachschaftskonferenzen bzw. Fachschaftsräte, Studierendenausschüsse (meist AStA), bisweilen auch Vollversammlungen, ferner Studentenwerke, Burschenschaften und Verbindungen, studentisch geprägte Cafés und Kneipen, Politgruppen und Lesezirkel.

1867 Vgl. 11. Studierendensurvey 2009/10, S. 75.

1868 Vgl. Burchard, Amory: Warum Studierende keine Lust auf Unipolitik haben, in: Der Tagesspiegel, 20.05.2015, online einsehbar unter: https://www.tagesspiegel.de/wissen/mitbestimmung-an-hochschulen-warum-studierende-keine-lust-auf-unipolitik-haben/11803996.html [eingesehen am 01.08.2019]

1869 „Politisches Interesse, Partizipation und Engagement auf der einen Seite, politische Richtungen und Positionen auf der anderen Seite bilden gleichsam die Grundkoordinaten politischer Hand- 
beurteilen Studierende generell ihre gesellschaftlichen Einflussmöglichkeiten? Was bedeuten politische Praxis und Engagement für sie? Insbesondere: Bleibt geäußerte Gesellschaftskritik eine intellektuelle Betätigung oder fließt aus ihr der Wunsch nach politischem Einfluss? Wie unterscheiden sich die Sichtweisen und Deutungsmuster zwischen zivilgesellschaftlich organisierten und nichtorganisierten Studierenden? Gibt es noch den Wunsch, die Studierendenschaft zu einer politisier- und mobilisierbaren Gruppe zusammenzuschmieden? Lässt das Studieren in Zeiten fortgesetzter Bildungsexpansionsdynamiken vielleicht auch neue Räume für Gruppenbildungsprozesse entstehen?

Schließlich: Welches Verständnis von Demokratie, demokratischen Prozessen, politischer Willensbildung und politischer Partizipation haben sie? Welche Ansprüche richten Studierende an eine funktionierende Demokratie, und wo sehen sie Funktionsdefizite? Die Art und Weise, wie Demokratie, demokratische Beteiligungsmöglichkeiten und demokratische Institutionen beurteilt werden, ist schließlich als integraler Bestandteil eines politischen Potenzials der Studierendenschaft anzusehen. Denn: Weder die nationalliberalen und sozialistischen Oppositionsbewegungen noch die konservativen Strömungen der Studierendenschaft hätten ohne plastische, kollektiv geteilte Überzeugung von der einen, der richtigen - sei es herbeizuführenden, sei es zu bewahrenden - Gesellschaftsform politisch reüssieren können. Allerdings ist im bisherigen Verlauf der Studie auch klargeworden: Das politische Interesse von Studierenden nährt sich mehrheitlich nicht mehr aus einem irgendwie gearteten „Klasseninteresse“ oder "Bildungshorizont“ von akademisch gebildeten Schichten. Lebenswelten, Alltagserfahrungen, familiäre Sozialisation, Mediennutzungsverhalten, kurz: Quellen politischer Überzeugungen haben sich den Verhältnissen der Mehrheitsgesellschaft der entscheidenden Rolle des Elternstudiums für die eigene Studienaufnahme zum Trotz - wahrscheinlich weitgehend angeglichen; es ist also jenseits der methodisch bedingten Verzerrung ${ }^{1870}$ in den Fokusgruppen grundsätzlich ein großes Spektrum von Meinungen, Einstellungen und Ordnungsvorstellungen zu erwarten. ${ }^{1871}$ Ebenso eine überwiegende Zustimmung zum politischen System der Demokratie bzw. zum bundesrepublikanischen Verfassungsstaat; interessanter wird daher sein, danach zu fragen, was Studierende heute angesichts der Vieldeutigkeit und Umkämpftheit von Begriffen wie „Demokratie“ konkret verstehen.

\section{Erwartete Einstellungsmuster:}

lungspotentiale: die der politischen Intensität und Energie einerseits, die des politischen Standortes und der Zugehörigkeit andererseits." Bargel: Wandel des politischen Bewußtseins, S. 2.

1870 Gemeint ist damit der klassische Bias der empirischen Sozialforschung, nämlich dass sich in erster Linie kommunikationsstärkere bzw. engagiertere Personen zur Teilnahme an Umfragen, Interviews und Gruppengesprächen bereit erklären.

1871 Eine naheliegende Ausnahme sozialmoralisch festgefügter Orientierungen könnten allerdings die heute verbliebenen bildungsbürgerlichen Milieus bzw. Subkulturen mit ihrem vergleichsweise hohen Grad an beruflicher Vererbung, v. a. in den Studienfächern Medizin und Jura, bilden. Ob Studierende aus diesem Milieu allerdings an der Teilnahme an Fokusgruppendiskussionen interessiert sind, ist fraglich. 
- Die Ergebnisse der einschlägigen empirischen Studien legen ein gesunkenes politisches Informationsniveau und geringe Positionierungsfreude nahe. Zudem ist insbesondere ein traditionell verschwindend geringes Interesse an Hochschulpolitik zu erwarten.

- Ein prinzipieller und verbal bekundeter Kosmopolitismus wird zu beobachten sein, der aber zugleich stark von Ordnungs-, Stabilitäts-, und Sekuritätssehnsüchten durchsetzt ist. Eventuell werden sich insbesondere in diesem Zusammenhang Widersprüchlichkeiten häufen.

- In politischer Hinsicht ist einerseits eine stark empfundene und zur Mitteilung drängende politische Verantwortungsempfindung zu erwarten, ferner ein offensiv bekundetes Interesse an politischen Vorgängen und eine verbreitete Kritik an der mangelnden Verwirklichung gesellschaftlicher Prinzipien wie Chancengleichheit und Wohlstandsgerechtigkeit. Zugleich aber erscheint auch der verbreitete Verzicht auf praktisch-politische Betätigung in (Hochschul-)Parlamenten, Initiativen oder politischen Zirkeln als wahrscheinlich, ferner eine weitgehend fehlende Parteiund Organisationsbindung, ja eine Abneigung, sich abseits von Einzelthemen politisch zu positionieren.

- Dementsprechend werden wohl auch die Residuen zwischen den groben politischen Konfliktlinien von „Rechts“ und „Links“ kaum noch orientierungsstiftend sein - und wenn, dann nur für die außergewöhnlich stark engagierten Studierenden. Allerdings: Offen ist angesichts der Wahlgewinne der AfD in den Jahren 2016 und 2017 - die sämtlich hinter dem Erhebungszeitraum des aktuellen Studierendensurveys liegen - noch, ob die Relevanz derartiger polarisierter Selbstpositionierungen im Richtungsschema doch wiederum gestiegen sein könnte.

- Wie es sämtliche Studien der Jugendforschung in den letzten Jahren nahelegen, wird die Skepsis gegenüber festen Organisationsstrukturen und langfristigen Verpflichtungen im politischen Bereich sehr ausgeprägt sein, besonders das Fremdeln mit dem Engagement in Parteien und politischen Gruppierungen. Auch engagementbereite Studierende werden daher flexible, unverbindliche und projektbezogene Aktivitäten präferieren, etwa die einmalige oder mehrmalige, ggf. „experimentelle“ Teilnahme an Demonstrationen, Unterschriftenaktionen, Petitionen, o. Ä.

- Manche Personen, die aus einem gut vernetzten „zivilgesellschaftlichen“ Milieu stammen, werden dennoch ein sozialisatorisch bedingtes langfristiges Engagement mit Schwerpunkt im vorpolitischen Bereich (Kirche, zivilgesellschaftliche Organisationen) vorweisen können, evtl. auch in Parteijugenden und Hochschulgruppen.

- Angesichts der empirischen Studien ist von einer mehrheitlichen praktisch-politischen Apathie auszugehen, die angesichts des Bildungsniveaus aber differenziert verbal reflektiert und rationalisiert werden kann.

- Jene Studierenden, die sich stark mit dem Studium oder mit ihrer Rolle als Studierende identifizieren, leiten daraus womöglich spezifische Pflichten und Verantwortungen $a b$, empfinden mithin einen stärkeren praktisch-politischen Handlungsdruck.

- Überdies erscheint absehbar, dass die Studierenden für sich selbst eine unverbrüchliche Parteinahme für die Demokratie reklamieren, aber unter Umständen stark 
auseinanderweisende rationale wie affektive Bedeutungsgehalte mit dem Demokratiebegriff verbinden - etwa hinsichtlich der Betrachtung als Gesellschaftsform, Staatsform oder Regierungsform, hinsichtlich des täglich erfahrbaren Widerspruchs zwischen der Herrschaft politisch gewählter Eliten und der plebiszitären, institutionelle Verhärtungen verurteilenden Seite des historisch bedeutungsschweren Demokratiebegriffs - oder hinsichtlich Ausmaß und Richtung des persönlich empfundenen Handlungsdrucks.

\section{II.4.3 Vorstellungen idealer gesellschaftlicher Ordnung}

Erkenntnisinteresse des Themenblocks: Hier lautet das Ziel, die möglichen Gesellschaftsbilder und Ordnungsvorstellungen von Studierenden aufzuschlüsseln, insbesondere im Hinblick auf das Verhältnis von möglichen Gesellschaftsidealen und diagnostizierten Gesellschaftsrealitäten. Wird Gesellschaft als anonymer Funktionszusammenhang im Stile eines perpetuum mobile wahrgenommen, dem man sozialpolitisch anspruchsberechtigt, aber auch ohnmächtig gegenübersteht - oder als geschichtlich und praktischpolitisch hervorgebrachte und veränderbarer Zusammenhang lebendiger Menschen gedacht, der praktisch - auch durch eigenes Handeln - vorangebracht werden kann und muss? Ist eine funktionierende Gesellschaft durch die gelingende Vermittlung von Konfliktpotenzial gekennzeichnet oder im Gegenteil durch die vollständige Abwesenheit von Konflikten? Gibt es darüber hinaus spezifisch studentische Utopien? Allerdings auch: Lassen sich hier überhaupt gesonderte Einstellungsmuster ausmachen, oder konvergiert die Frage nach utopischen Vorstellungen nicht letztlich mit der Frage nach grundierenden politisch-sozialen Deutungsmustern, d. h.: sind die Konzeptionen idealer gesellschaftlicher Ordnung nicht ohnehin in den Diskussionsverläufen wirksam und aus diesen zu rekonstruieren?

\section{Erwartete Einstellungsmuster:}

- Die referierten empirischen Studien über die Entwicklung studentischer Mentalitäten, aber auch das generelle Verblassen der "großen“ politischen Deutungssysteme im Verlauf des 20. und 21. Jahrhunderts lassen vermuten, dass Studierende (wie auch die Mehrheitsbevölkerung) keine plastischen Vorstellungen einer gänzlich anderen sozialen Ordnung mehr gegen den gesellschaftlichen status quo in Stellung bringen. Ob der hier zunächst nur tentativ einbezogene Themenblock überhaupt ergiebigen Gesprächsstoff gestattet, ist daher durchaus zu bezweifeln.

- Dennoch üben Studierende, wie gesehen, auch heute Gesellschaftskritik. Da es an transzendenten Sinnquellen mangelt, steht zu erwarten, dass sie dies durch Rückgriff auf heute ohnehin mehrheitsfähige Ideale tun, um deren mangelnde Realisierung anzuklagen. $\mathrm{Zu}$ diesen Idealen zählt vermutlich vorrangig die soziale Gerechtigkeit, gemessen an der Gültigkeit meritokratischer Kriterien der Güter- und Statuszuweisung und am Zugang aller zu den vielbesungenen "Chancen“ autonomer Karrieregestaltung (insbesondere Bildungschancen).

- Das schließt gleichwohl nicht aus, dass vereinzelt auch genuine Utopisten in den Fokusgruppen sitzen, die bereit sind, sämtliche aktuell gültigen gesellschaftlichen 
Ordnungsprinzipien substanziell in Frage zu stellen. Sollten sie sich zu Wort melden, werden sie in der jeweiligen Gruppe allerdings wahrscheinlich eher als Sonderlinge auffallen. 



\section{Auswertung der Fokusgruppenstudie}

Die im Rahmen der historisch-empirischen Längsschnittbetrachtung aufgeworfenen Aspekte des politischen Potenzials von Studierenden sollen nun mit einer eigenständigen qualitativen Analyse von Fokusgruppendiskussionen kontrastiert werden, welche den Blick auf die Gegenwart richtet: Welche neuen Tendenzen des studentischen Mentalitätswandels ${ }^{1}$ sind auf der Grundlage politisch-sozialer Deutungsmuster heutiger Studierender abzulesen, welche Zusammenhänge der im Studierendensurvey dokumentierten Einstellungsentwicklungen werden dadurch erhellt, und auf welche praktischpolitischen Dispositionen lässt all dies schließen? Der thematisch gegliederten Auswertung geht eine kurze Dokumentation des Erhebungs- und Auswertungsprozesses sowie eine Skizze des erzielten Realitätsausschnitts des Fokusgruppensamples voraus; diese beiden Teilkapitel dienen dem kritischen Nachvollzug der später gezogenen Schlüsse und deren möglichen Reichweite.

\section{III.1 Vorgehen und Verlauf der Erhebung}

Nach der Auseinandersetzung mit der einschlägigen Literatur erfolgte der Gang ins Feld. Der eigentlichen Erhebungswelle ging ein Pretest im Juni 2017 voraus. Das primäre Ziel war hier, erste Beobachtungen anzustellen, die Leistungsfähigkeit des vorläufigen Themenkatalogs zu testen, aber auch Thesen zu notieren. Rasch zeigten sich hier allerdings nicht nur gravierende Mängel des Themenkatalogs; ${ }^{2}$ auch wurde deut-

Zur sozialen und politischen Mentalität zählten stets, wie sich gezeigt hat, so unterschiedliche Elemente wie Gesellschaftswahrnehmung und Cesellschaftskritik, Status-Selbstzuschreibung bis hin zum Standesdünkel, Kollektivitätsverständnis (Zu welchen Gruppen fühlt man sich zugehörig?) politisches Empfinden, politische Urteilsbildungsprozesse und politische Praxisabsichten.

2 Die Themenfelder des ersten Themenkatalogs lauteten 1. Assoziationen zum Begriff „Demokratie" und persönliche Erfahrungen mit Demokratie; 2. Der Wahlkampf und seine Wahrnehmung; 3. Erwartungen ans Studium / Studiensituation und Orientierungen; 4. Cesellschaftsbild. Mit diessem Aufbau wurde die Absicht verfolgt, abstrakte Begriffsassoziationen dem im Laufe des Cesprächs herausgearbeiteten faktischen Verständnis politischer und gesellschaftlicher Prozesse gegenüberzustellen. Als aktuelles politisches Geschehnis wurde die Bundestagswahl 2017 gewählt. Darüber hinaus sollte mit dem Zitat von Johann Cottlieb Fichte ein Grundreiz eingegeben wer- 
lich, dass die Erwähnung von Signalwörtern wie „Politik“ und „Demokratie“, ${ }^{3}$ insbesondere bei fehlenden incentives, fachwissenschaftliche Assoziationen weckt, die zu einer erheblichen Ausdünnung der Interessierten sowie zu einer unkalkulierbaren Unzuverlässigkeit der bereits angemeldeten Personen führen. ${ }^{4}$ Besonders auffällig war, dass sich in erster Linie thematisch stark interessierte Menschen meldeten, denen das dort noch angekündigte Diskussionsthema „Demokratie“ reizvoll erschien. Eine interessierte Person versuchte sogar, ihre fachliche Eignung für die Diskussion vorab in einer E-Mail darzulegen. Der Pretest gab somit zwar Aufschluss über notwendige Adjustierungen des Erhebungsverfahrens, eine Verschriftlichung und Auswertung der hierbei entstandenen Aufzeichnung aber erschien nicht lohnenswert.

Die 44 Teilnehmerinnen und Teilnehmer der 7 Fokusgruppen der hier ausgewerteten Erhebung wurden im Verlauf des Jahres 2018 teils über Aushänge und Auslagen an den Plakatwänden sowie in den Foyers und Vorlessungssälen des Zentralgebäudes $^{5}$ des Geisteswissenschaftlichen Zentralcampus (GWZ, Göttingen), teils über Online-Aushänge in fakultätsübergreifenden Facebook-Gruppen (Göttingen/Frankfurt a.M.) rekrutiert. Hierbei galt es, vorab möglichst wenig Informationen über das geplante Forschungsvorhaben preiszugeben, einerseits um das Antwort- und Diskussionsverhalten möglichst wenig zu präformieren, andererseits um etwaige affektive Gesprächshürden zu umgehen. Als Thema wurde daher die unspezifischabstrakt gehaltene Formel „Studium und Gesellschaft" benannt, ferner eine ungefähre Diskussionsdauer von 90 Minuten (Göttingen) bzw. 120 Minuten (Frankfurt a.M.) ${ }^{6}$

den, der die Teilnehmenden zu einem Gespräch über ihre Erwartungen und ihr Verständnis von Studium, Bildung und Universität anregt. Bereits die Diskussion mit den zwei tatsächlichen Teilnehmern zeigte, auch über das bei vier Personen (Moderator, Protokollant, zwei Teilnehmer) eher sterile und angespannte Redeklima hinaus, überdeutlich, dass dieser erste, streckenweise eklektizistisch komponierte und auch von den Teilnehmern in der Feedback-Sektion des Fragebogens als sprunghaft wahrgenommene, Leitfaden schlecht geeignet war, die Vorstellungs- und Deutungsmuster der Befragten hervorzulocken. Begriffsassoziationen über „Demokratie“ anzustellen, war als Diskussionseinstieg ungeeignet und weckte überdies auch kaum konnotative Phantasie; zudem verfing das neuhumanistische Bildungsideal in seiner zeitgenössischen aufklärerischen Formulierung nicht. Der überarbeitete Themenkatalog ist daher stärker sukzessiv ausgerichtet, sodass er im konkreten Erfahrungsraum der Probanden beginnt und erst im Laufe des Cesprächs zu komplexeren und anspruchsvolleren Themen fortschreitet. Indem er so empathischer auf die persönliche Lebensrealität der Studierenden abhebt, sollte es mit ihm tatsächlich besser gelingen, eine selbstläufige Diskussion zu evozieren.

3 Die Begriffe „Politik" und "Demokratie“ wirken auf sozialwissenschaftliche Probanden in der Regel sperrig und komplex, wecken häufig überdies negative Konnotationen in Richtung Streit, Auseinandersetzung und Konflikt. So wird der Kreis möglicher Interessenten im schlimmsten Fall auf Personen reduziert, die sich entweder für besonders sachkundig halten oder die in sozialen Situationen generell überdurchschnittlich durchsetzungsfähig sind.

4 Zur Diskussion erschienen von den ursprünglich acht interessierten und fünf verbindlich angemeldeten Personen schlussendlich nur zwei tatsächlich.

5 Hierbei handelt es sich um einen Ort, an dem Angehörige verschiedener Fakultäten (Sozialwissenschaftliche Fakultät, Wirtschaftswissenschaftliche Fakultät, Juristische Fakultät, Philosophische Fakultät, usw.) zwischen Seminarräumen, Vorlesungssälen, Bibliotheken, Cafés und Mensa verkehren.

6 Die unterschiedliche Diskussionsdauer ist durch variierende Ressourcen bei der Incentivierung bedingt. 
angekündigt. Der Pool aus interessierten Personen erhielt teilnehmerbeschränkte URL-Links zu dem Organisationstool doodle, über welches man sich für einen der vorab festgelegten Fokusgruppentermine eintragen konnte. Die Rekrutierungsparameter waren niedrigschwellig gehalten, um unbeabsichtigte Vorsortierungen zu vermeiden: Teilnahmevoraussetzung war die Immatrikulation an einer Universität oder (im Sample marginal) an einer Fachhochschule; Vorsortierungen nach Studienfächern, Alter oder Fachsemesterzahl wurden nicht vorgenommen. So setzt sich das Fokusgruppensample weitgehend zufällig zusammen, was der Absicht einer möglichst heterogenen Gruppenzusammensetzung entspricht. Selbstverständlich ist das Teilnehmersample somit in keinerlei Hinsicht repräsentativ für die gesamtdeutsche Studentenschaft, was den Einsatz methodischer Korrektive erforderlich macht. ${ }^{7}$ In Göttingen fanden die Diskussionen in den Räumlichkeiten des Göttinger Instituts für Demokratieforschung statt und wurden mit den dort verfügbaren technischen Mitteln aufgezeichnet, in Frankfurt a.M. standen die Räumlichkeiten eines externen Dienstleisters mitsamt technischer Betreuung zur Verfügung. Um die Planbarkeit der Diskussionen und die Möglichkeit extrinsischer Teilnahmemotivationen zu gewährleisten, erhielten die Teilnehmer monetäre incentives. Im Rahmen dieser Erhebungswelle konnten so auch jene Studierende zur Teilnahme motiviert werden, die nicht unbedingt primär an der Themensetzung interessiert waren. Zwar ist wohl - wie in jeder sozialwissenschaftlichen Befragungssituation - von einem gewissen Engagierten-bias auszugehen: Zur Teilnahme an solchen Studien erklären sich in der Regel eher gesprächsbereite, eher mitteilungsfreudige, eher kommunikative und eher aufgeschlossene Personen bereit. ${ }^{8}$ Andererseits lässt das in den Fokusgruppen zutage geförderte breite Spektrum von Wahrnehmungen politischer Vorgänge wenig Zweifel an einer ausgewogenen Abbildung unterschiedlichster Sichtweisen. Die ersten fünf Fokusgruppen konnten in den Monaten März, April und Mai 2018 in Göttingen durchgeführt werden, die übrigen zwei im November 2018 in Frankfurt a.M. Ursprünglich waren zehn Fokusgruppen geplant. Nach der Durchführung und Auswertung der siebten Fokusgruppe aber erschien die empirische Sättigung der Erhebungsphase erreicht, ${ }^{9}$ da der bereits vorliegende Datenkorpus und die bisherigen Interpretationshypothesen weitgehend bestätigt

7 Zur Erinnerung: Dies legitimiert sich dadurch, dass hier nach übergreifenden politisch-sozialen Deutungsmustern von Studierenden als gesellschaftlich eingebettetem Kollektivsubjekt gefragt wird und dass standardisierter Fragebogen sowie historisch-empirischer Längsschnitt wesentliche Vergleichsdaten liefern, vgl. Kapitel I.5 dieser Studie. Freilich interessieren im Verlauf der Auswertung Differenzen zwischen den Geschlechtern, unterschiedlichen Fachhintergründen, Studierenden unterschiedlichen Alters und Studienfortschritts, etc. - sofern sie einen strukturbildenden Einfluss auf die Deutungsmuster selbst haben. Ähnlich verfahren auch die angeführten Studien von Schelsky, Habermas et al. und Krause et al., die jeweils nach einem studentischen Cesamtbewusstsein fragen, auch wenn sie im Einzelnen immer wieder auf Studiengangs- und Fächerdifferenzen hinweisen.

8 Die breite Einkommensspanne der Teilnehmenden lässt es unwahrscheinlich erscheinen, dass der finanzielle Anreiz allein insgesamt die maßgebliche Teilnahmemotivation gewesen ist, vgl. Kapitel III.2 dieser Studie. Vielmehr scheint ein entscheidender Faktor der deutlich regeren Teilnahmemotivation die Streuung über das soziale Netzwerk Facebook gewesen zu sein, wie sich auch am dadurch erzielten breiten Fächerprofil der Studierenden erkennen lässt. Vgl. Strübing u. a.: Cütekriterien qualitativer Sozialforschung, S. 88-90. 
wurden und, jenseits einiger vertiefender Details, nicht mehr um substanziell neue Aspekte erweitert werden konnten. Den festgesetzten Diskussionsterminen blieben in der Regel ein bis zwei Personen fern, allerdings nur etwa die Hälfte nach vorheriger Abmeldung (als Grund wurde meist persönliches Planungsversagen oder eine plötzliche Erkrankung angegeben). ${ }^{10}$ Bei jeder Fokusgruppe waren der Verfasser dieser Studie als Gruppenmoderator (I) und eine wechselnde Zahl von Diskutanten (B1 bis B3 bzw. B9) anwesend. In zwei Göttinger Fällen wurden knappe Beobachtungsprotokolle von einem ebenfalls anwesenden Protokollanten (P) angefertigt, die bei der Verarbeitung und Reflexion der ersten Eindrücke halfen. Der Verlauf der Diskussion richtete sich weitgehend nach dem überarbeiteten Themenkatalog: Auf eine kurze Begrüßung und Vorstellungsrunde ${ }^{11}$ (1.) folgte, der Phase der „Annäherung“ mit ihrem Erfordernis eines niedrigschwelligen Diskussionseinstiegs entsprechend, ein Block (2.) zu Studienmotivation, Studienwahrnehmung und (Aus-)Bildungsverständnis. Die Teilnehmer wurden hier aufgefordert, über ihre wesentlichen Motivationen zur Aufnahme eines Studiums und über ihre damaligen Erwartungen ans Studium und an das Studentenleben zu sprechen, bevor das Gespräch auf die positiven und negativen Aspekte der tatsächlich erlebten Studiensituation gelenkt wurde. Der Block zielt damit nicht nur auf Stereotype und Ideale des Studierens, sondern auch auf die grundierenden Werthaltungen der eigenen Lebensplanung, schließlich auf das studentische Verständnis von universitärer (Aus-)Bildung zwischen den Polen Humboldt'scher Persönlichkeitsbildung und karriereorientierter Leistungsbereitschaft. Anschließend wandte sich das Gespräch, nun zumeist in das dynamischere Stadium der „Vertrautheit“ eingetreten, dem Bereich gesellschaftspolitischer Themen zu. Eingeführt wurde dieser Block (3.) mit der Frage, welche aktuellen gesellschaftlichen Probleme die Fokusgruppenteilnehmer persönlich beschäftigen. Sodann wurde versucht, die allgemeine Sichtweise der Befragten auf Politik bzw. auf das Politische hervorzulocken, und zwar über die Frage, ob Politik (deutungsoffen und abstrakt gehalten) einen wichtigen Faktor in der persönlichen Alltagserfahrung darstellt. Im Rahmen dieses Themenkreises wurde auch der unmittelbare Übergang zur anspruchsvolleren Thematik des Demokratieverständnisses, des Demokratie-Erlebens und ggf. auch der Demokratie-Kritik vollzogen. Gewiss erfolgt dieser Schwenk spät; der Grund dafür liegt in der aus dem Pretest gefolgerten Annahme, dass stärker affektive und subjektive Deutungsgehalte über politische und gesellschaftliche Vorgänge eher zurückbehalten als geäußert werden, ja einem eher rationalistischen und theoretisierenden Gesprächsstil weichen, wenn sich die Diskussion zu früh einem eher honorigen Begriff wie dem der Demokratie zuwendet. Um dieses stets drohende Einrasten in ein eher „bequemes“ Reden über Themen, die dem eigenen Alltagserleben fernzustehen scheinen, nochmals zu irritieren, wird dieser Block mit der Einführung eines konkreten Handlungsproblems beendet, konkret mit der Bitte

10 Vereinzelte Nachfragen zeigten in diesem Zusammenhang, dass Irritationen bei dem Anmeldeverfahren mit dem Terminfindungstool doodle auftraten, etwa weil manche Personen auf eine weitere Anmeldebestätigung warteten oder andere den Termin vergaßen, für den sie sich eingetragen hatten.

11 In der 4. Fokusgruppe wurde testweise auf die namentliche Vorstellungsrunde verzichtet, da einige Teilnehmerinnen bereits vorher ins persönliche Gespräch kamen. Dies hatte allerdings eine zähere Annäherungsphase zur Folge. 
an die Diskussionsteilnehmer, Einschätzungen über einen adäquaten Umgang mit der AfD in den Parlamenten abzugeben. Abschließend wurden in dieser späten Phase der „Konformität“ die Befragten aufgefordert, ihre Vorstellungen einer idealen, d. h. utopischen Gesellschaft zu äußern (4.) Dieser letzte Teil erwies sich als unergiebig und wurde daher im Verlauf der Erhebung schließlich fortgelassen. ${ }^{12}$ Über die thematischen Vorgaben hinaus wurden keine sonstigen - etwa mediale - Diskussionsanreize eingesetzt.

Im Anschluss an die Diskussion wurden die Fokusgruppenteilnehmer gebeten, einen begleitenden standardisierten Fragebogen auszufüllen, der Angaben zu objektiven Daten wie Alter, Geschlecht, Studienfach, Einkommen, Wohnverhältnis, Mitgliedschaft in politischen und zivilgesellschaftlichen Organisationen sowie zum Wahlverhalten abfragt. Die hier erhobenen Daten geben Aufschluss über den erzielten Realitätsausschnitt des Fokusgruppensamples. Darüber hinaus enthielt der Fragebogen ein Freifeld für weiterführende Anmerkungen oder potenzielle Kritik, von welchem allerdings insgesamt kaum Gebrauch gemacht wurde. ${ }^{13}$

Die Gruppengespräche wurden per Bild und Ton aufgezeichnet und anschließend nach den Transkriptionsregeln einfacher inhaltlich-semantischer Transkripte (vollständig, wörtlich, Bereinigung von Störlauten und kleineren Fehlern, Kennzeichnung auffälliger Pausen, behutsame Korrekturen zugunsten der Lesbarkeit) ${ }^{14}$ vom Verfasser dieser Studie verschriftlicht. So entstanden aus ca. 12 Stunden Videomaterial 480 Seiten Transkript, die mithilfe der Software MaxQDA deduktiv sowie induktiv kodiert und schließlich $\mathrm{zu}$ fallimmanenten wie fallübergreifenden Thesen verarbeitet wurden. Ein erster Auswertungsschritt des Transkribierens, Kodierens und der Bildung von Arbeitshypothesen wurde nach der Durchführung der fünf Göttinger Fokusgruppen vorgenommen, ein zweiter nach der Durchführung der Frankfurter Fokusgruppen. Als Beispiel einer induktiv entdeckten „Schlüsselkategorie ${ }^{\text {“15 }}$ beim Herauspräparieren der Bedeutungskomponenten des (deduktiv eingeführten) Bildungsbegriffs ergab sich

12 Mehr noch, die Frage nach utopischen Vorstellungen einer idealen Gesellschaft wirkte in den entsprechenden Fokusgruppen als beinahe überfordernd abstrakter und gewaltsamer Import in die bis dahin fluide Gesprächsdynamik. Allein aus methodischen Gründen erfüllte sie ihren Zweck nicht, wird doch in Fokusgruppen überhaupt Wert auf eine möglichst hohe Selbstläufigkeit des Cesprächs gelegt; so griff denn auch der Moderator auf die Vertiefungsfragen immer nur dann zurück, wenn sie dem diskursiven stream of consciousness nicht mehr Gewalt antun mussten als für den Erhalt des thematischen Fokus notwendig; selbst die Reihenfolge der zentralen Themen musste er als variabel ansehen, wenn die Diskussion sich etwa frühzeitig auf politische Aspekte zubewegte.

13 Neben einigem Lob und wenigen kritischen Anmerkungen beklagten zwei Personen hier die Binarität der Ceschlechterauswahl „männlich/weiblich“ bzw. das Fehlen einer dritten Antwortoption. Da aber weder sie noch sonst jemand persönliche gender-bezogene Selbstzuordnungsschwierigkeiten hatte, scheint es sich hier mehr um eine symbolische Ermahnung zur political correctness gehandelt zu haben.

14 Vgl. Dresing, Thorsten/Pehl, Thorsten: Praxisbuch Interview, Transkription \& Analyse. Anleitungen und Regelsysteme für qualitativ Forschende, Marburg, 2018, S. 20-26, online einsehbar unter: https://www.audiotranskription.de/download/praxisbuch_transkription.pdf?q= Praxisbuch-Transkription.pdf [zuletzt eingesehen am 01.08.2019] sowie Mayring: Einführung in die qualitative Sozialforschung, S. 57.

15 Przyborski/Wohlrab-Sahr: Qualitative Sozialforschung, S. 211. 
etwa die Verhandlung von (politischer) Bildung als gesellschaftspolitisches Panazee. ${ }^{16}$ Die verschriftlichten Auswertungskapitel ${ }^{17}$ stellen das Ergebnis der im Verlauf des Erhebungs- und Auswertungsprozesses fortlaufend geübten Sichtung, Ergänzung und auch Revision der sich aus der Durchsicht der Transkripte sowie aus der Codierung ergebenden Eindrücke, Notizen, Interpretationen und Hypothesen dar. Für korrigierende Skepsis an den eigenen Interpretationen sorgte, wie bereits erwähnt, die Berücksichtigung des über den begleitenden standardisierten Fragebogen skizzierten Realitätsausschnitts der Fokusgruppenteilnehmer sowie der kontinuierliche Vergleich mit dem zuvor herausgearbeiteten historisch-empirischen Längsschnitt.

\section{III.2 Die Fokusgruppenteilnehmer in Zahlen}

Zur Veranschaulichung und zur Beurteilung des erzielten Realitätsausschnitts werden hier ausgewählte Daten auf der Basis des begleitenden standardisierten Fragebogens zusammengefasst, grafisch aufbereitet und mit repräsentativen Daten verglichen. Ansatzpunkte für statistisch generalisierende Aussagen oder Schlüsse bietet das Fokusgruppensample bei einer Teilnehmerzahl von $n=44$ ausdrücklich nicht, weswegen die folgenden Angaben primär in absoluten Zahlen (tatsächliche Fälle) gefasst und nur sekundär durch entsprechende Prozentwerte illustriert werden.

Zunächst $\mathrm{zu}$ den sozialstrukturellen Basisdaten. Mit 25 Teilnehmerinnen und 19 Teilnehmern befindet sich im Sample zwar ein leicht weiblicher Überhang von ca. 56 Prozent; im Vergleich mit der im repräsentativen Studierendensurvey erzielten geschlechtlichen Asymmetrie, die auf ein Verhältnis von einem Drittel männlicher zu zwei Dritteln weiblicher Befragter tendiert (2001: 55 Prozent weiblich, 45 Prozent männlich; 2010: 58 Prozent weiblich, 42 Prozent männlich; 2016: 63 Prozent weiblich, 37 Prozent männlich), ${ }^{18}$ fällt die Zusammensetzung des hier ausgewählten Samples allerdings verhältnismäßig ausgeglichen aus. Es scheint sich hierbei um einen strukturellen Effekt studentischer Teilnahmebereitschaft an sozialwissenschaftlichen Studien zu handeln.

Demgegenüber geben Alter und Studienfortschritt der Gesprächsteilnehmer zum Zeitpunkt der Gruppendiskussion durchaus Hinweise auf spezifische Konturen des hier ausgewerteten Realitätsausschnitts. Der größte Teil der Diskutanten (mit 28 Personen ca. 63 Prozent) ist zwischen 22 und 25 Jahren alt, im Studierendensurvey traf das zuletzt auf nur 43 Prozent der Befragten zu. ${ }^{19}$ In Verbindung mit dem im Fragebogen dokumentierten Studienfortschritt - die übergroße Mehrheit derjenigen, die die Frage beantwortet haben, ${ }^{20}$ befindet sich mindestens im dritten Fachsemester - ist davon

16 Weitere über den Themenkatalog hinausgehende induktive Codes werden im Fortgang der Auswertung erläutert.

17 Vgl. Kapitel III.3 dieser Studie.

18 Vgl. Datenalmanach Studierendensurvey 2017, S. 3. Die zitierten Zahlen gelten für das Befragtenspektrum an Universitäten.

19 Vgl. ibid., S. 4.

20 Auf welche Gründe die relativ hohe Antwort-Verweigerungsquote von ca. 43 Prozent zurückzuführen ist, konnte nicht geklärt werden. Indes liegt die Vermutung nahe, dass tendenziell eher 
auszugehen, dass hauptsächlich erfahrenere Studierende mitdiskutiert haben, welche die Abläufe und Strukturen ihres Studiums zumindest bereits haben kennenlernen können. Unterstrichen wird das durch die relativ geringe Zahl an Studienanfängern unter 22 Jahren im Sample, eine Gruppe, die mit 8 Personen (ca. 18 Prozent) deutlich schwächer vertreten ist als im Studierendensurvey (dort jüngst mit 29 Prozent), wiederum aber auch konterkariert durch die mit ebenfalls 8 Personen (ca. 18 Prozent) schwach vertretenen Spät- und Langzeitstudierenden ab 26 Jahren, welche sich im Studierendensurvey zuletzt auf 27 Prozent summierten. ${ }^{21}$ Das ist mit Blick auf die eventuell gesammelten Frustrations- wie Erfolgserfahrungen während des Studiums sowohl für die Frage nach der perzipierten Gültigkeit von Leistungs- und Bildungsidealen, besonders der Chancengerechtigkeit o. Ä., als auch für die erwarteten Status- und Berufsaussichten mitunter von Relevanz.

Die Daten zum sozialen und bildungsmäßigen Hintergrund der Fokusgruppenteilnehmer scheinen im Großen und Ganzen die in Kapitel II.1.4 herausgearbeitete aktuelle Situation des Zugangs zu Hochschulbildung zu spiegeln. Die überwältigende Mehrheit derjenigen, die studieren, hat zuvor eine Hochschulzugangsberechtigung auf dem Ersten Bildungsweg, also Fachhochschulreife oder Allgemeine Hochschulreife, erworben. Höchstwahrscheinlich zählen auch diejenigen, die bereits ein Hochschulzeugnis vorweisen können (sämtlich Masterstudierende), dazu; gerade einmal 3 Personen (knapp 7 Prozent) im Sample begannen ihr Studium nach abgeschlossener Berufsausbildung, davon nur eine auf dem Zweiten Bildungsweg. Allerdings: Nur ein gutes Drittel der Teilnehmer (16 Personen, also ca. 36 Prozent) stammt aus einem akademischen oder teilakademischen Elternhaus, verglichen mit jüngst 45 Prozent im Studierendensurvey und sogar 66 Prozent in der aktuellen Sozialerhebung. ${ }^{22}$ Somit sind zwar die Bildungsaufsteiger im Vergleich mit den Survey-Daten hier leicht überproportional vertreten, dennoch gilt offenbar auch für die Fokusgruppenteilnehmer: Wer sein Abitur in der Tasche hat, geht mit hoher Wahrscheinlichkeit studieren, hat er doch die im deutschen Bildungssystem entscheidende Selektionshürde überwunden und den verheißungsvollen Chancenmotor der Gymnasialbildung bemeistert. ${ }^{23}$

Die augenfälligste Selektivität des Samples liegt in den vertretenen Studienfächern. Studierende der Sozial-, Geistes-, und Sprachwissenschaften bilden hier eine Mehrheit von insgesamt 25 Personen (knapp 57 Prozent), während sie im Studierendensurvey zuletzt nur 37 Prozent der Befragten ausmachten. ${ }^{24}$ Ausgleichend wirkt allerdings die Tatsache, dass sich die Studierenden der Wirtschaftswissenschaften, der Rechtswissenschaften sowie der Natur- und Biowissenschaften - Gruppen, die wie gesehen trotz abgeschliffener Konfliktlinien immer wieder als politisch-weltanschauliche Kontrahenten der Sozial- und Geisteswissenschaftlichen Fakultäten beschrieben werden ${ }^{25}-$ mit $^{2}$

Studierende mit hoher Fachsemesterzahl ungerne Auskunft über ihren Studienfortschritt erteilen.

21 Vgl. ibid.

22 Vgl. ibid., S. 9; 21. Sozialerhebung, S. 27.

23 Wolter: Eigendynamik und Irreversibilität der Hochschulexpansion, S. $28 f$.

24 Vgl. Datenalmanach Studierendensurvey, S. 6.

25 Vgl. noch einmal exemplarisch Bargel/Simeaner: Gesellschaftliche Werte und politische Orientierungen, S. 10. 
17 Personen auf immerhin auf knapp 39 Prozent summieren (im Studierendensurvey bildeten sie jüngst 46 Prozent der Befragten ${ }^{26}$ ). Nur zwei Personen, die einen sozialen Beruf über das Fachhochschulstudium anstreben, durchbrechen diese prospektive dualistische Konfrontation grober Studienrichtungen mitsamt der sich an sie (womöglich) heftenden Mentalitätsdifferenzen. Zu beklagen ist allerdings das vollständige Fehlen angehender Ingenieure und Mathematiker im Sample.

Die Verteilung der Lebensverhältnisse der Studierenden - gemessen am persönlichen Netto-Einkommen, an der Wohnsituation und am Partnerschaftsverhältnis erscheinen unauffällig, ja beinahe durchschnittlich. In der aktuellen Sozialerhebung des Deutschen Studentenwerks verfügen die befragten Studierenden im Schnitt über 918 Euro monatlich, ${ }^{27}$ was zwar mit der hier verwendeten Skala nicht direkt vergleichbar ist, zumindest aber auch nicht unvereinbar erscheint: 31 Personen, ca. 70 Prozent, verfügen über Einkünfte zwischen 500 und 1.000 Euro im Monat. Über Einkunftsquellen, Alters- und Sozialverteilung ist damit freilich noch nichts gesagt. Dass mit 38 Personen etwa 86 Prozent des Samples in Wohngemeinschaften mit Partnern oder Bekannten, in Wohnheimen oder bei den eigenen Eltern leben, befindet sich im Einklang mit den in der Sozialerhebung ausgewiesenen 83 Prozent. ${ }^{28}$ Allein lebende Studierende bilden dort (17 Prozent) wie hier (6 Personen, knapp 14 Prozent) die Ausnahme. Allerdings: Der angesichts repräsentativer Zahlen bekundete steigende Anteil alleinstehender Studierender findet sich im Fokusgruppensample nicht wieder. Befinden sich dort 46 Prozent in einer festen Partnerschaft, ${ }^{29}$ sind es hier mit 25 Personen immerhin knapp 57 Prozent. In summa wird die übliche Vielfalt studentischer Lebensverhältnisse durch den hier erzielten Realitätsausschnitt aber doch abgedeckt.

Wie verhältnismäßig fallen Konfessionszugehörigkeit, zivilgesellschaftliche Einbindung und politischen Präferenzen der Fokusgruppenteilnehmer aus? Zur Konfession: In Ermangelung direkter Vergleichszahlen können hier nur vorsichtige Überlegungen angestellt werden. 21 Personen (knapp 48 Prozent) im Sample sind konfessionslos, 13 von ihnen (knapp 30 Prozent) evangelisch-lutherischer, 9 römisch-katholischer Konfession (knapp 21 Prozent), eine Person rechnete sich selbst dem Islam zu. Demgegenüber weist die Forschungsgruppe Weltanschauungen in Deutschland (fowid) zum Jahresende 2017 u. a. einen Anteil von 37 Prozent Konfessionslosen, von 28 Prozent Angehörigen der römisch-katholischen Kirche und von 26 Prozent Angehörigen der evangelisch-lutherischen Kirche in der Gesamtbevölkerung aus - neben ungefähr 5 Prozent konfessionsgebundenen Muslimen. ${ }^{30}$ Zwar korrespondieren diese Zahlen nicht direkt, widersprechen sich aber auch nicht fundamental; größere Verzerrungseffekte stehen nicht

26 Vgl. Datenalmanach Studierendensurvey 2017, S. 6.

27 Vgl. 21. Sozialerhebung, S. 39. Die Daten beziehen sich auf den sogenannten „Fokus-Typ“, d. h. auf individuell wirtschaftende, unverheiratete Vollzeitstudierende, vgl. ibid., Fn. 1.

28 Vgl. ibid., S. 64. Zusammengezählt sind hier 21 Prozent, die mit ihrem Partner zusammenwohnen, 30 Prozent Bewohner von Wohngemeinschaften, 12 Prozent Wohnheim-Bewohner und 20 Prozent, die noch bei ihren Eltern wohnen.

29 Vgl. ibid., S. 24.

30 Forschungsgruppe Weltanschauungen in Deutschland (fowid): Religionszugehörigkeiten in Deutschland 2017, 08.10.2018, online einsehbar unter: https://fowid.de/meldung/religionszugehoerigkeiten-deutschland-2017 [eingesehen am 01.08.2019] 
zu vermuten. Zum Engagement: Die meisten Studierenden (mit 40 Personen knapp 91 Prozent) des Fokusgruppensamples engagieren sich bürgerschaftlich bzw. zivilgesellschaftlich, sei es in Ehrenämtern, in Vereinen, oder in Parteien, Parteijugenden, und Hochschulgruppen; einige unter ihnen mehrfach. Dies passt zu den Beobachtungen des Zweiten Engagementberichts der Bundesregierung von 2017, welcher unter Verweis auf den so genannten Freiwilligensurvey 2014 bemerkt, dass höher Gebildete (neben Berufstätigen und Ruheständlern) allgemein zu den ressourcenstärksten und damit engagiertesten Gruppen in der Bundesrepublik gehören. ${ }^{31} \mathrm{Zu}$ den politischen Präferenzen: 19 Studierende gaben im Rahmen einer Mehrfachauswahl ${ }^{32}$ an, im Zuge der zum Befragungszeitpunkt nur ein halbes bzw. ganzes Jahr zurückliegenden Bundestagswahl von 2017 die Grünen gewählt zu haben, 6 die Linke und 5 die SPD (insgesamt 30 Personen, also ca. 68 Prozent) - gegenüber 6 CDU/CSU-Wählern, 3 FDP-Wählern und einer AfD wählenden Person (zusammen 10 Personen, ca. 23 Prozent). Für die kommende Bundestagswahl („Sonntagsfrage“) weicht das Muster aufgrund der vielen noch Unentschlossenen ab, ergibt aber grosso modo dasselbe Gesamtbild. Aus dem Sample spricht eine deutliche hegemoniale sozialdemokratisch-grüne Grundtendenz politischer Präferenzen. Ist daraus ein politisch-weltanschaulicher bias zu folgern? Die Frage zu beantworten fällt schwer, da es an repräsentativen Vergleichsdaten zum Wahlverhalten Studierender mangelt. Zieht man die Online-Erhebung des Studierendensurveys von 2010 als halbwegs aktuelle Datenquelle heran, so fällt zunächst auf, dass sich 67 Prozent der Studierenden an Universitäten - aufgefordert, sich im klassischen politischen Richtungsschema zu positionieren - in der politischen „Mitte“ verorten, während nur 20 Prozent sich „links" und lediglich 3 Prozent sich „rechts" sahen. ${ }^{33}$ Gleichwohl: Ebendiese befragten Studierenden gaben auch an, „christlich-konservative“ und "national-konservative“ politische Grundhaltungen zu 49 bzw. 86 Prozent „eher“ bis „völlig“ abzulehnen, während sie „sozialdemokratischen“ und „grünen/alternativen“ Grundhaltungen zu 57 bzw. 59 „eher“ bis „völlig“ zustimmten. ${ }^{34}$ Angesichts dieser Zahlen erscheint die Vermutung naheliegend, dass deutsche Studierende (noch immer!) generell mehrheitlich grün, sozialdemokratisch oder links „eingestellt" sind - wenn auch gebrochen durch die nicht gänzlich auszuschließende Möglichkeit, dass es vor allem traditionalistisch „eingestell-

31 Vgl. Bundesministerium für Familie, Senioren, Frauen und Jugend (BMFSF], Hg.): Zweiter Bericht über die Entwicklung des bürgerschaftlichen Engagements in der Bundesrepublik Deutschland. Schwerpunktthema: ,Demografischer Wandel und bürgerschaftliches Engagement: Der Beitrag des Engagements zur lokalen Entwicklung“. Drucksache 18/11800 des Deutschen Bundestages in der 18. Wahlperiode, Berlin 30.03.2017, S. 174. Dieser Effekt macht sich schon in der schulischen Bildung geltend: „Während sich von den einfach Gebildeten nur 42 Prozent schon einmal auf eine der genannten Weisen politisch beteiligten, haben das von den Bürgerinnen und Bürgern mit höheren Schulabschlüssen 72 Prozent getan." Ibid., S. 172. Vgl. hier auch Simonson, Julia/Hameister, Nicole: Sozioökonomischer Status und freiwilliges Engagement, in: Simonson, Julia/Vogel, Claudia/Tesch-Römer, Clemens (Hg.): Freiwilliges Engagement in Deutschland. Der Deutsche Freiwilligensurvey 2014. Endbericht, DZA Berlin 2016, S. 429-454, insbesondere S. 439 und $451 \mathrm{f}$. Vertiefende Informationen zur Verteilung auf Erst- und Zweitstimmen liegen hier nicht vor.

33 Vgl. Bargel/Simeaner: Gesellschaftliche Werte und politische Orientierungen, S. 58. 11 Prozent gaben an, diese Frage nicht beurteilen zu können. Ibid., S. 60. 
te" Studierende sind, die den Befragungen des Studierendensurveys in den letzten Jahren ihre Teilnahmebereitschaft entziehen. ${ }^{35}$

Die Zahlen sprechen insgesamt für ein Sample "durchschnittlicher" Studierender. Zwar sind durch die Absenz von Studierenden der Ingenieurswissenschaften und der Mathematik nicht alle Studienbereiche vertreten, doch gibt es auf der Grundlage der sozialstrukturellen Daten keinen Anlass, die Vernachlässigung spezifischer, statistisch signifikanter Teilgruppen zu beklagen. Insbesondere die Sorge, dass die hier erzielte Zufallsauswahl von irregulären „Ausreißern“ dominiert sein könnte, erscheint unbegründet. Unterstrichen wird diese optimistische Schlussfolgerung dadurch, dass auch drei Personen mit ausländischer Herkunft sowie vier Personen mit immigrierten Eltern oder Großeltern im Sample vertreten sind.

Abb. 21: Geschlecht der Fokusgruppenteilnehmer*

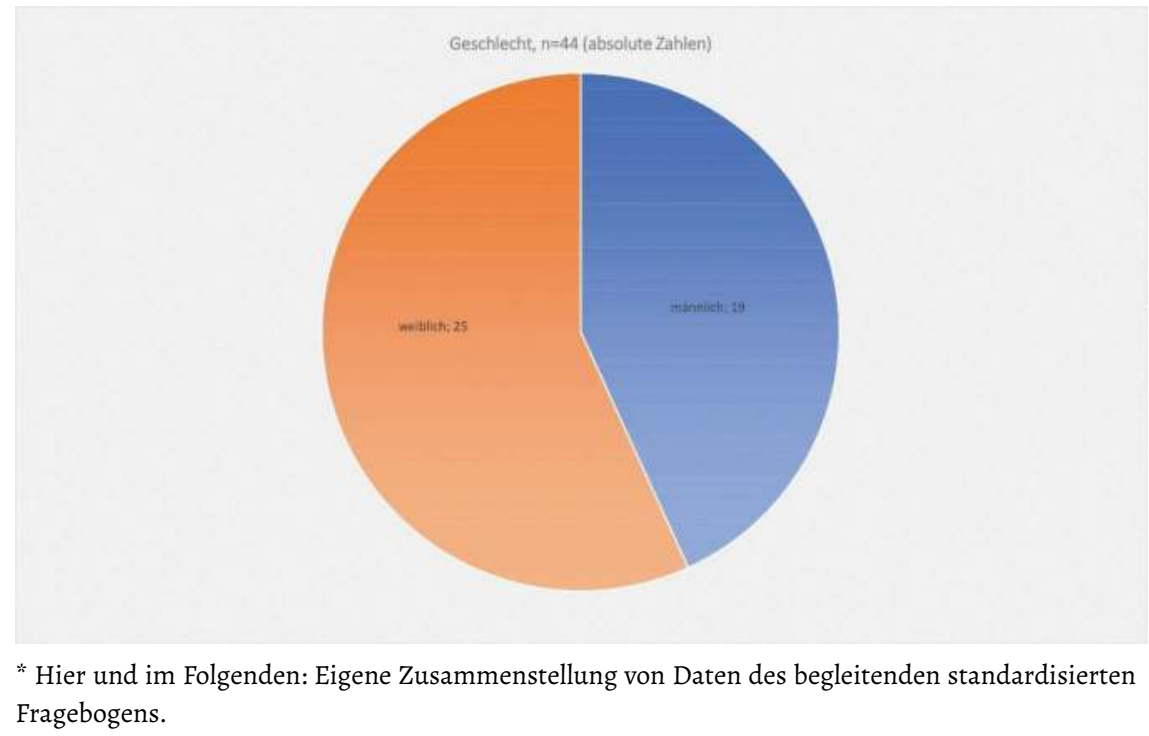


Abb. 22: Alter der Fokusgruppenteilnehmer

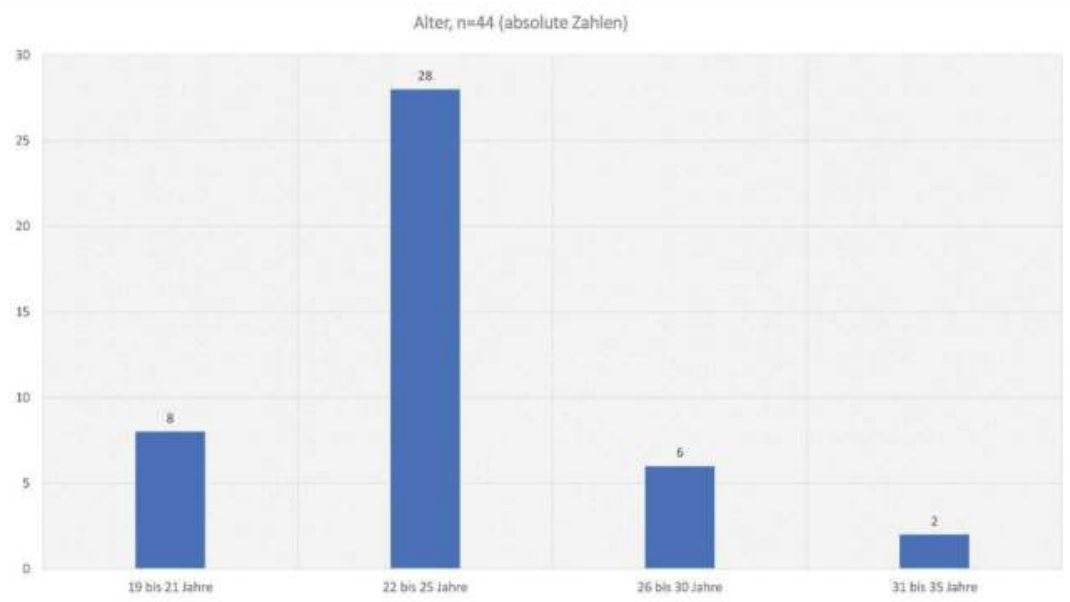

Abb. 23: Fachsemester der Fokusgruppenteilnehmer

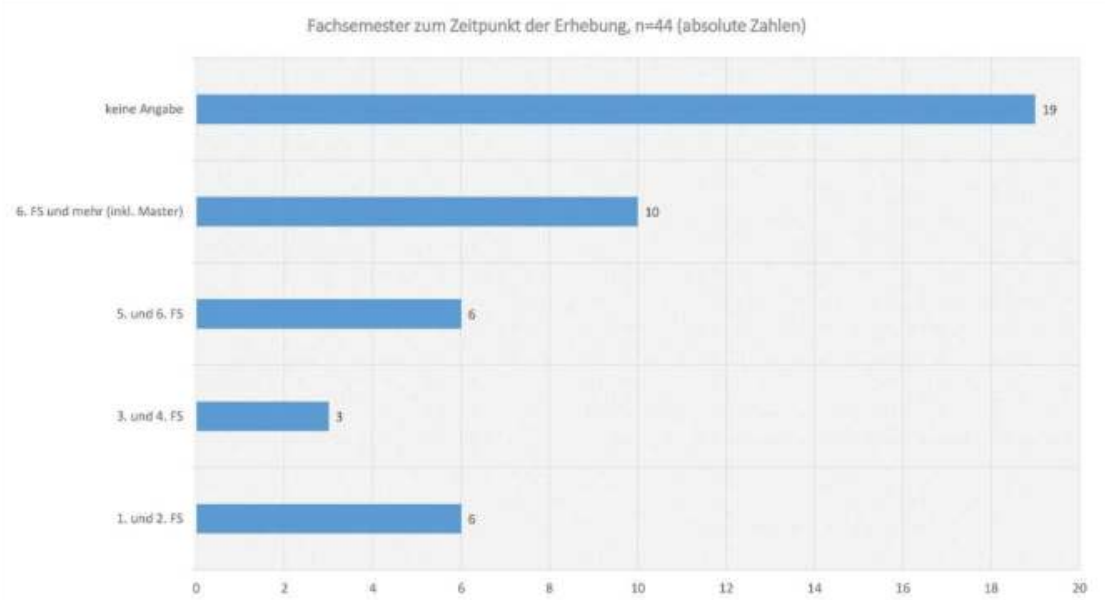


354 Student und Demokratie

Abb. 24: Höchster erreichter Bildungsabschluss der Fokusgruppenteilnehmer

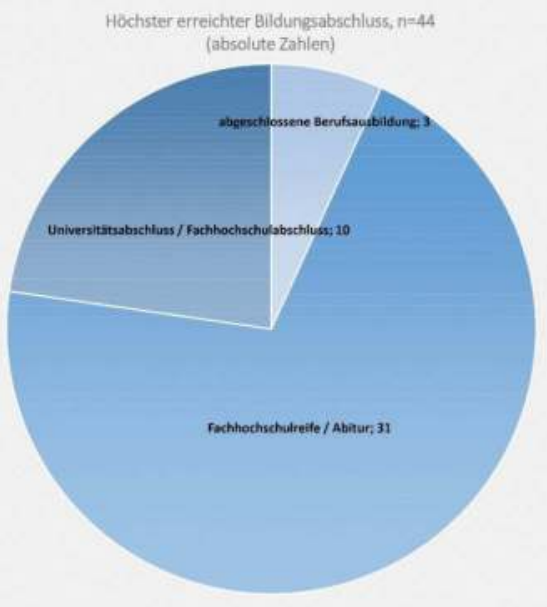

Abb. 25: Berufliche Tätigkeit der Mutter

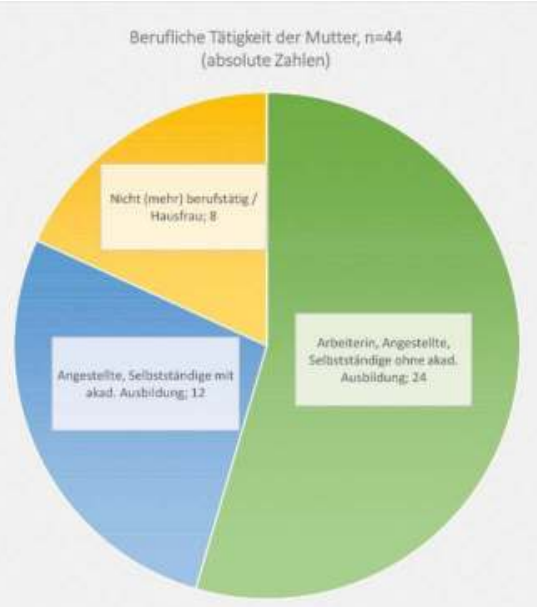


Abb. 26: Berufliche Tätigkeit des Vaters

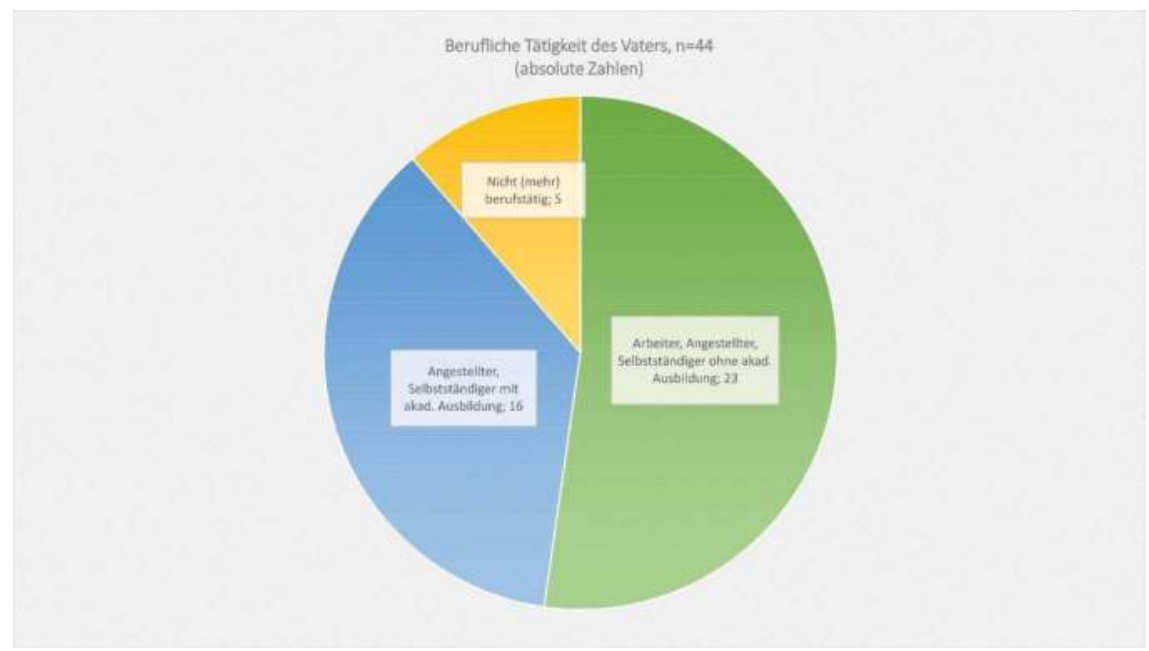

Abb. 27: Studienfächer der Fokusgruppenteilnehmer

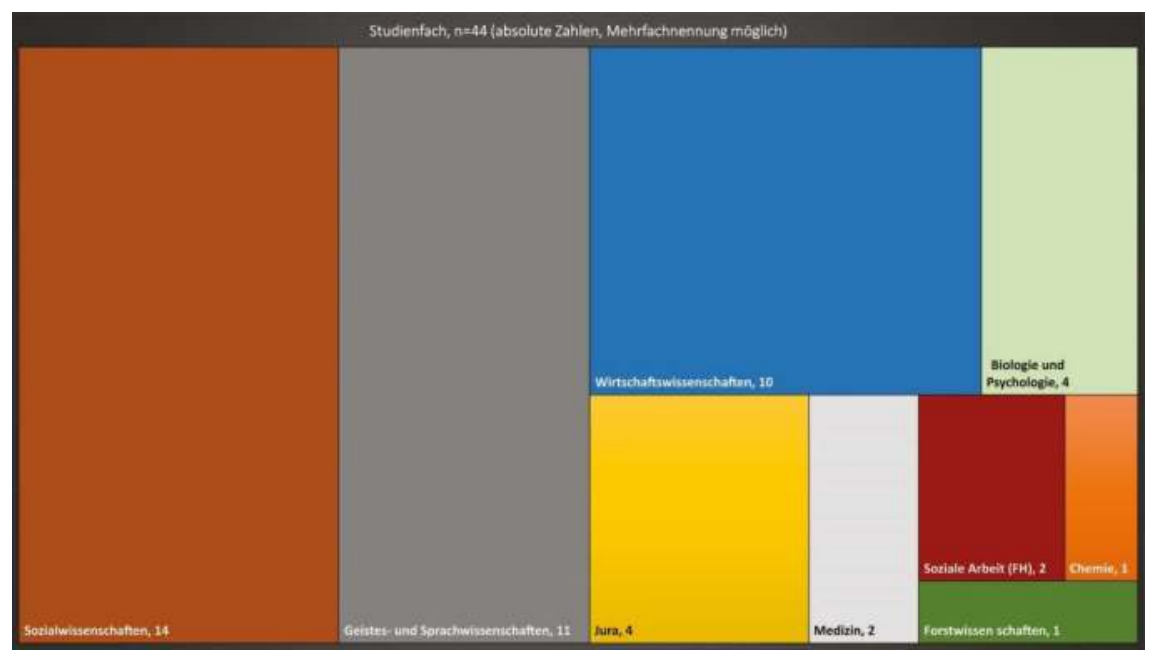


356 Student und Demokratie

Abb. 28: Persönliches Netto-Einkommen der Fokusgruppenteilnehmer

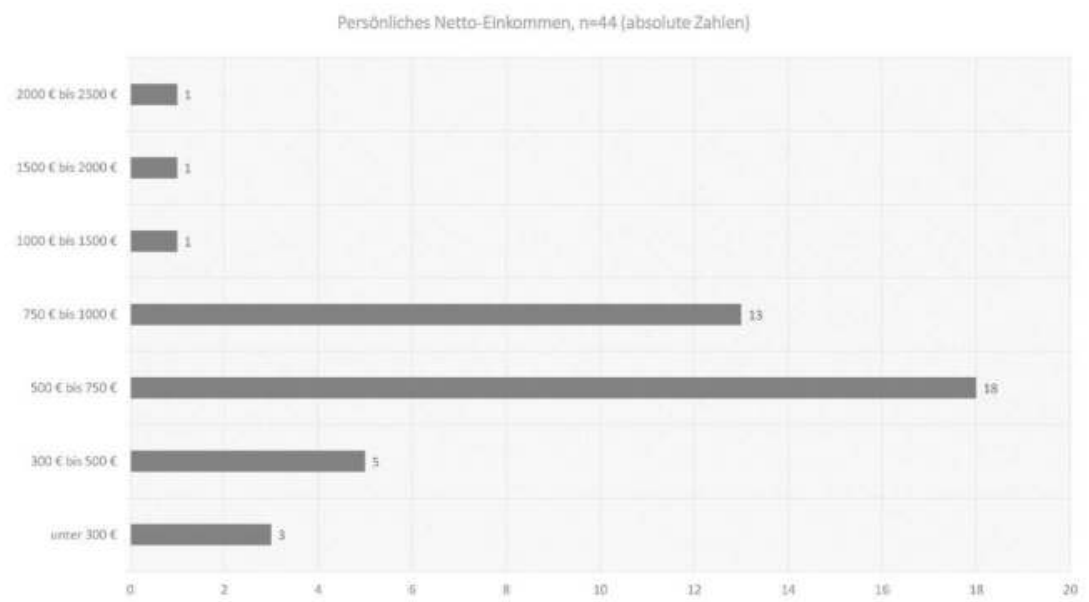

Abb. 29: Wohnverhältnis der Fokusgruppenteilnehmer

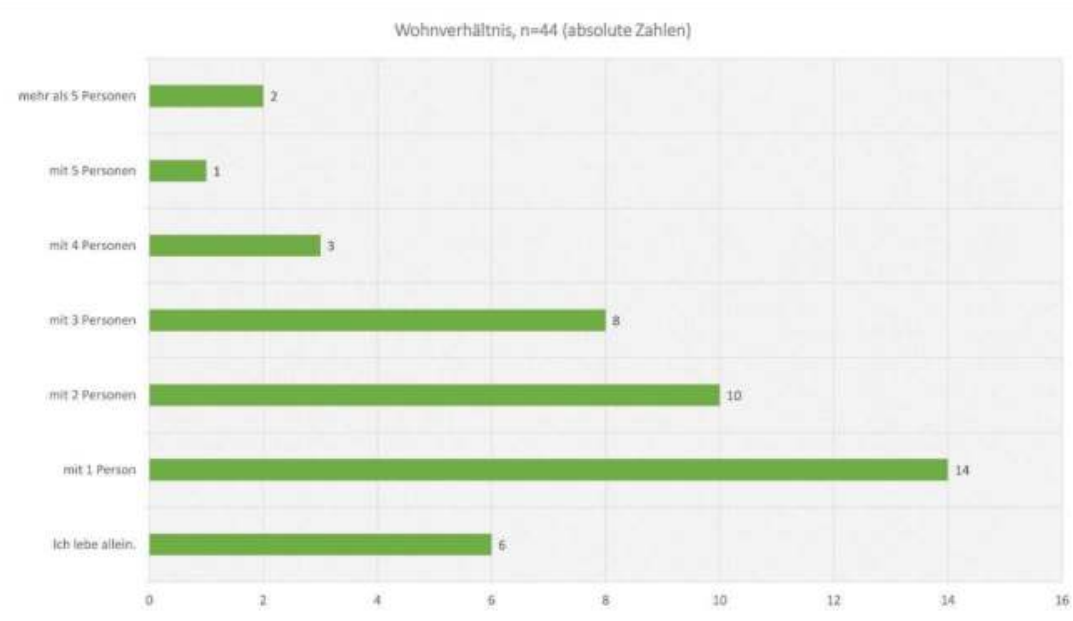


Abb. 30: Partnerschaftsstatus der Fokusgruppenteilnehmer

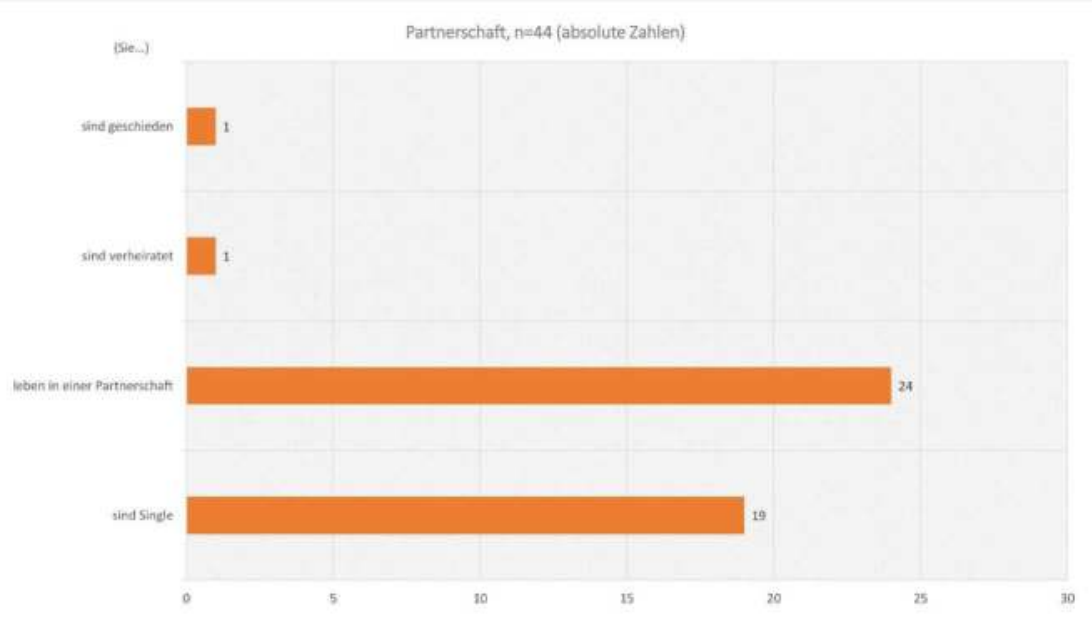

Abb. 31: Konfessionszugehörigkeit der Fokusgruppenteilnehmer

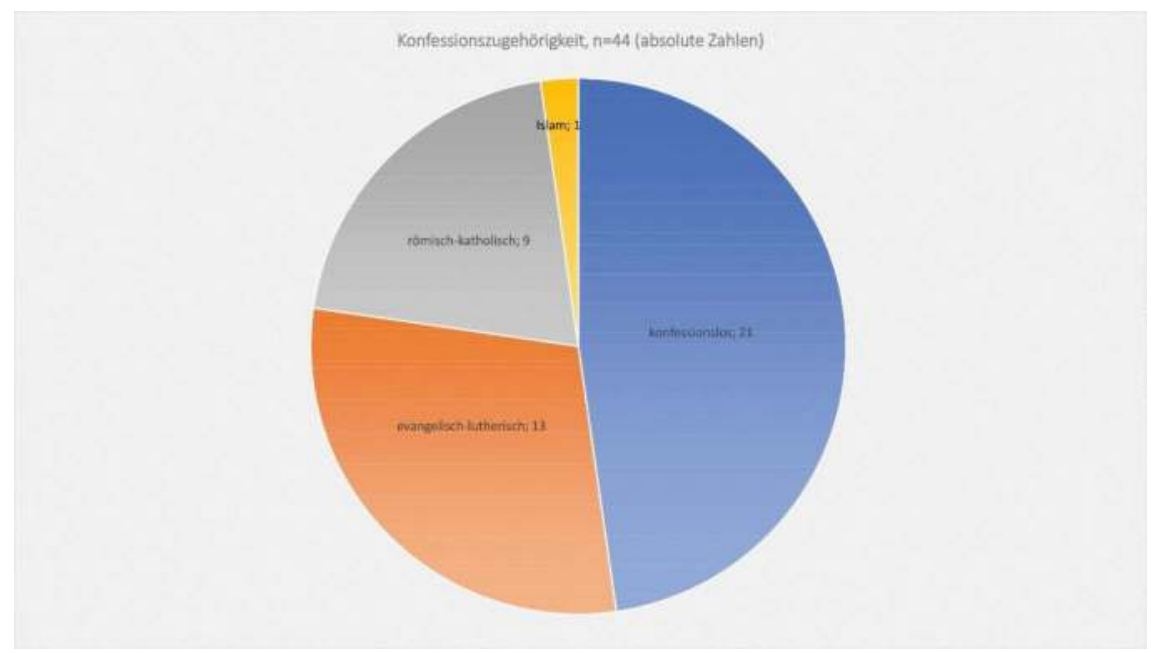


358 Student und Demokratie

Abb. 32: Zivilgesellschaftliches Engagement der Fokusgruppenteilnehmer

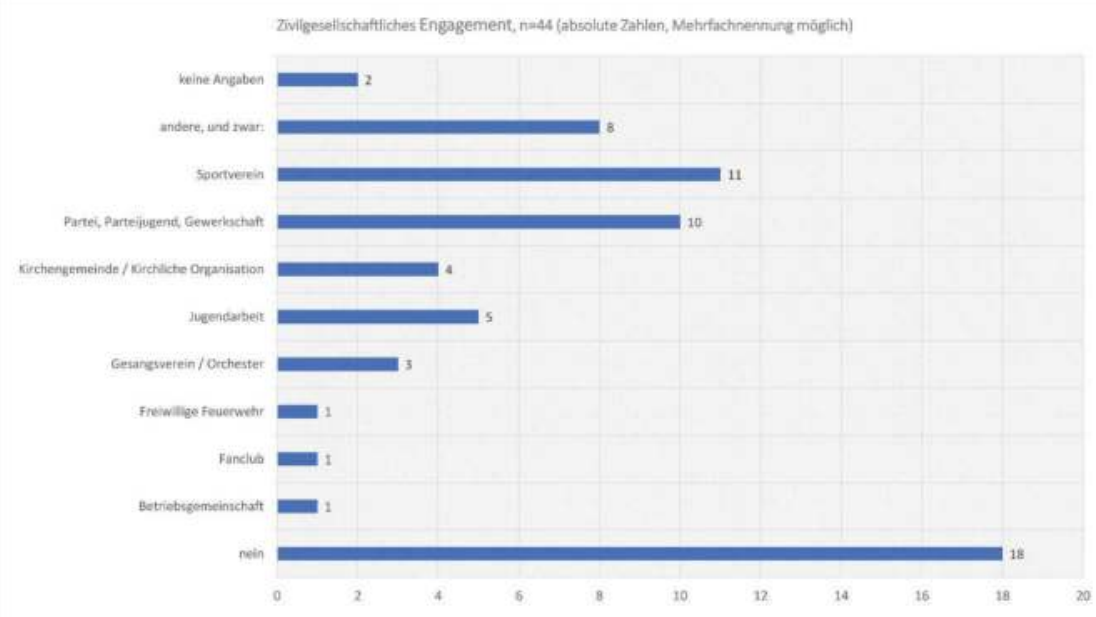

Abb. 33: Wahlverhalten bei der letzten Bundestagswahl

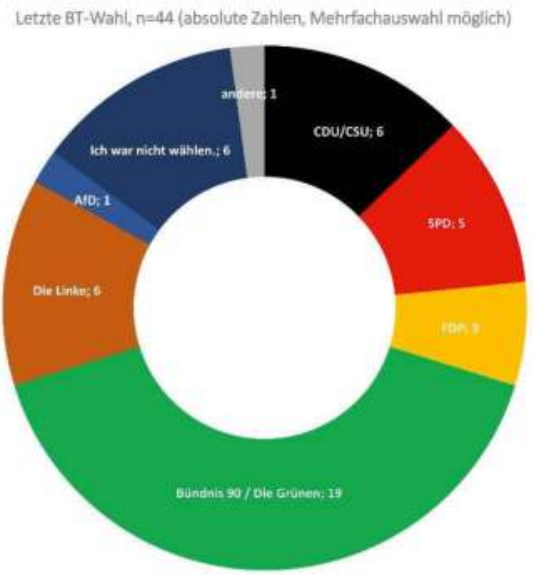


Abb. 34: Prospektives Wahlverhalten bei der nächsten Bundestagswahl

Nächste BT-Wahl, $n=44$ (absolute Zahlen, Mehrfachauswahl möglich;

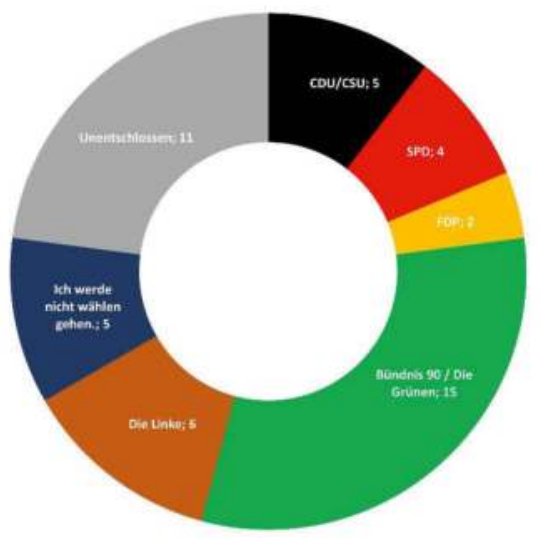




\section{III.3 Politisch-soziale Deutungsmuster von Studierenden 2018}

Gemäß dem hier gewählten qualitativen Forschungsparadigma galt es, sämtliche Interpretationen schrittweise und im Verlauf des Erhebungs- wie Auswertungsprozesses zu entwickeln. So wurden Beobachtungen und Thesen notiert, fortlaufend geprüft und mit neuen Ergebnissen konfrontiert, schließlich gegebenenfalls erweitert, verworfen, ergänzt oder ersetzt. Die in den folgenden Kapiteln vorgestellten Resultate sind somit das Ergebnis eines mehrschrittigen Vorgehens.

So wird die nun folgende Auswertung, ein kontinuierlicher Doppelschritt aus Deskription und Interpretation der Diskussionsverläufe, zwar von den bisher erarbeiteten und im Themenkatalog in die Fokusgruppen eingespeisten Aspekten des politischen Potenzials von Studierenden ausgehen. Gleichzeitig verfolgt sie aber auch den Anspruch, sich für neue Impulse zu öffnen, die dem Fokusgruppenmaterial entsteigen. Dazu zählen einerseits Beobachtungen, Perspektiven, und Zusammenhänge, die von den Befragten selbst ins diskursive Spiel gebracht (etwa in Gestalt unerwarteter Relevanzkriterien oder von Einstellungen, die den Surveydaten widersprechen) und zu induktiven Kategorien verarbeitet werden, andererseits abduktive Erklärungshypothesen, die sich im Verlauf des Auswertungsprozesses ergeben haben und am Material belegt sowie transparent gemacht werden müssen. Der MaxQDA-Codebaum gibt dieses Ineinander deduktiver wie induktiver Kategorien anschaulich wieder. Insbesondere die enge Verquickung gesellschaftlicher Ordnungsvorstellungen mit den verschiedensten Aspekten der eingegebenen Themenblöcke legte es schließlich nahe, die grundierenden Deutungsmuster in einem gesonderten Teilkapitel aufzuführen, anstatt sie „an Ort und Stelle“ zu benennen. Als methodisches Korrektiv dienen die oben aufgeführten soziostrukturellen Daten der Fokusgruppenteilnehmer, der herausgearbeitete historisch-empirische Längsschnitt sowie weitere Einzelaspekte aus den Hauptund Spezialberichten des Studierendensurveys. Weitere Bezugspunkte für die hier entfaltete Argumentation bieten, zumindest an ausgewählten Punkten, die in der Studie PEGIDA-Effekte? Jugend zwischen Polarisierung und politischer Unberührtheit des Göttinger Instituts für Demokratieforschung herausgearbeiteten Orientierungen und Deutungsmuster mehrheitlich nichtstudierender Jugendlicher und junger Erwachsener in den Jahren 2016 und 2017. Obwohl das Interesse dieser Studie am politischen Mentalitätswandel „der“ Jugend dezidiert als Frage nach möglichen Anknüpfungspunkten von PEGIDA-spezifischen Inhalten unter Jugendlichen und jungen Erwachsenen in Ostund Westdeutschland angelegt war, ergaben sich in den dortigen Gruppendiskussionen sehr unterschiedliche Gesprächspassagen, die die Rekonstruktion allgemeiner politisch-sozialer Orientierungen und Deutungsmuster "der" Jugend im Alter von 16 bis 35 Jahren (größtenteils aber zwischen 19 und 30 Jahren) erlaubten. ${ }^{36}$ 
Im Folgenden wird keine eigenständige Untersuchung des Wandels studentischer „Werte“, Werthaltungen oder Wertüberzeugungen ${ }^{37}$ geleistet - jenes Bereichs, in dem insbesondere im Kontext der Jugendforschung üblicherweise nach einem „inneren Kompass", ${ }^{88}$ eben nach Orientierung spendenden Vorstellungsstrukturen gesucht wird. ${ }^{39}$ Nicht einmal wurde das Signalwort der „Werte“ in die Fokusgruppen eingegeben. Der Grund dafür ist auf dem Fundament des hier visierten methodischen Zugriffs $^{40}$ leicht anzugeben: „Wertmuster“41 stellen durchaus eine wesentliche Komponente von Deutungsmustern dar, sie bilden eine Sphäre von Idealen, Forderungen, Handlungsmaximen und Bewertungsmaßstäben gesellschaftlicher Realität. Zugleich aber sind sie stets offen für Auslegungen, ihr jeweiliger semantischer Gehalt muss gezielt erfragt werden. Werte finden sich in einen größeren Deutungszusammenhang eingebettet, welcher ihren jeweiligen semantischen Gehalt bestimmt und damit ihre Gültigkeit für das eigene Handeln (als „Tugenden“) wie ihren Forderungscharakter gegenüber den gesellschaftlichen Verhältnissen erst subjektiv plausibel macht. Zum Beispiel wird das Interpretations- und Auslegungsspektrum des Werts der „Freiheit“ spätestens dann deutlich, wenn zwei der von Bargel und Simeaner identifizierten und diametral kontrastierten „Grundrichtungen“ studentischer Wertmuster, die "harmonisch-sensiblen Idealisten“ ebenso wie die „aktiv-kämpferischen“ Liberalen, jeweils um die „Deutungshoheit“ kämpfen. ${ }^{42}$ Fordert jemand, es möge mehr Freiheit herrschen, bezieht er sich auf einen spezifischen, durch ein grundierendes Deutungsmuster moderierten, Begriff derselben: sei es die Freiheit der Marktkonkurrenz bei Reduktion staatlicher Regulierung, sei es die Bewahrung der Freiheit, Meinungen frei kundzutun, seinen Arbeitsplatz frei zu wählen oder frei reisen zu dürfen; sei es die Freiheit zur Selbstentfaltung durch Abschaffung des Erwerbszwangs; sei es die Freiheit, das Wirtschaftssystem der Bundesrepublik zu ändern. Zudem: Werte fordern stets, realisiert zu werden. In Deutungsmuster aber münden nicht nur solche Sollens-Sätze ein, sondern auch erklärende und rationalisierende Ist-Urteile. Mit anderen Worten: Infolge der Annahme, dass sich die wesentlichen Wertbezüge der Studierenden ohnehin aus dem Gesprächsverlauf sowie aus den rekonstruierten politisch-sozialen Deutungsmustern - den „eigentlichen“ Tiefenstrukturen politischer Orientierungen - ergeben, wurde auf das konzeptuell enge thematische label der "Werte“ weitgehend verzichtet.

Die Kapitel III.3.1 bis III.3.3 entfalten die in der Gesprächsdynamik entstandenen studentischen Auffassungen, Einstellungen und Meinungen zu den eingegebenen Themen. Sie werden unter III.3.4 schließlich zu grundierenden Deutungsmustern kondensiert, die das studentische Denken und Empfinden bezüglich des Studiums, der Politik, der Demokratie und der Gesellschaft orientierend und rechtfertigend zu strukturieren scheinen.

Vgl. ibid., S. 105-109 sowie Lechleiter, Philipp: Wertekonstellationen im Wandel. Eine empirische Bestandsaufnahme, Wiesbaden 2016, S. $25 \mathrm{f}$.

38 Schenke et al.: PECIDA-Effekte?, S. 105.

39 Für eine überzeugende Interpretation studentischer Wertmuster vgl. Bargel/Simeaner: Gesellschaftliche Werte und politische Orientierungen, S. 6-11.

40 Vgl. Kapitel I.5 dieser Arbeit.

41 Ibid., S. 8.

42 Ibid., S. 9. 


\title{
III.3.1 "Stilles commitment": Die studentische Sicht auf das Studium sowie auf Leistungs- und Bildungsprinzipien
}

\author{
„Wir leben sowohl im Zeitalter der Leistung \\ als auch in dem der Leistungskritik. ${ }^{43}$ \\ „Ich möchte nicht direkt arbeiten, weil das \\ tu' ich noch mein Leben lang." 44
}

In der erwähnten Vorgängerstudie wurde eine starke Zentrierung der Alltagswahrnehmungen und Handlungsmaximen von Jugendlichen und jungen Erwachsenen um materielle Themen festgestellt: Mehrheitlich strebten sie ein saturiertes Mittelschichtsleben im Klischeebild des Golden Age (Eigenheim, Kleinfamilie, suburbane Wohngegend) als persönliches Lebensideal an; fast alle - und insbesondere jene, die mit ihren Einkünften unzufrieden waren - begriffen ihre Biographie als Kette von beruflichen Durchgangsstationen, ihre kontinuierliche Aufgabe dementsprechend als ein „Durchmanagen" und als ein situativ-flexibles Ergreifen der sich jeweils bietenden Gelegenheiten; ihre aktuell erreichte Lebenssituation begriffen sie als folgerichtiges Ergebnis erbrachter oder (noch) nicht erbrachter Leistungen, sich selbst dabei als autonome Herren des eigenen Schicksals, sowohl den Erfolg als auch das Scheitern subjektivierten sie dementsprechend; gesellschaftliche Probleme führten sie in einer spezifischen Perspektive auf materielle Elementarkategorien zurück - dort als „ökonomisches Prisma“ bezeichnet -, überhaupt erblickten sie in sozialen Ungleichheiten die entscheidende „tickende Zeitbombe“ der Gesellschaft; die unterhalb der Fassade souveränen und abgeklärten Auftretens dennoch unverkennbar gärenden Unsicherheiten bearbeiteten sie mit dem Lob rückversichernder sozialer Auffangnetze in Deutschland, die einen jeden immerhin davor bewahrten, „auf der Straße zu schlafen“. ${ }^{45}$ Kurzum: Aus der Not diskontinuierlicher Erwerbsbiographien machten sie, zu großen Teilen an ein frühes, aber oft schmales eigenes Einkommen gewöhnt, die Tugend einer internalisierten meritokratischen Grundhaltung, eines zugleich unumgänglichen wie tentativen Glaubens an die stets gegebene Möglichkeit des sozialen Aufstiegs durch individuelle Anstrengung. ${ }^{46}$ Wer Wünsche habe, müsse zunächst persönlichen Einsatz zeigen; wer Geld ausgeben will, habe es zuerst zu verdienen; wer ganz unten landet, trage höchstwahrscheinlich Mitschuld. Leistung und Bildung erschienen hier als die entscheidenden, den individuellen Marktwert steigernden "goldenen Prinzipien“ gegen die universell drohende Abstiegsgefahr. ${ }^{47}$ Die vereinzelten Studierenden, die sich unter den dortigen Fokusgruppenteilnehmern befanden, trugen das Ihre zum hegemonialen Gruppenklima bei, indem sie das Deutungsmuster der Selbstveredelung durch Leistungsinput mittrugen, aber stärker unter dem Aspekt einer besonderen Bildungsemphase verhandelten: Bildung kläre auf, Bildung sei eine lebenslange Aufgabe, Bildung verwandle Menschen in

\footnotetext{
43 Verheyen, Nina: Die Erfindung der Leistung. Bpb Lizenzausgabe, Bonn 2018, S. 191.

44 Transkript der 4. Fokusgruppe, S. 2, Z. 61-62.

45 Schenke et al.: PECIDA-Effekte?, S. 223-252.

46 Vgl. ibid., S. 233.

47 Ibid., S. 232.
} 
Fachkräfte und führe die Gesellschaft insgesamt zum Fortschritt. Zudem schien die Berufung auf Bildung den Studierenden, welche ordinär materielle Erwägungen (etwa die Messung der eigenen Lebenszufriedenheit am explizit genannten Netto-Einkommen) zu umgehen schienen, den Bezug auf eine surrogatartige Sphäre der Anerkennung und Selbstbestätigung zu verschaffen, welche Frustrationen über die eigene Erwerbsbiographie abzufedern vermag. ${ }^{48}$ Die schlagende Konvergenz all dieser Grundhaltungen mit den workfare-Leitmaximen der „Agenda 2010“, des „Förderns und Forderns“, ist ebendort notiert worden. ${ }^{49}$ Es bietet sich an, die in den hier ausgewerteten Fokusgruppen dokumentierten studentischen Auffassungen vom Zweck und Charakter des Studiums sowie, darauf aufsattelnd, von Leistung und Bildung im Kontrast zu diesen früheren Beobachtungen herauszuarbeiten. Denn bleiben Studierende im diskursiven Austausch unter sich, sind aufschlussreiche Verschiebungen zu beobachten: Die Fokusgruppen deuten nun nicht mehr auf eine Anreicherung bzw. Anverwandlung des Leistungsprinzips mithilfe von Bildungsideen hin, sondern zeigen, dass materielle Erwägungen tendenziell abgewehrt werden und dass eine kontinuierliche Spannung besteht zwischen individuellen Genussorientierungen, leistungszentrierten Lebens- und Gesellschaftsvorstellungen und bildungshumanistisch durchsetzter Innerlichkeit.

Zunächst: Aufgefordert, über die persönlichen Beweggründe zur Aufnahme eines Studiums zu sprechen, legten die Fokusgruppenteilnehmer ein erstaunliches Maß an Fremdlenkung durch sozialisatorische Größen wie familiäre oder freundschaftliche Einflüsse offen. Es bildeten sich hier sofort zwei Gruppen: Jenen, die der Nennung spezifischer Motive und Zweckabsichten die Bemerkung vorschalteten (mit 35 von 44 Teilnehmern die Mehrheit!), dass die Aufnahme eines Studiums a priori - „immer“ schon $^{50}$ - festgestanden hätte, stets „selbstverständlich“51 gewesen sei, standen solche gegenüber, die ihren Entschluss zum Studium als keineswegs unausweichliches Ergebnis rationaler Überlegungen darstellten, sondern sich zuerst an die „Überlegung “52 hatten gewöhnen müssen bzw. bereits eine Berufsausbildung vorweisen konnten. Zwar führten einige der ersten Gruppe auch spezifische Ursachen dieser individualbiographischen Selbstverständlichkeit an, etwa indem sie den frühen Entschluss, „ich will irgendwie Lehrerin werden“, ${ }^{53}$ offenlegen oder aber bekennen, vollends dem Wunsch der Familie gefolgt zu sein: „Also, meine Mutter wollte unbedingt, dass ich studiere. [...] Ich wollte eigentlich Kosmetikerin werden, und dann hab' ich ja sozusagen diesen Druck, da, von meiner Mutter, so 'n bisschen, gehabt. "'54 Auffällig ist, dass das Selbstverständlichkeitsnarrativ häufig noch vor konkreten Studienmotivationen oder Studienzielen geäußert wurde. Überdies scheint dieses Narrativ sowohl

49 „Dass sie [...] selbst, gleichsam unverschuldet, dem [sic] Konkurrenzkampf um attraktive Arbeitsplätze unterliegen könnten, da Bildung doch nach wie vor eine konstitutive Selektionsfunktion für den Arbeitsmarkt hat, scheint keine ernsthafte Befürchtung der Jugendlichen zu sein." Ibid., S. 242.

50 Transkript der 1. Fokusgruppe, S. 4, Z. 115.

51 Transkript der 2. Fokusgruppe, S. 4, Z. 112.

52 Transkript der 2. Fokusgruppe, S. 2, Z. 63.

53 Transkript der 4. Fokusgruppe, S. 1, Z. 31.

54 Transkript der 1. Fokusgruppe, S. 3, Z. 86 (Herv. i. O.) und S. 9, Z. 256-257. 
mit Bildungsvererbungs- als auch mit Bildungsaufsteigerbiographien kompatibel zu sein scheint. Allerdings: Je niedriger der Bildungsgrad der Herkunftsfamilie ist, desto tendenziell begründungsbedürftiger erscheint den Fokusgruppenteilnehmern offenbar dieser Automatismus. So äußert einerseits ein Student der Volkswirtschaftslehre und der Politikwissenschaft, dessen Eltern Akademiker ,jeweils in der ersten Generation“ seien, er habe zwar „,ne Zeit lang tatsächlich überlegt, ob ich 'ne Koch-Ausbildung mache“; andererseits aber habe es nie substanzielle Zweifel gegeben, „dass ich danach auf jeden Fall auch noch irgendwas, wahrscheinlich auch Geisteswissenschaftliches, studiere“, wäre der vorgeschaltete Bildungsweg anderenfalls doch „irgendwie nur zum Spaß, letztendlich, gewesen. “55 Zweifel sieht auch eine Studentin der Wirtschaftswissenschaften nicht, die „aus 'ner Familie“ kommt, „wo's eigentlich total normal ist, dass man studiert“, sodass ein anderer Ausbildungsweg als das Studium „einfach nicht üblich" erscheinen würde. ${ }^{56}$ Demgegenüber bemühen sich Kinder nichtakademischer Haushalte offenbar häufiger um Rationalisierungen ihres Verhaltens. So ringt die Tochter eines durchmischten Bildungshintergrundes (ein Elternteil ist Akademiker/in) auf der Suche nach Gründen, die die Schicksalsgegebenheit ihres Studienwegs rechtfertigen könnten, sichtbar nach Worten:

„Ähm, also für mich war das eigentlich schon irgendwie immer klar. Ich weiß auch nicht [...] aber irgendwie ist für mich selber... war es irgendwie schon immer klar, dass ich mal studieren möchte und halt nochmal länger an der Uni bleiben möchte, weil ich... Nach'm Abi sofort anfangen zu arbeiten, war jetzt für mich auch keine Option. Deswegen, genau, war das irgendwie... Weiß ich nicht, war das einfach für mich, so, klar, dass ich das schon immer machen wollte. ${ }^{\text {(57 }}$

Deutlich präziser und elaborierter - aber auch ohne einen eigentlichen Entscheidungsgrund anzuführen! - beschreibt ein zu Anglizismen neigender Student der Deutschen Literatur, nach eigenen Angaben „aus einem Nichtakademiker-Haushalt“ stammend, die latenten Kräfte, die sein Handeln heteronom anzuleiten scheinen, wie folgt:

„]a, man macht sein Abitur, und dann fragt sich erstmal: ,Okay, was mach' ich überhaupt?' Es war irgendwie so 'n stilles commitment, so, vom sozioökonomischen background her, aus dem ich komme. Und zwar: Man... Sehr idealer Lebenslauf: Lebenslauf: Abitur, und dann weiter, und dann hat sich das irgendwie so ergeben, dass man sich nach Studien-... nach Studium überhaupt erkundigt. Und ich wollte in Frankfurt auch bleiben, erstmal, weil, ich bin hier aus [...] der Cegend, und mir so mein... Einfach, um mal bei meinen hoods erstmal zu bleiben. Mich hat's, so, bisher nicht 'rausgezogen. Und meine Eltern haben mir da auch die Freiheit gegeben und haben gesagt, sie unterstützen mich. ${ }^{458}$

Dieses Muster - weitgehendes Verharren von Akademikerkindern bei der apodiktischen Feststellung des Bildungsdeterminismus, stark empfundene Begründungsbe-

55 Transkript der 1. Fokusgruppe, S. 5, Z. 138-142.

56 Transkript der 6. Fokusgruppe, S. 3, Z. 73-75.

57 Transkript der 4. Fokusgruppe, S. 1, Z. 21-28.

58 Transkript der 6. Fokusgruppe, S. 4, Z. 99-107 (Herv. i. O.) 
dürftigkeit aufseiten der Bildungsaufsteiger - durchzieht sämtliche Fokusgruppen. ${ }^{59}$ Worauf aber ist dieses Selbstverständlichkeitsnarrativ insgesamt zurückzuführen, welches laut Studierendensurvey eine Mehrheit von 57 Prozent der deutschen Studierendenschaft gemeinsam im Munde führt? ${ }^{60}$ Der entscheidende Einflussfaktor scheint schlicht der Erwerb des Abiturs zu sein, ganz nach der in Kapitel I.4 erwähnten gestiegenen Attraktivität des als verklammerte Einheit gedachten Bildungswegs Gymnasium-Universität. In der Unumgänglichkeit der Linie „Abitur-Studium“ als Grundlage einer gelungenen Lebensplanung scheinen sich die Milieus traditionell bildungsaffiner Schichten einerseits und der Bildungsaufsteiger andererseits zu treffen. Das belegt im Grunde schon die Formulierung, die Hochschulreife sei „nur zum Spaß ${ }^{\prime 61}$ erworben worden, finde sie ihre adäquate Verlängerung nicht auch in einer tatsächlichen Immatrikulation; Ähnliches bemerken weitere Studierende. ${ }^{62}$ Aber: Irritierend ist es schon, dass die dem Selbstverständlichkeitsnarrativ inhärente Verleugnung oder zumindest Relativierung individueller Entscheidungsautonomie bei der eigenen Lebensplanung vielen Diskutanten oft erst nach oder während ihrer Äußerung auffällt. Wo der naheliegende Eindruck elterlicher Bevormundung bzw. individueller Entscheidungsunfähigkeit entsteht, wird oft eilig die persönliche Entscheidungsfreiheit bekräftigt, das Gesagte nachträglich camoufliert. So irrlichtert eine Studentin der Sozial- und Geisteswissenschaften, die sich gerne als streitlustige und begabte Intellektuelle inszeniert:

„Keine Ahnung, es stand immer irgendwie fest, dass darauf Wert gelegt wurde, dass wir natürlich unser Abitur machen und so. ' $\mathrm{N}$ anderer Abschluss wär' irgendwie nicht infrage gekommen, weil unseren [sic] Kompetenzen nicht entspricht. So, was unsere Großeltern und so denken... Ja. Und so... Keine Ahnung, unsere Großeltern haben, so, ganz normale Berufsausbildung gemacht, meine Eltern haben anner Fachhochschule studiert, jeweils. Und sozusagen immer so 'n Aufstieg... Aber nicht, dass wir uns da irgendwie unter Druck gefühlt hätten, also mich haben die Ausbildungsberufe, auch, die so in meinem Umfeld, dann, von meinen Freunden gewählt wurden, nicht wirklich interessiert. So Bürokauffrau oder, irgendwie, Industriekauffrau - da, keine Ahnung, kann ich nichts mit anfangen. ${ }^{\text {6 }}{ }^{3}$

Ob die zitierte Studentin nun dem sozialisatorischen Determinismus erlegen ist, dem Wunsch der Familie gefolgt ist, oder doch vielmehr ein bestimmtes Tätigkeitsfeld - als objektiv Auserwählte und Prädestinierte - anstrebt, ist hier kaum zu entscheiden. Ähnderation aufgewachsen ist und vor diesem Hintergrund nüchtern bekundet: „)eder braucht ein Studium. [...] Fast alle studieren in Russland." Transkript der 4. Fokusgruppe, S. 3, Z. 69-70.

62 So etwa ein fortgeschrittener Jurastudent: „Und direkt 'ne Ausbildung zu starten, wär' für mich, glaub' ich, auch nicht so infrage gekommen. Wie viele schon gesagt haben, war das eigentlich auch, so, schon von sich aus vorgezeichnet: Wenn man Abi macht, dann macht man das mit 'nem Ziel, und das ist meistens das Studium." Transkript der 1. Fokusgruppe, S. 6, Z. 167-170. 
lich verhält es sich mit einer Lehramtsstudentin, die in kurzer Abfolge und unprovoziert zwei sich widersprechende Kausalitäten anführt:

„Was heißt zwingend, aber ich wusste, dass ich Lehrerin werden will, und dafür muss man halt studieren. [lacht] Aber ich, also... Also, ich sage mal: Selbst wenn ich nicht hätte Lehrerin werden wollen, hätte ich mir wahrscheinlich irgendeinen Job gesucht, wo man studiert... für studieren muss, weil ich schon schnell wusste, dass ich irgendwann will. Auch meine Eltern haben beide studiert und haben gesagt: ,Das ist einfach so eine coole Zeit, wo du so viele Freiheiten hast und einfach mal ein bisschen auch selbstständiger wirst, wenn du ein bisschen aus der... von Zuhause 'rausgekickt wirst, sozusagen, also mal dir dein eigenes... auf eigenen Beinen stehen musst.' Also, ich wollte schon immer studieren, und dann habe ich mir einen Job ausgesucht, wo ich halt sowieso studieren muss für. Ja." ${ }^{64}$

In beiden Fällen ist jedenfalls auffällig, dass, nach der persönlichen Studienmotivation gefragt, zuerst die Vorstellung eines äußeren Zwangs assoziiert wird, als wolle man die Verantwortung für die eigene Immatrikulation von sich schieben. Der Grund für dieses Phänomen mag darin liegen, dass jene Äußerungen in frühen Gesprächsphasen getätigt wurden und Zeugnis von einer generellen Unsicherheit ablegen könnten, persönliche Lebensentscheidungen vor einer unbekannten Gruppe zu exponieren. Vielleicht ist so auch der ausweichende Bezug auf familiär oder durch das erweiterte soziale Umfeld kolportierte Stereotype vom Studentenleben als „die Zeit deines Lebens“65 ${ }^{46}$ verstehen, welche zwar keine eigenständige Studienmotivation liefern, aber doch zumindest einen verstärkenden Faktor zu bilden scheinen, der die postulierte Selbstverständlichkeit subjektiv attraktiver macht.

Allgemein nennen die Studierenden diverse konkrete Beweggründe der persönlichen Entscheidung zur Studienaufnahme. Dazu zählen das Interesse am Studienfach ${ }^{66}$ oder der Wunsch, „viel zu lernen“67, ferner bestimmte Berufsziele (zumeist Lehrer oder

64 Transkript der 2. Fokusgruppe, S. 2, Z. 52-61.

65 „[...] und da ich dann gehört habe, ja... meine Eltern dann immer gesagt haben: ,]a, studieren ist so toll, und das ist die Zeit deines Lebens [ironisch]!', und meine Freunde, die dann halt auch schon ein, zwei Jahre älter waren, [...] dann auch angefangen haben zu studieren, ja, dann war für mich eigentlich klar: Ich möchte auch studieren! [lacht]" Transkript der 2. Fokusgruppe, S. 4, Z. 105-108, ähnlich auch eine andere Teilnehmerin S. 10, Z. 307-309; „Also, ich glaub', wir haben, sag' ich mal, mehr Freiräume, vielleicht, als unsere Elterngeneration, aber wenn die von ihren Studienzeiten erzählen, dann klingt das ja so, als hätten sie eigentlich jeden Abend 'ne WG-Party gehabt und eigentlich gar nicht gelernt. [allgemeine Erheiterung und Zustimmung]" Transkript der 4. Fokusgruppe, S. 11, Z. 342-345.

66 „Ja, bei mir war es das Interesse. Also, ich habe ja, wie gesagt, vorher eine Ausbildung gemacht zum Chemielaborant, [sic] und habe dann auch lange überlegt, ob ich dann studiere, weil man auch als Laborant ganz gutes Geld verdienen kann. Aber dann letzten Endes habe ich gedacht: $\mathrm{Na}$ ja, irgendwie bin ich sehr interessiert und würde mich ärgern, wenn ich's dann doch nicht gemacht hätte." Transkript der 2. Fokusgruppe, S. 2, Z. 46-50.

67 Transkript der 6. Fokusgruppe, S. 3, Z. 83; Transkript der 5. Fokusgruppe, S. 5, Z. 139; Transkript der 7. Fokusgruppe, S. 4, Z. 123. 
Arzt), die Freude an Büchern, ${ }^{68}$ allgemeine intellektuelle Suchbewegungen, ${ }^{69}$ aber auch das Umgehen körperlicher Arbeit ${ }^{70}$ oder das Hinauszögern des Übergangs in den Arbeitsmarkt zugunsten hedonistischer Freiheiten. Immerhin 16 von 44 Diskutierenden nannten als Bestandteil ihrer Studienmotivation explizit das Ziel, den Erwerbseintritt hinauszuzögern; exemplarisch dafür dient folgende besonders entschiedene Feststellung:

„Also ich hab' mir gedacht, für meine Persönlichkeitsentwicklung, dass ich das halt irgendwie auf jeden Fall brauche. [...] Ich möchte nicht direkt arbeiten, weil das tu' ich noch mein Leben lang. Möcht' ich halt nochmal 'n bisschen das Leben genießen." ${ }^{\text {"1 }}$

Das Spektrum der so umrissenen materiellen wie ideellen Studienmotivationen könnte bunter nicht ausfallen, eine detaillierte Auffächerung fiele müßig aus. Außerdem äußern viele Diskutanten mehrere Motivationen zugleich. Aufschlussreicher erscheint es hier, übergreifende Beobachtungen anzustellen. So ist eine bestimmte Studienmotivation hegemonial und allen anderen vorgeordnet: Insgesamt wird am weitaus häufigsten der Wunsch genannt, individuelle Freiheitsgrade zu erhalten bzw. zu erlangen und Zeit zur Konturierung eigener Interessen zu gewinnen. Dieses zentrale Motiv wird in Formulierungen wie den folgenden plastisch:

„Ich, glaub' ich, hatte keine Lust, irgendwie in 'nem Ausbildungsberuf oder so etwas... so 'ne untergeordnete Rolle irgendwie einzunehmen. [...] Ja, irgendwie hat mir das in der Schule schon irgendwie immer Spaß gemacht, Sachen zu lernen, irgendwie zu wissen. Also, gar nicht mal speziell irgendwie 'n... also, 'n spezielles Fach, irgendwie [...] Und ja, deswegen so dieser Aspekt des Sachen-lernens, glaub' ich einfach. Und seine eigene Zeit sich zu nehmen, und sich das selbst einteilen zu können, sowas. Und auf niemanden angewiesen zu sein. ${ }^{472}$

„Also, ich hatte das total vermisst in der Ausbildung, in der Berufsschule, dass wir da gar nicht mehr gelernt haben, zu lernen, sondern gelernt haben, zu arbeiten. ${ }^{473}$

68 „Das ist auch so etwas, was mich dann zum Studieren bewogen hat, weil ich mich relativ gern hinter Bücher geklemmt hab', war auch während der Schulzeit, tatsächlich." Transkript der 1. Fokusgruppe, S. 6, Z. 166-167 (Herv. i. O.); „Und wenn jemand sagt: , Ich lese nicht gern', das ist für mich sehr faszinierend." Transkript der 5. Fokusgruppe, S. 21, Z. 649.

69 „Den Horizont einfach breit zu halten, das ist wahrscheinlich auch generell die Motivation gewesen [...]“ Transkript der 1. Fokusgruppe, S. 5, Z. 143-146; „Dann hab' ich Literatur angefangen, Germanistik, und hab' mir dann im Laufe dessen gedacht, dass [das] Studium doch irgendwie notwendig ist, um irgendwie ein vernünftig-mündiger Mensch der Gesellschaft zu werden, der darin auch agieren kann." Transkript der 6. Fokusgruppe, S. 8, Z. 289-232 (Herv. i. O.)

„Also, ich arbeite in der Gastro, und da will ich auf keinen Fall hin, so, das ist einfach körperlich nicht möglich, find' ich, dass man das 'n ganzes Leben lang macht. Und, ähm, aber das führt mir halt immer auch vor Augen, warum ich studiere: weil ich irgendwie nicht genau diese Berufe machen will, wo ich halt auf meinen Körper angewiesen bin!“ Transkript der 4. Fokusgruppe, S. 16, Z. 493495 (Herv. i. O.); „Ich hab' vorher 'ne Ausbildung gemacht im Handwerk, hab' dann, äh, ein Jahr in der Industrie gearbeitet, ja, war den ganzen Tag voll mit Öl und so, und hab' mich mies abgefucked, so." Transkript der 7. Fokusgruppe, S. 3, Z. 93-95.

71 Transkript der 4. Fokusgruppe, S. 2, Z. 59-62 (Herv. i. O.)

72 Transkript der 3. Fokusgruppe, S. 6, Z. 159-173.

73 Transkript der 7. Fokusgruppe, S. 4, Z. 123-125. 
„Im Job kann ich nicht sagen: ,Ich hab' jetzt keinen Bock, hinzugehen!' In der Uni ist das anders. Und dann dacht' ich mir: ,Nimmst du dir nochmal so 'n bisschen die Zeit! [ $^{\text {7 }} 4$

„Geld macht nur bis zu 'nem gewissen Grad glücklich, sag' ich mal, bis man seine Grundbedürfnisse irgendwie befriedigt hat. [...] man ist'n Rechtsanwalt und arbeitet in 'ner Top-Kanzlei, aber eigentlich möchte man lieber in der NCO arbeiten und halt für die Umwelt kämpfen... Ähm, dadurch macht das Eine halt bis zu 'nem gewissen Crad glücklich, aber irgendwann, dann fragt man sich dann ja auch so: ,Wofür mache ich das Ganze eigentlich hier?' Und dann muss man halt sehr für sich selber entscheiden, ob man das damit kompensieren kann [...] also den Geldaspekt, oder ob man halt eher, dann, Ideale hat, für die man eintritt. ${ }^{75}$

Das Studium bietet für viele offenkundig eine Phase zwangsarmer Erkundung der eigenen Möglichkeiten und Vorlieben, ja schafft Raum für eine besondere Form des temporären savoir vivre - darauf spielt zumindest die oben zitierte Formulierung an, die Studiumsphase zu „brauchen“, fast wie einen entlastenden Kurzurlaub im WellnessHotel - oder scheint eine Genussorientierung des Lebens insgesamt zu ermöglichen, wie eine Studierende das als Bestandteil schwedischer „Kultur“ identifiziert: Dort „arbeite[]“ man, „um zu leben“, und nicht umgekehrt. ${ }^{76}$ Demgegenüber geben beispielsweise nur zwei Personen in den Eingangspassagen der Gruppendiskussionen an, ein hohes Einkommen erzielen zu wollen - etwa als grundlegenden Ausgangspunkt („Also auf jeden Fall so der erste Punkt ist Geld, da bin ich ehrlich. ${ }^{(77}$ ) oder weil der bisherige Ausbildungsberuf im Bankensektor aufgrund grassierenden Stellenabbaus „keine Perspektive“ für einen Karriereaufstieg und auch sonst „viel zu wenig Geld“ geboten habe. ${ }^{78}$ In beiden Fällen ließen diese Äußerungen an Resonanz vermissen, die Mitdiskutanten fuhren rasch mit neuen Wortbeiträgen fort. Insgesamt bestätigt sich hier also eines der wesentlichen Ergebnisse der Surveyforschung, nämlich dass die Studienentscheidung hauptsächlich vom Wunsch nach grundlegender Sicherheit (nicht nach dem „großen Geld“!) und vom Motiv der Vereinbarkeit von Erwerbsleben und Selbstentfaltung getragen ist - oder wie es eine Studentin der Medizin auf die Frage nach dem späteren Verdienst hin als Studienzweck formuliert:

„Der Begriff ,viel Geld' ist ja für jeden was Anderes. Also ich find' ich auf jeden Fall, dass es erstmal wichtig ist, dass man sich selbst versorgen kann, und wenn man 'ne Familie plant, auch Kinder und Partner. Ähm, jetzt, so, auch innerhalb eines Studiums, wenn man dann seinen Beruf einschlägt, kann man ja auch entscheiden: ,Okay, in welche Richtung möcht' ich gehen? Möcht' ich eher wirtschaftlich arbeiten oder in der Wissenschaft?' Und ich glaube, dass da weniger der... Also, für mich ist der Geldaspekt da weniger wichtig als meine eigene Zufriedenheit. ${ }^{\text {79 }}$ 
Indes ist hier als dritte Beobachtung die nur am qualitativen Material sichtbare Differenzierung anzubringen, dass die Verteilung der Studienmotive von der Linearität, oder besser: vom Linearitätsbewusstsein des eigenen Bildungswegs abhängt. Diejenigen nämlich, die das eingangs skizzierte Selbstverständlichkeitsnarrativ pflegen (nochmals: unabhängig davon, ob sie dabei aus akademischem Elternhaus stammen oder nicht), führen tendenziell häufiger intellektuelle Beweggründe und die Erlangung von Freiheitsgraden an:

„Ja, bei mir auch, so, irgendwie, selbstverständlich. Ich habe mir auch immer schon früher überlegt, wo ich gerne studieren möchte, weil ich auf jeden Fall ausziehen wollte als erstes Ziel. [lacht] Und in der Schule mochte ich am liebsten Geschichte, Politik und da macht es dann irgendwie auch am meisten Sinn, das zu studieren, weil... Weiß nicht, was man für eine Ausbildung mit Geschichte machen könnte? Na ja, und jetzt kann man ganz viele Texte schreiben und es wird auch noch gelesen [lacht] - von zumindest einer Person, und das ist cool. [allgemeines Lachen] “80

„Also, Ausbildung ist halt so strikt, da hast du einfach... da bist du halt einfach so'n kleiner Mann, sozusagen, da darfst du dir das nicht aussuchen! Wenn ich aber 'n Studium habe und vielleicht wirklich irgendwie auch 'nen guten Abschluss, dann kann ich mit der Firma höchstwahrscheinlich eher noch... hab' ich da noch 'ne gewisse Flexibilität, und dann kann ich halt noch irgendwie gucken, genau, wie ich mir meinen Tag einteile und meine Woche. ${ }^{\text {81 }}$

„I: [...] also, du [...] entscheidest lieber gern selber, was du machst, so? B4: Genau. Aber nicht im Sinne von, jetzt, so 'nem... so 'nem, sagen wir mal, puren Egoismus oder so 'ner..., sondern eigentlich eher da drin, dass ich - zumindest bei mir - [mir] die Freiheit nehmen möchte, da noch 'nen gewissen Handlungsspielraum irgendwo zu haben, und dann auch mich nicht zwangsläufig irgend 'ner vorgeschriebenen Norm oder sowas einfach unterordnen zu müssen, weil's jetzt halt eben so gemacht wird. ${ }^{482}$

Demgegenüber nennen diejenigen, für die das Studium nicht selbstverständlich war (darunter auch die zuvor Berufstätigen), häufiger konkrete Berufsziele, das fachliche Interesse im Sinne beruflicher Qualifikation oder eine Erhöhung des Einkommens:

"Ich hab' vorher 'ne Ausbildung als Bankkauffrau gemacht, und hab' auch erst überlegt, da in dem Beruf weiterzuarbeiten. Aber ich hab' dann schnell gemerkt, dass es eigentlich zurzeit nicht so die Perspektive ist, und auch nicht so gute Verdienstmöglichkeiten sind. [...] Und dann hab' ich ebent überlegt... Oder in der Ausbildung ist mir eben klar geworden, dass ich gern Berufsschullehrerin werden möchte, und hab' geguckt, wie ich da zu dem Ziel kommen kann. ${ }^{183}$

„Ähm, für mich war das eigentlich gar nicht so klar, also nach'm Abitur. [...] Also ich hab' auch erstmal gebraucht, um da irgendwie Anläufe zu finden. Ähm, aber hab' dann

80 Transkript der 2. Fokusgruppe, S. 4, Z. 112-118.

81 Transkript der 4. Fokusgruppe, S. 7, Z. 213-217.

82 Transkript der 6. Fokusgruppe, S. 5, Z. 149-156.

83 Transkript der 3. Fokusgruppe, S. 3, Z. 71-80. 
irgendwann festgestellt, dass ich vielleicht doch irgendwann Ärztin werden möchte, und dafür braucht man halt auch 'n Studium. Joa." ${ }^{84}$

Enge Zusammenhänge mit dem konkreten Studienfach scheinen dabei kaum zu bestehen; höchstens darin, dass sich sozial- und geisteswissenschafliche Fächer aufgrund ihrer Wahlfreiheiten zulassenden Kurrikula und ihrer stark auf gesellschaftliche Themen zugeschnittenen Perspektiven besser für die Figur der Horizonterweiterung eignen. ${ }^{85}$ Dem entspricht, dass jene wenigen Personen, deren intellektuelles Interesse dezidiert auf "gesellschaftlich relevante Fragen ${ }^{\text {“86 }}$, also auf das Verstehen und (politische) Verändern gesellschaftlicher Verhältnisse zielt, (auch) in den Fachbereichen Philosophie, Politikwissenschaft, Soziologie, und Soziale Arbeit eingeschrieben sind. Die dezidiertesten Diskussionsbeiträge dieser Art werden, wohl auch aufgrund des Andenkens an die kritische Theorie Max Horkheimers und Theodor W. Adornos, in Frankfurt a.M. geäußert. Dort konstatiert ein junger Bildungsaufsteiger, der zuvor als Kfz-Mechaniker gearbeitet hat, als vorrangigste Studienmotivation: „die Unfähigkeit, irgendwas zu bewirken in der Gesellschaft." Die Empfindung der persönlichen politischen Ohnmacht führt ihn, der sich extrakurrikular mit Texten von Aristoteles und Karl Marx beschäftigt, unmittelbar zum Wunsch nach intellektueller Bewältigung und daraus resultierender Identifikation praktischer Aussichten. „Deswegen hab' ich, glaub' ich, [ein] starkes Interesse dran, mich da irgendwie da $\mathrm{zu}$ engagieren und $\mathrm{zu}$ verstehen, wie das alles

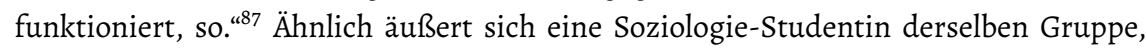
die aller Geringfügigkeit individueller Einflussmöglichkeiten zum Trotz der Überzeugung ist, „dass man trotzdem was machen muss $^{\text {“88. }}$. Und schließlich fällt weiterhin auf, dass einige Beweggründe erst später, allmählich und en passant im Laufe der Gruppendiskussionen, zum Vorschein kamen. Dass nämlich die Akzentsetzung auf Lebenszufriedenheit bei dem Wunsch, einen akademischen Titel zu erlangen, durchaus immer auch einen gewissen Sockel an erwarteten Einkommens-, Status-, und Komfortgewinnen voraussetzt, wird hier deutlich. Dazu drei Beispiele einer Lehramtsanwärterin im Fach Politikwissenschaft, einer bereits berufstätigen Masterstudentin eines biologischen Spezialfachs, und einer ehemals im Hotelgewerbe tätigen Soziologie-Studentin:

„B2: Also, wir reden immer über Geld, aber ich finde, was halt auch [...] 'n Vorteil des Studiums ist... Das ist vielleicht nicht'n Grund, warum man anfängt zu studieren, aber definitiv etwas, was vielleicht einem auch ganz gut tut für's eigene Selbstvertrauen,

84 Transkript der 4. Fokusgruppe, S. 2, Z. 45-50.

85 Das ist zum Beispiel im Falle eines Studenten deutlich, der sein wirtschaftswissenschaftliches Studium mit einem als Denkschule aufgefassten Philosophie-Studium kombiniert: „]a, ich studiere, weil ich Denken lernen will und weil ich Verstehen lernen will. [...] ich komme nicht aus 'ner Akademikerfamilie, aber es war trotzdem irgendwie keine Frage, dass ich nach der Realschule das Abitur mache und nach dem Abitur studieren gehe. Aber das kam nicht, weil meine Eltern das irgendwie vorgelebt haben oder vorgegeben haben, sondern weil ich mich für gesellschaftliche Fragen interessiere." Transkript der 3. Fokusgruppe, S. 8, Z. 227-231. Träger des Selbstverständlichkeitsnarrativs ist zwar auch dieser Student, doch vermag er für die Alternativlosigkeit seines Studiums tatsächlich auch ein konkretes Interesse als Beweggrund anzugeben.

88 Transkript der 7. Fokusgruppe, S. 41, Z. 1291. 
erstmal, dass man studiert hat. Aber auch so'n bisschen die gesellschaftliche Anerkennung. Also, das klingt immer so blöd, wenn man das sagt... B3: [nickt] Das stimmt schon. ${ }^{\text {(89 }}$

„Und durch 'n Studium werden wir ja auch eher für Führungspositionen ausgebildet als für die, äh, Ausführungspositionen. Also zumindest ist das bei uns so.“90

„[...] auf der anderen Seite bin ich jeden Tag an der Coethe-Uni vorbeigefahren, als ich noch nicht da studiert habe, und hab' echt immer die Studenten gesehen, die dann da, ähm... Was weiß ich, wenn ich um 5 Uhr morgens irgendwie zur Arbeit gefahren bin, kamen die grad' vom Feiern [...] Ich hab' die echt immer so 'n bisschen, ähm, mit Hassblicken verfolgt, bevor ich jetzt selber angefangen hab' “91

Selbst die unaufgeregtesten Hedonisten im Sample verraten im Laufe des Gesprächs bisweilen, dass die Aussicht auf den späteren finanziellen Komfort durchaus als Faktor in die eigenen Abwägungen einfließt:

„Also, als studierter Mensch verdient man halt grundsätzlich schon mal mehr als jetzt wahrscheinlich... als in der Ausbildung, so. [...] Also da hab' ich gemerkt, dass ich nicht den Antrieb habe, im Studium möglichst hoch irgendwie was zu erreichen, um dann damit viel Geld zu verdienen. Sondern wie ihr alle gesagt: Einfach so diesen... diese Sicherheit, einfach, haben, dass man auch... Und diese Unabhängigkeit." ${ }^{42}$

Freilich: Wie gut die späteren Aussichten auf dem Arbeitsmarkt tatsächlich sein werden, kann niemand schon während des Studiums vorhersehen. Diese mögliche Quelle von Zweifeln aber lassen die Studierenden nicht gerade nah an ihr Bewusstsein. Im Gegensatz zu den Jugendlichen und jungen Erwachsenen der Vorgängerstudie, die zur Bewältigung der aus der Erwerbssituation resultierenden Unsicherheiten immer wieder autosuggestiv ihre Souveränität, Flexibilität und Einsatzbereitschaft herausstrichen, nutzen die hier Befragten das Privileg, diese Thematik (noch) ignorieren zu können. Sie weichen auf einen vagen Zukunftsoptimismus aus oder wenden den stirnrunzelnden Blick auf die Unwägbarkeiten des Berufslebens vorzeitig ab; das Problem der späteren Einmündung in den Arbeitsmarkt behandeln sie lieber als Zukunftsmusik. So postulieren manche, ,'ne sehr gute Perspektive“ zu genießen und „auf lange Frist“ eine "sehr gute Entscheidung“ getroffen zu haben, ${ }^{93}$ so freuen sich andere (s. o.) auf die „Sicherheit" und „Unabhängigkeit" nach ihrem Abschluss, ${ }^{94}$ auf die „Anerkennung durch die Gesellschaft“95 oder beruhigen sich dadurch, dass man die gewünschte Stelle schon noch bekommen werde, „wenn man dann zäh genug war“96. Sogar Zynismus eignet sich zur Abwehr von Sorgenfalten: „Du darfst eh noch 50 Jahre arbeiten und so. Wer weiß, wenn ihr alle ins Rentenalter kommt, [ob es dann] sowas wie Rente überhaupt noch

89 Transkript der 4. Fokusgruppe, S. 7f., Z. 223-230.

90 Transkript der 6. Fokusgruppe, S. 6, Z. 182-183.

91 Transkript der 7. Fokusgruppe, S. 10f., Z. 316-323.

92 Transkript der 4. Fokusgruppe, S. 5f., Z. 159-165 (Herv. i. O.) und S. 6, Z. 171-174 (Herv. i. O.)

93 Transkript der 1. Fokusgruppe, S. 9, Z. 261-262.

94 Transkript der 4. Fokusgruppe, S. 6, Z. 174 (Herv. i. O.)

95 Transkript der 4. Fokusgruppe, S. 8, Z. 244.

96 Transkript der 6. Fokusgruppe, S. 24, Z. 762. 
gibt! [...] Also, ich hab’ mir da, wie gesagt, nie so einen Stress gemacht [...] ${ }^{497}$. Dass angehende, auf bestimmte Fachbereiche spezialisierte Lehrer und Chemiker wahrscheinlich bessere Berufschancen anmelden können als Sozialwissenschaftler und auch manche angehenden Juristen ohne spezifisches Profil, spielt hier kaum eine Rolle, wird der beschriebene vage Zukunftsoptimismus als argumentativ kaum unterfütterte heuristisch-pragmatische Annahme doch von allen in gleicher Weise geteilt. Zumindest die linear Studierenden nutzen das Studium somit - gleichgültig, ob es zu den primären Studienmotiven zählt oder nicht - erkennbar als ein besonderes mentales Moratorium verlängerter Postadoleszenz, d. h. als Phase der Entbundenheit von den Erfordernissen und Sorgen der Lebens- und Berufsplanung. Es wird von ihnen immer auch als Instrument der eskapistischen Ausdehnung eines Schutzzeitraums vor dem „Ernst des Lebens" genutzt; wenn auch selten so explizit formuliert, ist es doch als wesentlicher Motivationszug unverkennbar. Hierin haben sie einen wesentlichen Teil des „Erwachsenwerdens" noch vor sich, den (vormals bereits) Erwerbstätige bereits passiert haben. Es ist nicht auszuschließen, dass viele von ihnen infolge des nachholenden Erwerbseintritts ein ausgeprägtes Interesse für jene materiellen Themen erst noch entwickeln werden, die sie aktuell mit Distanz perzipieren.

Wie nehmen die Studierenden nun ihre faktische Studiensituation wahr und inwiefern ist ihnen ein selbstorganisiertes Studium möglich? Nimmt man die verbreiteten Klagen der Studierenden über das Fehlen selbstorganisierbarer Freiräume, über die Rigidität und Verschultheit der Studiumsinhalte, über die Linearität und Ressourcenintensität des Studierens, auch über dogmatische und autoritäre Elemente der Lehrpraxis beim Wort, könnte man hier prima facie leicht den Eindruck einer vom Bologna-System geknechteten, aller Freiheiten und beinahe noch der Luft zum Atmen beraubten Studierendengeneration gewinnen. Sehr viele Fokusgruppenteilnehmer klagen über zumindest vorübergehend auszehrende Prüfungsbelastungen und „extrem vollgeknallte“ Semester, über die Nötigung zum „Bulimie-Lernen“ mit darauffolgender großflächiger Amnesie ${ }^{98}$ oder über den Zwang, die Semesterferien mit Praktika zu füllen. ${ }^{99}$ Eine JuraStudentin staunt: „Das habe ich mir schon so vorgestellt. Ich habe es mir weniger, also, intensiv vorgestellt, also [lacht], ich weiß nicht, vielleicht liegt's auch an meinem Studienfach, aber ich muss schon sehr. Viel. Machen. ${ }^{\text {“100 }}$ Eine Psychologie-Studentin und eine Studentin der Volkswirtschaftslehre verweisen im Dialog miteinander auf „gnadenloses Aussieben" durch drakonische Klausurbewertungsstile. ${ }^{101}$ Und ein Student der Geschichtswissenschaft berichtet, er habe aufgrund überflüssigen, durch Kleinstprüfungen konditionierten Lernstoffs im Kurrikulum gerade einmal „ein Prozent genossen, eigentlich“ und sich dementsprechend „durchgemogelt das ganze Studium“. ${ }^{102}$ Andere beklagen den Anwesenheitszwang auch bei unergiebigen Seminarveranstaltungen,

97 Transkript der 6. Fokusgruppe, S. 22, Z. 687-689.

98 Transkript der 1. Fokusgruppe, S. 12, Z. 351 und S. 18, Z. 551-552.

99 Vgl. Transkript der 1. Fokusgruppe, S. 12, Z. 360-361.

100 Transkript der 2. Fokusgruppe, S. 5, Z. 144-146 (Herv. i. O.)

101 Transkript der 1. Fokusgruppe, S. 10, Z. 285-286 und 291-292.

102 Transkript der 1. Fokusgruppe, S. 8, Z. 244-246. 
welcher den Wunsch nach selbstständiger Lernorganisation durchkreuze. ${ }^{103}$ Vereinzelt ist auch angestaute Wut zu spüren:

„Ich will überhaupt niemandem was vorhalten, aber ich hab' einfach so einen straffen Zeit- und Arbeitsplan die ganze Woche durch, dass ich mir von niemandem irgendwie sagen lassen muss, ich komme zwei Minuten zu spät zum Seminar [...] “104

Man könne - so der Tenor vieler - „eigentlich nicht so wirklich sich das Studium so gestalten, wie man jetzt Lust drauf hätte.“105 Gelegentlich führt das zu einem nostalgischen Blick zurück in eine supponierte frühere Form von Universität und Studium, wie man sie aus den Berichten der eigenen Eltern rekonstruiert:

„Also, ich glaub', wir haben, sag' ich mal, mehr Freiräume, vielleicht, als unsere Elterngeneration, aber wenn die von ihren Studienzeiten erzählen, dann klingt das ja so, als hätten sie eigentlich jeden Abend 'ne WG-Party gehabt und eigentlich gar nicht gelernt. [allgemeine Erheiterung und Zustimmung] Und das haben wir ja heutzutage gar nicht mehr. Also wir haben ja... Klar, man jetzt in dem Sinne noch Freiräume! Aber wenn man sein Studium in Regelstudienzeit durchstehen will, dann hat man da eigentlich auch schon Todesstress, und so richtig Zeit, sich da jetzt großartig noch anders... Freiräume zu nutzen, gibt's eigentlich gar nicht. Das ist, glaube ich, utopisch. “106

Doch es tauchen auch gegenläufige Stimmen auf, die diese Entfremdungs- und Überlastungsempfindung gerade nicht teilen. Sie nehmen ihr Studium „eigentlich nie als Last“ wahr, „sondern eigentlich ab dem ersten Semester schon als Privileg“, „auch in Deutschland unter solchen Bedingungen, kostenlos" - obwohl gewisse Lerninhalte ob ihres Abstraktionsgrades zu inhaltlichem „Hadern“ führten. ${ }^{107}$ Sie fassen das Studium als so herausfordern wie motivierend auf, loben das "Gesamtpaket“ von Leistungsanforderung, Zeitautonomie, akademischer Gesellschaft und dem Angehen essenzieller Sinnfragen, ${ }^{108}$ erkennen schließlich im Studium auch die Möglichkeit, „erwachsen zu werden“, sehen einen „Prozess“ von „Lernen und Wachsen“ am Werk, welcher die Fähigkeit vermittelt, mündige Entscheidungen zu treffen. ${ }^{109}$ Achselzuckend wird konzediert, es sei „okay“, „, sich durch manche Sachen durchquälen“ zu müssen, „weil man die machen muss", ${ }^{110}$ auch etwa, um möglichst vielen verschiedenen Interessensschwerpunkten jeweilige Anknüpfungspunkte zu bieten, wie eine andere Person sekundiert. ${ }^{111}$ Wieder andere, wie eine Studentin der Wirtschaftspädagogik, stellen fest, dass es bei ihnen "schon so" sei, „dass sich die Erwartungen, die ich an mein Studium damals hatte... sich schon gewissermaßen jetzt auch im Studium widerspiegeln." Trotz striktem Lernplan und parallelem zivilgesellschaftlichem Engagement, auch trotz manch fehlender Wahlmöglichkeit zwischen Veranstaltungsmodulen konstatiert sie strahlend:

103 Vgl. Transkript der 5. Fokusgruppe, S. 8, Z. 229-240.

104 Transkript der 5. Fokusgruppe, S. 14, Z. 407-409.

105 Transkript der 6. Fokusgruppe, S. 5, Z. 150-151.

106 Transkript der 4. Fokusgruppe, S. 11, Z. 342-349 (Herv. i. O.)

107 Transkript der 1. Fokusgruppe, S. 11, Z. 320-322.

108 Transkript der 7. Fokusgruppe, S. 6, Z. 176-190.

109 Transkript der 4. Fokusgruppe, S. 10, Z. 300-309 (Herv. i. O.)

110 Transkript der 2. Fokusgruppe, S. 21, Z. 645-646 (Herv. i. O.)

111 Vgl. Transkript der 2. Fokusgruppe, S. 21, Z. 648-651. 
„Also ich finde schon, dass man sehr viel Zeit hat, sich das irgendwie selbst einzuteilen, dass man auch sehr unabhängig ist. Auch, so, gerade was zum Beispiel im Sommer, so, diese langen Semesterferien angeht. “112 Besonders begeistert äußert sich ein zuvor erwerbstätiger Student der Politikwissenschaft über „die ganzen Strukturen hier“ mitsamt der zugehörigen Selbstständigkeitszugewinne, die er nebenbei als unverzichtbare Lebenserfahrung wahrnimmt. ${ }^{113}$ Überhaupt ist nicht von der Hand zu weisen, dass sogar einige Kritiker der Lernbelastung prinzipiell gewisse Formen von Autonomie und Freiräumen nutzen. Dazu zählen einerseits inhaltliche und organisatorische Freiheiten. So konzediert die bereits zitierte Jura-Studentin, die über die Arbeitsintensität ihres Studiums klagt, dass sie ihre Immatrikulation keineswegs „bereue“, könne man sich doch „trotzdem noch alles irgendwie selbst... ja, einteilen. “114 Andererseits berichten viele Studierende ganz beiläufig über Variationen des Studienstils zugunsten der Freizeitgestaltung, etwa indem sie sich durch Vorarbeiten ganze Semesterferienmonate zum Zwecke des Verreisens „freischaufeln“115, indem sie ihre Prüfungsdichte dadurch reduzieren, dass sie die Regelstudienzeit um das eine oder andere Semester verlängern - ausgerechnet eine Jura-Studentin, die nach eigenen Angaben mehrere Semester lang das Studium zugunsten privater Genüsse schleifen ließ, klagt laut über einen ubiquitären und „total furchtbaren“ Leistungszwang, von dem die eigenen Eltern vermeintlich dispensiert gewesen seien $^{116}$-, oder indem sie schlicht die Bücher zuklappen und auf der Suche nach persönlichen Präferenzen des Denkens und Erlebens anderen Tätigkeiten nachgehen, sollte die Lernmotivation am Pflichtstoff einmal ausbleiben. ${ }^{117}$ Eine Studentin der Forstwissenschaft gibt zu Protokoll, Vorlesungen systematisch fernzubleiben, „weil mich das einfach nicht interessiert, da zuzuhören. Ich kann das nicht. Ich kann da nicht sitzen, und die ganze Zeit nach vorne gucken und zuhören. “118 Ein fachlich nahestehender Kommilitone gibt mit dem Blick auf vorgegebene Themen, die ihn weniger stark interessieren, zu: „[...] da kann ich mich einfach nicht dazu aufraffen, nachzuarbeiten. Das ist... [lacht] Und das ist so 'n bisschen die Schwierigkeit bei mir.“119 Und eine Studentin der Politikwissenschaft äußert sogar die Vermutung, dass die studentischen Freiräume - gemessen an internationaler akademischer Kooperation und an der Möglichkeit, Auslandsaufenthalte anzubahnen - im Vergleich zur Elterngeneration sogar zugenommen haben könnten. ${ }^{120}$ Wie sind diese stark auseinanderweisenden Perspektiven von Studierenden derselben Universitäten, teils sogar Fakultäten, zu erklären? Einen starken Zusammenhang zwischen erlebten Freiheitsgraden und spezifischen Studiengängen scheint es - jedenfalls jenseits der Frage nach dem Verschulungsgrad der Lehrpläne - nicht zu geben, abgesehen von einer Studentin der Musikwissenschaft, der das Volumen an Übungsstunden im Grunde

\footnotetext{
112 Transkript der 4. Fokusgruppe, S. 9, Z. 282-286 (Herv. i. O.)

113 Transkript der 3. Fokusgruppe, S. 13, Z. 402-411.

114 Transkript der 2. Fokusgruppe, S. 5, Z. 149.

115 Vgl. Transkript der 4. Fokusgruppe, S. 12, Z. 356-367.

116 Transkript der 4. Fokusgruppe, S. 13, Z. 386.

117 Vgl. Transkript der 6. Fokusgruppe, S. 11, Z. 315-328.

118 Transkript der 3. Fokusgruppe, S. 19, Z. 581-582 (Herv. i. O.)

119 Transkript der 3. Fokusgruppe, S. 26, Z. 789-792 (Herv. i. O.)

120 Vgl. Transkript der 4. Fokusgruppe, S. 15, Z. 454-465.
} 
jede „Zeit zur Selbstreflexion“ nimmt. ${ }^{121}$ Auch trägt die Vermutung, dass die Aussicht auf frei disponible Zeit vom banalen Faktum der eigenen Studienfinanzierung abhängen könnte, nicht weit. Natürlich stimmt es zunächst zwar, dass wer von Zuwendungen der Familie, vom BAföG oder von Stipendien leben kann, nicht darauf angewiesen ist, neben dem Studienalltag selbstständig Einkommensquellen aufzutun, und insofern einem geringeren Druck ausgesetzt ist. Doch dies bedeutet keineswegs eo ipso, dass die monetär Privilegierten ihre größeren Freiheiten auch wirklich nutzen. Im Gegenteil: Sowohl unter Langzeitstudierenden als auch unter jenen, die einem Nebenjob nur aus Gründen des Komfort-Surplus nachgehen - es also nicht tun müssten - finden sich einige, die sich außerstande sehen, einen größeren Teil ihrer Freizeit für private Lektüre zu opfern. Das mögen zwei Beispiele illustrieren: Jemand, der lapidar zu Protokoll gibt, dass die Regelstudienzeit „auch schon 'n bisschen hinter mir“ liege, bekennt: „Ich lese seit zwei Jahren das gleiche Buch. [allgemeines Lachen] Immer wieder neu angefangen, weil ich dann schon wieder vergessen hab', was ich da gelesen hab' vor einem halben Jahr, so.“122 Und eine weitere Studentin, die parallel zum Studium kellnert, obwohl sie „das Geld halt eigentlich gar nicht“ benötige, reflektiert Ähnliches mit schwerem Atem:

„]etzt ist es wirklich eher so, dass ich freizeitmäßig irgendwelche Romane lese oder sowas, aber selbst das... Also, ich hab' jetzt so'n Buch, und das ist so dick, und das hab' ich jetzt irgendwie seit 'nem dreiviertel Jahr oder so, und ich hab's halt immer noch nicht durch, weil ich halt... Keine Ahnung, manchmal, wenn ich bis Acht Uni habe, dann ess' ich was und dann geh' ich ins Bett, so, und dann bin ich fertig, so." ${ }^{\text {“123 }}$

Überhaupt: Die meisten, die einem Nebenjob nachgehen (wenngleich nicht alle!), scheinen das zwanglos und freiwillig zu tun - teils, um praktische Erfahrungen für spätere Tätigkeiten zu sammeln, häufig aber auch, um sich gelegentliche Anschaffungen oder Urlaubsreisen leisten zu können. Das wird nicht nur klar, wenn eine der Anklägerinnen mangelnder Freizeit, deren Studium von ihren Eltern finanziert wird, selbstironisch zugibt, im Grunde vor allem fehlende finanziell saturierte Freizeit zu monieren:

„Also, man hat ja auch viel... Oder ich hab' auch viel gehört: ,Im Studium kannst du doch so viel reisen, weil Semesterferien... Das ist auch nicht die Hauptsaison!' [allgemeine Erheiterung] Erstmal Semesterferien... Also, ich habe irgendwie Semesterferien, aber da auch fehlt das Geld! “'124

Viele Fokusgruppenteilnehmer aus den verschiedensten Studienfächern beschreiben ihre (tatsächliche oder geplante) parallele Erwerbstätigkeit darüber hinaus explizit als frei gewählte Beschäftigung, während das Studium hauptsächlich durch familiäre Zuwendungen, durch Stipendien, Studienkredite oder BAföG-Kredite bestritten wird. Es fällt schwer, aus der Reihe zahlreicher entsprechender Auskünfte eine Auswahl zu treffen:

121 Transkript der 6. Fokusgruppe, S. 8., Z. 240-252.

122 Transkript der 1. Fokusgruppe, S. 14, Z. 431 und S. 21, Z. 649-651.

123 Transkript der 4. Fokusgruppe, S. 15, Z. 480 und S. 18, Z. 546-550.

124 Transkript der 2. Fokusgruppe, S. 8, Z. 227-230. 
„Also, keine Ahnung, ich muss finanziell nicht arbeiten, aber ich tu's trotzdem. Ich muss meinen Eltern das Geld aber nicht geben. Also ich darf's dann behalten. “125 „Ich hab' 'nen Studienkredit vom ersten Semester an, hab' aber auch vom ersten Semester an immer als Werksstudentin ${ }^{126}$ nebenbei gearbeitet, um halt zusätzlich noch 'n bisschen was zu haben. Ich denke, meine Eltern würden mir auch Geld dazugeben, aber ich wollte das eben nicht, und hab' deswegen jetzt immer gearbeitet. Und jetzt arbeit' ich gerade nicht mehr und mach' das mit dem Studienkredit, und 'n bisschen so, das geht auch." ${ }^{\text {“127 }}$

„]a, ich hab' Glück, dass ich im Moment noch inner Stiftung drin bin, das heißt, ich... sodass ich nicht arbeiten gehen muss. [...] Und im Master will ich auch gucken, dass ich 'nen Job hab', weil es irgendwie spannend ist, in die Arbeitsgruppen 'reinzukommen, und gleichzeitig eben 'n bisschen Geld hab', doch auch mal in den Urlaub zu fahren oder so. [lacht] ${ }^{\text {u128 }}$

„B3: [...] Ich geh' in den Semesterferien arbeiten, aber das liegt auch daran, dass ich im Semester... Also, ich mach' 'n relativ stark ausgeprägtes Ehrenamt, wo ich quasi jeden Tag mehr oder weniger was für mache. [...] Also ich arbeite eigentlich immer so im Zeltbetrieb, so auf Schützenfesten, also auch gastromäßig, aber ich hab' auch zum Beispiel letztes Jahr vier Wochen bei Mercedes gearbeitet. So, also so das, was dann irgendwie grad' so passt und kommt. Ja. [...] B4: Also, ich hab'... teil' die StipendiumEhrenamts-Sache auch, und hab' so 'n kleinen Job an der Uni, aber das ist halt für einen selber mehr, gut, für 'ne kleine Anschaffung oder so.“129

„Also, ich krieg' ein bisschen BAföC und von meinen Eltern was, noch, und theoretisch müsste ich nicht arbeiten oder hätte ich nicht arbeiten müssen, aber man wollte sich... Ich wollte mir dann auch mal so was leisten [...], so, Luxus mal, 'ne? Mal mit Freunden mal wegfahren oder so $[. . .]^{4130}$.

Gelegentlichen oder dauerhaften Nebenjobs gehen den verbalen Selbstauskünften zufolge 25 von 44 Personen im Sample nach, von denen nur sechs angaben, zum Zeitpunkt der Gruppendiskussion unumgänglich auf Einkünfte aus Nebenjobs angewiesen zu sein, um ihr Studium zu finanzieren. ${ }^{131}$ Insgesamt wird man aus diesen Passagen zunächst schlussfolgern dürfen: Freiräume autonomer (Frei-)Zeitgestaltung existieren für die meisten Studierenden zweifellos. Wie sie aber diese Ressourcen nutzen und $o b$ sich Studierende selbst als souveräne Gestalter ihrer Studienzeit oder vielmehr als als überforderte, durch Pflichtleistungen und fortschreitende Semesterzahlen geknechtete Opfer des Bologna-Systems wahrnehmen, scheint von ganz unterschiedli-

125 Transkript der 1. Fokusgruppe, S. 14, Z. 406-408.

126 In Frankfurt a.M. bildete die mangelnde Verfügbarkeit attraktiver Tätigkeiten, etwa als Tutor oder Assistenz eines Professors, ein virulentes Thema. Stattdessen verdingen sich dort einige Fokusgruppenteilnehmer studienbegleitend als Werksstudenten. Ein Phänomen, das in Cöttinger Fokusgruppen unbekannt war; hier fiel nicht einmal das Wort.

127 Transkript der 7. Fokusgruppe, S. 12, Z. 376-380.

128 Transkript der 3. Fokusgruppe, S. 25f., Z. 774-781 (Herv. i. O.)

129 Transkript der 4. Fokusgruppe, S. 16f., Z. 497-530 (Herv. i. O.)

130 Transkript der 2. Fokusgruppe, S. 11, Z. 350-352.

131 Überdies steht es bei zwei weiteren Personen aufgrund ihres höheren Lebensalters und den daraus folgenden höheren Aufwendungen für Krankenversicherungsbeiträge u. a. zu vermuten. 
chen Variablen abzuhängen, nicht zuletzt sicher auch von charakterlichen Dispositionen und persönlichen Zielsetzungen. Paradoxerweise entsteht bei einzelnen Personen sogar der Eindruck eines antiproportionalen Zusammenhangs, so im Falle der MedizinStudentin, die erst nach einiger Überlegung zum Studium kam: Sie berichtet über ein besonders engmaschiges Netz an „Pflichtveranstaltungen“, über „alle vier Wochen“ „getaktet“ stattfindende Klausuren und über bei Studienbeginn „mit Praktika und Famulaturen“ förmlich gefüllte Semesterferien - und resümiert trotzdem lapidar, dass „man halt selber auch gucken“ müsse, „wo man seine Freiräume 'reinlegt“, habe doch „auch jeder 'ne andere, so Stressresilienz, würd' ich sagen. “132 Klagen also im Umkehrschluss vielleicht sogar jene Studierenden am häufigsten, die über vergleichsweise großes Maß an Freiräumen und disponibler Zeit verfügen? Eine launige Schlussfolgerung wäre das sicherlich, auch wenn sie sich durch das hier ausgewertete Fokusgruppensample nicht eindeutig belegen lässt.

Indes: Die Kritik des Studiums erschöpft sich nicht in der Anklage von Leistungsdruck, Prüfungsdichte und Anwesenheitspflichten. Einzelne Personen, zumeist solche mit klaren Vorstellungen gelingender Bildung oder mit festen sozialethischen Prinzipien, sondern auf den aus ihrer Sicht rezeptiven, devoten und verschulten Modus des Wissenserwerbs. Kritiker dieser Ausprägung argumentieren nicht quantitativ, sondern qualitativ; sie bringen explizit Gegenideale akademischer Bildung in Stellung gegen die gängige universitäre Lehr- und Lernpraxis. Sie berichten über Erfahrungen der intellektuellen Deaktivierung im Verlauf des Studiums. Eine Studentin der Literaturwissenschaft und der Soziologie fasst das so zusammen: „[...] diese Vorlesungsstrukturen oder diese Uni-Strukturen fördern 'ne irre - Merk' ich auch bei mir - ... 'ne richtig passive Haltung, so'ne... Ja. “133 Nachgerade befremdlich wirkt auf sie und ihre reformpädagogisch vibrierende Perspektive die auf Prüfungsformalia und auf den zügigen Abschluss fixierte Haltung ihrer Kommilitonen, die aus ihrer Sicht nichts als inhaltliches Desinteresse bekundet: „Da kam dann von den Studenten [aus] auch kaum mehr, irgendwie, 'ne Diskussion zustande, einfach auch, weil man so getrimmt worden war, irgendwie einfach immer in eine Richtung zu laufen und da durchzuhuschen, einfach. “134 Gelingende Bildung erfordere demgegenüber die Aktivierung und Ermutigung zu ungewöhnlichen und querdenkerischen Sichtweisen auch zum Preis des eventuellen Irrtums, den Abbau pädagogisch-didaktischer Hierarchien, schließlich die Ruhe zur Kontemplation. Ähnlich argumentiert eine Medizin-Studentin, die nicht nur breite Allgemeinbildung, sondern auch die Fähigkeit zur Reflexion sozialer Verantwortung und politischer Zusammenhänge als Voraussetzung einer angemessenen ärztlichen Tätigkeit identifiziert. Zudem wollen sich manche nicht mit den vorgegebenen Inhalten ihres Studiums abfinden. Der Dogmatismus abstrakter volkswirtschaftlicher Modelle führt etwa einen Studenten zum „proaktiven“ Versuch, im Rahmen einer Hochschulgruppe selbstständig heterodoxe Lehrveranstaltungen zu organisieren, ${ }^{135}$ einen anderen, $\mathrm{zu}$ dessen politischen Zielen die Förderung fairen Handels zählt, zum parallelen Studium der Philo-

132 Transkript der 4. Fokusgruppe, S. 14, Z. 421-434.

133 Transkript der 5. Fokusgruppe, S. 13, Z. 394-395.

134 Transkript der 5. Fokusgruppe, S. 6, Z. 181-184 (Herv. i. O.)

135 Transkript der 1. Fokusgruppe, S. 11, Z. 329-333. 
sophie. Dessen Skizzierung der individuellen Studienmotivation zählt zu den konzisesten, beeindruckendsten, aber auch humorlosesten Passagen überhaupt im Sample; das von ihm referierte, beinahe aus ihm hervorbrechende, selbstverordnete Schulungsprogramm differenziert nicht nur begrifflich zwischen fachwissenschaftlicher und holistischer Bildung, sondern bindet beide Aspekte darüber hinaus zu einer „studierfähigen“ Einheit zusammen, die sich aus dem Angebot akademischer Lehre bedient, anstatt die disparaten Lehrgehalte planlos und inhaltlich brav auf sich einwirken zu lassen:

„]a, ich studiere, weil ich Denken lernen will und weil ich Verstehen lernen will. Also, [...] ich komme nicht aus 'ner Akademikerfamilie, aber es war trotzdem irgendwie keine Frage, dass ich nach der Realschule das Abitur mache und nach dem Abitur studieren gehe. Aber das kam nicht, weil meine Eltern das irgendwie vorgelebt haben oder vorgegeben haben, sondern weil ich mich für gesellschaftliche Fragen interessiere. Also, VWL studier' ich, weil ich verstehen lernen will, wie Arbeitslosigkeit entsteht, warum Menschen in Arbeitslosigkeit leben, wie Preise entstehen. Und, vor allen Dingen, mein persönlicher Schwerpunkt liegt im fairen Handel oder in der Nachhaltigkeit, und zwar: Warum schaffen westeuropäische Länder oder Länder des globalen Nordens unfaire Arbeitsbedingungen in anderen Teilen der Welt? So, das war die, äh, Frage, warum ich VWL studiert habe im Wesentlichen, also das zu verstehen, warum das so ist - nicht erstmal, das zu beheben. Und Philosophie studier' ich begleitend, weil man da Verstehen lernt, also weil man halt... Es geht nicht darum, irgendwas zu wissen, sondern es geht darum, die Texte zu lesen und sie in den Kontext einzuordnen, und zu lernen, was die Autoren bewegt hat, das zu schreiben. Und auch, dass man sich vor 2.000 Jahren schon große Fragen stellen kann, auch wenn es komische Antworten gab." ${ }^{\text {'136 }}$

Derartigen Konzeptionen eines zielführenden Studiums liegt ein anspruchsvoller Bildungsbegriff zugrunde, der nicht nur auf Fachwissen und Selbstständigkeit, sondern auch auf den Erwerb einer gebildeten Persönlichkeitsstruktur setzt. Sie demonstrieren einen gewissen Ernst des Studierens, der ebenso in Gegensatz zum auf möglichst zügigen Abschluss schielenden Studium tritt wie zu genussorientierten Laissez-faireHaltungen. Auffassungen dieser Art, werden sie so dezidiert und konzentriert ausgeführt, erscheinen in der Gruppeninteraktion auf die Mitdiskutanten wie verstiegene und unnahbare Extrempositionen.

Das aber sollte nicht darüber hinwegtäuschen, dass in ganz unterschiedlichen Diskussionspassagen durchaus ein bildungsemphatischer mentaler Unterstrom von Studierenden erscheint. Bereits im Rahmen der Online-Sondererhebung des Studierendensurvey von 2011 ist notiert worden, dass zu den Spitzenreitern studentischer „Grundwerte" zunächst Freundschaft und Friede (Freiheit von Gewalt und Krieg), dann individuelle Autonomie im Sinne von Entscheidungsfreiheit und „ein Leben in Harmonie, ausgeglichen und mit sich im Reinen“ zählen: „Nahezu zwei Drittel der gegenwärtig Studierenden vertreten Freiheit und Harmonie ganz vehement [...] $]^{\star 137}$. Ebenso aber reüssierten unter Studierenden die „Tugenden“ der Wissbegierde und Neugier, der Toleranz

136 Transkript der 3. Fokusgruppe, S. 8, Z. 227-241 (Herv. i. O.)

137 Bargel/Simeaner: Gesellschaftliche Werte und politische Orientierungen, S. 6. 
und Vorurteilsfreiheit sowie der Kritikfähigkeit und des Hinterfragens, während nur etwa ein Drittel sich für Konventionalismus und Leistungsbereitschaft ausspreche. ${ }^{138}$ Zum adäquaten Habitus der Studentin bzw. des Studenten gehören also, so scheint es, durchaus auch intellektuelle und kontemplative Charakterzüge. Diese Beobachtungen lassen sich nun am Material der Fokusgruppen aus 2018 aktualisieren und differenzieren. Auch in den studentischen Gesprächen über Sinn und Zweck des Studiums reiben sich nicht nur die Ansprüche von Lerneifer und Lebensgenuss, sondern auch Leistungsund Bildungsorientierungen fortwährend aneinander, nicht selten sogar in verschiedenen Äußerungen derselben Personen. Mehr noch: In der direkten Abwägung siegt stets die leidenschaftliche Parteinahme für die Bildung, die immer auch als Teil und Ausfluss der im Austausch mit der Welt zu sich selbst findenden persönlichen Innerlichkeit wahrgenommen wird, ganz im Gegensatz zu den scheinbar von außen kommenden, gesellschaftlich produzierten Leistungsimperativen.

Um das nachzuvollziehen, lohnt sich zunächst ein Blick auf die Gründe, mit denen Studierende Prinzipien der Leistungs- und Anstrengungsbereitschaft - die sie als Kriterien fairer Zuteilung gesellschaftlicher Ressourcen nicht vollumfänglich ablehnen! - immer wieder als borniert ausweisen. Danach befragt, wie wichtig ihnen ein zügiger Abschluss des Studiums ist, gerieten die meisten Fokusgruppenteilnehmer ins Räsonieren. So müssen einige mit Rücksicht auf die herannahende Notwendigkeit, sich selbstständig krankenzuversichern oder auch auf den Wunsch, eine Promotion an das Studium anzuschließen, „zeitiger fertig werden“. ${ }^{139}$ Ähnliches gilt für jene, deren ältere Geschwister zuungunsten des eigenen BAföG-Anspruchs früher ihr Studium beenden oder deren Eltern der Verrentung entgegensteuern; sie ächzen angesichts dieser drohenden Fallbeile: „Das ist, so, Stichjahr, sozusagen, und das ist halt schon so 'ne Belas-

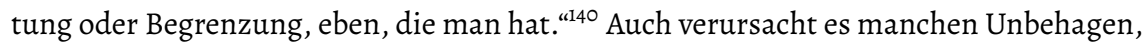
ihren Eltern „ewig auf der Tasche“ zu liegen, gerade wenn diese bereits einen kleineren oder größeren Anteil der Studienfinanzierung übernommen haben. ${ }^{141}$ „Da will man auch natürlich, auch, irgendwie Leistung bringen, und dann will man die Eltern auch nicht enttäuschen [...] “142 Jenseits dieses Aspekts der Studienfinanzierung plagt einige überdies die Ungeduld, ein zu langfristiges Studium könnte ihre persönliche Karriereplanung obstruieren. Einigen ist die Zeitplanung im Grunde schon durch die Qualifikationsschwellen ihres Karrierewegs vorgegeben, wie sie beinahe rechtfertigend darlegen:

\footnotetext{
„Aber [!] bei Psychologie ist das halt so: Wenn man in die therapeutische Richtung will - also in die Klinik, so wie man das kennt, so, mit Therapeutenquatsch und so -, also, macht man halt seinen Bachelor, dann macht man seinen Master, und dann macht man nochmal drei bis fünf Jahre Ausbildung, die man selbst finanzieren muss, und dann darf man erst arbeiten, also so im direkten Patientenkontakt." ${ }^{\text {“143 }}$
} 
Insbesondere wer dem Ende seines Studiums entgegensieht, bemerkt, „dass man schon jetzt auch bemüht ist, dass die Sache 'n Ende findet“, wolle man nun doch auch endlich „den nächsten Schritt gehen. ${ }^{\text {“144 }}$ Und wer sich ohnehin vergleichsweise spät in einem Studiengang eingeschrieben hat, möchte naheliegender Weise auch „nicht mit Mitte $30^{\text {“145 }}$ sein Berufsziel erreichen. Allerdings werden auch schlichte soziale Verpflichtungsempfindungen geäußert, die den Wunsch eines absehbaren Studienabschlusses begründen:

„B5: Ich bin jetzt, äh, in 'ner langen Beziehung schon, hab' ja 'ne Ausbildung gemacht, hab' gearbeitet, und man möchte ja Familie und Eigentum und sowas, und es ist wichtig, jetzt in den nächsten drei, vier Jahren... wollt' ich nicht nach 30 irgendwie erst dann komplett mein Leben wandeln, so, ne? [...] B6: Bei mir ist es genauso. Also wenn ich jetzt fertig werde in meiner Regelstudienzeit, dann wär' ich 27. Mein Freund hat halt schon zwei Kinder, und dann will ich jetzt auch nicht, dass der Unterschied da so groß sind. Und dann muss man ja auch noch 'n bisschen arbeiten, weil, man kann ja nicht nachm. Studium direkt 'ne Familie... kannste ja auch 'n bisschen schlecht, so..., dann auf'm Arbeitsmarkt wieder einzusteigen. Deswegen würd' ich, also wenn es irgendwie geht, auf jeden Fall in der Regelstudienzeit bleiben. ${ }^{\text {“146 }}$

Soweit die Motive eines zielstrebigen Studiums, die in den Fokusgruppen geäußert wurden: Finanzielle Gründe, der Wunsch nach dem nächsten Karriereschritt, schlechtes Gewissen gegenüber Familie oder Partnern. Erstaunlicherweise aber fasst niemand den Studienabschluss in Regelstudienzeit als Ausweis persönlicher Leistungsbereitschaft auf. Im Gegenteil, Leistungsanforderungen werden immer wieder als gesellschaftlich produzierte Zwänge wahrgenommen, denen zu widerstehen Teil eines gelungenen Studiums zu sein scheint. Wie sehr das einzelne Personen umtreibt, ist an der folgenden Passage gut zu erkennen:

„Irgendwie ist es so 'n... generell so 'n Leistungsdruck, irgendwie, in der Cesellschaft, und letztendlich... Ich stehe auf, um irgendwas zu lernen, damit ich irgendwie später durchkomme und irgendwie Geld verdiene, und dann irgendwann wieder sterbe. [lacht] [...] Ich will einfach mal gegen den Strom. [lacht] Ich will auch vielleicht mal 'n bisschen, ja, was Dummes machen, einfach. Einfach weil ich's kann. [allgemeine Erheiterung] ${ }^{\text {[147 }}$

Viele weniger verzweifelte Studierende stimmen dieser Jura-Studentin in der Sache zu. Zwei von ihnen äußern - ohne Widerstand vonseiten der jeweiligen Mitdiskutanten Sympathien für die Idee des Bedingungslosen Grundeinkommens oder für flächendeckende Arbeitszeitverkürzungen. ${ }^{148}$ Andere ziehen in Zweifel, dass man als Absolvent mit „Keine-Ahnung-wie-viel-Stunden-Woche“, d. h. ohne die „Zeit, das Geld auszuge-

144 Transkript der 2. Fokusgruppe, S. 16, Z. 495-496

145 Transkript der 3. Fokusgruppe, S. 20, Z. 618.

146 Transkript der 7. Fokusgruppe, S. 14f., Z. 446-458 (Herv. i. O.)

147 Transkript der 2. Fokusgruppe, S. 33, Z. 1051-1061 (Herv. i. O.)

148 Vgl. Transkript der 2. Fokusgruppe, S. 34, Z. 1060-1065; Transkript der 7. Fokusgruppe, S. 39, Z. 12451250. 
ben“, glücklich werden könne. ${ }^{149}$ Die Vorstellung des guten Lebens, wahrgenommen als Ideal älterer Generationen, werde aktuell gegen eine zwanghafte und genussfeindliche „Arbeitsmoral“ eingetauscht. ${ }^{150}$ Und das zugunsten einer Bildungsauslesepraxis, die nicht einmal besonders qualifiziertes Personal hervorzubringen scheint! Oft nämlich wirke das Studium wie eine „Gleichmachmaschine, wie so'n Laufband“, welches individuelle Qualitäten und Idiosynkrasien abschleife und schließlich alle „Möglichkeitsräume“, ,'nen eigenen Zugang, ,ne eigene Sprache“ im akademischen Beruf zu finden, abschneide. ${ }^{151}$ Auch im Falle der Rekrutierung von Ärztenachwuchs wünschen sich manche Studierende ein Ende der Fixierung auf Bildungszertifikate, Abschlüsse und Noten als Qualifikationsnachweis und fordern Einstiegsmöglichkeiten für jene, die „Passion“ und „Talent dafür“ haben, die „mega kompetent“ und aus beruflichem Interesse „motiviert" sind. ${ }^{152}$ Überhaupt nur drei der 44 Personen im Sample sahen gesellschaftliche Ungleichheiten an sich als gerechtfertigt und funktional $\mathrm{an}^{153}$ - ein fundamentaler Unterschied zum internalisierten Meritokratismus der nichtstudierenden Jugendlichen und jungen Erwachsen, wie er im Rahmen der Vorgängerstudie festgestellt wurde. ${ }^{154}$ Auch werden leistungsorientierte und formal zielstrebige Kommilitonen eher als befremdliche, instrumentell denkende und opportunistisch agierende Figuren gezeichnet („Welcher Medizinstudent macht das eigentlich noch, weil er's gerade wissen will, und wer macht's noch, um durchzukommen? ${ }^{(155}$ ), nicht zuletzt weil man andere Qualitäten eines Universitätsabsolventen ins Feld zu führen können glaubt, von denen man annimmt, dass sie künftigen Arbeitgebern wichtiger sein könnten:

„B4: Bei vielen Leuten, die ich kennengelernt hab', die 'n Ehrenamt auch irgendwie ausführen, ist es auch so, dass man im Hinterkopf irgendwie hat, dass es schon nützlich ist für 'nen Job! [...] B6: [...] ich muss gestehen, dass die Leute, bei denen das so ist, die ich kennengelernt habe, auch sehr fokussiert auf ihren Lebenslauf sind! Also die achten penibel da drauf, dass sie nach sechs Semestern fertig sind. Die achten penibel da drauf, was sie studieren, und nicht... Also, im Wesentlichen sind es BWLer bei mir im Umfeld. [allgemeine Erheiterung] [...] Ich hab' ein Auslandssemester gemacht, weil ich meinen Horizont erweitern wollte, und weil ich 'ne Kultur kennenlernen wollte, die ich noch nicht kannte. Die gehen da hin, weil es der fünfte Kontinent war, der ihnen irgendwie gefehlt hat im Lebenslauf, [allgemeines Lachen] wo sie noch keine Zeit ver-

149 Transkript der 4. Fokusgruppe, S. 6, Z. 161-173.

150 Transkript der 5. Fokusgruppe, S. 33, Z. 1023.

151 Transkript der 5. Fokusgruppe, S. 34, Z. 1035-1040.

152 Transkript der 6. Fokusgruppe, S. 35f., Z. 1117-1145.

153 Hier das expliziteste Beispiel: „Also, es muss schon aus meiner Sicht Unterschiede geben, dass man auch mehr Geld verdienen kann als andere. Wenn man halt... Wenn man nicht die Möglichkeit hat, mehr Geld zu verdienen, dann bringt man auch nicht mehr Leistung als andere, und dann bleibt man gesellschaftlich auch irgendwo stehen. Also, irgendwo will man sich ja auch weiter entwickeln, dass man, ja, irgendwie mal weiter fliegen kann als bis zum Mond oder so. [lacht]“ Transkript der 2. Fokusgruppe, S. 48, Z. 1525-1530 (Herv. i. O.) 
bracht haben. Und, also, ich glau-... Ich hoffe, dass die meisten Menschen Ehrenamt machen, weil sie Bock drauf haben.."156

Viele der zahlreichen Argumente, die gegen ein Studium im Schnelldurchlauf angeführt werden - so etwa Praktika und Auslandserfahrungen, ehrenamtliche Tätigkeiten und zivilgesellschaftliches Engagement, aber auch schlicht die durch Lebensalter und breites intellektuelles Interesse erlangte charakterliche Reife und die Möglichkeit, durch eine lockere Studiengestaltung ausprobierend zu sich selbst zu finden -, klingen ähnlich. Das nachgerade Wichtigste am Studium, so wird immer wieder, beinahe unisono herausgestrichen, könnte bei zu starker Leistungsfixierung schließlich auf der Strecke bleiben. Pointiert:

„Also für mich ist Studium eben nicht nur 'ne Ausbildung auf akademischem Niveau, sondern eher wirklich 'ne Art, ja, 'ne Art, eigentlich, intellektuelle Rundreise oder so. Also es sollte eigentlich zu jedem Studium gehören, dass man mindestens ein, zwei interdisziplinäre Sachen macht, und das geht durch so Sachen wie Regelstudienzeiten und den damit verbundenen Druck, oder erzeugten Druck, halt klar verloren.“157

Manch einer hat darüber hinaus „bei verschiedensten Karriereberatungen“vernommen, „dass oft drauf geachtet wird, dass man nicht zu schnell studiert“, weil „davon, dann, ausgegangen wird, dass man nicht die so genannten soft skills hat, die der Beruf [erfordert]. ${ }^{\text {“158 }}$ Auch Nebentätigkeiten und abgebrochene Ausbildungswege könnten auf diese Weise das Panier eines interessanten Bewerbers anreichern:

„Und ich weiß nicht, ob das zum Beispiel für Arbeitgeber dann besser ist, wenn man dann sagt - ja, meinetwegen -: , Ich hab' jetzt, also, hier diesen Agrar-Job, da, mit landwirtschaftlich, Marketing und Tourismus und so was, und dann halt noch 10 Stunden Kinderbetreuung die Woche!', ob das für den Arbeitgeber irgendwie besser ist und spannender, oder ob die wirklich sagen: ,]a, super, du hast hier 'nen 1,2er-Schnitt' oder so, ,und deshalb stellen wir dich jetzt ein! ‘159

Sicher, es sind $a b$ und zu auch jene Stimmen zu hören, die auf den hard fact des Erwerbslebens verweisen, dass der eigene Lebenslauf im Bewerbungsverfahren eben nur „'ne Nummer" darstelle, und man im scharfen Wettbewerb mit leistungsstarken Konkurrenten möglichst gute Noten vorweisen können sollte: ${ }^{160}$ „Du bist austauschbar in irgend 'ner gewissen Form und Art und Weise. Und das ist unangenehm! Weil, das ist jedes Mal begründungswürdig: Jedes Mal musst du begründen: ,Warum jetzt grad' du? ${ }^{\text {'161 }}$ Doch können sich die meisten stets darauf einigen, dass fachliche Leidenschaft und eine ausgebildete Persönlichkeit ebenso wichtig seien wie erworbenes und durch Prüfungsleistungen dokumentiertes Fachwissen, wenn nicht noch wichtiger. Bisweilen

156 Transkript der 3. Fokusgruppe, S. 30, Z. 910-912 (Herv. i. O.)

157 Transkript der 1. Fokusgruppe, S. 17, Z. 514-518 (Herv. i. O.)

158 Transkript der 6. Fokusgruppe, S. 28, Z. 883-886 (Herv. i. O.)

159 Transkript der 3. Fokusgruppe, S. 23, Z. 696-701.

160 Transkript der 6. Fokusgruppe, S. 29, Z. 923-929.

161 Transkript der 6. Fokusgruppe, S. 29, Z. 911-913 (Herv. i. O.) 
scheint es, als wäre die Studientätigkeit nebst der dabei erworbenen Persönlichkeitsstrukturen selbst die eigentliche Leistungserbringung, ob das nun in Gestalt eines verletzten Gebildetenstolzes vorgetragen wird (hier in Gestalt einer Studentin der Arabistik und der Literaturwissenschaft, die sich gegen eine Studentin der Volkswirtschaftslehre und der Sportwissenschaft zur Wehr setzt) oder eher als zarte Spekulation (hier vonseiten eines Studenten der Politikwissenschaft) Eingang in das Gespräch findet:

„B7: Wenn du keine praktische Erfahrung hast, ist der Einstieg später einfach [schwer]. B3: Ich hab' ja durch meine Nebenjobs, dann, praktische Erfahrung. B7: Ich arbeite auch nebenbei, aber ich finde, es ist... B3: Also, es kommt drauf an, in welchen Beruf man will. B7: ... Also, 'n Nebenjob ist was Anderes als wirklich 40 Stunden die Woche zu arbeiten. B3: Na, ich hab' für's Studium mehr getan als 40 Stunden in der Woche, von daher... Weiß ich nicht."162

„Ist das nicht auch 'ne andere Form von Zielstrebigkeit, wenn man die Softskills um's Studium 'rum aufbaut [...] ?4163

Obwohl viel Skepsis und abgeklärtes Abwinken im Zusammenhang mit der oft blumig wirkenden Figur von der "Selbstfindung“ und „Selbstentfaltung“ im Rahmen des Studiums auch geäußert wird (einige werden weiter unten noch zur Sprache kommen), ist doch unverkennbar, dass fast alle Personen im Sample ${ }^{164}$ Erfahrungen machen, die sie zu dieser Wortwahl bewegen. Dezidiert gegen die Vorstellung eines kurzen Weges zum Abschluss berichten die Studierenden darüber, dass das Studium zu einer "selbstkritischen" Haltung befähige, die einen in die Lage versetze, auch "seinen eigenen Weg“ $\mathrm{zu}$ "hinterfragen “165 und dass „Selbstverwirklichung“ mitunter darin besteht, sich Rechenschaft ablegen zu können über die Frage: „Was will ich wirklich machen? Was ist mir wichtig?“ und „Kompetenzen“ ohnehin ganz nebenbei aufzubauen ${ }^{166}$; dass sie „sowieso zwei Semester länger“ einplanen, um Zeit zu haben, „mich persönlich weiterzuentwickeln durch die freiwilligen Aktivitäten" etwa in der Flüchtlingshilfe, die sie seit Schulzeiten gewohnt sind ${ }^{167}$; dass es dazugehöre, sich zwischendurch „auch echt schöne Sommer ${ }^{\text {168 }}$ bzw. „'ne schöne Zeit und Möglichkeit zur Selbstreflexion" ${ }^{\text {“169 }}$ zu gönnen; dass man für die Befriedigung intellektueller Interessen und den damit zusammenhängenden „Findungsprozess“ „einfach 'nen gewissen Raum" benötige ${ }^{170}$; oder dass man sich ganz einfach seine "Zeit" nehme, da es "ja nicht schlimm" sei, „wenn ich ein bis zwei [Semester] dranhänge“. ${ }^{171}$ Es fällt im Übrigen auf, dass sogar die besonders aktiven, vielfältig engagierten und darin eben doch leistungsorientierten Studierenden offenbar

162 Transkript der 1. Fokusgruppe, S. 583-596.

163 Transkript der 3. Fokusgruppe, S. 28, Z. 852-853.

164 Die einzige offensichtliche Ausnahme bildet jene Studentin der Musikwissenschaft, der im Cruppengespräch - zum aufgeregten Unverständnis ihrer Mitdiskutanten - nur zu konstatieren bleibt, sie habe „sehr wenig Zeit für Selbstreflexion." Transkript der 6. Fokusgruppe, S. 8, Z. 240. Transkript der 1. Fokusgruppe, S. 28, Z. 853 und 861-862.

166 Transkript der 3. Fokusgruppe, S. 23, Z. 704-705.

167 Transkript der 3. Fokusgruppe, S. 22, Z. 677-680.

168 Transkript der 4. Fokusgruppe, S. 12, Z. 373-376.

169 Transkript der 6. Fokusgruppe, S. 11, Z. 326.

170 Transkript der 5. Fokusgruppe, S. 23, Z. 712 und S. 34, Z. 1046 (Herv. i. O.)

171 Transkript der 7. Fokusgruppe, S. 17, Z. 515-516. 
davor zurückschrecken, sich auf Leistungsprinzipien wie Zielstrebigkeit, Einsatz- und Entscheidungsbereitschaft oder zupackenden Opportunismus, zu berufen. Der Grund dafür scheint aber nicht primär in der völligen Ablehnung eines entschlossenen oder opportunistischen Vorgehens in der eigenen Lebensplanung zu liegen, sondern in der studentischen Gesellschaft der Fokusgruppen: Wertbezüge, die allzu leicht mit den Begriffen der ordinären Erwerbswelt verbunden werden können, scheinen hier unschön, ja unfein zu wirken. Wer den Leistungszwang bejaht, wirkt schnell bieder. Auch die Bejahung sozialer Ungleichheiten und Einkommensdifferenzen scheint dem gruppenhegemonialen ästhetischen Empfinden nicht zu entsprechen - obwohl die Studierenden doch wie gesehen künftige finanzielle Sekurität für sich reklamieren.

Denn schlussendlich laufen die Auskünfte der Studierenden auf eine spezifische, mehrheitsfähige Haltung hinaus: Ein Studium ist kein Studium, wenn man nicht auch Zeit "für sich" wahrnimmt und überdies nicht auch - und in diesem Wort bündelt sich ein außerordentliches Maß studentischer Ehrfurcht - Bildung erfährt. Denn Bildung soll, dem „ursprüngliche[n] Gedanken von Universitäten von vor Jahrhunderten “172 gemäß, mehr sein als die bloße universitär organisierte Ausbildung zur Fachkraft, eben so etwas eine „intellektuelle Rundreise“, die den zum guten bildungsbürgerlichen Ton gehörenden Bildungsreisen des späten 19. Jahrhunderts ähnelt, die in die Kernstätten vermeintlicher europäischer Kultur führten. Welche Motive versammeln sich in diesem studentischen Bildungsideal? Ein wesentliches Leitmotiv ist bereits zur Sprache gekommen: die das Studium begleitende Charakter- und Persönlichkeitsbildung im Sinne von Selbstfindung, Selbstentfaltung und Selbstverwirklichung, des Zu-sich-selbst-findens. Man beobachtet,

„dass ich gerade durch das Studium [...] mich schon sehr auch charakterlich nochmal anders entwickelt hab' [...] Man hinterfragt viel mehr, irgendwie [...] Es ist irgendwie, auch irgendwo 'ne Interessenbildung und -findung, und auch irgendwo 'ne Richtung, die man einschlägt $[\ldots . .]^{4173}$

Besonders imponierend empfindet ein zuvor berufstätiger Student der Politikwissenschaft die Lektüre von Kant und Schumpeter, die ihm „einfach für mich persönlich'n schönes Gefühl“ verschaffe, „wo ich auch glaube, dass ich dadurch weiterkomme.“174 Ähnliches berichtet eine Studentin der Wirtschaftswissenschaften, die sich „manchmal auch so 'n paar deutsche Klassiker" im Stile eines höheren Konsumguts zu Gemüte führe: „[...] so 'n bisschen intellektuell... 'n bisschen hochtrabender sich mal so Gedanken zu machen, find' ich eigentlich auch ganz schön. “175 Abgesehen vom Anreichern der eigenen Interessen und Erfahrungen zählt für einige zur „Persönlichkeitsentwicklung“ aber auch die bloße Nötigung, den eigenen Alltag zu organisieren, salopp: erwachsen zu werden, da man „einfach mal ins kalte Wasser geschmissen “176 werde; „zu überlegen, welche Entscheidungen man trifft, und... Ähm, aber ich glaub' das ist einfach 'n Lernen 
und Wachsen, ein Prozess, so ungefähr, nicht? ${ }^{\text {(177 }}$ Und in diesem Prozess des Sich-bildens lässt man sich ungerne stören, sei es doch beim späteren Berufseintritt ohnehin „teilweise [...] unnormal, was da die [...] Gesellschaft von einem fordert, also was man da alles gemacht haben soll! “178 Denn eingebettet in den Schutzraum der civitas academica stellt man fest, dass man durch das, „was das Studium mir auch persönlich irgendwie gibt auf der Ebene, dass ich lerne, dass ich irgendwie mich persönlich weiterentwickel' durch das, was ich irgendwie durch die Umgebung von Leuten [mitbekomme] “179, den Kern der eigenen Persönlichkeit erst freilege. In einer Frankfurter Fokusgruppe wird zwar, womöglich getragen von der Erfahrung großstädtischer Lebensweisen und der lokalen Massenuniversität, die Vorstellung der Selbstfindung ideologiekritisch problematisiert. Dort wird die Überlegung geäußert, dass viele Studierende die arbeitsmarktkonforme Funktion der kollektiv praktizierten „Flucht vor der Arbeitswelt" als volkswirtschaftliche „Knautschzone“ nicht sähen. In der finsteren Plötzlichkeit der in diesem Zusammenhang getätigten Aussage eines Bildungsaufsteigers kommt eine zynische Form von Sozialkritik zur Geltung: „Das ist der romantische Müßiggang des 21. Jahrhunderts. Das wiederum aber nur... kann sich nicht jeder leisten. “180 Unterstützt wird er von einem rhetorisch versierten Mitdiskutanten und Bachelor-Absolventen einer Privatuniversität, welcher mit beachtlich scharfer Klinge die im Selbstfindungsanspruch durchaus enthaltenen eskapistischen, vielleicht auch infantilen Gehalte seziert:

„[...] ich glaube, der entscheidende Faktor ist: Wir müssen realisieren, dass diese Bildungshoffnung nicht eingelöst wird, also dass wir alle studieren, studieren, studieren, irgendwie dadurch denken: ,Oh, jetzt müsste doch mal einer anerkennen, dass ich irgendwas Besonderes bin!', ne, dass mich einer wertschätzen soll für das, das ich bin. Aber du bist es nicht! Du bist austauschbar in irgend 'ner gewissen Form und Art und Weise. Und das ist unangenehm! “181

Deutet das auf eine Polarisierung des studentischen Bildungsbegriffs zwischen Idealisten und Pragmatikern hin? Nein: Dagegen spricht nicht nur die bereits referierte fächerübergreifende Fülle von Selbstentfaltungserfahrungen, sondern auch die sonstigen Äußerungen der Ideologiekritiker im Sample: Selbst der Diagnostiker des realitätsfernträumerischen „romantischen Müßiggangs“ verteidigt an anderer Stelle den Anspruch, dass nur Akademiker den vollen Status reflektierter Bürger einer Demokratie erheben können!

„Dann hab' ich Literatur angefangen, Germanistik, und hab' mir dann im Laufe dessen gedacht, dass [das] Studium doch irgendwie notwendig ist, um irgendwie ein vernünftig-mündiger Mensch der Cesellschaft zu werden, der darin auch agieren kann. Und die Zeit der Persönlichkeitsentwicklung auch zu haben und [sich] zu nehmen, weil das auch 'ne... während der Schullaufbahn bis zum Abitur nicht unbedingt gegeben ist, dass man sich da frei, eben, von Konventionen, Sozialstrukturen, wie auch immer... 
,Was ist cool, was ist nicht cool?'... Da geht man noch 'n bisschen unter, wahrscheinlich. Und das Studium ermöglicht jedenfalls diese Freiheit. Ja." ${ }^{\text {“182 }}$

Dieser Anspruch hängt wohl damit zusammen, dass die Studierenden einer gebildeten Persönlichkeit weitere Qualitäten als die bloße Reflexion der eigenen Vorlieben und Fähigkeiten abverlangen: Bildung impliziert für sie nachgerade ethische Pflichten zur rationalen wissenschaftlich-deduktiven Urteilsbildung, kurz: zum „kritischen Hinterfragen“ und zu dem - als daraus zwingend folgende perzipierten - Werthaltungen „Toleranz" und „Offenheit“. Es ist erstaunlich, wie einmütig in den jeweiligen Fokusgruppen, ungeachtet der durchaus rhetorische Differenzen produzierenden Studienfachzusammensetzung im Einzelnen, an diesem Punkt dieselben Motive, überdies auch weitgehend identische sprachliche Formeln eingebracht werden. Kaum eine handlungspraktische Maxime ist als kollektivierender Identifikationsanker unter Studierenden so leistungsfähig und zustimmungspflichtig wie die Gleichung „kritisch hinterfragen“ - „tolerant/vorurteilsfrei/offen sein“ - „Bildung“, 2018 ebenso wie schon $2011 .{ }^{183}$ Wie sehr diese Vorstellungen einer edlen Haltung die studentischen Leidenschaften binden, ist anhand von Studierenden verschiedener fachlicher Hintergründe leicht zu illustrieren, die auf die Frage antworten, welche Art von Charakterbildung man an der Universität erfährt:

„Ich, also, ich finde, man geht Vieles auch viel offener an. Also man ist nicht so engstirnig und nicht so 'ne... unbedingt nicht so 'ne Schiene, die man fährt, sondern man ist schon vielem gegenüber sehr offen und auch interessiert und neugierig und packt das nicht direkt in 'ne Schublade und sagt: ,Oh Gott, weil der jetzt das und das trägt,

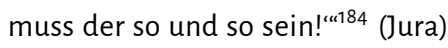

„Ich muss sagen, bei mir ist das eher so, dass ich viel kritischer geworden bin [...] In meinem Studiengang lernt man halt, alles total zu hinterfragen und kritisch zu sein mit den Ergebnissen, die man hat, und von daher... [...] Auf jeden Fall das kritische Hinterfragen. Das macht man, also, viel stärker als früher in der Schule. ${ }^{\text {“185 }}$ (Chemie) „Also, hier wird halt nicht nur gelernt, wie man lernt, sondern halt auch alles irgendwie mit 'ner eigenen Meinung, auch wenn man's... wenn es mit Auswendiglernen verbunden ist, zu kombinieren, und alles 'n bisschen kritischer zu hinterfragen. ${ }^{\text {“186 }}$ (Erziehungswissenschaft/Sportwissenschaft)

Befragt, welche Assoziationen man mit dem Begriff der Bildung verbindet, antworteten die Fokusgruppenteilnehmer:

„Bildung sind [...] die Wege und die Praxen und die Fähigkeit, die ich dabei erlange mit meinem eigenen, äh - Othering myself -, mit meinem eigenen Nichtwissen und meiner eigenen Unfassbarkeit in mir selber und anderen Dingen gegenüber umzugehen! Das ist eher 'ne, find' ich, 'ne Haltung oder so, die ich da erlang', und nicht Wissen, das ich auf 'nem Haufen anhäuf', irgendwie. Eher Praktiken, mit irgendwas umzugehen.

182 Transkript der 6. Fokusgruppe, S. 8, Z. 229-236 (Herv. i. O.)

183 Vgl. Bargel/Simeaner: Gesellschaftliche Werte und politische Orientierungen, S. 8.

184 Transkript der 2. Fokusgruppe, S. 26, Z. 810-814 (Herv. i. O.)

185 Transkript der 2. Fokusgruppe, S. 26, Z. 816-822 und 806-808.

186 Transkript der 3. Fokusgruppe, S. 10, Z. 295-298 (Herv. i. O.) 
Und für mich ist, äh, ist Bildung zum Beispiel, wenn ich Widerstände aushalten kann, wenn ich, keine Ahnung... Das sind ja Sachen, die man dann irgendwann lernt..187 (Deutsch/Englisch, Lehramt)

„Und das ist Bildung für mich auch auf jeden Fall: Reflexionsfähigkeit. Und das ist etwas, was Uni, glaub' ich, kann und versucht zu machen [...] ${ }^{4188}$ (Medizin)

„So 'n bisschen, auch, marktfernes, marktkritisches Denken vielleicht auch. ${ }^{\text {“189 }}$ (Politikwissenschaft/Arabistik)

„Ich würd' generell wahrscheinlich auch... einfach auch dieses kritische Denken, dass man, so, Sachen hinterfragt und auch, ja, einfach kritisch ist allem gegenüber, und halt nicht alles einfach so hinnimmt. ${ }^{\text {“190 }}$ (Betriebswirtschaftslehre)

Oft ist die Bildungsemphase in dieser Hinsicht so stark, dass sie nicht im Studium selbst erblickt, sondern im Gegenteil gegen dessen uniformierende Aspekte erst recht in Stellung gebracht wird. ${ }^{191}$ Durch das kritische Hinterfragen wird ein gebildeter Mensch eo ipso ein besserer Mensch als der bloß leistungsfähige; aus diesem Grund ist Bildung in den Augen eines Studierenden auch die volkswirtschaftlich wertvollere Produktionskraft als die stupide Anstrengungsbereitschaft: „Der ganze gesellschaftliche Mehrwert entsteht aus Bildung! Das war früher mal anders, als alle vom Land gelebt haben. ${ }^{\text {(192 }}$ Bedenken über die Konsequenzen einer weiter wachsenden Bildungsexpansion werden zwar vereinzelt geäußert, aber nicht weiter ausgeführt. ${ }^{193}$ Natürlich erschöpft sich das studentische Bildungsideal nicht allein in solchen Aspekten der wertbasierten Persönlichkeitsbildung. Ebenso gehören naheliegende Elemente wie das aufrichtige Interesse am Studienfach und die kontinuierliche Lernbereitschaft, verstanden als „Lernen um des Lernens willen“, als „Ich will das für mich grad' lernen! ${ }^{(194}$ und als praxisorientiertes Lernen, dazu. Bildung ist nicht $\mathrm{zu}$ denken ohne Fachwissen und ohne die letztlich ja auch berufsbefähigenden „Kompetenzen“ des Wissenserwerbs. ${ }^{195}$ Andere addieren hier

187 Transkript der 5. Fokusgruppe, S. 31, Z. 939-945 (Herv. i. O.)

188 Transkript der 5. Fokusgruppe, S. 33, Z. 1006.

189 Transkript der 1. Fokusgruppe, S. 26, Z. 776.

190 Transkript der 4. Fokusgruppe, S. 29, Z. $901-903$ (Herv. i. O.)

191 „Gerade dass wir Vieles hinterfragen, kommt zum Teil auch zu kurz. [...] Also, da kommt vielleicht irgendwie im Studium generell dieses... Selbstkritik und, äh, Gesellschaftskritik zu kurz, aber daraus resultiert dann auch, dass es eben nicht so passiert, sondern da ist man eben auch so sehr straight drinne, und dann kommt auch der Job nach dem BWL, ,das passt schon!'“ Transkript der 1. Fokusgruppe, S. 28f., Z. 864-869 (Herv. i. O.); „Wir hatten ja auch das kritische Hinterfragen, das zählt für mich auch zu dem Bereich "Bildung". Das ja manchmal recht aneckt, ähm. Die Uni macht intellektuelle Menschen, aber nicht immer intelligente." [lacht] Transkript der 5. Fokusgruppe, S. 31, Z. 948-950.

192 Transkript der 6. Fokusgruppe, S. 44, Z. 1392-1393.

193 Vgl. Transkript der 7. Fokusgruppe, S. 21, Z. 641-666.

194 Transkript der 5. Fokusgruppe, S. 14, Z. 424-425.

195 „Also, in vielen Fächern geht es ja [...], gerade wenn man in der Forschung sein will, auch einfach darum, viel zu wissen, nachher.“ Transkript der 3. Fokusgruppe, S. 10, Z. 291-293 (Herv. i. O.); „[...] dieser Unterschied zwischen Uni als einfach nur Wissensvermittlung, oder aber Uni auch als eine Institution, die mich auf meinen Beruf vorbereiten soll - und nicht nur für sich selbst." Transkript der 3. Fokusgruppe, S. 25, Z. 790-792. 
noch den Akzent der Allgemeinbildung und des „lebensnahen“ praktischen Alltagswissens; für sie ist der stereotype Bewohner des Elfenbeinturms noch kein Gebildeter. ${ }^{196}$ So lobt eine Studentin mit Erziehungsverantwortung für die Kinder ihres Partners die Waldorfschule für deren größere Nähe zu wahren Bildungsprinzipien: „[...] ich finde, da ist nochmal 'n bisschen mehr dieses Allumfassende, dieses Ganzheitliche mit drin, was man sonst gar nicht hat. ${ }^{197}$ Insofern enthält das studentische Bildungsideal auch formelle Bildung. Aufschlussreich aber ist, dass sich der studentische Bildungsbegriff eben nicht auf formelle Aspekte reduziert: Erst durch die Verinnerlichung bestimmter Werte und durch die nach außen demonstrativ zur Schau gestellte charakterliche Imprägnierung durch emphatische Bildung - durch möglichst kultiviertes, vorurteilsfreies Sozialverhalten sowie übrigens auch durch sprachliche Versiertheit und feinsinnige Ausdrucksformen ${ }^{198}$ - beweist man, wenn auch zunächst widerwillig, dass man dazugehört. Wer nichtoffen, nichttolerant, nicht „kritisch“ ist, muss zur Masse der Ungebildeten zählen, von welcher man sich selbst mental sukzessive fortbewegt. Intolerante Menschen erscheinen als dumm, unaufgeklärt, „konservativ“199 , wenn auch mitunter durchtrieben; so werden auch AfD-Politiker folgerichtig als „intelligente Deppen“200 rubriziert. Ein Hauch von Eribon durchzieht den Blick auf den einstigen Freundeskreis und aufs nichtakademische Herkunftsmilieu. ${ }^{201}$ Noch einmal: Zwar werden die durchgebildetsten, radikalsten Auffassungen bildungshumanistischer Innerlichkeit hauptsächlich von Studierenden der Geistes- und Sozialwissenschaften verfochten. Nicht alle, die unter Bildung die aktive Aneignung von Wissen und die Verarbeitung von Erfahrungsgehalten durch einen sich im Prozess selbst verändernden Geist verstehen, erwecken den Eindruck intellektueller Betriebsamkeit, Selbstentfaltung scheint nicht selten auf banale Genussorientierungen (,'n bisschen was Dummes machen“) hinauszulaufen. Doch auf die eine oder andere Weise normativ bindend wird die Bildungsemphase von allen empfunden. Bildung privilegiert, sie ist eine hoch zu schätzende Einflussgröße der eigenen Persönlichkeit und Innerlichkeit; insofern gehört sie offenbar jenen,

196 „Ähm, Bildung sollte sie [die Universität] auf jeden Fall schaffen, ähm, aber auch lebensnah und praktisch bezogen. Ich hab' manchmal das Gefühl, es wird so überbildet, überblendet - dass die Leute dann so hochintellektuell sind, dass auf der praktischen Ebene, irgendwie, ganz viel wegfällt. Also, 'n Telefonbuch auswendig lernen können, ist 'ne ganz tolle Sache, aber wenn ich nicht weiß, wie ich 'n Telefon bediene, um jemanden anzurufen, dann bringt es nichts." Transkript der 5. Fokusgruppe, S. 30, Z. 908-912 (Herv. i. O.)

197 Transkript der 7. Fokusgruppe, S. 22, Z. 684-685.

198 „Ich glaub', das entfernt auch, sag' ich mal, die Studenten von den Nichtstudenten. Weil, wenn ich manchmal mit meinen Freunden, halt, so zusammen bin, die nicht studieren, bin ich so der Meinung, ich leb' so in zwei unterschiedlichen Welten, sag' ich mal. Da muss ich so verhalten, da dann so." Transkript der 7. Fokusgruppe, S. 9, Z. 272-275 (Herv. i. O.); „Ähm, und ich komm' ja aus den Geisteswissenschaften, da wird man für [...] Sprache ja doch sehr sensibilisiert, und auch für, na, sagen wir mal: irgendwie korrekte Sprache im Sinne von: Man ist halt nicht beleidigend, man ist nicht herablassend, man benutzt gewisse Kraftausdrücke auch einfach nicht mehr, also gerade sowas wie, irgendwie, ,Fotze' oder so." Transkript der 7. Fokusgruppe, S. 10, Z. 293-297.

201 Vgl. dazu die Ausführungen der Studierenden über die mentale Isolation universitärer Lebenswelten in Kapitel III.2 dieser Studie. 
die studieren, schließlich unverbrüchlich. ${ }^{202}$ Aber Bildung enthält auch einen tief empfundenen, individuell verpflichtenden universalistischen Anspruch, dem sich die Studierenden nicht entziehen können. Sie adaptieren erst tentativ, dann überzeugt die Gepflogenheiten einer universitären Subkultur bzw. eines diffusen Gebildetenmilieus und können sich dabei häufig nicht entscheiden, ob diese Entwicklung sie „charakterlich versaut "203 oder das eigene Bewusstsein nicht doch auf eine höhere Stufe wissender Objektivität erhebt. Der studentische Bildungsbegriff setzt auf die disziplinierende und verpflichtende Wirkung von Rationalität und Vernunft von der schulischen Bildung bis zum Erwachsenenalter. Daher gilt Bildung den Studierenden nicht nur als Triebkraft der eigenen Biographie- und Persönlichkeitsveredelung, sondern auch als entscheidender übersubjektiver Fortschrittsagent auf gesamtgesellschaftlicher Ebene, wie weiter unten ausgeführt noch wird. ${ }^{204}$ Materielle Erwägungen und meritokratische Prinzipien hingegen erscheinen im studentischen Gruppenklima eben als begrenzt, partikular, schnöde. ${ }^{205}$

Der studentische Bildungsbegriff ist also voluminös und anspruchsreich. Bildung zählt aus Sicht der Studierenden - und je stärker sie sich mit ihrem Studium identifizieren, desto überzeugter - zu den „höchsten Güter[n]“206 schlechthin. Woher aber rühren Leidenschaft und semantische Dichte? Im hier skizzierten Bildungsideal scheinen sich sowohl akademisch-bildungshumanistische Traditionslinien zweier Jahrhunderte als auch der moderne bildungspolitische Jargon des workfare-Denkens („lebenslanges Lernen") zu kondensieren. Das weckt Interesse an einem begriffs- und sozialgeschichtlichen Rückblick; besonders an den Ursprung des neuhumanistischen Bildungsverständnisses der preußischen Reformbeamten im frühen 19. Jahrhundert ist zu erinnern. ${ }^{207}$ Das unübersetzbare deutsche Wort „Bildung“, noch weit bis ins 18. Jahrhundert hinein, im Grunde bis zu Herder und Goethe, verstanden als pädagogischer Begriff im Sinne der institutionengeleiteten theologischen und politischen Erziehung von zwar passiv, aber doch zunehmend als idiosynkratische Gesamtpersönlichkeiten gedachten

202 Das ist, abgesehen von den differenten inhaltlichen Vorstrukturierungen durch den Themenkatalog, womöglich nicht unwesentlich für die Frage, warum die Studierenden im Gegensatz zu den Jugendlichen und jungen Erwachsenen der Vorgängerstudie überhaupt nicht über den Besitz eines Eigenheims sinnieren.

203 Transkript der 2. Fokusgruppe, S. 29, Z. 906 (Herv. i. O.)

204 Vgl. Kapitel III.3.2 und Kapitel III.3.4 dieser Studie.

205 Sicher wird dieser Effekt dadurch verstärkt, dass rein „materialistische“ Werthaltungen schon im Zuge der1960er, 1970er und 1980er ]ahre aus der Mode gekommen sind: „[...] es hat auch viel damit zu tun, dass irgendwie, glaub' ich, wir alle so halbwegs in 'ner Ceneration sind, wo das immer eher so 'rüberkommt: ,Verwirkliche dich selbst und lebe deinen Traum!', so, und weniger: ,Such dir'nen Beruf, in dem du Geld verdienst!'“ Transkript der 1. Fokusgruppe, S. 28, Z. 845-848.

206 „Es ist aufjeden Fall eines der höchsten Güter, die wir in unserem alltäglichen Leben, wie wir es hier haben, erleben und leben dürfen. Und die Sache ist, dass man auch selber einmal verantwortlich ist, andere zu bilden, aber auch für sich selber verantwortlich ist, Bildung zuzulassen." Transkript der 4. Fokusgruppe, S. 28, Z. 890-893; „Wenn es jetzt bezogen auf Cesellschaft ist, [unverständlich] dass die Gesellschaft funktioniert, unser Rechtssystem und so weiter. Weil, ich glaub', mit Dummen kann man alles machen." Transkript der 6. Fokusgruppe, S. 31, Z. 990-992. 
Bildungsrezipienten, ${ }^{208}$ erweiterte sich im Zuge der preußischen Bildungsreformen und der Denkbewegung des spätaufklärerischen deutschen Idealismus um die Bedeutungsgehalte einer aktiv tätigen Vernunft. Damit aber trat der philosophische Bildungsbegriff aus der eng umgrenzten Zweckbestimmung, Nachwuchs für die Verwaltungen zu generieren, heraus, und schließlich in offenen Gegensatz zum Interesse des aufgeklärt-absolutistischen Staates an wohlerzogenen Untertanen: „Die Frage wurde gestellt, ob und inwiefern bei der Erziehung die Vollkommenheit des einzelnen Menschen seiner Brauchbarkeit aufzuopfern sei [...] “209. Bei Wilhelm von Humboldt schließlich impliziert der Begriff der Bildung nicht nur die weitgehende Freiheit von „äußeren Zwecken“210 , sondern auch einen unabschließbaren Prozess der „Entdeckung“ bzw. „Entfaltung“ persönlicher Anlagen des ganzen Menschen ${ }^{211}$ sowie dessen aktive Selbstbildung zum „sittlich handelnden Wesen“212 vom propädeutischen Gymnasium bis hin zur „reinen“ Wissenschaft. Die Verve des allgemeinbildenden Anspruchs wird nur verständlich, wenn man das damit bezeichnete Ziel eines spezifischen emanzipierten Menschentypus ernst nimmt; im einzelnen gebildeten Menschen sollte sich „Bildung, Weisheit und Tugend“ derart realisieren, „daß es seinen inneren Wert so hoch steiger[t], daß der Begriff der Menschheit, wenn man von ihm, also dem einzigen Beispiel, abziehen müßte, einen großen und würdigen Gehalt gewönne.“213 Humboldts berühmtes Konzept zur Einrichtung einer Berliner Reform-Universität, deren tragende Absichten sich in der Schrift Über die innere und äußere Organisation der höheren wissenschaftlichen Anstalten zu Berlin finden, atmet den Wunsch nach einer höheren Bildungsinstitution, die sich die zweckfreie emphatische Bildung zum Zweck mache, nach vorbereitender gymnasialer Bildung den akademischen Nachwuchs dazu anleite, eine einheitliche und fächerübergreifende „Wissenschaft als solche zu suchen“214, mithin dem vollen Begriff des Menschen Genüge zu tun. Sie ist trotz der für diese Schrift eigentümlichen, gegenüber der zeitgenössischen politischen Herrschaft werbenden, Rhetorik unübersehbar:

„Sobald man aufhört, eigentlich Wissenschaft zu suchen, oder sich einbildet, sie brauche nicht aus der Tiefe des Geistes heraus geschaffen, sondern könne durch Sammeln

208 Vgl. Vierhaus: Bildung, S. 512-518. „Die Vorstellung, daß die Erziehung das selbständige und ganzheitliche Wachstum einer einzigartigen Persönlichkeit fördern sollte, war unter den pädagogischen Reformern im Deutschland des 18. Jahrhunderts weit verbreitet. Jean-Jacques Rousseau und Heinrich Pestalozzi, Bernhard Basedow und die Bewegung des Philanthropismus hoben nur ein Thema besonders hervor, das nirgendwo in der pädagogischen Literatur jener Zeit fehlte. Durch den deutschen Neuhumanismus wurde es in das höhere Bildungswesen übernommen." Ringer: Die Gelehrten, S. 26.

209 Vierhaus: Bildung, S. 519 (Herv. i. O.)

210 Zit. nach ibid., S. 520.

211 Vgl. Weil: Die Entstehung des deutschen Bildungsprinzips, S. $120 f$.

212 Zit.. nach Herrlitz: Studium als Standesprivileg, S. 122.

213 Humboldt, Wilhelm von: Theorie der Bildung des Menschen. Bruchstück (1973), zit. nach Vierhaus: Bildung, S. 521.

214 Humboldt, Wilhelm von: Über die innere und äußere Organisation der höheren wissenschaftlichen Anstalten in Berlin [1809/10], in: Engel, Johann Jakob/Erhard, Johann Benjamin/Wolf, Friedrich August/Fichte, Johann Cottlieb/Schleiermacher, Friedrich Daniel Ernst/Savigny, Karl Friedrich/Humboldt, Wilhelm von/Hegel, Georg Wilhelm Friedrich: Gelegentliche Gedanken über Universitäten, Leipzig 1990, S. 273-283, hier S. 277. 
extensiv aneinandergereiht werden, so ist alles unwiederbringlich und auf ewig verIoren; [...] Denn nur die Wissenschaft, die aus dem Innern stammt und ins Innere gepflanzt werden kann, bildet auch den Charakter um, und dem Staat ist es ebenso wenig als der Menschheit um Wissen und Reden, sondern um Charakter und Handeln zu tun." ${ }^{215}$

„Auf der anderen Seite aber ist es hauptsächlich Pflicht des Staates, seine Schulen so anzuordnen, daß sie den höheren wissenschaftlichen Anstalten gehörig in die Hände arbeiten. [...] daß der Übertritt von der Schule zur Universität ein Abschnitt im jugendlichen Leben ist, auf den die Schule im Falle des Celingens den Zögling so rein hinstellt, daß er physisch, sittlich und intellektuell der Freiheit und Selbsttätigkeit überlassen werden kann [...] $]^{\text {«216 }}$

Der „ganze“, gebildete Mensch darf also kein reiner Fachwissenschaftler sein. Er vollzieht selbstständige Bildungsanstrengungen und gedeiht nur in größtmöglicher Freiheit von äußeren Zwängen und Interessen, mithin in einem durch die traditionell deutsche staatliche Finanzierung privilegierten akademischen Schutzraum - dass diese Überzeugung von den Studierenden im Sample geteilt und geschätzt wird, ist an ihrem Anspruch auf Selbstentfaltung abzulesen. Sie spüren die schon von Rousseau diagnostizierte "Bildungsbedürftigkeit des Seins“217 und fordern sie selbstbewusst sein, im Grunde wie die Demonstranten des Bildungsstreiks, die sich um die Parole des „Bildungsklaus“ gruppierten.

Wer aber bei geistesgeschichtlichen und etymologischen Betrachtungen verharrt, verfehlt die innere Dialektik des spezifisch deutschen Bildungsbegriffs. In sozialgeschichtlicher Hinsicht erfüllte und erfüllt er eine legitimatorische Funktion für gesellschaftliche Ungleichheiten, versprach aber gleichzeitig immer auch das individuelle Transzendieren derselben. Noch zu Humboldts Zeiten galt es, Leistung - und nur Leistung allein - als Anspruchsberechtigung von Privilegien, Status und Einkommen des gebildeten Mittelstandes gegen alle überkommenen altständischen Privilegien zu etablieren. Den Anspruch auf Status, Pfründen, Ämter und Funktionen erwarb man sich aus dieser Perspektive durch die Herausbildung eines umfassend gebildeten, intellektuell versierten und kultivierten Charakters; es erschöpfte sich nicht im Erwerb höherer Bildungszertifikate, auch wenn es diese doch als notwendige Bedingung voraussetzte. Bildung (die durch Zertifikate, aber auch durch sprachliche, ästhetische, lyrische Versiertheit nachgewiesene Gebildetheit) und Leistung (die Begründung von Ansprüchen auf durch Bildung erworbene Fähigkeiten und, modern gesprochen, „Kompetenzen") waren in dieser Schwellenphase gesellschaftlicher Modernisierung unmittelbar verschränkt, wenn nicht identisch. Bildung verpflichtete zu Aktivität, Arbeit, auch zu einer bestimmten Art der Lebensführung; sie war keineswegs allein als kontemplati-

215 Ibid., S. 276.

216 Ibid., S. 278.

217 Buck, Günther: Rückwege aus der Entfremdung. Studien zur Entwicklung der deutschen humanistischen Bildungsphilosophise, Paderborn/München 1984, S. 13-21. 
ve Passivität angelegt. ${ }^{218}$ Bis $\mathrm{zu}$ einem gewissen Grad war das neuhumanistische Bildungsideal also Instrument eines bürgerlich-mittelständischen Klasseninteresses: sie rechtfertigte die Verdrängung der aristokratischen und großbürgerlichen Eliten von den administrativen, kulturellen und politischen Schalthebeln. ${ }^{219}$ „Für die traditionelle Aristokratie [...] bedeutet der Übergang vom Feudal- zum Beamtenstaat ein katastrophales Sinken ihres Funktionswertes, und, im Einklang damit, ihrer staatlichen und gesellschaftlichen Geltung. “220 Der heute so häufig romantisierte Humboldt'sche Bildungsbegriff hatte auch diese Funktion einer ideologischen Veredelung des Elitenaustauschs. Mit dem Vollzug dieses Austauschs - also mit dem Erfolg - verzehrte sich ein großer Teil der Bildungsemphase, welche fortan, ihrer originären bildungsbürgerlichen Trägerschicht beraubt, in den Kanon kulturell kolportierter, vermeintlich überzeitlicher Ideale einmündete. Ihren Ansprüche legitimierenden Zug hat sie dennoch nicht verloren. Aus dem Reservoir entsprechender kultureller Zitate und Stereotype bedienen sich Gebildete und Bildungsanwärter verschiedener sozialer Herkünfte - nicht mehr nur, aber doch primär aus Abiturienten- und Akademikerfamilien - bis heute. 1815, 1890, 1970 und auch 2018 gilt trotz aller Bildungsexpansionsdynamiken ungebrochen: „Formal ist Bildung allgemein, inhaltlich elitär. Im konkreten sozialen Zusammenhang bleibt Bildung anschlußfähig nur für den, der am vorausgesetzten Bildungswissen teilhat und der Urteilsfähigkeit über Bildungsgüter erkennen läßt.“221 Nur aufgrund dieses zugleich allgemeinen, egalisierenden und elitären deutschen Bildungsbegriffs, nur aufgrund des damit in ihm enthaltenen Versprechens, über den Erwerb von Bildungswissen in den Genuss des sozialen Aufstiegs kommen zu können, können offizielle bildungspolitische Rhetoriken heute plausibel wirken. Der aktuelle deutsche Bildungsbericht spricht das in seinem programmatischen Vorwort aus, wenn er Bildung ganz im Sinne der „Chancenrhetorik“ der US-amerikanischen workfare-Programme bzw. der „dritten Wege“ der europäischen Sozialdemokratie ${ }^{222}$ als gesamtgesellschaftlich antidiskriminatorisch wirksame Integrationsmagie bestimmt, als Stützpfeiler der Realisierung des Leistungsprinzips durch Bereitstellung gleicher „Chancen“ für alle zur Herausbildung ihrer jeweiligen „Kompetenzen“ als autonome Manager ihrer eigenen Erfolgspotenziale. Man

„orientiert sich an einem Bildungsverständnis, dessen Ziele in den Dimensionen individuelle Regulationsfähigkeit, gesellschaftliche Teilhabe und Chancengleichheit sowie Humanressourcen Ausdruck finden. Individuelle Regulationsfähigkeit beinhal-

218 Koselleck, Reinhart: Einleitung - Zur anthropologischen und semantischen Struktur der Bildung, in: Ders. (Hg.): Bildungsbürgertum im 19. Jahrhundert. Teil II: Bildungsgüter und Bildungswissen, Stuttgart 1990, S. 11-46, hier S. 21-23. Vgl. Koselleck: Einleitung, S. 27.

220 Weil: Die Entstehung des deutschen Bildungsprinzips, S. 199 (Herv. i. O.) Paradoxerweise fügte erst das später stattfindende Aufgreifen des Bildungsprinzips durch aristokratische Schichten dem Bildungsbegriff jene würdevolle Patina hinzu, die heute mit dem neuhumanistischen Bildungsideal schlechthin verbunden wird. Weil zeigt, "daß das Aufgreifen des Bildungsprinzips durch aristokratische Schichten dem Prinzip selbst eine gewisse Dignität, das Merkmal des, Vornehmen', kurz etwas, Vorbildliches' für die Bürgerschichten gegeben hat. Ibid., S. 236 (Herv. i. O.) 
tet die Fähigkeit des Individuums, die eigene Biografie, das Verhältnis zur Umwelt und das Leben in der Cemeinschaft selbstständig zu planen und zu gestalten. Der Beitrag des Bildungswesens zu den Humanressourcen richtet sich sowohl auf die Sicherstellung und Weiterentwicklung des quantitativen und qualitativen Arbeitskräftevolumens als auch auf die Vermittlung von Kompetenzen, die den Menschen eine ihren Neigungen und Fähigkeiten entsprechende Erwerbsarbeit ermöglichen. Indem die Bildungseinrichtungen gesellschaftliche Teilhabe und Chancengleichheit fördern, wirken sie systematischer Benachteiligung aufgrund der sozialen Herkunft, des Geschlechts und anderer Merkmale entgegen. ${ }^{\text {“223 }}$

Noch einmal: Dieser moderne bildungspolitische Jargon des lebenslangen Lernens mag die Dignität der idealistischen Philosophie abgeworfen haben, in inhaltlicher Hinsicht aber aktualisiert er adäquat die „materielle“ Funktion des traditionellen Bildungsbegriffs, also sein traditionelles Aufstiegsversprechen, gepaart mit der Legitimation sozialer Stratifikation aufgrund nicht "genutzter" Chancen. ${ }^{224}$ Bildung hatte stets, nicht erst in der "Bildungsgesellschaft“, eine „Allokations- und Zertifizierungsfunktion.“225 Daher die eigenartige Schwäche und Unverbindlichkeit jener häufig von Professoren der Geisteswissenschaften publizistisch und feuilletonistisch lancierten polemischen Parteinahmen für „die“ Bildung als Schule des „kritischen“ Denkens gegen den Ökonomisierungswahn der jüngeren Bildungsreformen und den Niveauverlust universitärer Wissensproduktion, ${ }^{226}$ so berechtigt deren Kritik an den Verheerungen des ,akademischen Kapitalismus ${ }^{\text {“227 }}$ im Einzelnen auch sein mag. Mit der seit den 1970er Jahren final durchgesetzten „Massenbildung“ hat sich die Bildungsauslese de facto als allgemein akzeptiertes Zuweisungssystem von Anspruchsberechtigungen etabliert und dabei die alten Formen der geburtsständischen „natürlichen Auslese“ ersetzt. ${ }^{228}$ „Die Ungleichheit der Teilhabe an der gemeinsamen Kultur wird mit dem Leistungsprinzip durch Prüfungen legitimiert.“229 Objektive Erfolgsaussichten können heute daher immer auch durch die Rückführung auf individuelle Bildungsanstrengungen - den Erwerb von „Regulationsfähigkeit“ - subjektiviert werden. Dem entspricht, dass auch die moderne „Chancenrhetorik“ nach wie vor insbesondere für Menschen mit akademischen Lebensläufen

223 7. Bildungsbericht 2018, S. 1f.

224 „Wenn heute permanentes Lernen eingefordert wird und dieses nur noch am Zweck der ökonomischen Brauchbarkeit orientiert ist, wird die neuzeitliche Bildungsidee nicht, entsorgt', sie kommt bloß zu ihrer Kenntlichkeit. Es wird offensichtlich, dass Bildung, die auf den selbständigen und vernünftigen Gebrauch des Verstandes setzt, die Hoffnung, ein Instrument zum Transzendieren der Machtverhältnisse zu sein, nicht einlösen kann. Denn wenn, gemeinsam damit, dass der Bourgeois den Citoyen ,zu Tode umarmt', auch Bildung und Ausbildung in eins zusammenfallen, wird die aus der Aufklärung hinübergerettete und in kastrierter Form im Bildungsbegriff fortlebende Idee des selbstbestimmten Individuums ja nicht aufgegeben; sie kehrt wieder im Bild des Unternehmers seiner selbst, der ,durch vernünftige Akte freier Wahl' sein Leben formt." Ribolits: Abschied vom Bildungsbürger, S. 58.

225 Solga: Ohne Abschluss in die Bildungsgesellschaft, S. 29.

226 Vgl. exemplarisch Liessmann: Theorie der Unbildung und Ribolits: Abschied vom Bildungsbürger.

227 Münch: Akademischer Kapitalismus.

228 Titze: Bildungskrisen und sozialer Wandel, S. $362 f$.

229 Ibid., S. 362. 
und flexiblen Erwerbskarrieren attraktiv ist. Wohl auch deshalb ist in den Fokusgruppen der zumindest verhaltene Wunsch erkennbar, qua universitärer Bildung nicht nur subkulturelle Distinktionsgewinne, sondern auch Statusansprüche zu begründen. Die besonders Zielstrebigen unter ihnen, die ihre verträumteren Kommilitonen vor dem späteren bösen Erwachen warnen, erkennen dabei am klarsten die alte konkurrenzbasierte (und eben immer auch durch Leistung legitimierte) Selektionsfunktion von Bildung, wie sie stets unter manch heute „altzopfig“230 wirkender Phrase verborgen war:

„Und ist diese Selbstfindung dann irgendwie nicht [auch] sowas wie [...] ,Ich nutz' mal jetzt die Zeit und kann irgendwie sinnieren!'Am Ende des Tages arbeite ich trotzdem genau wie jeder andere irgendwo, und hab' nicht wirklich diesen Cut gemacht, ja? Also, ich hab' das... so 'n bisschen das Cefühl, dass dieses Studium halt eben die Möglichkeit für viele darstellt, schon so 'n Müßiggang..., aber auch eben so 'ne Möglichkeit ist, zu sagen: ,Okay, ich kann's einfach hinauszögern, irgendwann, so, zu realisieren, dass es denen da draußen trotzdem egal ist, was ich gemacht habe, bis zu 'ner gewissen Art und Weise, und wer ich bin!'«231

Doch natürlich ist es mit diesen ideologiekritischen Erwägungen allein nicht getan. Im deutschen Bildungsbegriff steckt ein Überschuss, der über die bloße Leistungsorientierung hinausreicht und der sich präzise benennen lässt: Die Bildungsemphase ist von Beginn an in ihrer Forderung nach einer materielle Partikularinteressen überragenden Gleichheit in einer Gesellschaft sich frei entfaltender Menschen - bildungsfähig erst als einerseits vernünftige, andererseits empfindungsfähige Wesen - ideell universalistisch gerichtet. Bildung war nicht nur der philosophische Widerschein einer sozialen Realität, sondern auch ein Anspruch, eine regulative Idee. „Das anthropologische Grundmuster der Bildung zielte auf den ganzen Menschen. Daraus folgte eine dauernd reflektierte Zuordnung zwischen Vernunft und Sinnlichkeit.“232 Der deutsche Bildungsbegriff enthält eine emanzipative Bedeutungsebene, die heutzutage vielfach als „schöngeistig“233 belächelt wird: den Wunsch nach ästhetischer Befriedigung und nach Harmonie, die pietistisch gefärbte ${ }^{234}$ Suche nach der verpflichtenden Wahrheit in der Ruhe der persönlichen Innerlichkeit, und damit auch die Hoffnung auf den besseren Zustand. Damit enthält der Bildungsbegriff in seiner Betonung der Selbstbefreiung des Menschen durch Vernunft auch die Klage über die Entzweiung der einstigen Einheit von Welt und Sinn, ein daraus resultierendes Sehnen nach Versöhnung. Bildung soll die Risse der Welt kitten, „Rückwege aus der Entfremdung ${ }^{4235}$ weisen, soll Ordnung und Rationalität in das Chaos bringen. In der Schiller'schen Ausprägung sollte Bildung über die Rehabilitierung der geknechteten Sinnlichkeit in einer materiell saturierten Umgebung - und somit im Gegensatz zur Vernunftemphase von Humboldt,

230 Koselleck: Einleitung, S. 46.

231 Transkript der 6. Fokusgruppe, S. 30, Z. 949-957.

232 Koselleck: Einleitung, S. 21.

233 Ribolits: Abschied vom Bildungsbürger, S. 27.

234 „Der pietistische Kultur persönlicher Betroffenheit und individueller Selbstverpflichtung, der sich gegen theologische Orthodoxie und gegen rationale Aufklärung richtete, wirkte hier nach." Koselleck: Einleitung, S. 24.

Buck: Rückwege aus der Entfremdung. 
Kant und Hegel - gar eine neue lustförderliche Kulturform auf der Basis des „Spieltriebs“ bzw. der „ästhetischen Erziehung“ begründen. Bildung konnte hier auch heißen: Befreiung durch Förderung der Lust, nicht durch Förderung der Vernunft. ${ }^{236}$ Allerdings blieb der emanzipative Impuls des Bildungsbegriffs in beiden Fällen stets Hoffnung, der durch ihn gestiftete Sinn letztlich Selbsttherapie des aufklärend zweifelnden Geistes. ${ }^{237}$ Es gehört zum Verhängnis des deutschen Bildungsbegriffs, abseits seiner politischen Vereinnahmungen nie immanent politisch gewesen zu sein, ${ }^{238}$ sondern die von ihm geweckten Befreiungshoffnungen, die auf die praktische Realisierung hätten drängen können, stets in der Sphäre des Geistes zu bannen. Selten ist der Doppelcharakter der neuhumanistischen Bildungsidee - wahr im Sinne des universalistischen Egalitätsanspruchs, falsch als ideologische Verklärung tatsächlicher gesellschaftlicher Verhältnisse - so präzise bestimmt worden wie im Vortrag Theorie der Halbbildung von Theodor W. Adorno aus dem Jahr 1959:

„Bildung sollte sein, was dem freien, im eigenen Bewußtsein gründenden, aber in der Gesellschaft fortwirkenden und seine Triebe sublimierenden Individuum rein als dessen eigener Ceist zukäme. Sie galt stillschweigend als Bedingung einer autonomen Cesellschaft: je heller die Einzelnen, desto erhellter das Canze. [...] Je weniger die gesellschaftlichen Verhältnisse, zumal die ökonomischen Differenzen dies Versprechen einlösen, um so strenger wird der Cedanke an die Zweckbeziehung von Bildung verpönt. Nicht darf an die Wunde gerührt werden, daß Bildung allein die vernünftige Gesellschaft nicht garantiert. Man verbeißt sich in die von Anbeginn trügende Hoffnung, jene könne von sich aus den Menschen geben, was die Realität ihnen versagt. ${ }^{\text {“239 }}$

Oft wirkt der Verweis auf das „Mehr“ am Bildungsbegriff altmodisch und abgetragen. Tatsächlich: Das Utopische am Bildungsbegriff ist zugleich sein Anachronistisches, und das im Grunde schon seit der großen Industrialisierungsphase des Kaiserreichs, als „Geisteswissenschaften“ und „Naturwissenschaften“ in offenen Konflikt traten und jene Umkehrung der tradierten Fächerhierarchie sich vollzog, die bis heute Gültigkeit behält. Waren Philosophie und Altertumswissenschaft im langen 19. Jahrhundert noch

$236 \mathrm{Vgl}$. die geniale Interpretation Schillers als heterodoxen, ja apokryphen deutschen Idealisten in Marcuse, Herbert: Triebstruktur und Gesellschaft [1965], Frankfurt a.M. 1995, S. 189 und 193.

237 Bildung sei, so Buck, „das negative Motiv der neuzeitlichen Diagnose der geschichtlichen Selbstentfremdung der Menschen und das positive Motiv ihrer Therapie“ gewesen. Ibid., S. 26.

238 „Bildung ist zunächst, und das zeugt von ihrer religiösen Herkunft, ein politischer Metabegriff. Auf ihre Bildung konnten sich deshalb alle Parteiungen berufen, die revolutionären wie die konservativen Romantiker, die Burschenschaftler so gut wie die sie verfolgenden Beamten, die Liberalen aller Dekaden und Schattierungen so gut wie Konservative und die Führer der Sozialdemokratie bis hin zur Arbeiterschaft selber mit ihrem unstillbaren Bildungsdurst." Koselleck: Einleitung, S. 27.

239 Adorno, Theodor W.: Theorie der Halbbildung [1959], in: Ders.: Soziologische Schriften I, Frankfurt a.M. 1972, S. 93-121, hier S. 97f. (Herv. J. S.) Bezeichnend ist auch die vergleichende Beobachtung mit dem politisch-praktisch deutlich aktiveren französischen Bürgertum und dessen Sprache: „Weder Bildung noch Geschichte erreichen - sowenig wie ,Geist' - in der deutschen Sprache jenen Grad sozialer und politischer Konkretion wie ,civilisation' oder jenen unmittelbaren Appellcharakter, den im Französischen ,révolution' oder ,république' gewonnen haben, um spezifisch bürgerliche Forderungen zu artikulieren oder durchzusetzen." Koselleck: Einleitung, S. 16. 
Königin der Wissenschaft und Trägerin der „echten“ Bildung in Frontstellung gegen die „bloße“ Erwerbsbildung, das „Brotstudium“ (hier sei an das von Bildungsbürgern gegenüber Wirtschaftsbürgern gern als Invektive verwendete Attribut „neureich“ erinnert), ${ }^{240}$ büßten sie ihren Führungsanspruch nun ein. Der wirtschaftliche und technische Fortschritt überflügelte jenes Bildungsbürgertum, welches ihn einst anstieß. Gewiss war Bildungsbewahrung auch Besitzstandswahrung, keineswegs nur ideell motiviert. ${ }^{241}$ Seither aber muss Wissenschaft grosso modo produktiv und leistungsfähig, $d$. h. ökonomisch verwertbar sein, „Leistungswissen“242 produzieren; wo die Geisteswissenschaften nicht ohnehin als "Quasselfächer" kürzungsverdächtig sind, pflegen sie ein Dasein als konservierte Prestigeträger. Aus diesem Grund erscheint der vom Bildungsbegriff nunmehr abgelöste Begriff der „Leistung“ lange Zeit als der modernere, zeitgemäßere Begriff, als das Leitprinzip meritokratisch organisierter Ressourcenzuteilung. Das demgegenüber spürbare „Mehr“ am Bildungsbegriff (die Kontemplation und Tiefe einer gebildeten Persönlichkeit) ergibt sich aus dem eigenartigen Charakter als Mixtur aufklärerischer aber auch vormoderner Komponenten; er ist ein - dem Bildungsbürgertum wie der der jungbildungsbürgerlichen Urburschenschaft vergleichbares - Interimsprodukt einer Gesellschaft an der Schwelle der säkularisierten Moderne. ${ }^{243}$ Und dennoch: Das Veraltete und Anachronistische am Bildungsbegriff ist zugleich auch sein Wertvollstes - nämlich dasjenige, was über die bloße Bejahung des Seienden hinausreicht; sein kritisches Potenzial, die Realität überhaupt an anspruchsvollen Ideen zu messen. ${ }^{244}$ Zwar ist, wer dem Humboldt'schen Bildungsbegriff aufsitzt, als hätten sich dessen soziale, kulturelle und politische Grundlagen nicht fundamental verschoben, und als hätte die mit ihm verwobene Vorstellung der Charakter- und Gesinnungsschulung nicht allzu leicht seine nationalchauvinistische und auch nationalsozialistische Instrumentalisierbarkeit bei den Korporationsstudenten des Kaiserreichs und, polemisch gesprochen, charakterlich einwandfreien führenden Medizinern des Dritten Reiches enthüllt, im Wortsinne aus der Zeit gefallen und historisch blind. Wer aber andererseits

240 Vgl. für die Zeit um 1900 den schwerer werdenden Kampf der Geisteswissenschaften um ihre Vorrangstellung, Ullmann: Das Deutsche Kaiserreich, S. 190-192.

241 „Bildung und Besitz gehörten um 1900 enger zusammen als ein Jahrhundert früher; Bildung war selber zu einem ,Besitz' geworden. Man ,erwarb' und ,hatte' Bildung; sie war eine Investition mit hoher Aussicht auf Honorierung im bestehenden politischen und sozialen System. Die Erhaltung des Besitzstandes entsprach dem sozialen Interesse der großen Mehrheit der Cebildeten so elementar, daß sie nach der politischen Niederlage des bürgerlichen Liberalismus im preußischen Verfassungskonflikt und nach seinem Zerfall im Zuge der konservativen Wende der deutschen Innenpolitik 1878 unter dem Eindruck wirtschaftlicher Depression und aus Sorge vor der sozialen Revolution zunehmend konservativer und staatsloyaler wurden." Vierhaus: Bildung, S. 411.

242 Vgl. Titze: Bildungskrisen und sozialer Wandel, S. 361.

243 Der Bildungsbegriff hat bezeichnenderweise nicht nur Gehalte der westlich geprägten Aufklärung, sondern eben auch einer spezifisch deutschen National romantik in sich aufgenommen. Vgl. dazu Bartol: Ideologie und studentischer Protest, S. 87-98.

244 „Es gibt Strukturen der einmal auf ihren Begriff gebrachten Bildung, die epochenübergreifend wirksam bleiben. Und wenn die altzopfig klingende ,Persönlichkeitsbildung', das Postulat, sein Leben auch in der Cesellschaft verantwortlich selbst zu führen, das Postulat also, das den Bildungsbegriff einst initiiert hatte, heute ideologiekritisch oder sozialdiagnostisch in Frage gestellt wird, so sei daran erinnert, daß hinter solcher Kritik die Selbstaufgabe des Kritikers lauert." Koselleck: Einleitung, S. 46. 
die eigenwillige Spannung der deutschen Bildungsidee verleugnet, sie dem Trümmerhaufen bildungsbürgerlichen Herrschaftswissens überantwortet, verspielt leichtfertig eine wesentliche Triebfeder kritischer Reflexionsfähigkeit der Wissenschaft - sei es in Bezug auf ihren gesellschaftlichen und politischen Stellenwert oder auf ihre eigenen Konstitutionsbedingungen, mithin auf die Vernunft oder Unvernunft der jeweils aktuellen Formen der Wissensproduktion und Wissensorganisation. Mit gutem Recht ließe sich aus diesem Dilemma 1959 wie heute geradezu folgern, dass „der Anachronismus an der Zeit“ ist: „an Bildung festzuhalten, nachdem die Gesellschaft ihr die Basis entzog $^{\text {‘225 }}$, also auf die Bedingungen ihres Scheiterns zu reflektieren.

An den semantischen Tiefengehalt an sich muss, wie schon gesehen, nicht unbedingt kulturkritisch gemahnt werden. Seine Stärke macht sich ja ganz von selbst in seiner noch heute alltäglichen Wirksamkeit geltend. Beide Seiten des deutschen Bildungsbegriffs - die legitimatorische, herrschaftsbegründende Seite ebenso wie die utopisch schillernde, herrschaftskritische Seite des nicht-realisierten Befreiungsanspruchs - sind als Eigengewicht historisch gewachsener Bedeutungsgehalte wie in vielen Begriffen der bürgerlich-aufklärerischen Ära $^{246}$ bis heute wirksam und werden daher auch in den Fokusgruppen assoziativ angesteuert. Im verkappten Schielen auf Distinktionsund Statusgewinn ebenso wie im immer wieder sichtbaren aufrichtigen Wunsch, an der Universität zur intellektuellen Auseinandersetzung mit gesellschaftlichen Themen befähigt zu werden, ist das historische Eigenleben des Bildungsbegriffs enthalten.

„Offenbar wohnt dem Begriff ,Bildung' eine produktive Spannung inne, sich durch selbstkritische Verwendung immer wieder zu stabilisieren. Anders läßt sich der über 200 Jahre anhaltende Gebrauch und seine ständige Wiederaufnahme über zahlreiche Friktionen hinweg nicht erklären."247

Natürlich aber stellt sich nun die Frage, inwieweit eine solche Spannung von den Studierenden auch tatsächlich als "produktive“ genutzt wird und nicht etwa nur als Instrument der rhetorischen Selbstveredelung. Denn generell droht die Bildungsemphase, wo sie nicht auf die konstitutive Janusköpfigkeit des Bildungsbegriffs reflektiert, ${ }^{248}$ zum bloßen Vehikel eines „kollektiven Narzissmus“249 derjenigen, die an der auserwählten Gruppe der Gebildeten teilhaben, zu verkommen. Es ist heute nach wie vor leicht, sich konformistisch in der „Sprache des Angebers“ zu üben, „in der Attitüde [...] des Ver-

245 Adorno: Theorie der Halbbildung, S. 121.

246 Man vergleiche die sich historisch wandelnden Bedeutungsgehalte von Begriffen wie Nation, Demokratie, Freiheit, usw.

247 Koselleck: Einleitung, S. 11.

248 Gemeint ist die innere Dialektik des Bildungsbegriffs zwischen der Legitimation eines Statusanspruchs und dem utopischen Gehalt der Selbstbefreiung.

249 „Subjektiv ist der Mechanismus, der das Prestige einer nicht mehr erfahrenen und kaum überhaupt mehr gegenwärtigen Bildung und die verunglückte Identifikation mit ihr befördert, einer von kollektivem Nazißmus. Halbbildung hat das geheime Königreich zu dem aller gemacht. [...] Die Bildungsidee ist dazu prädestiniert, weil sie [...] vom Individuum bloß ein Minimum verlangt, damit es die Gratifikation des kollektiven Narzißmus gewinne; es genügt schon der Besuch einer höheren Schule, gelegentlich bereits die Einbildung, aus guter Familie zu stammen." Adorno: Theorie der Halbbildung, S. 114f. 
fügens, Mitredens, als Fachmann sich Gebärdens, Dazu-Gehörens. “250 Also: Versuchen die Studierenden jenes anspruchsvolle Studiumsverständnis aktiv umzusetzen, welches sie im Rahmen ihrer Bildungsemphase fordern - etwa indem sie während ihres Studiums übergreifenden Fragestellungen nachgehen oder ihr allgemeines Bildungsniveau durch private und extrakurrikulare Lektüre zu verbessern trachten? Gleich vorweg: Es sind nachdrückliche Zweifel anzumelden. Die selbstständige, interessierte, Irritationen produzierende Herausforderung des eigenen Verstandes, etwa durch die Lektüre anspruchsvoller Texte oder die kontinuierliche Beschäftigung mit gesellschaftlichen Vorgängen, die über das situative Spekulieren hinausgingen, scheint in den meisten Fällen zum erlernten modus vivendi des Studierens quer zu stehen. Häufig bleibt es bei Phrasen und verbalen Bekundungen. Das wird besonders in den Passagen deutlich, in denen die Studierenden über studienbegleitendes Lesen Auskunft geben.

Befragt, ob sie abseits ihres Kurrikulums zu privater Lektüre greifen, scheiden sich zunächst die buchaffinen, lesefreudigen Studierenden von jenen, die ungerne lesen. Die einen bekunden, „sehr viele Bücher“ zu lesen, bekräftigen noch einmal: „Sehr viel“, und betonen überdies, „mit dünnen Büchern [...] nichts anfangen“ zu können. ${ }^{251}$ Für sie ist das Hinausgehen über die bloße Pflichtlektüre schon deshalb angezeigt, „weil ich halt auch gerne lese!“; sie versuchen daher, sich „das halt dann auch nicht nehmen zu lassen, so, dann die Zeit irgendwie trotzdem da 'rein zu investieren“, und sei es auch nur in den Semesterferien ${ }^{252}$ - während andere schweigen oder achselzuckend ihre Lustlosigkeit offenlegen:

„Ich hab' schon irgendwie als Kind oder als Jugendliche nicht wirklich gerne gelesen. [lacht, allgemeine Erheiterung] Ähm, ich entdeck'... Also, meistens vielleicht mal als Urlaubslektüre, wen man am Strand liegt und wirklich, ähm, sich langweilt vom Langweilen, irgendwie, dann ist mal so 'n Buch dabei, aber sonst [allgemeines Lachen] les' ich nicht so gerne. ${ }^{\text {(253 }}$

An erster Stelle steht für viele Lesefreudige, auch für die „sehr viele Bücher“ lesende Studentin, Belletristik. Besonders die Göttinger Studierenden greifen gerne zu FantasyRomanen, etwa aus der Feder von Walter Moers, J. R. R. Tolkien, Cornelia Funke, oder - besonders prominent - Joanne K. Rowling. ${ }^{254}$ Ihre Freude am Lesen tritt allerdings frappierend offen wie eine Freude am Rückzug in private, durch Schule und Kindheit geprägte Traumwelten auf. Sie vertiefen sich mit Vorliebe in die wiederholte Lektüre bereits bekannter Romane. In den folgenden Passagen antworten die Studierenden nicht nur auf die Frage nach beliebten Büchern, sondern dezidiert auch auf die Frage nach prägenden Leseerfahrungen:

„Also, wenn ich 'n Buch lese, dann bin ich komplett für mich, und die ganze Welt verschwindet irgendwie! Und, ja, das hat man beim Filmgucken nicht. [...] Und dann

250 Ibid., S. 115.

251 Transkript der 1. Fokusgruppe, S. 21, Z. 632 und S. 22, Z. 663.

252 Transkript der 7. Fokusgruppe, S. 18, Z. 571-574.

253 Transkript der 4. Fokusgruppe, S. 20, Z. 621-625 (Herv. i. O.)

254 Vgl. Transkript der 1. Fokusgruppe, S. 22, Z. 662 und 670; Transkript der 4. Fokusgruppe, S. 21, S. 20, Z. 631-637 und Z. 641-650; Transkript der 5. Fokusgruppe, S. 23, Z. 703-705. 
haben wir den Sandmann gelesen, das ist so 'ne kleine Horrorgeschichte, und das hat mich so begeistert, es hat mir so 'nen Spaß gemacht! Den les' ich auch ungefähr einmal im Jahr noch, weil ich das einfach klasse finde, und das hat so mein Denken, was Schullektüre auch sein kann, umgestellt!“255

„[...] auf jeden Fall Harry Potter, das war auch so richtig so 'n Familienritual: Wir haben uns das immer zusammen gekauft, und dann uns halt hingesetzt und haben abends gelesen, auch mit Freunden... haben wir eingeladen und immer so 'nen Lesekreis gemacht $[\ldots]^{\mu 256}$

„Harry Potter, ja. Die hab' ich jetzt auch nochmal... Werd' ich auch nochmal französ... Also hab' ich auf Englisch, und jetzt versuch ich's gerade, auf Französisch auch nochmal zu lesen. “257

Auf Platz Zwei stehen jene Bücher und Autoren, die in Buchhandlungen unter der Rubrik „Klassiker“ zu finden sind, etwa Max Frisch oder J. W. Goethe, etwa aus Genuss oder um, wie bereits zitiert, „'n bisschen hochtrabender sich mal so Gedanken zu machen“258. Insbesondere Studierende der Germanistik, Anglistik und der Literaturwissenschaft mit dem Ziel Lehramt versuchen hierüber, die Kenntnis ihrer Materie oder aber auch von historischen Zusammenhängen zu vertiefen, um ihre berufliche Eignung angesichts eines oft als defizitär empfundenen Studiums zu verbessern. ${ }^{259}$ An dritter Stelle - teilweise auch von jenen genannt, die Belletristik favorisieren - stehen gelegentliche fachbezogene Texte außerhalb der Pflichtlektüre, sei es in Gestalt von Aufsätzen oder von Büchern. Manchmal wird in ausliegenden Angeboten des eigenen Fachbereichs gestöbert. ${ }^{260}$ Fünf Personen im Sample zeigen ein starkes praktisches Selbstbildungsbestreben, so etwa jene bereits zitierten Studierenden, die im Namen eines individuellen und eines thematisch strukturierten Bildungsideals Kritik am Modus universitären Lernens üben. Weniger kritisch gegenüber akademischer Wissensvermittlung, aber nichtsdestotrotz bemüht um selbstorganisierte Bildung treten darüber hinaus einzelne Studierende auf, die mit dem Studium eine Entscheidung für einen spezifischen Lebensstil verbinden. Besonders dezidiert ist hier eine Studentin der Wirtschafts- und Sozialgeschichte:

255 Transkript der 5. Fokusgruppe, S. 23, Z. 694-696 und S. 18f., Z. 558-563 (Herv. i. O.)

256 Transkript der 4. Fokusgruppe, S. 21, Z. 646-650.

257 Transkript der 4. Fokusgruppe, S. 20, Z. 635-636.

258 Transkript der 4. Fokusgruppe, S. 20, Z. 617-618.

259 „Also, ich versuche gerade, dadurch dass ich ja Deutsch studiere, einfach mal so diese ganzen Klassiker, so, zu lesen, weil ich's einfach wichtig finde, wenn ich später in die Schule geh', dass ich mich dann nicht dann, wenn ich gerade irgendwas behandle von Goethe, mir das dann erst durchlesen muss. Sondern ich würde einfach schon gerne vorher so 'n bisschen... da 'n bisschen mehr eintauchen. Und ich finde, sowas kommt im Studium auch viel zu kurz." Transkript der 4. Fokusgruppe, S. 18, Z. 561-565 (Herv. i. O.) Vgl. auch Transkript der 4. Fokusgruppe, S. 18f., Z. 575-583.

260 „[...] da sind dann Bücher, die sie halt irgendwie aussortieren, weil sie keinen Platz mehr dafür haben, oder, so, irgendwelche wissenschaftlichen Zeitschriften oder sowas, oder, genau, Sammelbände halt, irgendwie. Und da hab' ich mir schon öfter irgendwas mitgenommen, und, ähm, das ist auch total interessant. Also wenn ich dann halt irgendwie mal keine Lust auf Romane habe, sondern auch auf was Intellektuelleres, dann, ähm, les' ich mir dann halt auch sowas durch." Transkript der 4. Fokusgruppe, S. 19, Z. 596-603. 
„Bei mir kann ich jetzt gar nicht immer sagen, was für die Uni ist und was nicht so, weil irgendwie... Keine Ahnung, für'ne Hausarbeit kann man drei Quellen haben oder fünfzehn, wenn ich das Thema cool finde. Und, weiß nicht, ich les' schon gerne morgens Zeitungen und ärger' mich, wenn ich das irgendwie nicht schaffe [...] “261.

Dementsprechend vielseitig interessiert liest sie auch „manchmal irgendwelche Aufsätze oder so aus der Geschichte, die ich mit nach Hause nehme. ${ }^{“ 62}$ Neben ihr legen noch ein Göttinger Student (Volkswirtschaftslehre) und zwei Frankfurter Studenten (Politikwissenschaft und Soziale Arbeit) Interesse an gesellschaftlichen Themen und an der Suche nach politischen Veränderungsperspektiven offen, denen sie mithilfe privater Lektüre oder auch selbstorganisierter Diskussion in Lesekreisen nachgehen. Dass letztere aufgrund organisatorischer Diskontinuitäten bzw. generellen Vereinzelung bei diesen Versuchen Frustrationsresistenz benötigen, ist ihren Bemerkungen anzusehen:

„B2: Also, ich les' grad' das Kapital von Marx. Hab ich jetzt angefangen. B4: Wow. [lacht] B2: ]a, direkt so 'n Knüller, und davor hab' ich auch schon so 'n bisschen, ähm, Aristoteles und so..., also so 'n bisschen, so, politische Crundlektüre gelesen. Aber nicht komplett, sondern eher so Zusammenfassendes, damit ich so 'nen Grundeinblick hab', weil sowas wie Kant und so - Das kann man ja nicht einfach so drauflos lesen, sondern... [deutet Kopfschuss an] Da gehste kaputt, ja.“263

„]a, also, wir hatten damals so 'n - bevor ich Soziale Arbeit angefangen habe zu studieren -... 'n Freunde-, ähm Lesekreis gemacht mit 'n paar Freunden, wo wir versucht haben, die ,Minima Moralia' von Adorno zu lesen. Das ist so 'n bisschen gescheitert, weil es dann doch relativ schwer war, so, aber das war auf jeden Fall ziemlich nice, also hat schon... Ja, war inspirierend." ${ }^{\text {264 }}$

Als weitere inspirierende und prägende Lektüre, die in irgendeiner - oft nicht näher elaborierten - Weise das eigene Denken und Empfinden beeinflusst oder deren „Grundgedanken“ man lobt, wurden die folgenden Bücher genannt: Neben uns die Sintflut von Stephan Lessenich, Nach Afghanistan kommt Gott nur noch zum Weinen von Siba Shakib, Die verlorene Ehre der Katharina Blum von Heinrich Böll (als Warnung vor dem journalistischen Beruf), This is water von David Foster Wallace (als Besinnungsaufforderung bezüglich des eigenen Verhaltens in der Gesellschaft), Empört euch! von Stéphane Hessel (als Aufruf zu praktischem Engagement), Schriften von Kant und Rousseau ${ }^{265}$, Siddharta von Hermann Hesse (wegen des als „ganz schön“ empfundenen, nicht näher bestimmten „tiefere[n] Sinn[s] dahinter ${ }^{\text {(266) }}$ ), Tess of the d'Urbervilles und Judith the

261 Transkript der 2. Fokusgruppe, S. 18, Z. 564-568 (Herv. i. O.)

262 Transkript der 2. Fokusgruppe, S. 18f., Z. 576-577.

263 Transkript der 7. Fokusgruppe, S. 17, Z. 535-543.

264 Transkript der 7. Fokusgruppe, S. 19, Z. 601-605 (Herv. i. O.)

265 Titel wurden hier nicht genannt.

266 „Und dann ist er ganz am Ende... Irgendwie, war da bei so 'nem Schiffer, also bei so 'nem Bootsfahrer, und hat dann da sozusagen irgendwann seine Erleuchtung gehabt, und dann war halt... Ja, genau. Aber das ist halt ganz schön, weil er, so, alles so durchlaufen hat, und dann hat er für sich selber... war er am Ende, glaub' ich, eigentlich ganz arm und ganz alleine, und hat dann aber irgendwie... Ja, hat dann so für sich die Erleuchtung gefunden, und das fand ich halt irgendwie so ganz schön." Transkript der 4. Fokusgruppe, S. 21f., Z. 652-677 und S. 23, Z. 708-718. 
Obscure von Thomas Hardy (als „proto-feministische“ Lektüre), Homo faber von Max Frisch (als Sensibilisierung für die unerwarteten Verzweigungen der Liebe), Der Sandmann von E. T. A. Hoffmann, Die Bücherdiebin von Markus Zusak, verschiedene Bücher von Richard David Precht (als „Einstieg“ für ein „Philosophie-Grundverständnis“), die Minima Moralia von Theodor W. Adorno, Any Human Heart von William Boyd (weil dort „Charaktere sehr menschlich“ dargestellt würden), aber auch die Masterarbeit eines befreundeten Studenten. ${ }^{267}$ Immer wieder fällt hier auf, dass Studierende offenbar Schwierigkeiten mit dem Konzept prägender, d. h. charakterlich, ethisch oder politisch instruktiver, Lektüre haben: Viele setzen es in eins mit der Unterhaltsamkeit oder Genussfähigkeit eines Schreibstils, verbinden damit weniger genuine intellektuelle Impulse. Bezeichnender Weise entstammen viele dieser Leseerfahrungen dem schulischen Lehrkontext, wie eine Studentin noch einmal explizit betont. ${ }^{268}$ Es entsteht der Eindruck, dass viele Studierende, sind sie einmal der strukturierenden Anleitung durch eine Lehrkraft ledig, nicht die Kraft zum selbstständigen Aufschließen anspruchsvollerer Literatur aufbringen - und dementsprechend kaum noch befriedigende Leseerfahrungen machen können. Das wird noch dadurch unterstrichen, dass sie bei der Frage nach extrakurrikularer Lektüre häufig zuerst die irritierte Rückfrage stellen, ob denn nun studiumsbezogenes oder privates Lesen gemeint sei. ${ }^{269}$ Ein großer Teil der Studierenden sieht in Studium (= Unlust produzierende Pflicht) und Freizeit (= Lust produzierendes Vergnügen) offenbar zwei distinkt getrennte Sphären. Schließlich gibt es noch Zeitschriften ${ }^{270}$ und Zeitungen. Manche - vor allem Studentinnen - legen Wert auf tagespolitische Informiertheit und flechten dieses Bedürfnis per Online- oder Radiokonsum von Nachrichtensendungen (tagesschau, Göttinger Tageblatt, NDR Info) in ihren regulären Tagesablauf ein, so etwa auch die dem Zweiten Bildungsweg folgende Studentin der Germanistik und Philosophie (Lehramt):

267 Transkript der 1. Fokusgruppe, S. 22f., Z. 679-691, S. 23, Z. 706-707 und S. 24, Z. 717-721; Transkript der 3. Fokusgruppe, S. 31, Z. 944-951, S. 32, Z. 968-974 und S. 32, Z. 979-981; Transkript der 4. Fokusgruppe, S. 21, Z. 655-659 und S. 22, Z. 681-704; Transkript der 5. Fokusgruppe, S. 18f., Z. 558-563 und S. 19f., Z. 583-593; Transkript der 7. Fokusgruppe, S. 19, Z. 585-590, S. 19, Z. 601-605 und S. 20, Z. 609-613.

268 „Ich hab' irgendwie in meiner Schulzeit, dass, ähm... Also, manche Bücher waren natürlich irgendwie auch blöd, aber... Auch irgendwie, so, Kafka oder sowas - Ich hab' halt gemerkt: Wenn wir uns mit bestimmten Sachen beschäftigt haben, dann hab' ich aus den Büchern auch immer irgendwie was mitgenommen. Also jetzt nicht, dass die mich so unbedingt mein ganzes Leben lang geprägt haben, aber so immer... Ich hab' daraus schon irgendwie so 'ne Weisheit, irgendwie, immer gezogen, und irgendwie... Also, ich hab' mir auch manche irgendwie noch als Reclam dann nachträglich, noch, gekauft, dass ich sie halt quasi jetzt auch nochmal lesen kann, und das, ähm, fand ich immer auf jeden Fall sehr spannend. Also, da war vielleicht auch unsere Schule relativ gut, weil wir mit... uns viel... also, wirklich intensiv mit dieser Interpretation und so beschäftigt haben, und was man daraus quasi ziehen kann. Und das hab' ich schon gemerkt, dass es schon auch wichtig ist, einfach." Transkript der 4. Fokusgruppe, S. 23, Z. 720-730.

269 Transkript der 1. Fokusgruppe, S. 23, Z. 693-700; Transkript der 3. Fokusgruppe, S. 31, Z. 935-939; Transkript der 4. Fokusgruppe, S. 17, Z. 533-539; Transkript der 5. Fokusgruppe, S. 16, Z. 474-480 und S. 18 , Z. 546-550.

270 „Also, ich beschäftige mich in meiner Freizeit auch mit Fußball, also so Fußball-Zeitschriften und so was. Aber, jetzt, Bücher schaffe ich eher nicht in der Freizeit, wenn's nicht irgendwie mit Uni irgendwie oder mit Studium zu tun hat." Transkript der 2. Fokusgruppe, S. 19, Z. 594-596. 
„Das war morgens immer mein Ritual. Ich hör' morgens immer gerne Radio 21, da gibt's dann Nachrichten; Läppi aufgemacht - Göttinger Tageblatt Newsticker auf. Die haben das jetzt aber so dämlich umstrukturiert, die Seite, dass es nicht mehr sehr informativ ist, [lacht] wie ich finde. Ähm, ja, und halt Austausch mit Freunden oder die Zeitung, die hier immer gratis ausliegt.“271

Von einem aktuellen oder zurückliegenden Abonnement einer Print-Zeitung (ZEIT, taz, fluter) berichten nur drei Studierende. ${ }^{272}$ Konterkariert werden diese Auffassungen im Übrigen durch eine Soziologie-Studentin, die - sehr zur Irritation der politisch Interessierten in ihrer Gruppe - das Studium zwar als bewusstseinserweiternden Genuss wahrnimmt, aber auf Medienkonsum weitgehend verzichtet, weil sie diesen als Einbruch des Dauerrauschens einer überkomplexen Welt wahrnimmt, für die „das menschliche Gehirn [...] nicht gemacht" sei. ${ }^{273}$ Studierende, die aktuell keiner weiteren Lektüre nachgehen, scheinen in der Gesprächssituation einen Rationalisierungsdruck zu spüren. Sie führen - unprovoziert! - Gründe für ihre ausbleibenden selbstständigen Bildungsanstrengungen an, die den Charakter der schlechten Ausrede tragen und so auch von einem Angestellten oder einem mittelständischen Familienunternehmer hätten stammen können. Sie folgen dem Muster eines überzeichneten zehnstündigen Studientages, der schlichtweg nicht die Zeit für private Lesetätigkeiten, für das „Abendsnochmal-hinsetzen“ lasse (während aus dem Gesamtzusammenhang der Diskussionen deutlich wird, dass solche Tage die Ausnahme bilden):

„[...] generell dadurch, dass ich Triathlon mache, trainier' ich eigentlich nur. Also, natürlich, ich lese auch, aber jetzt nicht so, dass ich, teilweise, wenn ich... Abends, wenn ich sitze und mit dem Rennrad gefahren bin, dann nicht mehr. [lacht, allgemeine Erheiterung] Mit 'nem Buch oder so.“274 (Sportwissenschaft)

„Ich selbst komm' da eigentlich auch gar nicht zu. Also, bei mir ist eigentlich jeden Tag von acht bis acht oder noch länger, und von daher dann... Am Abend sich noch mal hinzulegen und dann noch was zu lesen, da habe ich dann auch keine Lust mehr $\mathrm{zu}^{\text {“275 }}$ (Chemie)

„Also, ich hab' jetzt so'n Buch, und das ist so dick, und das hab' ich jetzt irgendwie seit 'nem dreiviertel Jahr oder so, und ich hab's halt immer noch nicht durch, weil ich halt... Keine Ahnung, manchmal, wenn ich bis Acht Uni habe, dann ess' ich was und dann geh' ich ins Bett, so, und dann bin ich fertig, so.“276 (Jura)

„Also, ich muss sagen: So in den Hochzeiten vom Studium, wo ich wirklich extrem viel für die Uni lesen musste, hab' ich teilweise nicht mehr die Energie dazu gehabt, noch irgendwie privat was zu lesen. Das hat es einfach 'n bisschen versaut, ehrlich

271 Transkript der 5. Fokusgruppe, S. 45, Z. 1377-1381.

272 Vgl. Transkript der 2. Fokusgruppe, S. 18, Z. 564-570; Transkript der 5. Fokusgruppe, S. 17, Z. 509 und S. 45 , Z. $1377-1393$.

273 Transkript der 7. Fokusgruppe, S. 40, Z. 1252-1261.

274 Transkript der 1. Fokusgruppe, S. 21, Z. 635-636.

275 Transkript der 2. Fokusgruppe, S. 19, Z. 601-603.

276 Transkript der 4. Fokusgruppe, S. 18, Z. 547-550. 
gesagt. Ähm, aber wenn, dann waren's tatsächlich auch eher Romane.“277 (Theaterwissenschaft)

Im Gegensatz dazu scheinen jene Studierenden, die generell überdurchschnittlich aktiv sind und etwa einem zivilgesellschaftlichen Engagement nachgehen, auch häufiger unvoreingenommen zu zusätzlicher Lektüre zu greifen.

Noch etwas fällt auf, das im Rahmen von Erwägungen über den studentischen Bildungsanspruch Erwähnung finden sollte: Die Studierenden, einige von ihnen bereits Mittzwanziger, bedienen sich immer wieder eines stark umgangssprachlichen Duktus' mit teils äußerst holprigen und ungeschickten Satzkonstruktionen, vielen infantilen Silben und Präfixen wie „mega-“, „super-“ oder „ultra-“. Manch einer bezeichnet Bücher als „cool“ oder „nice“, zum Lesen müsse man „Bock haben“, etc. Neben diese stereotyp jugendsprachlichen Versatzstücke treten vereinzelt geradezu infantile Sprachgewohnheiten, etwa wenn eine Studentin vor der Gruppe ihre Eltern als „Mama“ und „Papa“ bezeichnet. ${ }^{278}$ Nur in Einzelfällen verwenden Studierende in den Fokusgruppen so etwas wie ein gehobenes akademisches Idiom - und wirken gerade dann leicht deplatziert. Selbstverständlich kann es hier nicht darum gehen, Diskussionsteilnehmern ihren Idiolekt vorzuwerfen. Aber es ist doch auffällig, wie wenig von der studentischen Bildungsemphase im Feld des Rhetorischen verbleibt, sobald man einmal "aufgewärmt“ ist und sich seiner Zugehörigkeit zum universitären Milieu versichert hat.

Dennoch ist der Bildungsimpetus als zentraler Identifikationsanker der Studierenden ernstzunehmen. Er bietet Halt in der Orientierungsnot eines Studiums, das heute kaum noch „Vollzeitstudium“ im originären Sinne ist, sondern eine Phase der „Berufsbefähigung“ mit gewissen - wenn auch nicht mehr im Sinne des „Erprobens“ wirklich üppigen - Freiheiten. ${ }^{279}$ Die hier gepflegte Empfindung von akademischer Gruppenzugehörigkeit wird sekundiert durch das immer wieder durchscheinende (und offenbar durch die Herkunftsfamilie stark geprägte) Grundmotiv der Auserwähltheit als Kandidatin bzw. Kandidat höherer Bildung. Das Studium verspricht in ihren Augen nicht nur ein vergleichsweise sicheres Auskommen, sondern auch die Zugehörigkeit zur Sphäre der Gebildeten (was offenbar auch heißt: der Kritisch-Rationalen, Aufgeschlossenen und Toleranten) mit eigenen Wertehierarchien, die sich nicht nur auf die schnöde employability kaprizieren. Man teilt das „stille commitment" des Bildungswegs

277 Transkript der 7. Fokusgruppe, S. 18, Z. 564-567 (Herv. i. O.)

278 Dazu passen die vom Studierendensurvey betonten starken familiären Bindungen von Studierenden, die sich nicht zuletzt in jenen Passagen des Selbstverständlichkeitsnarrativs bestätigt haben, in denen die Identität der persönlichen Wünsche mit den elterlichen Wünschen zugegeben und bekräftigt wird.

279 „Das Studium findet nicht mehr im ,Elfenbeinturm' statt. Es ist zu einer Phase der Qualifizierung für die Erwerbstätigkeit geworden. Oft steht nicht mehr der anspruchsvolle Ertrag in einer ,Profession' in Aussicht, vielmehr wird der Anspruch auf die ,Berufsbefähigung' (employability) reduziert. Das Studium als Phase der Erprobung und der Alternativen ist kaum noch gefragt. Mehr und mehr dominiert, auch an den Universitäten, der Anwendungsbezug - das Praktikum wird wichtiger als das Studium. Eine erhöhte Erwerbstätigkeit der Studierenden geht damit einher, weshalb die Hochschule für viele nicht mehr den, Lebensmittelpunkt' darstellt. Das Zeitbudget lässt dadurch oft wenig Spielraum für außerfachliche, politische oder kulturelle Aktivitäten." Bargel: Wandel politischer Orientierungen, S. 4f. 
vom Gymnasium bis zur Universität. Es wirkt kollektivierend und führt zu raschem Gesprächsfluss sowie zu weitestgehendem Einverständnis in sämtlichen Fokusgruppen. Dass es irgendwie doch mehr sein müsse als nur das, wie es die spezifische Verbindung materieller und ideeller Motive (Geld verdienen und einen gesellschaftlichen Beitrag leisten ${ }^{280}$ ) bei der Aufnahme des Studiums andeutet, führt sie zum mentalen Bündnis mit Residuen eines alten Bildungsdünkels. ${ }^{281}$ Das erscheint ihnen einerseits aufgrund der starken Aufladung des Bildungsbegriffs als Aufstiegsvehikel in der Qualifizierungsmaschinerie seit den 1970er Jahren plausibel, streben sie doch danach, die eigene Biographie durch Bildungszertifikate zu veredeln. Zugleich aber hat der Bildungsbegriff sein emanzipatives, versöhnendes Glänzen nicht verloren: Er soll den verlorenen Sinn und jene Form eines höheren Zwecks stiften, den die als zu stark materiell fixierte, gesamtgesellschaftlich kaum erfolgversprechende ${ }^{282}$ und daher degoutierte Leistungsbereitschaft allein nicht verschaffen kann - was nebenbei natürlich wiederum auch zum Wachstum der eigenen Beschäftigungsfelder, also zur Sicherung der persönlichen Zukunft, beiträgt. Sicherheit und demonstrative Sorglosigkeit sind sehr wohl zu sehen - aber Mittelschichtssehnsüchte und Wohlstandsromantik liegen den Studierenden fern. Bemerkenswert ist, dass die Antreiber und maßgeblichen Deutungsagenten der Bildungsemphase nicht direkt bestimmten Studienfächern oder Fakultäten zuzuordnen sind. Auch scheinen sie sich nicht vorrangig aus der Gruppe der Akademikerkinder oder, im Gegenteil, aus derjenigen der Bildungsaufsteiger zu rekrutieren - auch wenn die Bildungsemphase vonseiten letzterer noch ein Stück weit leidenschaftlicher, hoffnungsgeladener, eifriger verfochten wird. Das anspruchsvolle Bildungsverständnis setzt sich in den Fokusgruppen zumeist als hegemoniale Auffassung durch, wo es nicht ohnehin von Beginn an zum selbstverständlichen Wertekanon der Studierenden gehörte; abseits der Zweifel an den eskapistischen Auswüchsen der Selbstentfaltungsmaximen findet sich keine prominente, etwa stark leistungsorientierte, Gegenkonzeptionen. Bildungshumanistische Versatzstücke scheinen also ein strukturbildendes Element studentischer Deutungsmuster insgesamt zu sein. Es handelt sich dabei offenkundig um einen sozialisatorisch erlernten Wertekanon, nicht mehr um die milieu-artige Festigkeit eines einstigen bildungsbürgerlichen Milieus. War die Leistungsemphase der nichtstudierenden Jugendlichen und jungen Erwachsenen als nur halb geglaubter, „internalisierter Sozialisationseffekt“ und als „nicht reflektierte Selbstverständlichkeit, eine bloße und daher unumgängliche Spiegelung der harten Realität" begriffen worden, ${ }^{283}$ so ist hier eine strukturanaloge Funktion der studentischen Bildungsemphase nachzutragen. Man hantiert mit ererbten Kategorien in einer traditionslos gewordenen Gesellschaft. ${ }^{284}$ Verfolgt werden primär Distinktionsgewinne „nach unten“, gegen un-

280 Vgl. Bargel/Simeaner: Gesellschaftliche Werte und politische Orientierungen, S. 13.

281 Wenig überraschend scheinen sich viele Stereotype und Idealvorstellungen im Verlauf des Studiums abzuschleifen und einer „realistischen“ Sicht Platz zu machen. Insgesamt aber motiviert das gegenüber sozialisatorisch-familiär vermittelten Werthaltungen keine besonders großen Zweifel.

282 Vgl. Bargel/Simeaner: Gesellschaftliche Werte und politische Orientierungen, S. 10 und 15.

283 Schenke et al.: PEGIDA-Effekte, S. 236.

284 Es handelt sich hier um „Versuche, sich mit Hilfe der Vokabeln und Vorstellungen der eigenen Elterngeneration, die ihrerseits schon mitunter an der Geltung des Leistungsprinzips zweifelte, einen Reim auf die eigene, nach dem Ende der Religions- und Milieuzugehörigkeiten traditionslos 
gebildete Schichten, die man für ihre ausgebliebene Erleuchtung bedauert, denen entkommen zu sein man dankbar ist - oder über die man, wofern biographisch unbekannt, ratlos die Achseln zuckt. Natürlich darf der forschende Interpret seinen Gesprächspartnern gegenüber keine normativ durchsetzten Vorwürfe erheben. Allerdings: Sowohl die stereotypen Bezugnahmen auf das unmögliche "Abends-noch-einmal-hinsetzen“ - als würde man tatsächlich fünf volle Tage pro Woche in den Gebäuden des Universitätscampus hausen, ohne jede Möglichkeit, sich zwischendurch einmal "hinzusetzen“ - als auch die durchaus genutzten Studienfreiheiten deuten auf eine simple Beobachtung hin: Durchaus existierende Freiräume für ein extrakurrikulares Selbststudium werden von einem großen Teil der Studierenden schlicht nicht genutzt. Sie nehmen eben die Rolle von Bildungskunden ${ }^{285}$ an, die ihnen institutionell geboten wird, als aktive Selbstbildner agieren sie nicht. Sie fetischisieren im Gespräch ein Ideal, dem sie weitestgehend selbst nicht gerecht werden. Verbindliche intellektuelle Projekte verfolgen nur Einzelne - das ist in aller Härte deutlich. Gelegentlich ist der Eindruck erfahrungsarmer Stereotypie selbst dort kaum abzuwehren, wo private Bildungsanstrengungen betrieben werden: Allein die Formulierungen „Klassiker“, „hochtrabend“ und „Lust“ auf „was Intellektuelleres" zu haben, ohne inhaltliche Aspekte einzubeziehen oder gedankliche Fortschritte benennen zu können, weckt Zweifel daran, ob diese Form von Bildungsbeschäftigung überhaupt noch von anderen Freizeitbeschäftigungen abweicht. Den leicht hart beurteilten Studierenden aber fehlt es auch an strukturellen Ermutigungen zum Selbststudium, an durch das dichte Netz von ECTS-Teilprüfungen reduzierte Muße, ergebnisoffen an Inhalte heranzutreten, aber schlicht auch an intellektuellen Vorbildern und inspirierenden Lehrerfiguren. Dass das Studium unter Bologna-Bedingungen damit wesentliche Aspekte verloren hat, die für die Studienzeit der Elterngeneration noch gegolten haben mögen, ist wahrscheinlich. Jenseits aller altbekannten Jeremiaden über den Verfall des Geistes und den Niedergang der Universität spricht aus den studentischen Ausführungen doch spürbar eine Studienerfahrung, die das mit den Vorstellungen von „Horizonterweiterung“ „Kompetenzen“ und Wissenserwerb erhoffte inspirierte Selbststudium eher sabotiert als ermöglicht. Geradezu beklemmend lesen sich manche Auskünfte über den Verlust einstiger intellektueller Leidenschaften im Verlauf des Studiums. Hier wird nicht mangelnde Zeit beklagt, sondern abnehmende geistige Aufnahmefähigkeit: ${ }^{286}$

„Aber ich glaub' früher, weiß ich nicht, haben die auch noch irgendwie mehr kritischer gedacht und mehr hinterfragt und mehr diskutiert. Und heutzutage hab' ich halt das Gefühl: Wenn man das anfängt... Also, irgendwie, so... Am Anfang meines Studiums

gewordene Gesellschaft zu machen. Denn alternative Deutungsangebote, die die gesellschaftlichen Prozesse rational erklärbar machen, gibt es nicht." Ibid., S. 235f. Zu den erwähnten Zweifeln der erwachsenen "Mitte" am Aufstiegsversprechen und an der Geltung meritokratischer Verteilungskriterien vgl. Marg: Mitte in Deutschland, S. 175-182.

285 „Sie richten sich in der Rolle des Kunden ein, verlieren damit aber an Verantwortung und Mitgestaltung." Bargel/Simeaner 2011, S. 16.

286 Wenngleich Naturwissenschaftler, Mediziner und Lehramtsanwärter hauptsächliche ihre Freizeit beschädigt sehen, wenn sie über mangelnde Zeit zum Lesen während des Studiums klagen; sie sehen damit weniger zentrale instrinsische Triebfedern ausgehängt. Sie fassen das Studium primär als „Werkzeug“ zur Berufsbefähigung auf. Vgl. Transkript der 5. Fokusgruppe, S. 5, Z. 139-149. 
hab' ich noch alles hinterfragt, aber man hört halt irgendwann auf, weil man merkt, das kostet [...] viel zu viel Kraft..."287

„Also, ich hab' früher richtig gerne gelesen, auch richtig viel - Bei mir hat das mit dem Studium komplett aufgehört. Ich guck' mir jetzt nur noch Videos an oder Dokumentarfilme, Serien. Also wenn ich mich über was informieren will, guck' ich immer erstmal, wie ich das in irgend'ner anderen medialen Form - auch wenn es, keine Ahnung, 'n Hörbuch ist oder so -... [...] $]^{\text {«288 }}$

„Aber früher war ich da mehr so: ,Boah, jetzt 'ne Zeit am Sonntag!' Und jetzt denk' ich: ,Ha, ja, guckste halt mal in 'nen Artikel 'rein!' So ungefähr, ja. Dieser Lesedrang ist nicht mehr da, einfach. Und ich hoff', der kommt wieder! “289

„B2: Und ich find' diese... diese Vorlesungsstrukturen oder diese Uni-Strukturen fördern 'ne irre - Merk' ich auch bei mir -... 'ne richtig passive Haltung, so'ne... Ja. B1: Ja, das merk' ich auch, ja. B2: Und dass man dann auch irgendwie abschaltet, dieses... weil man... Es braucht ja auch Energie, und dann geht man mal gegen 'ne Wand, und... Ja. B3: Ja, man resigniert irgendwann, ne, von dieser Situation!“290

Trotzdem ist zugleich der Bogen zurück zum skizzierten Gemisch studentischer Orientierungen auch jenseits der Bildungsemphase zu schlagen. Nicht die kontinuierliche Spannung von Anspruch und Wirklichkeit lässt die Studierenden so häufig lavieren, sondern innere Unentschiedenheiten des Anspruchs selbst. Es vermengen sich Leistungsimperative, Bildungsimperative und Sehnsüchte nach harmonischem Lebensgenuss zu einem nicht immer stimmigen Stimmungscocktail. Nicht zuletzt am Selbstverständlichkeitsnarrativ wird deutlich, dass die Aufnahme eines Studiums für viele zwar einem - wie weiter oben zitiert - „stillen commitment" folgt. Doch ob man sich nun stärker dem eigenen Fortkommen committed fühlen sollte, ob man lieber den eigenen Wünschen und Sehnsüchten folgt, solange die Moratoriumsphase andauert, oder ob es nicht doch höhere Prinzipien einer Bildung der Gesamtpersönlichkeit gibt, die anzustreben seien - das ist für sehr viele außerordentlich schwer zu entscheiden. Das Nebeneinander (vormals) widersprüchlicher Wertbezüge mag also tatsächlich seinen Grund in einer strukturellen Unentschiedenheit der Studierenden haben. Daraus ließe sich mit Blick auf etwaige politische Dispositionen von Studierenden - zugegebenermaßen zugespitzt - zweierlei folgern:

Erstens lernen viele Studierende die Praxis des Lernens, Denkens und Verstehens wie es von vielen so postuliert und in Einführungsveranstaltungen sowie von offizieller Seite gerne behauptet wird - gerade nicht mehr, sondern konsumieren weitestgehend verstreute, ungestalte, unzusammenhängende Lernmaterie, über welche sich gleichsam nachträglich der ideologische Schaum der Bildungsemphase legt. Eine wachsende intellektuelle Orientierungslosigkeit bis zum Ende des Studiums scheint vorprogrammiert, souverän nach Bildung suchend hingegen wirken nur jene Vereinzelten mit hoher Energie zum Selbststudium und der Fähigkeit, selbstständig Synthesen zu stiften,

287 Transkript der 4. Fokusgruppe, S. 13, Z. 401-405.

288 Transkript der 1. Fokusgruppe, S. 21, Z. 641-644 (Herv. i. O.)

289 Transkript der 5. Fokusgruppe, S. 17, Z. 509-511.

290 Transkript der 5. Fokusgruppe, S. 13, Z. 394-402. 
die die Studieninhalte eben als eine Erkenntnisquelle neben anderen in sich aufnehmen. Praktisch behandeln Studierende ihr Studium wie eine Variante von Ausbildung, die zahlreiche Freiheiten lässt, theoretisch aber beanspruchen sie mithilfe des Bildungsbegriffs zugleich aber auch, dass es mehr sei als nur das - ohne alltagspraktische Konsequenzen. Die gängige universitäre Lehrpraxis kommt ihnen dabei fraglos entgegen, wie das Beispiel eines Studenten der Politikwissenschaft zeigt: Dass einstige Gesellschaftstheorien, an der Universität mit den Namen Kant und Rousseau als Lerninhalte vermittelt, zum toten Bildungsgut geronnen sind und wie steinerne Büsten aus Gedanken betrachtet werden können, ermöglicht es überhaupt erst, diese einstigen theoretischen Verarbeitungsformen sozialrevolutionärer Impulse als „großartige Ideen“ $\mathrm{zu}$ loben, die „meinen Horizont 'n bisschen voran“ bringen. ${ }^{291}$ Dass Schriften, die - würde ihr politischer Gehalt ernst genommen - unweigerlich zur Frage führen müssten, ob seit der Zeit ihrer Niederschrift der von ihnen geforderte vernünftigere Zustand gesellschaftlicher Ordnung erreicht worden ist oder nicht, heute konsumiert werden können wie eine Form von unverbindlichem höherem entertainment im Stile des nice to know, ist auch ein institutionelles Phänomen.

Zweitens läuft die umfassende Offenheit und Unentschiedenheit der Studierenden gegenüber stark konfligierenden Auffassungen vom Zweck des Studiums (Leistung erbringen vs. umfängliche Bildung erlangen vs. Genießen) auf einen oberflächlichen Werte-Relativismus hinaus, welcher wiederum auf einen weitgehend abwesenden Problemdruck vonseiten perzipierter Berufschancen verweist. Dass internalisierte meritokratische Prinzipien, anders als bei den Jugendlichen und jungen Erwachsenen der Vorgängerstudie, unter Studierenden nicht einmal behelfsmäßig das Vakuum zu füllen vermögen, welches das Verschwinden verbindlicher traditioneller und religiöser Wertsphären hinterlässt, deutet sogar noch auf weitaus größere Orientierungsbedürfnisse hin. Denn keineswegs verzichten die Studierenden in ihrer vielseitigen spielerischen Toleranz auf materielle Ansprüche; wie gesehen, erwarten sie alle als angehende Akademiker sowohl finanzielle Sekurität als auch einen gewissen sozialen Status. Vorerst müssen sie über solche Themen nicht allzu häufig nachdenken, ja pflegen ein gewisses Maß an Eskapismus. Doch was steht zu erwarten, wenn ein solcher Problemdruck schließlich entsteht? Sollte sich der Bedarf an akademischen Arbeitskräften, etwa im Zuge einer wirtschaftlichen Rezession, stark verringern, könnte dieser mentalen Gemengelage eine neue Rigorosität rivalisierender Wertehierarchien entspringen, gleich einem Wiedereinrasten in alte weltanschauliche Fronten, die sich in ihrer wechselseitigen Konfliktstellung auch wieder schärfer sortieren und konturieren. Das in der Gesprächssituation fraglos angenehme Weiche, Konziliante und Nachsichtige an den Studierenden erscheint durchaus auch als "Wohlstandsprodukt" einer alles in allem - wohlverstanden: abgesehen von jenen, die unter dem Prüfungsdruck tatsächlich ächzen, die Prüfungsbewertungen nicht nachvollziehen können und die schon Fehlversuche sammeln mussten - doch eher genussförderlichen Studiensituation. Dass momentan keine neue akademische „Überfüllungskrise“ absehbar ist, sondern die Zeichen - trotz akuter volkswirtschaftlicher Wachstumshemmnisse ausgehend 
vom industriellen Sektor mit ungewissem Ausgang - weiterhin auf Bildungswachstum stehen, ist den Studierenden anzumerken. Gedanken über ihre Aussichten bei Erwerbseintritt hüllen sie in abstrakt optimistische Formeln, wo sie sie nicht gänzlich ignorieren und als Gegenstand biographisch späterer Problemstellungen fürs Erste von sich schieben. Die Maxime des lebenslangen Lernens jedenfalls hat man verinnerlicht - und trifft sich dann doch mit den internalisiert-meritokratischen Jugendlichen und jungen Erwachsenen der Vorgängerstudie, wenn auch nicht ohne ihnen kraft des Lobs der Bildung eine feinsinnige Leistungskritik entgegenzuhalten.

\title{
III.3.2 Jeder sollte etwas tun: Über politisches Interesse, politische Themen und politisches Engagement
}

\author{
"Halb tragisch, halb komisch, dass die, \\ die jetzt dauernd ,Weimar' rufen, nicht so \\ recht ihren eigenen Weimarisierungsbeitrag \\ wahrzunehmen vermögen. ${ }^{\text {2292 }}$ \\ „Wir sind in der Uni-Blase."293
}

Der Studierendensurvey dokumentiert, wie gesehen ${ }^{294}$, ein jüngst (seit 2016) wieder angestiegenes allgemeines politisches Interesse der Studierenden analog zur Gesamtbevölkerung. Die Gründe für diese Entwicklung mögen in der thematischen Dominanz der Migrationsfrage seit 2015 sowie im Aufstieg nationalprotektionistischer, nationalkonservativer und sozialchauvinistischer politischer Offerten in internationaler (BrexitVotum 2016, später verstärkt durch die Wahl Donald Trumps zum US-Präsidenten 2016) sowie bundesrepublikanischer (Genese von Bürgerprotesten rechts der Mitte in Gestalt von PEGIDA u. a., elektoraler Siegeszug der AfD seit 2016) Hinsicht bedingt sein. Das Auftreten von migrationskritischen Protestbündnissen in verschiedenen ost- wie westdeutschen Städten regte dementsprechend die spezifische Fragestellung der bereits erwähnten Vorgängerstudie an, nach Anzeichen eines veränderten politischen Klimas unter Jugendlichen und jungen Erwachsenen an eben diesen Schauplätzen zu fragen. ${ }^{295}$ Ebendort fiel allerdings ein Phänomen auf, das mit der Formel „politische Unberührtheit" eingefangen wurde: Jugendliche und junge Erwachsene erschienen 2016 und 2017 insbesondere deshalb polarisierungsresistent, weil Politik und politische Themen ihrer Lebensrealität auffällig fern standen. Aber: Gezielt nach politischen Themen befragt, zeigten sie sich keineswegs - gemäß einem gängigen Schlagwort - „politikverdrossen“, sondern als durchaus politisch denkende und (in Fragen von Migration und Integration bisweilen harsch) politisch urteilende Menschen. ${ }^{296}$ Überhaupt gehört es zu den beinahe schon traditionellen Verdachtsmomenten gegenüber "der" Jugend, dass sie in bedenklicher Weise antiinstitutionelles Misstrauen hegten, ja „politikfeindlicher" seien

292 Manow, Philipp: Der Extremismus der Mitte, in: Merkur. Gegründet 1947 als Deutsche Zeitschrift für europäisches Denken, 73. Jg., H. 836/2019, S. 5-13, hier S. 8.

293 Transkript der 3. Fokusgruppe, S. 47, Z. 1456.

294 Vgl. Kapitel II.3.4 dieser Studie.

295 Vgl. Schenke et al.: PEGIDA-Effekte?, S. 12-15.

296 Vgl. ibid., S. 198 und 254-260. 
als die erwachsene Bevölkerung. Dass das in dieser Simplizität nicht stimmt und einer Kette von Missverständnissen jugendlicher Gesellschaftssicht entspringt, ist etwa von Gert Pickel herausgearbeitet worden. ${ }^{297} \mathrm{Zu}$ diesen Missverständnissen zählt es, aus der häufigen Distanz Jugendlicher und junger Erwachsener zum konnotativ stark aufgeladenen Begriff „Politik“, zu politischen Eliten und zu klassischem parteiförmigem Engagement ein allgemeines politisches Desinteresse abzuleiten, ohne aber das „unsichtbare Politikprogramm “298 $\mathrm{zu}$ sehen, welches eben oft in der jugendspezifischen Verhandlung gesellschaftlich relevanter Themen (Lebenschancen, Ungerechtigkeiten, Probleme, Hoffnungen und Sehnsüchte, etc.) besteht. ${ }^{299}$ Auch in der erwähnten Studie gingen die Jugendlichen und jungen Erwachsenen auf Distanz zur großen Bühne gesellschaftlicher und politischer Themen, welche ihnen wie das Hallen jenseitiger Dramen erschien, die das persönliche Leben nur marginal betreffen. Gesellschaft erschien aus der stark am individuellen sozialen Nahbereich orientierten Sicht von Jugendlichen und jungen Erwachsenen 2016 und 2017 als fremde, selbstständig funktionierende, also im Grunde autopoietisch und ohne menschliches Zutun sich erhaltende, überzeitlich vorhandene Sphäre. ${ }^{300}$ Wichtig erschien ihnen die Beschäftigung mit solchen Themen daher nicht. In den „rein“ studentischen Fokusgruppen in Göttingen und Frankfurt a.M. von 2018 ist das grundsätzlich anders. Obgleich auch hier - ganz wie es der Studierendensurvey nahelegt - kaum von allgemeiner "Positionierungsfreude“ im Sinne politischer Selbstverortung gesprochen werden kann, fällt doch eine genuine Freude an der Diskussion, ja am Parlieren und Reflektieren auf. Nur drei von 44 Personen geben ohne Verschleierungsversuch, aber auch hier mit demonstrativem schlechtem Gewissen zu

297 Pickel, Gert: Jugend und Politikverdrossenheit. Zwei politische Kulturen in Deutschland nach der Vereinigung?, Opladen 2002, S. 166 und 403.

298 Kohl, Wiebke/Seibring, Anne (Hg.): „Unsichtbares“ Politikprogramm? Themenwelten und politisches Interesse von „bildungsfernen“ Jugendlichen, Bonn 2012.

299 Pickel differenziert zwischen „Staatsverdrossenheit“ (Ablehnung der Zugehörigkeit zum politischen Kollektiv), „Demokratieverdrossenheit“ (Ablehnung des politischen Systems), „diffuser Politikverdrossenheit" (absente politische Kompetenz und allgemeines Desinteresse), „Involvierungsverdrossenheit“ (Ablehnung politischer Aktivität) und „Politikerverdrossenheit“ (Ablehnung politischer Eliten und Institutionen), um herauszustellen, dass nur die - seltene! - „diffuse Politikverdrossenheit“ überhaupt fehlendes politisches Interesse impliziert. Pickel: Jugend und Politikverdrossenheit, S. 90-92.

300 Vgl. Schenke et al.: PEGIDA-Effekte?, S. 186-192, siehe insbesondere S. 208: „Die Befragten scheinen in einem nicht-politisierten Kontext und Umfeld aufzuwachsen, ihnen werden kaum andere Beziehungen zu und Auffassungen von Politik vermittelt. Auch insofern ist die Annahme der Politikverdrossenheit der jungen Menschen unzutreffend, da es nicht um Frustration, sondern um Unberührtheit durch Politik geht." 
Protokoll, sich kaum bis gar nicht mit politischen Themen zu beschäftigen. ${ }^{301}$ Natürlich gibt es sowohl unter nichtstudierenden Jugendlichen und jungen Erwachsenen wie unter Studierenden zentrale Themen und Probleme, die den Diskutanten wichtiger sind als andere, und über die sie daher auch engagierter sprechen. Sicher ist die Distanz zu politischen Autoritäten und Institutionen sowie zu traditionellen politischen Beteiligungsformen ähnlich groß wie aufseiten der nichtstudierenden Jugend. Insgesamt aber sticht hervor, dass die Studierenden das Wort „Politik“ und die damit zusammenhängenden Assoziationen „großer" und abstrakter gesellschaftlicher Themen nicht als abschreckend wahrnehmen, sondern als Markstein eines Bereichs herausragender gesellschaftlicher Relevanz, an dem man als politisch gebildeter Mensch (zumindest experimentell) redend und reflektierend teilhaben kann - wobei zunächst unklar bleibt, ob diese Perspektive in der mehrheitlich rot-grünen Prägung der Studierenden, in differenten Sozialisationserfahrungen oder aber in der bereits skizzierten grundierenden Bildungsemphase gründet. Dementsprechend sehen sich die Studierenden mehrheitlich als aktiv agierende und zu gewissen Verantwortungen verpflichtete Bürger der demokratischen Gesellschaft; nicht wenige sind in ihrer Freizeit zivilgesellschaftlich (etwa ehrenamtlich) eingebunden. Ebenfalls verbreitet ist eine allgemeine Verpflichtungsempfindung zu politischer Aktivität, die allerdings mit weitgehender politischer Apathie im Alltag kollidiert. In allen Fokusgruppen führt das zu individuellem Rechtfertigungsdruck sowie zu einem sorgenvollen bis sentimentalen Blick auf die ebenfalls mehrheitlich politisch-apathische Gesamtgesellschaft.

Zunächst: Wie informieren sich die Studierenden des Fokusgruppensamples über politische Themen; wo und wann tauschen sie sich über solche Themen aus? Über diese Frage haben zwar nicht alle Auskunft gegeben, auch weil sie nicht in jeder Fokusgruppe explizit thematisch wurde. Als wiederkehrendes Motiv sämtlicher Gruppen kann jedoch eine Verpflichtungsempfindung zur politischen Informiertheit - eine immer wieder konstatierte und in den Diskussionen unangefochtene Pflicht, zumindest rudimentär informiert und urteilsfähig zu sein - identifiziert werden, die durch Überforderungserfahrungen bei der Suche nach persönlicher Orientierung im Feld gesellschaftspolitischer Vorgänge flankiert wird. Die Navigation durch den Meinungsdschungel wird insbesondere durch die unausweichliche mediale Aufbereitung - und damit immer auch: Vereinseitigung - von Zusammenhängen erschwert. Häufig wird gefordert, die medial aufbereiteten Informationen, gerade auch die von persönlich präferierten Quellen bezogenen, zu „hinterfragen“, um persönliche Urteilsfähigkeit zu erlangen („selber seine Meinung zu bilden“): „Das ist wichtig, dass man sowas tut.“302 Dabei verfügen, wie be-

301 „I: Würdet ihr sagen, dass Politik in eurem Leben 'ne Rolle spielt? B6: Ja, sollte sie schon, ne? Aber dummerweise hab' ich zu wenig Zeit, um die Nachrichten immer gut zu verfolgen [...]" Transkript der 2. Fokusgruppe, S. 34, Z. 1073-1077; „B3: [...] ich glaube, ich bin das Paradebeispiel [dafür], was in der Cesellschaft schief läuft. [allgemeine Erheiterung] Also wenn irgendwas in der Politik ansteht, denk' ich mir: ,]a, der neben mir wird's schon machen! [allgemeines Lachen] Warum sollt' ich mich drum kümmern?' Und ich glaub', so denken viele. Auch viele aus meinem Freundeskreis denken sich: ,Ja, was soll ich schon bewirken? Es macht schon irgendjemand anders!' Und ich bin ehrlich, so denk' ich auch. Also: ,Warum gerade die Zeit verschwenden?' B4: Ich bin... Ja, ich muss ehrlich sein, ich hab' den Gedanken auch ab und zu!" Transkript der 7. Fokusgruppe, S. 38, Z. 1188-1195. 
reits erwähnt, nur drei Studierende über ein Abonnement einer Print-Zeitung, ${ }^{303}$ während eine Medizin-Studentin fachbezogene Zeitschriften als Informationsquelle für aktuelle Entwicklungen nennt. ${ }^{304}$ In erster Linie aber werden Nachrichten per Video, etwa über die tagesschau oder den Newsticker der Lokalpresse, ${ }^{305}$ über Talkshows wie An$n e$ Will, ${ }^{306}$ per Radio (NDR Info, radio2 $1^{307}$ ) oder über die Präsenz von Presseportalen, Zeitschriften und Zeitungen in den sozialen Medien - etwa Zeit Online und SPIEGEL ONLINE ${ }^{308}$-, verfolgt. Als geradezu bereichernde Entdeckung beschreibt eine Lehramtsanwärterin die Möglichkeit, über den individuell gestalteten Facebook-Newsfeed aktuelle Beiträge verschiedener Zeitungen beziehen zu können:

„Da hab' ich mal angefangen, mich drüber zu informieren, und da hat mein Freund mir den Tipp gegeben, mir einfach auf Facebook die ganzen Seiten von ganz vielen verschiedenen Zeitschriften und so zu liken, damit auch man linken und rechten - also nicht linksextrem oder so! [allgemeines Lachen] -..., aber linker Cestalt und rechter Cestalt, und dass man so ganz viele verschiedene Sichten auf ein Thema hat. [...] Allein, wenn ich nur durch mein Facebook-Dings morgens scrolle und abends, bin ich schon so informiert, jetzt. Und da merke ich nämlich, dass mir das richtig gut gefällt, informiert zu sein. Also, inzwischen fehlt mir das auch, wenn ich das mal einen Tag nicht checke, und da merke ich, dass Politik in dem Sinne jetzt eine Rolle in meinem Leben spielt, dass es mich halt interessiert [...] ‘309.

Das bringt ihr allerdings auch den schnippischen Kommentar einer Leserin von Print-Zeitungen ein, dass das „[...D]urch-soziale-Medien-Nachrichten-konsumieren“ aufgrund der Vereinseitigung der Informationsquellen durch Algorithmen „manchmal als ein Teil von Entpolitisierung" aufgefasst werden könne. ${ }^{310}$ Damit macht sie auf ein Problem aufmerksam, welches viele Studierende in den Fokusgruppen regelrecht umtreibt: Das Missverhältnis von (stets irgendwie gefärbten) Informationsquellen und persönlicher, zeitlich limitierter Aufnahmefähigkeit. Die Stilisierung politischer Informiertheit zur Mammutleistung muss zur Verzweiflung führen: Richtig informiert könne nur sein, wer politisch gegensätzliche Quellen beziehe und idealerweise „Minimum drei Stunden am Tag, wenn man sich wirklich als, ähm, mündiger, demokratischer Bürger [informieren will]“311, investiere. „Es ist ja irgendwie schwierig zu sagen, was richtig und falsch ist und so. Aber dann, weiß ich nicht, müsste man sich vielleicht irgendwie die taz, die FAZ kaufen, und die dann beide lesen. Am besten

303 Vgl. Transkript der 2. Fokusgruppe, S. 18, Z. 564-570; Transkript der 5. Fokusgruppe, S. 17, Z. 509 und S. 45 , Z. $1377-1393$.

304 Transkript der 5. Fokusgruppe, S. 43f., Z. 1333-1335.

305 Vgl. Transkript der 1. Fokusgruppe, S. 37, Z. 1121; Transkript der 4. Fokusgruppe, S. 29, Z. 909-911; Transkript der 7. Fokusgruppe, S. 41, Z. 1311-1325. Vgl. auch Transkript der 4. Fokusgruppe, S. $37 f$., Z 1181-1186; Transkript der 5. Fokusgruppe, S. 45, Z. 1368-1381.

306 Vgl. Transkript der 4. Fokusgruppe, S. 38, Z. 1188-1193.

307 Transkript der 5. Fokusgruppe, S. 43, Z. 1128-1131 und S. 45, Z. 1377-1381.

308 Transkript der 1. Fokusgruppe, S. 37, Z. 1129.

309 Transkript der 2. Fokusgruppe, S. 34f., Z. 1085-1095 (Herv. i. O.)

310 Transkript der 2. Fokusgruppe, S. 35, Z. 1103-1105. Vgl. auch Transkript der 3. Fokusgruppe, S. 52f., Z. 1597-1613, wo dieses Problem diskutiert wird.

311 Transkript der 7. Fokusgruppe, S. 39, Z. 1241-1243. 
noch die Zeit, und so.“312 Man stehe nachgerade „unter dem Druck“, als Nachrichtenkonsument „alles mitzukriegen!“313 Für manche verfehlen die Öffentlich-Rechtlichen Medien dabei ihren Vermittlungsauftrag, da sie es nicht fertigbrächten, nach dem Muster des Wahl-O-Mat einmal „drei Minuten pro Partei, die Knackpunkte“ vermittelten; nicht einmal die Schule bereite jenseits von Institutionenlehre auf das politische Handgemenge vor. ${ }^{314}$ Daher resignieren manche ganz und lehnen das mediale „hohle[] Rauschen“ mit der Bemerkung ab, dass "die Welt an sich“ zu komplex ist, also dass kein Mensch, egal wie gebildet man ist, da wirklich durchblicken kann [...] weil das menschliche Gehirn dafür nicht gemacht ist. ${ }^{315}$ Wohlgemerkt: Manche, nicht alle. Es gibt auch „große[] Verfechter der Medien“, die die Verurteilung insbesondere sozialer Medien nicht hinnehmen wollen und darauf verweisen, dass "die Sachen“ noch „relativ neu“ seien und man ihren adäquaten Gebrauch erst noch zu erlernen habe. „Wenn man sie nicht richtig benutzt, dann hat man eben einfach nur dieses Rauschen. ${ }^{316}$ Daraus folgt logisch, dass man das, was der biologischen Natur widerspricht, besser gar nicht erst versucht. Dennoch scheint fast allen der Gedanke fernzuliegen, dass sich auch vermöge des Durchdenkens eines kleinen Ausschnittes von Kommentaren $\mathrm{zu}$ gesellschaftlichen Vorgängen, etwa eines einzelnen Meinungsbeitrages einer Plattform zu einem politischen Thema, ein klareres politisches Urteil gewinnen ließe. Nur eine einzige Studentin im Sample besteht darauf, dass auch die Anhäufung von Informationen nicht von der Notwendigkeit des selbstständigen Denkens dispensieren könne. ${ }^{317}$ Die skizzierte mediale Überforderung mag also auch der Rationalisierung eigener Medienabstinenz dienen - was nicht heißt, dass die Studierenden nicht auch tragfähige medienkritische Argumente vorbringen. Denn dass Themen je nach Quelle in der Regel auf ein spezifisches Teilpublikum zugeschnitten und daher stets mit reflektierter Zurückhaltung aufzunehmen sind, ja dass vielleicht nicht einmal die geballte bundesrepublikanische Pressemacht die volle Faktenwahrheit abdecken kann, ${ }^{318}$ ist ja durchaus zutreffend. Angesichts der Skripal-Affäre aber zu behaupten, dass „gerade alle gegen die Russen“ hetzen, während man nirgendwo erfahre, „was die Russen dazu sagen" - eine von der Gruppe akzeptierte Deutung -, erscheint angesichts der Ausstrahlung von RT (Russia Today) auch in Deutschland sowie angesichts des Internetzeitalters dann doch wenig glaubwürdig. ${ }^{319}$ Jenseits des Medienkonsums scheint der Austausch über politische Themen zum Alltag der meisten Studierenden zu gehören, insbesondere die Diskussion mit Freunden, Familie und Wohngemeinschaft, etwa im Vorfeld von Wahlen. ${ }^{320}$ Indes stört es eine Person besonders, dass politische

312 Transkript der 2. Fokusgruppe, S. 35, Z. 1110-1113.

313 Transkript der 5. Fokusgruppe, S. 69, Z. 2109-2115.

314 Vgl. Transkript der 6. Fokusgruppe, S. 56f., Z. 1791-1815.

315 Transkript der 7. Fokusgruppe, S. 41, Z. 1299-1301 und S. 40, Z. 1252-1261 (Herv. i. O.)

316 Transkript der 7. Fokusgruppe, S. 42f., Z. 1339-1355.

317 Transkript der 3. Fokusgruppe, S. 35, Z. 1103-1113.

318 Vgl. Transkript der 2. Fokusgruppe, S. 32, Z. 1001-1012; Transkript der 3. Fokusgruppe, S. 63, Z. 19241934; Transkript der 5. Fokusgruppe, S. 39, Z. 1195-1199 und S. 46, Z. 1396-1406; Transkript der 6. Fokusgruppe, S. 40, Z. 1261-1263; Transkript der 7. Fokusgruppe, S. 37, Z. 1161-1166. Transkript der 2. Fokusgruppe, S. 35f., Z. 1115-1123.

320 Vgl. Transkript der 1. Fokusgruppe, S. 37, Z. 1125-1127; Transkript der 4. Fokusgruppe, S. 37f., Z. 11811186. Transkript der 5. Fokusgruppe, S. 43, Z. 1128-1131 und S. 44, Z. 1337-1343. 
Themen hier häufig zu „Smalltalk“verkommen, „aber keine wirkliche Auseinandersetzung mehr stattfindet“321 - während eine andere sich (aus Rücksicht auf ihr späteres Lehramt) unter Pseudonym nach eigenen Angaben auf der Plattform youtube über die Entwicklungen im „Schulsektor“ „auskotzt ${ }^{\text {(322 }}$. Eine Studentin der Psychologie zieht, anstatt auf die Frage nach politischen Austauscharenen zu antworten, diese mit einem bemerkenswerten, persönliche Überforderung indizierenden Verweis auf eine in ihren Augen stark politisierte Lebenswelt in Zweifel:

„Also, ich hab' grad' tatsächlich überlegt: Wo kommt man denn nicht mit politischen Themen in Berührung? Weil, ich finde, es gibt eigentlich kaum noch politikfreie Räume, so. [...] Also, ich hab' das Gefühl, in jedem sozialen Netzwerk ist irgendwo immer was Politisches zu finden. Cenerell im Alltag ist das ja... Also, allein wenn man sich irgendwie so die Uni Göttingen hier anguckt, wo dann so 20 politische Botschaften auf irgendwelchen Stickern drauf sind, so. [...] $]^{3323}$

Im Gegensatz dazu mangelt es einer Studentin der Politikwissenschaft und Arabistik derselben Fokusgruppe an der Diskussion „revelante[r] Tatsachen der Politik“ im Studium. ${ }^{324}$ Insgesamt informieren sich Studierende also wahrscheinlich über ähnliche Kanäle und mit denselben Vorbehalten gegenüber manipulativen Vereinseitigungen wie nichtstudierende Jugendliche und junge Erwachsene $e^{325}$ - wenngleich sie öffentlichrechtliche Medien, Zeitungen und Presseportale gegenüber alternativen Medien deutlich bevorzugen. Obwohl bisweilen ironisch und auch kritisch gebrochen, trauen sich die Studierenden dabei eine recht hohe Medienkompetenz zu.

Welche politischen Themen und Probleme beschäftigen die Studierenden? Am häufigsten werden Wahrnehmungen sozialer Ungerechtigkeiten, anwachsender gesellschaftlicher Konfliktpotenziale bei abnehmender Eintracht bzw. kommunikativer Überbrückbarkeit solcher Konflikte, und allgemeine politische Apathie genannt. Tatsächlich beschäftigt die Studierenden in erster Linie also das, was Freundschaft, Friede, Harmonie und Freiheit in einer intakten sozialen Umgebung - die herauspräparierten „Grundwerte" von Studierenden $2011^{326}$ - zu gefährden scheint. Beim Themenkomplex sozialer Ungleichheiten ist das wechselseitige intuitive Verständnis der Studierenden derart ausgeprägt, dass nicht einmal bei vergleichsweise abstrakten Bekundungen ein Nachhaken vonseiten der Moderation erforderlich wurde. Eröffnet etwa ein Student der Volkswirtschaftslehre mit: „[...] weil du ja fragtest, welche Themen uns generell umtreiben: Auch, ja, Ungleichheit, also international aber auch intranational' ${ }^{\text {‘327, so }}$ springt ihm umgehend eine Kommilitonin zur Seite, die diese Mehrdimensionalität von Ungerechtigkeiten erläuternd ergänzt:

„]a, Ungleichheit, und auch, dass andere Menschen ausgenutzt werden, weil... Also, das stört mich ehrlich gesagt immer am meisten [...] ich hab' auch mal in 'nem Hotel

321 Transkript der 5. Fokusgruppe, S. 37f., Z. 1140-1151.

322 Transkript der 5. Fokusgruppe, S. 48, Z. 1467-1471 und S. 58f., Z. 1798-1805.

323 Transkript der 1. Fokusgruppe, S. 37, Z. 1131-1141 (Herv. i. O.)

324 Transkript der 1. Fokusgruppe, S. 38, Z. 1154-1158.

325 Vgl. Schenke et al.: PECIDA-Effekte, S. 283-300.

326 Bargel/Simeaner: Gesellschaftliche Werte und politische Orientierungen, S. 6-8.

327 Transkript der 1. Fokusgruppe, S. 34, Z. 1049-1051. 
gekellnert, und die Leute, die zahlen so viel, und die Mitarbeiter werden dann einfach schlecht behandelt. Und das ist auch allgemein so der Fall, also national als auch international, dass egal... Sogar wenn man fairtrade kauft, dass sozusagen nur 20 Prozent der Inhaltsstoffe, teilweise sozusagen, fairtrade sind, und man zahlt halt so 'nen Aufschlag! [...] In der Wirtschaft ist es halt das Problem, dass halt der Fokus sogar bei Fairtrade auf Profit ist und nicht auf, sozusagen... die Lebensbedingungen der Menschen zu verbessern. [...] Weil, man ist ja bereit, sozusagen was Gutes zu tun, aber auch wenn man was macht, dann verbessert man trotzdem nicht die Lebensbedingungen der Menschen. “328

Ein funktionierendes gesellschaftliches Miteinander, so lautet es an anderer Stelle im Dialog zwischen einer Medizin-Studentin und einer sozialwissenschaftlichen Lehramtsanwärterin, setze

„B4: [...] voraus, dass die Menschen alle gleich von ihren Möglichkeiten und Ressourcen [her] sind [...] Also die müssten körperlich/seelisch gesund sein, damit das funktionieren kann, es müssen überall gleiche Ressourcen vorhanden sein, gleiche Bedingungen. [...] B5: Wobei: Man könnte halt versuchen, dann... Dadurch, dass es ja nicht so ist, dass alle gleich sind, dass man halt auf diese Unterschiede eingeht, möglichst, halt. Möglichst, dass allen trotzdem 'ne relativ ähnliche Chance, irgendwie, zumindestens [sic] zuteil wird."329

Der Themenkomplex sozialer Ungleichheit kehrt auch dort wieder, wo nach Vorstellungen einer idealen Gesellschaft ${ }^{330}$ oder nach dem persönlichen Verständnis der Kategorie des Gemeinwohls ${ }^{331}$ gefragt wird. Ungleichheit, so postuliert ein Student der Politikwissenschaft und der Soziologie, sei „das größte Gift und Manko von allem“. ${ }^{332}$ Vereinzelt führt das Phänomen sozialer Ungleichheiten die Studierenden zwar zu einer Kritik des Wirtschaftssystems insgesamt: „Ähm, ich bin kein Fan vom Kapitalismus. Ich würde immer im ganz Großen ansetzen und überlegen, [...] wie man Wirtschaft und dann Gesellschaft gestalten könnte“, auch wenn es an einer "konkreten Idee“ mangele. ${ }^{333}$

328 Transkript der 1. Fokusgruppe, S. 34f., Z. 1054-1067 (Herv. i. O.)

329 Transkript der 4. Fokusgruppe, S. 55, Z. 1744-1755 (Herv. i. O.)

330 „Kein Mensch verhungert. Ein klima- und sozialverträgliches Wirtschaftssystem." Transkript der 1. Fokusgruppe, S. 56, Z. 1730. „]a, aus meiner Sicht erstmal, dass man keine Kriege startet. Und dass man [...] 'ne Cleichberechtigung, auf jeden Fall, kriegt, und dass alle Menschen alle Chancen haben durch das..., weil sie finanziell nicht so schlecht dastehen, dass sie Möglichkeiten verbaut kriegen oder hungern müssen." Transkript der 2. Fokusgruppe, S. 47, Z. 1475-1478.

331 „Gemeinwohl ist vielleicht einfach Sicherung eines Existenzminimums, also dass keiner auf der Straße schlafen muss. Keiner muss hungern [...]" Transkript der 2. Fokusgruppe, S. 47, Z. 1480-1481. Transkript der 7. Fokusgruppe, S. 59, Z. 1862 (Herv. i. O.)

333 Transkript der 2. Fokusgruppe, S. 58, Z. 1828-1830. Alltagsnäher, aber im Kern übereinstimmend wird das an anderer Stelle durch Ausführungen bekräftigt, die durch Rückgriff auf eine Hauptund Nebenwiderspruchsthese traditionsmarxistischer Manier AfD-Wahlpräferenzen zu erklären versuchen: „Meiner Meinung nach - um mal nochmal direkt zu der Frage zu kommen - ist ja das große Problem, dass fortgeschrittener Kapitalismus und Neoliberalismus in der Cesellschaft [...] also dass sich dieses Defizit in der Cesellschaft, dieses ganze Konsumieren und nicht Nicht-teilhaben daran..., und die Oma kriegt nur 800 Euro Rente, und der Flüchtling mit fünf Kindern kriegt 3.000 Euro... Das ist ja das eigentliche Problem, dass die Oma nicht 1.800 Euro kriegt, sondern nur 
Verlagert sich die Diskussion in diese Richtung, werden gelegentlich Gegenpositionen aktiviert, die auf der grundsätzlichen Intaktheit sozialer Umverteilung und Existenzsicherungsinstrumente in Deutschland insistieren. In einem Fall wird durch eine beinahe genervte Äußerung deutlich, dass es solche „konservativen“, Kritik stillstellenden Sichtweisen durchaus gibt, auch wenn sie in den Diskussionen häufig unterlegen scheinen:

„Ja, auf jeden Fall muss man mal sagen, dass es uns in Deutschland auf jeden Fall allen hier in der Runde im Vergleich zur westlichen Welt auf jeden Fall verdammt gut geht. Keiner von uns, der hier sitzt, hat irgendwelche existenziellen Probleme. Wir können alle relativ entspannt irgendwas machen, wo wir Interesse zu haben, haben nicht irgendwie Angst, dass uns direkt körperliche Gewalt oder so angedroht wird, haben auch ein Bildungssystem, was uns allen ermöglicht, doch hier zu sitzen, auch wenn's teilweise mit finanziellen Problemen verbunden ist. Grundsätzlich kann man sagen: Perfekt wird es nie sein, aber wir sind schon ziemlich gut dabei in Deutschland, hier. $^{\text {“334 }}$

Doch den Gedanken einer grundstürzenden Veränderung des Wirtschaftssystems finden nur wenige reizvoll, und auch sie kommen über den Mangel tragfähiger Gegenrezepte selbst ins Zweifeln. Weitaus häufiger richtet sich die Kritik an Ungleichheiten auf die mangelnde Realisierung von Strukturen der Chancen- bzw. Bildungsgerechtigkeit. So wird etwa beklagt, dass "die Krankenkasse“ zum Leidwesen der gesetzlich Versicherten „ein Wirtschaftssektor geworden ist ${ }^{4335}$, dass es nichtakademischen und nichtkarrieristischen Berufsbildern drastisch an „Wertschätzung“ fehle ${ }^{336}$, oder eben dass aufgrund sozioökonomischer Prädeterminationen die gesellschaftliche und politische Teilhabefähigkeit für bildungsbenachteiligte und damit aufstiegsblockierte Schichten unterminiert sei. ${ }^{337}$ Chancen müssen, so die Sicht nahezu aller Diskutanten, in erster Linie durch bildungs- und sozialpolitische Ausgleichsinstrumente hergestellt werden: Dass Bildung „halt nix kosten“ darf, wird dementsprechend als Vorteil bundesrepublikanischer Lebensverhältnisse hervorgehoben, ${ }^{338}$ wird in den Augen vieler derzeit aber auch durch neue Verschärfungen einer „Vorschaltung der sozialen Ungleichheit“ bzw. eine „Vorschaltung der Bildungsungerechtigkeit" durch steigende Mieten und lebensweltliche Segmentierungen zwischen Besser- und Schlechterverdienenden (Stichwort: Privatschule) unterlaufen. ${ }^{339}$ Die derzeitige Bildungspolitik, gemessen am Schulsystem und an den Bologna-Reformen, erscheint immer wieder verfehlt: zu leistungszentriert, $\mathrm{zu}$ autoritär und gleichmacherisch, zu wenig sozial ausgleichend, kurzum: zu bildungsfeindlich. ${ }^{340}$ Ein besonders elaboriert auftretender Student der Philosophie geht noch

800, sie aber trotzdem [die] AfD wählt, weil der Flüchtling mehr kriegt. Aber der Kapitalismus sie einfach, so, über's Knie legt [...]" Transkript der 7. Fokusgruppe, S. 66, Z. 2103-2109.

337 Vgl. Transkript der 3. Fokusgruppe, S. 34, Z. 1031-1054.

338 Transkript der 6. Fokusgruppe, S. 14, Z. 430-431.

339 Transkript der 3. Fokusgruppe, S. 48, Z. 1460-1468.

340 Vgl. Transkript der 1. Fokusgruppe, S. 17, Z. 508-518; Transkript der 3. Fokusgruppe, S. 34, Z. 10411050 und S. 53f., Z. 1626-1644; Transkript der 5. Fokusgruppe, S. 39f., Z. 1195-1224 und S. 41, Z. 12671271; Transkript der 6. Fokusgruppe, S. 35-37, Z. 1117-1181. Eine Diskutantin fordert sogar die völlige 
einen Schritt weiter und betont - dabei die Dynamik der Bildungsexpansion sowie den von ihm erwarteten Bildungshunger zukünftiger innovationsgetriebener Arbeitsmärkte in evolutionstheoretischer Weise aufgreifend -, dass es angesichts eines noch viel $\mathrm{zu}$ „anarchischen“ gesellschaftlichen Fortschritts verstärkter Planungen in Investitionen in die Bereitstellung von an das Studium oder an noch zu schaffende alternative Ausbildungsformen anschließende Berufsbilder bedürfe:

„Also, ich finde das gut, dass es viel mehr Bio-Master gibt und viel mehr Wirtschaftswissenschaftler, viel mehr Juristen, viel mehr Rechtswissenschaften. Wir brauchen diese Leute, weil das alles im... Also, im vorherigen Wirtschaftsschritt - das wurde alles etabliert. Das Problem ist: Das sind gar nicht die Universitäten. Die müssten wirklich jeden nehmen, den sie kriegen können. Jeder gebildete Mensch ist extra! Das ist keine Knappheit, dass die ja plötzlich keinen Job finden. Sondern der Job muss irgendwie da sein. [...] Man muss im Grunde eine Stabilität schaffen, irgendwo ein Auffangnetz, einfach, für Talente. ${ }^{\text {“341 }}$

Durchaus wird, ein derartiges ausgeweitetes Verständnis von Bildungs- und Chancengerechtigkeit konterkarierend, von einer eher ideologiekritischen Natur derselben Fokusgruppe angemerkt, dass die Betonung einer durch kostenlose Bildung hergestellten Chancengleichheit auch studentische Komfortansprüche beim Selbstfindungsprozess rechtfertigen kann und dann eben kein Ausweis eines sozial sensiblen politischen Bewusstseins sein muss. ${ }^{342}$ Insgesamt aber ist die sich durchsetzende hegemoniale Perspektive für die Aussichten von Gesellschaftskritik verhängnisvoll, da das Kaprizieren auf die Bereitstellung von Bildungschancen eben immer auch die Legitimation von fortbestehender Ungleichheit ermöglicht: Wer trotz guter Startchancen Misserfolge erleidet, ist nach klassischer „meritokratischer Leitfigur sozialer Ungleichheit in Bildungsgesellschaften" zumindest verdächtig, seine Chancen in einem rational organisierten System der Ressourcenzuweisung nicht adäquat genutzt zu haben. ${ }^{343}$ Das muss den Fokusgruppenteilnehmern, die doch vage Vorstellungen einer deutlich egalitäreren, von

Abschaffung der von ihr als Relikt der "Steinzeit“ (!) verurteilten Schulpflicht, ruft damit aber sofortigen Widerstand hervor. VgI. Transkript der 4. Fokusgruppe, S. 25f., Z. 780-805. Transkript der 6. Fokusgruppe, S. 44-46, Z. 1407-1459 (Herv. i. O.) „Aber ich find' [...] das immer so 'n bisschen paradox, diese Cerechtigkeitsthese, weil das ja von irgendjemand auch bezahlt wird. Also die, die 'ne Ausbildung machen, bezahlen quasi deine Lust, jetzt, irgendwie doch was Anderes zu machen." Transkript der 6. Fokusgruppe, S. 14, Z. 439-442. Konkret erscheint soziale Ungleichheit so 1. "natürlich“ fundiert, 2. als gesellschaftliches Funktionserfordernis, 3. durch Bildungszertifikate beglaubigt, 4. als individuelles statt als strukturelles Problem, 5. von der "Definitionsmacht statushöherer Gruppen“ befreit. Siehe dazu Solga: Ohne Abschluss in die Bildungsgesellschaft, S. 34-42. 
„Marktlogiken“344 freieren Gesellschaft zu pflegen scheinen, so nicht unbedingt bewusst sein, zumindest ziehen sie einen Schluss dieser Art nirgendwo explizit. Ein zentraler Hinweis auf Sinnstrukturen politisch-sozialer Deutungsmuster ist dem trotzdem zu entnehmen: ${ }^{345}$ dass nämlich eine intakte, funktionsfähige Gesellschaft auf der Herstellung, Modernisierung und - durch den unterstützenden sozialpolitischen Ausgleich von familiären, migrantischen o. Ä. handicaps - Instandhaltung eines Bildungsauslesesystems basiert. Eine Gesellschaft, die derart allen anstrengungsbereiten „Talenten“ die Hand reicht, ist gerecht. Ungleichheiten und Ungerechtigkeiten, etwa fundamentale Einkommensdifferenzen des Elternhauses, werden erst als Störungen des Auslesesystems politisch skandalträchtig, nicht als Reichtumsspreizung per se. ${ }^{346}$ „Also es wird oft gesagt, Chancengerechtigkeit wär' vorhanden, aber ich seh’ das nicht so.“347 „Und man kann ja dann wieder diskutieren, dass es unfair ist, dass dann manche Menschen 10.000 Euro im Monat haben und manche 450 Euro im Monat, wenn überhaupt. Das ist ja auch vielleicht 'ne Frage ${ }^{\text {‘348 }}$ - nur für Studierende eben nicht die entscheidende.

Auch der Themenkomplex sozialer und diskursiver Desintegration treibt die angehenden Akademiker um. Das Gefühl: „Die Welt wird immer unkontrollierter“ treibt sogar Studierende um, die sich dagegen mental zu panzern versuchen. ${ }^{349}$ Man zeigt sich besorgt über wachsende Kommunikationshürden und steigendes Konflikt- bzw. Polarisierungspotenzial in unterschiedlichsten Teilen der Gesellschaft; auch spüren viele dort, wo sie kommunikativ interagieren, einen Trend zum Positionierungszwang inmitten sich radikalisierender, zunehmend unversöhnlicher Fronten (gerne als „Blasen“ bezeichnet):

„B4: [...] Und zwar, irgendwie, wird man mittlerweile dazu gezwungen, sich für eine Seite zu entscheiden. B7: ]a, ja! B1: [nickt] Also, sobald du dich für Russland entscheidest, bist du gegen, äh, die USA, oder... Gut, Palästina/Israel ist schon immer 'n sehr

344 Hinweise darauf finden sich in der Kritik an einer „Ökonomisierung von Journalismus“ und der "Ökonomisierung des Studiums" (Transkript der 1. Fokusgruppe, S. 57, Z. 1747-1759-dort auch die Formulierung, dass "Marktlogiken“ das Zusammenleben stärker bestimmten würden als „soziale Zusammenhänge“), in der Klage über gesellschaftlich erzeugten „Leistungsdruck“ und im damit verbundenen Gedanken an die Idee des Bedingungslosen Grundeinkommens (Transkript der 2. Fokusgruppe, S. 33f., Z. 1051-1065), sowie in der diagnostizierten Dominanz des Qualifikationskriteriums „Anforderungen erfüllen“ bei der immer stärker verschulten Ausbildung von Ärzten (Transkript der 5. Fokusgruppe, S. 34, Z. 1044-1052).

345 Eine pointierte Bestimmung der in den Diskussionen wirksamen Deutungsmuster findet sich in Kapitel III.3.4 dieser Studie.

346 So überlegt gerade ei ne kapitalismuskritische Studentin der Wirtschafts- und Sozialgeschichte: „Aber es ist vielleicht auch gut, dass es Leute gibt, die megaviel verdienen und irgendwie Unternehmer sind, weil die dadurch 'nen Anreiz haben, irgendwie Arbeitsplätze zu schaffen. Ist das vielleicht auch gut für's Cemeinwohl, oder ist das zu sehr'ne Klassengesellschaft, und das ist halt nicht mehr gut für's Allgemeinwohl? Das ist ja schwierig." Transkript der 2. Fokusgruppe, S. 48, Z. 1510-1514 (Herv. i. O.)

347 Transkript der 3. Fokusgruppe, S. 35, Z. 1064-1065.

348 Transkript der 2. Fokusgruppe, S. 47, Z. 1492-1495.

349 „Aber dieses Gefühl von, irgendwie: ,Die Welt wird immer unkontrollierter’... Ich weiß auch nicht, ob das was ist, dass ich älter werde, dass ich mehr Zugang zu allem hab', also so 'n digitales Ding [...] Also ob die Welt schlimmer wird, ob ich es alles als schlimmer empfinde [, kann ich nicht sagen]." Transkript der 5. Fokusgruppe, S. 36, Z. 1109-1114 (Herv. i. O.) 
schwieriges Thema gewesen, so, aber das ist... sozusagen nochmal 'n anderes Thema, glaub' ich, aber, keine Ahnung... Also, nationalistische Politik, sag' ich mal, oder protektionistische, oder sehr liberale Politik oder sowas: Sobald man irgendwie ein Argument für oder gegen das andere, irgendwie, macht, wird man sofort in das andere eingeordnet, so... B7: Ja! B4: ..., ist man direkt in 'ner... in so'ner anderen Blase, irgendwie. Also es sind so zwei Blasen oder mehrere Blasen, die immer aufeinander, irgendwie, stoßen $[. . .]^{4350}$

Dass die Wahrnehmung mentaler Polarisierungen bei gleichzeitigem Kommunikationsabbruch von vielen geteilt wird, ist an folgender dichter Passage besonders gut zu sehen:

„B7: [...] Ich hab' den Eindruck, dass im Moment in Deutschland so 'ne Tendenz herrscht, dass sich so Gruppen bilden, so Männer/Frauen, divers... B3: Genau, und dann wird so eingeteilt... B7: ... links/rechts, Behinderte, Ausländer, Deutsche... B3: ..., und man hasst sich, mal krass ausgedrückt... B7: ]a. [...] Man versucht so, sich irgendwo 'reinzu-... zu fühlen: ,Ich bin jetzt in dieser Cruppe, und alle anderen Gruppen sind irgendwie doof!', oder: ,Ich muss mich gegen die verteidigen!' Man muss immer auf die political correctness achten, und bloß Studenten... Studentinnen am besten noch...“351

Viele sehen dabei ein Problem im Vordergrund, das sie als „Rechtsruck“ mit internationaler Dimension bezeichnen, wie er an „so vielen [Orten] gleichzeitig, gerade“ zu beobachten sei, ${ }^{352}$ oder aber - deutlich häufiger - über die Leitvokabeln „Intoleranz“ bzw. „Ignoranz“353 einführen. Der größte Teil der hier geäußerten Bedenken setzt an der Diskussion über die Flüchtlingsfrage seit 2015 und, damit zusammenhängend, an diskursiven Verrohungen, an den Wahlerfolgen der AfD sowie an der Genese neuer rechter Milieus an. „Wie gehen wir mit Leuten um, die nicht nur die AfD wählen, sondern gleichzeitig auch noch vor'm Flüchtlingsbus stehen und schreien: ,Wir sind das Volk!? ‘354 Das fragen sich viele Studierende erkennbar bereits seit mehreren Jahren, auch weil sie an sich selbst oder an nahestehenden Personen vorurteilsbehaftete Neigungen - das „schnell auf irgend'nen Zug aufsteigen“ - feststellen ${ }^{355}$ oder sich nach dem Abklingen der „Willkommenskultur“-Euphorie, in deren „Strom“ (!) man 2015 „da so voll mitgeschwommen“ ist, „mal aber kritisch in die andere Richtung reflektiert“ haben und nunmehr die Notwendigkeit erkennen "auch dann mal 'ne andere Meinung“ akzeptieren zu müssen, ohne sie „gleich in die rechte Ecke“ zu stellen, „weil sie mal 'n

350 Transkript der 3. Fokusgruppe, S. 38f., Z. 1170-1187.

351 Transkript der 6. Fokusgruppe, S. 61, Z. 1921-1941 (Herv. i. O.)

352 Transkript der 7. Fokusgruppe, S. 27, Z. 855-857.

353 Transkript der 1. Fokusgruppe, S. 29, Z. 898; Transkript der 3. Fokusgruppe, S. 36, Z. 1104-1111; Transkript der 7. Fokusgruppe, S. 27, Z. 850-853.

354 Transkript der 1. Fokusgruppe, S. 30, Z. 904-906.

355 „Zum Beispiel durch diese Flüchtlingsdebatte, das... Also, das merk' ich so im Umfeld, dass super... Wenn man halt jemanden sieht, der halt 'ne andere Hautfarbe hat, dass man direkt denkt: ,Okay, das ist 'n Flüchtling!', und dieses Stereotyp mitdenken [...]“ Transkript der 1. Fokusgruppe, S. 30, Z. 912-922. 
paar Bedenken äußern“. ${ }^{356}$ Eine Person, die demgegenüber angibt, „von Anfang an sehr kritisch" gewesen zu sein und nach wie vor auf die unnachgiebige Notwendigkeit kultureller sowie ziviler Einfügung zu pochen ${ }^{357}$, fügt nach dem eher vorsichtig überlegenden Einwurf einer Mitdiskutantin, es handle sich angesichts der ,interkulturelle[n] Bedeutung“ Deutschlands um ein „sehr, sehr zwiespältiges Thema“, da hier stärker Fragen eines „Allgemeinknigges“ als kulturelle Differenzen zur Debatte stünden, eilig hinzu, sie habe sich „überhaupt nicht in irgendeine Ecke stellen“ wollen. ${ }^{358}$ Als Hauptursachen für die Abwanderung von Wählern zur AfD machen die Studierenden „Ängste“359 und Deprimierungen ${ }^{360}$ aus, die entweder aus dem Gefühl eines Repräsentationsdefizits konservativer, ordnungsfixierter Geister in einem mehrheitlich kosmopolitischen und liberalen Land ${ }^{361}$ oder allgemein aus deinem Stillstand des politischen Wettbewerbs resultieren, welcher nach einem „Korrektiv“ verlangt habe. ${ }^{362}$ Verschärft werde das Problem durch Defizite politischer Bildung in (hauptsächlich in den Neuen Bundesländern lokalisierten) Schwerpunktregionen der AfD - doch mehr dazu weiter unten. Dabei sehen Einzelne durchaus integrationspolitische Versäumnisse, vermissen insbesondere ein klar kommuniziertes und auch konzertiertes Programm, das der Merkel'schen Durchhalteparole „Wir schaffen das!“ hätte folgen können ${ }^{363}$ und das auch ein Konzept zur Vermittlung der zunächst einmal konfligierenden freiheitlichen politisch-kulturel-

356 Transkript der 4. Fokusgruppe, S. 31, Z. 964-981 (Herv. i. O.) Ähnlich auch Transkript der 5. Fokusgruppe, S. 56, Z. 1707-1708 (Herv. i. O.): „Ich hab' gesagt: ,Alle Flüchtlinge dürfen bleiben!", und was weiß ich was. Und dann war ich zwei Jahre Nachhilfelehrerin, und hab' da jetzt 'n viel differenzierteres Bild. Und mit den Sachen, mit denen man sich beschäftigt, da ist dann plötzlich kein ,Ja/Nein-Schwarz/Weiß' mehr, irgendwann, sondern, ja... Da muss man sich aber erstmal mit beschäftigen, so 'n bisschen."

357 „Da muss ich ganz ehrlich sagen, bin ich da, ehrlich gesagt, sogar noch vorsichtiger geworden, weil ich... Ich möchte nicht irgendwie belästigt werden, und ich finde, man hat sich hier im Land so zu verhalten, dass es allen gut geht, und dass man sich anständig benimmt. Und wenn das nicht der Fall ist, dann find' ich halt... ja, muss halt was gemacht werden." Transkript der 4. Fokusgruppe, S. 31f., Z. $985-998$.

358 Transkript der 4. Fokusgruppe, S. 32f., Z. 1017-1030.

359 Transkript der1. Fokusgruppe, S. 43, Z. 1310, ähnlich und dabei selbst wutgeladen Transkript der 6. Fokusgruppe, S. 63, Z. 1993-1995.

360 Transkript der 4. Fokusgruppe, S. 35f., Z. 1119-1127.

361 Vgl. Transkript der 7. Fokusgruppe, S. 66, Z. 2081-2099.

362 Transkript der 3. Fokusgruppe, S. 63, Z. 1937-1946; vgl. auch die Kritik an den „Allerweltsparteien“ (Kirchheimer) in Transkript der 6. Fokusgruppe, S. 58, Z. 1836-1845, außerdem die Schilderung des Erkenntnismoments bei der vergangenen Bundestagswahl: „Und das ist voll der Aufwachmoment gewesen, der vielleicht auch jetzt sehr wichtig war, um eben mal zu gucken: Warum ist das eigentlich so? [...] Warum sind die Menschen unzufrieden?“" Transkript der 5. Fokusgruppe, S. 62, Z. 1917-1921.

Vgl. Transkript der 4. Fokusgruppe, S. 34., Z. 1017-1059. 
len mit muslimischen Werthierarchien enthält. ${ }^{364}$ Sie sind selbst verunsichert, geben zu: „Ich hab' Angst, in die Innenstadt zu gehen, mittlerweile [lacht], wenn's dunkel ist $^{\text {«365 }}$ - und vermögen das in den Fokusgruppen durchaus sanktionsfrei zur Diskussion stellen. Verständnis für politische Frustrationen aufseiten vieler Büger bringen die Studierenden also auf. Dass aber einige dann tatsächlich ihr Kreuz bei einer Partei (weit) rechts der Mitte setzen, erschüttert sie bis ins Mark, insbesondere weil sie nach wie vor davon ausgehen, dass die Mehrheit der Stimmen einem Protestwahlverhalten entstammen, keiner ernst gemeinten „Überzeugung“. ${ }^{366}$ Tatsächlich findet sich im Sample nur eine einzige, als solche in der Diskussion unsichtbare, AfD-Wählerin. Auch wenn in den Diskussionen durchaus Platz ist für kritische Erwägungen über die bundesrepublikanische Integrationspolitik, scheint der Austausch über die Themen Migration und Integration auch unter Studierenden noch immer erkennbar mit großen Unsicherheiten behaftet. Ähnliches gilt für eine der vermittelnden Vernunft verlustig gegangene, durch Machterhalt und nationalistisches Eigeninteresse geprägte internationale politische Bühne, wenn etwa bemerkt wird, dass „die allgemeine Politik [...], wenn man so auf Deutschland guckt oder ebent auch auf Europa“ durch den opportunistischen Egoismus des „,Hauptsache, mir geht's gut, ich steh' gut da' oder ,meine Partei steht gut da!'“ gezeichnet sei. „Also es wird gar nicht mehr so geguckt: Was ist allgemein für die Welt, für Deutschland [gut]? ${ }^{\text {367 }}$ Stattdessen würde einem jeden nach alter KalterKriegs-Manier das Bekenntnis zu den USA oder Russland abverlangt, stattdessen folge auch das Wahlverhalten auf dem Dorf diffusen Sympathien und Antipathien nach dem Muster alten volksparteidualistischen Lagerdenkens und nicht etwa dem zwanglosen Zwang des besseren Arguments. ${ }^{368}$ Selbst in der Kommunalpolitik, so weiß jemand aus zweiter Hand zu berichten, herrschten „Intrigen und was weiß ich alles [...] echt wie House of Cards“369 - ganz zu schweigen von den Grabenkämpfen zersplitterter linker Politgruppen! ${ }^{370}$ Abseits der institutionalisierten Politik wird mit tiefsitzender Skepsis auf Störungen der sozialen Eintracht durch identitätspolitische Diskursverhärtungen

364 So pointiert eine Lehramtsanwärterin: „Und ich finde, das ist schon echt 'n schwieriges Thema, weil: Ich als Deutsche würde im Zweifelsfall immer die Gleichberechtigung zwischen Mann und Frau über die Religionsfreiheit stellen, wenn ich... wenn mir da so 'n Konflikt kommt. Das würden aber nicht unbedingt alle so sehen, und das sind teilweise wirklich manchmal kulturelle Probleme, die natürlich dadurch jetzt auch auftreten, wo wir uns irgendwie als, ja, Deutsche... Oder die Politik, die müssen sich da irgendwie mit beschäftigen. Und gucken, wie wir damit umgehen, vor allem!" Transkript der 4. Fokusgruppe, S. 34, Z. 1061-1084.

365 Transkript der 5. Fokusgruppe, S. 35, Z. 1081.

366 „B3: Ich find's auch sehr erschreckend. Also, ich hätte es auch nicht so erwartet, dass es so krass wird. Also, ich hab' mir schon gedacht, dass es wirklich viele Leute gibt, die irgendwie sagen, so: "Ja, okay, ich bin jetzt stinkig und böse und mach' jetzt auf einen auf Protest!", aber dass die ernsthaft das wählen, was die AfD vorschlägt und an ihrem... in ihrem Programm stehen hat, das fand ich schon sehr erschreckend! Also das hätt' ich echt nicht gedacht, dass es so negativ wird. B5: Na, ich glaub', manche [!] haben es wirklich aus Überzeugung auch... [...]" Transkript der 4. Fokusgruppe, S. 48f., Z. $1533-1539$ (Herv. i. O.)

367 Transkript der 3. Fokusgruppe, S. 37, Z. 1125-1132.

368 Vgl. Transkript der 3. Fokusgruppe, S. 38f., Z. 1176-1182; Transkript der 4. Fokusgruppe, S. $45 f$., Z. 1439-1449.

369 Transkript der 7. Fokusgruppe, S. 34f., Z. 1087-1090.

370 Vgl. Transkript der 7. Fokusgruppe, S. 34, Z. 1076-1083. 
im Sinne der political correctness verwiesen, etwa auf die Ausartung einer „FeminismusKultur ${ }^{\text {‘371 }}$ zu einem Tugendprogramm, kraft dessen dem „einem ja vorgeschrieben“ werde, „Von was man sich diskriminiert zu fühlen hat, irgendwie“. ${ }^{372}$ Besonders häufig sind es Studentinnen, die ihrem Unmut über exaggerierte Feminismen Luft verschaffen:

„Also, zum Beispiel, dass wir das gleiche Geld verdienen sollten wie Männer - ja, auf jeden Fall! Aber dass man sich jetzt..., dass jedes Wort jetzt geändert soll, dass es jetzt nicht mehr Doktor und Professor heißen soll, sondern halt ,Dotox' und ,Protox - ganz ehrlich! ${ }^{4373}$

Ähnliches wird auf dem Feld moralisierten Konsumverhaltens ausgemacht. Anstatt die entscheidenden Tendenzen der Zeit in den Griff zu bekommen, sich „überhaupt klar zu machen“, was derzeitige wirtschaftliche Entwicklungen bedeuten und wie eine zeitgemäße, beispielsweise linke, Antwort aussehen könnte, pflege man „immer den linken Wahnsinn" der Diversität, der sein Komplement in der Genese neurechter Identitätspolitik der Autochthonen finde. ${ }^{374}$ Angesichts der Verengung von Diskussionen auf lebensstilbezogene Individualethiken und identitätspolitische Tribalisierungen möchten Einzelne förmlich die Hände über dem Kopf zusammenschlagen:

„Wir haben nichts miterlebt, keinen Abgrund oder kein [...] für uns sind Probleme irgendwie Kaffee-to-go-Becher und irgendwie so 'n Zeug - was natürlich berechtigt ist! -, aber so die großen Sachen aus den 68ern, die werden... die fragt man sich nicht mehr so! Kapitalismus und wie wir alle zerdrückt werden, und, keine Ahnung, heut' ist halt Feminismus und Kaffee-to-go-Becher und so. ${ }^{\text {،375 }}$

Wohlgemerkt: In der Gesamtschau besteht unter den politisch stark Interessierten im Sample ein Dissens bezüglich der Einstufung ökologischer und konsumkritischer Diskussionen. Handelt es sich für die einen um das „Kombattieren“von „Strohmännern“376, die davon ablenken, dass „wir halt mit Informationen überflutet werden, und halt uns nicht die essenziellen Sachen fragen ${ }^{\text {‘377 }}$, sehen andere den fairen Handel und den klimasensiblen Konsum als veritables Feld politischer Verantwortungsübernahme an. Sie meinen es ernst mit der Durchsetzung fairen Handels und klimafreundlicher Ernährung als Weg zu einer besseren Gesellschaft. ${ }^{378}$ Natürlich nehmen längst nicht alle Studierenden im Sample politische Positionen ein. Viele bilden ihr Urteil gesellschaftlicher Polarisierungen und Kommunikationsverluste an unmittelbaren Alltagserfahrun-

371 Transkript der 1. Fokusgruppe, S. 30, Z. 903.

372 Transkript der 1. Fokusgruppe, S. 32, Z. 974-975.

373 Transkript der 1. Fokusgruppe, S. 31, Z. 952-958.

374 Transkript der 6. Fokusgruppe, S. 67, Z. 2124-2135 (Herv. i. O.)

375 Transkript der 7. Fokusgruppe, S. 28, Z. 883-889.

376 Transkript der 6. Fokusgruppe, S. 50, Z. 1578-1581.

377 Transkript der 7. Fokusgruppe, S. 28, Z. 884-885.

378 „Also ich hab' das Cefühl, dass viele Menschen häufig gegen ihren eigenen Horizont laufen, und aber den Blick über den Tellerrand nicht wagen und sich mal Gedanken darüber machen, welche Auswirkungen ihr Handeln hat. [...] Und zwar werf' ich den Leuten nicht vor, dass sie Schokolade mit Kinderblut kaufen. [allgemeines Lachen] Ähm, ich werf' den Leuten vor, dass sie sich keine Gedanken da drüber machen." Transkript der 3. Fokusgruppe, S. 36, Z. 1104-1111 und S. 41, Z. 12671269. 
gen wie persönlichen Kontakten oder Medienkonsum - im Falle Göttingens etwa am Campus, auch wenn hier die Urteile auseinanderweisen:

„Und in Göttingen ist's natürlich [lacht] auch extrem, ne. Also man... Ich find', es wird schon... Es gibt irgendwie keine Mitte. Es gibt so die linken Gruppen und die rechten, und... [allgemeine Zustimmung] Weiß nicht." ${ }^{\text {(379 }}$

„B2: Aber ich finde das auch, hier in Göttingen ist das richtig extrem. Entweder du bist extrem links, extrem rechts, und es führt nichts dazwischen. Da denkst du dir so: ,Okay!' B1: Aber ich glaub', das ist auch allgemein so die Uni, und nicht unbedingt... B2: Ja, das kann ich mir auch vorstellen. B1: ... [unverständlich] das Problem. Das ist auch mit den Jugendparteien, also mit den Jugendvereinen der großen Parteien. Die sind ja auch deutlich extremer als dann letztendlich..., wenn sie dann mal oben angekommen sind. ${ }^{380}$

Während eine konservativ auftretende Studentin nochmals bekräftigt: „Man ist halt 'n Nazi oder 'ne Zecke, also jetzt mal ganz salopp gesagt", entgegnet ein anderer, sich selbst kaum verortender Student achselzuckend: „Mir ist das noch nicht aufgefallen.“381 Einige im Sample, die Kontakte zu nichtakademischen Milieus in Familie und Freundeskreisen pflegen, identifizieren ganz besonders die Ablösung universitärer Mentalitäten von der Restbevölkerung als wesentlichen Motor identitätspolitischer Emotionalisierungen. Man studiere in einem „Mikrokosmos“, der bedenklich weit „ab von der Realität“ liege. ${ }^{382}$ Die Unvermittelbarkeit vieler Diskussionen um „Feminismus und Gender“, aber auch Naturschutz, sei dem Problem zuzuschreiben,

„dass der universitäre Diskurs oder auch das, was Studenten darüber denken, recht realitätsfern ist von dem, was da die Restbevölkerung und auch ja die arbeitende Bevölkerung anbelangt... Was ich immer so, dann, aus meinem privaten Umfeld mitbekomme, wenn ich mich mit Studenten unterhalte, oder wenn ich mich mit Leuten unterhalte, die halt 'ne Ausbildung gemacht haben oder die jetzt arbeiten - dass da doch sehr unterschiedliche, ja, doch Ansprüche sind an Politik. Nicht unbedingt, dass da jetzt irgend'n Rechts/Links-Schema vorhanden ist, aber dass es einfach andere Aspekte gibt, auf die dann Wert gelegt wird in einem Diskurs.“383

„Also, ich find' grad' Feminismus und, ähm, auch die Gender-Debatte und wie auch immer... Das ist 'ne Sache, das wird in dieser studentischen Blase total geführt, also da hat jeder [...] zumindest 'ne Meinung dazu und ist auf jeden Fall schon mal damit konfrontiert worden. Aber wenn du auf die Straße gehst... Also, das ist einfach 'ne ganz andere Realität!"384

„Ich glaube, es ist nicht nur die Ignoranz, die dazu führt, dass sie [die Menschen im Allgemeinen, J. S.] manche Themen nicht angehen. Teilweise ist es auch die Blase, in

379 Transkript der 2. Fokusgruppe, S. 39f., Z. 1248-1250 (Herv. i. O.)

Transkript der 3. Fokusgruppe, S. 39, Z. 1198-1203. Darüber hinaus erschwert schon die unausweichliche mediale Aufbereitung von Zusammenhängen für viele die politische Orientierung-doch soll auch das noch kurz zurückgestellt werden. 
der wir auch sind. Wir sind in der Uni-Blase. Das ist was, was mich selber beschäftigt: ,Wie komm' ich aus meiner Blase 'raus? ${ }^{\text {'“385 }}$

Worauf auch immer die Probleme kausal zurückgeführt werden: Inmitten eines so skizzierten diskursiven Handgemenges wächst der Wunsch nach Verständigung, Vermittlung, Einheit im Chaos. Die Sehnsucht nach der vermittelnden Vernunft des verständnisvollen Gesprächs im Gezänk der Emotionen ist groß. Selbst wo sie ohne konkreten inhaltlichen Bezug geäußert wird, ist er für die anderen Studierenden in den Fokusgruppen intuitiv verständlich:

„[...] ich hab' auch das Gefühl, dass..., also, dass es momentan so in beide Extreme strebt, oder halt Leute komplett sich 'raushalten. Also es gibt zu wenig Einigung über Vieles und auch über so viele Begrifflichkeiten. “386

„Was ich 'n Problem find', wenn viel über sowas läuft: dass das Zuhören fehlt. Dass meine Cousine, zum Beispiel - äh, vier Kinder, ganz früh Kinder gekriegt in Bayern ganz klar anders Stellung bezieht als ich, und ganz klar gegen Ausländer und so, und sich auch auf Facebook positioniert. Aber ich hab' das Gefühl, ich kann mich da nicht auf Facebook mit ihr drüber unterhalten! Ich müsste mit ihr da face-to-face sein. Und auch mit den youtubern oder was weiß ich was: Ich find', so Leute, ähm... also mit vielen Leuten, da fehlt einfach 'ne Auseinandersetzung.“387

Bisweilen scheint eine alte (deutsche) Vorliebe für das soziale wie sozialmoralische Ideal von „Mitte und Maß" aus den durch „konservative Sorge“ wie kapitalismuskritische Diagnostik gleichermaßen inspirierten Verweisen auf Anomie und Unversöhnlichkeit ${ }^{388}$; eine Vorliebe, die Halt bietet, etwa indem sie anti-alarmistische Verweise auf einen insgesamt doch gut funktionierenden deutschen „Mittelweg ${ }^{\text {“389 }}$ oder gar die Behauptung einer zweieinhalbtausend Jahre überbrückenden Wesenskonstante des Ausgleichs inmitten politischer Konflikte gestattet. ${ }^{390}$ Seinen Gipfel erreicht das im relativistischen

385 Transkript der 3. Fokusgruppe, S. 47, Z. 1455-1456 (Herv. i. O.)

386 Transkript der 1. Fokusgruppe, S. 30, Z. $907-910$ (Herv. i. O.)

387 Transkript der 5. Fokusgruppe, S. 54, Z. 1649-1655 (Herv. i. O.)

388 Vgl. zu den Traditionslinien dieser Diskussion um den Verlust der Mitte und ihres rechten Maßes Münkler, Herfried: Mitte und Maß. Der Kampf um die richtige Ordnung, Reinbek bei Hamburg 2012, S. 59-68, insbesondere S. 63.

389 „Also manchmal bin ich der komische VWLer, manchmal bin ich der Wein trinkende und rauchende Philosoph. [allgemeine Erheiterung] Und immer, wenn ich versuche, neutral für die andere Position zu argumentieren, sieht man wieder nur meine Chino-Hose, oder man sieht irgendwie nur, dass ich seit acht Wochen nicht mehr beim Friseur war, so. Das stört mich schon, und ich würd' das auch gerne als eins von den gesellschaftlichen Problemen wahrnehmen, aber ich weiß nicht, ob das wirklich 'n Problem ist. Sondern ich glaube, dass wir im Moment, auch wenn es so ist, irgendwie doch 'nen ganz guten Mittelweg fahren in Deutschland. [...] Auch, wenn ich mit meinen Eltern diskutiere, dann denk' ich manchmal: "Was ist das denn für 'ne hinterwäldliche braune Dorfmeinung?"[allgemeine Erheiterung] Aber eigentlich ist es genau dieser Mittelweg, den die fahren!“ Transkript der 3. Fokusgruppe, S. 42f., Z. 1298-1315.

390 „Also, vor zweieinhalbtausend Jahren hat Aristoteles ja schon mal sowas geschrieben wie, dass es immer in der Politik Ausschweifungen nach links oder rechts gibt; es wird immer mal Extreme geben, die sich wieder einpendeln und woanders hingehen. Und das hat mich schon ziemlich beruhigt!" Transkript der 7. Fokusgruppe, S. 63, Z. 1993-1996. 
Toleranzdiktum einer Soziologiestudentin, welche überhaupt keine leidenschaftliche Parteinahme, gleich für welche Position, gelten lassen will und demgegenüber die radikale „Offenheit" als oberste Erziehungsmaxime einfordert. ${ }^{391}$ Geradezu brachial flapsig bemerkt sie am Gegenstand des gesellschaftlichen Umgangs mit der AfD, auch die „Hitler-Zeit" sei letztlich „nur so 'ne Phase“ gewesen, und auch das habe „sich ja auch irgendwie wieder eingerenkt“. ${ }^{392}$ Welchen Eindruck hinterlässt der Blick auf diesen Themenkomplex insgesamt? Man ist einerseits versucht, die studentischen Klagen über ein neues erbittert-identitäres Lagerdenken als Ausdruck einer offenbar alltäglichen Erfahrung zu werten. Wäre die Überforderung nicht real empfunden, würde sie nicht so freimütig verbalisiert. Dabei können die Studierenden auch auf Zustimmung etwa aus dem Feuilleton wichtiger Zeitungen zählen, in dem immer wieder ähnliche Zeitdiagnosen gestellt werden. ${ }^{393}$ Andererseits muss das dadurch ausgedrückte Selbstbild, vermöge der analytischen Distanzierung über all jenen Konfliktparteien und „Blasen“ $\mathrm{zu}$ stehen, deren Borniertheit man Bescheid wissend durchschaut, und nur zu Unrecht von bösartigen („extremen“) Rabulisten einsortiert zu werden, auch Misstrauen wecken. Auszuschließen ist es nicht, dass die Klage über Positionierungszwänge auch genutzt wird, um sich ganz generell davon zu dispensieren, überhaupt eigene politische Positionierungen argumentativ zu entwickeln und interaktiv zu verteidigen. Als unzumutbar erscheint es etwa einem generell mehr fragend als behauptend auftretenden Studenten der Politikwissenschaft und der Arabistik, in Diskussionen begründen zu müssen: „,Wieso bist du gegen Merkel?!', oder: ,Wieso bist du für Merkel?!‘, oder so, was auch immer.“394 Konfliktiven weltanschaulichen Auseinandersetzungen im Stile der 1970er Jahre stünden die insgesamt doch merklich harmoniebedürftigen Studierenden, so scheint es, entsetzt und hilflos gegenüber. Dabei navigieren sie oftmals selbst mithilfe suggestiver, identitätspolitischer Phrasen durch den Dschungel politischer Diskussionen, etwa mit rückversichernden Sätzen wie "Rechts ist extrem sexistisch, seien wir ehrlich“. ${ }^{395}$ Es drängt sich der Eindruck auf, dass also besonders der Rekurs auf eine diskursorientierte universitäre Gemeinschaft die Studierenden davor bewahrt, die Gesellschaft in ein Chaos zerfallen zu sehen.

391 „[...] ich hab' durchaus, ähm, durchaus gute Freunde von mir, wo ich das teilweise echt beobachte, wo ich mir denke: Älter!", und: Ïch möcht' mich mit deinen Eltern eigentlich nicht mehr unterhalten!"Ähm, aber das ist für mich... Das ist immer noch eine meiner besten Freundinnen, und ich urteile nicht, sondern ich kann irgendwie drauf blicken und kann irgendwie, wenn ich mich 'ne ruhige Minute hinsetze, fünf Gründe aufführen, warum das wahrscheinlich so ist, ähm, und dann ist es auch irgendwie für mich gegessen, so. Ich finde gerade dieses, einfach, Draufblicken und Urteilen [...] muss man echt unterscheiden. Weil, generell seh' ich das auch so, dass in dem Moment, wo man urteilt, irgendwie so 'ne Spaltung entsteht, so, also: „Ich bin im richtigen [Licht], und die andere Person ist im Falschen!" Transkript der 7. Fokusgruppe, S. 25f., Z. 797-809 (Herv. i. O.) Transkript der 7. Fokusgruppe, S. 64, Z. 2023-2025. Man ist natürlich versucht zu fragen: Was hätte ein Deutschland unter nationalsozialistischer Herrschaft noch anrichten können, wäre das „Einrenken" ausgeblieben? 
Als wesentliche Einflussgröße gefährdeter gesellschaftlicher Eintracht machen die Studierenden allgemeine politische Apathie aus. Dabei setzen sie immer auch bei sich selbst an. Hier scheiden sich die politisch und zivilgesellschaftlich vielseitig Engagierten von den eher apathisch Individualisierten: 14 von 44 Personen im Sample betätigen sich in NGOs, in der Flüchtlingshilfe, übernehmen ein Ehrenamt oder sind in kirchlichen Organisationen oder Vereinen assoziiert; sechs von 44 waren oder sind in Politgruppen, in der Hochschulpolitik, in Parteien oder Parteijugenden aktiv. ${ }^{396}$ Zwischen beiden Gruppen gibt es einige Überschneidungen, wodurch eine deutliche Mehrheit politisch nicht aktiver Studierender im Sample entsteht. Viele zögern daher, sich überhaupt als „politisch“ zu rubrizieren bzw. dem Thema Politik berechtigterweise eine große Bedeutung in ihrem Leben einzuräumen, sofern sie kein praktisches politisches Engagement vorweisen können; zwei Personen tun es mithilfe unorthodoxer Privatdefinitionen $^{397}$, einige tun es tentativ unter Verweis auf ihre Versuche, sich regelmäßig politisch zu informieren. ${ }^{398}$ „Politisch sein“ aber impliziert für viele (auch Nichtengagierte) eben auch politische Praxis, zumal in einem demokratischen System. Darauf deuten folgende Äußerungen hin:

„Das ist nämlich das Ding, weshalb ich so überlegen musste, ob ich mich als politisch... als besonders politisch einstufen würde, weil ich, äh, neben dem Studium... nichts Politisches nebenher laufen. Deswegen würd' ich auch sagen: Interessiert mich natürlich, die Politik, ja, aber sicherlich nicht so wie manche Andere, die ich jetzt auch im Freundeskreis hab', die sich hochschulpolitisch engagieren oder tatsächlich inner Partei $[. . .]^{\text {‘399 }}$

„Weil, ich glaub', wenn man das selber halt nicht macht und sich damit nicht auseinandersetzt, dann passiert halt auch nichts. Aber man muss halt da selber auch 'n bisschen aktiv werden." ${ }^{400}$

Umso schlimmer, dass auch die Mitmenschen so selten politisch partizipieren. Politisches Desinteresse und „gemütliche “401 , „bequeme ${ }^{\text {“402 }}$, „angenehme ${ }^{\text {“403 }}$ Praxisabstinenz zählt für die Studierenden zu den drängendsten Problemen in der bundesrepublikanischen Gesellschaft. Zu geringe Wahlbeteiligung auf Bundes- wie auf Hochschulebene sei „traurig“. 404 „Wenn die Leute nicht wählen gehen, dann scheitert irgendwie Demo-

Überregionale studentische Oganisationen und Verbände spielen wie erwartet keine Rolle, es handelt sich um stark lokal verankerte Gruppenzusammenhänge.

397 „Ähm, also wenn es so um die Pflege geht, find' ich schon, dass ich mich politisch engagiere, indem ich ständig zur Pflegedienstleitung renne, ähm, und sage: ,Hier, das ist Mist, was ihr macht!' - und das war O-Ton! -, oder bei der Heimaufsicht mich beschwere oder sowas. Also ich finde schon, dass das da 'n politisches Engagement ist." Transkript der 5. Fokusgruppe, S. 42, Z. 1276-1279 (Herv. i. O.) „Ich geh' hin und wieder mal mit 'n paar Freunden containern. Irgendwie, find' ich, ist das auch 'n politisches Engagement." Transkript der 5. Fokusgruppe, S. 42, Z. 1299-1300.

398 Vgl. etwa Transkript der 5. Fokusgruppe, S. 41, Z. 1245-1248.

399 Transkript der 1. Fokusgruppe, S. 35, Z. 1078-1082 (Herv. i. O.)

400 Transkript der 4. Fokusgruppe, S. 38, Z. 1191-1193.

401 Transkript der 1. Fokusgruppe, S. 44, Z. 1364-1365.

402 Transkript der 3. Fokusgruppe, S. 57, Z. 1766.

403 Transkript der 6. Fokusgruppe, S. 53, Z. 1680-1684.

404 Transkript der 2. Fokusgruppe, S. 38, Z. 1200-1201. 
kratie natürlich auch 'n bisschen. “405 Zahlreiche gesellschaftliche Fragen blieben ferner beantwortet, weil „die Leute mit 'ner gewissen Ignoranz oder mit 'nem gewissen $\mathrm{Au}$ genverschließen [...] einhergehen“. ${ }^{406}$ Eine „Konsumentengesellschaft“ habe sich hergestellt, die Politik als Freizeitangebot betrachte, welches man nach Belieben nutzen oder ausschlagen könne. ${ }^{407}$ Doch gerade mit Blick auf die Funktionsfähigkeit der Demokratie bedürfe es dringend einer Bevölkerung aus kompetenten Bürgern, denn „Demokratie ist nur lebendig und Menschenrechte... und viele Werte, die wir vertreten, sind nur lebendig, wenn wir sie aktiv leben und dafür kämpfen! “408 Die Distanz der Menschen zur Politik müsse mithilfe neuer Methoden abgebaut werden, etwa durch ein „Forum“, „formal auf jedem Dorf, in jeder Stadt [...] wo man dann frei seine Meinung sagen kann [...]“, ganz besonders um der Kanalisierung der Frustration in Richtung AfD-Wahl oder rechtsradikale peer groups einen präventiven Riegel vorzuschieben. ${ }^{409}$ Im Rahmen der herrschenden „individualistische[n] Sicht“ gehe den Menschen generell die Perspektive praktischer Kollektivität - „Wie kann ich mit den Anderen das eigentlich organisieren? [...] Wie können wir zusammen uns anders organisieren?" - ab. ${ }^{40}$ Mehrere Personen sehen hier auch einen Generationseffekt am Werk; man sei mitsamt der eigenen Altersgenossen, „sagen wir mal bis plusminus fünf Jahre“ sie - auch wenn „Trump und AfD“ hier einen Trend zur stärkeren Aktivierung markieren - „entpolitisiert“, ${ }^{411}$ werde „halt auch überhaupt nicht politisch wirksam“, ${ }^{412}$ gehöre einer beinahe lethargischen „Wohlfühl-Generation“ an, von der zurecht häufig das „Symptom“ kolportiert werde, dass sie „sich über nichts aufregen würde und so, obwohl wir vielleicht gerade voll den Grund dazu hätten. “413 Mit besonderem Blick etwa auf die Handlungsnot in Klimafragen muss das zu Wut über sich selbst und die anderen führen, sei doch „[das] Bewusstsein [...] eigentlich $d a$, aber die Leute ändern sich trotzdem nicht [...]":

„Ich glaub', das ist so 'n bisschen das Hauptproblem. Man weiß ja, was richtig und falsch ist, das hat ja eigentlich jeder Mensch so 'n bisschen in seinem Inneren drin, dann, und gerade, wenn man in so 'ner Gesellschaft schon lange lebt, dann braucht man das einem eigentlich nicht erklären. In der Theorie weiß es jeder, aber die Frage ist halt, was angewandt wird. “414

Und das, so werfen zwei Personen zusätzlich zum Generationsaspekt ein, obwohl es unter Studierenden und in Bildungseinrichtungen doch einmal um „Rebellion“ gegangen sei, obwohl es „historisch gesehen [...] doch relativ viele Studentenaufstände“ gegeben habe und man gemeinhin davon ausgehe, dass Studierende tendenziell „so Rich-

405 Transkript der 4. Fokusgruppe, S. 44, Z. 1406-1407.

406 Transkript der 3. Fokusgruppe, S. 36f., Z. 1115-1117.

407 Transkript der 5. Fokusgruppe, S. 69, Z. 2114-2121.

408 Transkript der 3. Fokusgruppe, S. 61, Z. 1877-1879. Mehr dazu weiter unten, Kapitel III.3.3 dieser Studie.

409 Transkript der 5. Fokusgruppe, S. 67, Z. 2055-2057.

410 Transkript der 6. Fokusgruppe, S. 40f., Z. 1278-1282 (Herv. i. O.)

411 Transkript der 1. Fokusgruppe, S. 29, Z. 886-890.

412 Transkript der 7. Fokusgruppe, S. 28, Z. 868-869 (Herv. i. O.)

413 Transkript der 7. Fokusgruppe, S. 28, Z. 873-881.

414 Transkript der 7. Fokusgruppe, S. 33f., Z. 1046-1058 (Herv. i. O.) 
tung leicht revolutionäres Denken manchmal auch an den Tag legen“!115 Die Haltung, um drängende Probleme zu wissen, aber dennoch untätig zu bleiben, von zwei Diskutanten abfällig als „sehr deutsch“ oder „bürgerlich“ bezeichnet. ${ }^{416}$ Die Empfindung einer Verpflichtung zu politischem Engagement ist aber auch abseits dieser vereinzelt identifizierten historischen Tradition denkbar groß. Diejenigen, die es dabei bewenden lassen, „dass man wenigstens so 'n bisschen... so 'n bisschen über Politik Bescheid weiß ${ }^{4417}$, werden in den Diskussionen regelmäßig von Verfechtern anspruchsvollerer Politikbegriffe und Bürgerpflichten förmlich übertrumpft. Da nur wenige das so vielfach als wünschenswerte, ja gesellschaftsnotwendige Engagement selbst leisten, sind Selbstbezichtigungen und Rechtfertigungsversuche nahezu unvermeidlich. Diese werden stets unprovoziert geäußert, also ohne dass der Vorwurf politischer Apathie zuvor vonseiten der Moderation oder von Mitdiskutanten erhoben worden wäre. Es gehört weitgehend zum guten Ton, immer auch über die persönliche Verantwortlichkeit zu reflektieren. Dass im Grunde fortwährend Ansprüche verfochten werden, gegen die man selbst konsequent verstößt, lässt sich durch analytisch auftretende Urteile über strukturelle Hindernisse oft gut verdecken, ${ }^{418}$ verleiht einigen offenherzigeren Diskussionspassagen aber auch eine eigenartige, fatalistisch durchsetzte Büßerstimmung:

„Wenn mich was stört, auch an mir selber, ist das einfach 'n gewisses Hinnehmen, 'ne Passivität, 'n, ähm, einfach so... Das stört mich zwar, aber ich engagier' mich nicht dagegen, und ich schieb' das jetzt auch wieder weg, ist ja nicht direkt... bin ja auch nicht ganz direkt, so, jetzt betroffen. ${ }^{\text {4419 }}$

„Was ich auch manchmal selber schade finde, aber ich geh' jetzt nicht auf irgendwelche Demos oder organisier' mich in irgendeinem politischen... keine Ahnung, in irgendeiner politischen Cruppe oder so. Das Einzige, was ich mache, ist halt, die Nachrichten zu verfolgen und zu versuchen, mir eine Meinung zu bilden. “420

„Und das ist aber super schwierig, irgendwie, so! Weil wir vielleicht aus 'ner WohlfühlGeneration sind, oder so. Ich weiß es nicht." ${ }^{421}$

„B3: [...] ich glaube, ich bin das Paradebeispiel [dafür], was in der Cesellschaft schief läuft. [allgemeine Erheiterung] Also wenn irgendwas in der Politik ansteht, denk' ich mir: ,ja, der neben mir wird's schon machen! [allgemeines Lachen] Warum sollt' ich

415 Transkript der 1. Fokusgruppe, S. 26f., Z. 779-817. Ähnliches wird in einer anderen Gruppe angesichts geringer Hochschulwahlbeteiligung bemerkt: „Vor allen Dingen: Man sagt auch von Studenten: ,Das sind gerade die, die politisch interessiert sind!“" Transkript der 2. Fokusgruppe, S. 38,

Z. 1212-1213 (Herv. i. O.)

416 Transkript der 6. Fokusgruppe, S. 42f., Z. 1331-1354.

417 Transkript der 3. Fokusgruppe, S. 37, Z. 1155-1156.

418 „Weil ich auch glaube, dass die Demokratie auch schon dazu verleitet, 'n bisschen bequem zu werden in gewissen Fällen. Es wird ja für einen alles entschieden, und das... [...] Ähm, und da würd' ich [...] mir einfach wünschen für die Zukunft, dass man da, ja, so'n bisschen mehr Aktivität - sei es nur auf der kommunalen Ebene oder wie auch immer - fördert." Transkript der 3. Fokusgruppe, S. 57f., Z. 1766-1772.

419 Transkript der 5. Fokusgruppe, S. 37, Z. 1140-1144 (Herv. i. O.)

420 Transkript der 2. Fokusgruppe, S. 35, Z. 1097-1101 (Herv. i. O.)

421 Transkript der 7. Fokusgruppe, S. 28, Z. 880-881 (Herv. i. O.) 
mich drum kümmern?' Und ich glaub', so denken viele. [...] B4: ]a, ich muss ehrlich sein, ich hab' den Gedanken auch ab und zu! “422

Sehr direkt, selbstbewusst und bisweilen sogar kreativ hingegen werden die Gründe für das Ausbleiben eigenen politischen Engagements entfaltet. Als Hauptursachen nennen die Studierenden Zeitmangel und logistische Schwierigkeiten, die lähmende Atomisierung mitsamt der Erfahrung oder Erwartung mangelnder Wirksamkeit sowie ein substanzielles Befremden angesichts der "großen“ Politik und ihrer konfrontativen, ja schmutzigen Praktiken, teils unterlegt mit zuvor erlebten Frustrationserfahrungen. Dass politische Betätigung für sehr viele Studierende voraussetzt, sich regelmäßig und umfassend politisch zu informieren (denn nur, wer kundig ist, scheint zur Beteiligung fähig zu sein ${ }^{423}$ ), führt wenig überraschender Weise $\mathrm{zu}$ ähnlichen Überlastungsauskünften wie schon im Falle der extrakurrikularen Lektüre, für welche es ebenso an Muße mangelte. ${ }^{424}$ Sie fühlen sich auch jetzt schon - manche mehr, manche weniger - in ein Proto-Erwerbstätigenleben „,von 8 bis 16 Uhr“ eingebunden, nach welchem man „müde“ nach Hause kommt und eben „keine Zeit" habe, „über Gesellschaft, Politik, sonst was nachzudenken." Denn auch das „ist Arbeit. ${ }^{425}$ Und da es eben Arbeit ist, erschlafft bei einigen der Eifer. Aus diesem Grund wird mehrfach zu Protokoll gegeben, dass ein früher ausgeprägteres politisches Interesse im Laufe des Studiums sogar zurückgegangen sei, man in dieser Hinsicht sukzessive introvertiertere Züge angenommen habe. ${ }^{426}$ Ein junger Student der Volkswirtschaftslehre verweist darüber hinaus auf ,andere Probleme" und Sorgen, die die zusätzliche Akkumulation von Unruhequellen unattraktiv machten, ${ }^{427}$ während eine Studentin der Sozialen Arbeit ihren Verzicht auf eine Beteiligung an Hochschulgremien - welche sie mit Blick auf den späteren Diskussionseintritt für durchaus opportun hält - damit, zu ihrem Studienort pendeln zu müssen. ${ }^{428}$ In einem Fall wird die Überforderung eingestanden, überhaupt „'ne Meinung zu finden“, sich „entscheidungsfähig genug“ zu fühlen. ${ }^{429}$ Mit Blick auf die Notwendigkeit, sich für engagierte politische Teilhabe regelmäßig informieren zu müssen, wird an einer Stelle unfreiwillig ironisch - da entlarvend - eingeworfen, dass „nicht nur bei den Studenten das Problem“ mangelnder Zeit existierte, sondern „dass einfach keiner die Zeit

422 Transkript der 7. Fokusgruppe, S. 38, Z. 1187-1195.

423 Vgl. Kapitel III.3.1 dieser Studie.

424 Vgl. Kapitel III.3.1 dieser Studie.

425 Transkript der 6. Fokusgruppe, S. 12, Z. 377-384 (Herv. i. O.)

426 Vgl. Transkript der 2. Fokusgruppe, S. 34, Z. 1071-1078 und S. 37, Z. 1170-1178; Transkript der 6. Fokusgruppe, S. 55f., Z. 1753-1172.

427 „B3: [...] ich hab' im Leben andere Probleme, als jetzt in der Politik was zu bewirken, sag' ich mal. Finanzielle Probleme oder auch, so, Probleme mit meinem Sozialleben, sag' ich mal. Und dann noch was für die Politik zu machen? [Da] denk' ich mir: ,Warum mach' ich mir so unnötigen Stress?' B6: Mhm. [bejahend] B3: Weil, es hat ja keine direkten positiven Veränderungen, jetzt, für mich.“ Transkript der 7. Fokusgruppe, S. 38, Z. 1205-1212.

428 „Ehrlich gesagt, weil das für mich, irgendwie, anstrengend ist, wenn ich da anderthalb Stunden hinfahre, um da was zu machen, und dann wieder zurückzufahren. Das war für mich auch 'n großer Grund, dass ich da nicht 'reingegangen, obwohl das sich ja eigentlich immer ganz gut, irgendwie, in der Bewerbung oder so was liest, wenn man dann sagt, man war im Fachschaftsrat oder so was." Transkript der 2. Fokusgruppe, S. 39, Z. 1239-1244. 
dazu hat, eigentlich.“430 Noch knapper als Zeit sind positive Erfahrungen politischer Teilhabe. Dass die Partei, die man hoffnungsfroh wählte, ihre Wahlversprechen nicht umsetzt und somit das Prinzip der Interessenaggregation ins Zwielicht rückt, ${ }^{431}$ dass es keine „direkten“ Möglichkeiten politischer Partizipation und „Blasen“ überbrückender Kommunikation gebe, ${ }^{432}$ ja nicht einmal ein „Forum“ für die kontrollierte kathartische Entladung politischer Frustrationen, ${ }^{433}$ ruft ein tiefsitzendes Gefühl individueller Ohnmacht hervor. Es fehlt, bisweilen explizit bekundet, an Kollektivitätsbewusstsein, an Zielvorstellungen und an positiven Erfahrungen tatsächlicher gesellschaftspolitischer Wirksamkeit. Viel zu viel Energie verschlinge die oft erfolglose Betätigung in den vorhandenen Organisationen wie Parteien, Parteijugenden oder Hochschulgruppen. $\mathrm{Zu}$ zementiert die Verhältnisse: „Der Output, der fehlt, und es ist relativ fern, dass irgend 'n Output auch entstehen könnte, dass man irgendwas bewirkt. Weil alles so gefestigt ist, so, Establishment und alles.“434 Auch wird hier sehr schnell klar, warum das auch von Jugendstudien und vom Studierendensurvey als Breitenphänomen herausgearbeitete flexible und unverbindliche Engagement in kleinen und themenzentrierten Betätigungsfeldern, etwa im Ehrenamt der Flüchtlingshilfe, den Studierenden so viel attraktiver erscheint: „Ich glaube, was auch einfach dann der Unterschied in der Motivation, $\mathrm{da}$, so 'n bisschen ist, ist: Wenn man das so auf so kleinerem Level macht, dass man tatsächlich Resultate sieht. ${ }^{4435}$ Am unerbittlichsten, aber auch mutigsten, wird das Problem individueller Bedeutungslosigkeit durch fehlendes Organisationswissen und fehlende Selbstwirksamkeitserfahrungen in der folgenden Passage anhand der eigenen Kommilitonen analysiert:

„Der kooperative Akteur, das Unternehmen, das bestimmt unser aller Leben ja in 'ner gewissen Form, ja, diese Riesenschiffe, irgendwie, amazon, Apple, Coogle, was auch immer. Dass diese... Was wir zusammen schaffen können, ist irgendwie das, was uns ja beeindruckt! Und was uns auch ängstigt, ja, weil irgendwie... Wir können so viel schaffen als Kollektiv, und dann so: ,Oh Cott, ich alleine, ey. Völlig bedeutungslos!', ja? Und das ist für mich schon 'ne [...] Spannung, die aktuell halt zutage tritt, und die auch diese Konfrontation irgendwie so, dann, zwischen den Gebildeten, Ungebildeten, und diesen ganzen Sachen..., weil dieser Zugriff nicht mehr da ist. ${ }^{\text {“436 }}$

Hinzu tritt die von vielen empfundene lebensweltliche Distanz von der „großen“ Politik, einer fernen Welt mit eigenen Gesetzen: „Die Regierung und die Politiker, die man so aus'm Fernsehen [lacht], aus den Zeitungen kennt, das ist nochmal 'ne ganz abstraktere Welt, ähm, find' ich." Stets spräche „so 'n Politiker“ unentwegt, „ohne eigentlich wirklich [...] was zu sagen“, zeige überdies nur „Präsenz [...] wenn die Wahlen wieder anstehen“, sei sonst aber „immer sehr unantastbar“. ${ }^{437}$ Allerdings können es gerade auch

430 Transkript der 7. Fokusgruppe, S. 39f., Z. 1232-1250.

431 Vgl. Transkript der 4. Fokusgruppe, S. 39, Z. 1227-1237.

432 Vgl. Transkript der 3. Fokusgruppe, S. 52, Z. 1582-1591.

433 Transkript der 5. Fokusgruppe, S. 59, Z. 1801-1813.

434 Transkript der 7. Fokusgruppe, S. 34, Z. 1077-1079.

435 Transkript der 7. Fokusgruppe, S. 35f., Z. 1120-1127.

436 Transkript der 6. Fokusgruppe, S. 41, Z. 1289-1297 (Herv. i. O.)

437 Transkript der 5. Fokusgruppe, S. 41, Z. $1245-1248$ und S. 69, Z. 2135-2139 (Herv. i. O.) 
persönliche Erfahrungen mit politischem Engagement sein, die Entfremdungseffekte angesichts opportunistischer und „destruktiv“-konfliktiver politischer Praktiken und daraus folgende politische Apathie erzeugen. Eine Jura-Studentin berichtet über eine Serie von Enttäuschungen über die durch rivalisierendes Machtgebaren gezeichnete Niederträchtigkeit „echter“ Politik, die sie im Umfeld von Kommunal- und Jugendpolitik erlebt hat. Politische Praxis sei, so resümiert sie, „noch viel schlimmer“, als zu ahnen sei: „Ich saß da so und ich war da halt, weiß nicht, unter 20 , und da waren dann halt teilweise SPD-Politiker und CDUler, die sich halt so kindisch angekeift haben und halt irgendwie so total kontraproduktiv." Ausflüchte von Nichtwählern toleriert diese Studentin aufgrund der gebotenen Pflicht der Beschäftigung mit Politik auch weiterhin nicht, doch ist die aktive Beteiligung ihr vergällt: „Boah, ich konnt' einfach nicht mehr [...] $]^{4338}$ Ähnliches berichtet ein Student anhand von Erzählungen einer politisch aktiven Freundin: „In der Kommunalpolitik, was die halt für, ähm, keine Ahnung, also Intrigen und was weiß ich alles... So echt wie House of Cards, so! [...] Das geht so wie auf 'nem scheiß Spielplatz, so.“" ${ }^{\text {“39 }}$ Erfahrungen mit abschreckenden politischen Praktiken sammelte auch eine andere Studentin mit politischen Hochschulgruppen: Ein $\mathrm{zu}$ „polarisiertes“, zu wenig „konstruktives“ Klima halte sie von weiteren Tätigkeiten ab. ${ }^{440}$ Anderen wiederum genügen schon flüchtige Eindrücke und Mutmaßungen, um ihr Naserümpfen etwa gegenüber der gängigen (hochschul-)politischen Praxis auszudrücken. ${ }^{441}$ Denjenigen, die diesen Kampf nicht vorzeitig aufgeben, blüht aus der Sicht der Studierenden der vollständige Verlust aller ursprünglichen Motivationen, mithin die Selbstvernichtung jedes authentischen Ansinnens durch die Mühlen des Interessenkampfes:

„[...] ich glaub', da ist auch wirklich das Problem, weil man wirklich - also in der Politik, Parteipolitik - was ange-..., äh, was erreichen will, so, dann muss man nach ganz oben kommen, irgendwie. Und um da oben hinzukommen, musst du so viele Kompromisse eingehen, musst du also deine Ideale eigentlich verraten, und irgendwie 20 Jahre da 'rein investieren, und immer irgendwie 'n gutes Bild nach außen machen und so, und immer schön lächeln und Hände schütteln - Den richtigen Leuten die Hände schütteln, auch wenn die richtig scheiße sind, so! “442

438 Transkript der 4. Fokusgruppe, S. 36f., Z. 1137-1161 (Herv. i. O.)

439 Transkript der 7. Fokusgruppe, S. 34f., Z. 1087-1090 (Herv. i. O.)

440 „Also, ich find', dass es an der Hochschule sehr, immer, aufgebauscht ist und sehr polarisierend ist, und dann meiner Ansicht auch durchaus intolerant gegenüber anderen Hochschulgruppen, zum Beispiel. Das ist... Keine Ahnung, da fühl' ich mich persönlich einfach nicht wohl, weil das dann mitunter kein konstruktiver Widerstreit mehr ist, sondern einfach nur ein [unverständlich] und ein Gegeneinander, so wie es halt mir vorkommt. Und dann hab' ich mich auch bei... Also, ich hab' mir auch andere, nicht-politische Hochschulorganisationen angeguckt, das hat mir aber irgendwie auch nicht so viel Spaß gemacht. Deswegen ist das jetzt auch erstmal auf Eis gelegt." Transkript der 1. Fokusgruppe, S. 36, Z. 1091-1098.

441 „B2: Weil die... Die... Ähm, die Hochschulpolitik an sich ist relativ demokratisch, glaub' ich, aber wie dann wirklich die Hochschulpolitik am Ende gemacht wird... B5: Ist halt wie in der richtigen Politik, ne. B2: ... da wird ja echt von oben 'runterdiktiert, oder nicht? B5: Ja." Transkript der 4. Fokusgruppe, S. 38f., Z. 1215-1222 (Herv. i. O.)

442 Transkript der 7. Fokusgruppe, S. 36, Z. 1129-1135 (Herv. i. O.) 
Auch diesem Redner der insgesamt äußerst fatalistisch gestimmten 7. Fokusgruppe bleibt die Beteiligung „im ganz Kleinen“, hier auf dem Gebiet der Sozialen Arbeit, der politischen Bildung und der Rassismusprävention, als einziger Ausweg; zwar nicht als probater Ersatz zur Aufrechterhaltung der Illusion, „im Großen und Ganzen“Veränderungen herbeiführen zu können, aber doch immerhin als Möglichkeit - die Übernahme des expliziten Vokabulars sei hier gestattet - „die Scheiße irgendwie“ zu „verwalten, dass es nicht ganz so schlimm steht, so. “443 Eine Studentin der Wirtschaftswissenschaften aus derselben Gruppe, die „'ne Zeitlang [...] Deutsch-Unterricht gegeben“ hat „für Flüchtlinge“, stimmt ihm darin zu: Diese Tätigkeit habe ihr das Gefühl verschafft, effektive Hilfe zu leisten und Veränderungen zu bewirken. ${ }^{444}$

Durch das vielfach monierte Fehlen einer vermittelnden, idealerweise über allen Streitparteien stehenden, Rationalität im durch verselbstständigte Kalküle verzerrten Interessenstreit als zentraler Begründung eigener politischer Apathie erscheint nun auch die bereits referierte kritische Sicht über allgemeine politische Polarisierungsprozesse in einem neuen Licht. Könnten beide Motivkomplexe nicht auf eine Klage über die strukturelle Konfliktivität von demokratischer Politik ${ }^{445}$ und über die Unübersichtlichkeit des demokratischen Meinungsstreits insgesamt hinauslaufen, gleichsam auf einen Hilfeschrei des gestörten kleinbürgerlich-privatistischen ${ }^{446}$ Ruhebedürfnisses? Zugespitzt: Auf ein Leiden am Politischen ${ }^{447}$ Auf wenige der hier vertretenen Fokusgruppenteilnehmer würde das exakt zutreffen; dass es aber zumindest als mentaler Unterstrom auf die studentischen Orientierungen einwirkt, ist kaum von der Hand zu weisen. Das bleibt auch dann gültig, wenn man zugesteht, dass sich Politikeliten stets auch um Machterhalt bemühen und dass sich die medial präsentierte politische Diskussion in Öffentlichkeit und Parlamenten tatsächlich häufig in symbolträchtigen und aufmerksamkeitsmagnetischen Streitthemen verfängt und dann auch so medial präsentiert wird, während langfristige und wenig populäre Aufgaben in den Hintergrund treten. Interessant ist, dass nicht eine einzige Studentin und nicht ein einziger Student auch nur auf die Idee kommt, politische Apathie als legitimes Verhalten

443 Transkript der 7. Fokusgruppe, S. 36, Z. 1136-1139 (Herv. i. O.)

444 Transkript der 7. Fokusgruppe, S. 34f., Z. 1105-1110.

445 Vgl. Dahrendorf, Ralf: Cesellschaft und Demokratie in Deutschland, München 1965, S. 171 und 173f., wo die - Deutschen schwerfallende - Anerkennung des Konflikts als Grundlage gelingender demokratischer Prozesse bestimmt wird.

446 „Denn eigentlich ist der Kleinbürger völlig unpolitisch. [...] Sein Zuhause ist [...] in Wirklichkeit das reich der apolitischen Normalität. Dort findet der Kleinbürger Unterstand in Zeiten relativer Ruhe und Schutz vor der Politik, die doch nur ein ,schmutziges Ceschäft' ist. [...] Er selbst strotzt vor Normalität, ja er ist geradezu die Inkarnation einer in Gefahr geratenen Normalität, nämlich eines echten Mittelmaßes. Immer im Dienste des Allgemeinen, des Sittlichen und Natürlichen, immer im Namen der Mitte und des Durchschnitts.“ Dabei „steht die kleinbürgerliche Kultur der Normalität auf schwankendem Boden, sie ist eigentlich nichts anderes als der aus Verdrängung gewonnene Schein einer Normalität, die, je selbstgewisser sie propagiert wird, desto offenkundiger die ihr zugrundeliegende Unsicherheit, nämlich die prekäre Lage des Mittelstands im Kapitalismus, preisgibt." Franke, Berthold: Die Kleinbürger. Begriff, Ideologie, Politik, Frankfurt a.M./New York 1988, S. $214 f$.

447 „Die spezifisch politische Unterscheidung, auf welche sich die politischen Handlungen und Motive zurückführen lassen, ist die Unterscheidung von Freund und Feind." Schmitt, Carl: Der Begriff des Politischen [1932], Berlin 1979, S. 26. 
der demokratischen Mehrheit zu denken. Angesichts des auch in Deutschland präsenten kontinentalen Demokratieverständnisses sowie der seit den 1990er Jahren durch politische Bildung, zivilgesellschaftliche Träger und Regierenden-Rhetorik forcierten Idealisierung des „kompetenten Bürgers“, welche für den Erhalt einer Funktionsfähigkeit der demokratischen Gesellschaft auf die Heranbildung aktiver Träger von „Normen und Werten“, mithin auf „Partizipationsbereitschaft, Partizipationsfähigkeit und [die] Übernahme von Aufgaben, die sich an dem Gemeinwohl orientieren ${ }^{\text {“448 }}$ in einer möglichst vitalen „Bürgergesellschaft“ oder „Zivilgesellschaft“ setzt ${ }^{449}$, verwundert das allerdings nicht. Konkurrenztheoretische oder „realistische“ Funktionsauffassungen demokratischer Systeme, wie sie in den 1940er Jahren von Joseph Schumpeter („demokratische Methode“) oder in den 1960er/70er Jahren auch von Wilhelm Hennis (,vertrauensbasierte Personalwahl“) die Existenz eines Rousseau'schen Volkswillens konsequent infrage stellen, die zentrale Aufgabe von Wahlen in der Rekrutierung von Führungseliten für einen „Herrschaftsauftrag auf Zeit“ erkennen ${ }^{450}$ und damit gerade die mehrheitliche Passivität der als politisch entscheidungsunfähig und schnell überfordert gedachten Bürger als entscheidenden Stabilitätsanker der demokratischen Gesellschaft verstehen, ${ }^{451}$ liegen außerhalb des Denkhorizonts von Studierenden.

Jenseits dieser drei großen Themenkomplexe werden noch weitere Problemthemen genannt, die aber zumeist keine ausgiebige Diskussion, höchstens ein kurzes Zwiegespräch, auslösen. Ab und zu wird ein durch die international ausgreifende Seite der Verschärfung von Konfliktpotenzial, nämlich den beobachteten Aufstieg von Nationalismen und Machterhaltsfokussierungen bedingtes steigendes Risiko militärischer Auseinandersetzungen angemerkt. Als Grundbedingung einer intakten Zukunft mahnt ein Fokusgruppenteilnehmer, der sich an anderer Stelle über eine russlandfeindliche Berichterstattung mokiert, „dass man keine Kriege startet.“452 Ähnlich argumentiert eine Studentin aus einer anderen Fokusgruppe, die eine allgemeine „Angst vor 'nem zweiten Kalten Krieg“ beobachtet, anlässlich des Gift-Anschlags auf den ehemaligen russischen Doppelagenten Sergej Skripal in Großbritannien, „dass jetzt so sich das Lager gegen Russland bildet“, dass „Russland immer mehr zum absoluten Feind deklariert wird.“453 Kritisch, aber eher beiläufig wird in einer Fokusgruppe die Video-Werbung der Bundeswehr in Apps und Online-Plattformen erwähnt. ${ }^{454}$ Andere Studierende wünschen sich mehr entschlossene Lösungsansätze für die ganz großen außenpolitischen „richtigen“ Probleme, etwa zukunftsfähige „konstruktive“ Konzepte für eine international funktionierende Wirtschafts- und Umweltpolitik ${ }^{455}$ oder eine Stabilisierung und Forcierung

448 Münkler, Herfried: Der kompetente Bürger, in: Klein, Ansgar/Schmalz-Bruns, Rainer (Hg.): Politische Beteiligung und Bürgerengagement in Deutschland. Möglichkeiten und Grenzen, BadenBaden 1997, S. 153-172, hier S. 153 und 155.

449 Vgl. Schulz: Lebenswelt und Kultur des Bürgertums, S. 103-106.

450 Vgl. Lenk, Kurt: Wie demokratisch ist der Parlamentarismus? Grundpositionen einer Kontroverse, Stuttgart Berlin Köln Mainz 1972, S. 13-23 und 30-34.

451 Für das Beispiel von Hennis' „vertrauensbasierter Personalwahl“ vgl. ibid., S. 34f.

452 Transkript der 2. Fokusgruppe, S. 47, Z. 1475-1478.

453 Transkript der 3. Fokusgruppe, S. 38, Z. 1154-1166.

454 Vgl. Transkript der 6. Fokusgruppe, S. 46-48, Z. 1471-1504.

455 Transkript der 2. Fokusgruppe, S. 54, Z. 1709-1721 (Herv. i. O.) 
des „Zusammenwachsens“ der Europäischen Union gegen die grassierenden Fragmentierungstendenzen - „Dann erzählt man sich [später] nicht von den Kriegsgeschichten und den blöden Nachbarländern, sondern dann erzählt man halt von dem tollen Auslandssemester in Spanien oder so. ${ }^{456}$ Andere, die dem grundsätzlich zustimmen, wünschen sich aber ebenso eine Konkretisierung dieses Zusammenwachsens, einen Fahrplan mitsamt Konsequenzen und (politischen) Kosten, gerade angesichts der 2018 noch strikt antieuropäisch auftretenden AfD. ${ }^{457}$ Mangelnde Geschlechtergleichstellung, etwa in Sachen gender pay gap oder Alltagssexismus, wird in drei Fokusgruppen thematisiert, ${ }^{458}$ insgesamt aber deutlich seltener als die oben referierte Kritik eines identitätspolitisch überdrehten Feminismus. In einer Fokusgruppe wird infolge von Erfahrungen mit pflegebedürftigen Angehörigen wütend eingeworfen, dass die Zustände in Pflegeheimen und Pflegeberufen unhaltbar seien. ${ }^{459}$ Ebenfalls singulär findet sich die Thematisierung der Wohnraumpolitik, die mit dem Lob einer lokalen Hausbesetzung zugunsten von Flüchtlingen abgerundet wird ${ }^{460}$ sowie die Kritik an marktwirtschaftlichen Funktionsweisen des Gesundheitssystems. ${ }^{461}$ Abseits von der Thematik kritischen Konsums wird selten wird über ökologische Themen gesprochen, auch in den Frankfurter Fokusgruppen, die nach dem medienpräsenten Dürresommer 2019 stattfanden. Wird das Thema erwähnt, dann erscheint das Gesamtproblem der Umweltverheerung angesichts der weltweiten kapitalistischen Wirtschaftsweise kaum durch Reformen, Gesetze, veränderte Konsumstile allein lösbar:

„Natürlich hat es was damit zu tun, mit der Rolle, die dieses Land in der Welt spielt, und mit... Wir fahren unseren ganzen Shit, unseren ganzen Müll in die Meere, nach Afrika - da liegt er 'rum, da geht's Leuten schlecht, weil die irgendwie neben, irgendwie, Elektroschrott wohnen. Das ist kacke, die trinken dreckiges Wasser, irgendwelche kleinen Kinder nähen unsere Hosen und so. Da kann ich jetzt, irgendwie, direkt nichts dafür, aber... Ja. Unser System. “462

In derselben Fokusgruppe beklagen sich zwar auch zwei Studierende naturwissenchaftlicher bzw. naturwissenschaftsnaher Fächer über eine Dämonisierung von Landwirtschaft, Industrie und Technik. ${ }^{463}$ Beide Vorstöße indes - Umweltschäden als Konse-

456 Transkript der 4. Fokusgruppe, S. 15, Z. 459-463 (Herv. i. O.)

457 „Wenn man 'ne Podiumsdiskussion, auch in der Uni, hat, und man diskutiert über irgendwelche Punkte, dann sind sich die anderen Parteien in vielen Punkten einig. So, dass wir zum Beispiel mehr Europa brauchen, so. Da würde kaum eine Partei sagen: ,Ist nicht!' Aber wie dieses ,mehr Europa' aussehen soll, zu der Debatte kommen wir überhaupt nicht, weil die AfD sagt: ,Wir brauchen kein Europa!'“ Transkript der 3. Fokusgruppe, S. 6of., Z. 1859-1863 (Herv. i. O.)

458 Vgl. Transkript der 2. Fokusgruppe, S. 57, Z. 113-1824; Transkript der 4. Fokusgruppe, S. 22, Z. 681701; Transkript der 7. Fokusgruppe, S. 28f., Z. 895-909.

459 Vgl. Transkript der 5. Fokusgruppe, S. 38f., Z. 1157-1199.

460 Vgl. Transkript der 5. Fokusgruppe, S. 36f., Z. 1113-1133.

461 Vgl. Transkript der 2. Fokusgruppe, S. 60-62, Z. 1891-1955.

462 Transkript der 2. Fokusgruppe, S. 58, Z. 1848-1853 (Herv. i. O.)

463 „Gestern war jetzt wieder in den Nachrichten: ,Jo, Bayer darf jetzt Monsanto nun doch übernehmen', und dann dieses ständige Misstrauen gegenüber der heutigen Forschung/Wissenschaft, auf die sich die derzeitige Landwirtschaft und Ernährungsproduktion beschränkt. Und egal, worum es geht - ob es die Verfahren in der Tierhaltung sind, Pflanzenschutz, Düngung -, hört man ständig eigentlich so... Es ist immer dieser negative Ton darin [...]“ „]a, ist aber generell so, dass man 
quenz des „Systems“ anzuprangern wie die Parteinahme für die Reputation der Naturbeherrschung - bleiben Statements und verpuffen weitgehend. Vollends randständig ist das Thema öffentlicher Sicherheit. Nur eine Studentin äußert „Angst, in die Innenstadt zu gehen, mittlerweile [lacht], wenn's dunkel ist“, obwohl sie „früher immer gerne feiern gegangen“" sei, relativiert das aber sogleich als mögliche kognitive Verzerrung ihrerseits. ${ }^{464}$ Das macht auch deutlich, welche Perspektiven nicht mehrheitsfähig zu sein scheinen: Die Wahrnehmung gefährdeter öffentlicher Sicherheit oder die Forderung nach dem rigorosen Prinzip von law and order. Parteipolitische Deutungsangebote, die auf derartige Konzepte setzen, werden es wahrscheinlich auch in Zukunft schwer haben unter Studierenden. Der „Willkommenskultur“-Impuls von 2015 mag erloschen sein, doch wurde er nicht nur durch eine skeptische, sondern auch weitgehend wohlwollende Sichtweise auf die gegenwärtige Asyl- und Integrationspolitik ersetzt. Ferner fällt insgesamt auf, dass die politische Problemwahrnehmung immer auch stark von charakterlichen Dispositionen abhängt. Während die einen ernst, passioniert, bisweilen moralisierend auf Fragen der Bildungsgerechtigkeit und Nachhaltigkeit eingehen, gehen andere spielerischer und experimenteller mit dem Blick auf gesamtgesellschaftliche Entwicklungen um. Auch sind manche spürbar vom Drang getrieben, „positive“ Entwicklungen und Ereignisse zu benennen, „für" etwas sowie im Einzelnen einmal zufrieden und glücklich zu sein, um die von ihnen als deprimierend, beinahe beißend empfundenen Spannungen negativer Stimmungslagen herabzusetzen. ${ }^{465}$

Die Diskussion über politische Probleme treibt in den Fokusgruppen von sich aus zur Frage nach möglichen Lösungskonzepten. In diesen aufschlussreichen Passagen greifen die Studierenden wiederum fast durchweg auf bildungsemphatische Rezepte zurück. Sie reichern die schon in Fragen der Persönlichkeitsschulung so hochgelobte Triebkraft der Bildung um eine gesellschaftliche Dimension an; als politische Bildung wird sie zur beinahe universalen Erklärungsschablone und zugleich zur produktiven Gegenkraft negativer Entwicklungen. Politische Bildung ist für die Studierenden ein essenzieller Kampfbegriff, ja ein gesellschaftspolitisches Panazee aus dem Arzneischrank der sozialen Integration. Ganz so, wie es Koselleck bereits in den 1980er Jahren über das Bildungsbürgertum des langen bürgerlichen Jahrhunderts schreibt, legen sie den Bildungsbegriff politisch aus: „Bildung ist [...] primär überpolitisch, aber politisch abrufbar, weshalb im Deutschen die Zusatzbestimmung der ,politischen` Bildung erfor-

alles, womit man irgendwie Lobby machen kann, irgendwie negative Schlagzeilen machen kann, machen... also, das verunsichert die Leute einfach. Also wenn ich sage, ich studier' Chemie, dann sind auch immer alle total kritisch, und dann wird da irgendwie... ,Umweltvergifter!', oder so was [gerufen]... Ja." Transkript der 2. Fokusgruppe, S. 31, Z. 966-982 (Herv. i. O.)

464 „Es war wahrscheinlich totaler Schwachsinn, aber das hat mir mega Angst gemacht, und nimmt mir auch Lebensqualität, dass ich nicht mehr so unbefangen in die City gehen kann zum Feiern.

Ähm, viele Geschichten von Freunden, die in der Innenstadt wohnen, die immer mal wieder von verrückten Leuten hören, die Menschen anschreien und mit Flaschen werfen. Ich weiß nicht, ob ich früher einfach nicht so den Blick drauf hatte, weil, natürlich, klar, das Bier floss in rauen Mengen. [lacht] Aber, ja, das ist so mein persönliches Empfinden." Transkript der 5. Fokusgruppe, S. 36, Z. 1088-1094.

465 Vgl. beispielsweise Transkript der 2. Fokusgruppe, S. 58, Z. 1832-1855; Transkript der 3. Fokusgruppe, S. 42f., Z. 1298-1315; Transkript der 5. Fokusgruppe, S. 37, Z. 1135-1138; Transkript der 7. Fokusgruppe, S. 74, Z. $2344-2352$. 
derlich ist.“466 Die Fokusgruppenteilnehmer „rufen“ sie „ab“ als Kraft der Domestizierung der Einzelnen Trägern einer rationalen, gemäßigten, zivilisierten, prodemokratischen Innerlichkeit und hoffen damit, das ihnen angemessen erscheinende Spektrum gesellschaftspolitischer Auseinandersetzungen zu sichern. Ein Student mit teilweise französischen Wurzeln, der in Deutschland im Vergleich zum unruhigen Frankreich einen „durchschnittlich höher[en]“ „Bildungsgrad“ ausmacht, mutmaßt schon anhand des originären Bildungsbegriffs vorsichtig, „dass auch 'ne Bildung wichtig ist für Stabilität in der Gesellschaft und für die Pressefrei-... für Gesellschaften, die demokratisch aufgebaut sind." Dies hält er gerade angesichts aktueller politischer Entwicklungen für dringend:

„Da wir gerade in Zeiten sind [..., in denen medial nochmal eher Meinungen als Fakten diskutiert und prominent gemacht werden, find' ich, es wird auch die gesellschaftliche Rolle von Bildung in Zukunft auch nochmal größer werden. “467

Ähnlich, aber unter Hinzuziehung des Adjektivs „politisch“, formuliert es einer jener Studierenden, die ihr Studium explizit mit dem Ziel aufgenommen haben, Gesellschaft $\mathrm{zu}$ verstehen und $\mathrm{zu}$ verändern, wenn er als zentrales Movens angibt, „politische Bildung“ für sich selbst zu erwirken und „die Unfähigkeit, irgendwas zu bewirken in der Gesellschaft" zu begreifen. ${ }^{468}$ Dieses Konzept der (Selbst-)Erziehung für eine funktionierende demokratische Ordnung ist unter den Studierenden des Fokusgruppensamples über alle Studiengänge und Studienfortschritte hinweg mehrheitsfähig. So soll politische Bildung im Zeitalter von fake news und Online-Hetze auch zum korrekten Mediennutzungsverhalten erziehen ${ }^{469}$, wie in einer dramatischen Skizze des Einflusses von Hasskommentaren im Internet nachzuvollziehen ist, die politische Emotionalisierung mit Unbildung korrelieren lässt:

„Ich glaube, dass die wenigste politische Bildung bei den Leuten, die immer wieder schreien: "Wir haben ja nichts mitzubestimmen!", wirklich über die ÖffentlichRechtlichen laufen würde. Ich hab' mal so 'n bisschen, ähm, youtube gestalkt, [lacht] kann man, glaub' ich, so sagen: Es gibt so furchtbar viele volksverhetzende, antidemokratische Videos von solchen hirnlosen Spasten! Die haben sehr viele Likes, die haben so viele Kommentare - und das find' ich gefährlich! Die Vierte Staatsgewalt - was so über Facebook-Cruppen, Whatsapp -, was da läuft, wo sich da viele informieren, das find' ich gefährlich!“470

Im Idealfall müssten heranwachsende demokratische Bürger von Klein auf intensiven politischen Bildungsbemühungen ausgesetzt sein, gerade auch im Sinne des Nachteilsausgleichs in der Chancengesellschaft schon als Kinder die entsprechenden „demokratischen Werte" so früh wie möglich eingeimpft bekommen:

466 Koselleck: Einleitung, S. 27.

467 Transkript der 6. Fokusgruppe, S. 40, Z. 1250-1257.

468 Transkript der 7. Fokusgruppe, S. 18, Z. 548-549.

469 Vgl. Transkript der 7. Fokusgruppe, S. 21, Z. 670-672 und S. 43, Z. 1351-1366.

470 Transkript der 5. Fokusgruppe, S. 53, Z. 1631-1637 (Herv. i. O.) 
„[...] 'ne gewisse Teilhabe an Demokratie muss es doch geben, weil Demokratie nur funktioniert, wenn sie auch gelebt wird. [...] Und ich glaube, da ist... ist schon die Schule ' $n$ wichtiger Weg, weil: Natürlich, die wirklichen demokratischen Werte lernt man irgendwie außerhalb der Schule, aber das lernen wieder die, wo sich die Eltern dafür einsetzen, dass die Kinder was außerhalb der Schule machen. “471

In einer anderen Fokusgruppe ruft eine angehende Lehrerin, nachdem die Diskussion einmütig zu dem Ergebnis gekommen ist, dass die parlamentarischen Einflussmöglichkeiten per Wahlstimme unbedingt zu „schätzen“, erleichtert aus: „Deswegen ist politische Bildung ja auch so wichtig, und deswegen mach’ ich das ja auch! [lacht] ${ }^{4472}$ Und eine Studentin der Germanistik und Anglistik, die sich im Rahmen eines Nebenjobs mit „Demokratiepädagogik“ beschäftigt hat, legt darüber hinaus Wert auf praktische Aspekte politischer Bildung, welche sich auf die Gestaltung des schulischen Umfelds beziehen, kurzum

„so Politik im Kleinen halt. So: ,Wie ist 'ne Schule organisiert? Wie werden Entscheidungen in Klassen getroffen? Wie weit werden die Schüler mit einbezogen? Welche Haltungen werden vermittelt? Wie sehen die... gehen die Lehrer mit Problemen um? So, so 'rum, einfach so strukturell, auch, so 'n bisschen. ${ }^{4473}$

Gelingt das, so ein weiterer Student der Forstwissenschaft und Waldökologie, könne das auch zur Teilhabe etwa in der Kommunalpolitik anregen. ${ }^{474}$ Doch folgt man der Beurteilung der Studierenden, sind wir von einer solchen, der empowerment fähigen, schulischen Pädagogik aktuell weit entfernt. Liegt die Wurzel zahlreicher besprochener Probleme nicht gerade in aktuellen Defiziten politischer Bildung begründet? Demokratische Stabilität, Wählerzufriedenheit, Repräsentationsdefizite - „Irgendwie, es führt halt nachher alles wieder zur Schule und zum Schulsystem zurück. “475 Die geringe politische Bildung der Klassenkameraden ihres Bruders hinsichtlich gewisser „Basics“ ruft bei einer zuvor berufstätigen Lehramtsanwärterin blankes Entsetzen sowie den Eindruck, dass bereits in der Schule „irgendwie schon Fehler gemacht werden“, hervor. ${ }^{476}$ Ein Ausbau der bestehenden Lehrpläne und Lehrpraxen erscheint nicht wenigen daher plausibel und angebracht. Dass man in einer Demokratie fortwährend zur aktiven

471 Transkript der 3. Fokusgruppe, S. 57, Z. 1746-1749 (Herv. i. O.)

472 Transkript der 4. Fokusgruppe, S. 37, Z. 1176-1177 (Herv. i. O.)

473 Transkript der 5. Fokusgruppe, S. 1, Z. 24 und S. 41, Z. 1267-1271 (Herv. i. O.)

474 Vgl. Transkript der 3. Fokusgruppe, S. 57, Z. 1742-1764.

475 Transkript der 3. Fokusgruppe, S. 54, Z. 1649-1650.

476 „Mein Bruder hat auch 'ne Ausbildung gemacht, ist jetzt auf 'nem Wirtschaftsgymnasium. Man sollte ja davon ausgehen: Wirtschaftsklasse, kurz vor'm Abschluss, dass die wenigstens die Basics haben. Und dann war letztens 'ne Politik-Klausur [...] So, und da haben welche... auch, wussten das nicht, haben auch geschrieben: ,In der Opposition ist die CDU.' Und das find' ich persönlich, wenn ich so was höre, total schockierend. [...] Die sagen, die lesen keine Zeitung, sie hören keine Nachrichten, die beschäftigen sich mit ihrem Leben. [...] Also, ich will jetzt nichts unterstellen, dass die vielleicht keine Zeitung lesen, aber wenn sogar mal angebliche... die studieren gehen wollen später, sich da nicht mit beschäftigen, find' ich, fängt das schon in der Schule an, dass da irgendwie schon Fehler gemacht werden." Transkript der 3. Fokusgruppe, S. 55, Z. 1685-1701 (Herv. i. O.) 
Beteiligung aufgefordert sei, führt etwa zur Idee einer frühzeitigen, am besten verpflichtend zu prüfenden, Staatsbürgerkunde:

„]a, aber ich seh's auch [als] gefährlich [an], [dass Demokratien die praktische Teilhabe des Einzelnen fordern, J. S.] und ich würd's daran koppeln, vielleicht Politik als... Weiß ich nicht, wie, was weiß ich, so 'ne verbindliche Zehntklässlerprüfung, MatheDeutsch-Politik oder so, äh, einzuführen. Dass man wirklich auch, äh..., sich davor, äh, so 'n bisschen irgendwie kontrovers mit dem beschäftigen musste. ${ }^{\text {“477 }}$

Ergänzend sei eine frühzeitige „Politikberatung“, ja ein lebensweltsensibles coaching sowohl unter Schülern als auch unter Erwachsenen notwendig, die einem jeden zur allgemeinen politischen Urteilsfähigkeit verhilft:

„,Was will ich eigentlich? Weil, ich weiß das gar nicht so.' Und deswegen find' ich den Wahl-o-Mat auch so gut, weil er vielen Menschen, glaub' ich hilft, klarzukommen.“478 „Und wer macht das denn, ehrlich jetzt mal, sich... Keine Ahnung, fünf, sechs, sieben Stunden investieren, bis man von jeder Partei mal 'nen Plan hat? Die Allerwenigsten wahrscheinlich. Wenn's schon so 'nen Wahl-o-mat gibt, warum dann nicht als... was weiß ich, vielleicht nicht die Bundesregierung..., aber dann als Öffentlich-Rechtliche Videos, keine Ahnung, drei Minuten pro Partei, die Knackpunkte? ${ }^{4479}$

Die oftmals nachdenklich auftretende Pädagogisierung politischer Auseinandersetzungen kann auch dazu führen, dass Provokationen, die eine Orientierungskrise hervorrufen, mit einem festeren Griff zum mentalen Oberlehrer-Rohrstock beantwortet werden. Auf die Kritik einer in Russland aufgewachsenen Studentin an der allgemeinen Schulpflicht entgegnet eine Mitdiskutantin besonders entrüstet. Nicht die Möglichkeit ungebildeter und potenziell benachteiligter Sprösslinge schockiert sie, sondern vielmehr, dass unter der Ägide ungeeigneter Eltern eine Masse von Kindern mit „ganz andere[n] Werte[n]“ entstehen könnte - wie „in Amerika“:

"Ich weiß nicht, wenn man sich schon in Amerika oder so das anguckt: [...] Wenn du halt dann schwierige Familien hast, dann geben die denen vielleicht ganz andere Werte mit, und die Kinder lernen das dann gar nicht so sehr, sag' ich mal, wie wenn sie's in der Schule lernen würden, weil, ja, in der Schule kommen ja dann diese Werte mit... Demokratie, und dass man offen sein sollte und so, und ich glaub', da gibt's viele, doch, Familien, die das vielleicht noch irgendwie anders sehen. Und deswegen find' ich Schulpflicht eigentlich an sich sogar sehr gut. Also, dass Kinder wirklich hingehen müssen. ${ }^{480}$

Nur ein einziges Mal wird die frühzeitige politische Bildung infrage gestellt, und zwar von einer Studentin der Forstwissenschaft, die bemerkt, Schülern fehle "die Reife für das Verständnis politischer Themen. ${ }^{481}$ Doch ihr Einwurf findet keine Resonanz, er verstößt vielmehr sichtlich gegen Kernüberzeugungen der anderen Fokusgruppenteilneh-

477 Transkript der 5. Fokusgruppe, S. 52, Z. 1598-1604.

478 Transkript der 5. Fokusgruppe, S. 70, Z. 2164-2166 (Herv. i. O.)

479 Transkript der 6. Fokusgruppe, S. 57, Z. 1810-1814.

480 Transkript der 4. Fokusgruppe, S. 25f., Z. 794-805 (Herv. i. O.)

481 Vgl. Transkript der 3. Fokusgruppe, S. 54, S. 1562-1657. 
mer. Überzeugungen, die auch in anderen Gruppen so entschlossen und unumstößlich markiert werden, dass man versucht ist, hierin Bewältigungsversuche spezifischer Ängste zu sehen. Dem ist nachzugehen, verspricht es doch näheren Aufschluss über die Gesellschaftsauffassungen von Studierenden: Welche Ziele soll die so leidenschaftlich geforderte politische Bildung erfüllen? Ihr wird zugemutet, nahezu sämtliches gesellschaftliches Polarisierungs- und Konfliktpotenzial schon an der Wurzel auszuheben. Dies soll insbesondere durch die Herabsetzung von Irrationalität, Affekten, Emotionalisierungen und Wut geschehen. Denn: Je „bildungsferner“ die soziale Herkunft, desto größer wird das Problem, dass Menschen „so wenig, auch, hinterfragen und so wenig kritisch sind, dass sie einfach sagen: ,Ja, och, jetzt mal wat Anderes, mach' ich jetzt mal aus Protest! “482 Des Öfteren erscheint die aus Überdruss geborene, aufgebrachte, angestachelte und reflexionsunfähige "Masse“ (ein nur pejorativ gebrauchter Begriff, der hier immer auch Formlosigkeit suggeriert) als entscheidende Gefahr für das demokratische Miteinander. Unbildung, Emotionalisierung und Irrationalität sind für viele Studierende unmittelbar eins - und offenbar auch zentrales Scharnier des elektoralen Siegeszugs der AfD. Der visierte politisch gebildete Wähler wird demgegenüber als der bedächtige, umfassend informierte und rational abwägende Bürger imaginiert, der - und das ist ganz entscheidend - Partei- und Wahlprogramme liest. ${ }^{483}$ Für die Studierenden ist das ein entscheidendes Publikationsformat, glauben sie doch an solchen Programmschriften des „wahren“, da rational argumentierten und schriftlich bezeugten Gehalts der jeweiligen Partei habhaft zu werden, wie er sich hinter den rhetorischen Serpentinen manipulativer politischer Eliten zu verstecken scheint. Wer das nicht sieht und sich bei der Wahl obendrein von Affekten treiben lässt, wird verspottet - so etwa die eigenen elitengläubigen Großeltern:

„Also ich find's total interessant, irgendwie, ich war schon immer, so, mehr so mittig und grün und, so, rot quasi, so, aber trotzdem ist es mal halt ganz gut, so, irgendwie FDP- oder CDU-Parteibücher zu lesen und einfach zu gucken: ,Hey, manches ist gar nicht so verkehrt, was... oder gar nicht so unterschiedlich!' Und das fänd' ich irgendwie auch ganz interessant. [...] meine Oma ist halt so... Ich weiß nicht, ich kann mich da irgendwie vor 'n paar Jahren... Da war es irgendwie halt [...] kurz vor der Wahl, und dann hat Merkel halt irgendwie so 'ne Rede gehalten, und meine Oma hat so... danach so...: , Boah, das ist so toll, was die erzählt!', und so. Und die war so begeistert, und ich dachte mir nur so: ,Och Mensch, Oma, du hast doch keine Ahnung!' [lacht] Das fand ich irgendwie ganz krass." 484

Wahlsimulationen oder die gemeinsame Lektüre von Wahlprogrammen scheinen daher auch aus der Sicht angehender Lehrkräfte als das Mittel der Wahl für die schulische Bildung, so etwa in dem hier wiedergegebenen best practice-Beispiel:

„Ein Lehrer hat zum Beispiel auch, ähm, alle Wahlprogramme zu den sechs großen Themen, die es so gibt - also so Bildung, Familie, Sicherheit, äh, Flüchtlinge war auch ein Thema, was er da zusammengefasst hat..., und jeweils auf einer Seite von allen

482 Transkript der 4. Fokusgruppe, S. 50, Z. 1584-1589 (Herv. i. O.)

483 Vgl. Transkript der 2. Fokusgruppe, S. 1655-1661.

484 Transkript der 4. Fokusgruppe, S. 49, Z. 1555-1558 und 29f., Z. 927-932. 
relevanten Parteien - auch von der AfD -, dann, halt aufgeschrieben, was so in deren... was so in deren Partei-... oder deren Wahlprogrammen dazu stand. Und dann konnten die Schüler sich das durchlesen, und es wurde auch immer thematisiert und drüber gesprochen. “485

Besonders beliebt unter Studierenden ist dementsprechend auch der Wahl-o-Mat, wähnt man mit ihm doch ein übersichtliches Aufbereitungs- und Filterinstrument von Wahlprogrammen in den Händen. ${ }^{486}$ Nur einmal wird der Einwand erhoben, dass auch andere, nicht-demagogisch agierende Parteien grundsätzlich eher aufgrund affektiver Affiliationen und aktueller Themen, aber "nicht unbedingt wegen ihres Programms“ gewählt werden - und daraufhin ignoriert. ${ }^{487}$ Es dominiert die Pädagogisierung und auch Pathologisierung von Wählern rechter und rechtsradikaler Parteien. Folgerichtig treten die Studierenden - zumindest dort, wo dieses Thema angesprochen wird als entschiedene Gegner plebiszitärer Entscheidungsverfahren auf Bundesebene auf. Zwar befürworten sie moralisch die damit verbundene Idee stärkerer Einflussnahme von unten; zu gefährlich aber erscheint auch hier das Risiko einer Beteiligung von Ungebildeten, Emotionalisierten und Verführten. Wenn Volksentscheide denn unbedingt durchgeführt werden sollen, dann müsste jedenfalls „die Aufklärung über das [...], was da abgestimmt werden soll, ganz, ganz, ganz groß sein, weil, sonst kann's halt echt total nach hinten losgehen“, sodass Menschen „mit so 'nem Halbwissen“488 (aus der Gruppe ertönt entschiedene Zustimmung) mitentscheiden. In der 4. und 5. Fokusgruppe wird diese Angst, dass etwa politischer Schutz von Minderheiten gefährdet sein könnte, durch die wechselseitige Bestärkung am drastischsten formuliert:

„B5: [...] Gerade die politische Bildung müsste sehr viel höher sein. Weil, ansonsten ist es halt echt ' $n$ bisschen schwierig, dann denken... Also, ich hätte davor echt ' $n$ bisschen Angst, wenn da jeder... B3: Ich auch. Ich hätte ganz schön Angst davor. B5: ... jeder Mensch mit 'ner radikalen Meinung dann halt einfach irgendwie..." ${ }^{489}$

„Du kannst die Menschen ja auf keinen Fall zwingen, sich irgendwie über Dinge zu informieren, und so. Aber so bestimmte, eben große, schwerwiegende, Entscheidungen einer Masse zu überlassen, die mal eben aus dem Bauch heraus, nachdem sie - jetzt völlig plakativ gesagt $-\ldots$ gerade irgendwie von zuhause vom Abendessen kommt, jetzt nochmal wählen geht und dann wieder nach Hause geht, ist [...] schwierig. ${ }^{4900}$

Nur im letzten Falle wird anschließend selbstkritisch konzediert: „Andererseits: Was nehm' ich mir das Recht 'raus, das zu beurteilen, was die Leute wählen wollen?“491 $\mathrm{Na}$ türlich gibt es gute Argumente gegen Volksentscheide. Wichtig aber sind hier die an den Äußerungen abzulesenden Beweggründe und Ängste, die sich an die Thematik heften; es handelt sich um die diffuse Furcht vor politisch emotionalisierten Mitmenschen, besonders unkontrollierbaren und verführbaren Massen, die sich von weit rechts anschi-

485 Transkript der 4. Fokusgruppe, S. 50, Z. 1573-1579.

486 Vgl. etwa Transkript der 6. Fokusgruppe, S. 57, Z. 1810-1814.

487 Transkript der 2. Fokusgruppe, S. 52f., Z. 1663-1664.

488 Transkript der 4. Fokusgruppe, S. 43, Z. 1350-1360 (Herv. i. O.)

489 Transkript der 4. Fokusgruppe, S. 41, Z. 1299-1306 (Herv. i. O.)

490 Transkript der 5. Fokusgruppe, S. 53, Z. 1615-1624 (Herv. i. O.)

491 Transkript der 5. Fokusgruppe, S. 53, Z. 1624-1625. 
cken, die politischen Kräfteverhältnisse umzustürzen. So ist denn politische Bildung, ist auch das Lesen von Wahlprogrammen für viele Studierende der entscheidende Lösungsansatz für das AfD-Problem. Aufklärung schlägt Rechtspopulismus:

„Ich glaub', das AfD-Phänomen basiert so'n bisschen, einfach, wirklich auf Ängsten, weil: Allein, dass so Bundesländer wie Mecklenburg-Vorpommern, die 'ne extrem geringe Ausländerquote faktisch haben, eine ausländerfeindliche Partei wählen, ist halt auch so'n bisschen, so, Uninformiertheit. Ich glaub', dass da auch viel, einfach, Schwächen im Bildungssystem vielleicht auch waren... und da nicht gegriffen haben, oder Schwächen im Kontakt mit anderen Leuten, so.“492

„Also, ich hatte jetzt ein Seminar, wo Rechtspopulismus war, und wir haben ganz viel über die AfD gelesen, also ganz viele Texte und wer das gewählt hat und warum, und haben uns auch das Parteiprogramm durchgelesen. Und erst, als wir das wirklich, so, gelesen haben, dieses Parteiprogramm... ist einem aufgefallen, wie schockierend das ist, dass die Partei so weit vorne ist, oder die stärkste Opposition geworden ist, und dass es so viele Wähler gibt, die der Partei folgen, oder so viele Eintritte - weil sie sich einfach gut vermarkten können und einfach wirklich, so, ja, 'ne andere Wahl gegeben haben. Weil viele unzufrieden haben. [...] Wenn man wirklich jedem Wähler mal das Parteiprogramm gegeben hätte und die sich das wirklich mal durchgelesen hätten, was da für'n Schwachsinn wirklich drinsteht. Und das find' ich eher so schockierend, dass sich keiner damit auseinandersetzt, sondern nur auf die Medien hört... was da preisgegeben wird. ${ }^{493}$

„]a, durch Statistiken und sowas weiß man ja mittlerweile, woher zum Beispiel [der] Rechtsruck in Deutschland kommt, oder was Unbildung für 'ne... für Auswirkungen auf die Gesellschaft hat. “494

In gewissem Sinne dämpft die so visierte politische Bildung nicht nur AfD-Erfolge, sondern hilft zugleich auch dem Problem der politischen Apathie ab - indem nämlich per Aufklärung der „Richtigen“ eine Gegenmobilisierung möglich wird:

„]a, es ist legitim, natürlich, die AfD zu wählen, aber momentan sind sie überrepräsentiert! Im Großen und Ganzen gibt es zu viele Nichtwähler, und wenn diese Nichtwähler hätten mobilisiert werden können von den anderen Parteien, vielleicht auch durch mehr politische Bildung aus den anderen Richtungen, dann wär's zu diesem Ergebnis sicherlich nicht gekommen." ${ }^{\text {495 }}$

Dass die sich in der Wahl der AfD immer auch ausdrückenden inhaltlichen Interessen, etwa die Forderung nach einem Rückbau der Migrationsgesellschaft und die Sehnsucht nach Protektionismus vermeintlicher Etabliertenvorrechte, immer wieder durchaus auch nüchtern und intransigent formuliert werden, ohne dass ein maliziöser Verführer mithilfe demagogischer Tricks solches erst hervorruft, und dass sich solche materiellen Interessenlagen nicht allein durch die formalistische Zivilisierung des Modus 
der Konfliktregulation allein nivellieren lassen, kommt allenfalls als marginaler Gedanke auf. Wo er erscheint, wird er von anderen wieder eingefangen. ${ }^{496}$ Erkennbar wird das demokratisch und politisch Richtige auf Rationales reduziert - denn gebildete Rationalität und durch Vernunft gereinigte Innerlichkeit schafft eo ipso Verständigung, mithin Integration und „tolerante“, „offene“, kosmopolitische Eintracht integrer Demokraten. Entscheidend ist, dass alle Mitglieder der Gesellschaft zentrale „Werte“ und „Haltungen“ verinnerlichen. Ohne für politische Deutungsangebote rechts der Mitte Partei zu ergreifen, lässt sich daraus doch folgern: Unter der besorgt-liberalen studentischen Rhetorik der politischen Bildung haust ein deutlicher paternalistisch-autoritativer Zug. Damit aber befinden sie sich im Grunde auf einer Linie mit der spezifisch deutschen, aus dem Geiste der re-education geborenen Tradition politischer Bildung. Ein kurzer Seitenblick verdeutlicht das: Per Kontrollratsdirektive Nr. 54 initiierten die US-amerikanischen Besatzungsmächte am 25. Juni 1947 den Versuch einer postfaschistischen Umerziehung der deutschen Bevölkerung zur Demokratie bzw. einer Herausbildung demokratischer Resistenzkräfte, ansetzend bei der Jugend und damit an der Reformierung des Bildungswesens. ${ }^{497}$ In der Tradition demokratischer Egalität, aber auch geprägt vom Philosophen John Dewey, Galionsfigur des amerikanischen Pragmatismus, zielte die Umerziehung auf „Erhöhung des Staates und Unterwerfung des einzelnen ${ }^{4498}$ in expliziter Abgrenzung von den als proto-totalitär eingeschätzten deutschen Bildungsvorstellungen mit ihren vom Deutschen Idealismus herrührenden Selbstverständnis. So wie Deweys Betonung der "Demokratisierung“ des gesellschaftlichen Lebens und die Herausbildung einer spezifisch demokratischen Lebensform gerade den „Individualismus“ zugunsten einer kollektiv-verantwortlichen Sozialmoral beschränken sollte, ${ }^{499}$ zielte das re-education-Programm zwar auf den Abbau schulischer Hierarchien zugunsten freien Meinungsaustauschs, aber eben auch auf die Durchsetzung einer ausgeprägten, werte- und wettbewerbsorientierten sozialen Konformität mit besonderer Betonung von „Bürgersinn“ und „sozialer Verantwortung“ in einer Gesellschaft allgemeiner Chancengleichheit. ${ }^{500}$ Demokratie als „Lebensform“ hieß, die Verinnerlichung von „Grundwerten“ wie „Würde des Individuums, Toleranz, individuelle Freiheit, Teilnahme an bürgerlichen Verantwortlichkeiten sowie Anerkennung der Gleichheit aller Nationen und Rassen" sicherzustellen. ${ }^{501}$ Die entscheidende Differenz der deutschen politischen Bildung zur US-amerikanischen bestand in der Installierung eines eigenen Unterrichtsfachs, der „Sozialkunde“, welche unter Rückgriff auf sozialwissenschaftliche Kenntnisse die Vermittlung politischer Bildung an alle künftigen Staatsbürger sichern

496 „B1: [...] Gut, wär' da jetzt irgendwelche Aufklärung 'ne Möglichkeit gewesen? Oder wenn Leute mehr politisches Wissen gehabt hätte, wär' das anders ausgegangen? Oder haben die Leute einfach alle diese Meinung, die ich eher nicht so schön finde, und...? B2: Die haben sich ebent viel blenden lassen, hab' ich das Gefühl. B1: Ja." Transkript der 3. Fokusgruppe, S. 62, Z. 1915-1922.

497 Vgl. Gagel, Walter: Geschichte der politischen Bildung in der Bundesrepublik Deutschland 19451989/90. Zwölf Lektionen, Wiesbaden 1994, S. 32-35.

498 Ibid., S. 34.

499 Vgl. Dewey, John: The Ethics of Democracy, in: Boydston, Jo Ann (Hg.): Early Works of John Dewey, 1882-1953, Bd. 1, Carbondale 2008, S. 243f.

500 Vgl. Gagel: Geschichte der politischen Bildung, S. 34-37.

501 Ibid., S. 37. 
sollte. ${ }^{502}$ An politischen Auseinandersetzungen über den Zweck der politischen Bildung seit Gründung der Bundesrepublik mangelt es ebenso wenig wie an wiederholten Reformen und Neukonzeptionen dieses fraglos wichtigen Bereichs der Bildungspolitik. $\mathrm{Zu}$ nennen wären hier, neben konzeptuellen Disputen und Schulstreits, etwa der angesichts der „Politisierungsversuche“ in den 1970er Jahren verabschiedete Beutelsbacher Konsens („Überwältigungsverbot“, Kontroversitätsgebot, Ermächtigung zur Erkenntnis eigener Interessenlagen und Einflussmöglichkeiten in der schulischen politischen Bildung ${ }^{503}$ ) oder das im vereinigten Deutschland auf neue rechtsextremistische Phänomene reagierende Münchner Manifest der Bundeszentrale und der Landeszentralen für politische Bildung von 1997, welches unter dem Titel Demokratie braucht politische Bildung als künftige Aufgabe politischer Bildung die Förderung der „Demokratiekompetenz" der Bürger „für die Stabilität der Demokratie auch in schwierigen Zeiten“, insbesondere deren Fähigkeit zur Partizipation und Intervention in einer aktiven Zivilgesellschaft, fixierte. ${ }^{504}$ Die „Prinzipien des Pluralismus, der Kontroversität und der Rationalität“505 in einer aktiven Gesellschaft „mündige[r] Bürger“506 gehören bis heute zu den Leitidealen politischer Bildung in Deutschland. Trotz der unverkennbaren rhetorischen Modernisierungsarbeit mithilfe von Begriffen wie „Kompetenzen“ oder „Fähigkeiten“ ist jene starke paternalistisch-erzieherische Schlagseite des (west-)deutschen Verständnisses politischer Bildung bis heute erhalten geblieben, die in der aus politischer Unbildung drohenden Unmündigkeit eine potenziell destabilisierende Gefahr der demokratischen Ordnung sieht. In einer Zeit eines vielfach konstatierten ${ }^{507}$ wachsenden Institutionen-Misstrauens und rechter Wahlerfolge kann sich diese Auffassung zu einem vermeintlich überpolitischen, tatsächlich aber hochpolitisierten (links-)liberalen Kampfprogramm radikalisieren, welches der Politikwissenschaftler Philipp Manow vor dem Hintergrund eines tatsächlichen langjährigen Bedeutungsverlusts von grundstürzenden Sachauseinandersetzungen im Parlament durch eine starke „disruptive“ Exekutiv- und Konsensorientierung der Regierungspraxis ${ }^{508}$ jüngst polemisch als „Extremismus der Mitte“ bezeichnete:

„Wenn sich zentrale politische Fragen nicht mehr in den zentralen politischen Institutionen abbilden, sehen sich diese zentralen Institutionen selber schnell infrage gestellt. Hierauf ist mit mehr Appellen an die Zivilgesellschaft, intensiveren Demokratiebekenntnissen oder mit noch mehr schlechter Musik in guter Absicht [gemeint

502 Vgl. ibid.

503 Ibid., S. 219.

504 Vgl. o. V.: Demokratie braucht politische Bildung. Zum Auftrag der Bundeszentrale und der Landeszentralen für politische Bildung. „Münchner Manifest" vom 26. Mai 1997, in: Aus Politik und Zeitgeschichte, H. 32/1997, S. 37-39.

505 Massing, Peter: Bundes- und Landeszentralen für politische Bildung, in: bpb.de, 19.03.2015, online einsehbar unter: https://www.bpb.de/gesellschaft/bildung/politische-bildung/193394/bundes-und-landeszentralen? $p=$ all [eingesehen am 01.08.2019]

506 Detjen, Joachim: Die Demokratiekompetenz der Bürger, in: bpb.de, 26.05.2002, online einsehbar unter: https://www.bpb.de/apuz/25554/die-demokratiekompetenz-der-buerger?p=all [eingesehen am 01.08.2019]

507 Vgl. etwa Rosanvallon, Pierre: Counter-Democracy. Politics in an Age of Distrust, Cambridge/New York 2008.

508 Vgl. Meinel, Florian: Vertrauensfrage. Zur heutigen Krise des Parlamentarismus, München 2019. 
sind etwa Benefizkonzerte unter dem Motto \#wirsindmehr und „Konzert für die Vielfalt" nach den rechtsextremen Ausschreitungen in Chemnitz 2018, J. S.] nicht angemessen geantwortet. [...] Die Kombination aus Exekutivföderalismus und aufgesplittertem Parteiensystem befördert diese sehr deutsche Liaison aus ,Cesinnungsethik und Bürokratie' (Meinel). Über den Funktions- und nachfolgenden Ansehensverlust des Parlamentarischen muss man sich dann nicht weiter wundern. ${ }^{\text {} 509}$

Dass es immer wieder Versuche gibt, die vermeintliche demokratische Mitte als „moralischen Schlagbaum“ gegen Wähler „populistischer“ Parteien in Stellung zu bringen, wird sogar im epistemologischen Rüstzeug von Studien wie dem Populismusbarometer deutlich. ${ }^{510}$ Tatsächlich: „Die implizite Position vieler Antipopulisten scheint zu sein, dass sich eine demokratische und tolerante Geisteshaltung bei dem Großteil der Bürger irgendwie spontan selbst generiert" ${ }^{\text {511 }}$ - und diese implizite Position, wie sie sich in den Köpfen von Politikwissenschaftlern, Publizisten und Journalisten, Politikern, Lehrkräften oder eben auch Studierenden findet, ist auch das Produkt des hierzulande vermittelten Verständnisses politischer Bildung. Freilich: Aus der Sicht der Studierenden stellt sich die politische Bildung nur als logische Verlängerung der allgemeinen Bildungsemphase dar. Sie verwenden die Begriffe „Bildung“ und „politische Bildung“ häufig synonym. Aber es ist doch nachdrücklich in Zweifel zu ziehen, ob sich denn die Humboldt'sche Selbstbildung vernunftfähiger, über die bürgerliche Gesellschaft interagierender Monaden überhaupt mit re-education, d. h. mit der pädagogischen Imprägnierung durch als demokratieförderlich angesehene Werthaltungen und Einstellungen, kurz: mit einem letztlich vor-neuhumanistischen oder zumindest trans-neuhumanistischen Verständnis von Pädagogik vermitteln lässt. Die Diskussion, ob Bildungsideale überhaupt etwas zur Lösung aktueller politischer Konfliktlinien beizutragen vermögen, soll hier nicht aufgenommen werden; wichtig ist, dass sie es in den Augen der Studierenden durchaus tun - und zwar als Aufklärung der Massen mit dem Ziel der Befähigung zum „richtigen“ Engagement.

$\mathrm{Zu}$ resümieren ist erstens zwar, dass die Studierenden die Beschäftigung mit Politik und politischen Themen für wichtig, ja verpflichtend halten, und daran eine in den Fokusgruppen dominante Sozialethik ableiten. Politische Apathie im Sinne von Anteilnahmslosigkeit gehört nicht zum guten Ton, ja erscheint amoralisch, weshalb manche Fokusgruppenteilnehmer strategisch abwarten, bevor sie ihre persönliche Praxisabstinenz gestehen, oder aber auf ihr stetes Bemühen um ein angemessenes Informationsniveau verweisen. Für das Nichtwählen optiert niemand, obwohl es durchaus institutionenkritische Passagen gibt, in denen ein solches aus der Entfremdung vom „großen“ politischen Prozess resultierendes Verhalten immerhin plausibel wäre. Gesellschaft funktioniert, zumindest den verbalen Bekundungen nach zu urteilen, nicht ohne das verantwortungsbewusste Zutun der Einzelnen. Darin besteht ein großer Unterschied zu den nichtstudierenden Jugendlichen und jungen Erwachsenen der Vor-

509 Manow: Der Extremismus der Mitte, S. 8 und gf.

510 Vgl. Boehncke, Clemens: „Die Hölle, das sind die Anderen“. Das Populismusbarometer 2018 als moralischer Schlagbaum, in: Demokratie-Dialog, H. 3/2018, S. 68-74.

511 Jörke, Dirk/Selk, Veith: Der hilflose Antipopulismus, in: Leviathan, 43. Jg., H. 4/2015, S. 484-500, hier S. 496. 
gängerstudie, die das Funktionieren gesellschaftlicher Zusammenhänge als gegeben und das Nichtwählen infolge geringer individueller Einflusschancen als legitim erachteten. ${ }^{512}$ Allerdings ergeben sich doch Zweifel, wie weit die hier zu beobachtende Neigung zum gesellschaftspolitischen Parlieren führt, wenn es um die Herausbildung und um das Durchfechten politischer Positionen im Einzelfall geht. Konkrete politische Themen beschäftigen sie - hier wiederum der nichtstudierenden Jugend identisch ${ }^{513}$ - nur, wo sie sich persönlich betroffen sehen, etwa bei Themen wie BAföG, Nebenjob, Miete und Krankenkassenbeitrag. Oft flüchten sich die Studierenden in allgemeine Bekenntnisse, die auf ihren Königsweg, die (politische) Bildungsemphase zurückdeuten. An der wiederkehrenden Reduktion rechter Wahlerfolge auf durch politische Bildungsdefizite bedingte Frustrationen und Emotionen, an der rationalistischen Engführung von Wahlprogrammen und an der Verbindung von Apathie-Klage und Konfliktscheu ist das zu erkennen. Man ist „pragmatisch“ und „tolerant“, aber dadurch eben auch indifferent, beliebig, praxisavers, ja tatsächlich: ratlos. ${ }^{514}$ Gerade im Vergleich mit den 1970er und 1980er Jahren ist das auffällig, lässt sich doch ohne falsche Romantisierung sagen: Damals schärften und konturierten sich die weltanschaulichen Profile zwischen „linken“ und „rechten“ Studierenden in kontinuierliche Auseinandersetzung, ja im konfrontativen Streit. ${ }^{515}$ Heute wird Politisierung ideell befürwortet, aber praktisch abgelehnt - einerseits, weil sie aktuell rechten und rechtsradikalen Bewegungen zugutekommt, andererseits, weil Unruhe, Konfliktivität und Streit den Studierenden Kopfschmerzen bereiten. Sie präferieren den ruhigen, geordneten und vor allem: vernünftigen Disput. Gut ist, was rational bleibt; schlecht ist, was emotional zu werden droht. Politische Bildung soll zu Ersterem erziehen.

Darauf aufbauend zweitens: Obwohl sie viel und gerne reflektieren, führt das vollmundige Bekenntnis zum politischen Handlungsbedarf im Zeichen der Funktionsfähigkeit demokratischer Ordnungsprinzipien nicht zu einem tatsächlich hohen politischen Aktivitätsniveau, was großen Rechtfertigungsdruck auf die Studierenden ausübt, ja ein beinahe drückend schlechtes Gewissen verursacht. Wie bereits die OnlineErhebung des Studierendensurveys von 2011 suggerierte, ${ }^{516}$ üben sie häufig stark moralisierende Gesellschaftskritik bei nur geringem persönlichem Engagement für bestimmte Ziele, betätigen sich auch kaum aktiv und ausdauernd in politischen Organisationen. Deutlich höher ist, wie erwartet, der Grad an zivilgesellschaftlichem, insbesondere ehrenamtlichem und themen- bzw. projektbezogenem Engagement. Hier wird häufiger die Erfahrung gemacht, im Kleinen zuzupacken, ohne institutionelle Verfälschungen etwas „bewirken“ zu können. Und grundsätzlich bestätigt sich ein in vielen sozialwissenschaftlichen Studien immer wieder auffallender Zusammenhang auch hier: Wer Er-

512 Vgl. Schenke et al.: PEGIDA-Effekte, S. 190f. und 204.

513 Vgl. ibid., S. $190 f$.

514 „Was auf den ersten Blick nach mehr Toleranz oder Großzügigkeit aussieht, erweist sich, genauer besehen, als Konzept- und Positionslosigkeit. Bei immer mehr Studierenden geht damit eine Scheu vor der eigenen Meinungsbildung einher. Die studentische Zurückhaltung mag als ein Ausweis von Ideologiefreiheit angesehen werden, beinhaltet aber vor allem Cleichgültigkeit und Beliebigkeit." Bargel/Simeaner: Gesellschaftliche Werte und politische Orientierungen, S. $15 f$. 
fahrung mit politischem Engagement und politischen/zivilgesellschaftlichen Organisationen hat, der entwickelt ein gewisses Maß an Selbstbewusstsein und Durchsetzungsfähigkeit; dessen politische und institutionelle Informationslage fällt voluminöser und differenzierter aus; dessen Diskussionsstil gerät energischer, zupackender, analytischer und lösungsorientierter. Alle Studierenden aber - auch die praktisch Engagierten - zeigen in ihrer Distanz zur "großen“ Politik als alltagsferner Sphäre ein ausgeprägtes Maß an „Politikerverdrossenheit “517. Den in Kapitel III.2 wiedergegebenen Wahlpräferenzen der Studierenden ist hinzuzufügen, dass im Grunde keine politische Partei - nicht einmal die Grünen - ein größeres Maß an studentischem Vertrauen für die Herstellung einer besseren Zukunft binden kann. Die persönlichen Einflussmöglichkeiten durch die Partizipation an Wahlen werden im Grunde von allen als bedauernswert gering eingeschätzt; Parteibürokratien, Machtkalküle und das Verhängnis der Interessenaggregation absorbieren aus ihrer Sicht jeden originären Veränderungsimpuls oder überformen ihn im Laufe einer langen Ochsentour so nachhaltig, dass die Aufnahme solcher Anstrengungen vollends unattraktiv gerät. Über konkretes politisches Personal und über Inhalte und Vorhaben von Parteien reden sie - ähnlich wie die nichtstudierenden Jugendlichen und jungen Erwachsenen ${ }^{518}$ - nicht. Lösungen für dieses Problem finden auch die in Politgruppen aktiven Studierenden nicht. Vollkommen eliminiert ist insbesondere die historisch gesehen einst elementare Vorstellung einer kollektiven Zugehörigkeit zur Gesamtmasse der Studierendenschaft, und sei es in Gestalt eines Wunschbildes, einer erst herzustellenden Kollektivität mit gemeinsamen Interessen. Es gibt derzeit keinen Verband und keine Hochschulgruppe, die bundesweit legitime Repräsentationsansprüche erheben und auf der Grundlage dieser Legitimität politische Ziele durchsetzen kann. Das verweist wiederum zurück auf die in Kapitel III.3.1 skizzierte Disparatheit und Zerstreutheit studentischer Orientierungsmaßstäbe: Sie ist auch Resultat der fehlenden Bündelungs- und Formungsarbeit einer organisierten Studierendenschaft. Man pflegt das Idealbild des „kompetenten“ Bürgers, der souverän und mutig partizipiert, doch scheitert daran, gesteht schließlich zerknirscht seine Überforderung ein oder sucht nach - teilweise beeindruckend elaborierten - Rechtfertigungen im Büßergewand des mea culpa. Warum setzen sich die Studierenden derart selbst unter Druck?

517 Eine der fünf Pickel'schen Dimensionen der Politikverdrossenheit, vgl. Pickel: Jugend und Politikverdrossenheit, S. 90-92. 


\title{
III.3.3 "Total wichtig!" Demokratie: Verständnis, Begriff, Erfahrung und das konkrete Handlungsproblem AfD
}

\author{
„Dadurch, dass man auf extreme Positionen \\ stößt, [muss man] sich ja auch wieder selbst \\ infrage stellen [...] Was dann ja vielleicht \\ auch immer ein wichtiger Fingerzeig ist, \\ in welche Richtung man da schauen soll, \\ welche Probleme mal angesprochen werden \\ müssen. “519 \\ „Also, ich finde, man kann die AfD halt \\ irgendwie auch nicht [...] ganz so ernst \\ nehmen, [...] es ist halt irgendwie auch so'n \\ bisschen so 'n Deppenverein [...] $]^{4520}$
}

Gesellschaftliche Ordnungsvorstellungen bilden eine entscheidende Determinante politisch-sozialer Deutungsmuster, wenn nicht ihren eigentlichen Kerngehalt. Einige Konturen studentischer Ordnungskonzeptionen konnten bereits aus der Auswertung des Studiums-, Leistungs-, und Bildungsverständnisses sowie aus der Diskussion politischer Themen gewonnen werden. Um sie $\mathrm{zu}$ vervollständigen und $\mathrm{zu}$ einem plastischen Bild politisch-sozialer Deutungsmuster von Studierenden zu gelangen, wurde im Rahmen zweier Frageblöcke auch nach dem Demokratieverständnis und - in den früheren Fokusgruppen - nach Vorstellungen idealer gesellschaftlicher Ordnung gefragt. Am reichhaltigen Gesprächsmaterial zum Demokratieverständnis der Studierenden wird nachvollziehbar, wie Studierende über Konfliktregulation, demokratische Partizipation und eine wünschenswerte gesellschaftspolitische Zukunft denken. Dabei ist ein komplizierender Faktor zur berücksichtigen, der auch im Themenkatalog aufgegriffen wurde: Der Verfasser konnte im Rahmen diverser Forschungsprojekte auch die Erfahrung machen, dass es vielen Menschen schwerfällt, den Begriff der Demokratie ad hoc inhaltlich zu füllen und auf das persönliche alltägliche Leben $\mathrm{zu}$ beziehen; seinen Grund hat das nicht zuletzt in einer voluminösen, bisweilen feierlichen Aura des Demokratiebegriffs, die zu definitorisch-philosophischen Exkursen geradezu einzuladen scheint. Oft findet sich ein Muster der rückhaltlosen Parteinahme für demokratische Prinzipien im Allgemeinen („Demokratie als Idee“) bei gleichzeitiger Bemängelung der demokratischen Praxis in der Bundesrepublik; tiefer sitzende Emotionen hingegen werden mit Rücksicht auf die Risiken möglicherweise anstößiger Auffassungen in der Regel gut behütet. Um also an das demokratische Denken und Empfinden der Studierenden zu gelangen, wurden die geäußerten Konzepte mit einem aktuellen Reizthema kontrastiert: dem Umgang mit Partei AfD in Parlamenten, seit 2017 auch im Bundestag. Die Thematik löste wie erwartet eine Orientierungskrise aus, die die Studierenden dazu zwang, ihr theoretisches Verständnis demokratischer Verkehrsformen an einem praktischen Handlungsproblem zu messen. Insgesamt zeigt

519 Transkript der 1. Fokusgruppe, S. 51, Z. 1574-1579.

520 Transkript der 4. Fokusgruppe, S. 51, Z. 1624-1629. 
sich hier, dass die Studierenden im Gegensatz zu den nichtstudierenden Jugendlichen und jungen Erwachsenen der Vorgängerstudie ${ }^{521}$ ein ausgeprägtes Bewusstsein von den komplexen Problemen des Meinungspluralismus, der Interessenaggregation und der Konflikteinhegung beweisen, zu deren Lösung alle Bürger als „kompetente Bürger"522 gleichermaßen aufgerufen seien - während die Demokratie für sie primär auf Werten und Haltungen, weniger auf Institutionen fußt, sie konkreten aktuellen Handlungsproblemen daher weitgehend ratlos gegenüberstehen. Diese Ratlosigkeit drückt sich auch darin aus, dass die Studierenden kaum über gesellschaftspolitische Ideale oder Fluchtpunkte verfügen, die über die bereits bestehenden Vergesellschaftungsmodi hinausreichen.

Die Frage, was unter Demokratie genau zu verstehen ist bzw. wie man sie imaginären Unkundigen erklären würde, produzierte zunächst erwartungsgemäße Überforderung. Erst nach und nach trugen die Diskutanten Wesens- und Strukturmerkmale zusammen, wobei die einen eher Elemente existierender demokratischer Systeme nannten, während andere stärker allgemeine Grundprinzipien des Demokratischen assoziierten. Sie greifen häufig auf schulische Lehrbestände oder lexikalisch anmutende Attribute zurück, bemühen sich aber auch um veranschaulichende Beispiele. Durchweg wird „Demokratie“ in diesen stark definitorisch-philosophischen Diskussionabschnitten selten als etwas alltagspraktisch Relevantes und Erfahrbares vorgestellt, mehr als das Medium eines gesamtgesellschaftlichen Prinzipienkatalogs, den man - ähnlich einer Vereinssatzung - nur selten auf die Tagesordnung setzt. In bester liberaler Tradition gehen die Studierenden dabei zumeist vom Individuum, dessen Möglichkeiten, Freiheiten, Privilegien und Pflichten aus. In der Regel assoziieren sie zuerst institutionelle Faktoren, genauer: die verfassungsgeschützte wahlbasierte Möglichkeit der Mitbestimmung als Machtkontrolle, den Meinungspluralismus und die Orientierung an regulierter Diskussion als zentrale Elemente des Demokratiebegriffs. Anders als es der vieldiskutierte - auch durch Bürgerproteste wie Stuttgart 21 und PEGIDA prominent inszenierte - Trend zum Misstrauen gegenüber politischen Eliten und Institutionen suggeriert, gehen die Studierenden davon aus, „[d]ass das Volk bei wichtigen Entscheidungen sozusagen mitentscheiden kann ${ }^{\text {“523 }}$ bzw. „mitbestimmen darf “524, indem es der den eigenen Präferenzen entsprechenden Partei sein Vertrauen schenkt. „Wir können [...] entscheiden, wer die Macht [hat], und wenn die das nicht gut machen, die auch abwählen. “525 Dazu gehört die verfassungsrechtlich gesicherte Ermöglichungsbedingung, „dass alle Bürger gleichberechtigte Chancen haben ${ }^{\text {“526 }}$, bzw. in ihren Wahlmöglichkeiten „theoretisch laut Verfassung [...] alle gleich sind, und [...] alle das Gleiche machen könnten“527, gerade in Abgrenzung „zur Diktatur“528 und unabhängig von ihrem Einkommen $^{529}$. Zur Mitbestimmung gehört dabei, auch das ist den Studierenden wich-

521 Vgl. Schenke et al.: PEGIDA-Effekte?, S. 209-212.

522 Vgl. oben, Kapitel III.3.2 dieser Studie.

523 Transkript der 1. Fokusgruppe, S. 45, Z. 1391-1393.

524 Transkript der 2. Fokusgruppe, S. 41, Z. 1284 und 1295. Vgl. außerdem Transkript der 7. Fokusgruppe, S. 52, Z. 1660-1662.

525 Transkript der 7. Fokusgruppe, S. 52, Z. 1647-1649.

526 Transkript der 1. Fokusgruppe, S. 45, Z. 1395.

527 Transkript der 2. Fokusgruppe, S. 41, Z. 1309-1310.

528 Transkript der 4. Fokusgruppe, S. 40, Z. 1254-1257.

529 Vgl. Transkript der 5. Fokusgruppe, S. 49, Z. 1512-1514. 
tig, die Möglichkeit der Machtkontrolle, die ihnen - neben der strukturellen Trennung Staatsgewalt in Legislative, Judikative und Exekutive - in Gestalt des Rechts gegeben sei, die nur temporär inthronisierten Regierungsparteien nach dem Ende der Legislaturperiode abzuwählen. ${ }^{530}$ Eine in Russland aufgewachsene Teilnehmerin identifiziert die generelle Liberalität von Wahlfreiheiten mit der Demokratie, wenn sie assoziiert: „Ein bestimmter Grad von Freiheit. In bestimmten Bereichen bis zu einer bestimmten Grenze zu wählen. Was will ich heute essen? [lacht] Von ,Was will ich heute essen?' bis, äh, ,Wie werde ich morgen regiert?“ Also, so.“531 Entscheidend ist für viele schlicht: „Es muss halt 'ne Kontrollinstanz geben." ${ }^{\text {"32 }}$ Als allgemein geteiltes Element der Demokratie (sowohl ihrer Idee wie ihrer bundesrepublikanischen Verwirklichung) wird überdies ein uneingeschränktes „Recht auf Meinung“ erkannt, welches auch beinhalte, für ebendiese Meinung politische Mitstreiter werben zu dürfen. ${ }^{53}$ Ein adäquater demokratischer Umgang setzt für die Studierenden daher auch voraus, auch Auffassungen Raum zuzugestehen, die den eigenen diametral widersprechen: „Es gehört ja eben auch zur Demokratie, dass man die Meinung der anderen akzeptieren muss. “534 Oder: „Es muss eine Meinungsvielfalt, -verschiedenheit, auch geben, dass man dann letztendlich auch zu einer mehrheitlichen Entscheidung dann irgendwie kommt. Das ist ja gerade das, [...] was die Demokratie ausmacht.“535 „[...] Demokratie ist Kompromissbereitschaft, also es ist Akzeptanz der anderen Meinung [...] “536 Hier wird das Wissen um die Gleichberechtigung konfligierender Überzeugungen aufgenommen, denn: „Demokratie ist nicht immer moralisch und sagt: ,Richtig - falsch: so, und so nicht!' Sondern wir diskutieren darüber. “537 Das gilt für viele gerade auch mit Blick auf einen neuen politischen Konkurrenten auf parlamentarischer Ebene, die $\mathrm{AfD}^{538}$, wenngleich nicht für alle, da doch einige Studierende gewisse Positionen für „unter aller Kritik ${ }^{\text {“539, }}$, mithin nicht vom allgemeinen Pluralismus gedeckt halten. Hier werden augenscheinlich Limitierungen der Liberalität und Diskursivität erforderlich. Bisweilen wird sogar angemerkt, dass gerade der Bundesrepublik Deutschland eine exponierte, historisch begründete Verpflichtung zur „Musterdemokratie“ eigen sei, welche sich in „Rechtsstaatlichkeit" und „historische[r] Verantwortung aus dem NS-Regime“ ausdrücke; gerade da es aktuell Gründe gebe, die Demokratie durch „ein erstarkendes Rechtsaußen“ „schon teilweise gefähr-

530 Vgl. Transkript der 2. Fokusgruppe, S. 41, Z. 1295-1302.

531 Transkript der 4. Fokusgruppe, S. 40, Z. 1250-1252 (Herv. i. O.)

532 Transkript der 6. Fokusgruppe, S. 80, Z. 2542 (Herv. i. O.)

533 Transkript der 1. Fokusgruppe, S. 46, Z. 1406-1412.

534 Transkript der 6. Fokusgruppe, S. 56, Z. 1791-1792 (Herv. i. O.)

535 Transkript der 2. Fokusgruppe, S. 43, Z. 1364-1368.

536 Transkript der 6. Fokusgruppe, S. 60, Z. 1895.

537 Transkript der 5. Fokusgruppe, S. 52, Z. 1592-1593 (Herv. i. O.)

538 „Z] ]entral [...] für meinen Demokratiebegriff ist, dass [...] Demokratie vor allem zum einen von Diskussion lebt, sich 'ne Meinung bilden zu können, und sie mit anderen [...] frei austauschen zu können. [...] Dass die Demokratie auch von Diskussionen lebt, ist auch der Grund, warum man zum Beispiel Dinge wie gewisse Parteien, die jetzt neu im Parlament sind, aushalten muss [...], weil das halt das Diskussionsbild erweitert [...] Transkript der 6. Fokusgruppe, S. 56, Z. 1775-1787. 
$\operatorname{det}^{\text {“ }} \mathrm{zu}$ sehen ${ }^{50}$, bedürfe es hier wacher Abwehrkräfte. Auf den Punkt gebracht wird dieses Ineinander von Meinungspluralismus, Diskussionsorientierung und notwendig beschränkender Konfliktregulation mit dem Satz, „dass Demokratie oder Politik einfach Streit mit Regeln ist. “541 Eine Fokusgruppenteilnehmerin assoziiert mit „Demokratie“ spontan den anspruchsvollen Begriff „Freiheit“, umfänglich verstanden als „persönliche Freiheit, das zu tun, was [man] eben tun möchte. Grundsätzlich“, auch wenn aus der Notwendigkeit, sich mit anderen zu arrangieren, eben „leider Einschränkungen“ entstünden und man „gemeinsam" einen „Konsens" wechselseitig eingeräumter Freiheiten aushandeln müsse. ${ }^{542}$ Sie ist es auch, die als Einzige - wenn auch durch die Gruppe unterstützt - auf die besondere Aufgabe verweist, Minderheiten zu schützen. ${ }^{543}$ Auf den ersten Blick konterkariert, letztendlich jedoch unterstrichen wird dieser Kommentar durch einen Studenten einer anderen Fokusgruppe, der die körperliche Unversehrtheit als grundstürzende Voraussetzung eines intakten demokratischen Prozesses bestimmt; er beruft sich auf Carl Schmitt, wenn er schlussfolgert: „Und das einzige, sozusagen das wirkliche Prinzip ist, dass [...] nachts nicht vier Leute kommen dürfen und dich abholen kommen. [...] Das ist auch schon alles!" Hier habe jede Diskussion unmissverständlich zu enden: „Das muss von oben nach unten gewährt werden, wirklich. Also es gibt Grundnormen, gegen die darf man nicht verstoßen, da muss man auch lernen, [...] dass es daran keinen Diskurs gibt! Überhaupt keinen." ${ }^{\text {"544 }}$

Selten, aber doch wiederkehrend versuchen die Studierenden, die Bedeutungsgehalte des Begriffs „Demokratie“, „im Wesentlichen halt eine Regierungsform, die vom Volk gewählt und bestimmt ist“545, aber sich in je spezifischen Systemen manifestiere, an die historisch wie geographisch variierenden konkreten Demokratien zu knüpfen. Dabei nehmen sie einen analytisch distanzierten, tentativen, ja leicht agnostischen Blick ein, der nur noch wenig Einblick in ihre persönlich empfundenen Überzeugungen freigibt. Eine Studentin der Wirtschafts- und Sozialgeschichte setzt damit ein, dass Demokratie „eigentlich die Herrschaft des Volkes“ bedeute, fährt aber mit dem Hinweis fort, dass es „viele verschiedene, so, Spielarten“ davon gebe, „wie das aussehen kann“; so weiche die „praktische Demokratie“ in der weniger dicht bevölkerten Schweiz fundamental von den Verhältnissen einer US-Demokratie $a b$, sodass mit besonderer Rücksicht auf die nie abreißende historische Veränderungsdynamik als behelfsmäßige Schlussfolgerung nur verbleibt: „Und dann sieht's da aber zu verschiedenen Zeiten immer anders aus, und es kann irgendwie ganz viel bedeuten. ${ }^{4546}$ Hier wird auch gesehen, dass der Demokratiebegriff, immer auch eine Legitimationskategorie politischer

Transkript der 1. Fokusgruppe, S. 39, Z. 1205-1209. Der Diskutant fügt allerdings ibid. hinzu, dass auch „ökonomische Ungleichheit, solche Sachen“ einen potenziellen Destabilisierungsfaktor bilden.

541 Transkript der 6. Fokusgruppe, S. 61, Z. 1950-1951.

542 Transkript der 5. Fokusgruppe, S. 49, Z. 1501-1508 (Herv. i. O.)

543 Vgl. Transkript der 5. Fokusgruppe, S. 49f., Z. 1517-1521. Ähnliches wird allerdings auch nahe gelegt durch das anderswo getätigte Stakkato: „Einhaltung der Menschenrechte. Pressefreiheit. Versammlungsfreiheit." Transkript der 1. Fokusgruppe, S. 46, Z. 1414. 
Herrschaft, nicht vor manipulativer Instrumentalisierung gefeit sei. ${ }^{547}$ Mögliche künftige Entwicklungsdynamiken werden von zwei Studenten (Volkswirtschaftslehre/Philosophie, Wirtschafts- und Finanzsoziologie) angedeutet. Hier ist zum einen zu hören, man lebe „aktuell“ in einer repräsentativen „Staatsform“, erfahre mithin nur eine partikulare Realisierung der Möglichkeiten des demokratischen Gedankens: „Das muss ich ja keinem erklären. Aber, also, dass es wenige Leute gibt, die glauben, dass sie ganz viele Leute vertreten und dann etwas aushandeln, so, das ist ja die Idee hinter der Demokratieform [!], in der wir gerade leben. ${ }^{“ 548}$ Zum anderen stellt sich ein Diskutant in einer anderen Fokusgruppe die Frage, ob „das Organisationsmedium der Partei“ in Zeiten digitaler Kommunikationsformen und allgemeiner politischer Apathie nicht mittlerweile „das falsche Medium“ sei, um Menschen an der Teilnahme an kollektiver Entscheidungsfindung zu beteiligen. Er bekundet, „aus so 'ner republikanischen Idee“ heraus die Überzeugung: „[...] die Leute müssen selbst verwalten lernen mit dem, was sie haben. ${ }^{4549}$ Und ähnlich, wenn auch deutlich abstrakter, äußert einer seiner Mitdiskutanten am Gegenstand des diskursiven Einbezugs der AfD, man habe nicht nur die eigenen Gewissheiten einer kontinuierlichen Revision zu unterziehen, sondern eigentlich auch den jeweils üblichen Modus der Diskussion: „Ich find', [...] das macht auch Demokratie aus, dass sie sich immer in Frage stellt. ${ }^{\text {"550 }}$ Aus diesen Ausführungen wird deutlich, dass manche Studierende in der Demokratie auch ein fortschrittsorientiertes regulatives Ideal sehen, dem die konkreten politischen Erscheinungsformen bisher nicht vollends gerecht werden konnten. Sie werfen ein, dass einzelne demokratische Prinzipien in der praktischen Wirklichkeit ausgehebelt seien bzw. „eher theoretisch als praktisch“' ${ }^{\text {“51 }}$ gelten würden. Den Grund für die mangelnde Verwirklichung des „Grundgedankens“ der Demokratie machen sie vor allem im Erfordernis der Interessenaggregation und -repräsentation aus. Während die einen auf die hypothetische Möglichkeit aller verweisen, sich im demokratischen Prozess einzubringen, zeigen sich andere mit ihren konkreten praktischen Optionen unzufrieden:

„B4: [...] Also, ich denk', 'n wichtiger Teil von Demokratie ist auch einfach, dass du irgendwie die Leute hörst und den Leuten das Gefühl gibst, dass sie gehört werden. Und ich glaube, je mehr Leute, die mehr - auch Randgruppen - an Politik irgendwie beteiligt sind auf irgend 'ner Ebene, desto mehr ist das irgendwie gewährleistet. B2: [...] im Endeffekt ist es einfach nur: 'ne Stimme abgeben auf Bundes- und Landesebene. Und das ist für mich zuwenig Teilhabe. [...] Wie könnt ihr persönlich Interessen oder Interessensgemeinschaften... Wie könnt ihr [die] durchbringen mit 'ner Stimme, die ihr irgendwo macht?" ${ }^{552}$

547 „Ich will nur ganz kurz sagen, dass... Demokratie ist 'n viel zu großer Deckmantel, weil man das immer so krass 'runterbrechen und spezifizieren kann, dass auch Nationalsozialismus demokratisch sein kann." Transkript der 7. Fokusgruppe, S. 58, Z. 1836-1838 (Herv. i. O.)

548 Transkript der 3. Fokusgruppe, S. 49, Z. 1502-1507.

549 Transkript der 6. Fokusgruppe, S. 52, Z. 1649-1663.

550 Transkript der 6. Fokusgruppe, S. 56, Z. 1788-1789.

551 Transkript der 7. Fokusgruppe, S. 52, Z. 1653.

552 Transkript der 7. Fokusgruppe, S. 56, Z. 1777-1788 (Herv. i. O.) 
In diesem Zusammenhang ist auch an den weiter oben wiedergegebenen Fatalismus politischer Betätigung, das Verzerren authentischer politischer Impulse im Prozess einer langjährigen Ochsentour durch Parteikader und Parlamente, zu erinnern. ${ }^{553}$ Aber: Das Messen der demokratischen Realität am supponierten demokratischen Ideal gibt selbst den stark fatalistisch Gestimmten Anlass zur Hoffnung. Zweifel an den aktuellen Verhältnissen können so unmittelbar wiedereingefangen werden: Zumeist erkennen die Fortschrittsdenker gerade in inhärenten objektiven Tendenzen der bereits herrschenden demokratischen, im Grunde alternativlos erscheinenden Gesellschaftsform (insbesondere Tendenzen zur Egalisierung, Liberalisierung und Rationalisierung sozialer Verhältnisse) jene Triebfedern, die auf die sukzessive Realisierung des Besseren zu verweisen scheinen. ${ }^{554}$ Konterkariert wird das nur durch generell zivilisationsskeptische, biologistisch durchsetzte Stimmen, die eine funktionierende (stumm akklamativ gedachte) Demokratie nur in archaisch-kleinräumlichen Strukturen für möglich halten. Eine Teilnehmerin, die unverkennbar Sympathien für kleinräumliche Lebenszusammenhänge hegt (an anderer Stelle beklagt sie die Überlastung der biologisch gegebenen Gehirnkapazitäten durch die moderne Medienwelt), geht etwa davon aus, dass

„die Cesellschaften viel zu groß sind, als dass Demokratie noch so wirken könnte. In 'ner kleinen Cruppe, wie wir es jetzt sind [gemeint sind die sechs Teilnehmer plus Moderator der betreffenden Fokusgruppe, J. S.], würde es super funktionieren, aber bei so riesigen Staaten geht das Konzept gar nicht mehr auf, und dann muss man ganz viele Kompromisse eingehen, die das Konzept dann irgendwie 'n bisschen kaputt machen, find' ich. “555

$\mathrm{Ab}$ und $\mathrm{zu}$ wird die Selbstläufigkeit des Diskussionszusammenhangs durch die Sorge unterbrochen, zu keinem „richtigen“ Begriffsverständnis zu gelangen. Hier sehnen sich einige Studierende nach letztgültigen Klärungen und richten zu diesem Zweck verschiedene Fragen an die Gruppe oder auch an den als Politikwissenschaftler kenntlichen Moderator, welchem dadurch die Rolle eines Seminardozenten zukommt:

„B6: Muss das denn so sein [in der Demokratie, J. S.], dass alle gleichgestellt sind? [...] Also, ich weiß das ehrlich gesagt nicht, wie das geregelt ist. Aber kann man nicht auch 'ne Demokratie haben, wenn [...] geschichtlich, äh [...], dass Frauen dann halt nicht die gleichen Rechte hätten wie Männer. Wäre es dann trotzdem 'ne Demokratie, wenn die Männer, also, zusammen entscheiden können?“556

553 Vgl. Kapitel III.3.2 dieser Studie.

554 „Was sich vielleicht positiv entwickeln kann, oder... ja, oder was generell vielleicht schon 'ne positive Entwicklung ist, die man in den letzten - bestimmt schon Minimum - 50 Jahren oder so hier feststellen kann, ist, dass die, äh, zunehmende, ähm, Pluralisierung der Gesellschaft, indem immer mehr Gesellschaftsteile - also nicht nur die weißen Männer -, äh, an der Gesellschaft und an den Medien teilnehmen, sondern immer mehr Leute. Dass damit auch, ähm, ja, weiß nicht: gesellschaftliche Fragen gestellt werden, die vielleicht früher nicht gestellt wurden. Wenn wir diese Entwicklung weiter [...] beibehalten können, kommen wir vielleicht in 'ne Gesellschaft, die irgendwie fairer für alle ist, so." Transkript der 7. Fokusgruppe, S. 75, Z. 2381-2391 (Herv. i. O.) 
„Ist eigentlich 'ne Technokratie... Würd' man das als Demokratie immer noch beschreiben?" ${ }^{557}$

„Darf ich kurz was fragen? Wäre 'ne Volksabstimmung, jetzt ganz banal gesehen, weil, mit Politik, also, beschäftige ich mich gar nicht -... Wäre 'ne Volksabstimmung denn irgendwie das Vorzeige-Objekt der Demokratie? ${ }^{\text {‘58 }}$

Erkennbar gibt es einen großen Unterschied zwischen jenen, die nach einem statischen Prototypen eines demokratischen Systems suchen, um an ihm alle konkreten Ausprägungen messen zu können, und jenen, die die Demokratie als dynamische Kategorie fassen, die sich durch das Zutun geschichtlicher und menschlicher Praxis weiterentwickelt, ja eigentlich erst noch verwirklicht. Letztere verweisen in den beiden Frankfurter Fokusgruppen insbesondere auf Erkenntnishürden, die aus einer spezifisch deutschen Einengung auf das liberale Demokratieverständnis resultieren; republikanische Ideen wie die kommunale Dezentralisierung von Entscheidungsprozessen ${ }^{559}$ oder aber die ernsthafte Reflexion materieller Voraussetzungen (wie soziale Angleichung, Einkommenssicherheit und verfügbare Freizeit) der Fähigkeit, die verfassungsmäßig verbürgten liberalen Teilhaberechte überhaupt wahrzunehmen, ${ }^{560}$ würden so derzeit strukturell ausgeklammert.

Nach der gemeinsamen Klärung der begrifflichen und institutionellen Faktoren pflegen sich die Gespräche Reflexionen über die mentalen Voraussetzungen von Bürgern in einer Demokratie zuzuwenden. Hier wird klar, dass die Studierenden gemäß ihrer Konzeption vom „kompetenten“ Bürger ${ }^{561}$ eine spezifische innere Haltung und Lebensweise von ihren Mitmenschen fordern, die sich nicht nur in der Wertschätzung des politischen Systems ausdrücken soll, sondern sich darüber hinaus auf ein robustes Wertefundament stützt und sich gegebenenfalls in politische Engagementbereitschaft übersetzen lässt. So heißt es: „Demokratie ist ja mehr als das politische System“562 ${ }^{\text {, }}$, sie sei auch ein Set von praktischen Fähigkeiten und „sozialen Kompetenzen“ wie „Solidarität oder Teamgeist" und eine Sozialmoral des Miteinanders; diese „Grundsäulen der Demokratie“ erlerne man etwa im „Mannschaftssport“ oder „im Jugendorchester“. ${ }^{563}$ Das Leben in der Demokratie erschöpfe sich nur im Wahlakt, dies sei „nicht das, was die Demokratie am wesentlichsten ausmacht“; vielmehr gehe es darum: „Wie [...] werden

557 Transkript der 6. Fokusgruppe, S. 80, Z. 2544.

558 Transkript der 3. Fokusgruppe, S. 49, Z. 1509-1511.

559 „Aber was mich da immer fasziniert [hat], als ich das Buch [von Alexis de Tocqueville über die amerikanische Demokratie, J. S.] gelesen hab', ist, dass wir, wenn wir von Demokratie sprechen, immer eher von dieser liberalen Demokratie sprechen, und selten zum Beispiel von dieser republikanischen. Also die Leute finden sich zusammen und müssen jetzt irgendwie 'rausfinden, wie man es organisieren soll. [...] Wir müssen uns als Kollektive Leute [suchen], die dann auch wirklich für uns sprechen und unsere Interessen vertreten, und nicht nur irgendwelche abstrakten Wahlprogramme, et cetera, ja. Und das ist so für mich das, was Demokratie und Bildung miteinander dann auch wieder fusionieren kann, wo die Menschen nämlich dann diesen Diskurs suchen [...]" Transkript der 6. Fokusgruppe, S. 51, Z. 1609-1629 (Herv. i. O.)

560 Vgl. etwa Transkript der 6. Fokusgruppe, S. 88, Z. 2810-2814; Transkript der 7. Fokusgruppe, S. 38 , Z. 1205-1212, S. 39f., Z. 1241-1250 und S. 59, Z. 1871-1875.

561 Vgl. oben, Kapitel III.3.2 dieser Studie.

562 Transkript der 3. Fokusgruppe, S. 55f., Z. 1703.

563 Transkript der 3. Fokusgruppe, S. 1716-1735. 
bestimmte Dinge wertgeschätzt, wie werden bestimmte Dinge entschieden oder nicht entschieden? Vermittelte Werte ${ }^{\text {“564 }}$ - wobei Vermittlung auch bedeuteten kann, dass „Grundwerte [...] einer Demokratie“ ohnehin durch die Vergesellschaftung in demokratischen Systemen von Klein auf strukturell ansozialisiert werden. ${ }^{565}$ Viele wünschen sich insbesondere eine stärkere (Selbst-)Verpflichtung zur politischen und zivilgesellschaftlichen Aktivität, begrüßen das persönliche Gefordert-sein:

„Ich finde [...], dass Demokratie zu selbstverständlich ist heutzutage, und es deswegen so wenig Leute gibt, die tatsächlich aktiv dafür kämpfen! Demokratie ist nur lebendig und Menschenrechte und viele Werte, die wir vertreten [...], wenn wir sie aktiv leben und aktiv dafür kämpfen! ${ }^{4566}$

Dabei scheinen den Studierenden immer wieder auch kollektivierende und „identitätsstiftende" Erfahrungen zu fehlen, wie eine Teilnehmerin im Rückblick auf die letzte Stimmabgabe beinahe sehnend ventiliert. ${ }^{567}$ Zur gelingenden demokratischen Praxis zählt es für sie daher schon, wenn in einer besonders kontroversen Wohngemeinschaft ohne Zwang zum Konsens „dann auch Meinungen einfach nur mal ausgetauscht“ werden, „man dann provoziert“ werde; „sehr wichtig“ sei das insbesondere, „um sich seiner eigenen Haltung nochmal so'n bisschen bewusster zu werden. ${ }^{\text {"568 }}$ Zur notwendigen Bedingung eines funktionierenden demokratischen Miteinanders erklären sie insbesondere die Pflicht, der Demokratie als Staats- und Gesellschaftsform innigen Respekt, ja tiefempfundene Dankbarkeit entgegenzubringen, sie zu „schätzen“. Geschichtliche Zusammenhänge werden selektiv aufgegriffen, um dieser (Selbst-)Ermahnung die nötige Dignität zu verleihen: ${ }^{569}$

„B5: [...] Demokratie ist halt total wichtig, und das funktioniert halt nur, wenn da... Ich meine, man kann sich halt nicht beschweren, wenn man halt auch nicht wählt, so. [...] B6: Ja, weil es fair ist. Aber so wie in Russland, zum Beispiel... Da gibt's kein Parlament. [...] B1: ]a, genau, deswegen müssen wir das auch grad' so schätzen, dass wir auch diese eine Stimme haben [...] B2: Deswegen ist politische Bildung ja auch so wichtig, und

564 Transkript der 5. Fokusgruppe, S. 50f., Z. 1541-1555 (Herv. i. O.)

565 Transkript der 3. Fokusgruppe, S. 58, Z. 1785-1787.

566 Transkript der 3. Fokusgruppe, S. 61, Z. 1875-1878 (Herv. i. O.)

567 „Was mir gerade noch eingefallen ist zu Demokratie, war: Dieses Gefühl, als ich das letzte Mal wählen war, und da waren ganz viele unterschiedliche Leute - da war 'ne junge Mutter mit dem Kind, ältere Leute, und so weiter -... So 'n Cemeinschaftsgefühl, was Verbindendes, was, äh, auch irgendwie Identitätsstiftendes, was... Weiß ich nicht, was macht uns eigentlich aus als Demokratie, als Deutschland, als Gruppe? Ja, das... Ja, wenn wir jetzt Anarchie... Dann hätten wir das nicht, so 'n bisschen. Und ich find' dieses identitätsstiftende Moment [...] wichtig für mich selber, irgendwie, um wieder das ganz..., also um mich mit den Leuten, die um mich 'rum sind, die da in Beziehung zu sehen, so 'n bisschen, und auch mit diesem... dieser Regierung, diesem hohen Ding, da, Politik, was auch immer, was so weit weg ist. [...] Ich muss in 'ne aktivere Rolle gezogen werden als Bürger, damit das irgendwie... damit ich mir der Sache... dieser Rolle auch bewusst bin, so 'n bisschen." Transkript der 5. Fokusgruppe, S. 61, Z. 1876-1887 (Herv. i. O.)

568 Transkript der 5. Fokusgruppe, S. 44, Z. 1340-1343.

569 Die Suggestion von historischem Bewusstsein scheint unter den Studierenden überhaupt als ausgezeichnetes Entreebillet einer Diskussion unter verantwortungsbewussten und gebildeten Bürgern zu fungieren. 
deswegen mach’ ich das ja auch! [lacht] “570

„Ich glaube, die einzige Überzeugung, die man irgendwie als gemeinsames Cut irgendwie braucht, ist, dass wir Demokratie brauchen. “571

„Das ist für mich schon in Deutschland definiert, irgendwie, als: ,sollte eine Musterdemokratie sein. Äh, Rechtsstaatlichkeit, die historische Verantwortung aus dem NS-Regime $[. . .]^{4572}$

„B6: Ja, es hat ja in Deutschland irgendwie 100 Jahre gedauert, bis die Demokratie eingeführt wurde. Das muss man ja irgendwie würdigen. [...] Es wird ja darum auch gekämpft, in Syrien oder sonstwo, dass Demokratie eingeführt wird. Deswegen sollte man das wirklich zu schätzen wissen, dass man so was hat. [...] B2: Wir leben in der Demokratie, aber schätzen das irgendwie nicht richtig. B1: Cenau. [...] Man will's haben, gleichzeitig weiß man's nicht so richtig zu schätzen, nimmt das so 'n bisschen für selbstverständlich hin, obwohl wir das Land sind, was es wahrscheinlich am wenigsten als selbstverständlich ansehen sollte. ${ }^{\text {(573 }}$

Erleichtert merkt eine Fokusgruppenteilnehmerin angesichts all dieser anspruchsvollen Anforderungen an - und darin die faktische, selten eingestandene Distanz zum demokratischen Prozess im engeren Sinne, d. h. dem parlamentarischen zu spüren -, „dass man froh sein kann, dass es auch Leute gibt, die sich dafür engagieren oder die da sind, um Meinungen zu vertreten, durchzusetzen, und auch rechtlich irgendwie zu vollziehen“574, also dass Menschen den Beruf des Politikers tatsächlich ergreifen, um die an ihrem eigenen Kompetenzanspruch versagenden Bürger zu entlasten. Auffällig ist im Übrigen, dass die Notwendigkeit, integrativ und demokratiestabilisierend wirkende Werte zu inkorporieren, von den Studierenden insgesamt häufiger programmatisch deklamiert wird, als dass sie konkrete Werte benennen können. Einige berufen sich auf abstrakte Bestimmungen wie „zusammen [...] entscheiden“ oder „miteinander zu leben“ ${ }^{475}$ oder „[d]ie Anforderung, aktiv mitzugestalten und Verantwortung zu tragen“ sowie „Diversität und Differenzen auszuhalten“ ${ }^{456}$ oder auf „das Wissen, woran ich partizipieren kann, Delegation, Verantwortung und Vertrauen“577 (sämtlich Bestimmungen, die je nach Kontext auch außerhalb von demokratischen Staatsformen vorstellbar sind); vereinzelt auch auf „Menschenrechte “578, „Gleichberechtigung“ bzw. „Chancengleichheit“579 oder „Freiheit ${ }^{\text {“580 }}$. Letztlich aber werden auch diese konkreten Bezüge mehr zaghaft als entschlossen vorgetragen. In manchen Fokusgruppen wurde daher

570 Transkript der 4. Fokusgruppe, S. 37, Z. 1159-1176 (Herv. i. O.)

571 Transkript der 7. Fokusgruppe, S. 58, Z. 1827-1828 (Herv. i. O.)

572 Transkript der 1. Fokusgruppe, S. 39, Z. 1205-1209.

573 Transkript der 1. Fokusgruppe, S. 44f., Z. 1358-1375 (Herv. i. O.)

574 Transkript der 4. Fokusgruppe, S. 40, Z. 1259-1261.

575 Transkript der 3. Fokusgruppe, S. 58, Z. 1786-1787.

576 Transkript der 5. Fokusgruppe, S. 50, Z. 1530-1532.

577 Transkript der 6. Fokusgruppe, S. 54, Z. 1711-1712 (Herv. i. O.)

578 Transkript der 1. Fokusgruppe, S. 46, Z. 1414; Transkript der 3. Fokusgruppe, S. 61, Z. 1877; Transkript der 7. Fokusgruppe, S. 58, Z. 1846 und 1849.

579 Transkript der 1. Fokusgruppe, S. 46, Z. 1403; Transkript der 4. Fokusgruppe, S. 40, Z. 1256-1257; Transkript der 7. Fokusgruppe, S. 62, Z. 1973.

580 Transkript der 1. Fokusgruppe, S. 47, Z. 1441; Transkript der 4. Fokusgruppe, S. 40, Z. 1250; Transkript der 5. Fokusgruppe, S. 49, Z. 1501-1504. 
gezielt versucht, eine Diskussion über den äußerst variabel interpretierbaren Wert des „Gemeinwohls“ auszulösen, um zu konkreteren Vorstellungen zu gelangen. Doch auch das führte eher zu Distanzierungen und Konfusionen als zu einer Klärung der konkreten mentalen Voraussetzung demokratisch vergesellschafteter Bürger. Die Studierenden können mit dem Konzept des Gemeinwohls schlicht nichts anfangen. Man traut Begriffen nicht recht, die auf lokale wie internationale Fragen, auf ökonomische oder moralische Themen applizierbar sind, ,wie auch immer man das definieren möchte“ ${ }^{481}$; schon gar nicht ist jemand bereit, die Möglichkeit eines volonté générale Rousseau'scher Manier beziehungsweise eines objektiven Interesses marxistischer Provenienz einzuräumen und dafür Einschnitte im Bereich individueller Freiheiten hinzunehmen. Das ist den sporadischen Einlassungen auf den Gemeinwohlbegriff sowie entsprechenden Rückfragen anzumerken:

„Das Cemeinwohl... [Damit] ist ja gemeint, dass ich wählen kann. Auch wenn man Wahlen hat, dann schaut man ja erst auf der Mikro-Ebene: Was ist am besten für mich?' Das heißt, man schaut auf sein eigenes Wohl. [...] Und das Gemeinwohl, das könnt', glaube ich... das würde man eher, sozusagen, auf der Makro-Ebene festlegen können. Aber die Frage ist: Wer legt das fest? Weil, das wär' dann auch wieder so'n bisschen Cewalt, irgendwie. Also ich find', das Cemeinwohl festzulegen, ist sehr schwierig. “582

„I: Ist das Konzept des Cemeinwohls in euren Augen wichtig? B4: Also sprich: dass es allen gut geht, oder was? [lacht] [...] B6: So wie es gerade ist, oder wie der Wunschgedanke ist? [...] B4: Geht es da auch darum, dass es der ganzen Cemeinschaft gut geht $[\ldots]$ [.. ${ }^{\circ 83}$

„So Grundbedürfnisse, die sollten irgendwie abgedeckt sein. Aber ich finde, alles, was darüber hinausgeht, ist extrem schwer, dass [...] eine Person oder eine Partei dann: ,So, das ist jetzt das, was die Mehrheit will!' Weil, dafür sind die Menschen einfach viel zu individuell, als dass man jetzt entscheiden könnte, was die Mehrheit und ich wollen. ${ }^{4584}$

Eine Studentin bringt, vermutlich unter Rücksicht auf die auch anderen dräuenden potenziellen Zwänge von Kollektivierungsimperativen, dezidiert „Freiheit“ gegen „Gemeinwohl“ in Stellung. ${ }^{585}$ Überhaupt wird einzelnen eher institutionalistisch Denkenden beim Rekurs auf Werte als demokratischen Größen sichtlich unwohl. Sie wittern in der Moralisierung politischer und demokratischer Fragen, in der Scheidung von „ja“ versus „nein“ und „gut und richtig“ versus „böse“586, selbst wo sie die konstatierten Gehalte grundsätzlich unterstützen, ein Eindringen sentimentaler Engführungen und

581 Transkript der 1. Fokusgruppe, S. 47, Z. 1432-1433.

582 Transkript der 1. Fokusgruppe, S. 48, Z. 1461-1470 (Herv. i. O.)

583 Transkript der 2. Fokusgruppe, S. 46, Z. 1454-1468.

584 Transkript der 7. Fokusgruppe, S. 53, Z. 1680-1684.

585 Vgl. Transkript der 1. Fokusgruppe, S. 47, Z. 1438-1443.

586 Transkript der 5. Fokusgruppe, S. 56, Z. 1713-1714. 


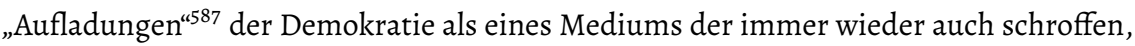
konfliktiven, institutionell gerahmten Diskussion. Eine Studentin der Politikwissenschaft und Arabistik trennt hier schon auf analytischer Ebene klar:

„Ich seh' Demokratie eher so als Struktur und nicht unbedingt als etwas, was moralisch behaftet ist. Deswegen, keine Ahnung, ist das für mich eher etwas, an dem man Staaten messen kann, ob die demokratisch sind oder nicht. Aber mit, so, moralischen Begriffen würde ich das eher nicht belegen. ${ }^{\text {“588 }}$

Jedoch gibt es nur einen einzigen Fokusgruppenteilnehmer, der mit den im Grundgesetz fixierten Persönlichkeitsrechten, insbesondere im Recht auf körperliche Unversehrtheit, einen konkreten institutionellen Faktor nennt, ohne den keine funktionsfähige Demokratie bestehen könne. ${ }^{59}$ Das Pochen auf normative Faktoren, auf die Vermittlung demokratischer Werte und demokratischer Mentalitäten im praktischen Vollzug, bleibt insgesamt hegemonial und scheint noch die Zentralität unabhängiger Institutionen, insbesondere der unabhängigen Gerichtsbarkeit, zu überflügeln. Wo die selbstläufige Vermittlungsform (Leben in der Demokratie führt zu Inkorporation demokratischer Werte und Haltungen) nicht auszureichen scheint, um gute und aufgeschlossene Demokraten hervorzubringen - hier wird ein zaghafter Blick auf bildungsferne und sozioökonomisch schlechter gestellte Schichten gewagt -, bedürfe es der gezielten Erziehung zur demokratischen Mentalität ab dem frühen Kindesalter. Wie weiter oben bereits deutlich wurde ${ }^{590}$ ist politische Bildung inklusive Konflikt- und Medienkompetenz für die Studierenden daher ein unerlässliches Integrationsmedium bei Defiziten der Internalisierung einer demokratischen Mentalität:

„Demokratie zu lernen, fängt schon [...] vor der Kita an. Also es gibt in immer mehr Kindertagesstätten Kita-Parlamente [allgemeines Lachen] [...] wo die gefragt werden, ob es Pommes oder Salzkartoffeln zum Mittagessen geben soll. Und so fängt [...] für mich Demokratie [an]. ${ }^{4591}$

„[...] wenn es um Diskriminierung geht, halt generell Rechtspopulismus oder so etwas. Da ist Bildungsarbeit für mich schon auch sehr wichtig. [...] Die Welt [...] wird ja immer offener, und das, find' ich, gehört halt irgendwie auch dazu, dass man das Kindern auch schon vermittelt, dass man halt irgendwie, ähm... weiß nicht, was es alles für Möglichkeiten gibt und was die Welt alles zu bieten hat, und wo es vielleicht auch Probleme gibt. Und dass wir vielleicht aus Industrieländern auch unsere Kapazitäten nutzen könnten, um vielleicht daran was zu verbessern. Also ich finde halt so 'n bisschen, dieses Gutmenschentum kann man ja auch durch Bildung echt weiter verbreiten." ${ }^{\text {" } 92}$

„Also, womit jetzt auch'n Straßenfeger mit Sicherheit was anfangen kann, wären ja

587 „Die Frage ist eben, ob man's eben noch mit so Werten auflädt, also... Ja, Chancengleichheit wäre dann schon die nächste... Beispielsweise Recht auf Nonkonformität. Solche Sachen." Transkript der 1. Fokusgruppe, S. 46, Z. 1400-1404.

588 Transkript der 1. Fokusgruppe, S. 40, Z. 1211-1214 (Herv. i. O.)

589 Vgl. Transkript der 6. Fokusgruppe, S. 83, Z. 2627-2642.

590 Vgl. Kapitel III.3.2 dieser Studie.

591 Transkript der 3. Fokusgruppe, S. 56, Z. 1707- (Herv. i. O.)

592 Transkript der 4. Fokusgruppe, S. 24f., Z. 763-773 (Herv. i. O.) 
halt so Grundzüge von Demokratiebildung oder sowas halt [...] Oder halt sowas, auch, wie, keine Ahnung, dass er vielleicht medienkritischer einschätzen kann [...], also vielleicht weiß, dass nicht alles, was auf Facebook steht, [...] stimmt, oder so.“593

Gerade auch Herausforderungen wie die AfD müsse man als Chance begreifen, „Leuten Demokratie wieder oder mehr bei[zu]bringen“594 - worauf ein anderer Fokusgruppenteilnehmer schnaubend entgegnet: „Ich hab' schon gedacht, [ironisch] Trump wär' Chance genug, [allgemeines Lachen] um nochmal zu erkennen, dass bestimmte Werte wichtig sind. ${ }^{595}$ Der Gedanke, dass gerade die Aktivitäten neuer rechter Parteien eben jenes leidenschaftlich geforderte Kriterium der persönlichen Einsatzbereitschaft erfüllen, wird vehement abgewehrt. So verpufft auch der singuläre Einwand, dass Demokratiepädagogik eben auch „immer mehr Demokraten fördert“ und damit „immer mehr Hemmer“, ja dass man schließlich bedenklicherweise „nur noch Kosmopoliten [...] großziehen möchte“596, ohne Resonanz.

Die Studierenden loben an der Demokratie, dass die Probleme, Sorgen und Bedürfnisse der der in ihr lebenden Menschen Gehör fänden ${ }^{597}$, dass sie in vergleichsweise kurzen Zeiträumen auf veränderte Präferenzen $\mathrm{zu}$ reagieren vermöge ${ }^{598}$, dass sie das Potenzial des vernunftorientierten Austauschs divergierender Ansprüche und Forderungen berge ${ }^{599}$, dass sie veränderungsfähig bleibe, indem sie „extreme“ Impulse durch ihre vielfältigen institutionellen Transmissionsriemen potenziell integriere ${ }^{600}$, und dass sie sich in Deutschland im Fall des Scheiterns dieser Integration durch juristische Mittel und polizeiliche Vollzugsorgane, etwa durch das scharfe Schwert des Parteiverbots, im Rahmen einer Eskalationsstufenlogik zur Wehr setzen könne, wenn der volksseitige Einspruch einmal über die Stränge schlägt. ${ }^{601}$ Nachteile oder auch strukturelle Probleme - ein offensichtlich ungewohnter Denkgegenstand ${ }^{602}$ - sehen sie darin, dass das Instrument der Interessenrepräsentation durch Parteien und Politiker, die der eigenen Alltagsrealität fern erscheinen, zu Bequemlichkeit und Passivität und bisweilen auch Überforderung aufseiten der einzelnen Bürger führt, ja zur tiefen Empfindung persönlicher Ohnmacht, wodurch sich die Demokratie immer auch selbst entde-

593 Transkript der 7. Fokusgruppe, S. 662-666.

594 Transkript der 3. Fokusgruppe, S. 63, Z. 1943.

595 Transkript der 3. Fokusgruppe, S. 63, Z. 1948-1949 (Herv. i. O.)

596 Transkript der 3. Fokusgruppe, S. 58f., Z. 1789-1801.

597 Vgl. Transkript der 2. Fokusgruppe, S. 44, Z. 1393-1397, Transkript der 4. Fokusgruppe, S. 40, Z. 12501252; Transkript der 5. Fokusgruppe, S. 49, Z. 1499-1508; Transkript der 7. Fokusgruppe, S. 52, Z. 1647-1649;

598 Vgl. Transkript der 2. Fokusgruppe, S. 43, Z. 1347-1349; Transkript der 4. Fokusgruppe, S. 40, Z. 12681274.

599 Vgl. Transkript der 6. Fokusgruppe, S. 60, Z. 1894-1906.

600 Vgl. Transkript der 1. Fokusgruppe, S. 51, Z. 1574-1579; Transkript der 4. Fokusgruppe, S. 44, Z. 13871395; Transkript der 5. Fokusgruppe, S. 60, Z. 1844-1858; Transkript der 6. Fokusgruppe, S. 56, Z. 1775-1789; Transkript der 7. Fokusgruppe, S. 54, Z. 1708-1713.

601 Vgl. Transkript der 1. Fokusgruppe, S. 51, Z. 1559-1564; Transkript der 2. Fokusgruppe, S. 50, Z. 15911594.

602 „Ich glaub', das ist was, worüber man nicht so oft nachdenkt.“ Transkript der 1. Fokusgruppe, S. 50, Z. 1544. 
mokratisiere, ${ }^{603}$ ferner in der Diskurshoheit und Dominanz einzelner Machtgruppen und Netzwerke ${ }^{604}$, in der Schwerfälligkeit, Mühsamkeit und Ineffizienz von Entscheidungsprozessen, welche mit dem Tempo globaler Entwicklungen kaum noch schritthielten $^{605}$, in der Beteiligung politisch uninformierter und unkundiger (insbesondere Wahlprogramme ignorierende), manipulierbarer oder radikaler Kräfte ${ }^{606}$ - „es können auch Dumme wählen“607 - , in einem schlussendlichen Verschwinden letztgültiger Verantwortlichkeiten durch die Fluktuation des politischen Personals und durch die Freiheit politischer Mandatsträger, zuvor gegebene Wahlversprechen nicht einzuhalten, ${ }^{608}$ oder aber auch in einer Unfähigkeit der unterschiedlichen Milieus und Lebensstilpräferenzen, miteinander zu debattieren. ${ }^{609}$ Ein Fokusgruppenteilnehmer deutet darüber hinaus Verschwörungskonstrukte im Sinne eines deep state an und spricht von einer „große[n] Maschine“, die hinter der demokratischen Fassade arbeite. ${ }^{610}$ Dass man als Bürger in der Demokratie von der tatsächlichen praktischen Teilhabe weitgehend abgeschnitten sei - und dies von der Mehrheit auch so hingenommen werde -, lässt einen Jura-Studenten an die Tradition der einstigen studentisch-korporativen Hochschulreformbewegung erinnern:

„Im PoWi-Unterricht zum Beispiel [...] erfährt [man] eigentlich nur instrumentell, wie die Demokratie hier [...] verwaltet wird. Aber so wirklich, wie man sich irgendwie selber verwalten kann, man sich selber... wie man selber irgendwie Demokratie... sich Demokratie gestalten kann, sich demokratisch einbringen kann, wird wenig beachtet, ne? [...] Und ich glaub', es ist einfach ein Demokratiebild, das in letzter Zeit sich irgendwie entwickelt hat. Weil, früher gab's ja zum Beispiel diesen Anspruch, dass studentische Selbstverwaltung zu Demokratisierung führt und zum demokratischen Menschen. “611

603 Vgl. Transkript der 3. Fokusgruppe, S. 50f., Z. 1535-1553 und S. 57, Z. 1766-1780; Transkript der 5. Fokusgruppe, S. 50, Z. 1530-1534; Transkript der 6. Fokusgruppe, S. 54f., Z. 1711- 1729; Transkript der 7. Fokusgruppe, S. 37, Z. 1168-1183 und S. 56f., Z. 1775-1821.

604 Vgl. Transkript der 6. Fokusgruppe, S. 71, Z. 2251-2261; Transkript der 7. Fokusgruppe, S. 53, Z. 16731677.

605 Vgl. Transkript der 1. Fokusgruppe, S. 50, Z. 1524-1532; Transkript der 2. Fokusgruppe, S. 43, Z. 13511354; Transkript der 7. Fokusgruppe, S. 52, Z. 1653-1657.

606 Vgl. Transkript der 1. Fokusgruppe, S. 42, Z. 1288-1294; Transkript der 2. Fokusgruppe, S. 44f., Z. 1405-1413; Transkript der 3. Fokusgruppe, S. 50, Z. 1523-1525; Transkript der 4. Fokusgruppe, S. 41, Z. 1305-1306; Transkript der 5. Fokusgruppe, S. 53, Z. 1615-1619; Transkript der 6. Fokusgruppe, S. 57, Z. 1808-1814; Transkript der 7. Fokusgruppe, S. 66f., Z. 2103-2115.

607 Transkript der 2. Fokusgruppe, S. 45, Z. 1440.

608 Vgl. Transkript der 4. Fokusgruppe, S. 45, Z. 1409-1419; Transkript der 6. Fokusgruppe, S. 77f., Z. 2453-2490.

609 Vgl. Transkript der 1. Fokusgruppe, S. 43, Z. 1319-1332; Transkript der 3. Fokusgruppe, S. 58f., Z. 17831803; Transkript der 5. Fokusgruppe, S. 55f., Z. 1695-1725; Transkript der 6. Fokusgruppe, S. 64 f., Z. 2038-2057; Transkript der 7. Fokusgruppe, S. 33, Z. 1036-1042.

610 "Meiner Meinung nach ist Politik... Was wir außen sehen, ist nicht das, was die eigentliche große Maschine dahinter ist. Und da ist es so fernab, was zu beeinflussen, was, äh, [an] Meinungsbild in der Mehrheit geht, was da für'ne Maschinerie im Hintergrund abläuft - Lobbyismus und Medien und Vermittlung von Informationen und so." Transkript der 7. Fokusgruppe, S. 36f., Z. 1150-1156. 
Alternativen zum aktuellen demokratischen System werden kaum erwogen, abgesehen vom bereits zitierten einsamen Republikaner im Sample. ${ }^{612}$ Auch plebiszitäre Formen der Entscheidungsfindung fordern die Studierenden nicht ein; Volksentscheiden stehen sie aufgrund der befürchteten Gefahr politischer Emotionalisierung und aufgrund des angenommenen allgemeinen Defizits an politischer Bildung, wie oben ausgeführt ${ }^{613}$, grundsätzlich kritisch gegenüber. Trotz aller Zweifel an der (einer technizistischen Vokabel der quantitativen politischen Kulturforschung folgend) Demokratieperfomanz im Einzelnen trifft man sich schlussendlich insgesamt in der gemeinsamen Überzeugung, die Demokratie sei, - auch aufgrund ihrer inhärenten Weiterentwicklungsdynamiken -, wenn auch nicht frei von Mängeln, so doch die bestmögliche politische Ordnung:

„Und wir sagen immer, wie dieses Churchill-Zitat, irgendwie: Demokratie ist die schlimmste Beruf-... äh, Gesellschaftsform, aber die einzige oder so was - Ich kann's jetzt nicht genau. Jedenfalls geht's so in die Richtung, dass: Es gibt keine bessere Gesellschaftsform momentan.“614

„Ich mein', Demokratie ist halt nicht perfekt, aber wir haben mal in Politik so'n Zitat... Also: ,Demokratie ist irgendwie 'ne schlechte Staatsform, es ist die beste, die wir haben', oder so. Also, da gibt's halt Nachteile, aber ich denke immer, dieser Vorteil, dass das Volk nicht übergangen wird, sozusagen, überwiegt halt die Nachteile.“615

„[...] ich glaub', 'ne bessere Alternative als die Demokratie ist jetzt so schnell nicht zu finden, ähm, zumindest im Bereich der Fairness nicht.“616

„Jede Staatsform hat halt auch so ihre... ihre negativen Seiten, aber die Demokratie ist, glaub' ich, schon, ja, eine der besten. “617

„Der Weg, sich immer näher an diese Demokratie anzunähern... find' ich persönlich gut. Schon fast das Optimalste. “618

Dass im Grunde niemand an der grundsätzlichen Legitimität des demokratischen Herrschaftssystems zweifelt, wird auch in der einzigen Situation deutlich, in der eine außerhalb Europas geborene und aufgewachsene Studentin, die bekundet, auch eine Diktatur wäre ihr recht, wenn sich nur alle einig seien ${ }^{619}$, mit schweigsamer Irritation bedacht wird. Selbst eine Studentin der Medizin, die Sympathie für „anarchistische Ideen“ bekundet, kann sich den Vorzügen der hier klug integrierten Machtkontrollmechanismen nicht entziehen. ${ }^{620}$ Es gibt schlicht keine Alternative, auch wenn die im Sample vertrete-

612 „Also, ich find' diese parlamentarische Organisation problematisch! Ich hab' nichts gegen Demokratie, aber mir ist diese parlamentarische Organisaton zuwider, weil die einfach zu wenig vor Ort [...] agiert. [...] Also eigentlich bin ich halt in dem Sinne immer für Dezentralität, weil das am... das stabilisierendste Prinzip, irgendwo, ist, ja." Transkript der 6. Fokusgruppe, S. 82, Z. 2598-2604 (Herv. i. O.)

613 Vgl. Kapitel III.3.2 dieser Studie.

614 Transkript der 3. Fokusgruppe, S. 58, Z. 1790-1793.

615 Transkript der 2. Fokusgruppe, S. 44, Z. 1388-1391.

616 Transkript der 3. Fokusgruppe, S. 58, Z. 1777-1778.

617 Transkript der 4. Fokusgruppe, S. 44, Z. 1393-1395.

618 Transkript der 5. Fokusgruppe, S. 60, Z. 1836-1837 (Herv. i. O.)

619 „Von mir aus ist es egal, [...] ob Demokratie oder Diktatur in der Cesellschaft besteht. Hauptsache, alle denken gleich." Transkript der 4. Fokusgruppe, S. 56, Z. 1767-1768 (Herv. i. O.)

620 Vgl. Transkript der 5. Fokusgruppe, S. 60, Z. 1844-1858. 
nen Studierenden naturwissenschaftlicher Fächer gewisse Sympathien für technokratische Ordnungsvorstellungen zu hegen scheinen. Ein Grund für die geringe Beschäftigung mit möglichen Alternativen zur oder Weiterentwicklungsformen von Demokratie mag darin liegen, dass die Studierenden die parlamentarische Bundesrepublik im Grunde als unangefochten betrachten und schon deswegen kaum Anlass für substanzielle Zweifel sehen. Nur sechs von 44 Personen im Sample machen aktuell Gefährdungslagen für den Fortbestand der demokratischen Ordnung aus. Mäßige Sorgen bereitet ihnen die Möglichkeit eines „Kippens“ von „bestimmte[n] latente[n] Stimmungsprozesse[n]", etwa in Gestalt eines wachsenden Einflusses von Rechtsaußen-Parteien wie der AfD, den die Demokratie aufgrund zu geringer Resistenzkräfte nicht mehr „aushält" ${ }^{\text {‘621 }}$; komplementär dazu die Befürchtung einer Aushöhlung der Demokratie durch den diskursiven Ausschluss ebendieser Kräfte, ${ }^{622}$ aber auch eine im Gegenteil durch politischen Stillstand bzw. ausbleibenden politischen Wettbewerb der etablierten Parteien hervorgerufene „Entdemokratisierung der Gesellschaft“623, ferner sozioökonomische Ungleichheit ${ }^{624}$ oder die Überforderung der Bürger durch die Diversität von politischen Wahlmöglichkeiten. ${ }^{625}$

In den Ausführungen zum Demokratieverständnis und $\mathrm{zu}$ den erforderlichen demokratischen Werten zeigt sich, dass die Studierenden häufig die Demokratie als durch einen Rechtsstaat gestützte Regierungsform mit Liberalismus, Pluralismus und einer allgemeinen Zivilität gesellschaftlicher Diskurs-, Verkehrs- und Umgangsformen gleichsetzen. Einer einzigen Studentin fällt dieser im Grunde sentimentale Vorgang beiläufig auf:

„Ich glaub', Pressefreiheit und Versammlungsfreiheit - Das ginge alles schon... Wenn man eine Demokratie hätte, bräuchte man das, glaube ich, nicht zwangsläufig ,demokratisch' irgendwie, so die Strukturen der Wahl und so weiter zu haben.“626

Da sich jedoch die moralisierende und gesinnungsethische Deutungsvariante Demokratie $=$ Liberalismus/Zivilität in den Fokusgruppen - und im Einklang mit tradierten Gehalten deutscher politischer Bildung ${ }^{627}$ - stets durchsetzt, sind Verengungen des tatsächlich akzeptierten Konfliktspielraums zulasten nicht-kosmopolitischer Kräfte, die die (links-)liberalen „Grenzen der Gemeinschaft“628 markieren, die kaum zu vermeidende Konsequenz. Das wird an praktischen Handlungsproblemen deutlich.

Konfrontiert mit den Wahlerfolgen der AfD sowie mit der wachsenden Präsenz von AfD-Politikern in den Parlamenten, herrscht weitgehend Ratlosigkeit. Die unmittelbare Reaktion auf diese Frage besteht in geschürzten Lippen, Stirnrunzeln, kritischer Di-

621 Transkript der 1. Fokusgruppe, S. 40, Z. 1221-1228. Vgl. übereinstimmend Transkript der 3. Fokusgruppe, S. 61, Z. 1871-1879.

622 Vgl. Transkript der 1. Fokusgruppe, S. 41, Z. 1250-1254.

623 Transkript der 2. Fokusgruppe, S. 33, Z. 1027-1029.

624 Transkript der 1. Fokusgruppe, S. 39, Z. 1208-1209.

625 Transkript der 4. Fokusgruppe, S. 45, Z. 1429-1431.

626 Transkript der 1. Fokusgruppe, S. 46, Z. 1416-1418.

627 Vgl. Kapitel III.3.2 dieser Studie.

628 Plessner, Helmuth: Grenzen der Gemeinschaft [1924]. Eine Kritik des sozialen Radikalismus, Frankfurt a.M. 2002. 
stanz. Während manche sich vorsorglich für unkundig und uninteressiert erklären ${ }^{629}$, machen andere ihrer kategorischen Ablehnung der Partei mitsamt ihres unreputierlichen Personals Luft. Aus den Antworten sprechen unverarbeitete Überraschtheit und der Unwillen, die veränderten Kräfteverhältnisse zu akzeptieren:

„I: Was haltet ihr denn davon, dass die AfD im Bundestag sitzt? B2: Nichts. “630 „B2: Scheiße. B4: Scheiße. [lacht] “631

„B3: [...] Wenn das jetzt 'ne Partei wäre, wo man sagen würde: ,Okay, die haben zwar vielleicht nicht so die Ansichten, die ich teile, aber es ist schon sinnvoll, was die da irgendwie treiben!', dann ist es ja noch was Anderes. Aber es ist halt irgendwie auch so ' $n$ bisschen so 'n Deppenverein, so ' $n$ bisschen. [lacht, allgemeine Erheiterung] So. B5: Aus meiner Sicht intelligente Deppen, so, ne. [lacht] “632

„Von den Einzelpersonen [her], die da so sind und so, denk' ich mir nur so: ,Wo kommt ihr überhaupt her? '“633

„Und wenn dann die AfD sich da hinstellt und dann, äh, wirklich fast nur mit negativen Dingen versucht, Leute zu gewinnen, dann ist es nochmal was ganz Anderes und nochmal viel schlimmer, auch wenn Andere das vielleicht schon vorher getan haben! “634

Diese heftige Ablehnung speist sich aus der Wahrnehmung, der Siegeszug der AfD signalisiere einen wachsenden Einfluss radikal rechter Kräfte in der Bundesrepublik mit ihrer Agenda des nationalen Chauvinismus, des Ethnonationalismus, der reaktionären Geschlechterbilder und ihrer Politik der sprachlichen Verrohung. ${ }^{635}$ Zudem erscheint es einigen ärgerlich oder auch "schade“, dass AfD-Politiker in den Gremien und Parlamenten die Auseinandersetzung über „die richtigen Probleme“ durch ihre Streitereien und Symbolgefechte blockierten, man somit nicht mehr „konstruktiv über Probleme

629 „B2: Ehrlich gesagt, habe ich mich nicht so mit deren Parteiprogramm auseinandergesetzt. [lacht, allgemeine Erheiterung und Zustimmung] Ich hab'... Was ich mitbekommen hab', hat mir gereicht. [...] B4: Ich kann nicht viel dazu sagen, weil, ich hab' auch nicht so nachgeguckt, was die jetzt anbieten, weil, ich [...] von vornherein mit gesagt habe... AfD, dass ich die nicht wähle." Transkript der 2. Fokusgruppe, S. 54f., Z. 1728-1735 (Herv. i. O.)

630 Transkript der 4. Fokusgruppe, S. 48, Z. 1520-1522.

631 Transkript der 7. Fokusgruppe, S. 1979-1981.

632 Transkript der 4. Fokusgruppe, S. 51, Z. 1624-1633.

633 Transkript der 5. Fokusgruppe, S. 62, Z. 1901.

634 Transkript der 7. Fokusgruppe, S. 66, Z. 2094-2097 (Herv. i. O.)

635 Vgl. Transkript der 2. Fokusgruppe, S. 53f., Z. 1687-1705; Transkript der 3. Fokusgruppe, S. 62, Z. 19011918; Transkript der 4. Fokusgruppe, S. 48f., Z. 1522-1558; Transkript der 5. Fokusgruppe, S. 62 f., Z. 1914-1925; Transkript der 6. Fokusgruppe, S. 76, Z. 2413-2429; Transkript der 7. Fokusgruppe, S. 66, Z. 2081-2099. 
reden“ könne. ${ }^{636}$ Sie sorgten für Obstruktionen in den Abläufen des demokratischen Prozesses, ja sabotierten die Gesetzgebungsmaschinerie:

„Die AfD bringt so viele Schwachsinns-... Also, tut mir leid. Also, so viele Anträge ein, die viele Menschen in Deutschland nicht unterstützen würden - sodass sich der ganze Bundestag oder die ganzen Ausschüsse mit diesen Anträgen beschäftigen müssen, was immer mehrere Stunden kostet [...] “637

Zwar könne die AfD auf „'ne gewisse Berechtigung“ pochen, im Bundestag zu sitzen, „weil sie ja dann auch demokratisch gewählt wurde.“ Störend aber sei schlicht die „nicht vorhandene Qualität" ihrer parlamentarischen Arbeit, welche faktisch auf ein Zurückdrehen gesellschaftspolitischer Fortschritte hinauslaufe: „Die bringen Probleme mit, die, glaub' ich, schon einfach behoben wurden, die bringen Debatten mit, die schon längst abgeschlossen wurden. “638 Ob die hier zitierten Redner wirklich über das für ihr harsche Urteil nötige Informationsniveau (etwa über einen Überlick sämtlicher Anträge und Anfragen der AfD im Bundestag) verfügen? Wie dem auch sei: Man könne das, „Was die da irgendwie treiben“, schlicht nicht ernst nehmen. ${ }^{639}$ Mehr noch, es habe gefährliche Auswirkungen, weil sie „eben nicht versuchen, das Problem zu beheben“, das sie sehen, „sondern da immer 'nen anderen Sündenbock finden ${ }^{4640}$ und populistisch, d. h. mithilfe von jederzeit revidierbaren Nebelkerzen und „Parolen ${ }^{\text {“641 }}$ arbeiteten. Nur ein Student im Sample widerspricht dieser Sichtweise; seiner Ansicht nach liegt das Problem gerade darin, der AfD „nie [...] wirklich 'ne Handlungsrolle zu geben, mal zu sagen: ,Ja, dann komm, hopp! Du kritisierst das, dann mach!'“642 Auf der anderen Seite aber bemühen sich die Studierenden, Vorzüge der neuartigen Situation auszumachen. Dass die Wahlerfolge der AfD eine nun offensichtlich gewordene vormalige Repräsentationslücke abdecken und damit auch das Spektrum demokratisch abgebildeter Konfliktlinien erweitern, lasse sich kaum abstreiten. Dies grundsätzlich anzuerkennen, sei ein dringend notwendiges sachliches Eingeständnis:

636 „Ich weiß nicht, was sehr schade ist, dass irgendwie die richtigen Probleme, oder da, wo ich sie sehe, in den Diskussionen und im Diskurs um das, was jetzt mehr gehen wird im Bundestag... Na, so was wie, ähm, keine Ahnung: ,Wie gehen wir mit Freihandel und Zöllen mit anderen Ländern um? Was hat das auf deren Wirtschaft für Auswirkungen, auf deren Politik?' Sodass vielleicht zum Beispiel gar nicht so viele Leute irgendwie fliegen müssen. Wir bauen voll viele Waffen, wir, weiß nicht... Alles, was wir tun, ist total schlecht für die Umwelt, was dazu führt, dass sich Wüsten vergrößern und so weiter. Und da ist das Problem, dass es irgendwie Leute gibt, die auf der Flucht sind, und das ist irgendwie im Programm der AfD - aber auch der anderen Parteien! - irgendwie nicht so richtig an der Tagesordnung. Und deshalb geht's viel um so, finde ich, um so Oberflächlichkeiten, und das ist so schade. Wenn man konstruktiv über Probleme reden würde oder schauen würde: ,Wo sind denn die eigentlichen Sprünge und Probleme?', dann könnte man so viel mehr machen und schaffen, aber..." Transkript der 2. Fokusgruppe, S. 54, Z. 1709-1721 (Herv. i. O.)

637 Transkript der 3. Fokusgruppe, S. 60, Z. 1837-1840 (Herv. i. O.)

638 Transkript der 3. Fokusgruppe, S. 61f., Z. 1886-1891 (Herv. i. O.)

639 Vgl. Transkript der 4. Fokusgruppe, S. 51, Z. 1624-1629.

640 Transkript der 7. Fokusgruppe, S. 67, Z. 2137-2138.

641 Transkript der 7. Fokusgruppe, S. 68, Z. 2145.

642 Transkript der 6. Fokusgruppe, S. 73, Z. 2333-2335 (Herv. i. O.) 


\begin{abstract}
„Aber die wurde ja sozusagen auch gewählt, also die vertreten ja sozusagen auch die Meinung von Menschen und müssen ja auch ernst genommen werden. “643

"Andererseits zeigt es halt auch, dass die Demokratie doch noch funktioniert, wenn so relativ zeitnah auch 'ne Partei - auch wenn man jetzt persönlich nicht dafür steht, ist ja vollkommen egal -, wenn sie dann einfach, sag' ich mal, vom Volk legitimiert ist, und dann letztendlich auch Teil unserer Regierung ist, auch wenn sie am Ende in der Opposition sitzt." ${ }^{\text {"644 }}$
\end{abstract}

„Also, die AfD hat 'ne gewisse Berechtigung im Bundestag, weil sie ja dann auch demokratisch gewählt wurde. ${ }^{\text {“645 }}$

„Also, ich find' es auch schon nicht..., also nicht nur 'ne schlechte Entwicklung, weil: Je mehr Parteien vertreten sind, desto mehr Meinungen sind zumindest immer im Parlament. ${ }^{\text {“646 }}$

„Also, das war 'ne Backpfeife in das Cesicht vieler Politiker, die endlich mal sehen müssen: ,Okay, wir sind nicht Hipster-Deutschland, und alles neu und schön für die oberen Zehntausend!' Deutschland besteht aus Arbeitern, aus Rentner, aus Pflegern, aus angehenden Lehrern, aus jedem, der hier lebt..., und nicht nur für die coolen Leute! ${ }^{4647}$

„Also, ich hab' die nicht gewählt, aber es ist einfach mal 'ne Schelle! Es ist so 'ne Respektschelle: ,Hört doch verdammt nochmal eurem Volk zu! Die Leute, [...] die haben Angst! ${ }^{\text {‘6 } 648}$

Und ist es nicht sogar möglich, dass diese neue weit rechte Partei zu einer allgemeinen Vitalisierung des politischen Prozesses führen könnte, ja als „extremes“ Korrektiv die etablierten Parteien aus ihrem Winterschlaf der nüchternen, aber substanzlosen und lethargischen Einigkeit holen kann? ${ }^{649}$ Dass sich durch diese neue Dynamik auch die AfD wiederum selbst domestiziert? ${ }^{650}$ Ist nicht demgemäß auch eine erfrischende, potenziell fruchtbare allgemeine Politisierung zu beobachten, eine Rückkehr der agonalen, der leidenschaftlichen und engagierten Debatte in das alltägliche Miteinander, aber auch in den Plenarsaal des Bundestags, mithin Entwicklungen, die auf den gelungenen Lackmustest einer funktionierenden und responsiven Demokratie hindeuten ${ }^{651}$ Vermisst man nicht gerade die Phase des „bipolaren Wettbewerbs“ zwischen den 1960er

643 Transkript der 1. Fokusgruppe, S. 40, Z. 1215-1219 (Herv. i. O.)

644 Transkript der 2. Fokusgruppe, S. 51, Z. 1605-1609.

645 Transkript der 3. Fokusgruppe, S. 61, Z. 1886-1887 (Herv. i. O.)

646 Transkript der 7. Fokusgruppe, S. 54, Z. 1711-1712 (Herv. i. O.)

647 Transkript der 5. Fokusgruppe, S. 63, Z. 1927-1936.

648 Transkript der 6. Fokusgruppe, S. 63, Z. 1993-1995 (Herv. i. O.)

649 Vgl. Transkript der 1. Fokusgruppe, S. 51, Z. 1574-1570; Transkript der 3. Fokusgruppe, S. 60, Z. 18351844; Transkript der 4. Fokusgruppe, S. 51, Z. 1612-1622; Transkript der 6. Fokusgruppe, S. 56, Z. 1775-1789; Transkript der 7. Fokusgruppe, S. 54, Z. 1708-1713.

650 „Und ich glaube und ich hoffe, dass sich da 'n bisschen was tut, dass die Parteien das so 'n bisschen aufgreifen, und versuchen, irgendwie da 'n bisschen, ja, ähm, dem Volk das Gefühl zu geben, dass sie das aufgefasst haben und so weiter. Und dann kann ich mir nämlich vorstellen, dass die AfD sich so 'n bisschen, so, [...] unter Zugzwang gesetzt fühlt." Transkript der 7. Fokusgruppe, S. 71f., Z. 2269-2273 (Herv. i. O.)

651 Vgl. Transkript der 1. Fokusgruppe, S. 29, Z. 886-890; Transkript der 2. Fokusgruppe, S. 51, Z. $1605-$ 1608; Transkript der 3. Fokusgruppe, S. 63, Z. 1937-1946; 
und 1990er Jahren mit ihren zwei identifizierbar gegensätzlichen und konkurrierenden politischen Angeboten ${ }^{652}$ Sensibilisiert die AfD nicht gerade für die Demokratiegefährdungen durch politische Angebote von Rechtsaußen nach dem Muster Weimars, sodass die demokratischen Kräfte wieder wachsamer würden ${ }^{653}$ Ist sie nicht ein dringend benötigter Indikator substanzieller und unbeachteter Probleme, ein Paukenschlag, der zum Aufwachen aus dem „Weiter so" motivieren sollte? Müsse man nicht viel stärker durch das dahinterliegende Problem schockiert, entsetzt, aufgeschreckt sein als durch die Partei selbst?

„Aber ich glaub' schon, dass das ein wichtiger Moment für Deutschland war, zu sehen: Es gibt Menschen, die finden das gut, und die finden vielleicht das auch gut, obwohl sie wissen, dass das eben irgendwelche Dussel sind. Und wer sind diese Menschen, warum sind diese Menschen so und warum wollen diese Menschen das, und wie kommen wir an diese Menschen 'ran, dass sie vielleicht wieder mehr in die Demokratie wollen?"654

„Ich find's auch sehr erschreckend. Also, ich hätte es auch nicht so erwartet, dass es so krass [wird]. Also, ich hab' mir schon gedacht, dass es wirklich viele Leute gibt, die irgendwie sagen, so: , Ja, okay, ich bin jetzt stinkig und böse und mach' jetzt auf einen auf Protest!', aber dass die ernsthaft das wählen, was die AfD vorschlägt und an ihrem... in ihrem Programm stehen hat, das fand ich schon sehr erschreckend! Also das hätt’ ich echt nicht gedacht, dass es so negativ wird. ${ }^{“ 655}$

Ja, das alles könnte sein, doch geschehe es schlicht auf die falsche Weise; zum richtigen Zeitpunkt, doch mit den falschen Personen und Ansichten. Zwar werden die diskursive Ausgrenzung, moralische Selbstüberhöhung und öffentliche Denunziation vonseiten der arrivierten politischen Kräfte sowie institutionelle Blockaden gegenüber AfDPolitikern bei der Aufstellung von Wahllisten oder Spitzenpersonal durchaus als ernstzunehmendes Problem erkannt, auch weil dieses Vorgehen die Viktimisierungsrhetorik der AfD erst ermögliche. ${ }^{656}$ Von der eigenen Position abrücken möchte man im Konkreten trotzdem nicht. Letztendlich können die Studierenden einfach nicht verstehen, dass Menschen allen Ernstes den Schritt zur Wahl der AfD tun. Sie kapitulieren im Grunde vor dem Versuch, die Ursachen gedanklich zu durchdringen - die Erklärungsfigur einer ungebildeten, sozial deprivierten Wählerklientel und der darauf aufsetzende Ruf nach einer aus dem reinigenden Bad der (politischen) Bildung entsteigenden Phalanx der Wahlprogramme aufmerksam lesenden Demokratieverteidiger rangieren hier wie

652 Vgl. Lehmbruch: Parteienwettbewerb im Bundesstaat, S. 31-58.

653 Vgl. Transkript der 1. Fokusgruppe, S. 52, Z. 1611-1620; Transkript der 6. Fokusgruppe, S. 71f., Z. 22682276.

654 Transkript der 5. Fokusgruppe, S. 62, Z. 1905-1910 (Herv. i. O.)

655 Transkript der 4. Fokusgruppe, S. 48f., Z. 1533-1538 (Herv. i. O.)

656 Vgl. Transkript der 1. Fokusgruppe, S. 41, Z. 1250-1254 und 42, Z. 1277-1284; Transkript der 2. Fokusgruppe, S. 51, Z. 1615-1626; Transkript der 4. Fokusgruppe, S. 31, Z. 964-981; Transkript der 5. Fokusgruppe, S. 63f., Z. 1939-1955; Transkript der 6. Fokusgruppe, S. 74, Z. 1347-2353 und 75f., Z. 2398-2411. 
gesehen hoch ${ }^{657}$ - , können vor allem eine AfD-Wahl „aus Überzeugung“ kaum hinnehmen:
„Also, ich will aber auch, dass alle... man alle einlädt und, sag' ich mal, so'n bisschen... Man kommt ja dann auch zur Diskussion. Das Problem ist halt, dass viele Leute dann vor dem Fernseher sitzen, die sich vielleicht nicht so weiterbilden oder sich mal die Wahlprogramme an-... oder mal durchlesen, weil... Keine Frau oder... Wenn 'ne Frau mal das Wahlprogramm der AfD durchliest, dass sie dann auch den... Also, das ver- stehe ich nicht, dass sie 'ne AfD wählt! Also, was da teilweise für Punkte draufstehen! Weiß ich nicht, also..." ${ }^{658}$

Manche flüchten sich gar in abstrakte, überhistorische Gleichnisse, um sich selbst $\mathrm{zu}$ beruhigen. ${ }^{659}$ Das allgemeine Unverständnis motiviert denn auch wiederkehrende identitätspolitische Verpanzerungen, einen alle pluralistischen Prämissen überlagernden antirechten Bekenntnisdrang. Als Beispiel hierfür mag eine Studentin dienen, die ihre intransigente AfD-Kritik mit liberalen Grundauffassungen zu verbinden sucht und anmerkt, sie würde eine „neue konservative Partei, die 'n bisschen rechts von der CDU steht“, eine „CSU auf Bundesebene“ präferieren; jedoch belässt sie im Unklaren, worin sich eine solche imaginäre - höchstwahrscheinlich ja migrationsskeptische - BundesCSU von der jetzigen AfD unterscheiden würde. ${ }^{660}$ Die AfD gilt den Studierenden des Samples im Grunde nicht als legitimer politischer Wettbewerber, sondern als ein unerträgliches Sammelbecken unzivilisierter Unruhestifter und Chaoten, ja Extremisten ${ }^{661}$

657 Vgl. Kapitel III.3.2 dieser Studie.

658 Transkript der 1. Fokusgruppe, S. 42, Z. 1288-1293 (Herv. i. O.)

659 „Ich find's auf der einen Seite extrem erschreckend, aber auf der anderen Seite seh' ich's auch in so 'nem großen Zusammenhang, dass ich denke: ,Ja, das hat's immer gegeben, und das wird's auch immer geben, und es wird sich auch immer irgendwie wieder einrenken!' Also, ähm, das Einzige, was ich daran schlimm finde, ist, dass es dann, dadurch, dass es das immer gegeben hat, eben auch immer Leute gibt, die dadurch irgendwie 'n ganzes Leben lang vielleicht..., denen es dadurch ganz schlecht gegangen ist. Also sei es jetzt in der Hitler-Zeit oder so, das war ja dann auch in dem Sinne nur so 'ne Phase, und es hat sich ja auch irgendwie wieder eingerenkt, aber in der Phase sind ja eben so viele schlimme Sachen passiert, dass es trotzdem schwer zu akzeptieren ist, dass es sowas überhaupt gibt. Und dass man trotzdem immer versuchen sollte, und... ja, das irgendwie zu vermeiden, wenn es denn irgendwie möglich ist." Transkript der 7. Fokusgruppe, S. 64, Z. 2018-2028 (Herv. i. O.) „Also, vor zweieinhalbtausend Jahren hat Aristoteles ja schon mal sowas geschrieben wie, dass es immer in der Politik Ausschweifungen nach links oder rechts gibt; es wird immer mal Extreme geben, die sich wieder einpendeln und woanders hingehen. Und das hat mich schon ziemlich beruhigt!" Transkript der 7. Fokusgruppe, S. 63, Z. 1993-1999.

660 „Ja, um das politische Spektrum besser abzubilden, hätt' ich mir auch statt 'ner, ich sag' mal, ja, na ja, 'ner populistischen Partei wie der AfD halt irgendwie eher, na ja, so 'ne ,CSU auf Bundesebene' gewünscht. Da wär' ich mit denen auch eigentlich ganz selten mal einer Meinung, aber es ist halt trotzdem weniger radikal, ne. [...] Und was dann so diese, na, diese Diskussion im Bundestag angeht und im Parlament, und auch so 'n bisschen dieses Spektrum an verschiedenen Positionen und Meinungen, glaub' ich, da fänd' ich 'ne neue konservative Partei, die 'n bisschen rechts von der CDU steht, hilfreicher als so 'ne populistische Partei wie die AfD." Transkript der 4. Fokusgruppe, S. 52, Z. $1637-1649$ (Herv. i. O.) 
- „rechtslastig“662, minderheitenfeindlich ${ }^{663}$, Abläufe störend, inkompetent und „das generelle Qualitätslevel der Politik in Deutschland“664 mindernd, „eher nicht so demokratisch ${ }^{4665}$, soziale Ungleichheiten eher verschärfend als dämpfend. ${ }^{666}$ So berechtigt die Frustration mancher ihrer Wähler den Studierenden erscheint, so ungerechtfertigt erscheint es ihnen, die Wut derart zu entladen. Die vereinzelt ausgemachte inhaltliche Berechtigung einzelner AfD-Kritiken etwa im Bereich mangelhafter Integrationspolitik $^{667}$ wird in den Augen der Studierenden alleine schon durch das demagogische Auftreten und die kaum verhüllte „extreme“ Gesinnung ihrer Protagonisten vergiftet. Man betrachtet mit Sorge, dass keine politisch linke Kraft jene Frustration hat bündeln können, die nun eben einer neuen Rechten zugute kommt. ${ }^{668}$ Man hofft, dass sich das nun entstandene Problem selbstständig erledigt, indem die AfD an der eigenen Inkompetenz und Konzeptlosigkeit scheitert oder aber ihre hässliche Fratze enthülle:

„Ich war erst sehr skeptisch und dagegen, ich habe aber auch gemerkt: Jetzt, da sie da ist, ähm, merken erstmal viele von deren Wähler... wie dusselig die eigentlich sind. Also ich hoffe, das war das erste und das letzte Mal, [lacht] dass sie da drin sind. Einfach, um ihren Wählern mal zu zeigen: ,ja, die sind eigentlich total bescheuert und kriegen nichts auf die Reihe! [ $669^{6}$

„Ich glaub' aber auch [...], dass sie nicht ewig lang ruhig bleiben, oder dass, ähm, 'ne Partei, die so 'n Prinzip [des populistischen Agitierens, ]. S.] hat, niemals genauso lange oder länger durchhalten wird wie alle anderen Parteien, die das Prinzip nicht haben, weil die eben dadurch irgendwann auf die Nase fallen. [...] Und da haben die halt bis jetzt noch gar keine Lösungen vorgebracht. ${ }^{4670}$

Über das tatsächliche Agieren der AfD in den Parlamenten, ganz besonders über die Funktion der AfD als Oppositionsführerin im Bundestag wird jenseits der hier wiedergegebenen allgemeinen Wahrnehmungen nicht gesprochen. Darin könnte sich allerdings auch die vielfach als technokratisch beurteilte politische Praxis der letzten Jahre und Jahrzehnte spiegeln, die die Rolle der Opposition in den zurückliegenden Jahren ohnehin stark gemindert habe. ${ }^{671}$ Jedenfalls: Dass man schlussendlich kaum zu einem praktischen Ergebnis kommt, ruft eine Studentin schließlich hilflos aus: „Das sind Menschen, die haben jetzt 'ne Stimme. Das sind Menschen, die machen was. Wir können nicht immer nur sagen: ,Das sind ja die Idioten!' Ja, das sind aber die Idioten

662 Transkript der 2. Fokusgruppe, S. 55, Z. 1734.

663 Vgl. Transkript der 7. Fokusgruppe, S. 66, Z. 2094-2097.

664 Transkript der 3. Fokusgruppe, S. 62, Z. 1897.

665 Transkript der 5. Fokusgruppe, S. 62, Z. 1910 (Herv. i. O.)

666 Vgl. Transkript der 2. Fokusgruppe, S. 55, Z. 1746-1752.

667 „)a, es werden sozusagen, so, Probleme angesprochen, die die anderen Parteien, um politisch korrekt zu sein, halt nicht ansprechen werden. Zum Beispiel Integrationsprobleme - und so was gibt es, es gibt Parallelgesellschaften! Und irgendwie muss man die Leute ja auch bewegen." Transkript der 1. Fokusgruppe, S. 52, Z. 1592-1595 (Herv. i. O.) Vgl. auch Transkript der 4. Fokusgruppe, S. 35f., Z. 1119-1127.

668 Vgl. die Diskussion dieses Aspekts in Transkript der 7. Fokusgruppe, S. 66-67, Z. 2081-2121.

669 Transkript der 5. Fokusgruppe, S. 62, Z. 1894-1898 (Herv. i. O.)

670 Transkript der 7. Fokusgruppe, S. 68, Z. 2152-2158 (Herv. i. O.)

671 Vgl. Meinel: Die Republik der Außenseiterin, S. 9-11. 
mit'nem gewissen Prozentsatz Stimmen! “672 Die allgemeine Schwierigkeit, einen angemessenen Umgang mit strittigen Themen zu finden, der über die weitere Vertiefung der bestehenden weltanschaulichen Gräben hinausreicht, wird durchaus immer wieder auch (selbst-)kritisch gesehen. ${ }^{673}$ Dabei mag es eine Rolle spielen, dass fünf von sieben Fokusgruppen in Niedersachsen stattgefunden haben, einem Bundesland, das noch immer als Refugium volksparteilicher Wählersockel gilt, und in welchem die AfD bisher kaum Erfolge feiern konnte. Für weitere Studien könnte es gewinnbringend sein, Fokusgruppen in Bundesländern zu initiieren, in denen die AfD aktuell volksparteiliche Ansprüche anmelden kann, also etwa mit brandenburgischen, sächsischen oder thüringischen Studierenden.

Das Dilemma des studentischen Demokratieverständnisses liegt hierin: Angesichts der unmittelbar vorangegangen Diskussion über Grundsäulen und Grundwerte der Demokratie bleibt den Fokusgruppenteilnehmern wenig übrig, als die zuvor so vollmundig konstatierten Prinzipien guter Demokraten nun auch auf den konkreten Gegenstand AfD zumindest verbal zu verlängern. Man müht sich, die Maximen des Meinungspluralismus an diesem konkreten Handlungsproblem zu bekräftigen. ${ }^{674}$ Doch es bleibt ein Akt der Pflichtschuldigkeit. Der faktische Unwillen, die eigenen Maximen der Toleranz und Offenheit auf jene auszuweiten, die mit populistischen Mitteln gegen Kosmopolitismus und Migrationsgesellschaft antreten, aber für nationalen Protektionismus zugunsten der Privilegien einer ländlich und kommunal verankerten autochthonen Bevölkerung werben, ja sie auch nur als demokratische Mitbewerber anzuerkennen, führt unvermeidlich in eine Reihe von Widersprüchen:

- Die Studierenden fordern aufrichtige pluralistische Aufgeschlossenheit gegenüber allen politischen Meinungsdifferenzen, zweifeln aber die Legitimität politischer Konkurrenten an, welche das Werteset „Toleranz - Offenheit - Kosmopolitismus“ nicht zuvor inkorporiert haben. Sie blenden dabei aus, dass solcherlei Werthaltungen eo ipso zu inhaltlichen Präformierungen des zulässigen Meinungsspektrums führen müssen.

- Alle Menschen, auch die Unzufriedenen, sollen grundsätzlich mitbestimmen dürfen; sobald sie sich jedoch für die „falsche“ Option entscheiden und damit selbst als verloren erweisen, wird politische Bildung nötig, um den künftigen Nachwuchs

672 Transkript der 5. Fokusgruppe, S. 64, Z. 1965-1968 (Herv. i. O.)

673 „Es gibt ja nur 'gut' und 'böse' und 'richtig' und 'falsch'! Und dass es eben nicht so ist... Und diese Diskussion ist, glaub' ich, gerade eben in diesen Internet-... in Kommentaren, unter irgendwelchen Zeitungen, überhaupt nicht drin. Also da ist halt nur ,voll für' oder ,voll gegen', und meistens argumentieren die, [die] vielleicht sogar noch irgendwie demokratisch sind, einfach nur noch irgendwie gegen die, die so völlig rechts sind. Und man kommt gar nicht dazu, in so 'nen angemessenen demokratischen Austausch zu kommen [...]" Transkript der 5. Fokusgruppe, S. 58, Z. 1790-1794 (Herv. i. O.)

674 So etwa hier: „Also, ich denke, wenn man die... Also, was die CDU, SPD, sonstwas angeht - da muss man auch AfD einladen, wenn man das ,gerecht' darstellen möchte. [...] Ansonsten kann man ja auch gar keine Position irgendwie demaskieren, wenn man den Personen immer nur den Raum gibt, den sie durch irgendwelche mediale Berichterstattung irgendwie erhalten mit: ,Der und der hat das und das getan' [...] Da kann man ja irgendwie gar keinen richtigen Diskurs führen.“ Transkript der 1. Fokusgruppe, S. 41f., Z. 1269-1274. 
rechtzeitig zu belehren. Dazu gehört insbesondere, aufgeheizte Stimmungen und Emotionen zu nivellieren, die durchweg als Gefahrenfaktoren des demokratischen Miteinanders gelten. ${ }^{675}$

- Die Relativierung der zuvor skizzierten AfD-Bedrohung durch Argumente der Repräsentationsausweitung (besserer Stimmenproporz = demokratieförderlich) widerspricht eklatant der sonst angemahnten Wertefundierung der Demokratie.

- Oft wird das Urteil einer ungebildeten AfD-Wählerschaft daran festgemacht, dass diese das Wahl- bzw. Parteiprogramm der nun favorisierten Partei (beides scheint überdies häufig gleichgesetzt zu werden) nicht lesen würde, während man selbst zumeist nur Auszüge kennt oder einzelne schockierende Aspekte medial aufgeschnappt hat.

- Einerseits gesteht man über die These vom Schließen der Repräsentationslücke zu, dass die AfD genuine Interessen vertrete, die zuvor vom demokratischen Prozess ausgeschlossen worden seien, andererseits beruht die - häufig von denselben Rednern vorgebrachte - Hoffnung auf ein Verebben der AfD-Welle auf der These des Protestwählers, d. h. auf der Annahme, hier hätte ein Emotionsüberschuss eine Masse von Frustrierten dazu getrieben, über die Stränge zu schlagen.

- Auch AfD-Politiker und -wähler, auch PEGIDA-Demonstranten und ähnliche Bürgerproteste engagieren sich freiwillig in kollektiven Zusammenschlüssen, sind damit Teil der so häufig geforderten Zivilgesellschaft, wenn auch womöglich ihrer „schmutzigen“, aggressiv auftretenden Segmente. ${ }^{676}$ Das findet keine Berücksichtigung in der Partizipationsrhetorik der Studierenden.

Zuspitzend ließe sich daraus schlussfolgern: Zu bekräftigen, ja zum höchsten Prinzip zu erklären, dass die Demokratie „wichtig“ sei und man sie zu schützen habe, kann auch dazu dienen, sich selbst von der systematischen Auseinandersetzung mit konkreten Handlungsproblemen zu dispensieren. Die Studierenden, die in der hier ausgewerteten Fokusgruppenstudie Rede und Antwort standen, sind so gesehen schlecht gerüstet für fundamentale Auseinandersetzungen mit derzeit gesamtgesellschaftlich wachsenden, oft offensiv und aggressiv auftretenden Deutungen von (weit) rechts. Sie sind vom Phänomen AfD und einer neuen rechten Zivilgesellschaft überfordert. Ausnahmen finden sich überall dort, wo im Rahmen von Politgruppen, Lesekreisen und im Ehrenamt praktische Erfahrungen verarbeitet werden können und wo den Fragen künftigen politischen Konfliktpotenzials mit intellektuellem und politischem Anspruch nachgegangen wird. Nein, es wäre ungerecht, von Studierenden die Lösung von Problemen abzuverlangen, an denen auch professionelle Politiker scheitern. Aber es fällt doch auf, dass das Demokratieverständnis der Studierenden - an sich eine reichhaltige Quelle von Vorstellungen, Wünschen, Begriffen und Leidenschaften, die sich von der distanzierten Gleichgültigkeit nichtstudierender Jugendlicher und junger Erwachsener prägnant absetzt ${ }^{677}$ - keinen Weg findet, mit der neuen Situation umzugehen.

675 Vgl. dazu vertiefend Kapitel III.3.2 dieser Studie.

676 Vgl. Geiges/Marg/Walter: Die schmutzige Seite der Zivilgesellschaft?, S. 179-207.

677 Vgl. Schenke et al.: PEGIDA-Effekte?, S. 210f. 
Hier ist einem naheliegenden Missverständnis vorzubeugen: Selbstverständlich existiert keine „korrekte“ Auffassung des Demokratiebegriffs. Die Demokratie ist ein gesellschaftshistorisches Phänomen. Sie lässt sich nicht überzeitlich „definieren“. Natürlich gehört es zu ihrem gewachsenen Bedeutungsgehalt, eine Herrschaftsform bzw. ein politisches System zu bezeichnen, welches beansprucht, direkt oder qua Repräsentation der Kontrolle der unter ihr befassten Bürger unterworfen zu sein oder zumindest in deren Interesse agiert. ${ }^{678}$ Doch gerade in ihrer empirisch gesättigten historischen Bewegung stecken jene Tendenzen, die zum Wunsch nach dem so oft als utopisch gescholtenen Weiterentwicklung des demokratischen Miteinanders führen können. Demokratie kann ${ }^{679}$ als eine Form politischer Herrschaft und als Methode der Rekrutierung von Führungseliten aufgefasst werden; sie ist zugleich aber auch undenkbar ohne einen sie tragenden Verfassungsstaat (eine „konkrete“ Demokratie, etwa die Bundesrepublik), welcher den institutionellen Rahmen für den demokratischen Prozess herstellt; sie enthält aber auch eine regulative Idee der vollendeten Volkssouveränität, pointiert: der Selbstgesetzgebung als Herrschaftsfreiheit, die sich stets nur partiell realisieren kann. Es stehen drei dynamische Bestimmungsmomente in einem Wechselverhältnis, die den Zustand eines demokratischen Gemeinwesens zu einem gegebenen Zeitpunkt umschreiben:

\section{Demokratische Methode - Demokratische Idee - Demokratischer Staat.}

Alle drei Aspekte sind in empirisch vorhandenen demokratischen Systemen wirksam; sie bezeichnen eine dialektische Prozesslogik, die zu keinem Zeitpunkt stillsteht. ${ }^{680}$ Aus ihnen speist sich das hier betrachtete Assoziationsspektrum. Demokratien modernen Typs legitimieren Herrschaft, fordern deren Legitimität aber auch vermöge ihrer historischen Bewegung, die immer auch auf eine Ausweitung von Volkssouveränität zielt, heraus. Demokratisierung, in welcher Form auch immer, fordert das Selbsterhaltungsinteresse des Verfassungsstaats sowie die Legitimität politischer Führungseliten heraus. Wahr am Partizipationsdrang der von Studierenden geforderten „Bürgerkompetenz ${ }^{\prime 681}$, so sehr er sich auch ideologiekritisch infrage stellen ließe, ist daher vor allem die Erinnerung an eine niemals auszutreibende innere Tendenz der Demokratie, an der auch ein Wolfgang Abendroth, ein Johannes Agnoli und ein (früher) SDS einst ansetzten: ihre inhärente Möglichkeit, Herrschaft selbst infrage zu stellen. ${ }^{682}$ Diese Wahrheit wird zugleich verstellt, wo Demokratie mit Liberalismus in eins gesetzt wird. Denn

678 Vgl. Schmidt, Manfred G.: Demokratietheorien, Opladen 2000, S. 19

679 Zu den hier wiedergegebenen konkurrierenden demokratietheoretischen Auffassungen vgl. noch einmal Kapitel III.3.2 dieser Studie.

680 Vgl. Marg, Stine/Schenke, Julian/Finkbeiner, Florian: Gegen einen formalistischen Demokratiebegriff. Zwischenstand der begriffshistorischen und -theoretischen Reflexion im Forschungsprozess, in: Demokratie Dialog, H. 5/2019, S. 2-13.

681 Münkler: Der kompetente Bürger, S. 155.

682 „Im heutigen Parteienstaat beinhaltet eine permanente Demokratisierung sowohl eine innerparteiliche Reorganisation als auch eine Stärkung der Verantwortlichkeit der Volksvertreter über die Parteien zum Volk hin [...] Die kritische und selbstkritische Verfolgung dieser Ziele mag heute noch [...] als Illusion erscheinen. Ihre Preisgabe jedoch wäre das sichere Ende jeglicher Demokratie. Zwar ist sie auch eine Form der Herrschaft. Doch was sie von allen übrigen Herrschaftsformen abhebt, 
statt gegen die AfD pädagogisch einzuimpfende "Werte“ anzurufen, böte es sich an, stattdessen mit Nachdruck auf die weitgehende Ausblendung des sozialen Aspekts ${ }^{683}$ der „Würde des Menschen“ im liberalistisch strukturierten Grundgesetz als Ursache von antiliberaler Verbitterung und Frustration ${ }^{684} \mathrm{zu}$ verweisen. Dass den Studierenden der Zugriff auf eine solche - für sie „utopische“ - Perspektive wiederum gerade durch die von deutschen Maximen politischer Bildung imprägnierten bürgergesellschaftlichen Formeln verstellt ist, schafft Konfusion und verstärkt den Rückgriff auf frühliberale Deutungsmuster. Die „linke“ Demokratiekritik der frühen 1970er Jahre (Agnoli, Habermas, et al.) erscheint demgegenüber unverändert aktuell:

„Abstrakt geforderte kooperative und partnerschaftliche Verhaltensweisen, die einen Zustand allgemeiner Solidarität und Gerechtigkeit erzeugen sollen, obgleich die Bedingungen und Ziele eines solchen Verhaltens nicht aus der Analyse der politischsozialen Realität gewonnen werden, gerieten [...] zur Integrationsideologie, während die wirklichen Interessengegensätze innerhalb einer Cesellschaft ausgeblendet und nicht als strukturelle Gegensätze begriffen werden. “685

\title{
III.3.4 Rekonstruktion der politisch-sozialen Deutungsmuster und Ertrag der Fokusgruppenstudie
}

\author{
"Monotheismus der Vernunft und des Her- \\ zens, Polytheismus der Einbildungskraft und \\ der Kunst, dies ist's, was wir bedürfen. “686
}

Abschließend soll der Versuch unternommen werden, den bunten Strauß der diskutierten studentischen Sichtweisen, Motivationen, Einstellungen und Orientierungen zu politisch-sozialen Deutungsmustern zu verdichten. Diese Deutungsmuster sind als untergründige verklammernde und vermittelnde Sinnstrukturen wirksam. Sie werden, da Bestandteil sozialisatorisch vermittelter und im Zuge persönlicher Erfahrungen internalisierter und einverwandelter Selbstverständlichkeiten, von den Diskutanten nicht explizit geäußert, sind ihnen wohl auch selbst kaum bewusst. Sie bezeichnen Elemente privater Gesellschaftstheorien der Studierenden, die das politische und soziale Ge-

ist die in ihr angelegte Möglichkeit, Herrschaft in Frage zu stellen." Lenk: Wie demokratisch ist der Parlamentarismus?, S. 25

683 Dazu gehört nicht nur soziale Deprivation in „abgehängten“ Teilen der Gesellschaft, sondern gerade auch die Statusangst der arrivierten „Mitte“, die zur nationalprotektionistischen und sozialchauvinistischen Berufung auf Etabliertenvorrechte führt. Vgl. Koppetsch, Cornelia: Soziologiekolumne: Eine Welle der Nostalgie. Die akademische Mittelschicht und die illiberale Gesellschaft, in: Merkur. Gegründet 1947 als Deutsche Zeitschrift für Europäisches Denken, 72. Jg., H. 832/2018, S. 51-58.

684 Vgl. Lenk: Wie demokratisch ist der Parlamentarismus?, S. $47 f$.

685 Ibid., S. 48.

686 Hegel, Georg Wilhelm Friedrich: Ältestes Systemprogramm des deutschen Idealismus [1796]. Gesammelte Werke Bd. 1, Frankfurt a.M. 1979, S. 235. (Ob dieses dem jungen Hegel zugeschriebene Zitat tatsächlich von ihm stammt oder von seinen Studienfreunden Schelling oder Hölderlin, die sich alle der Anfertigung eines idealistischen philosophischen Systems verschrieben hatten, gilt als ungeklärt.) 
schehen sinnhaft ordnen und rechtfertigend deuten. Sie gehören der Sphäre politischer Soziokultur an und stellen, gemessen am traditionellen Begriff (politischer) Ideologie, ideologische Leitlinien dar, gleichsam Bruchstücke von Ideologie, die von politisch-kulturell kolportierten Beständen zehren. Im Gegensatz zu den einstigen Deutungssystemen, den politischen Ideologien, erheben die stärker fragmentierten Deutungsmuster nicht mehr den Anspruch, „die Totalität der Gesellschaft zu erfassen“687, sondern bieten Erklärungen und Lösungen für gesellschaftspolitische Handlungsprobleme. Sie vermitteln gesellschaftliche Ordnungsvorstellungen mit konkreten Beobachtungen in der Gegenwart; ähnlich den von Habermas et al. herausgearbeiteten "Gesellschaftsbildern“.

„erschließen und beschränken sie in einem: sie lassen Material sehen, indem sie es verarbeiten; andererseits behindern sie den Blick für alles, was diesen Zusammenhang sprengt; sie schirmen insofern ab und sichern eine feste, vielfach dann auch starre Haltung. “688

Und sie „institutionalisieren ein politisches Votum ${ }^{4689}$ unterhalb der oberflächlicheren politischen Deutungskultur, spenden damit auch handlungsleitende Maximen. Deutungsmuster wie auch Gesellschaftsbilder ringen dabei im Kern um die Erklärung und Rationalisierung gesellschaftlich bedingter Ungleichheiten. ${ }^{60}$ Die politisch-sozialen Deutungsmuster werden vom Forscher aus einer „hinter“ den Einstellungen liegenden, nicht direkt empirisch zugänglichen mentalen Tiefenschicht rekonstruiert und bleiben daher notwendig hypothetisch. Ähnlich den sozialwissenschaftlich häufig gebrauchten Idealtypen von Einstellungsmustern kann auf der Grundlage des hier verfolgten methodischen Zuschnitts dabei nicht entschieden werden, wie umfänglich und kohärent die Deutungsmuster von Einzelpersonen im Sample „verkörpert“ werden; Einzelaussagen können bisweilen verschiedene Deutungsmuster zugleich indizieren. ${ }^{691}$ Anders als Idealtypen aber zielen sie nicht auf die größtmögliche Homogenität nach innen bei größtmöglicher Heterogenität nach außen, sondern auf die Identifikation tatsächlich wirksamer Sinnstrukturen mitsamt der ihnen eigenen paradoxen Züge. Jene Bruchstellen von Deutungsmustern, die auf ein ungelöstes Orientierungsdefizit verweisen, treten durch einen solchen Bündelungsversuch besonders hervor. Wichtig ist, dass die rekonstruierten Deutungsmuster empirische Regelmäßigkeiten in den Einzelaussagen erklärbar machen, mithin durch Rückschluss von ihren diskursiven „Effekten“ (Kapitel III.3.1-III.3.3 dieser Studie) sichtbar gemacht werden. Ihr Anspruch ist nicht, sämtliche Motive aufzunehmen, die die Fokusgruppenteilnehmer bewegen, sondern allein jene, die Aufschluss über Dispositionen politischer Handlungspotenziale geben.

In den Äußerungen $\mathrm{zu}$ Studienerwartungen, Studienwahrnehmungen sowie Leistungs- und Bildungskonzeptionen, zu politischen Problemen sowie deren Lösungsansätzen und zum Begriff der Demokratie sowie zum konkreten Handlungsproblem

687 Habermas et al.: Student und Politik, S. 152.

688 Ibid.

689 Ibid.

690 „Einen zentralen Teil von Gesellschaftsbildern stellen Urteile zur sozialen Ungleichheit dar, und zwar hinsichtlich ihres Ausmaßes wie ihrer Gerechtigkeit; damit verknüpft ist die Frage nach der Chancen- und Leistungsgerechtigkeit in unserer Gesellschaft." Studierendensurvey 1980er, S. 233. Vgl. Kelle/Kluge: Vom Einzelfall zum Typus. 
AfD finden sich zahlreiche Hinweise auf solche latent wirksamen Sinnstrukturen studentischer Ordnungsvorstellungen und Ordnungsansprüche, auf Elemente einer „allgemein verbindlichen Alltagsmoral ${ }^{\text {(692 }}$ mit gesellschaftstheoretischen Zügen. Die Grundmotive des politischen Denkens und Empfindens von Studierenden, die sich bildenden Meinungshegemonien, Orientierungslücken, usw. treten gleichsam als eine Architektur zutage, welche die einzelnen Einstellungen und Überzeugungen der Studierenden vermittelt und Handlungsmaximen bereitstellt. Versucht man, diese Architektur auf der Grundlage der vorgestellten Auswertung hypothetisch zu rekonstruieren, so ergeben sich als deren Grundprinzipien die folgenden drei politischsozialen Deutungsmuster:

- Das Deutungsmuster einer (herzustellenden) chancengerechten Gesellschaft,

- das Deutungsmuster eines einheitsstiftenden und harmonisierenden Rationalitätsbzw. Vernunftprinzips und

- das Deutungsmuster der (politischen) Bildung des Einzelnen als gesellschaftspolitisches Panazee.

In diesen Deutungsmustern drücken sich spezifische Ordnungsideale aus, deren mangelnde Realisierung jeweils zu gesellschaftskritischen Überlegungen führt. Dabei ist zu berücksichtigen: Wie in den Erläuterungen zum Vorgehen und Verlauf der Erhebung ${ }^{693}$ bereits erwähnt, erwies sich die direkte Frage der idealen Gesellschaft - nach der Utopie - wie in einigen anderen Studien, an denen der Verfasser beteilig gewesen ist, als weitgehend unergiebig und wurde in späteren Fokusgruppen fallen gelassen. Sie wirkte auf viele Studierende überfordernd und zugleich amüsierend, evozierte schließlich primär Wiederholungen früherer Gesprächspassagen und bremste den Gesprächsfluss aus. Überforderung, Spott und Stirnrunzeln sprechen aus vielen studentischen Reaktionen auf die Frage nach der idealen Gesellschaft:

„I: [...] Wie würde eurer Meinung nach die ideale Cesellschaft aussehen? B2: [lacht, allgemeine Erheiterung] $]^{4694}$

„Lauter Harmonie. Weltfrieden. [lacht] ${ }^{4695}$

„Wir hatten mal darüber gesprochen [im Studium, J. S.], dass man das Idealbild eigentlich nie erreichen kann. Das geht irgendwie gar nicht." ${ }^{496}$

Die bloße Vorstellung von Transzendenz, früher entscheidendes Movens nicht nur von eschatologischem Bewusstsein, sondern auch von politischen Bewegungen, scheint dem zeitgemäßeren Pragmatismus nicht einmal unter Studierenden, denen Vernunft und Bildungsidee so wichtig ist, standhalten zu können. Dennoch bieten die in der 1., 2. und 4. Fokusgruppe erfragten und in der 7. Fokusgruppe selbstständig aufgekommenen studentischen Vorstellungen gesellschaftspolitischer Fernziele und Wünsche

692 Lepsius: Kulturelle Dimensionen der sozialen Schichtung, S. 111.

693 Vgl. Kapitel III.1 dieser Studie.

694 Transkript der 4. Fokusgruppe, S. 53, Z. 1694.

695 Transkript der 2. Fokusgruppe, S. 56, Z. 1779.

696 Transkript der 2. Fokusgruppe, S. 56, Z. 1772-1774 (Herv. i. O.) 
aufschlussreiche Äußerungen, welche die herausgearbeiteten Deutungsmuster illustrieren und erhärten.

Das Deutungsmuster der (herzustellenden) chancengerechten Gesellschaft. In einer gerechten Gesellschaft verfügen alle Individuen über identische Startchancen im Wettbewerb um Bildungsabschlüsse, Statusansprüche und Karrieren. Daher ist die chancengerechte Gesellschaft auch der Inbegriff demokratischer Fairness. Wo sich Ungleichheiten ergeben, die auf der ethnischen und sozialen Herkunft oder aber auf biologischen Unterschieden gründen, ist es eine der höchsten Aufgaben des Staates, durch geschickte Sozial- und Bildungspolitik antidiskriminatorisch gegenzuwirken. Subjektiv tritt dieses Deutungsmuster damit gesellschaftskritisch und sozial egalisierend auf, im Kern jedoch fordert es die Realisierung des modernen meritokratischen Gedankens, wie er in den 1960er Jahren satirisch von Michael Young ${ }^{697}$ formuliert worden ist und Eingang in die workfare-Politik seit den 1990er Jahren gefunden hat. Die daraus hervorgegangene Rhetorik der "Chancengesellschaft" - eigenverantwortliche Bildungskarrieren als magisches Tor zum Aufstieg - ist durch dieses Deutungsmuster bis auf den letzten Tropfen aufgesogen und internalisiert:

„,Meritokratie: Das Wort klingt wie der Inbegriff des Guten, schrieb schon 2005 Ralf Dahrendorf. [...] Denn in der meritokratischen Cesellschaft zählt allein die Leistung, die der Einzelne nachweislich erbringt, nicht Nobilitierung der Vorfahren, nicht Merkmale der Herkunft, nicht Zufall, nicht Clück, auch kein göttlicher Plan. [...] Aber auch, wer es im meritokratischen Cefüge nicht ganz nach oben schaffen kann, hat in diesem System dennoch prinzipiell die Möglichkeit, seine Lage zu verbessern, seine soziale Position auszubauen, voranzukommen - wenn er sich mehr anstrengt als andere in seiner Stellung. [...] Bildung entscheidet, ist das Motto von Sozial- wie Christdemokraten, von Crünen und Freidemokraten. ${ }^{6998}$

Dieses Deutungsmuster ist somit zwar jüngerer gesellschafts- und geistesgeschichtlicher Herkunft als die spätaufklärerische Vernunft- und Bildungsemphase, aber im Zuge der Bildungsexpansionsbewegungen zweier Jahrhunderte ${ }^{699}$ doch auch historisch aus ihr und der mit ihr verbundenen „Zielutopie“ der leistungsbasierten bürgerlichen Gesellschaft entsprungen. Diese traditionellen Gehalte verbinden sich mit der offiziellen Bildungs- und Chancenrhetorik der vergangenen Jahre und Jahrzehnten zu einem sozialisatorisch wirkmächtigen Motiv, das die Studierenden beinahe wie einen Religionsersatz anverwandeln.

Die Figur der Chancengerechtigkeit ist ein wesentliches Scharnier der Herstellung einer harmonisch funktionierenden Gesellschaft. Vereinzelte Zweifel an Leistungsprinzip und Martkwirtschaft sind mit ihr grundsätzlich vereinbar, nämlich dann, wenn dieses Deutungsmuster bisweilen auch Talente, Begabungen und Leidenschaften als Fähigkeiten anerkennt, die jenseits von formalen Bildungszertifikaten zu Ansprüchen auf Berufschancen berechtigen sollten - so etwa bei der Rekrutierung des

697 Vgl. Young, Michael: The Rise of Meritocracy, London 1961.

698 Walter/Marg: Von der Emanzipation zur Meritokratie, S. 95f. (Herv. i. O.)

699 Vgl. Kapitel II.1 dieser Studie. 
Ärzte-Nachwuchses. ${ }^{700}$ Aber: Dass der im Deutungsmuster der chancengerechten Gesellschaft beschlossene Leistungsgedanke immer wieder auch mit den Selbstfindungsund Persönlichkeitsbildungsansprüchen des studentischen Bildungspathos kollidieren muss, ist unverkennbar. Denn zwar bilden Störungen der Chancengerechtigkeit den zentralen Empörungsfaktor für studentische Gesellschaftskritik, nicht aber soziale Ungleichheiten per se. Mit dem Begriff des Gemeinwohls fremdeln alle. Obwohl die Schlussfolgerung ungern gezogen wird, muss die Kehrseite der Chancengerechtigkeit doch stets lauten: Wer über vergleichsweise gute Startchancen verfügt und diese nicht nutzt, unterliegt $\mathrm{zu}$ Recht im Kampf um Anteile am gesellschaftlichen Sozialprodukt. Aus dieser, gleichsam contre cœur eingehandelten, Sackgasse können sie nicht herausfinden, weil sich beinahe jedwede utopische Regung im Ideal der Chancengesellschaft als oberstem sozialpolitischem Ziel erschöpft. Sonstige utopische Quellen sind versiegt. ${ }^{701}$ Dass die Träume von der besseren Gesellschaft regelmäßig in meritokratischen Leitidealen der Fairness gleicher Startchancen münden, demonstriert etwa jene Lehramtswärterin, die sich von John Rawls' Theorie der Gerechtigkeit begeistert zeigt, ${ }^{702}$ oder aber in der folgenden, kollektiv erarbeiteten Lösung der konkurrierenden Ansprüche von Freiheit und Gleichheit:

„B2: Ich glaub', gleiche Freiheit ist vielleicht ganz gut zur... Jeder hat die gleiche Freiheit [...] B4: Und utopischer Weise [...] die gleichen Möglichkeiten, vielleicht. B2: Ja. Chancengleichheit. B6: Ja. ${ }^{\text {"703 }}$

In den studentischen Konzeptionen idealer gesellschaftlicher Zustände drückt sich das Deutungsmuster besonders in den verbreiteten Forderungen nach Nachteilsausgleich und Gleichstellungspolitik aus:

„Also, für mich würde es [die ideale Gesellschaft, ]. S.] sich daran abzeichnen, dass Personen, die in irgendeiner Art und Weise - sei es psychisch, körperlich - lerneingeschränkt..., dass diese Personen vollwertig an der Gesellschaft teilhaben können. Was meiner Meinung nach absolut nicht gegeben ist in Deutschland, überhaupt nicht. “704 „B5: Chancengleichheit. B2: Ja, ich wollte auch gerade sagen [...], dass jeder die gleichen Chancen für alles hat. “705

„Ich glaub', in der idealen Cesellschaft bräuchte man ehrenamtliches Engagement gar nicht mehr so, weil's dann, glaub' ich... Also, weil man viele Ehrenämtler nicht mehr bräuchte im Sinne von: weil niemand mehr benachteiligt werden würde im besten Fall. ${ }^{706}$

„Also es hat nicht jeder die gleichen Voraussetzungen zum Studieren! Sonst müsste keiner 'nen Nebenjob machen neben dem Studium. Und das ist halt einfach 'n Problem aus meiner Sicht. Genau so, dass man als Student einfach schlechter gestellt ist

700 Vgl. Kapitel III.3.1 dieser Studie.

701 Vgl. Saage: Das Ende der politischen Utopie?

702 Vgl. Transkript der 4. Fokusgruppe, S. 56f., Z. 1782-1793.

703 Transkript der 7. Fokusgruppe, S. 62, Z. 1964-1975 (Herv. i. O.)

704 Transkript der 1. Fokusgruppe, S. 55, Z. 1689-1695.

705 Transkript der 2. Fokusgruppe, S. 57, Z. 1795-1798.

706 Transkript der 1. Fokusgruppe, S. 55f., Z. 1702-1707 (Herv. i. O.) 
als 'n Hartz-IV-Empfänger. Der kriegt ja das Celd, aber als Student nicht unbedingt.“707 „[...] dass das auch so 'n bisschen mehr gleichgestellt wird, dass auch Frauen, obwohl sie vielleicht auch genau so 'n Job machen oder vielleicht auch bessere Arbeit [...], dass die dann halt auch das gleiche Gehalt kriegen wie Männer." ${ }^{\text {708 }}$

„Ein faireres Krankenkassensystem wäre nett. ${ }^{\text {709 }}$

Durchbrochen wird dieses Deutungsmuster in zwei Passagen, die eine Abschaffung der Not und der ökologischen Verheerungen bzw. eine Abschaffung der kapitalistischen Produktions- und Wirtschaftsweise fordern:

„Kein Mensch verhungert. Ein klima- und sozialverträgliches Wirtschaftssystem.“"710 „Ähm, ich bin kein Fan vom Kapitalismus. Ich würde immer im ganz Großen ansetzen und überlegen, was... wie man Wirtschaft und dann Cesellschaft gestalten könnte..$^{4711}$

Das Deutungsmuster eines einheitsstiftenden und harmonisierenden Rationalitäts- bzw. Vernunftprinzips. Es enthält das Ideal einer Gesellschaft der Gleichgesinnten ohne Konfliktpotenzial. Die Triebkraft der Integration ist die umfassende Bildung der Persönlichkeit. Qua (Selbst-)Bildung erschafft sich das eigenverantwortliche Individuum als Vernunftwesen neu und findet dadurch, von oberflächlich divergierenden Präferenzmustern abgesehen, zur mentalen Identität mit seinen Mitmenschen. Als „kritisch Hinterfragende“ und „kritisch Denkende“ qualifizieren sich auch die Studierenden zur Mitgliedschaft in einer solchen Gesellschaft. In dieser Identität des Wollens zwischen Vernunftwesen verwandelt sich Gesellschaft wieder in Gemeinschaft, Irritation in Balance, sie vollzieht den „Rückweg aus der Entfremdung ${ }^{\text {“712 }}$. Eine intakte Demokratie lebt von dem so geschaffenen robusten Wertebewusstsein: Siegt die Vernunft in der politischen Diskussion, so siegen auch die „richtigen“ Werte; Meinungspluralismus wird zwar verbal gefordert, aber bleibt in der Relevanzhierarchie doch zweitrangig. Daran knüpft sich eine rationalistische Fortschrittshoffnung: Interessenstreit, politisches Kalkül, Machthunger, Konflikt und Umstürzlerei gehören den zu überwindenden Schattenseiten gesellschaftlicher Verwicklungen an. Daher lohnt sich persönliches Engagement nur in kleinen zivilgesellschaftlichen Zusammenhängen; die harte politische Auseinandersetzung hingegen stört den inneren Frieden rationalitätsbasierter Harmonie und droht, die ursprünglich authentischen Intentionen zu vergiften. Unverkennbar an diesem Ordnungsideal ist nicht nur der Nachhall der neuhumanistischen Bildungsidee, sondern auch der späten Aufklärungsphilosophie, welche den Fortschritt der menschlichen Freiheit an die Durchsetzung der Rationalität im Recht knüpfte; über dieses Recht sollte hier das Vernunftprinzip ein harmonisches Kräftegleichgewicht im bürgerlichen Staat gewährleisten. ${ }^{713}$ Vernünftige, rationale, prodemokratische

707 Transkript der 2. Fokusgruppe, S. 56, Z. 1788-1792 (Herv. i. O.)

708 Transkript der 2. Fokusgruppe, S. 57, Z. 1821-1824.

709 Transkript der 2. Fokusgruppe, S. 59, Z. 1863.

710 Transkript der 1. Fokusgruppe, S. 56, Z. 1730.

711 Transkript der 2. Fokusgruppe, S. 58, Z. 1828-1830.

712 Buck: Rückwege aus der Entfremdung.

713 „Das Cesetz eines mit jedermanns Freiheit notwendig zusammenstimmenden wechselseitigen Zwanges, unter dem Prinzip der allgemeinen Freiheit, ist gleichsam die Konstruktion jenes Begriffs, d. i. Darstellung desselben in einer reinen Anschauung a priori, nach der Analogie der Möglichkeit 
Bürger sprechen nicht nur dieselbe Sprache, sondern wollen, so lässt sich daraus nur schlussfolgern, im Kern dasselbe.

Ist das Ordnungsideal dieser alles durchwirkenden Rationalität verletzt, entstehen Störungen und Probleme in gesellschaftlichen Abläufen: Werden die Individuen durch Strukturen sozialer Ungleichheit in ihrer freien Selbstentfaltung gehindert, schafft das Dissonanzen im gesellschaftlichen Gefüge. Und: Die „große Politik“ erscheint so intrigant und dem archaischen Kräftespiel verhaftet wie das Skript von House of Cards. Die AfD und ihre Wähler treten daher nicht als legitime politische Wettbewerber auf, sondern als gefährliche Querulanten, die der Belehrung oder Bekehrung zu gediegeneren Diskursformen und Werthaltungen bedürfen.

Im studentischen Nachdenken über eine ideale Gesellschaftsform macht sich dieses Deutungsmuster in Forderungen nach Freiheit, Eigenverantwortlichkeit und sozialer Harmonie (inklusive Pazifismus und Abschaffung politischen Kalküls) geltend:

„Vielleicht auch, dass die Personen frei sind, das für sich selbst zu entscheiden: wieviel Miteinander und Nebeneinander sie haben wollen. ${ }^{\text {"17 }}$

„Auf jeden Fall, dass man die Kriege mal alle beendet, die gerade noch am Laufen sind. ${ }^{\text {،715 }}$

„[...] auch Aufrichtigkeit. Also, ich weiß nicht, ob es das richtige Wort ist in dem Sinne, das zum Beispiel wir jetzt nicht einerseits sagen: ,Wir wollen Weltfrieden!', aber andererseits Waffen liefern, und daraus das ganze Geld schlagen. So was zum Beispiel. Würde für mich zu einer idealen Gesellschaft gehören, wo sowas nicht der Fall ist.."716 „Ich fänd's auch schön, wenn Menschen so handeln würden oder so über andere Menschen denken würden, dass sie weder ihnen noch den anderen um sich herum noch sich selbst gefährden. [...] Das müssten dann aber alle durchziehen, damit das wirklich funktioniert. Also es muss ja nur einer aus der Reihe springen, und dann geht das nicht mehr. ${ }^{u 717}$

Das Bildungsideal fordert auch die Einebnung von Entwicklungshemmnissen der Gesamtpersönlichkeit, die durch ökonomische Ungleichheiten und durch die herrschenden Arbeits- und Lebensverhältnisse bedingt sind, sowie die Ermutigung aller zu freiwilligem Engagement:

„Sozusagen faire Löhne, gute Arbeitsbedingungen, und dass Menschen sich halt auch... ehrenamtliches Engagement zum Beispiel [... “"178

„Ich glaube, das würd' ich, glaub' ich, zum Kriterium machen, dass Leute Zeit haben, sich selbst zu verwirklichen - sei es jetzt in irgend'nem [unverständlich], was ihm naheliegt, oder wirklich eben, um der Cesellschaft irgendwas zu geben, irgendwelche

freier Bewegungen der Körper unter dem Gesetze der Gleichheit der Wirkung und Gegenwirkung." Kant, Immanuel: Metaphysische Anfangsgründe der Rechtslehre. Metaphysik der Sitten, Erster Teil [1797], Hamburg 2009, S. 41 (Herv. i. O.)

714 Transkript der 1. Fokusgruppe, S. 57, Z. 1740-1741 (Herv. i. O.)

715 Transkript der 2. Fokusgruppe, S. 56, Z. 1783-1784.

716 Transkript der 2. Fokusgruppe, S. 57, Z. 1807-1811 (Herv. i. O.)

717 Transkript der 4. Fokusgruppe, S. 54f., Z. 1724-1732 (Herv. i. O.)

718 Transkript der 1. Fokusgruppe, S. 55, Z. 1699-1700. 
Funktionen. ${ }^{\text {“119 }}$

„Dass Marktlogiken im sozialen Zusammenleben tendenziell weniger wichtig sind als soziale Zusammenhänge..720

In der folgenden, bereits zitierten Äußerung aus einer Diskussionssequenz über politische Systemalternativen wird die Sehnsucht nach mentaler Identität der Einzelnen und der Abschaffung des Konflikts in beinahe sozial unverträglicher Konzentration verbalisiert:

„Von mir aus ist es egal, welche... ob Demokratie oder Diktatur in der Cesellschaft besteht. Hauptsache, alle denken gleich. “721

Das Deutungsmuster der (politischen) Bildung der Einzelnen als gesellschaftspolitisches Panazee. Das Bewusstsein von gesellschaftlich gegeneinander wirkenden Interessengruppen fordert den Anspruch des Rationalitätsprinzips heraus, ein harmonisches Miteinander guter Demokraten zu stiften. Konflikt, politische Emotionen und Aggressionen stellen ein Handlungsproblem dar. Bilden Disharmonien und Konflikte, Chancenungerechtigkeiten und politische Emotionalität bzw. Radikalität die entscheidenden Hemmnisse des gesellschaftlichen Fortschritts, so ist (politische) Bildung das entscheidende Medium rettender Heilungskräfte. Semantische Gehalte des neuhumanistischen Bildungsbegriffs erzeugen in Vermengung mit solchen des deutschen Verständnisses politischer Bildung einen neuartigen Synkretismus. Wesentliches Instrument der Durchsetzung einer überbordenden prodemokratischen Vernunft, welche auf der Vermittlung von Werten aufsattelt. Es bedarf der eigenverantwortlichen Individuen - Nähe zur neuhumanistischen Bildungsemphase, dabei aber Vermengung mit deutschem Verständnis politischer Bildung. Dieses Deutungsmuster ist das praktisch-pädagogisch orientierte Komplement der im einheitsstiftenden Vernunftprinzip vorgedachten Gesellschaft von partizipierenden, eigenverantwortlichen, reflektierten und gebildeten Individuen. (Politische) Bildung beseitigt das Chaos, indem sie demokratiestützende, zivilisierte, aktiv partizipierende Charaktere heranzieht, pointiert: indem sie die ersehnte Identität des Wollens stiftet.

Wo das nicht gelingt, also wo sich gesellschaftlich signifikante Gruppen diesen pädagogischen Segnungen verwehren oder ihr freiwilliges Engagement gerade diametrale Ziele (chauvinistische Forderungen, inzivilen Protest, zelebrierte Intoleranz, demagogische Rhetoriken, etc.) verfolgt, regiert Ratlosigkeit. Auf eine Außerkraftsetzung der funktionierenden Werte- und Kompetenzvermittlung für ein intaktes demokratisches Miteinander findet dieses Deutungsmuster keine Antwort. Der drohenden Beunruhigung begegnet man in der Regel damit, sich auf die Rolle des verzichtbaren Zuschauers zurückzuziehen und auf das Zurückschwingen des Pendels, auf die eigendynamische Ausgleichskraft langfristiger Zyklen (von der „Mitte“ zu den „Extremen“ und zurück) zu hoffen.

719 Transkript der 1. Fokusgruppe, S. 56, Z. 1715-1718 (Herv. i. O.)

720 Transkript der 1. Fokusgruppe, S. 57, Z. 1747-1748. Vgl. hier auch Transkript der 5. Fokusgruppe, S. 39f., Z. 1203-1224.

721 Transkript der 4. Fokusgruppe, S. 56, Z. 1767-1768 (Herv. i. O.) 
Auch das schlechte Gewissen über die eigene politische Apathie, das dieses Deutungsmuster produziert, muss verarbeitet werden; in der Regel geschieht das über ein vorauseilendes mea culpa, über die Anklage der eigenen wie der allgemeinen politischen Apathie und über die Forderung, Demokratie wenigstens innig zu „schätzen“.

Der Weg in eine ideale Gesellschaft wird durch den üppigen Rückgriff auf das Panazee der (politischen) Bildung geebnet. Der gebildete Mensch ist ein sozial kompetenter und ästhetischer Mensch; er hat sich Vorurteile und Intoleranz ausgetrieben und damit das Unrecht aus der Welt verbannt:

„Über Psychologie-Studenten hör' ich immer ganz gerne auch abends in der Kneipe nochmal: ,Haben doch alle selbst 'nen Dachschaden!' [allgemeine Erheiterung] Also, ich glaube, dass so [bezüglich] Vorurteilen: Wenn die abgebaut wären, hätte man schon sogar etwas wie ideale Gesellschaft. ${ }^{722}$

„Das Miteinander, nicht das Nebeneinander [...]" $]^{423}$

„Humanismus, irgendwie. [...] Also irgendwie so dieses Tolerante, Offene, dass man halt irgendwie [...] den Menschen versucht, ohne Vorurteile zu begegnen, dass man sich hilft. [...] Und nicht so dieses: In seiner eigenen kleinen Blase leben und nicht gucken, was rechts und was links ist [...] Dass halt auf Bildung... dass da sehr viel mehr investiert wird, [...] ja, dass wir 'n bisschen mehr Dichter und Denker werden, so. [allgemeine Erheiterung] ${ }^{\text {“724 }}$

Es fallen zwei allgemeine Grundzüge der vorgestellten Deutungsmuster auf: ein starker frühliberaler Einschlag insbesondere bei den letzten zwei Deutungsmustern und eine starke Ausrichtung auf Angstbewältigung.

Die Studierenden denken sich selbst als aktive und partizipierende Staatsbürger oder tragen doch zumindest die Erwartung an sich selbst und an andere vor, sich zu solchen zu bilden. Das eigenverantwortliche Individuum, das sich zivilgesellschaftlich mit Gleichgesinnten zusammentut, ist der zentrale Bezugspunkt ihrer Ansprüche und Hoffnungen. Hier finden sich frappante Übereinstimmungen mit stark studentisch geprägten NoPegida-Aktivisten von 2015 und 2016: Aufgrund ihrer Parteinahme für kulturelle Vielfalt und Toleranz gemeinhin als „linker“ Gegenprotest zu PEGIDA rubriziert, offenbarten die NoPegidisten eine Herkunft aus protestaffinen bildungsbürgerlichen Milieus sowie eine starke „Affinität zu den frühliberalen Leitideen und frühbürgerlichen Identitäten“725. Von klassisch linker Politik, also der Veränderung oder dem Umsturz gesellschaftlicher Verhältnisse durch eine solidarisch organisierte, durch ein emanzipatives Ziel zusammengehaltene Gruppe waren die NoPegidisten und sind, ganz analog, auch die hier nur partiell aktiven Studierenden weit entfernt, ist doch

„das primäre Elixier und der Motor einer guten Cesellschaft nicht das Kollektiv, sondern das mündige, selbst-denkende, in eigener Entscheidungssouveränität handelnde Individuum. Dieses selbstbewusste, durch Wissen befähigte Individuum ist der

722 Transkript der 1. Fokusgruppe, S. 56, Z. 1724-1728.

723 Transkript der 1. Fokusgruppe, S. 56, Z. 1736.

724 Transkript der 4. Fokusgruppe, S. 54, Z. 1700-1721 (Herv. i. O.)

725 Marg, Stine/Trittel, Katharina/Schmitz, Christopher/Kopp, Julia/Walter, Franz: NoPegida. Die helle Seite der Zivilgesellschaft?, Bielefeld 2016, S. 135. 
Nukleus der ,Bürgergesellschaft', wie man 1840 gesagt hatte, beziehungsweise ,Zivilgesellschaft', wie es in der Gegenwart heißt. Und damals wie heute ist für diese liberale Bürgerlichkeit die Stadt, welche Freiheit und Optionsvielfalt von Lebensnormen, auch Orte der Debatten und Diskurse bietet, die ideale Sphäre einer selbstverwalteten, infolgedessen durch und durch liberalen Öffentlichkeit.“726

Insofern kann voll und ganz bestätigt werden:

„Das neuhumanistische Bildungsideal und die liberalen Leitsterne aus der Zeit vor dem Kaiserreich, vor der Nationalstaatsbildung, vor der Hochindustrialisierung, vor der Macht zentralistischer Großorganisationen haben offenkundig mehr Spuren und Prägungen hinterlassen als oft vermutet. ${ }^{\text {i727 }}$

Die Studierenden beziehen Stolz und Selbstbewusstsein aus ihrer Zugehörigkeit zur civitas academica, einem Milieu von Gebildeten. Sie sehen sich demgemäß unter Rechtfertigungsdruck, neigen zur wortreichen Rationalisierung ihrer eigenen Wahrnehmungen und Verhaltensweisen. Aus dieser Zugehörigkeit fließt ein latenter Elitismus, der im Widerspruch zur chancengesellschaftlichen Egalisierungsrhetorik und zur Anklage persistenter sozialpolitischer Ungerechtigkeiten steht. Selbstreflexive Diskussionseinwürfe der Fokusgruppenteilnehmer, die das aufspießen, verhallen weitgehend resonanzlos; so auch dieser:

„[W]elche Machtressourcen besitzt welche Bildung? Also welche Stimme kann sich durchsetzen, einfach dadurch, dass sie 'ne gesellschaftlich legitimierte oder 'ne gewisse Macht besitzt? Und dann ist nämlich dieses mit der Demokratie und diesem ganzen... dieser flachen Ebene vorbei. ${ }^{\text {" } 28}$

Im Feld des Politischen führen die beachtlichen Kontinuitätslinien vielmehr zu moralischen Simplifizierungen gesellschaftlicher Auseinandersetzungen: Wie in der skizzierten NoPegida-Studie, so sehen sich auch die hier „Befragten größtenteils auf der moralisch richtigen Seite ${ }^{\text {“729 }}$, damit im Grunde als der (bösartigen) Masse, die für sie stets einen potenziellen (rechten) Mob darstellt, als überlegen an. Die Berufung auf den "richtigen“, den "guten“ und damit verabsolutierten Wertehorizont legitimiert diesen doch beachtlichen Hochmut gegenüber allen nicht Geläuterten. Wo demokratische Wettbewerber auf den Plan treten, die sich den Segnungen (politischer) Bildung verwehren, brechen die studentischen Deutungsmuster ab. Bestimmte Personengruppen - insbesondere „die Dummen“ - vom demokratischen Prozess fernhalten zu wollen, verträgt sich durchaus mit dem grundierenden Bildungsideal, nicht aber mit den vollmundig bekräftigten demokratischen Grundprinzipien. Auch das, nicht allein die demagogische Raserei gegen die Migrationsgesellschaft, ist ein Effekt identitätspolitischer Tribalisierung der Gesellschaft.

Da sämtliche Deutungsmuster immer auch der Selbstversicherung dienen, d. h. sich und anderen die Gültigkeit gewisser gesellschaftlicher Ordnungsprinzipien be- 
weisen sollen, verraten sie auch etwas über spezifische Ängste, die sie zu bewältigen versuchen. Das Deutungsmuster der Chancengesellschaft etwa kompensiert die studentische Angst vor dem Misserfolg. Das meritokratische Ideal zeigt bereits seit Jahren deutliche Risse. In den 2000er Jahren sei, so heißt es in einer Online-Erhebung des Studierendensurvey von 2011, die vollständige „Abwendung von traditionellen Bindungsund Ordnungsinstanzen wie Tradition, Religion, Nation“ und sozial verbindlicher „früherer Stützen“ und „Wertspender“ vollzogen worden. Im Ergebnis stehe eine „studentische Haltung, keine fertigen Muster zu übernehmen“ und Wertbezüge „selektiv und nicht weiter verbindlich“, ja eklektizistisch herzustellen. ${ }^{730}$ Allgemeine Skepsis, Distanziertheit und Ratlosigkeit sei das vordringlichste Merkmal des studentischen Blicks auf Gesellschaft; ein Phänomen, das letztlich auf politisch-sozialen Defätismus zurückzuführen sei, der mit der Wahrnehmung eines aus den Fugen geratenen Zuteilungsmechanismus von Ressourcen und Statuspositionen zusammenhänge:

„An die fairen Aufstiegschancen glauben $55 \%$ der Studierenden nicht. [...] Als gesellschaftliches Kriterium für Aufstieg und Anerkennung wird das Leistungsprinzip von den Studierenden am meisten befürwortet; vielen erscheint es aber in der Cesellschaft nicht angewandt, zwar beschworen, aber ohne Geltung. Daher ist der Eindruck von sozialer Ungerechtigkeit weit verbreitet; offenbar wächst das Unbehagen, faire Aufstiegschancen gingen zurück. ${ }^{\text {7731 }}$

Bereits seit Anfang des Jahrzehnts zweifelten viele an der Gültigkeit des Prinzips, Wohlstand und Aufstieg durch Leistung erlangen zu können. Sie wünschen sich die Chancengesellschaft nicht unbedingt für den sozialen Aufstieg, sondern um Harmonie zwischen Erwerb und Freizeit bei grundierender materieller Sicherheit zu erlangen. ${ }^{732}$ Tatsächlich sieht sich die junge Generation insgesamt einer anhaltenden Spreizung von Einkommens- und Vermögensdifferenzen und stark gedämpfter intergenerationeller Aufstiegschancen gegenüber, ferner tendenziellen Fragilität einmal erreichter Statuspositionen durch die Zunahme befristeter Beschäftigungsverhältnisse und einen sinkenden Wert der immer öfter schlicht vorausgesetzten höheren Bildungszertifikate; Erwerbsbiographien, auch akademische, verwandeln sich mehr und mehr in ein lebenslanges Ringen um den Frieden einer auskömmlichen Position, in eine Jagd nach dem ersehnten glücklichen Zufall. ${ }^{733}$ Auf die Realisierung der Chancengesellschaft zu pochen, erscheint vor diesem Hintergrund auch als defensiver, ja hoffender Akt. Das verrät eine Beschädigung des Deutungsmusters, die das Bedürfnis nach zusätzlichen Orientierungsankern weckt, um die Deutung gesellschaftlicher Ordnung zu vollziehen; daher wohl auch die Hinwendung zu frühliberalen Motiven. Die traditionelle, oft aber stereotyp und geschichtslos vorgetragene Bildungsemphase bietet demgegenüber Zuflucht, ja fungiert bisweilen als Identitätssurrogat, als Selbstberuhigungs-

730 Vgl. Bargel/Simeaner: Gesellschaftliche Werte und politische Orientierungen., S. 7.

731 Ibid., S. $10 f$.

732 Vgl. ibid., S. 10 und 15.

733 Vgl. Voswinkel, Stephan: Das (schwindende) Versprechen des sozialen Aufstiegs, in: Aulenbacher, Brigitte/Dammayr, Maria/Dörre, Klaus/Menz, Wolfgang/Riegraf, Birgit/Wolf, Harald (Hg.): Leistung und Gerechtigkeit. Das umstrittene Versprechen des Kapitalismus, Weinheim 2017, S. 64-79, hier S. 69-72. 
und Selbstwert-Prothese, schließlich eben als gesellschaftspolitisches Panazee. Bezugspunkt ist der Rückzug in die befriedete Zone marktenthobener (imaginierter) Kollektivität der Gebildeten. Das stiftet Gruppenzugehörigkeit. Augenfällig wird das auch und gerade in zweifelnden Sequenzen und durch Äußerungen von jenen, denen gerade nicht recht wohl ist in diesem „Mikrokosmos“ Universität: ${ }^{734}$ Ihre Sicht untermauert, dass die Interaktionsarenen der Universität tatsächlich ein solcher Mikrokosmos sind, und zwar mit allen dadurch implizierten Behaglichkeiten und Unbehaglichkeiten eines mental (nicht durchweg räumlich!) relativ isolierten Bevölkerungssegments. Das Deutungsmuster der einheitsstiftenden Rationalität wiederum verweist auf die Angst vor dem Chaos einer ungezügelten Welt, Angst vor emotionsgetriebenen Personen und Gruppen, Angst vor allem Extremen, Radikalen, Zwielichtigen. Besonders bewegend scheint für viele Studierende die Begegnung mit wissenschaftlich-deduktivem Denken zu sein, die sie zur optimistischen Ineinssetzung von Rationalität und gesellschaftlichen Fortschrittskräften verleitet. Erfahrungen wie diese halten zur Dankbarkeit und Eintracht an, scheinen sie doch zu gebieten, die demokratische Staatsform, den allgemeinen Wohlstand und die zwischenmenschlichen Verständigungspotenziale im Innersten zu schätzen, als könnten sie jederzeit weggenommen werden, als würde der Luxus eines weitgehend sorgenfreien Lebens ihnen das schlechte Gewissen von unverdient Bessergestellten bescheren. ${ }^{735}$ Auch das Deutungsmuster des Panazees der (politischen) Bildung spricht das Schreckbild des Chaos, der unlösbaren gesellschaftlichen Probleme, des anwachsenden, aggressiv geladenen Konfliktpotenzials und einer ungewissen Zukunft aus. Es antwortet auf das Verlangen nach Erleichterung durch eingängige Lösungsrezepte. Eingängig jedoch können sie nur bleiben, solange man nicht allzu tief in die Struktur konkreter Handlungsprobleme sowie in die Brüchigkeit der Heilungskraft Bildung (manchen vermittelt sie „nur“ Kenntnisse, ohne den Charakter in die gewünschte Richtung zu lenken) selbst vordringt. Man muss ein Stück weit draußen stehen, damit die Idealisierung plausibel sein kann, ja sich eine Portion Stereotypie gönnen. Aus diesem Grund scheinen insbesondere Bildungsaufsteiger am stärksten an die gesellschaftsumbildenden Kräfte der Bildung zu glauben - sie scheinen am ehesten darüber hinwegsehen zu können, dass die heutige marktorientierte Universität mit jener traditionellen Bildungsinstitution nur noch wenig zu tun hat, die sie einst war. Mit den hier identifizierten Deutungsmustern, auch und gerade mit den inbegriffenen anachronistischen Bezugnahmen, retten die Studierenden den Anspruch, dass es alles in allem rational zugehe, verfolgen mithin eine Kontingenzbewältigungs- und Selbstberuhigungsstrategie.

Die Ergebnisse erlauben eine Reihe von Schlussfolgerungen, welche das empirische Wissen über die politischen und sozialen Orientierungen von Studierenden mit besonderem Blick auf ihr politisches Potenzial ${ }^{736}$ erweitern. Erstens ist die Beobachtung

734 Vgl. Transkript der 5. Fokusgruppe, S. 24, Z. 726-742 und Transkript der 7. Fokusgruppe, S. 24, Z. 758-768 und 26, Z. 813-831.

735 Unter den nichtstudierenden Jugendlichen und jungen Erwachsenen der Vorgängerstudie wäre das undenkbar: Sie träumen vom sozialen Aufstieg. Vgl. Schenke et al.: PECIDA-Effekte, S. 226245.

Vgl. die Aufschlüsselung dieses Begriffs in Kapitel I.3 dieser Studie. 
der Autoren des Studierendensurveys zu bestätigen, dass es Studierenden im Falle verschärften gesellschaftlichen Konfliktpotenzials oder auch eingetrübter Berufsaussichten durchaus nicht an politischen Energiequellen mangelt. Empörung entsteht schnell, wo Ungerechtigkeiten - verstanden als erhebliche Störungen im Gleichgewicht der Bildungs- und Berufschancen - gewittert werden. Diese gesellschaftskritischen Regungen können sicher auch zu Protestpotenzial führen, scheinen sich aber nicht $\mathrm{zu}$ gefestigten und ausdauernden „Gegenkonzepten“ zu verdichten: Für die einstigen Reservoirs an Ordnungsideen und indiskutablen Wahrheiten, die die von Bargel und Simeaner als "traditionell“ zusammengefassten Rezepte einst bereitgehalten haben, ist bisher kein tragfähiger Ersatz vorhanden. ${ }^{737}$ Zwar könnte der in seinem leistungskritischen Moment anspruchsvolle Bildungsbegriff wie im Bildungsstreik von 2009/10 hier ein naheliegendes Vehikel politischer Mobilisierung auch für klassische „egoistische“ Interessen bilden. Aber wo - wiederum anders als im Bildungsstreik von 2009/10 - ein Mobilisierungsnetzwerk fehlt, gibt es kaum politische Formativkräfte, die das Vakuum füllen: Es mangelt an organisatorischer Einbindung und Erfahrungswissen, an attraktiven politischen Betätigungsfeldern, letztlich schlicht an Kollektivität. Eine breite Beteiligung an Protestbündnissen mit außeruniversitären und außerschulischen Zielsetzungen, die über die verhältnismäßig kleine Gruppe von Aktiven in Politgruppen hinausgeht, erscheint insgesamt eher unwahrscheinlich.

Zweitens ist darüber hinaus festzuhalten: Präpariert man die politisch-sozialen Deutungsmuster heraus, die die studentischen Einstellungen, Orientierungen, Werthaltungen und Urteile sinnhaft und rechtfertigend strukturieren, werden die angestrebten Tiefenschichten ideologischer Leitlinien bzw. privater Gesellschaftstheorien erreicht, zu denen die repräsentative Survey-Studien methodisch bedingt nicht vordringen können. Daher sind Zweifel an der in II.3.5 referierten mentalen Fragmentierung angebracht, die der Studierendensurvey diagnostiziert. Gewiss erscheinen die politischen Einstellungsmuster zerklüftet und widersprüchlich, auch die Wertbezüge bisweilen selektiv, doch in jener politisch-mentalen Tiefendimension, die einst (politische) Ideologie hieß, finden sich durchaus einheitsstiftende Orientierungen und verklammernde Sinnstrukturen, die so etwas wie einen einigenden gesellschaftspolitischen Kompass von Studierenden ergeben. Die Glättung von widersprüchlichen Einstellungen und Narrationen (beispielsweise das Ineinander von egalitär gerichteter Gesellschaftskritik und der Einforderung marktferner Freiräume für das eigene Gebildetenmilieu) wird innerhalb einzelner Deutungsmuster (hier das Vernunftund Bildungspathos) möglich; widersprüchliche Deutungsmuster (beispielsweise das Einfordern radikaler Korrektive in einer Demokratie bei gleichzeitiger Paternalisierung einer mehrheitlich als unmündig, da politisch verführt wahrgenommenen AfDWählerschaft oder die Vermengung von neuhumanistischen Bildungskonzeptionen mit dem deutschen Begriff politischer Bildung) hingegen führen zum Orientierungsverlust

737 „Für die Zukunft wird es bestimmend sein, wie die Studierenden mit diesen Defiziten [an sozialer Cleichheit und Toleranz, J. S.] umgehen. Cegenwärtig sind damit nur Ansätze von Protest und Ablehnung verbunden, vielleicht auch deshalb, weil es an Gegenkonzepten fehlt und traditionelle nicht mehr ausreichend erscheinen. Auch bremst die Solidarität der Studierenden ein engagiertes Einlassen auf diese Probleme." Ibid., S. 11. 
und Reflexionsabbruch. Zu einem alle gesellschaftlichen Zusammenhänge integrierenden Deutungssystem organisieren sich auch die studentischen Deutungsmuster nicht mehr. Aber: Darin nur eine melancholisch zu zeichnende Verfallsgeschichte zu sehen, verfehlt die Doppelseitigkeit dieses Verlustes einstiger Gewissheiten. Zu den Folgen gehört nicht nur, dass verbindliche, sozialmoralisch verpflichtende Überzeugungen jenseits individueller ethischer Reflexionen weitgehend abgerieben sind und Studierende daher sprunghafter und volatiler urteilen - sondern eben auch, dass sie tatsächlich toleranter und kritischer mit konkurrierenden Sichtweisen umgehen können.

Drittens wird das partielle Fortleben tradierter Mentalitätselemente aus der 200-jährigen Geschichte moderner akademischer Jugend sichtbar. Zwar sind wesentliche Kerngehalte des herausgearbeiteten gesellschaftspolitischen Kompasses gesellschaftsgeschichtlich ererbt. Aber: Während bildungshumanistische Versatzstücke einen starken Einfluss auf das Denken und Empfinden der Studierenden ausüben, ist von der einst starken Tradition verbandsmäßiger Organisationsversuche als Gesamtstudentenschaft - bzw. in anderen Worten: der sozialmoralischen Festigkeit des Eingebundenseins in ein repräsentierbares Kollektiv von Studierenden, sei es in Gestalt von Burschenschaft, DSt oder SDS - nur noch bei Einzelnen eine Ahnung vorhanden. Beide Traditionslinien waren einst eng verwoben und an die relative sozialstrukturelle Homogenität eines bildungsbürgerlichen Herkunftsmilieus geknüpft. Warum sich die eine erhält, während die andere verblasst, hängt mit der inneren begriffs- wie sozialgeschichtlichen Evolutionslogik des deutschen Bildungskonzepts als Amalgam moderner Bildungsauslese und anachronistischem Emanzipationsanspruch zusammen. Der studentische Korporationsgedanke ist verschwunden, und mit ihm das besondere Verlangen „nach größerer studentischer Selbstbestimmung “738 als Motor studentischer Organisation und (politischer) Subkultur. ${ }^{739}$ Trotz aller Kritik an Autonomie-hemmenden Studienbedingungen ist damit auch das entscheidende Movens des einstigen Dauerthemas „Hochschulreform“, verstanden als Steigerung der Einflussmöglichkeiten einer demokratisch verfassten Studierendenschaft mit allgemeinem Repräsentationanspruch, erloschen. Die normative Kraft des Bildungshumanismus aber erhält sich. Oder anders: Humboldt erscheint noch heute plausibel; Urburschenschaft und SDS sind Historie. Dies macht, abgesehen von den sich historisch wandelnden einzelnen Einstellungsmustern, den entscheidenden Aspekt des nun vollständig erzählten jungakademischen Mentalitätswandels im Längsschnitt aus. Es existieren auch heute noch Strukturen eines Milieubewusstseins der Gebildeten, die sich die Studierenden, wo nicht bereits zuvor im sozialen Nahbereich, so doch spätestens während ihres Studiums zu eigen machen.

738 Jarausch: Deutsche Studenten, S. 244.

739 „Der, heimliche Lehrplan' der korporativen Charaktererziehung war für den akademischen Stil und die Verhaltensweisen ebenso wichtig wie das formelle Studium." Ibid., S. 9. 



\title{
IV. Formbares Bildungspathos? Ein Fazit
}

\author{
„SCHÜLER. Ich wünschte, recht gelehrt zu \\ werden, \\ Und möchte gern, was auf Erden \\ Und in dem Himmel ist, erfassen, \\ Die Wissenschaft und die Natur. \\ MePhistopheles. Da seid Ihr auf der rechten \\ Spur; \\ Doch müßt Ihr Euch nicht zerstreuen lassen. \\ SCHÜLER. Ich bin dabei mit Seel' und Leib; \\ Doch freilich würde mir behagen \\ Ein wenig Freiheit und Zeitvertreib \\ An schönen Sommerfeiertagen. “1 \\ „Der Traditionsverlust durch die Entzau- \\ berung der Welt [...] terminiert in einem \\ Stand von Bilderlosigkeit. [...] Nichts verhält \\ mehr den Geist zur leibhaften Fühlung mit \\ Ideen."
}

Gefragt wurde nach dem politischen Potenzial von Studierenden in Geschichte und Gegenwart. Die vorliegende Studie nahm ihren Ausgang bei einem - oft mit „1968“verbundenen - kulturell überlieferten Stereotyp, nämlich der Auffassung, die Studierenden in Deutschland neigten zu einem kritisch-subversiven Bewusstsein, zu rebellischen Haltungen oder gar zu subversivem, oppositionellem politischen Denken. Sie kam vermittels einer aspektzentrierten historischen Längsschnittbetrachtung zu dem Zwischenergebnis, dass studentisches Protestpotenzial zwar weiterhin besteht, dass sich aber infolge gesamtgesellschaftlicher Entwicklungen - Industrialisierung, Konsumgesellschaft, Bildungsexpansion - jene relative soziale wie sozialmoralische Homogenität der Studierendenschaft, mithin jenes subkulturell verwurzelte Organisationsleben verflüchtigt hat, das einst den politischen Deutungshorizont maßgeblich mitbestimmte.

Goethe, Johann Wolfgang: Faust. Eine Tragödie. Erster und zweiter Teil [1797-1832], München 1997, S. 57.

2 Adorno: Theorie der Halbbildung, S. 105. 
Dabei hatte sich die Frageperspektive dem historischen Verlauf anzupassen, um den studentischen Mentalitätswandel adäquat nachzuzeichnen. Insbesondere das Auftreten ausdauernder Studentenbewegungen, welche stets Ergebnis einzigartiger soziohistorisch bestimmter Ursachenbündel und Gelegenheitsfenster gewesen sind, erscheinen aktuell unwahrscheinlich. Während zudem das langfristige Verblassen weltanschaulicher Konfliktlinien zwischen „linken“ und „rechten“ Studierenden in der Bundesrepublik auffiel, schienen die jüngsten Studierendenproteste auf einem weiterhin lebendigen, wenn auch genetisch alten Bildungspathos aufzusatteln. Die aus der Auswertung des Fokusgruppenmaterials gewonnenen politisch-sozialen Deutungsmuster einer (herzustellenden) chancengerechten Gesellschaft, eines einheitsstiftenden und harmonisierenden Rationalitäts- bzw. Vernunftprinzips und der (politischen) Bildung des Einzelnen als gesellschaftspolitisches Panazee differenzierten dieses Zwischenergebnis entscheidend: Bildungshumanistische Versatzstücke dienen nicht nur als verbale Ornamentik von Forderungen nach geringerem Prüfungsdruck, sondern fungieren als strukturbildendes Element eines gesellschaftspolitischen Kompasses von Studierenden insgesamt. Bildung, situativ vermengt mit semantischen Gehalten politischer Bildung, bedeutet nicht nur Fachwissen und Kompetenzerwerb, ist nicht nur ein Karrieremotor, sondern auch Medium der Charakter- und Persönlichkeitsveredelung; sie treibt gesellschaftlichen Fortschritt an und vermittelt sogar spezifische liberale Werte und Handlungsmaximen, soll nicht zuletzt als Impfung gegen den Rechtspopulismus wirken. Der starke bildungshumanistische Einschlag hebt die akademische Jugend ${ }^{3}$ in der Tat von nichtstudierenden Jugendlichen und jungen Erwachsenen frappant ab. Früher Element eines spezifischen bildungsbürgerlichen Gesellschaftsbildes, hat sich der Bildungshumanismus offenbar zu einer von seinem Herkunftsmilieu emanzipierten, verselbstständigten und fungiblen Deutungskomponente universalisiert, ganz so wie die Bildungsexpansionsdynamik die einst vergleichsweise kleine Gruppe von Studierenden exponentiell erweitert und dem Bildungsbürgertum die Festigkeit einer abgrenzbaren Sozialformation genommen hat. Das bestätigt eine Tendenz, die bereits Mitte der 1950er Jahre unter einem großen Teil von Frankfurter Studierenden registriert wurde, nämlich der Einfluss neuhumanistisch-bildungsbürgerlicher Denktraditionen auf gesellschaftliche Ordnungsvorstellungen (etwa als Vorstellung von einer akademisch gebildeten geistigen Elite) unabhängig von der Schichtenzugehörigkeit der Studierenden. ${ }^{4}$

„Das traditionsfeste Motiv aus dem Zusammenhang jenes bildungshumanistischen Cesellschaftsbildes der nationalliberalen Phase ist die Dichotomie zwischen Innerlichkeit und bloß äußerem, gesellschaftlichem Bereich. [...] Ceblieben ist die Auflösung sozialer Merkmale in psychologische. Nicht Interessenlagen, nicht die Lebensbedingungen von Gruppen, sondern Charakter, Mentalität, Lebensstil, Haltung, mit einem Wort: Bildung, nämlich Geist und Cesinnung werden zu den zentralen Kategorien des Cesellschaftsbildes. [...] Das Elternhaus mit akademischer Tradition scheint 
freilich als solches auf das gesellschaftliche Bewußtsein der Kinder keinen besonderen Erziehungseinfluß auszuüben. Die akademische Tradition ist eher als Moment des sozialen Status insgesamt wirksam, denn als Faktor, auf den die bildungshumanistischen Ideale spezifisch zurückgehen. ${ }^{5}$

Dass das Bedeutungsspektrum von „Bildung“ eine so zentrale Rolle für studentische politisch-soziale Deutungsmuster innehat, ist kein Zufall. Wie in Kapitel III.3.1 angedeutet, lässt sich schon die neuhumanistische Bildungsphilosophie selbst als Versuch begreifen, den mit dem Verschwinden der theokratischen Weltordnung - also der inhärenten Sinnhaftigkeit des Seins - verbundenen Bruch zwischen ideellen Sinnstrukturen und gesellschaftlicher Realität wieder zur Übereinstimmung zu bringen. Zudem wird es Studierenden beinahe täglich als Signalwort gelungener Lebensplanung und gesellschaftlichen Wohlstands serviert; das oft weihevoll vibrierende Stichwort „Bildung“ zählt, wenn auch nicht streng humboldtianisch gemeint, zu den großen Mantras der deutschen Universitäten und der deutschen Bildungspolitik. Bildung verbessert das Individuum, Bildung verbessert die Gesellschaft, ja Bildung soll sogar demokratisch konfliktstillend wirken. Das aber schürt auch ein konformistisches, kollektivnarzisstisch grundiertes Ressentiment gegen die Nichtgebildeten, die Zurückgebliebenen, gegen „die Rechten“. Es vollbringt das Kunststück, zugleich der Mehrheit der Vernünftigen anzugehören als auch jener Gruppe an Auserwählten, die die Weihen der höheren Bildung empfangen. Während aber diese mindestens zweihundert Jahre alte Bildungsphilosophie fröhliche Urständ im jungakademischen Bewusstsein feiert, hat der ebenso altehrwürdige studentische Korporationsgedanke - die Studierendenschaft als potenzielles politisches Subjekt mit gemeinsamem reformerischem Interesse - seine Prägekraft weitgehend eingebüßt. Das geht über die Dezimierung studentischen Organisationswesens hinaus, streicht im Grunde die einstige ideelle Grundlage kollektiver studentischer Praxis. Das limitiert die praktisch-politische Handlungsfähigkeit der Studierenden entscheidend. Unter dem von ihnen häufig geforderten „Engagement“ verbirgt sich in der Regel der Wunsch, über zivilgesellschaftliche oder ehrenamtliche Tätigkeiten im Kleinen Selbstwirksamkeitserfahrungen zu sammeln, während die konfliktive politische Auseinandersetzung verzagt gemieden wird. Sollte es zu tieferreichender politischer Frustration kommen, etwa wenn die Berufsaussichten für Universitätsabsolventen das Bedürfnis nach materieller Absicherung nicht mehr plausibel decken können, ist zurzeit kein politischer Akteur in Aussicht, dem die Studierenden ihr Vertrauen schenken. Aber: Die besondere Lebenssituation des Studierens bietet grundsätzlich nach wie vor Freiräume für selbstständige zivilgesellschaftliche, politische und intellektuelle Betätigung, die von vielen sowohl identifiziert als auch genutzt werden. Auch, wenn es richtig sein mag, dass sich diese Freiräume in den letzten Jahren und 
Jahrzehnten zugunsten eines neuen Selbstoptimierungszwangs reduziert haben, ${ }^{6} \mathrm{zu}$ mal nach den Bologna-Reformen. ${ }^{7}$

Das berührt die Frage des politischen Potenzials von Studierenden im Innersten. Denn damit die Freiräume und Motivationsquellen politischer Aktivität genutzt werden, etwa durch ein umtriebiges Mobilisierungsnetzwerk nach dem Muster des Bildungsstreiks 2009/10, wäre derzeit eine spezifische gesellschaftskritische Sprache erforderlich. Eine Sprache, die an die spezifischen Interessen der gebildeten Jugend, genauer: an die in sozialethisches Vokabular gekleideten gehobenen Ansprüche der Bildung appellieren kann, über marktenthobene, von Staatsseite gesicherte Enklaven und komfortable Berufsaussichten zu verfügen. Gewiss war das nie fundamental anders, wie die ausführlichen Exkurse zu studentischen Oppositionsbewegungen gezeigt haben, auch während des vielgerühmten demokratischen Aufbruchs der 1960er Jahre. Das Besondere an den emanzipativen Studentenbewegungen von „1848“ und „1968“ aber war ihr Surplus, ihre über das Privilegiensicherungs- und Aufstiegsinteresse hinausgreifende Anteilnahme an gesellschaftspolitischen Themen. Dass die Hochschulreform von unten die Reform der Gesamtgesellschaft antizipieren könne, war die Prämisse der frühen Burschenschaftsbewegung, der späteren Freistudentenschaft und des SDS. Diese Traditionslinie ist aufgrund der relativen Dezimation organisierter Studierender beinahe vollständig erloschen. Die heutigen Studierenden haben ihren nichtstudierenden Altersgenossen in Sachen utopischen Vorstellungsvermögens nichts mehr voraus. $^{8}$ Sie treten genauso „realistisch“ auf, haben die für moderne (post-)industrielle Gesellschaften charakteristische "transzendentale Obdachlosigkeit" ${ }^{\text {“9 }}$ adaptiert und die Charaktermaske jener Bescheidwissenden angenommen, die sich nichts vormachen lassen. Einen eindrücklichen Kontrast mag man aus den Hochschulreformdebatten der 1960er Jahre beziehen, als besonders umtriebige Studenten Bücher über die demokratische Umgestaltung der Universitäten als Schritt in eine freiere Gesellschaft schrieben ${ }^{10}$ und von der herausgeforderten professoralen Seite (selbst-)kritische Antwort erhielten. ${ }^{11}$ Natürlich spielen hier auch grundstürzende sozialgeschichtliche Verschiebungen eine Rolle. In der Bildungsgesellschaft die alte „Systemfrage“ zu stellen, ergibt für ihre Profiteure wenig Sinn. Nur: Sollte es zu flächendeckender akademischer Arbeitslosigkeit kommen, fehlt den Studierenden, die ihre spätere materielle Absicherung für

6 Vgl. Reinders, Heinz: Vom Bildungs-zum Optimierungsmoratorium, in: Diskurs Kindheits- und Jugendforschung, 11. Jg., H. 2/2016, S. 147-160 und Hoffmann, Dagmar/Stecher, Ludwig: Bildungsmoratorium revisited (Editorial), in: Diskurs Kindheits- und Jugendforschung, 11. Jg., H. 2/2016, S. 143-145.

7 Vgl. Kühl, Stefan: Der Sudoku-Effekt. Zu den Gründen und Folgen der Komplexitätssteigerung an den Hochschulen, in: Soziale Systeme, 16. Jg., H. 2/2010, S. 440-456.

8 Vgl. Schenke et al.: PEGIDA-Effekte, S. $234 \mathrm{f}$.

9 Lukács, Georg: Die Theorie des Romans. Ein geschichtsphilosophischer Versuch über die Formen der großen Epik [1916], Darmstadt/Neuwied 1984, S. 32.

10 Gemeint ist der - sicher in vielerlei Hinsicht zeitgebundene und ohne die Unterstützung des damaligen außerordentlichen Professors Habermas wohl auch undenkbare - Band von Nitsch et al.: Hochschule in der Demokratie.

11 Vgl. Schwan, Alexander/Sontheimer, Kurt (Hg.): Reform als Alternative. Hochschullehrer antworten auf die Herausforderung der Studenten, Köln/Opladen 1969. 
garantiert halten, jeder Ansatzpunkt einer begrifflichen Handhabe. Navigation im Alltag wird ihnen schwerfallen, die berühmte gewohnte „Welt“ zusammenbrechen; daraus kann destruktive Aggression, ein neues solidaritätsbasiertes Engagement (beides Phänomene der organisationsstarken Jahrzehnte des Kaiserreichs und der Weimarer Republik) oder eskapistische Resignation (wie unter den alternativbewegten Studierenden der frühen 1980er Jahre) folgen. Andererseits fehlt es für breiteren politischen Aktivismus tatsächlich auch an einem identifizierbaren Gegner, an etwas, woran man sich abarbeiten könnte. An etwas, was dann auch Ziele visieren lässt, Sinn generieren kann, den Wunsch nach Organisation und Bündelung nähren könnte. Derzeit dominiert hingegen die Scheu vor der politischen Selbstpositionierung. ${ }^{12}$

Es mag sich allerdings die Frage anschließen, ob in den kommenden Jahren nicht gewisse Konfliktszenarien wahrscheinlicher werden könnten, die dann doch zur Aktivierung des studentischen Interesses am eigenen Statuserhalt oder an der Durchsetzung sozialpolitischer Gerechtigkeit führen mögen, mithin zu einem stärkeren Eingriff von Studierenden in gesellschaftspolitische Auseinandersetzungen. Gesamtgesellschaftlich gesehen sind wir schließlich Zeugen eines politkulturellen Rumorens. Einerseits hat die Apotheose von Partizipation und Transparenz infolge von „1968“ bis heute Freiräume für staatsbürgerlichen Unmut, für Protestbewegungen und Demonstrationen geschaffen und somit auch Resonanzräume und Korrektive für das Handeln der politischen Eliten, gar „Fermente für rechtzeitige systemimmanente Innovation, die andernfalls zu spät hätte kommen können ${ }^{\text {‘13 }}$, bereitgestellt. Andererseits hat gerade dieser verschärfte Legitimitäts- und Transparenzanspruch die Weichen für jene Ausbreitung von Misstrauen gegenüber den politischen, kulturellen und wirtschaftlichen Eliten zu stellen geholfen, die heute - nicht erst durch die Etablierung der digitalen Medien - Legion sind. ${ }^{14}$ Am Gegenstand der Studierenden könnte sich das mit der ohnehin wechselhaften Geschichte der Bildungsexpansion und der durch sie geradezu periodisch produzierten Friktionen vermischen. Szenarien der Eskalation sind jedenfalls rasch skizziert: Was, wenn die Arbeitsmärkte die rasant steigenden Absolventenzahlen nicht mehr absorbieren können? Was, wenn sich der oft konstatierte Kulturkonflikt zwischen Kosmopolitismus und Kommunitarismus im Zuge der weiteren Entwicklung der Bundesrepublik zur Migrationsgesellschaft parallel weiter zuspitzt? Was, wenn der Trend in Richtung Vielparteiensystem die noch verbliebenen politischen Fronten weiter durcheinanderwirbelt? Werden Studierende eine wesentliche Rolle in den kommenden Auseinandersetzungen spielen? Ist unter bestimmten Voraussetzungen und Rahmenbedingungen womöglich massenhafter politischer Aktivismus, gar eine vierte Studentenbewegung denkbar? Dass es derzeit an den wesentlichen Voraussetzungen massenhafter Jugendbewegungen fehlt, hat Franz Walter herausgearbeitet: Dazu zählen uto-

12 Vgl. die Kapitel II.3.4, II.3.5 und III.3.2 dieser Studie.

13 Vgl. Walter: Zeiten des Umbruchs?, S. 19.

14 Vgl. Rosanvallon: Counter-Democracy. Inwiefern hier die Kausalketten zu ziehen sind, ob etwa die Erosion der traditionellen Volksparteien-Herrschaft nicht viel stärker mit der Ausdifferenzierung von Lebensstilen und Präferenzmustern zusammenhängt, oder ob das Eigengewicht von Mentalitäten den Wandel des Bewusstseins zeitigt, berührt konzeptionelle Grundfragen der politischen Kulturforschung. Eine bündige Antwort ist hier schon aus epistemologischen Gründen nicht möglich. 
pische und visionäre Energien potenzieller Gegeneliten, besonders der feste Glaube an eine mögliche, radikal andere Form von Gesellschaft, die Überzeugung von der Richtigkeit des avisierten Weges sowie charismatische Führerfiguren, die diese Hoffnungen $\mathrm{zu}$ inkorporieren und in sinnfällige, vermittelbare Parolen zu gießen vermögen. Dazu zählt aber auch die demographische Schwäche der Jugend in einer alternden Gesellschaft. ${ }^{15}$ Hat sich demgegenüber nicht aber doch gezeigt, dass sich unter Studierenden manche einigenden Orientierungen finden, die die verloren gegangene Bindekraft politischer Fernziele und kollektiven Zugehörigkeitsbewusstseins zumindest temporär stiften könnten? Könnten nicht jene Vereinzelten, die trotz allem nach einem tieferreichenden Verständnis der Gesellschaft und nach Perspektiven ihrer praktischen Veränderung suchen, sich zu Anführern und Einpeitschern aufschwingen? Derzeit erwarten zwei Drittel der Studierenden nach wie vor günstige Berufsaussichten, so viele wie nie zuvor. Nur noch 14 Prozent fühlen sich von schlechten Berufsaussichten im Studium belastet. ${ }^{16}$ Was aber, wenn plötzlich akademische Arbeitslosigkeit einsetzen sollte? Das naheliegende Modell politischen Protests wäre hier ein „Aufruhr der Ausgebildeten ${ }^{417}$ : In (Süd-)Europa, Südamerika und im arabischen Raum revoltierten in den 2010er Jahren häufig die Gutausgebildeten, der nachrückende Kadernachwuchs der saturierten Mitte, denen der Zugang zu auskömmlichen Karrieren versperrt ist. Zudem weckt die Emergenz der Fridays for Future-Klimaproteste von 2018/19 Erinnerungen an die dem Bildungsstreik von 2009/10 vorangegangenen Schülerstreiks von 2008, aber auch an die bewegten 1960er Jahre, in denen der Protest durchaus auch unter Schülerinnen und Schülern um sich griff ${ }^{8}$ - ganz abgesehen davon, dass sich auch in den Reihen dieser neuen Protestbewegung ein beträchtlicher Anteil von Studierenden findet. ${ }^{19}$

Tatsächlich dürfte genau hier - je nach gesamtwirtschaftlicher Lage - das größte Potenzial studentischen politischen Protests liegen: In der identitätspolitischen und privilegiensichernden Verhärtung eines gebildeten, liberalen Bürgertums gegen die technisch-industriell, gewerblich und ländlich orientierten Mittelschichten. Denn die Wahlerfolge neuer rechter Parteien in ganz Europa, in Deutschland der zwischen den Bundestagswahlen 2013 und 2017 nationalkonservativ bis völkisch gewendeten AfD, aber auch das Aufkommen rechtspopulistischer Protestformationen wie PEGIDA sind aus der Sicht verschiedener Autoren nur das sichtbarste Signum einer politisch-kulturellen Verschiebung, die die gesamten Mittelschichten erfasst, ja identitätspolitisch tribalisiert. Die Rede ist, ob wörtlich oder sinngemäß, von einem „neuen Cleavage“ zwischen urbanen Kosmopoliten/Linksliberalen und eher ländlichen, „kommunitaristisch“ orientierten Ethnozentristen, der quer zum traditionellen politischen Richtungsschema von „links/rechts“ liege, und der durch die klassischen mittig linken und

15 Vgl. Walter: Rebellen, Propheten, Tabubrecher, S. 115-124.

16 Vgl. 13. Studierendensurvey 2015/16, S. $73 f$.

17 Kraushaar: Aufruhr der Ausgebildeten.

18 Vgl. Schildt, Axel: Nachwuchs für die Rebellion. Die Schülerbewegung der späten 6oer Jahre, in: Reulecke, Jürgen (Hg.): Cenerationalität und Lebensgeschichte im 20. Jahrhundert. Schriften des Historischen Kollegs, Bd. 58, München 2003, S. 229-251.

19 Vgl. Wahlström, Mattias/Kocyba, Piotr/Vydt, Michiel De/Moor, Joost de (Hg.): Protest for a future: Composition, mobilization and motives of the participants in Fridays For Future climate protests on 15 March, 2019 in 13 European cities, 2019, S. 8-10. 
mittig rechten Volksparteien nicht mehr aufgefangen werden könne. ${ }^{20}$ Die Soziologin Cornelia Koppetsch diagnostiziert einen sozialstrukturell bedingten antiliberalen Mentalitätswandel der politischen Kultur der Bundesrepublik, der einer Invertierung der mit „1968“ etikettierten Liberalisierungstrends gleichkomme: soziale Stagnation bzw. Abstieg und sich nach unten isolierende Eliten statt „Fahrstuhl-Effekt“, Verhärtung gegenüber Veränderungsdynamiken und Drang zur Konformität statt Liberalisierung und Pluralisierung, nostalgisch durchzogener Überdruss an Gegenwart und Zukunft statt politischer Gestaltungseuphorie. ${ }^{21}$ „Die daraus entstandenen Mentalitäten sind zwar nicht explizit rechts, doch enthalten sie eine spezifische Grundbotschaft: Die Gesellschaftsordnung ist nicht verhandelbar und verlangt unbedingte Anpassung und Unterordnung. ${ }^{\text {22 } 2}$ Epistemologische Hürden macht Koppetsch demgegenüber dort aus, wo die Zustimmung zu Parteien wie der AfD mit Deprivationsphänomenen erklärt wird, also die Wähler der AfD zu Modernisierungs- bzw. „Kulturalisierungsverlierern“

20 Vgl. Cuperus, René: Wie die Volksparteien (fast) das Volk einbüßten - Warum wir den Weckruf des Populismus erhören sollten, in: Hillebrand, Ernst (Hg.): Rechtspopulismus in Europa. Cefahr für die Demokratie?, Bonn 2015, S. 149-158, hier S. 151-153. Vgl. auch Geiges/Marg/Walter: Pegida, S. 198-200. Der Begriff „Cleavage“ (dt. „Spaltung“ oder „Kluft") stammt aus der politikwissenschaftlichen bzw. politiksoziologischen Theoriebildung der 1960er Jahre und erfuhr seine Prägung durch Seymour Martin Lipset und Stein Rokkan. Entscheidendes Cewicht messen die Autoren der Frage bei, inwieweit demokratische Parteiensysteme es vermögen, die fundamentalen gesellschaftlichen Cleavages (damals Kapital versus Arbeit, Kirche versus Staat, Stadt versus Land, Zentrum versus Peripherie) verschiedener politischer Kulturen durch politische Interessenaggregation vermittelnd zu integrieren und mithin zu pazifizieren, vgl. Lipset, Seymour Martin/Rokkan, Stein: Party Systems and Voter Alignments. Cross-National Perspectives, New York 1967, insbesondere S. 3-6 und S. 33-50. Zwar soll hier nicht entschieden werden, ob die Vorstellung eines neuen Cleavage die Ausführungen Lipsets und Rokkans überhaupt theoretisch zu erweitern vermag und nicht etwa als Reaktualisierungsversuch der klassischen vier Konfliktachsen für den Kontext der Bundesrepublik dienlicher wäre. Dennoch liegt die Aktualität der Frage angesichts des Ringens um den Umgang mit der AfD zwischen Anerkennung als tatsächlicher demokratischer Alternative einerseits und Verurteilung als Sammlungsbewegung potenziell demokratiegefährdender Rechtsradikaler andererseits auf der Hand - verweist dieses Ringen doch auf die grundlegendere und spätestens seit der Flüchtlingskrise 2015 offenkundig virulente Frage, inwieweit der Konflikt zwischen technokratisch-kosmopolitischen Eliten und migrationsfeindlichen unteren bis mittleren Mittelschichten als demokratisch repräsentationsbedürftiger Konflikt anerkannt werden soll. Inwiefern diese Konstellation auch bei anderen virulenten Konjunkturthemen die politischen Auseinandersetzungen strukturiert und durch eine aktualisierte Cleavage-Perspektive gefasst werden kann, diskutiere ich gemeinsam mit Kollegen in Schenke, Julian/Finkbeiner, Florian/Neumann, Amelie: Das Potenzial der Cleavage-Perspektive. Wahlverhalten als Oberflächenphänomen der politischen Kultur, in: Demokratie-Dialog, H. 6/2020, S. 2-11.

21 Vgl. Koppetsch: Die Wiederkehr der Konformität, S. 17-30 und S. 165-178; aktualisierend und pointierend auch Koppetsch, Cornelia: eine Welle der Nostalgie, hier S. 55ff. und insbesondere S. 57: "So wie 1968 nicht die Ursache, sondern Ausdruck und Kulminationspunkt gesellschaftlicher Liberalisierungsprozesse war, so ist auch der Rechtspopulismus nicht der Anfangspunkt, sondern der Kulminationspunkt illiberaler Entwicklungen, die aus dem autoritären Kapitalismus, das heißt aus eskalierenden Ungleichheiten, Abstiegsspiralen und Schließungsbewegungen hervorgegangen sind und in die Regression politischer Haltungen und gesellschaftlicher Mentalitäten münden." 
oder kulturell rückständigen, renitenten Widersachern des unumgänglichen Fortschritts deklariert werden - nicht zuletzt auch von sozialwissenschaftlicher Seite. ${ }^{23}$ Wer zu den status-, einkommens-, und bildungsbezogenen Ressourcenstarken zählt, mithin zur seit „1968“ kulturell hegemonialen Gruppe, neige auf der anderen Seite zu einer Verhärtung des „auf Rationalisierung und Selbstdisziplin gegründete[n] Muster[s] der Selbstverfeinerung“, vulgo zu bürgerlichem „Klassenbewusstsein“ mit postindustriellem Einschlag. ${ }^{24}$

„Man hebt sich selbst und sein soziales Image hervor, indem man rechte Haltungen von sich abweist und in Form einer Schwarz-Weiß-Cegenüberstellung den anderen zuschreibt (liberale vs. autoritäre, moderne vs. antimoderne Haltungen, Kosmopolit/innen vs. Globalisierungsverlierer/innen etc.). Doch bei genauerem Hinsehen sind die beiden Lager nicht so gegensätzlich, sondern finden sich gleichermaßen eingebettet in einen untergründig von rechts tickenden Zeitgeist. Die scharfe Abgrenzung folgt auf beiden Seiten dem Skript absoluter Zugehörigkeiten und trägt somit das Signum einer ,Rückkehr zum Stammesfeuer' (Bauman). ${ }^{25}$

Die Mitte, folgt man Koppetschs provokanten Beobachtungen, tribalisiert sich also unter identitätspolitischen Vorzeichen - was die Bekenntnisse zu klassisch bürgerlichen Werten wie Freiheit, Weltoffenheit, Liberalismus und Toleranz im Lichte eines unversöhnlichen Interessenkampfes erscheinen lässt. ${ }^{26}$ Ähnlich formulieren es Nadine Schöneck und Sabine Ritter in ihrem Band Die Mitte als Kampfzone, wenn sie einen verschärften Statuskampf zwischen Angehörigen der Mittelschicht in einer „SandwichPosition“ zwischen dem sozialen Oben und dem sozialen Unten herausstreichen, welche zur Notwendigkeit einer „kontinuierlichen Justierung der eigenen Lebensführung und ihrer Maximen" führe. ${ }^{27}$ Schon aus dem Bildungspathos der Studierendenproteste der frühen $2000 e r$ Jahre konnte der jederzeit drohende Umschlag in eine Anklage versagender Bildungsversprechen, in ein Instrument der kämpferischen Statusabsicherung gelesen werden:

„[...] eben diese Bildungsgläubigkeit kann aus den wohlerzogenen Kindern der Republik - nicht heute, aber vielleicht dann morgen - die Rebellen gegen die Künder ihrer eigenen Maximen machen. [...] Nicht ganz auszuschließen ist, dass nunmehr die

23 So am Beispiel des Soziologen und Kulturwissenschaftlers Andreas Reckwitz: „Schließlich stellen auch die Deutungsschablonen und Konzepte, mit denen der Aufstieg der AfD im Allgemeinen untersucht wird, keine neutralen Untersuchungsinstrumente dar, sondern sind selbst ein Stück Identitätspolitik in den Sozialwissenschaften, die scharfe Frontstellungen zwischen den Lagern behaupten und sich dabei selbst bestätigen, auf der richtigen Seite zu stehen. [...] Der Verdacht liegt nahe, dass die Ursachen für den Aufstieg der neuen Rechtsparteien sich nicht durch individuelle Enttäuschungserfahrungen, Charakterdeformationen oder materielle Deprivationen ihrer Wähler hinreichend ermitteln lassen, sondern grundsätzliche Veränderungen im sozialmoralischen und gesellschaftlichen Kräftefeld moderner Gesellschaften anzeigen." Ibid., S. 54. Vgl. ibid., S. 57.

25 Ibid., S. 58.

26 Vgl. auch hier Schenke et al.: Das Potenzial der Cleavage-Perspektive.

27 Vgl. Schöneck, Nabine M./Ritter, Sabine: Zur Einleitung. Die gesellschaftliche Mitte als Kampfzone - Perspektiven und Fragestellungen, in: Dies. (Hg.): Die Mitte als Kampfzone. Wertorientierungen und Abgrenzungspraktischen der Mittelschichten, Bielefeld 2018, S. 11-26, hier S. 14. 
Mitte ,mittiger' wird, dass sie sozial und ökonomisch ihre Interessen härter verteidigt, sich in den Zeiten eines unkomfortabel gewordenen Verteilungskampfes stärker nach unten abgrenzt und abschließt. Die Kinder der Aufsteigerschichten aus der ersten Bildungsreform, die derzeit die Universitäten bevölkern, fürchten schließlich um ihren Statuserhalt." ${ }^{\text {28 }}$

Dass sozialistische Impulse weitgehend fehlen, ja dass auch die angesichts leistungskritischer Motive naheliegende Überlegung, auf der Basis des Grundgesetzes über andere Wirtschaftsordnungen als die liberal-marktwirtschaftliche nachzudenken, ${ }^{29}$ den Studierenden so fern liegt, hat seinen Grund nicht nur in der Beschädigung der einstigen „Systemalternative“ durch den Zerfall des Sowjetsystems, sondern auch im stillen Einverständnis mit den aktuell herrschenden Modi der Reichtumsverteilung, von denen künftige Universitätsabsolventen fraglos profitieren. Keineswegs muss der „blockierte Gebildete“ als „Repräsentativtypus der flammenden revolutionären Rede und umstürzlerischen Programmatik“, ohne dessen Mobilisierungs- und Bündelungsarbeit keine revolutionäre Bewegung des 19. und frühen 20 . Jahrhunderts ausgekommen wäre, für immer abgetreten sein. ${ }^{30}$ Zwar hat die bundesrepublikanische Jugend rein demografisch betrachtet wenig Gewicht, auch ist die Akademikerarbeitslosigkeit gering, insbesondere unter ingenieurs- und naturwissenschaftlichen Absolventen. Aber gänzlich unmöglich ist es nicht, dass sich infolge einer stärkeren marktbasierten Aufspreizung der Berufschancen akademisch Qualifizierter zwischen wirtschafts-, ingenieursund naturwissenschaftlichen Fachkräften einerseits und weniger begehrten Absolventen der Geistes- und Sozialwissenschaften andererseits „eine neue Form des Elitendissens entwickelt“, ja sich „daraus ein Bündnis der blockierten - sagen wir: geisteswissenschaftlichen - Intelligenz mit den übrigen Geschädigten und Bedrohten des mobilen Globalkapitalismus“ bildet. ${ }^{31}$ Allerdings: Ob das gegenwärtig wünschenswert wäre, ist fraglich. Denn insbesondere die kosmopolitisch orientierten Gebildetenmilieus leben angesichts ihrer privilegierten Situation, welche sie noch immer für die eher sicheren, eher besser bezahlten Positionen der bundesdeutschen Gesellschaft prädestiniert, nach wie vor

„im Spannungsfeld zwischen verallgemeinerbaren Ideen-, Wert- und Institutionenprogrammen einer sich globalisierenden Welt und eigenen Klasseninteressen. In dem Maße, in dem die weltbürgerliche Gesellschaft von Erfolg gekrönt wäre, würden diese

Walter: Bildungsgläubiger Studentenprotest, S. 38-40.

29 Das Bundesverfassungsgericht bekräftigte 1979 in einer Entscheidung eine frühere Position Wolfgang Abendroths, dass das Crundgesetz „keine unmittelbare Festlegung und Cewährleistung einer bestimmten Wirtschaftsordnung" enthalte, mithin diese Entscheidung dem demokratischen Staat überlasse, zit. nach: Richter: Die Außerparlamentarische Opposition, S. 43, Fn. 22. Vgl. zu Abendroths Hinweis auf die veränderliche Auslegungspraxis des durch das Grundgesetz verbürgten „demokratischen und sozialen Rechtsstaat“ Abendroth, Wolfgang: Der demokratische und soziale Rechtsstaat als politischer Auftrag (1965), in: Ders.: Arbeiterklasse, Staat und Verfassung. Materialien zur Verfassungsgeschichte und Verfassungstheorie der Bundesrepublik, hg. von Joachim Perels, Köln/Frankfurt a.M. 1975, S. 179-201. 
ständisch-bürgerlichen Imprägnierungen möglicherweise verschwinden. Vorläufig jedoch bleibt diese Färbung erhalten: Nicht nur sozialstrukturell, auch kulturell knüpfen die weltbürgerlich Orientierten dabei an alte bürgerliche Traditionen an. Das europäische Weltbürgertum ist in die großstädtischen Cründerzeitviertel zurückgezogen, die schon im Kaiserreich bürgerliche Domizile waren. ${ }^{\text {“32 }}$

Denn: „Zwar sieht sich die obere Mittelschicht als Träger einer weltbürgerlichen und im globalen Maßstab repräsentativen Kultur [...] und fühlt sich einem Ideal universalistischer Teilhabe- und Aufstiegschancen verpflichtet", leidet zugleich jedoch an einer geradezu strukturell bedingten kognitiven Verzerrung, „die Reichweite postnationaler Vergesellschaftungsmuster für Milieus, die über weniger Ressourcen und geringere Bewegungsspielräume verfügen, zu überschätzen. ${ }^{\text {(33 }}$ Das Ergebnis ist der Rückzug in die identitätspolitische Abschottung, die tribalistische Verkapselung, der „Rückbau der Gesellschaft ${ }^{\text {“34 }}$ und das Zurücksinken in unversöhnliche Teilgemeinschaften sowohl unter erwachsenen als auch unter Nachwuchs-Akademikern. Ausgetragen werden solche Abgrenzungskämpfe vonseiten Studierender wahrscheinlich auch in näherer Zukunft durch die neo-autoritäre Unterbindung von Auseinandersetzungen nach dem Vorbild der US-amerikanischen safe space-Agitation. ${ }^{35}$ Schon in den letzten Jahren fielen an deutschen Universitäten studentische Aktionen auf, die verbal politische Diskriminierung anklagten, doch deren Funktion primär darin lag, vermeintliche politische Gegner zum Schweigen zu bringen. $\mathrm{Zu}$ diesen Vorfällen zählen die anonymen Blogger-Attacken von Münkler-Watch auf den Berliner Politikwissenschaftler Herfried Münkler im Namen der Diversitätspolitik 2015, ${ }^{36}$ der erfolgreiche Protest des lokalen AStA gegen ein Gedicht des Autoren Eugen Gomringer auf der Fassade der Alice Salomon Hochschule Berlin 2017/18, dessen Gedichtzeile „Allen und Blumen und Frauen und ein Bewunderer“ sexistisch gebrandmarkt und daraufhin übermalt wurde, ${ }^{37}$ der Vorwurf des antimuslimischen Rassismus und daran anschließende Rücktrittsforderungen an die Frankfurter Ethnologin Susanne Schröter unter dem Hashtag \#schroeter_raus 2019, ${ }^{38}$ oder aber die Hörsaalbesetzung in Frankfurt a.M. 2019, die die Teilnahme des AfD-Politikers Jörg Meuthen verhindern sollte. ${ }^{39}$ Sensible Geister sehen gerade im Zuge der neuen Rigoro-

Koppetsch, Cornelia: Soziologiekolumne. Weltbürgerlichkeit als repräsentative Kultur?, in: Merkur. Gegründet 1947 als Deutsche Zeitschrift für Europäisches Denken, 72. Jahrgang, Nr. H. $838 / 2019$, S. 43-50, hier S. 50.

33 Ibid., S. 49 (Herv. i. O.)

34 Nickel: Rückbau der Cesellschaft.

35 Vgl. Kaldewey: Der Campus als ,Safe Space'.

36 Vgl. Wagner: Das Recht gehört den Beleidigten.

37 Vgl. Allweiss, Marianne: Die „Alleen“ müssen gehen, in: Deutschlandfunk Kultur, 23.01.2018, online einsehbar unter: https://www.deutschlandfunkkultur.de/streit-um-gomringer-gedicht-aufuni-fassade-die-alleen.2165.de.html?dram:article_id=409035 [eingesehen am 01.08.2019]

Vgl. Toprak, Cigdem: Die Kopftuchdiskussion gehört an die Universität, in: Die Welt, 26.04.2019, online einsehbar unter: https://www.welt.de/kultur/article192466205/Ruecktrittsforderungengegen-Susanne-Schroeter-ein-Wahnsinn.html [eingesehen am 01.08.2019]

39 Vgl. Dillmann, Daniel: Uni Frankfurt: Polizei räumt Audimax, in: Frankfurter Rundschau, 08.04.2019, online einsehbar unter: https://www.fr.de/frankfurt/frankfurt-am-main-ort28687/ joerg-meuthen-frankfurt-studenten-besetzen-audimax-frankfurt-university-applied-sciences12068983.html [eingesehen am 01.08.2019] 
sität der political correctness "die freie Wissenschaft [...] durch Diskursverbote in Gefahr“ und gemahnen daran, dass Studierenden und Forschenden wieder mehr „zugemutet“ werden müsse, dass die diskursive Auseinandersetzung der Gebildeten untereinander wie nach außen, zur Gesellschaft, hin wieder erlernt werden müsse. ${ }^{40}$ In der Tat ist es möglich, dass studentische Protestaktivitäten angesichts der beschriebenen mentalen Arretierung, der starken Gegenwartsfixierung und der unverändert hohen Sekuritätsorientierung stärker auf die Verteidigung von Privilegien, auf autoritäre und restriktive Forderungen setzen werden (und sei es über den Ausschluss jener, die die Künste antidiskriminatorischer Rhetoriken nicht beherrschen) denn auf die Sehnsucht nach demokratischer, sozialer, ökonomischer, oder kultureller Egalisierung. Gewiss ist das problemlos unter Rückgriff auf eine prodemokratische Rhetorik möglich. ${ }^{41}$ Dass hier auch das alte politische Richtungsschema „links/rechts“als Kampfmittel eingesetzt wird, unterstreicht die starke Moralisierung dieser Auseinandersetzung nach dem Ende integrierender industriegesellschaftlicher Strukturen. ${ }^{42}$ Und dass Organisation, Sozialmoral und gesellschaftspolitische Interessenlagen für sich genommen auch destruktiv zusammenwirken können, zeigt nicht zuletzt die antidemokratische Studentenbewegung von Weimar. ${ }^{43}$

Wenn das alles ist, wäre wenig gewonnen. Indes: Protestnetzwerke, die auf eine emanzipative Veränderung gesellschaftlicher Verhältnisse hinauswollten, bedurften intellektueller und philosophischer Ressourcen, um über die Bedingtheit ihres sozioökonomischen Partikularinteresses zumindest ein Stück weit hinauszugelangen. Der erste Schritt wäre demgemäß die Einsicht in diese Bedingtheit des bildungsaffinen Bewusstseins. Das ist auch heute nicht undenkbar. Für die Aussicht auf zukunftsweisende Projekte aus den Reihen der akademischen Jugend bedürfte es der Anstrengung der subjektiven Erfahrungs- und Denkfähigkeit zu einer unerschrockenen Auseinandersetzung mit den gesamtgesellschaftlichen Verhältnissen des frühen 21. Jahrhunderts. Auch die intellektuelle Produktivität war lange Zeit eine Stärke nichtinkorporierter politisch aktiver Studierender, die auf der Suche nach einer auf freie Assoziation gründenden Kol-

40 Hartung, Manuel ].: Streiten bildet, in: DIE ZEIT, 17.04.2019, S. 1.

41 Denkbar wäre im Falle einer Bildungsexpansionskrise durchaus ein Protestbündnis aus Studierenden und jungen Absolventen, die sich für eine Reduktion der Studierendenzahl und für eine Verengung des Hochschulzugangs einsetzen. Das kann auch im Zeichen antidiskriminatorischer Maximen und Quotenregelungen geschehen.

42 Gewiss nicht zuletzt, weil insbesondere Ordnungsschemata wie die politische (Selbst-)Zuordnung „Links/Rechts“ sich oft in einem solchen Maße „adaptionsfähig“ erweisen, dass sie sich über mehrere Metamorphosen ihrer Bedeutungsgehalte hinüberzuretten vermögen, Raschke, Joachim: Die Erfindung von Links/Rechts als politisches Richtungsschema, in: Greve, Michael/Münkler, Herfried/Schmalz-Bruns, Rainer (Hg.): Bürgersinn und Kritik. Festschrift für Udo Bermbach zum 60. Geburtstag, Baden-Baden 1998, S. 185-206, hier S. 203f. Zur bereits um die Jahrtausendwende registrierten Renaissance vormals domestizierter kultureller, ethnischer und religiöser Spaltungen infolge der Erosion der „Klassenkonflikte“ regulierender industriell fundierten Wohlfahrtsstaaten vgl. exemplarisch Rokkan, Stein: Staat, Nation und Demokratie in Europa. Die Theorie Stein Rokkans aus seinen gesammelten Werken rekonstruiert und eingeleitet von Peter Flora, Frankfurt a.M. 2000 sowie zupackend Stender: Ethnische Erweckungen.

43 Dass Versuche politischer Mobilisierung von rechts unter Studierenden derzeit recht sicher scheitern werden, ergibt sich aus diesem Zusammenhang natürlich auch. 
lektivitätsform immer wieder unvollendete Projekte hinterließ, so etwa die Weimarer Freistudenten und der nach Orientierung ringende SDS der frühen 1960er Jahre. Diese Erbschaft der ungebundenen Suchbewegungen ist aus dem studentischen Gedächtnis verschwunden. Man darf sich etwa fragen, ob der Verlust des vielfach gescholtenen undogmatisch-marxistischen (auch des freudianischen) Theorie-Instrumentariums unter den Studierenden - wie fragmentarisch adaptiert, wie sehr im demagogischen Abusus versunken auch immer! - à la longue nicht vielmehr gerade jenen erwähnten Rückfall in frühliberale Denkmuster befördert hat als eine Evolution des Intellekts oder der politischen Urteilskraft. Angesichts der vielen teils realisierten, teils überformten, teils aufgegebenen Versuche, kollektiv politischen Einfluss zu nehmen, möchte man dem virtuellen Gesamtstudenten - als einer durch die Lebenssituation hinsichtlich Zeitressourcen sowie intellektuellen, hedonistischen und politischen Freiheiten nach wie vor reich ausgestattetem, auf verschlungenen Pfaden vielleicht noch immer zu besonderer Empathie, Phantasie und Einsicht in die Unvollständigkeit erreichter gesellschaftlicher Freiheit befähigten Sozialfigur -, diesem virtuellen Gesamtstudenten also, ermutigend zurufen: „Erinnern, Wiederholen, Durcharbeiten!“44 Gewiss wird heute nicht mehr so studiert wie noch in den 1960er Jahren, und sicher fehlt es schlicht an Vorbildern, Gelegenheiten, lebendigen Projekten. Doch wie sollen ausdauernde Kritik an den Verhältnissen und Entwürfe eines Besseren entstehen, wenn der Versuch marginal bleibt, gesellschaftliche Vorgänge jenseits des eng gestecken Fachhorizonts zu begreifen, ja wenn nur Einzelne die Konfrontation mit anspruchsvollen Leseerfahrungen suchen? Wie, wenn - überspitzt formuliert - Studierende selbst nach mehreren Semestern ihre Deutungsbedürfnisse mehrheitlich noch mit narzisstischen Bezügen auf die Wertmuster ihrer wohlmeinenden, auf Bildungskarrieren setzenden Herkunftsfamilie nebst der aus ihr sich speisenden Überzeugung der eigenen Auserwähltheit stillen? Wie, wenn nicht wenige von ihnen die Frage nach prägenden Leseerfahrungen mit einem Lob der anheimelnden erzählerischen Stereotypie von Harry Potter-Romanen beantworten, in die sie sich so gerne immer wieder wie in einer Traumwelt vertiefen - anstatt etwa die biedere klassisch-ideologische Leiterzählung des sich durch bestandene Prüfungen hindurch bewährenden Helden zum Anlass zu nehmen, über eine Welt nachzudenken, in der vielen Menschen ganz unabhängig von ihrer Leistungsbereitschaft die materielle und politische Teilhabe eben deshalb verwehrt ist, weil sie nicht als magiebegabte Auserwählte (also als privilegierter Nachwuchs gutsituierter und besserverdienender Schichten) zur Welt gekommen sind ${ }^{45}$ Im traditionellen deutschen Bildungsbegriff ist in der Tat mehr aufgespeichert als nur das in ihm vorgedachte, heute weitgehend inthronisierte Ausleseprinzip, nämlich ein nie eingelöster utopischer Tiefengehalt des Weltbürgertums, der Anspruch auf eine Gesellschaft der Freien und Gleichen, die die volle Entfaltung sämtlicher Potenziale eines Individuums erst ermöglicht. Die Realisierung dieses Anspruchs ist ohne eine demokratische Gesellschaftsform, die Teilha-

44 Freud, Sigmund: Erinnern, Wiederholen und Durcharbeiten, in: Ders.: Studienausgabe. Ergänzungsband, Frankfurt a.M. 1975, S. 205-215.

45 Auszuschließen ist nicht, dass eine breite politische Aktivierung von Studierenden derzeit dazu führen könnte, dass auch in der Bundesrepublik der eine oder andere Universitätscampus neoautoritär zum „Safe Space“ erklärt wird. Vgl. Kaldewey: Der Campus als ,Safe Space’. 
be auch sozioökonomisch, d. h. durch die Abschaffung materieller Not gewährleistet, nicht zu denken. Die heute gängige Berufung auf den Bildungsbegriff hingegen, die auf ein diffuses Lob der Kontemplation, des philosophischen Gedankens oder der akademischen Ehrwürdigkeit hinausläuft, fast so, als wäre nur die rechte bildungspolitische und professorale Besinnung vonnöten, um „wahre“ Bildung zu restituieren, wirkt zurecht staubig anachronistisch. Wer es mit der Bildung heute ernst meint, verzichtet auf die moralisierende Panzerung eines verabsolutierten status quo gegen die allseits gewitterten fortschrittsrenitenten Kräfte und wendet sich - gerade in einer Phase nachhaltiger Konfusion über den Zweck und Inhalt demokratisch verfasster Gesellschaften! - dem herausfordernden, sicher auch überfordernden Projekt zu, „Gesellschaft unter dem Aspekt ihrer Veränderbarkeit“46 $\mathrm{zu}$ denken.

46 Vgl. Schneider, Gregor-Sönke: Fortzusetzen... Detlev Claussen zum 70. Geburtstag, in: faust-kultur.de, 22.02.2018, online einsehbar unter: https://faustkultur.de/3430-o-Detlev-Claussen-zum-70. html [eingesehen am 01.08.2019] 



\section{Literaturverzeichnis}

\section{V.1 Zitierte Surveys}

Zentrale mehrfach zitierte Langzeiterhebungen wurden in Fließtext und Fußnotenverweisen nach folgendem Muster abgekürzt:

„Sozialerhebung“ Empirischer Survey „Das soziale Bild der Studentenschaft in Westdeutschland und Berlin“ (1951-1963) bzw. „Das soziale Bild der Studentenschaft in der Bundesrepublik Deutschland“ (1967/68-1997) bzw. „Die wirtschaftliche und soziale Lage der Studierenden in der Bundesrepublik Deutschland“ (seit 2000) des Deutschen Studentenwerks (DSW), von 1951 bis einschließlich 1979 durchgeführt von Gerhard Kath, Geschäftsführer des Studentenwerks Frankfurt a.M., seit der 10. Erhebung 1982 durchgeführt vom Deutschen Zentrum für Hochschul- und Wissenschaftsforschung (DZHW) Hannover (zuvor Hochschul-Informations-System (HIS) eG Hannover), seit 1973 gefördert vom Bundesministerium für Bildung und Forschung (BMBF), zuvor Bundesministerium für Bildung und Wissenschaft (BMBW), Korpus: 21 Erhebungen seit SoSe 1951 (Stand: 08/2019).

„Studierendensurvey“ „Datenalmanach Studierendensurvey“ Empirischer Survey „Studiensituation und studentische Orientierungen“, durchgeführt von der AG Hochschulforschung der Universität Konstanz, Korpus: 13 Erhebungen seit WiSe 1982/1983 (Stand: 08/2019). Rohdaten des Studierendensurvey, fortlaufend aktualisiert und veröffentlicht. „Bildungsbericht“ Indikatorengestützter Bericht „Bildung in Deutschland“, durchgeführt vom Konsortium Bildungsberichterstattung (2006) bzw. der Autorengruppe Bildungsberichterstattung (seit 2008) unter Beteiligung verschiedener Institute und der Statistischen Ämter des Bundes und der Länder, gefördert vom Bundesministerium für Bildung und Forschung (BMBF), Korpus: 7 Erhebungen seit 2006 (Stand: 08/2019).

Die Zitierkürzel der verwendeten Einzelberichte tragen zur besseren Übersicht, wo differierend, das Datum des Erhebungszeitraums, nicht das Datum der Veröffentli- 
chung. Nachfolgend die Zuordnung der Kürzel zum vollständigen Publikationsnachweis:

1. Sozialerhebung 1951 Kath, Gerhard: Das soziale Bild der Studentenschaft in Westdeutschland und Berlin, hg. vom Verband Deutscher Studentenwerke, Bonn 1952.

2. Sozialerhebung 1953 Kath, Gerhard: Das soziale Bild der Studentenschaft in Westdeutschland und Berlin, hg. vom Verband Deutscher Studentenwerke, Bonn 1954.

3. Sozialerhebung 1956 Kath, Gerhard: Das soziale Bild der Studentenschaft in Westdeutschland und Berlin, hg. vom Deutschen Studentenwerk, Bonn 1957.

4. Sozialerhebung 1959 Kath, Gerhard: Das soziale Bild der Studentenschaft in Westdeutschland und Berlin, hg. vom Deutschen Studentenwerk, Bonn 1960.

5. Sozialerhebung 1963 Kath, Gerhard: Das soziale Bild der Studentenschaft in Westdeutschland und Berlin, hg. vom Deutschen Studentenwerk, Bonn 1964.

6. Sozialerhebung 1967/68 Kath, Gerhard: Das soziale Bild der Studentenschaft in der Bundesrepublik Deutschland, hg. vom Deutschen Studentenwerk, Bonn 1969.

7. Sozialerhebung 1973 Kath, Gerhard: Das soziale Bild der Studentenschaft in der Bundesrepublik Deutschland. Ergebnisse der 7. Sozialerhebung des Deutschen Studentenwerks im Sommersemester 1973, Frankfurt a.M. 1974.

8. Sozialerhebung 1976 Kath, Gerhard: Das soziale Bild der Studentenschaft in der Bundesrepublik Deutschland. Ergebnisse der 8. Sozialerhebung des Deutschen Studentenwerks im Sommersemester 1976, Frankfurt a.M. 1977.

9. Sozialerhebung 1979 Kath, Gerhard: Das soziale Bild der Studentenschaft in der Bundesrepublik Deutschland. Ergebnisse der 9. Sozialerhebung des Deutschen Studentenwerks im Sommersemester 1979, Frankfurt a.M. 1980.

10. Sozialerhebung 1982 Schnitzer, Klaus/Isserstedt, Wolfgang/Narten, Renate: Das soziale Bild der Studentenschaft in der Bundesrepublik Deutschland. Ergebnisse der 10. Sozialerhebung des Deutschen Studentenwerks im Sommersemester 1982, Frankfurt a.M. 1983.

11. Sozialerhebung 1985 Bundesminister für Bildung und Wissenschaft (Hg.): Das soziale Bild der Studentenschaft in der Bundesrepublik Deutschland. 11. Sozialerhebung des Deutschen Studentenwerkes, Bonn 1986.

12. Sozialerhebung 1988 Bundesminister für Bildung und Wissenschaft (Hg.): Das soziale Bild der Studentenschaft in der Bundesrepublik Deutschland. 12. Sozialerhebung des Deutschen Studentenwerkes, Schriftenreihe Studien zu Bildung und Wissenschaft Nr. 84, Bonn 1989.

13. Sozialerhebung 1991 Bundesminister für Bildung und Wissenschaft (Hg.): Das soziale Bild der Studentenschaft in der Bundesrepublik Deutschland. 13. Sozialerhebung des Deutschen Studentenwerkes, Schriftenreihe Studien zu Bildung und Wissenschaft Nr. 103, Bonn 1992.

14. Sozialerhebung 1994 Bundesministerium für Bildung, Wissenschaft, Forschung und Technologie (Hg.): Das soziale Bild der Studentenschaft in der Bundesrepublik Deutschland. 14. Sozialerhebung des Deutschen Studentenwerkes, Bonn 1995.

15. Sozialerhebung 1997 Schnitzer, Klaus/Isserstedt, Wolfgang/Müßig-Trapp, Peter/Schreiber, Jochen: Das soziale Bild der Studentenschaft in der Bundesrepublik Deutschland. 15. Sozialerhebung des Deutschen Studentenwerks, durchgeführt 
durch HIS Hochschul-Informations-System, hg. vom Bundesministerium für Bildung und Forschung, Bonn 1998.

16. Sozialerhebung 2000 Schnitzer, Klaus/Isserstedt, Wolfgang/Middendorff, Elke: Die wirtschaftliche und soziale Lage der Studierenden in der Bundesrepublik Deutschland 2000. 16. Sozialerhebung des Deutschen Studentenwerks, durchgeführt durch HIS Hochschul-Informations-System, hg. vom Bundesministerium für Bildung und Forschung, Bonn 2001.

17. Sozialerhebung 2003 Isserstedt, Wolfgang/Middendorff, Elke/Weber, Steffen/Schnitzer, Klaus/Wolter, Andrä: Die wirtschaftliche und soziale Lage der Studierenden in der Bundesrepublik Deutschland 2003. 17. Sozialerhebung des Deutschen Studentenwerks, durchgeführt durch HIS Hochschul-Informations-System, hg. vom Bundesministerium für Bildung und Forschung, Bonn/Berlin 2004.

18. Sozialerhebung 2006 Isserstedt, Wolfgang/Middendorff, Elke/Fabian, Gregor/Wolter, Andrä: Die wirtschaftliche und soziale Lage der Studierenden in der Bundesrepublik Deutschland 2006. 18. Sozialerhebung des Deutschen Studentenwerks, durchgeführt durch HIS Hochschul-Informations-System, hg. vom Bundesministerium für Bildung und Forschung, Berlin 2006.

19. Sozialerhebung 2009 Isserstedt, Wolfgang/Middendorff, Elke/Kandulla, Maren/Borchert, Lars/Leszczensky, Michael: Die wirtschaftliche und soziale Lage der Studierenden in der Bundesrepublik Deutschland 2009. 19. Sozialerhebung des Deutschen Studentenwerks, durchgeführt durch HIS Hochschul-Informations-System, hg. vom Bundesministerium für Bildung und Forschung, Berlin 2009.

20. Sozialerhebung 2012 Middendorff, Elke/Apolinarski, Beate/Poskowsky, Jonas/Kandulla, Maren/Netz, Nicolai: Die wirtschaftliche und soziale Lage der Studierenden in der Bundesrepublik Deutschland 2012. 20. Sozialerhebung des Deutschen Studentenwerks, durchgeführt durch das HIS-Institut für Hochschulforschung, hg. vom Bundesministerium für Bildung und Forschung, Berlin 2012.

21. Sozialerhebung 2016 Middendorff, Elke/Apolinarski, Beate/Becker, Karsten/Bornkessel, Philipp/Brandt, Tasso/Heißenberg, Sonja/Poskowsky, Jonas: Die wirtschaftliche und soziale Lage der Studierenden in der Bundesrepublik Deutschland 2016. 21. Sozialerhebung des Deutschen Studentenwerks, durchgeführt vom Deutschen Zentrum für Hochschul- und Wissenschaftsforschung, hg. vom Bundesministerium für Bildung und Forschung, Berlin 2017.

1. Studierendensurvey 1982/83: Der Bundesminister für Bildung und Wissenschaft (Hg.): Studiensituation und studentische Orientierungen. Eine empirische Untersuchung im Wintersemester 1982/83, Bad Honnef 1984.

2. Studierendensurvey 1984/85 Peisert, Hansgert/Bargel, Tino/Framhein, Gerhild: Studiensituation und studentische Orientierungen an Universitäten und Fachhochschulen. 2. Erhebung zur Studiensituation im WS 1984/85, hg. vom Bundesminister für Bildung und Wissenschaft, Bonn 1988.

Studierendensurvey 1980er Bargel, Tino/Framhein-Peisert, Gerhild/Sandberger, JohannUlrich: Studienerfahrungen und studentische Orientierungen in den 8oer Jahren. Trends und Stabilitäten. Drei Erhebungen an Universitäten und Fachhochschulen 
1983, 1985 und 1987, hg. vom Bundesminister für Bildung und Wissenschaft, Bonn 1989.

4. Studierendensurvey 1989/90 Bargel, Tino/Sandberger, Johann-Ulrich/Ramm, Michael: Studiensituation und studentische Orientierungen. Vierte Erhebung zur Studiensituation an Universitäten und Fachhochschulen. Kurzfassung, hg. vom Bundesminister für Bildung und Wissenschaft, Bonn 1992.

Studierendensurvey 1990er Bargel, Tino/Multrus, Frank/Ramm, Michael: Studium und Studierenden in den 9oer Jahren. Entwicklung an Universitäten und Fachhochschulen in den alten und neuen Bundesländern, hg. vom Bundesministerium für Bildung, Wissenschaft, Forschung und Technologie, Bonn 1996.

7. Studierendensurvey 1997/98 Bargel, Tino/Ramm, Michael/Multrus, Frank: Studiensituation und studentische Orientierungen. 7. Studierendensurvey an Universitäten und Fachhochschulen, hg. vom Bundesministerium für Bildung und Forschung, Bonn 2001.

8. Studierendensurvey 2000/01 Bargel, Tino/Ramm, Michael/Multrus, Frank: Studiensituation und studentische Orientierungen. 8. Studierendensurvey an Universitäten und Fachhochschulen, hg. vom Bundesministerium für Bildung und Forschung, Bonn 2003.

9. Studierendensurvey 2003/04 Bundesministerium für Bildung und Forschung (Hg.): Studiensituation und studentische Orientierungen. 9. Studierendensurvey an Universitäten und Fachhochschulen, Hauptbericht, Bonn/Berlin 2003.

10. Studierendensurvey 2006/07 Multrus, Frank/Bargel, Tino/Ramm, Michael: Studiensituation und studentische Orientierungen. 10. Studierendensurvey an Universitäten und Fachhochschulen, hg. vom Bundesministerium für Bildung und Forschung, Bonn/Berlin 2008.

11. Studierendensurvey 2009/10 Ramm, Michael/Multrus, Frank/Bargel, Tino: Studiensituation und studentische Orientierungen. 11. Studierendensurvey an Universitäten und Fachhochschulen, hg. vom Bundesministerium für Bildung und Forschung, Bonn/Berlin 2011.

12. Studierendensurvey 2012/13 Ramm, Michael/Multrus, Frank/Bargel, Tino/Schmidt, Monika: Studiensituation und studentische Orientierungen. 12. Studierendensurvey an Universitäten und Fachhochschulen, hg. vom Bundesministerium für Bildung und Forschung, Berlin 2014.

13. Studierendensurvey 2015/16 Bundesministerium für Bildung und Forschung (Hg.): Studiensituation und studentische Orientierungen. 13. Studierendensurvey an Universitäten und Fachhochschulen, Berlin 2017.

Datenalmanach Studierendensurvey 2007 Simeaner, Hans/Dippelhofer, Sebastian/Bargel, Tino/Bargel, H./Michael Ramm: Datenalmanach Studierendensurvey 1983-2007. Studiensituation und Studierende an Universitäten und Fachochschulen. Hefte zur Bildungs- und Hochschulforschung, AG Hochschulforschung, Universität Konstanz, H. 51/2007.

Datenalmanach Studierendensurvey 2017 Simeaner, Hans/Multrus, Frank/Kolbert-Ramm, Christa: Datenalmanach Studierendensurvey 1993-2016. Hefte zur Bildungs- und Hochschulforschung, AG Hochschulforschung, Universität Konstanz, H. 97/2017. 
1. Bildungsbericht 2006 Konsortium Bildungsberichterstattung (Hg.): Bildung in Deutschland. Ein indikatorengestützter Bericht mit einer Analyse zu Bildung und Migration, Bielefeld 2006.

2. Bildungsbericht 2008 Autorengruppe Bildungsberichterstattung (Hg.): Bildung in Deutschland 2008. Ein indikatorengestützter Bericht mit einer Analyse zu Übergängen im Anschluss an den Sekundarbereich I, Bielefeld 2008.

3. Bildungsbericht 2010 Autorengruppe Bildungsberichterstattung (Hg.): Bildung in Deutschland 2008. Ein indikatorengestützter Bericht mit einer Analyse zu Perspektiven des Bildungswesens im demografischen Wandel, Bielefeld 2010.

4. Bildungsbericht 2012 Autorengruppe Bildungsberichterstattung (Hg.): Bildung in Deutschland 2012. Ein indikatorengestützter Bericht mit einer Analyse zur kulturellen Bildung im Lebenslauf, Bielefeld 2012.

5. Bildungsbericht 2014 Autorengruppe Bildungsberichterstattung (Hg.): Bildung in Deutschland 2014. Ein indikatorengestützter Bericht mit einer Analyse zur Bildung von Menschen mit Behinderungen, Bielefeld 2014.

6. Bildungsbericht 2016 Autorengruppe Bildungsberichterstattung (Hg.): Bildung in Deutschland 2016. Ein indikatorengestützter Bericht mit einer Analyse zu Bildung und Migration, Bielefeld 2016.

7. Bildungsbericht 2018 Autorengruppe Bildungsberichterstattung (Hg.): Bildung in Deutschland 2018. Ein indikatorengestützter Bericht mit einer Analyse zu Wirkungen und Erträgen von Bildung, Bielefeld 2018.

\section{V.2 Weitere verwendete Literatur}

Sofern abweichend: In [ ] das Jahr der Ersterscheinung des angegebenen Textes;sofern abweichend und in der zitierten Sammlung so gekennzeichnet: In ( ) das Jahr der Ersterscheinung des angegebenen Textes gemäß dem dortigen Titel.

Abendroth, Wolfgang: Der demokratische und soziale Rechtsstaat als politischer Auftrag (1965), in: Ders.: Arbeiterklasse, Staat und Verfassung. Materialien zur Verfassungsgeschichte und Verfassungstheorie der Bundesrepublik, hg. von Joachim Perels, Köln/Frankfurt a.M. 1975, S. 179-201.

Adorno, Theodor W.: Studien zum autoritären Charakter [1973], Frankfurt a.M. 2016.

—: Zur Lehre von der Geschichte und von der Freiheit [1964/1965], Frankfurt a.M. 2006.

—: Theorie der Halbbildung [1959], in: Soziologische Schriften I, Frankfurt a.M. 1972, S. 93-121.

—: Minima Moralia. Reflexionen aus dem beschädigten Leben [1951]. Gesammelte Schriften, Frankfurt a.M. 2003.

—- Die auferstandene Kultur [1949], in: Ders.: Gesammelte Schriften in 20 Bänden, Bd. 20.2, Frankfurt a.M. 1997, S. 453-464.

Agnoli, Johannes: Zur ApO [1968], in: Ders.: 1968 und die Folgen, Freiburg 1998, S. 31-49. 
- Die Transformation der Demokratie, in: Ders.: Die Transformation der Demokratie und verwandte Schriften, Hamburg 2004, S. 13-93.

Ahrens, Rüdiger: Bündische Jugend. Eine neue Geschichte 1918-1933, Göttingen 2015. Albert, Mathias/Hurrelmann, Klaus/Quenzel, Gudrun: Jugend 2015: Eine neue Generationsgestalt?, in: Shell Deutschland Holding (Hg.): Jugend 2015. Eine pragmatische Generation im Aufbruch, bpb Lizenzausgabe, Bonn 2016, S. 33-46.

Albrecht, Clemens: Umziehende Götter. 1968 und die Transformation des revolutionären Enthusiasmus, in: Merkur. Gegründet 1947 als Deutsche Zeitschrift für Europäisches Denken, 72. Jg., H. 832/2018, S. 65-70.

Allerbeck, Klaus R.: Eine sozialstrukturelle Erklärung von Studentenbewegungen in hochentwickelten Industriegesellschaften, in: Allerbeck, Klaus R./Rosenmayr, Leopold (Hg.): Aufstand der Jugend? Neue Aspekte der Jugendsoziologie, München 1971, S. 179-201.

—: Eine strukturelle Erklärung von Studentenbewegungen in entwickelten Industriegesellschaften, in: Kölner Zeitschrift für Soziologie und Sozialpsychologie, 23. Jg. 1971, S. 478-493.

Allerbeck, Klaus R./Rosenmayr, Leopold: Einleitung. Neue Theorien und Materalien zur Soziologie der Jugend - Ergebnisse eines internationalen Symposions, in: Dies: (Hg.): Aufstand der Jugend? Neue Aspekte der Jugendsoziologie, München 1971, S. 11-27.

Almond, Gabriel: Politische Kultur-Forschung - Rückblick und Ausblick, in: BergSchlosser, Dirk/Schissler, Jakob: Politische Kultur in Deutschland. Bilanz und Perspektiven der Forschung, Politische Vierteljahresschrift, Sonderheft 18/1987, S. 2738.

Almond, Gabriel/Verba, Sidney: The Civic Culture. Political Attitudes and Democracy in Five Nations, Boston 1963.

Aly, Götz: Unser Kampf: 1968 - Ein irritierter Blick zurück, Frankfurt a.M. 2008.

Anderson, Benedict: Die Erfindung der Nation. Zur Karriere eines folgenreichen Konzepts [1996], Frankfurt a.M. 2005.

Aristoteles: Politik, Reinbek bei Hamburg 1994.

Arnold, Rolf: Deutungsmuster. Zu den Begriffselementen sowie den theoretischen und methodologischen Bezügen eines Begriffs, in: Zeitschrift für Pädagogik, H. 29/1983, S. 893-912.

Bargel, Tino: Student und Politik: die ratlose Generation, News 30.3, AG Hochschulforschung, Universität Konstanz 2009.

— Wandel politischer Orientierungen und gesellschaftlicher Werte der Studierenden. Studierendensurvey: Entwicklungen zwischen 1983 und 2007, Bundesministerium für Bildung und Forschung (BMBF), Referat Wissenschaftlicher Nachwuchs, wissenschaftliche Weiterbildung, Bonn/Berlin 2008.

- Wandel des politischen Bewußtseins und der Meinungsführerschaft deutscher Studierender? Befunde des Studierendensurveys 1983-1998. Referat bei der Fachtagung der Hessischen Landeszentrale für Politische Bildung „Politisches Bewußtsein von Studierenden in Hessen 1918 - 1998“ am 17. Juni 1998 im Studentenhaus der J. W. Goethe Universität, Frankfurt a.M. AG Hochschulforschung, Universität Konstanz 1998. 
- Zum politischen Potential der Studierenden an Universitäten in Ost- und Westdeutschland, in: hochschule ost. politisch-akademisches journal aus ostdeutschland, 3. Jg., H. 3/1994, S. 9-18.

Bargel, Tino/Simeaner, Hans: Gesellschaftliche Werte und politische Orientierungen der Studierenden. Online-Erhebung im Rahmen des Studierendensurveys im Sommer 2010. Hefte zur Bildungs- und Hochschulforschung Nr. 63, Arbeitsgruppe Hochschulforschung, Universität Konstanz, Bonn/Berlin 2011.

Bartol, Gerda: Ideologie und studentischer Protest. Untersuchungen zur Entstehung deutscher Studentenbewegungen im 19. und 20. Jahrhundert, München 1978.

Bauer, Franz J.: Bürgerwege und Bürgerwelten. Familienbiographische Untersuchungen zum deutschen Bürgertum im 19. Jahrhundert. Schriftenreihe der Historischen Kommission bei der Bayerischen Akademie der Wissenschaften, Bd. 43, Göttingen 1991.

Bauß, Gerhard: Die Studentenbewegung der sechziger Jahre in der Bundesrepublik und Westberlin, Köln 1977.

Bebnowski, David: Die Ostermärsche und das Jahr 1964, in: Lorenz, Robert/Walter, Franz (Hg.): 1964. Das Jahr, mit dem „68“ begann, Bielefeld 2014, S. 259-274.

— : Generation und Geltung. Von den „45ern“ zur „Generation Praktikum“. Übersehene und etablierte Generationen im Vergleich. Studien des Göttinger Instituts für Demokratieforschung zur Geschichte politischer und gesellschaftlicher Kontroversen, Bd. 4, Bielefeld 2012.

Beck, Heinrich: Machtkampf der Generationen? Zum Aufstand der Jugend gegen den Autoritätsanspruch der Gesellschaft, Frankfurt a.M. 1970.

Beck, Ulrich: Risikogesellschaft. Auf dem Weg in eine andere Moderne, Frankfurt a.M. 1986.

Beck, Ulrich/Gernsheim, Elisabeth: Zu einer Theorie der Studentenunruhen in fortgeschrittenen Industriegesellschaften, in: Kölner Zeitschrift für Soziologie und Sozialpsychologie, 23. Jg. 1971, S. 439-477.

Behre, Silja: Bewegte Erinnerung. Deutungskämpfe um ,1968' in deutsch-französischer Perspektive, Tübingen 2016.

Bell, Daniel: The End of Ideology. On the Exhaustion of Political Ideas in the Fifties, Glencoe 1960.

Ben Prestel, Joseph: Palästina-Solidarität. Bruchstelle einer globalen Linken, in: Merkur. Gegründet 1947 als Deutsche Zeitschrift für europäisches Denken, 73. Jg., H. 839/2019, S. 61-67.

Berger, Peter L./Luckmann, Thomas: Die gesellschaftliche Konstruktion der Wirklichkeit. Eine Theorie der Wissenssoziologie [1969], Frankfurt a.M. 2012.

Berman, Sheri: Civil Society and the Collapse of the Weimar Republic, in: World Politics, 49. Jg., H. 3/1997, S. 401-429.

Best, Heinrich: Soziale Morphologie und politische Orientierungen bildungsbürgerlicher Abgeordneter in der Frankfurter Nationalversammlung und in der Pariser Assemblée nationale constituante 1848/49, in: Kocka, Jürgen (Hg.): Bildungsbürgertum im 19. Jahrhundert, Teil IV: Politischer Einfluß und gesellschaftliche Formation, Stuttgart 1989, S. 53-94. 
Bias-Engels, Sigrid: Zwischen Wandervogel und Wissenschaft. Zur Geschichte von Jugendbewegung und Studentenschaft 1896-1920. Edition Archiv der deutschen Jugendbewegung, Bd. 4, Köln 1988.

Bleuel, Hans Peter/Klinnert, Ernst: Deutsche Studenten auf dem Weg ins Dritte Reich. Ideologien - Programme - Aktionen 1918-1935, Gütersloh 1967.

Blome, Frerk: „Da kann man auch gleich Künstler werden." Selbstausschluss und habituelle Verläufe von Personen aus hochschulfernem Elternhaus in akademischen Karrieren, in: Pfaff-Czarnecka, Joanna (Hg.): Das soziale Leben der Universität, Bielefeld 2017, S. 323-351.

Blücher, Viggo Graf: Die Generation der Unbefangenen. Zur Soziologie der jungen Menschen heute, Düsseldorf/Köln 1966.

Bock, Hans Manfred: Geschichte des ,linken Radikalismus' in Deutschland. Ein Versuch, Frankfurt a.M. 1976.

Bode, Thilo: Die Diktatur der Konzerne. Wie globale Unternehmen uns schaden und die Demokratie zerstören, Frankfurt a.M. 2018.

Boehncke, Clemens: „Die Hölle, das sind die Anderen“. Das Populismusbarometer 2018 als moralischer Schlagbaum, in: Demokratie-Dialog, H. 3/2018, S. 68-74.

Bohnsack, Ralf: Rekonstruktive Sozialforschung. Einführung in qualitative Methoden, Opladen 2010.

- Rekonstruktive Sozialforschung. Einführung in qualitative Methoden, Opladen 2003.

- Gruppendiskussionsverfahren und Milieuforschung, in: Friebertshäuser, Barbara/Langer, Antje/Prengel, Annedore: Handbuch Qualitative Sozialforschung in der Erziehungswissenschaft, Weinheim 1997, S. 492-502.

Bohnsack, Ralf/Przyborski, Aglaja: Diskursorganisation, Gesprächsanalyse und die Methode der Gruppendiskussion, in: Bohnsack, Ralf/Schäffer, Burkhard/Przyborski, Aglaja (Hg.): Das Gruppendiskussionsverfahren in der Forschungspraxis. Verlag Barbara Budrich, Leverkusen 2006, S. 233-248.

Bohrer, Karl Heinz: 1968: Die Phantasie an die Macht? Studentenbewegung - Walter Benjamin - Surrealismus, in: Gilcher-Holtey, Ingrid (Hg.): 1968. Vom Ereignis zum Gegenstand der Geschichtswissenschaft. Geschichte und Gesellschaft, Sonderheft 17, Göttingen 1998, S. 288-300.

Boltanski, Luc/Chiapello, Ève: Der neue Geist des Kapitalismus, Köln 2006.

Borowsky, Peter: Studenten in der deutschen Revolution 1848, in: Ders.: Schlaglichter historischer Forschung. Studien zur deutschen Geschichte im 19. und 20. Jahrhundert. Aus dem Nachlass herausgegeben von Rainer Hering und Rainer Nicolaysen, Hamburg 2005, S. 187-199.

Bossler, Mario/Gürtzgen, Nicole/Kubis, Alexander/Moczall, Andreas: Befristungen bei Neueinstellungen. Institut für Arbeitsmarkt- und Berufsforschung (IAB), Nürnberg 2017.

Bourdieu, Pierre: Über den Staat. Vorlesungen am Collège de France 1989-1992, Frankfurt a.M. 2017.

- : Homo academicus, Frankfurt a.M. 2010.

Böckenförde, Ernst-Wolfgang: Staat, Gesellschaft, Freiheit. Studien zur Staatstheorie und zum Verfassungsrecht, Frankfurt a.M. 2016. 
Bödeker, Hans Erich: Die ,gebildeten Stände‘ im späten 18. und frühen 19. Jahrhundert. Zugehörigkeit und Abgrenzungen, Mentalitäten und Handlungspotentiale, in: In Kocka, Jürgen (Hg.): Bildungsbürgertum im 19: Jahrhundert, Teil IV: Politischer Einfluß und gesellschaftliche Formation, Stuttgart 1989, S. 21-52.

Bögelein, Nicole/Vetter, Nicole: Deutungsmuster als Forschungsinstrument. Grundlegende Perspektiven, in: Dies. (Hg.): Der Deutungsmusteransatz. Einführung - Erkenntnisse - Perspektiven, Weinheim Basel 2019, 12-38.

Brandt, Georg/HerausgeberInnengruppe Lucky Streik (Hg.): „Lucky Streik“ - ein Kampf um Bildung. Gießener Studierende berichten, Gießen 1998.

Braubach, Max: Bonner Professoren und Studenten in den Revolutionsjahren 1848/49. Wissenschaftliche Abhandlungen der Arbeitsgemeinschaft für Forschung des Landes Nordrhein-Westfalen Bd. 38, Köln und Opladen 1967.

Bruch, Rüdiger vom: Die Universitäten in der Revolution von 1848/49. Revolution ohne Universität - Universität ohne Revolution?, in: Hardtwig, Wolfgang (Hg.): Revolution in Deutschland und Europa 1848/49, Göttingen 1998, S. 133-160.

—-: Abschied von Humboldt? Die deutsche Universität vor dem Ersten Weltkrieg, in: Strobel, Karl (Hg.): Die deutsche Universität im 20: Jahrhundert. Die Entwicklung einer Institution zwischen Tradition, Autonomie, historischen und sozialen Rahmenbedingungen. Abhandlungen zum Studenten- und Hochschulwesen, Bd. 5, Greifswald 1994, S. 17-29.

— : Gesellschaftliche Funktionen und politische Rollen des Bildungsbürgertums im Wilhelminischen Reich - Zum Wandel von Milieu und politischer Kultur, in: Kocka, Jürgen (Hg.): Bildungsbürgertum im 19: Jahrhundert, Teil IV: Politischer Einfluß und gesellschaftliche Formation, Stuttgart 1989, S. 146-179.

Brückner, Peter: Paradoxien der ,Protestbewegung [1973/74], in: Ders.: Zerstörung des Gehorsams. Aufsätze zur Politischen Psychologie, Berlin 1983, S. 86-108.

Brunner, Otto: Staat und Gesellschaft in Preußen 1815-1848, in: Conze, Werner (Hg.): Staat und Gesellschaft im deutschen Vormärz 1815-1848, Stuttgart 1962, S. 113-142.

Buck, Günther: Rückwege aus der Entfremdung. Studien zur Entwicklung der deutschen humanistischen Bildungsphilosophie, Paderborn/München 1984.

Budde, Gunilla: Die Blütezeit des Bürgertums. Bürgerlichkeit im 19. Jahrhundert [2009], Wissenschaftliche Buchgesellschaft 2012.

Bultmann, Torsten: Die standortgerechte Dienstleistungshochschule, in: PROKLA. Zeitschrift für kritische Sozialwissenschaft, H. 104/1996, S. 329-355.

Bundesministerium für Familie, Senioren, Frauen und Jugend (BMFSFJ, Hg.): Zweiter Bericht über die Entwicklung des bürgerschaftlichen Engagements in der Bundesrepublik Deutschland. Schwerpunktthema: „Demografischer Wandel und bürgerschaftliches Engagement: Der Beitrag des Engagements zur lokalen Entwicklung“. Drucksache 18/11800 des Deutschen Bundestages in der 18. Wahlperiode, Berlin 30.03.2017.

Bundesministerium für Umwelt, Naturschutz und nukleare Sicherheit (Hg.): Naturbewusstsein 2017. Bevölkerungsumfrage zu Natur und biologischer Vielfalt, Berlin/Bonn 2018.

Busse, Britta/Hashem-Wangle, Alexandra/Tholen, Jochen/Wolnik, Kevin: Parallele Welten politischer Partizipation. Junge Menschen und politische Partizipation in 
Deutschland, in: In Kühnel, Wolfgang/Willems, Helmut (Hg.): Politisches Engagement im Jugendalter. Zwischen Beteiligung, Protest und Gewalt, Weinheim/Basel 2017.

Claussen, Detlev: Chiffre 68, in: Harth, Dietrich/Assmann, Jan (Hg.): Revolution und Mythos, Frankfurt a.M. 1992, S. 219-230.

—: Abschied von gestern. Kritische Theorie heute, Hannover 1985.

Converse, Philip E.: The nature of belief systems in mass publics (1964), in: Critical Review, 18. Jg., H. 1-3/2006, S. 1-74.

Conze, Werner: Ereignisse und Entwicklungen 1851-1918, in: Langewiesche, Dieter (Hg.): Das deutsche Kaiserreich 1867/71 bis 1918. Bilanz einer Epoche, Freiburg/Würzburg 1984, S. 81-116.

Conze, Werner/Kocka, Jürgen (Hg.): Einleitung, in: Dies. (Hg.): Bildungsbürgertum im 19. Jahrhundert, Teil I: Bildungssystem und Professionalisierung in internationalen Vergleichen, Stuttgart 1985, S. 9-26.

Crouch, Colin: Postdemokratie, Frankfurt a.M. 2008.

Cuperus, René: Wie die Volksparteien (fast) das Volk einbüßten - Warum wir den Weckruf des Populismus erhören sollten, in: Hillebrand, Ernst (Hg.): Rechtspopulismus in Europa. Gefahr für die Demokratie?, Bonn 2015, S. 149-158.

Dahrendorf, Ralf: Gesellschaft und Demokratie in Deutschland, München 1965.

Demirović, Alex: Die politische Metapher links und die politischen Orientierungen von Studierenden, in: PROKLA. Zeitschrift für kritische Sozialwissenschaft, H. 104/1996, S. 371-394.

Demirović, Alex/Paul, Gerd: Demokratisches Selbstverständnis und die Herausforderung von rechts. Student und Politik in den neunziger Jahren, Frankfurt a.M. 1996.

Dewey, John: The Ethics of Democracy, in: Boydston, Jo Ann (Hg.): Early Works of John Dewey, 1882-1953, Bd. 1, Carbondale 2008.

Deutsch, Karl W.: Der Nationalismus und seine Alternativen, München 1972.

Dirks, Walter: Der restaurative Charakter der Epoche, in: Frankfurter Hefte, 5. Jg., H. 50/1950, S. 942-954.

Distelhorst, Lars: Leistung. Das Endstadium der Ideologie, Bielefeld 2014.

Does, Karl-Josef: Studenten 1975 - Ergebnisse einer Befragung unter Studenten zu Studium, Beruf, Politik und Hochschule. Sozialwissenschaftliches Forschungsinstitut der Konrad-Adenauer-Stiftung, St. Augustin 1976.

Dowe, Christopher: Auch Bildungsbürger. Katholische Studierende und Akademiker im Kaiserreich. Kritische Studien zur Geschichtswissenschaft, Bd. 171, Göttingen 2006.

Dreesen, Josef: Das Fürstentum Lichtenberg (1816-1834) im Vormärz. Ein Provisorium, Selbstverlag 2008.

Dubiel, Helmut: Ungewißheit und Politik, Frankfurt a.M. 1994.

Easton, David: A Framework for political Analysis, Prentice Hall 1965; Easton, David: A Re-Assessment of the Concept of Political Support, in: British Journal of Political Science, H. 5/1975, S. 435-457.

Eberl, Oliver/Salomon, David (Hg.): Perspektiven sozialer Demokratie in der Postdemokratie. Staat-Souveränität-Nation, Wiesbaden 2017.

Engelhardt, Ulrich: Bildungsbürgertum. Begriffs- und Dogmengeschichte eines Etiketts. Stuttgart 1986. 
Engelmeier, Hanna/Felsch, Philipp: „Gegen die Uni studieren.“ Ein Vorwort, in: Mittelweg 36, H. 4-5/2017, S. 4-13.

Erbentraut, Philipp: Theorie und Soziologie der politischen Parteien im deutschen Vormärz 1815-1848, Tübingen 2016.

Eßbach, Wolfgang: 1968 - Aufstand der Werte? Beitrag zur Tagung Vergesellschaftung der Werte: Wertedebatten in Deutschland seit 1945. Systematische und historische Aspekte, Mitteleuropa Zentrum der TU Dresden, Dresden 2006.

—: Die Junghegelianer. Soziologie einer Intellektuellengruppe, Übergänge, München 1988.

Etzemüller, Thomas: 1968 - Ein Riss in der Geschichte? Gesellschaftlicher Umbruch und 68er-Bewegungen in Westdeutschland und Schweden, Konstanz 2005.

Europäische Kommission, Generaldirektion Justiz und Verbraucher: Gleichstellung der Geschlechter 2017. Spezial Eurobarometer Nr. 465, 2017.

Faas, Thorsten/Huber, Sascha: Experimente in der Politikwissenschaft. Vom Mauerblümchen zum Mainstream, in: Politische Vierteljahresschrift 51/2010, S. 721-749.

Falter, Jürgen W: The social bases of political cleavages in the Weimar Republic, 1919-1933 (1992), in: Historical Social Research, Supplement, H. 25/2013, S. 194-216.

Fichter, Tilman/Lönnendonker, Siegward: Kleine Geschichte des SDS. Der Sozialistische Deutsche Studentenbund von 1946 bis zur Selbstauflösung, Berlin 1977.

Fiedler, Leslie A.: Cross the Border - Close the Gap, New York 1972.

Finkbeiner, Florian: Schicksalsjahre des Konservatismus. Konservative Intellektuelle und die Tendenzwende in den 1970er Jahren. Göttinger Junge Forschung, Bd. 30, Stuttgart 2017.

Fischer, Joschka: Von grüner Kraft und Herrlichkeit, Reinbek bei Hamburg 1984.

Fläschendräger, Werner: „Magd der Theologie“: Generalstudien unter der Herrschaft der Scholastik, in: Steiger, Günter/Fläschendräger, Werner (Hg.): Magister und Scholaren, Professoren und Studenten. Geschichte Deutscher Universitäten und Hochschulen im Überblick, Leipzig/Jena/Berlin 1981, S. 15-27.

Fläschendräger, Werner/Klaus, Werner/Köhler, Roland/Kraus, Aribert/Steiger, Günter: Vernunft kontra Autoritäten. Universitäten im „Jahrhundert der Aufklärung“, in: Steiger, Günter/Fläschendräger, Werner (Hg.): Magister und Scholaren, Professoren und Studenten. Geschichte Deutscher Universitäten und Hochschulen im Überblick, Leipzig/Jena/Berlin 1981, S. 55-71.

Frank, Robert: 1968 - ein Mythos? Fragen an die Vorstellung und an die Erinnerung, in: Gilcher-Holtey, Ingrid (Hg.): 1968. Vom Ereignis zum Gegenstand der Geschichtswissenschaft. Geschichte und Gesellschaft, Sonderheft 17, Göttingen 1998, S. 301307.

Franke, Berthold: Die Kleinbürger. Begrif, Ideologie, Politik, Frankfurt a.M./New York 1988.

Franzen, Axel/Pointner, Sonja: Die Black Box der Studierenden. Studienmotivation und -verhalten vor und nach der Bologna-Reform, in: Beiträge zur Hochschulforschung, 36. Jg., H. 2/2014, S. 8-32.

Frei, Norbert: 1968. Jugendrevolte und globaler Protest, München 2018. 
Freud, Sigmund: Erinnern, Wiederholen und Durcharbeiten, in: Ders.: Studienausgabe. Ergänzungsband, Frankfurt a.M. 1975, S. 205-215.

Frey, Klaus-Walter: Die bürgerliche Revolution des Jahres 1848 an den Universitäten in Wien, Graz und Innsbruck unter dem Einfluß der freiheitlich-burschenschaftlichen Bewegung. Univ.-Diss., Würzburg 1983.

Friedeburg, Ludwig von: Bildungsreform in Deutschland. Geschichte und gesellschaftlicher Widerspruch, Frankfurt a.M. 1989.

Friedeburg, Ludwig von/Horlemann, Jürgen/Hübner, Peter/Kadritzke, Ulf/Ritsert, Jürgen/Schumm, Wilhelm: Freie Universität und politisches Potential der Studenten, Neuwied/Berlin 1968.

Fukuyama, Francis: The End of History and the Last Man, New York 1992.

Fulda, Hans Friedrich: Vorbegriff und Begriff von Philosophie bei Hegel, in: Henrich, Dieter (Hg.): Hegels Logik der Philosophie. Religion und Philosophie in der Theorie des absoluten Geistes, Stuttgart 1984, S. 13-34.

Füssel, Marian: Schulfüchse, Streithähne und gelehrte Affen. Topoi des Antiakademismus seit der Frühen Neuzeit, in: Mittelweg 36, H. 4-5/2017, S. 30-46.

Gabler, Andrea: Sturm im Elfenbeinturm. Positionen und Aktionsformen des Göttinger AStA zu Wissenschaftsbetrieb und politischem Mandat von 1967 bis 1987, Göttingen 1993.

Gagel, Walter: Geschichte der politischen Bildung in der Bundesrepublik Deutschland 1945-1989/90. Zwölf Lektionen, Wiesbaden 1994.

Gall, Lothar: Bürgertum in Deutschland, Berlin 1989.

Gallus, Alexander/Jesse, Eckhard (Hg.): Staatsformen von der Antike bis zur Gegenwart. Ein Handbuch, Köln 2007.

Galtung, Johan: Eine strukturelle Theorie der Revolution, in: Jänicke, Martin (Hg.): Herrschaft und Krise. Beiträge zur politikwissenschaftlichen Krisenforschung, Opladen 1973, S. 121-167.

Gassert, Philipp: „1968“ als Wahrnehmungsrevolution. Eine kluge These, die umfassender untersucht werden müsste, in: Gilcher-Holtey, Ingrid (Hg.): „1968“ - eine Wahrnehmungsrevolution? Horizont-Verschiebungen des Politischen in den 1960er und 1970 Jahren. Zeitgeschichte im Gespräch, Bd. 16, München 2013, S. 123-134.

Gassert, Philipp: Bewegte Gesellschaft. Deutsche Protestgeschichte seit 1945, Stuttgart 2018.

Geiges, Lars/Marg, Stine/Walter, Franz: Pegida. Die schmutzige Seite der Zivilgesellschaft?, X-Texte zu Kultur und Gesellschaft, Bielefeld 2015.

Geronimo: Feuer und Flamme. Zur Geschichte der Autonomen, Berlin/Amsterdam 1990.

Gevers, Lieve/Vos, Louis: Studentische Bewegungen, in: Rüegg, Walter (Hg.): Geschichte der Universität in Europa Bd. III: Vom 19. Jahrhundert zum Zweiten Weltkrieg (1800-1945), München 2004, S. 227-299.

Gietinger, Klaus: November 1918. Der verpasste Frühling des 20. Jahrhunderts, Hamburg 2018.

Gilcher-Holtey, Ingrid: Mai 68 in Frankreich, in: Dies.: (Hg.): 1968. Vom Ereignis zum Mythos, Frankfurt a.M. 2008, S. 15-45. 
Kritische Theorie und Neue Linke, in: Dies: (Hg.): 1968. Vom Ereignis zum Gegenstand der Geschichtswissenschaft. Geschichte und Gesellschaft, Sonderheft 17, Göttingen 1998, S. 168-187.

- „Die Phantasie an die Macht“. Mai 68 in Frankreich, Frankfurt a.M. 1995.

Glotz, Peter/Malanowski, Wolfgang: Student heute. Angepaßt? Ausgestiegen?, Reinbek bei Hamburg 1982.

Goethe, Johann Wolfgang: Faust. Eine Tragödie. Erster und zweiter Teil [1797-1832], München 1997.

Goltz, Anna von der: Eine Gegen-Generation von 1968? Politische Polarisierung und konservative Mobilisierung an westdeutschen Universitäten, in: Livi, Massimiliano/Schmidt, Daniel/Sturm, Michael (Hg.): Die 1970er Jahre als schwarzes Jahrzehnt. Politisierung und Mobilisierung zwischen christlicher Demokratie und extremer Rechter, Frankfurt a.M./New York 2010, S. 73-89.

Göllnitz, Martin: Der Student als Führer? Handlungsmöglichkeiten eines jungakademischen Funktionärskorps am Beispiel der Universität Kiel (1927-1945), Ostfildern 2018.

Grazia, Victoria de: Irresistible Empire. America's Advance through Twentieth-Century Europe, Cambridge 2006.

Greven, Michael Th.: Systemopposition. Kontingenz, Ideologie und Utopie im politischen Denken der 1960er Jahre, Opladen 2011.

Großbölting, Thomas: 1968 in Westfalen. Akteure, Formen und Nachwirkungen einer Protestbewegung. Regionalgeschichte kompakt Bd.1, Münster 2018.

Große, Jürgen: 1968. Revolte und Regression, in: Merkur. Gegründet 1947 als Deutsche Zeitschrift für Europäisches Denken, H. 829/2018, S. 79-87.

Habermas, Jürgen/Friedeburg, Ludwig von/Oehler, Christoph/Weltz, Friedrich: Student und Politik. Eine soziologische Untersuchung zum politischen Bewußtsein von Frankfurter Studenten, Neuwied am Rhein 1961.

Hardtwig, Wolfgang: Einleitung, in: Ders. (Hg.): Revolution in Deutschland und Europa 1848/49, Göttingen 1998, S. 7-10.

—: Studentische Mentalität - Politische Jugendbewegung - Nationalismus. Die Anfänge der deutschen Burschenschaft, in: Historische Zeitschrift, Bd. 242/1986, S. 581-628.

—: Auf dem Weg zum Bildungsbürgertum. Die Lebensführungsart der jugendlichen Bildungsschicht 1750-1819, in: Lepsius, M. Rainer (Hg.): Bildungsbürgertum im 19: Jahrhundert, Teil III: Lebensführung und ständische Vergesellschaftung, Stuttgart 1985, S. 19-41.

— Krise der Universität, studentische Reformbewegung (1750-1819) und die Sozialisation der jugendlichen deutschen Bildungsschicht. Aufriß eines Forschungsproblems, in: Geschichte und Gesellschaft, 11. Jg., H. 2/1985, S. 155-176.

Heer, Georg: Geschichte der Deutschen Burschenschaft, Bd. 2: Die Demagogenzeit. Von den Karlsbader Beschlüssen bis zum Frankfurter Wachensturm (1820-1833), Heidelberg 1927.

Hegel, Georg Wilhelm Friedrich: Ältestes Systemprogramm des deutschen Idealismus [1796]. Gesammelte Werke Bd. 1, Frankfurt a.M. 1979. 
- : Grundlinien der Philosophie des Rechts oder Naturrecht und Staatswissenschaft im Grundrisse [1821]. Gesammelte Werke Bd. 7, Frankfurt a.M. 2004.

Heinemann, Angela Luise: Studenten im Aufbruch. Die Entstehung der Jenaer Urburschenschaft und das Wartburgfest als mediale Inszenierung, in: In Lönnecker, Harald (Hg.): „Deutschland immer gedient zu haben ist unser höchstes Lob!“ Zweihundert Jahre Deutsche Burschenschaften. Eine Festschrift zur 200. Wiederkehr des Gründungstages der Burschenschaft am 12. Juni 1815 in Jena, Heidelberg 2015, S. 1-78.

Heinrich, Klaus: Zur Geistlosigkeit der Universität heute. Oldenburger Universitätsreden, Nr. 8, Oldenburg 1987.

Heither, Dietrich/Gehler, Michael/Kurth, Alexandra/Schäfer, Gerhard: Blut und Paukboden. Eine Geschichte der Burschenschaften, Frankfurt a.M. 1997.

Hermand, Jost/Trommler, Frank: Die Kultur der Weimarer Republik, München 1978.

Herrlitz, Hans-Georg: Studium als Standesprivileg. Die Entstehung des Maturitätsproblems im 18. Jahrhundert, Frankfurt a.M. 1973.

Herrmann, Ulrich: Über ,Bildung im Gymnasium des wilhelminischen Kaiserreichs, in: In Koselleck, Reinhart (Hg.): Bildungsbürgertum im 19: Jahrhundert. Teil II: Bildungsgüter und Bildungswissen, Stuttgart 1990, S. 346-368.

Himpele, Klemens: Vom Bildungsstreik zur Bewegung?, in: Blätter für deutsche und internationale Politik, H. 8/2009, S. 11-15.

Hirschman, Albert O.: Engagement und Enttäuschung. Über das Schwanken der Bürger zwischen Privatwohl und Gemeinwohl, Frankfurt a.M. 1984.

Hobsbawm, Eric J.: Das Zeitalter der Extreme. Weltgeschichte des 20. Jahrhunderts, München 2007.

—: Europäische Revolution. 1789 bis 1848, Köln 2004.

—: Das imperiale Zeitalter. 1875 - 1914, Frankfurt a.M./New York 1989.

—: Die Blütezeit des Kapitals. Eine Kulturgeschichte der Jahre 1848 - 1875, Frankfurt a.M. 1980.

Hodenberg, Christina von: Das andere Achtundsechzig. Gesellschaftsgeschichte einer Revolte, München 2018.

Hoffmann, Dagmar/Stecher, Ludwig: Bildungsmoratorium revisited (Editorial), in: Diskurs Kindheits- und Jugendforschung, 11. Jg., H. 2/2016, S. 143-145.

Humboldt, Wilhelm von: Über die innere und äußere Organisation der höheren wissenschaftlichen Anstalten in Berlin [1809/10], in: Engel, Johann Jakob/Erhard, Johann Benjamin/Wolf, Friedrich August/Fichte, Johann Gottlieb/Schleiermacher, Friedrich Daniel Ernst/Savigny, Karl Friedrich/Humboldt, Wilhelm von/Hegel, Georg Wilhelm Friedrich: Gelegentliche Gedanken über Universitäten, Leipzig 1990, S. 273283.

Hurrelmann, Klaus/Quenzel, Gudrun: Lebensphase Jugend. Eine Einführung in die sozialwissenschaftliche Jugendforschung, Weinheim/Basel 2013.

Illies, Florian: Generation Golf. Eine Inspektion, Frankfurt a.M. 2001.

Infratest Wirtschaftsforschung (Hg.): Politischer Protest in der Bundesrepublik Deutschland. Beiträge zur sozialempirischen Untersuchung des Extremismus, Stuttgart/Berlin/Köln/Mainz 1980. 
Institut für Sozialforschung: Ideologie, in: Soziologische Exkurse. Nach Vorträgen und Diskussionen, Frankfurter Beiträge zur Soziologie Bd. 4, Frankfurt a.M. 1956, S. 162-181.

Jaide, Walter: Eine neue Generation? Eine Untersuchung über Werthaltungen und Leitbilder der Jugendlichen, hgg. vom Deutschen Jugendinstitut, München 1961.

Jaide, Walter/Veen, Hans-Joachim: Bilanz der Jugendforschung. Ergebnisse empirischer Analysen in der Bundesrepublik Deutschland von 1975 bis 1987. Studien zur Politik, Bd. 13, Paderborn 1989.

Jarausch, Konrad H.: The Sources of German Student Unrest 1815-1848 (1974), in: Historical Social Research, Supplement, H. 24/2012, S. 80-114.

—: Frequenz und Struktur. Zur Sozialgeschichte der Studenten im Kaiserreich (1980), in: Historical Social Research, Supplement, H. 24/2012, S. 125-156.

—: Verkannter Strukturwandel. Die siebziger Jahre als Vorgeschichte der Probleme der Gegenwart, in: Ders. (Hg.): Das Ende der Zuversicht? Die siebziger Jahre als Geschichte, Göttingen 2008, S. 9-26.

—: Die Krise des deutschen Bildungsbürgertums im ersten Drittel des 20. Jahrhunderts, in: Kocka, Jürgen (Hg.): Bildungsbürgertum im 19. Jahrhundert. Teil IV: Politischer Einfluß und gesellschaftliche Formation, Stuttgart 1989, S. 180-205.

—- Deutsche Studenten 1800-1970, Frankfurt a.M. 1984.

- Students, Society and Politics in Imperial Germany. The Rise of Academic Illiberalism, Princeton 1982.

Jarausch, Konrad H./Sabrow, Martin: ,Meistererzählung. Zur Karriere eines Begriffs, in: Dies. (Hg.): Die historische Meistererzählung. Deutungslinien der deutschen Nationalgeschichte nach 1945, Göttingen 2002.

Jesse, Eckhard: 1968 - und 50 Jahre später. Eine deutsch-deutsche Bestandsaufnahme, in: INDES. Zeitschrift für Politik und Gesellschaft, H. 1/2018, S. 88-99.

Jörke, Dirk/Nachtwey, Oliver (Hg.): Das Volk gegen die (liberale) Demokratie. Leviathan Sonderband 32, Baden-Baden 2017.

Jörke, Dirk/Selk, Veith: Der hilflose Antipopulismus, in: Leviathan, 43. Jg., H. 4/2015, S. 484-500.

Kaase, Max: Politisches Verhalten von Studenten im Vergleich mit anderen Gruppen, in: Albrecht, Günter/Daheim, Hansjürgen/Sack, Fritz (Hg.): Soziologie. Sprache, Bezug zur Praxis, Verhältnis zu anderen Wissenschaften. René König zum 65. Geburtstag, Opladen 1973, S. 560-572.

- Demokratische Einstellungen in der Bundesrepublik Deutschland, in: Wildenmann, Rudolf (Hg.): Sozialwissenschaftliches Jahrbuch für Politik, München/Wien 1971, S. 119-326.

- Die politische Mobilisierung von Studenten in der BRD, in: Allerbeck, Klaus R./Rosenmayr, Leopold (Hg.): Aufstand der Jugend? Neue Aspekte der Jugendsoziologie, München 1971, S. 155-177.

Kaelble, Hartmut: 1848: Viele nationale Revolutionen oder eine europäische Revolution?, in: Hardtwig, Wolfgang (Hg.): Revolution in Deutschland und Europa 1848/49, Göttingen 1998, S. 260-278.

Kaldewey, David: Der Campus als ,Safe Space'. Zum theoretischen Unterbau einer neuen Bewegung, in: Mittelweg 36, H. 4-5/2017, S. 132-153. 
Kampe, Norbert: Studenten und „Judenfrage“ im Deutschen Kaiserreich. Die Entstehung einer akademischen Trägerschicht des Antisemitismus. Kritische Studien zur Geschichtswissenschaft, Bd. 76, Göttingen 1988.

Kant, Immanuel: Metaphysische Anfangsgründe der Rechtslehre. Metaphysik der Sitten, Erster Teil [1797], Hamburg 2009.

Kaschuba, Wolfgang. 1848/49: Horizonte politischer Kultur, in: Hardtwig, Wolfgang (Hg.): Revolution in Deutschland und Europa 1848/49, Göttingen 1998, S. 56-78.

Kater, Michael H.: Studentenschaft und Rechtsradikalismus in Deutschland 1918-1933. Eine sozialgeschichtliche Studie zur Bildungskrise in der Weimarer Republik, Hamburg 1975.

Kaupp, Peter (Hg.): Stamm-Buch der Jenaischen Burschenschaft. Die Mitglieder in der Urburschenschaft 1815-1819. Abhandlungen zum Studenten- und Hochschulwesen Bd. 14, Köln 2005.

Kelle, Udo/Kluge, Susann: Vom Einzelfall zum Typus. Fallvergleich und Fallkontrastierung in der qualitativen Sozialforschung, Wiesbaden 2010.

Kern, Horst: Empirische Sozialforschung. Ursprünge, Ansätze, Entwicklungslinien, München 1982.

Kersting, Franz-Werner: Helmut Schelskys ,Skeptische Generation` von 1957. Zur Publikations- und Wirkungsgeschichte eines Standardwerkes, in: Vierteljahrshefte für Zeitgeschichte, 50. Jg., H. 3/2002, S. 465-495.

Keune, Hannes/Schenke, Julian: ,Weitsicht und Naivität‘. Ein studentischer Blick auf die Ambivalenz der Frankfurter Schule, in: INDES. Zeitschrift für Politik und Gesellschaft, H. 3/2014, S. 78-86.

Kiel, Sabine: Studierende und Politik. Eine kritische Analyse zur politischen Sozialisation. Forum Wissenschaft Studien Bd. 32, Marburg 1996.

Kießling, Simon: Die antiautoritäre Revolte der 68er. Postindustrielle Konsumgesellschaft und säkulare Religionsgeschichte der Moderne, Köln 2006.

Kleemann, Frank/Krähnke, Uwe/Matuschek, Ingo: Interpretative Sozialforschung. Eine Einführung in die Praxis des Interpretierens, Wiesbaden 2013.

Kleifeld, Helge: ,Wende zum Geist'? Bildungs- und hochschulpolitische Aktivitäten der überkonfessionellen studentischen Korporationen an westdeutschen Hochschulen 1945-1961, Köln 2002.

Klenke, Dietmar: Deutsche Nationalreligiosität zwischen Vormärz und Reichsgründung. Zur innen- und außenpolitischen Dynamik der deutschen Nationalbewegung, in: Historisches Jahrbuch, H. 123/2003, S. 389-448.

Klimke, Martin: The Other Alliance. Student Protest in West Germany and the United States in the Global Sixties, Princeton and Oxford 2010.

Klose, Werner: Freiheit schreibt auf eure Fahnen. 800 Jahre deutsche Studenten, Oldenburg 1967.

Knoll, Joachim H.: Typisch deutsch? Die Jugendbewegung. Ein essayistischer Deutungsversuch, in: Knoll, Joachim H./Schoeps, Julius: Typisch deutsch. Die Jugendbewegung, Opladen 1988, S. 11-34.

- Kritik und Verantwortung, in: Schoeps, Hans Julius/Dannenmann, Christopher: Die rebellischen Studenten. Elite der Demokratie oder Vorhut eines linken Faschismus?, München und Esslingen/Neckar 1968, S. 9-17. 
Knopke, Katharina/Krüger, Laura/Siri, Jasmin: Vereinzelt, konfliktscheu, weltoffen? Studierende und Politik, Bonn 2017.

Kocka, Jürgen: Bildungsbürgertum - Gesellschaftliche Formation oder Historikerkonstrukt?, in: Ders. (Hg.): Bildungsbürgertum im 19: Jahrhundert. Teil IV: Politischer Einfluß und gesellschaftliche Formation, Stuttgart 1989, S. 9-20.

Koebner, Thomas/Janz, Rolf-Peter/Trommler, Frank (Hg.): Mit uns zieht die neue Zeit. Der Mythos Jugend, Frankfurt a.M. 1985.

Koenen, Gerd: Das rote Jahrzehnt. Unsere kleine deutsche Kulturrevolution 1967 - 1977, Frankfurt a.M. 2011.

Köhler, Helmut: Bildungsbeteiligung und Sozialstruktur in der Bundesrepublik. Zu Stabilität und Wandel der Ungleichheit von Bildungschancen. Studien und Berichte des Max-Planck-Instituts für Bildungsforschung Nr. 53, Berlin 1992.

Koppetsch, Cornelia: Soziologiekolumne: Weltbürgerlichkeit als repräsentative Kultur?, in: Merkur. Gegründet 1947 als Deutsche Zeitschrift für Europäisches Denken, 72. Jg., H. 838/2019, S. 43-50.

- Soziologiekolumne: Eine Welle der Nostalgie. Die akademische Mittelschicht und die illiberale Gesellschaft, in: Merkur. Gegründet 1947 als Deutsche Zeitschrift für Europäisches Denken, 72. Jg., H. 832/2018, S. 51-58.

—: Die Wiederkehr der Konformität. Streifzüge durch die verunsicherte Mitte. Bpb Lizenzausgabe, Bonn 2015.

Koselleck, Reinhart: Sozialgeschichte und Begriffsgeschichte, in: Ders.: Begriffsgeschichten. Studien zur Semantik und Pragmatik der politischen und sozialen Sprache, Frankfurt a.M. 2006, S. 9-31.

- Einleitung. Zur anthropologischen und semantischen Struktur der Bildung, in: Ders. (Hg.): Bildungsbürgertum im 19. Jahrhundert. Teil II: Bildungsgüter und Bildungswissen, Stuttgart 1990, S. 11-46.

— : Preußen zwischen Reform und Revolution. Allgemeines Landrecht, Verwaltung und soziale Bewegung von 1791 bis 1848, Stuttgart 1967.

— Staat und Gesellschaft in Preußen 1815-1848, in: Conze, Werner (Hg.): Staat und Gesellschaft im deutschen Vormärz 1815-1848, Stuttgart 1962, S. 79-112.

Kracauer, Siegfried: Geschichte - Vor den letzten Dingen, Frankfurt a.M. 1971.

Kraus, Hans-Christof: Kultur, Bildung und Wissenschaft im 19. Jahrhundert. Enzyklopädie Deutscher Geschichte, Bd. 82, München 2008.

Krause, Christian/Lehnert, Detlef/Scherer, Klaus-Jürgen: Zwischen Revolution und Resignation? Alternativkultur, politische Grundströmungen und Hochschulaktivitäten in der Studentenschaft. Eine empirische Untersuchung über die politischen Einstellungen von Studenten, Bonn 1980.

Kraushaar, Wolfgang: 1968: 100 Seiten, Ditzingen 2018.

- Der Aufruhr der Ausgebildeten. Vom Arabischen Frühling zur OccupyBewegung, Hamburg 2012.

—: Die Bombe im Jüdischen Gemeindehaus, Hamburg 2005.

—: Die Frankfurter Sponti-Szene. Eine Subkultur als politische Versuchsanordnung, in: Archiv für Sozialgeschichte, H. 44/2004, S. 105-121.

—: 1968 als Mythos, Chiffre und Zäsur, Hamburg 2000.

—: 1968. Das Jahr, das alles verändert hat, München 1998. 
- (Hg.): Autonomie oder Getto? Kontroversen über die Alternativbewegung, Frankfurt a.M. 1978.

Krippendorff, Ekkehart: Die Idee der Universität, in: PROKLA 104, 26. Jg., H. 3/1996, S. 431-439.

Kühl, Stefan: Der Sudoku-Effekt. Zu den Gründen und Folgen der Komplexitätssteigerung an den Hochschulen, in: Soziale Systeme, 16. Jg., H. 2/2010, S. 440-456.

Kühn, Thomas/Koschel, Kay-Volker: Gruppendiskussionen. Ein Praxis-Handbuch, Wiesbaden 2017.

Kunze, Manuel/Tielesch, Simon: Bologna auf dem Markt der Meinungsmöglichkeiten. Was mit den Studierendenprotesten gesagt werden sollte - und was verstanden wurde, in: Psychologie \& Gesellschaftskritik, H. 34/2010, S. 105-112.

Kurz, Karl: Lebensverhältnisse der Nachkriegsjugend. Eine soziologische Studie, Bremen 1949.

Langewiesche, Dieter: Kulturelle Nationsbildung im Deutschland des 19. Jahrhunderts, in: Hettling, Manfred/Nolte, Paul (Hg.): Nation und Gesellschaft in Deutschland. Historische Essays, München 1996, S. 46-64.

— : Wirkungen des „Scheiterns“. Überlegungen zu einer Wirkungsgeschichte der europäischen Revolutionen von 1848, in: Die Revolutionen von 1848 in der europäischen Geschichte. Ergebnisse und Nachwirkungen. Beiträge des Symposions in der Paulskirche vom 21. bis 23. Juni 1998. Historische Zeitschrift, Beihefte New Series, H. 29/2000, S. 5-21.

—: Bildungsbürgertum und Liberalismus im 19. Jahrhundert, in: In Kocka, Jürgen (Hg.): Bildungsbürgertum im 19. Jahrhundert. Teil IV: Politischer Einfluß und gesellschaftliche Formation, Stuttgart 1989, S. 95-121.

Laqueur, Walter: Die deutsche Jugendbewegung. Eine historische Studie [1962], Köln 1978.

Leggewie, Claus: Der Mythos des Neuanfangs. Gründungsetappen der Bundesrepublik Deutschland: 1949 - 1968 - 1989, in: Berding, Helmut (Hg.): Mythos und Nation. Studien zur Entwicklung des kollektiven Bewußtseins in der Neuzeit, Bd. 3, Frankfurt a.M. 1996, S. 275-302.

— Die 89er: Portrait einer Generation: 1: Aufl: Hamburg: Hoffmann und Campe, 1995:

Lehmbruch, Gerhard: Parteienwettbewerb im Bundesstaat. Regelsysteme und Spannungslagen im politischen System der Bundesrepublik Deutschland [1976], Wiesbaden 2000.

Leischner, Franziska/Krüger, Anne K./Moes, Johannes/Schütz, Anna: Beschäftigungsbedingungen und Personalpolitik an Hochschulen in Deutschland. Projektbericht, Berlin 2016.

Lenk, Kurt: Zum Strukturwandel politischer Ideologien im 19. und 20. Jahrhundert Begriff und Phänomen des ideologischen Bewußtseins (1981), in: Ders.: Rechts, wo die Mitte ist. Studien zur Ideologie: Rechtsextremismus, Nationalsozialismus, Konservatismus, Baden-Baden 1994, S. 27-41.

—: Ideologie. Ideologiekritik und Wissenssoziologie, Frankfurt a.M./New York 1984. 
: Wie demokratisch ist der Parlamentarismus? Grundpositionen einer Kontroverse, Stuttgart Berlin Köln Mainz 1972.

Lepsius, Mario Rainer: Parteiensystem und Sozialstruktur. Zum Problem der Demokratisierung der deutschen Gesellschaft (1966), in: Ders.: Demokratie in Deutschland. Soziologisch-historische Konstellationsanalysen. Ausgewählte Aufsätze, Göttingen 1993, S. 25-50.

—: Kulturelle Dimensionen der sozialen Schichtung [1963], in: Ders. (Hg.): Interessen, Ideen und Institutionen, Opladen 1990, S. 96-116.

—: Das Bildungsbürgertum als ständische Vergesellschaftung, in: Ders.: (Hg.): Bildungsbürgertum im 19. Jahrhundert. Teil III: Lebensführung und ständische Vergesellschaftung, Stuttgart 1985, S. 9-18.

—: Soziale Ungleichheit und Klassenstrukturen in der Bundesrepublik Deutschland, in: Wehler, Hans-Ulrich (Hg.): Klassen in der europäischen Sozialgeschichte, Göttingen 1979, S. 166-209.

—: Demokratie in Deutschland als historisch-soziologisches Problem, in: Adorno, Theodor W. (Hg.): Spätkapitalismus oder Industriegesellschaft? Verhandlungen des 16. Deutschen Soziologentages in Frankfurt a.M. 1968, Stuttgart 1969, S. 197-213.

Levsen, Sonja: Elite, Männlichkeit und Krieg. Tübinger und Cambridger Studenten 1900-1929. Kritische Studien zur Geschichtswissenschaft, Bd. 170, Göttingen 2006.

Liebersohn, Harry: The American Academic Community before the First World War. A comparison with the German ,Bildungsbürgertum', in: Conze, Werner und Kocka, Jürgen (Hg.): Bildungsbürgertum im 19: Jahrhundert. Teil I: Bildungssystem und Professionalisierung in internationalen Vergleichen, Stuttgart 1985, S. 163-185.

Liessmann, Konrad Paul: Theorie der Unbildung. Die Irrtümer der Wissensgesellschaft, Wien 2006.

Lipp, Volker/Möllers, Christoph/von der Pfordten, Dietmar (Hg.): Heinrich Heine. Dichter und Jurist in Göttingen. Göttinger Juristische Schriften, Bd. 1, Göttingen 2007.

Lipset, Seymour Martin/Rokkan, Stein: Party Systems and Voter Alignments. CrossNational Perspectives, New York 1967.

Litt, Theodor: Hochschule und öffentliches Leben in der Weimarer Republik, in: Zilius, Wilhelm/Grimme, Adolf (Hg.): Kulturverwaltung der zwanziger Jahre. Alte Dokumente und neue Beiträge, Stuttgart 1961, S. 49-59.

Lönnecker, Harald: Vorwort, in: Ders. (Hg.): Deutschland immer gedient zu haben ist unser höchstes Lob! Zweihundert Jahre Deutsche Burschenschaften. Eine Festschrift zur 200. Wiederkehr des Gründungstages der Burschenschaft am 12. Juni 1815 in Jena, Heidelberg 2015, S. VII-XIV.

- Sand, Carl Ludwig, in: Neue Deutsche Biographie (NDB), Bd. 22, Berlin 2005, S. 413-414.

Lorenz, Robert/Walter, Franz: 1964. Anfänge des tiefgreifenden gesellschaftlichen Wandels, in: Dies. (Hg.): 1964. Das Jahr, mit dem „68“ begann, Bielefeld 2014, S. 9-31.

—: 1968: Kulminationspunkt und politische Eruption, in: Dies. (Hg.): 1964. Das Jahr, mit dem „68“ begann, Bielefeld 2014, S. 327-372.

Lösche, Peter/Walter, Franz: Katholiken, Konservative und Liberale. Milieus und Lebenswelten bürgerlicher Parteien in Deutschland während des 20. Jahrhunderts, in: Geschichte und Gesellschaft, H. 26/2000, S. 471-492. 
Löwith, Karl: Von Hegel zu Nietzsche. Der revolutionäre Bruch im Denken des neunzehnten Jahrhunderts [1941], Stuttgart 1958.

Lübbe, Hermann: 1968. Zur deutschen Wirkungsgeschichte eines politromantischen Rückfalls, in: Ders.: Politik nach der Aufklärung. Philosophische Aufsätze, München 2001, S. 129-149.

Luckscheiter, Roman: Der postmoderne Impuls. ,1968‘ als literaturgeschichtlicher Katalysator, in: Klimke, Martin/Scharloth, Joachim (Hg.): 1968. Handbuch zur Kulturund Mediengeschichte der Studentenbewegung. Bpb Lizenzausgabe, Bonn 2007, S. 151-159.

Lukács, Georg: Die Theorie des Romans. Ein geschichtsphilosophischer Versuch über die Formen der großen Epik [1916], Darmstadt/Neuwied 1984.

Lundgreen, Peter: Sozial- und Kulturgeschichte des Bürgertums. Eine Bilanz des Bielefelder Sonderforschungsbereichs (1986-1997), Göttingen 2000.

—: Einführung, in: Ders. (Hg.): Sozial- und Kulturgeschichte des Bürgertums. Eine Bilanz des Bielefelder Sonderforschungsbereichs (1986-1997), Göttingen 2000, S. 1339.

——: Zur Konstituierung des ,Bildungsbürgertums‘. Berufs- und Bildungsauslese der Akademiker in Preußen, in: Conze, Werner/Kocka, Jürgen (Hg.): Bildungsbürgertum im 19. Jahrhundert. Teil 1: Bildungssystem und Professionalisierung in internationalen Vergleichen, Stuttgart 1985, S. 79-108.

—: Bildung und Besitz. Einheit oder Inkongruenz in der europäischen Sozialgeschichte? Kritische Auseinandersetzung mit einer These von Fritz Ringer, in: Geschichte und Gesellschaft, H. 7/1981, S. 262-275.

Lüders, Christian: Deutungsmusteranalyse. Annäherungen an ein risikoreiches Konzept, in: Garz, Detlef/Kraimer, Klaus (Hg.): Qualitativ-empirische Sozialforschung. Konzepte, Methoden, Analysen, Opladen 1991, S. 377-408.

Lüders, Christian/Meuser, Michael: Deutungsmusteranalyse, in: Hitzler, Ronald/Honer, Anne (Hg.): Sozialwissenschaftliche Hermeneutik. Eine Einführung, Wiesbaden 1997, S. 57-80.

Mangold, Werner: Gruppendiskussionen, in: König, René: Handbuch der empirischen Sozialforschung Bd. 2, Stuttgart 1973.

—: Gegenstand und Methode des Gruppendiskussionsverfahrens. Aus der Arbeit des Instituts für Sozialforschung, Frankfurt a.M. 1960.

Mann, Michael: The Ideology of Intellectuals and Other People in the Development of Capitalism, in: Lindberg, Leon N./Alford, Robert/Crouch, Colin/Offe, Claus (Hg.): Stress and Contradiction in Modern Capitalism. Public Policy and The Theory of the State, Lexington/Massachusetts/Toronto/London 1975, S. 275-307.

Mannheim, Karl: Das Problem der Generationen [1928], in: Ders.: Wissenssoziologie. Auswahl aus dem Werk, Berlin/Neuwied 1964, S. 509-565.

Manow, Philipp: Der Extremismus der Mitte, in: Merkur. Gegründet 1947 als Deutsche Zeitschrift für europäisches Denken, 73. Jg., H. 836/2019, S. 5-13.

Marcuse, Herbert: Triebstruktur und Gesellschaft. Ein philosophischer Beitrag zu Sigmund Freud [1955], Frankfurt a.M. 1967.

Marg, Stine: Nach Pegida - Politische Orientierungen junger Menschen. Fokusgruppen als Instrument zur Deutungsmusteranalyse, in: Bögelein, Nicole/Vetter, Nico- 
le (Hg.): Der Deutungsmusteransatz. Einführung - Erkenntnisse - Perspektiven, Weinheim Basel 2019, S. 107-127.

—: Mitte in Deutschland. Zur Vermessung eines politischen Ortes, Bielefeld 2014. Marg, Stine/Trittel, Katharina/Schmitz, Christopher/Kopp, Julia/Walter, Franz: NoPegida. Die helle Seite der Zivilgesellschaft?, Bielefeld 2016.

Marg, Stine/Schenke, Julian/Finkbeiner, Florian: Gegen einen formalistischen Demokratiebegriff. Zwischenstand der begriffshistorischen und -theoretischen Reflexion im Forschungsprozess, in: Demokratie Dialog, H. 5/2019, S. 2-13.

Maßmann, Hans Ferdinand: Kurze und wahrhaftige Beschreibung des großen Burschenfestes auf der Wartburg bei Eisenach am 18ten und 19ten des Siegesmondes 1817, Eisenach 1817, online einsehbar unter: https://archive. thulb.uni-jena.de/collections/rsc/viewer/HisBest_derivate_00015889/THUESA_ BurschenfestWartburg_Massmann_387154183_1817_0040.tif [eingesehen am 28.02.2020]

Maurer, Trude: „... und wir gehören auch dazu“. Universität und „Volksgemeinschaft“ im Ersten Weltkrieg, Göttingen 2015.

Mausfeld, Rainer: Warum schweigen die Lämmer? Wie Elitendemokratie und Neoliberalismus unsere Gesellschaft und unsere Lebensgrundlagen zerstören, Frankfurt a.M. 2018.

Mayring, Philipp: Einführung in die qualitative Sozialforschung. Eine Anleitung zu qualitativem Denken, Weinheim 1999.

McClelland, Charles: Professionalization and Higher Education in Germany, in: Jarausch, Konrad H. (Hg.): The Transformation of Higher Learning 1860-1930. Expansion, Diversification, Social Opening and Professionalization in England, Germany, Russia and the United States, Stuttgart 1982, S. 306-320.

Meinel, Florian: Vertrauensfrage. Zur heutigen Krise des Parlamentarismus, München 2019.

Menke, Christoph: Philosophiekolumne. Am Tag der Krise, in: Merkur. Gegründet 1947 als Deutsche Zeitschrift für europäisches Denken, 71. Jg., H. 820/2017, S. 49-57.

Meuser, Michael: Repräsentation sozialer Strukturen im Wissen. Dokumentarische Methode und Habitusrekonstruktion, in: Bohnsack, Ralf/Nentwig-Gesemann, Iris/Nohl, Arnd-Michael (Hg.): Die dokumentarische Methode und ihre Forschungspraxis, Wiesbaden 2013, S. 209-224.

Michels, Eckard: Schahbesuch 1967. Fanal für die Studentenbewegung, Berlin 2017.

Mies, Ullrich/Wernicke, Jens (Hg.): Fassadendemokratie und Tiefer Staat. Auf dem Weg in ein autoritäres Zeitalter, Wien 2017.

Möller, Horst: Die Weimarer Republik. Eine unvollendete Demokratie, München 2004 [ursprgl. 1985].

Mrozek, Bodo: Jugend - Pop - Kultur. Eine transnationale Geschichte, Berlin 2019.

Mueller-Benedict, Volker: Confirming long waves in time series of German student populations 1830-1990 using filter technics and spectral analysis. Historical Social Research, H. 25/2000, S. 36-56.

Multrus, Frank: Der Studierendensurvey. Konzept, Aufbau und theoretische Grundlagen. Hefte zur Bildungs- und Hochschulforschung, H. 87/2016. AG Hochschulforschung, Universität Konstanz 2016. 
Müller, Frank Lorenz: Die Revolution von 1848/49, Darmstadt 2012.

Münch, Richard: Akademischer Kapitalismus. Zur politischen Ökonomie der Hochschulreform, Berlin 2011.

Münkler, Herfried: Mitte und Maß. Der Kampf um die richtige Ordnung, Reinbek bei Hamburg 2012.

— : Der kompetente Bürger, in: Klein, Ansgar/Schmalz-Bruns, Rainer (Hg.): Politische Beteiligung und Bürgerengagement in Deutschland. Möglichkeiten und Grenzen, Baden-Baden 1997, S. 153-172.

Nagel, Katja: Die Provinz in Bewegung. Studentenunruhen in Heidelberg 1967-1973. Buchreihe der Stadt Heidelberg, Bd. XIII, Heidelberg - Ubstadt-Weiher - Neustadt a. d. W. - Basel 2009.

Nentwig, Teresa: „Kultusminister der vierzehn Tage“. Der Skandal um Leonhard Schlüter 1955, in: Walter, Franz/Nentwig, Teresa (Hg.): Das gekränkte Gänseliesel. 250 Jahre Skandalgeschichten in Göttingen, Göttingen 2015, S. 126-138.

Nickel, Carsten: Rückbau der Gesellschaft, in: Merkur. Gegründet 1947 als Deutsche Zeitschrift für Europäisches Denken, 73. Jg., H. 839/2019, S. 27-36.

Nida-Rümelin, Julian: Der Akademisierungswahn. Zur Krise beruflicher und akademischer Bildung, Hamburg 2014.

Nietzsche, Friedrich: Über die Zukunft unserer Bildungs-Anstalten. Sechs öffentliche Vorträge [1872], in: Ders.: Kritische Studienausgabe (KSA) Bd. I. Die Geburt der Tragödie. Unzeitgemäße Betrachtungen I-IV. Nachgelassene Schriften 1870-1873, S.641-752.

Nipperdey, Thomas: Verein als soziale Struktur im späten 18. und frühen 19. Jahrhundert, in: Boockmann, Hartmut/Esch, Arnold/Heimpel, Hermann/Nipperdey, Thomas/Schmidt, Heinrich: Geschichtswissenschaft und Vereinswesen im 19. Jahrhundert. Veröffentlichungen des Max-Planck-Instituts für Geschichte, Bd. 1, Göttingen 1972, S. 1-44.

— : Die deutsche Studentenschaft in den ersten Jahren der Weimarer Republik, in: Zilius, Wilhelm/Grimme, Adolf (Hg.): Kulturverwaltung der zwanziger Jahre. Alte Dokumente und neue Beiträge, Stuttgart 1961, S. 19-48.

Nitsch, Wolfgang/Gerhardt, Uta/Offe, Claus/Preuß, Ulrich K.: Hochschule in der Demokratie. Kritische Beiträge zur Erbschaft und Reform der deutschen Universität, Berlin/Neuwied am Rhein 1965.

o. V.: Demokratie braucht politische Bildung. Zum Auftrag der Bundeszentrale und der Landeszentralen für politische Bildung. „Münchner Manifest“vom 26. Mai 1997, in: Aus Politik und Zeitgeschichte, H. 32/1997, S. 37-39.

Obermann, Karl: Gustav Adolph Schlöffel, in: Ders.: Männer der Revolution von 1848, Westberlin 1970, S. 191-216.

—- Die Berliner Universität am Vorabend und während der Revolution von 1848/49, in: Göber, Willi/Herneck, Friedrich: Forschen und Wirken. Festschrift zur 150-JahrFeier der Humboldt-Universität zu Berlin 1810-1960. Beiträge zur wissenschaftlichen und politischen Entwicklung der Universität, Bd.1, Berlin 1960, S. 165-202.

Oberndörfer, Ralf: Studentische Politik oder politische StudentInnen, in: PROKLA. Zeitschrift für kritische Sozialwissenschaft, 26. Jg., H. 104/1996, S. 395-414.

OECD: Under Pressure. The Squeezed Middle Class, Paris 2019. 
Oevermann, Ulrich: Klinische Soziologie auf der Basis der Methodologie der objektiven Hermeneutik - Manifest der objektiv hermeneutischen Sozialforschung, Institut für hermeneutische Sozial und Kulturforschung e. V. 2002.

— Die Struktur sozialer Deutungsmuster - Versuch einer Aktualisierung, in: Sozialer Sinn, H. 1/2001, S. 223-229.

—: Zur Analyse der Struktur von sozialen Deutungsmustern (1973), in: Sozialer Sinn, H. H. 1/2001, S. 3-33.

Osterhammel, Jürgen: Die Verwandlung der Welt. Eine Geschichte des 19. Jahrhunderts. Lizenzausgabe der Bundeszentrale für politische Bildung, Bonn 2010.

Pfaff-Czarnecka, Joanna: Einleitung. Universitäten als Orte der Heterogenität und Un/Gleichheit, in: Dies. (Hg.): Das soziale Leben der Universität. Studentischer Alltag zwischen Selbstfindung und Fremdbestimmung, Bielefeld 2017, S. 11-41.

Pickel, Gert: Jugend und Politikverdrossenheit. Zwei politische Kulturen in Deutschland nach der Vereinigung?, Opladen 2002.

Pickel, Susanne/Pickel, Gert: Politische Kultur- und Demokratieforschung. Grundbegriffe, Theorien, Methoden. Eine Einführung, Wiesbaden 2006.

Plaß, Christine/Schetsche, Michael: Grundzüge einer wissenssoziologischen Theorie sozialer Deutungsmuster, in: Sozialer Sinn, H. 3/2001, S. 511-536.

Plessner, Helmuth: Die verspätete Nation. Über die politische Verführbarkeit bürgerlichen Geistes [1935], in: Ders. (Hg.): Die Verführbarkeit bürgerlichen Geistes. Gesammelte Schriften Bd. VI, Frankfurt a.M. 2003.

—: Grenzen der Gemeinschaft [1924]. Eine Kritik des sozialen Radikalismus, Frankfurt a.M. 2002.

Przyborski, Aglaja/Wohlrab-Sahr, Monika: Qualitative Sozialforschung. Ein Arbeitsbuch, München 2010.

Pöppinghege, Rainer/Klenke, Dietmar: Einführung, in: Dies. (Hg.): Hochschulreformen früher und heute - zwischen Autonomie und gesellschaftlichem Geltungsanspruch, Göttingen 2011, S. 7-24.

Quinn-Judge, Paul: Die Revolution, die keine war, in: Merkur. Gegründet 1947 als Deutsche Zeitschrift für Europäisches Denken, 72. Jg., H. 831/2018, S. 50-60.

Raphael, Lutz: Jenseits von Kohle und Stahl. Eine Gesellschaftsgeschichte Westeuropas nach dem Boom, Frankfurt a.M. 2019.

Raschke, Joachim: Die Erfindung von Links/Rechts als politisches Richtungsschema, in: Greve, Michael/Münkler, Herfried/Schmalz-Bruns, Rainer (Hg.): Bürgersinn und Kritik. Festschrift für Udo Bermbach zum 60. Geburtstag, Baden-Baden 1998, S. 185-206.

Reinders, Heinz: Vom Bildungs- zum Optimierungsmoratorium. Diskurs Kindheitsund Jugendforschung, H. 2/2016, S. 147-160.

Ribolits, Erich: Abschied vom Bildungsbürger. Über die Antiquiertheit von Bildung im Gefolge der dritten industriellen Revolution, Wien 2013.

Richter, Claus (Hg.): Die Überflüssige Generation. Jugend zwischen Apathie und Aggression, Königstein/Ts 1979.

Richter, Pavel A.: Die Außerparlamentarische Opposition in der Bundesrepublik Deutschland 1966 bis 1968, in: Gilcher-Holtey, Ingrid (Hg.): 1968. Vom Ereignis zum 
Gegenstand der Geschichtswissenschaft. Geschichte und Gesellschaft, Sonderheft 17, Göttingen 1998, S. 35-55.

Ringer, Fritz K.: Die Gelehrten. Der Niedergang der deutschen Mandarine 1890-1933, Stuttgart 1987.

Ritter, Gerhard Albert: Die deutschen Parteien 1830-1914. Parteien und Gesellschaft im konstitutionellen Regierungssystem, Göttingen 1985.

Ritter, Joachim: Hegel und die französische Revolution [1957], Frankfurt a.M. 1989.

Rohe, Karl: Politik. Begriffe und Wirklichkeiten, Stuttgart Berlin Köln 1994.

: Politische Kultur. Zum Verständnis eines theoretischen Konzepts, in: Niedermayer, Oskar/Beyme, Klaus von (Hg.): Politische Kultur in Ost- und Westdeutschland, Berlin 1994, S. 1-21.

—: Wahlen und Wählertraditionen in Deutschland. Kulturelle Grundlagen deutscher Parteien und Parteiensysteme im 19. und 20. Jahrhundert, Frankfurt a.M. 1992.

—: Politische Kultur und der kulturelle Aspekt von politischer Wirklichkeit. Konzeptionelle und typologische Überlegungen zu Gegenstand und Fragestellung Politischer Kulturforschung, in: Berg-Schlosser, Dirk/Schissler, Jakob: Politische Kultur in Deutschland. Bilanz und Perspektiven der Forschung. Politische Vierteljahresschrift, Sonderheft 18/1987, S. 39-48.

Rokkan, Stein: Staat, Nation und Demokratie in Europa. Die Theorie Stein Rokkans aus seinen gesammelten Werken rekonstruiert und eingeleitet von Peter Flora, Frankfurt a.M. 2000.

Rommel, Manfred: Die überflüssige Generation - Übersteigerte Hoffnungen, in: Richter, Claus (Hg.): Die überflüssige Generation. Jugend zwischen Apathie und Aggression, Königstein/Ts 1979, S. 88-95.

Rosanvallon, Pierre: Counter-Democracy. Politics in an Age of Distrust, Cambridge/New York 2008.

Rosenberg, Arthur: Geschichte der Weimarer Republik, Frankfurt a.M. 1961.

Rosenmayr, Leopold: Vorbemerkung, in: Allerbeck, Klaus R./Rosenmayr, Leopold (Hg.): Aufstand der Jugend? Neue Aspekte der Jugendsoziologie, München 1971, S. 7-10.

Rucht, Dieter: Die Ereignisse von 1968 als soziale Bewegung. Methodologische Überlegungen und einige empirische Befunde, in: Gilcher-Holtey, Ingrid (Hg.): 1968. Vom Ereignis zum Gegenstand der Geschichtswissenschaft. Geschichte und Gesellschaft, Sonderheft 17, Göttingen 1998, S. 116-130.

Ruppert, Wolfgang: Zur Konsumwelt der 6oer Jahre, in: Schildt, Axel/Siegfried, Detlef/Lammers, Karl Christian (Hg.): Dynamische Zeiten. Die 6oer Jahre in den beiden deutschen Gesellschaften. Hamburger Beiträge zur Sozial- und Zeitgeschichte, Bd. 37, Hamburg 2000, S. 752-767.

Saage, Richard: Das Ende der politischen Utopie? Zum Begriff der politischen Utopie, in: Ders.: Das Ende der politischen Utopie?, Frankfurt a.M. 1990, S. 13-25.

Sachweh, Patrick: Deutungsmuster sozialer Ungleichheit. Wahrnehmung und Legitimation gesellschaftlicher Privilegierung und Benachteiligung, Frankfurt a.M./New York 2010. 
Sandberger, Johann-Ulrich: Zwischen Legitimation und Kritik. Vorstellungen von Akademikern, Studenten und Bevölkerung zur sozialen Ungleichheit, in: Zeitschrift für Soziologie, 12. Jg., H. 3/1983, S. 181-202.

Schelsky, Helmut: Der „Begriff des Politischen“ und die politische Erfahrung der Gegenwart. Überlegungen zur Aktualität von Carl Schmitt, in: Der Staat, 22. Jg., H. 3/1983, S. 321-345.

— : Die skeptische Generation. Eine Soziologie der deutschen Jugend [1957], Frankfurt a.M. 1984.

—: Die Bedeutung des Schichtungsbegriffs für die Analyse gegenwärtiger Gesellschaft, in: Ders.: Auf der Suche nach Wirklichkeit, Düsseldorf/Köln 1965, S. 331-336.

—: Einsamkeit und Freiheit. Idee und Gestalt der deutschen Universität und ihrer Reformen, Reinbek 1963.

Schenke, Julian/Schmitz, Christopher/Marg, Stine/Trittel, Katharina: PEGIDA-Effekte? Jugend zwischen Polarisierung und politischer Unberührtheit, Bielefeld 2018.

Schenke, Julian/Finkbeiner, Florian/Neumann, Amelie: Das Potenzial der CleavagePerspektive. Wahlverhalten als Oberflächenphänomen der politischen Kultur, in: Demokratie-Dialog, H. 6/2020, S. 2-11.

Scheuch, Erwin K.: Die Jugend gibt es nicht. Zur Differenziertheit der Jugend in heutigen Industriegesellschaften, in: O. V.: Jugend in der Gesellschaft. Ein Symposion, München 1975, S. 54-78.

Scheuch, Erwin K./Klingemann, Hans-Dieter: Theorie des Rechtsradikalismus in westlichen Industriegesellschaften, in: Hamburger Jahrbuch für Wirtschafts- und Sozialpolitik, 1967, S. 11-19.

Schieder, Theodor: Partikularismus und Nationalbewußtsein im Denken des deutschen Vormärz, in: Conze, Werner (Hg.): Staat und Gesellschaft im deutschen Vormärz 1815-1848. Sieben Beiträge von Theodor Schieder, Otto Brunner, Reinhart Koselleck, Wolfgang Zorn, Wolfram Fischer, Erich Angermann, Werner Conze, Stuttgart 1962, S. 9-38.

Schildt, Axel: Die Sozialgeschichte der Bundesrepublik Deutschland bis 1989/90. Enzyklopädie deutscher Geschichte, Bd. 80, München 2007.

- Nachwuchs für die Rebellion. Die Schülerbewegung der späten 6oer Jahre, in: Reulecke, Jürgen (Hg.): Generationalität und Lebensgeschichte im 20. Jahrhundert. Schriften des Historischen Kollegs, Bd. 58, München 2003, S. 229-251.

—: Materieller Wohlstand - pragmatische Politik - kulturelle Umbrüche. Die sechziger Jahre in der Bundesrepublik, in: Schildt, Axel/Siegfried, Detlef/Lammers, Karl Christian: Dynamische Zeiten. Die 6oer Jahre in den beiden deutschen Gesellschaften. Hamburger Beiträge zur Sozial- und Zeitgeschichte, Bd. 37, Hamburg 2000, S. 21-53.

—: Konservatismus in Deutschland: von den Anfängen im 18. Jahrhundert bis zur Gegenwart, München 1998.

Schlicht, Uwe: Vom Burschenschafter bis zum Sponti. Studentische Opposition gestern und heute, Berlin 1980.

Schmid, Thomas: Stämme und Stammtisch oder Bescheidener Vorschlag, die alternativen Institutionen wieder abzuschaffen, in: Kraushaar, Wolfgang (Hg.): Autonomie 
oder Getto? Kontroversen über die Alternativbewegung, Frankfurt a.M. 1978, S. 8694.

Schmidt, Daniel/Sturm, Michael: „Wir sind die, vor denen Euch die Linken immer schon gewarnt haben“. Eine Einleitung, in: Livi, Massimiliano/Schmidt, Daniel/Sturm, Michael (Hg.): Die 1970er Jahre als schwarzes Jahrzehnt. Politisierung und Mobilisierung zwischen christlicher Demokratie und extremer Rechter, Frankfurt a.M./New York 2010, S. 7-29.

Schmidt, Manfred G.: Demokratietheorien, Opladen 2000.

Schmidt, Rudi: Der späte Nachhall von '68 - Alte Erkenntnisse in neuen Gewändern?“, in: Kölner Zeitschrift für Soziologie und Sozialpsychologie, 70. Jg., H. 4/2018, S. 705-725.

Schmidtke, Michael A.: Reform, Revolte oder Revolution? Der Sozialistische Deutsche Studentenbund (SDS) und die Students for a Democratic Society (SDS) 19601970, in: Gilcher-Holtey, Ingrid (Hg.): 1968. Vom Ereignis zum Gegenstand der Geschichtswissenschaft. Geschichte und Gesellschaft, Sonderheft 17, Göttingen 1998, S. 188-206.

Schmitt, Carl: Der Begriff des Politischen [1932], Berlin 1979.

Schoeck, Helmut: Der Student als Gesellschaftskritiker, in: Schoeps, Hans Julius/Dannenmann, Christopher: Die rebellischen Studenten: Elite der Demokratie oder Vorhut eines linken Faschismus?, München und Esslingen/Neckar 1968, S. 154-160.

Scholz, Christian/Stein, Volker: Einführung der Herausgeber, in: Dies. (Hg.): BolognaSchwarzbuch, Bonn 2009, S. 9-13.

Schöneck, Nabine M./Ritter, Sabine: Zur Einleitung. Die gesellschaftliche Mitte als Kampfzone - Perspektiven und Fragestellungen, in: Dies. (Hg.): Die Mitte als Kampfzone. Wertorientierungen und Abgrenzungspraktischen der Mittelschichten, Bielefeld 2018, S. 11-26.

Schröder, Martin: Der Generationenmythos, in: Kölner Zeitschrift für Soziologie und Sozialpsychologie , H. 2/2018, S. 1-26.

Schultheis, Franz/Hector, Franz/Roca i Escoda, Marta (Hg.): Humboldts Albtraum. Der Bologna-Prozess und seine Folgen, Konstanz 2008.

Schulz, Andreas: Lebenswelt und Kultur des Bürgertums im 19. und 20. Jahrhundert. Enzyklopädie Deutscher Geschichte, Bd. 75, Berlin 2014.

Schulze, Friedrich/Ssymank, Paul: Das deutsche Studententum von den ältesten Zeiten bis zur Gegenwart, München 1931.

Schülein, Johann August: Veränderungen der Studentenrolle?, in: Huber, Ludwig/Wulf, Manfred (Hg.): Studium nur noch Nebensache?, Freiburg 1989, S. 133-152.

Schütz, Alfred: Der Fremde. Ein sozialpsychologischer Versuch, in: Gesammelte Aufsätze Bd. 2, Den Haag 1972, S. 53-69.

Schwan, Alexander/Sontheimer, Kurt (Hg.): Reform als Alternative. Hochschullehrer antworten auf die Herausforderung der Studenten, Köln/Opladen 1969.

Schwarz, Jürgen: Studenten in der Weimarer Republik. Die deutsche Studentenschaft in der Zeit von 1918 bis 1923 und ihre Stellung zur Politik, Berlin 1971.

Seitenbecher, Manuel: Mahler, Maschke \& Co. Rechtes Denken in der 68er-Bewegung?, Paderborn 2013. 
Sellert, Wolfgang: Die Aufhebung des Staatsgrundgesetzes und die Entlassung der Göttinger Sieben [1987], in: Blanke, Edzard/Kamp, Norbert/Schöne, Albrecht/Sellert, Wolfgang/von Thadden, Rudolf/Wellenreuther, Hermann (Hg.): Die Göttinger Sieben. Ansprachen und Reden anläßlich der 150. Wiederkehr ihrer Protestation, Göttingen 1988, S. 23-45.

Shell Deutschland Holding (Hg.): Jugend 2006. Eine pragmatische Generation unter Druck, Bpb-Lizenzausgabe, Bonn 2006.

Siemann, Wolfram: Die deutsche Revolution von 1848/49, Frankfurt a.M. 1985.

Simonson, Julia/Hameister, Nicole: Sozioökonomischer Status und freiwilliges Engagement, in: Simonson, Julia/Vogel, Claudia/Tesch-Römer, Clemens (Hg.): Freiwilliges Engagement in Deutschland. Der Deutsche Freiwilligensurvey 2014. Endbericht, DZA Berlin 2016, S. 429-454.

Sohn-Rethel, Alfred: Notizen von einem Gespräch zwischen Theodor W. Adorno und Alfred Sohn-Rethel am 16.03.1965, in: Ders.: Warenform und Denkform. Mit zwei Anhängen, Frankfurt a.M. 1978, S. 137-141.

Solga, Heike: Ohne Abschluss in die Bildungsgesellschaft. Die Erwerbschancen gering qualifizierter Personen aus soziologischer und ökonomischer Perspektive, Opladen 2005.

Söllner, Alfons: „1968“ - eine Nachlese, in: Mittelweg 36, H. 6/2008/09, S. 33-60.

Sonnemann, Ulrich: Institutionalismus und studentische Opposition. Thesen zur Ausbreitung des Ungehorsams in Deutschland, Frankfurt a.M. 1968.

Sontheimer, Kurt: Antidemokratisches Denken in der Weimarer Republik. Die politischen Ideen des deutschen Nationalismus zwischen 1918 und 1933, München 1978.

Spix, Boris: Abschied vom Elfenbeinturm? Politisches Verhalten Studierender 1957-1967. Berlin und Nordrhein-Westfalen im Vergleich, Essen 2008.

Statistisches Bundesamt: Studierende an Hochschulen: Wintersemester 2017/18, 2018.

—: Bildung und Kultur. Schnellmeldungsergebnisse der Hochschulstatistik zu Studierenden und Studienanfänger/-innen. Vorläufige Ergebnisse Wintersemester 2017/18, 2017.

Statistisches Bundesamt (Destatis)/Wissenschaftszentrum Berlin für Sozialforschung (WZB) (Hg.): Hrsg: Datenreport 2018. Ein Sozialbericht für die Bundesrepublik Deutschland, Bonn 2018.

— : Datenreport 2016. Ein Sozialbericht für die Bundesrepublik Deutschland, Bonn 2016.

Stender, Wolfram: Ethnische Erweckungen. Zum Funktionswandel von Ethnizität in modernen Gesellschaften. Ein Literaturbericht, in: Mittelweg 36, H. 4/2000, S. 6582.

Steiger, Günter: Aufbruch. Urburschenschaft und Wartburgfest, Leipzig Jena Berlin 1967.

Stifterverband für die deutsche Wissenschaft: Das geistige Bild der Studenten. Ihre Einstellung zu Politik, Kultur und Hochschulfragen. Wirtschaft und Wissenschaft: Sonderdruck des Stifterverbandes für die deutsche Wissenschaft, Essen-Bredeney 1961.

Strobel, Karl/Schmirber, Gisela: Drei Jahrzehnte Umbruch der deutschen Universitäten. Die Folgen von Revolte und Reform 1968-1974, Vierow bei Greifswald 1996. 
Strübing, Jörg: Grounded Theory. Zur sozialtheoretischen und epistemologischen Fundierung eines pragmatistischen Forschungsstils, Wiesbaden 2014.

Strübing, Jörg/Hirschauer, Stefan/Ayaß, Ruth/Krähnke, Uwe/Scheffer, Thomas: Gütekriterien qualitativer Sozialforschung. Ein Diskussionsanstoß, in: Zeitschrift für Soziologie, 47. Jg., H. 2/2018, S. 83-100.

Studier, Manfred: Der Corpsstudent als Idealbild der Wilhelminischen Ära. Untersuchungen zum Zeitgeist 1888 bis 1914, Erlangen 1965.

Szabó, Anikó: Vertreibung. Rückkehr. Wiedergutmachung. Göttinger Hochschullehrer im Schatten des Nationalsozialismus, Göttingen 2000.

Tanner, Jakob: „The Times They Are A-Changin“. Zur subkulturellen Dynamik der 68er Bewegungen, in: Gilcher-Holtey, Ingrid (Hg.): 1968. Vom Ereignis zum Gegenstand der Geschichtswissenschaft. Geschichte und Gesellschaft, Sonderheft 17, Göttingen 1998, S. 207-223.

Thielbeer, Heide: Universität und Politik in der Deutschen Revolution von 1848, Bonn 1983.

Thomann, Björn: Die Rolle der Burschenschaften in Jena, Bonn und Breslau in der Revolution 1848/49, in: Cerwinka, Günter/Kaupp, Peter/Lönnecker, Harald/Oldenhage, Klaus: 200 Jahre burschenschaftliche Geschichte. Von Friedrich Ludwig Jahn zum Linzer Burschenschafterturm. Ausgewählte Darstellungen und Quellen, Heidelberg 2008, S. 312-401.

Titze, Hartmut: Bildungskrisen und sozialer Wandel 1780-2000, in: Geschichte und Gesellschaft, 30. Jg., H. 2/2004, S. 339-372.

—: Wie wächst das Bildungssystem?“, in: Zeitschrift für Pädagogik, 45. Jg., H. 1/1999, S. 103-120.

—: Von der natürlichen Auslese zur Bildungsselektion 1780 - 1980. Argumentationsmuster und Bilanz einer zweihundertjährigen Diskussion, in: Zeitschrift für Pädagogik, 42. Jg, H. 3/1996, S. 389-406.

—: Die zyklische Überproduktion von Akademikern im 19. und 20. Jahrhundert, in: Geschichte und Gesellschaft, H. 10/1984, S. 92-121.

Turner, R. Steven: The Bildungsbürgertum and the Learned Professions in Prussia, 17701830. The Origins of a Class, in: Histoire Sociale - Social History, H. 13/1980, S. 105-135.

Tümmler, Hans: Wartburg, Weimar und Wien. Der Staat Carl Augusts in der Auseinandersetzung mit den Folgen des Studentenfestes von 1817, in: Historische Zeitschrift, H. 1/1972, S. 49-106.

Uhlenbrock, Henning: Der Staat als juristische Person. Dogmengeschichtliche Untersuchung zu einem Grundbegriff der deutschen Staatsrechtslehre. Schriften zur Verfassungsgeschichte, Bd. 61, Berlin 2000.

Ullmann, Hans-Peter: Das Deutsche Kaiserreich 1871-1918, Frankfurt a.M. 1995.

Valjavec, Fritz: Die Entstehung der politischen Strömungen in Deutschland 1770 - 1815 [1951], Kronberg/Ts 1978.

Verheyen, Nina: Die Erfindung der Leistung. Bpb Lizenzausgabe, Bonn 2018.

Vierhaus, Rudolf: Umrisse einer Sozialgeschichte der Gebildeten in Deutschland, in: Quellen und Forschungen aus italienischen Bibliotheken und Archiven, H. 60/1980, S. 395-419. 
—: Bildung, in: Brunner, Otto/Conze, Werner/Koselleck, Reinhart (Hg.): Geschichtliche Grundbegriffe: Historisches Lexikon zur politisch-sozialen Sprache in Deutschland, Bd. I A-D, Stuttgart 1972, S. 508-551.

Vogel, Bernhard: Vorwort. 68 hat uns für die Zukunft wachsamer gemacht, in: Vogel, Bernhard/Kutsch, Matthias (Hg.): 40 Jahre 1968. Alte und neue Mythen. Eine Streitschrift, Freiburg im Breisgau 2008, S. 7-8.

Voswinkel, Stephan: Das (schwindende) Versprechen des sozialen Aufstiegs, in: Aulenbacher, Brigitte/Dammayr, Maria/Dörre, Klaus/Menz, Wolfgang/Riegraf, Birgit/Wolf, Harald (Hg.): Leistung und Gerechtigkeit. Das umstrittene Versprechen des Kapitalismus, Weinheim 2017, S. 64-79.

Wahlström, Mattias/Kocyba, Piotr/Vydt, Michiel De/Moor, Joost de (Hg.): Protest for a future: Composition, mobilization and motives of the participants in Fridays For Future climate protests on 15 March, 2019 in 13 European cities, 2019.

Walter, Franz: Die SPD. Biographie einer Partei von Ferdinand Lassalle bis Andrea Nahles. Überarbeitete und erweiterte Taschenbuchausgabe, Reinbek bei Hamburg 2018.

—: 1873 - 1923 - 1973. Krisendramen im 50-Jahre-Takt?, in: INDES. Zeitschrift für Politik und Gesellschaft, H. 1/2018, S. 35-55.

—: Rebellen, Propheten und Tabubrecher. Politische Aufbrüche und Ernüchterungen im 20. und 21. Jahrhundert, Göttingen 2017.

— Weigerung und Eschatologie. Die neue Linke entdeckt den alten Herbert Marcuse, in: Lorenz, Robert/Walter, Franz (Hg.): 1964: Das Jahr, mit dem „68“ begann, Bielefeld 2014, S. 149-168.

—-: Baustelle Deutschland. Politik ohne Lagerbindung, Frankfurt a.M. 2008.

: Sozialistische Akademiker- und Intellektuellenorganisationen in der Weimarer Republik. Solidargemeinschaft und Milieu. Sozialistische Kultur- und Freizeitorganisationen in der Weimarer Republik, hgg, von Peter Lösche, Bd. 1, Bonn 1990.

Walter, Franz/Marg, Stine: Von der Emanzipation zur Meritokratie. Betrachtungen zur 150-jährigen Geschichte von Arbeiterbewegung, Linksintellektuellen und sozialer Demokratie, Göttingen 2013.

Wehler, Hans-Ulrich: Deutsche Gesellschaftsgeschichte. Bundesrepublik und DDR 1949 - 1990, Bpb Lizenzausgabe, Bonn 2010.

—: Die Zielutopie der „Bürgerlichen Gesellschaft“ und die „Zivilgesellschaft" heute, in: Lundgreen, Thomas (Hg.): Sozial- und Kulturgeschichte des Bürgertums. Eine Bilanz des Bielefelder Sonderforschungsbereichs (1986-1997), Göttingen 2000, S. 8592.

: Deutsches Bildungsbürgertum in vergleichender Perspektive - Elemente eines „Sonderwegs"?, in: Kocka, Jürgen (Hg.): Bildungsbürgertum im 19. Jahrhundert. Teil IV: Politischer Einfluß und gesellschaftliche Formation, Stuttgart 19189, S. 215-237.

Wehrs, Nikolai: Protest der Professoren. Der „Bund Freiheit der Wissenschaft" in den 1970er Jahren, Göttingen 2014.

White, Hayden: Metahistory: Die historische Einbildungskraft im 19. Jahrhundert in Europa, Frankfurt a.M. 2008.

Wildenmann, Rudolf/Kaase, Max: „Die unruhige Generation“. Eine Untersuchung zu Politik und Demokratie in der Bundesrepublik. Lehrstuhl für Politische Wissenschaft, Universität Mannheim 1968. 
Winkler, Heinrich August: Der lange Weg nach Westen, Bd. 2: Deutsche Geschichte vom „Dritten Reich“ bis zur Wiedervereinigung, München 2000.

—- Der lange Weg nach Westen, Bd. 1: Deutsche Geschichte vom Ende des Alten Reiches bis zum Untergang der Weimarer Republik, München 2000.

Wipf, Hans Ulrich: Studentische Politik und Kulturreform. Geschichte der Freistudenten-Bewegung 1896-1918. Edition Archiv der deutschen Jugendbewegung, Bd. 12, Schwalbach/Taunus 2004.

Wolter, Andrä: Eigendynamik und Irreversibilität der Hochschulexpansion. Die Entwicklung der Beteiligung an Hochschulbildung in Deutschland, in: Banscherus, Ulf/Bülow-Schramm, Margret/Himpele, Klemens/Staack, Sonja/Winter, Sarah (Hg.): Übergänge im Spannungsfeld von Expansion und Exklusion: Eine Analyse der Schnittstellen im deutschen Hochschulsystem, Bielefeld 2014, S. 19-38.

Young, Michael: The Rise of Meritocracy, London 1961.

Zunkel, Friedrich: Das Verhältnis des Unternehmertums zum Bildungsbürgertum zwischen Vormärz und Erstem Weltkrieg, in: Lepsius, M. Rainer (Hg.): Bildungsbürgertum im 19. Jahrhundert. Teil III: Lebensführung und ständische Vergesellschaftung, Stuttgart 1985, S. 82-101.

\section{V.3 Zeitungsartikel und Online-Ouellen}

Allweiss, Marianne: Die „Alleen“ müssen gehen, in: Deutschlandfunk Kultur, 23.01.2018, online einsehbar unter: https://www.deutschlandfunkkultur.de/streitum-gomringer-gedicht-auf-uni-fassade-die-alleen.2165.de.html?dram:article_id= 409035 [eingesehen am 01.08.2019]

Bargel, Tino: Entwicklung von sozialer Lage, Studienbedingungen und studentischem Bewusstsein. Interview von Heinz Heinemann, Rosa Luxemburg Stiftung 2012, online einsehbar unter: https://www.rosalux.de/publikation/id/5592/tinobargel-entwicklung-von-sozialer-lage-studienbedingungen-und-studentischembewusstsein/ [eingesehen am 01.08.2019]

Bender, Justus: Die Revolution ist nicht zu erwarten. Interview mit dem Protestforscher Dieter Rucht, in: Die Zeit, 26.11.2009.

BMBF: Die Sozialerhebung des Deutschen Studentenwerks, online einsehbar unter: https://www.bmbf.de/de/die-sozialerhebung-des-deutschen-studentenwerks1035.html [eingesehen am 01.08.2019]

BMBF: Der Studierendensurvey, online einsehbar unter: https:/www.bmbf.de/de/derstudierendensurvey-1036.html [eingesehen am 01.08.2019]

Destatis: Bildung, Forschung und Kultur, online einsehbar unter: https:// www.destatis.de/DE/ZahlenFakten/Indikatoren/LangeReihen/Bildung/lrbilo1. html\#Fussnotera [eingesehen am 01.08.2019]

Detjen, Joachim: Die Demokratiekompetenz der Bürger, in: bpb.de, 26.05.2002, online einsehbar unter: https:/www.bpb.de/apuz/25554/die-demokratiekompetenzder-buerger? $\mathrm{p}=$ all [eingesehen am 01.08.2019] 
Dillmann, Daniel: Uni Frankfurt: Polizei räumt Audimax, in: Frankfurter Rundschau, 08.04.2019, online einsehbar unter: https:/www.fr.de/frankfurt/frankfurt-ammain-ort28687/joerg-meuthen-frankfurt-studenten-besetzen-audimax-frankfurtuniversity-applied-sciences-12068983.html [eingesehen am 01.08.2019]

Eßbach, Wolfgang: 8. Vorlesung: II. Marxbilder, in: Karl Marx und die Frage nach der Gesellschaft (Theorie I), Podcasts der Albert-Ludwigs-Universität Freiburg, Winter 2004-2005, 01:16-2:00, online einsehbar unter: https://www.podcasts. uni-freiburg.de/geschichte-gesellschaft/gesellschaft/karl-marx-und-die-fragenach-der-gesellschaft-theorie-i-winter-2004-2005 [eingesehen am 01.08.2019]

—: Unterm Rad der Planierraupe. Die deutschen Universitäten leiden unter den Bologna-Reformen, in: Süddeutsche Zeitung, Nr. 295, 20.12.2004, S. 16.

Fokken, Silke: Das leere Versprechen vom Aufstieg durch Bildung, in: Spiegel Online, 22.10.2018, online einsehbar unter: http:/www.spiegel.de/lebenundlernen/schule/ deutschland-das-leere-versprechen-vom-aufstieg-durch-bildung-a-1234211.html [eingesehen am 01.08.2019]

Forschungsgruppe Weltanschauungen in Deutschland (fowid): Religionszugehörigkeiten in Deutschland 2017, 08.10.2018, online einsehbar unter: https://fowid.de/ meldung/religionszugehoerigkeiten-deutschland-2017 [eingesehen am 01.08.2019]

Fries, Meike: „Studenten sind ein Unruheherd“. Interview mit Dieter Rucht, in: Zeit Online, 18.01.2011, online einsehbar unter: http://www.zeit.de/studium/hochschule/ 2011-01/studenten-tunesien [eingesehen am 01.08.2019]

Fritz-Vannahme, Joachim: Die optimistische Generation Student '95: Die große ZEITUmfrage unter Deutschlands Studenten korrigiert das Klischee von den unpolitischen Bummelanten. Sie halten Werte hoch, engagieren sich in ihrem privaten Umkreis und jobben neben dem Studium, in: Die Zeit, 20.10.1995, online einsehbar unter: https:/www.zeit.de/1995/43/Die_optimistische_Generation_ Student_95_Die_grosse_ZEIT-Umfrage [eingesehen am 01.08.2019]

Fritz-Vannahme, Joachim: Humboldts Erbe wird verspielt, in: Die Zeit, 17.05.1996, online einsehbar unter: https://www.zeit.de/1996/21/Humboldts_Erbe_wird_verspielt [eingesehen am 01.08.2019]

Graw, Ansgar: Die politisch Hyperkorrekten erobern US-Unis, in: Die Welt, 27.01.2016, online einsehbar unter: https:/www.welt.de/politik/ausland/article151523626/Diepolitisch-Hyperkorrekten-erobern-US-Unis.html [eingesehen am 01.08.2019]

Hartung, Manuel J.: Streiten bildet, in: DIE ZEIT, 17.04.2019, S. 1.

Internetpräsenz des bundesweiten Bildungsstreiks 2009, online einsehbar unter: https://web.archive.org/web/20090802074629/http://www.bildungsstreik2009.de/ [eingesehen am 01.08.2019]

Internetpräsenz des Statistischen Bundesamtes: Destatis: Bildung, Forschung und Kultur, online einsehbar unter: https://www.destatis.de/DE/Themen/GesellschaftUmwelt/Bildung-Forschung-Kultur/Hochschulen/Tabellen/studierendeinsgesamt-bundeslaender.html [eingesehen am 24.03.2020]

Introduction to the Fateh Constitution. The Essential Principles of the Constitution, in: Ariel Center for Policy Research, online einsehbar unter: http://www.acpr.org.il/ resources/fatehconstitution.html [eingesehen am 01.08.2019] 
Jasper, Willi: Gegen die Germanomanie, in: Der Tagesspiegel, 07.08.2017, online einsehbar unter: https://www.tagesspiegel.de/kultur/der-reformator-saul-ascher-gegendie-germanomanie/20149716.html [eingesehen am 28.02.2020]

Jessen, Jens: Links oder rechts, in: Die Zeit, 02.05.2019, S. 37.

Kix, Martina: Einer von denen, in: Zeit Online, 26.09.2016, online einsehbar unter: https:/www.zeit.de/campus/2016/05/pegida-hochbegabter-student-rechteprotestbewegung [eingesehen am 01.08.2019]

Kolwitz, Kai/Hudemann, Steffen: Studenten geht die Luft aus, in: Spiegel Online, 06.01.2004, online einsehbar unter: https://www.spiegel.de/lebenundlernen/ uni/berliner-streik-kehraus-studenten-geht-die-luft-aus-a-280728.html [eingesehen am 01.08.2019]

Kühne, Anja: Funktionieren ist kein Lernziel, in: Zeit Online, 17.06.2009, online einsehbar unter: https://www.zeit.de/online/2009/25/bildungsstreik-demonstration [eingesehen am 01.08.2019]

Landsberger, Antonio/Bühler, Andreas/Schmidt, Tobias/ Fest, Andreas/Schulze, Henning/Ott, Simone/Winter, Marcel/Wernicke, Jens: Proben für den großen Krach. Handbuch zur studentischen Protestorganisation, Münster 2005, online einsehbar unter: https://ffmdieunibrennt.files.wordpress.com/2012/08/protesthandbuch. pdf [eingesehen am 01.08.2019]

Massing, Peter: Bundes- und Landeszentralen für politische Bildung, in: bpb.de, 19.03.2015, online einsehbar unter: https://www.bpb.de/gesellschaft/bildung/ politische-bildung/193394/bundes-und-landeszentralen?p=all [eingesehen am 01.08.2019]

o. V.: Was denken die Studenten? SPIEGEL-Umfrage an deutschen Hochschulen, in: Der Spiegel, H. 26/1967, S. 28-39.

o. V.:Abgeschlossene Forschungsbereiche, in: Internetpräsenz der Universität Bielefeld, o. D., online einsehbar unter: https://www.uni-bielefeld.de/(de)/Universitaet/Forschung/SFB-GK-Archiv.html [eingesehen am 01.08.2019]

o. V.: Bildung in Deutschland, online einsehbar unter: https://www. bildungsbericht.de/de/nationaler-bildungsbericht [eingesehen am 01.08.2019]

o. V.: Verrat vor dem Schuss, in: DER SPIEGEL, H. 22/2009, S. 42-51.

o. V.: Nachbessern an der Uni, in: SZ.de, 17.05.2010, online einsehbar unter: https://www.sueddeutsche.de/karriere/nach-dem-bildungsstreik-nachbessern-ander-uni-1.124587 [eingesehen am 01.08.2019]

o. V.: Occupy? Von wegen, in: SPIEGEL ONLINE, 17.11.2011, online einsehbar unter: https://www.spiegel.de/lebenundlernen/uni/bundesweite-bildungswutoccupy-von-wegen-a-798370.html [eingesehen am 01.08.2019]

o. V.: Diskriminierungs-Umfrage geht gewaltig nach hinten los, in: Die Welt, 27.02.2016, online einsehbar unter: https://www.welt.de/vermischtes/ article152704626/Diskriminierungs-Umfrage-geht-gewaltig-nach-hinten-los.html [eingesehen am 01.08.2019]

o. V.: Zwei Drittel begrüßen „Fridays for Future“, in: ZDF-Politbarometer, online einsehbar unter: https://www.zdf.de/nachrichten/heute/politbarometer-zwei-drittelbegruessen-fridays-for-future-100.html [eingesehen am 01.08.2019] 
Ribi, Thomas: Das große Wagnis der Freiheit: Was moderne Demokratien zusammenhält, in: Neue Zürcher Zeitung (NZZ), 26.02.2019, online einsehbar unter: https:/www.nzz.ch/feuilleton/was-saekulare-staaten-zusammenhaelt-dasgrosse-wagnis-der-freiheit-ld.1469858?fbclid=IwAR11Cf8MnFcShSl2TK\%E2\% 80\%A6 [eingesehen am 01.08.2019]

Schneider, Gregor-Sönke: Fortzusetzen... Detlev Claussen zum 70. Geburtstag, in: faustkultur.de, 22.02.2018, online einsehbar unter: https:/faustkultur.de/3430-0-DetlevClaussen-zum-70.html [eingesehen am 01.08.2019]

Statistisches Bundesamt: Studierende an Hochschulen. Wintersemester 2017/18, S. 13, online einsehbar unter: https://www.destatis.de/DE/ Publikationen/Thematisch/BildungForschungKultur/Hochschulen/

StudierendeHochschulenEndg2110410187004.pd?__blob=publicationFile [eingesehen am 01.08.2019]

Stoldt, Till-Reimer: Deutschlands Studenten geben sich der Sorglosigkeit hin, in: Welt Online, 06.07.2018, online einsehbar unter: https:/www.welt.de/politik/ deutschland/article178866492/Studenten-Studie-Beruflicher-Erfolg-verliertextrem-an-Stellenwert.html [eingesehen am 01.08.2019]

Stoldt, Till-Reimer: Hauptsache gechillt, in: WELT Online, 09.07.2018, online einsehbar unter: https://www.welt.de/print/welt_kompakt/print_politik/article179016726/ Hauptsache-gechillt.html [eingesehen am o1.08.2019]

Titz, Christoph/Menke, Birger/Waleczek, Torben/Leffers, Jochen: Mehr als 100.000 Schüler und Studenten auf den Straßen, in: SPIEGEL ONLINE, 17.06.2009, online einsehbar unter: https://www.spiegel.de/lebenundlernen/uni/bildungsstreikmehr-als-100-000-schueler-und-studenten-auf-den-strassen-a-630965.html [eingesehen am 01.08.2019]

Toprak, Cigdem: Die Kopftuchdiskussion gehört an die Universität, in: Die Welt, 26.04.2019, online einsehbar unter: https://www.welt.de/kultur/article192466205/ Ruecktrittsforderungen-gegen-Susanne-Schroeter-ein-Wahnsinn.html [eingesehen am 01.08.2019]

United Nations: Universal Declaration of Human Rights, 10.12.1948, online einsehbar unter: https://www.ohchr.org/EN/UDHR/Documents/UDHR_Translations/eng.pdf [eingesehen am 01.08.2019]

Wagner, Gerald: Das Recht gehört den Beleidigten, in: Frankfurter Allgemeine Zeitung, 17.02.2016, online einsehbar unter: https:/www.faz.net/aktuell/ feuilleton/forschung-und-lehre/ein-jahr-nach-blooger-angriff-auf-herfriedmuenkler-14072301.html [eingesehen am 01.08.2019]

Walter, Franz: Die Janusköpfigkeit des linksliberalen Leitmodells, in: Frankfurter Allgemeine Zeitung (FAZ), 16.03.2018, online einsehbar unter: https://www.faz. net/aktuell/politik/inland/fuehrt-buergerliches-engagement-zur-stabilisierungder-demokratie-15543519.html [eingesehen am 01.08.2019]

Zeki Min: „When everything's collapsing, trust the kids!“, in: zekimin.com, 03.04.2014, online einsehbar unter: https://zekimin.com/2014/04/03/when-everythingscollapsing-trust-the-kids/ [eingesehen am 1.08.2019] 



\section{Abbildungsverzeichnis}

Abb. 1: Soziale Herkunft der Studierendenkohorte $1810 \ldots \ldots \ldots \ldots \ldots \ldots \ldots \ldots \ldots \ldots \ldots \ldots \ldots \ldots$

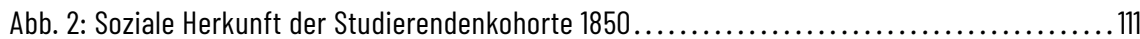

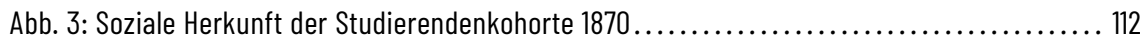

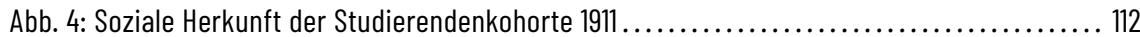

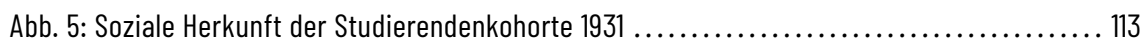

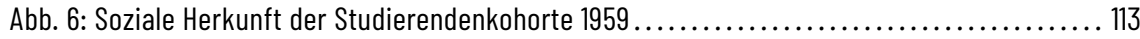

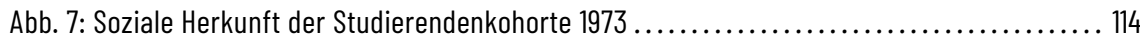

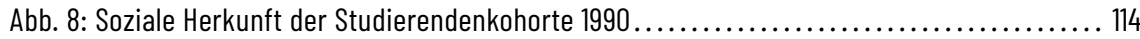

Abb. 9: Soziale Herkunft der Studierendenkohorte 2017 ............................... 115

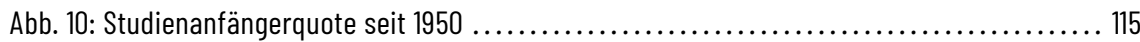

Abb. 11: Studierende an Universitäten und Fachhochschulen seit 1950 nach Geschlecht ......... 116

Abb. 12: Studierende an deutschen Universitäten und Fachhochschulen 1830-Abb. 12: Studierende an deutschen Universitäten und Fachhochschulen 1830-2019 ...................... 116

Abb. 13: Anteil der Studierenden mit akademisch gebildeten Elternteilen.................... 117

Abb. 14: Höchster Schulabschluss der Eltern von Studierenden .......................... 117

Tabelle 1: Studentische Generationskonturen und ihre gesellschaftspolitischen Hintergrundthematiken*

Abb. 15: Politisches Interesse der Studierendenschaft im Vergleich zur Gesamtbevölkerung 1983-Abb. 15: Politisches Interesse der Studierendenschaft im Vergleich zur Gesamtbevölke-

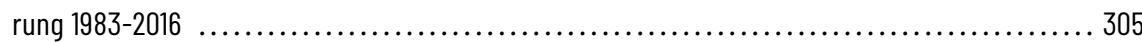

Abb. 16: Zustimmung zur harten Bestrafung vom Kriminalität ........................ 305

Abb. 17: Zustimmung zur Begrenzung von Immigration ............................... 306

Abb. 18: Zustimmung zur Abschaffung des Privateigentums ........................ 306

Abb. 19: Zustimmung zur Sicherung von Marktliberalismus........................... 307

Abb. 20: Zustimmung zur Förderung der technologischen Entwicklung .................... 307

Abb. 21: Geschlecht der Fokusgruppenteilnehmer* ............................... 352

Abb. 22: Alter der Fokusgruppenteilnehmer ........................................ 353

Abb. 23: Fachsemester der Fokusgruppenteilnehmer .............................. 353

Abb. 24: Höchster erreichter Bildungsabschluss der Fokusgruppenteilnehmer............... 354

Abb. 25: Berufliche Tätigkeit der Mutter ............................................ 354

Abb. 26: Berufliche Tätigkeit des Vaters..................................... 355

Abb. 27: Studienfächer der Fokusgruppenteilnehmer ................................ 355 
534 Student und Demokratie

Abb. 28: Persönliches Netto-Einkommen der Fokusgruppenteilnehmer.................. 356

Abb. 29: Wohnverhältnis der Fokusgruppenteilnehmer............................. 356

Abb. 30: Partnerschaftsstatus der Fokusgruppenteilnehmer .......................... 357

Abb. 31: Konfessionszugehörigkeit der Fokusgruppenteilnehmer ......................... 357

Abb. 32: Zivilgesellschaftliches Engagement der Fokusgruppenteilnehmer ................ 358

Abb. 33: Wahlverhalten bei der letzten Bundestagswahl .......................... 358

Abb. 34: Prospektives Wahlverhalten bei der nächsten Bundestagswahl.................. 359 


\section{Politikwissenschaft}

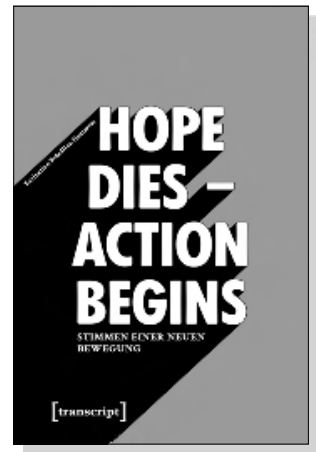

Extinction Rebellion Hannover

"Hope dies - Action begins":

Stimmen einer neuen Bewegung

2019, 96 S., kart.

7,99€ (DE), 978-3-8376-5070-9

E-Book: kostenlos erhältlich als Open-Access-Publikation, ISBN 978-3-8394-5070-3

EPUB: kostenlos erhältlich als Open-Access-Publikation, ISBN 978-3-7328-5070-9

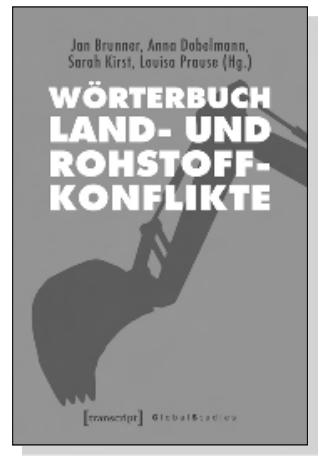

Jan Brunner, Anna Dobelmann,

Sarah Kirst, Louisa Prause (Hg.)

\section{Wörterbuch Land- und Rohstoffkonflikte}

2019, 326 S., kart., Dispersionsbindung, 1 SW-Abbildung 24,99€ (DE), 978-3-8376-4433-3

E-Book: 21,99 € (DE), ISBN 978-3-8394-4433-7

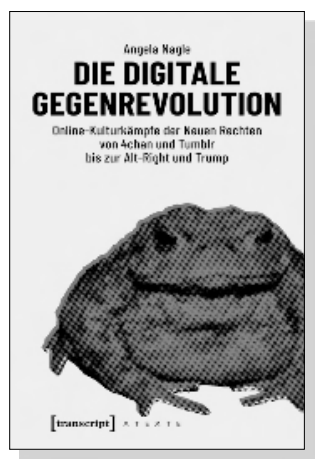

Angela Nagle

\section{Die digitale Gegenrevolution}

Online-Kulturkämpfe der Neuen Rechten

von 4chan und Tumblr bis zur Alt-Right und Trump

2018,148 S., kart.

$19,99 €(D E), 978-3-8376-4397-8$

E-Book: 17,99 € (DE), ISBN 978-3-8394-4397-2

EPUB: $17,99 €$ (DE), ISBN 978-3-7328-4397-8 


\section{Politikwissenschaft}

Ines-Jacqueline Werkner Gerechter Frieden Das fortwährende Dilemma milltärischer Gev/alt

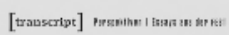

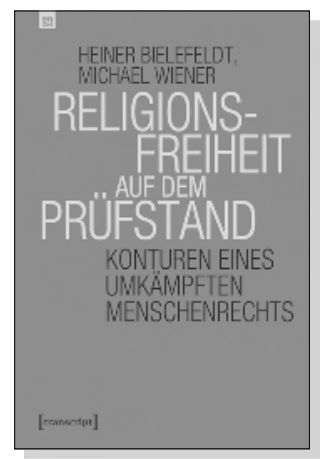

Judith Vey, Iohanna Leinius, Ingmar Hagemann ( $\mathrm{Hg}$.)

Handbuch

Poststrukturalistische

Perspektiven auf

soziale Bewegungen

Ansätze, Methaden

und Farschungspraxis
Ines-Jacqueline Werkner

\section{Gerechter Frieden}

Das fortwährende Dilemma militärischer Gewalt

2018, 106 S., kart.

$14,99 €(D E), 978-3-8376-4074-8$

E-Book: $12,99 €$ (DE), ISBN 978-3-8394-4074-2

Heiner Bielefeldt, Michael Wiener

Religionsfreiheit auf dem Prüfstand

Konturen eines umkämpften Menschenrechts

Februar 2020, 278 S., kart.

$32,99 €(D E), 978-3-8376-4997-0$

E-Book: 32,99€ (DE), ISBN 978-3-8394-4997-4

Judith Vey, Johanna Leinius, Ingmar Hagemann (Hg.)

Handbuch Poststrukturalistische Perspektiven auf soziale Bewegungen

Ansätze, Methoden und Forschungspraxis

2019, 306 S., kart., Dispersionsbindung,

2 SW-Abbildungen, 2 Farbabbildungen

24,99 € (DE), 978-3-8376-4879-9

E-Book: kostenlos erhältlich als Open-Access-Publikation,

ISBN 978-3-8394-4879-3 